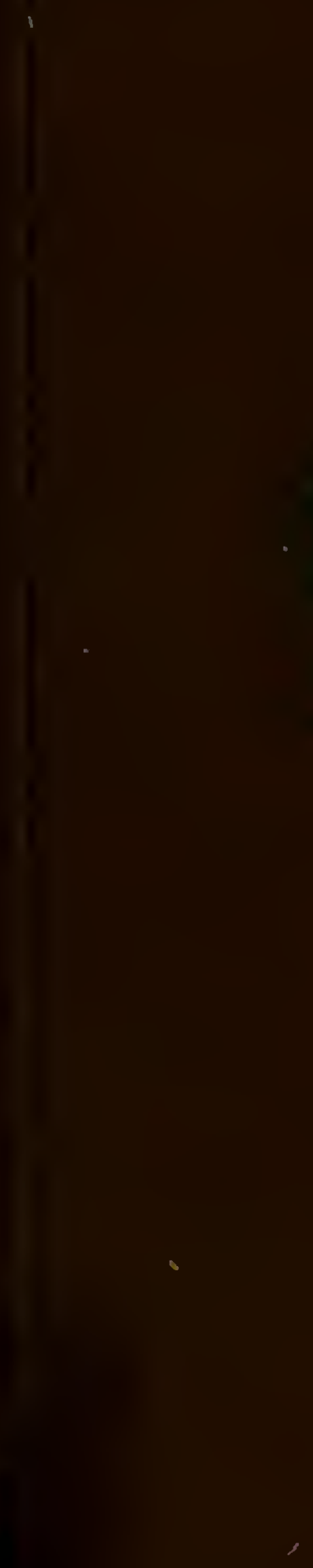




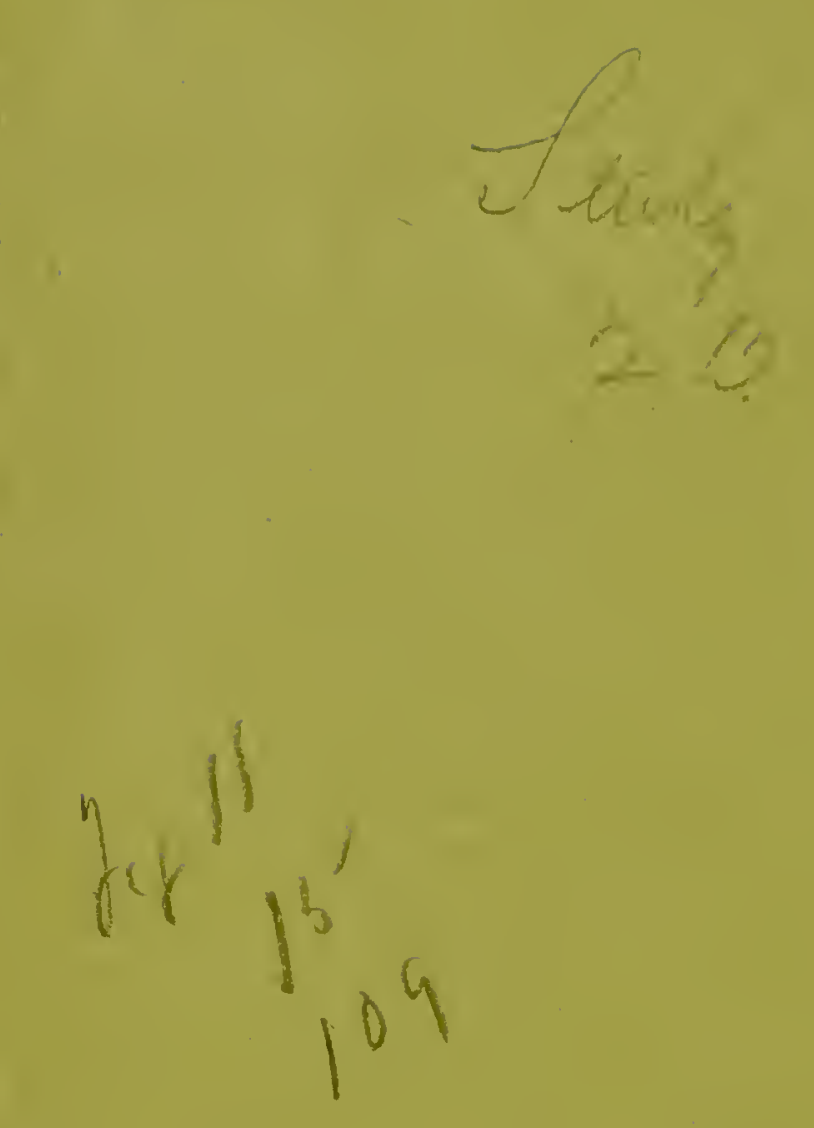


Die Suffulenten.

$\Phi$ 



\section{Die}

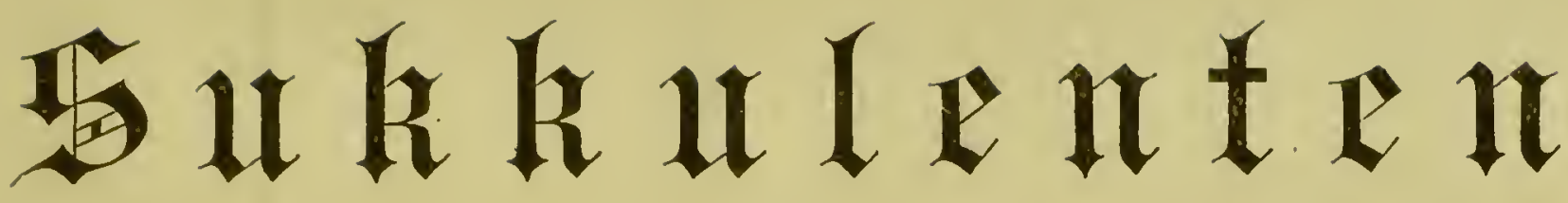 \\ (fettpflanzen unt Kalteen)}

Befdreibuntor, 2lbbildung und Sultur Serfelben

voll

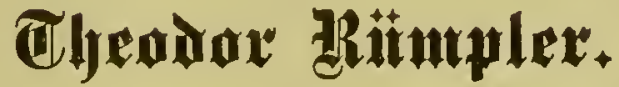

laad) Sem Tode des Derfaffers berauggegeben

wol1

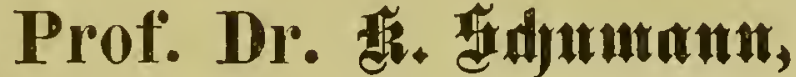

fiuftos am fröniglidben botanifden 2rtufetum in Berlin.

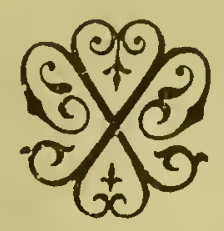

D̊rit 139 Textabbilounger.

炡erlin.

$\mathfrak{D} \mathfrak{e} \mathfrak{\mathfrak { l }} \mathfrak{a} \mathfrak{g}$ v

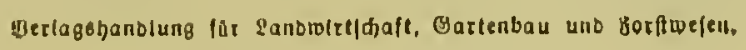

SW., 10 B̨coemannftrafict,

1892. 
$6^{0^{0^{0^{-1}}}}$

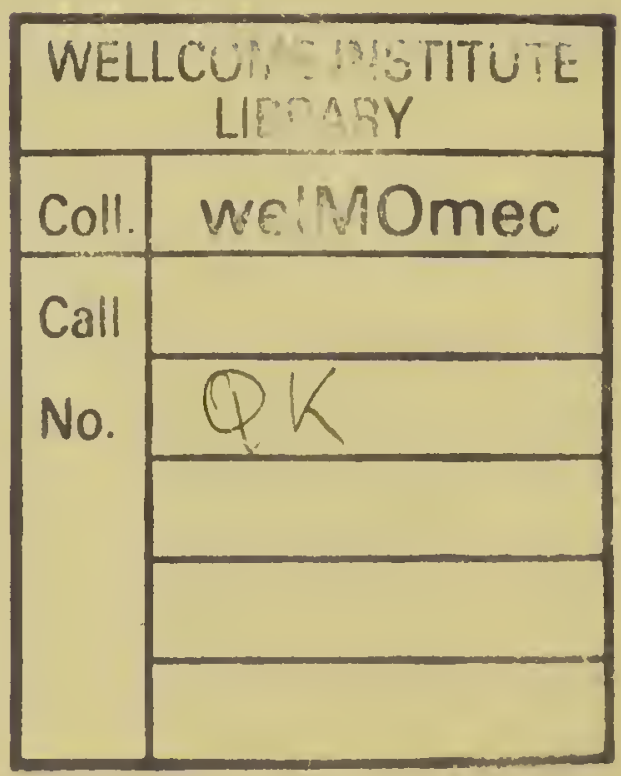




\section{Dorwort.}

Das Mamufript des vorliegentoen Budes murbe mir nad) bent

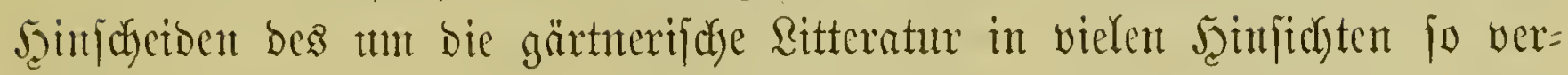

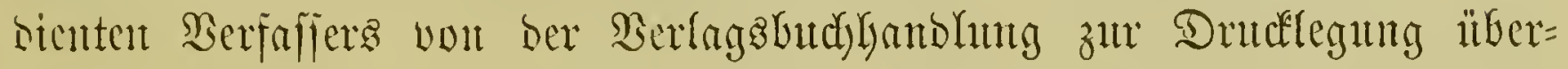

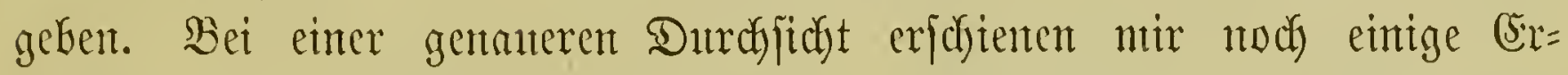
gänzungen untb Berä̈berungen nötig, bie wahridjeintidy ber Serfaffer felbjt

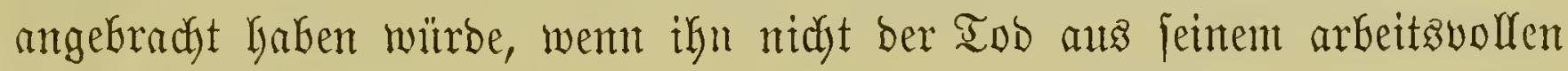
seben entfübrt bätte.

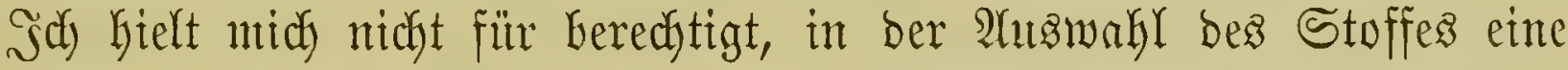
Yenberung eintreten zu Yaffen: einesteils meinte id), baj ich jonft fein gciftiges (sigentum erheblid) beeinträdytigt hätte; antberenteils aber glautbte id), baf $\Re$ ümpler burch feine umfangreidye (Errafgrumg unb feine baternbe

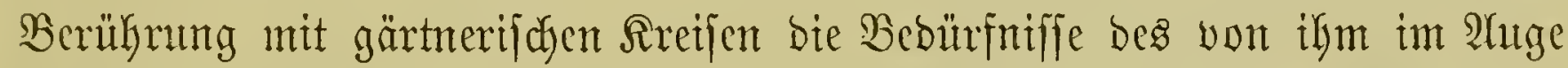

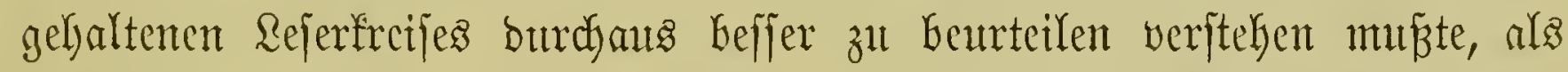

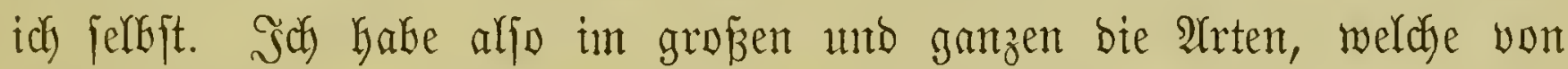
bem Serfafjer ausgewählt worben waren, beibefalten.

Dagegen habe id ben gegebenen Stoff yolffommen anbers georbnet

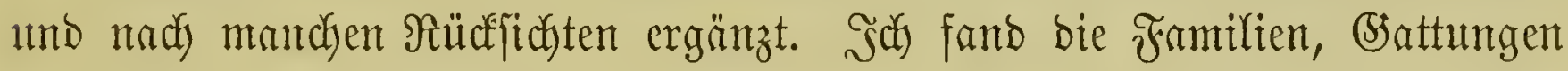

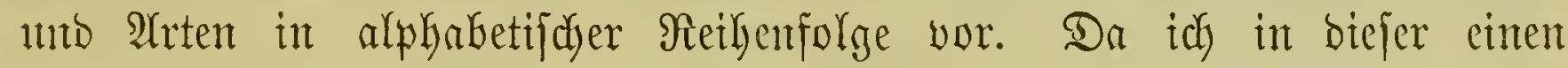

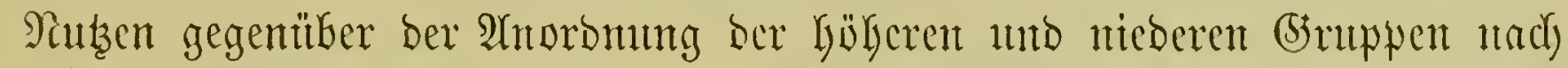
bem natitrlidfen Syftem nidyt zll erfemen verntodyte, fo labe id bas

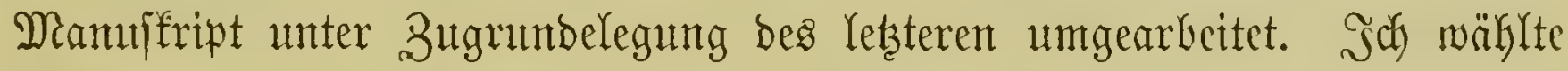
bazu bie Anreifung, welde (Engler zuletst gegeben hat und bie fich an

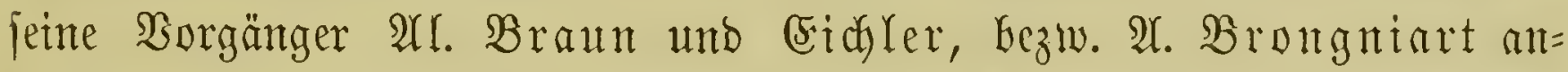

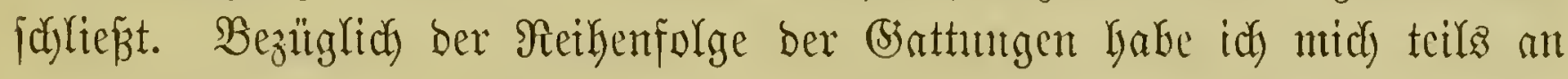
bie Bruppienungen gefalten, weldye bie Mionugraplyen ber Familie gegeben Gaben, teils habe idy meine eigenen Bebanfen zum atusbrude gebradt. Namentlich gilt bas Rebtere von berjentigen Familie, weldye ben größten

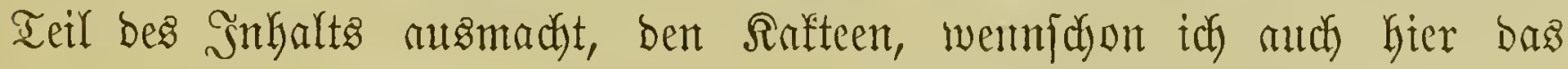
altberwährte Sujtem won Salm-Dyde gern als Fülyrer benthte.

Die (Sharalteriftif ber Familien fowohl wie ber (5)attungen war in bem Manuffripte nod) unvolftänbig unb mangelfaft; beibe finto befwegen won 


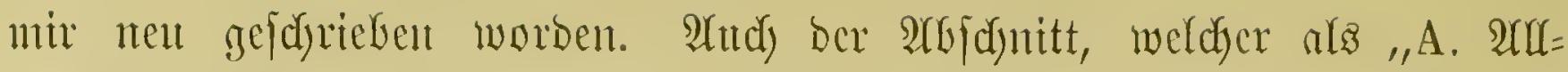

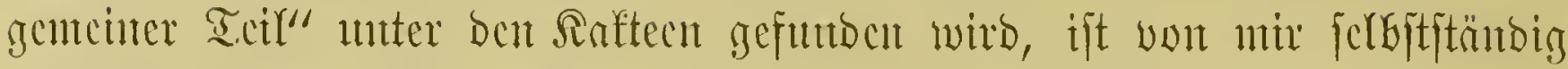

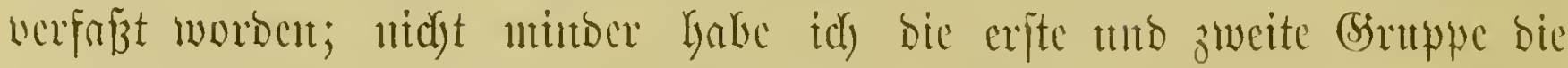

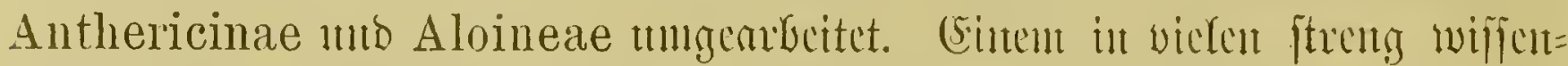

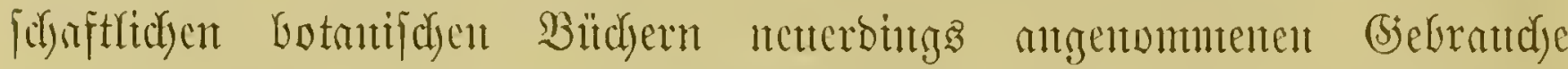

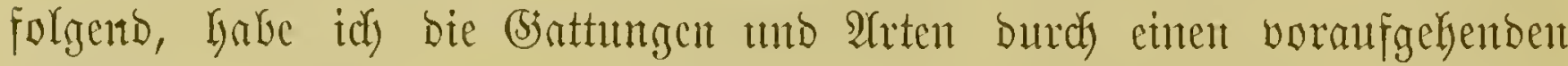

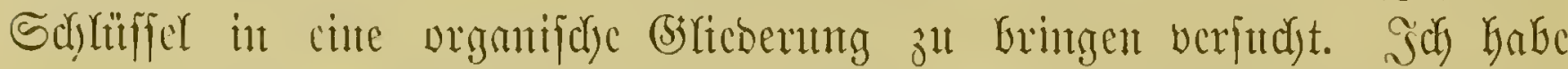

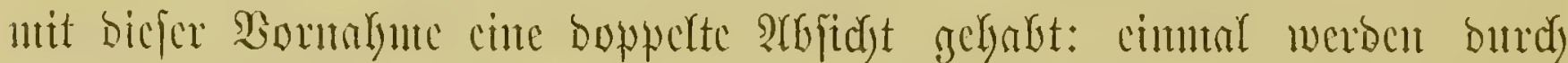

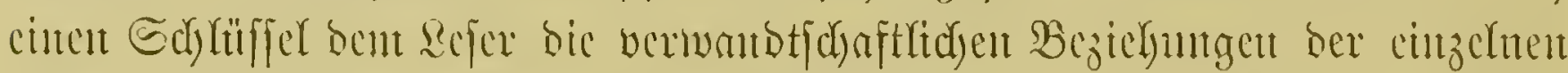

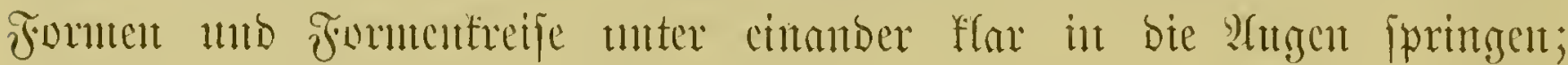

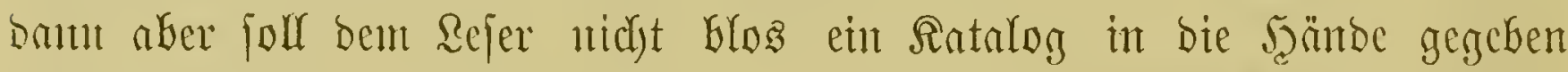
werben, fonbern er folf aud) in ber Sage fecit, bic Ridjtigfeit ber Bejtim=

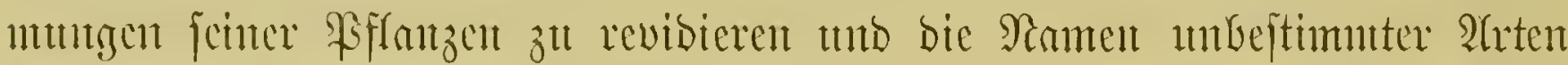

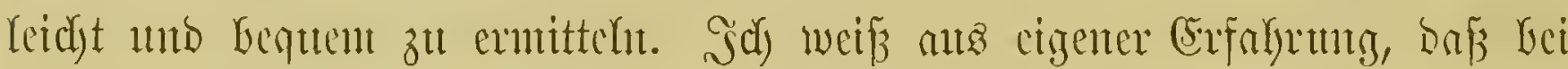

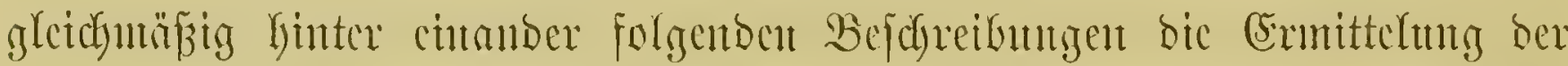

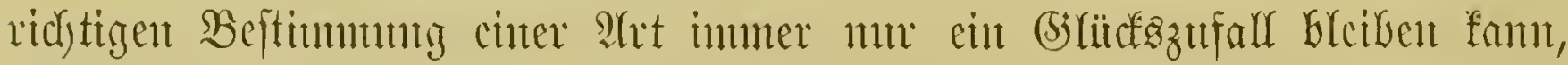

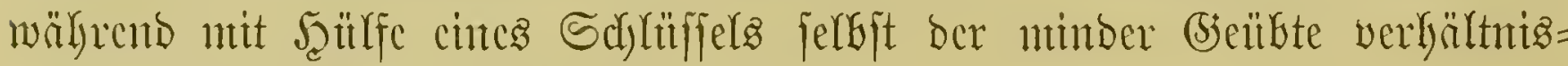

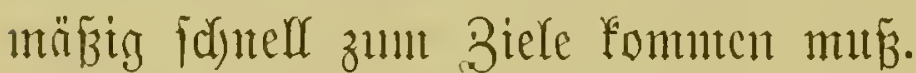

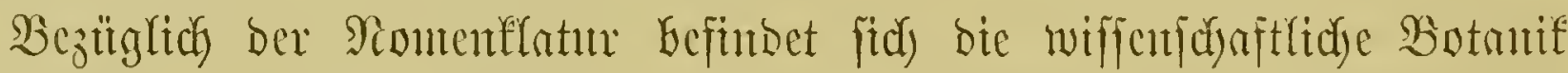

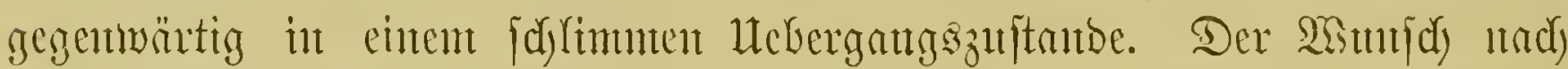

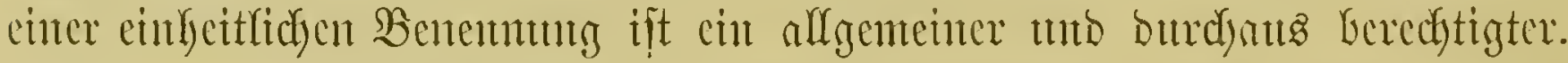

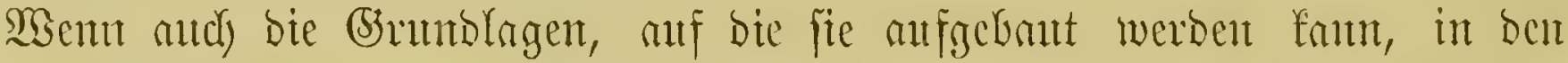
weiteren Sinien gezogen fint und wemn and bie Forberung, bie Prioritüt walten zut Yaffen, cine viclfadye Seredytigung lyat: fo Yefren bod gernbe bie

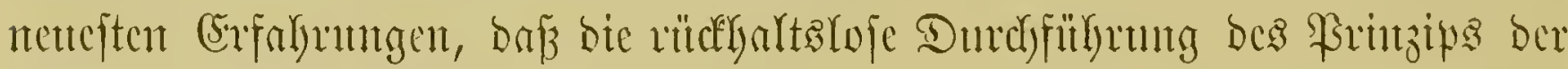

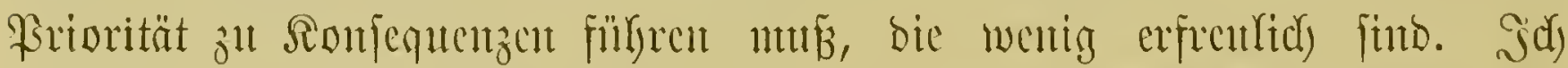

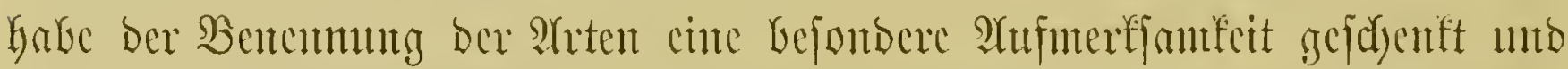

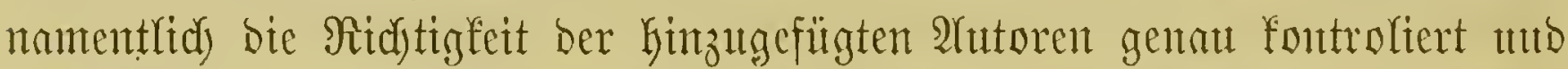
wo nötig verbeffert. Dagegen habe id won ber Sinfuthrung neuer Ramen,

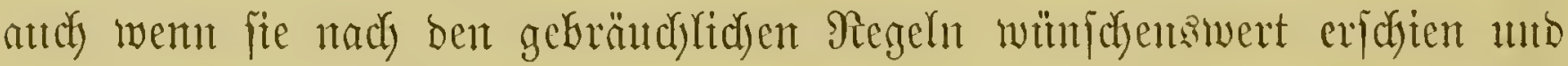

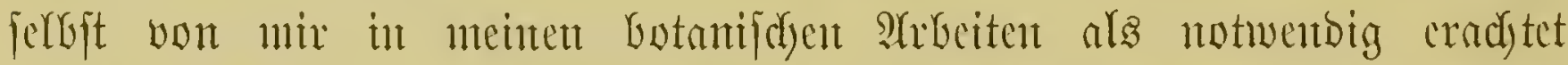

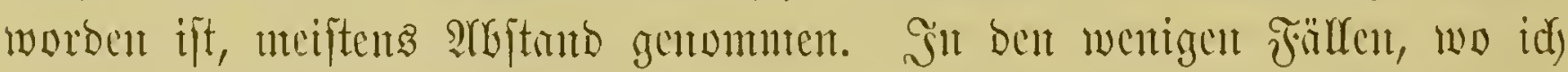

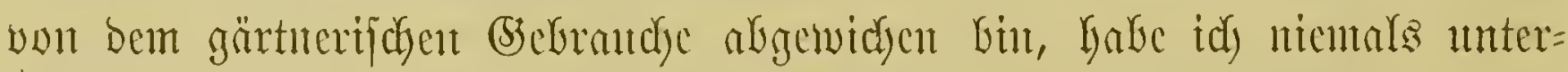

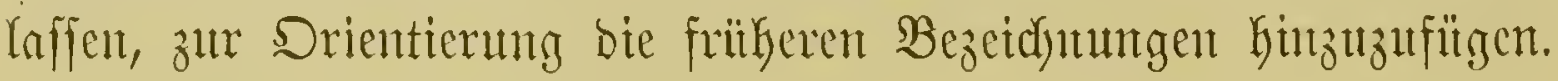

Bertiu, Eeptontser 1892.

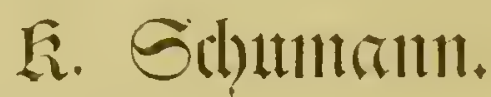




\section{直 $\mathfrak{n} \mathfrak{h} \mathfrak{a} \mathfrak{l} \mathfrak{t}$.}

I. Familie Liliaceae. Riłinngewädyje.

Seite

Stamm I. Anthericinae. Bragltititartige Bjetwächje . . . . . . . . . 3

1. Battıng Bulbine ............... 3

Stamı II. Aloineae. Âtoëgewäd̆je . . . . . . . . . . . . . . 5

1. B̉attung. Aloë Linn. $\mathfrak{A}$ ฉё . . . . . . . . . . . . . 5

2. Biattung Gasteria Duval . . . . . . . . . . 14

3. Satturg Apicra Willd. . . . . . . . . . . . . . 17

4. (Battung Haworthia Duval . . . . . . . . . . . 19

II. Framilie Portulacaceae. Portulafgerväd)j.

1. Biattung Calandrinia. Humb. Bonpl. Kth. Enlanbrinte . . . . 27

2. Banttung Portulaca Linn. Fortulą . . . . . . . . . 29

III. Fantilie Mesembrianthemaceae. Mittagabłumengewädyje.

(5)attung Mesembrianthemum L. Mittagăbhume . . . . . . . . 31

IV. Familie Crassulaceae. Didf́lattgemädyje.

1. Battung Sedum Linn. Mauerpfeffer, Fretthente . . . . . . 44

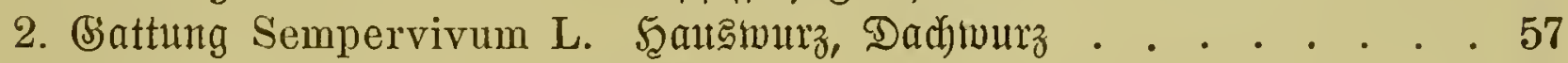

3. Battung Cotyledon L. Rakelfraut . . . . . . . . . . 69

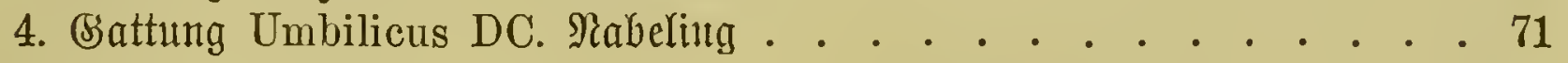

5. Battung Echeveria DC. (5eneberie .......... 75

6. Brattıng Bryophyllum Salisb. Brutblatt . . . . . . . 86

7. (Sattung Kalanchoë Adanson §alautd)ö . . . . . . . 86

8. Biattung Crassula L. Dicfblatt. . . . . . . . . . . 89

9. (3attung Rochea DC. Yiochea . . . . . . . . . . 95

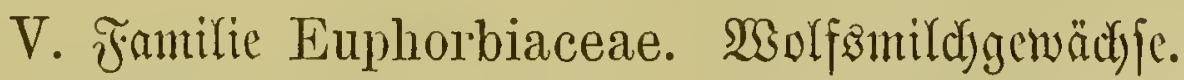

(3)attung Euphorbia L. Wsolfamild . . . . . . . . . 98

VI. Familic Cactaceae. Raftusgcwächje.

1. Saattung Cereus Haw. Fadeltaftug . . . . . . . . . . . 121

2. Brattung Echinocereus Lem. Sgelfacteltaftı . . . . . . 135 
Sattutg Pilocereus Lem. Saarfacfelfatus

4. (S)attung Phyllocactus Lk. Blattfaftus . . . . . , . . . . 145

5. (B)attıng Disisocactus Lindl. Bierblattfafłı . . . . . . . . . 156

6. Battung Epiphyllum Pfeiff. (SIliederblattfaftı . . . . . . . 158

7. Sattıtg Echinopsis Zucc. Sccigclfattu . . . . . . . . 165

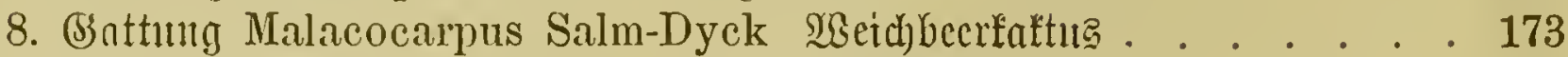

9. Siattıng Echinocactus Lk. et Otto Sgelfaktug . . . . . . . . 175

10. Sattung Astrophytum Isemaire SterufaftuE . . . . . . . . . 188

11. Battıng Anhalonium Lem. Arloëfaftıอ . . . . . . . . . 189

12. Battung Leuchtenbergia Fisch. Reuthtenbergie . . . . . . . . 191

13. Battıng Mamillaria Haw. W̧arzentaltı . . . . . . . . . 193

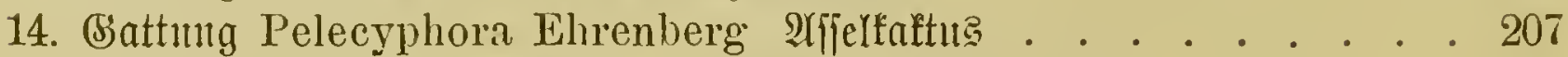

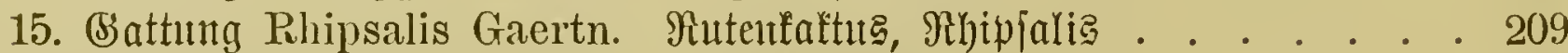

16. BSattung Opuntia Tournef. Feigenfaftus . . . . . . . . . . . 213

17. Sattung Peireskia Plum. Laublatug . . . . . . . . . 219

VI. Frmilie Asclepiadaceae. Seibenpf(anzengemäd)fe.

1. Sattung Ceropegia L. Reutfterblume . . . . . . . . . . 235

2. Biattung Hoya R. Br. WGachblume . . . . . . . . . . . . 239

3. Sattung Stapelia L. Stapelte . . . . . . . . . . . . . 242

4. (Jattuntg Huernia R. Br. F̧uernie R. Br. . . . . . . . . . . . 247

VIII. Fanilie Compositae. Rorbblütler.

1. S̋attıtı Ǩleinia DC. Sleinie . . . . . . . . . 250

2. Jathung Senecio Linn. Breisfratt . . . . . . . . . 252

3. Jiattıntg Hertia Less. F̨ertie . . . . . . . . . . . . 253 


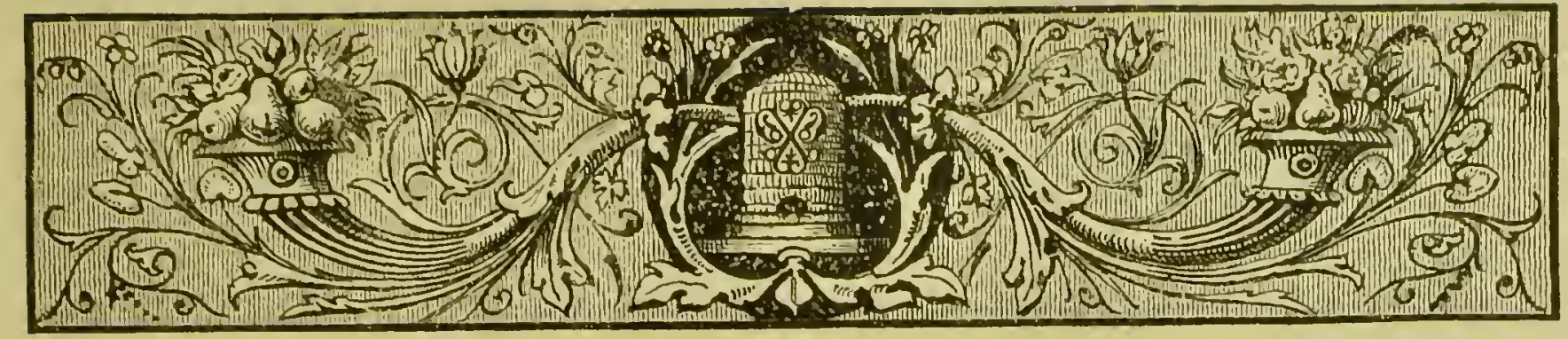

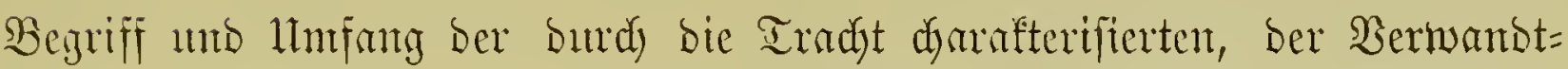

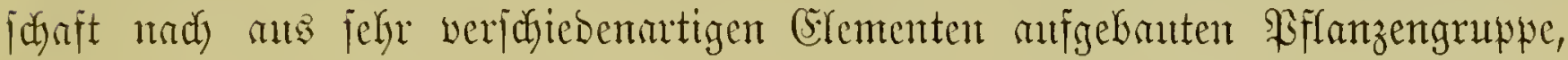
bie wir Suffulenten nemten, werben in jehre verichicbener Saseife aufgefáft. Der Rame ijt ans bent Rateinifden Succus, Saft, gebilbet unto bezeidjet

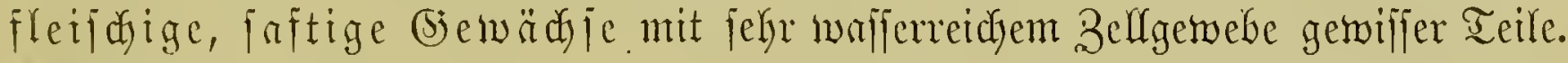

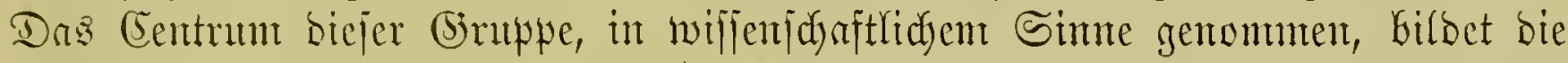

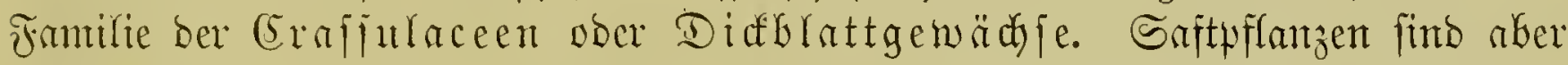
and Afngehörige anberer Familien, weldye nit jener bie faftige Bejdaffentyeit bes

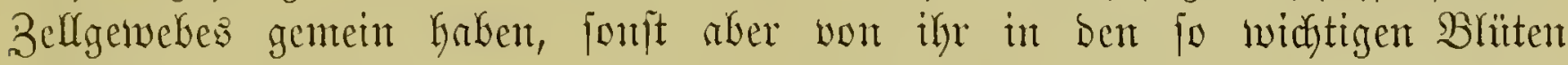
wejentlidy veridficben finto, unter biejen vomehmlidy bie Raftusgewädje in igrem ganjen Irtenbeftmbe, fonie bic Biatturgen Mesembrianthemum,

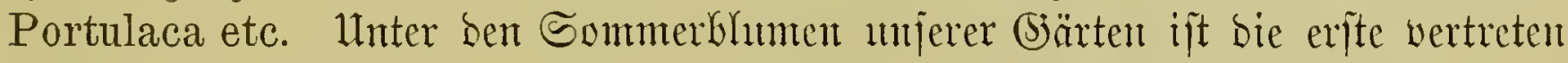
burd) Mesembrianthemum tricolor, in ben Sï̈hengärten bie z'weite burd Portulaca sativa, ben ßoortıllat.

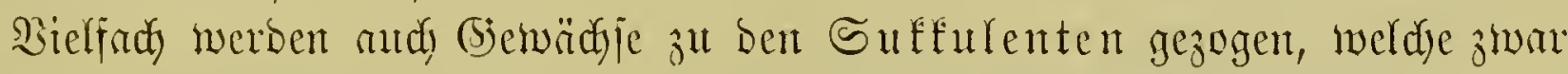

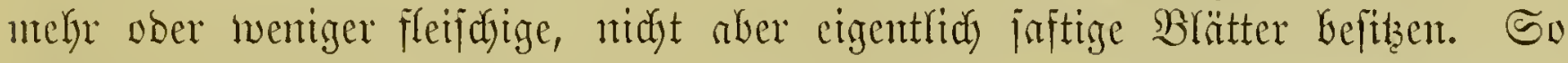

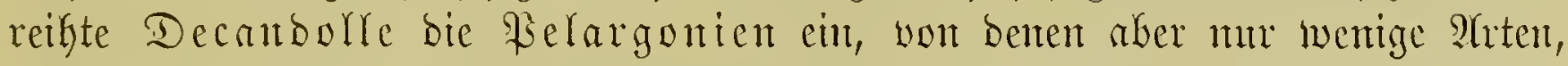

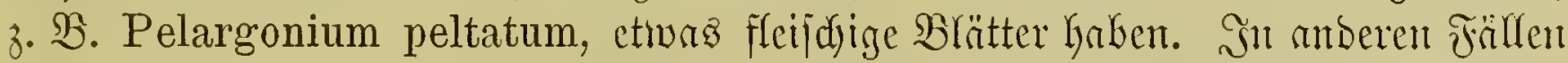

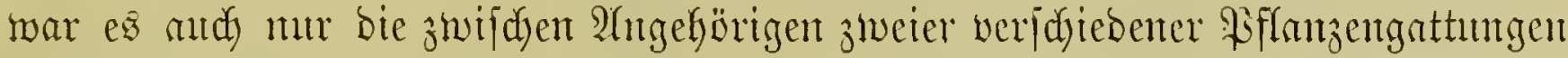

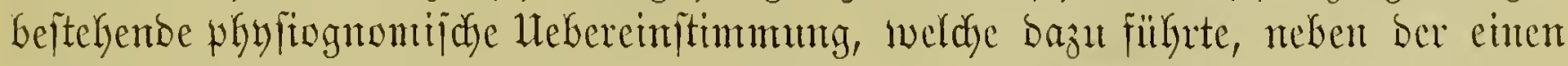
Form and bie antoere cinzulorbnen, obwohr biejer ber eigentfidye Sulfullenten= d)arafter abging. S5s gilt bies nuter anteren wou ber (Siattung Agave, weldye

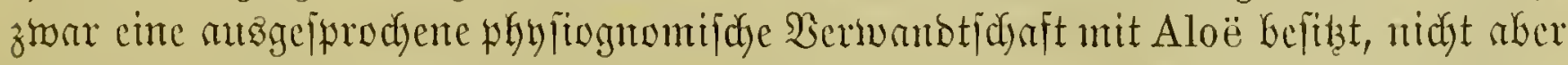

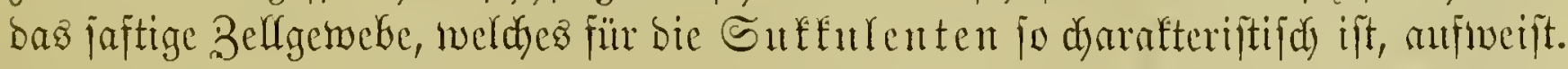

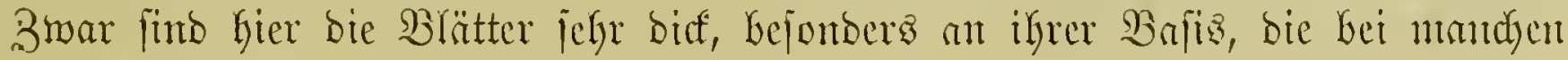


Trten bie Stärfe eines Minmeajdyenfels erreidyt, bagegen finto fie aber, mit Aloë

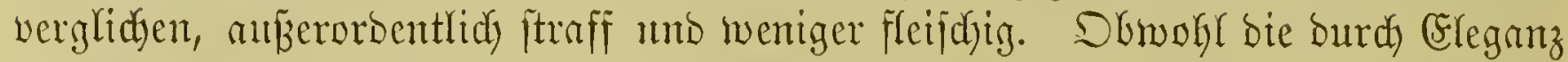

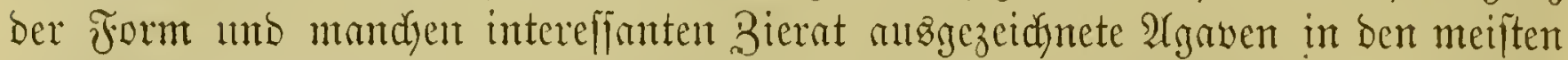

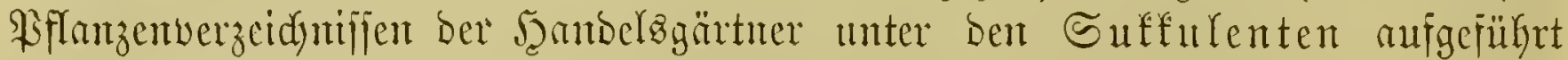

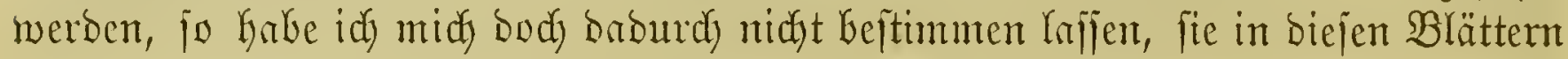
neben ber (S)attunts Aloë worzuffilifrent.

Sie sben bemertt, Gilben bie Erajjulaceen und Eactaceen baz Eentrum ber Suffulenter.

Itm ite herum gruppieren fid nody mandye anbere, im Suffulenten=

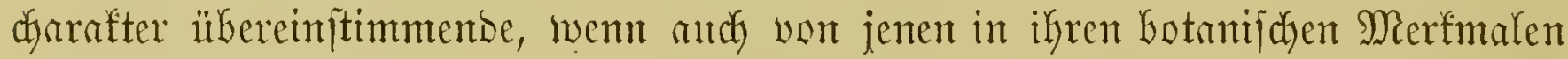
afweidyento Siflanzen: inter biejen viele Arten ber (Sattıng Euphorbia, burdy

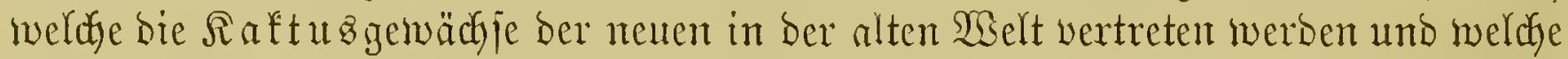
biejen nidyt nur in ber Bejdyaffentyeit bes Belfgewebes, jonbern audy in phyjüg= nomijater Beziefuntiz jefr nafye itelyen. So ijt Euphorbia trigona bas trene

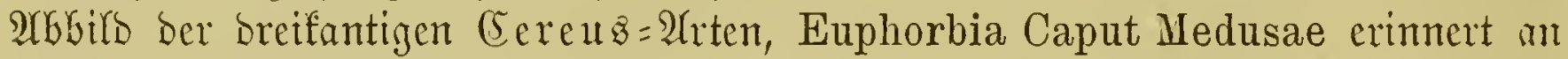
einzelne wayzenförmige Dpuntien. Euphorbia mamillaris äfnelt mandyen Eefinofafen, Euphorbia meloformis Den Melofaften. Euphorbia

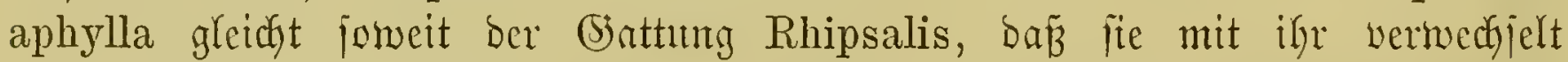

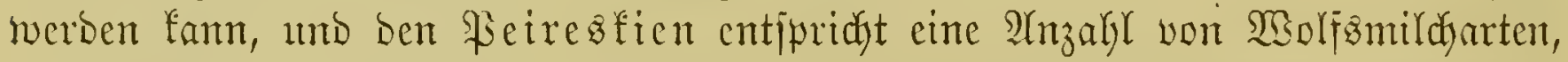
wie Euphorbia lophogona, neriifolia u. j. w. In ähnlidjer 绿ije repräjentieren bie Etapelien Eubafrifas bie Sambelaberfornt ber Sereen, einzelne Arten ber (5)attung Ceropegia bie Rhipsalis= Form.

भYU

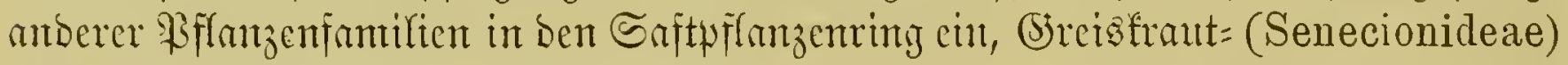
unb Fortulafigemädje (Portulacaceae) u. F. ho., jowie andere, von benen

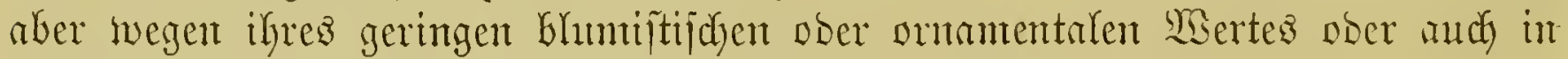

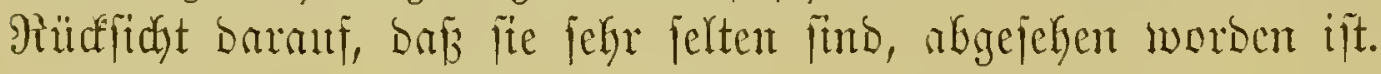

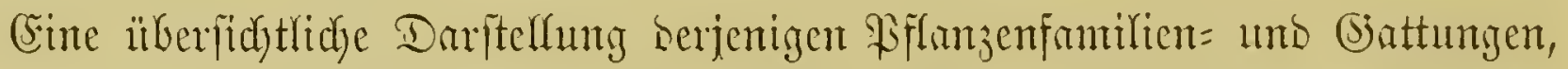

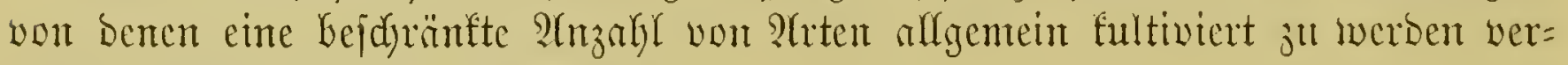
bienen, bürite Gier am gilatie jein.

I. a) Liliaceae - Anthericinae. - (Sattung Bulbine.

b) Liliaceae - Aloineae. - (battungen Aloë, Gasteria, Apicra, Haw orthia.

II. Portulacaceae. - Bjattungen Calandrinia, Portulaca.

III. Me sembrianthemaceae. - (Sattung Mesembrianthemum.

IV. Crassulaceae. - ßattungen Sedum, Sempervivum, Cotyledon, Umbilicus, Echeveria, Bryophyllum, Kalanchoë, Crassula, Rochea.

V. Euphorbiaceae. - Battung Euphorbia.

VI. Cactaceae. - Bsattungen Cereus, Echinocereus, Pilocereus, Phyllocactus, Disisocactus, Epiphyllum, Echinopsis, Malacocarpus, Echinocactus, Astrophytum, Anhalonium, Leuchtenbergia, Mamillaria, Pelecyphora, Rhipsalis, Opuntia, Pereskia.

VII. Asclepiad a cea e. - (3attungent Ceropegia, Hoya, Stapelia, Huernia.

VIII. Compositae. - Battungen Kleinia, Senecio, Hertia (0thouna). 


\section{Familie Liliaceae. Riliengemädhie.}

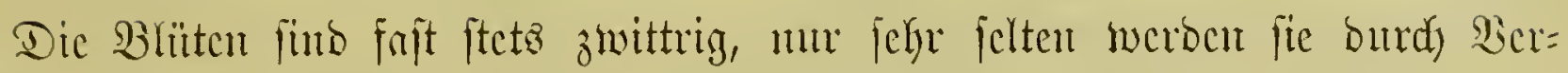

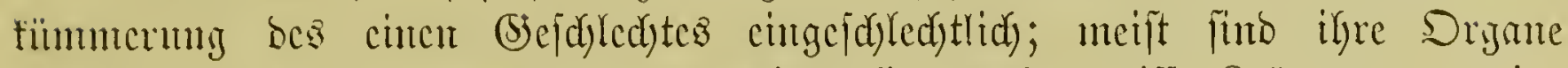

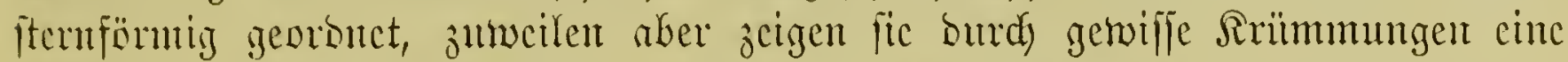

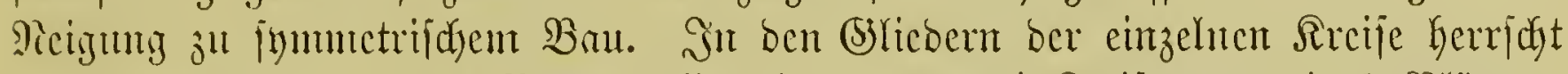

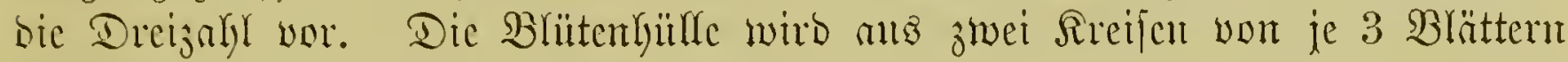

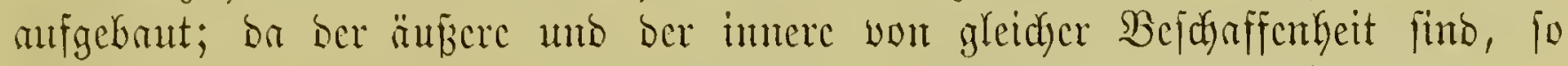

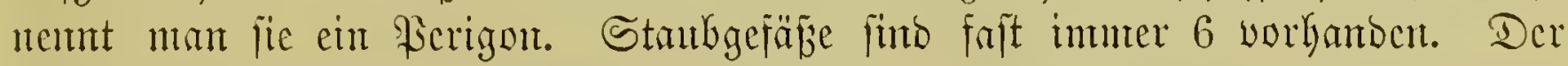

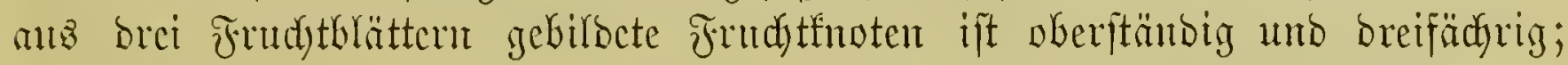

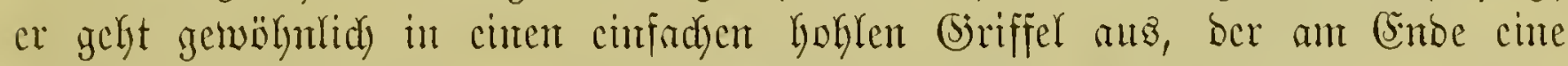
breilappige Rarbe trägt. Die Santentanlagen jitzen im Sinnern bes Frudft=

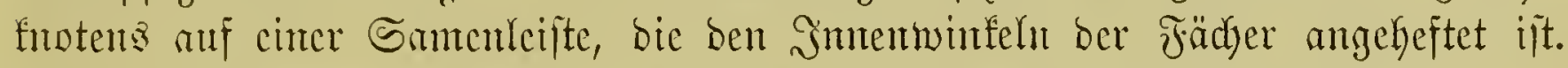

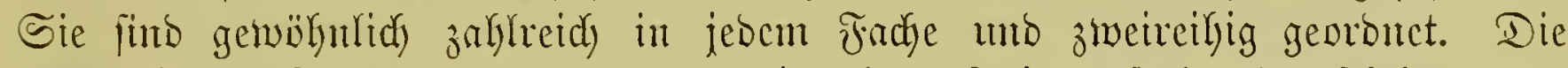

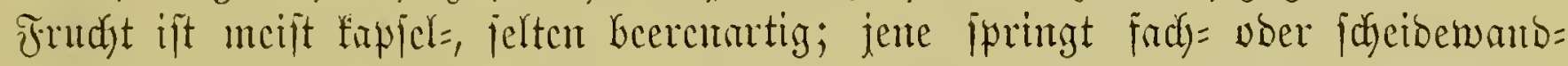

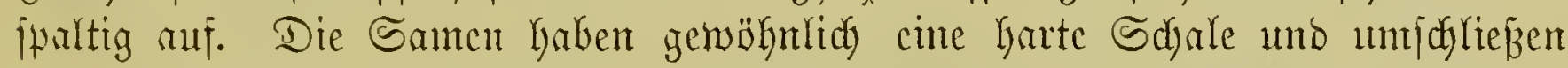

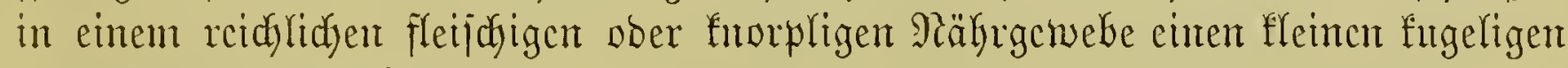
obcr cylinorifdycu Reimling.

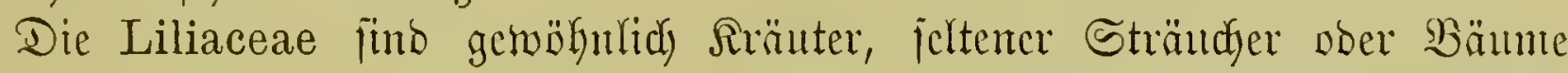

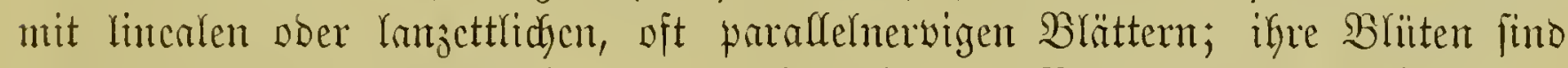

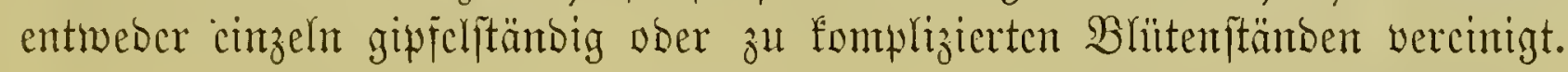

\section{Stanm I, Anthericinae. Girnglilienartige Ģemädje.}

Daz \$icrigon ift ticf 6 teilig rnojürmig. Die Staubbrätter finto unter scm

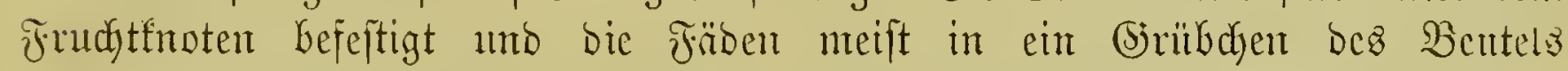

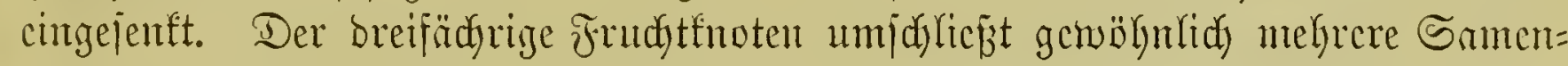

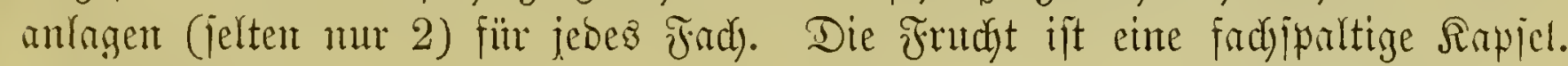

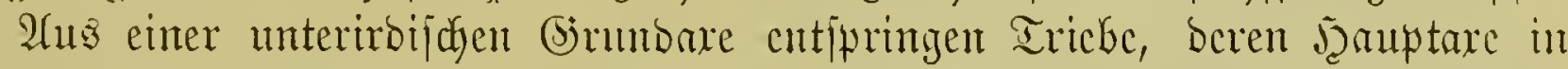

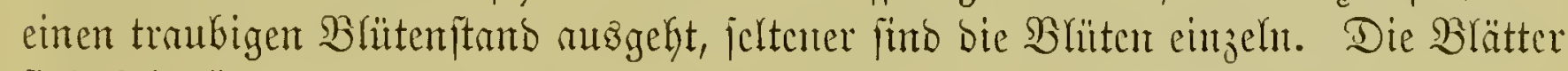

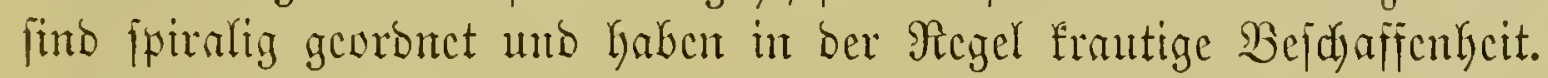

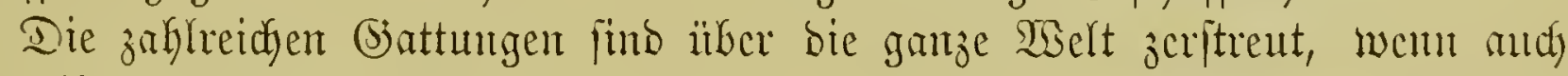

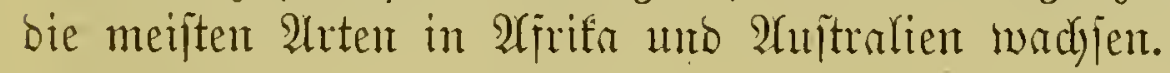

\section{Brattung Bulbine.}

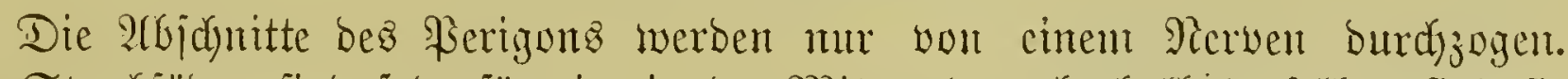
Die Strubfäben fint fabenförntig, in ber Mitte obcr oberhalb berjelben finto jic langgebärtet; fic jinb ben Staubbenteln oberflädylich autgcheftet, aljo nidjt in cin

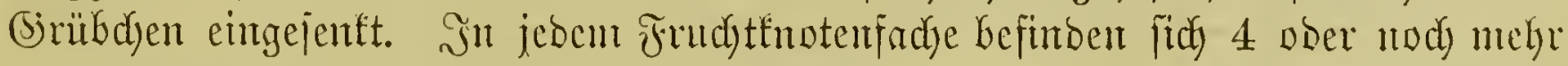
Samenanlagen. Die Samen funb breifantig.

Die Sorunbare jenbet frontige pber iafwad) verholzente Stengel ans, bic an

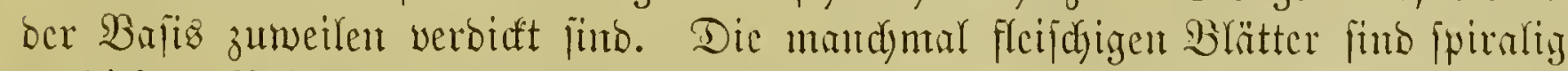

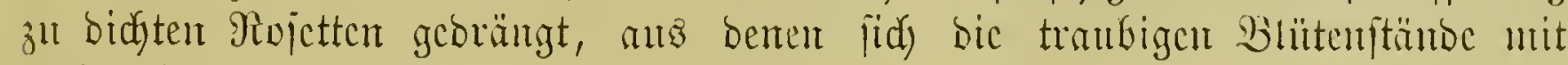
gelben Shlitten ergebcr. 


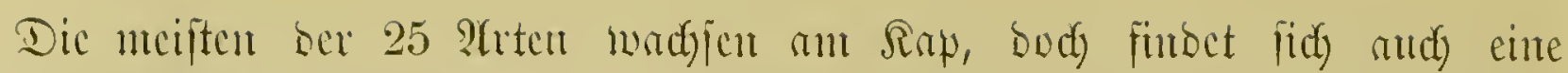

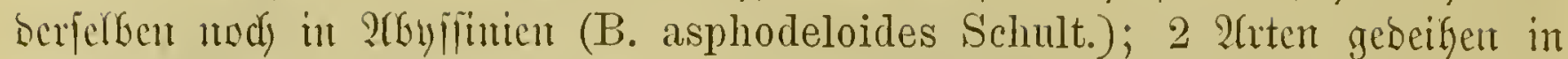
Dit=2uftralien. Sie furo in ber Rultur gegennörtig nur wenig werbreitet, aber Dod) volffommen ber Berïffict)tigumig wert.

Der Rante ftrmmt vou bent Iateinifaen bulbus, bie 3wiebel.

Sd liiffel für die befariebenen Urterr. Artert

A. Straudige mit eillem furzen, verholzten, verzweigten Stämmchen verjehene

B. Nicht itrauchige 2lrten mit bodenjtändigen Rojetten.

a) Blätter pfriemlich, höchitens von Der Dicfe einte BLeiptiftę

b) Blätter flach).

a) Blätter lauzettlich, Duntelgrïı

§) Blätter oblonglanzettlich), bla

2. B. pugioniformis Link

3. B. alooides Willd.

4. B. latifolia Schult.

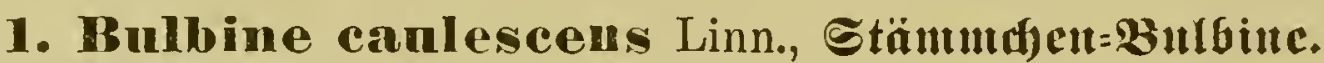

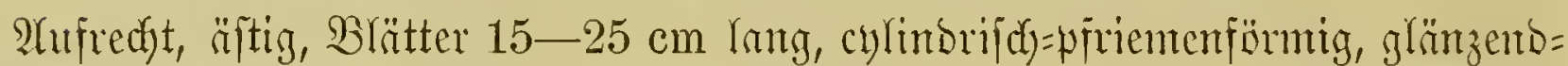

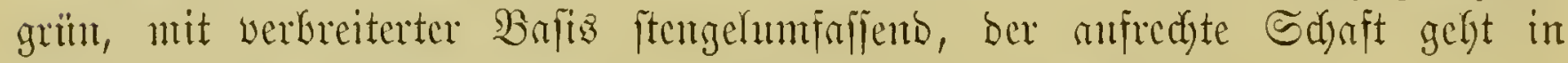

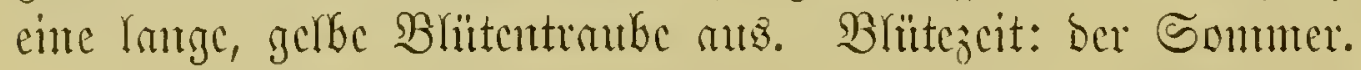

Diejcr ât' älunlidy ift Bulbine longiscapa Willd, fie hat aber fürjere,

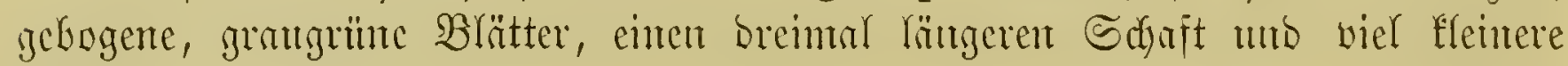
Błïten.

\section{Bulbine pngioniformis Lk., boldblätterige Bulbinc.}

Strmmloje Stmoe mit priemförmigen, oben von einer Rinne burdjogenten,

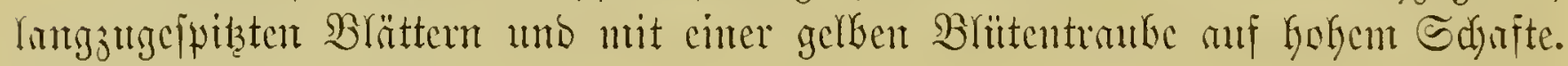
Brïtejcit: Der Sonmer.

\section{Bulbine alooides Willd, aloëblättcrigc Bulbiute.}

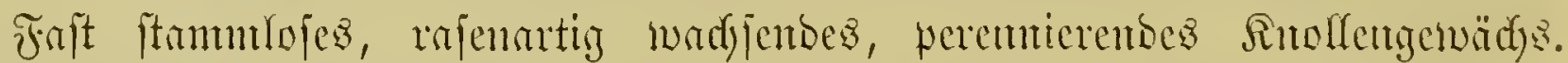

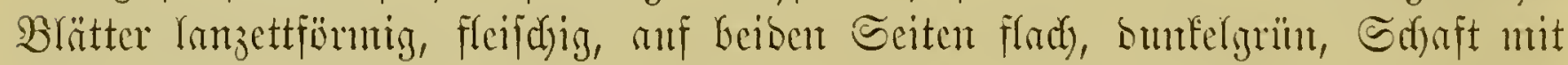

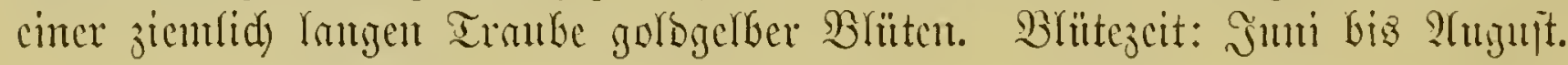

\section{Bulbine Iatifolia Schult, breitblättcrige Bulbiuc.}

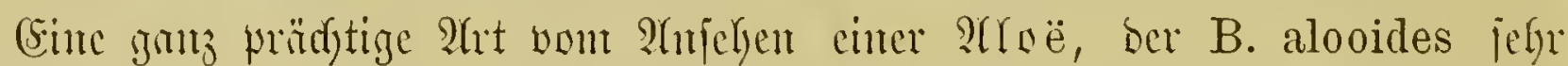

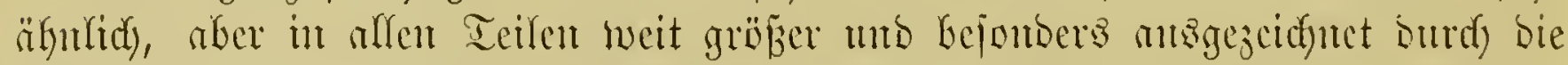

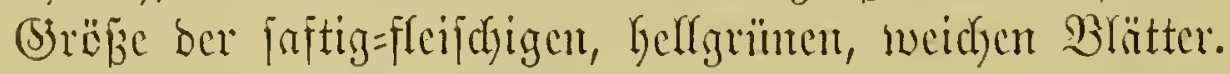

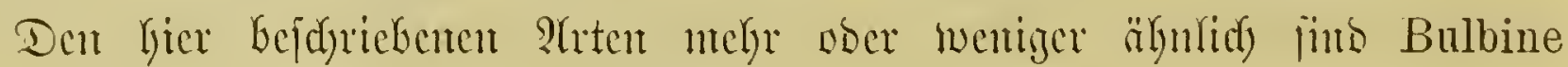
Mackeni Bak., B. rostrata Willd. «. ґ.

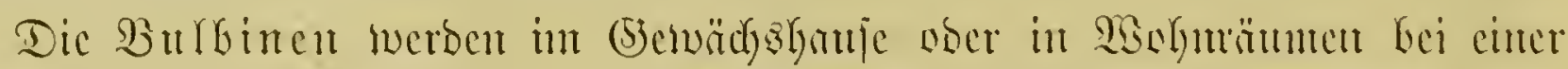

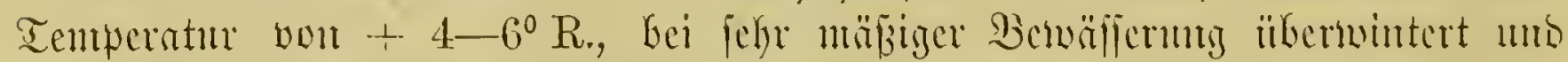

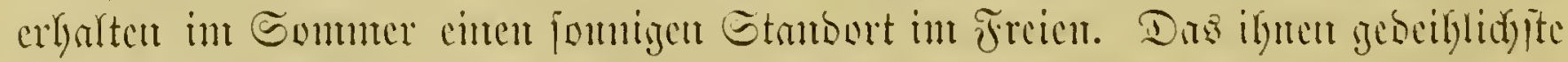

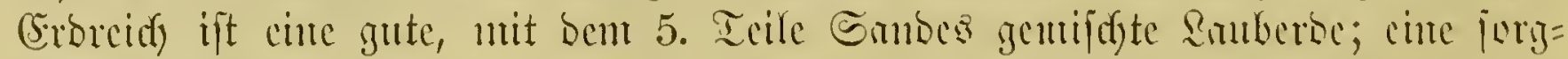

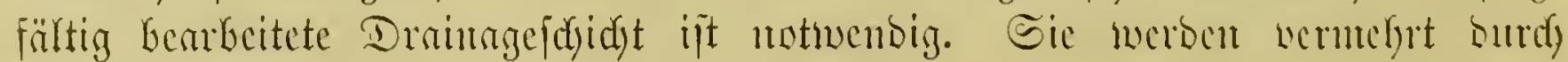

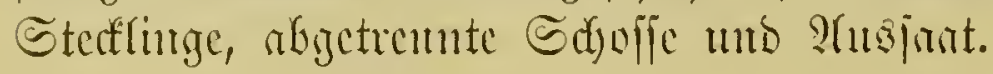




\section{Stanı II. Aloineae. Âtuëgetwäd)je.}

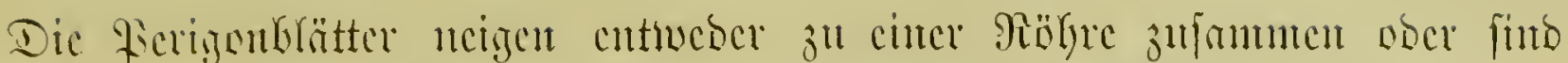

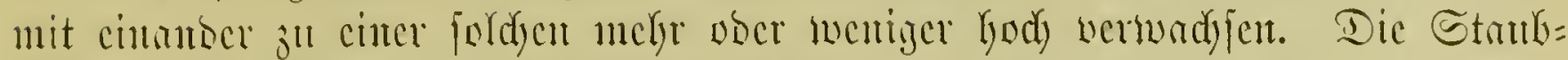

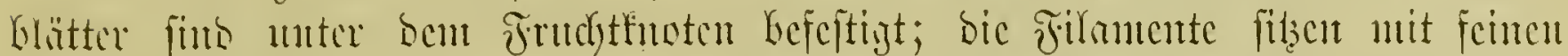

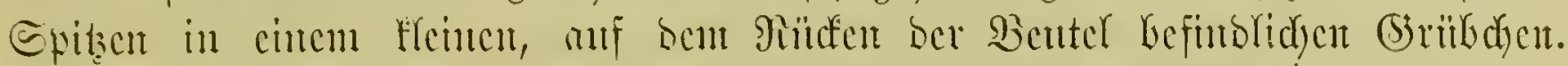

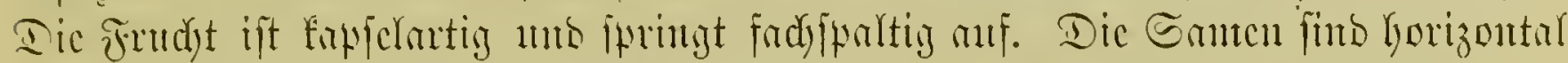
geraigert, cuttucber flad wor sucifuntig.

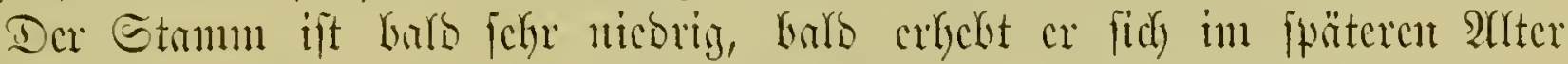

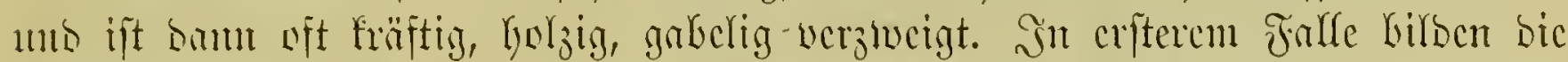

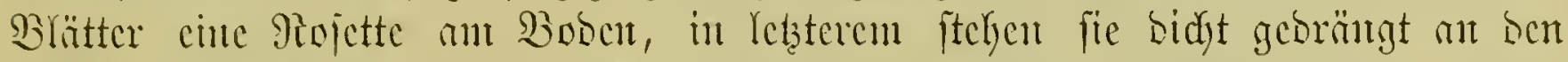

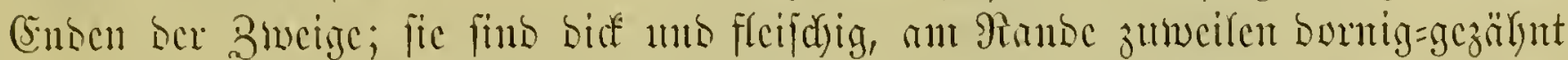

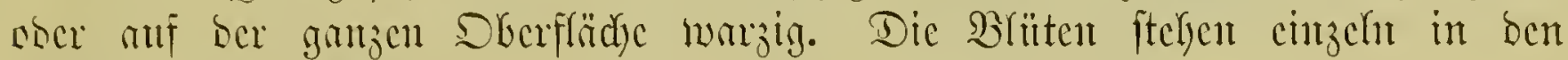

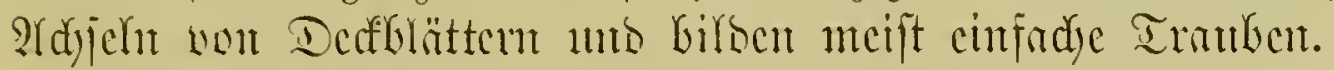

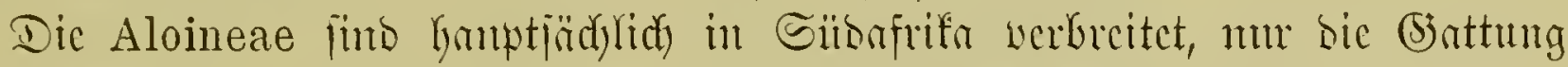

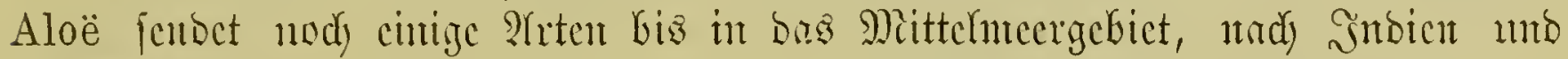
Gis mady Crgint.

\section{Shlïffel für die Battungen.}

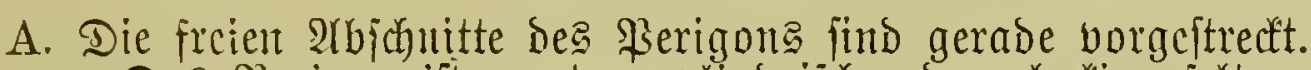

a) Dab Scrigon ift gerabc, chlinbrifach ober gloctig, feltenter ein wentig ge=

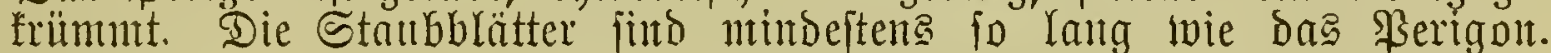
Die Blätter fitto pitt am 丹anbe Dornig=gczähnt

b) Das \$serignit ift bcutlich geftrimmt, ant (Srunde baudjig. Die Staub=

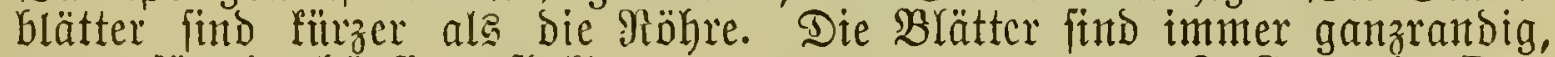
zungeñörming, häurfig geflecét

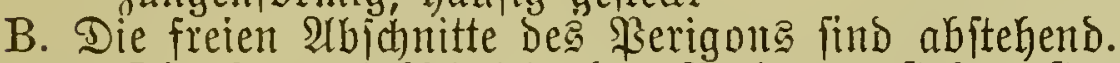

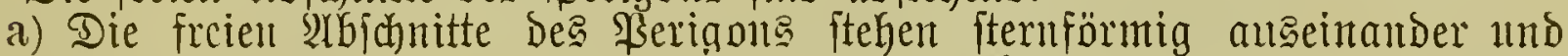

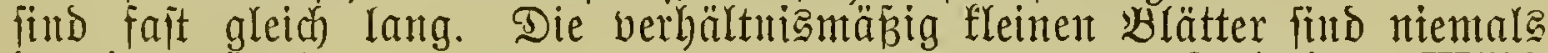
Dornig=gezähnt

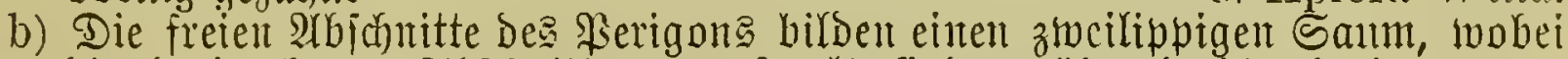

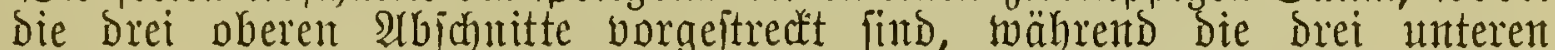
jparrig abftehent. Die fulržct und breiten 'Blätter find häufig twarzig, nicht jeltert gezähnelt noer gemimpert 4 . Haworthia Duv.

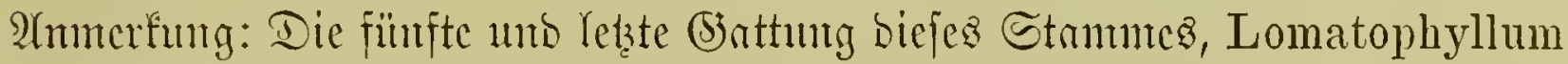

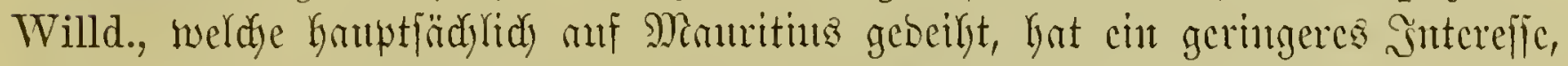

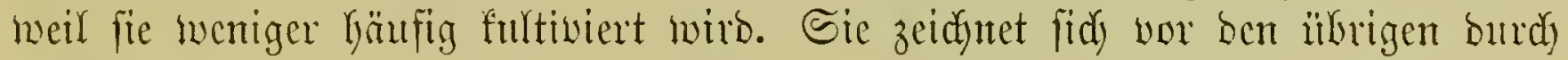
fleipdrige Fritid)te חus.

\section{Giattung Aloë Linn. MAloë.}

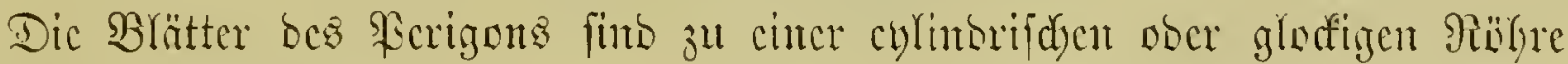

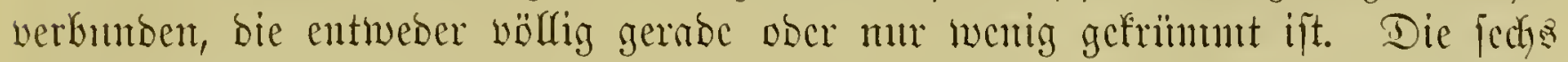

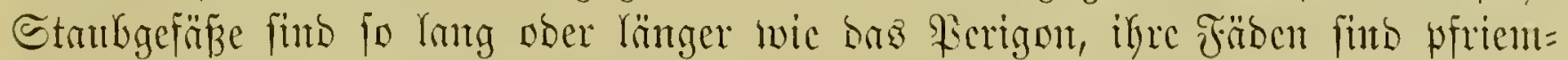
Yidy. Die Camen fint oft jdymf breifmetig, zuncilen jogar geflügct.

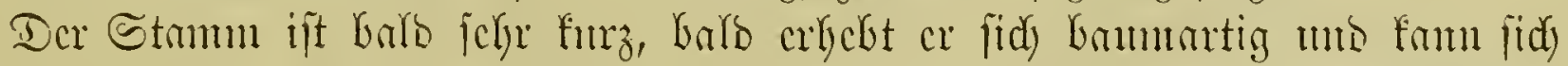

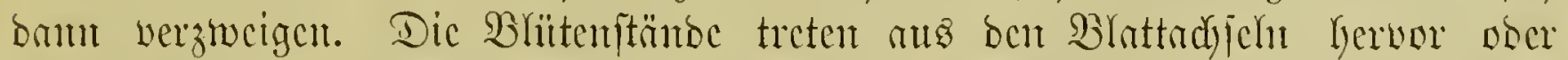

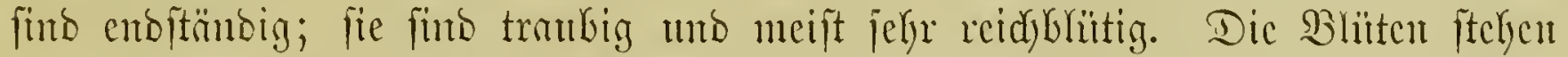

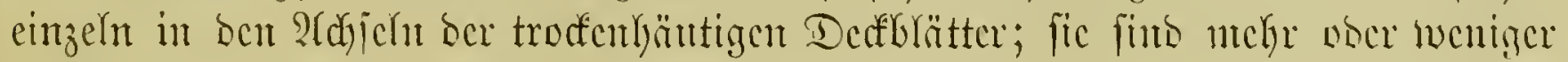

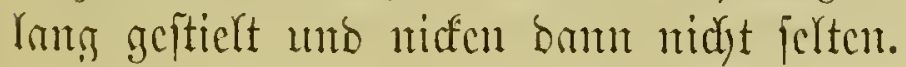




\section{Sdlïffel für die bejdriebenen Urten.}

I. Untergattung Evaloë Bal. Blätter viel=, lelten zmeireifig; ßerigon gerade.

A. Stantmilofe $\mathfrak{A r t e n}$, die Blattrofette berïhrt die Froe.

a) Strubblätter nno Stempel von ber Ränge des łerigong.

a) Blr̈tter in eine $1-1,5 \mathrm{~cm}$ lange burchicheinende Spize verjhmälert, nid)t linitert

1. A. aristata Haw.

ß) Wlätter ohne jene durchicheinende Spize, linitert 2. A. humilis Mill.

b) Strubblütter mb Stempel länger ale das ßertgon 3. A. Bowiea Hav.

B. Urten mit furzem, bei ben beid)riebenen 2rten unberzweigtent Stamme.

a) Blätter ungefleclt oder nur undeutlich geflect.

a) Blätter lanzettliţ, gezähnt

B) Blätter cblong=lanzettlich, ganzrandig

b) Brätter geflect̆t.

a) Blüten fopfig bi⿱ doldentraubig

ß) SBlüten traubig.

4. A. brevifolia Mill.

5. A. striata Haw.

I. Blätter unterhalb der Spize auf ber Dberjeite flach, linitert.

1. Blätter $15-30$, die höchjtens $25 \mathrm{~cm}$ lang werden, Traube bicht

7. A. obscura Mill.

2. Blätter $12-20$, Doppelt fo lang mie bei voriger 2 ht und jehr lang zugeipizt, Traube locfer 8. A. grandidentata S.-Dyck.

II. Blätter anf ber Dberjeite gewölbt, nidht linitert 9. A. tricolor Bal.

C. Mit $3-4 \mathrm{~m}$ hohem Stamme 10. A. Salm-Dyckiana Schult. fil.

II. Intergattung Gonialoe Bak. Blätter ftarł geflectt in 3 Beilen; ßerigon gerabe

11. A. variegata Lim.

III. Untergnttung Pachydendron Bal. Bläiter vielreihig ungefledt'; ßerigon leicht gefritmmt, Staubblätter lang herborragend, bentlich nach unten geneigt

12. A. ferox Mill.

IV. Itntergattung Kumara Medic. Blätter in 2 Beilen; ßerigon gerade, die intueren $\mathfrak{U} b$ fichitte frei

13. A. plicatilis Mill.

Die Siattung Aloë in bem Sinne, welder ilyr jucrit won Tournefort, ipäter von Rinné gegeben wurbe, umfä́te jämtlidje (Stejdyledjter ber Aloineae. Duyal war ez zuerft, ber Gasteria uno Haworthia abtrente, wornuf enolich Milrbenom bie Sattung Apicra jumf. Die übrigen jonft nody gebilbeten

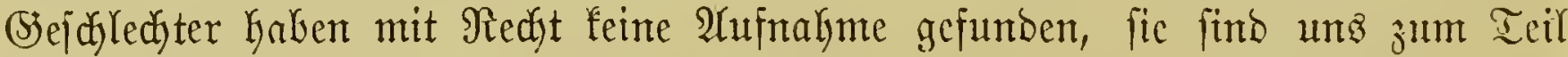
(Rhipidendron unter bem ältern Namen Kumara unb Pachydendron) alz Geftionen yon Aloë begegnet.

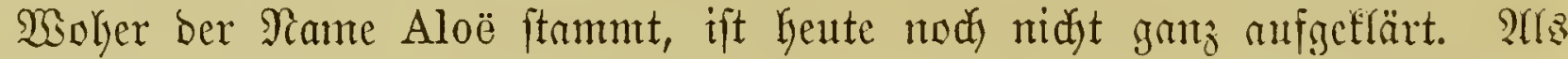

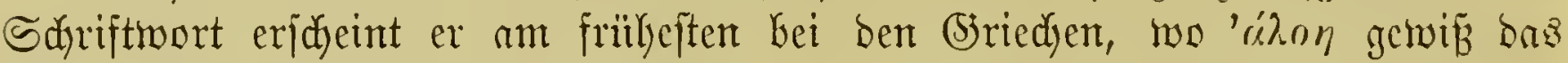

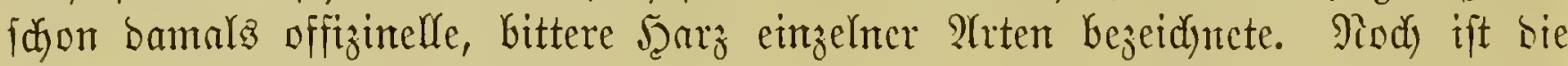

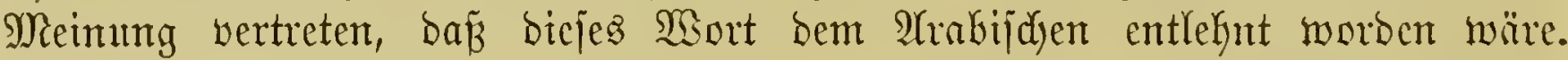

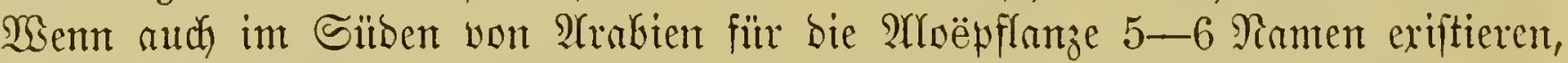
io bat bod feiner berjelben etwas mit minerer Bezeidynumg ju thun. Der gelr̈ufigfte Name für bie Aloë vulgaris L. unb allgemein befannt aud im alten $\mathfrak{A}$ rabijaç ift Sobbârâ.

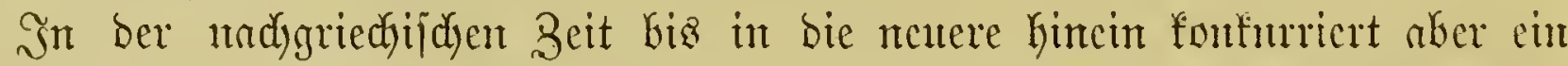

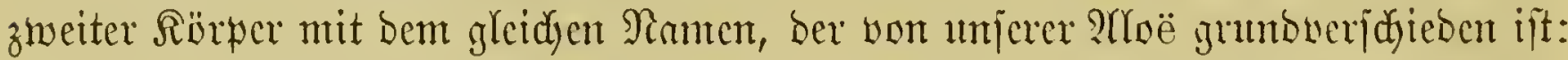

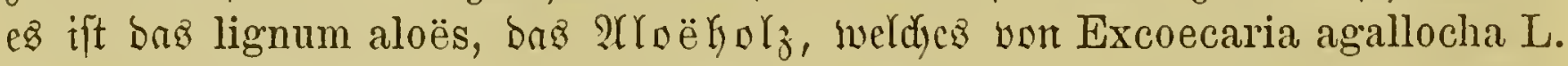
ftammt unb fütr bas ans bent inbijdyen গanten agkil ber Trivialname agalloch

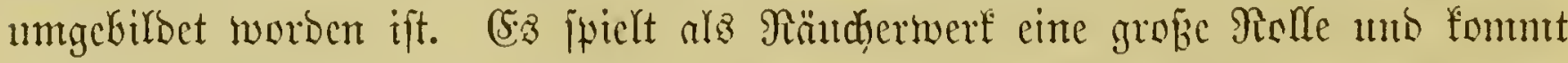
fomolyl in früben talmudifden Sdyriften unter ber Bezcidynung alwaj ober

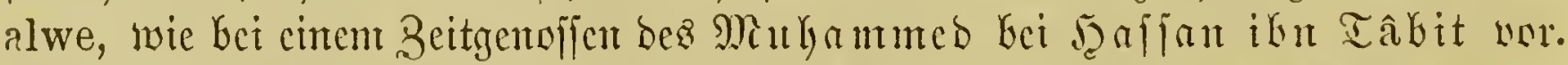

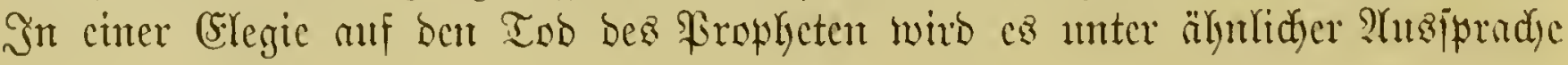


crwähnt. Mit Redyt vermutet man aber unter bem hebräifden Siamen nur cine in bicje Spradye ilbertragene Form bes griedjifden aloë. Wanthidyeinlidy

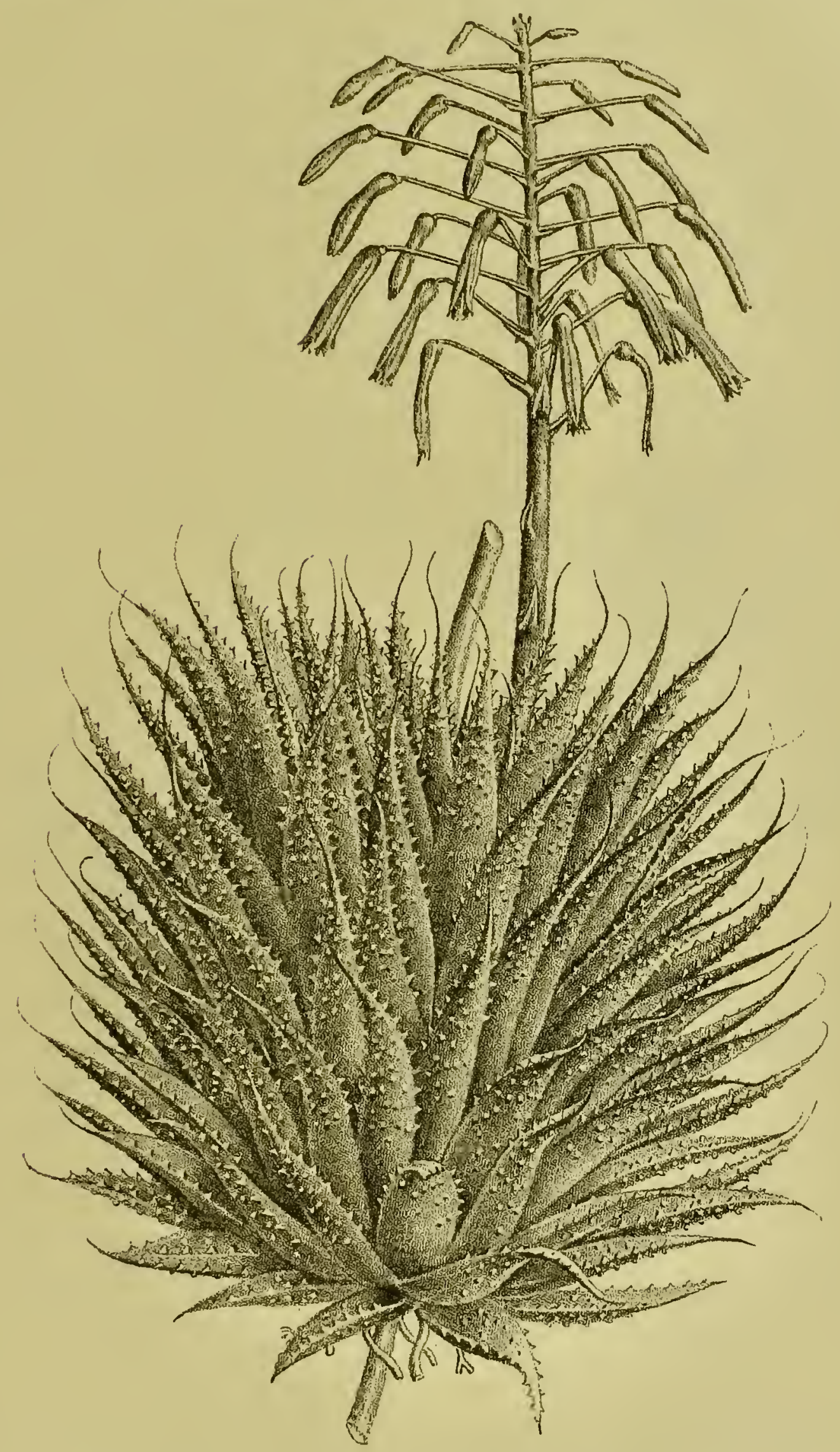

Frig. 1. Aloë aristata Haw. Begrannte भroë.

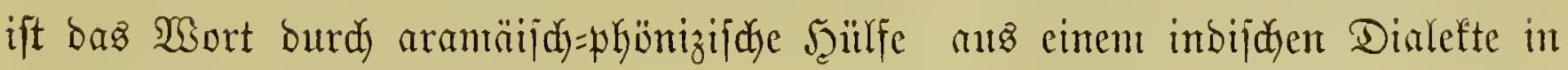
bie griedifaje Spradje gelongt.

Bon ben oben nufgefïfyten Siffanzen enthayten A. ferox Mill., A. plicatilis

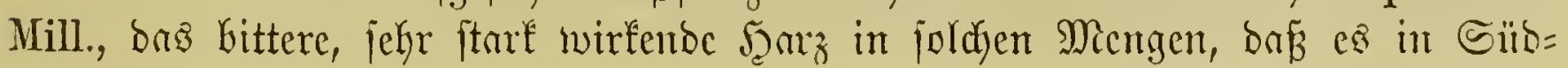




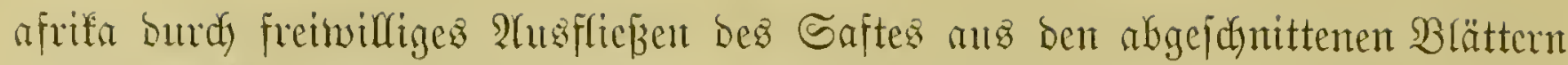

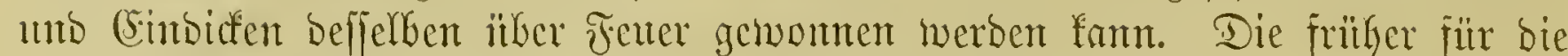
Gejte gelgaltente Socotora-Aloë jtrmmt nidyt won Aloë succotrina L., fondern won A. Perryi Bak.; bie eriftere wädjit mur am Siap, anf ber Jinfel Eofotra fommt fie nidyt wor.

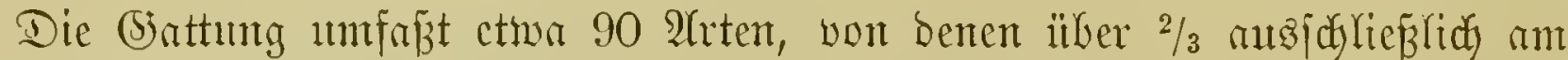

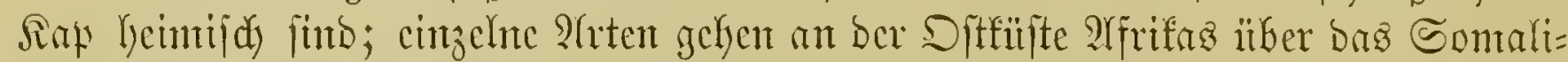

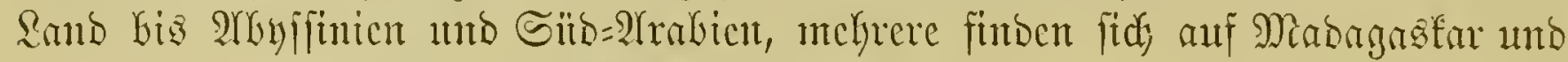
Solfotra; mud auf ber Whefffilite fömten fie Gis in bas Rigergebict verfolgt werben; in Smmern finbet fid) eine ?Yrt (A. Schweinfurthii Bak.) Die nöro=

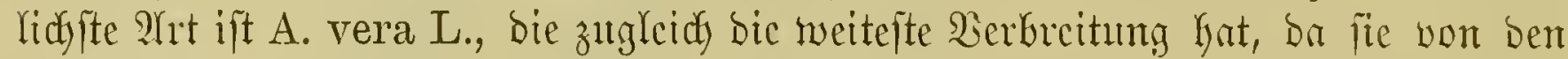

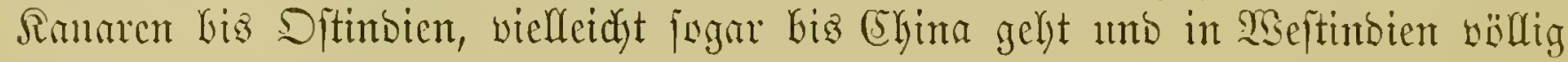
eingebïrgert ift.

Die fdyönften und für bie Sultur banfensmerteften finto folgenbe:

\section{Aloë aristata Hav. Begranute $\mathfrak{\text { Ulo }}$ ë.}

(A. longiaristata Roem. et Schultes.)

(Sin Stämmedjen ift in ber Negel nidyt musgebildet. 40-50 bidyt

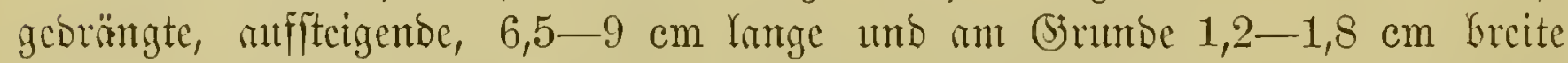

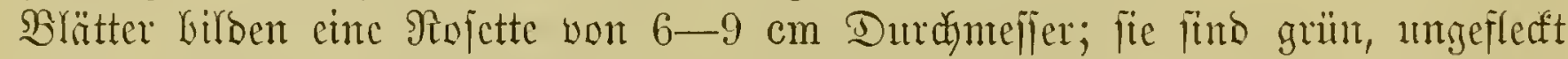
und ungeptreift, oberjeits flady und ipärlid marzig, unterjeits jeitlide mit

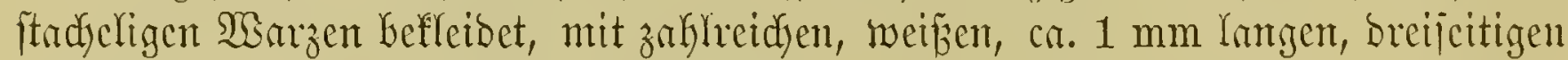

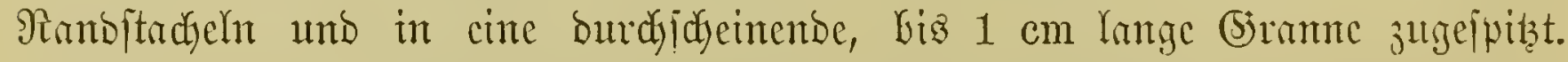

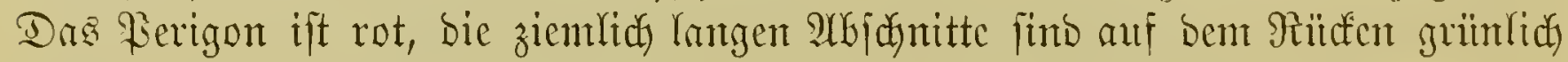

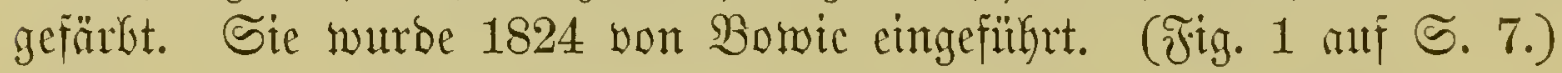

\section{Alö̈ hnmilis Mill. Micbrige $\mathfrak{A}$ foë.}

(A. echinata Willd.)

Fin Stanm mirb nidyt entwidfelt. 30-40 Blätter birben cinte bidyt gebrängte

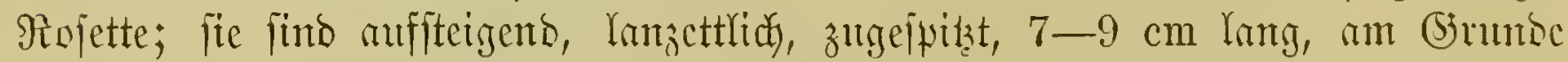
1,2-1,5 cm Greit, Glangrün uno unbentfid) Yiniert, oberjeits flad), untericits connex mit breifeitigen, zugeipizaten, blaffen Rantojtadjeln verjelyen. Das

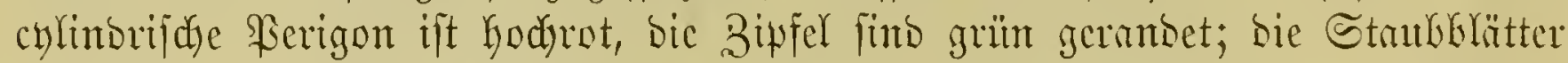
finto von ber \&änge beßs Perignns. Die var. acuminata Bak. (A. acuminata

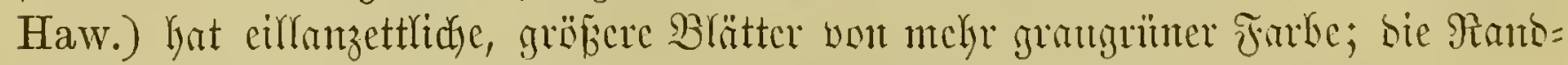

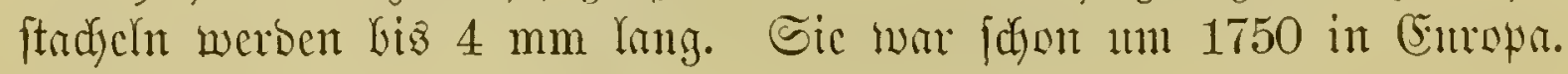

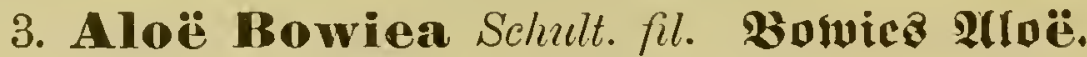

(Bowiea africana Haw.)

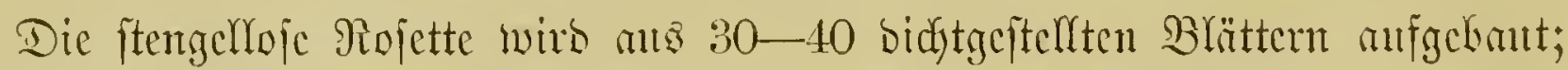

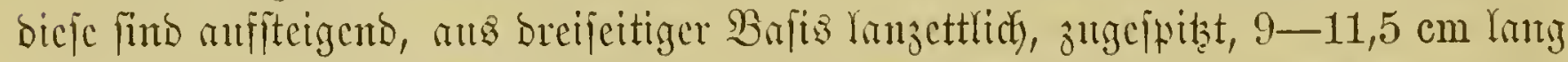

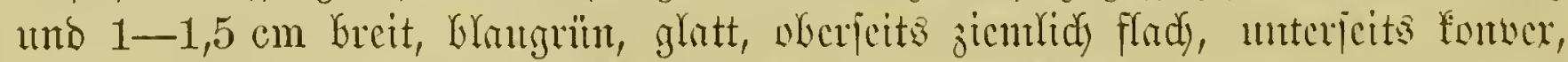

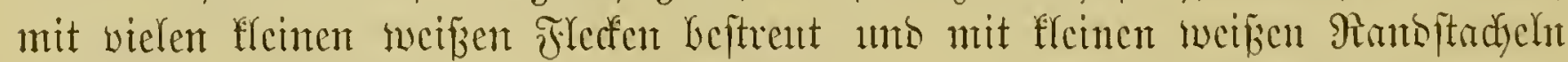
verjelyen. Das Serigon ift fentenfürmig, mur $1-1,3 \mathrm{~cm}$ lants, grïntidy weif und rot iiberflogen, bic Stankblätter ftelyen 3-5 mm weit herwor. Sic wutroc 1822 von Bonvic eingefülfyt. 


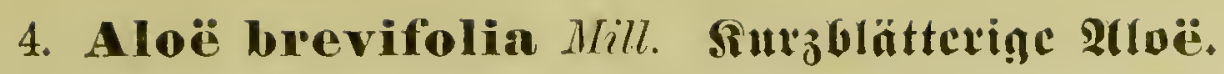

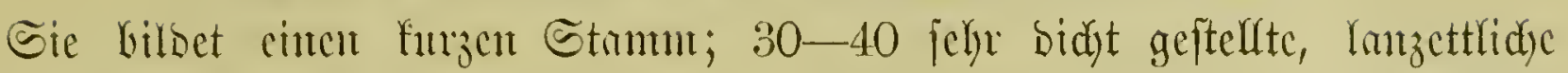

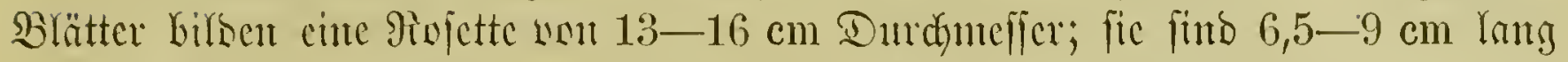
und $2,2 \mathrm{~cm}$ breit, Glougrïn, ungeffectit unb nidgt Yintiert, oberjeits glatt und nad)

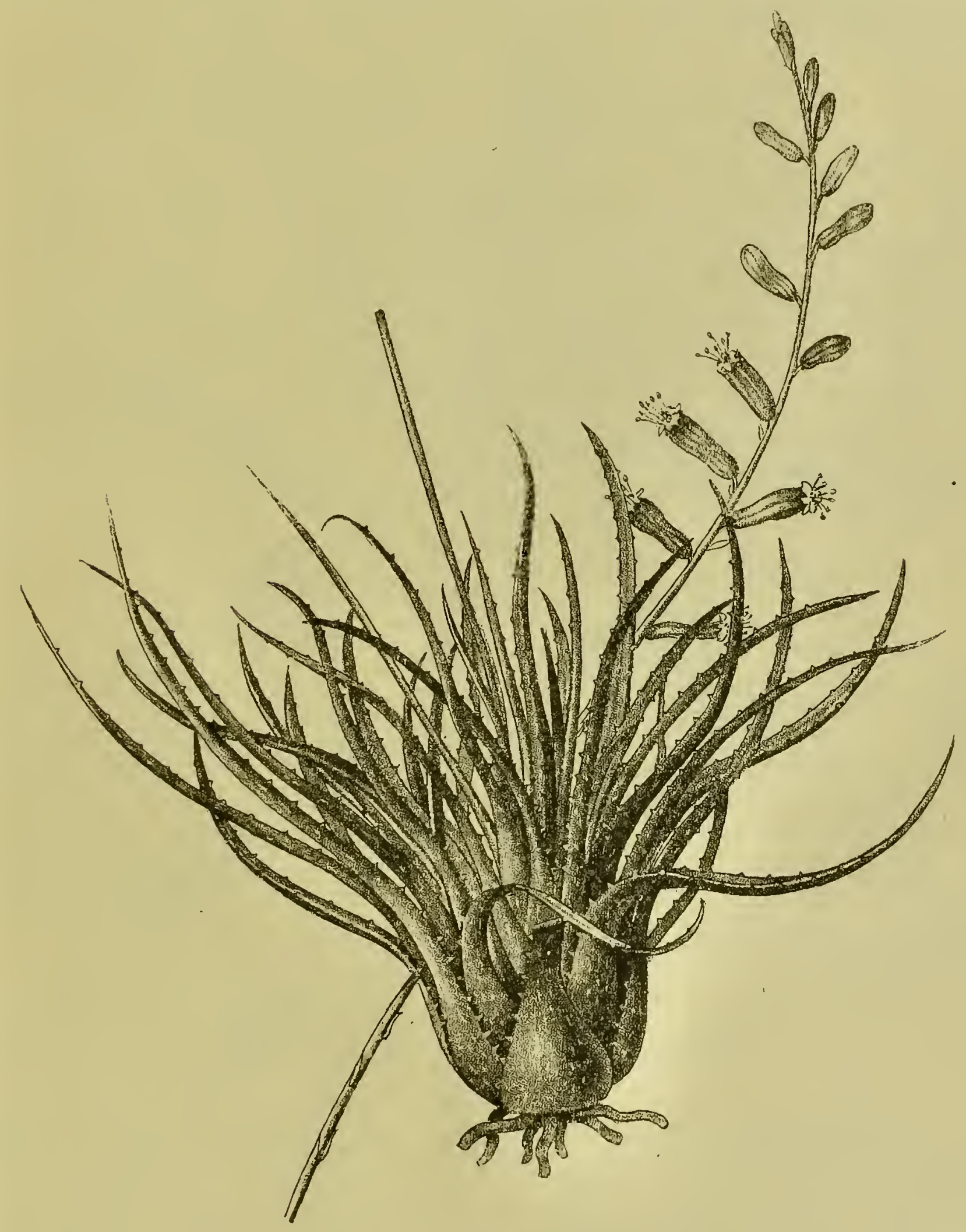

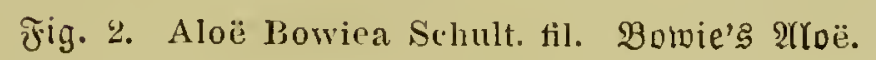

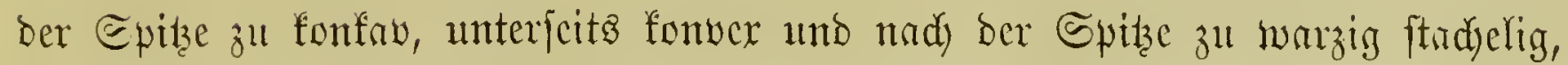

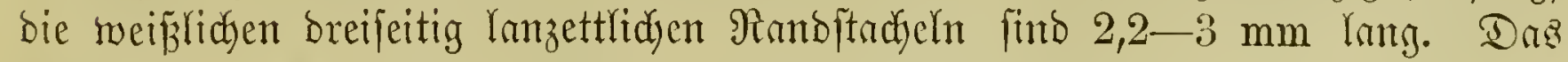
Ferigon ift 2,6-3,3 cm lantg, rot, bie Bisfel finto lanzettlich, länger als bic Säbre, bie Etaubblätter find jo lang wie bas Ferigon. (Jig. 2.) 
Die var. depressa Bak. (A. depressa Haw.) ijt etraa grö̉er, benn ifre $\mathfrak{B l a ̈ t t e r ~ e r r e i d y e n ~ e i n e ~ S a ̈ n g e ~ w o n ~} 12 \mathrm{~cm}$ und zumcilen nody barüber, babei fint fie $3-4,5 \mathrm{~cm}$ brcit und mandymal oberfeits göberig; aud bie Blüten fint erfeblid) grëßzer.

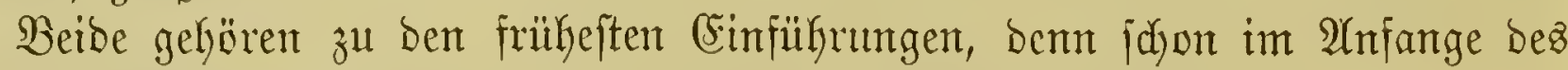
XVIII. Jahrlyumbertz waren beibe in ben europäifchen (Särten.

\section{Aloë striata Haw. Greitreifte 2 (loë.}

(A. albo-cincta Haw., A. Hanburyana Naud.)

Sie Gitbet im Allter einen $30-60 \mathrm{~cm}$ hohen Stamm won 6-9 $\mathrm{cm}$ Durd $=$ meffer. Die Rojette wirb aus 10-20 bidjt geftellten, 45-60 cm langen und am (brunde 9-13 cm breitcn Brättern aufgebaut; fie finto lanzettlids, bie äußzeren

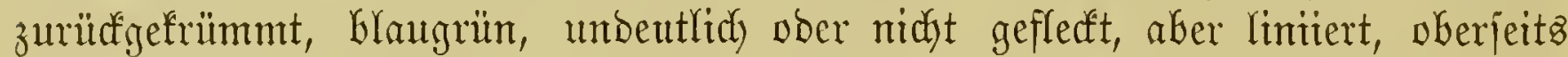

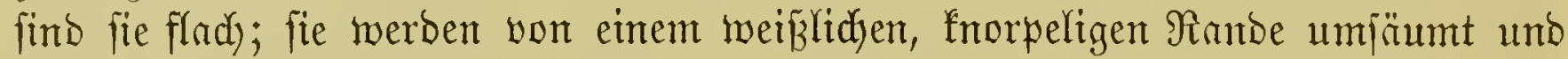
find völlig unbemehrt. Der fräftige, reid)lidy verzmeigte Bhiütenfitiel trägt 20 unb mefyr fopfig gebrängte Trauben von glünzent roten, 2,2-2,5 cm langen B̉üten,

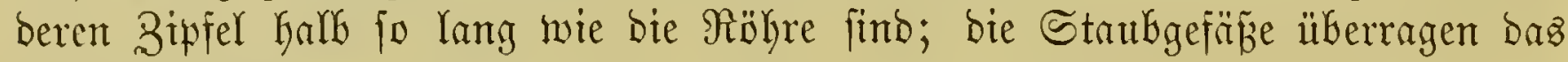
Berigon nidyt.

Sie war fdon vor 1795 in bie Ģärten eingejülfyrt.

\section{Aloë saponaria Haw. Seifen=\{loë.}

(A. umbellata Salm-Dyck.)

Sie entroiffelt mur einen furzen, Gis 4,5 cm biffen Stamm. 15-20 bidyt gefteflte, $20-30 \mathrm{~cm}$ lange uno $3,5-4,5 \mathrm{~cm}$ breite, nad) Der Spitze zul ver= ja)mälerte Brätter Gilben eine $35-45 \mathrm{~cm}$ im Durdymefier Galtenbe 9Rofette;

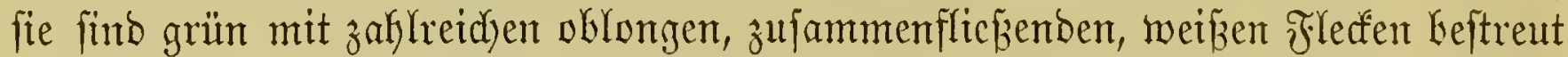

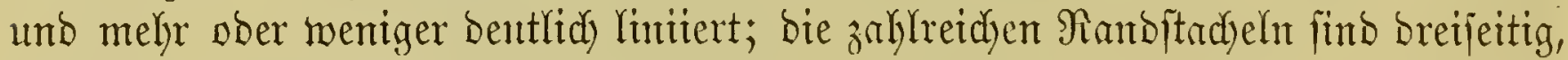
zugejpizt, hornfarbig uno an ber Spitze rotbraun, 3-4,5 mm Yang. Der Bhlütenftanto ift einfady traubig cober verğbeigt, bie glänzend rotgelben Blüten find $3,3-4 \mathrm{~cm}$ lang und boldentraubig gcorängt, bic auf bem Rürfen grïn=

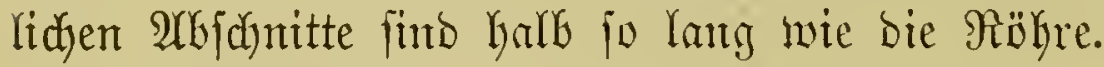

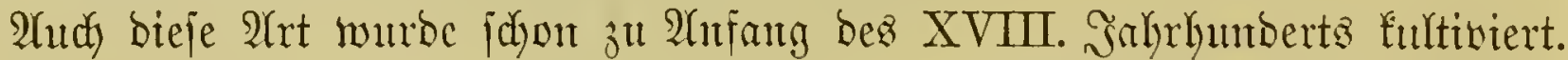

\section{Alö̈ obscura Mill. Dutfle Tlloë.}

(A. picta Thunberg z. Th.)

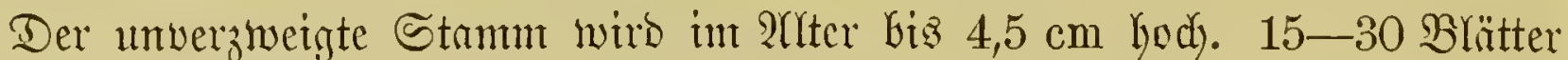
Gilden eine bidjte $\Re$ ojette; fie fint bis $15 \mathrm{~cm}$ long und 4,5-6,5 $\mathrm{cm}$ breit, grü̈n

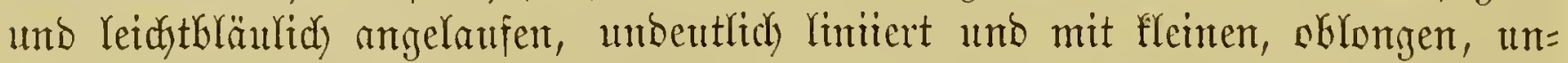

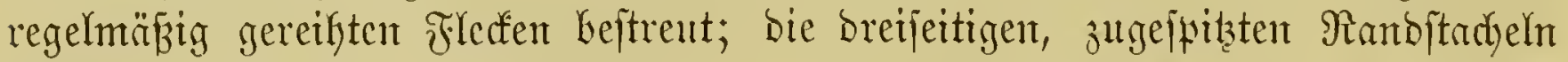
fino 2-3 mm lang, hornfarben und an ber Sprize braun. Der $30-45 \mathrm{~cm}$

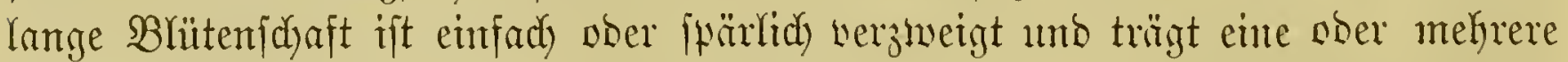

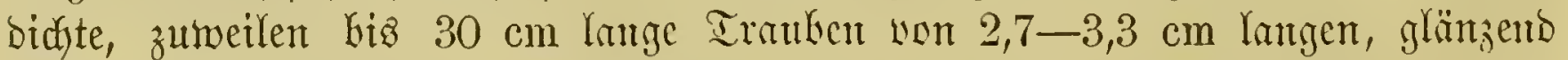

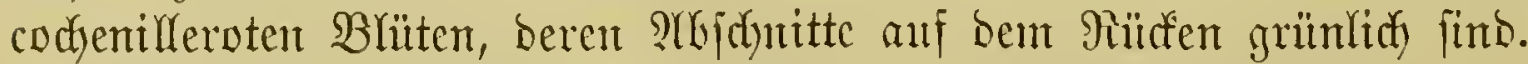

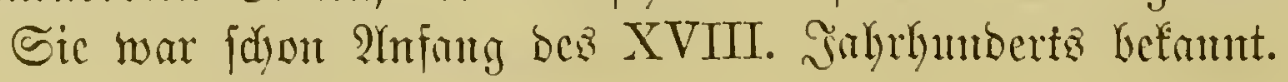




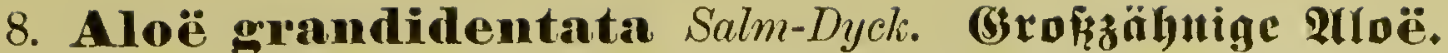

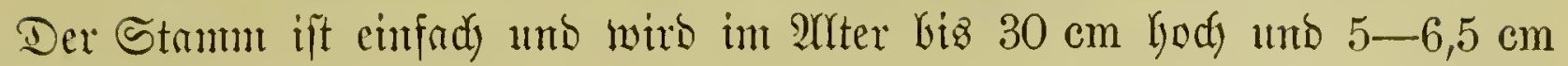

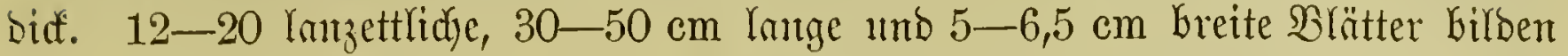

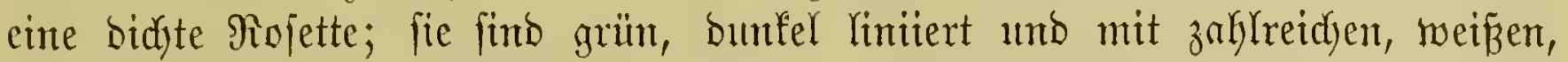

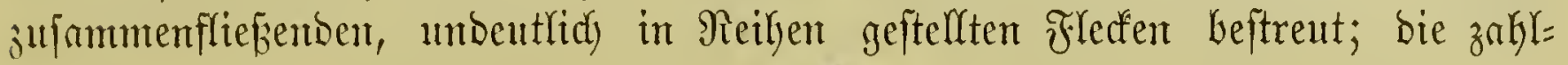

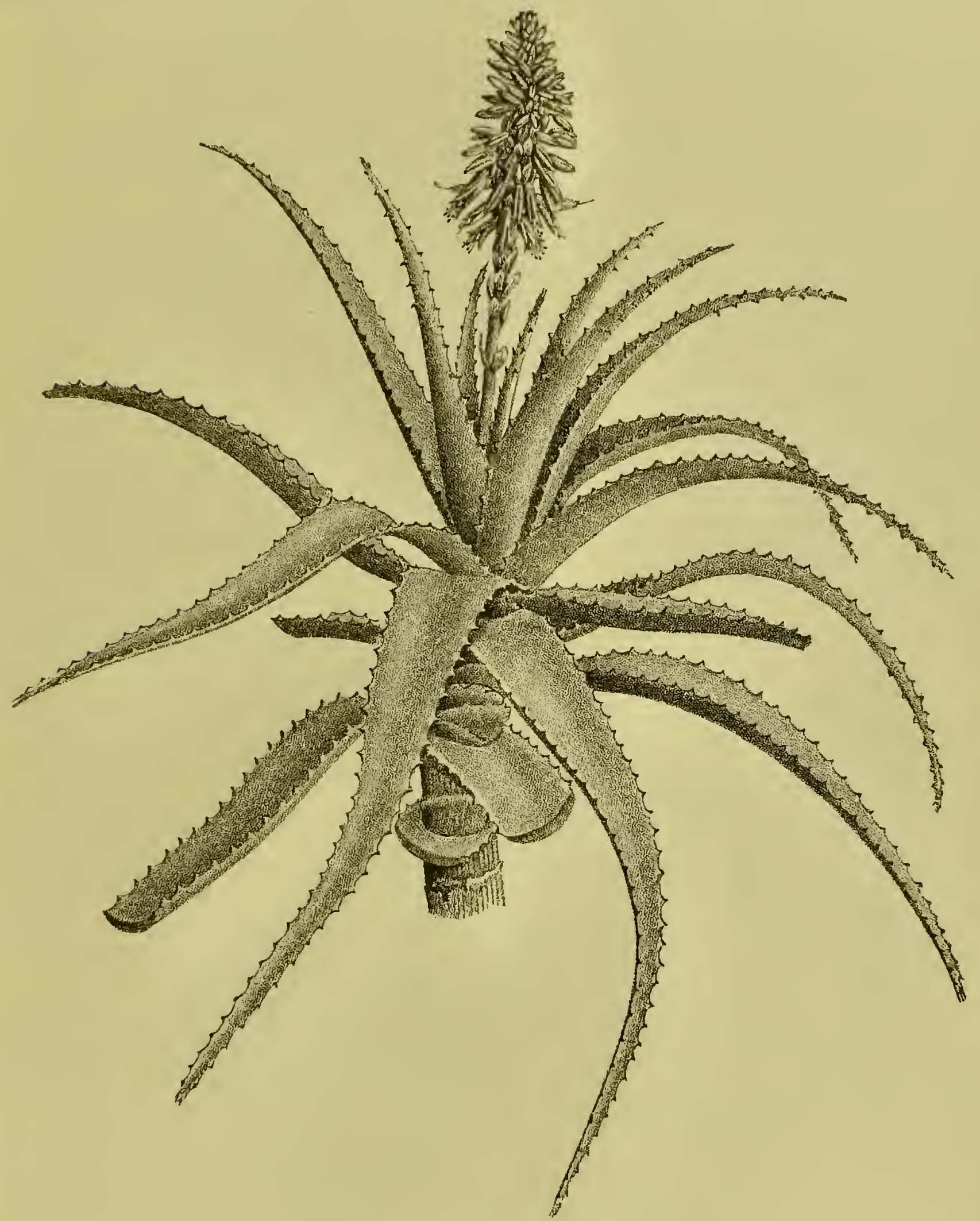

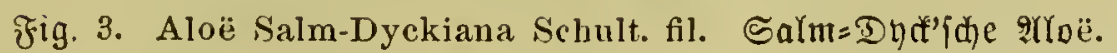

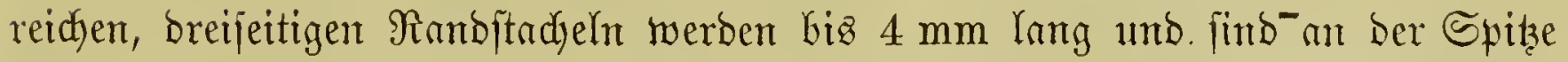
hornig und braunrot. Der fräftige biz $60 \mathrm{~cm}$ lange SBlütenjdyaft hat $5-7$

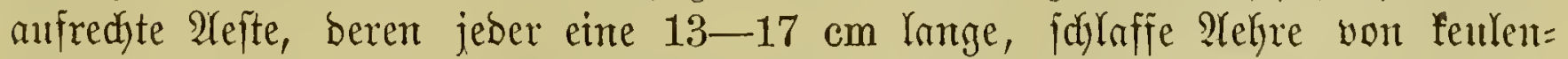
förmigen, 2,2-2,5 cm langen, Glaßjrotgelben B̉hüten trägt.

Sie murbe 1822 cingefüfrt. 


\section{Aloë tricolor Bali. Drafintbige $\mathfrak{A l o e ̈ . ~}$}

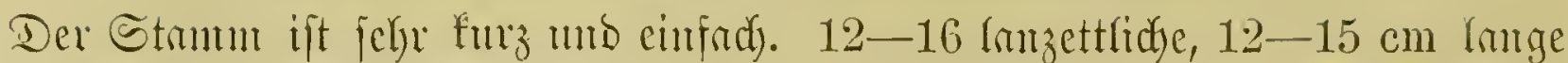

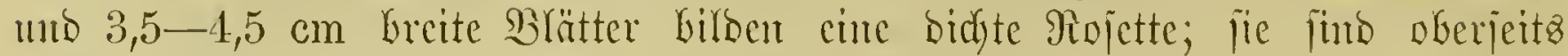

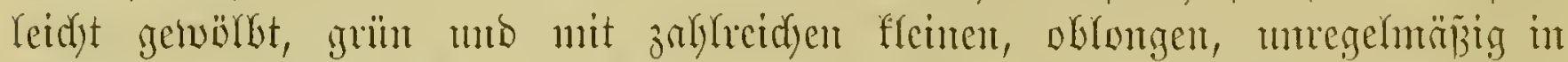

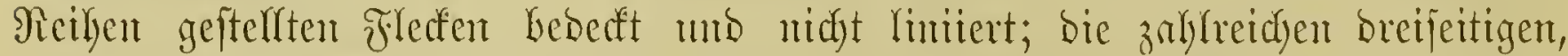

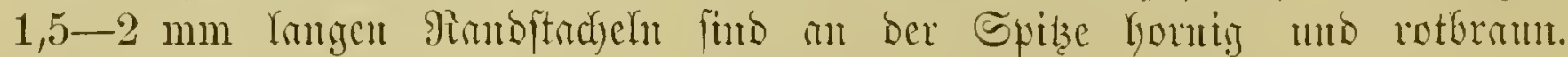

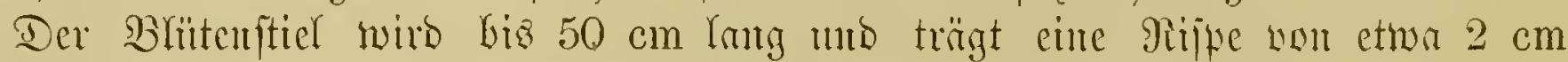
lantgen, codyenteferoten, cylinbrifdyen Bhäten.

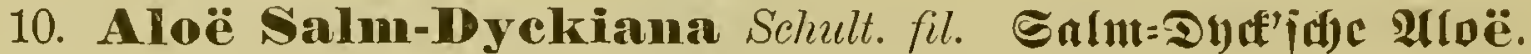
(Pachydendron principis Haw.)

Der cinfactye Strunm wirb in 2 ater bis $3-4 \mathrm{~m}$ hody. Die $45-60 \mathrm{~cm}$

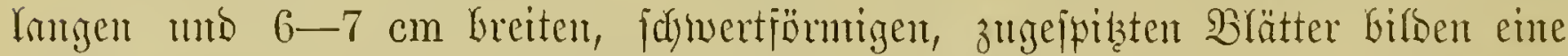

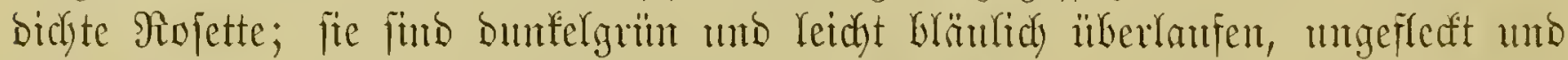

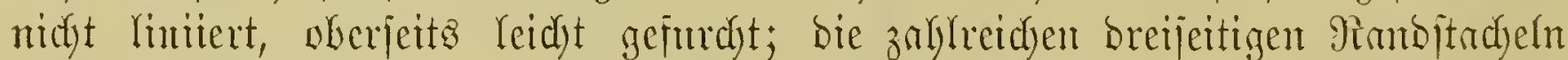

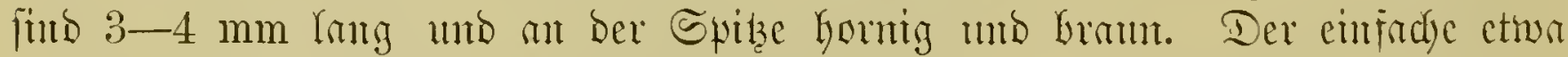
$30 \mathrm{~cm}$ Yange Brütenftiel trägt eine bidyte, faft ebenfo lange Trante von cylin=

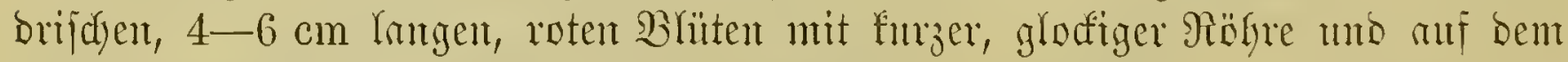

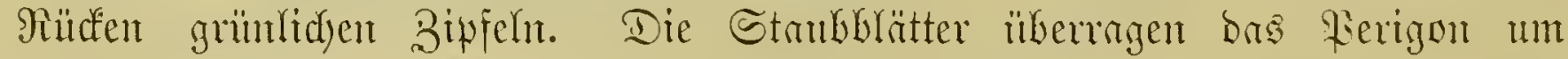
$4-5 \mathrm{~mm}$. (テ่ig. 3. ङ. 11.)

Sie wurbe un 1815 eingefürfyrt.

\section{Aloë variegata Limn. Geflente Ploë.}

(A. punctata Haw.)

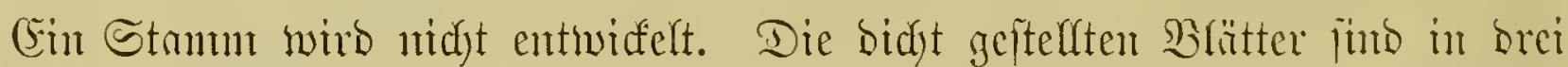

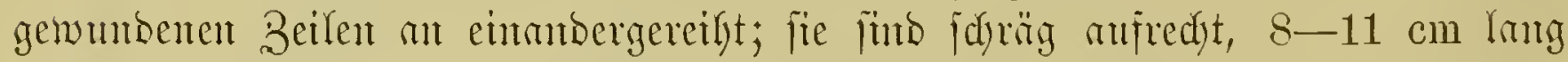

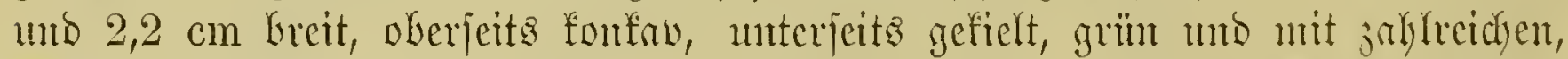

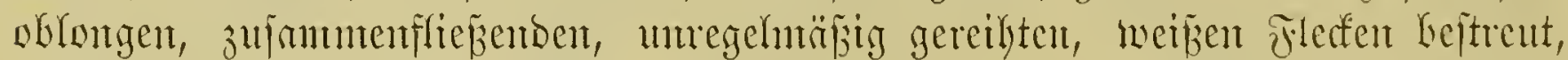

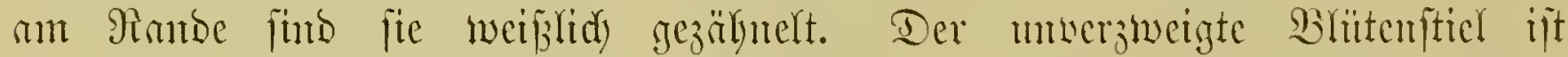

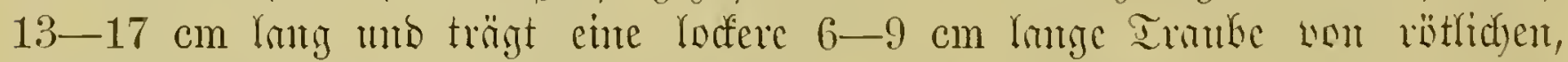

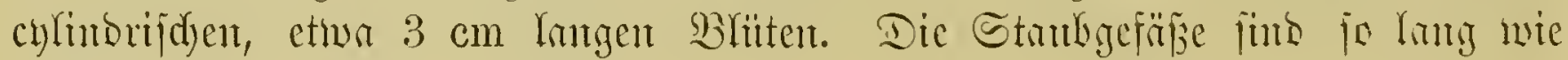
dors Perigon. (Fig. 4. S. 13.)

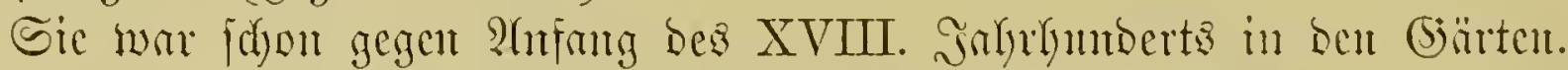

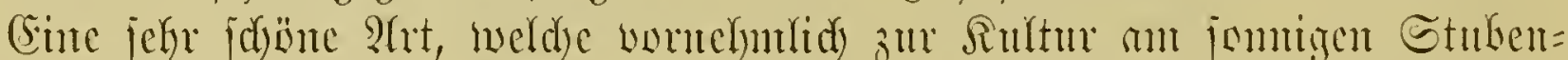

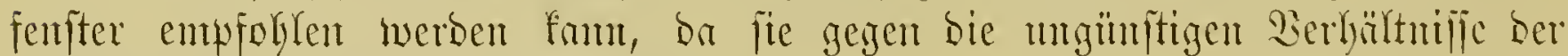

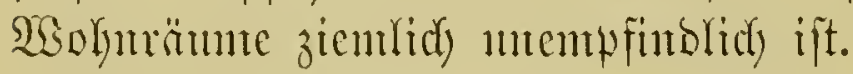

\section{Alö̈ ferox Mill. Wiclitadhclige 2 (lö̈.}

(Pachydendron ferox Haw.)

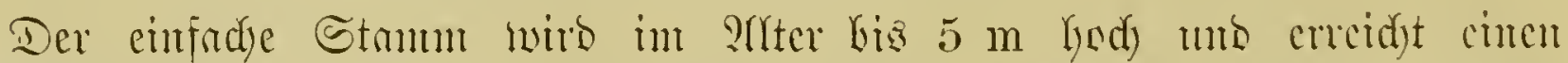
Durdynefijer von $12 \mathrm{~cm}$. 30-50 Blätter bilben eine bidyte Miojette; fie füro

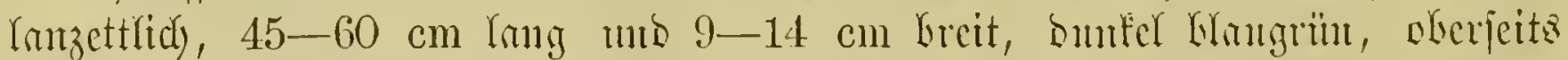

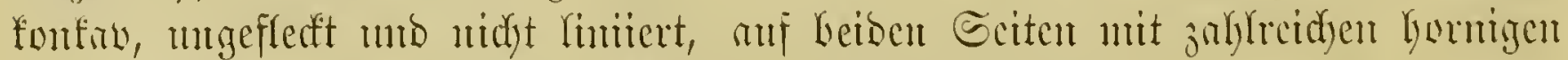

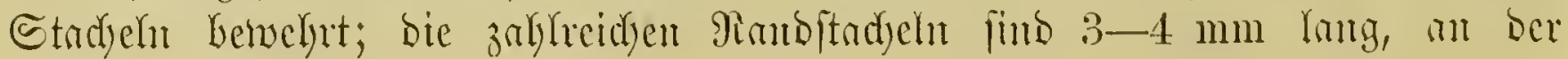




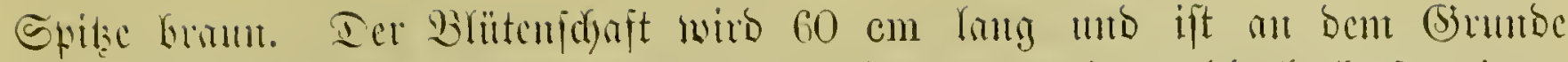

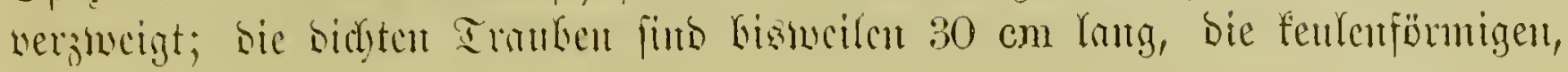

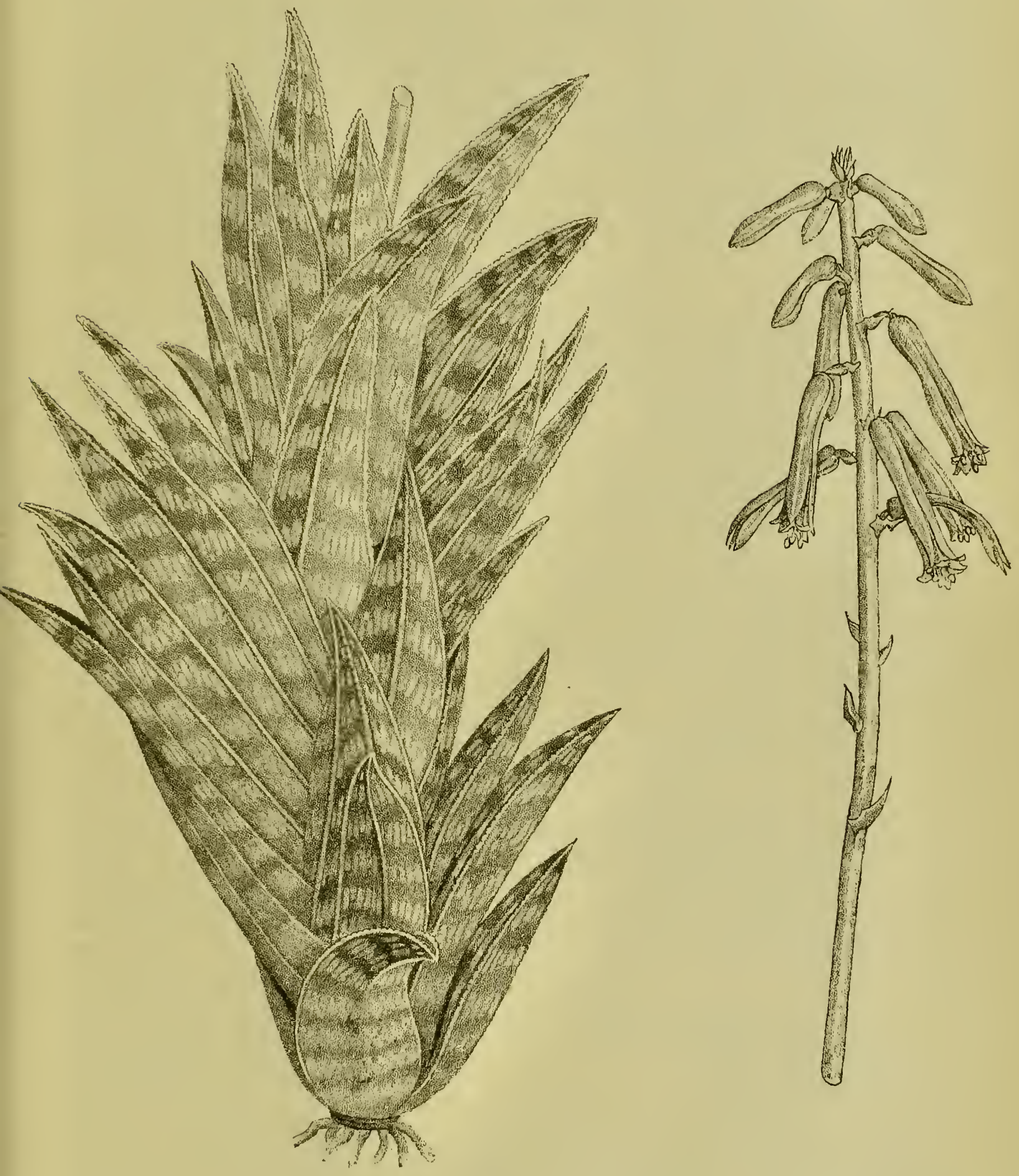

Fig. 4. Aloẹ variegata Linn. Befleâte Mroë.

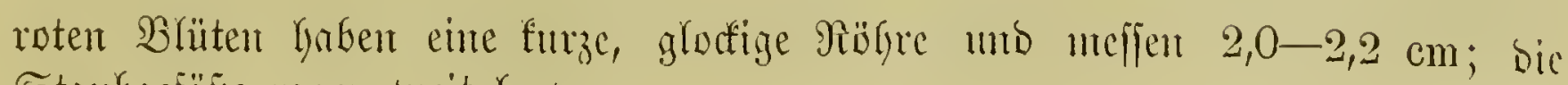
Etrubgeräpe riggen weit yervor. 


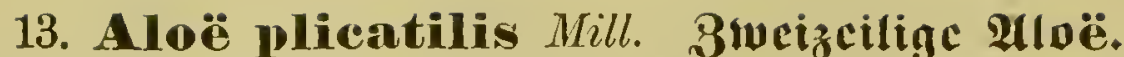

(Rhipidodendron distichum Willd., Rhipidodendron plicatile Haw.)

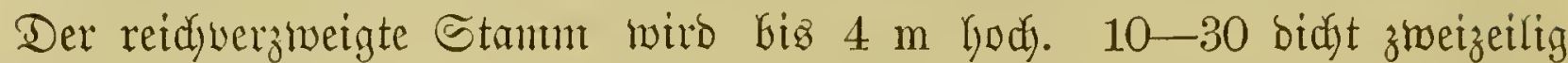

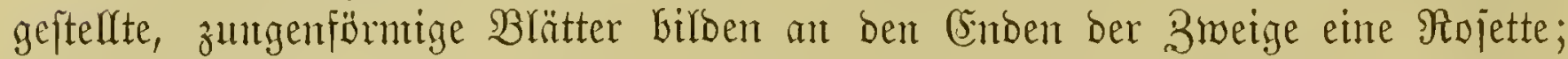
fie find 13-22 cm lang und 2,7--3 cm breit, graublau, ungeflectit am Enoe

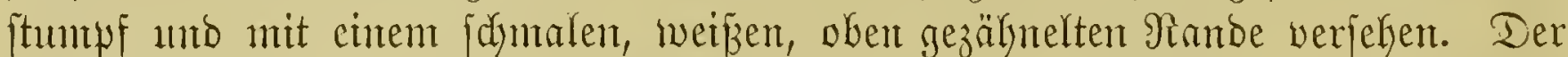

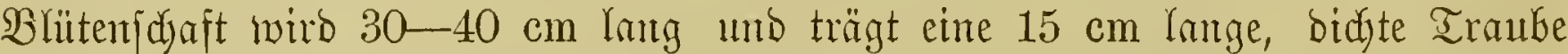
von rotgelben, chlinbrifden Bhlüten, berent immere Perigonblätter unter fid jajt

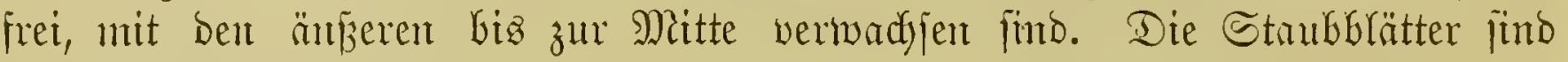
fo lang wie das Rerigun.

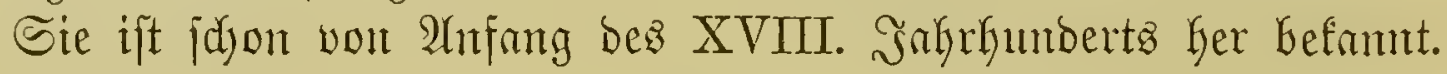

\section{2. Şattung Gasteria Duval.}

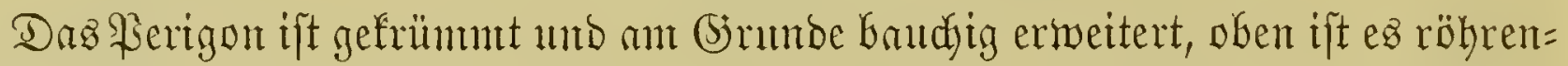
förmig mit furzen, freien 2UG nad) unter gefrümmt, mit fabenförmigen Fäben. Der (Sriffel ift nady unten gefrümmt, mit furz breilappiger Rarbe. Die Sapjel ift an ber Spike genabelt, leberartig. Die Samen füb jajeibenförmig, geflügelt.

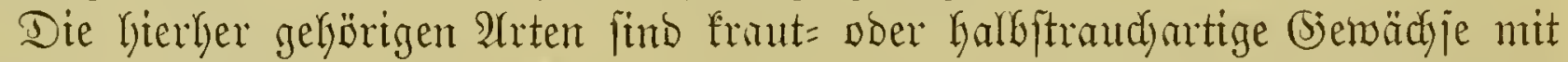
bidyt rojettig geftellten, biffen, fleijdjigen, oft zuntgenförmigen ober jidwertförmigen, zuneilen ungleidffeitigen unt breifantigen, meift geflectten Blättern, bie entweber in zwei vft gewumbenen vber melyreren Beilen ftehen. Die Brüten jün traubig ober rijpig gejtellt, gewölynlid rot und grün, und ftehen auj roten Stielen in ber 2ldyjel Gleibender Dectblätter.

Die fämtlidjen ca. 50 2trten ber (Sjattung wadjjen ant Saplanbe, nur jegr wenige geken bis Patal.

Der Rame ftrmmt von bem griedjijden Marte gaster, ber Baudy.

Sḑlïffel für die befdriebenen Urtent.

A. Blätter in żwei geraben Beilen.

a) Blätter von erhabenen, perlenartigen $\mathfrak{W a r z e n ~ r a u b ~ 1 . ~ G . ~ v e r r u c o s a ~ H a u . ~}$

b) Blätter toarzenlo

a) Blätter fteif gerade

ア) Blätter zurïcf́gefrümmit

B. Blätter it żwei gewundencu 3eilent.

a) Flectelt Elein, in geringen Miaße zujanmenfließ̄ent

b) Fłlecten groß̧, ftart zujanmenfließ̧end

C. Blätter in nuehreren Zeilent.

a) $\mathfrak{B l a ̈ t t e r ~ h o ̈ c f e r i g ~}$

b) Blätter glatt
4. G. colubrina N. E. Broun.

5. G. pulchra Haw.

6. G. maculata Haw.

7. G. subcarinata Haw. 8. G. nitida Haw.

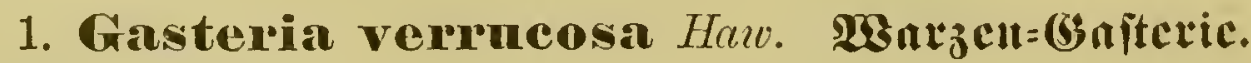

10-12 jodnertförmige, bunfelgrüute, $13-20 \mathrm{~cm}$ lange, 2,5-3,5 cm breite blätter ftehen bid)t gebrängt in zwei gernben Beilen, fie jün mi beiben Eeiten

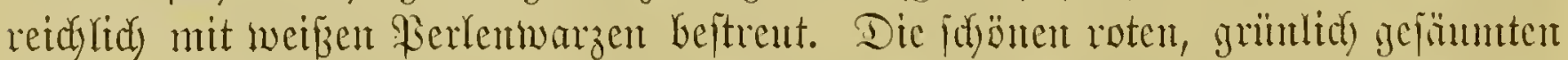

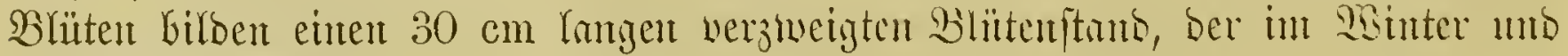
Frübjabr erjobeint. 
Die var. scaberrima Bak. (Aloë scaberrima Salm-Dyck) ift burd)

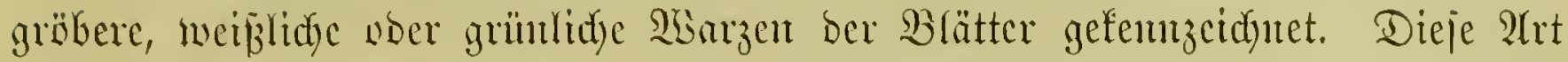

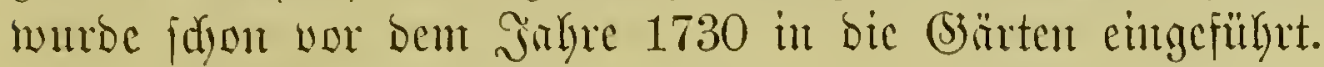

\section{Gasteria nigricans Haw. Dunfelgriate (bafterie.}

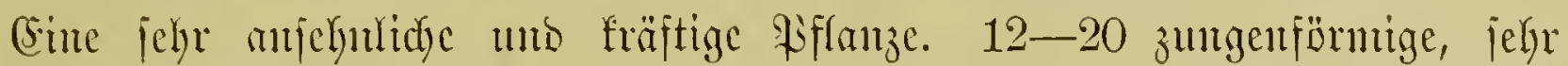
bunfel= ober purpurgrüne, 9-20 cm lange unt $3,5-4,5 \mathrm{~cm}$ breite, auf beiben

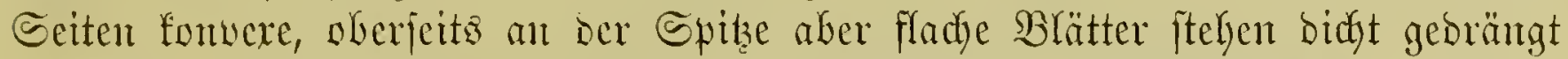

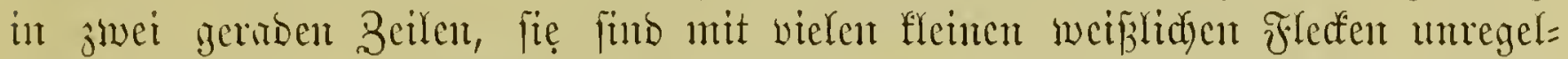

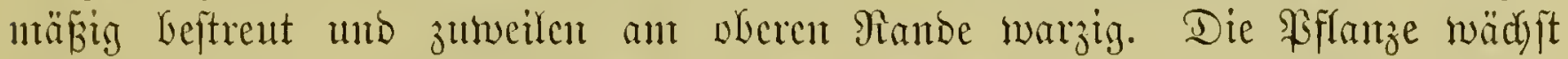

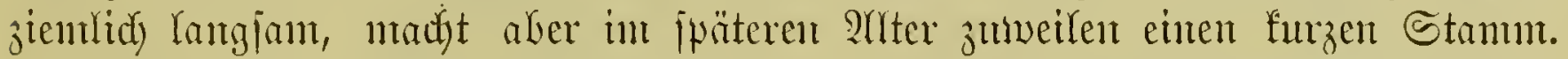

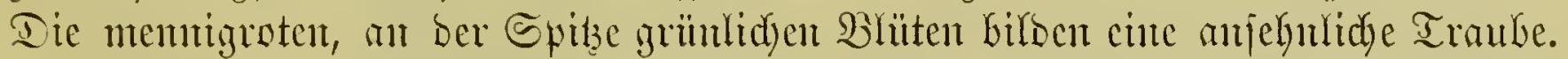

Sie wurbe un 1730 cingefülynt unt wirb heute and) fefre oft mit vielen Barietäten fultivicrt.

\section{Gasteria disticha Haw. Bweizcilige Gaiteric.}

(G. denticulata Haw. Aloë Lingua Thunb. z. Th.)

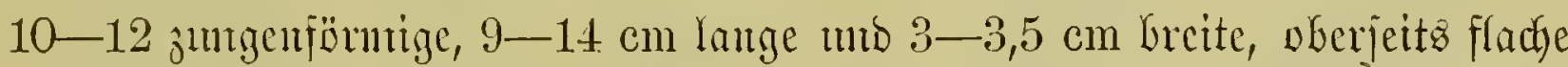

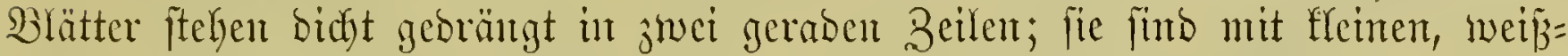

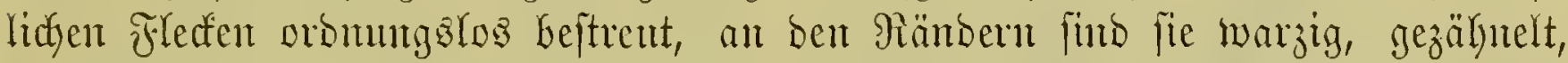

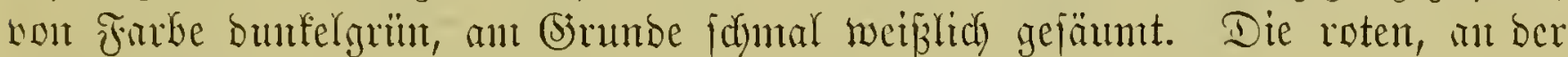

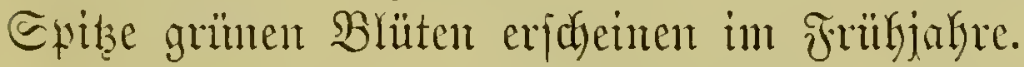

Tív var. conspurcata Bak. (Aloë conspurcata Salm-Dyck, Gasteria conspurcata N. E. Brown) ijt burd) längere, ca. $30 \mathrm{~cm}$ mejienbe SBlätter,

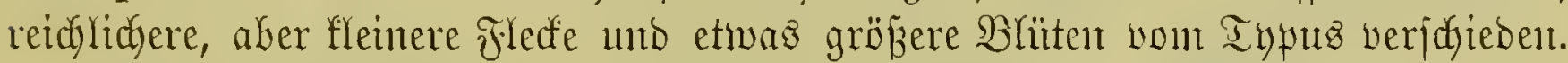

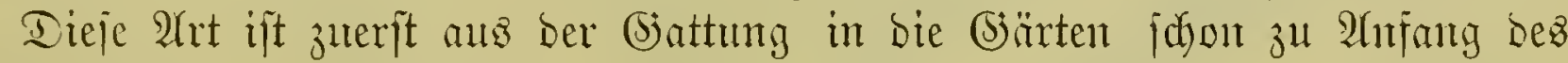

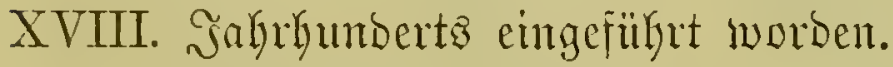

\section{Gasteria colubrina $N$. E. Brown. Edflattgent=6initeric.}

8-10 riententïrmige, zumeilen über $30 \mathrm{~cm}$ lange, $4-4,5 \mathrm{~cm}$ breite, ober=

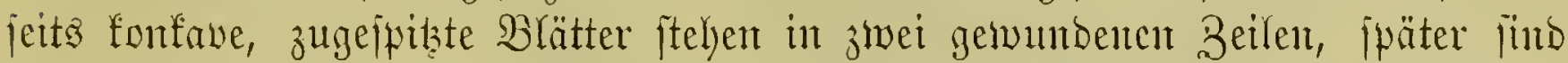

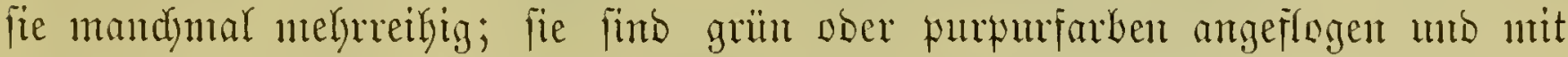

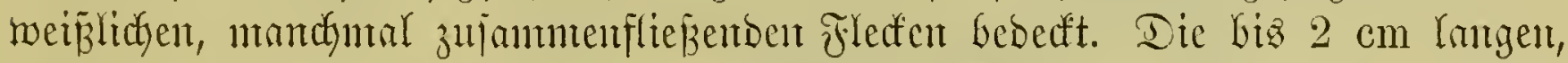
oben grangrünen, am Srrunbe roten Blüten befleiben einen 1-1,3 m lantgen B̉iütenịtiel.

Sie nutbe etwa un 1870 von Bohus eingefiilyrt.

\section{Gasteria pulchra Haw. Gdjünc Gáteric.}

Die Pfflanze bitbet einen bis $20 \mathrm{~cm}$ bohen Stanum. 16-18 lucfer geitellte, aufiteigento, zuweilen $30 \mathrm{~cm}$ Yange uno $2-2,2 \mathrm{~cm}$ breite, fuswertförntige, affntäblid

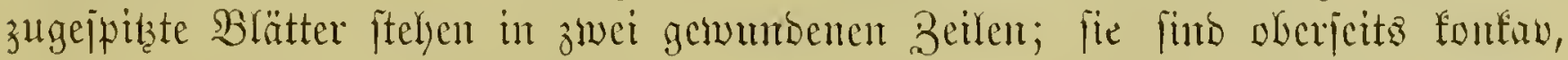

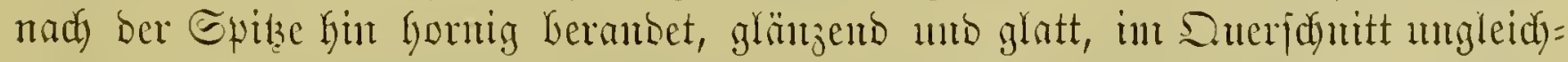

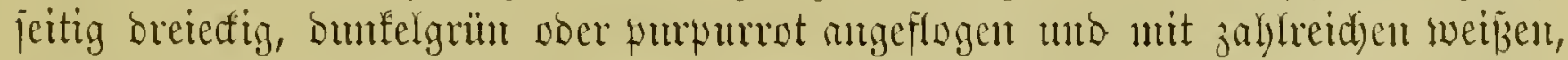

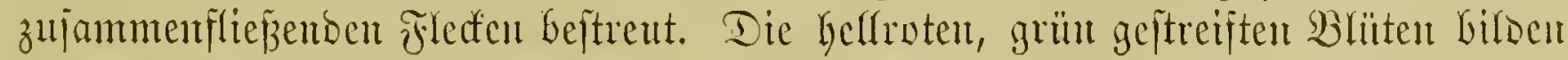

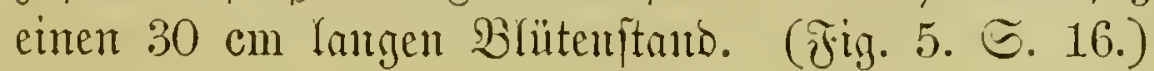

Eic wiro ebenfalfs fonon jeit alten Beiten fultiviert. 


\section{Gasteria macnlata Haw. Gerlerfte Gajteric.}

(G. obliqua Haw.)

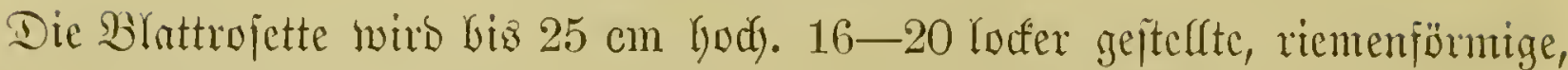

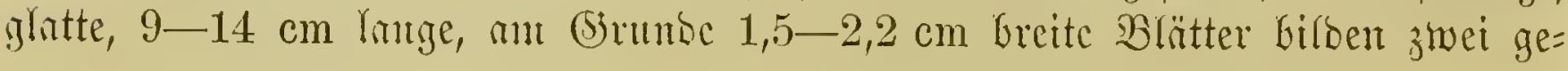

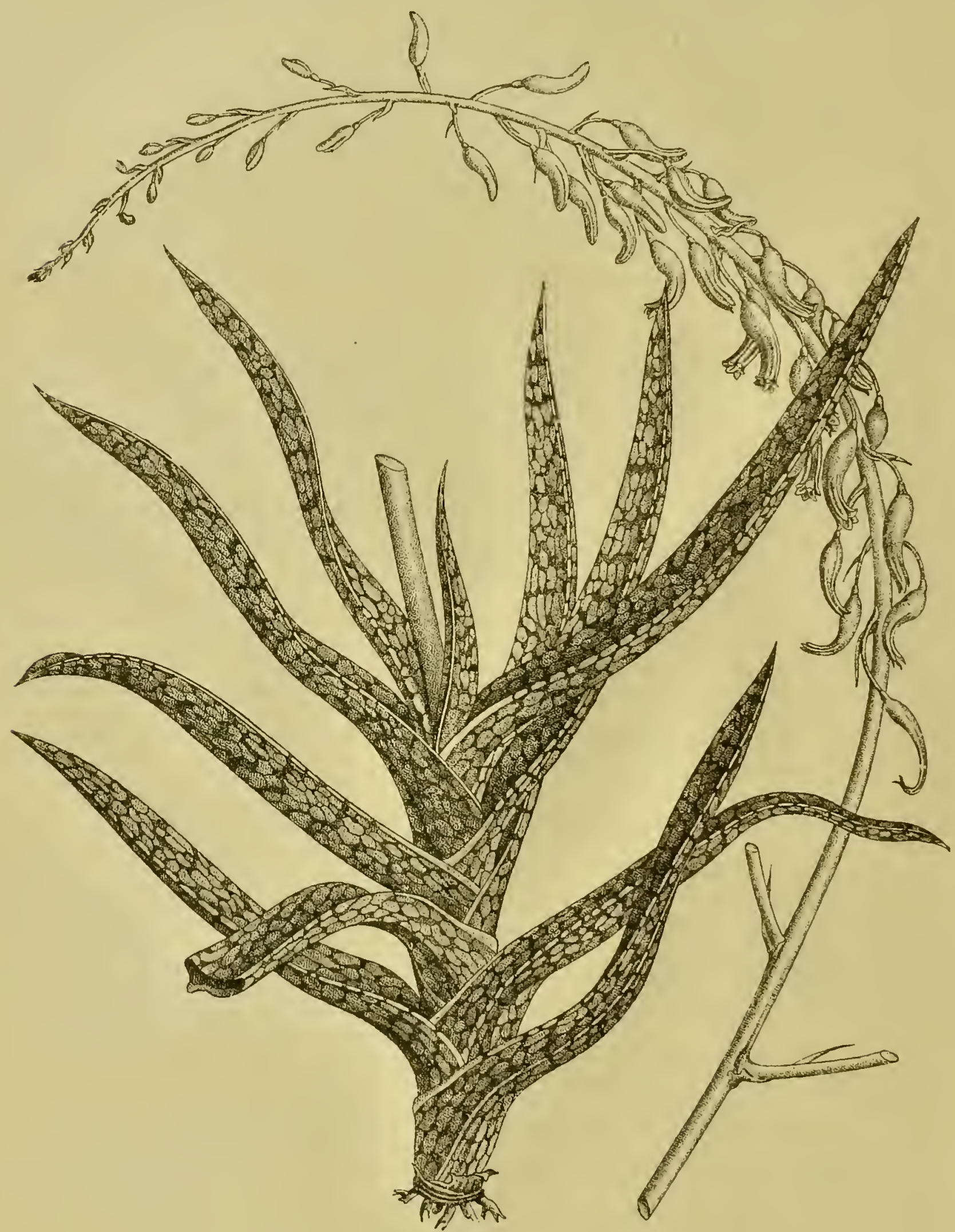

Fig. 5. Gasteria pulchra Haw. Ed)önc Bajterie.

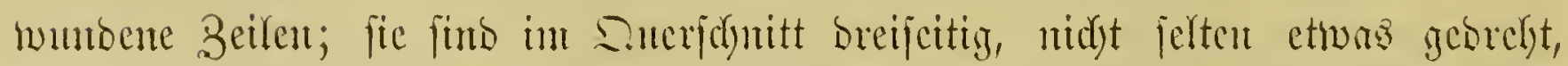

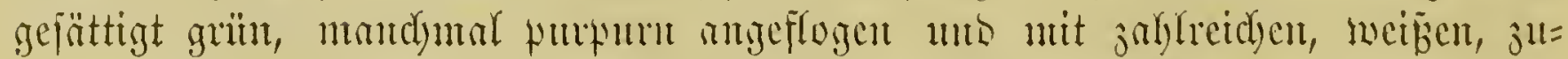

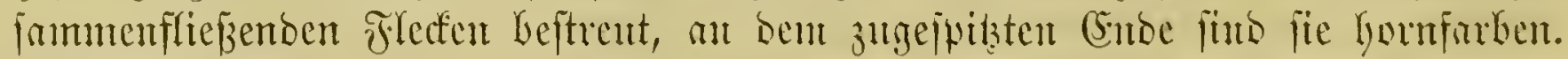

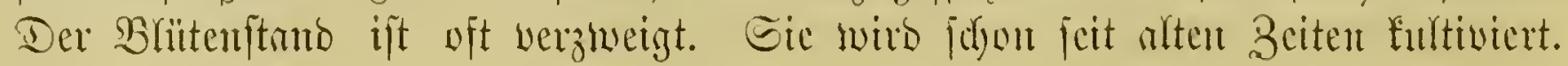


7. Gasteria subcarimata Haw. Srdwad)geficlte Gäateric.

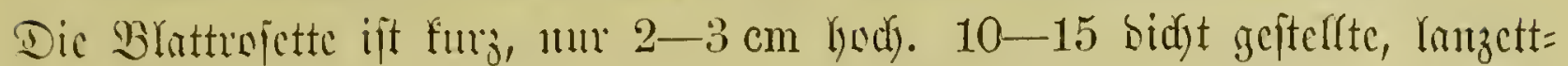

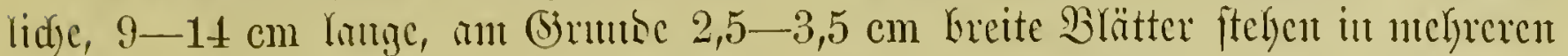

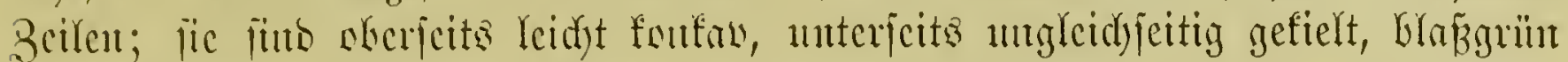

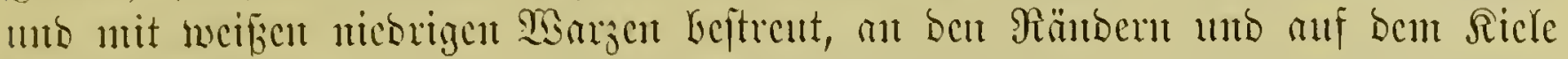

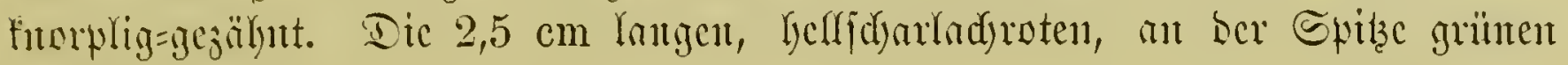

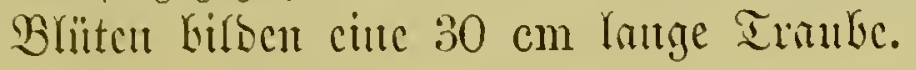

\section{Gasteria nitida Haw. Glänzenbe Gạteric.}

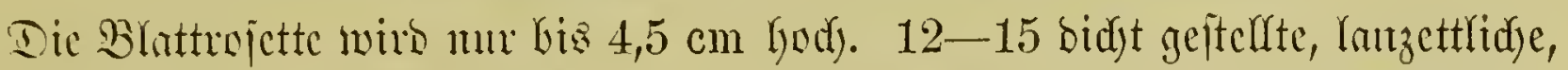
18-20 cm Kantge, ant Gruntbe 4,5-5,5 cm Greite B̧ätter Gillocut mefrere Beilen;

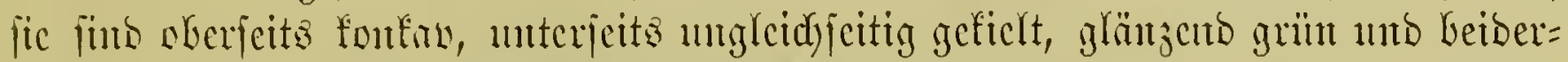

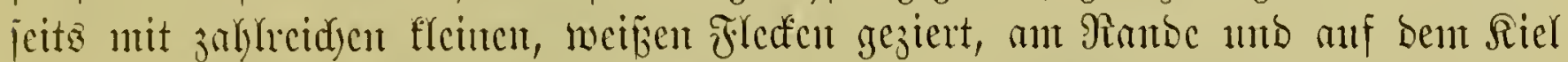

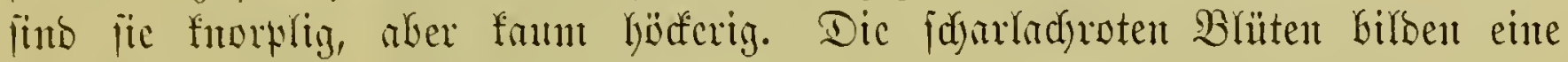
30-40 cm Vonge, cinfadye Irantse.

Sie murte un 1790 cingefillyrt.

\section{Gattung Apicra Willd.}

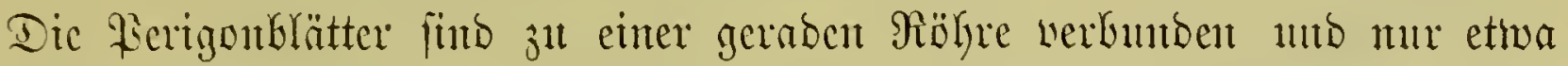

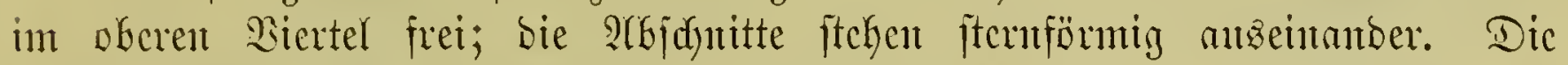
6 Strubblätter füto fürzer wie bas Rerigon, ifre Fäbon fints fabenförmig, bie

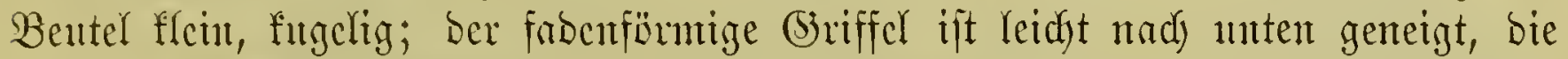
Rarbe ijt fopfig. Dic Rapfel ijt oben gentabelt; bic Santen finto flad fdheiben= förming.

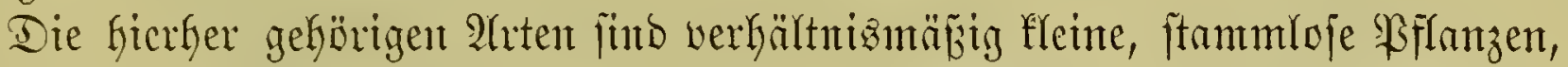

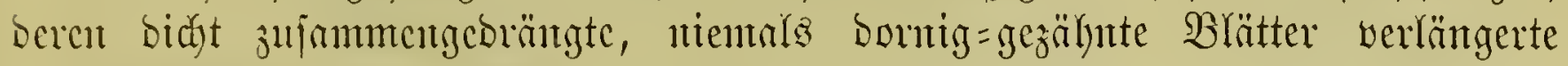

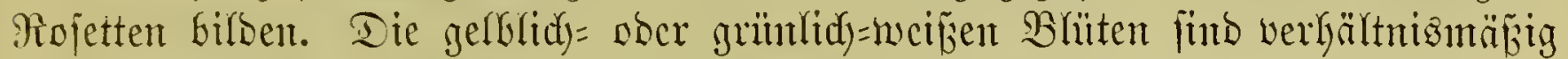

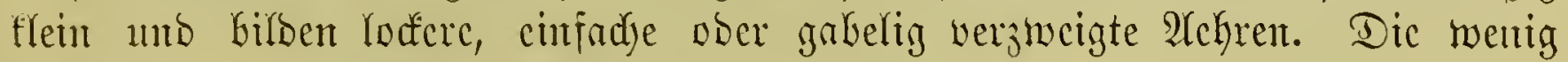
zaflecidyen (8-9) Afrten wadjict mux am Siap.

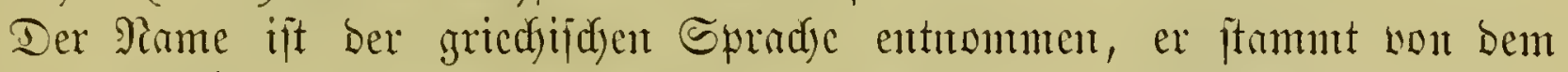

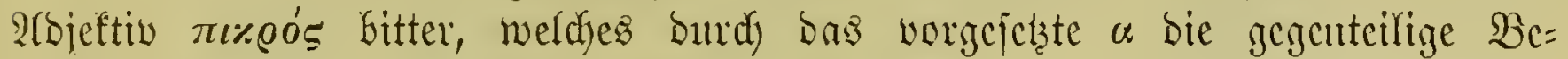

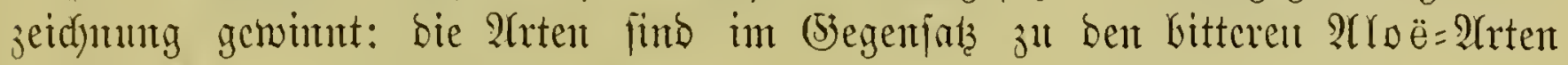
geidjmadfor.

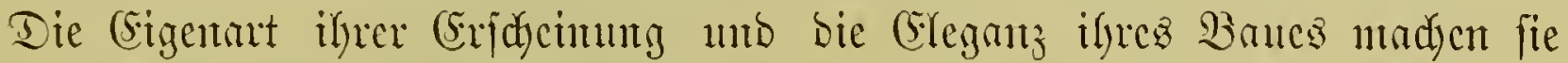

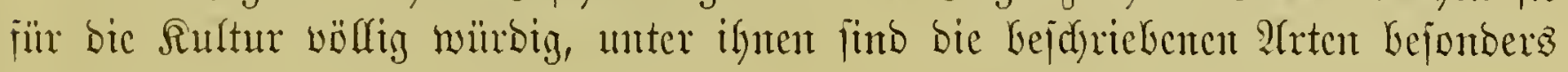
entrifehlenşwert.

\section{S丸llüfjel für die befąriebenen Urten.}

A. Slätter in 5 geraben ober twenty getwutndenten Beilen

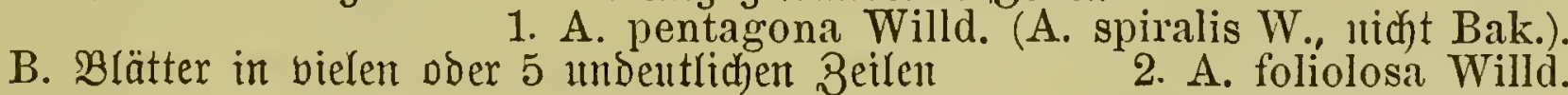

\section{Apiera pentagona Willd. Fïnffantige 2 picra.}

Tic Blattrojettc erreidyt eintc Ränge vou $15-20 \mathrm{~cm}$ unto cincu Durd)=

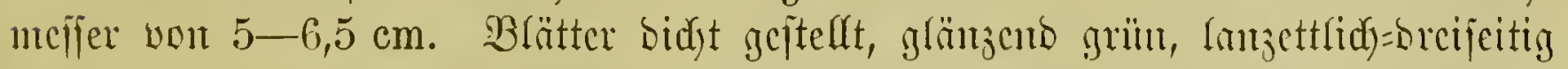

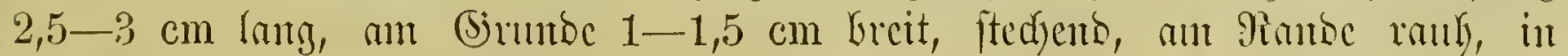

Sutfulenten. 


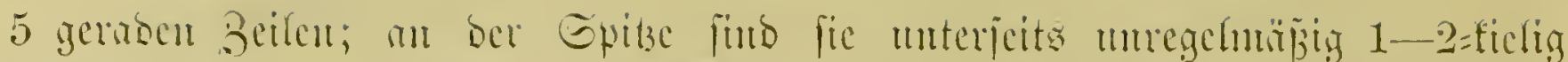

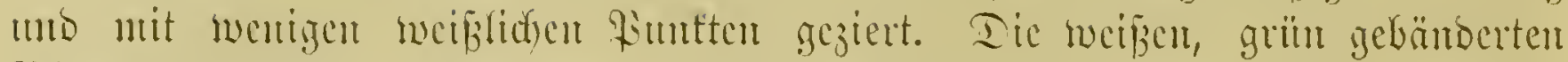
Blïten fiurs glatt. Dic var. Willdenowii Bak. ijt etwas grö̈per uto bic

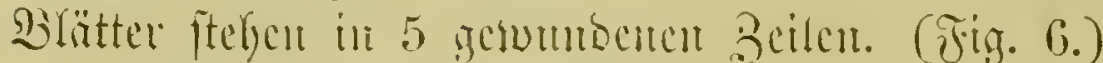

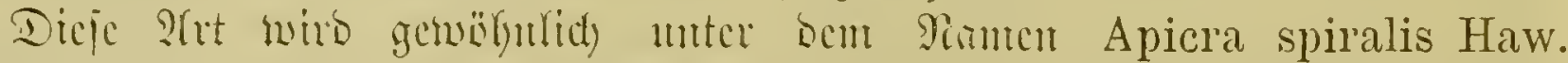

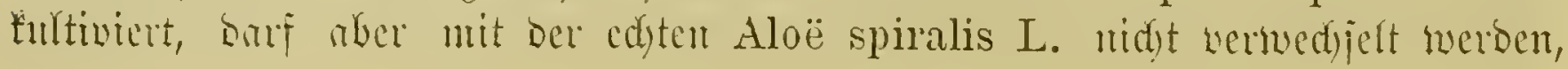

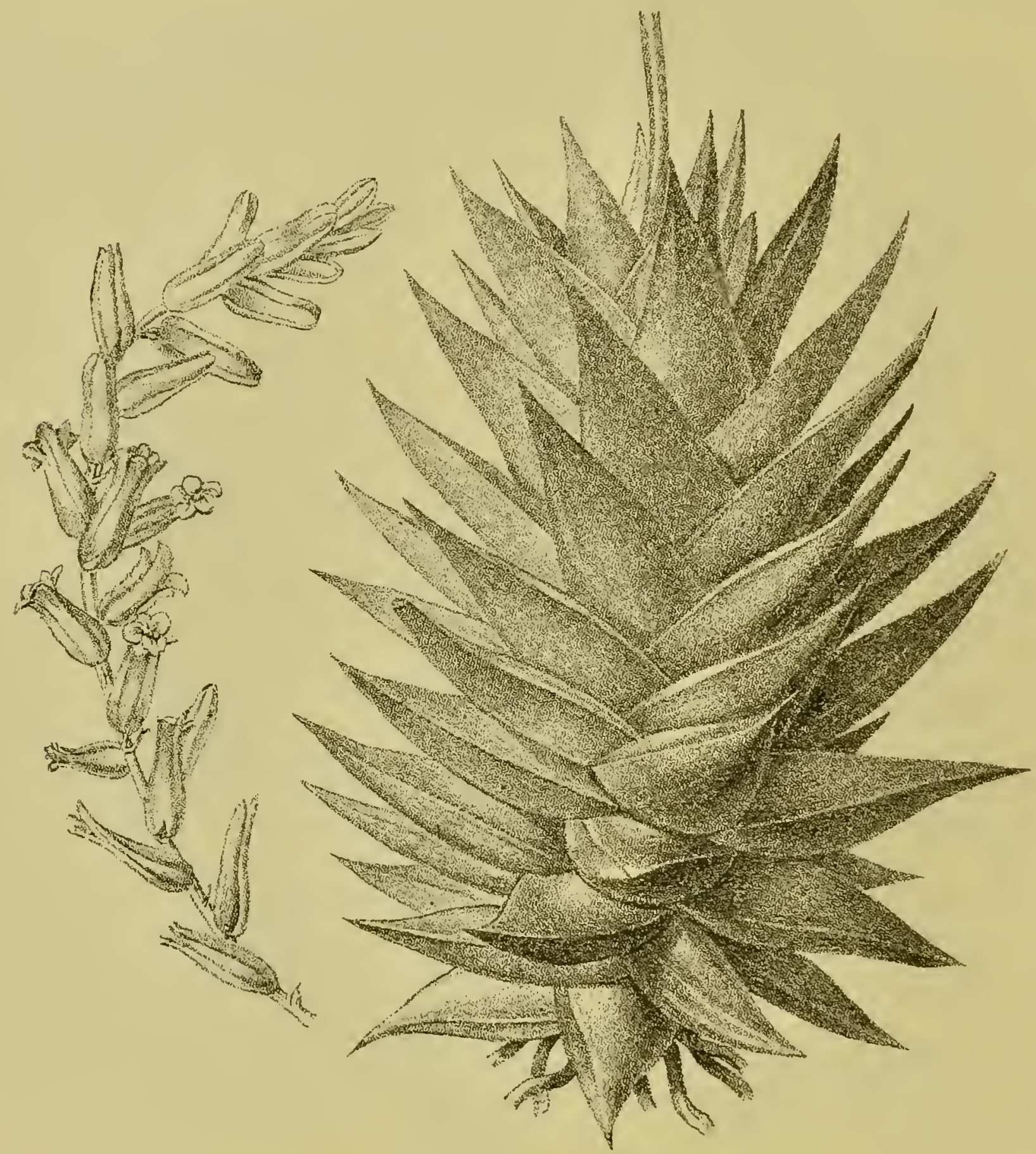

Fig. 6. Apicra pentagona Willd. Finnjiuntige :Ppicra.

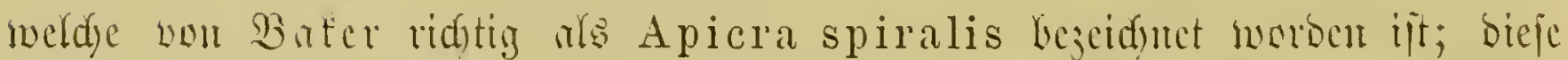

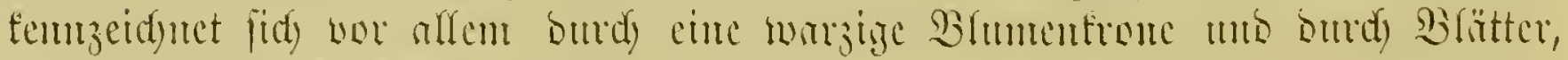
bie in megrere Beilen gevionet finto.

\section{Apicra foliolosa Wille Dilattecide 2 (picra.}

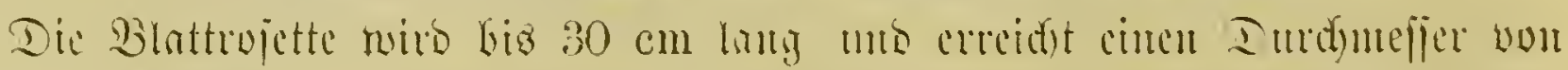

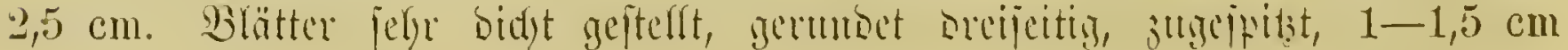




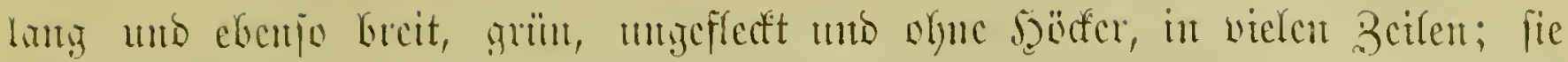

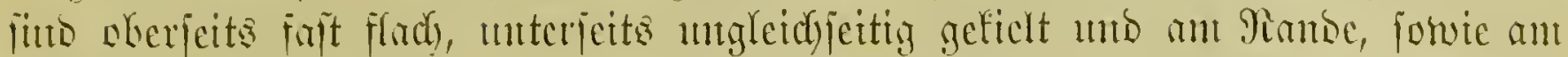

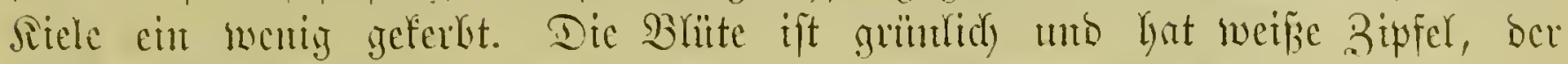
Bhäteritans creidyt cinc S̈̈nge won $40 \mathrm{~cm}$ mb bariber.

Sic wube 1795 wou Majpu cingefithrt.

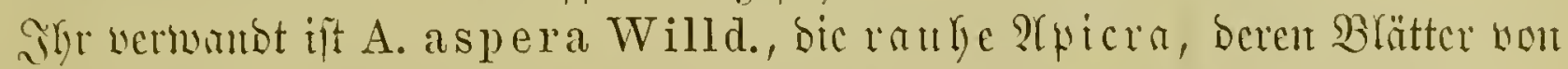

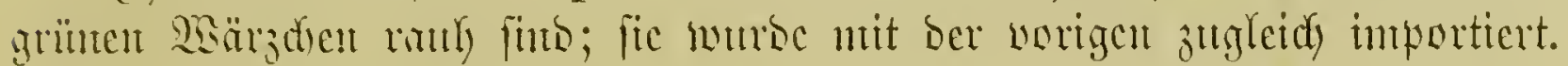

\section{Battung Haworthia Duval.}

Die Sertigntbrätter futo ju cuter geraben Rïbre verbutbent mo mut int

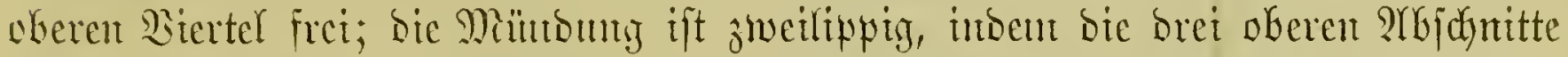
gerabe vorgeftredt, bie brei unteren nach unten gefrimmt füb. Die 6 Stanbblätter

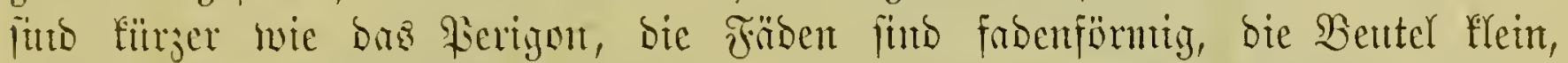

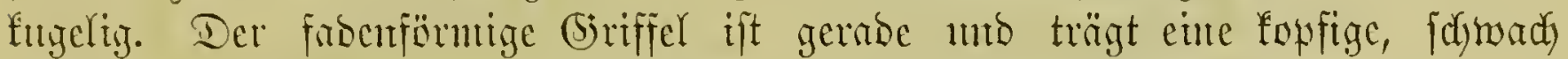

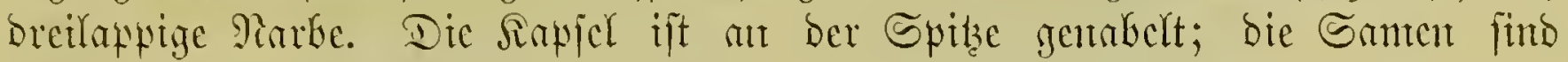
jưcibertörmig, geflïgelt.

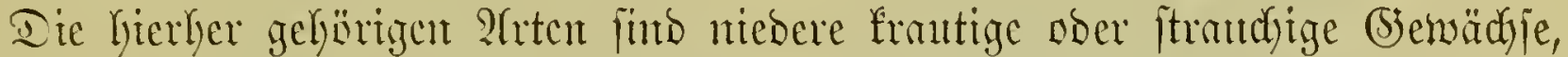
beren furje, Greite Brätter gruntoftänbige Rojetten Gilben. Dic flemen, weifs=

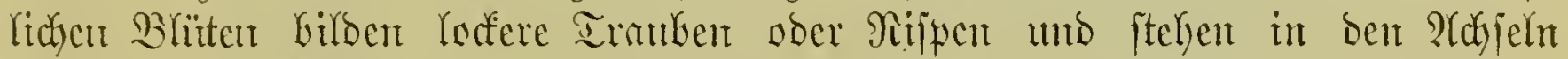
bleibender Dedforätter.

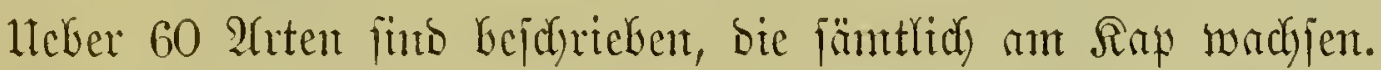

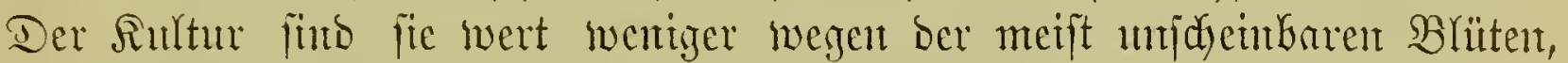
als megen ifges cleganten Baucs und ber oft eigentigen Berjierung ber flcį̧̣igen Blätter.

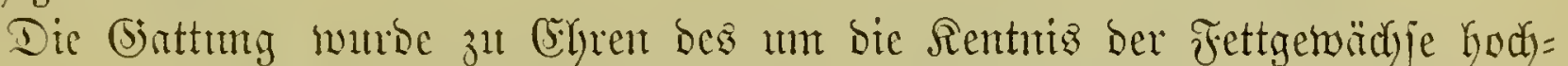

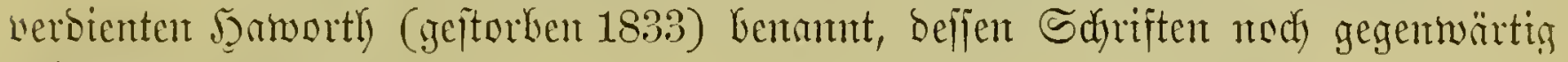
gebülyend gejdä̈lat werbert.

\section{Sœliifiel für die bejhriebenen Zlrten.}

A. Blattrojetten verlängert.

a) Blätter in 3 Beilen untgeflect und uid)t warzig

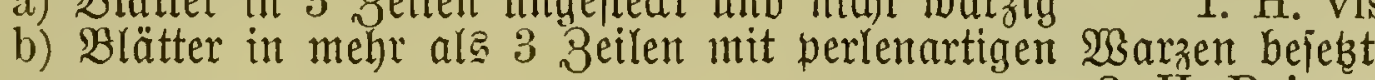

B. SBlattrojetten nid)t verlängert.

2. H. Reinwardtii Haw.

a) Blätter ganzrandig.

a) Blätter mit warzen bejebt.

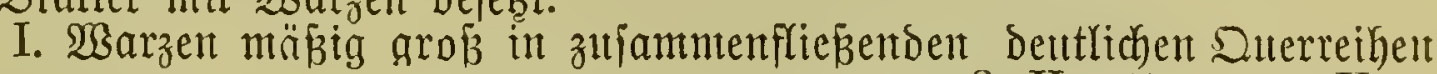

3. H. attenuata Haw.

II. Waarzen, mäßig groß̧, nicht quergereiht 4. H. margaritifera Hax. III. SWarzen tlein, nidht quergereigt

5. H. subulata Bal.

ß) Blätter glatt, lintiert, mit eincr Endborite

6. H. altilinea Haw.

b) Blätter gezähnelt.

a) Brâtter gefeldert.

I. Blätter nodh nicht boppelt fo lang wie breit, mit bentlichent nad) hintent geridhteten 3ähnen bejebzt

II. B̉lätter viermal länger alg breit, gezähnelt

7. H. tessellata Haw.

९) Brätter nidbt gefeldert, an ber Spibze lintiert

8. H. venosa Haw.

9. H. vittata Bali. $2 *$ 
c) Blätter boritig gezähnt.

a) Boritelt furz, faum $1 \mathrm{~mm}$ lantg.

I. Blätter $2 \mathrm{~cm}$ lang, am Sirunde $1 \mathrm{~cm}$ breit, 20 bis 30 in einer Stojette

10. H. pilifera $B a k$.

II. Blätter 3-4 cm lang, am (Srumbe $1,5 \mathrm{~cm}$ breit, $30-40$ in einer

Pojette

3) Boriten 2-3 mm lang

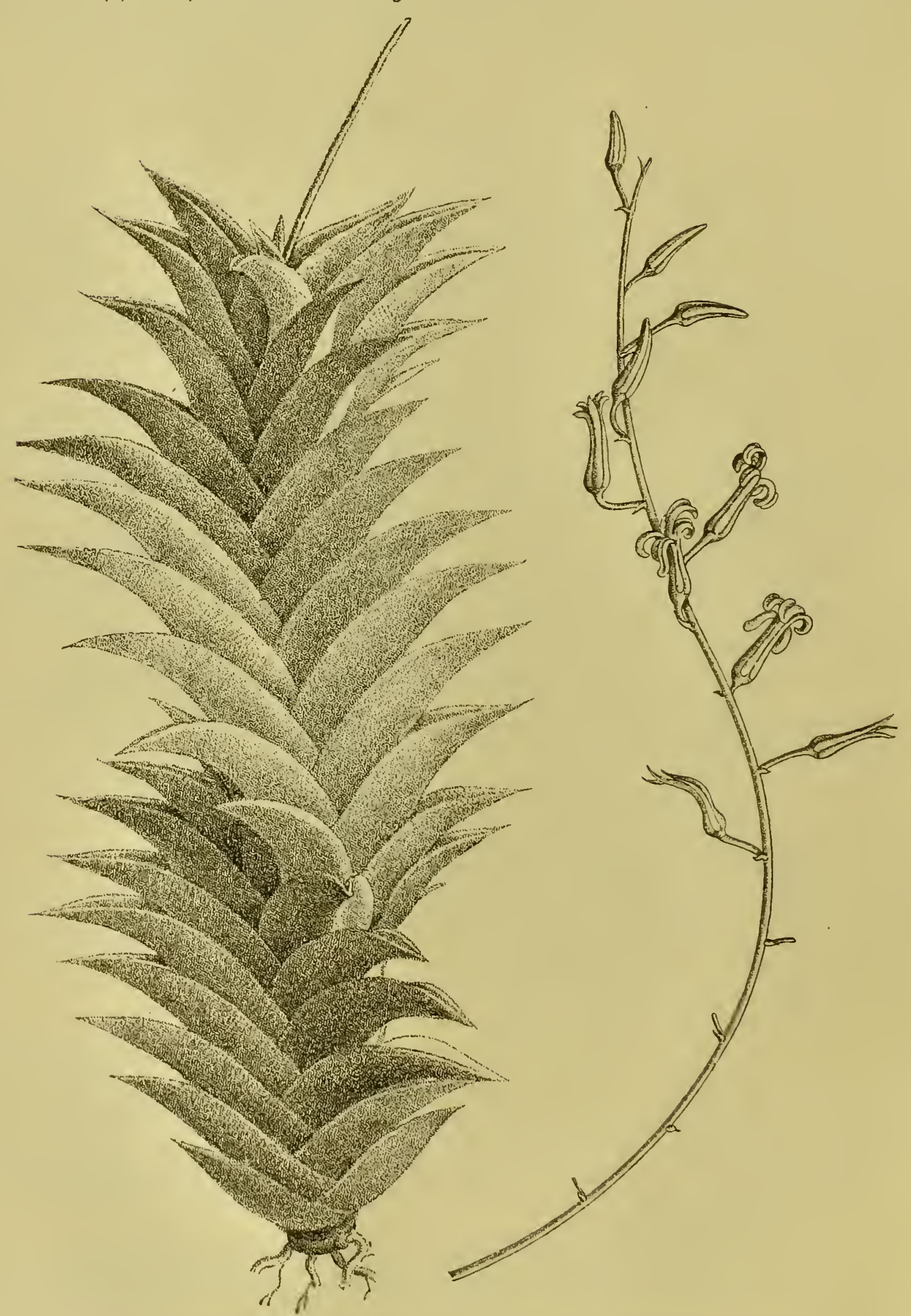

fig. 7. Haworthia viscosa Haw, var. torquata Bak. Slebrige Gawortfie.
11. H. Cooperi Bak.

12. H. setata Haw. 


\section{Haworthia viscosa $H a w$. Ilefrige \$aworthie.}

Brattrofette $12-25 \mathrm{~cm}$ Vodj. Blätter in brei geraben Beilen, bid bad =

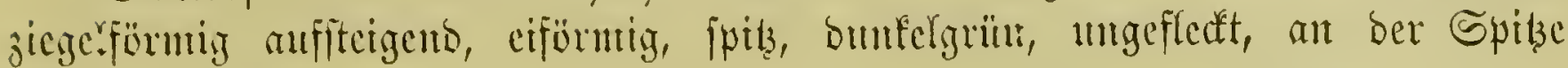

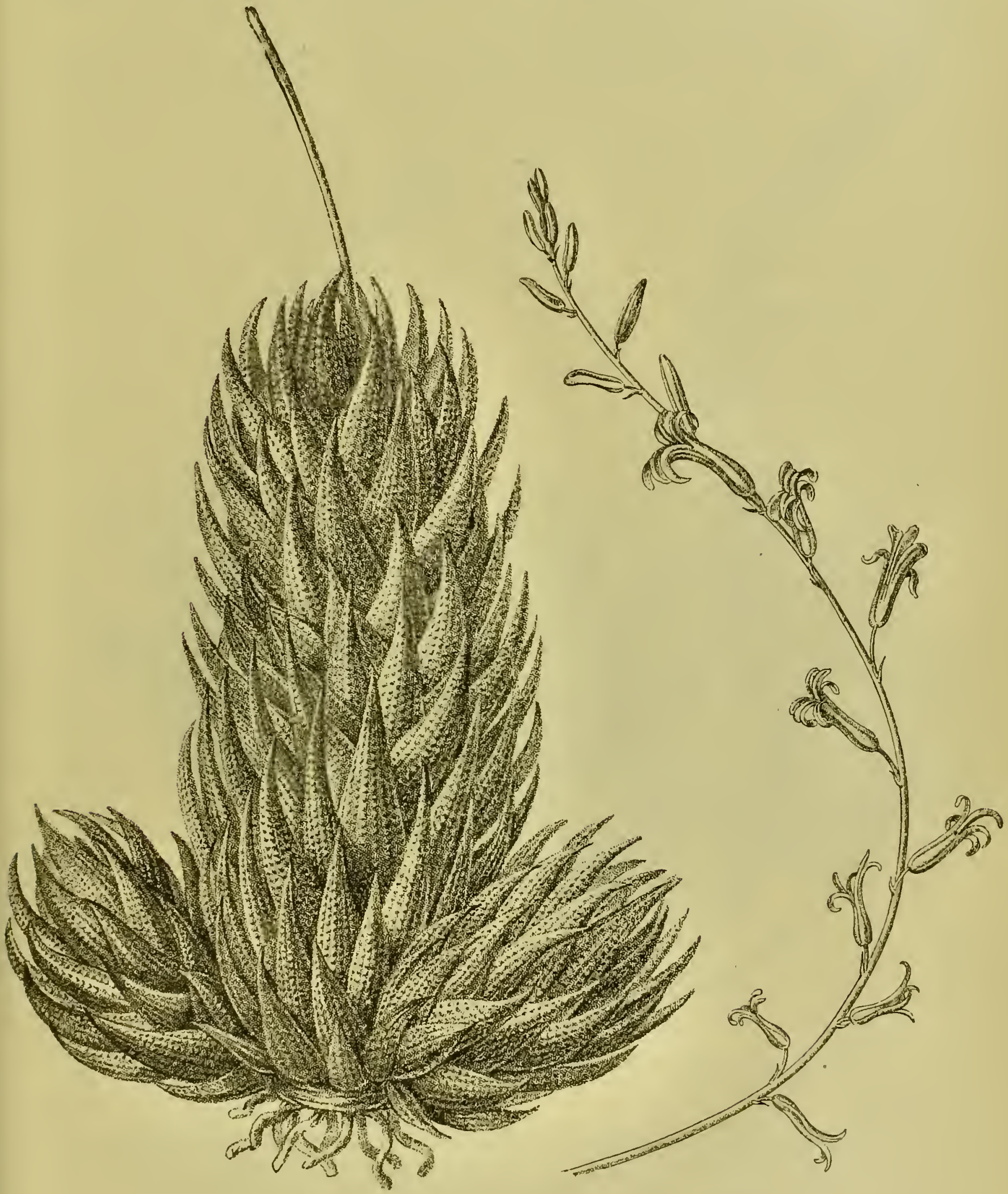

Æig. S. Haworthia Reinwardtii Haw. Reintwarot's Salvortfic.

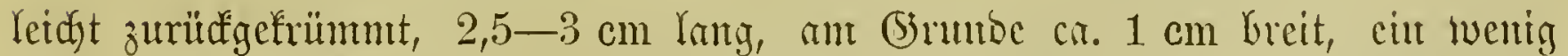

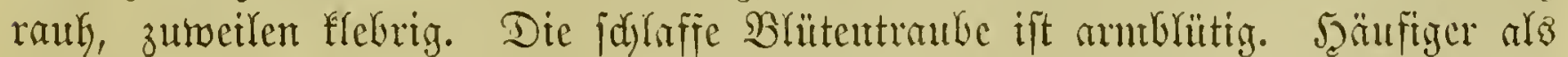
bie Stammart wiro bie var. torquata Bak. (H. torquata Haw. als 9rrt) 


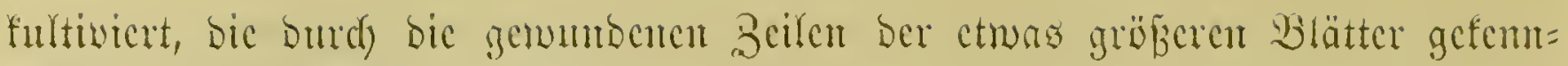
jeichutet ijt. (Fin. 7, ভ. 20.)

Dic H. psendo-tortnosa Haw. (Aloë subtortuosa Salm-Dyck) ijt cben=

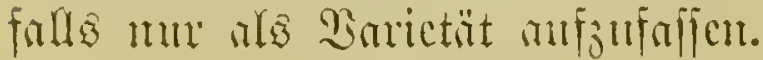

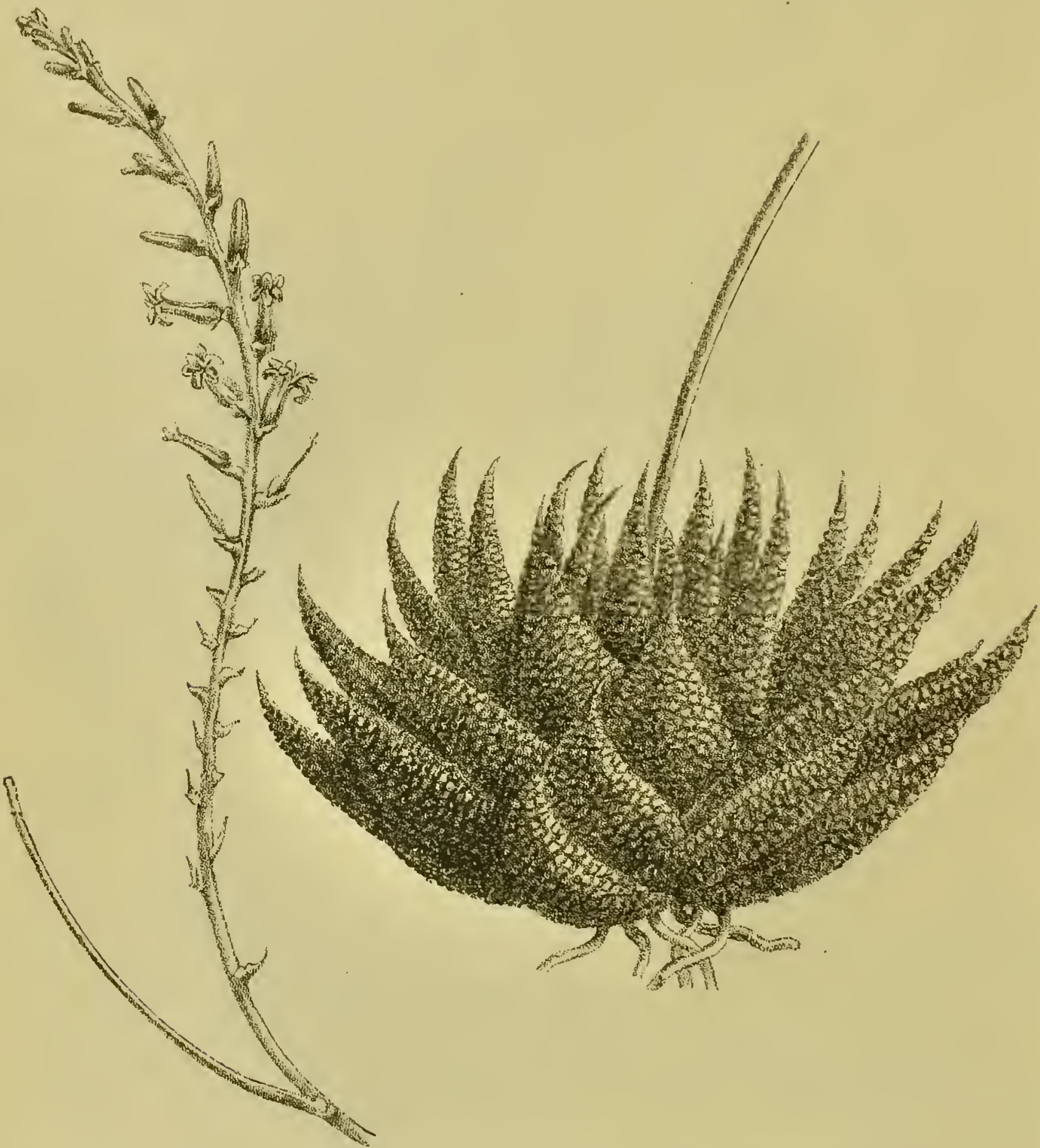

Fig. 9. Haworthia margaritifera Haw, var. granata Bak. Ferlen=5amorthie.

2. Haworthia Reinwardtii Hau. Micinwarbt's sanothic.

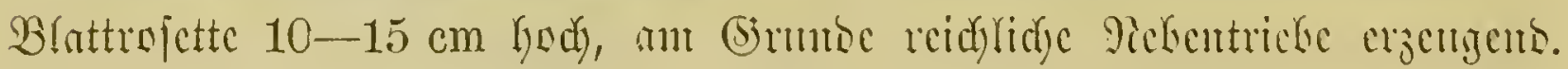
Bblätter bidjt badjziegelig in mefhreren Micifen, cilantjettlidy, 2,5-3,5 cm lantg

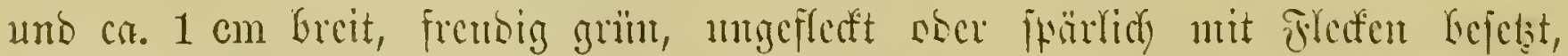

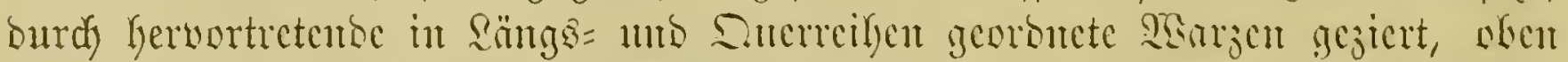

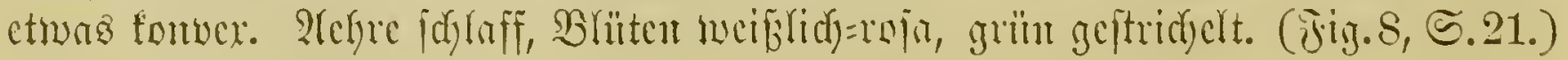




\section{Haworthia attenuata IIan. 3ugcipiztc sanunthic.}

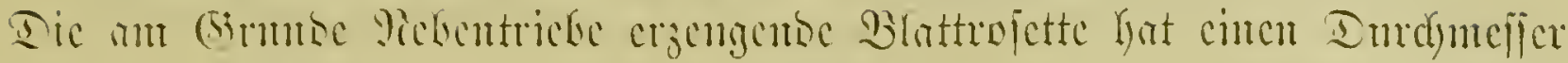

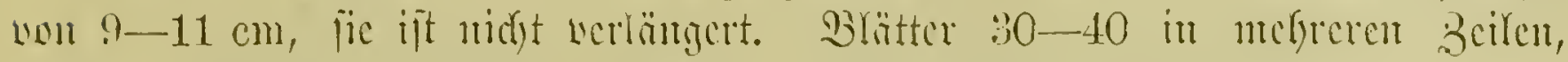

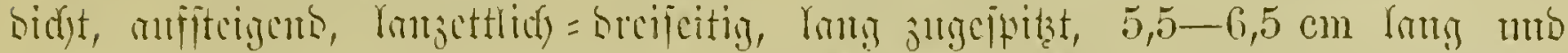

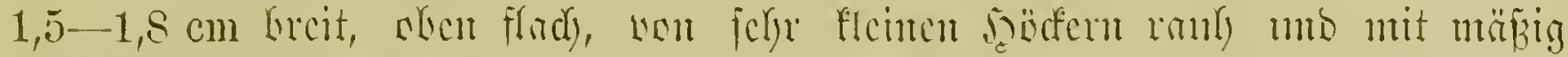

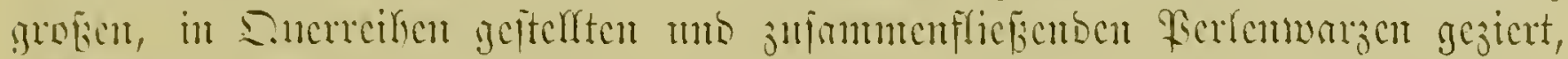

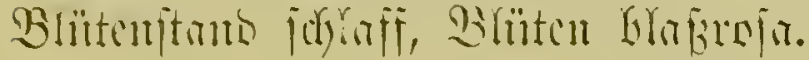

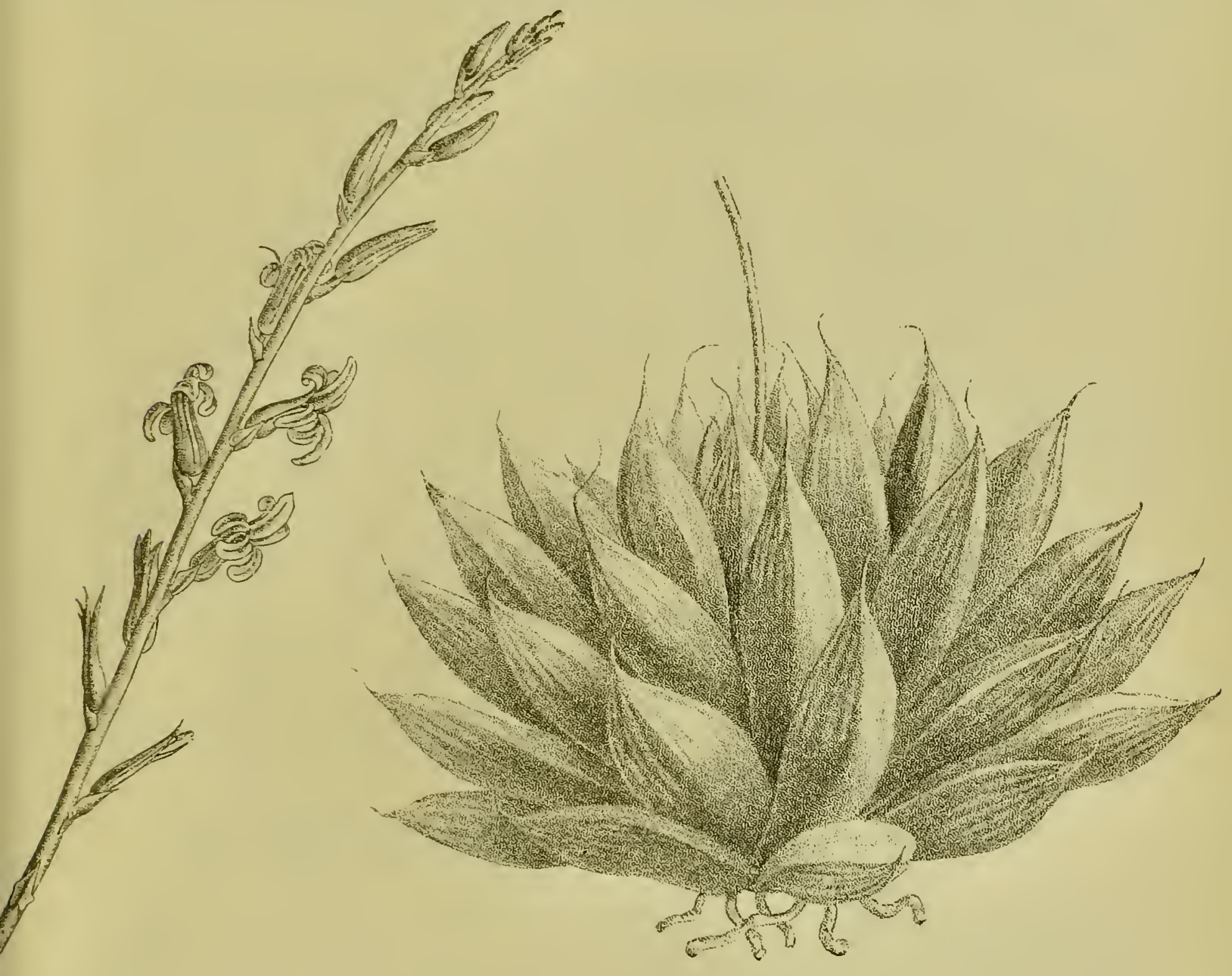

Jig. 10. Hawortbia altilinea Maw. Sicftreijte Şaworthie.

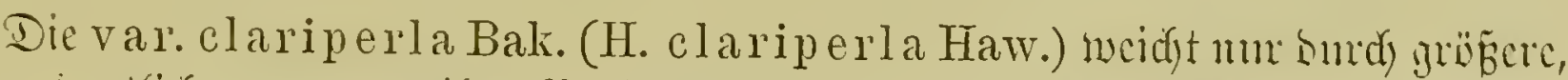

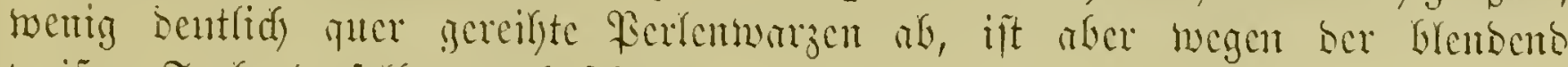

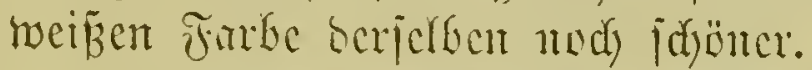

\section{Haworthia margaritifera Hau. Berlen=sawortfic.}

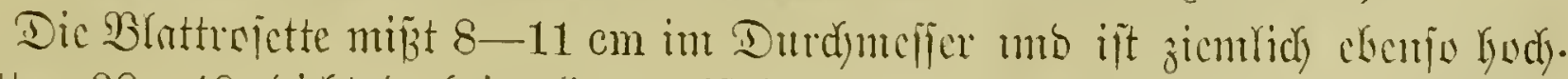

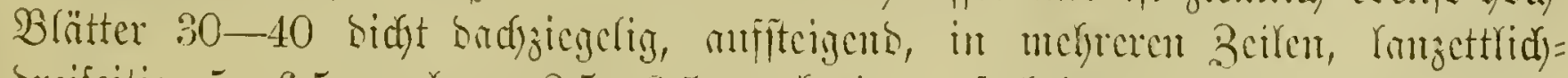
orcifeitig, $5-6,5 \mathrm{~cm}$ Yong, $2,5-3,5 \mathrm{~cm}$ breit, mif beiocn Geiten mit meregel=

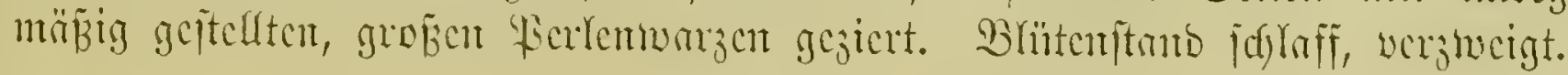


Die var. granata Bak. (H. granata Haw.) ift etrua fleitter uno hat zaflreichere uno etwas fleintere Perlentuarzen. (Fig. 9, S. 22.)

\section{Haworthia subulata $B a k$. Pfricuten=\$atworthic.}

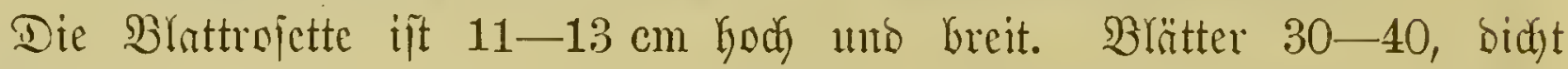

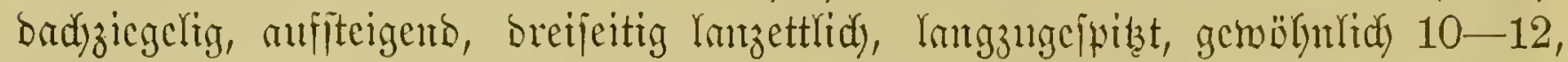
zuveilen bis $15 \mathrm{~cm}$ lantg und 2-2,5 cm breit, oberjeits flach gerunzelt, muter=

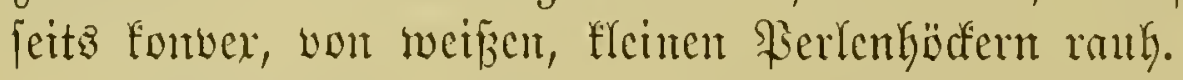

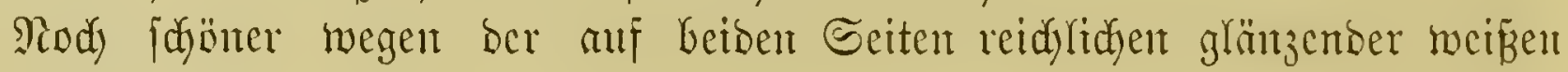
Bertenfödfer ift H. radula Haw.

\section{Haworthia altilinea Haw. Gejtreifte saworthic.}

Die Blattrojette ift $5 \mathrm{~cm}$ hod unb hat einen Dumbefifer vout $6,5-9 \mathrm{~cm}$

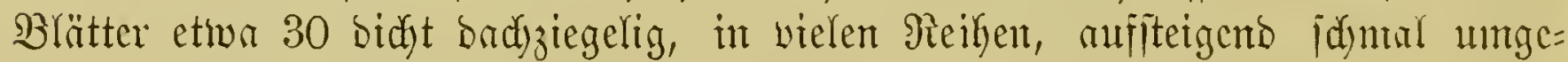

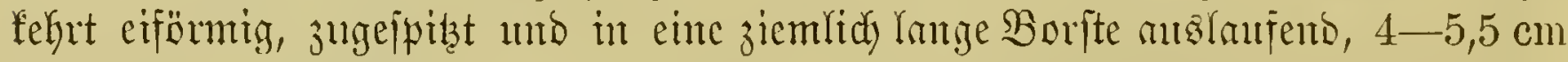
lang, über ber Mitte 1,5-1,8 cm Greit, won Grägrünter Farbe, unterjeits vou 5-7 dunfteren Streifen burdjogen. (Fig. 10, S.23.)

\section{Haworthia tessellata Haw. Mroiaif=5aworthic.}

Die Brattrojette ift 4-4,5 cm hod unt 5-6,5 cm breit. B Blätter 12-15,

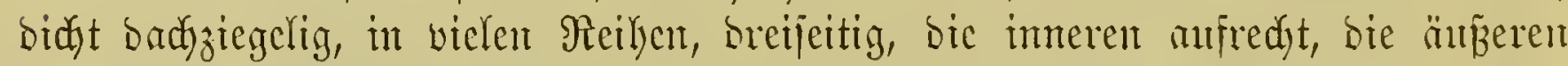

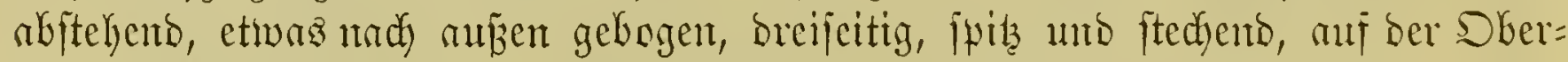

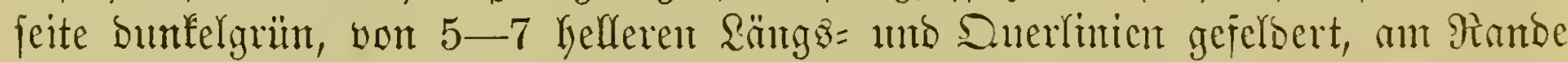

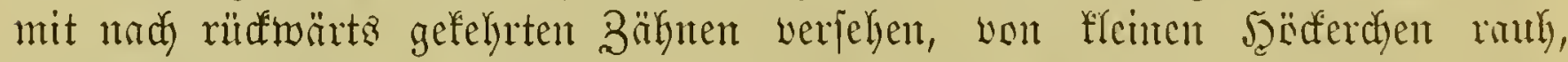
4,5-5 $\mathrm{cm}$ Inng, am (Sinutbe $2-2,5 \mathrm{~cm}$ breit. Trmule armblïtig, ids)laff; şlïten weijlid $=$ rot und grün geftrcift.

Die var. parva Bak. (H. parva Haw.) unteridyeiset fidy mur sund flemere

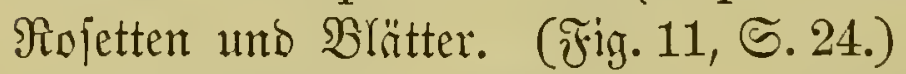

Dem Ban ber \$irlanze unb ber Beidynutg ber Brätter und) gefört bieje Ârt zu ben jujönjten ber Giattung.

\section{Haworthia venosa Haw. ㄱocutetrige gatuorthic.} (H. distincta N. E. Broun.)

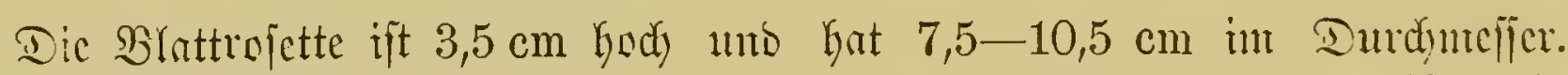

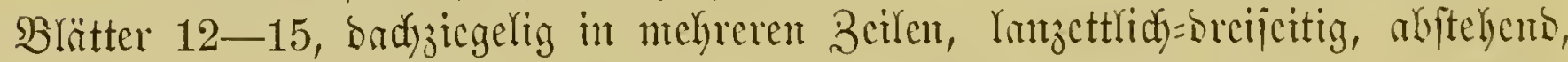

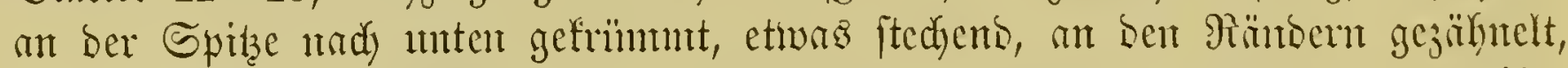
4-6 cm Yantg, ant Sinmbe 1,2-1,5 cm breit, oberjeits suntelgrün, jumcilen

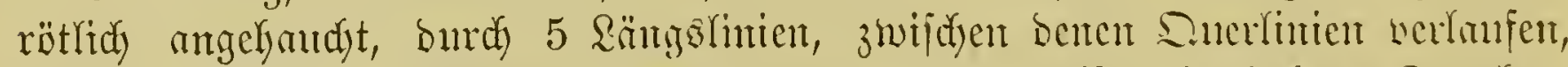

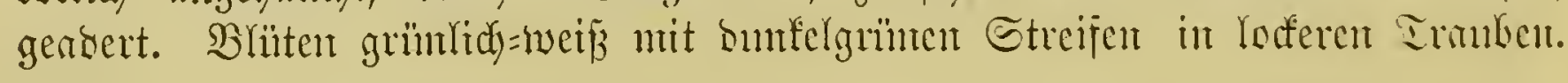

\section{Haworthia vittata $B a k$. Géchältocrte $\mathfrak{g a w o r t h i c . ~}$}

Dic SBrattrojette wirb biz $3,5 \mathrm{~cm}$ hody mo crreidyt cince Durdymejier vou

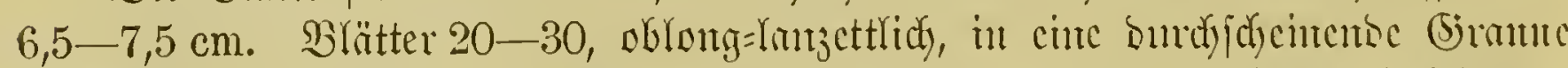

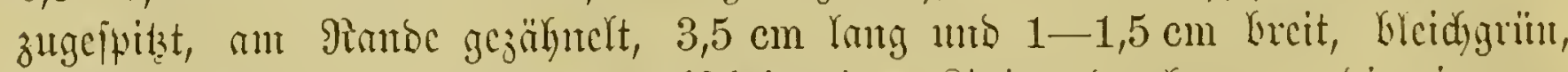

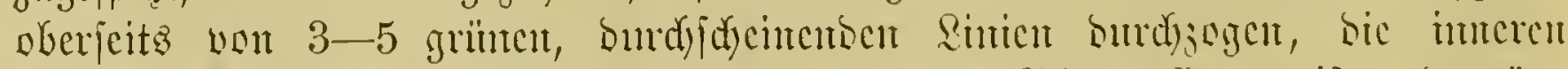

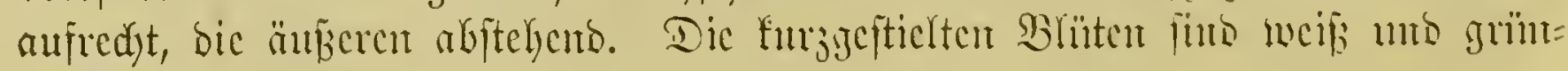
gejtreift. 
10. Haworthia pilifera Bali, 5aartragenbe saavorthic.

Die Blattrojette ift $2-2,5 \mathrm{~cm}$ hod unto wirb bis $5 \mathrm{~cm}$ breit. Bääter 20-30, bidyt badjiegelig, in melyeren Beilen, oblong, nad unten unt oben werjdyntälert mo an ber Spitze in cine burdjidyemento Borfte anzlaufend, $2-2,5 \mathrm{~cm}$ Kang unt in ber Mitte $1-1,2 \mathrm{~cm}$ breit, Glafigriin, oben gefielt, Gier

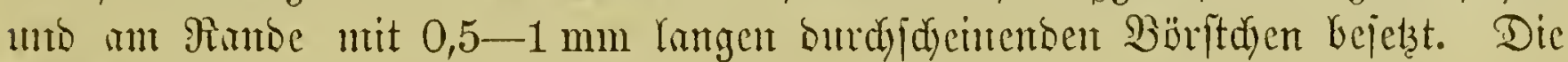
weijen Brïten fints faft fitzents.

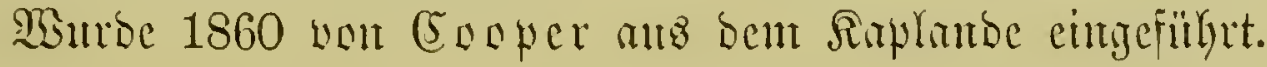
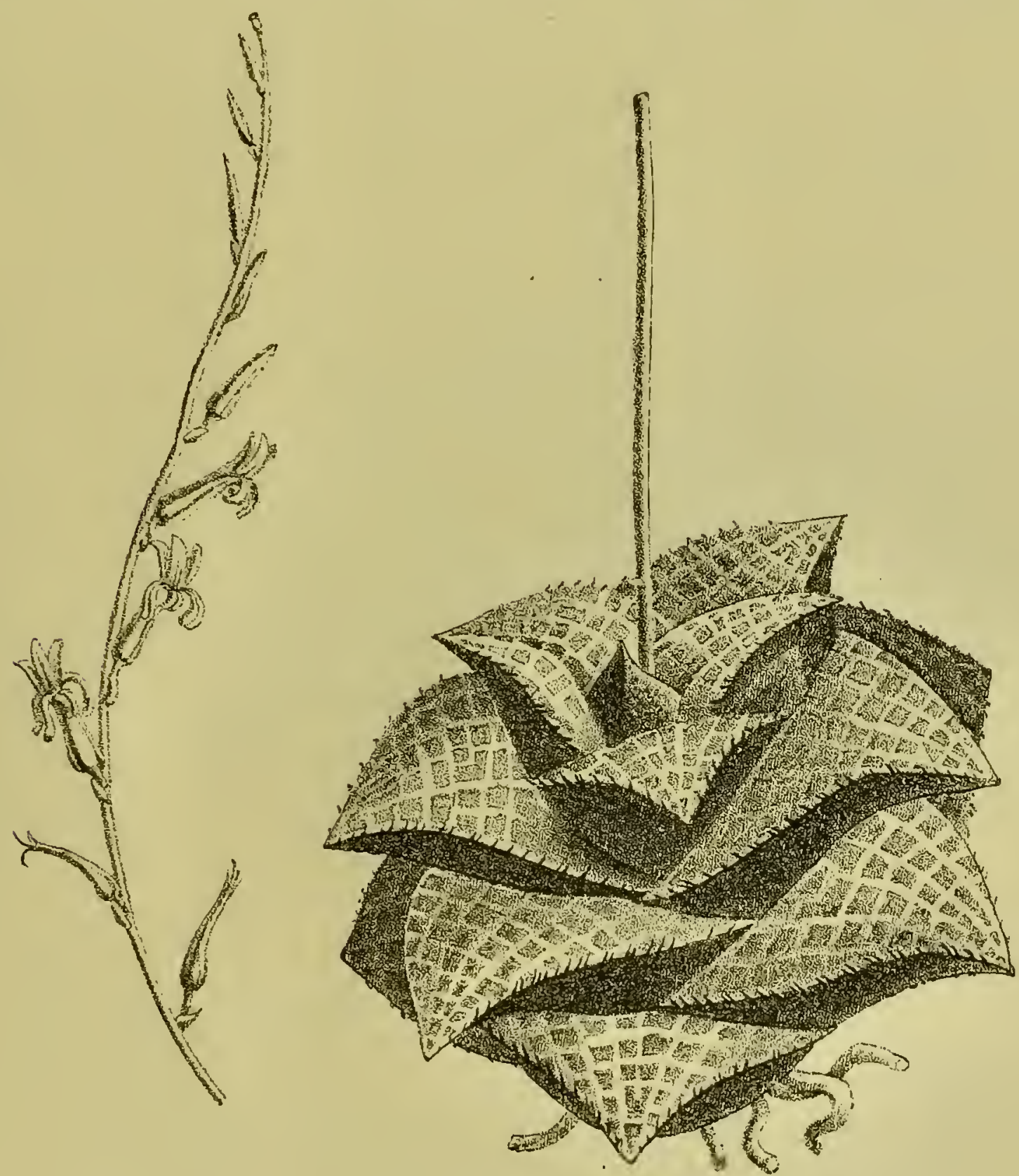

Fig. 11. Haworthia tessellata Haw. var, parva Bak. Mgojaif=5̃anortfie.

\section{Haworthia Cooperi $B a k$. Copperz sawnethic.}

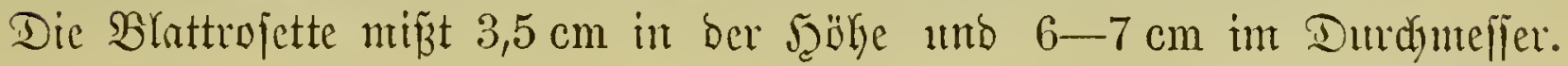

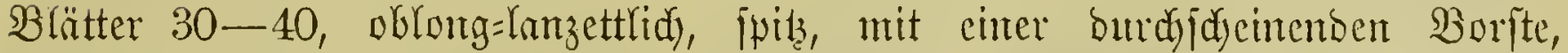
$3,5-4 \mathrm{~cm}$ lang unt $1,5-2 \mathrm{~cm}$ breit, Ghajgriün, oberjeits gefielt unb yon 7-9

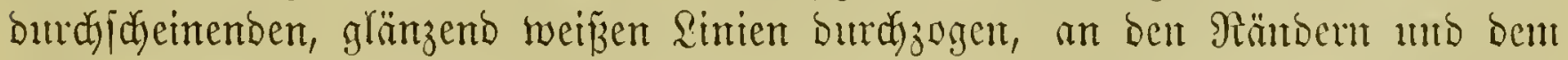

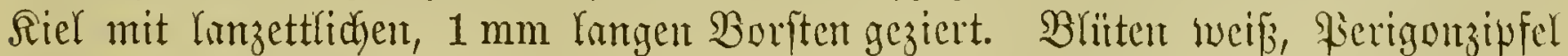

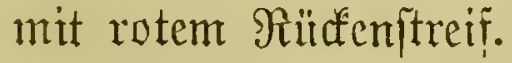

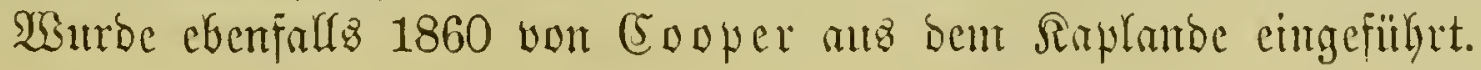




\section{Haworthia setata Haw. Boriten=\$aworthic.}

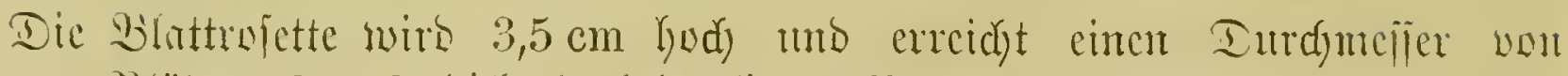

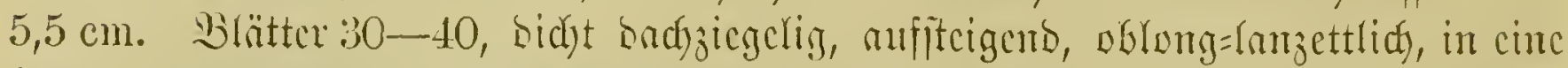

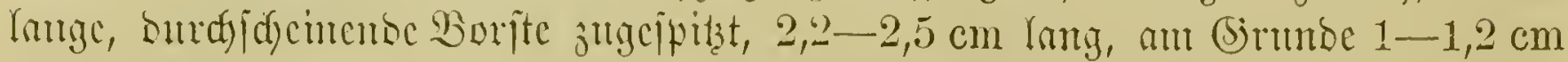

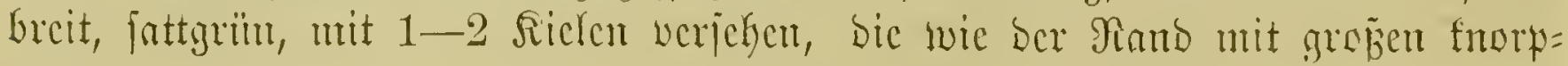
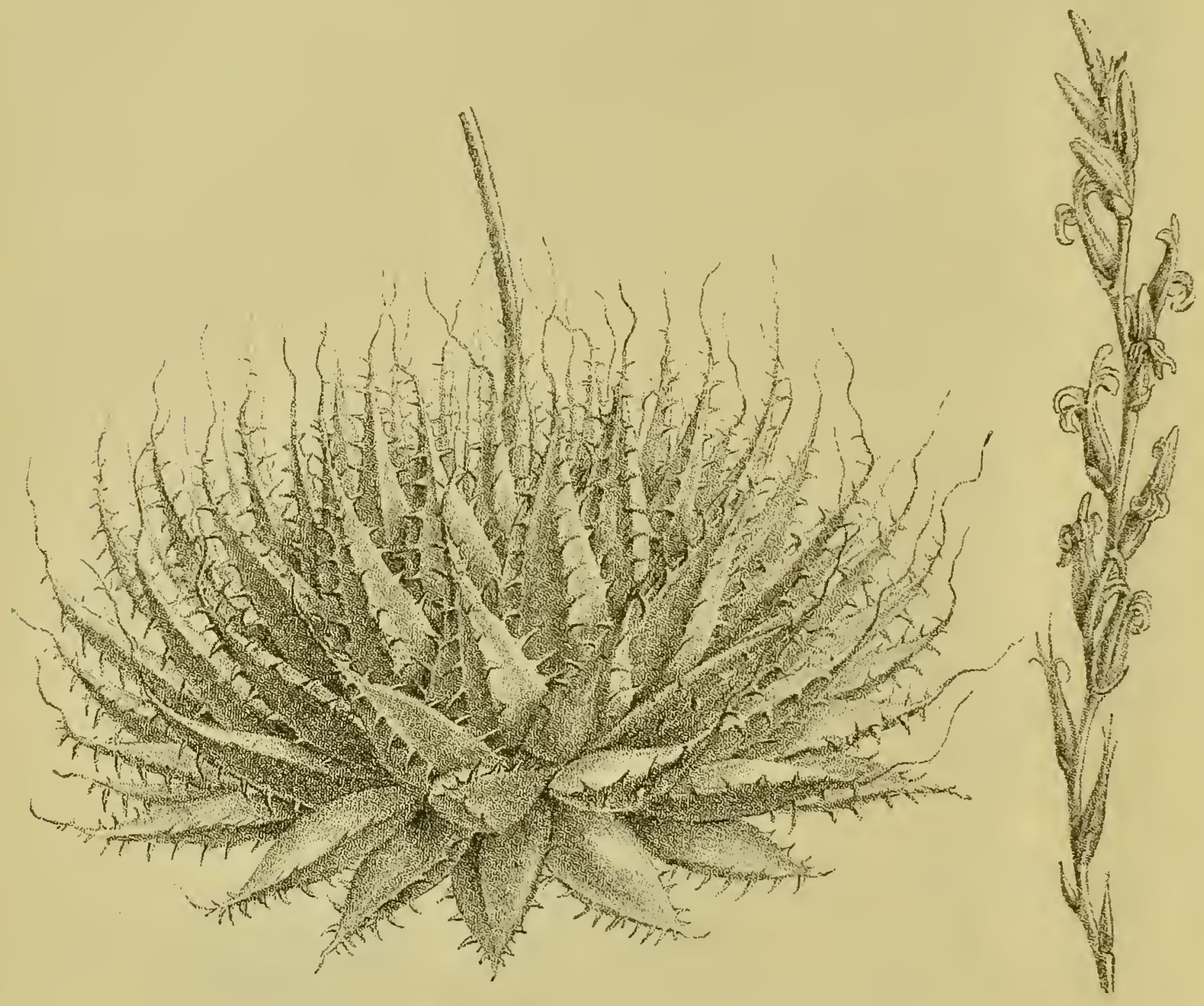

Jig. 12. Haworthia setata Haw. Borften=5̧anorthie.

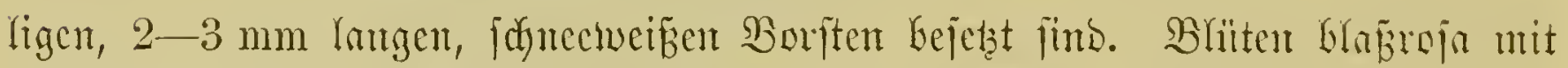

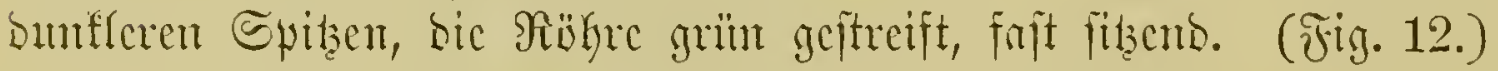

Gie ift cinc ber elegantejten Prten ber (S)ittumg.

\section{Familie Portulacaceae. Fortutlafgetwädjie.}

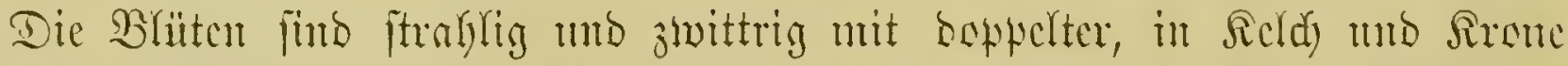

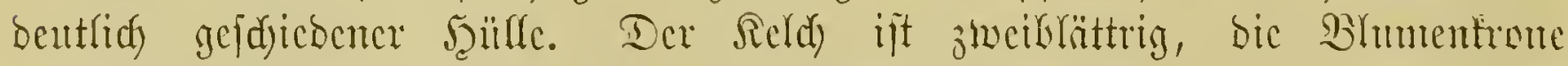

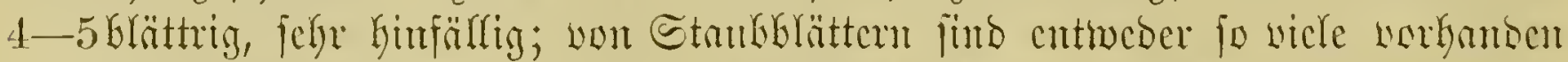

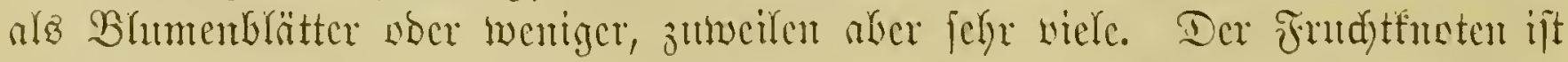

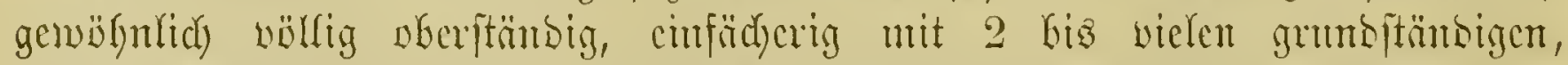

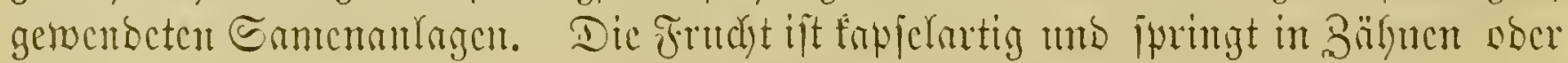




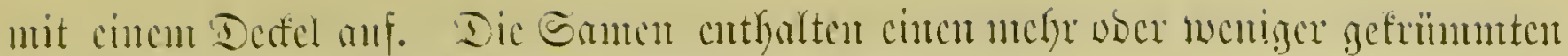

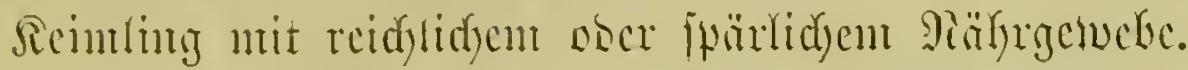

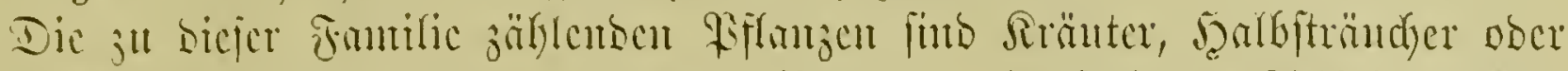

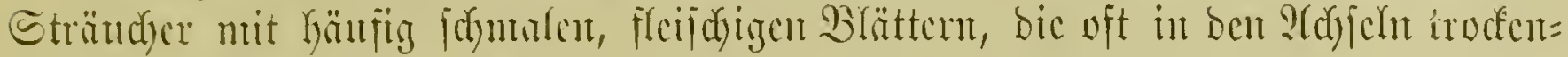

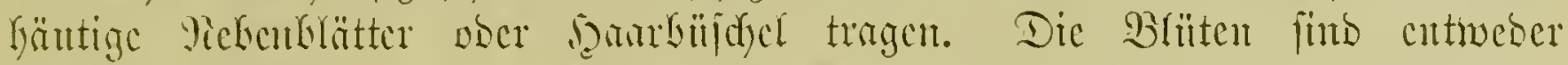

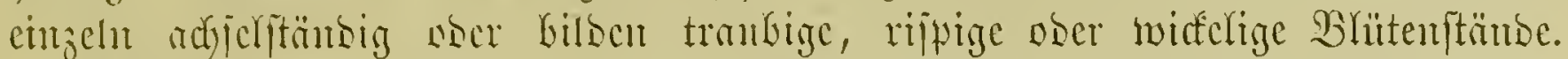

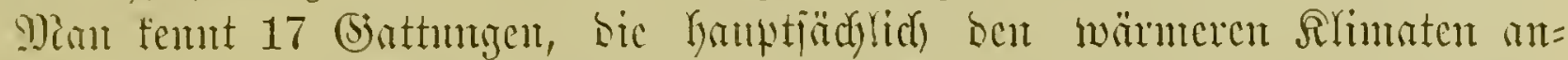

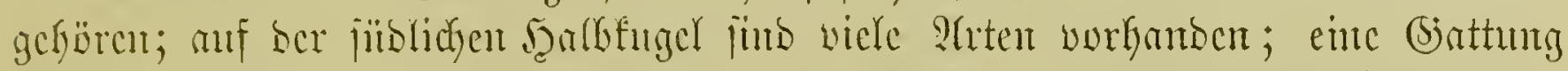
Montia funset fid) ïber bie ganje (5roc jeritreut mo geft nod) bis in bic polaren (jegenton.

\section{Sdliujiel der bejhriebenen Gattungent.}

A. Jrudutfnoten oberftänsig; Rapjel oreiflappig 1. Calandrinia H. B. K.

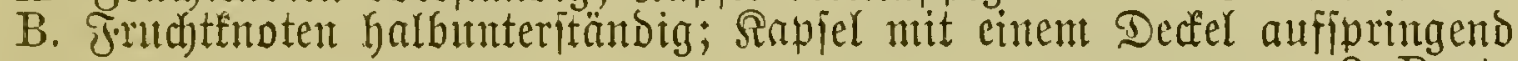

2. Portulaca $L$.

\section{Giattung Calandrinia. Humb. Bonpl. Kth. Galandxinte.}

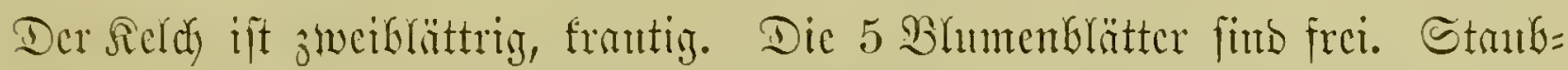

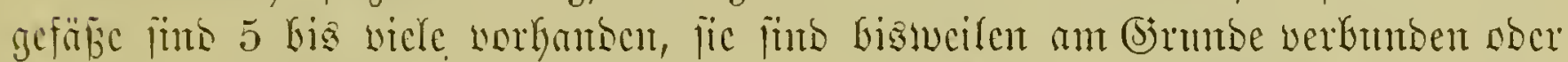

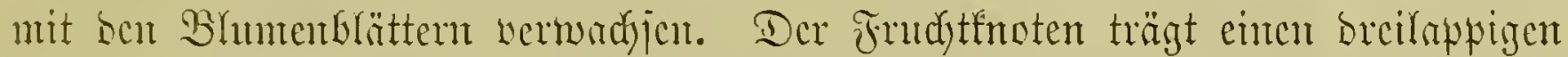

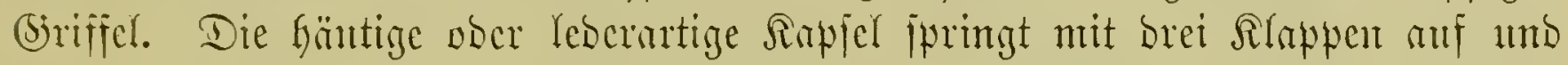
entfärlt sicle Gamcr. Der Remulung ift freisförmig gebogen.

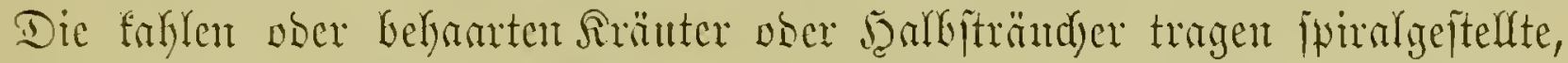
zumeilen rojettig gebrängte Blätter. Dic B̧lïten find bänfig lamiggejticlt, fic iteben eingeln ober in langen seiffeln, ober went fie fungeftielt fint in Rëpidfen bcifanmen.

Nean femt mely als 60 Mrten, sie jüntlidy in bem mbinifden Mutrifa,

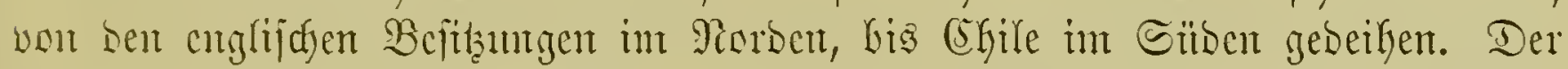
Rame ift nady Salanbrini, cinem im vorigen Sabrfunbert in Benf wirfenben Botanifer gegebar borbcn.

\section{S丸lüfjel für die beiqriebenen Zrten.}

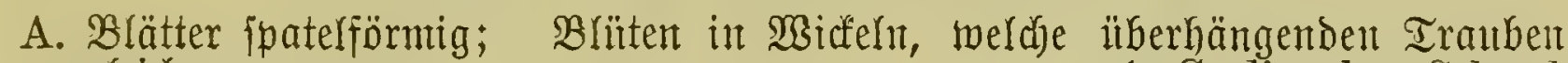
gleichen 1 . C. discolor Schrad.

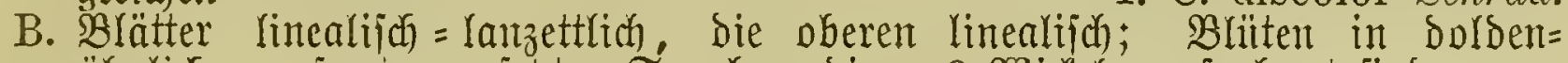
ähnlichen jujammengeiebten Iranben, bie ang Niddeln anfgebaut fints

2. C. umbellata $D C$.

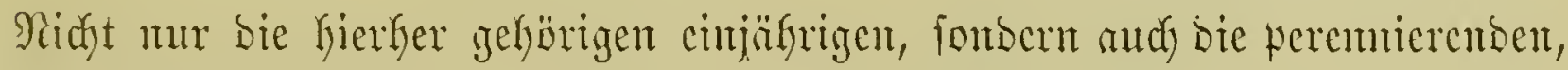
als Eonmergemäbje befandelten $\mathfrak{A}$ ren find viel beliebte Bierpflanzen bes freicu

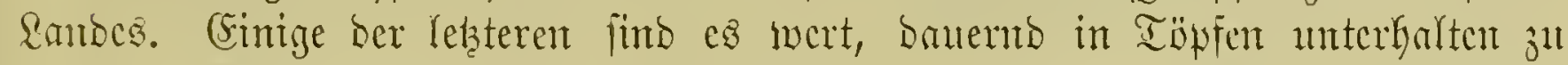
merben, alfen anberen woram folgente zhoc:

\section{Calandrinia discolor Schad. Bucifarbigc Enlanbrute.}

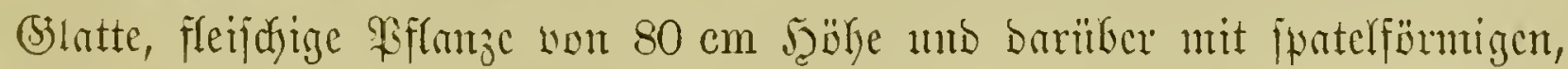
bicfen, itumpflicfen, oben grangrünen, unten purpurvoten Brättcrn, Stengel uno

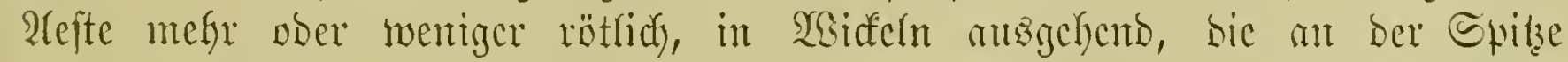

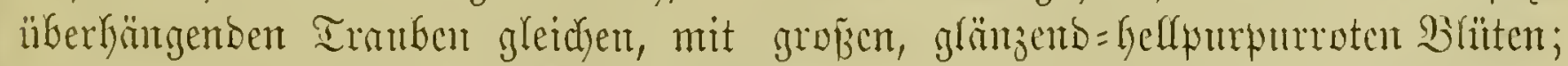

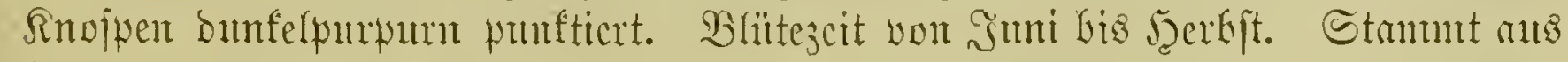
(sfille. (jig. 13, 厄. 28.) 


\section{Calandrinia nmbellata $D C$. Dolbenblïtige Calanbrinte.}

Stengel rötlidy, an ber $\mathfrak{B} a f i z$ etwa holzig, mit viclen auzgebreiteten, bam aufredyten Sfeften, nidjt über $10-15 \mathrm{~cm}$ hody unb $15-20 \mathrm{~cm}$ im Durchntefier.

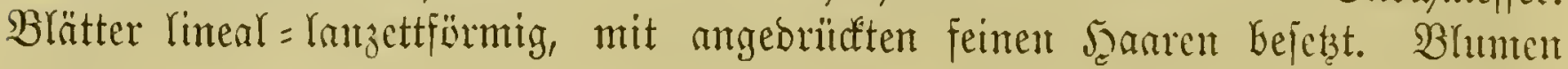

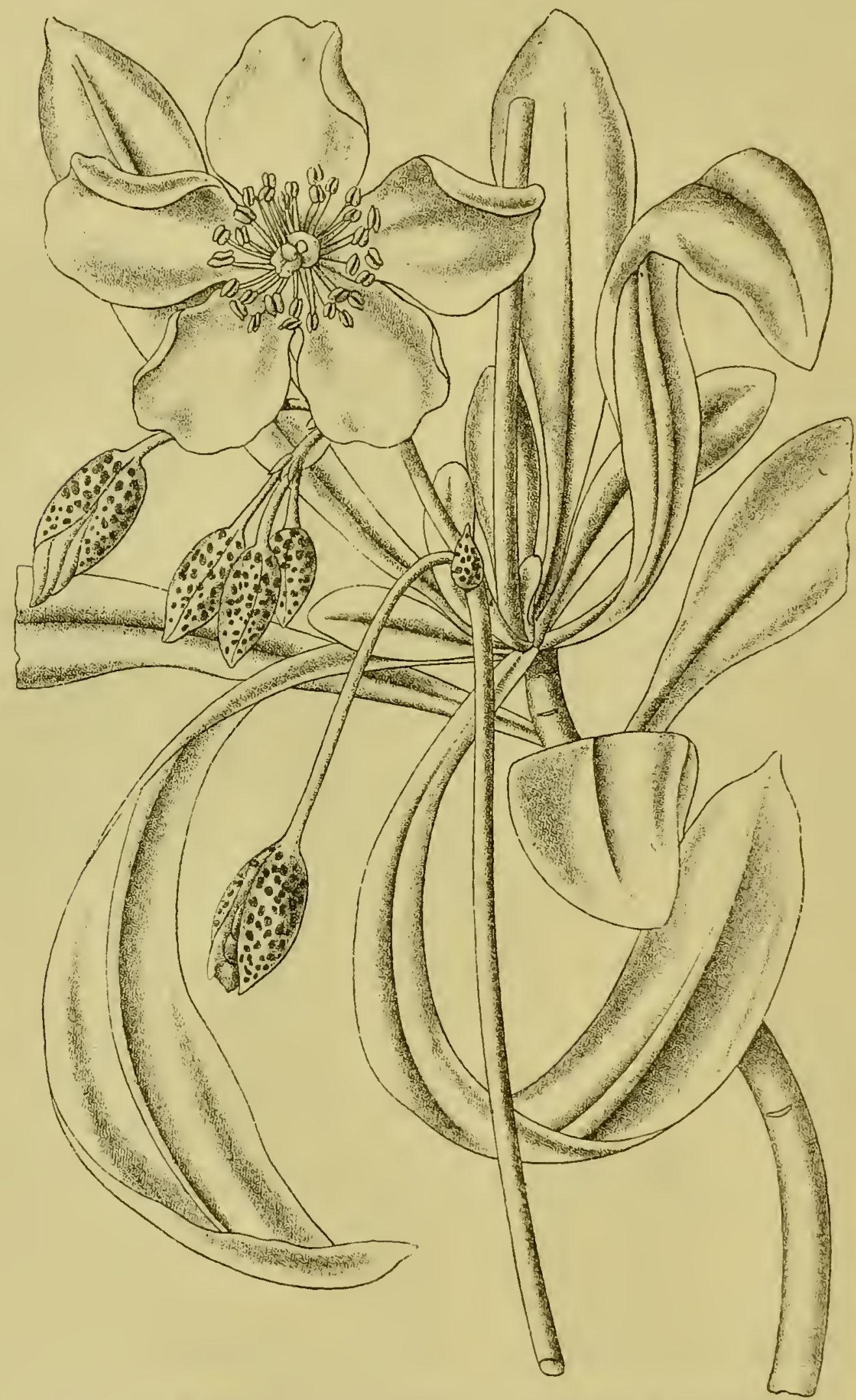

Fig. 13. Calandrinia discolor Schrad. 3weifarbige Calantrinic.

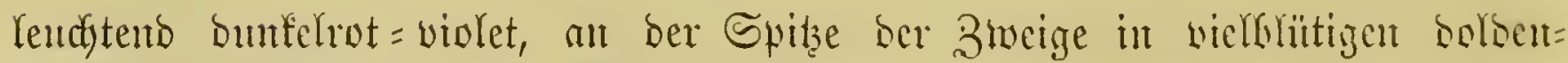

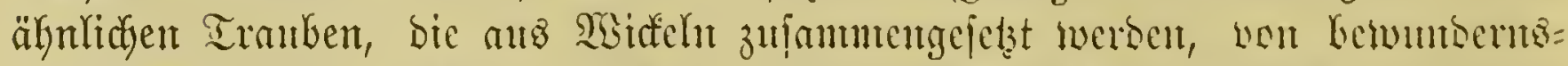

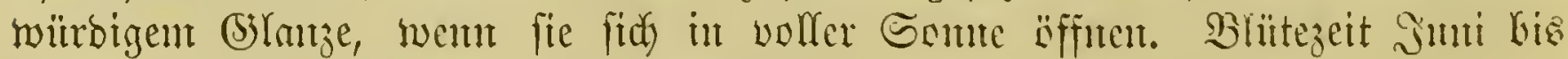
2luguit. Sit ebenfalla in CGyile heimija). 


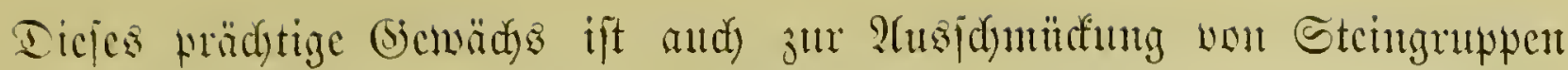

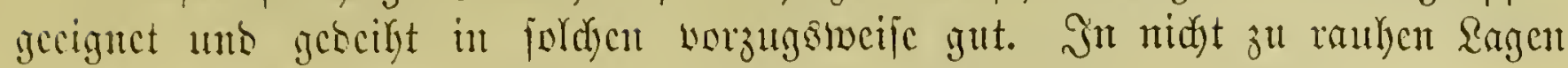
bancert jie unter cince. Deffe won Stroh über Fidstenreifig im Freien aus.

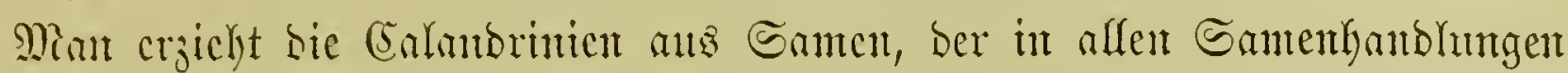

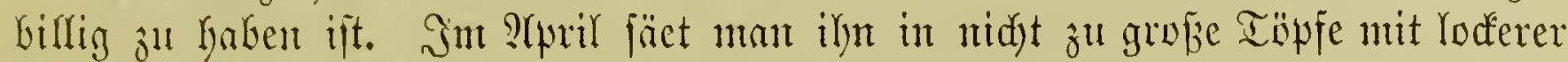

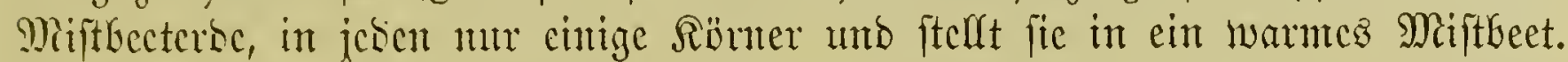
Son ben aufgegangenen \$iflanjen läßjt man in jebem Topfe mur eine, bie fräftigfte,

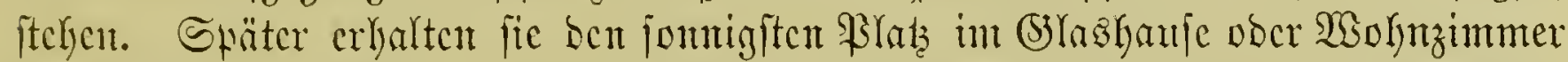

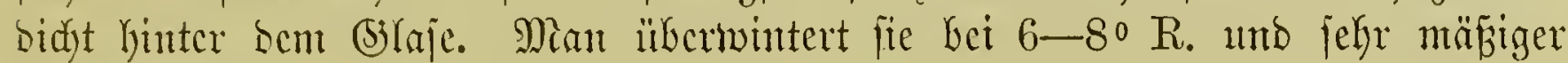
Bchrifferung.

\section{Siattuntg Portulaca Linn. Portutlaf.}

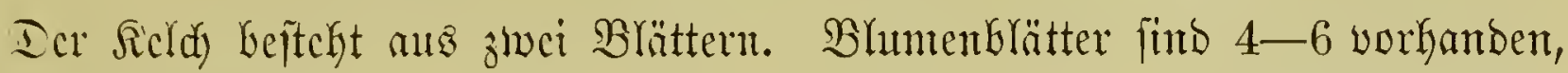

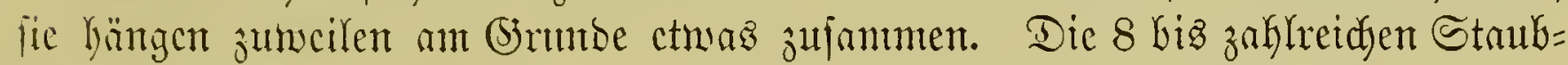
blätter fïto jencn angewadjicn. Der halbunterftänbige Fruddtfnoten trägt an ber

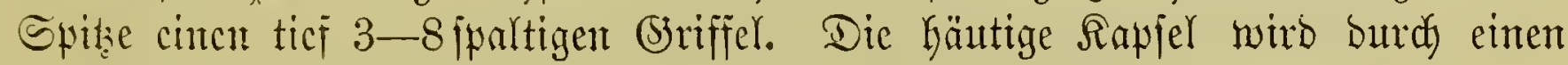
"brfälligen Decter geöffrnet.

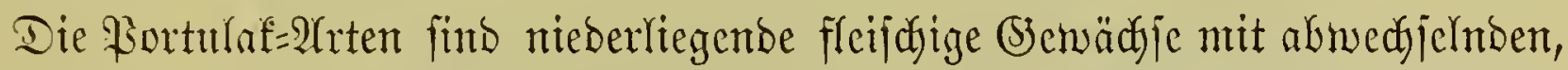

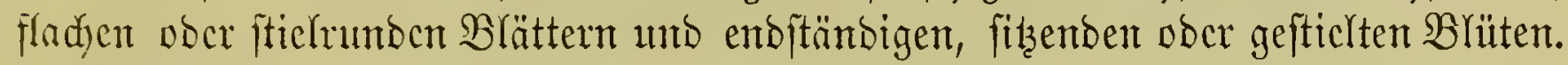

Man fennt gegentwärtig mefr als 20 Urten, bie hauptjächlidy in ben wärmeren

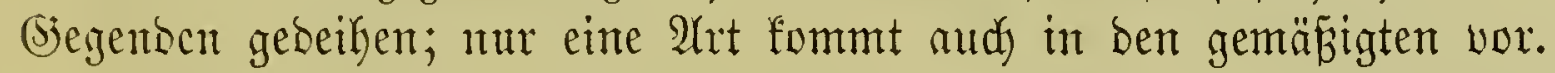

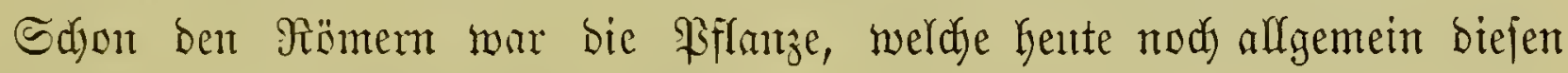

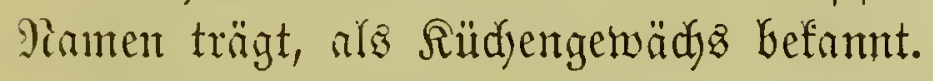

Peben bem Portulaf (Portulaca oleracea L.), ber aud) Geute nod) zumeilen in (S)ärten fultiviert, alş (Şemüje gebaut wirb, ber fid aber burd) jein menig

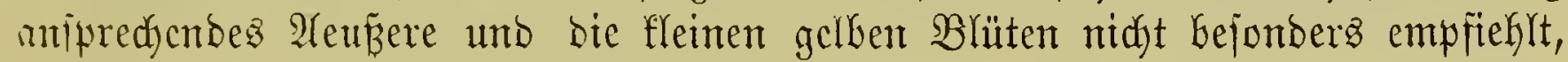
fonmt Gier mur bie folgenbe 2 rat in Betradj:

\section{Portulaca grandiflora Hook. Grof̧blumiger $\mathfrak{B o v t u l a \mathfrak { f } .}$}

Die Brfange ftammt aus Brafilien. Stengel ftielrumb, fleifdjig, veräftelt

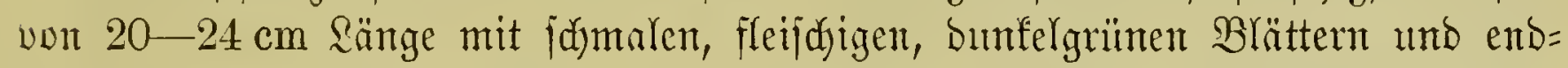
ftänbigen $4 \mathrm{~cm}$ uns barüfer in Durdjnefjer Gartenbon, Gelfpurpumen ober

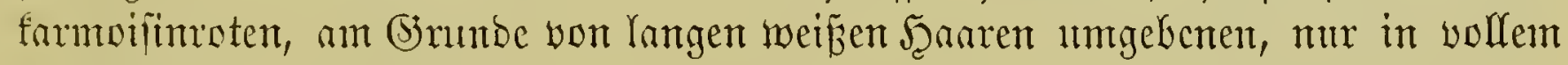
Sonnenlidyte geöfrneten Blüten. (Fig. 14, હ.30.)

2hus biejer wahrhaft prädytigen 2 art ijt wohl ein Dutsent von Forment uno Farbentwarietäten hervorgegnugen. CSB mögen won biejen mur folgentbe (Srmälyming fincen:

Var. aureo-striata, Blume weiß, gchb geitreift - var. aurantiaca, Bhlume

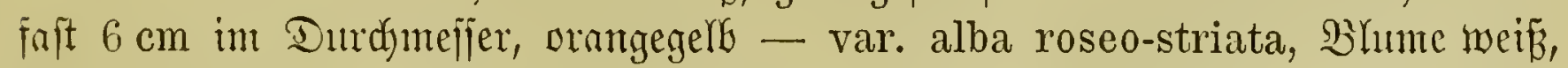
rojemrot gebänbert - var. rosea pallida, Bhlume GKajurojemrot - var. splen-

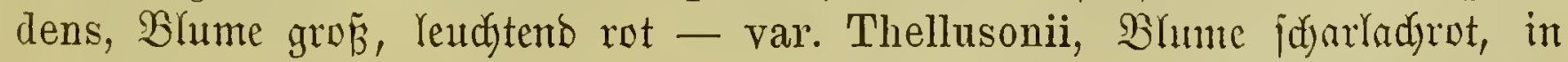

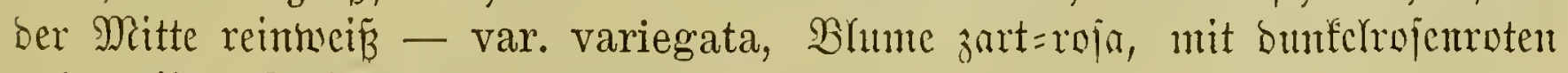
uno tweipen હtridjen uno હtreifen. 


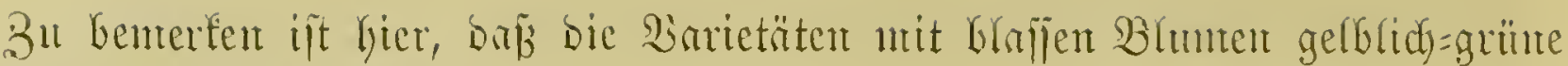
Stergel tutb BShätter befizent.

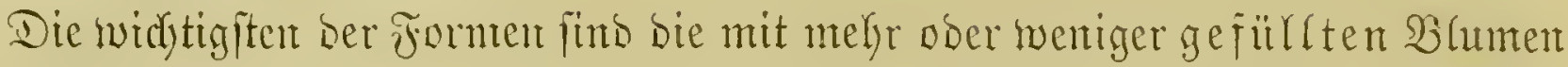
(var. plena), in benen bie Furben ber oben angefüfyrten Barietäten wicber żn

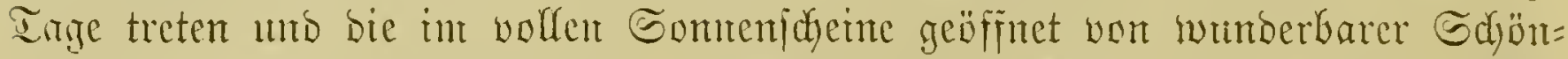

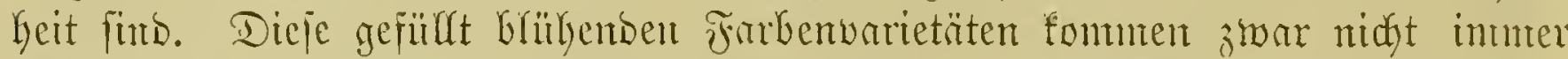

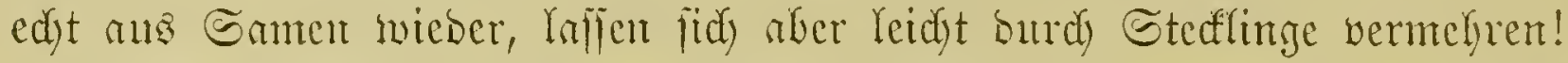

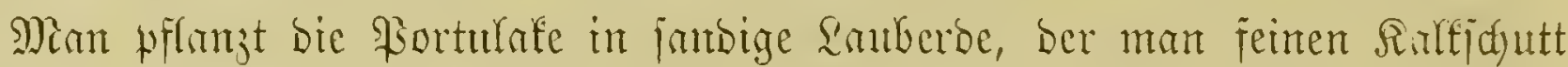

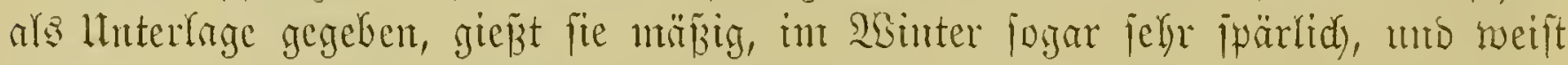

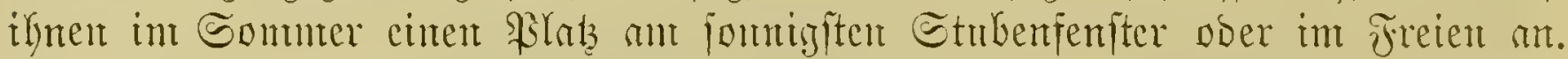

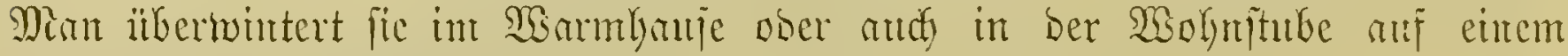
entipredjentoen Stamborte.

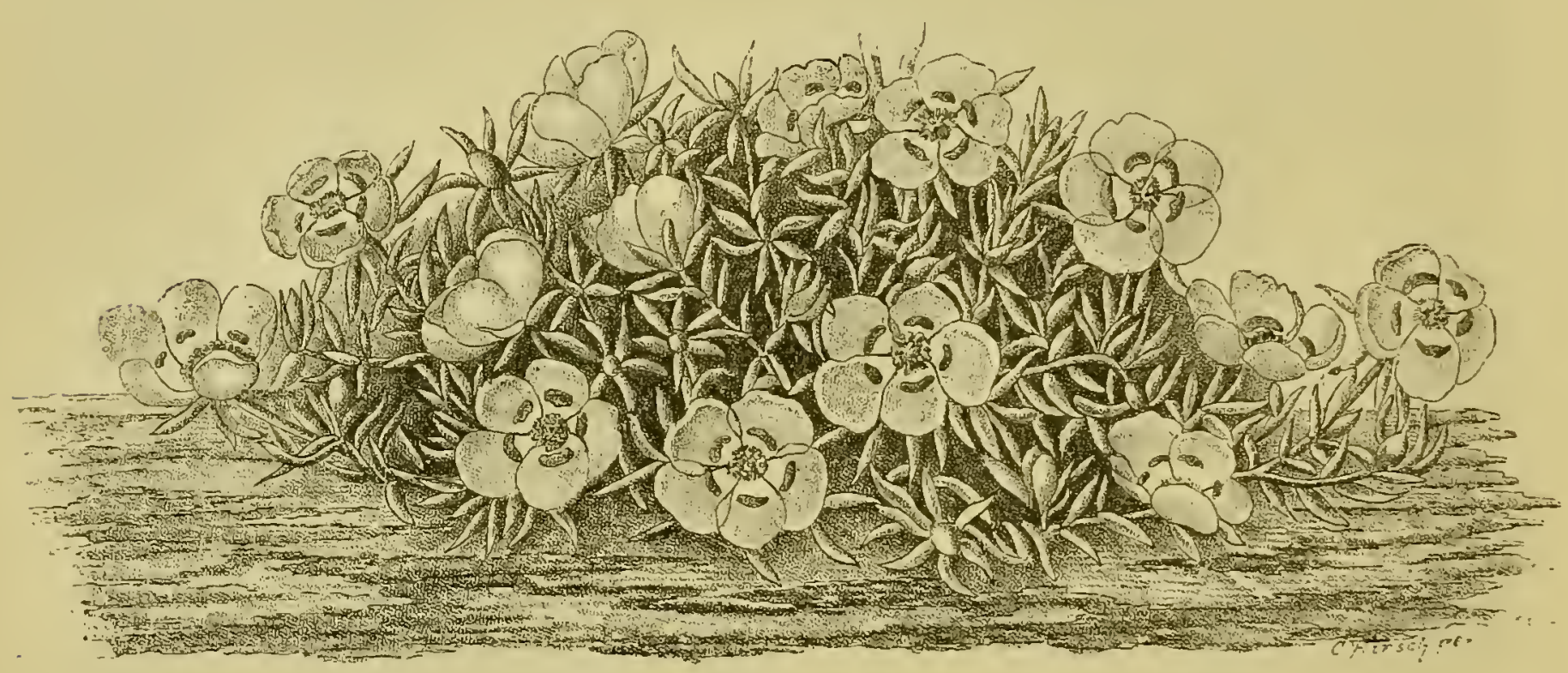

Fig. 14. Portulaca grandiflora Hook. Grobblumiger Rortufat.

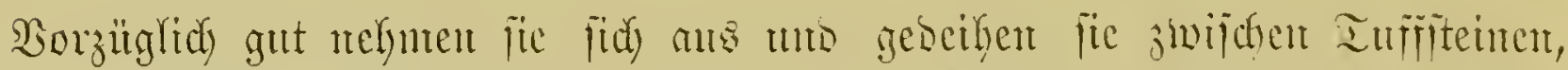

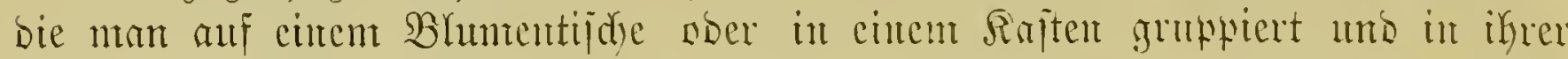

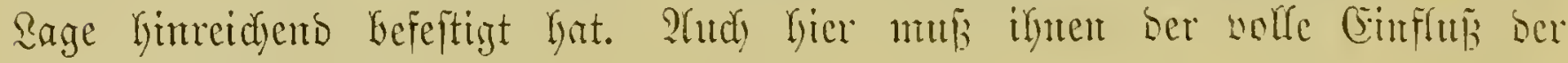
Sonme gefictjert jein.

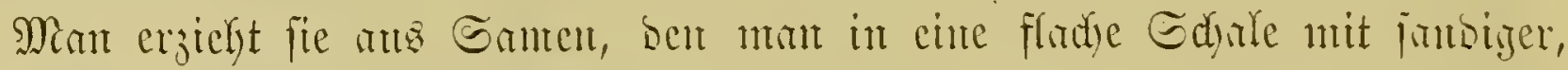

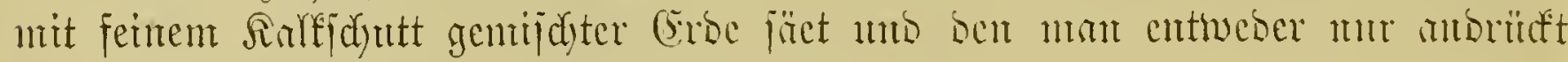

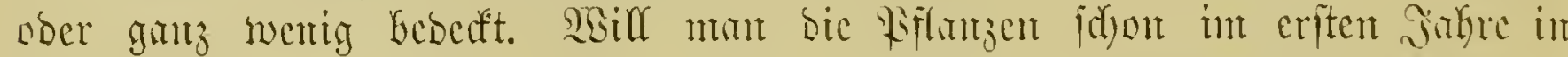

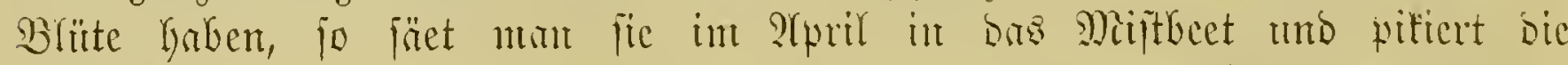

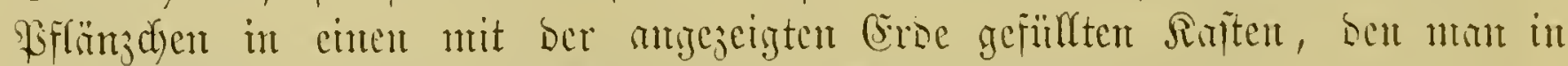

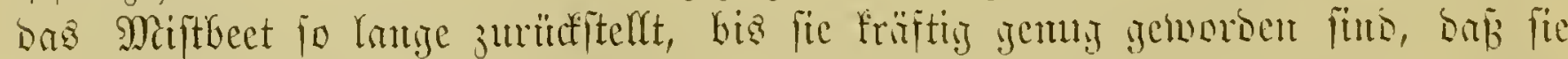

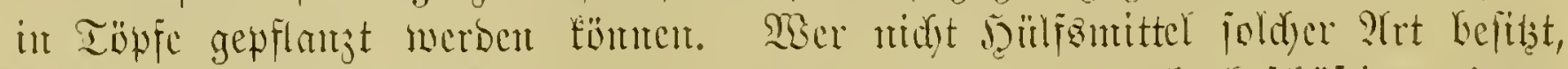

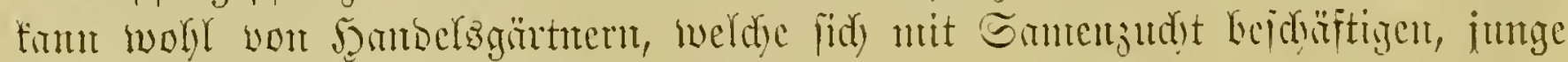

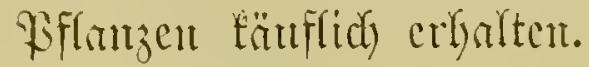

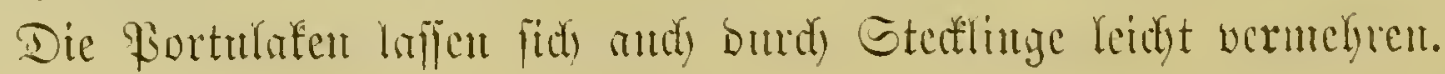




\section{Familie Mesembrianthemaceae. Mittag bluntentgewüidfje.}

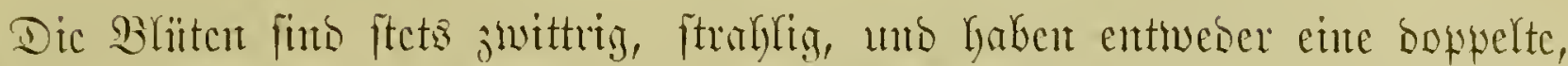

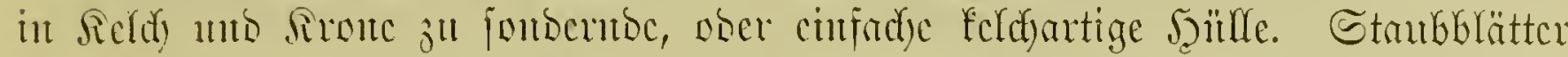

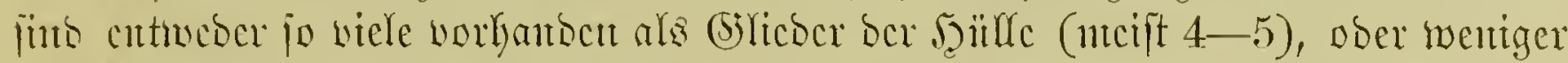

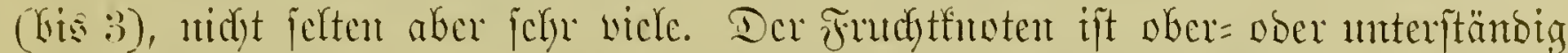

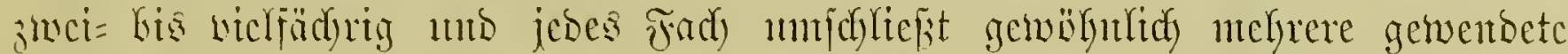

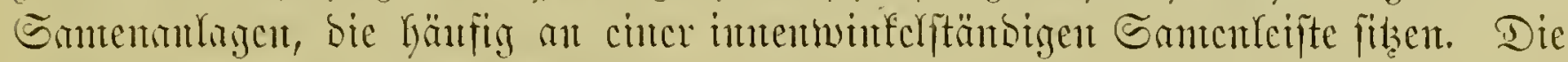

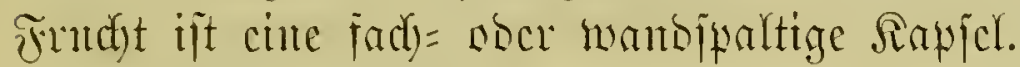

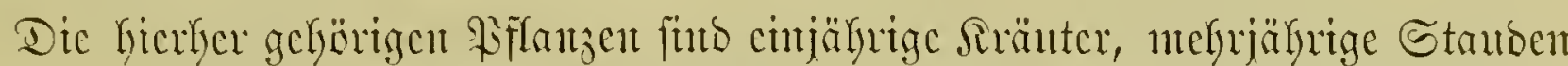

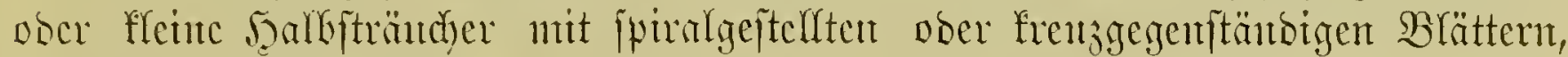

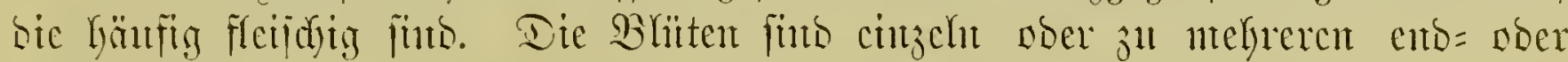
jeitcuitünoig.

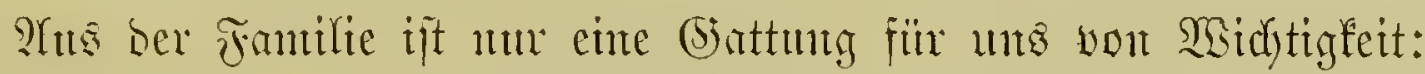

\section{(Siattung Mesembrianthemum L. Mrittagghlume.}

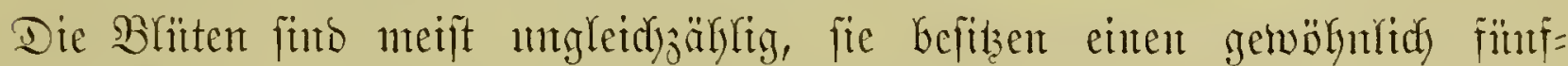
blättrigen, grïnten Reld) unto einte aus vielen Guntent Blättern beitebende Bhumen=

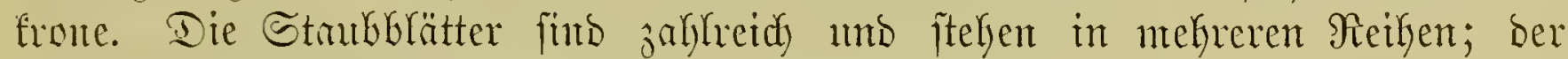

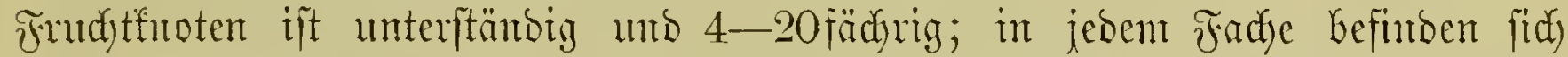
mefrere grumb= ober wanditündige Samenanlagen; Siriffel ober Rarben find jo

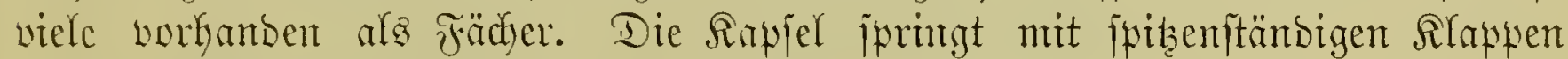

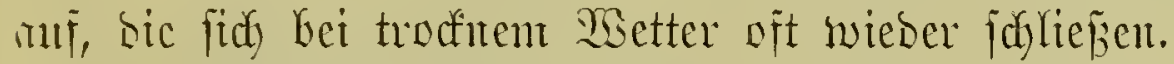

Dic Sränter obcr Salbjträudjer Gaben entweber einen nieberliegenden ober

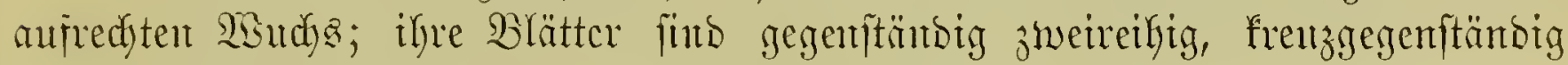

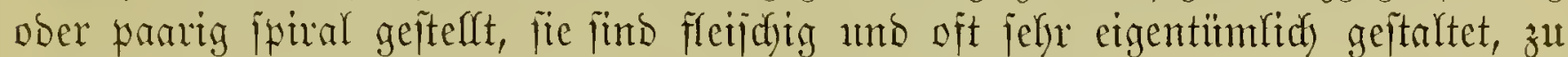

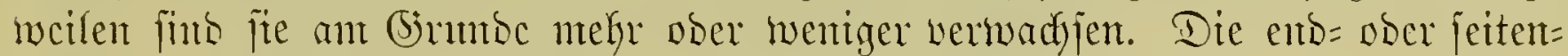

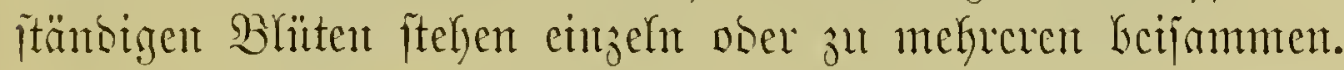

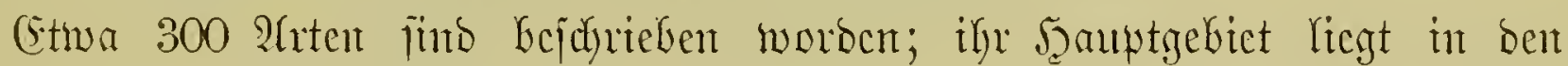

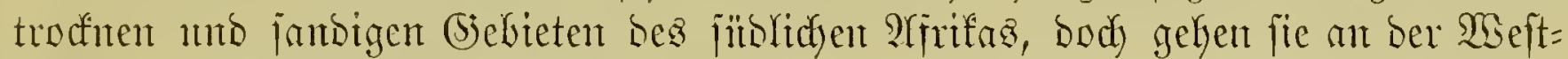
fiijte biejes Rontintentes ïber Gintuea bis ju Len Ranmen und in bas Mittel=

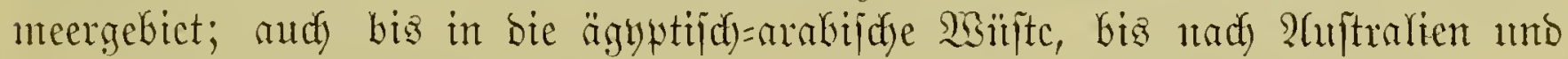
(Éfile loaben jie fich werbreitet.

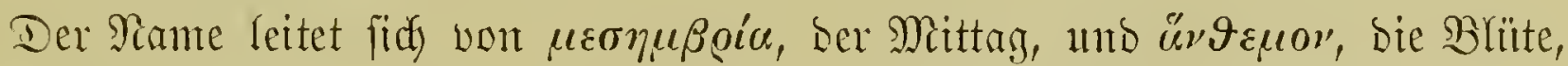
ab; es ijt aljo falfd, went er Mesembryanthemum gejdrieben wirb.

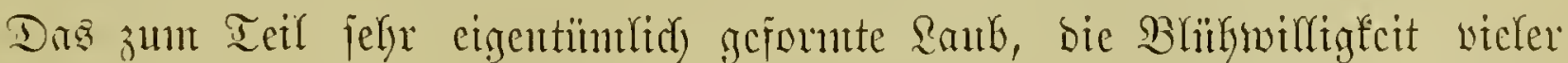

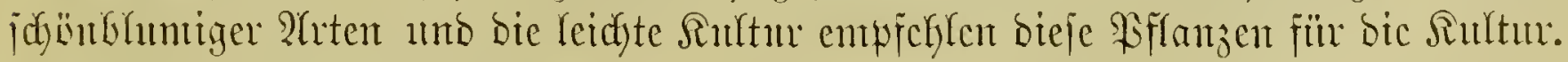

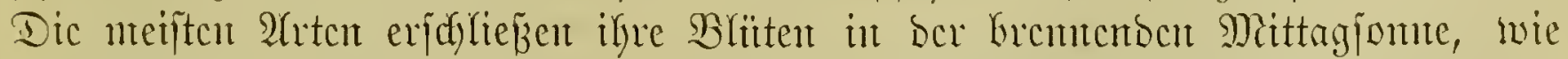

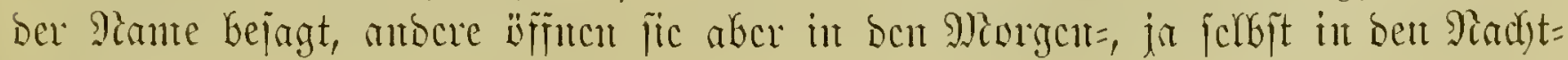
ftutbent. 


\section{Shliiffel für die befariebenen Urten.}

I. Reihe Epapulosa. Blätter nidjt mit $\mathfrak{B a p i l l e n ~ b e j e z ̧ t . ~}$

A. Ohne ober mur mit felyr furzem Stengel, $\mathfrak{O l u ̈ t e n ~ g e l b . ~ I . ~ ( S r u p p e ~ S u b a c a u l i a . ~}$ a) BSlätter gleichjeitig.

a) Bliiten einzeln; Blätter aut ben Spiken verbreitert mit gezähntem oder gewimpertem গautbe.

1. Hotte Ringentia.

I. Blïten fikend; Błätter ftengelumfafiend, grïn, weif marmoriert

1. M. tigrinum Haw.

II. Blïten geftielt; Blätter am Brunde bericuälert, graugrïn

2. M. caninum Haw.

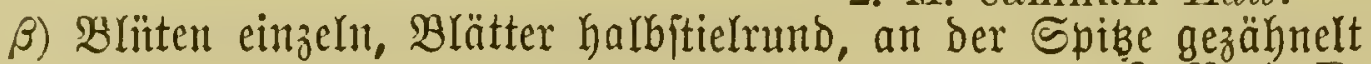

3. M. albidum Linn.

2. Rotte Rostrata.

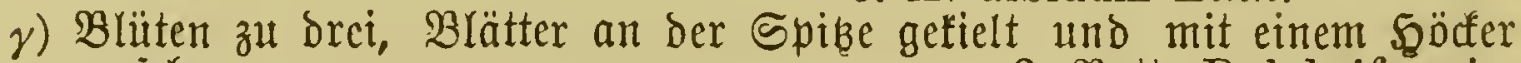
verichen

3. Rotte Dolabriformia.

4. M. dolabriforme Linn.

b) Błätter ungleidjeitig, zungenförmig, an ber Spike ichief gefielt

4. Atotte Linguiformia.

a) Selch 5 partig; B̧lïtent etwas geitielt

B) Sield 4 fpaltig; Blüten fikend

5. M. fragrans S.-Dyck.

B. Stengel entwicfelt.

6. M. linguiforme Haw.

a) şlätter breif̧neioig.

a) Blätter nicht ober faum am (S)rutbe verbunben II. Siruppc Triquetra.

I. Briffel bezm. Yarben 8 biz viele.

1. Blüten gelb

2. Błïten roja.

5. Rotte Pugioniformia.

7. M. pugioniforme Limn.

* Narben 10; Stengel aufrecht; Blätter ausgefrejien gezähnt

6. Hotte Acinaciformia.

** Sarben 12-20; Stengel nieberliegend; Blätter am Rande fraus

9. M. acinaciforme Linn.

II. Brifiel 5 , felten mehr.

1. Blïten weī́ ober rötlich zu 2-3.

* Blätter an ber Spike veridymälert.

$\triangle$ Blätter fichelförmig

10. M. falcatum Limn.

$\triangle \Delta$ B̉ätter nicht fïchelförmig getrümmt.

$\S$ Blätter am Girunde ein twentig zufammenhängent, aber nicht zat einer glöhre berwachien.

$\uparrow$ Stengel niederliegents 8. Ftotte Virentia.

11. M. virescens Haw.

t† Stengel aufred)t

o şlätter blaıgrïn

9. Motte Amoena.

12. M. spectabile Haw.

oo Blätter lebhaft grïn

13. M. formosum Haw.

$\S \S$ Blätter am Sirunbe frei 10. Rotte Blanda.

14. M. blandum Hau:

: Blätter an ber Spibe verbreitert und eingeorilit

11. Sirte Deltoidea.

10. M. deltoides Mill.

2. Blüten gelb

12. Hotte Aurea.

16. M. aurantiacum Haw.

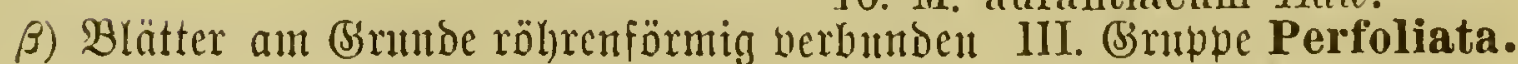
Blätter breifeitig, begraunt

b) Blätter ftielrund oder loalbitielrumb

«) $\mathfrak{B}$ lätter pfriemlid)

13. Motte Microphylla.

17. M. microphyllum Haw.

IV. Siruppe Teretiuscula. 14. Rotte Haworthiana.

18. M. Haworthii Willd. 
B) Blätter lintealij(d)

I. Stcugel alfirecht

II. Etengel nieserlicgend
15. Atotte Tenuifolia.

19. M. coccineum Haw.

20. M. tenuifolium Limu.

II. Ticihe Papulosa. Blätter mit Bapillen bejeçt.

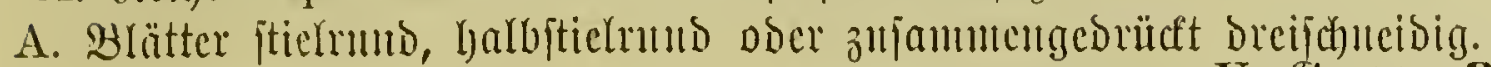

V. (3rutpe Papillosa.

a) Brä̈tter an ber Spize mit Borfenbiif(t)eln veriehen 16. Siotte Barbata.

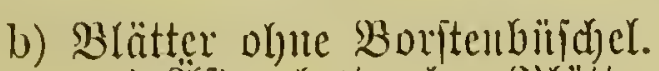

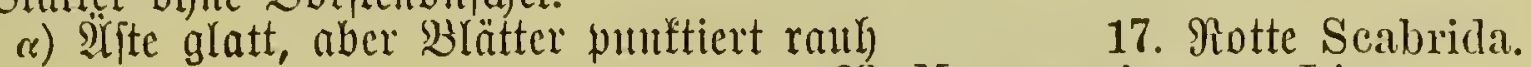

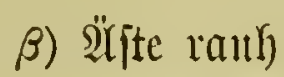

22. M. emarginatum Linn.

18. Potte Aspericaulia.

23. M. speciosum Haw.

B. SLlätter flach)

Brätter Fatelförunig, bicht mit \$apiffen bejebt
VI. Gruppe Planifolia. 19. গotte Platyphylla.

24. M. crystallinum Linn.

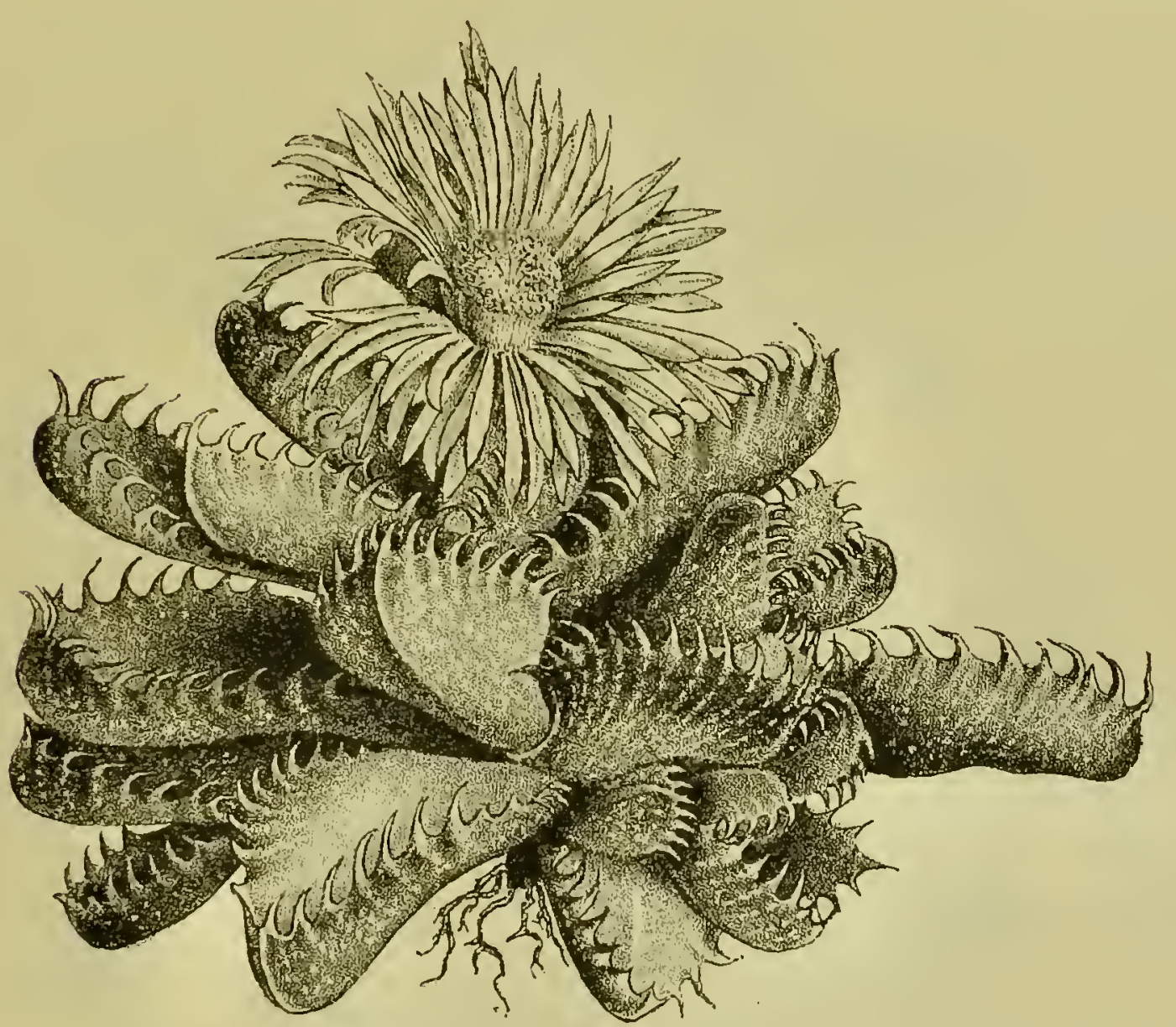

Fig. 15. Mesembrianthemum tigrinum Haw. Tiger:3ajerblume.

\section{Mesembrianthemum tigrinum Haw. Tigcr= $\mathbf{3 a j a b}$ flunc.}

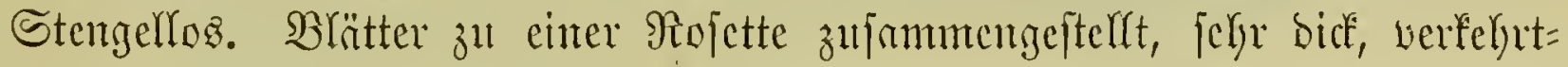

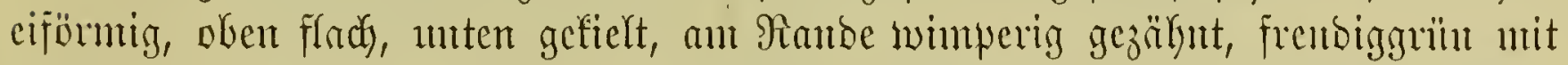

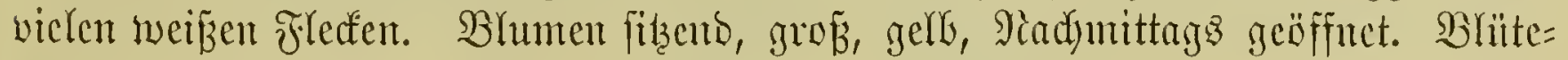
zeit Eommer, Jerbit. (Fig. 15.)

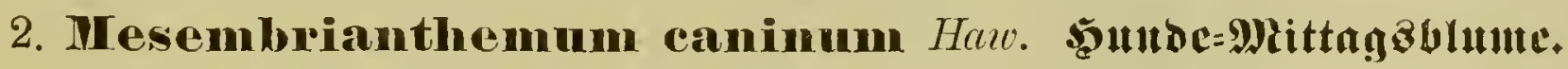

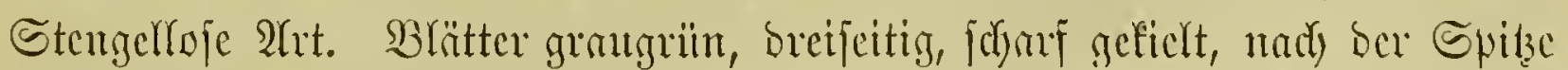

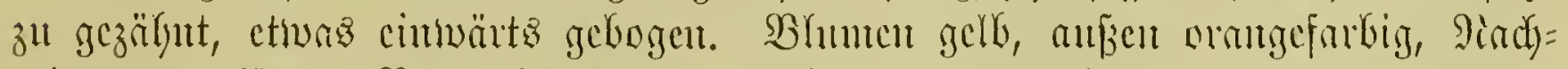

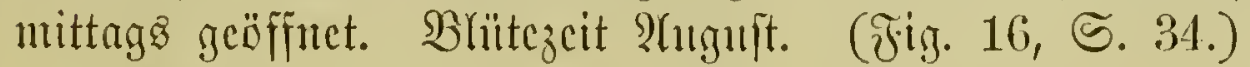




\section{Mesembrianthemum albidum $L$. Wsecislidbe Mittagablumc.}

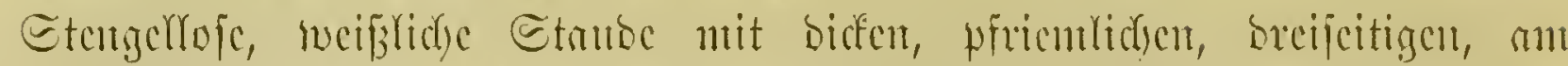

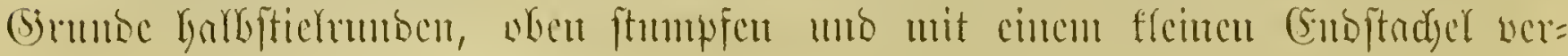

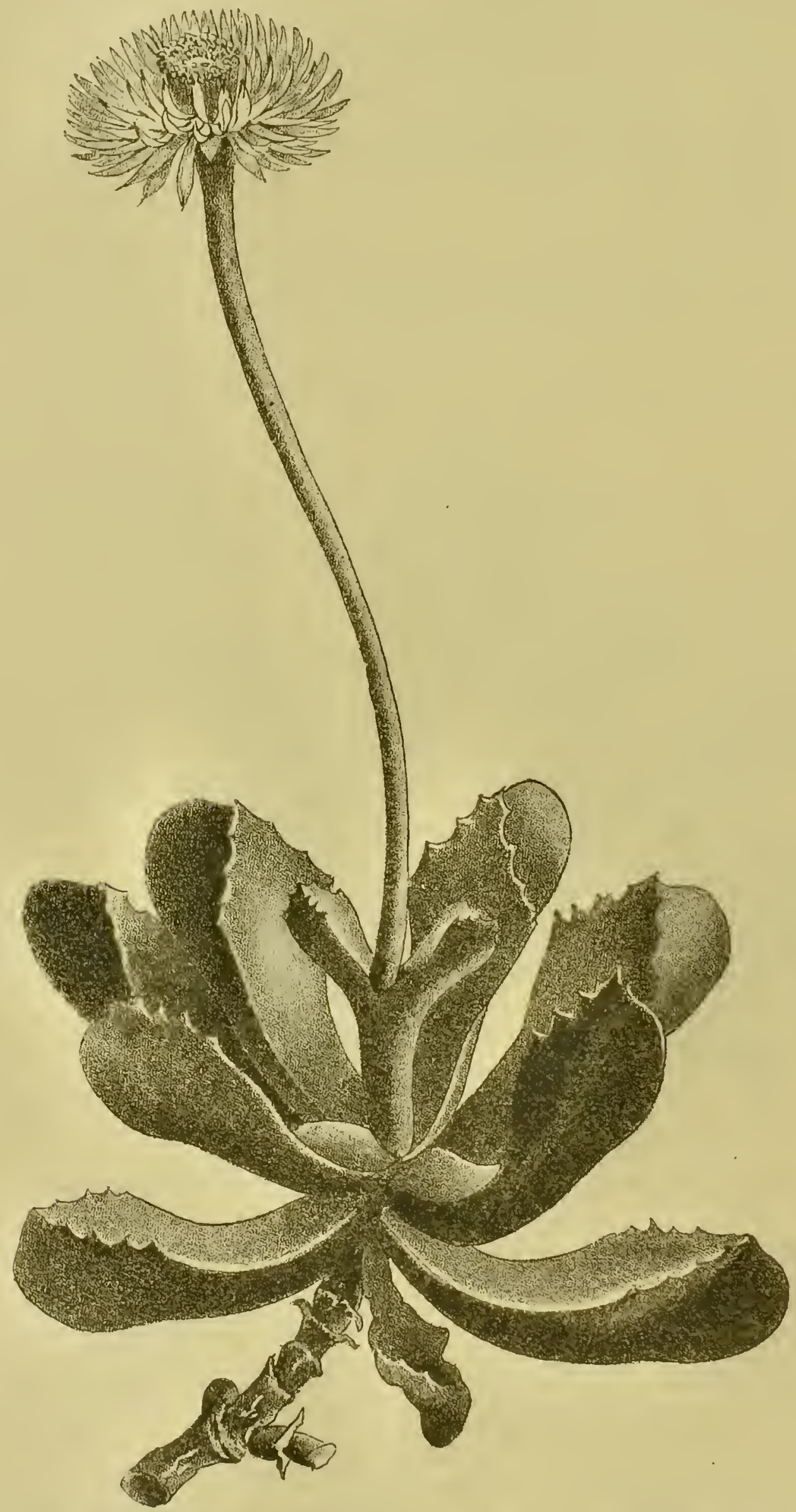

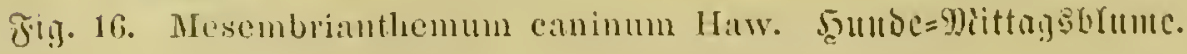

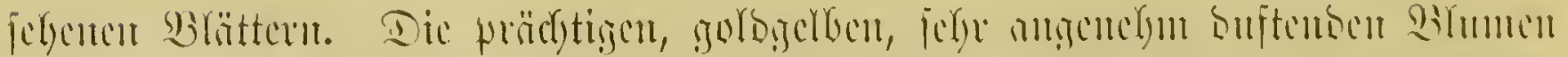

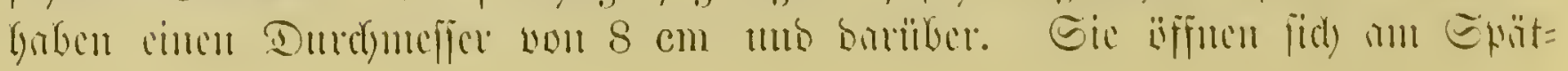




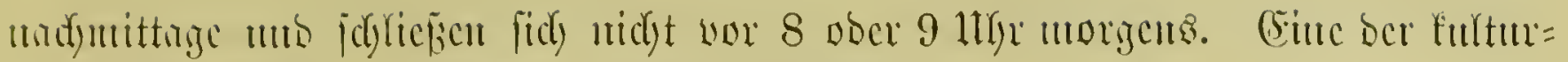

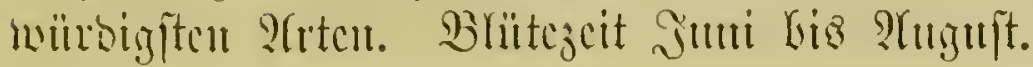

\section{Mesembrianthemum dolabriforme $L$. \$gobelfärntige Mrittagzblunte.}

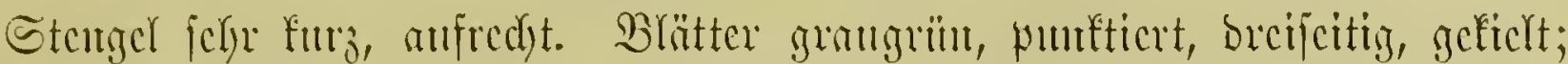

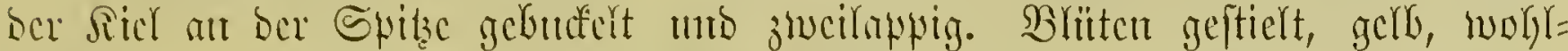

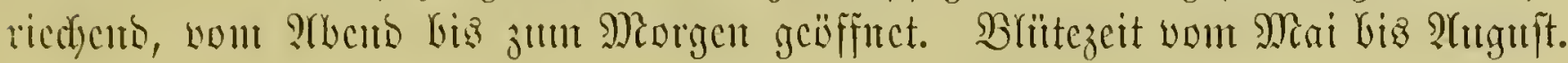

\section{Mesembrianthemmm fragrans $S . D c k$. Duftige Mittagabhute.}

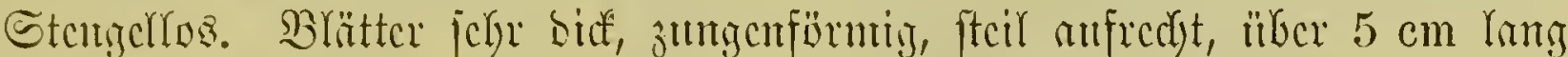

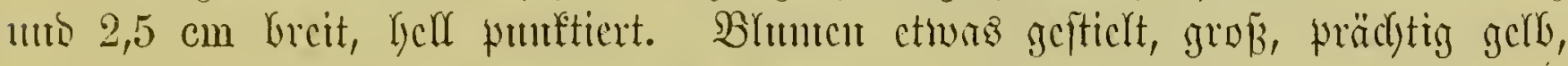

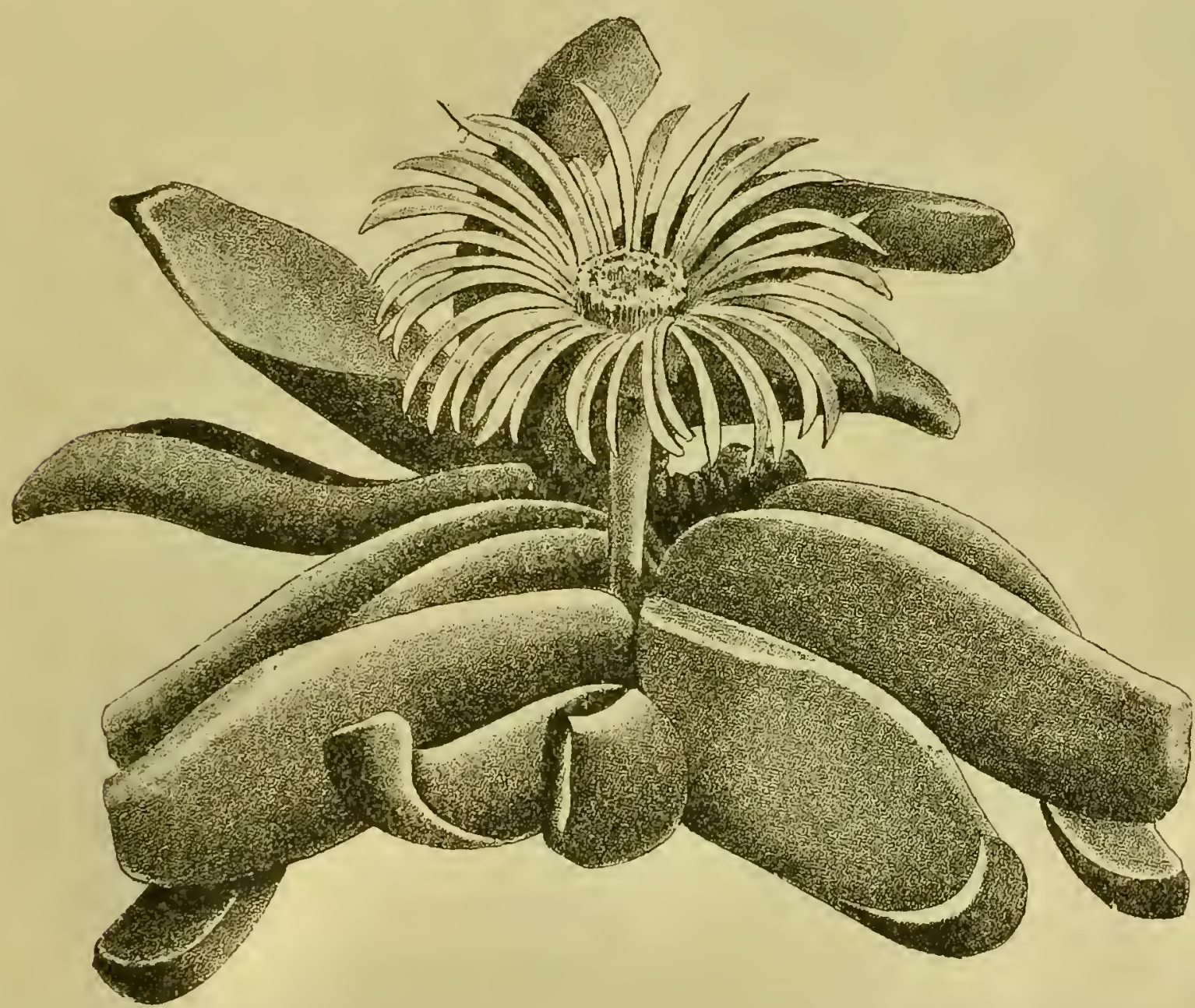

Fig. 17. Mesembrianthemum linguiforme S.-Dyck. Bungenblättrige Mittag引Głume.

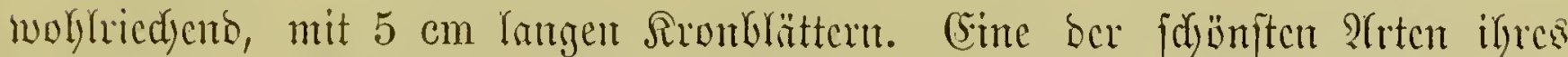

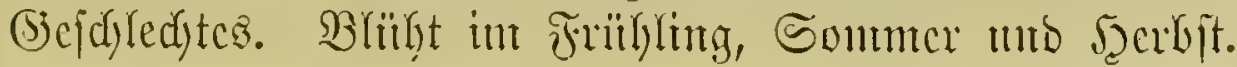

\section{Mesembrianthemmm linguiforme S. Dyck. 3utgenblättrige Mittngzblunte.}

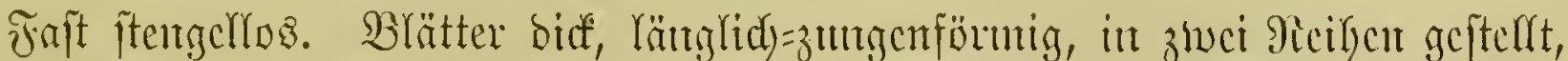

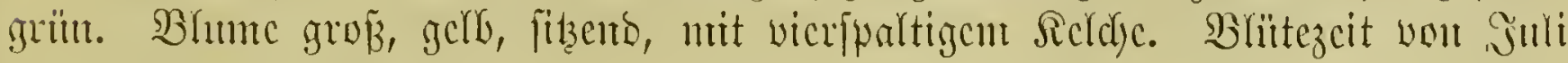
bis Dftulder. (Fig. 17.)

Ifelyultid find: M. cultratum S.-Dyck; M. depressum S.-Dyck; M. long $n$ m, Haw. 1. भ. 


\section{Mesembrianthemmm pngioniforme $L$. Doldblatt= Mittagablutuc.}

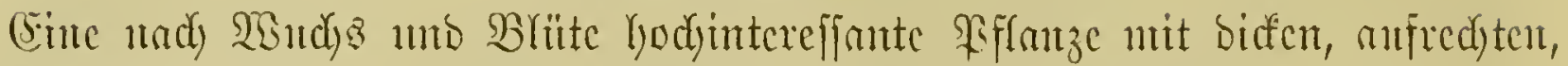

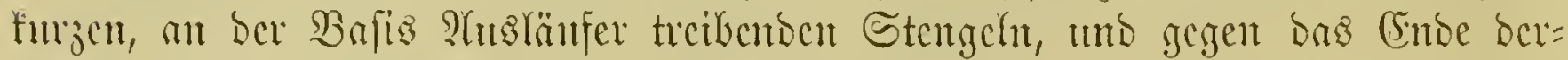

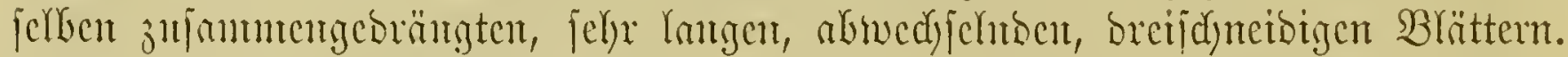

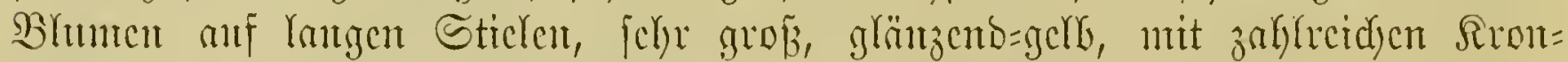

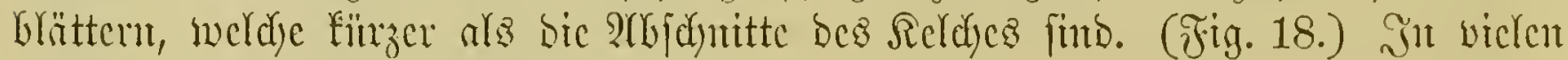
Stïlfon bicjer 2 hrt ähnllidy fint: M. capitatum Haw.; M. brevicanle Haw.

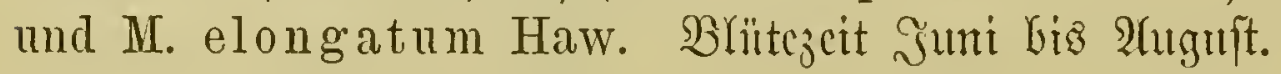

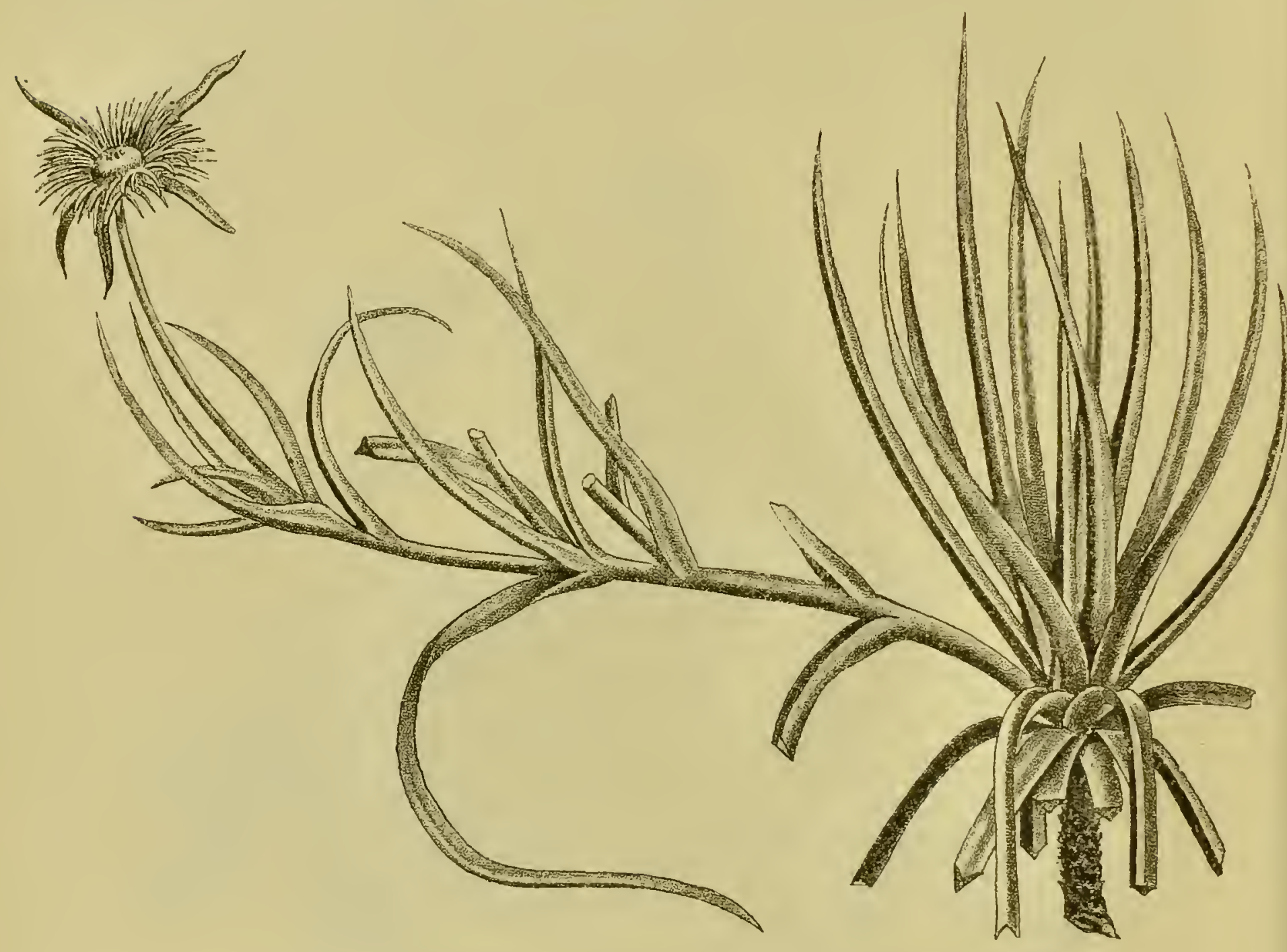

Fig. 15. Mesembrianthemum pugioniforme I. Dold)= Mittagsh(ume.

\section{Mesembrianthemmm lacernm S.-Dyck. Bcruifieuc Mittagsobutc.}

Stengel über $1 \mathrm{~m}$ lod d), aufredgt, bejekst mit oreifinntigen, jäbelfärmigen,

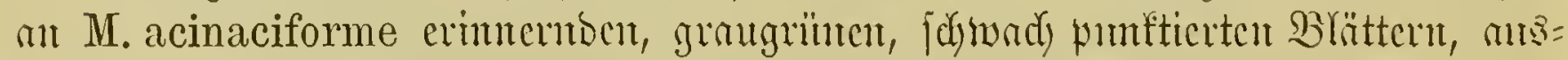

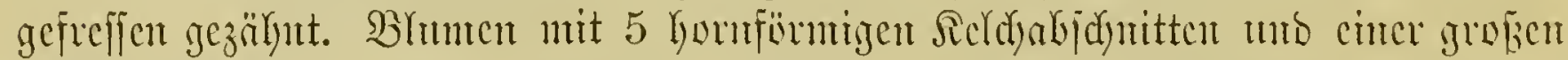

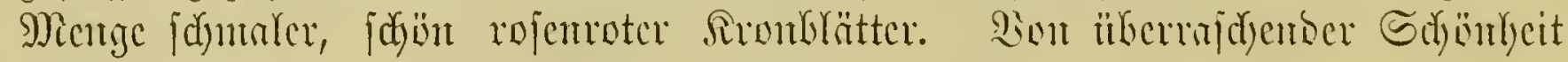

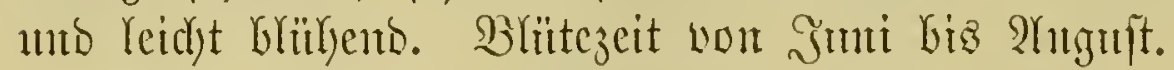

\section{Mesembrianthemmm acinaciforme $L$. Säbch= Mhittagabunte.}

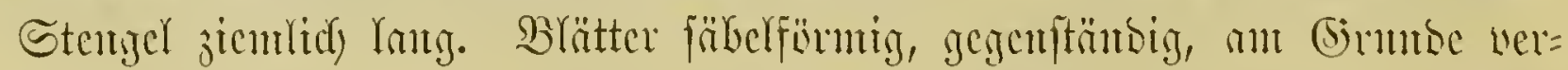

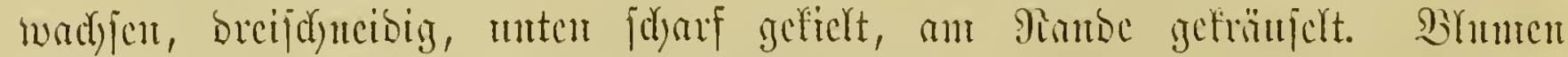

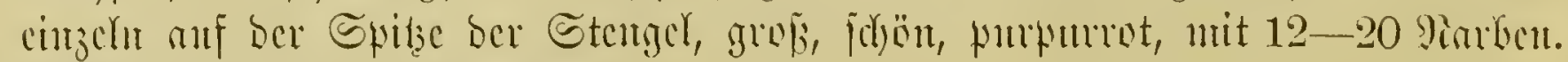
Bhlïtezcit Julli biz Septentber. 
10. Mesembrianthemmm falcatum $L$. Eidjelblatt=Mlittagzblunte.

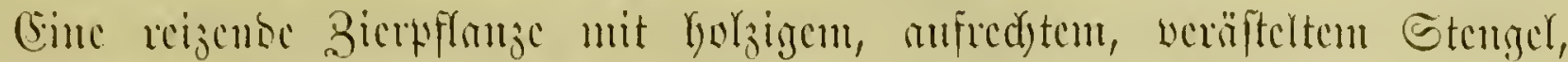

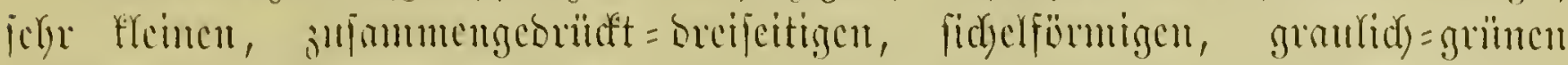

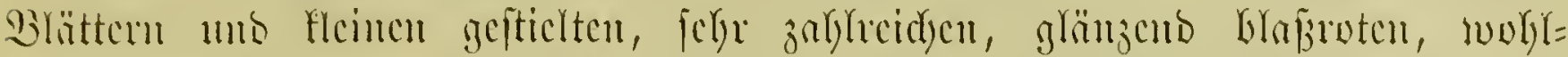

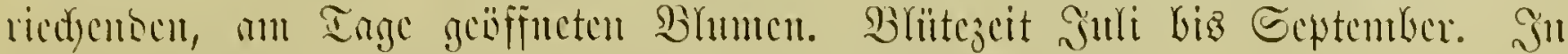

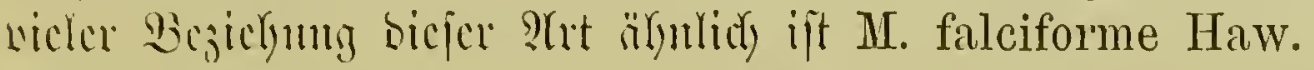

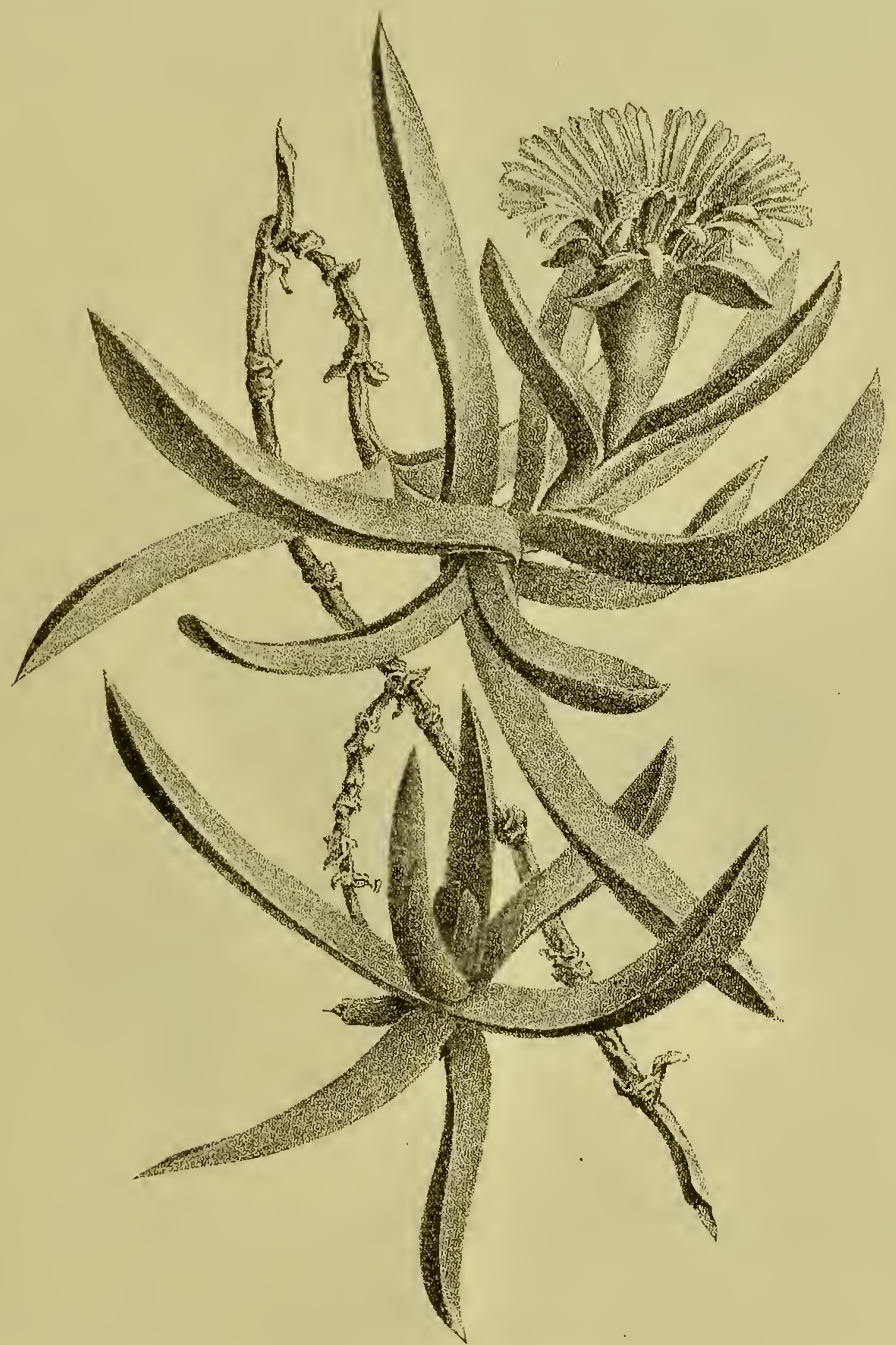

Fig. 19. Mesembrianthemum virescens Haw. Grïnlide Miittaggblume.

11. Mesembrianthemum virescens Itav. Griinlidye Mittngablume.

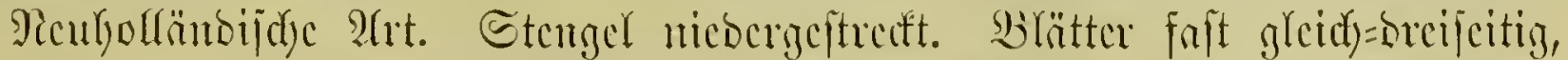

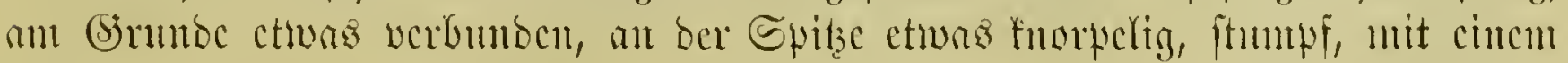




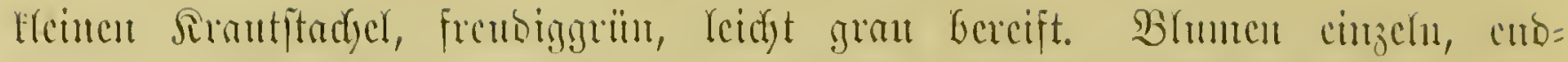

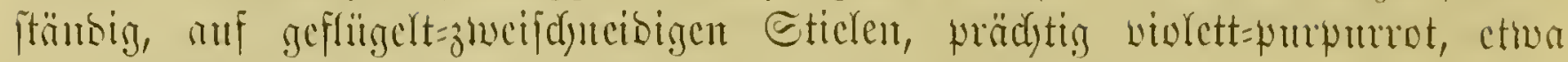
4 cm rreit, blitht leidyt, im Esmmer. (Fig. 19, Є. 37.)

\section{Mesembrianthemum spectabile Haw. Itnichulidge Mittagzbolute.}

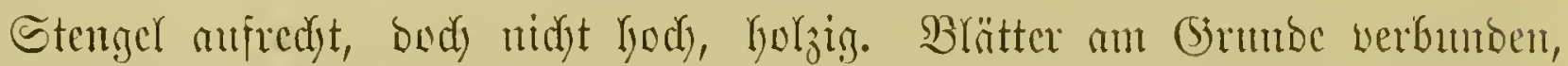

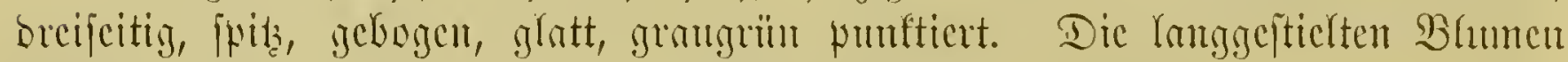

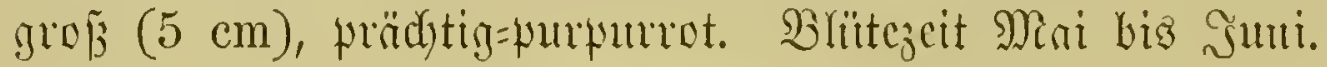

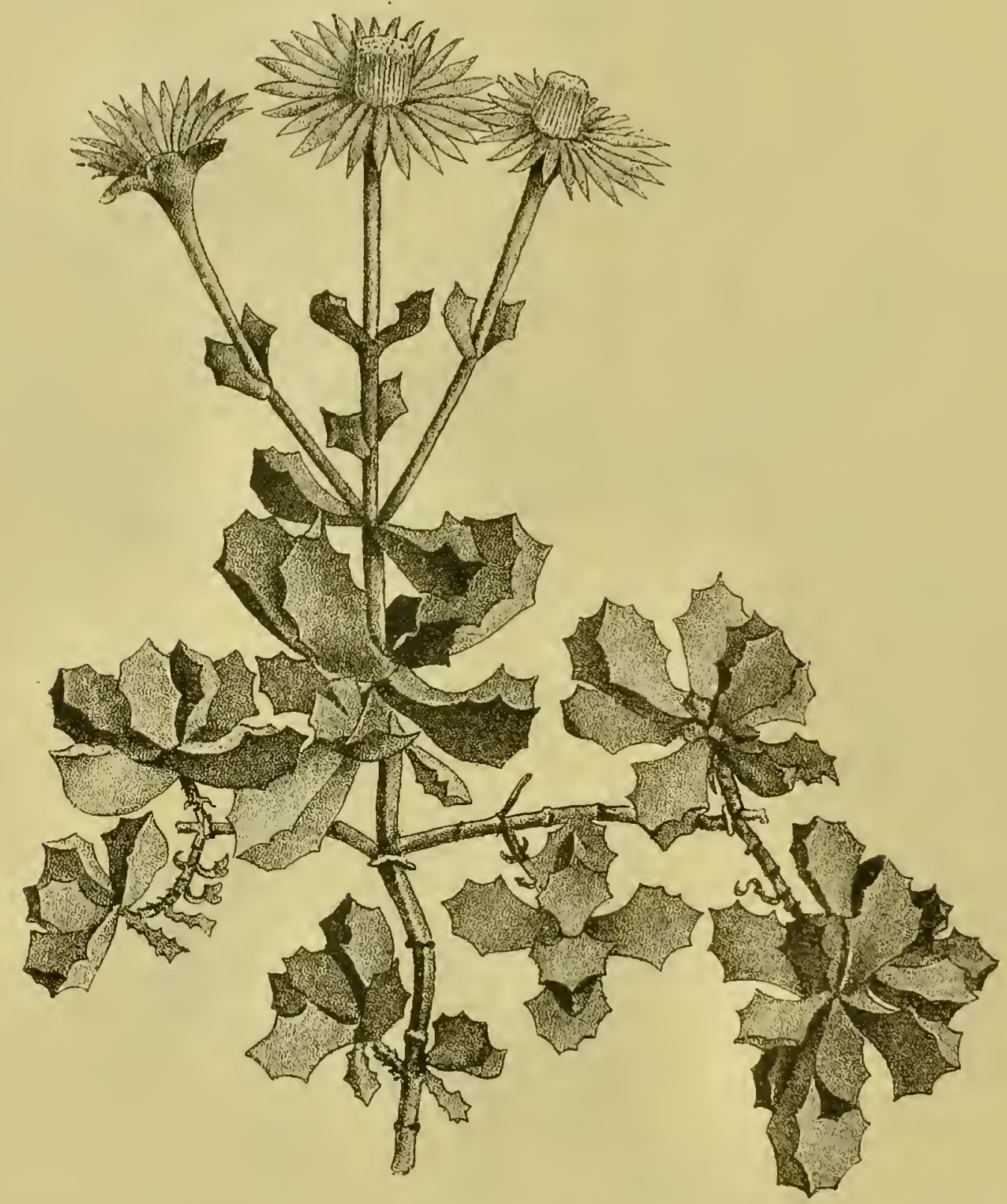

Fig. 20. Mescmbrianthemum deltoides Mill. Deltaförmige Mittagß̆Gume.

13. Mesembrianthemmm formosum Haw. Grjüne Mittagabume.

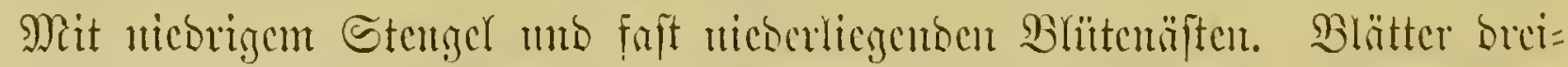

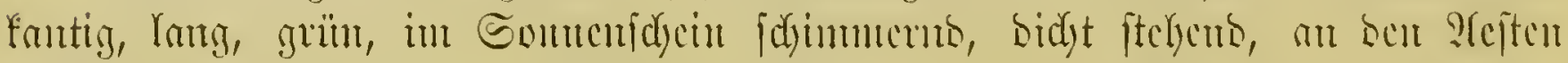

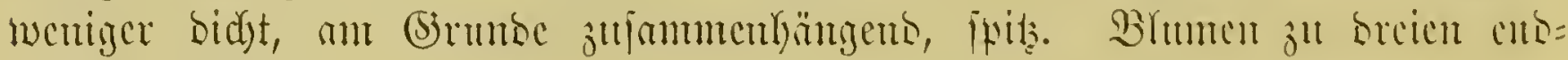
ftünoig, rötlidy.

\section{Mesembrianthemum blandum Han. Miciocube Mhittagablute.}

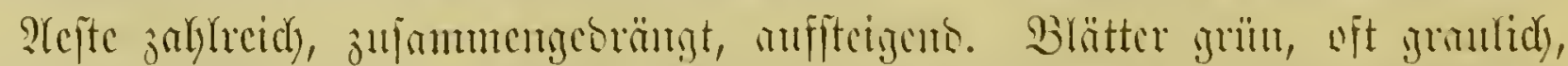

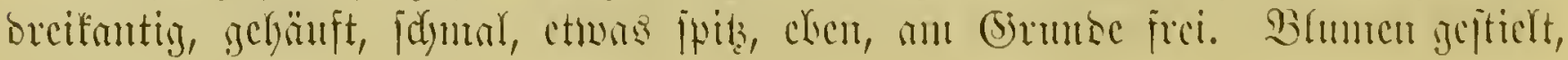




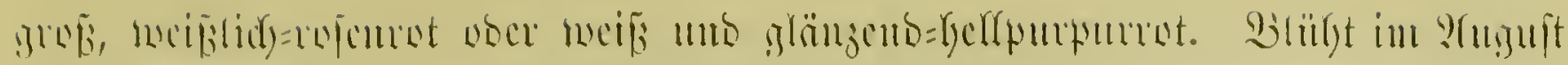
mis Giptemkin.

\section{Mesembrianthemum deltoides Mill. Doftafïrutige Mittag8นumc.}

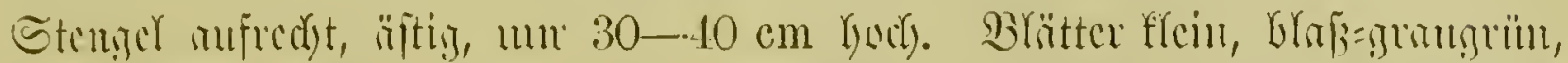

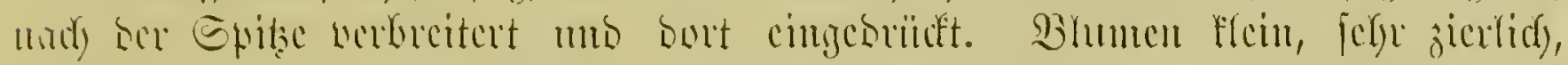

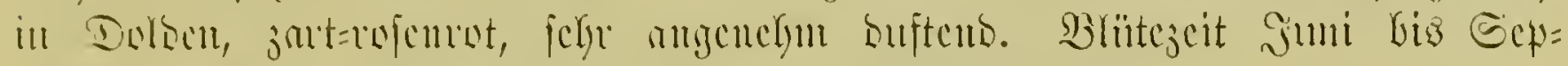
tomker. (Jing. 20, E. 38.)

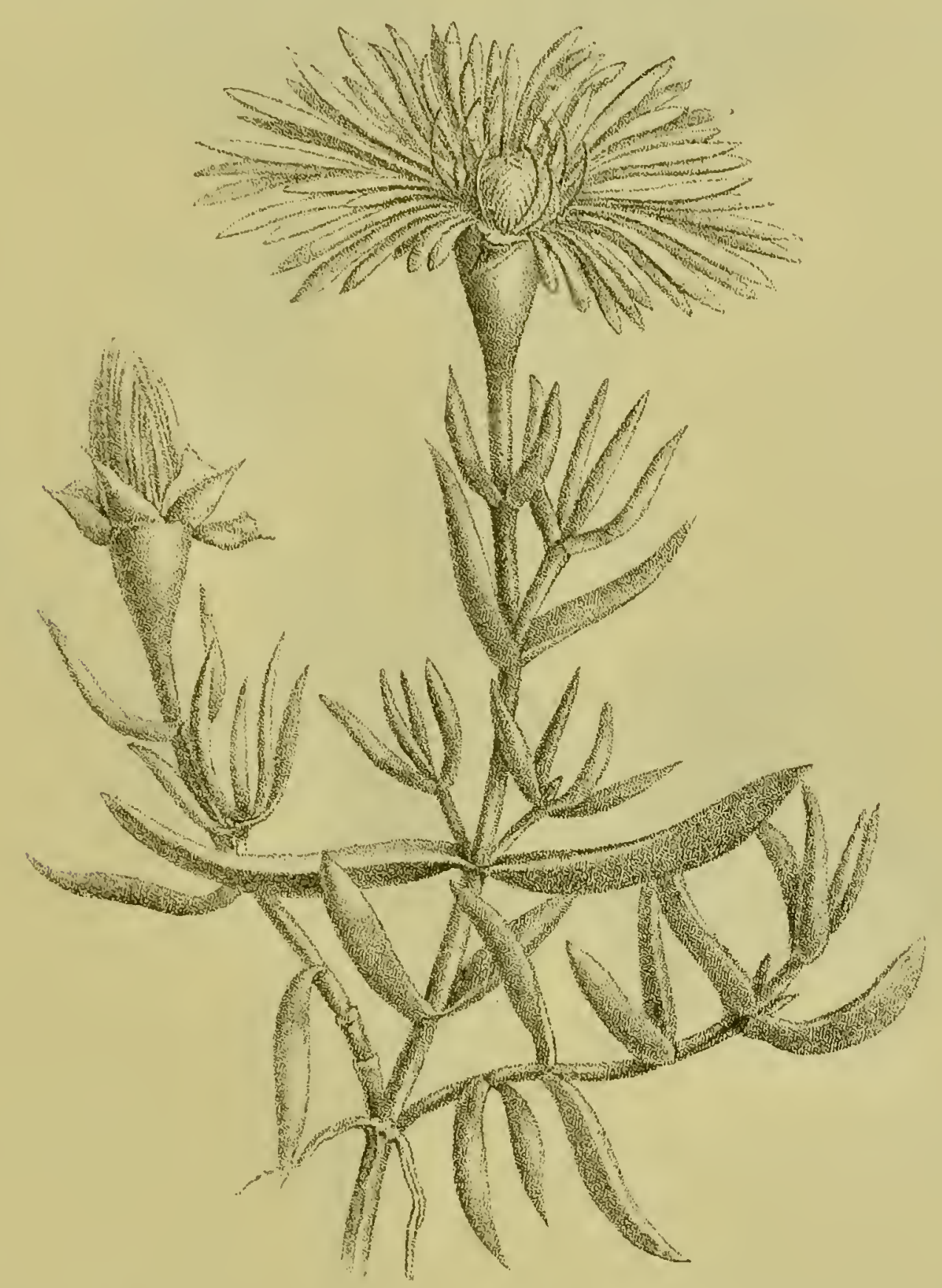

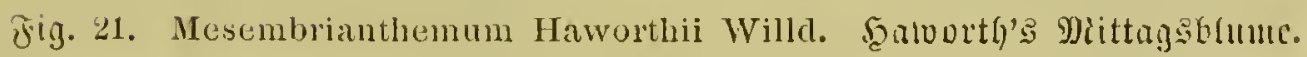

16. Mesembrianthemum aurantiacum Hau. Bouncranzenarbige Mrittag8blutute.

Etcngel $60 \mathrm{~cm}$ bis

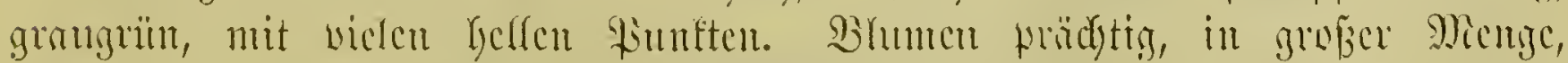

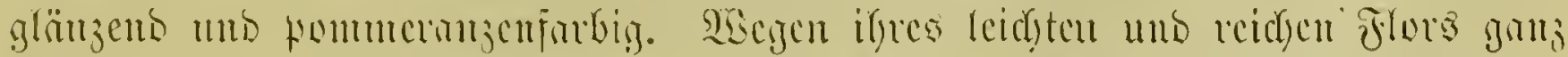

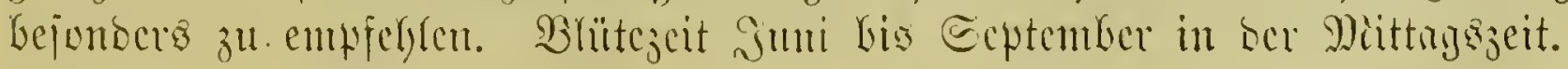




\section{Mesembrianthemmm microphyllum Haw. Rlciublättrige Mittagą)โuแtc.}

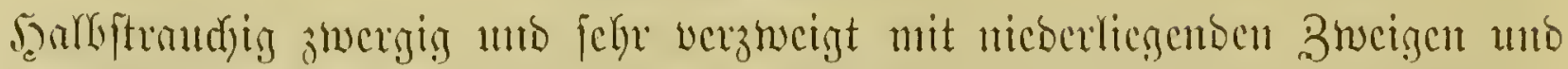
breif

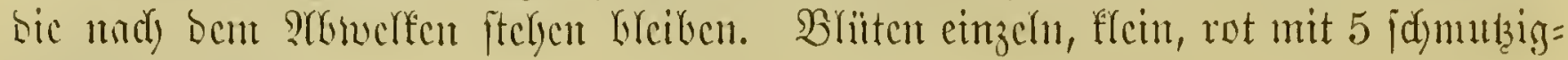
grüuten Piarben.

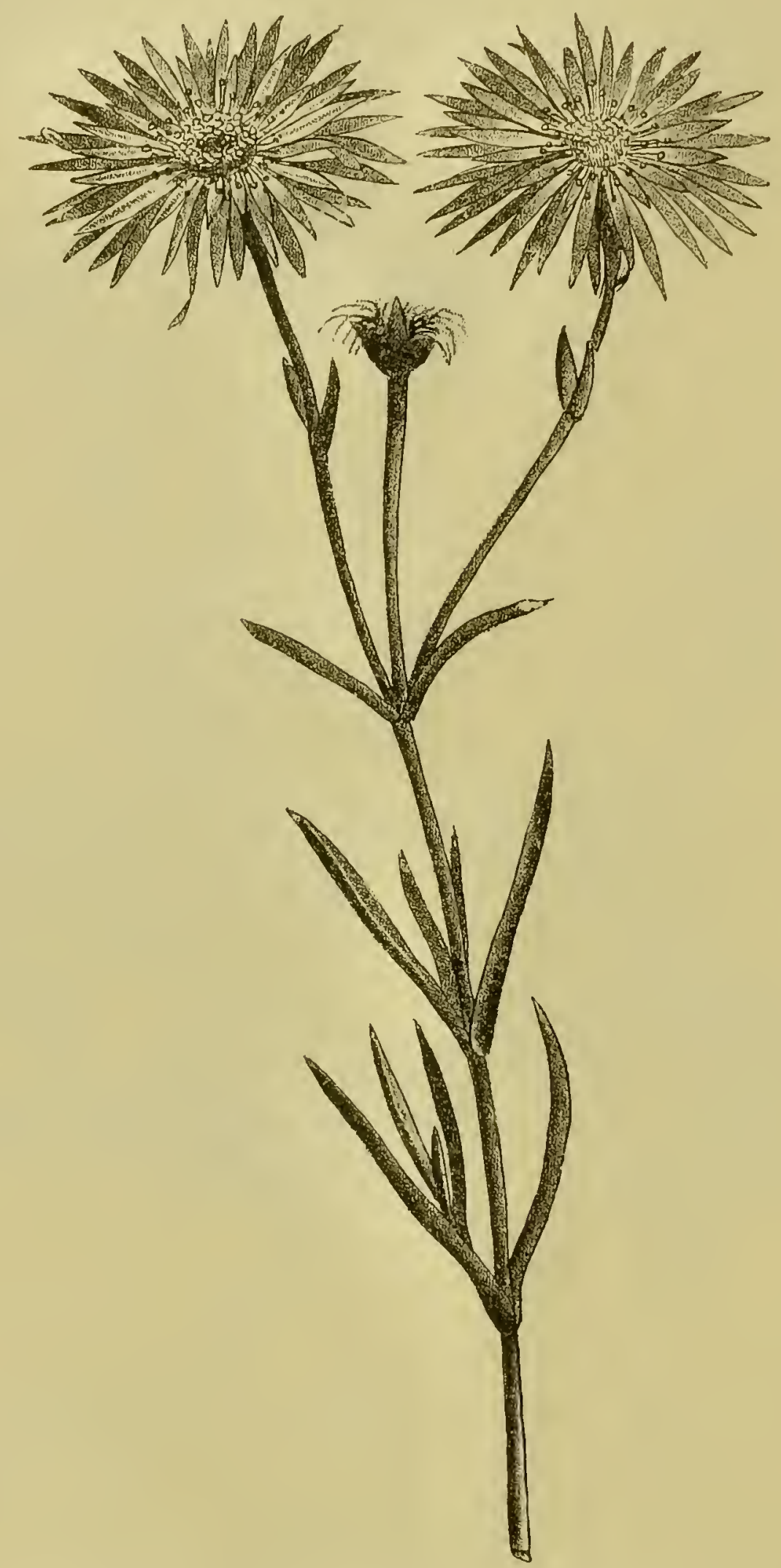

Fig. 22. Mesembrianthemum coccineum Hav. Sdarlad)=Mittagşume.

\section{Mesembrianthemum Haworthii Willd.}

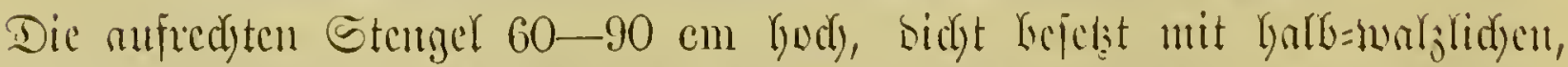

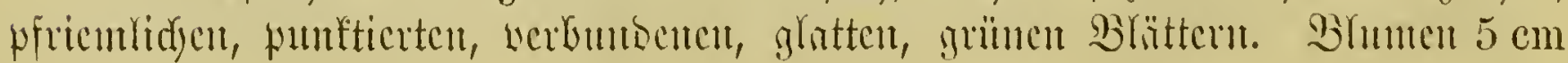




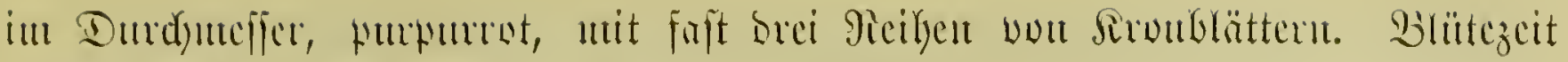

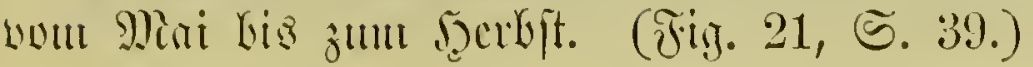

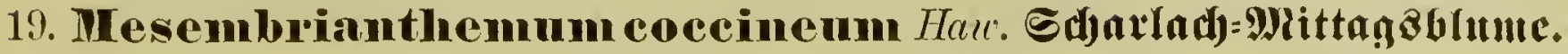

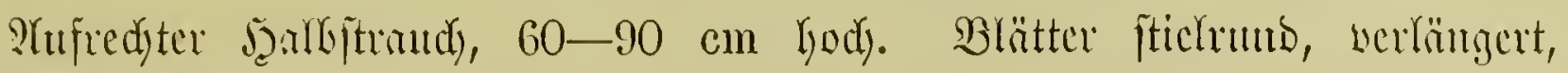

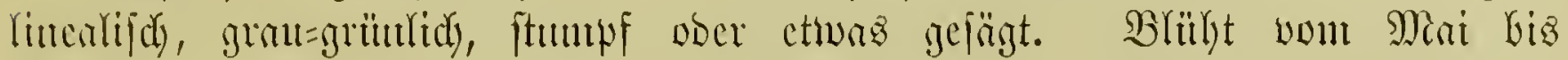

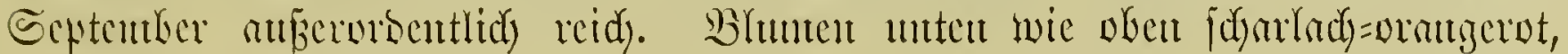
g)lüıjent. (Jig. 22, ธ. 40.)

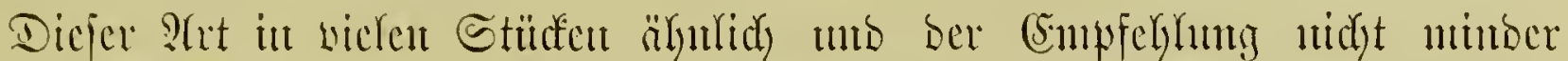

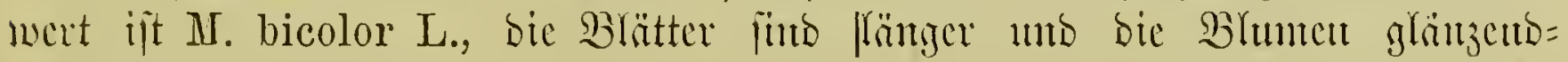

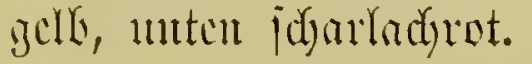

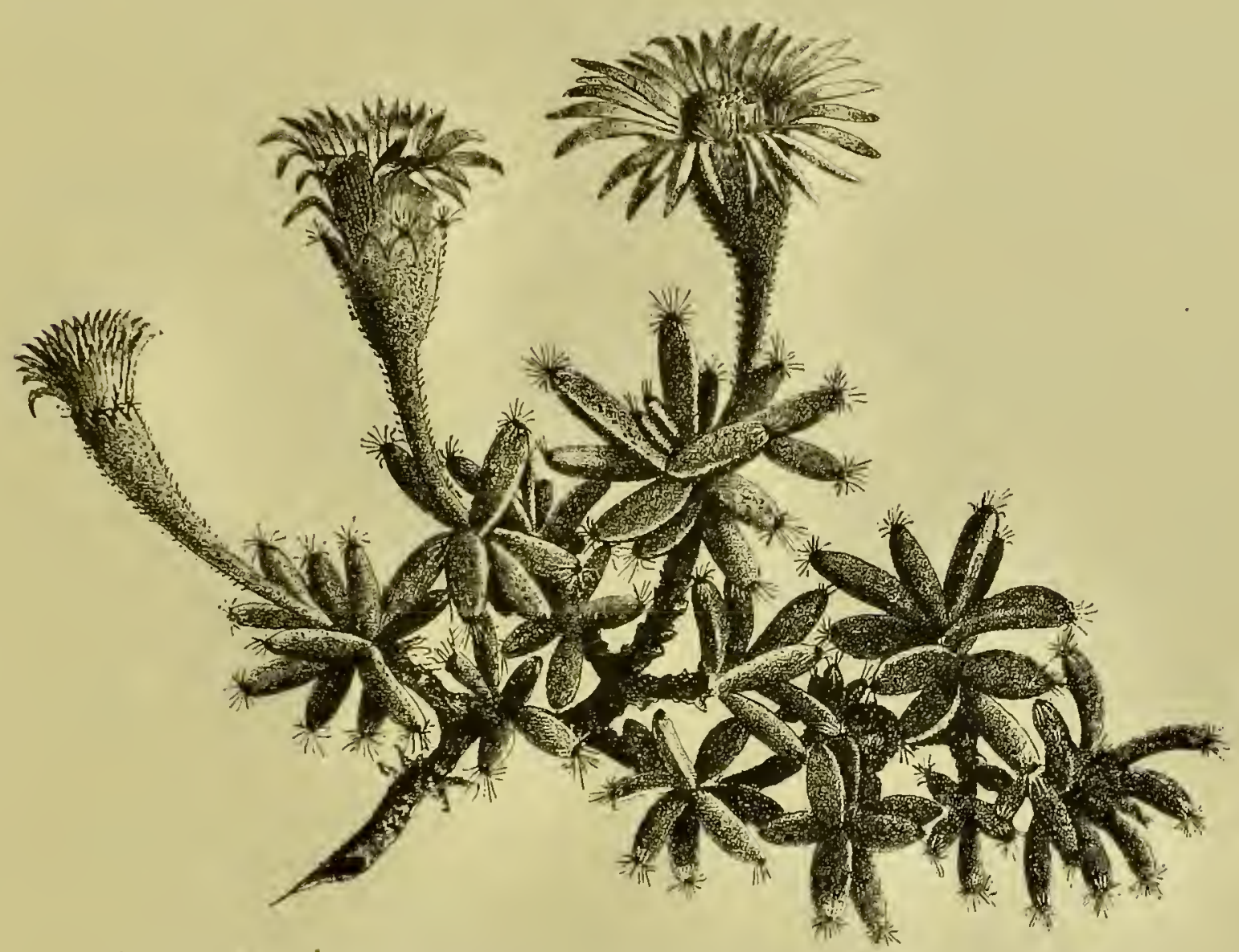

Fig. 23. Mesembrianthemum densum Haw. Didft beblätterte Mittaggblume.

\section{Mesembrianthemum tenuifolium $L$. Diinnblättrige Mittagâb̆unte.}

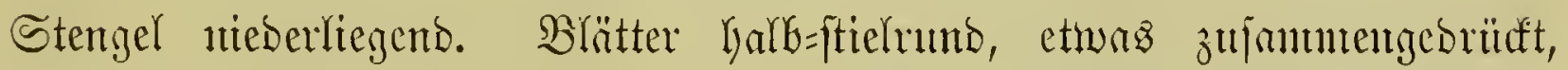

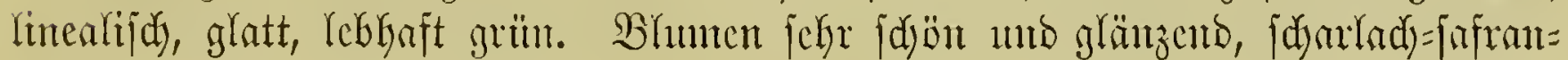

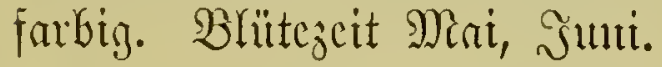

\section{Mesembrianthenmm densum Haw. Didjtbcblättcrtc Mrittagablunte.}

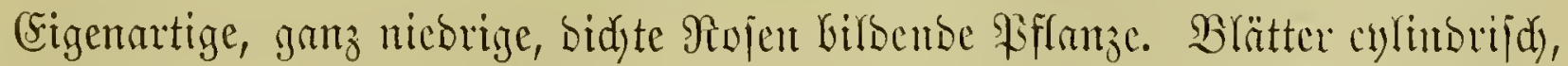

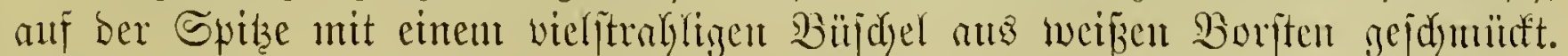

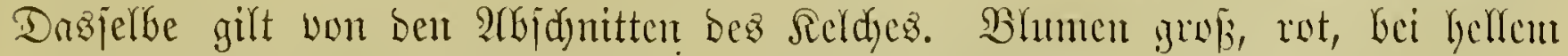

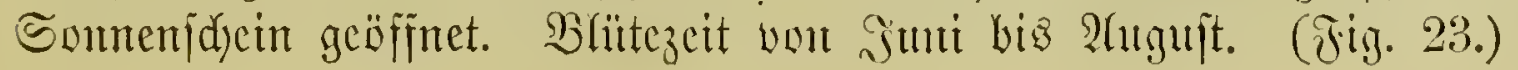




\section{Mescmbrianthemum mearginatum $L$. 2uagerandete Mittngablunc.}

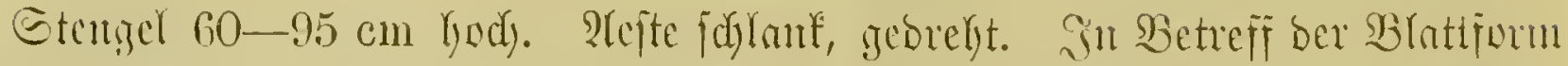

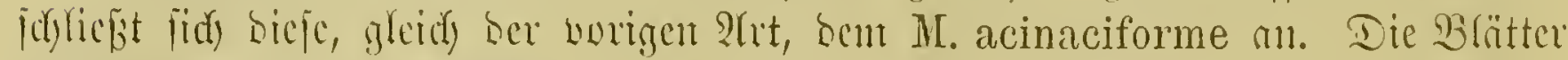

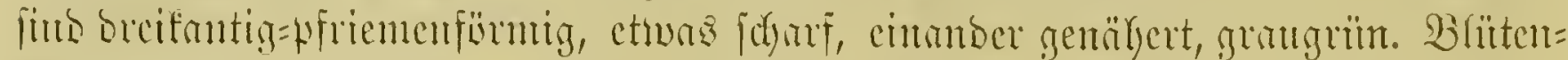

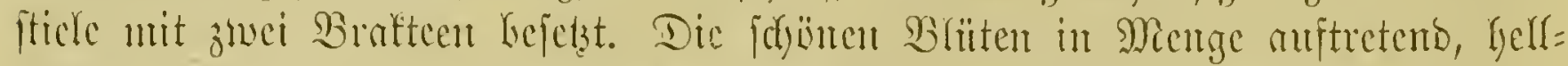

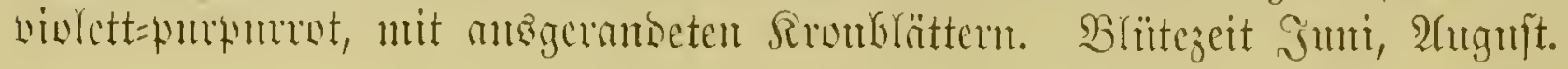

\section{Mesembrianthemum speciosum Haw. Prähtige Mittag}

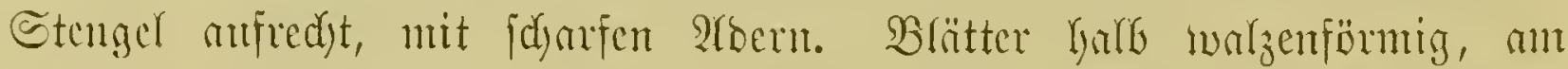

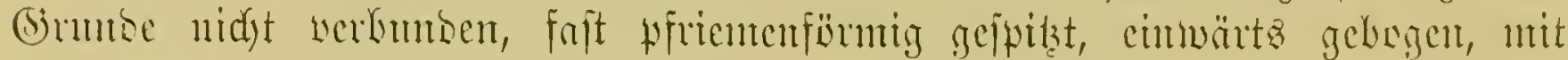

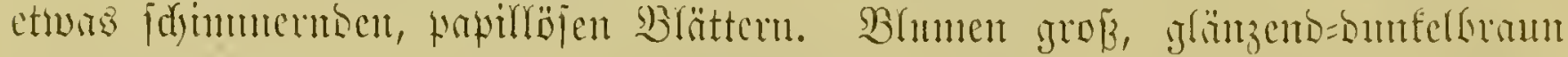

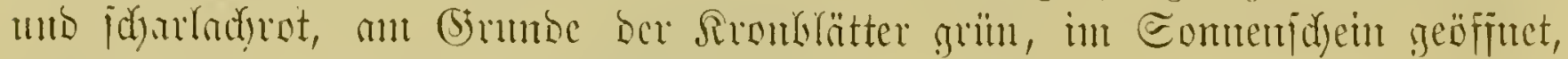
tridjterfürmtig. Slïtezeit Sonmer.

\section{Hesembrianthemum crystallinum $L$. Sivitalltraut.}

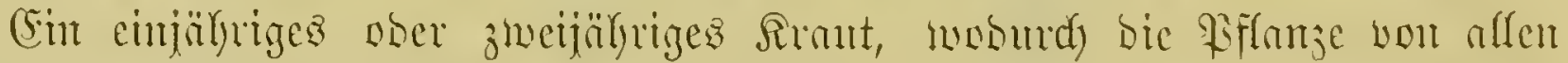

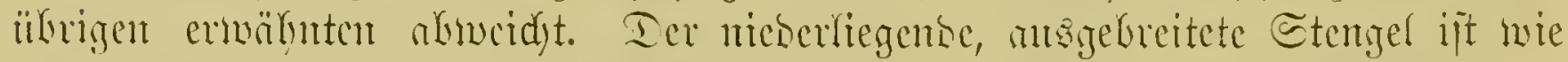

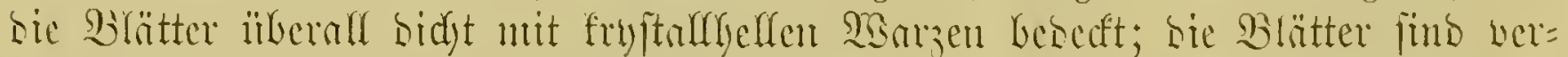

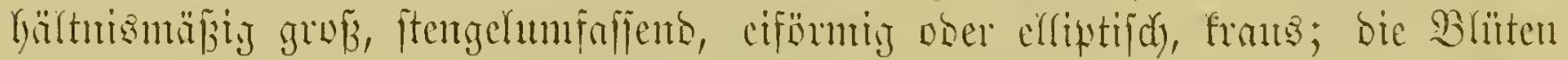

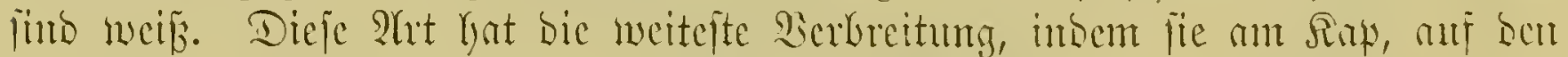

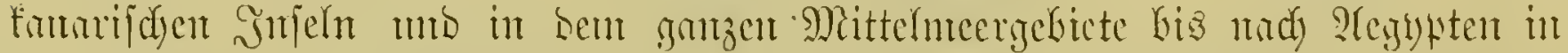

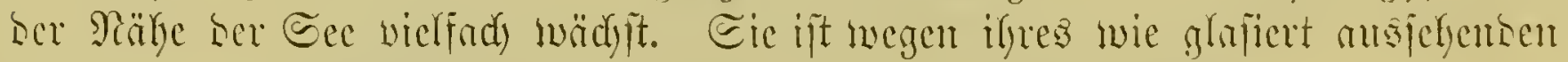

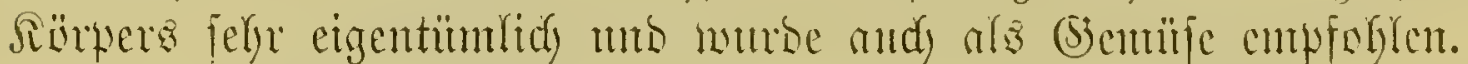

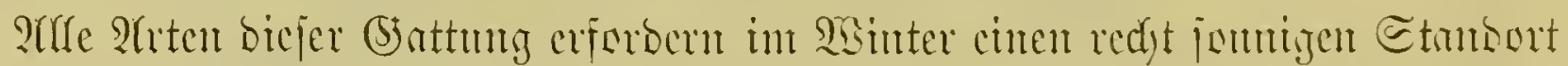

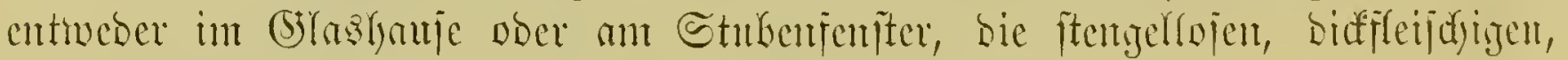
cine Temperatur won $+6-80 \mathrm{R}$., bie firmontigen cine joldye went $+3-60 \mathrm{R}$.,

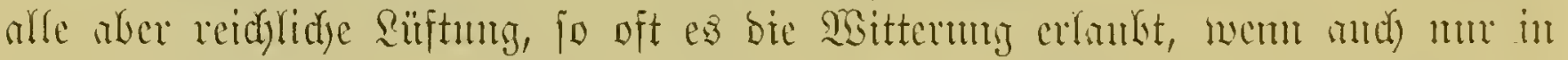

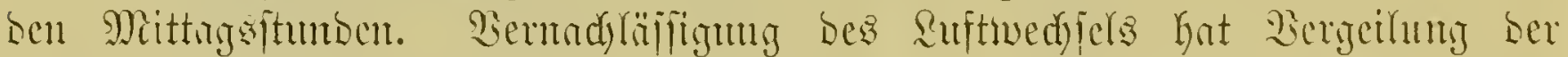

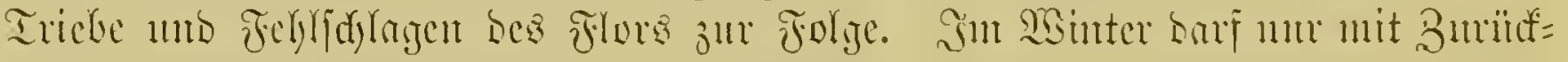

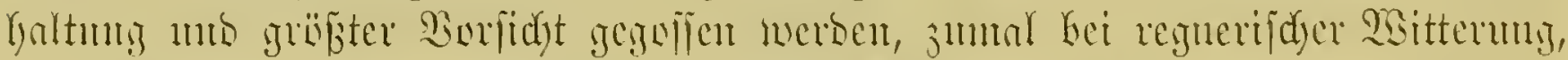

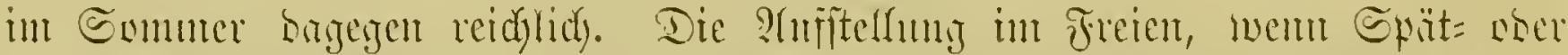

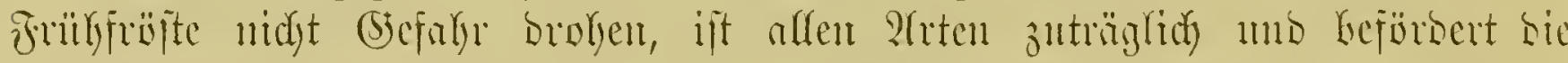

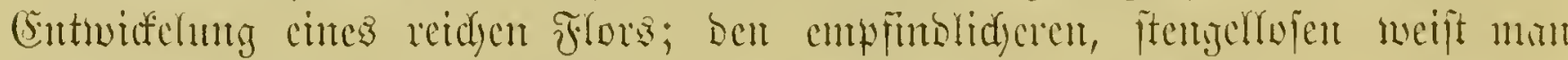

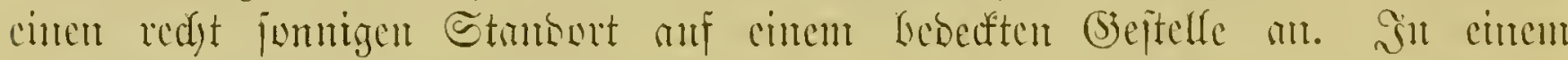

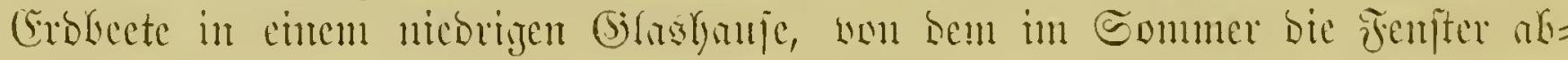

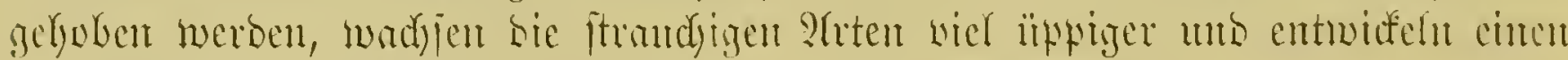

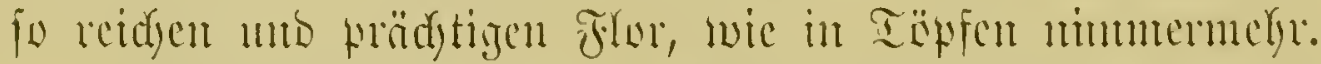

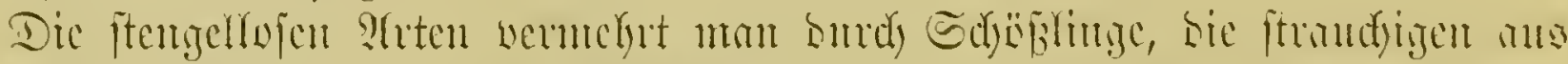

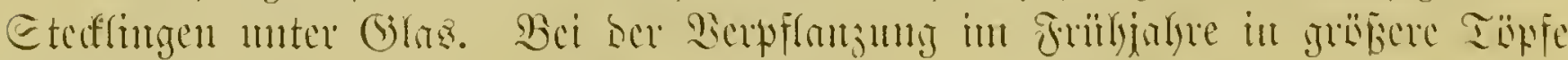

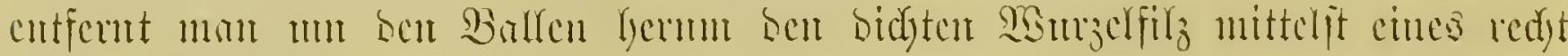
ja)arfon Meijer.

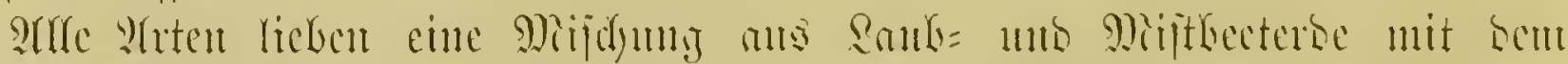

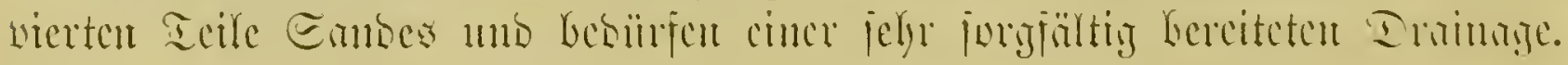




\section{Familie Crassulaceae. Diff́lfattgewiïdje.}

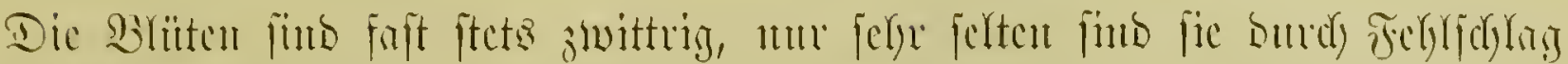

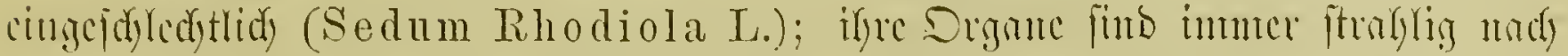

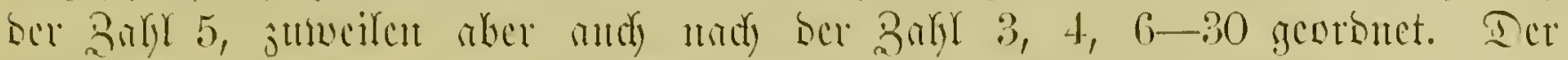

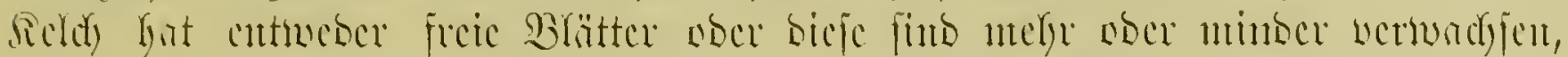

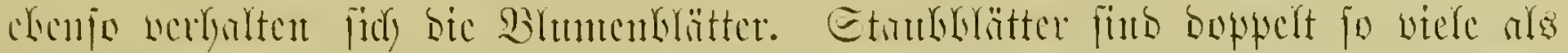

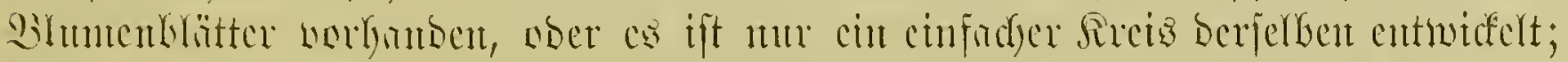

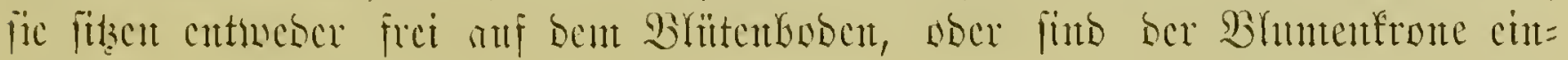
gciüigt.

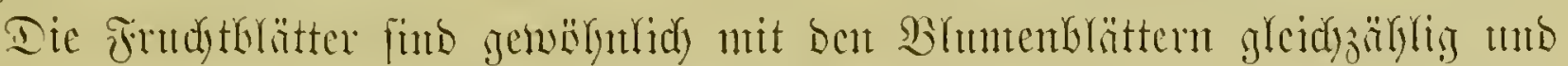

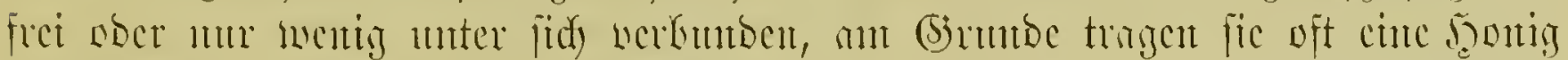

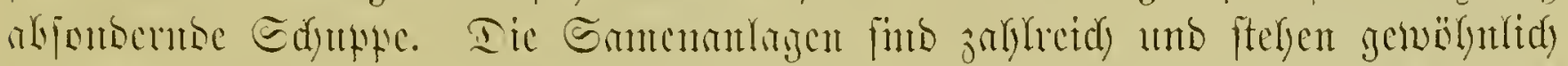

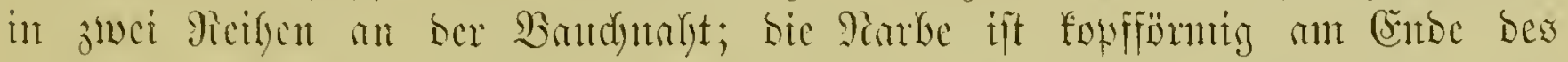

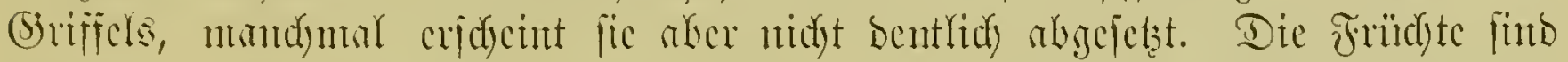

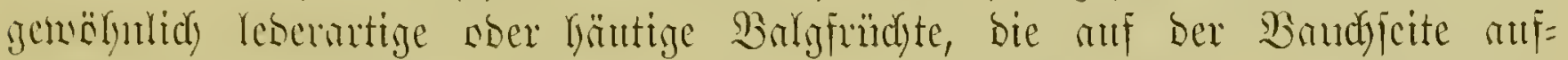

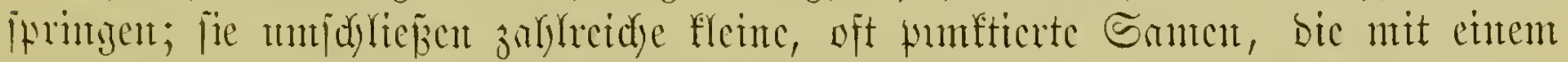

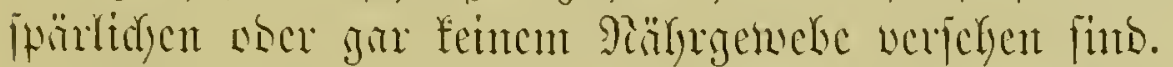

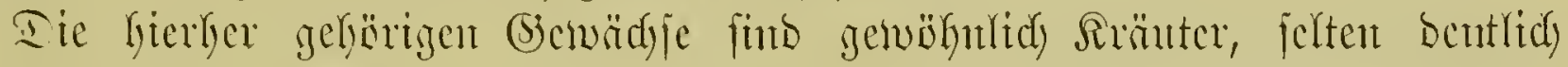

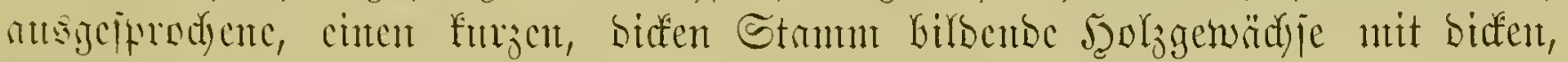

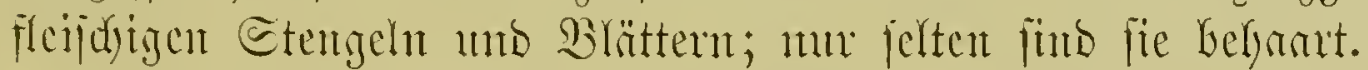

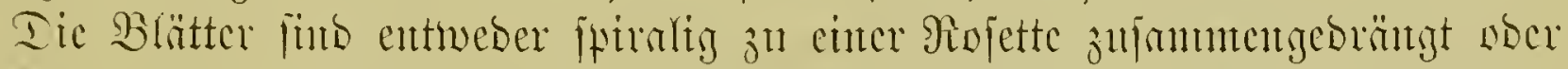

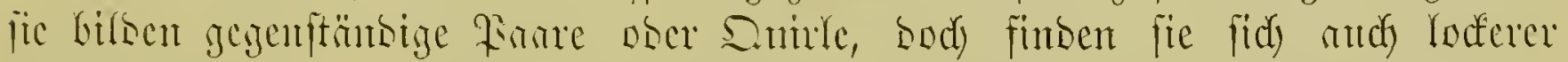

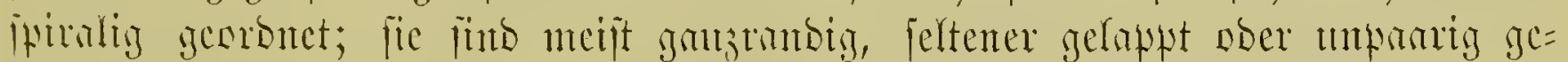

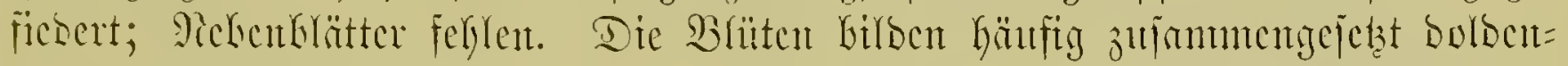

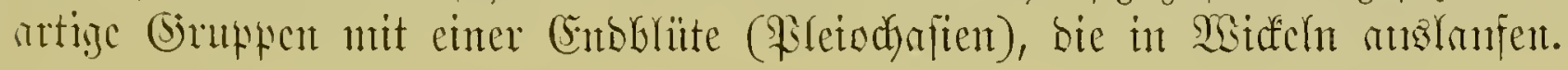

\section{Schliaffel für die Battungen.}

A. Staubbrätter dopwelt jo viel ale Blumenblätter oder forollenabidulttte.

a) SBltumenblätter frè.

a) Blïten 4-5zählia; Blätter ant Stengel fpiralig geitellt ober in Baaren oder Drifingen georonet 1 . Sedum.

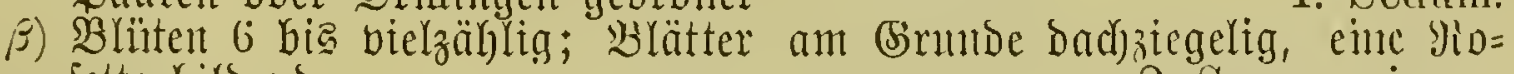
jette billoello

2. Sempervivum.

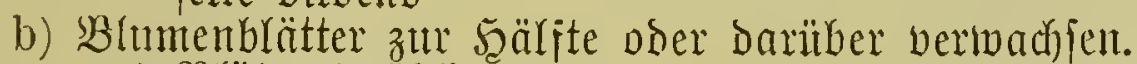

a) B̧ïtell 5 zählig. *)

I. Relch viel Eürzcr wie bie Blumenfronte

II. Selch faft von der Ränge der Blumentrone.

3. Cotyledon.

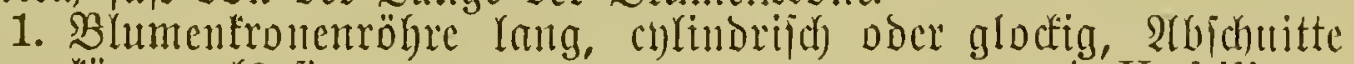
fiirzer als fie 4. Umbilicus.

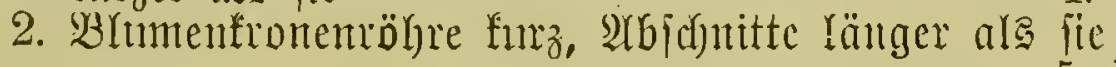

5. Echeveria.

ア) Brïten 4 zählig.

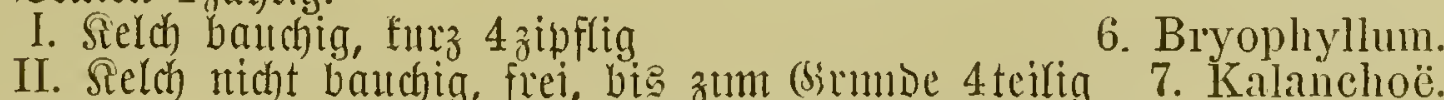

B. Staubblätter io biel alg Blinenblätter voer Sorollenabichntte.

a) Bluntenblätter frei oder un am unterfen Grumbe verbumbent 8. Crassula.

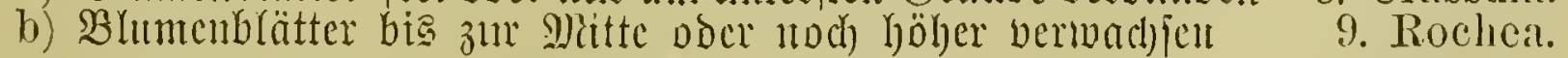

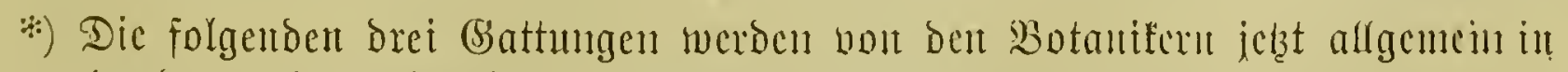
eine verbundu mo madyen brei Sectionen won Cotyledon ans. 


\section{Brattung Sedum Linn. Maucrpfeffer, Fetthentte.}

Dic B̧lüten finto ftral)lig, 5 (jelten 3-7) zählig, meift zwittrig, felten

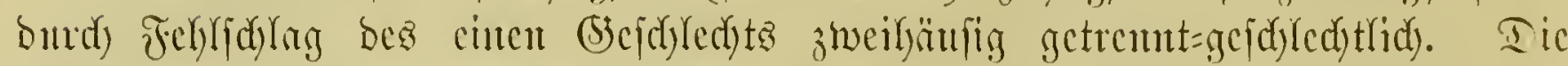

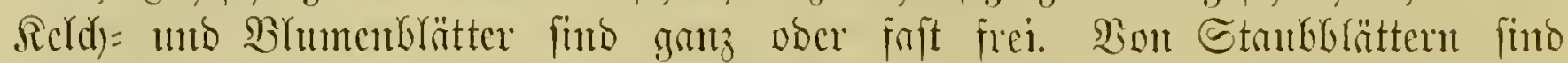

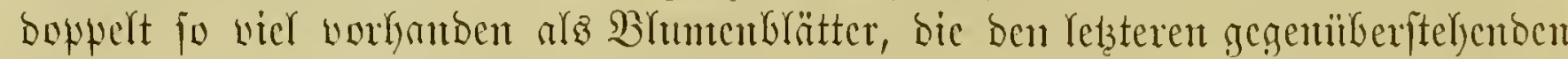

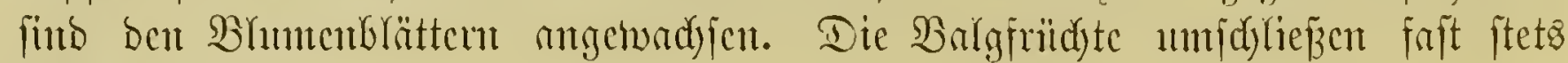
vicle Ermen.

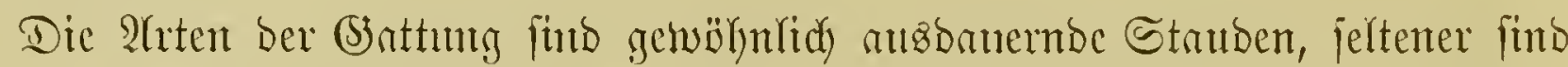

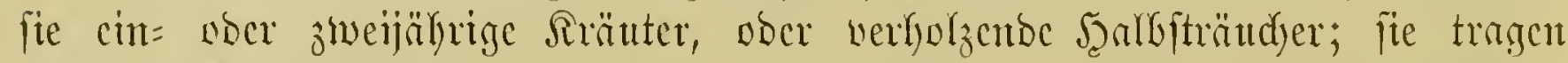

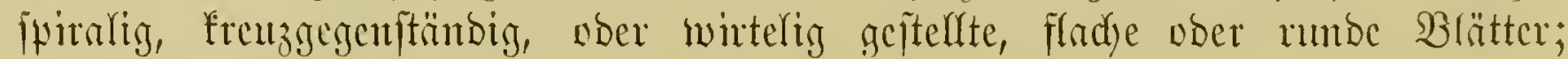

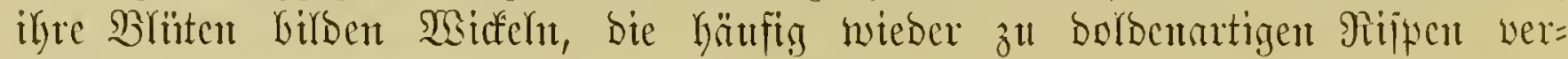
Gumben fint.

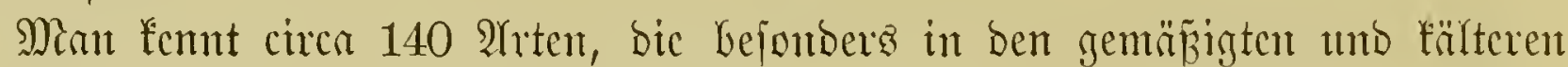

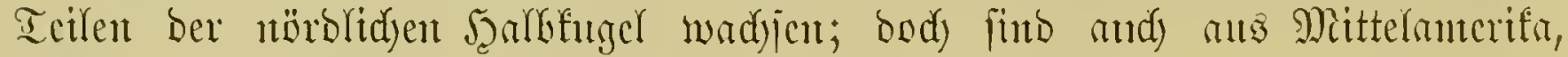

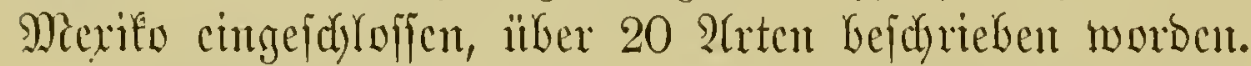

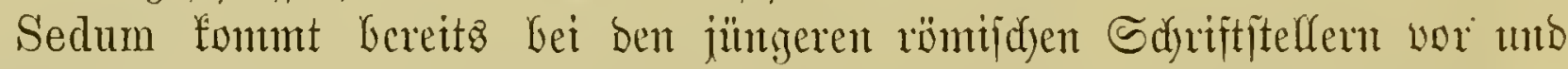
bezcidyntet ein anf bon Dë̈dyern fițenbeß Rrmut, viefleidyt ein Sempervivum.

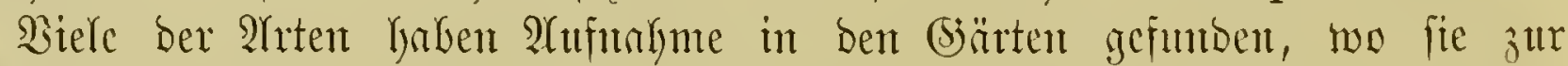
Deforativn won Manterwerf ober Steinguppen, fün Teppidgecte und Ein= faffungen Borwentoung finden. Sintige pflegt mon gern in Töpfen; melgrere

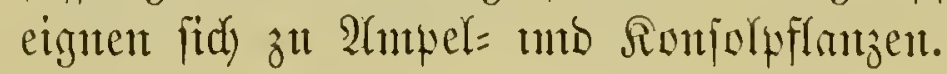

\section{Sçliuffel für die befhriebenen 2urten.}

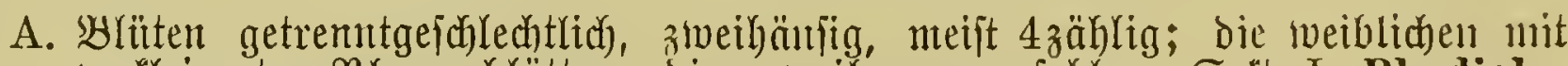
vertleinerten Bhumenbrättern, Dic zutweilen gantz fehlen Gelt. I. Rhodiola.

B. B̉ïten zinittrig.

a) Blätter flach

a) B̉üten weís

B) Blititen rofa, rot ober violett.

1. Sedum Rhodiola $D C$.

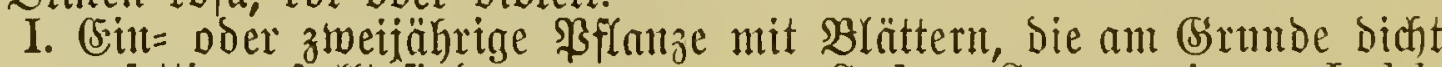
rojettig geitellt finto

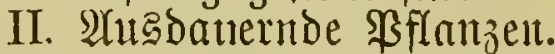

1. BRlätter quirlyg zu breieı

2. Blättcr frenzgegenitüutbig.

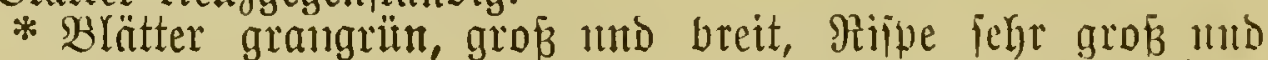
vielblïtig

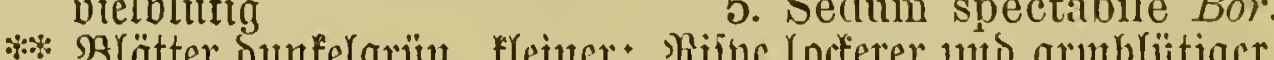

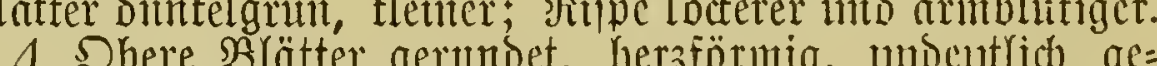
zähnelt, fahl

6. S. Ewersii Ledeb.

$\Delta \Delta$ Dbere $\mathfrak{B l a ̈ t t e r}$ feilförmia, an Der Epiłe gekerbt, ntit

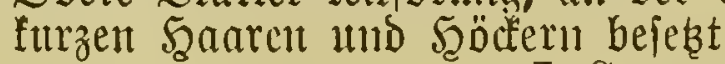

3. SBlättcr fpiralig geitellt.

7. S. spurium M. Bieberst.

* Brätter Yincalifich, am Brutube verbreitert

** Brätter oblong bia fajt freisförnnig.

S. S. pulchellum MIchx.

$\Delta$ B̧ä̈tter ganzrautsig.

o Blïtent violett, Blätter oblong, ipila

9. S. cyaneum Rud.

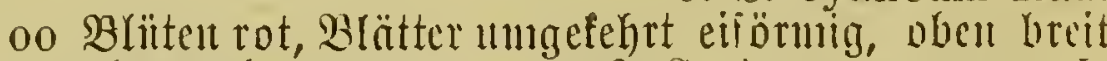
abgermitisct

10. S. Anacampseros $I$.

$\Delta \Delta$ Bglätter gejägt oder gejähnt 11. S. purpurascens Kóch. 


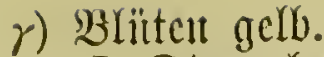

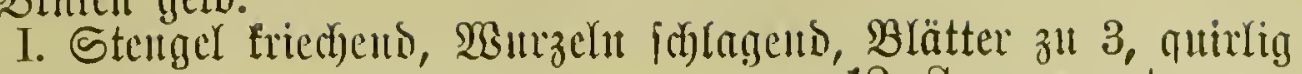

II. Stengel aufredjt obcr aufftrbend, Brätter pipiralig geitellt.

1. Qutsläufer treibento

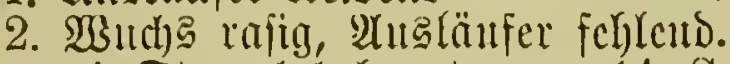

* Stengel bchaart 14. S. Selskianum Reg. et Macacli. * Eterigel fabl.

13. S. kamtschaticum Fisch.

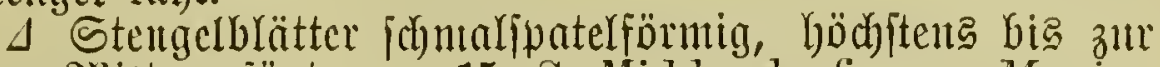
9)itte gejägt 15. S. Middendorfianum Maxim.

b) Blätter walzig

$\Delta \Delta$ Stengelblätter oblong ober ungetebrt eiförntig bis ïber bie ylitte gejägt 16. S. Maximowiczcii Rey.

a) Blïtelt iveíp.

I. Feld) und Brintentitiele srifigh

III. Selt. Eusedum.

II. Reld ulto SBlittenjtiele fahl.

1. Rijpe obent flad)

2. Rijpe verlängert, plrantioal

17. S. dasyphyllum $I_{\text {. }}$

в) Blitten gelb.

18. S. album $L$.

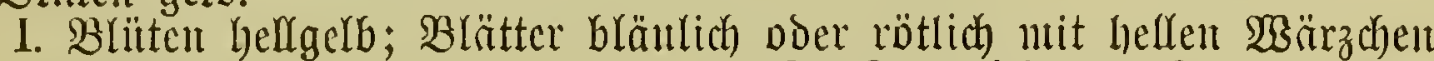
beitrelet

20. S. multiceps Coss. et I)ur.

II. Bliiten fanariengelb; Blätter Dutkelgrüu

21. S. acre Lin.

\section{Sedum Rhodiola $D C$. Mojenwurò.}

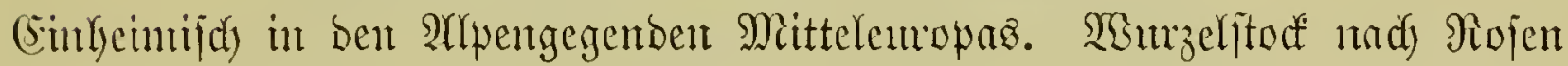

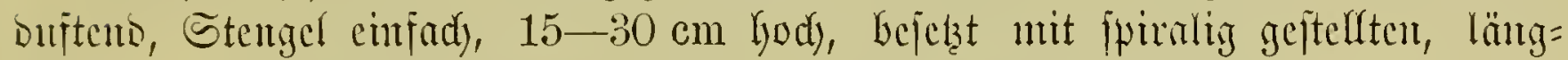

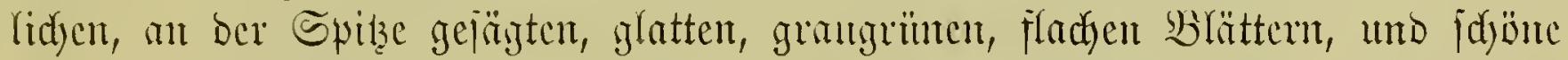

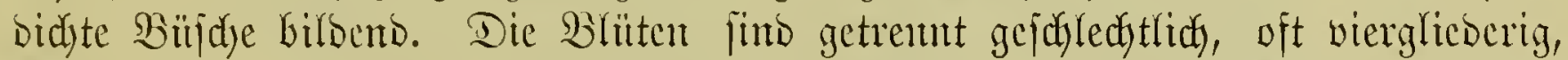
flein, gelb ober rütlid) mo bilben einte entoftänbige bolbige Rifpe. SBlütezeit Miai- Juni.

Tar. linifolia Rgl., nit linear = länglidyen, fpitzen, ganzranbigen ober mefr ober weniger gezähnten B̧r̈̈tern uns roten SBhmen. Blütezeit dicjelbe.

\section{Sedum populifolium $L$. Bappclblätterige Fettheute.}

Dieje 价 ftamnt aus Den Siebirgen Sibiriens und bilbet einen fleinen,

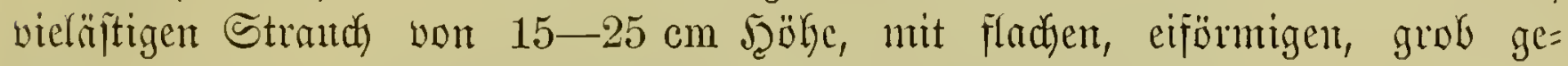

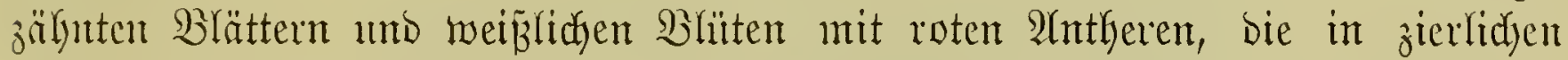

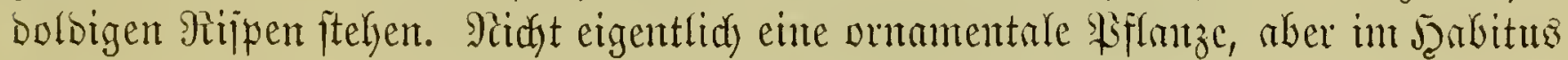

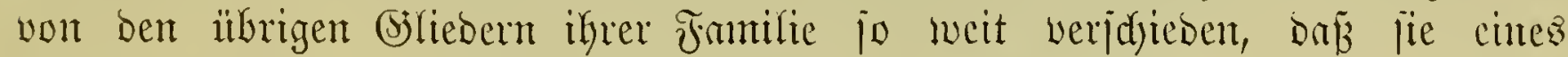

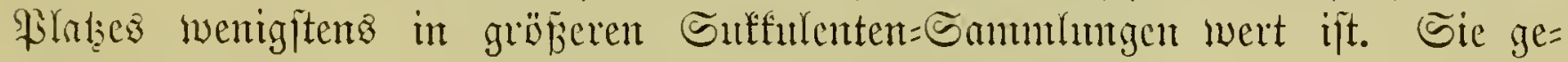
Deigt in jeber Bodenart und blübt zientidy ipät in Sommer.

\section{Sedum Sempervivmm Ledb.}

(S. sempervivoides Fisch.)

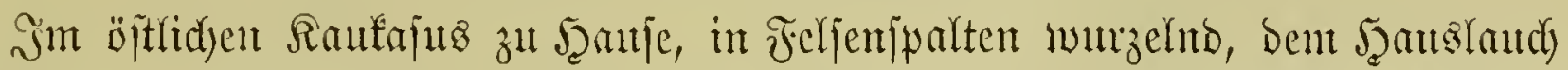

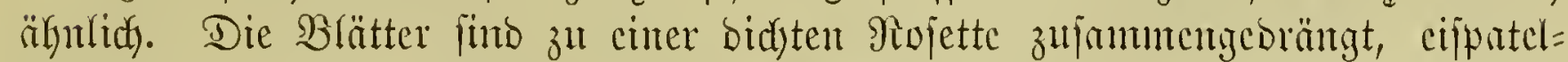

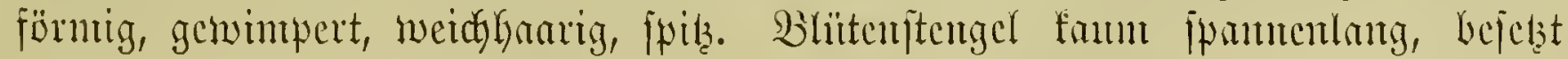

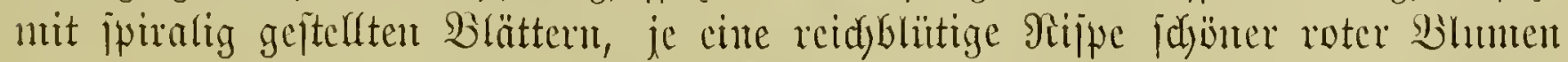

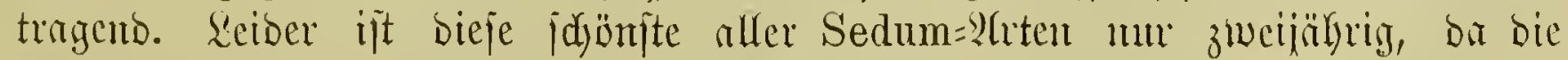
Wiflamzen mady ber Samemeife abjterben. (Fig. 24, ธ.46.)

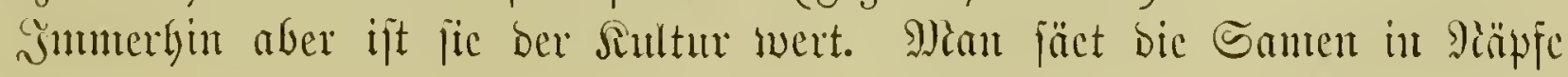




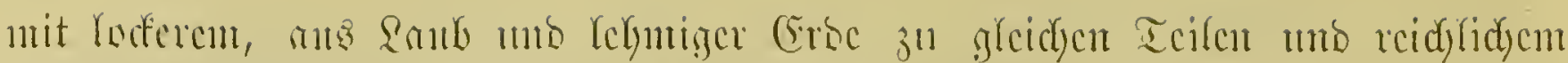

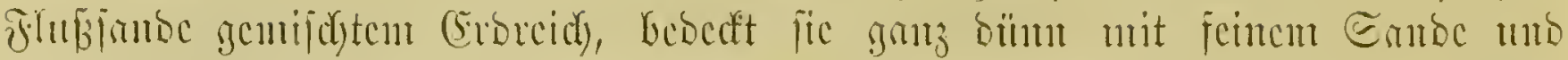

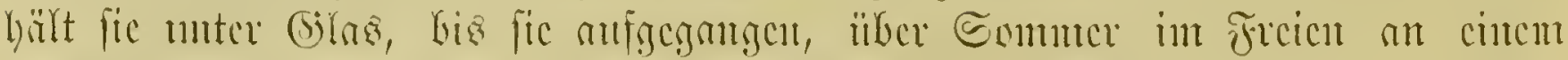

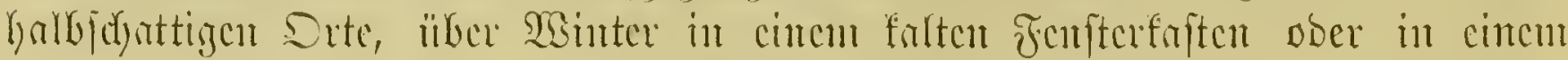

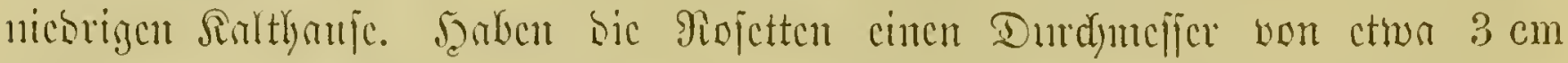

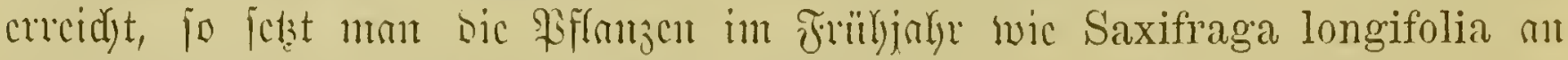

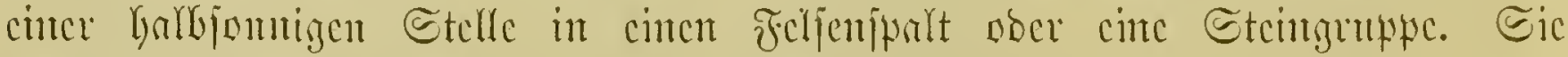

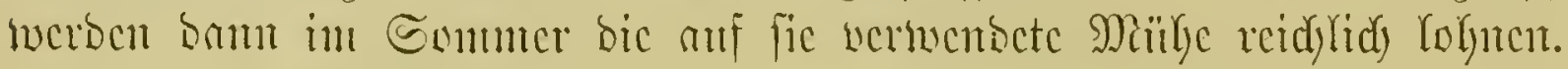

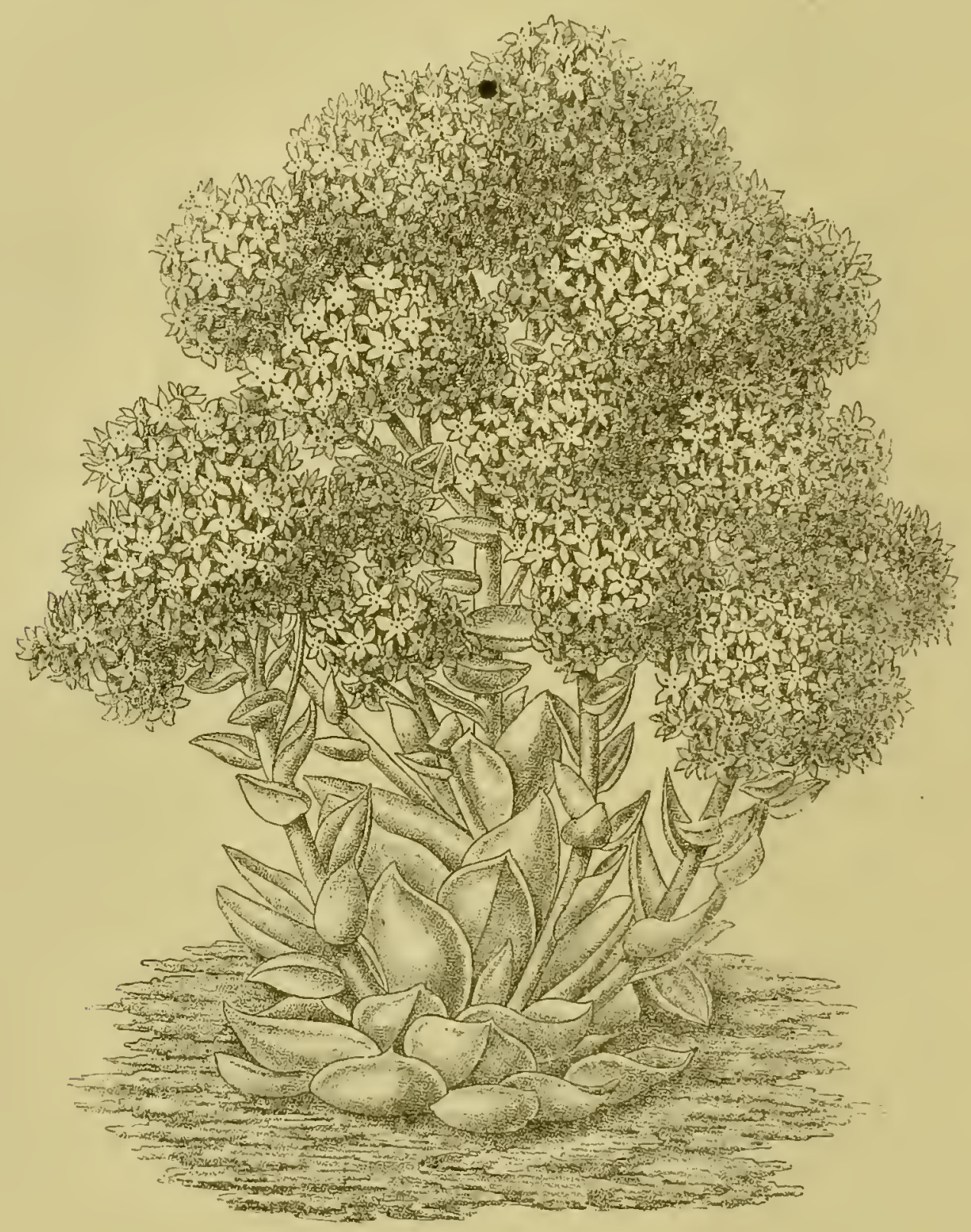

Jig. 21. Sedum Sempervivum Ledb.

\section{Sedmm Sieboldii Suct. Sichorba Fette seunt.}

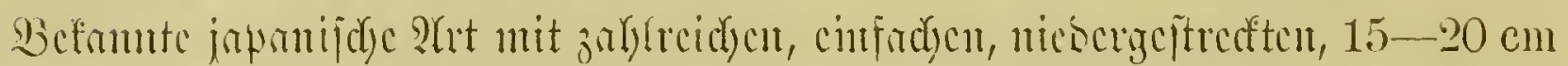

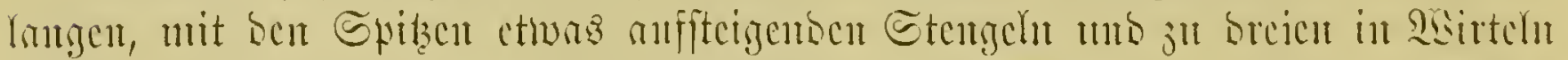

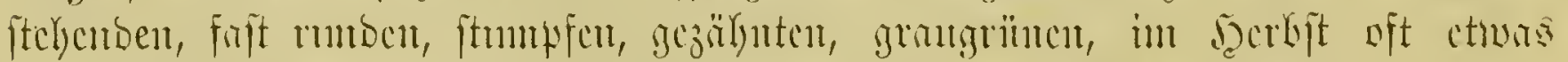

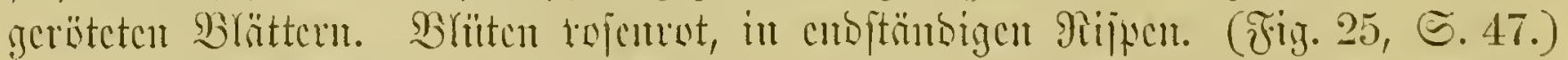

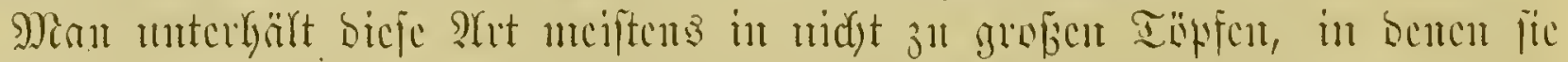

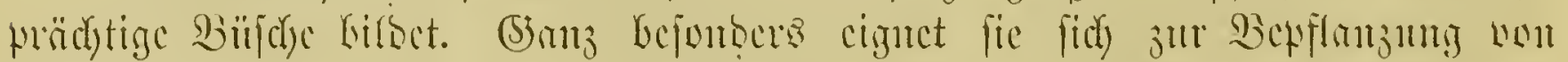

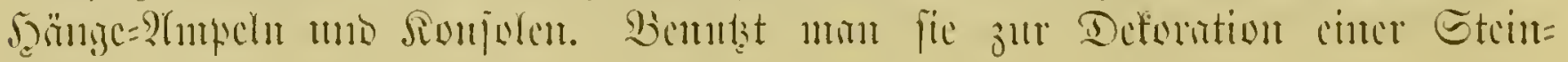




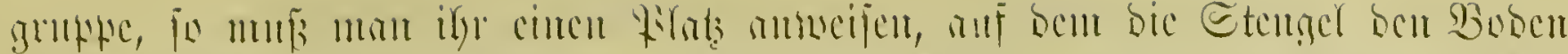

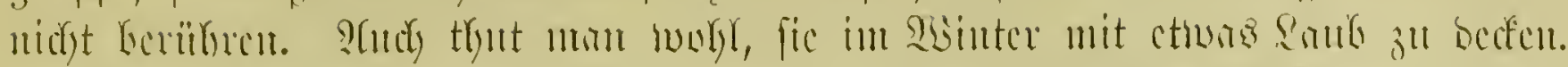

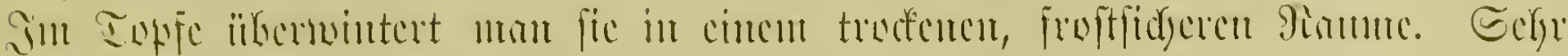
Guibjic) uns intereffunt ift var. variegatum (var. foliis medio-pictis), seren

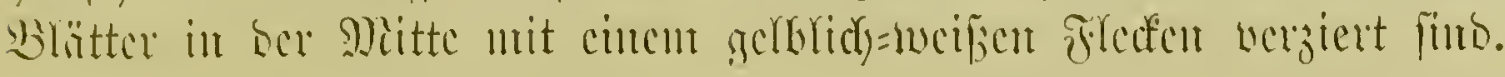

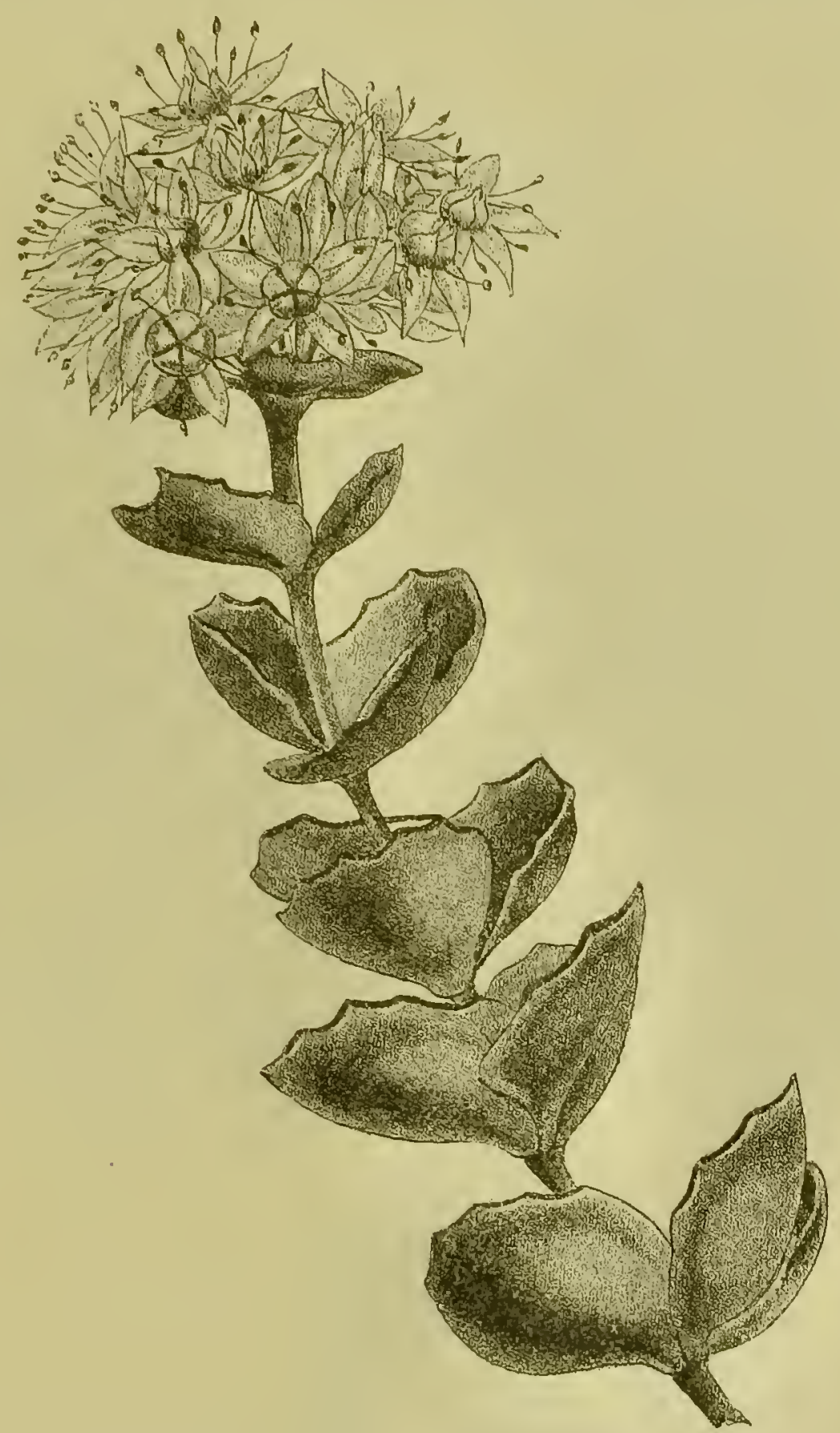

Fig. 25. Sedum Sieboldii Swect. Eiebold' Fette Scmuc.

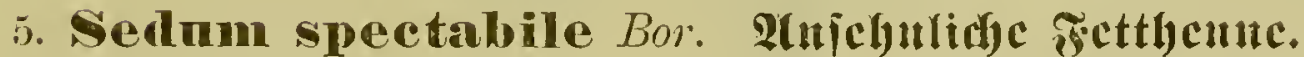

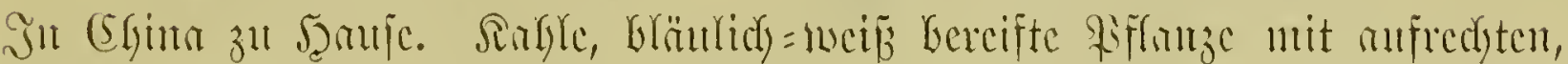

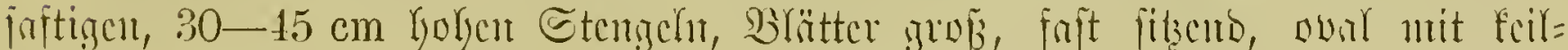

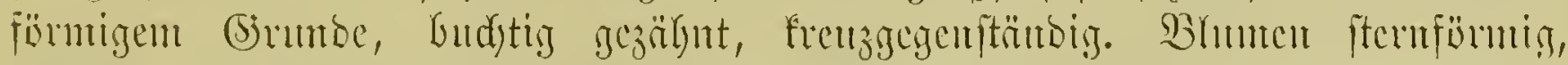

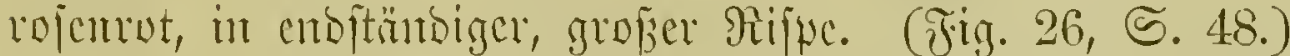

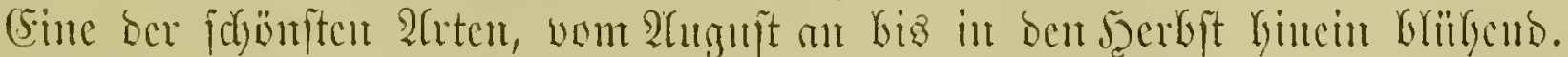

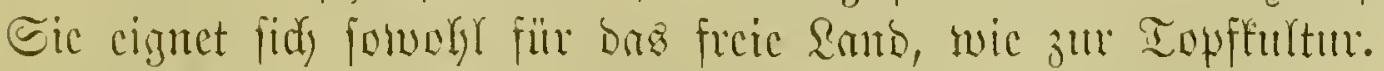

Dafjelfe gilt von ber buntbrätterigen Barictüt (var. foli is variegatis).

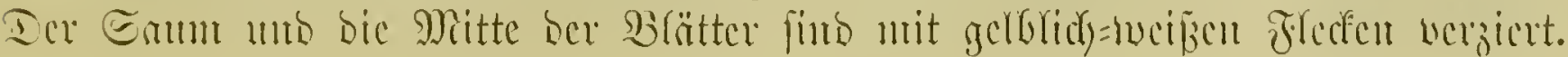


6. Sedmm Ewersii Ledl. Erwerz̧ Fette sente.

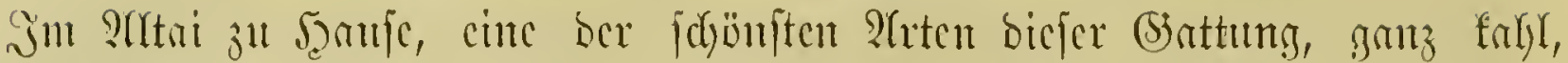

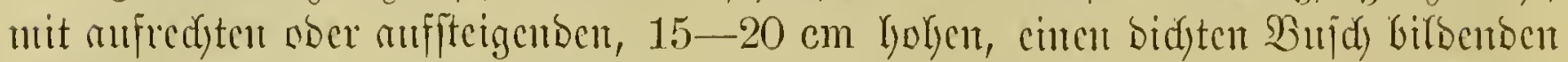

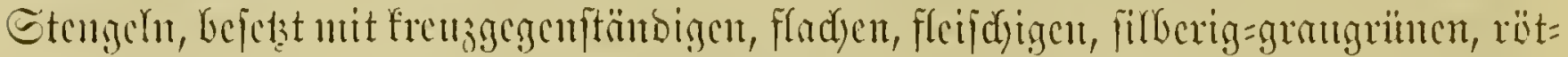

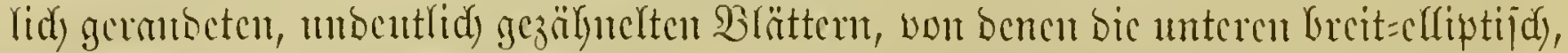

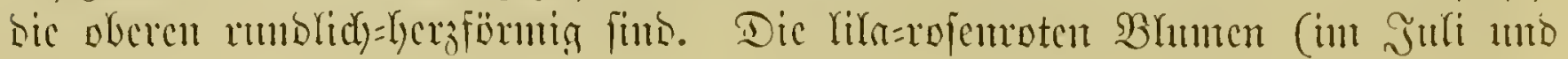

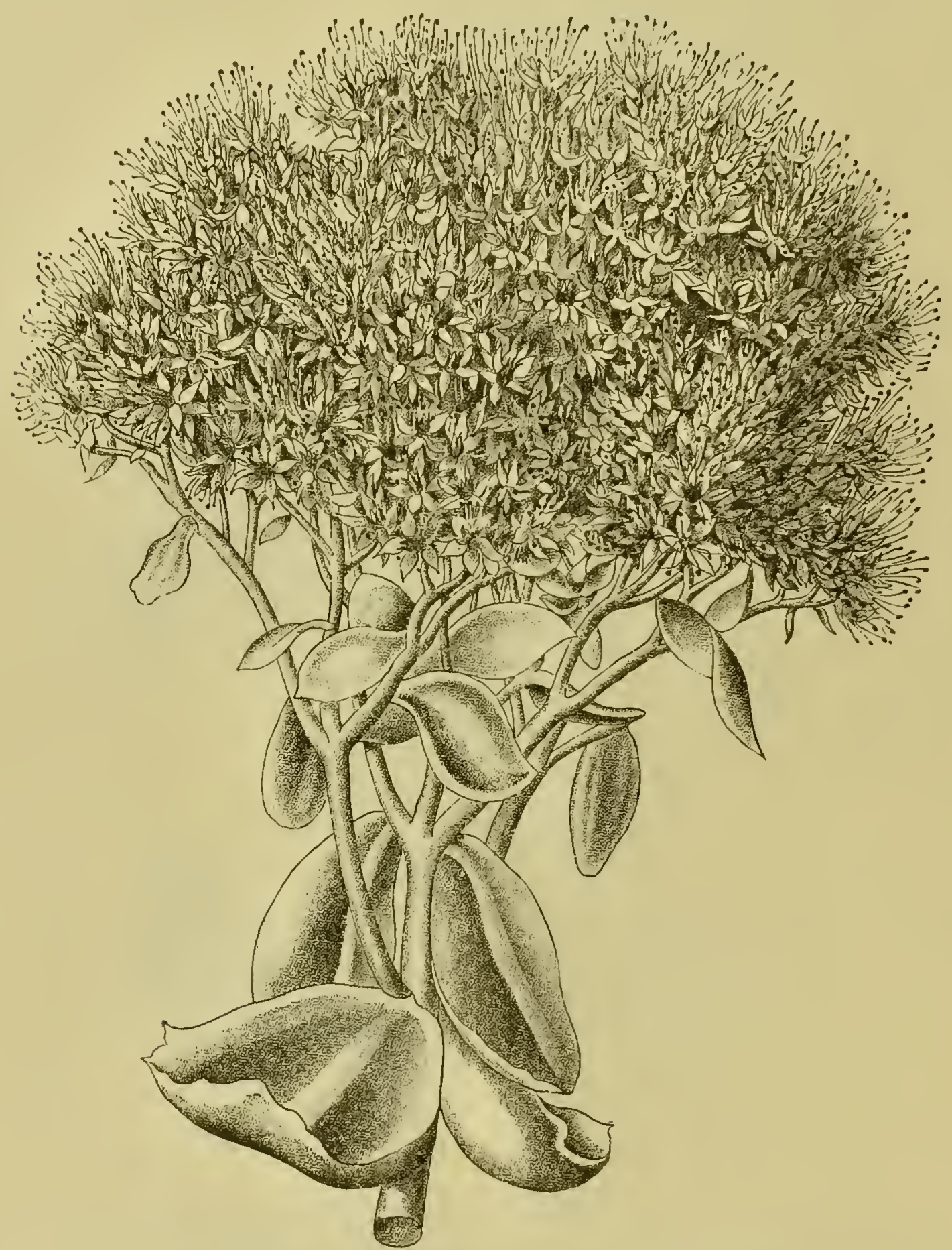

Fig. 26. Sedum sprectabile Bor. Thiefulidye Jetthenne.

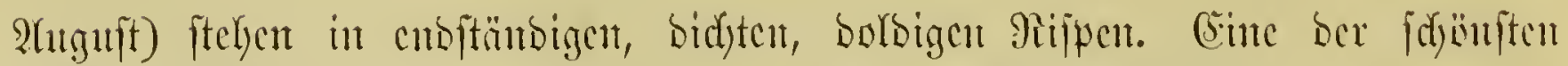

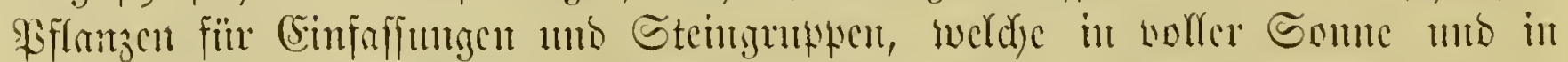

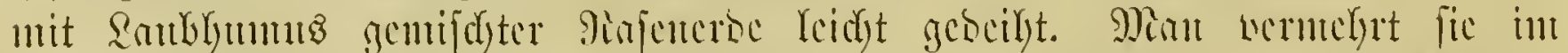

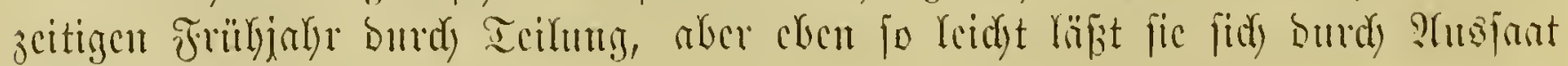
fortpflanzen. 


\section{Sedum spurium M. Bbrst. Baitard=Fettheute.}

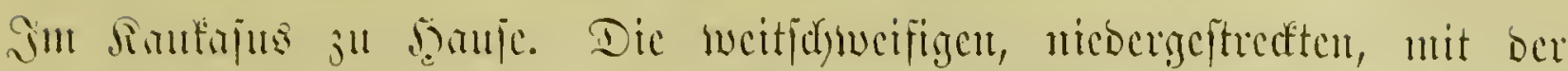

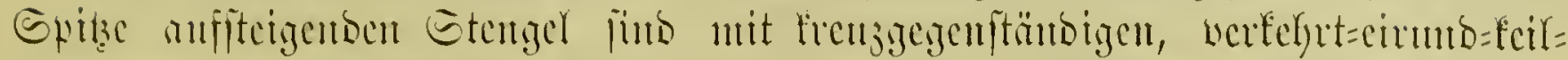

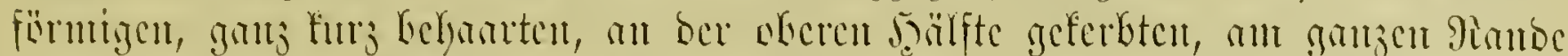

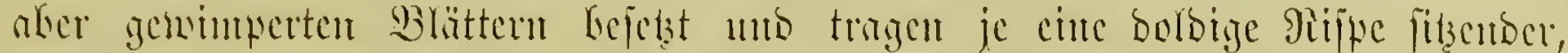

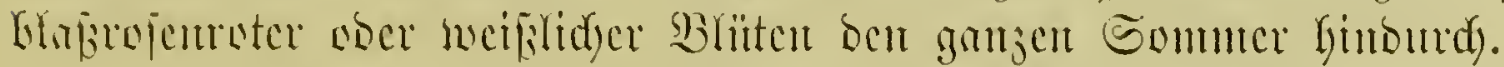

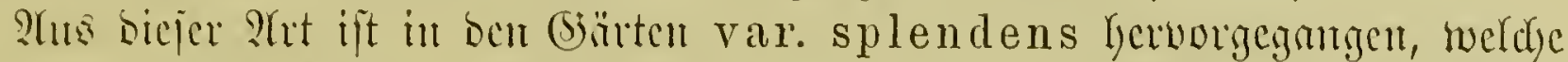

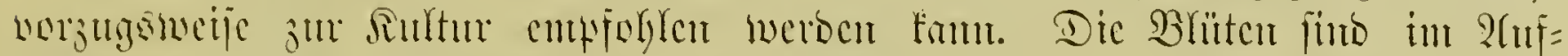

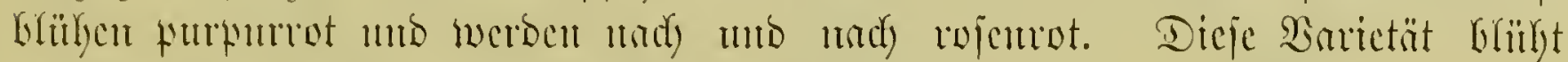

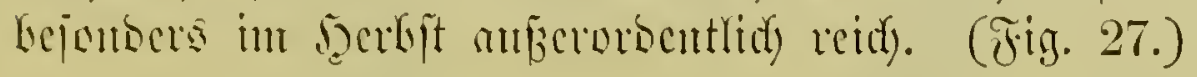

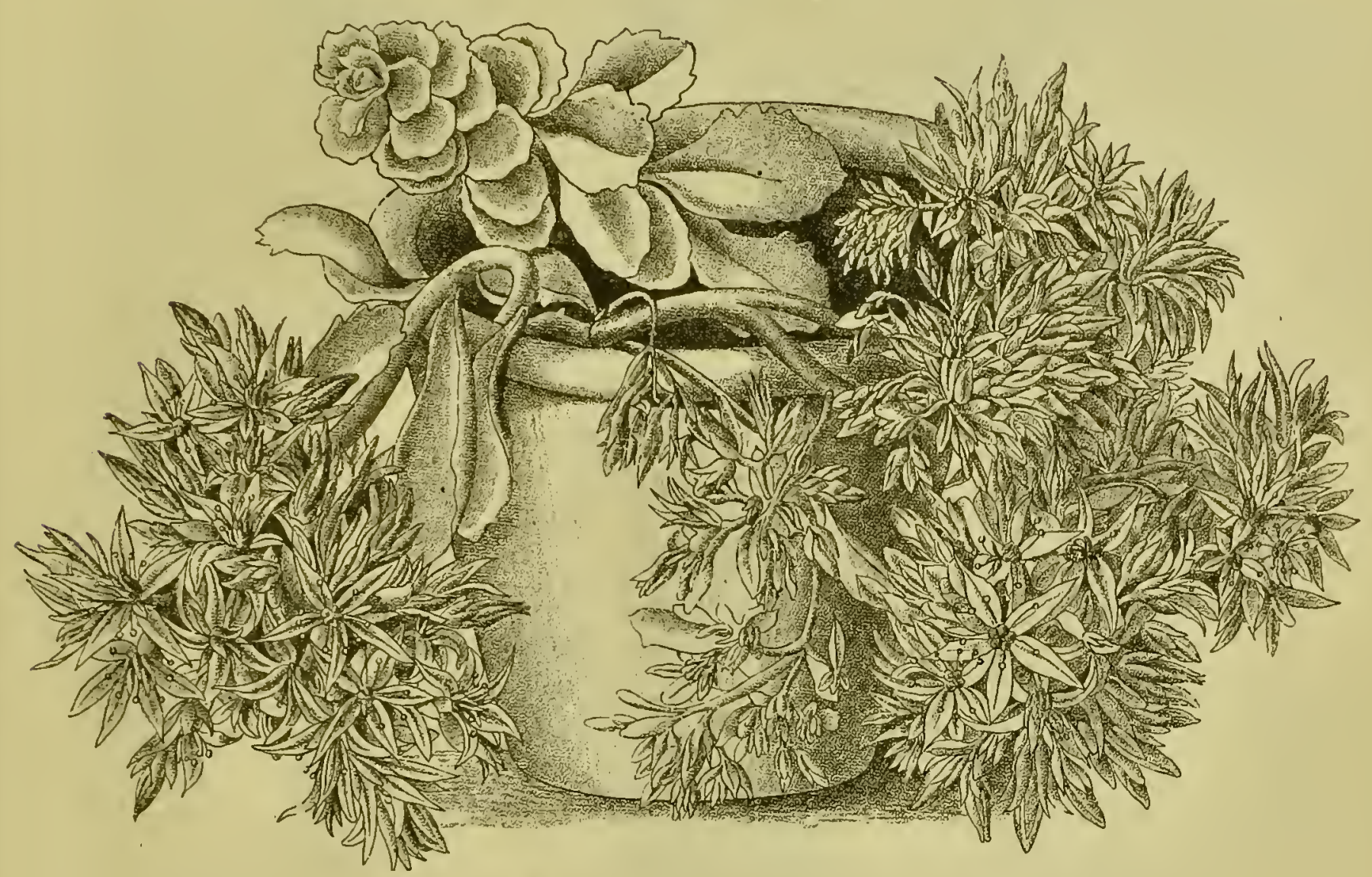

Fig. 27. Sedum spurium MI. Bieb. var. splendens Hort. Baftard $=$ Fetthenne.

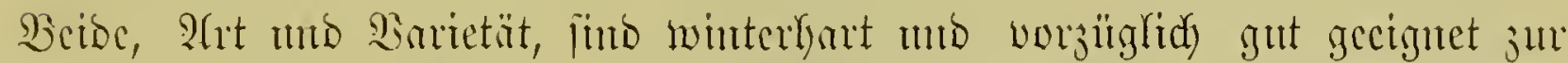

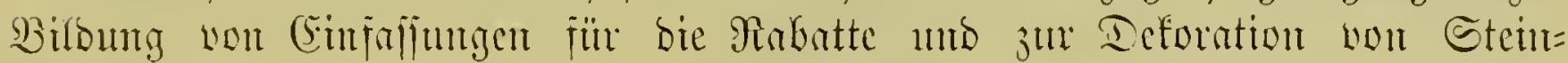
grupkent.

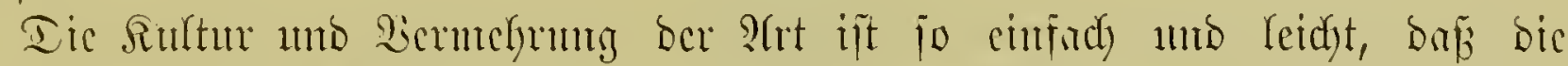

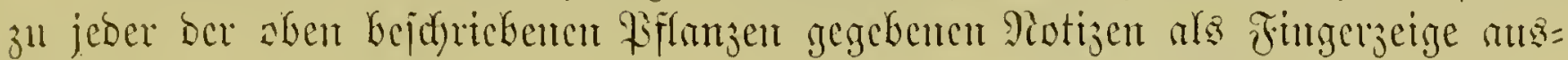
reidjett.

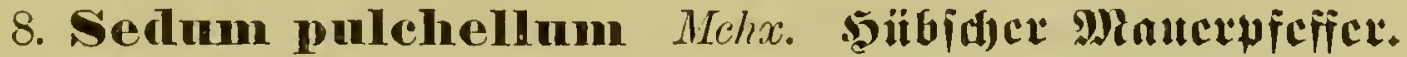

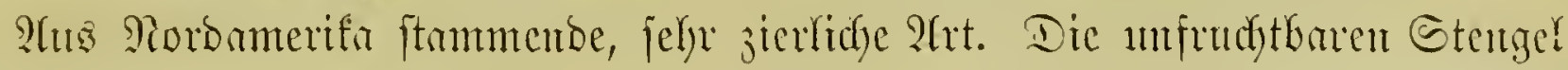

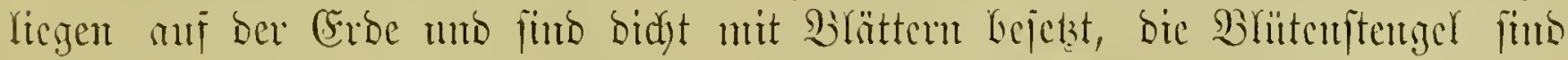

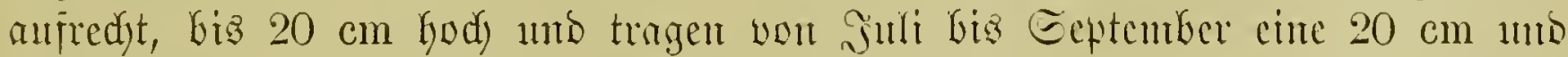

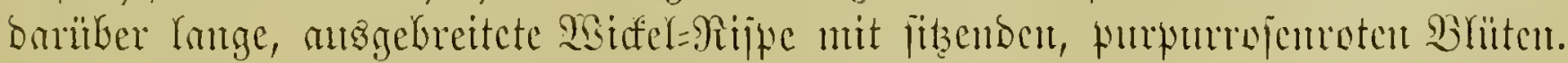

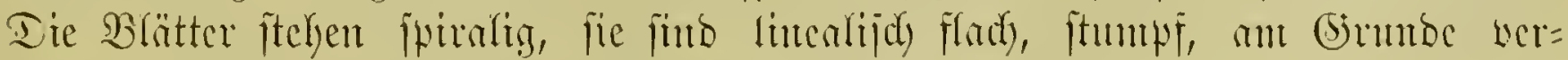

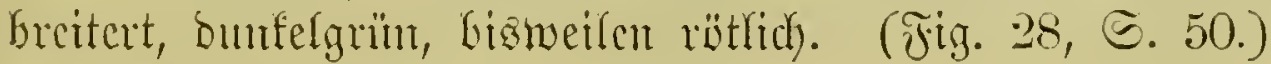

Enffucenten. 


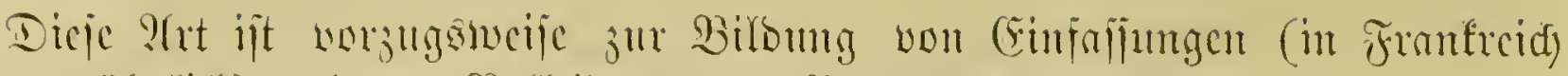

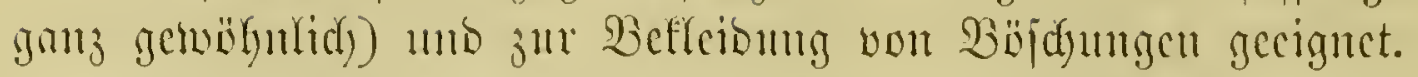

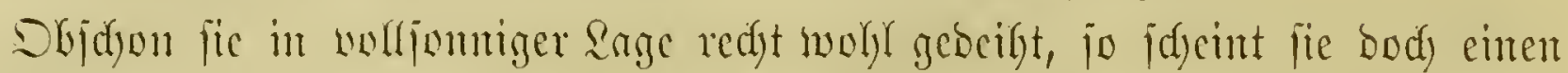

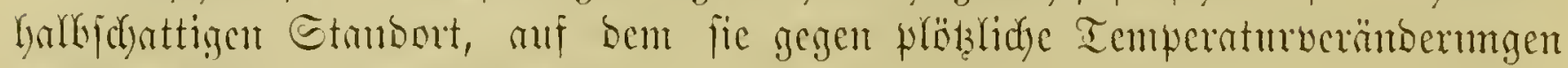

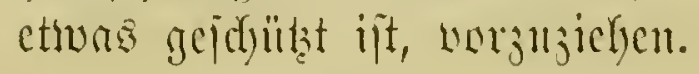

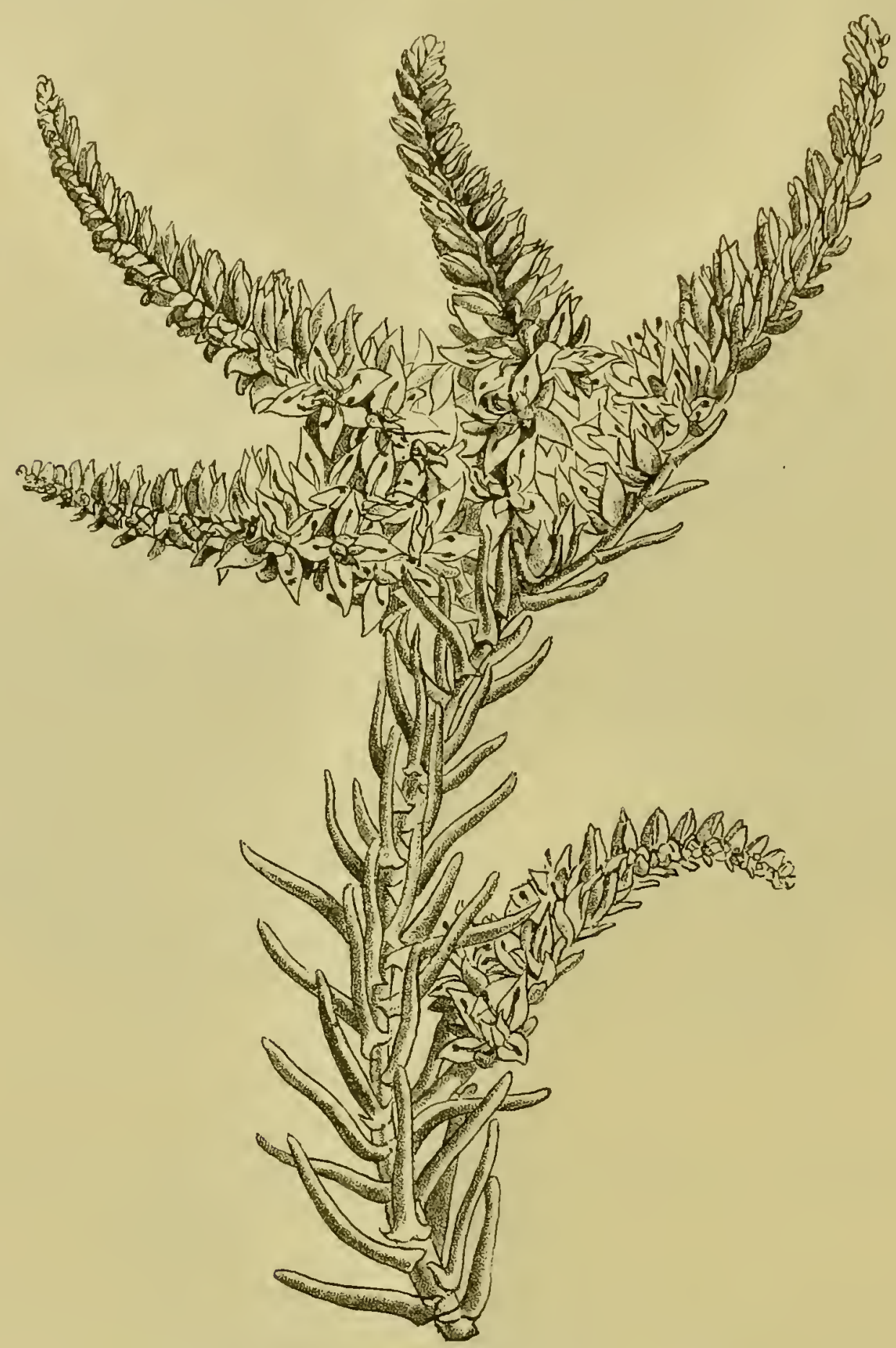

Fig. 28. Sedum pulchellum Mchx, Së̈bjder Mauerpicfier.

\section{Sedum cyanenm Rud. Branc Fettlycute.}

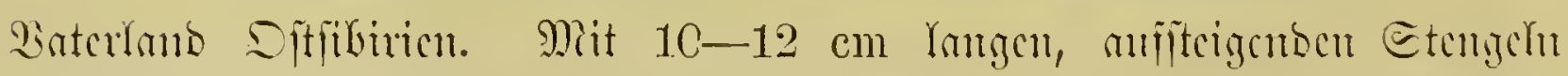

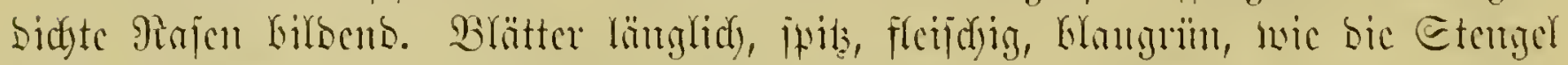

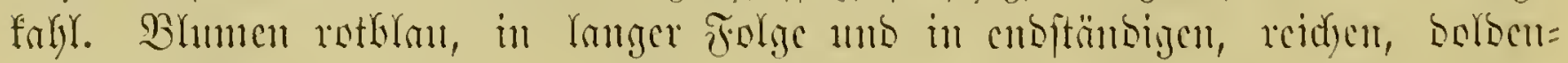

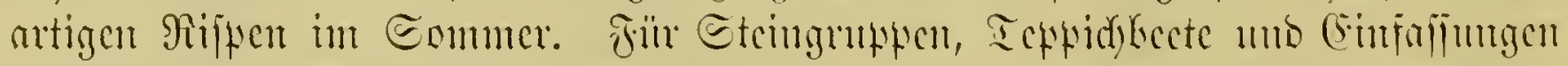

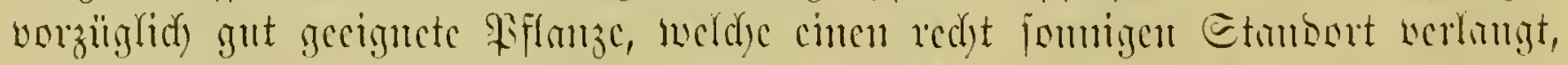

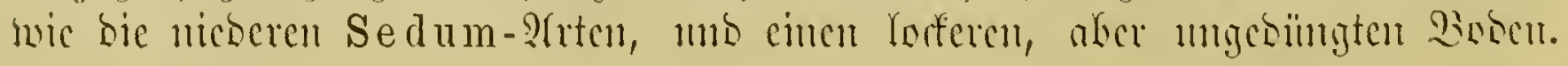


10. Sedum Anacampsemos $L$. Jumucrinuiue Fettlyenc.

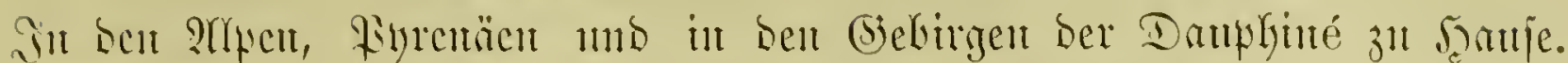

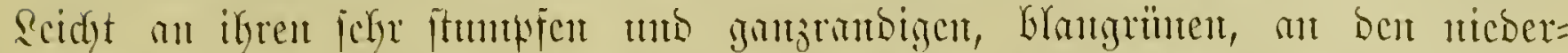

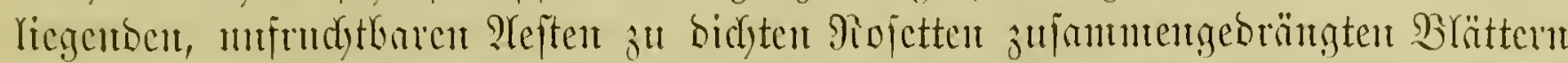

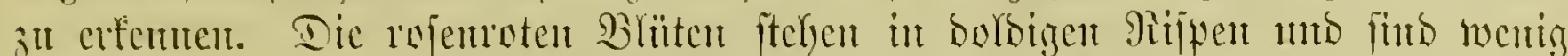

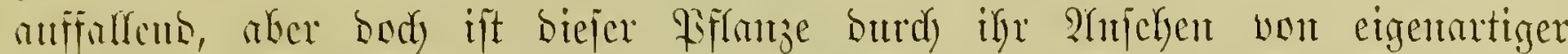

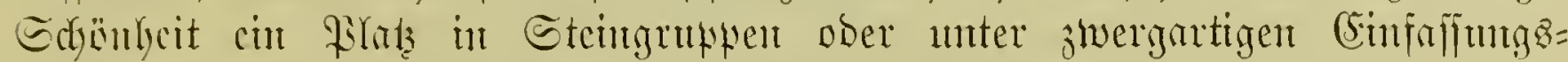

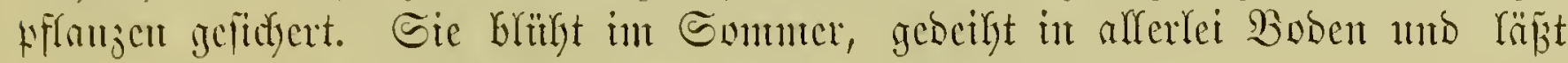

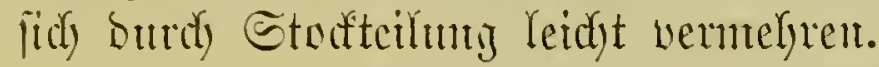

\section{Sedmm purpurascens Koch. Burwutuc Fetthente.}

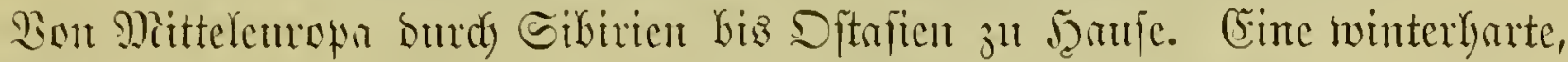

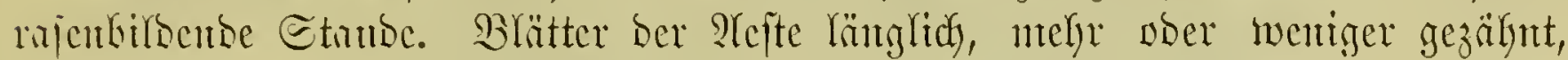

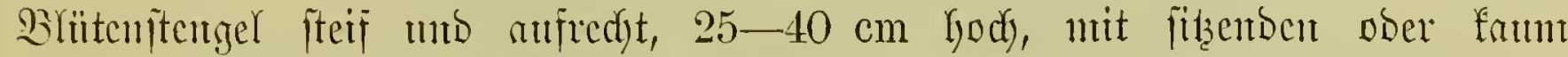

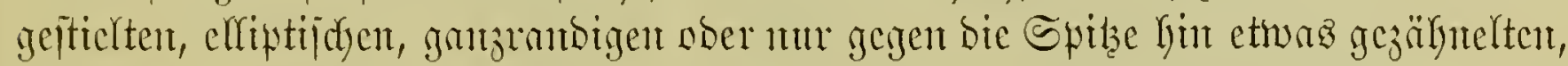

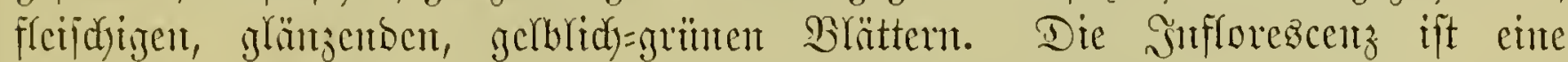

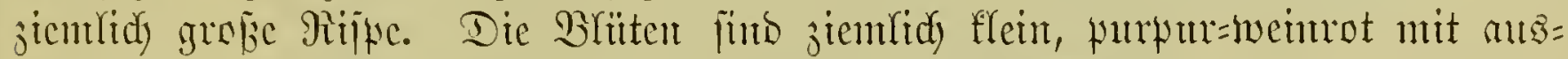

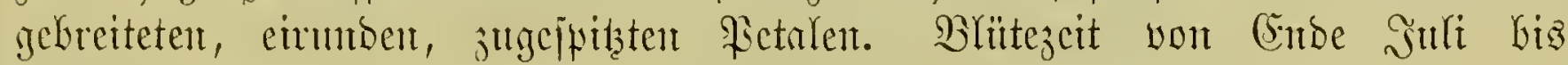
Ditober.

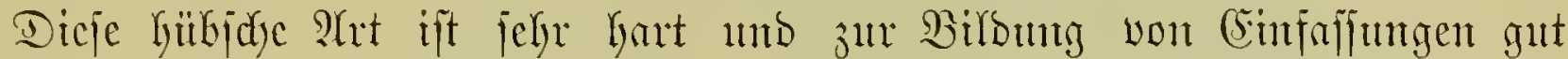

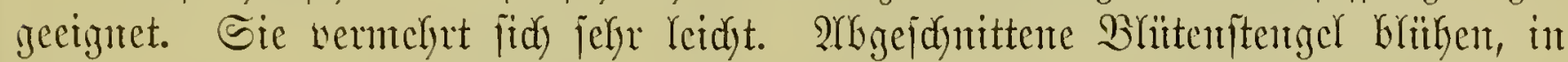

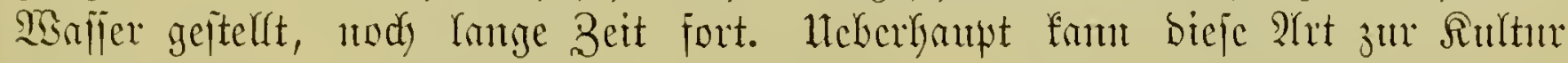
suarn entwoblent werben.

\section{Sednm sarmentosnm Bge. Paufige Fsettlycute.}

(Carneum variegatum Hort.)

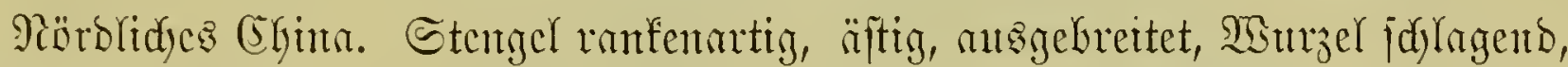

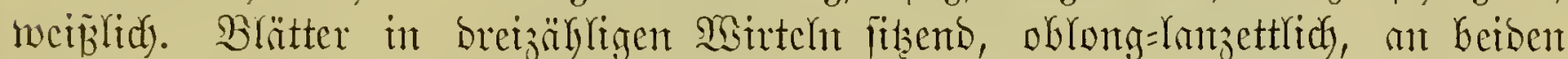

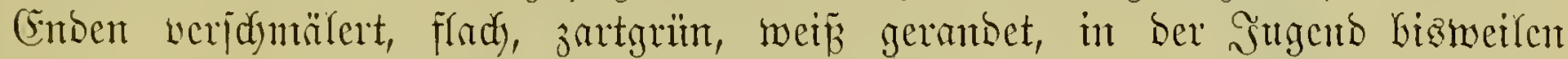

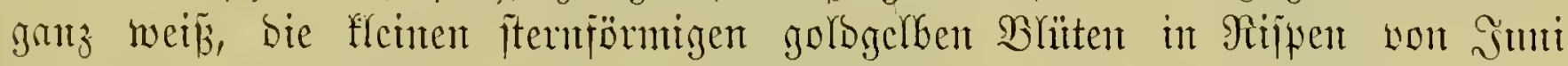
bis gitli.

Dieje $\mathfrak{Z}$ rt ijt a aber einc jefre anjpredjende Form mo verbient bei ber. Deforation von Feljen

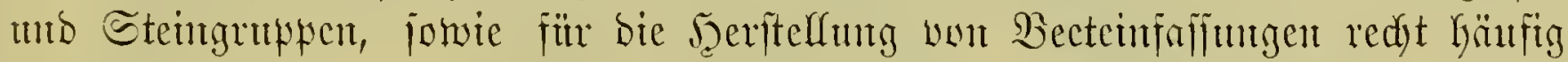

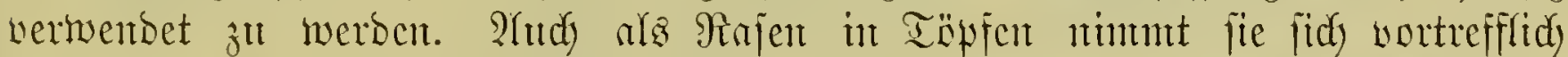

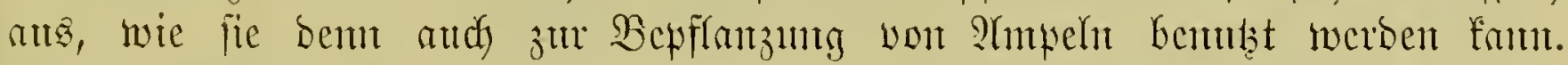

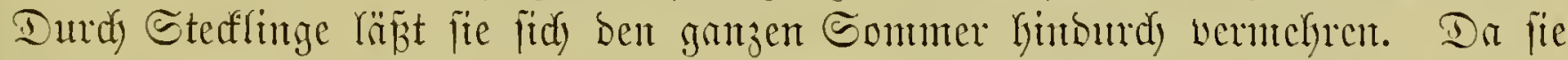
nidyt gans winterbart ift, jo ift es geraten, fie int sinter in Töpfer in cintem Gelfen, proitjicheren Raum ju haltent.

\section{Sednm kamtschaticum Fisch. Sinutidjatfijdge Fetthenuc.}

S. Maximowiczii unhejteyent, aber niebriger mo mit veräftelten, ant (Simuto

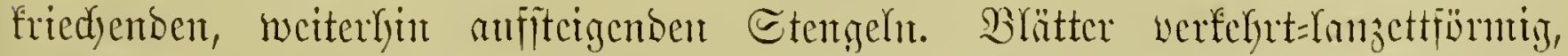

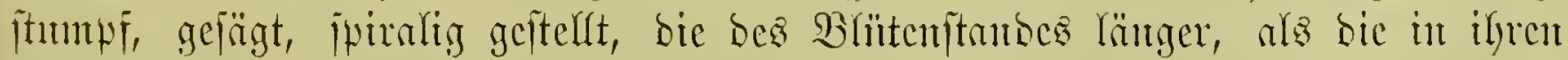

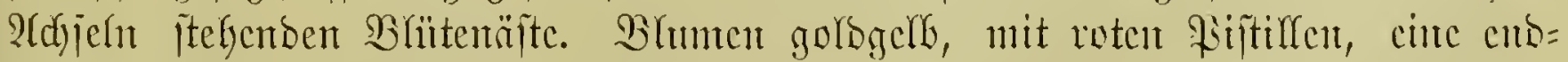
itünbige, bidyte, fladje, boldige Gitipe billocto. 


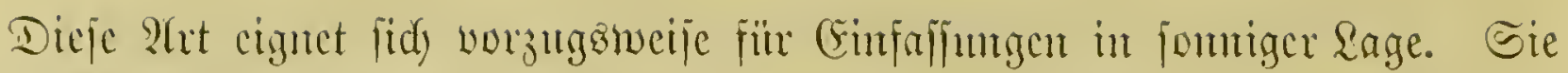

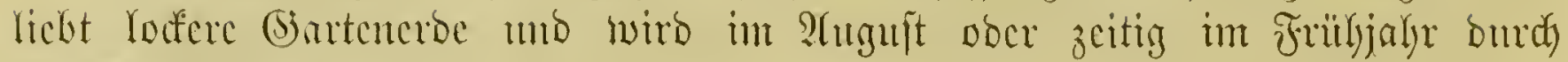
Etorfteilung vermetret.

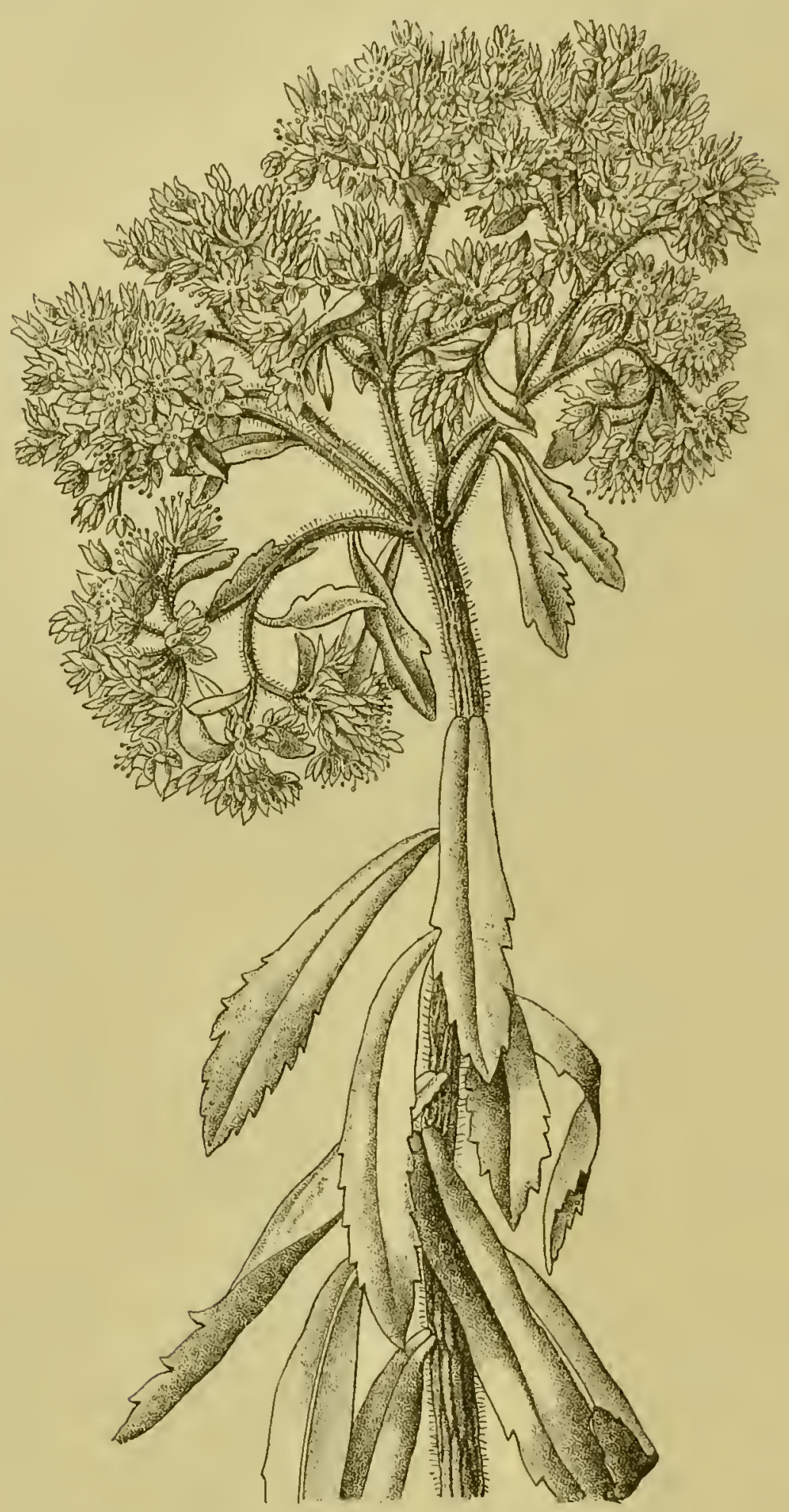

Fig. 29. Sedum Selskianum Rgl. et Maack.

14. Sedum Selskianum Rgl. et MICk.

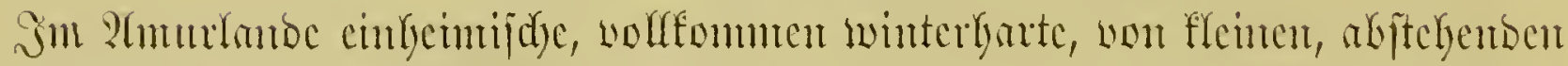

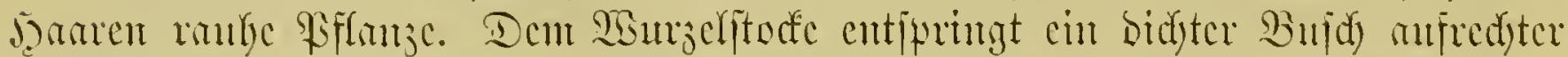

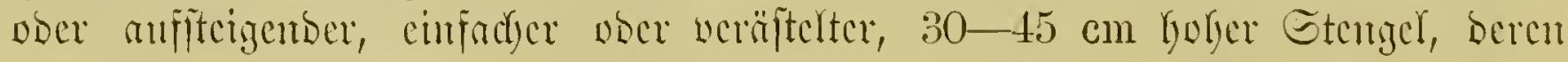

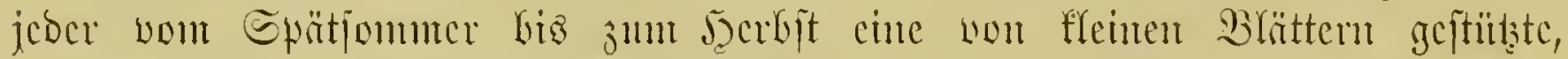

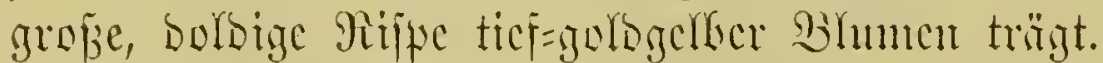

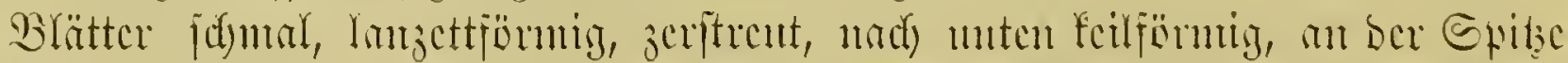

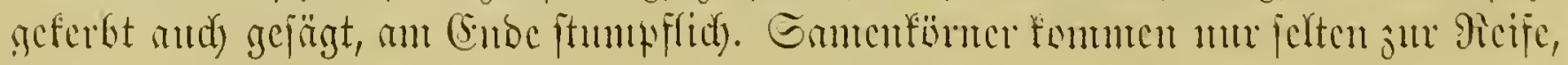




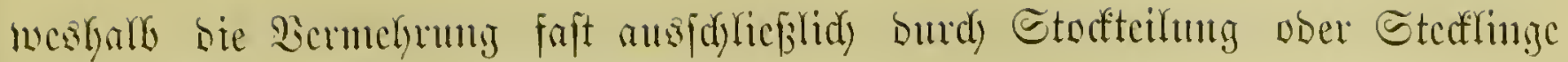

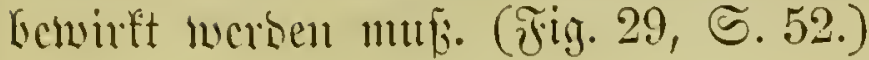

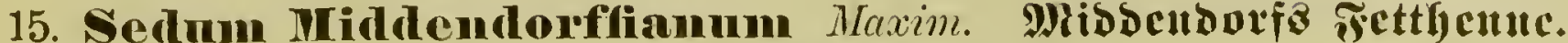

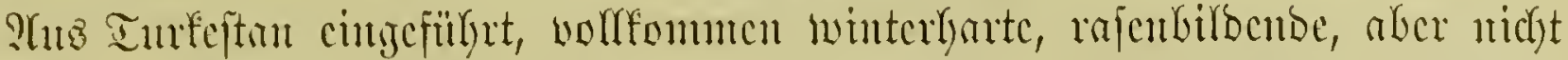

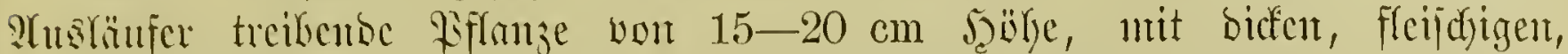

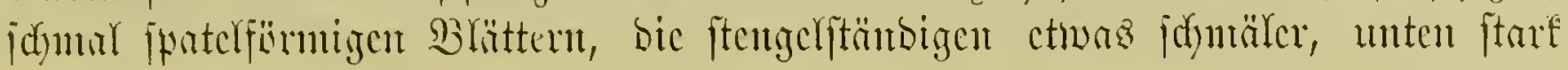

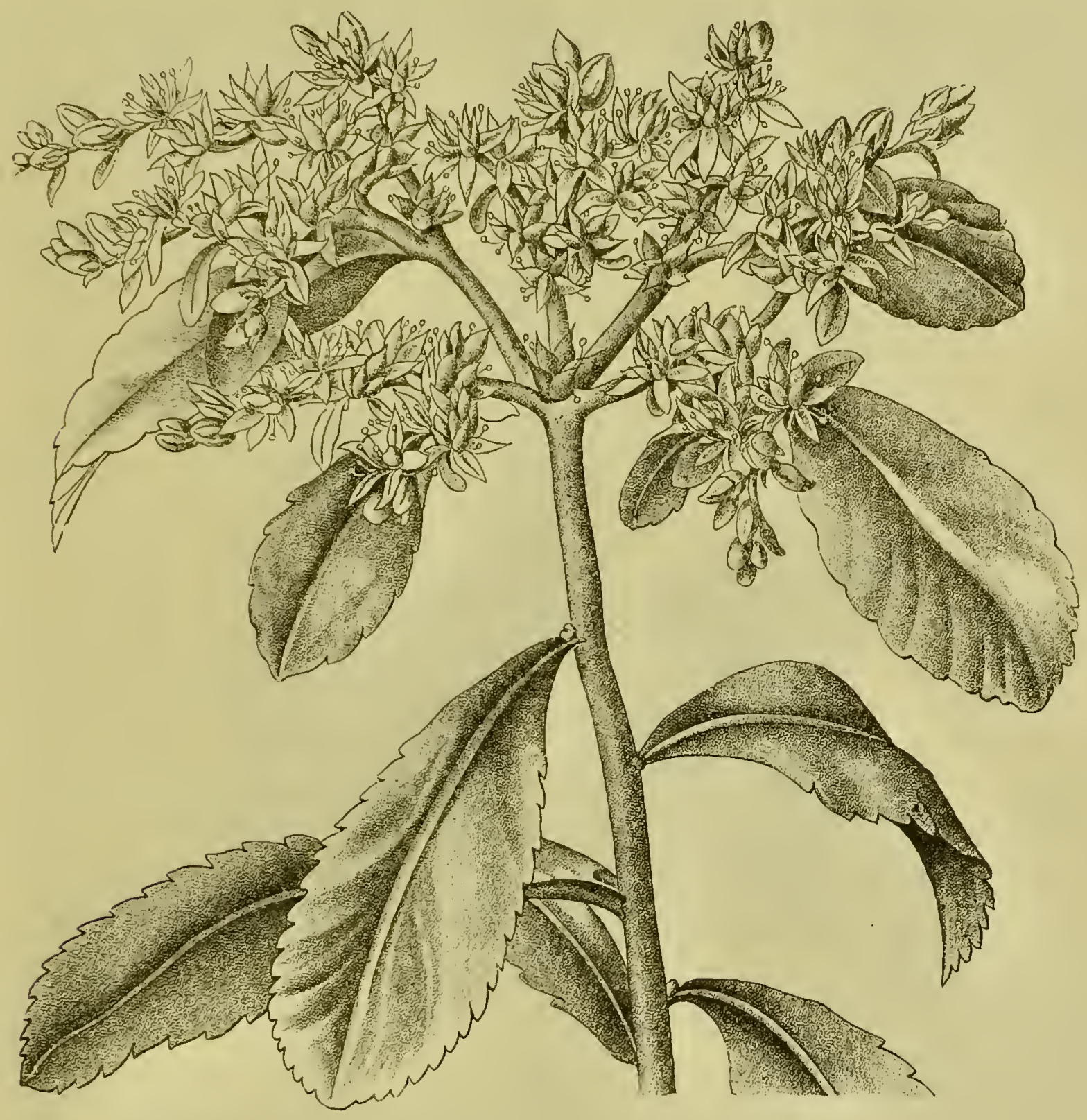

Fig. 30. Sedum Maximowiczii Rgl. Maximowicj's Jette Denne.

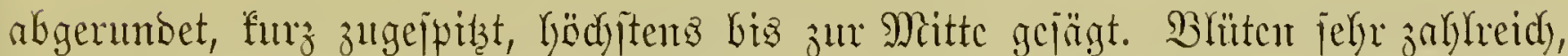

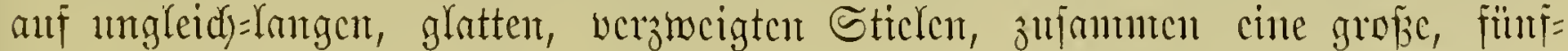

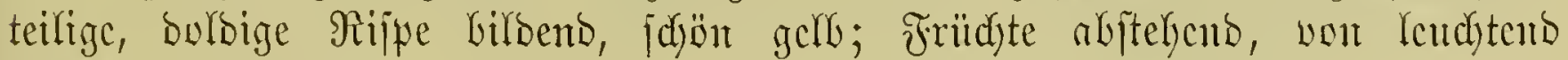
Dunfelroter Farbe.

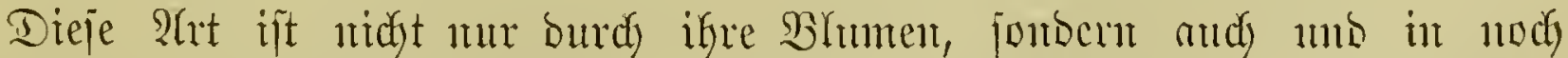

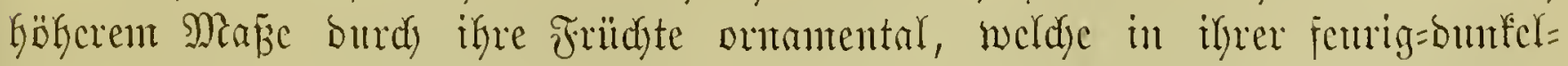

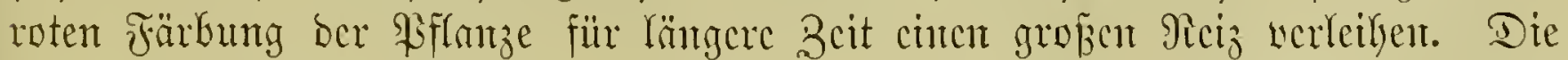
Blütczeit beginnt in Juni und jekt fid) oft burd bie anz ber Mitte bes Storfes

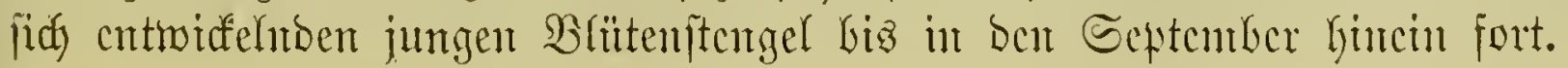




\section{Sednm Maximowiczii Rgl. Max̧imotwicz'z Fettlenuc.}

Gibirijdye ?ht. Gebr fräftige mo winterlyate \$ffanze, weldye vorzugs=

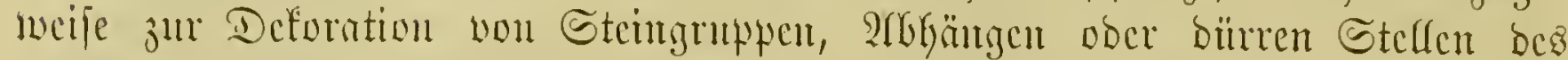
Sintens gecigntet ift. Gie bat robufte, aufredite, bis $75 \mathrm{~cm}$ bohe Etengel,

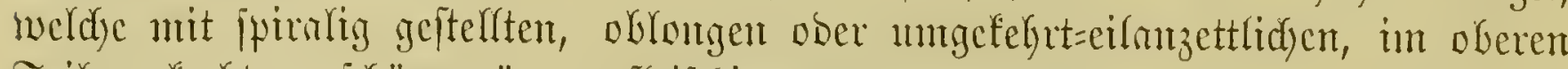

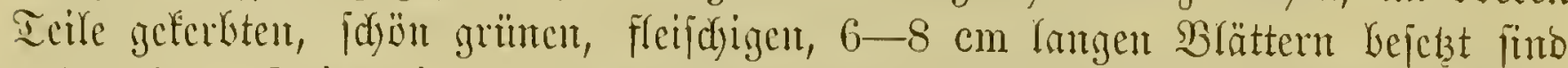

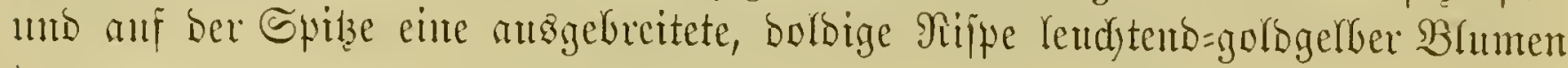
tringen.

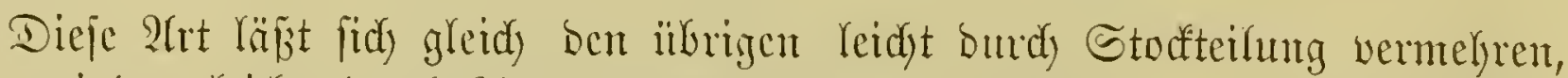

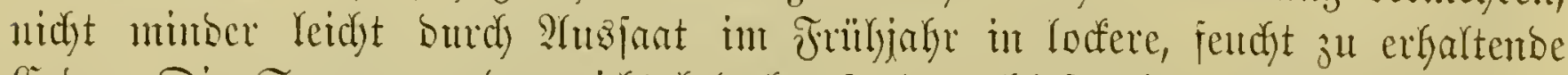

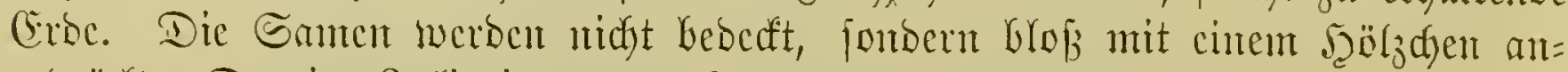

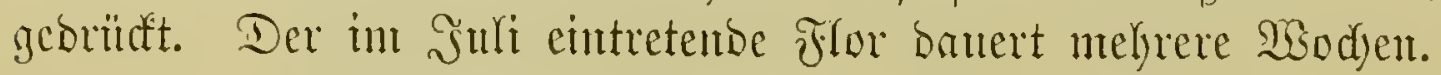

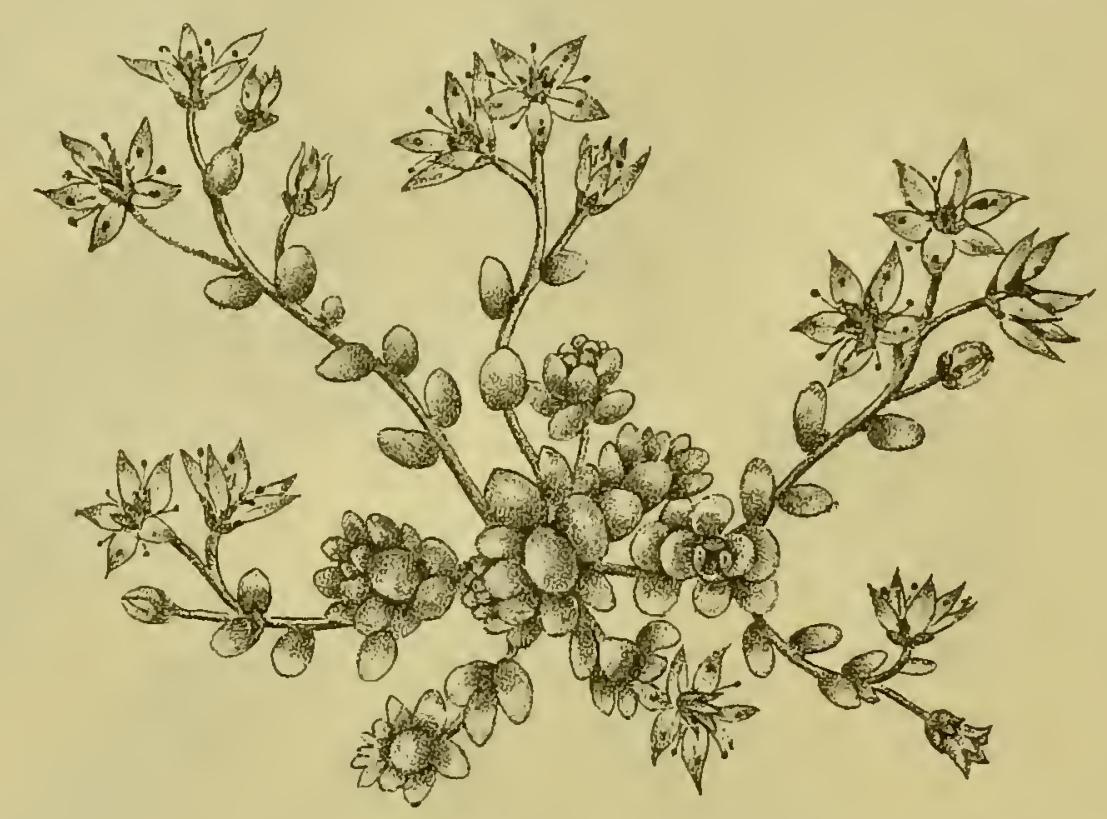

Fig. 31. Sedum dasyphyllum Linn. Die̛bătriger Miauerpieffer.

\section{Sedum dasyphyllum $L$. Siłfblätteriger Młaucrpfef̈er.}

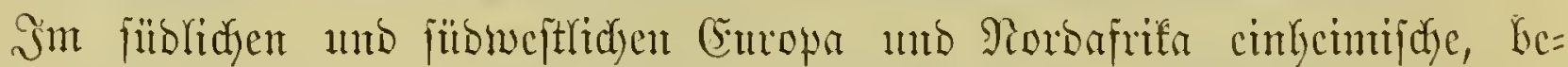

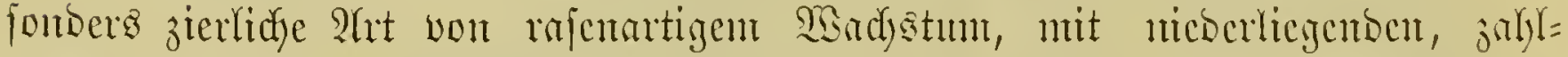

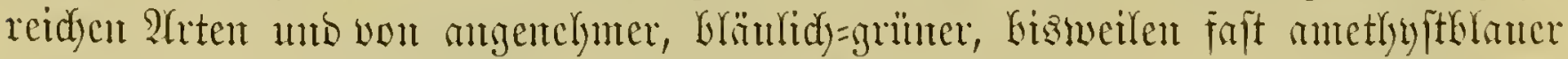
Färbung. SBlätter fpiralig, wolffunmen fabl, flein, waljenförmig, bicht ju=

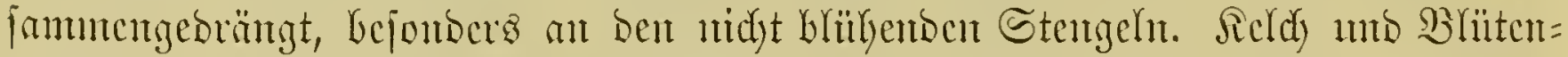

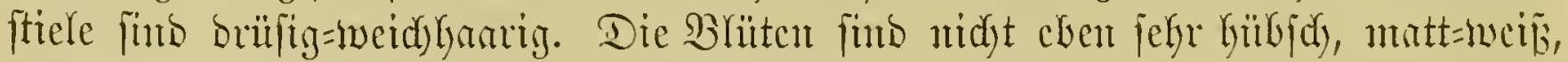

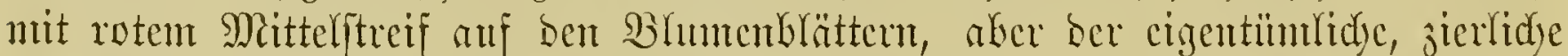

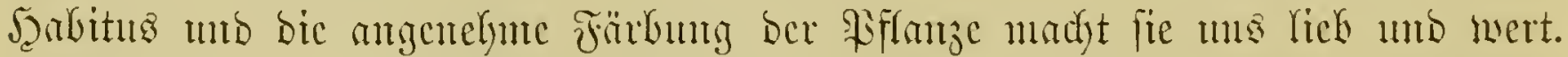

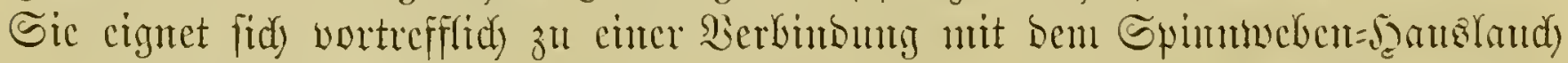

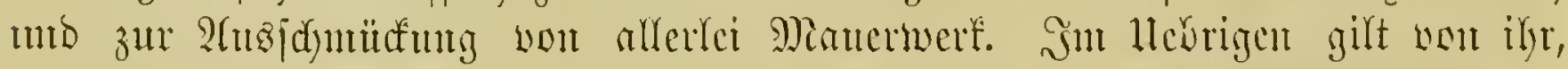
was in Betreff ber Sultur wou ber vorigen ?ht gejagt wubc. (Fig. 54.)

\section{Sedum album $L$. 2Bcifick Minucrpfefïer.}

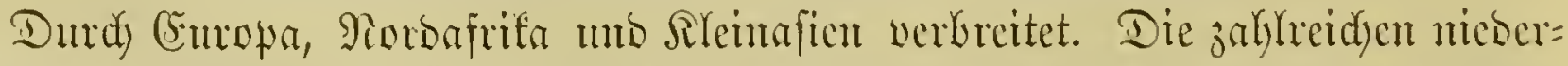

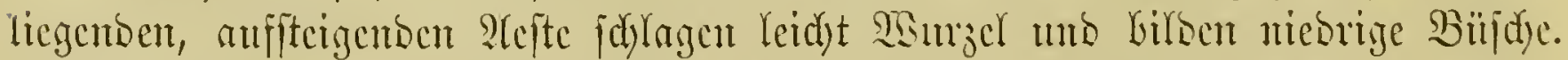

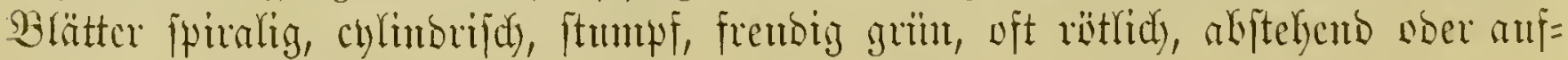




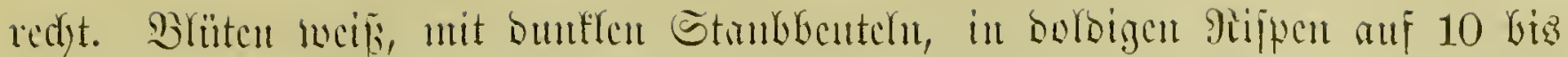

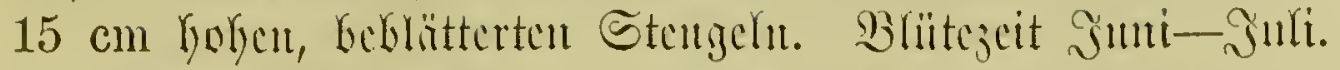

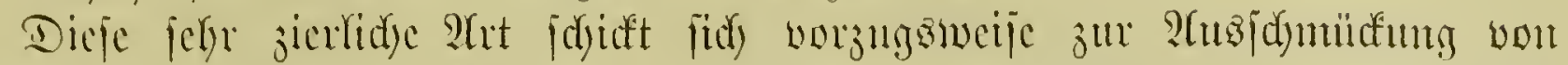

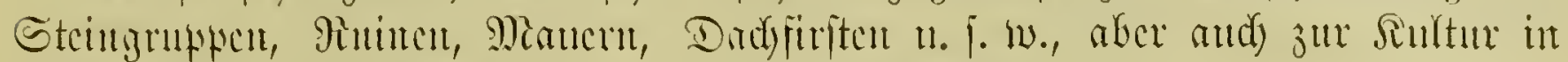

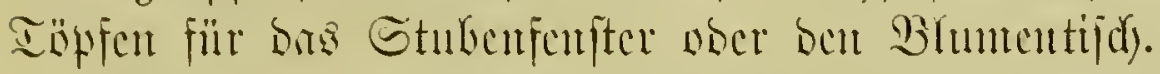

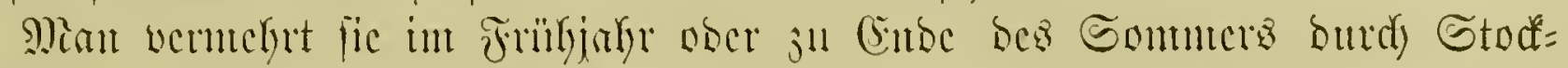

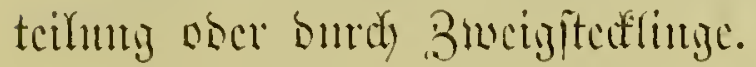

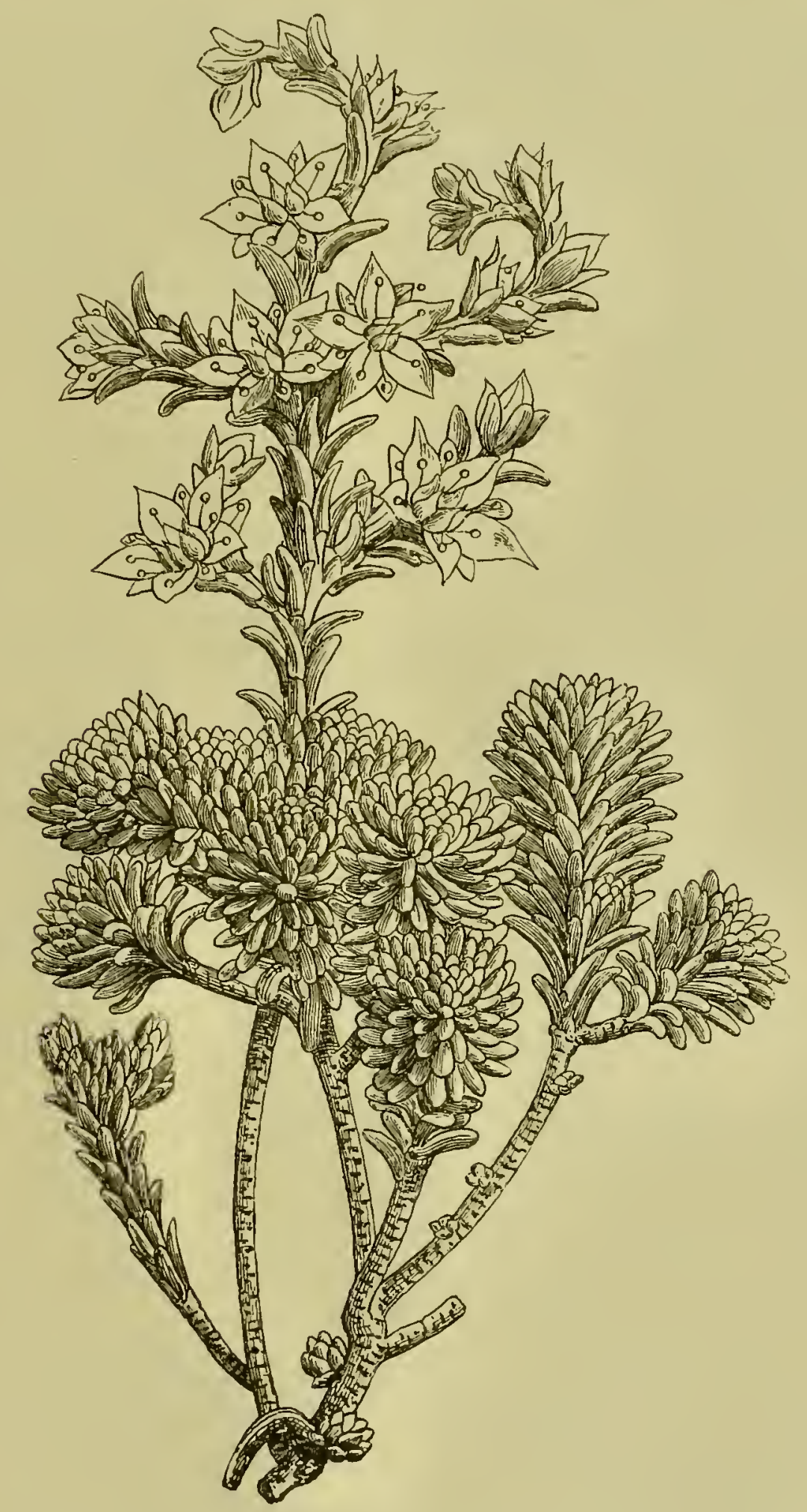

Fig. 32. Sedum multiceps Coss. et Dur. Bielföpfige Fetthenne.

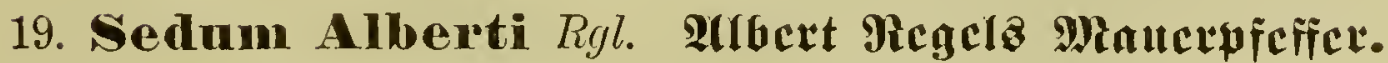

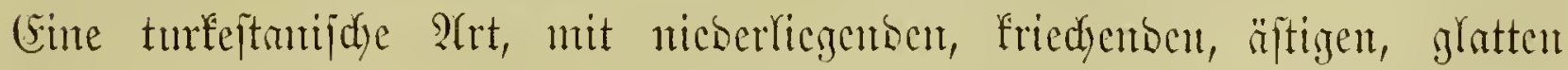

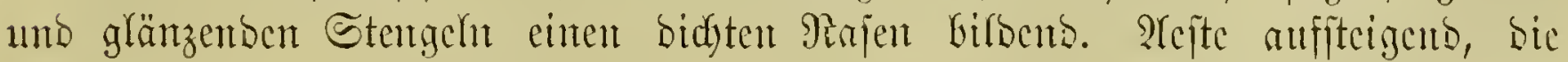

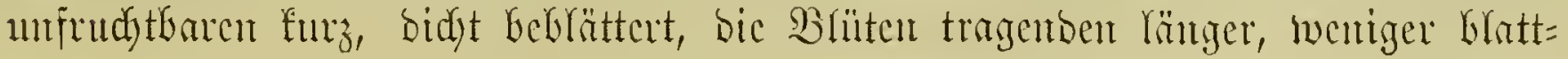




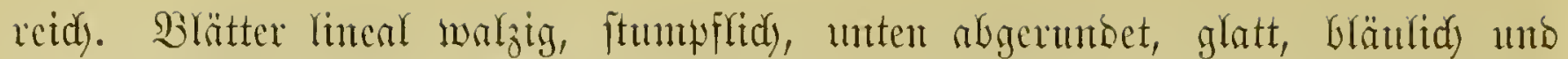

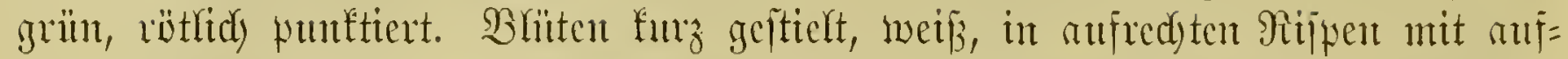

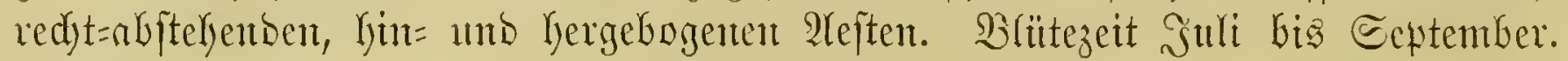

20. Sedmm multiceps Coss. et Dur. Bielfäprige Fetthente.

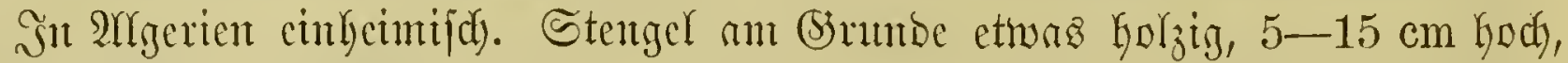

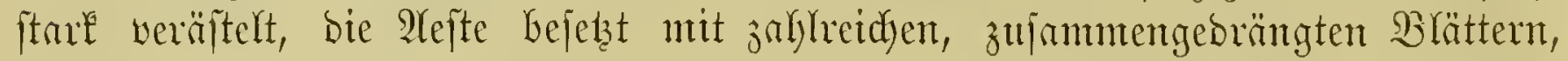

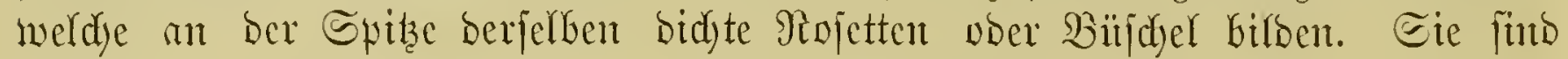

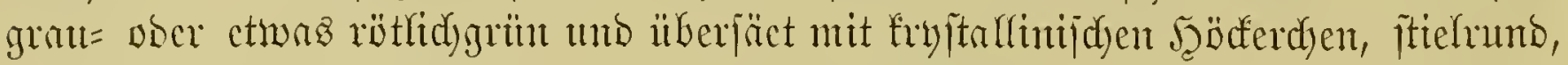

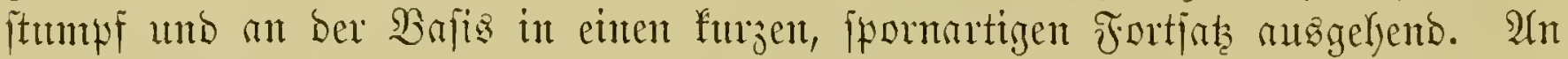

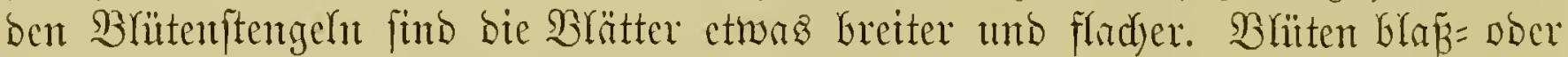

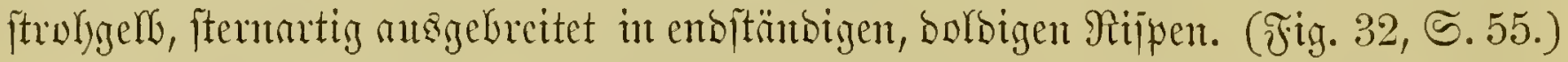

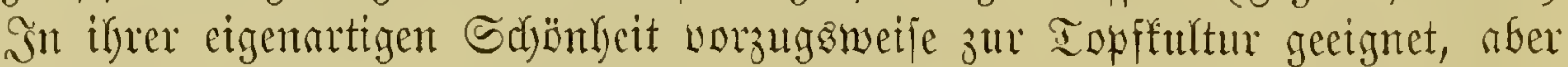

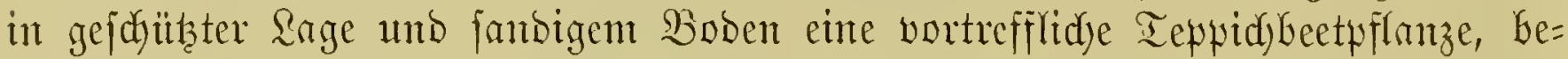

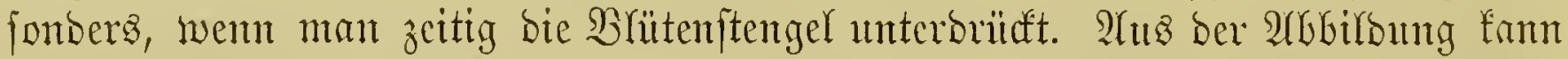

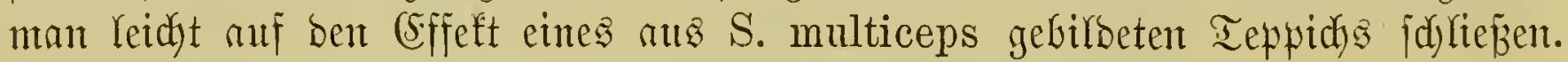

\section{Sedum acre $L$. Miatcrpicficr.}

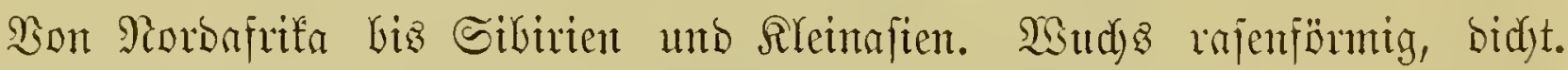
Stengel fabenförmig, ftiełrund mit ftumpfen, cylintorifden, faftigen Brättern, bic an ben nidyt brïbenden Sprofjen 6 beutlidye Beiten birben. BShïten gerb, in

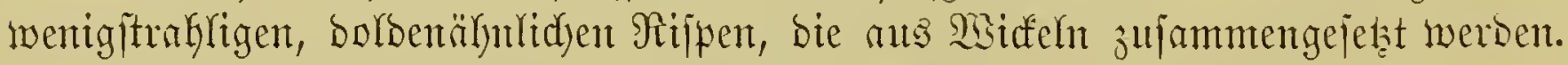
Die Pffanze fdymedt pefferartig fdarf und wirb fïr giftig gelyalten.

Var. aureum Hort., (5) ord = Minuerpfefier.

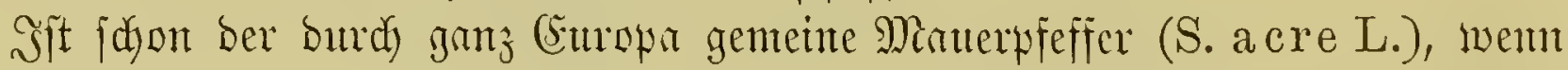

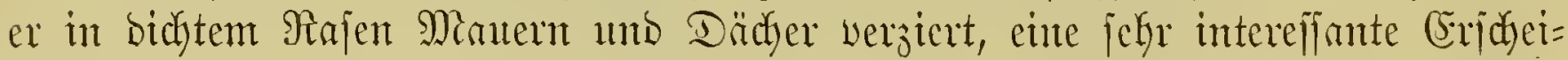

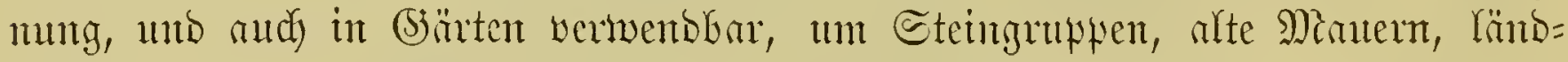

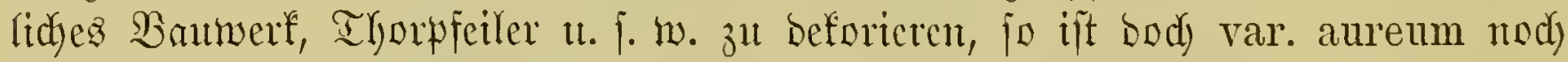

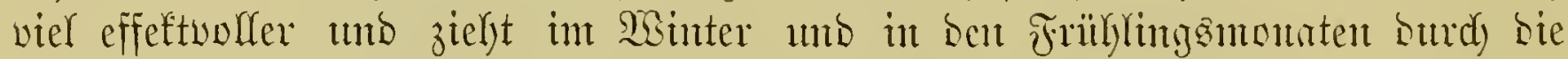

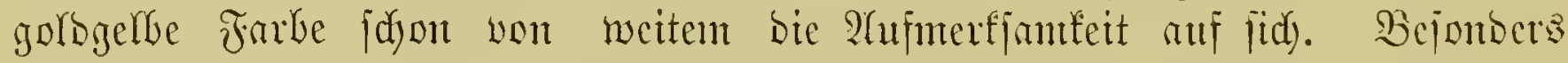

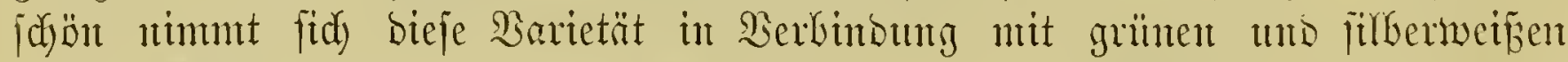
Sedum-2̂ten ober aud mit A ubrietia purpurea atı. Șm Sormmer freilidy werliert fich etwas bie Rebraftigfeit bes Solorits.

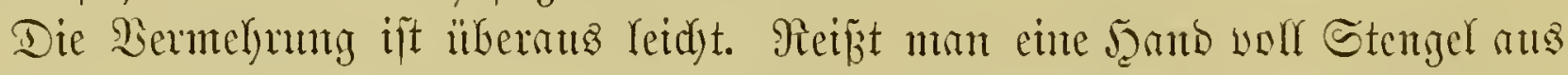

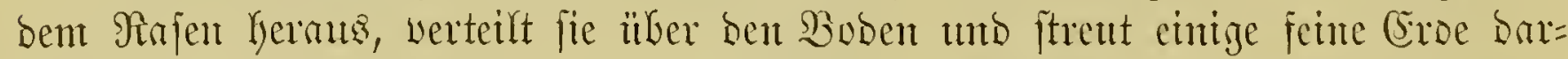

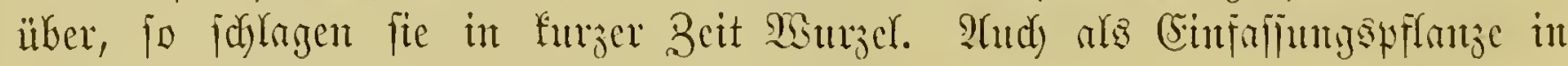
janbigent Boben ijt bieje Barictüt won

Sedum acre var. elegans, won fräftigem SGadjstum uno in furjer Beit

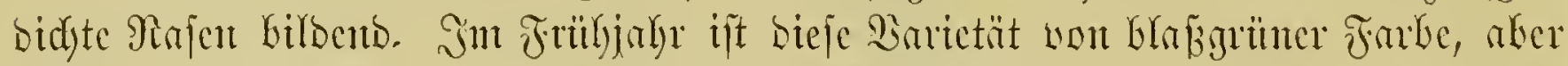

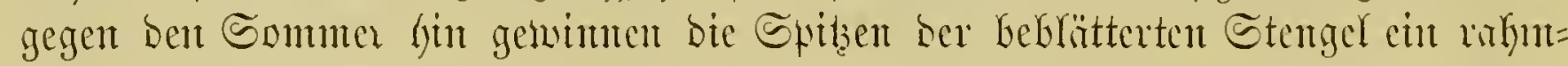

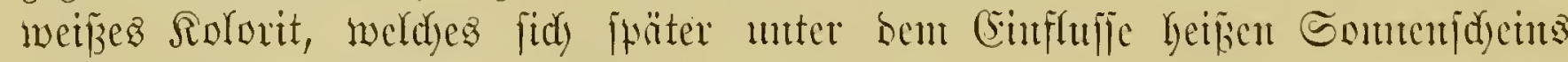

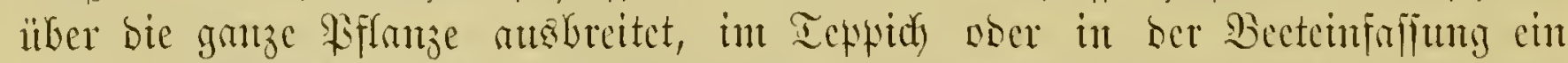

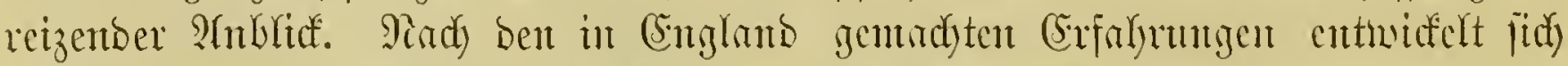

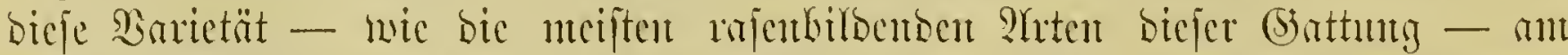

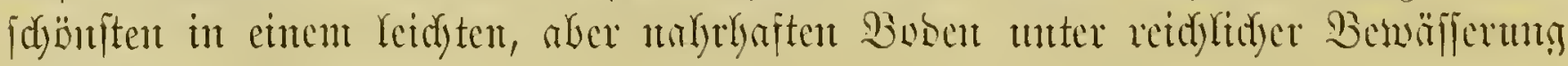
im Sommer. 


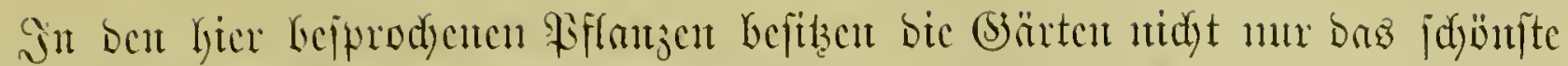

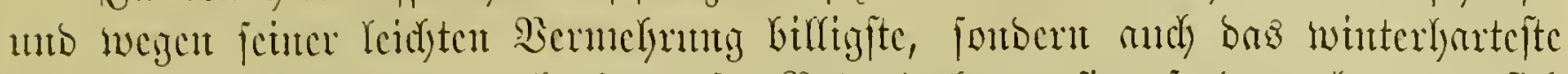

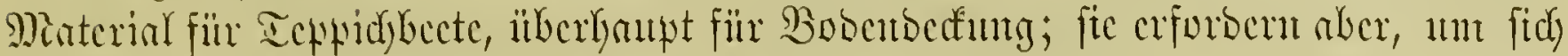

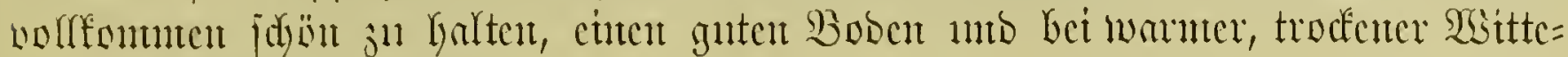
runtg reidy)tidye Fendytigfeit.

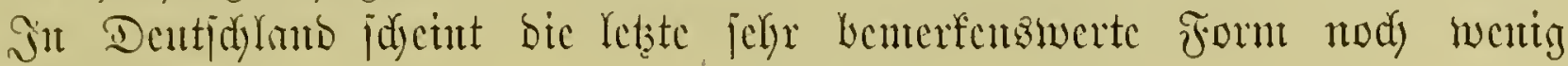
befinunt jut jeirt.

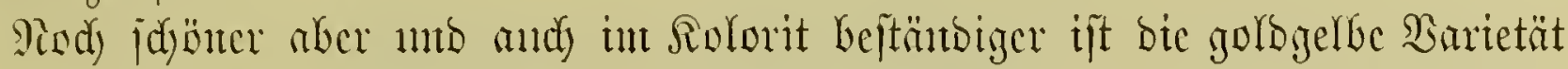

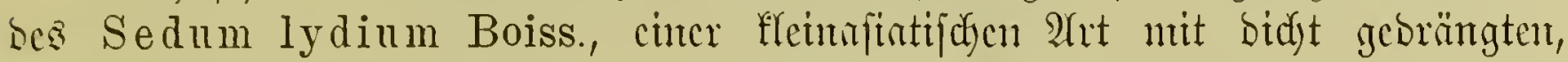
linereren, fajt ftichrumben, an ber Brfis geöhrten unto an ber Spitze mit bewaff=

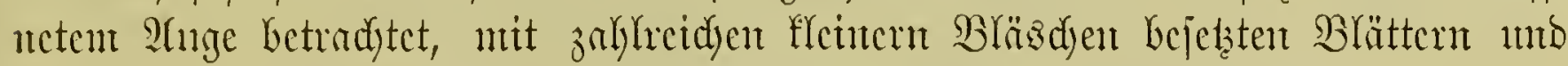

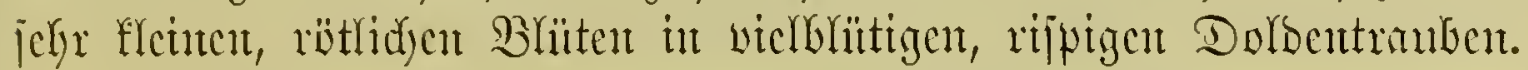

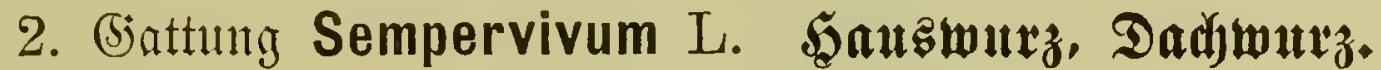

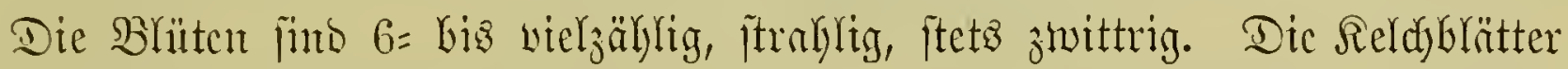

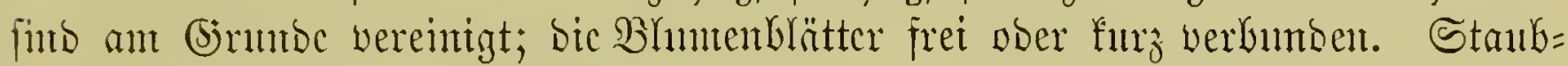

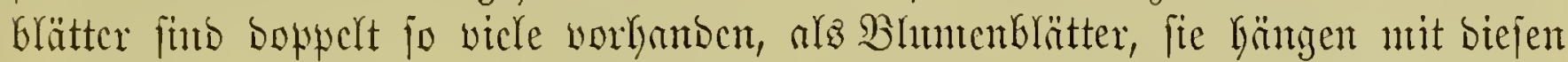

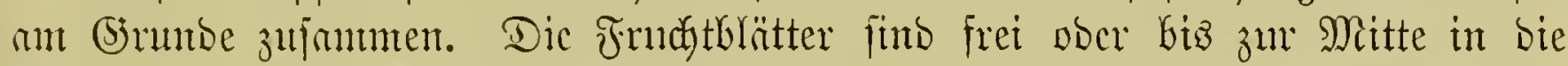

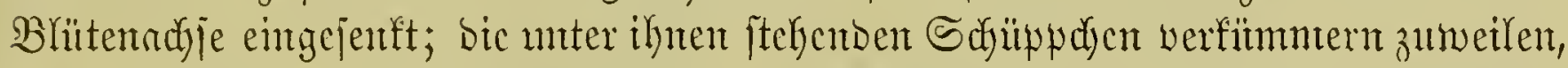

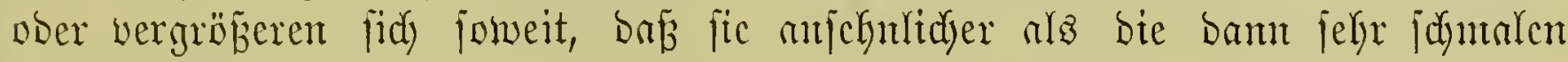
Błhımenblätter werben.

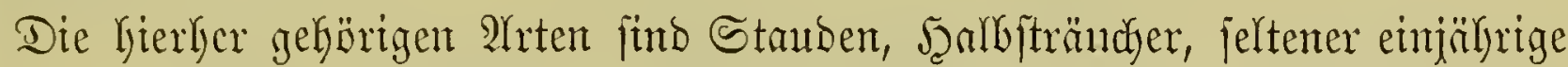

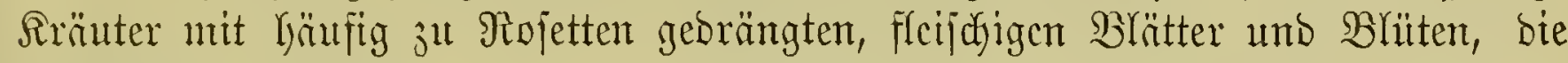

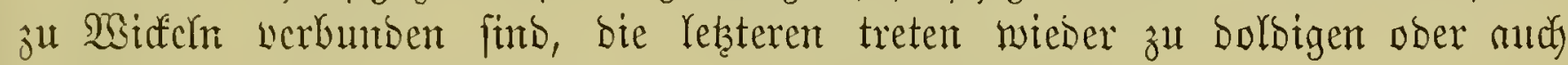
pyramibrlen Rijpen juj anmen.

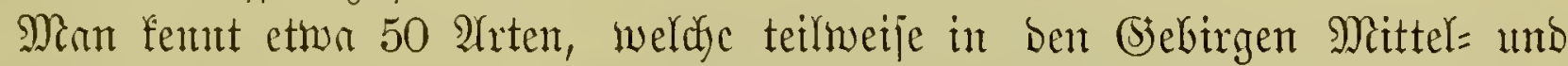

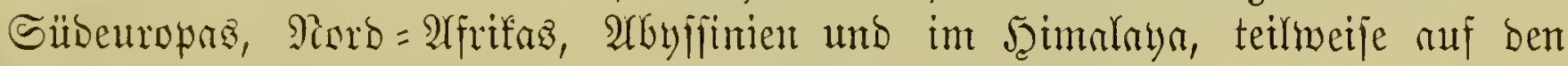
Simarifden Smieln utmb auf Mabcira wadyjen.

Die un mir als lekzte Seftion bcibelgaltene (5ruppe Monanthes (Petrophyes Webb) wirb gegenwärtig allgemcin als bcjontore (5)attung rufgefantst.

Der Mame ijt ms bon lateinilden. SGorten semper, inmer unt vivus rebenbig zujammengejebzt.

\section{S丸lïfiel für die befdriebenen Zrten.}

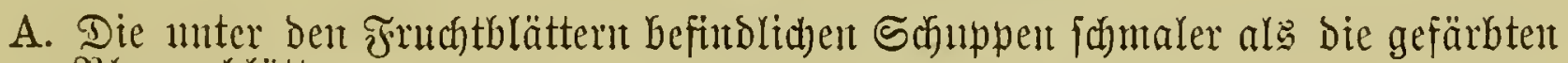
Błlumenblätter.

a) Bliiten $6=$ bỉ $20 z$ ählig.

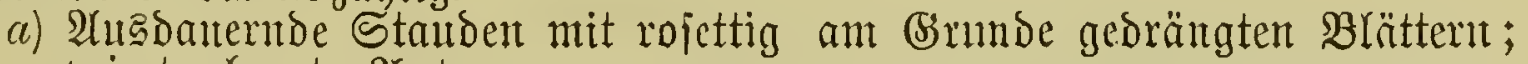
winterharte arten.

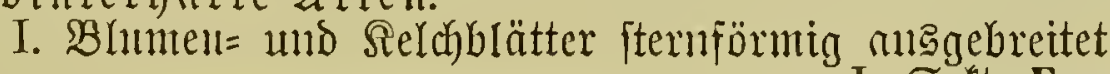

1. Blüten rot.

I. Seft. Eusempervivum.

* Silätter getwimpert, an ber Spice weder gebartet noch jpimntwebia.

$\Delta$ Blätter fonft anf beiben Seiten kahl

1. (sinppe Ciliata.

o Blätter mit Dentficher bramule: EptBęe, grof

1. S. tectorum $L$.

oo $\mathfrak{B l a ̈ t t e r ~ o h n t e ~ E n i k e , ~ f l c i n ~} 2$ 2. S. Funckii $F . B r$. 


\section{$\Delta\lrcorner$ Blätter anf beioen Seiten brüiig}

2. (Srutppe Pubescentia.

3. S. montanum Linn.

:m: Blätter gewimpert an der Spibe gebartet

3. (Siruppe Barbatula.

4. S. fimbriatum Lehm. $\iota$. Sclensp.

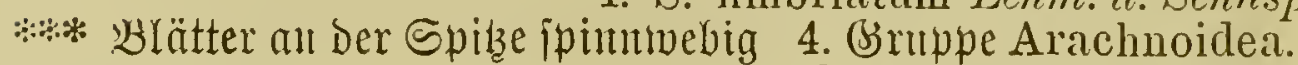

5. S. arachnoideum Linn.

2. Slütent gelb.

5. Siruppe Chrysantha.

* slüten von $2,8-3,5 \mathrm{~cm}$ Durdmeijer, Etaubblätter halb fo lang wie bie Blmutenblätter, Frudbtblätter fïrzer alg die Staubfäben.

6. S. grandiflorum Hare.

Blïten $2-2,5 \mathrm{~cm}$ im Durdmeijer, Staubblätter fait jo lang wie die Blumenblätter, Fruthtblätter fo lant als dic - Stumbfäden.

7. S. ruthenicum Koch.

II. Błumen= แnd Sieldblättter gloctenförmig; $\mathfrak{B l u ̈ t e n ~ g e l b ~}$

II. Seftion Jovis barba.

1. Blïten groß̉, $\mathfrak{S l u m e n b l a ̈ t t e r ~ a ı ~ b e r ~ E p i ß ̨ e ~ g e m i m m e r t . ~}$ * Șunge Яiofetten fitgelförmig surnge Rojetten niaht Lugelig

8. S. soboliferum Sims. 9. S. hirtum Linn.

2. Blïten flein, Shlumenblätter am Stande nidht gewimpert

10. S. Heuffelii Schott.

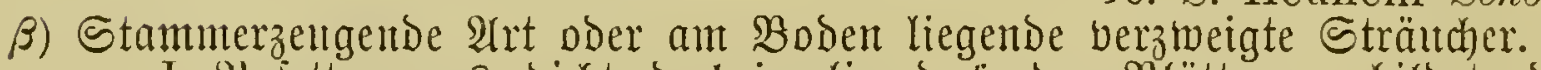

I. Ftojetten aus bicht Dachiegelig Decfenden Blättern gebildet, die fleijhig, aber auf bem Stuten frach futd. Dieje und die folgende Seftion ertragen unjeren gainter uidht.

\section{Seft. Aeonium.}

1. Hojetter flach oder conber

11. S. tabuliforme Hau:

2. Pojetten vertieft, Blätter groß (bis $10 \mathrm{~cm}$ lang) meichbarig; Stamm einfach oder mur jelyr wenig berzmeigt

12. S. canariense Limn.

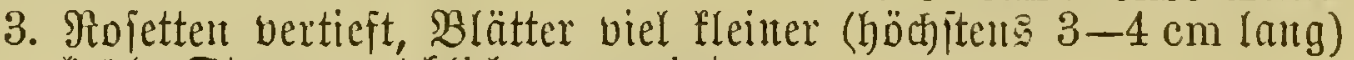
fabl; Etantm reichlich verzmeigt.

* Silätter umgefehrt eiförmig

** Blätter feilförntig

13. S. ciliatum Willd.

II. S) Tojetten locferer (mie bei Sempervivim mont

dem gïldét conver

1. $\mathfrak{B l a ̈ t t e r ~ g e w i n t p e r t ~}$

2. Şlätter fahl
IV. Eeft. Goochia.

15. S. caespitosum Chr. Sm. 16. S. tortuosum Ait.

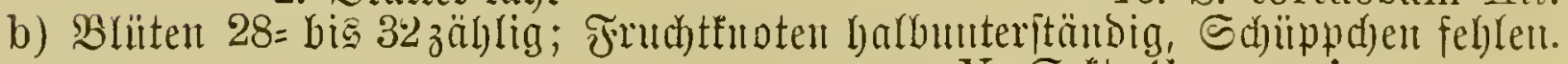

$\checkmark$. Eeft. Greenovia.

17. S. aureum Chr. Sin.

B. Sdjüppd)en unter ben Frud)tblättern größer ale bie Błmmenblätter, gefärbt,

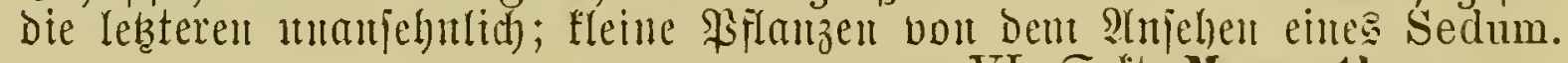

\section{Geft. Monanthes.}

18. S. Monanthes Ait.

\section{Winterharte 2lrten.}

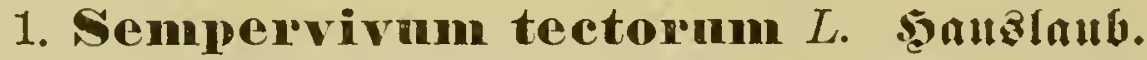

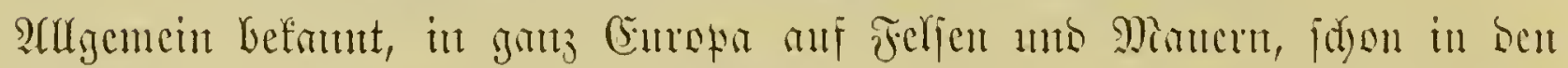

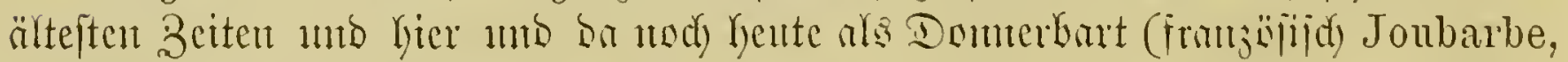

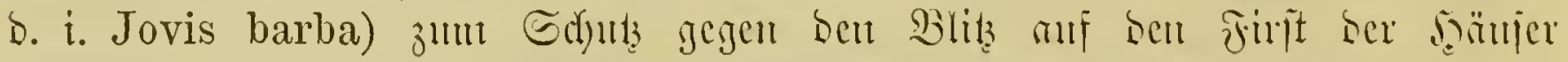

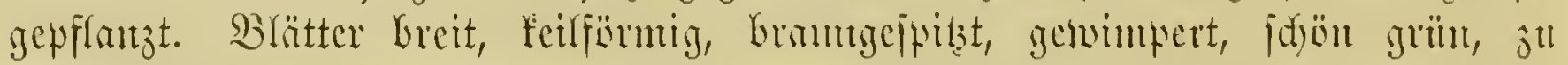

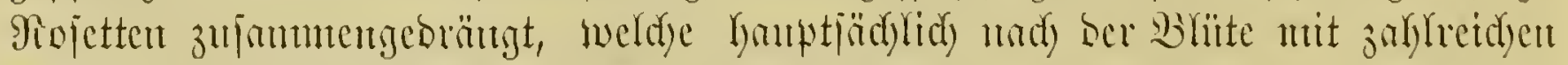

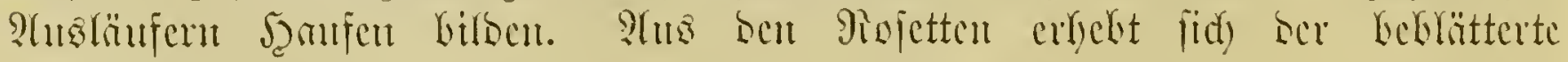

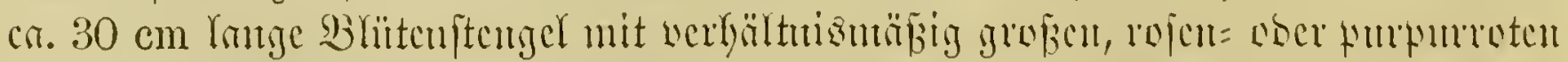

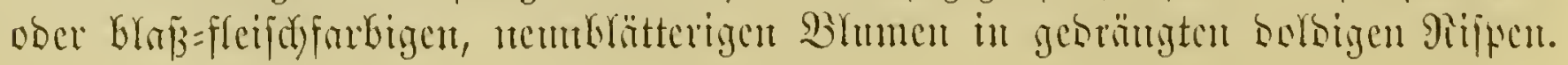




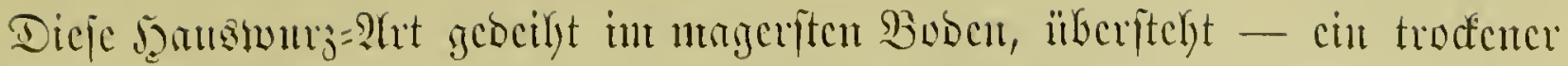

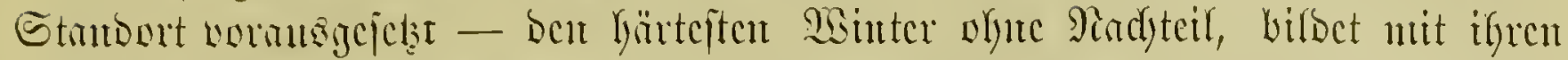

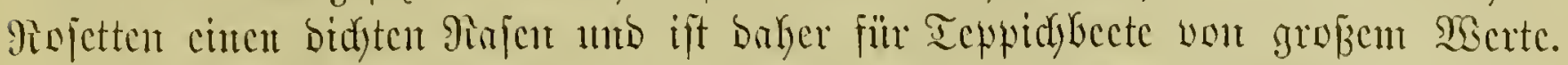

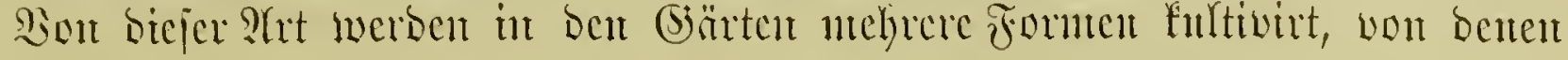

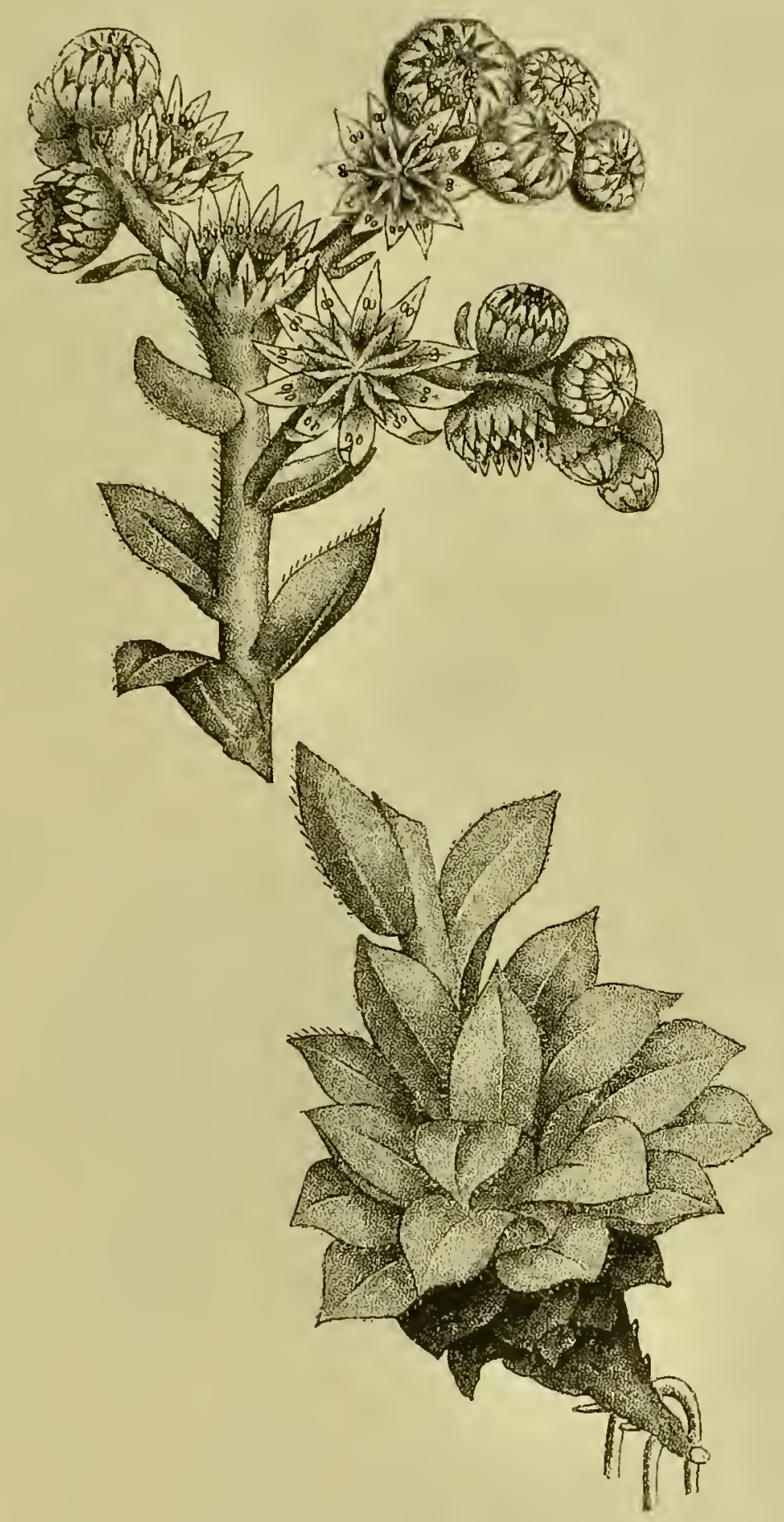

Fig. 33. Sempervivun tectorum Liun. Şauslaub.

a) var. bicolor burd) helfgrüne Brätter mit fdarfabgejeşter, braner Spitze;

b) var. violascens burd) unten vivlette, wben grangrüne Brätter gefenuzcichuet finto. (Fig. 33.)

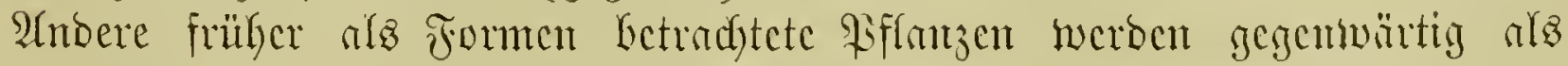
bejonbcre 2frten betradjet, namentfidy gilt bas vou

Sempervivum atlanticum Bak., bie verhältniantäjig fchl grofic, vofa, wcipgermocte BGütert Geftrat, 
Sempervivum Schottii Bak. (S. acuminatum Schott) mit länger jugeipiżten B Bättern,

Sempervivum glaucum Tenore mit Grangrünen Brättern,

Sempervivum triste Hort. mit bunfelgrünen, ins Fompume gefenden Brättern,

Sempervivum Boutignyanum Bill. et Gren. (S. Mettenianum

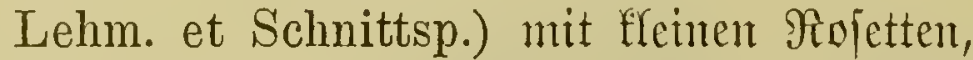

Sempervivum calcareum Jord. mit präd)tig Glaugrünen Brättern, bie braun z̆ugefpizzt finto.

\section{Sempervivum Fumckii $F$. Brann.}

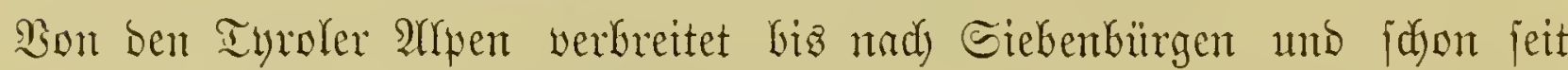
Yanger Beit in Rultur. Rojetten bis $5 \mathrm{~cm}$ im Durdemeffer, umgeben von einem

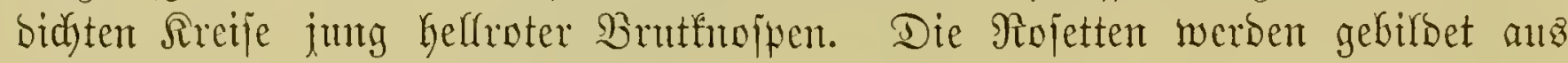

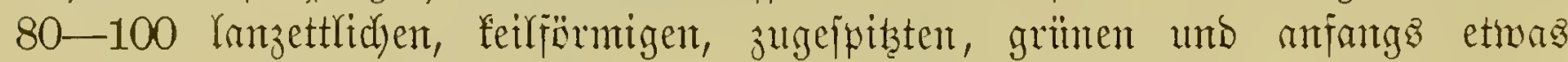
Gehanten, fpäter fablen, bidjt unb lang getwimperten Brättern, von benen bie

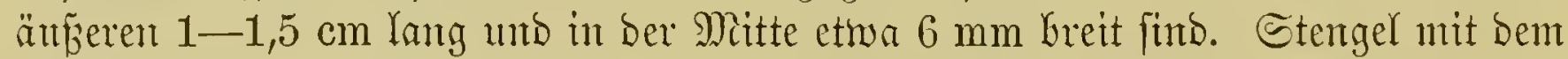

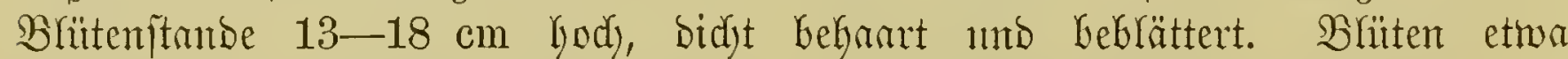

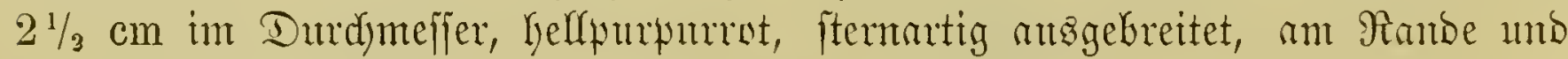

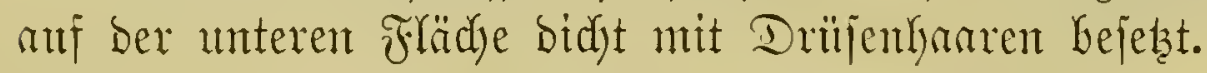

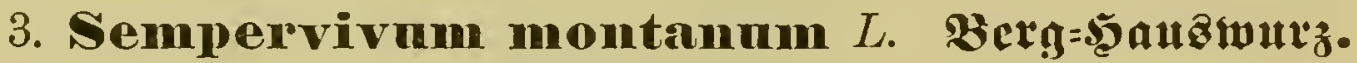

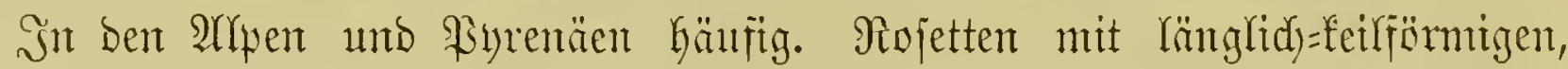

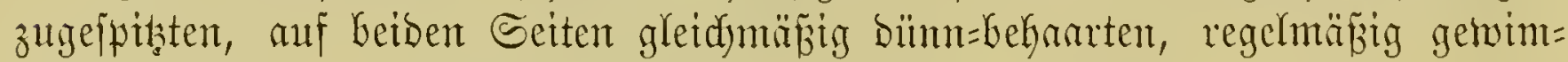
perten Blättern. Sm Minter fins bie Rojetten gejejtofien, int Sontmer aber

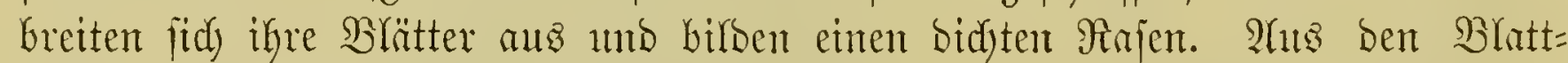
adjfeln treten nur wentige rote, behante $\mathfrak{H}$ eite von $1 \mathrm{~cm}$ Sänge, mit fleinen zur

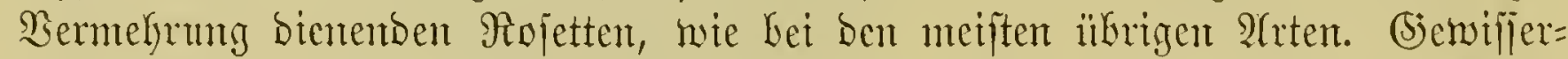
majen cine Miniaturangabe biejer Sht ijt Sempervivum pumilum M. B. (S. anomalum Hort.). Die briifenfarigen Rojetten laben einen Durdymejier von Gödjfens $2 \frac{1}{2} \mathrm{~cm}$, Deren än

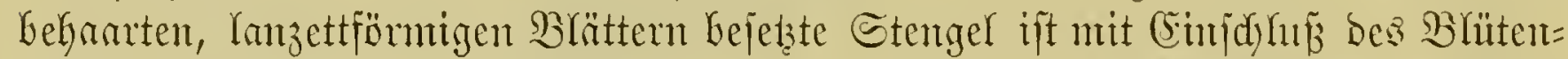

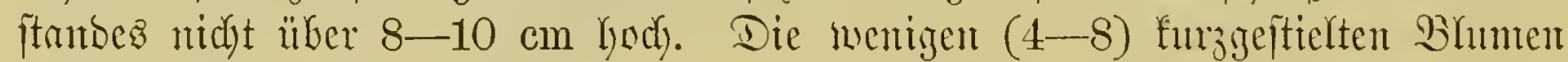

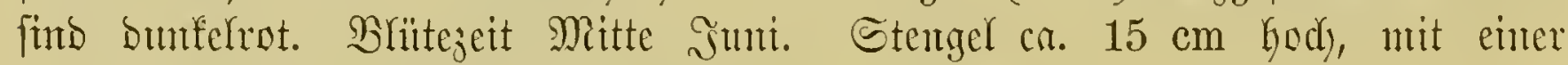

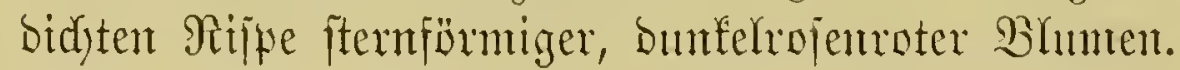

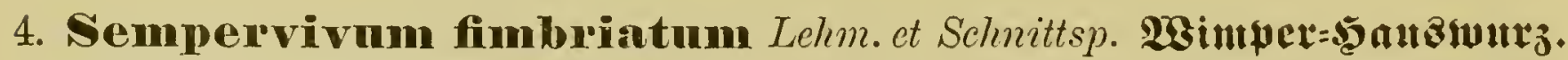

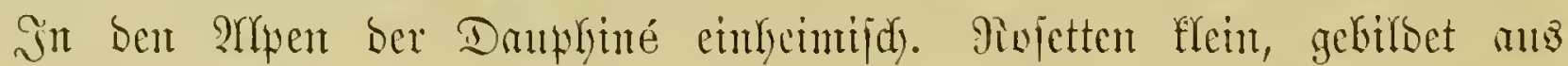

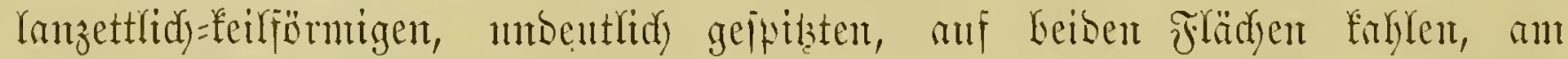

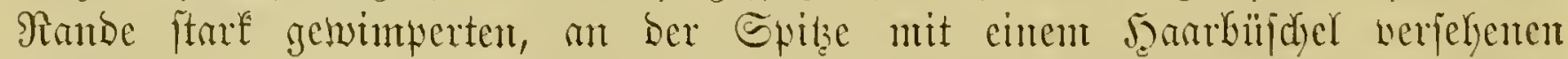

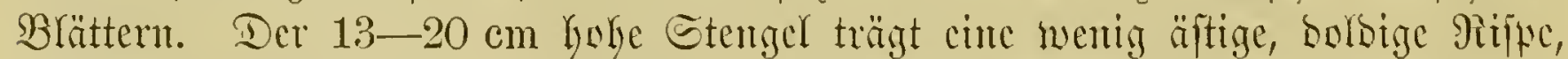

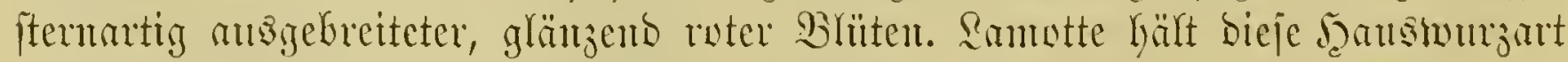
für cinten Bajtato won Sempervivum arachnoideum unt S. montanum.

Sin bie (jormppe ber Barbatula gefgirt andy S. Maggridgei Hook. fil., bie in Englnots fultiviert wirb. 


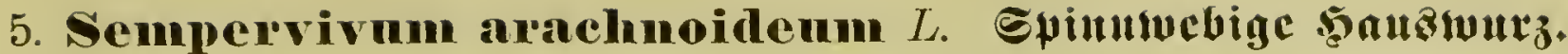

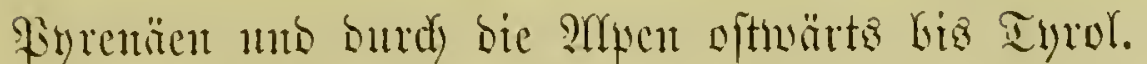

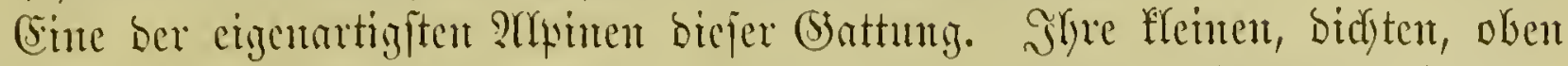

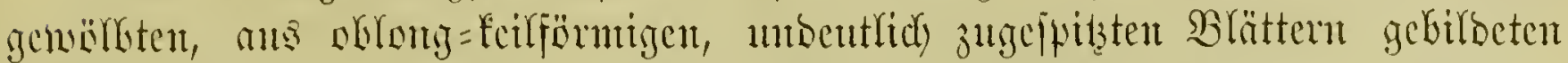

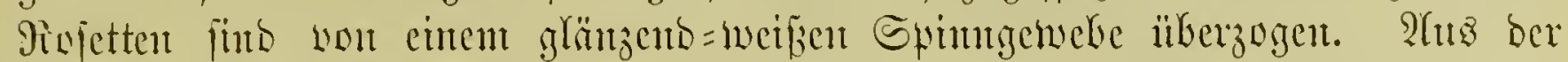

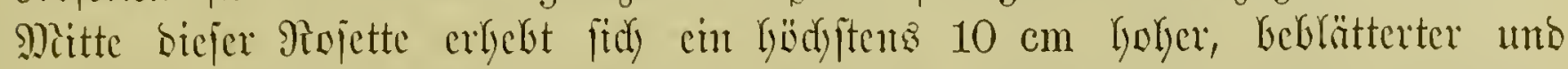
Gebanter, oben in che borbige gifpe jerteilter Etengel mit tiefroten Bhamen.

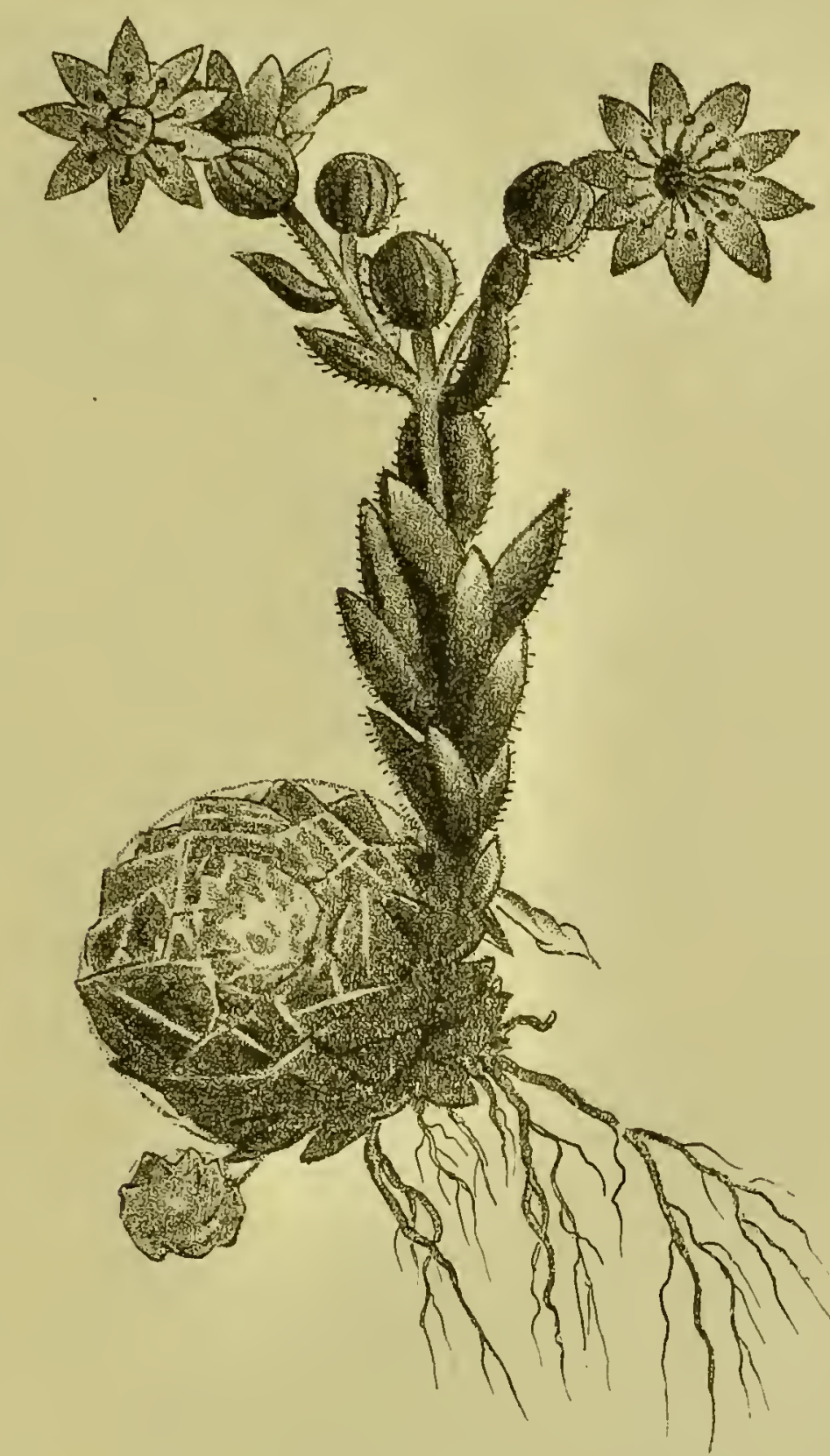

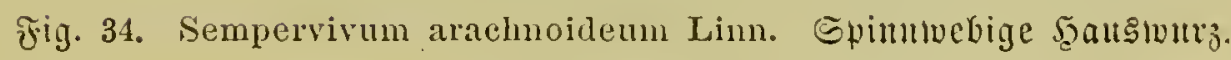

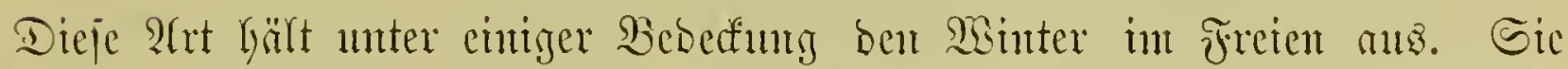

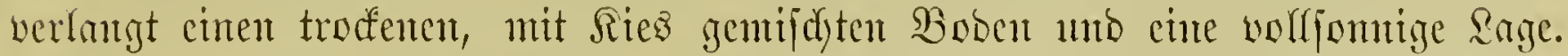
Der gejpinnjtartige Heberzug, ber fie fo intereffant madjt, cuttwiffelt fid int

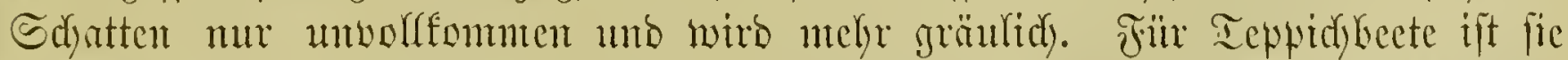

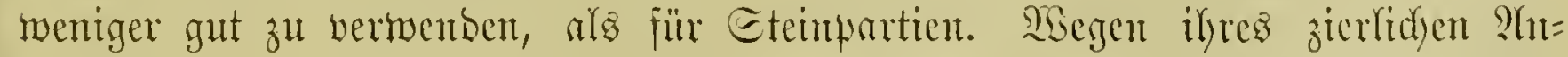

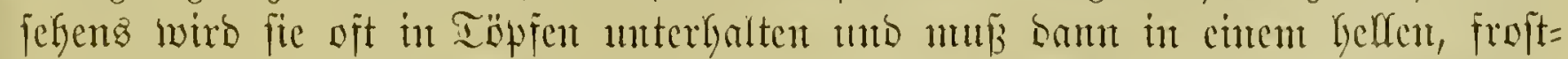

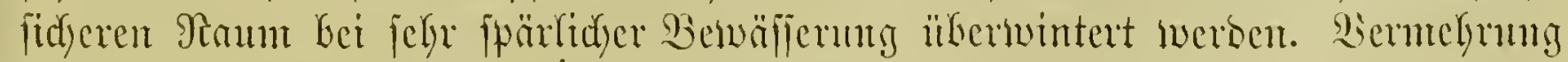

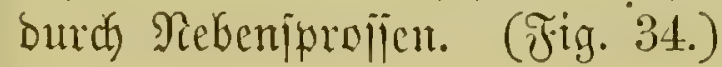




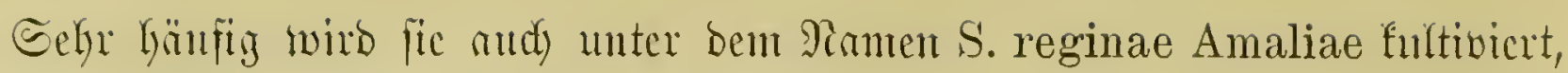
bic unten bei S. hirtum crwähynt werben wirb; S. Laggeri Hort. unt S. tomentosum Lehm. et Schnittsp. find nur Formen bicjer 2lrt.

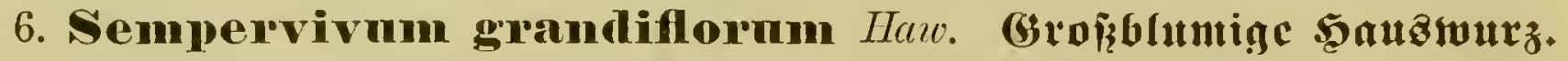

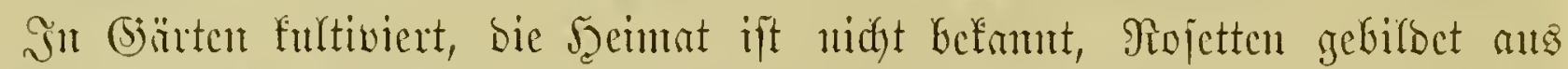

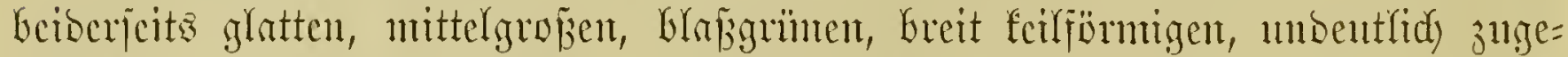

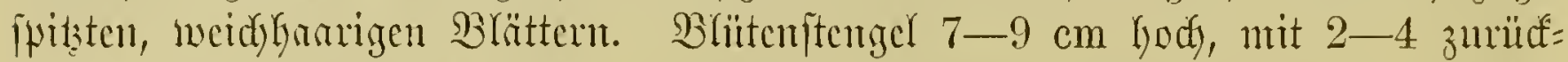

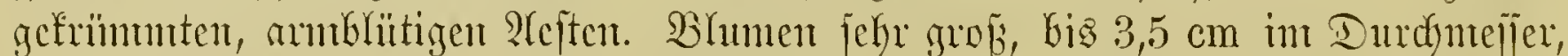

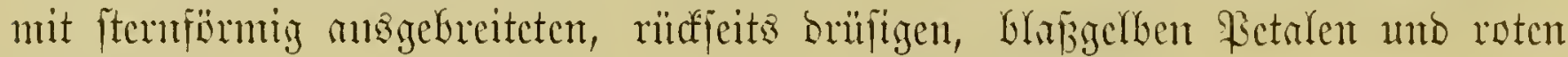
Strubfïben.

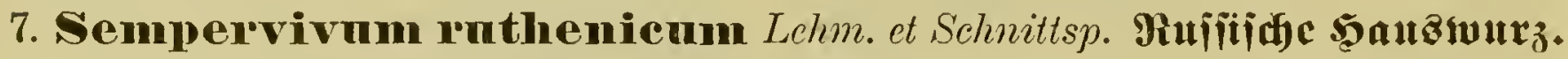

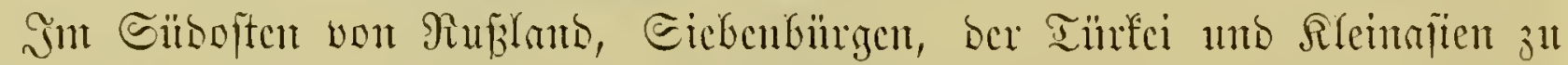

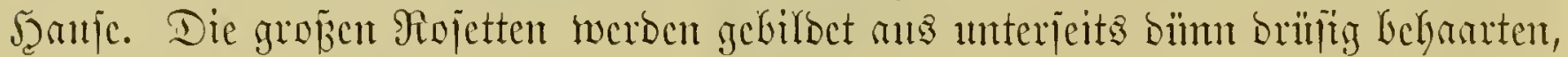

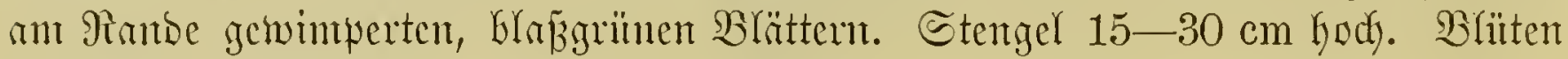
ftemiörmig, Glabgelb.

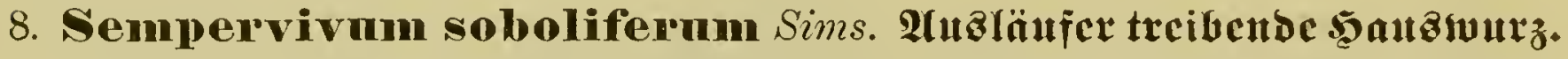

In ben 2Yhen, ben Ricjengebirge, nber and in ber norbbentidyen Tiejebene

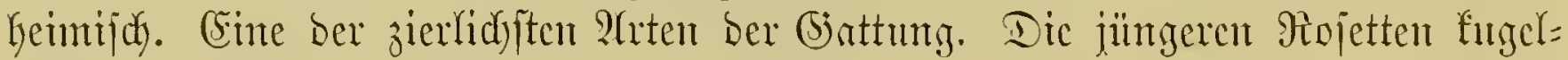

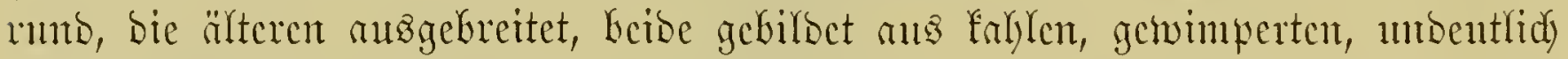

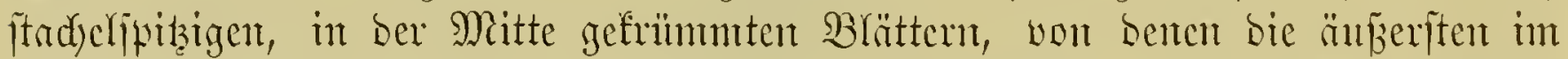

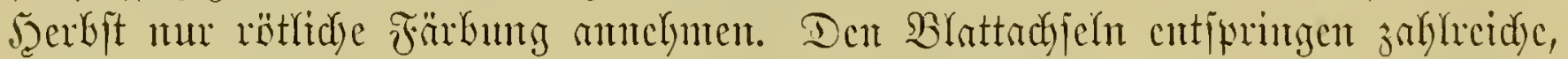

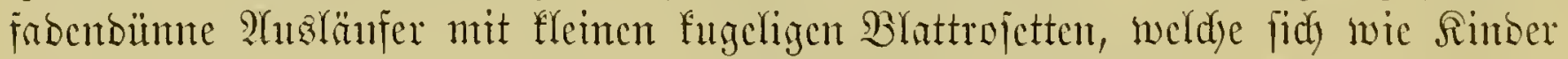

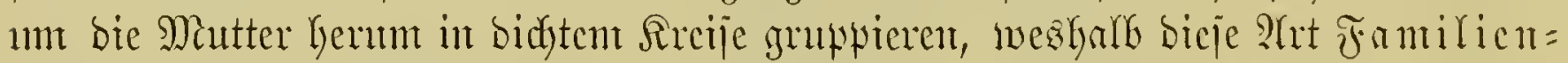

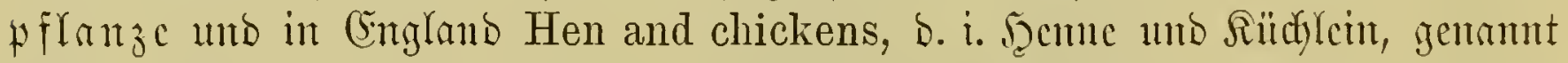
mirb. Später fälnt bie junge Brunt ab mo murjelt jidy im Boben cint. Sie ift

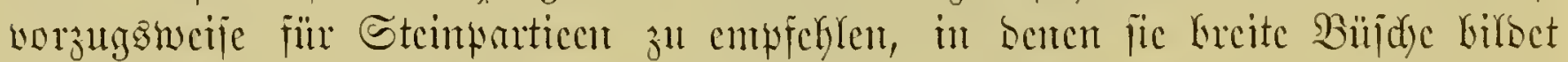

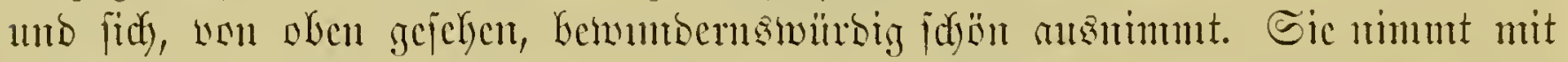

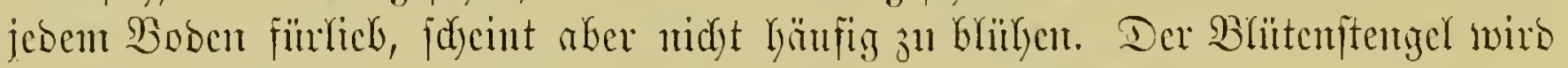

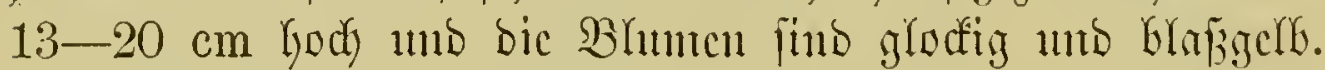

Berwanbt mit ify ift Sempervivum arenarium Koch, in bon 2 repen

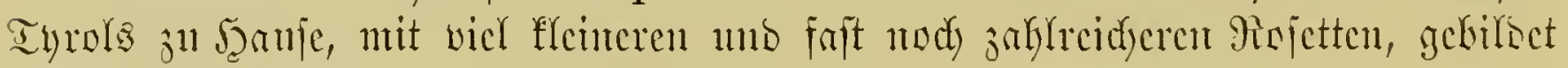

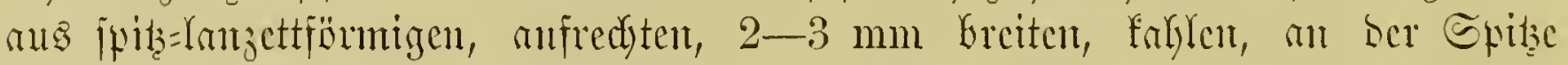

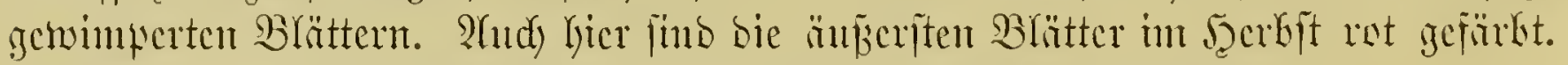
Stengel $13-20 \mathrm{~cm}$ hodb, mit glodenförmigen, Gedfgelfen Bhliten.

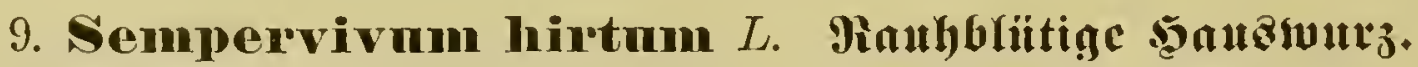

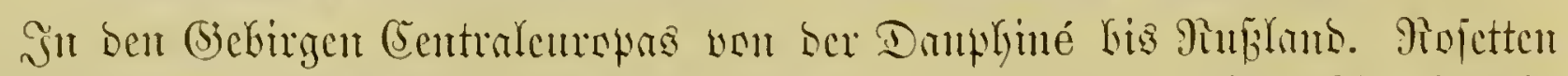
2,2-3 cm in Durdyeffer, bie jungen midyt wie fei ber worigen ?ret fugetig

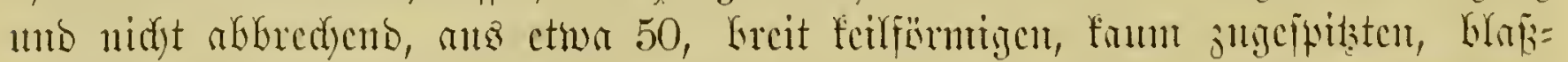

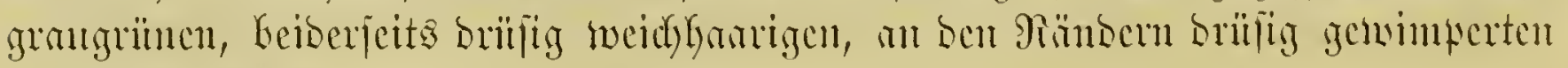
Brättern gebilóst.

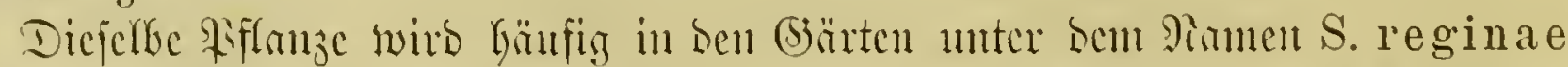

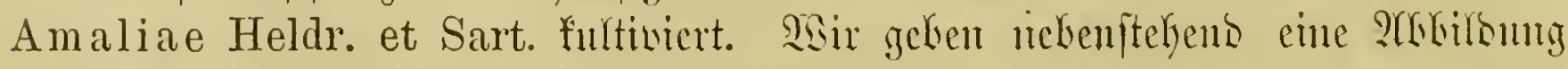




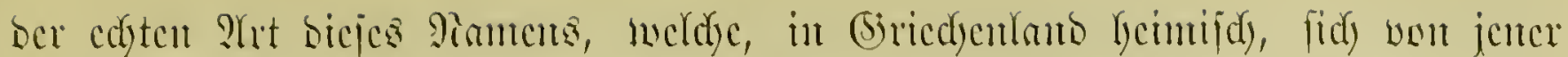

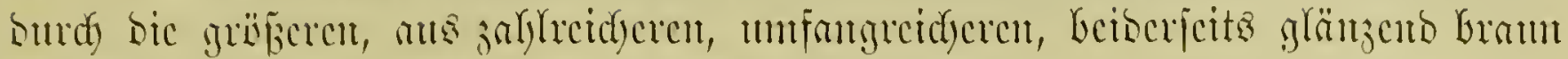

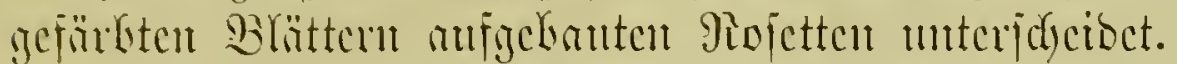

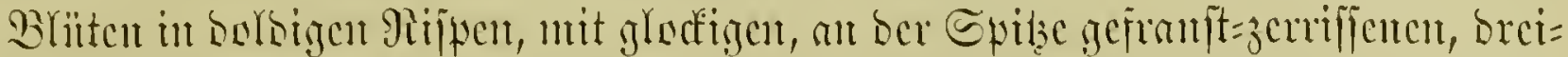

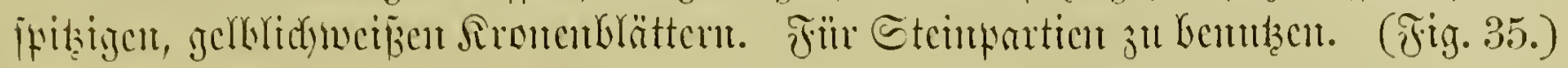

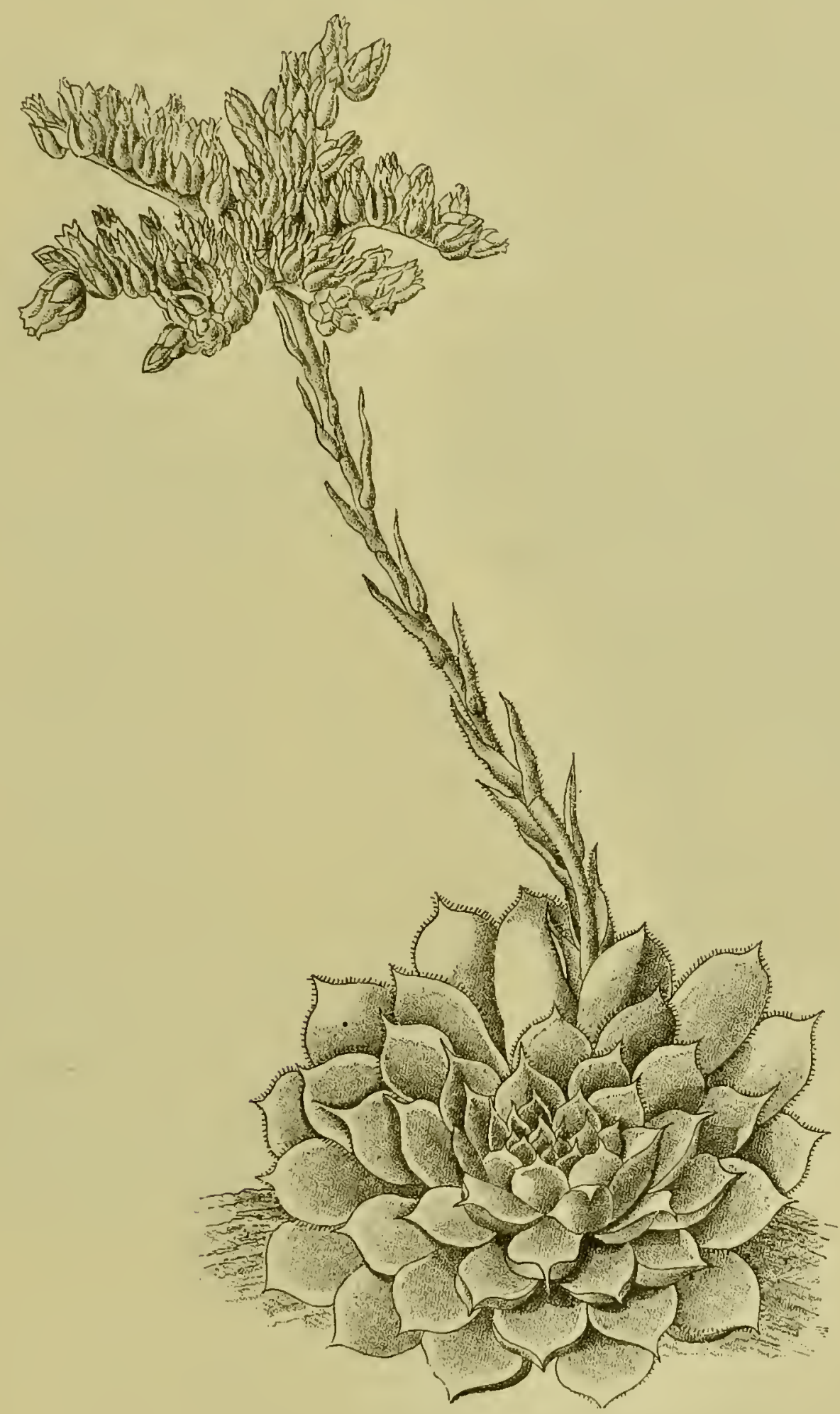

Fig. 35. Sempervivum Reginae Amaliae Heldr, et Sart.

Daz jä̈uc Sempervivum cornutum Lehm. et Schnittsp. itcht bicjer

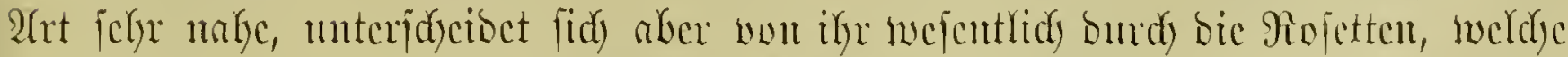

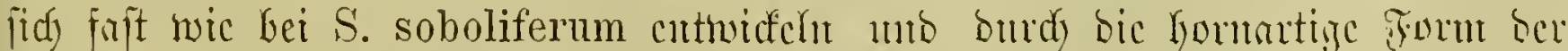

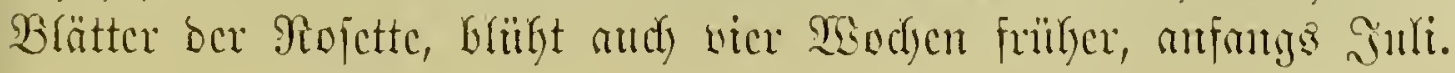




\section{Sempervivum Henffelii Schott.}

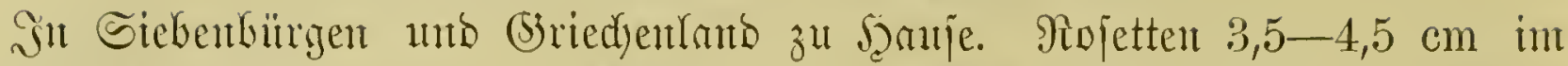
Dudymefler, gebilset ats breit feiförmigen, bentlidy zugeipibten, oben fablen,

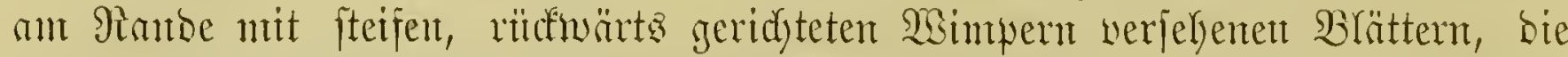
au ber Spibe bis zur Mitte furumbram gefärbt find. Der $13-15 \mathrm{~cm}$ lobe,

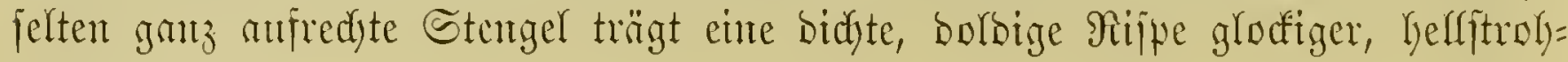
gerber Britten.

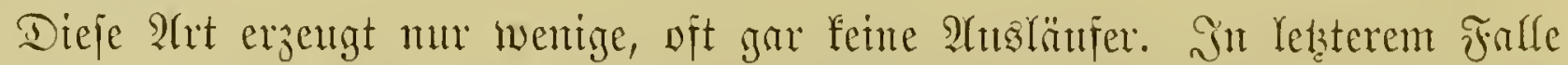

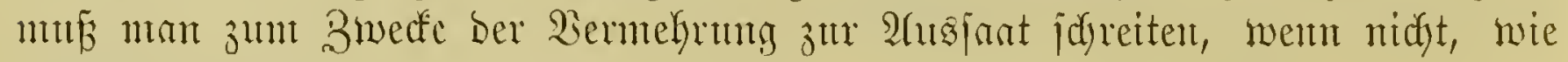

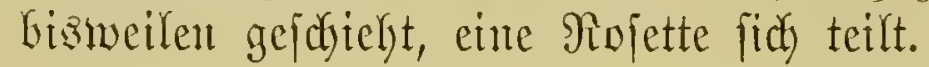

\section{Im Glashauje ju überwinternde 2rrten.}

\section{Sempervivmm tabuliforme Haw. Gdjcibutsaußnurz.}

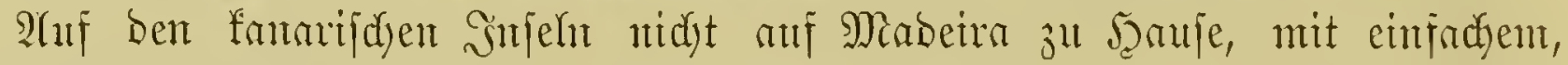

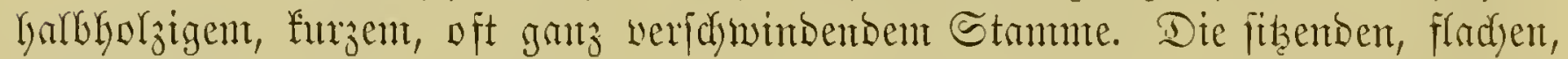

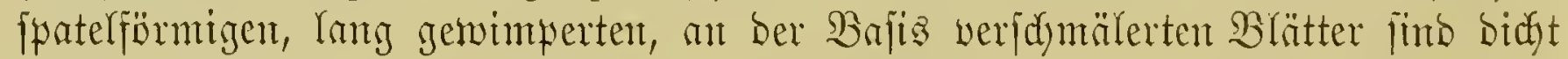
zulanmengebrängt tmb birben cine jueibenförmige ober gemölbte Rojette won

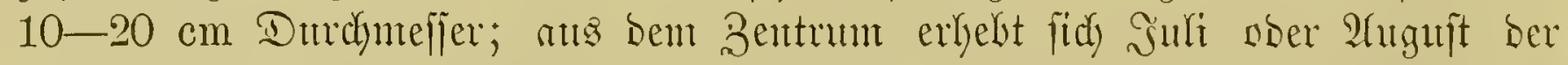

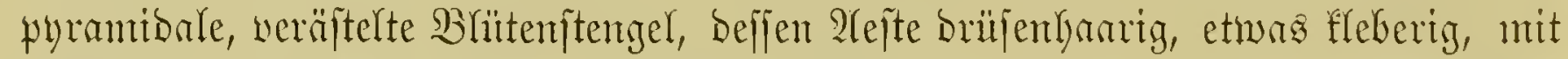
zeritreuten, fleidjigen, biffen Brätten bejekst füb und anf ifrer Eprise cine

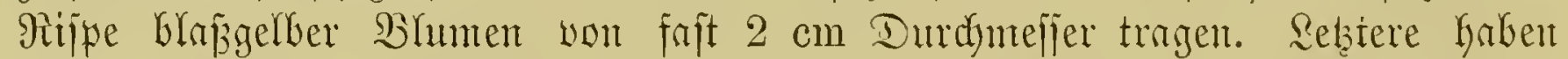

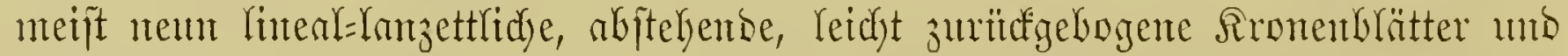

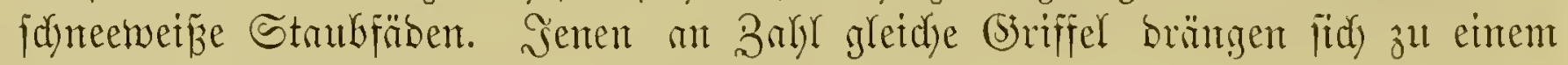

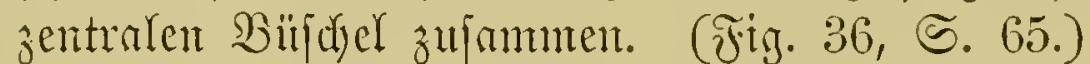

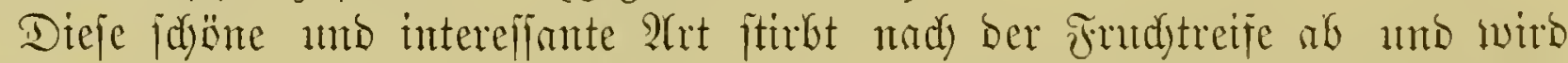
bann in temperterten Miftbeete ans Smen nen erjogen, fan aber atud gleid

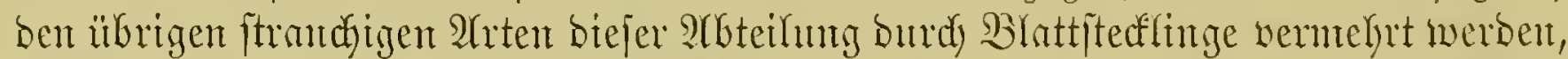
weldye an ber Bafiz Triebe entwidelu, bie man ablibjt und einjeln in flente

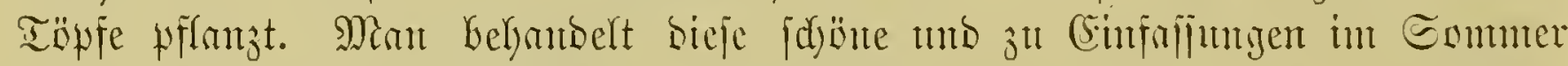

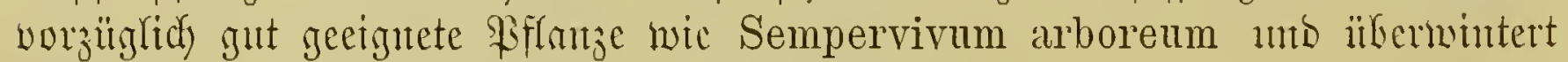
fie bei einer Tentperatu won $+4-6^{0} \mathrm{R}$.

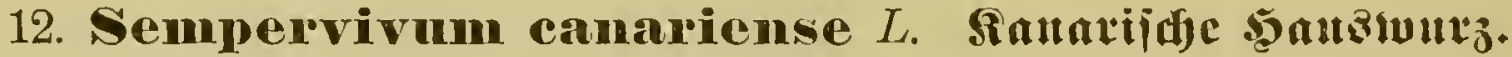

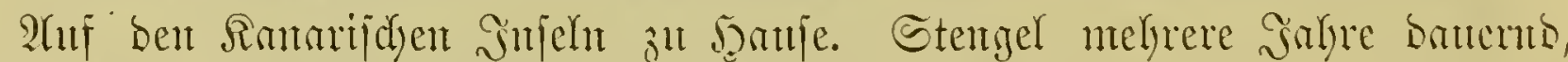

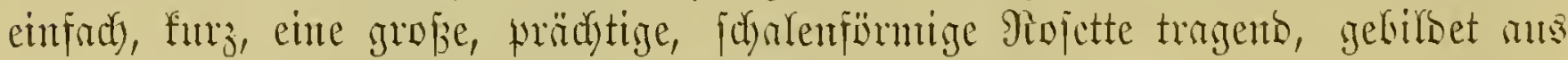

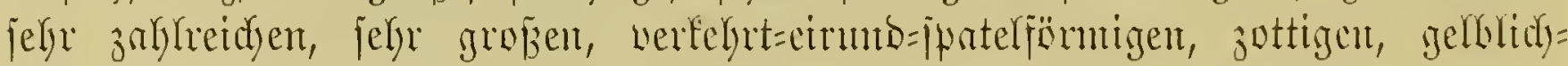

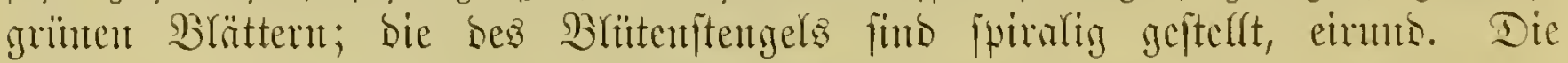

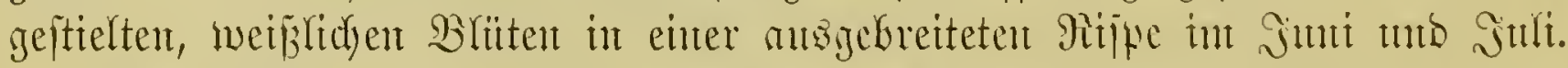

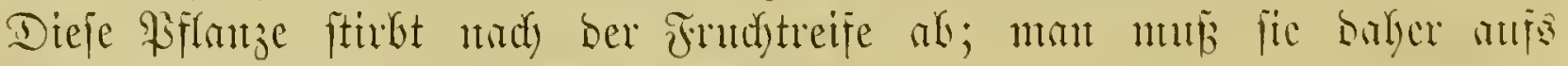
nene ans ben gemontenen Ganten wermebrut.

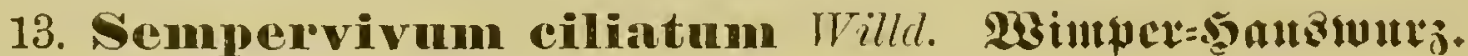

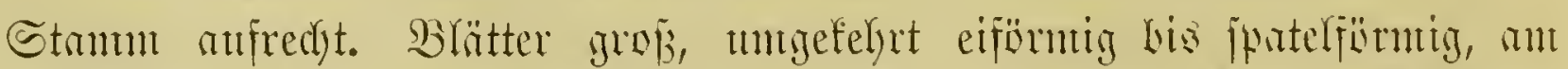
(5)

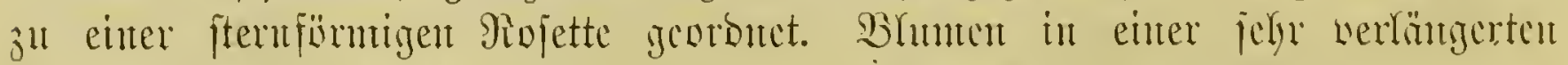

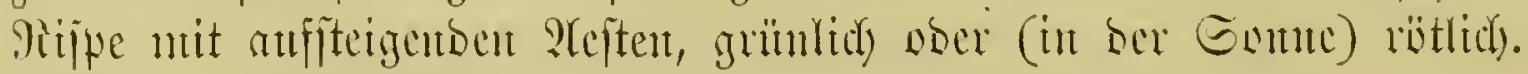




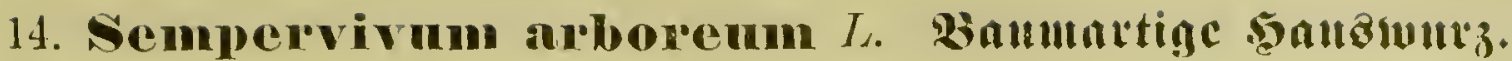

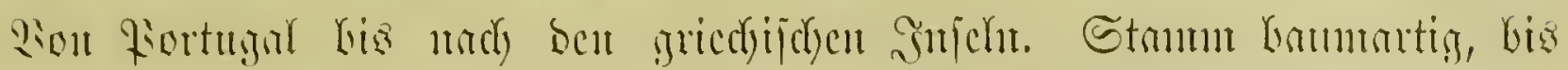

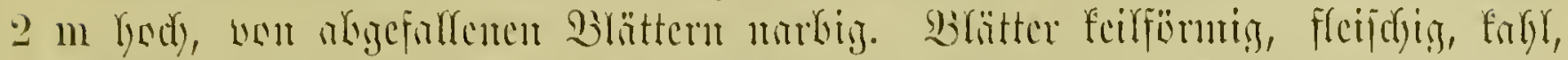

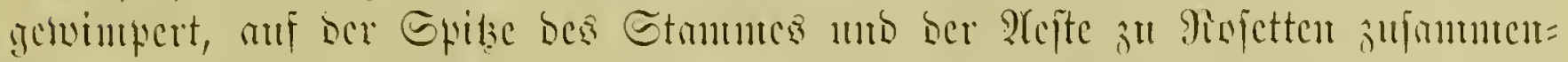

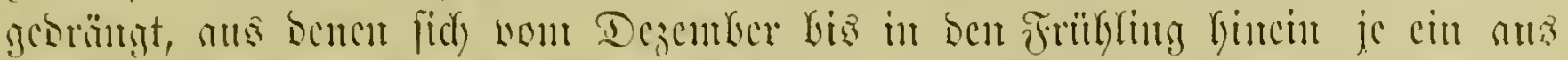

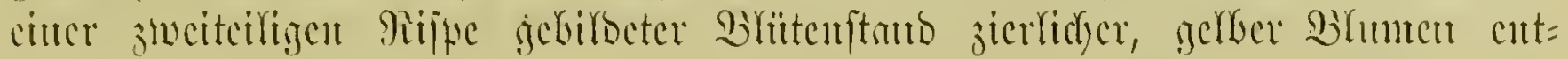
mirfeit.
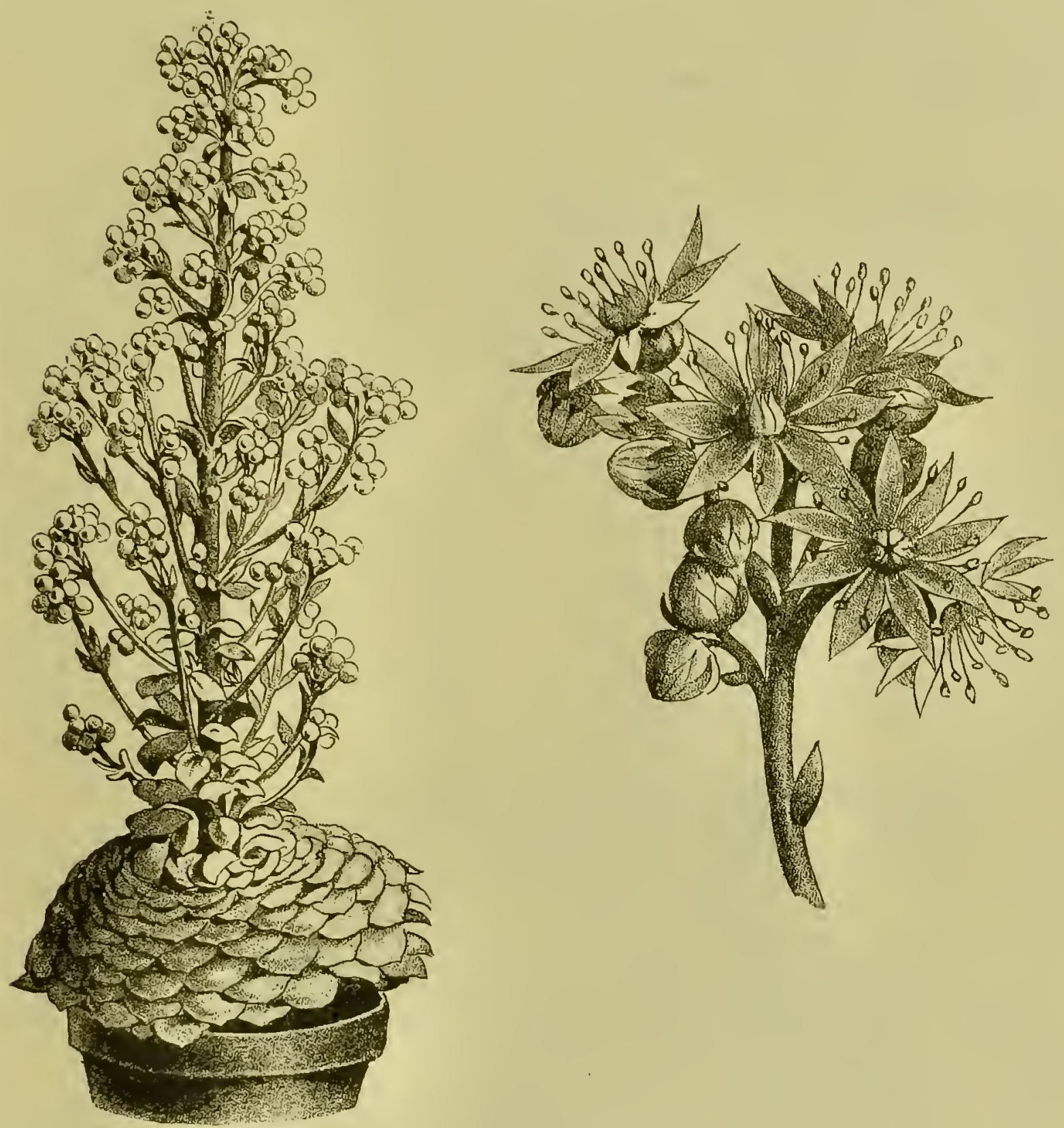

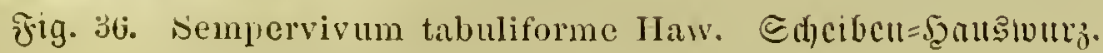

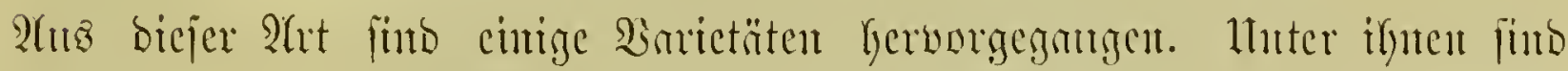

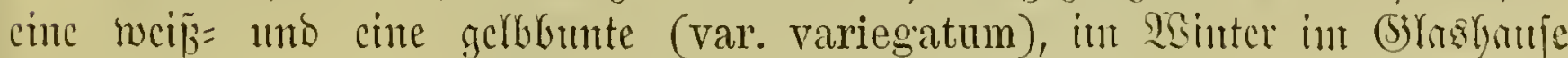

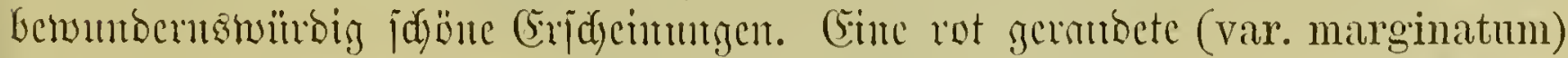
unb cine bunfelpunturote (var. atropurpureum), cignen fiét) für flcincre

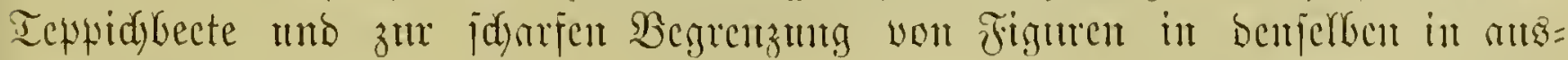
gezcidyucter 和ije.

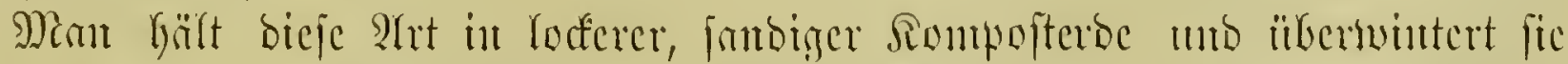

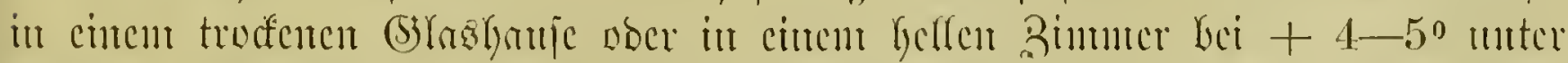

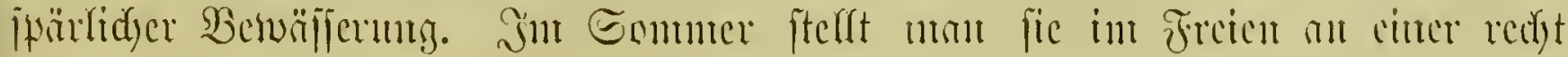




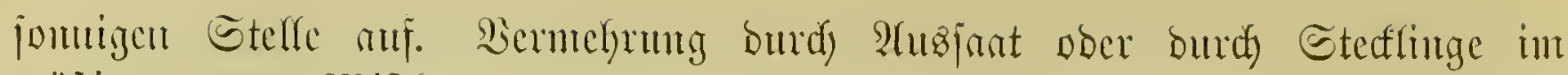
mï̈ig summen Miijteet.

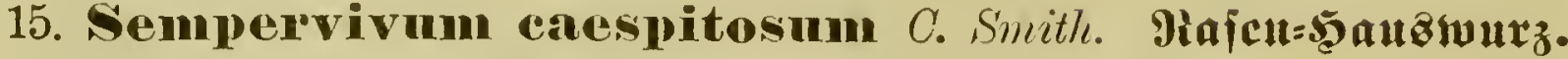

Sn ben (B)̈̈rten zientid) werbreitet, in benen es and bie 9iamen S. barbatum Horm. uns S. ciliare Haw. fülfrt. Der Strnum ift niebrig uno wädjit minoer

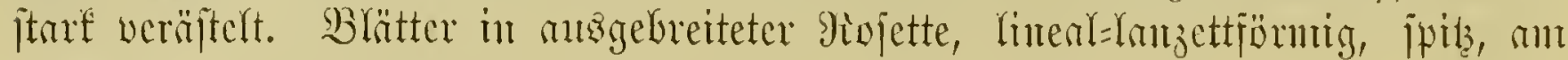

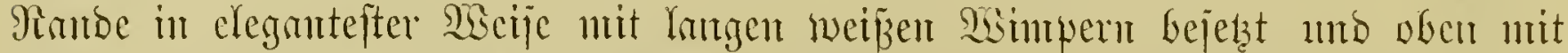

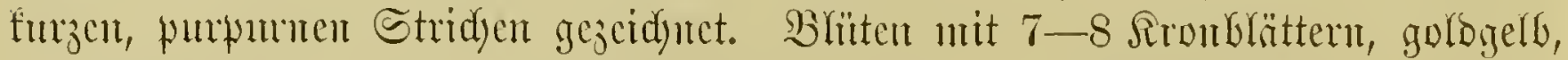

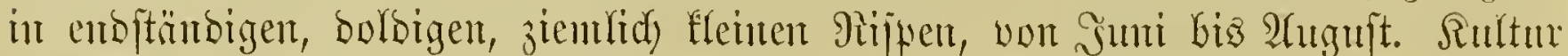
wie bei Sempervivum arboreum.

\section{Sempervivmm tortuosmm Ait. Dieljitengel-\$anawarz.}

2huf Tenteriffa, an jomnigen Feljen. Stengel holzig, gebrelyt, brüdyig, ftarf

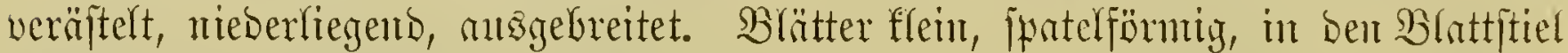

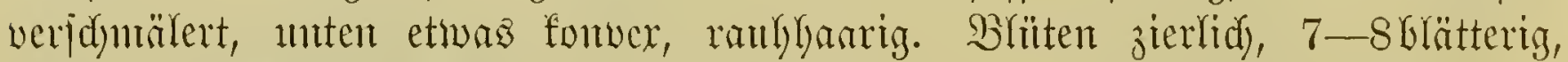

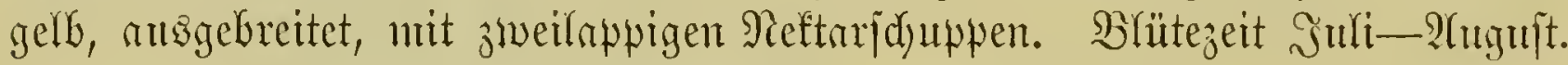

\section{Sempervivum anrenum C. Smith.}

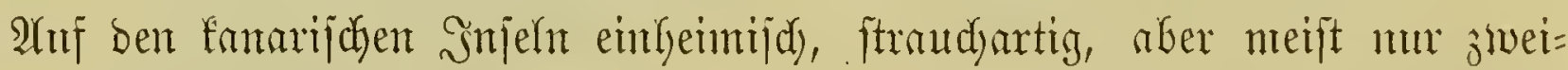
jülyrig. Die fpatelfürmigen, ftumpfen, ganzrandigen, Glat= ober graugrünen,

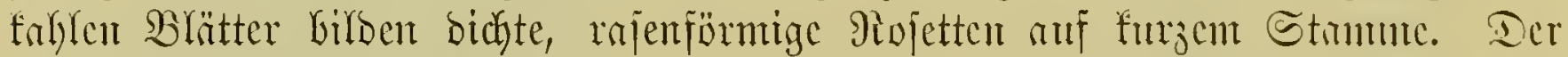

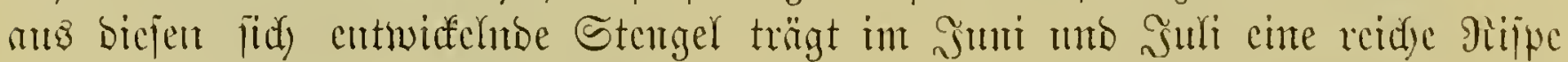

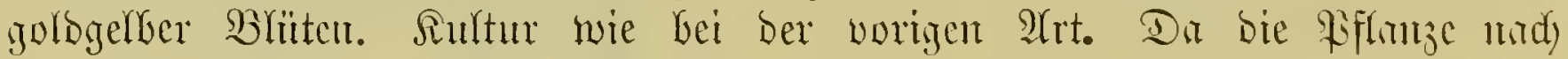

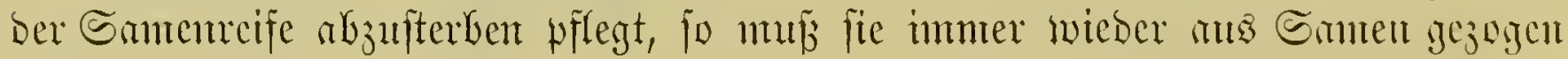
werben.

\section{Sempervivnm Monanthes Ait.}

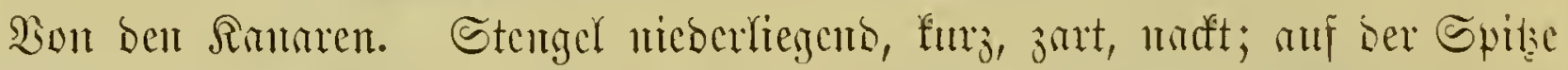

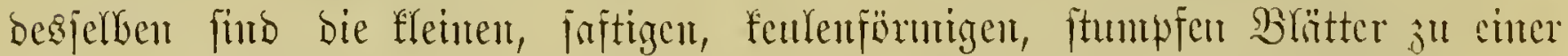

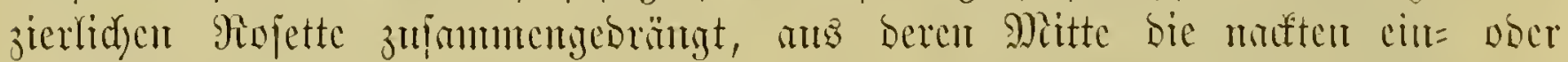

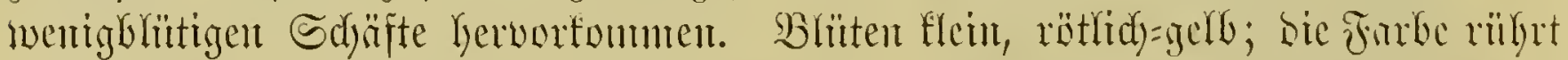

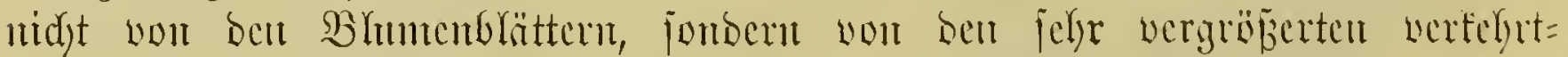

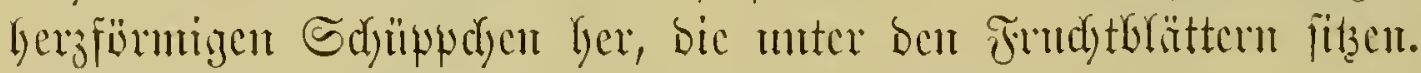

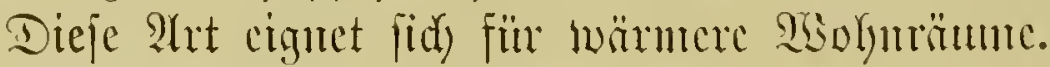

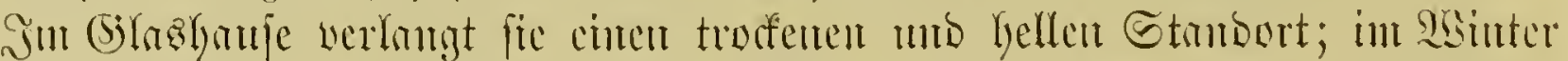

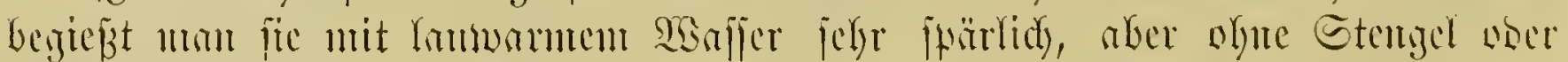

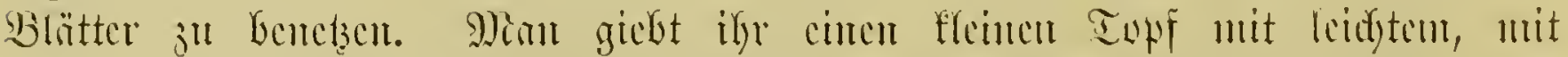

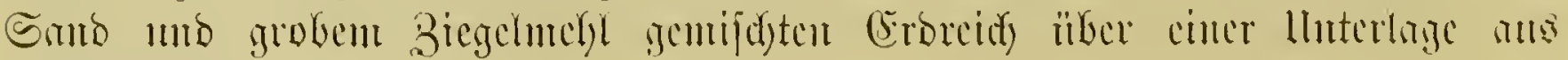
Inifidyerbert.

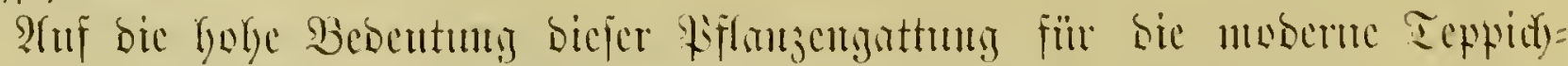

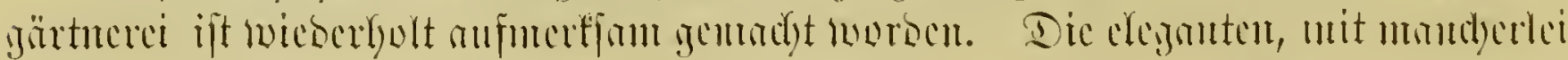

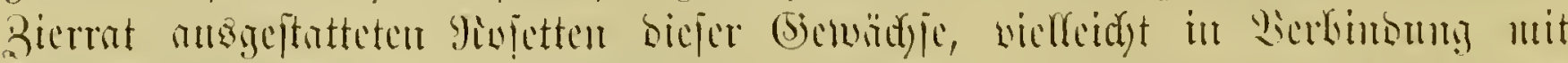

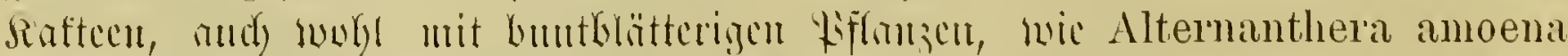
un atropurpurea, Iresine Verschatfeltii แm, Wallisii

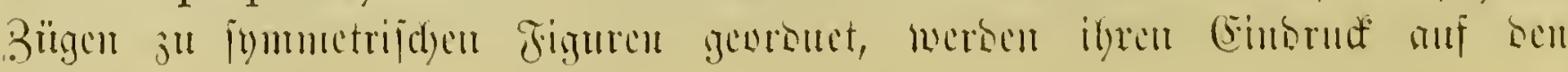




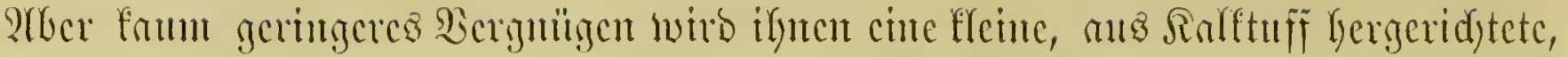

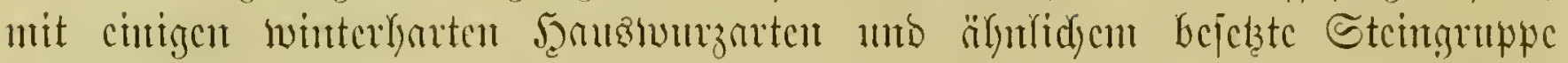

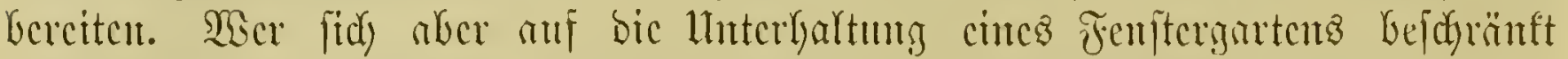

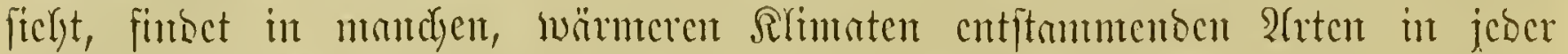

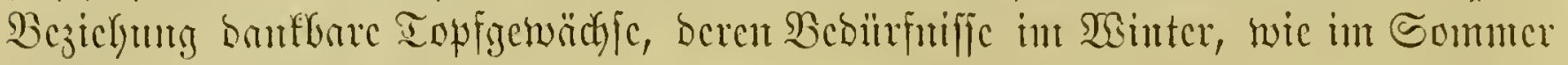
Ycidyt zut befricsigen futs.

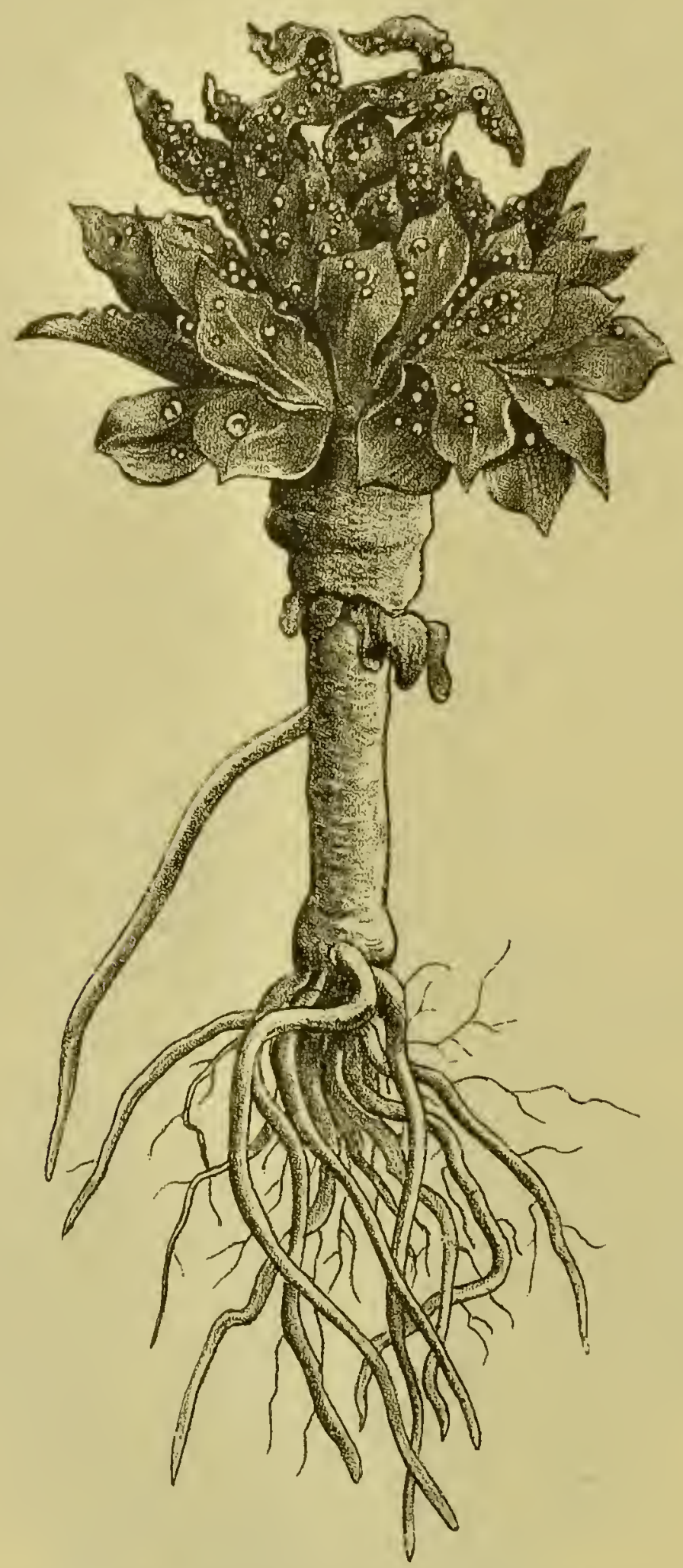

รig. 38. Sempervivum, von cincu Pilje bcjallen.

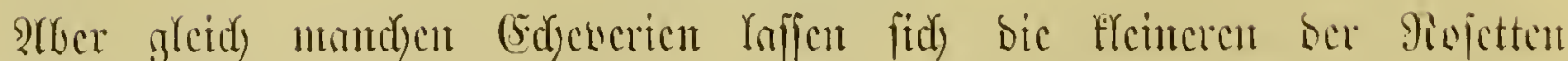

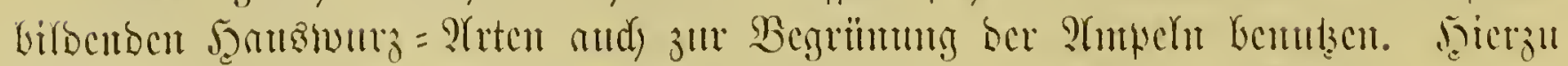

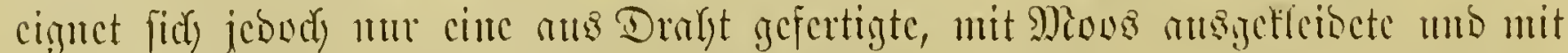

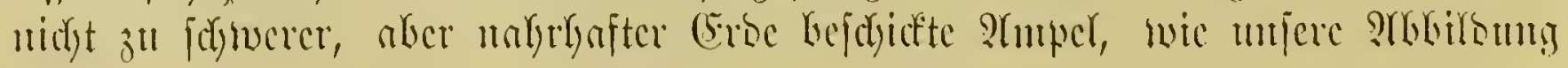




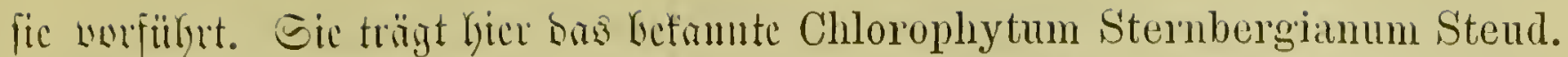
(Cordyline vivipara) und ift muffeibet nit ben ziexlidyen Siojetten bes Sempervivum calcareum Jord. (fiche unter S. tectorum). (テig. 37, ऽ. 67.)

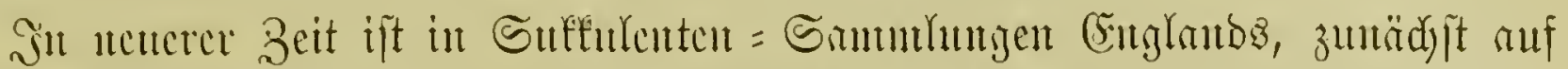

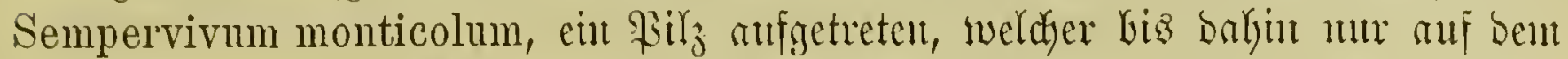

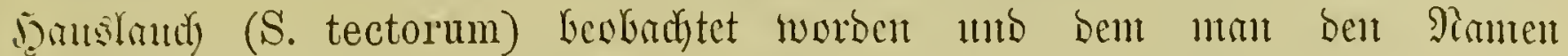
Endophyllum (Uredo) sempervivi gejeben hatte. Sin furzer Beil fielen ifm

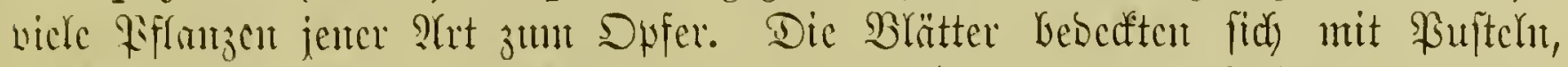
melften mo werbortut in fumer Beit. Jeber Teil ber toten Pflanzen war mit

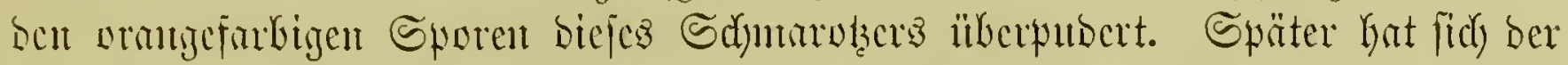

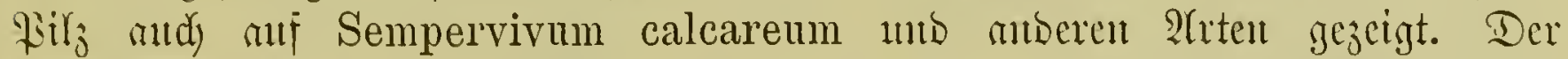

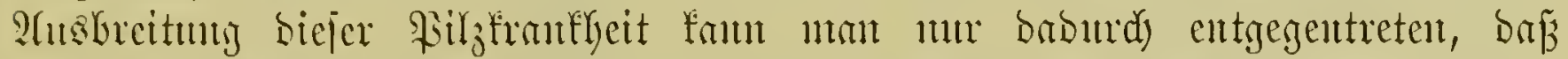

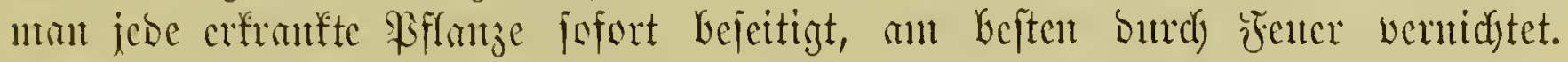

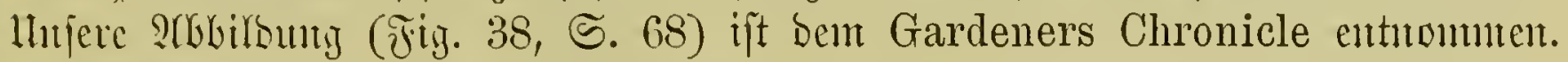

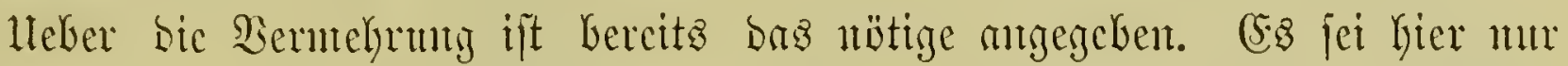

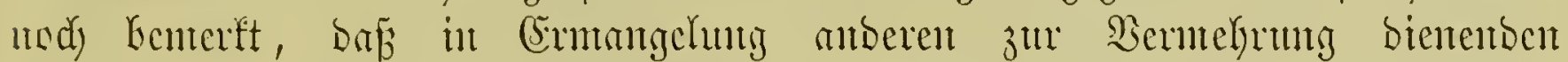

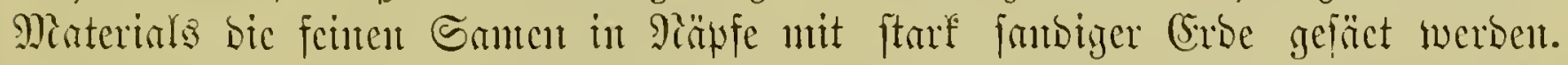
Man barf jie aber nur ganz wentig bebecten. Die gä̈pfe ftellt man in ein tenteriertes Mriptbeet ober an einen anberen näfig wamen Drt.

\section{S3attung Cotyledon L. Nabelfraut.}

Die Blüten funs regelmäpig, fünfgliebrig. Der Reld ift faft freiblättrig

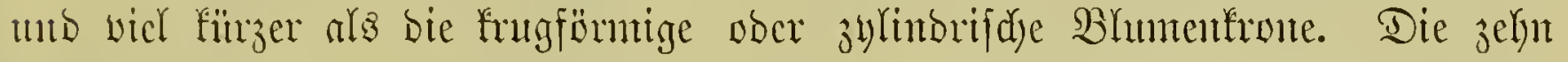
Stanbblätter find ber Röbre angebeftet; bie Frudyblätter find frei. Dic fleijdigen Strmben tragen am Srmmbe bänfig rojettig gejtellte, Dam freuzgegen= itünbig ober fpiral geftelfte, flache ober rumbe Blöttcr. Die meift zaljreichen

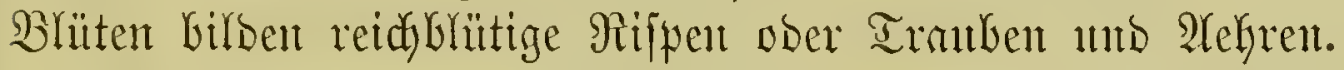

Die 25 arten wadjen faft mux mu Rrp ber guten Soffmutg, einige geben aud) nod) weiter nad) Rorben bis nady (Sutner.

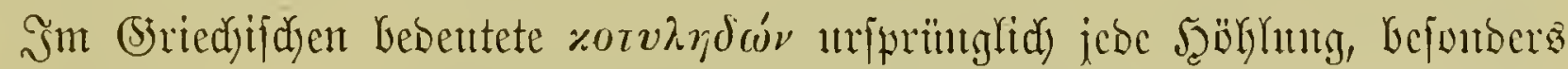

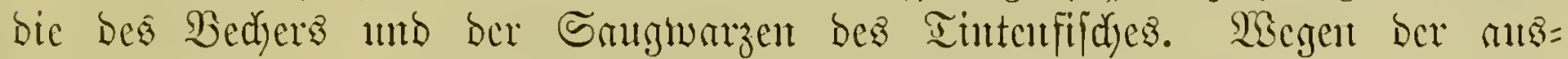

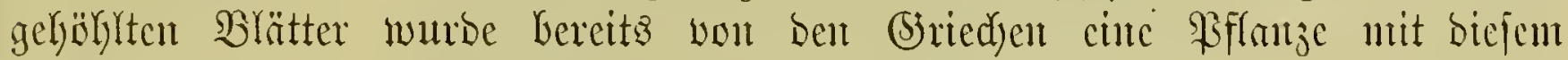
गamen belegt.

\section{S丸lüfifel für die befđriebenen Jrtert.}

A. SBlïten in Rijpen, fehr bcutfich gefticlt, häugcub.

a) Blätter freuzgcgentiäutoig.

a) SBlätter flach).

I. SBätter ıimgef́ch)rt ciförnig 1. C. orbiculata $L$.

II. Blätter oblong=fcilförmitg

2. C. coruscans Haw.

B) Blätter halbitielrumb, am oberen (Ende mit cincul fantöjen Spibchen.

I. Siallz faljl

II. Düıtı behaart

b) Blätter zerftrent.

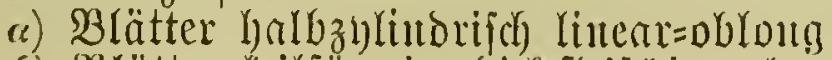

§) Wlätter fcilförmig, Didéfleifd)ig, aber flad)
3. C. ungulata Lam.

4. C. papillaris Linn. fil.

5. C. tuberculosa Lam. 6. C. fascicularis Ait. 


\section{Cotyledon orbiculata $I_{\text {. }}$. Srubblätriges Mabclfraut.}

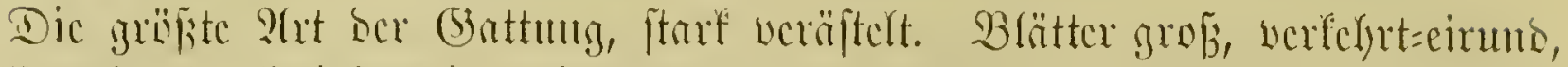

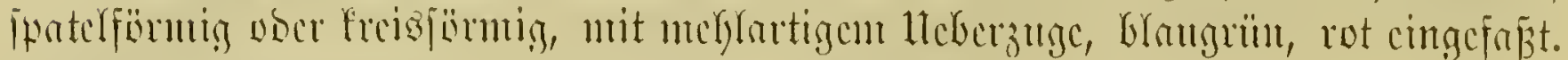

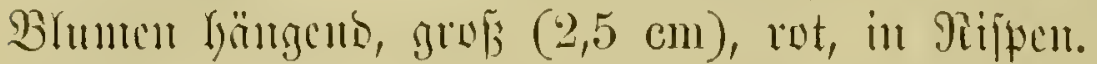

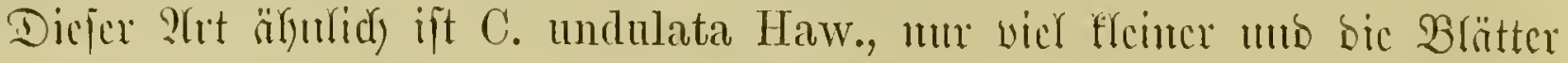

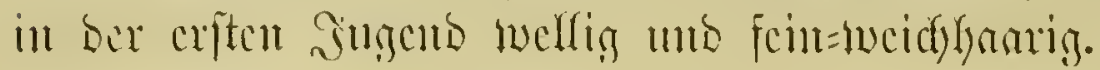

\section{Cotyledon coruscans Haw. Gruinntubez Siabchrant.}

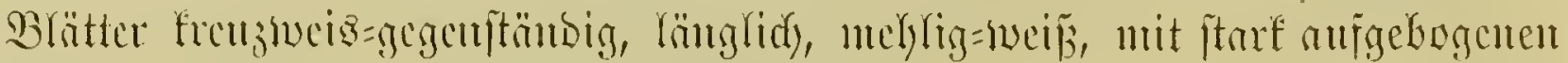

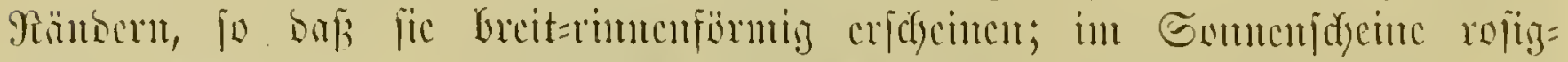

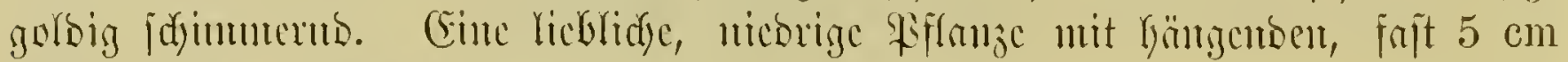
lamign, roteu B̊łutucu.

\section{Cotyledon ungulata Lam. Gcuagcltez Mabclfuat.}

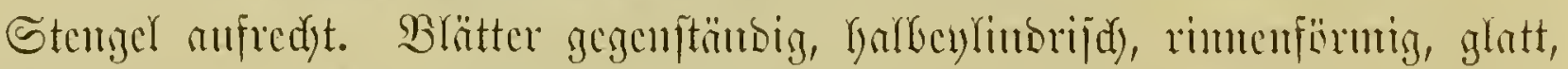

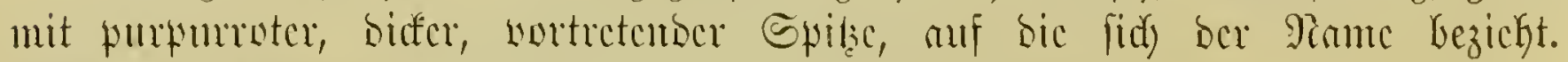
Bhumen beucu ber Cotyledon orbiculata äbulid), brä́rot.

\section{Cotyledon papillaris Linn. fil.}

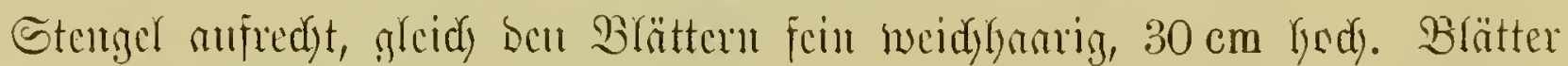

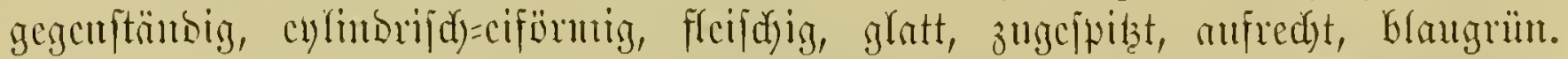

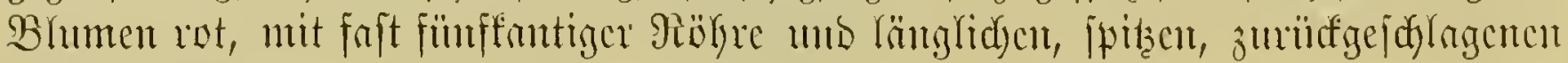
Srumtrippon.

\section{Cotyledon tuberculosa Lam. 5öderigez Minbelfiant.}

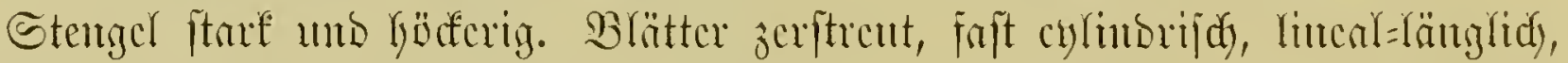

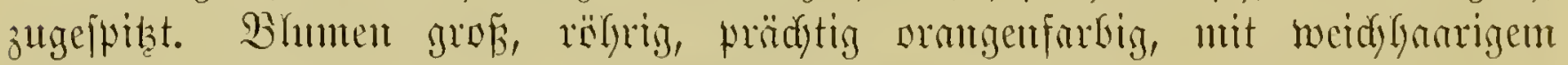

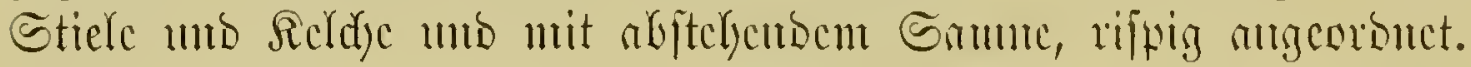

\section{Cotyledon fasciculanis Ait. Biijd)l=9iabclfinut.}

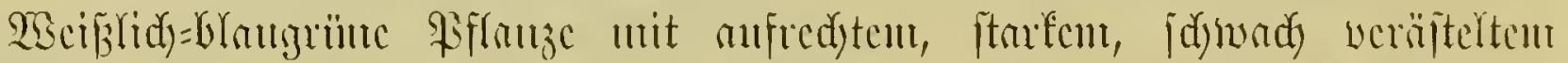

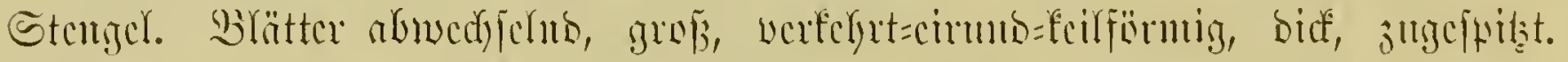

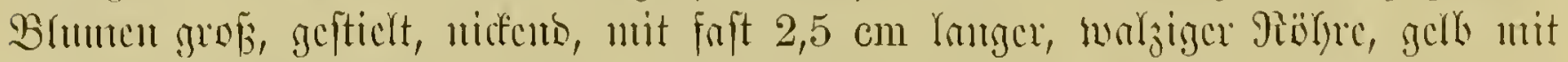

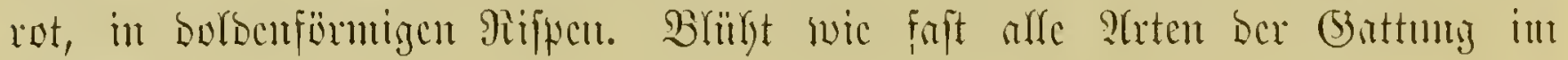
Gommer.

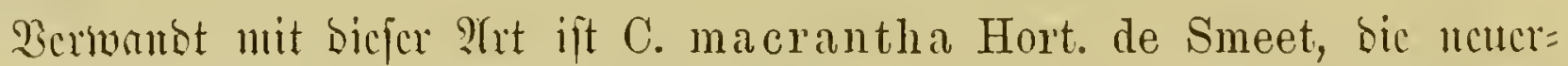

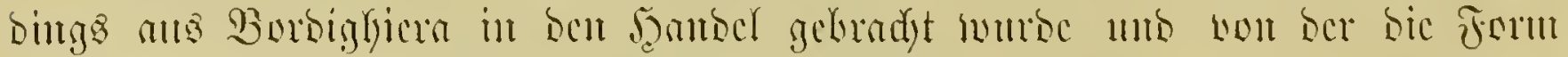

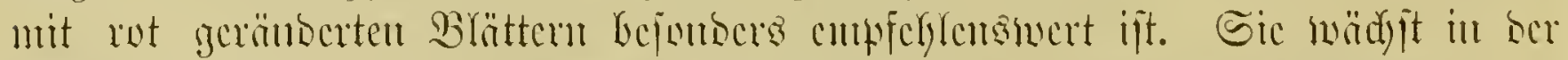

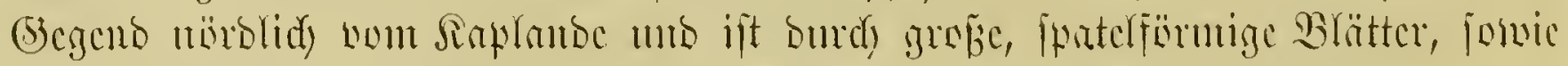

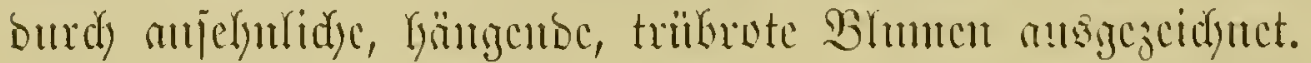

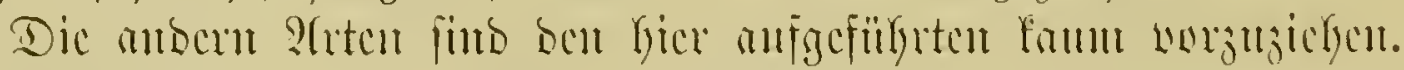

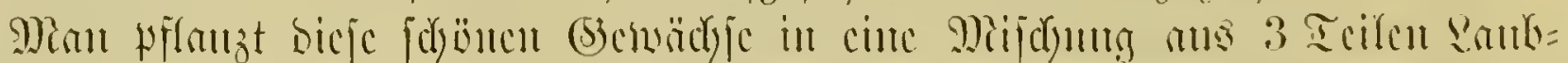
croe mo je 1 I

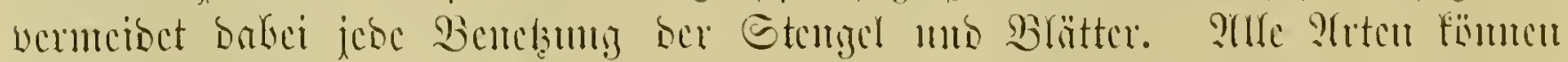

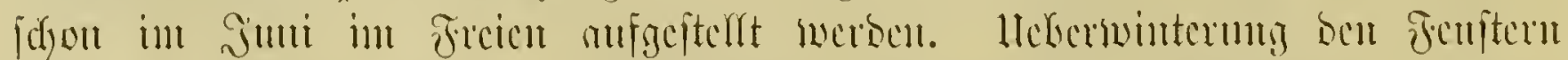

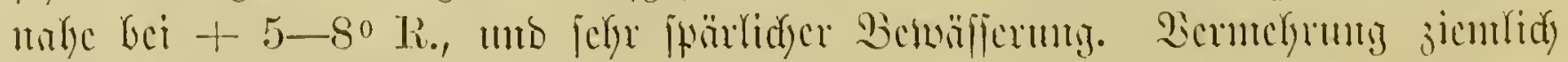
reidyt nuв Blattitectring̣cu. 


\section{Gittunis Umbilicus. Rabeling.}

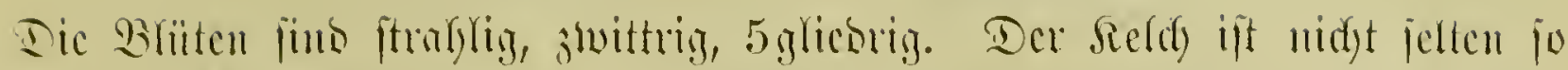

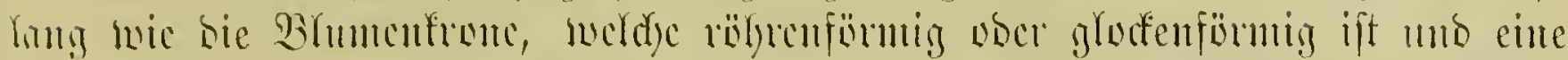

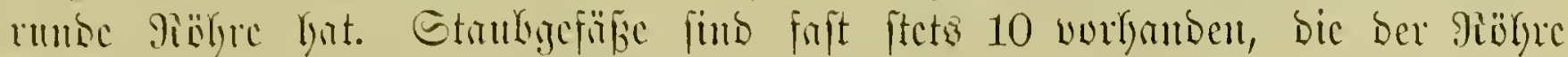

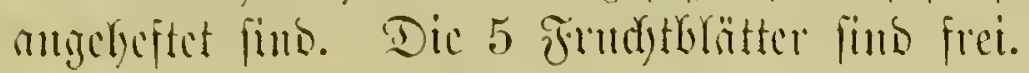

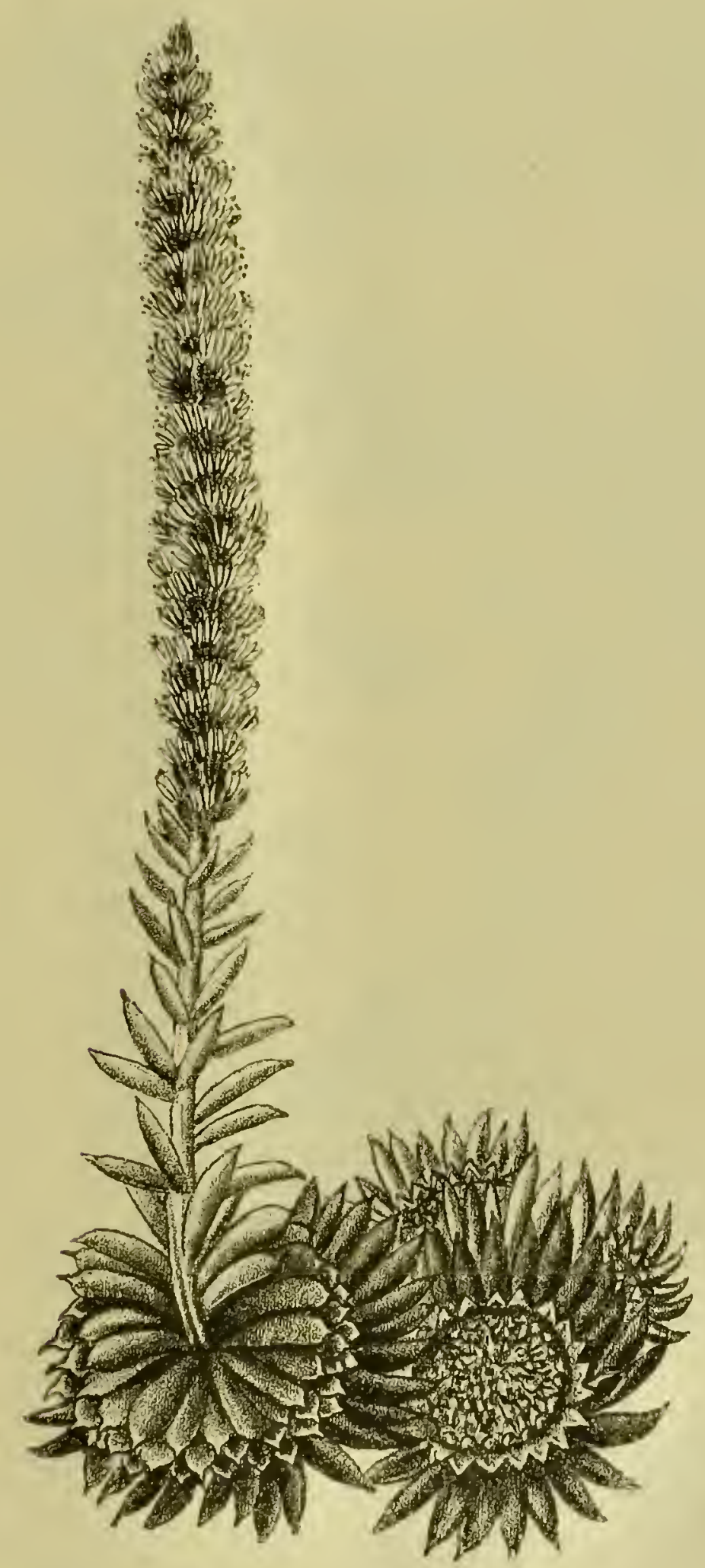

Fig. 39. Umbilicus spinosissimus DC. Bedornter Tabeling.

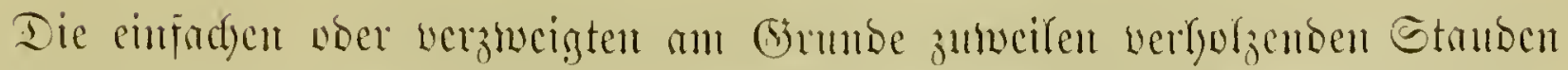

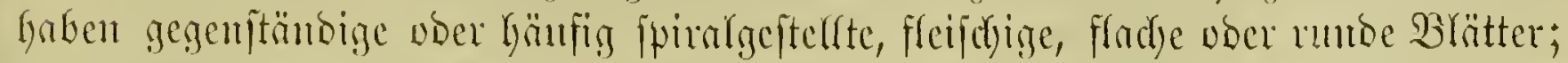

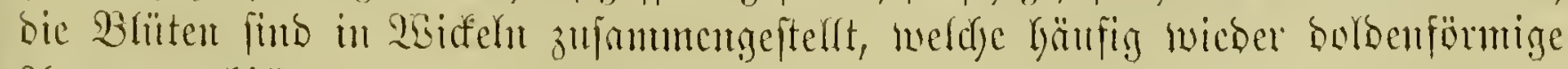
2fggregate bilbert. 


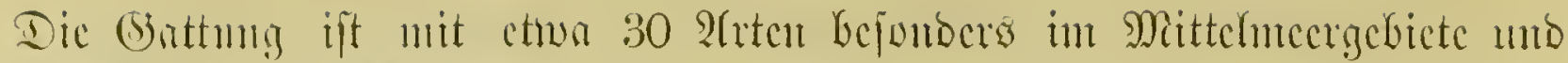
in Sinter=?(jicu cotturiffert.

Umbilicus ftrmment ans bem Eateintifyen mob bebentet ben Rabcl, weil bie

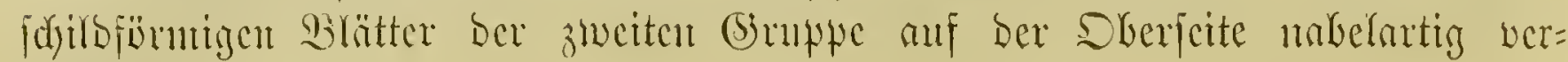
ticft fints.

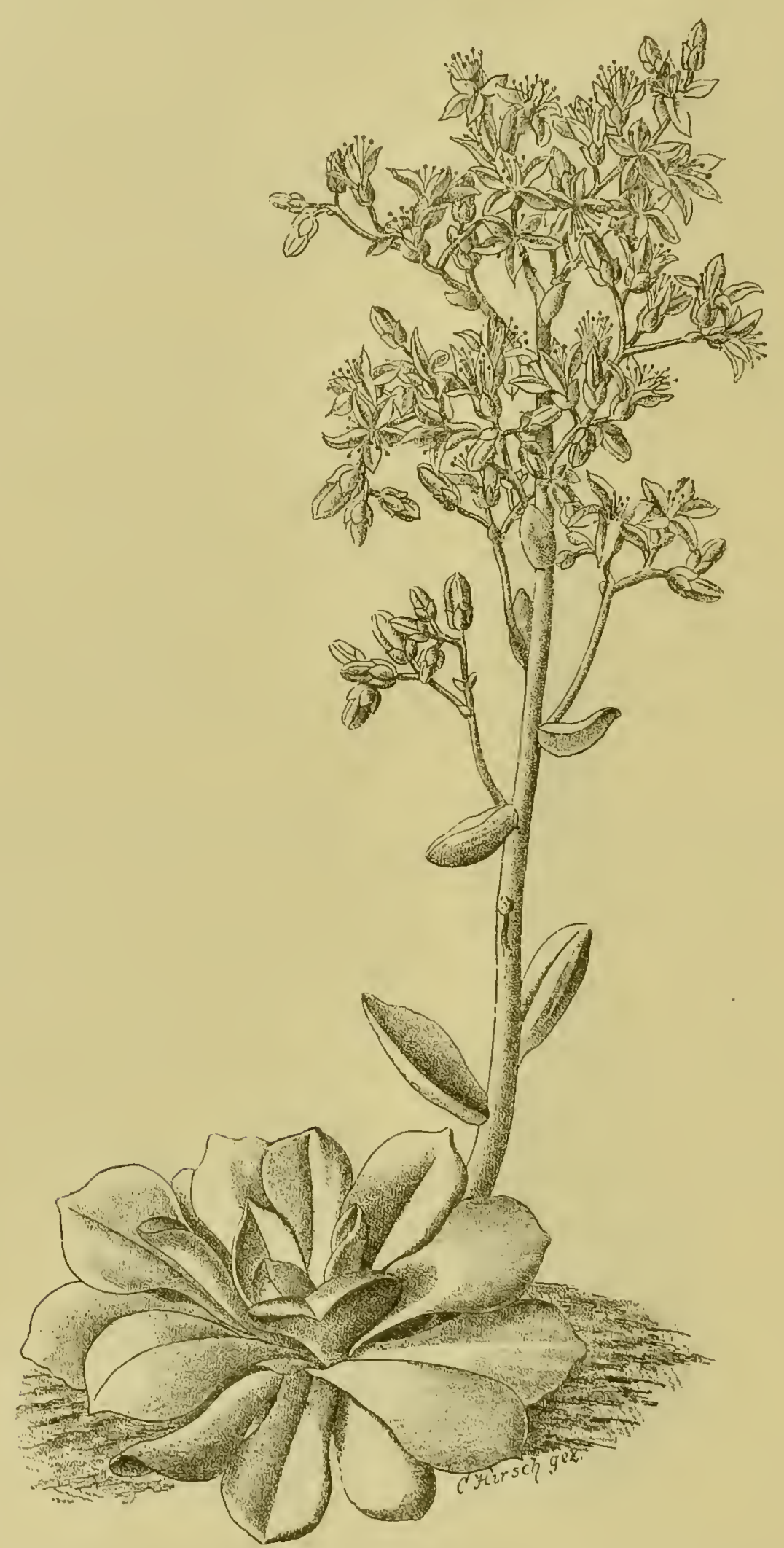

Jig. 40. Umbilicus glaber Reg. et Winkl. Sablex Rabeling.

Ghliiffel fïr die befaricbonen Urten.

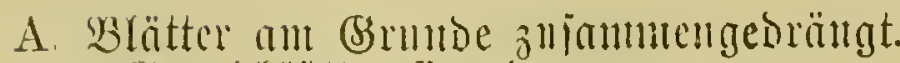

a) (3)runtoblütter fibento

I. Seft. Rosularia $D C$.

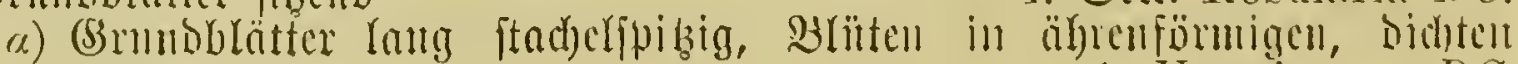
Sitipelt 


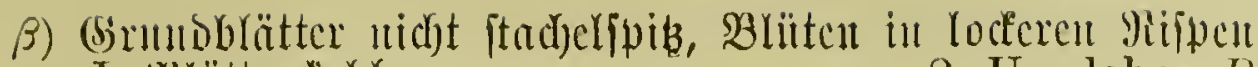
1. Blä̈tter fahl

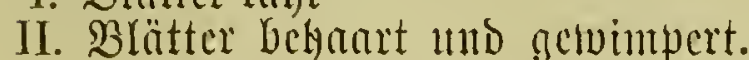

2. U. glaber Reg. et Wlilr.

1. Simuloblätter lanzettlich)=Ecilförmitas

3. U. turkestanicus $R$. et Wlilr.

2. Brinnoblätter verferyrt ciförmig 4. U. platyphyllus Sehrenk.

b) Sirntoblätter geiticlt, obcrjeits becfenförmig wertieft.

II. Seft. Cotyle $D C$.

B. Brätter an Girunte nicht sulanumcugebrängt.

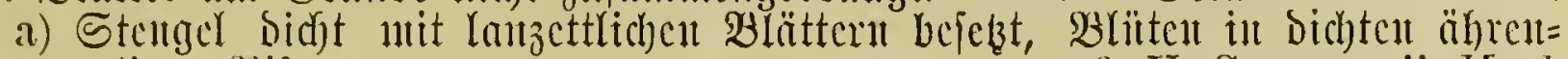
artigen siifpen

5. U. pendulinus $D C$.

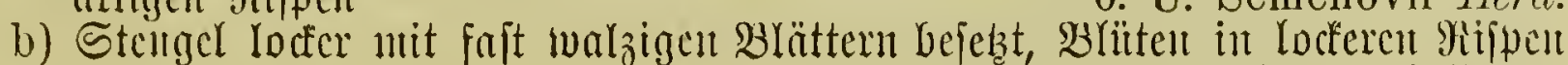

7. U. Lievenii Ledeb.

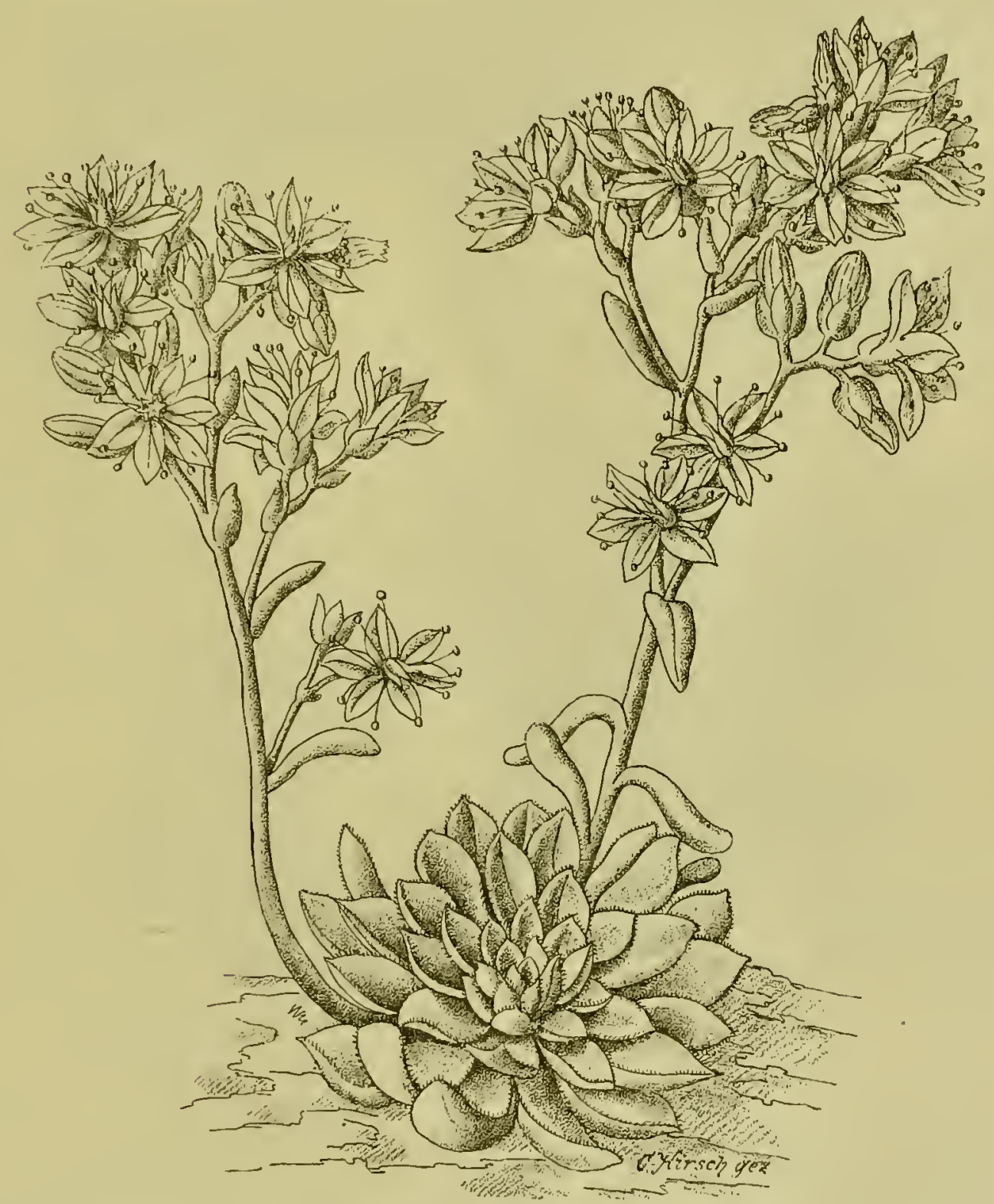

Fig. 41. Umbilicus turkestanicus Reg. et Wklr.

\section{Umbiliens spinosns $D C$. Bebornter Rabcling.}

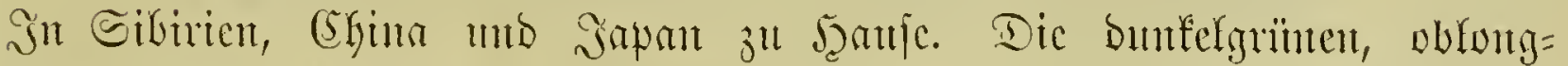

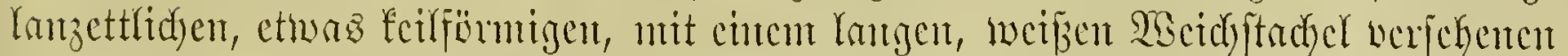

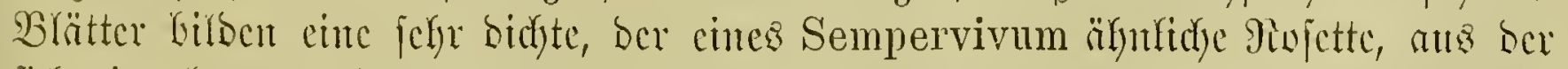

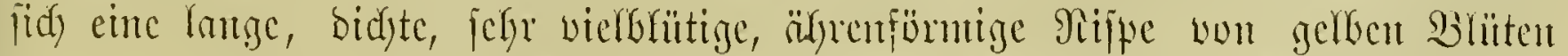

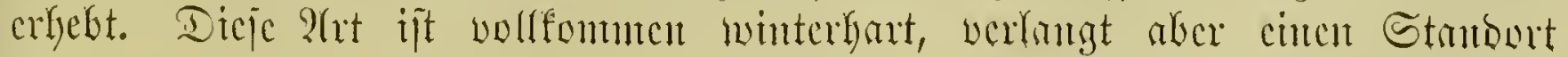




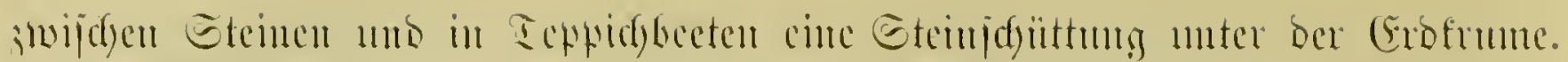

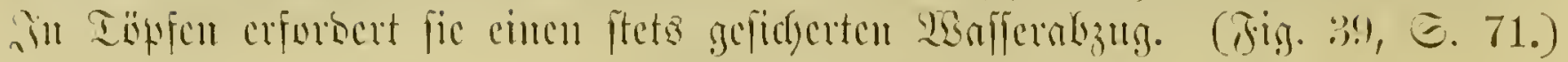

\section{Umbilicus glaber Rgl. et Winkler. Sinblex Mabcling.}

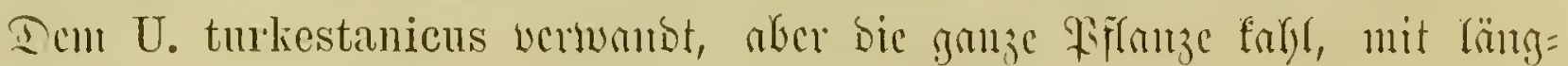

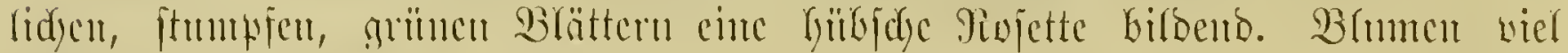

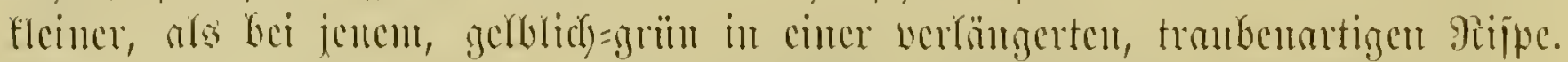

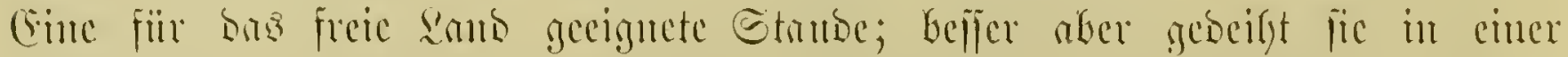

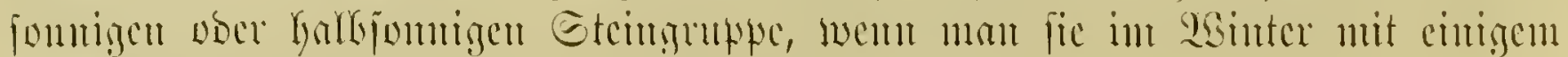

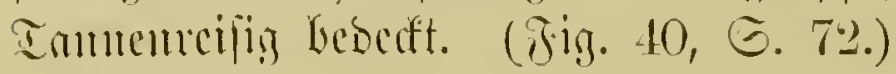

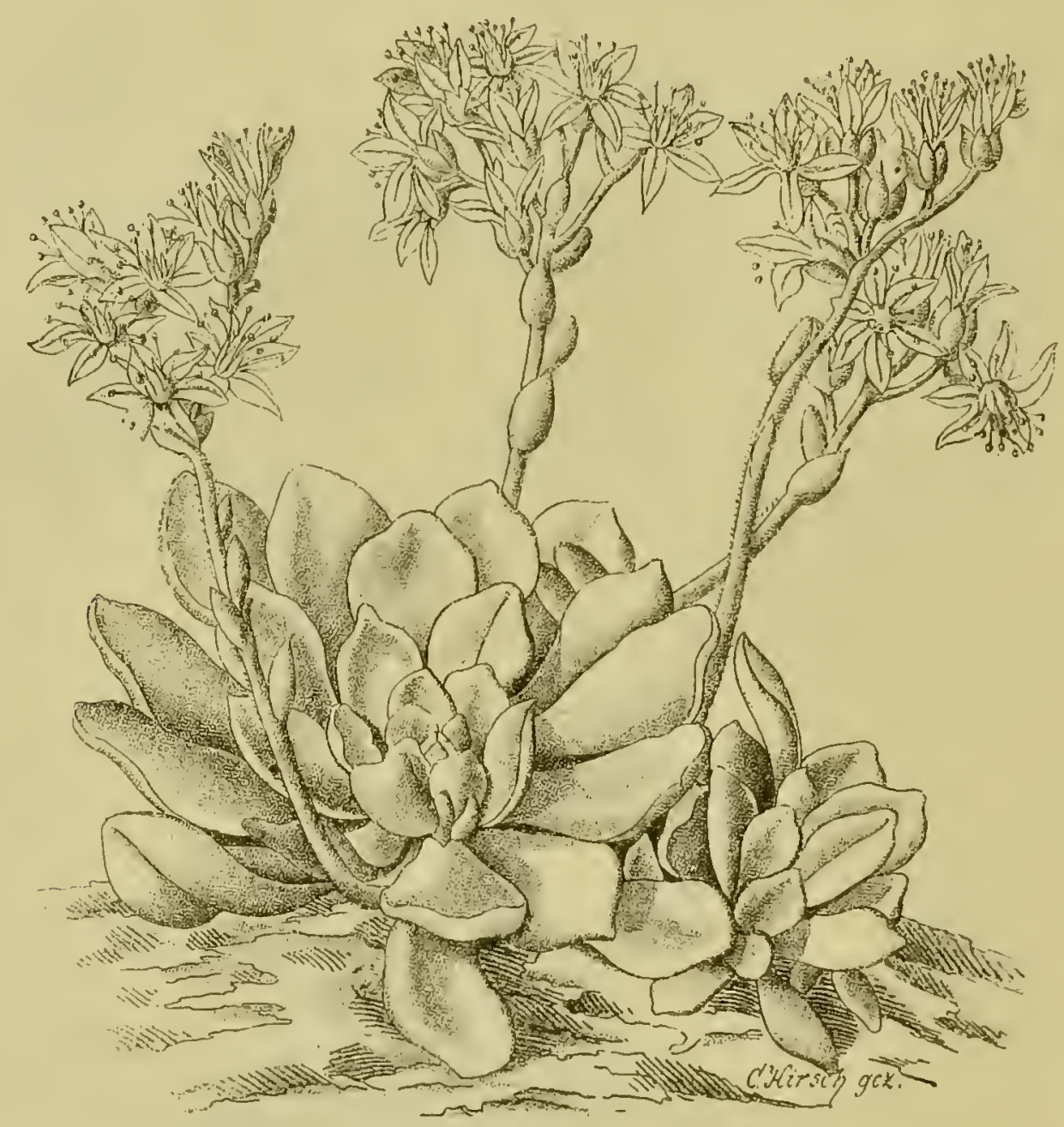

Fig. 42. Umbilicus platyphyllus Schrk. Fladblätteriger Rabeling.

\section{Umbilicus turkestanicus Rgl.}

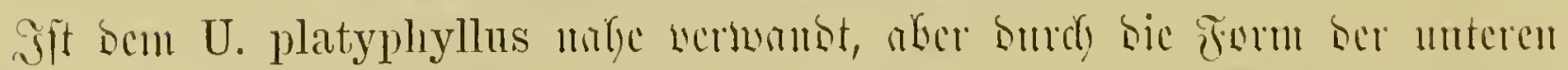

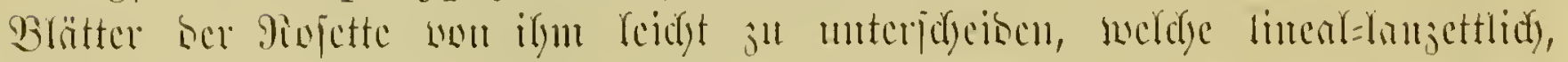

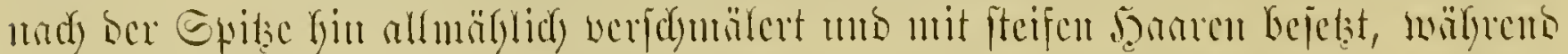

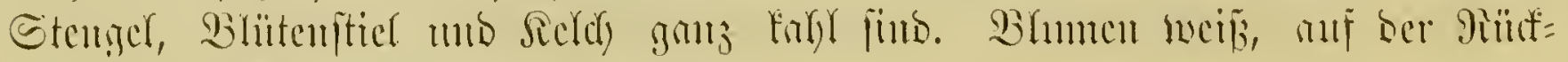
peite rot pruftiert. (Fin. 41, E. 73.)

Dicje ?ht ift chempo bart, wic U. platyphylhus, mo gebeifyt anf cinem

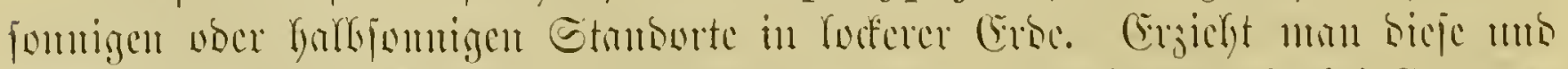

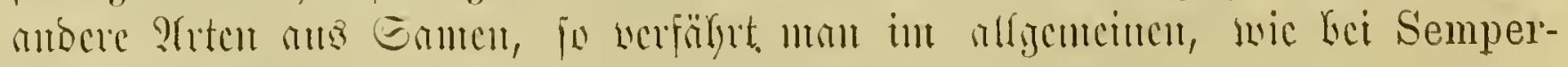
vivum antgezcigt fumbe. 


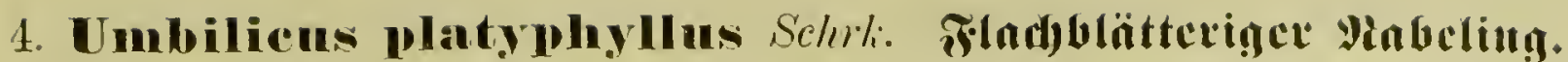

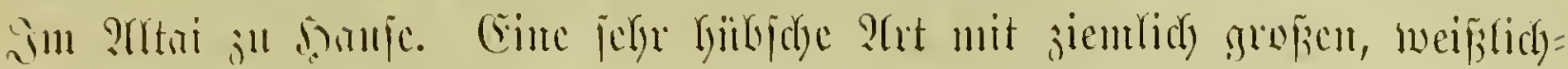

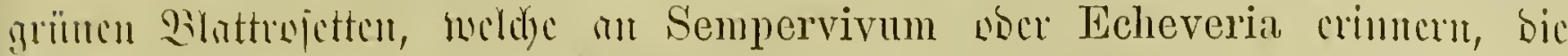

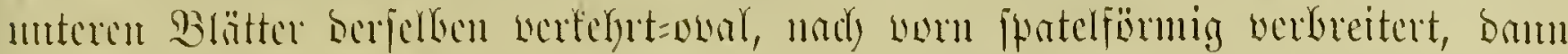

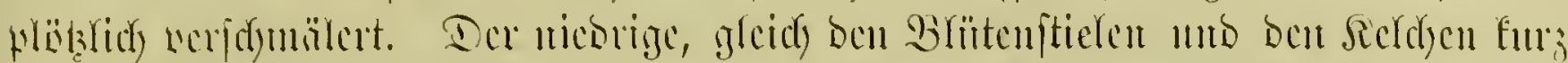

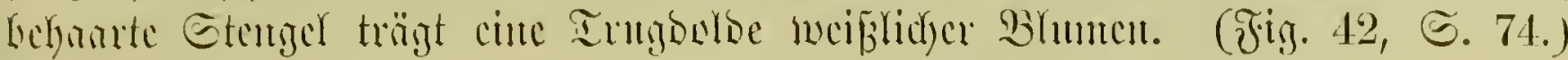

\section{Umbilicus pendulinus $D C$. sä̈ugeuber গinfeliug.}

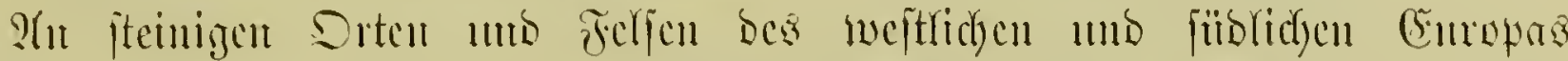

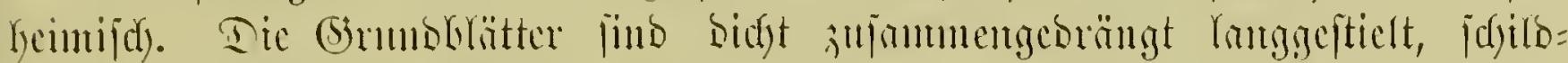
förmig, bedyerfömig wertieft, metre noer weniger gejdyeift geterbt, bie bes

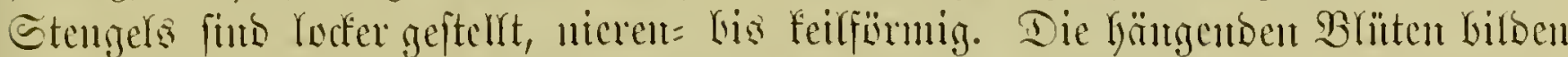

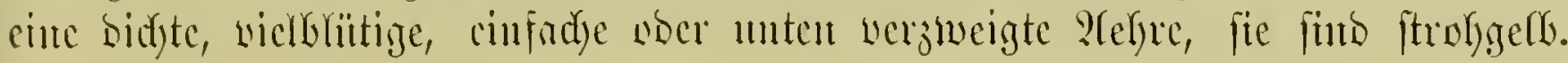

\section{Umbilicus Semenowii Herd.}

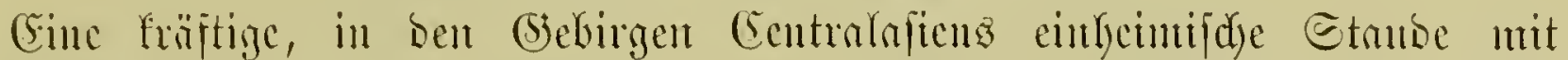

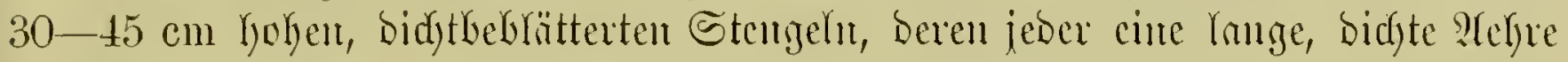

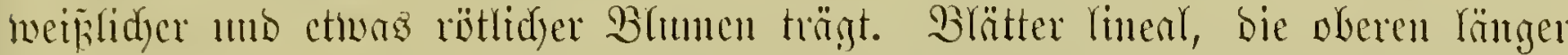

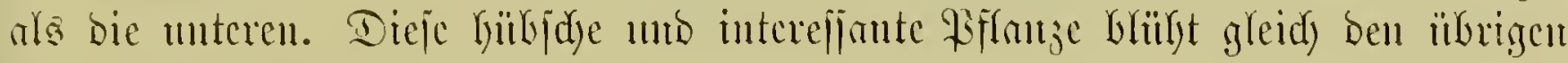

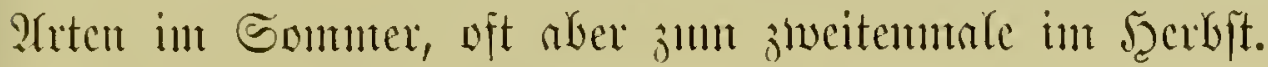

\section{Umbilicus Lievenii $L d b r$.}

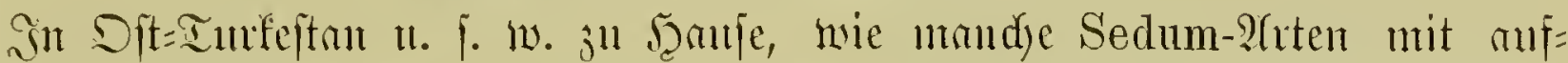

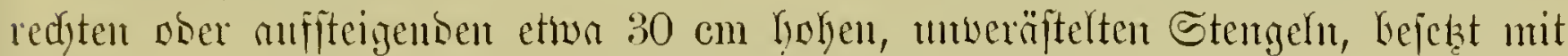

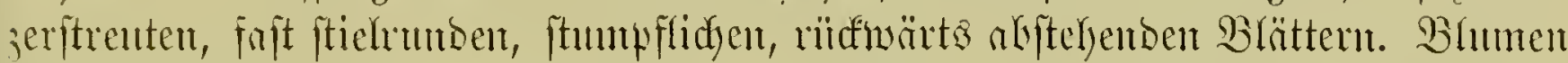

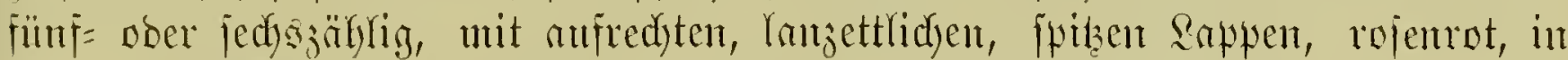

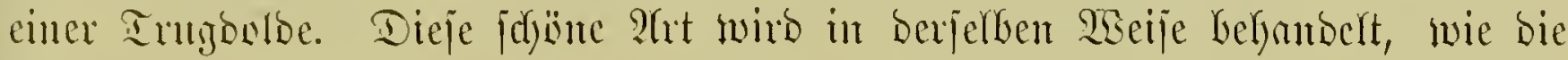
worige.

\section{Binttunty Echeveria. (sheverie.}

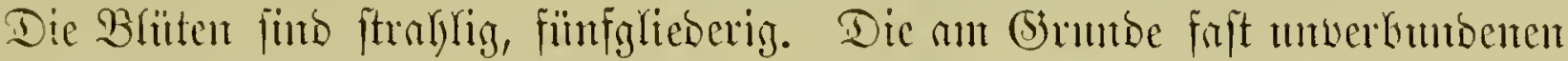

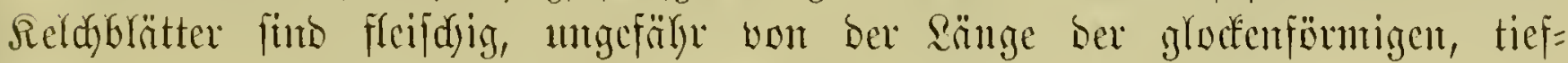

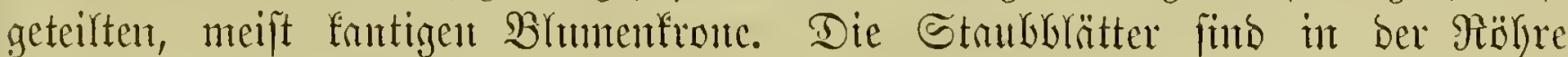
angeheftet, bie Frudyturätter frei.

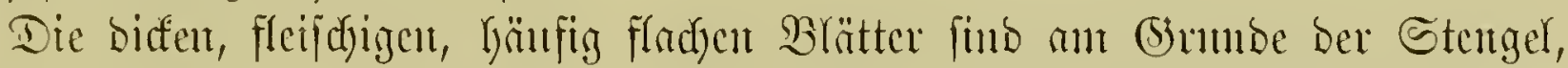

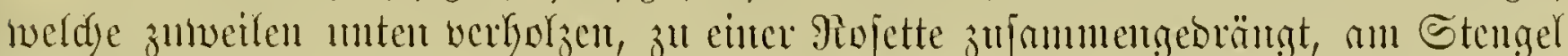

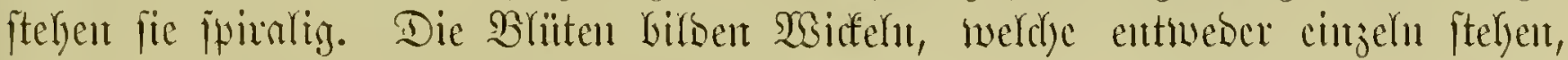

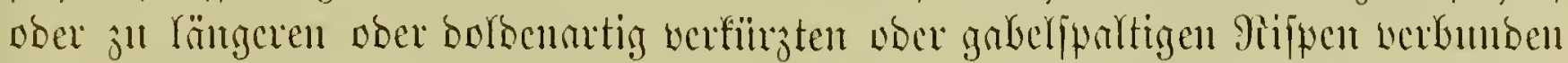

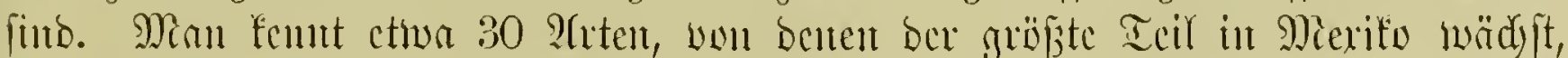

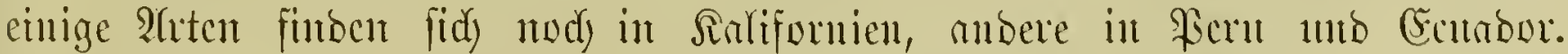

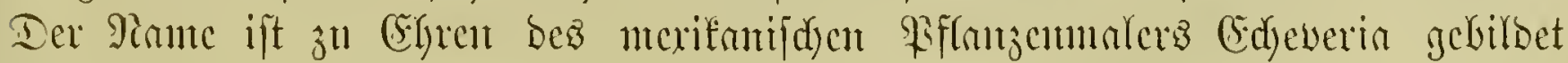
worbert.

Die (Battumgent Cotyledon, Umbilicus umb Echeveria Kaffon fid

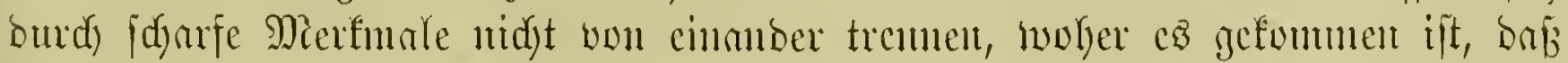
mm fie in ber Botnnif gegenwärtig allgemein zu ber eirtigen Cotyledon ver= 


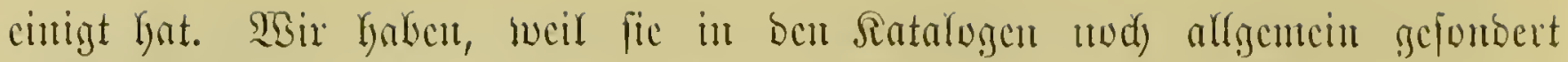

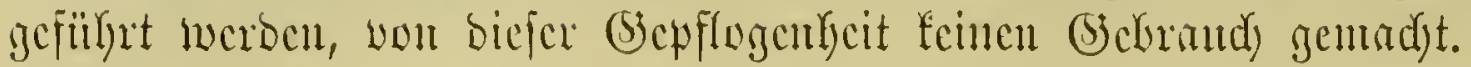

Sḑlïffel für die befdriebenen 2rrten.

A. Bhïtenftand cunfad), nur bic unterften Blüten zutweilen mit einter zweiten.
a) Blitten fikello
a) Blätter Itho Stengel beljaart
I. Reihe Spicatac.

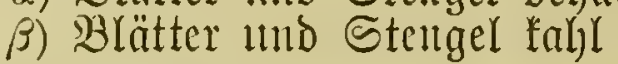
1. E. coccinea $D C$.
2. E. rosea Lindl.

b) $\mathfrak{B}$ lïten geftielt.

a) Britten nicht bentlich einfeitswendig II. Micife Racemosae.

I. Sillent kutzen Stann bildent.

1. Blätter żl einter Rofette ant Birmtibe gebrängt

3. E. canaliculata Hool.

2. Blätter von ciunatser entfent tehend 4 . E. linguifolia Lem.

II. Stanmlog, Blätter 3-4 mal po laug ale breit

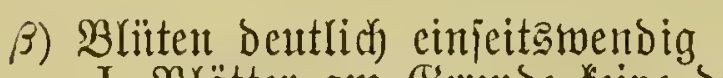

5. E. lurida Lindl.

I. $\mathfrak{B l a ̈ t t e r}$ am Grimbe feine bichte Rojette birbend

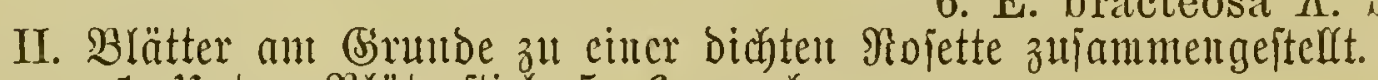

1. Hlutere $\mathfrak{B l u ̈ t}$ enftiele $5-6 \mathrm{~mm}$ lantg.

: BRlätter toenig blangriint

:

7. E. secunda Isindl. $\triangle$ Blätter ımmgefelhrt eiförmig = Keilig

8. E. glauca Hort. $\Delta \triangle$ Blätter umgefehrert eiförmig = lanzettlich

y. E. pumila Van Houtte.

B. Blïtenitände żliammengeję̧t

IV. Reihe Gibbiflorae.

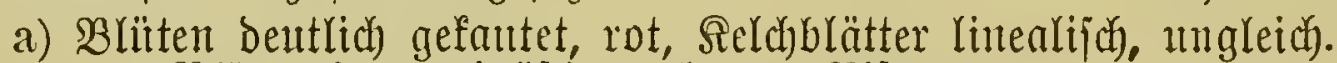

a) Bhïten in twentgäjtigen, futrzent Riipent.

I. Mit furrzem Stamme; Blä̆ter faum blaugrïn. jpäter an ber Spize ein wenig geträujelt,

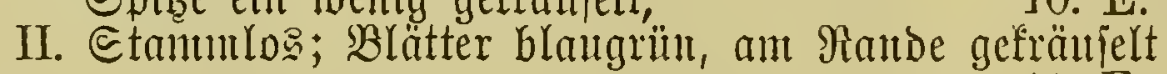

10. E. fulgens Lem.

11. E. retusa Lindl.

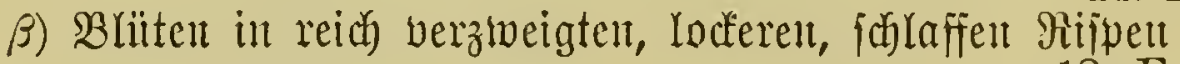

12. E. gibbiflora $D C$.

b) B̉ïten runts, gelb, Reldbblätter Lanızettlich ober Dreifeitig.

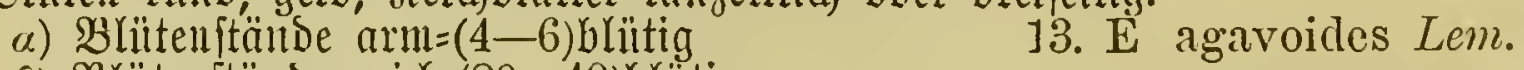

3) SBlittenffände reich $=(20-40)$ blititig.

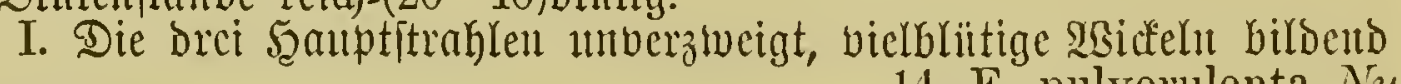

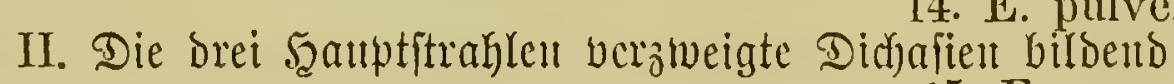

15. E. campanulata Tǐe.

\section{Echeveria coccinea $D C$. Edjariadiote Edjeucric.}

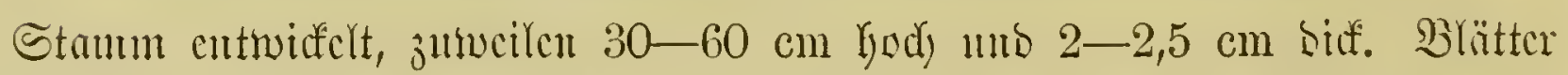

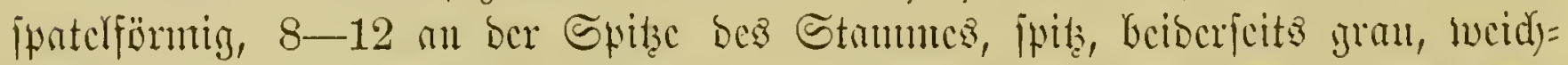

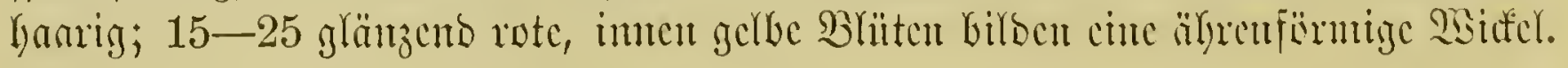

\section{Echeveria mosea Iindl. Mofurote Edjeucric.}

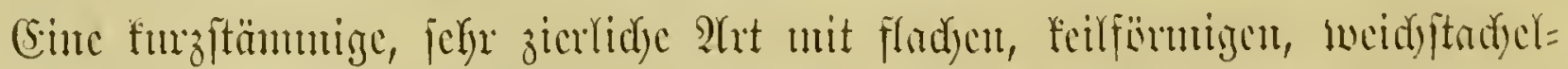

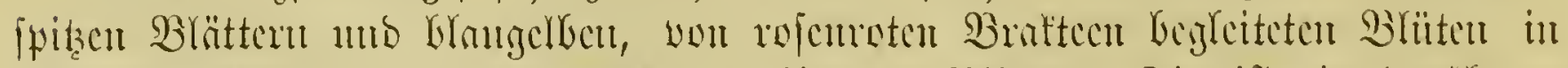

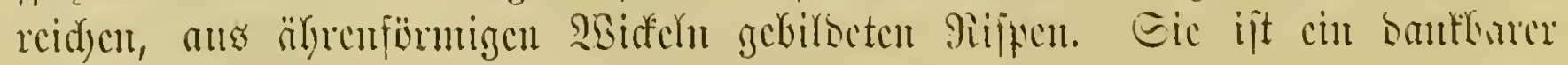
2⿰纟interblïber. 


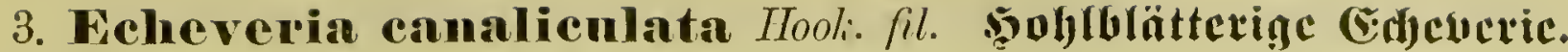

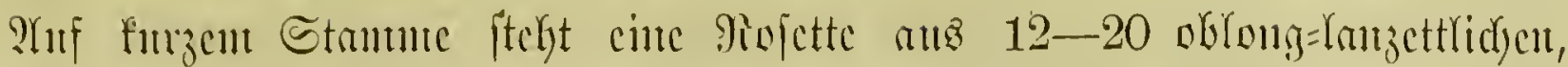

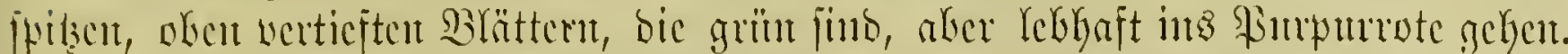

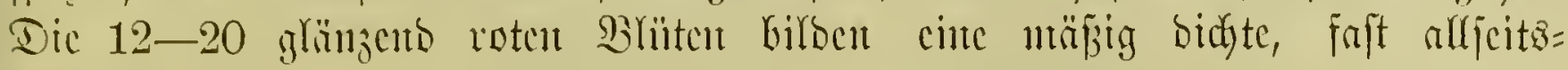
mentige 1 istofel.

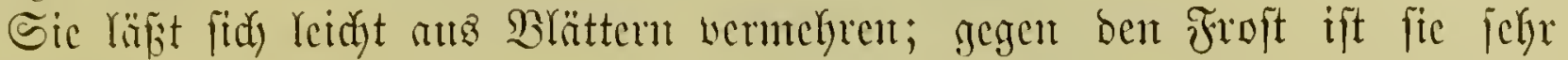
centefutolidy.

\section{Echeveria lingnifolia Lem. 3ungenbütterige Erheveric.}

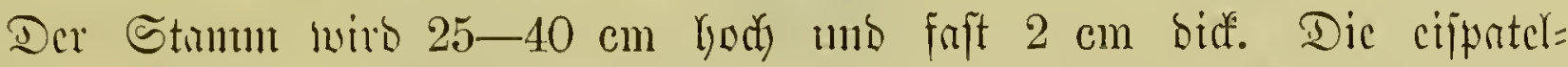

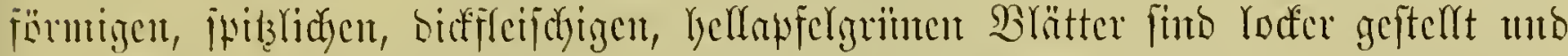

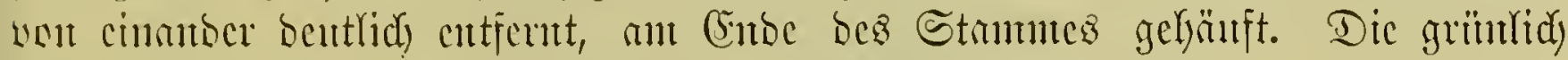

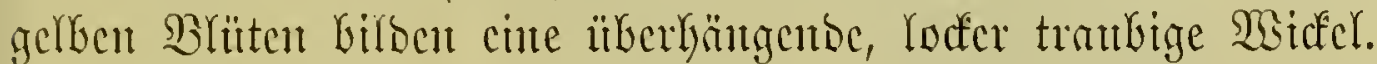

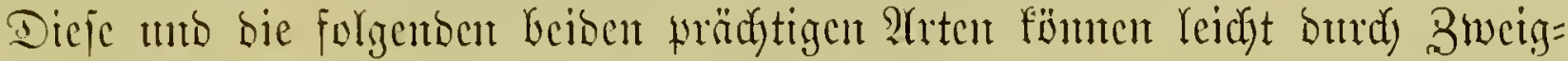
unto Brattifeceflinge vermedyet iverbert.

\section{Echeveria Inrida Lindl. Triibjarbige Edjeucric.}

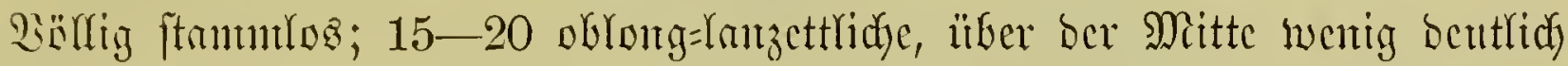
werbreiterte, jpilise, oben ctwas vertiefte, Glangrünc, trïb purpunn ïberfanfente

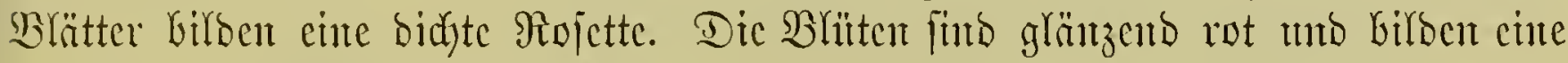
aufredjte, traubenförmige SBiffel.

\section{Echeveria bracteosa $K$. Schum. Diffblätterige Erdheveric.} (Pachyphytum bracteosum Klotzsch.)

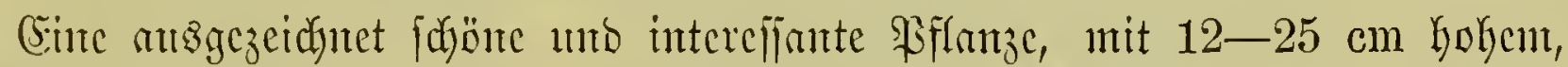

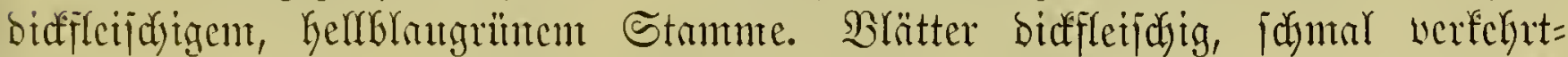

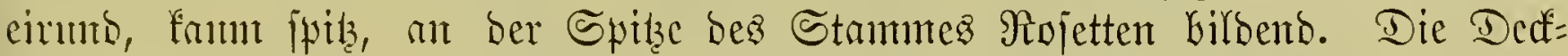

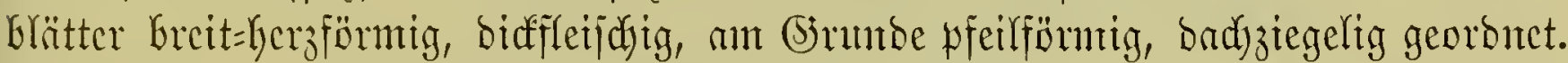
Blitten febr lang gef́tielt, in ïbergebogenter, ipäter anfred) ter, $15 \mathrm{~cm}$ lantger,

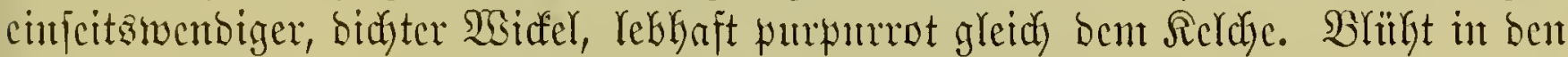
sintermonaten.

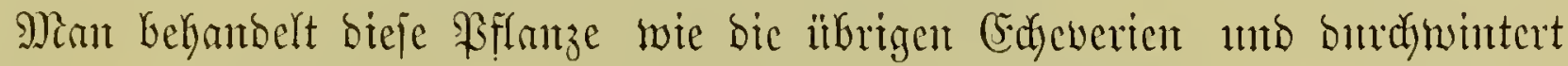
fie bei $+5-8^{0} \mathrm{R}$.

\section{Echeveria secnuda Lindl. Einjeitzwentige Edheucric.}

Strummlos, mit rojettenartig georoneten, zientlid breit ipatclförmtigen,

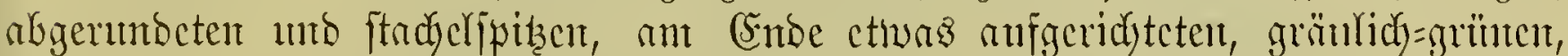

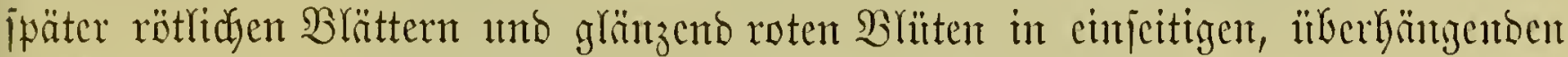

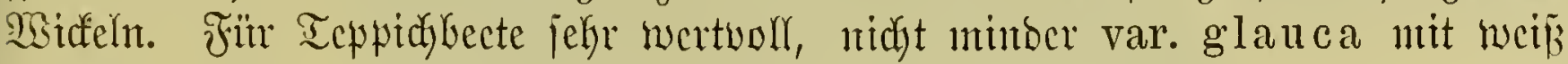
bereiften Brlättern uno feuterroten Bhlunten.

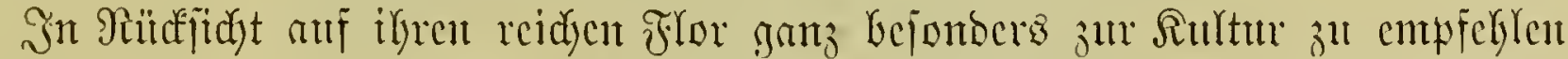
ift var. major. Sie bringt nidyt mur mebre Błhïtenftentigel, als bie Strumment unb bie Barietät glanca, jonbern and an jebcnt ber Bhlitentranben jwei. Da= gegent ift fie für Teppidjbecte weniger brandbar, ate bicje. Trfe aber gebüren

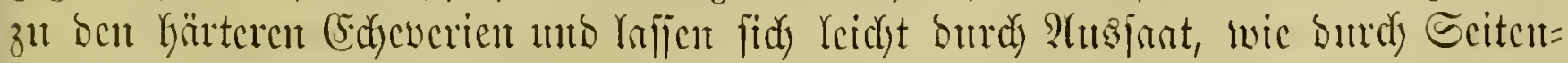
ifrofien bermefren. 


\section{Echeveria glauca Hort. Blaugriute Edfelucric.}

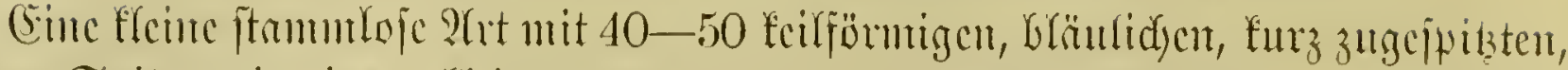

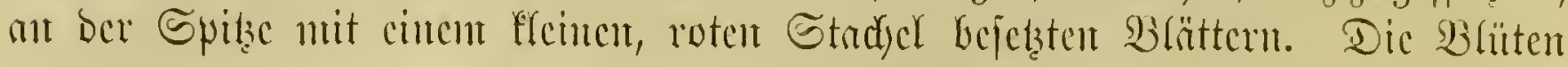

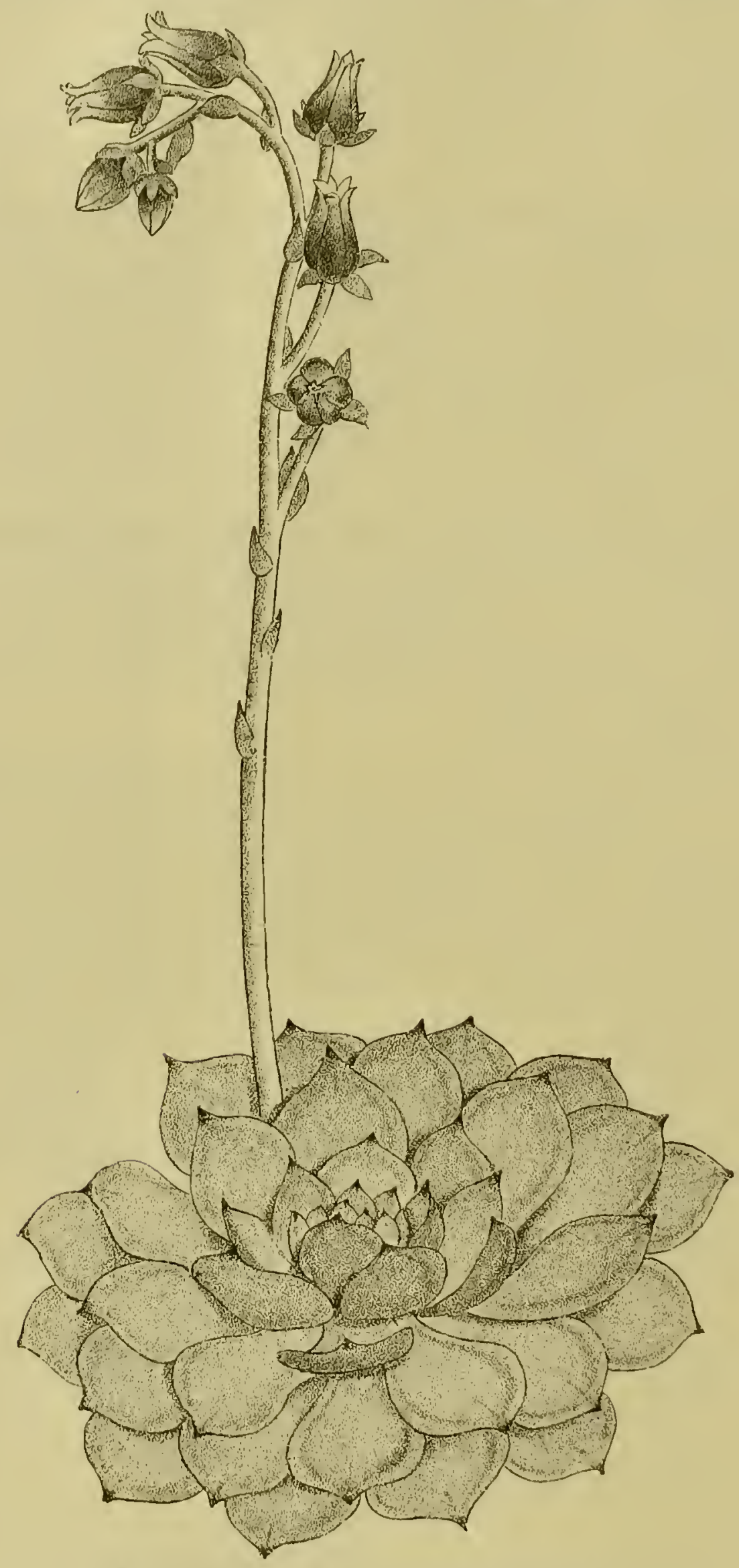

Jig. 43. Echereria glanea Jort. Blangrïne E(t)everia.

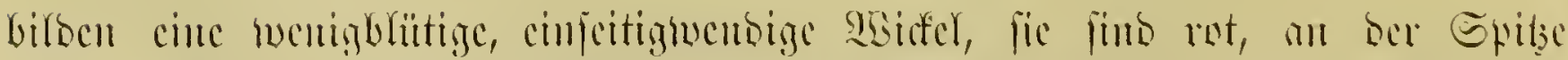

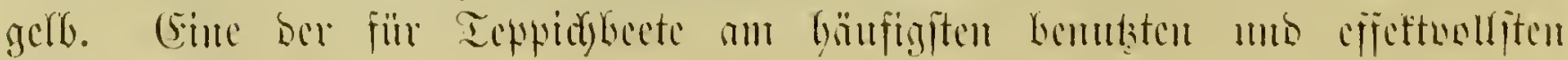
ghten. (gin. 43.) 
Echeveria globosa Hort. (E. rosacea Lind. et André), wogl mur

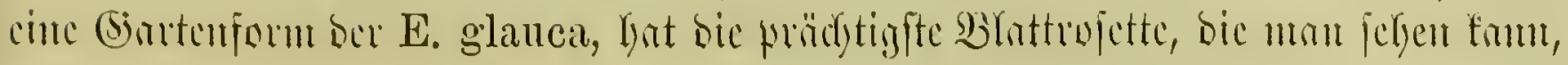

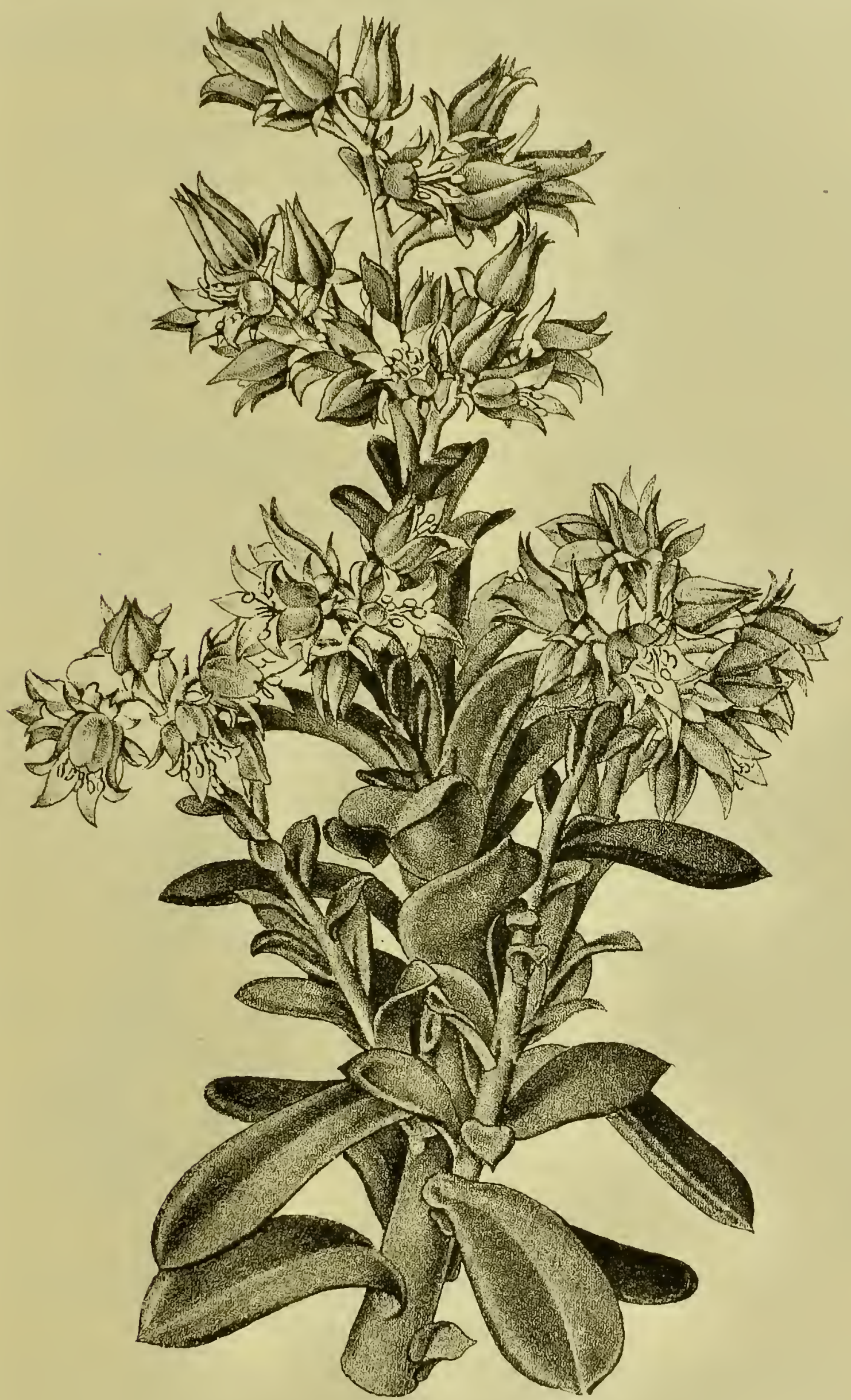

Jig. 44. Echeveria retusa Lindl. ?tuggejdnttent (Ed)cucria.

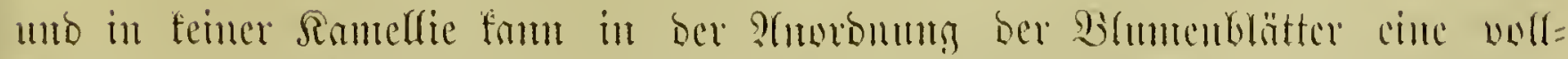

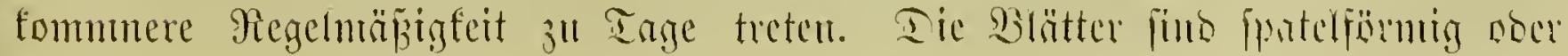




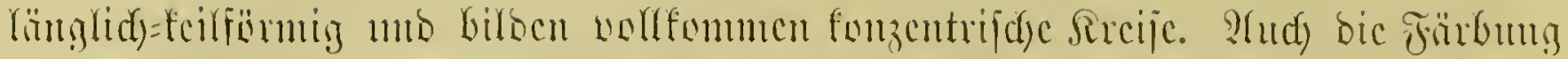

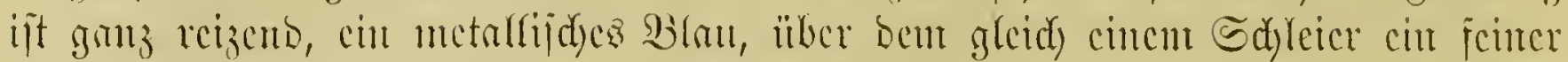
Reif liegt. Fïr Teppidjbecte won horem SGarte.

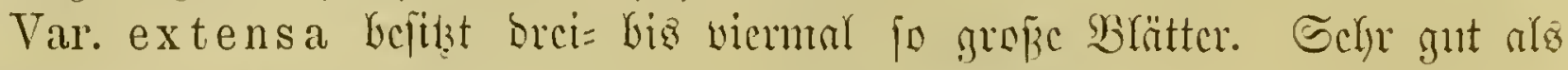

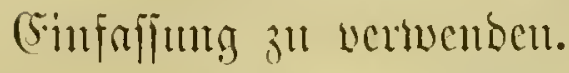

\section{Echeveria pumila Van Houtte. Rlcinc (Edjeveric.}

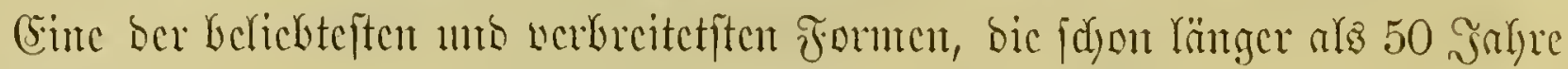
in Sinltur ift.

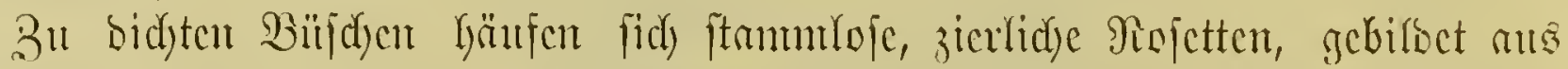

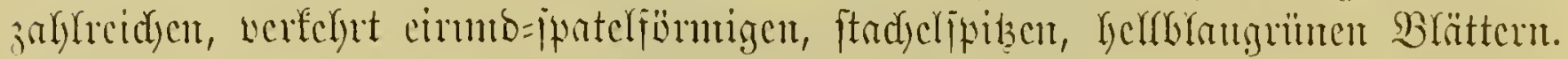

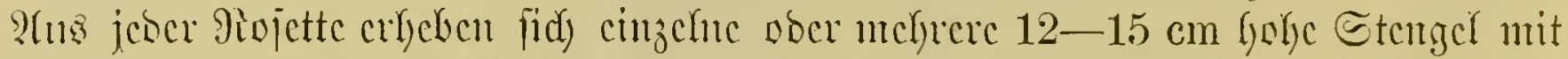

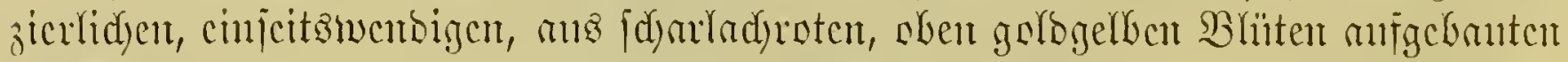

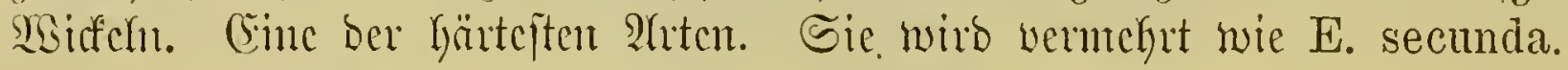

\section{Echeveria fulgens Lem. (Glünzchoc Erheveric.}

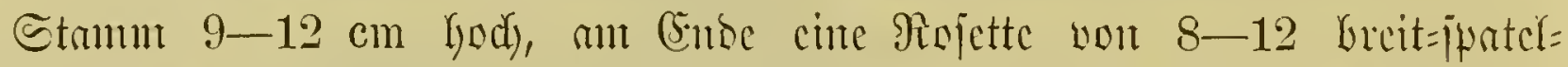

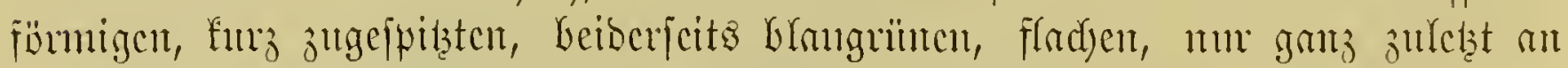

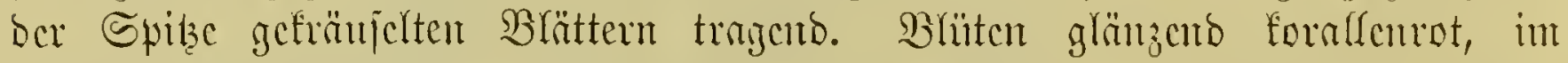

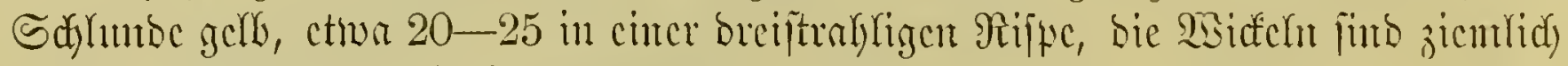
bidyt unto uidjt beutfidy cinfeitsinentoig.

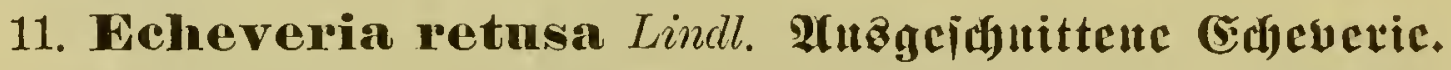

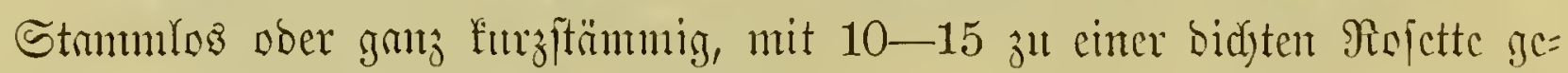

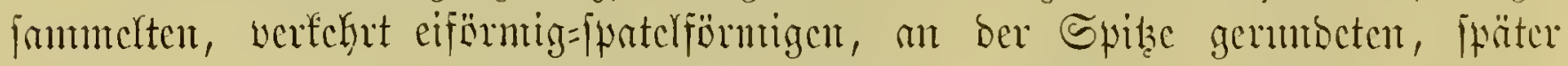

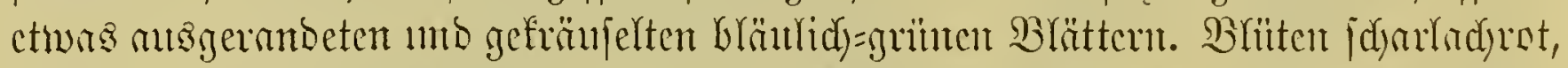

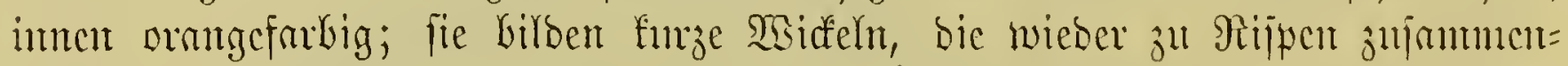

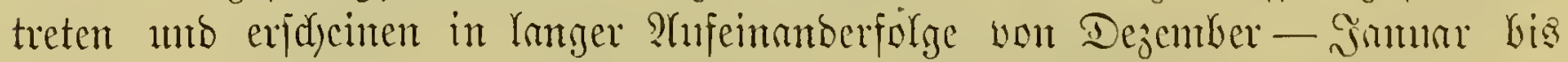

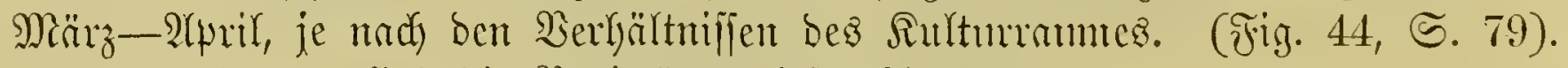

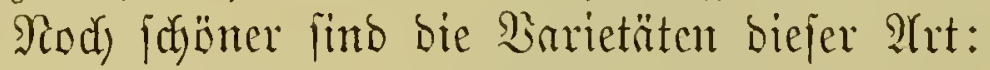

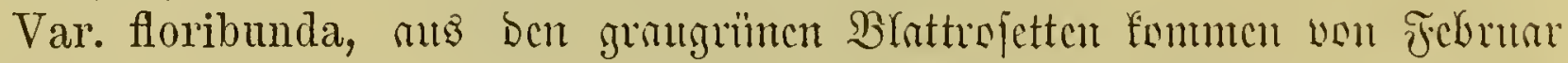

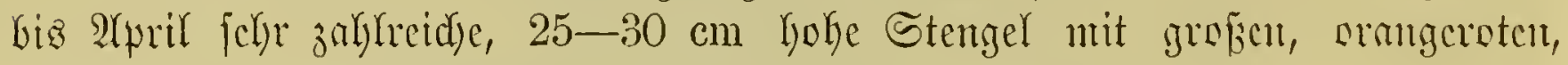

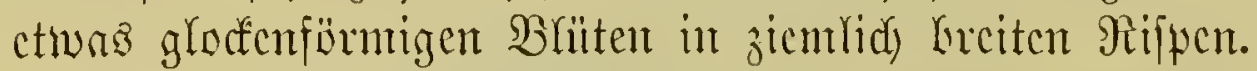

Var. floribunda splendens, tod d) reidjer im Flor als bic worige; jober

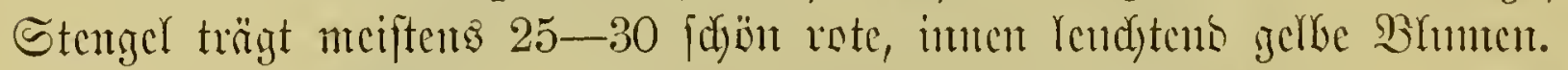

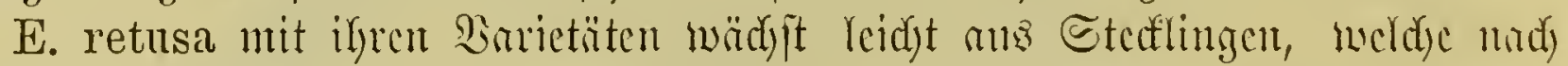

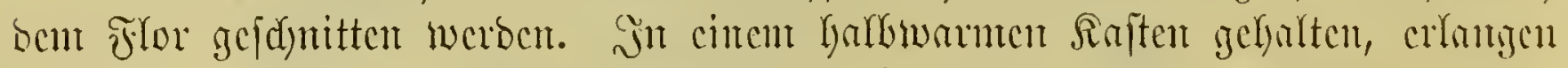

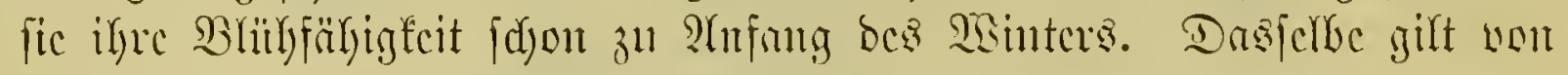

\section{Echeveria gibbiflora $D C$. פärferbliitige Erfjecric.}

(E. grandifolia Haw.)

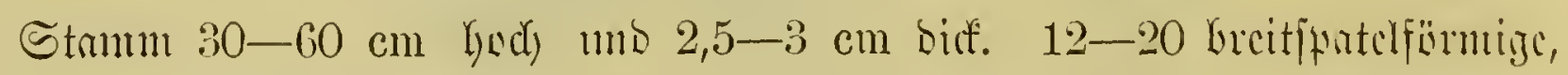

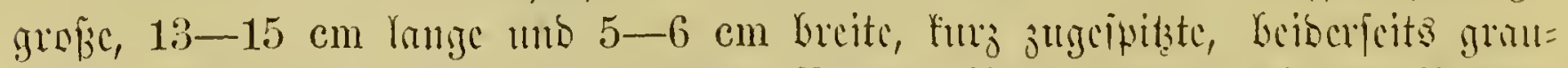

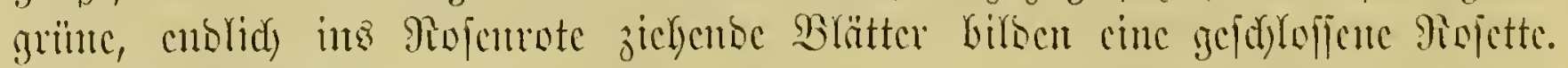

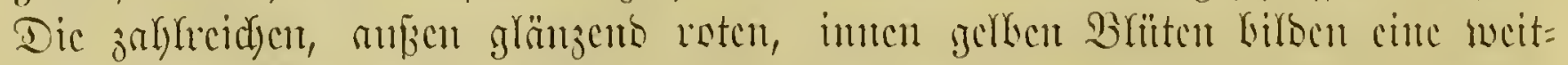

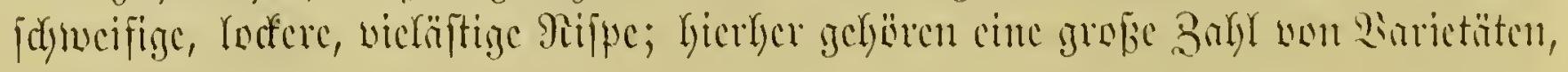




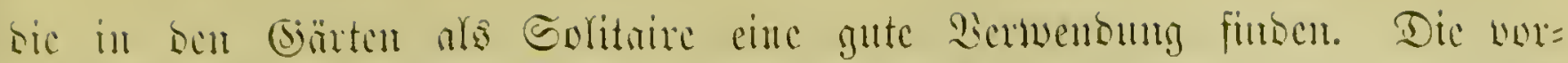
jüglidjfte itt var. metallica Bak. won ber Tradyt bes Typus, aber mit nods

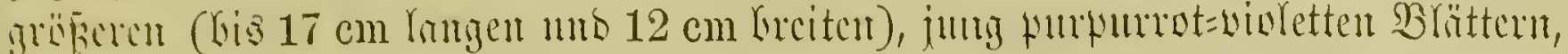

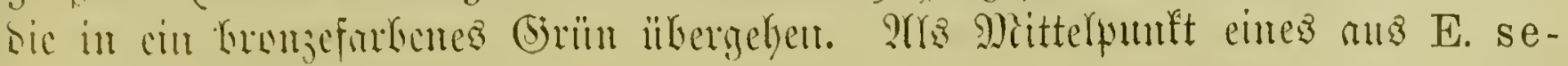

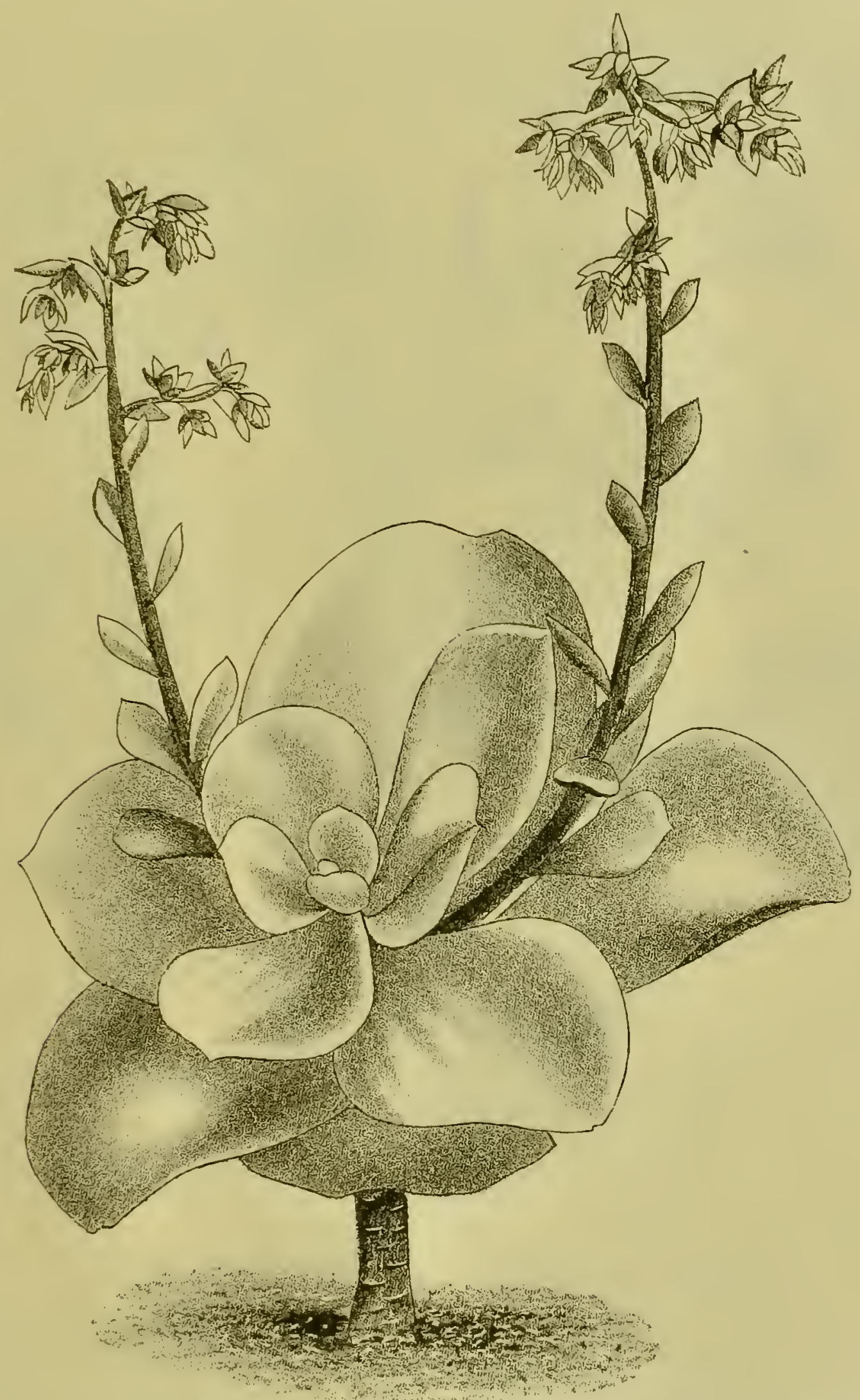

Jig. 45. Echeveria gibbiffora DC. var. metallica Bak. Scöcterbhitige Edeneric.

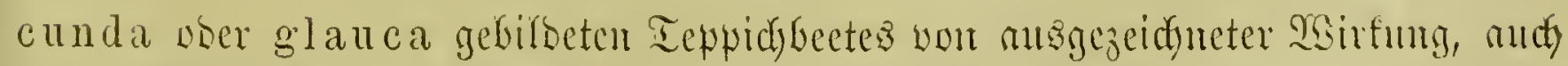

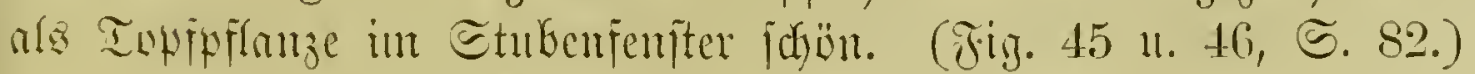

2hus biejer 2ret, befrudytet burdy E. glanca, ging herwor Var. glancoEuffutenten. 


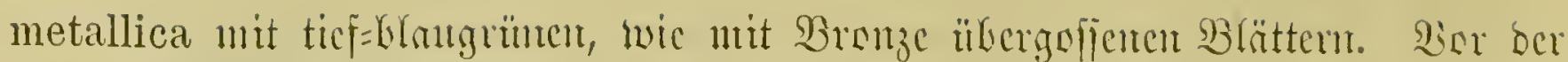
Strnmform fort fic bon Sorzug, baf fie feinen Etrmm befizzt.

Son fonftigen Barietäten ift bie bebeutenbfte Var. de cora; Blätter rojenrot,

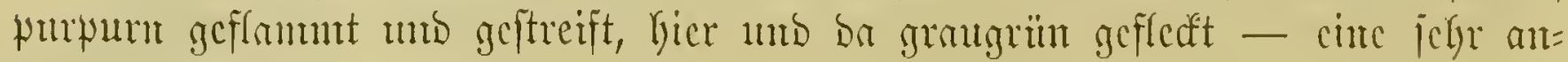

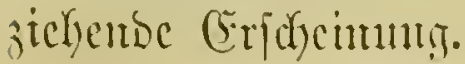

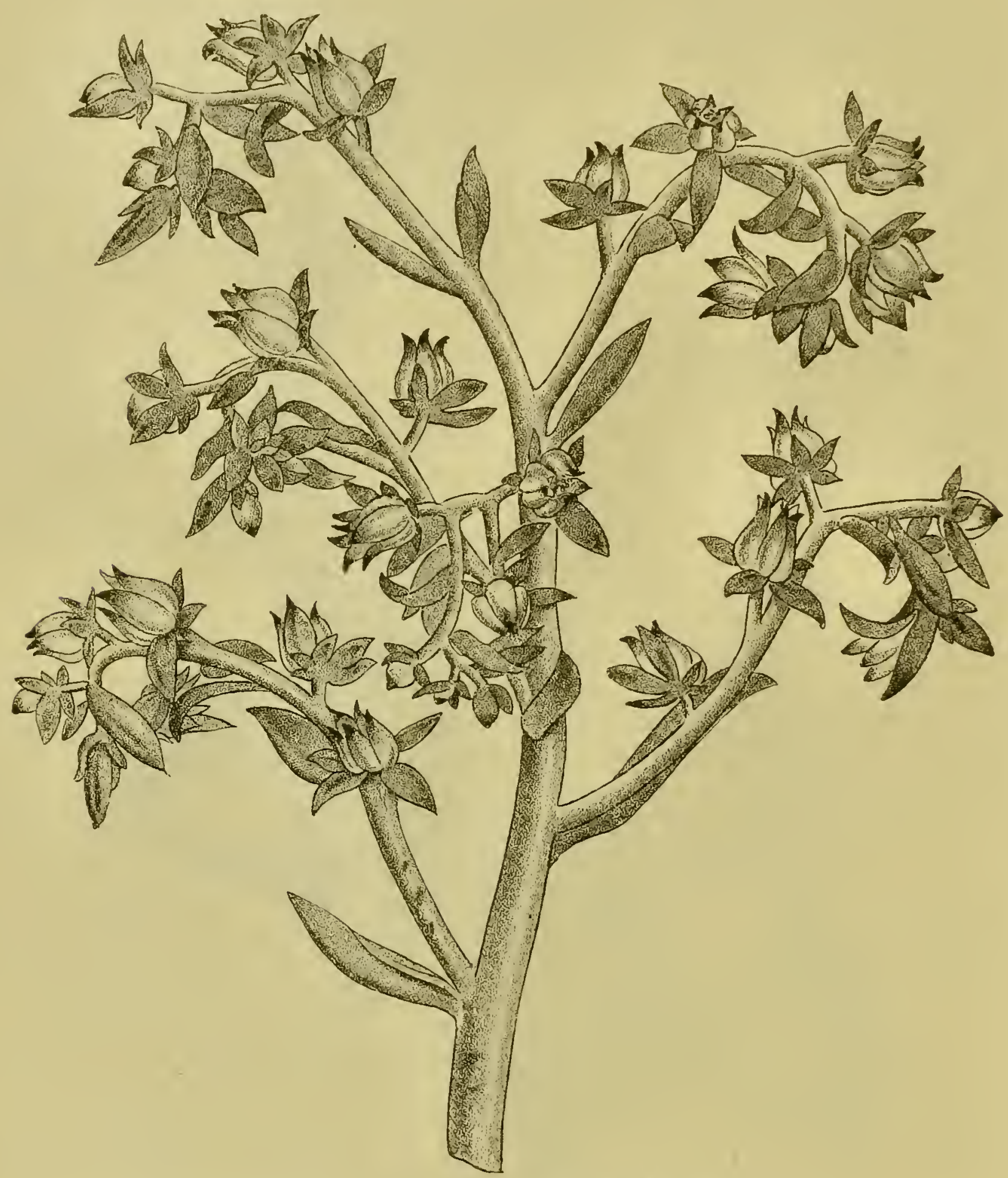

Jig. 46. Echeveria gibbiflora DC. var. metallica Bak. (Silutenftano.)

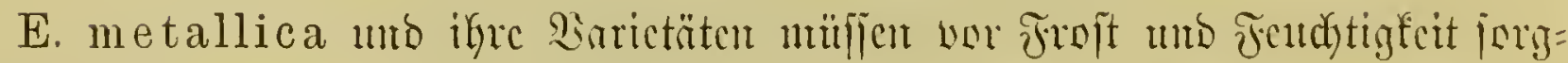

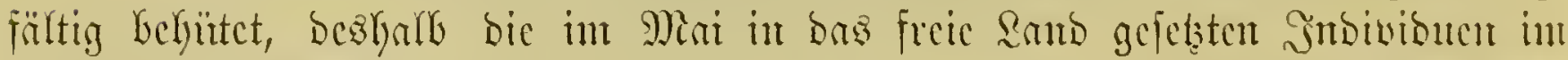

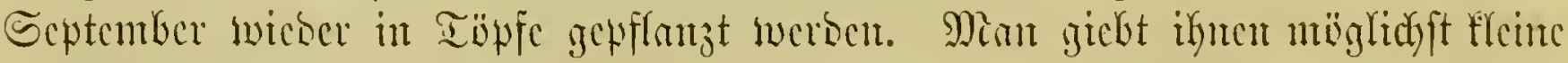

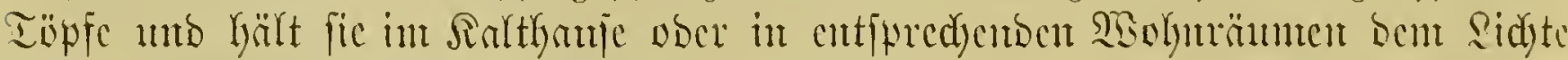

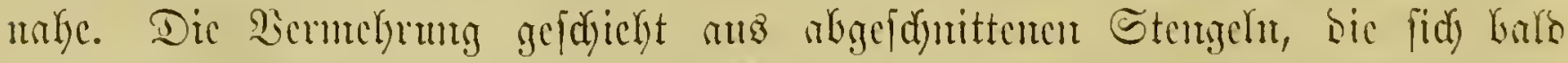

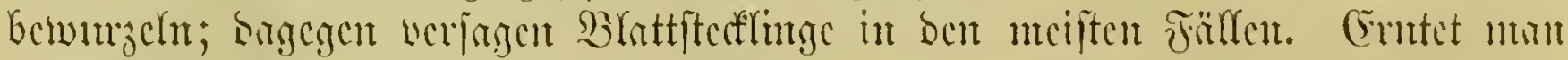
Samen, fo fäe man ifn fofort ans mo halte ifn mäpig want. 
13. Feheveria agavodes Lem. Plgnumatige Erocuctic.

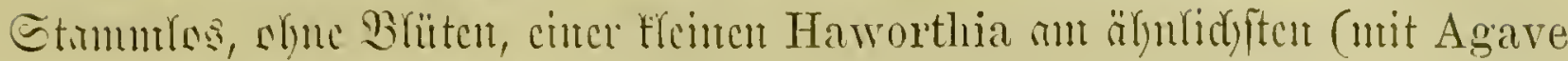

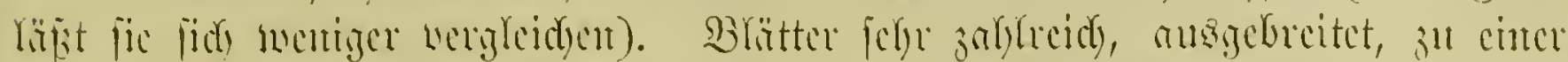

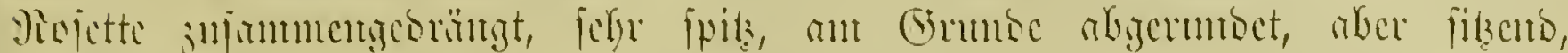

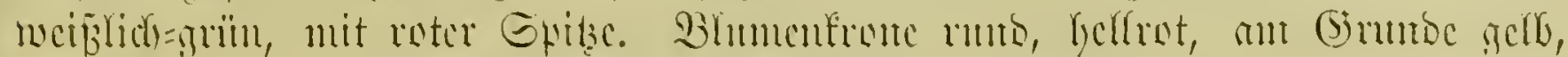

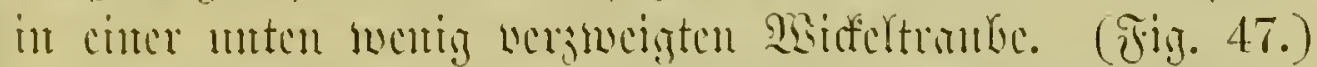

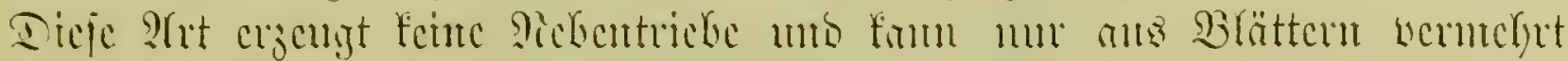

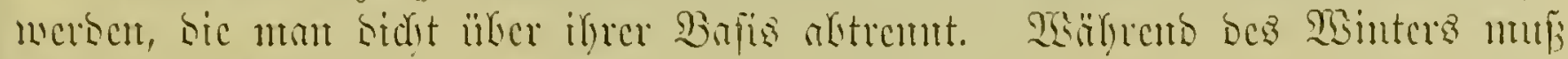

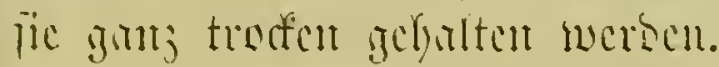

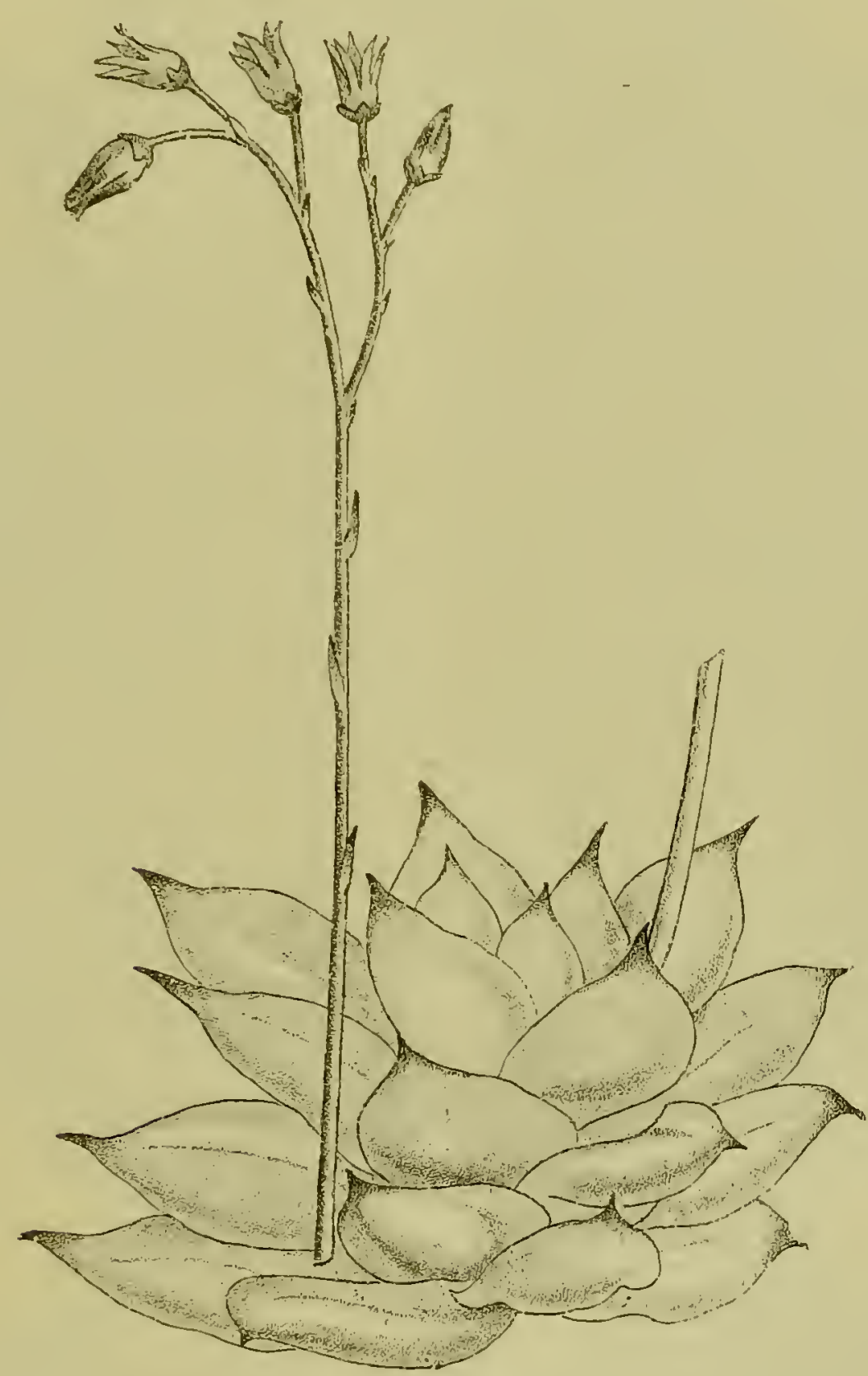

Fig. 47. Echereria agavoides Lem. Ngavenartige Edeverie.

\section{Echeveria pulverulenta Nutt. Pubcr=Ödoucric.}

Etamm gegen $16-25 \mathrm{~cm}$ Yod). Brätter ber 9iojette ansgebreitet, bis

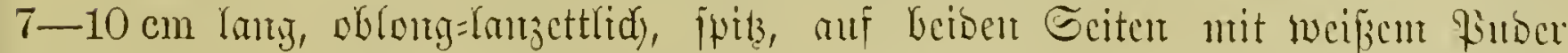

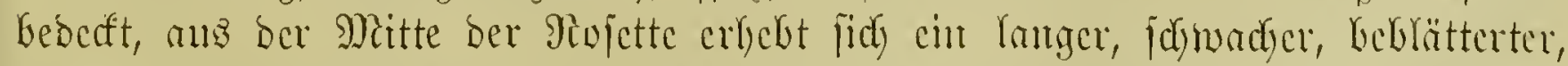
ctruas werätelter Etengel, ber fich gabelig teilt; jeber srit ift mit gelbroten, bängendon Blïten Yocfer Gejelzt. 


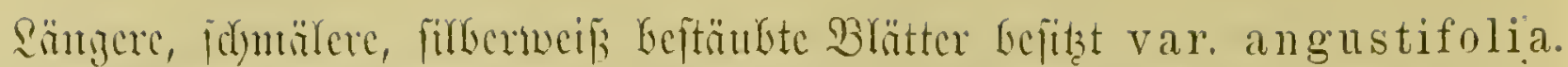

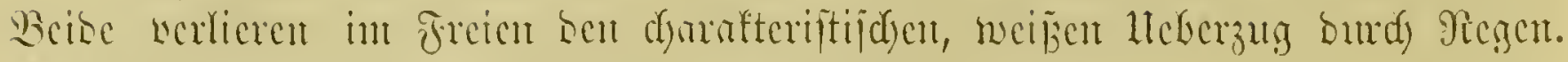

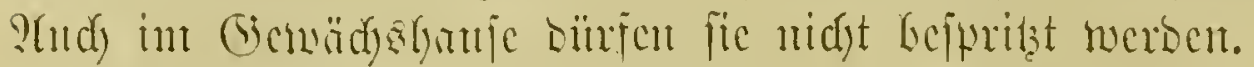

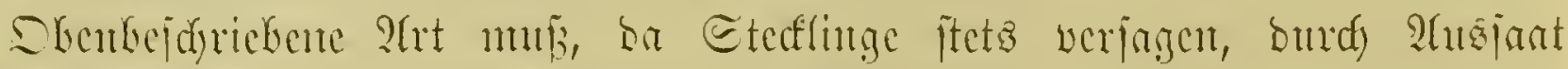

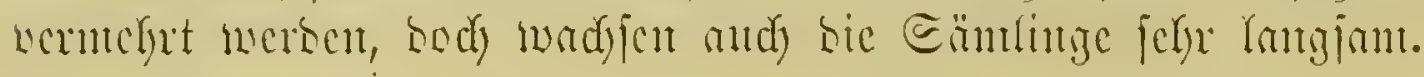

\section{Echeveria campanulata Kre. Glodfublumige Ed)cucric.}

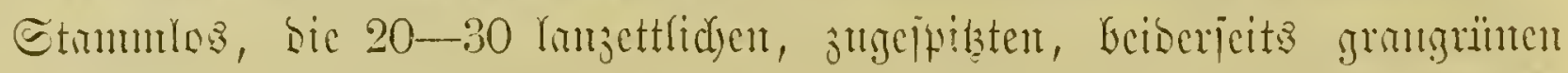

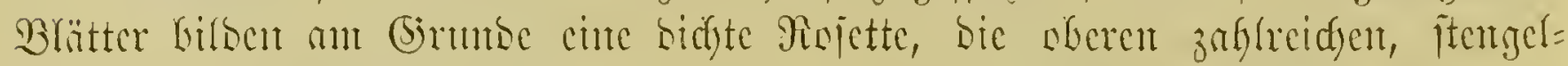

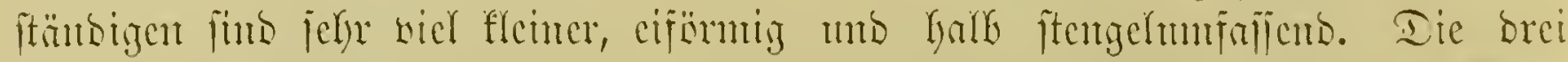

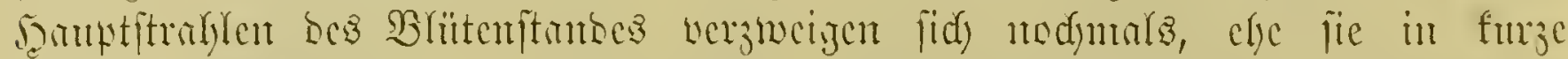

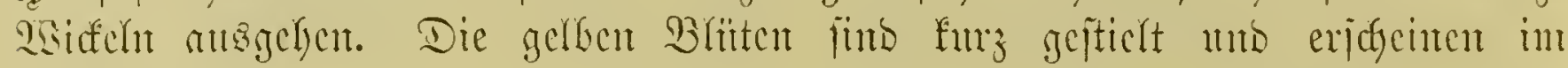
Fritigommer.

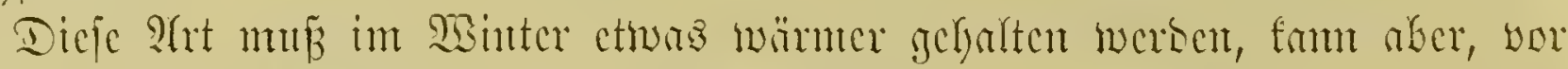

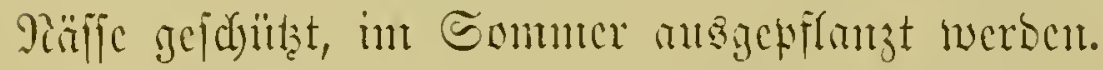

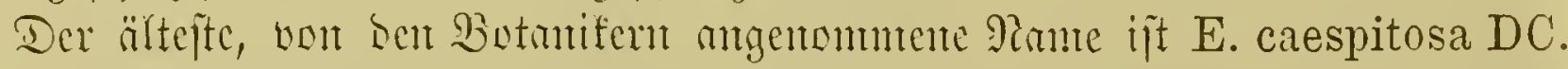

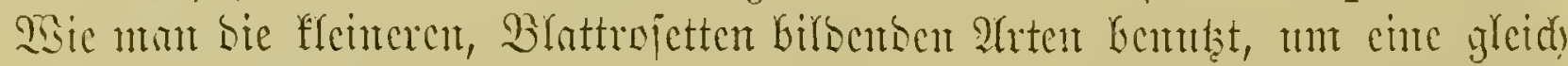

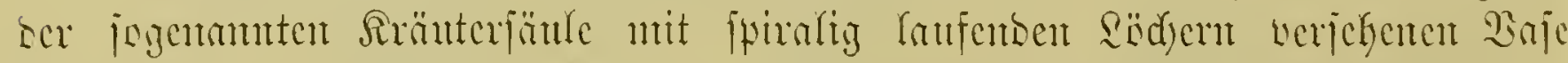

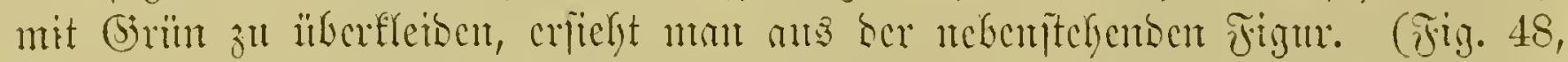
હ. 85.) Sic obcufteluctic Fiflanje ijt Echeveria metallica.

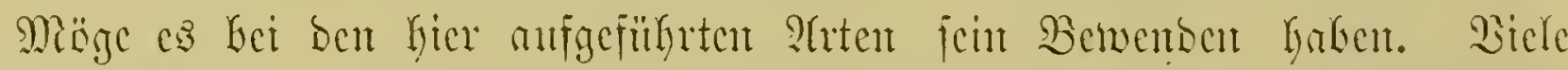

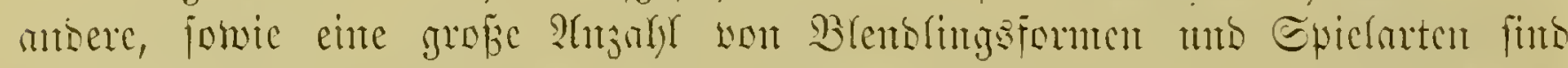

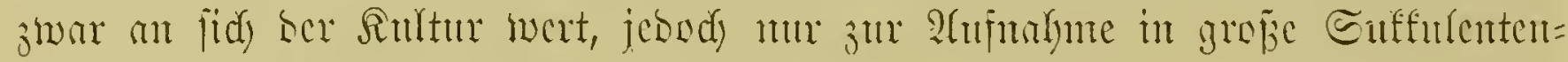
iannmluntgen geeignet.

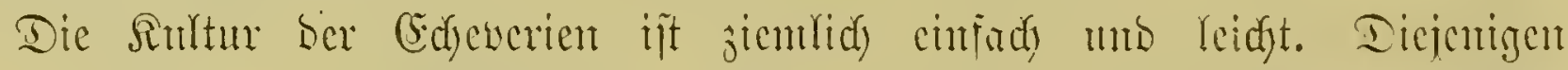
Srten, weldye cinen Etanm bilsen, werlangen in sinter cinten redyt beflen

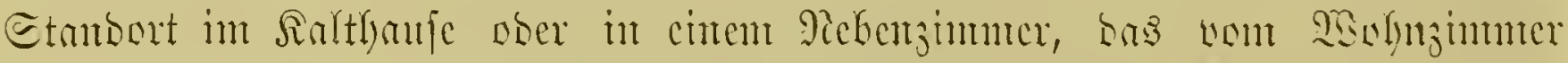

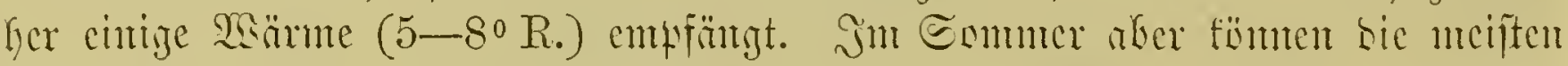

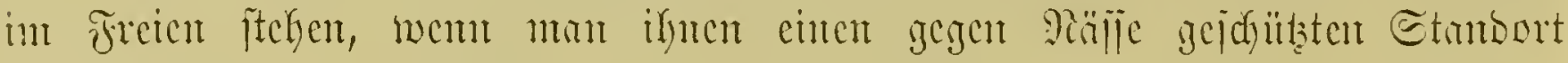
motucifen famt.

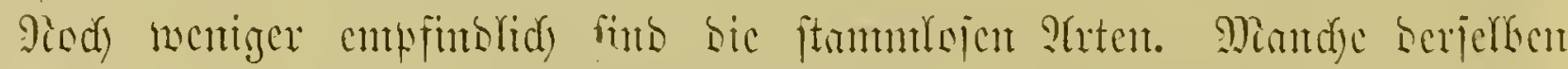

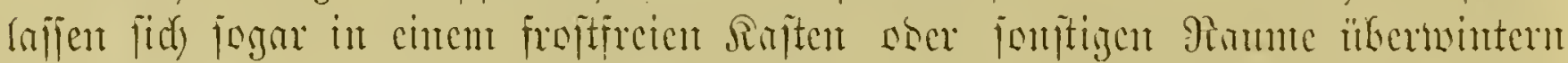

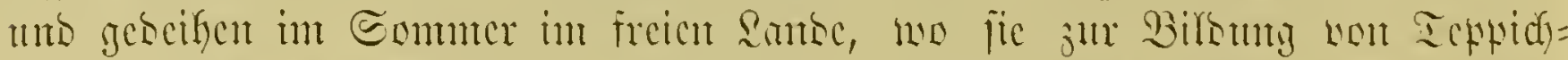

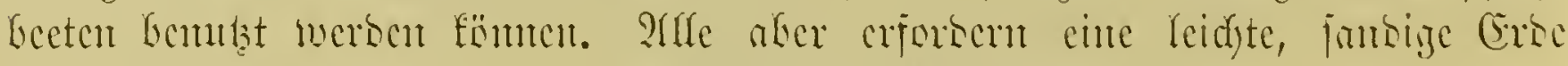

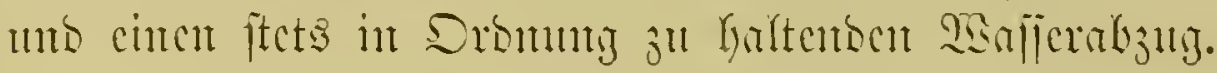

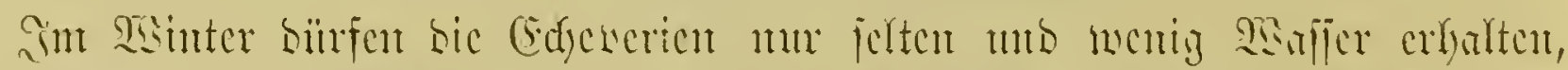

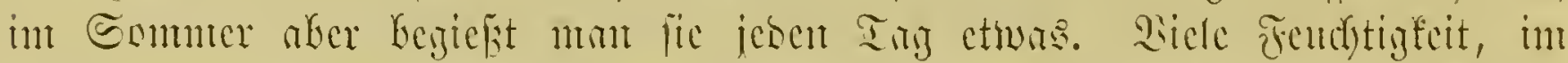

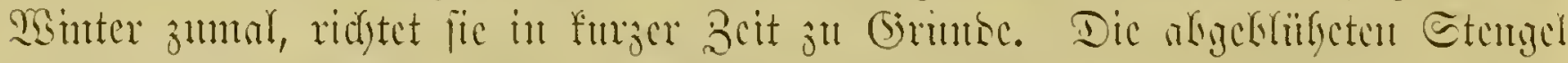

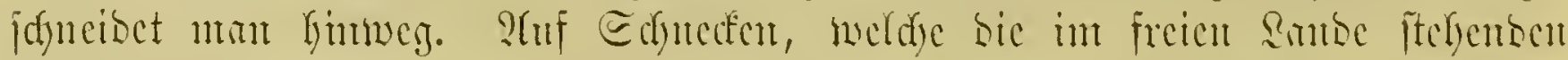

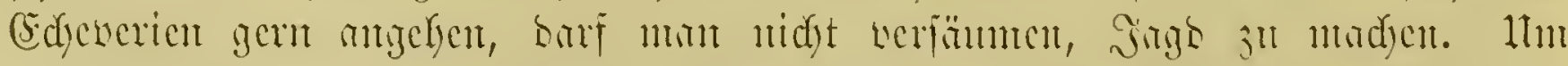

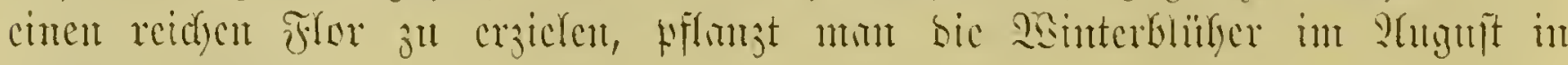
frifdes (sioreidy.

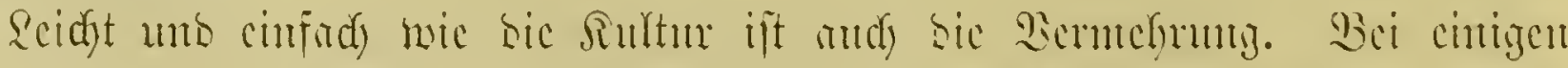

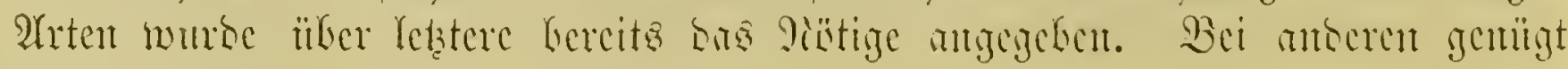




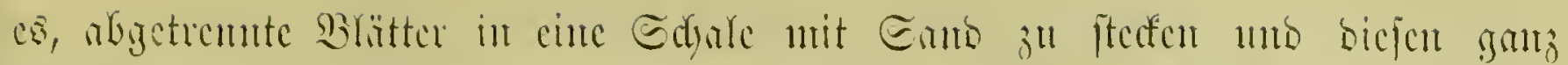

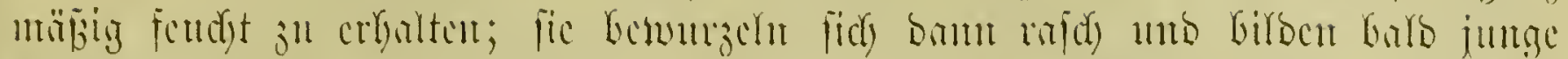

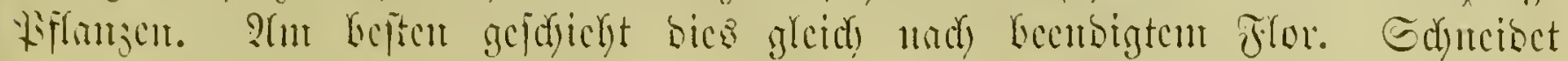

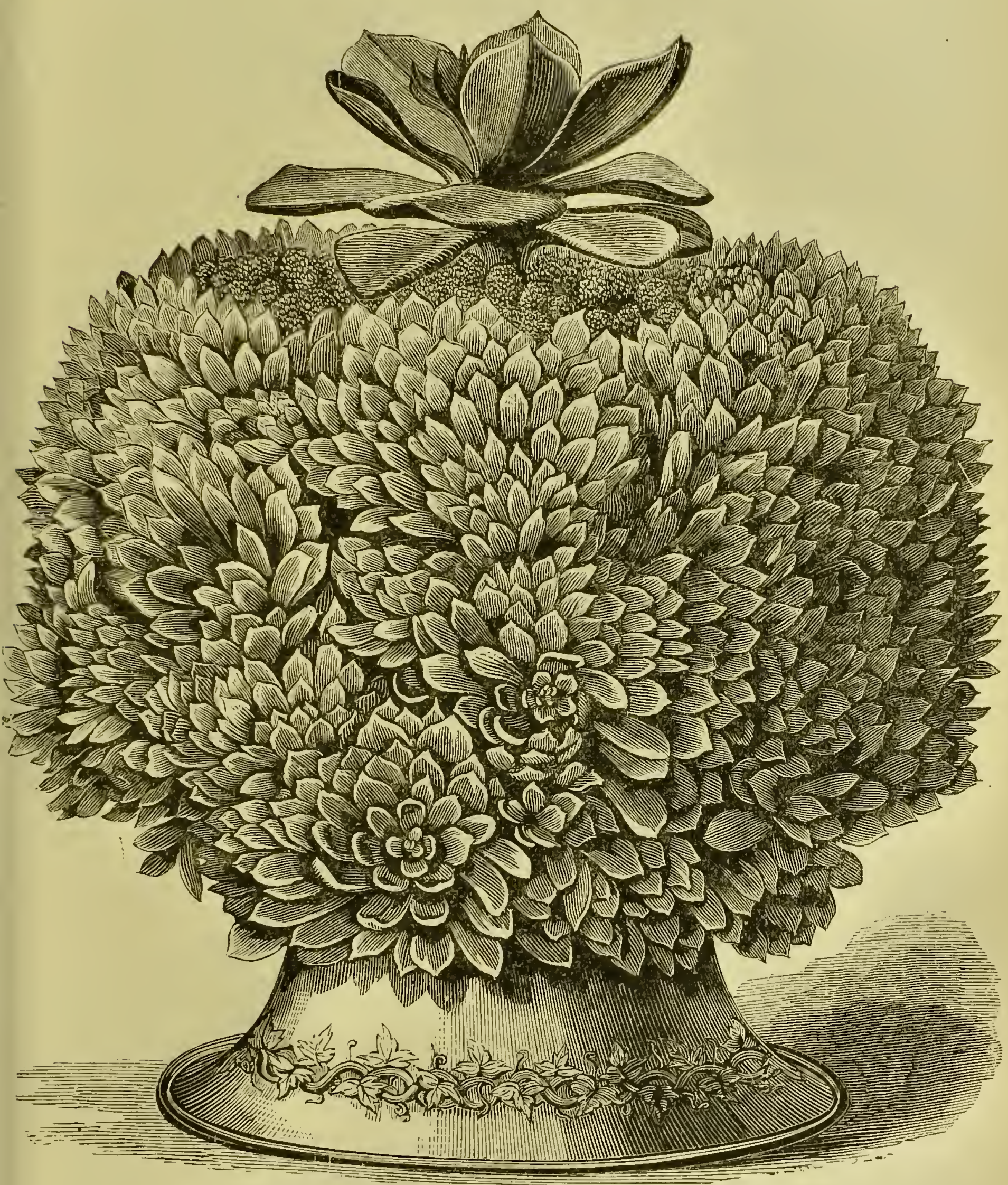

Fig̣. 48. Mit Edeverien befleibete $\mathfrak{B}$ aje.

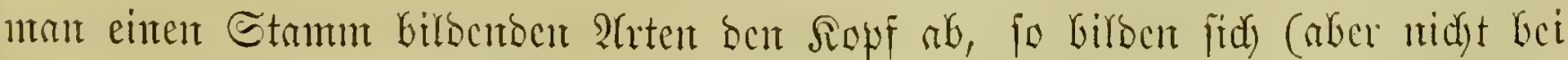

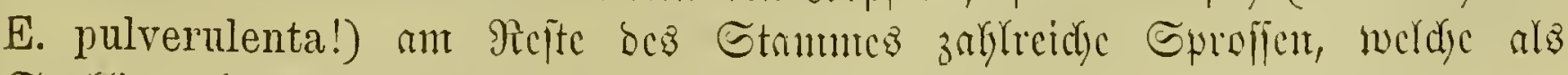
Stcuflinge bemubt werbour. 


\section{Battuniz Bryophyllum Salisb. Srutblatt.}

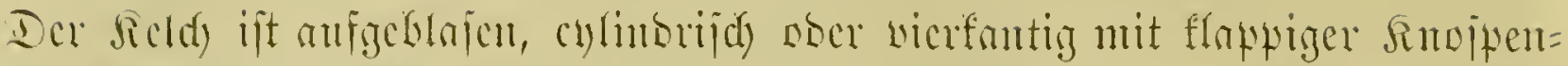

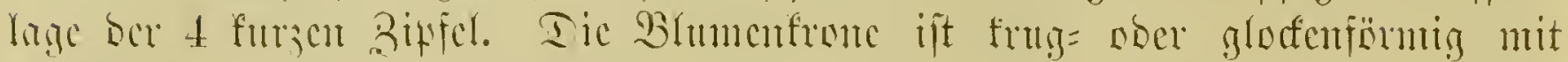

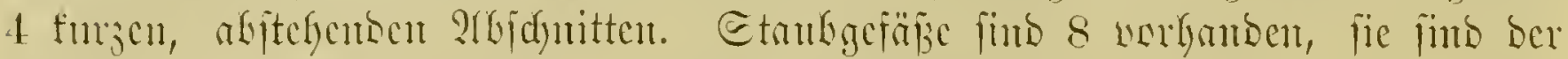

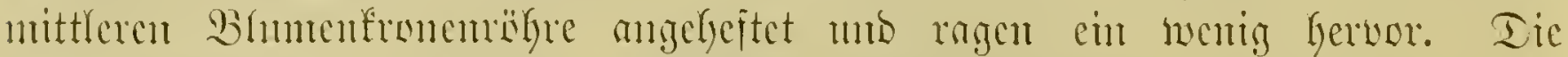

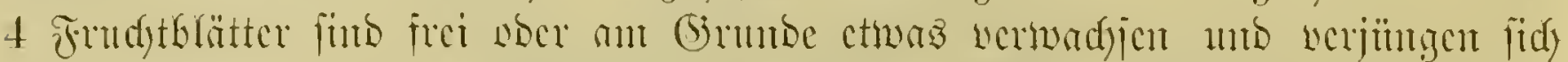

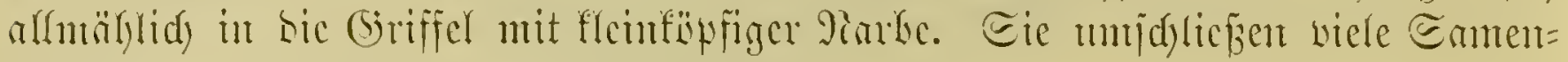
anlagen. Die Frudet ijt balgfapiclartig.

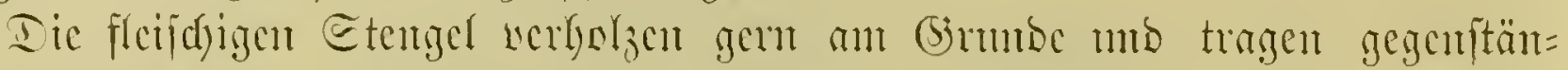

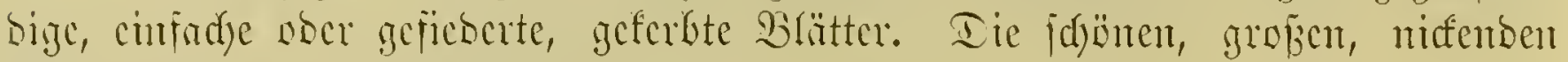

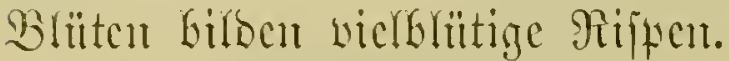

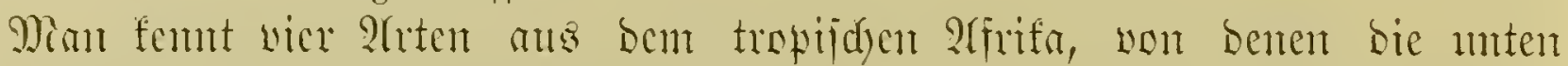
bejd)riebenc hente in alfen warnten Gegenben cine weit werbreitete Edyutt= pflonse ijt.

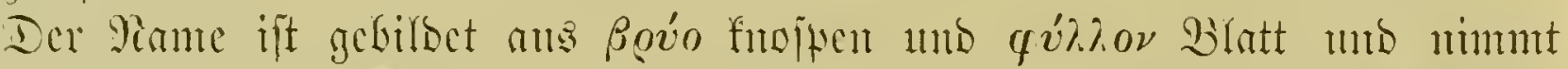

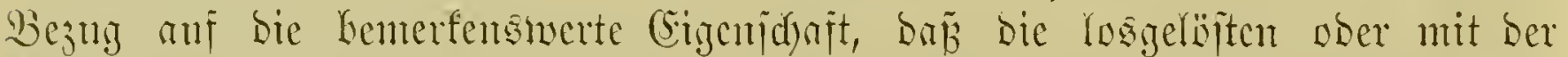

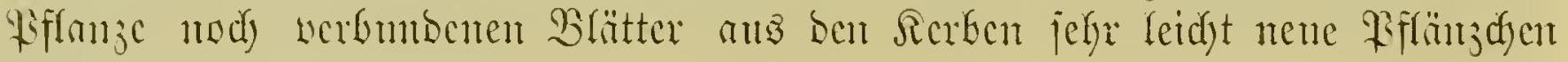
erjengent.

\section{Rryophyllum calycinum Salisb. Grofefelobigez Brutblatt.}

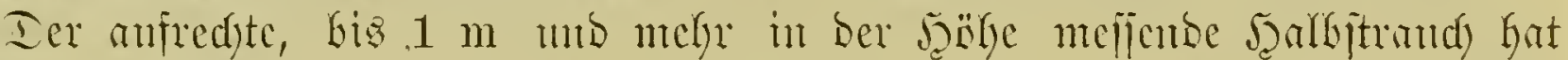

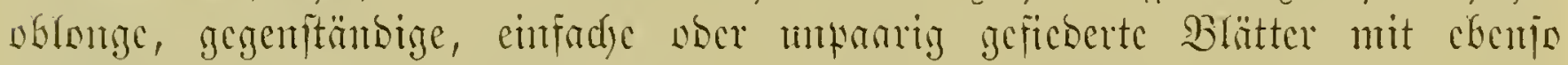

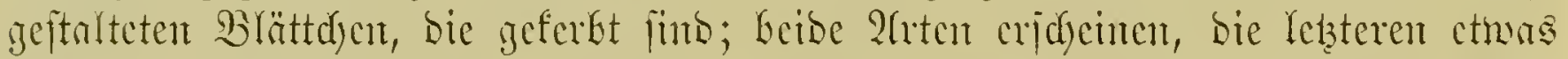

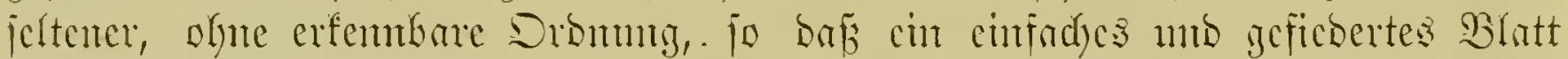

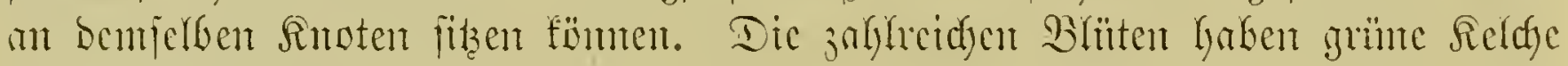

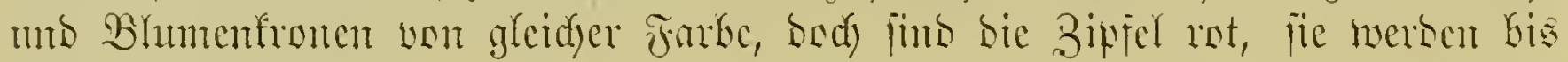
$3 \mathrm{~cm}$ lants.

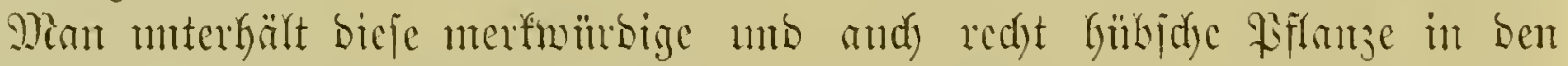

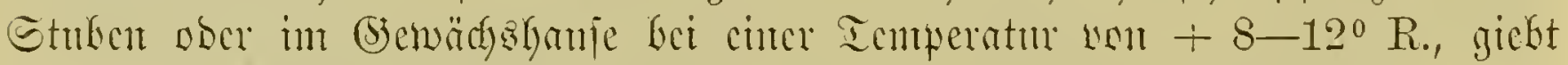

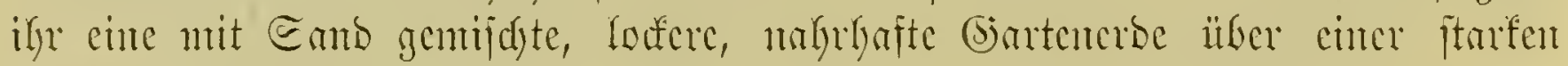
Edjerbonlage.

\section{Battını Kalanchoë Adanson. Sinlaudjoë.}

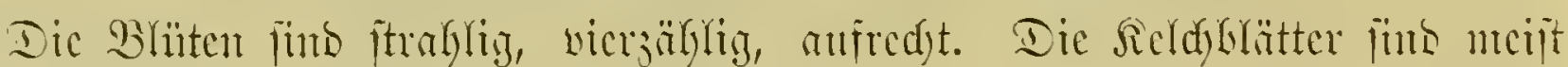

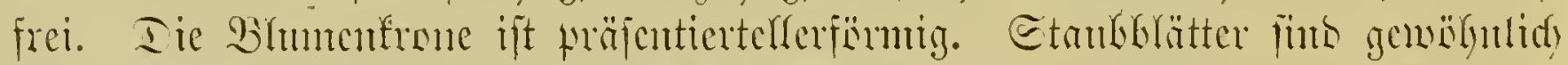

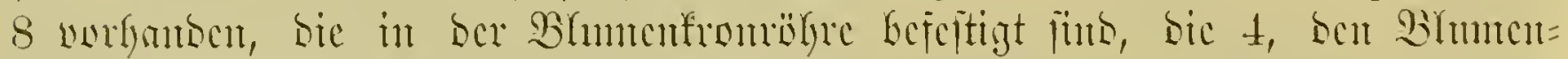

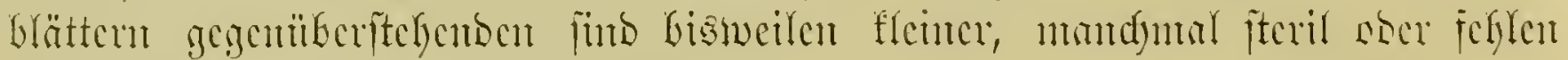
gans. Sic Frudetblätter jüb frei.

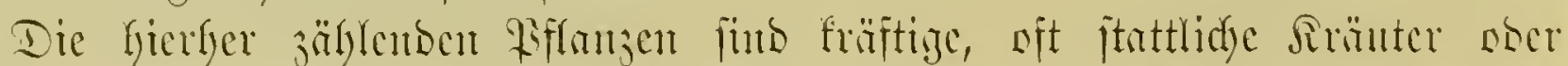

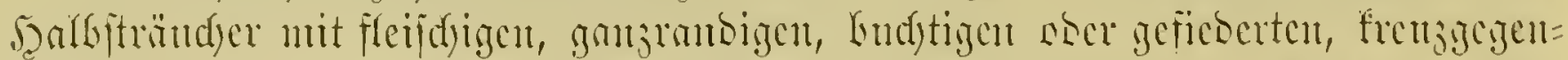

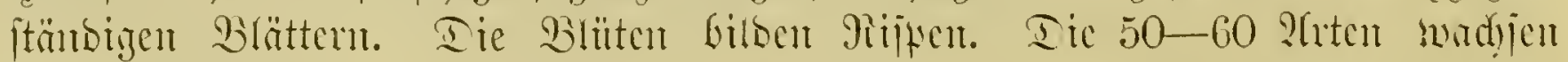

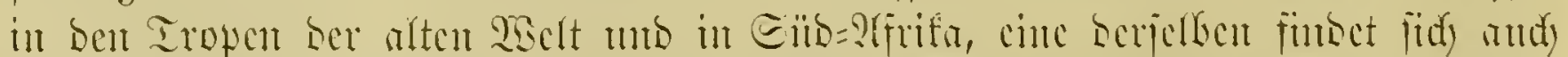

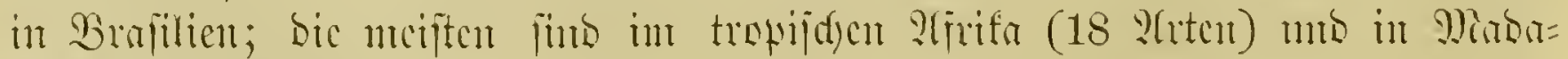

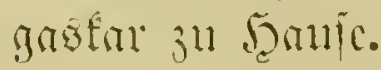

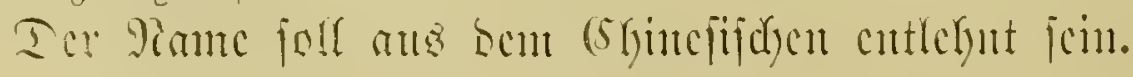


Sdilifiel fiir die befdriebenen Zrten.

A. Brïten $2-3 \mathrm{~cm}$ Inng

B. Blïtelt $1-1,5 \mathrm{~cm}$ lnutg.

a) Brätter tief ficolerpaltig

b) Blätter gamz.

a) $\mathfrak{R}$ lätter ganzrantoig

ア) $\mathfrak{B l a ̈ t t e r ~ g e t e r b t . ~}$

I. Brätter jeicht geferbt, ipib

II. Blätter tief boppelt=geterbt, ftumpf

1. K. grandiflora Wight et Avn.

2. K. laciniata $D C$.

3. K. farinacea Balfour.

4. K. spathulata $D C$. 5. K. crenata Haw.

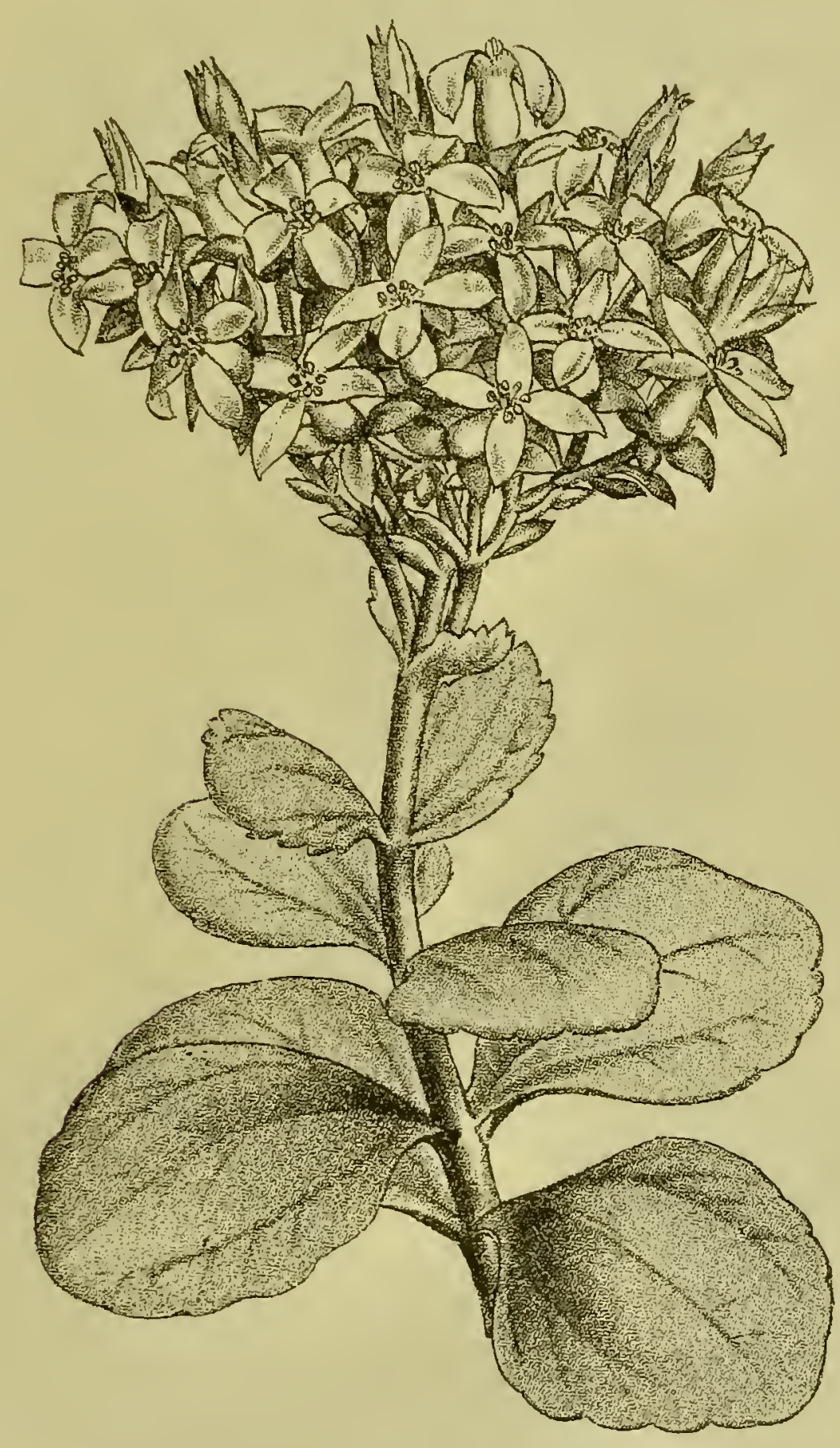

Fig. 49. Kalanchoë grandiflora W. et Aln. Groß̧blumize Ialandyö.

\section{Kalanchoё grandiflora $W$. et Am. Grophblunige Salaudjoë.}

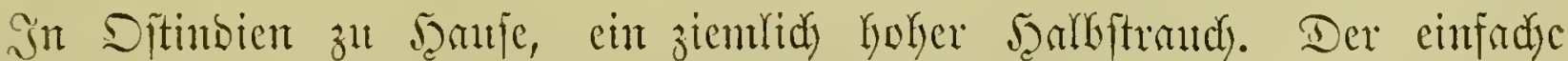

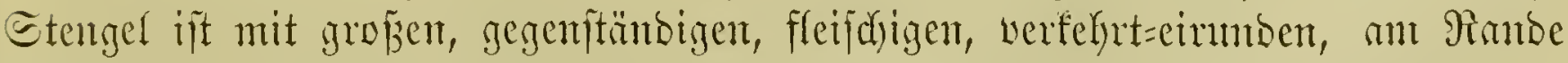

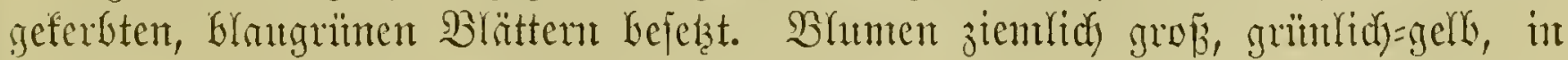

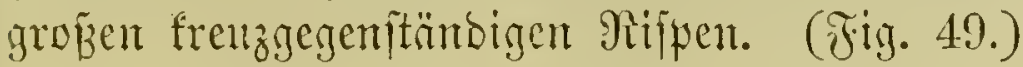




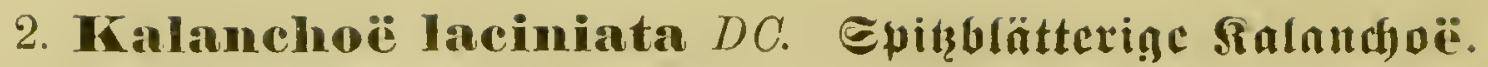

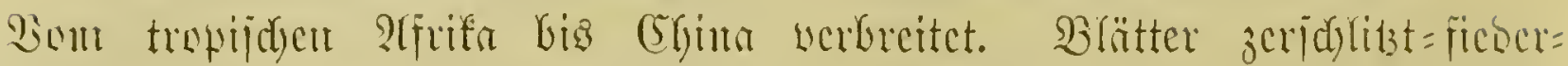

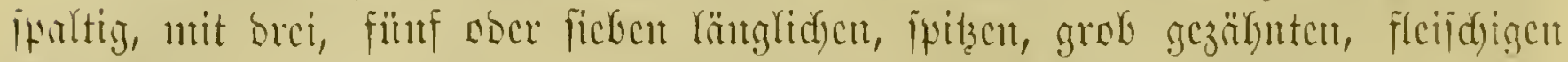

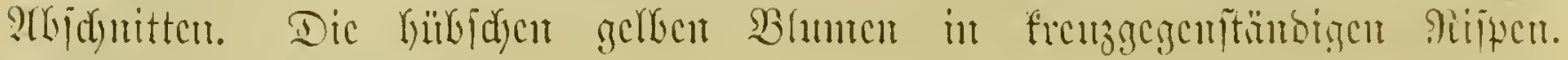
Blittescit ber Goututer.

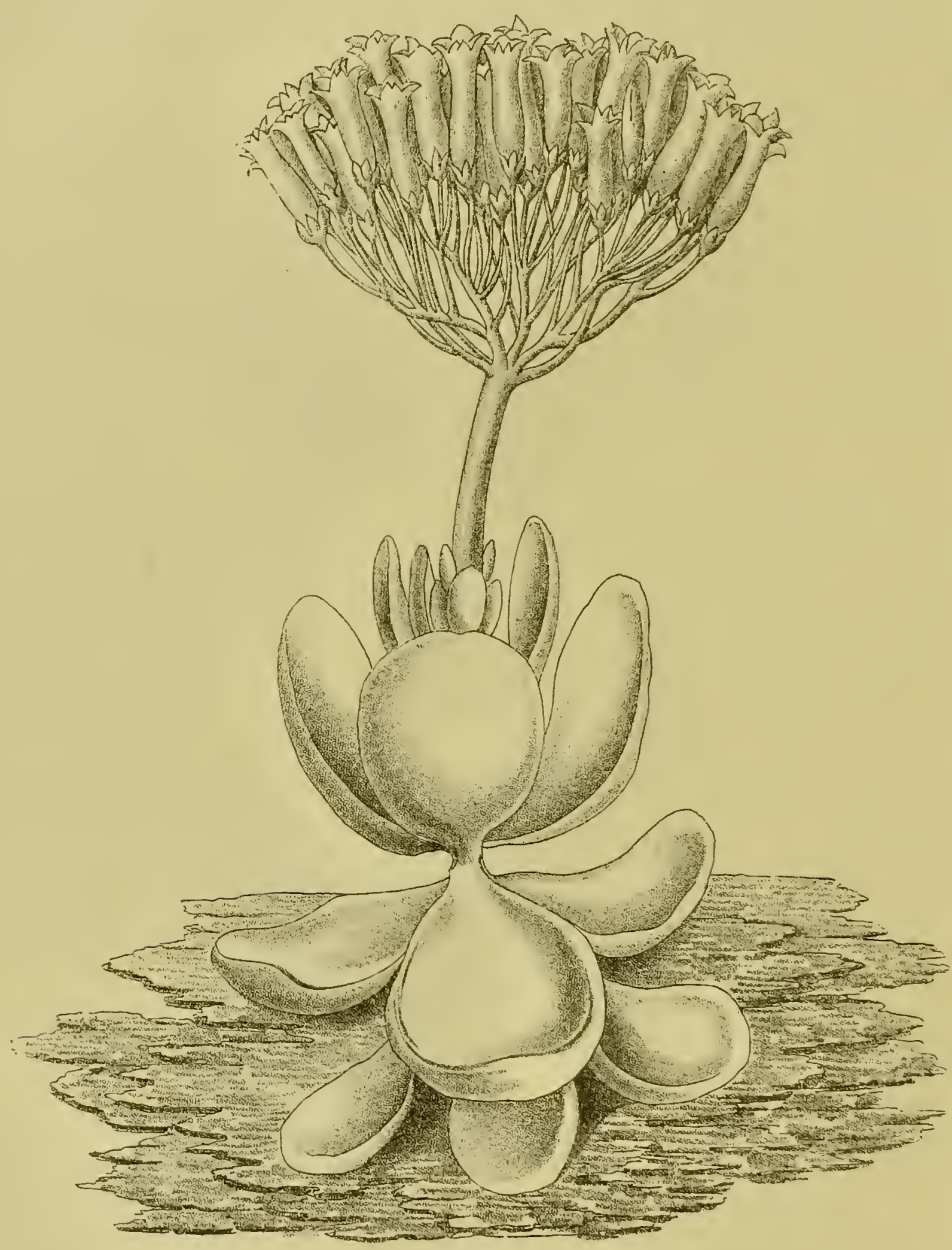

Fig. 50. Kalanchoë farinacea Balf. Mehlige Siafanduvë.

\section{Kalanchoë farinacea Balf. Michlige Sialandyoë.}

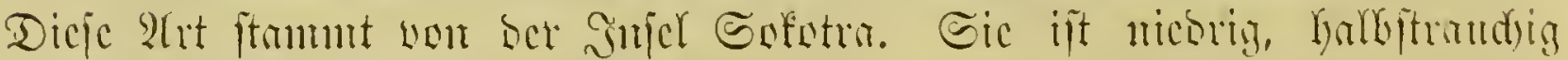

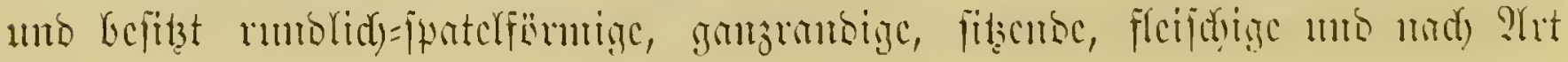




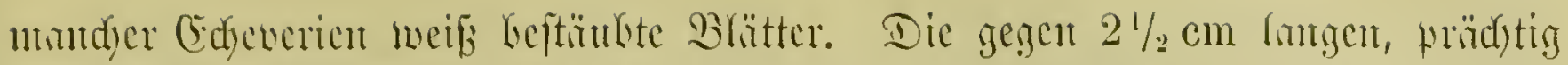

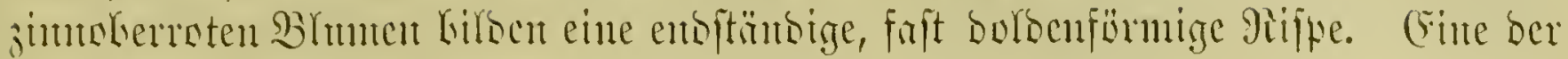

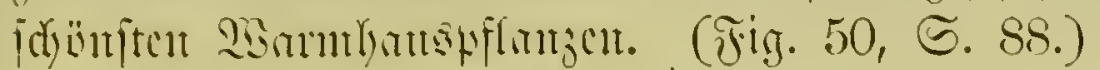

\section{Kalanchoë spathulata $D C$. Epatelblütterige Salautdoë.}

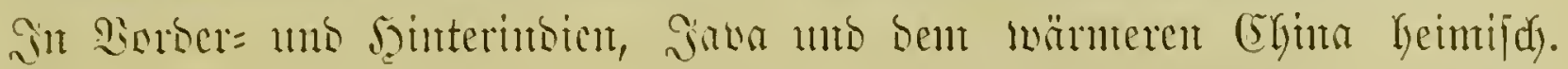

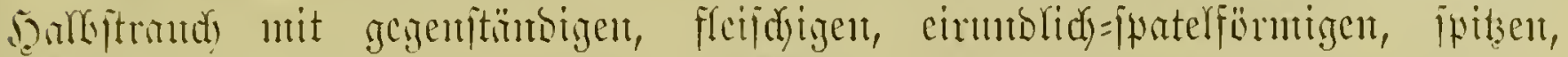

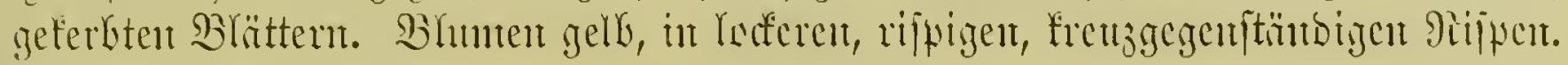
B̧Yïtçeit ber Gonumter.

\section{Kalanchoë crenata Haw. Geferbte Salandjoë.}

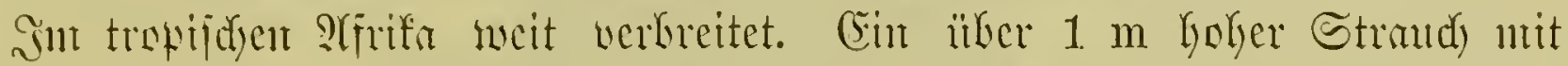

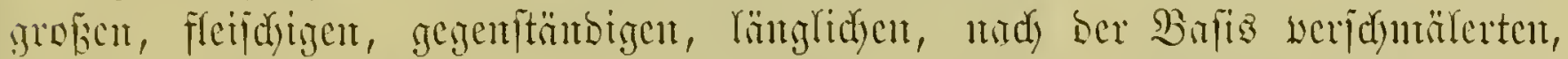

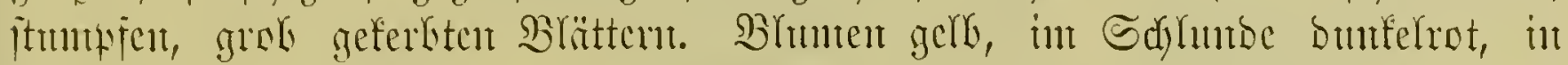

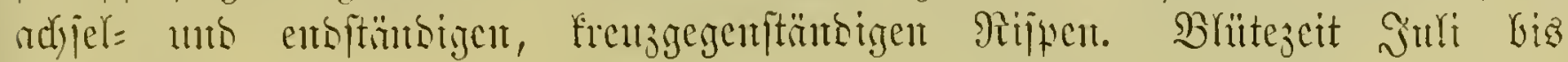
Septentier.

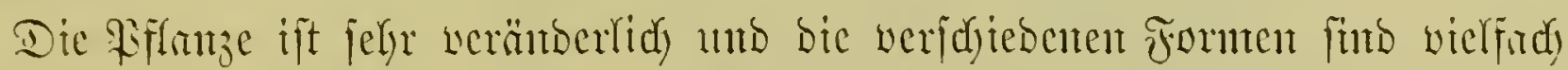

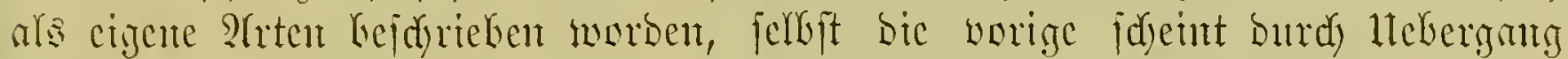

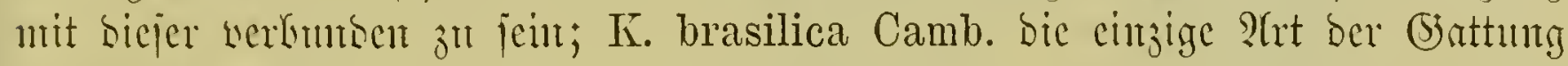

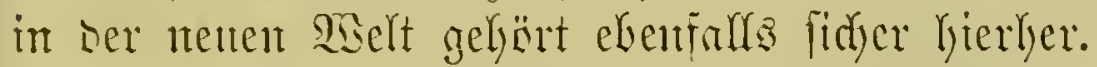

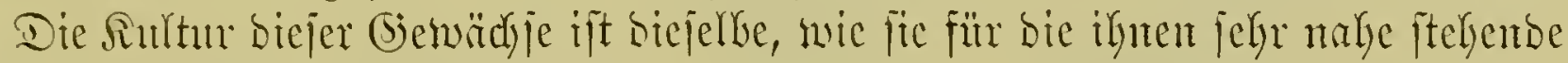
(5isttung Cotyledon intgegebut ivurbe.

\section{Gattung Crassula L. Didablatt.}

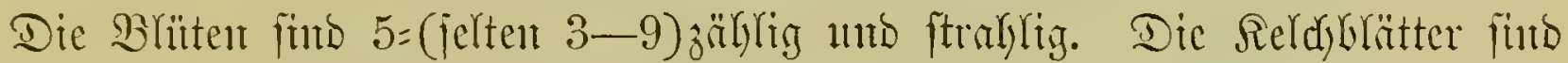

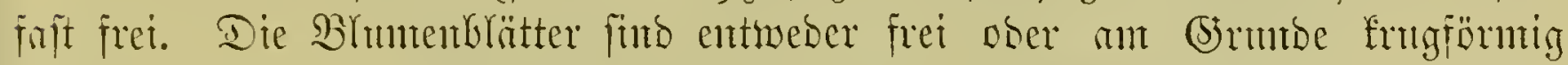
wereint und io grof ober gröfier als ber Reldy. Staubbrätter fint mur fo viele

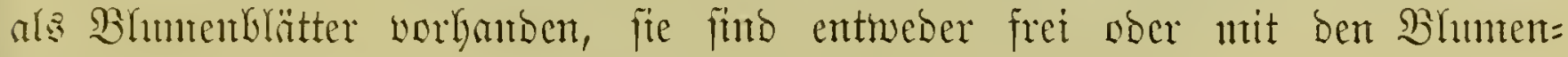
Grätterut wermadjen.

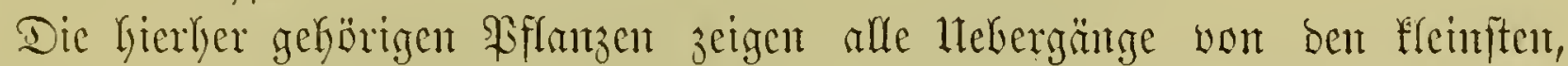

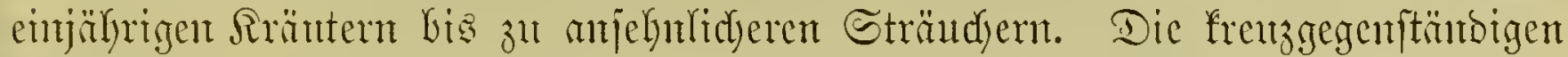

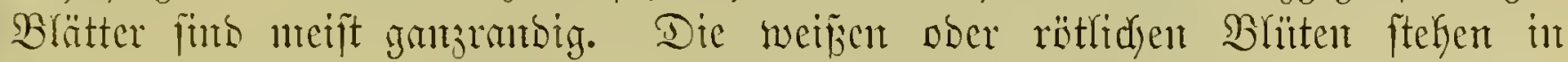

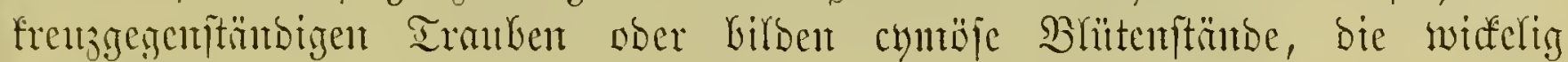

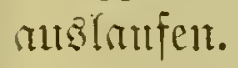

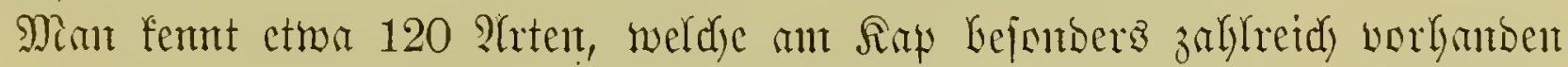

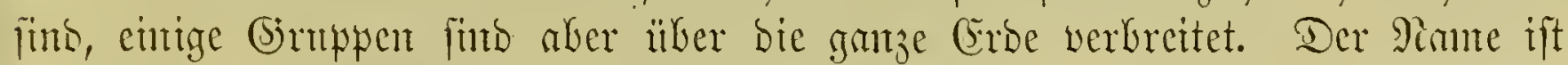

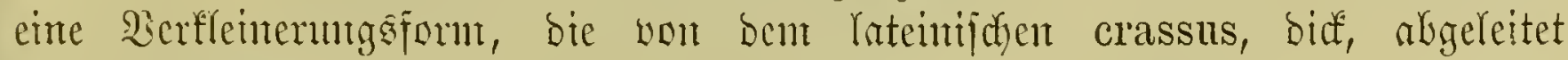
worbent ijt.

\section{Sđlïffel für die befdriebenen 2Urter.}

A. Blumenblätter eiförmig ober umgelehrt eiförntig olye pfriemenförmige Spike. a) Stiflansent $\mathfrak{k} \mathfrak{a} \mathfrak{h l}$.

I. Seft. Eucrassula $D C$.

a) Slätter eiippatelförmig, am Bsrunte veriüngt, bort mit cinander zu= fammenhä̈tgend oder frei.

I. SBlätter frei, Relabblätter breit breijeitig; Blïten rot

1. C. portulacea Lam. 
II. Blätter verbmiden.

1. Blätter brcit berfebrt cifönnig, ftumpf mit Etachelipibc, Blitten roja 2. C. arborescens Willd.

2. Blatt oblong ungcfehrt ciförmig, ipiz, B̉ïten tocí

3. C. lactea $A$ it.

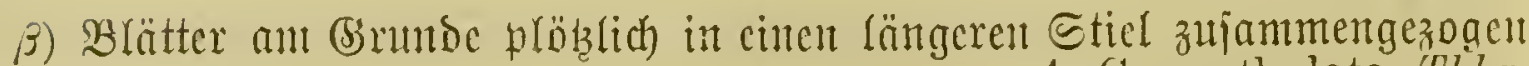
4. C. spathulata Thbg.

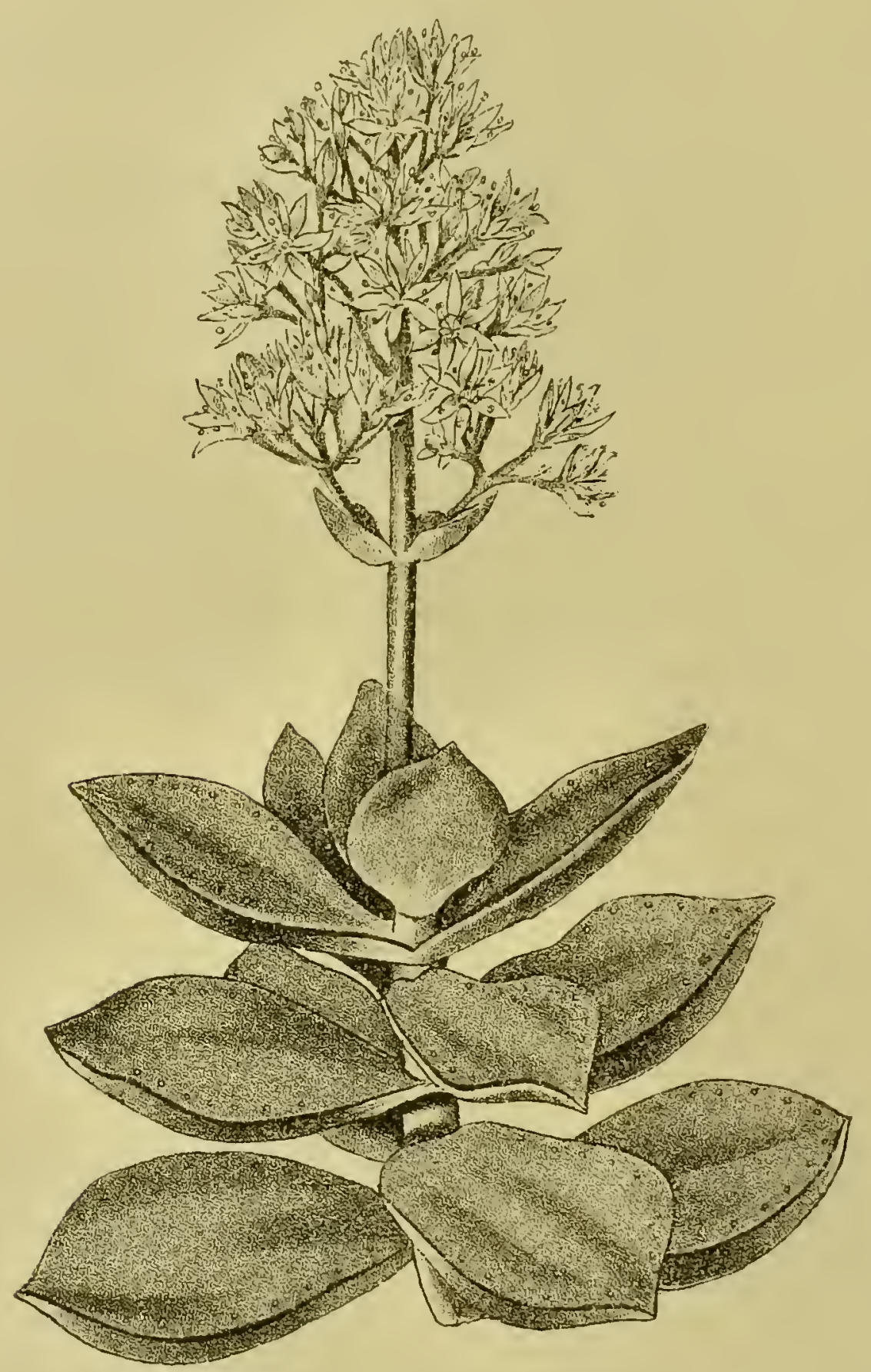

Fig. 51. Crassula lactea Ait. Miildweifes Didfblatt.

r) Blätter an Gimmbe nidht verichntälert.

I. Blätter lang, jhief fichelïormig anf bie hohe Rante gejtellt, Barare in getwunbenen 3eilen

5. C. falcata Willd. II. Blätter lang, eilanzettlid), Gorizontal aufgebangen!

6. C. perfoliata $L$. III. SBrätter fumz, eiförmig, anf ber ganzen Bajis breit mit eintudor b) Stengel behaart. verivadjien
7. C. perfossa Lam.

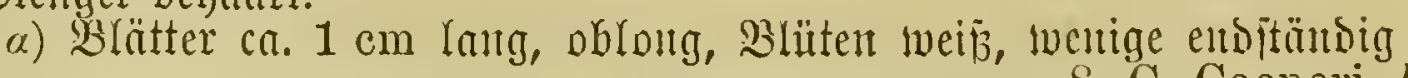

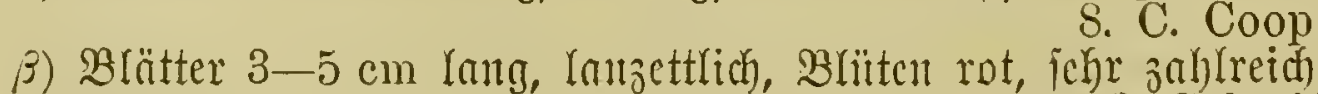

9. C. Schmidtii Regel. 


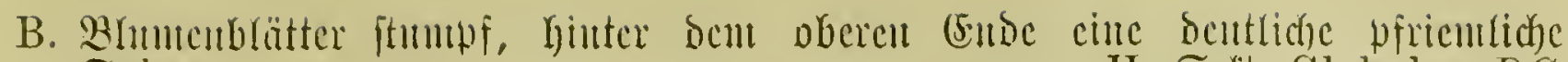
Enitic

II. Scft. Globulea $D C$. 10. C. ramuliflora $L /$.

\section{Crassula portulacea Lam. Purtulaf $=$ Dirfulatt.}

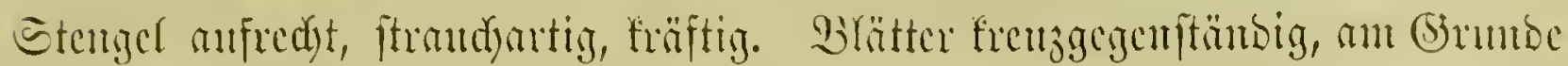

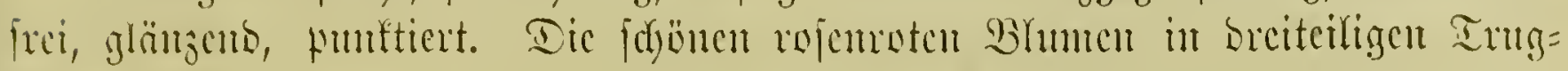
solson in Gonmer.

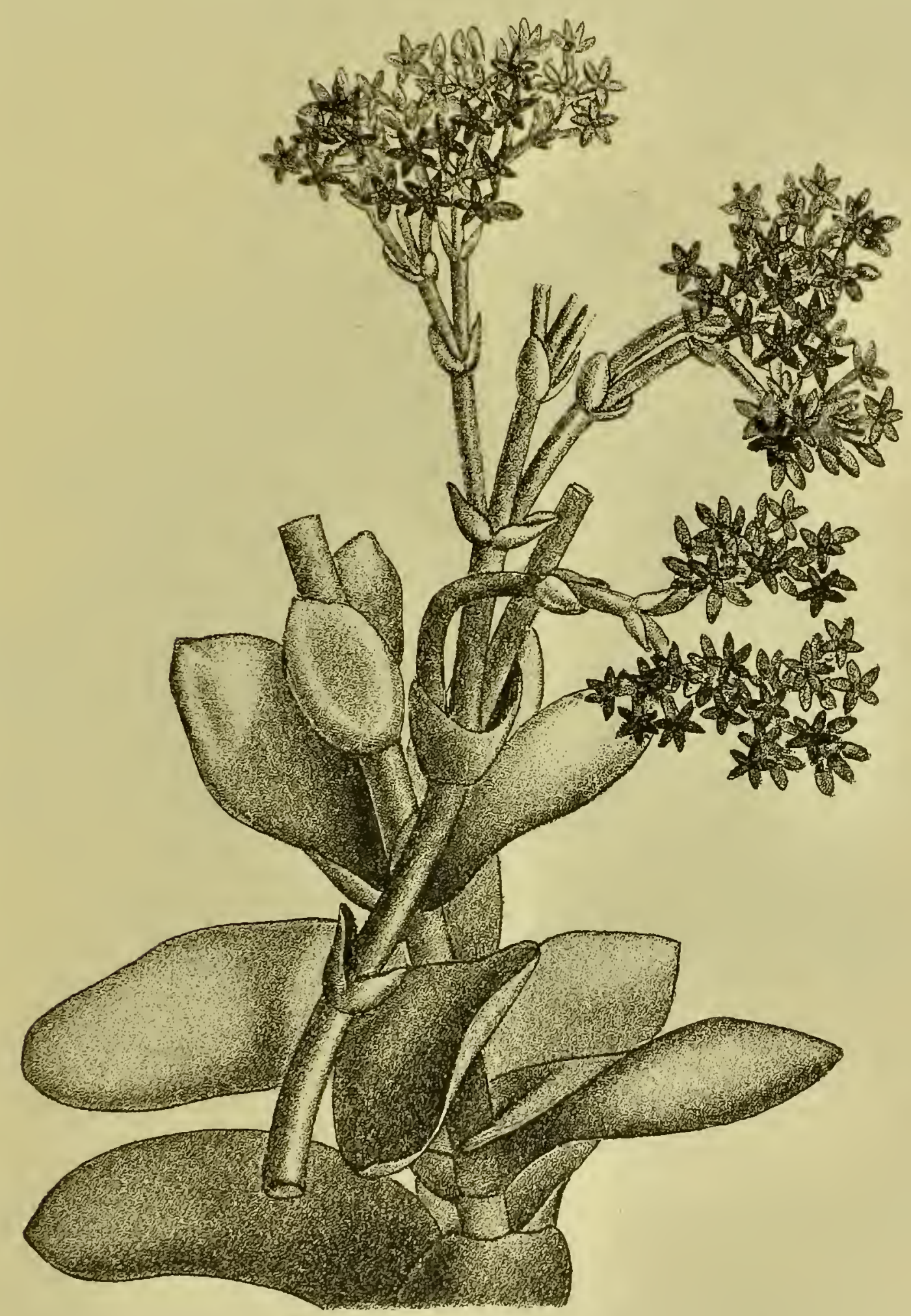

Fig. 52. Crassula falcata Willd. Eidfelblätteriges Dicfblatt.

\section{Crassula arborescens Willd. Baumnrtigez Dirfolntt.}

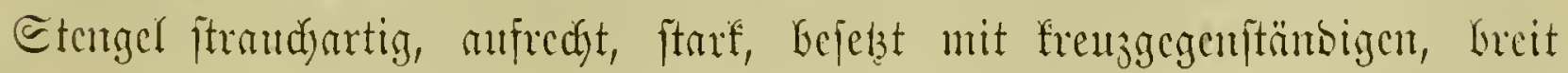

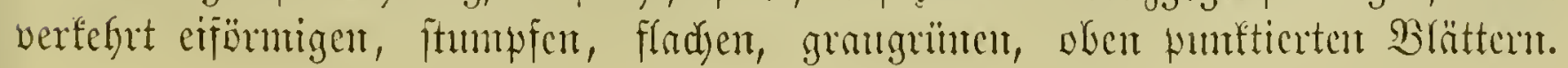




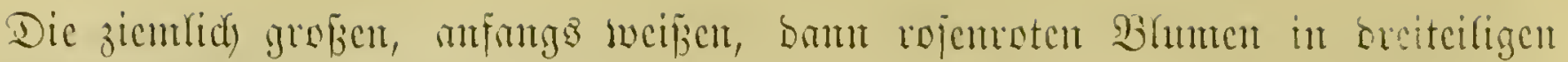
2fferbolben int Jumi unb Juti.

\section{Crassula lactea Ait. Milúfucižcz Diffblatt.}

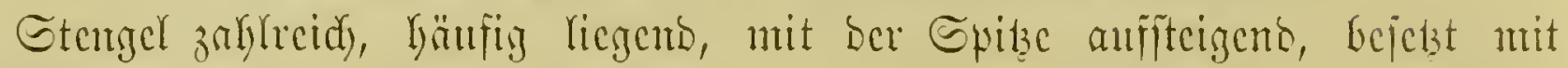

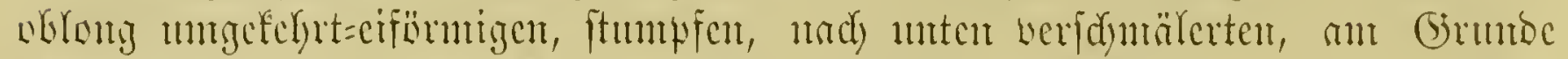

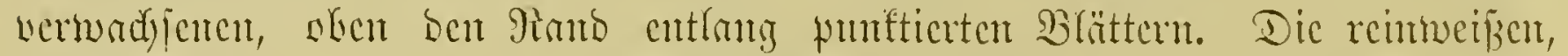

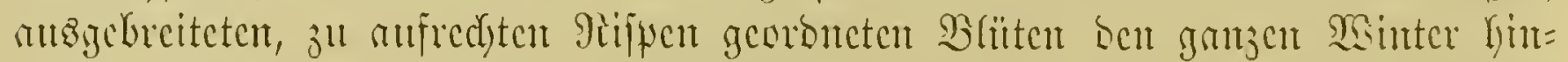

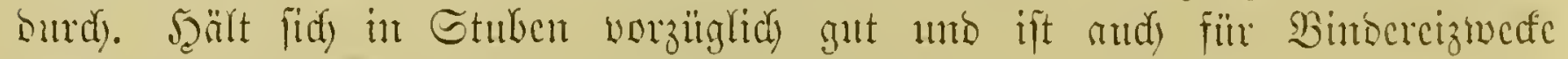
wertuoll. (Fig. 51, ธ. 90.)

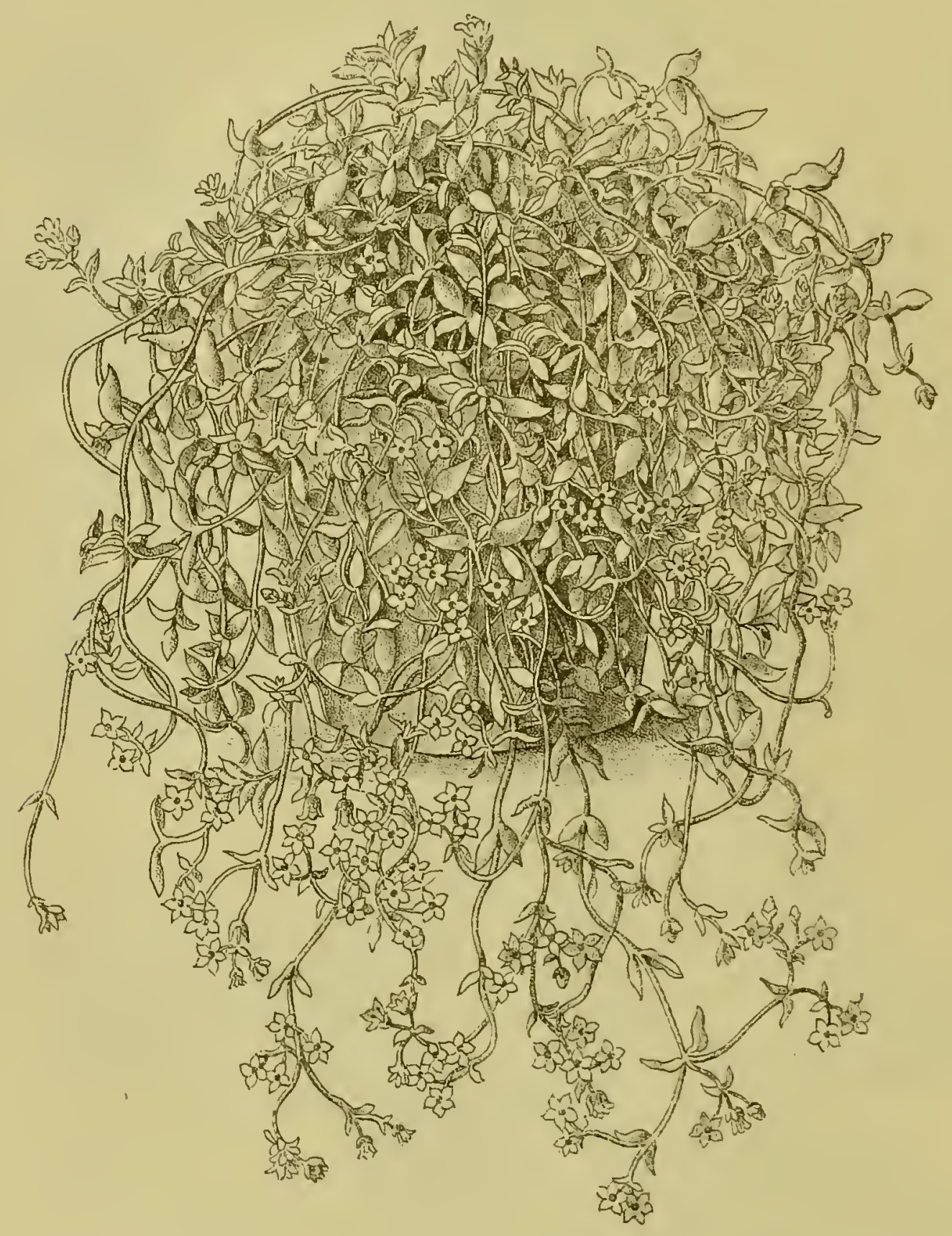

Fig. 53. Crassula Cooperi Rgl. Couper's Didfuratt.

\section{Crassula spathulata Thbg. Epatelblätterigez Dirfblatt.}

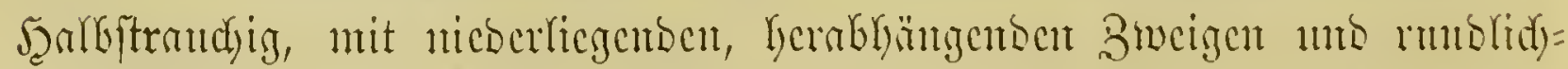

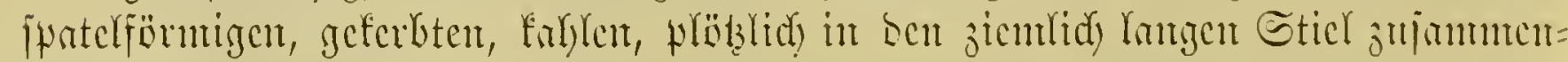

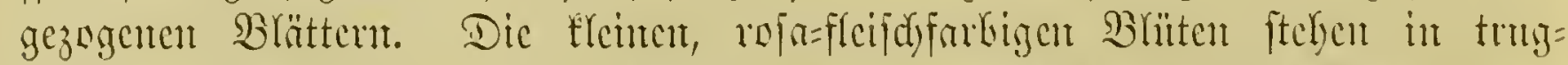

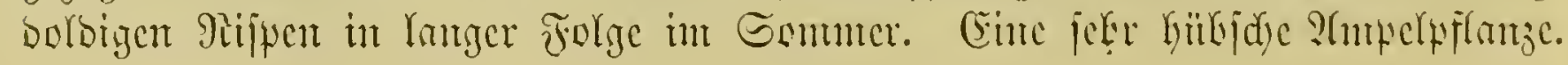




\section{Crassula falcata Willd. Eidbelblätteriges Dirfblatt.}

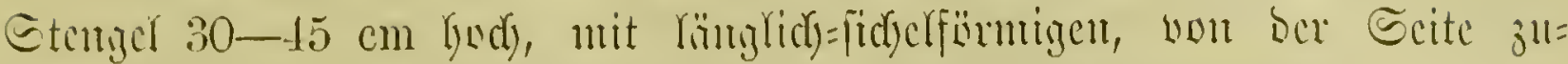

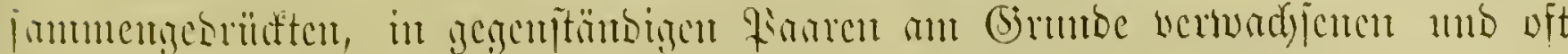

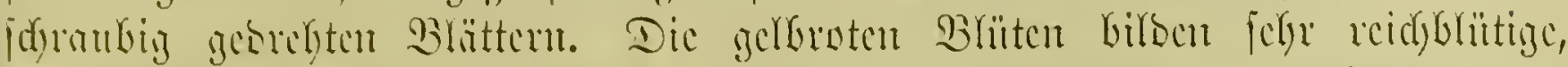

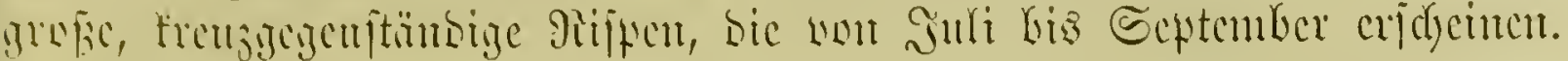

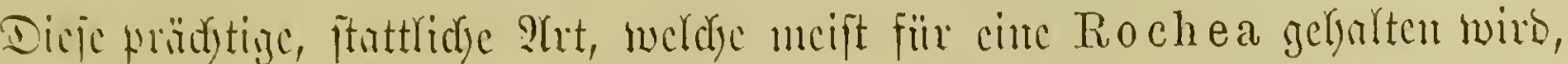

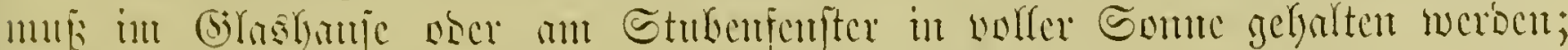

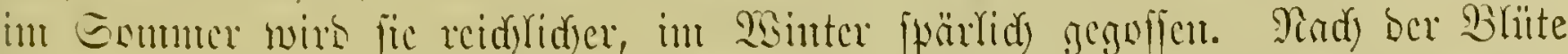

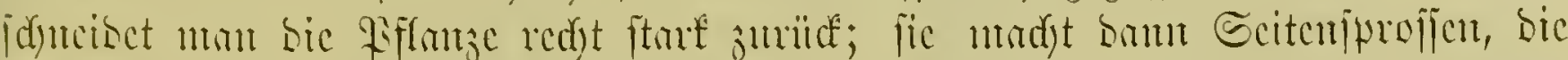

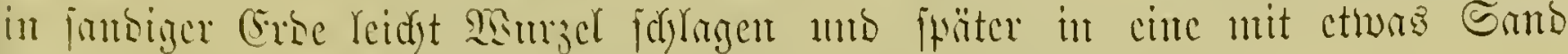

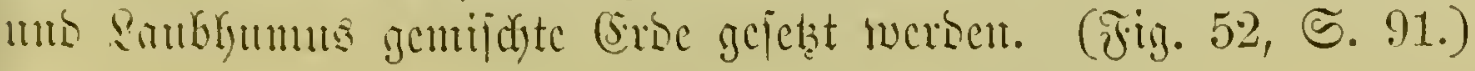

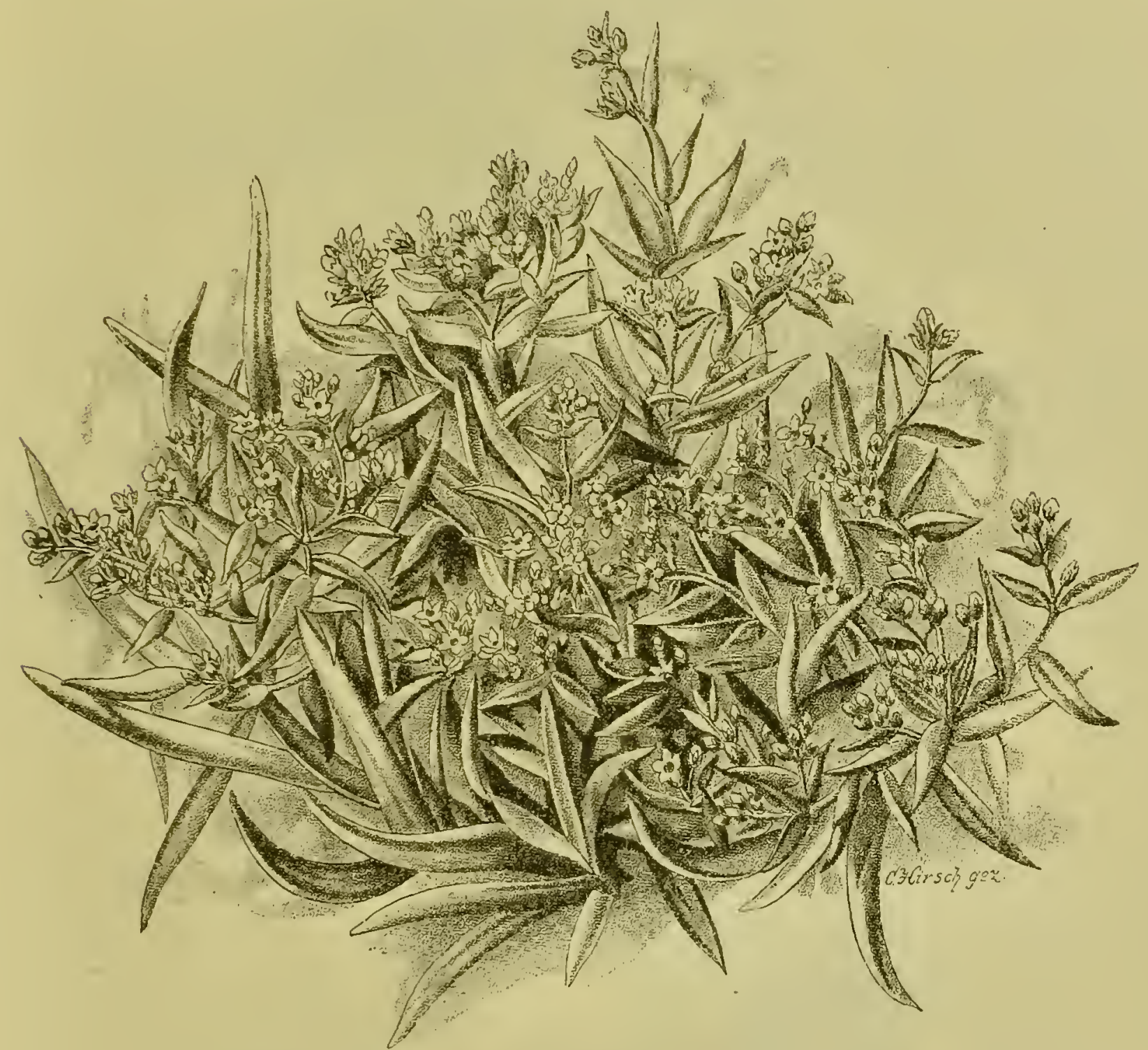

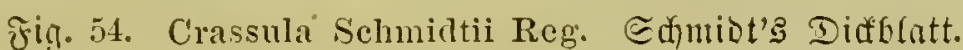

\section{Crassula perfoliata $L$. Berwadhicublätterige sinforatt.}

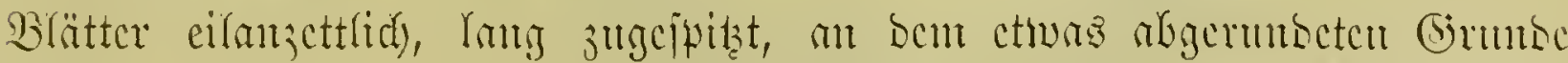

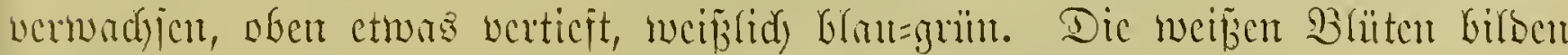

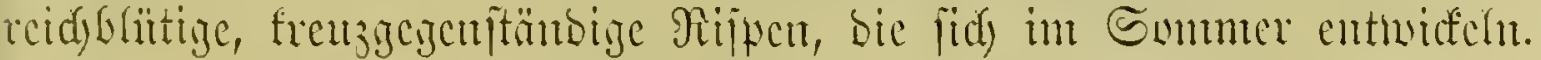

\section{Crassnla perfossa Lam. Durdhohrtez Diffblatt.}

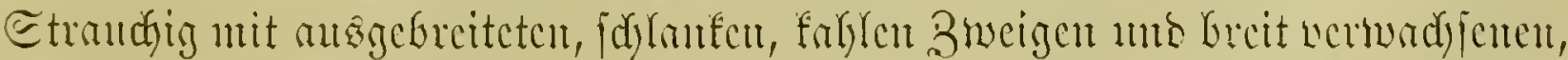

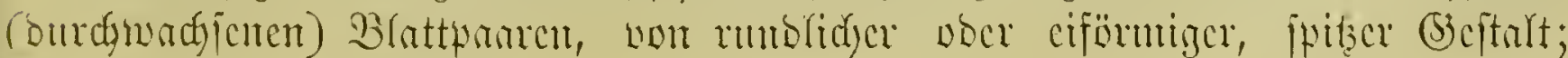




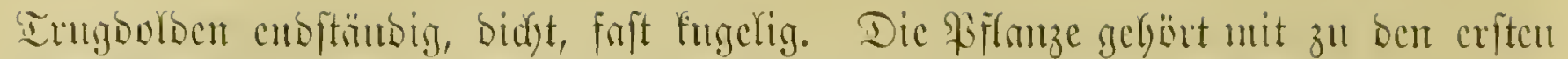

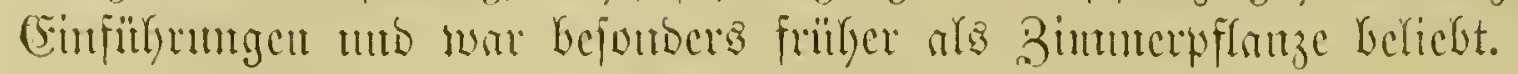

\section{Crassula Cooperi Rgl. Eoppev'a Dirtblatt.}

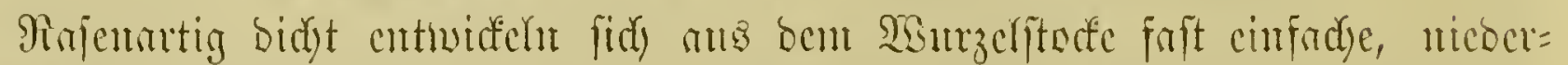

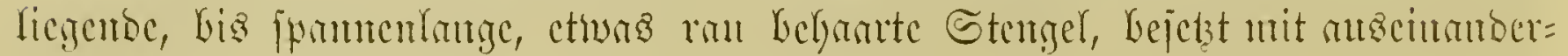

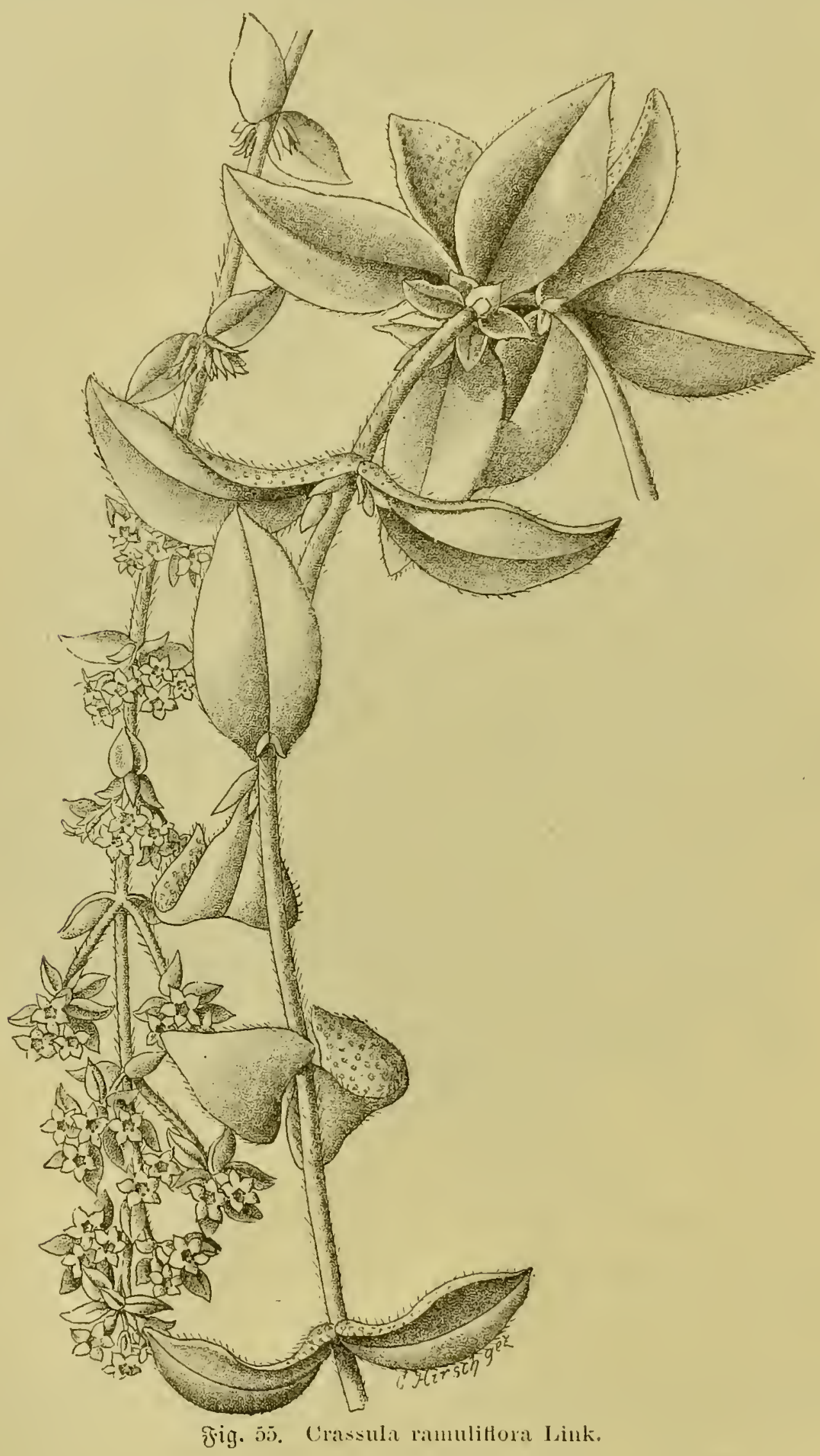

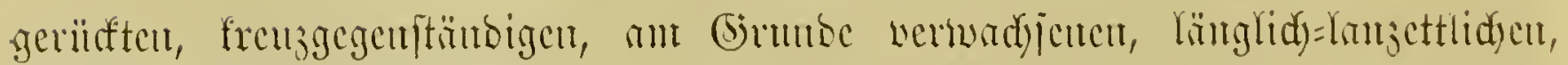

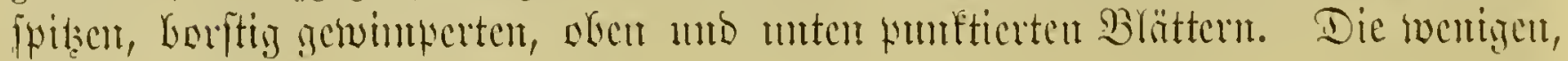




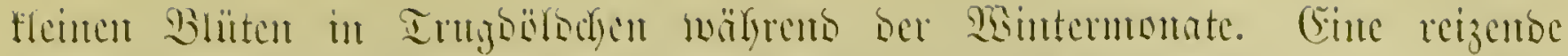

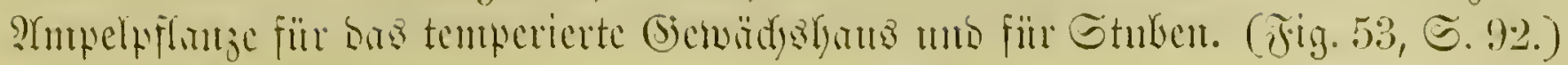

\section{Crassula Schmidtii Rgl. Grfmist'z Dirfelatt.}

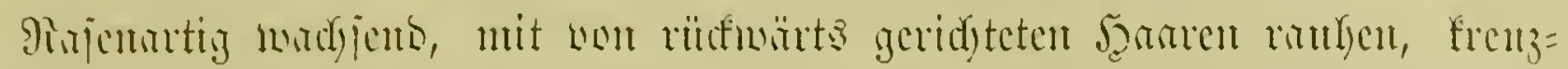

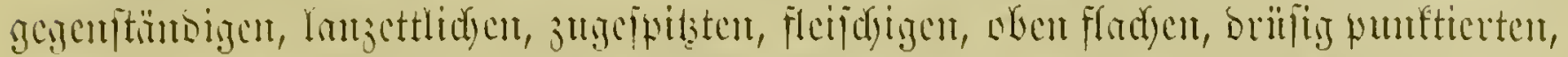

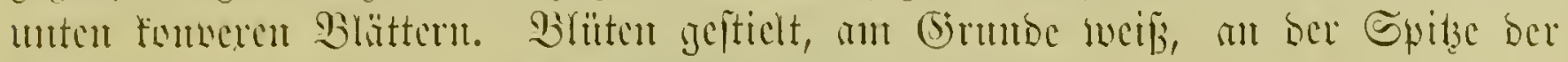

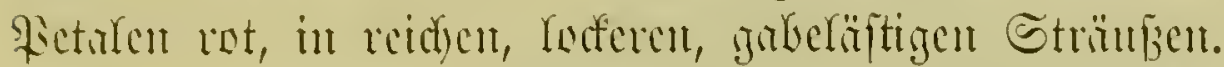

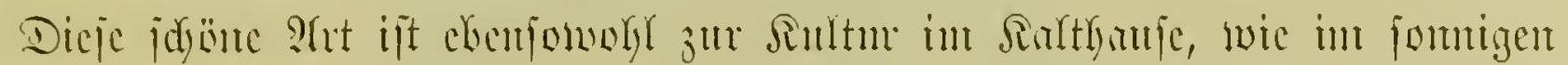

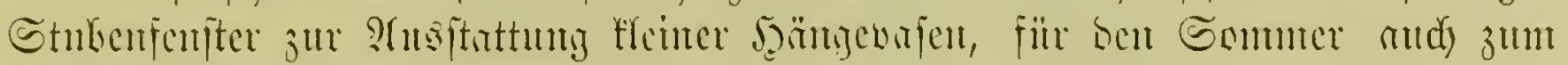

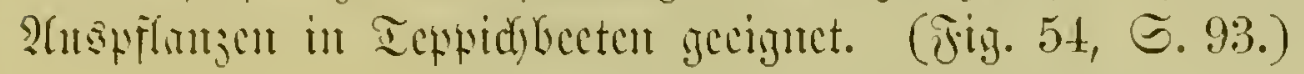

\section{Crassula ramuliflora $L k$.}

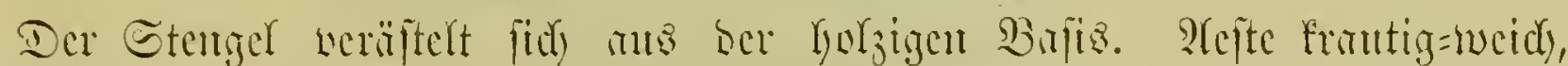

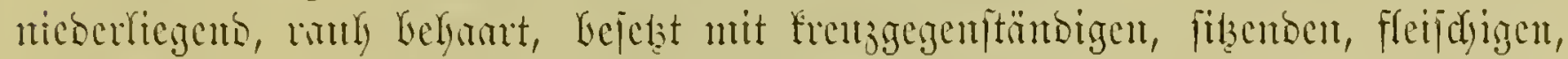

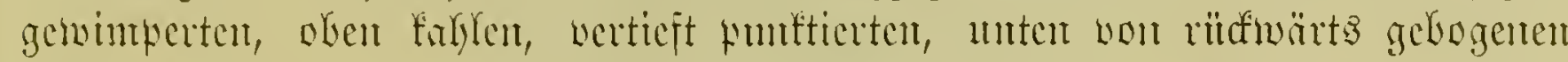

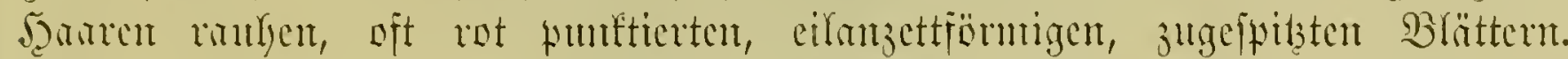

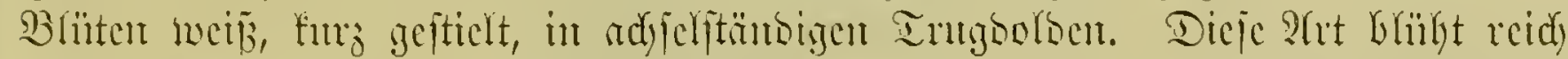

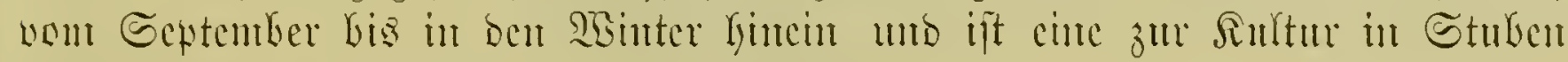

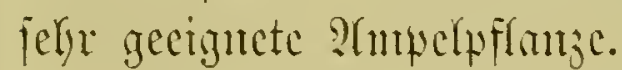

Dic Crassula= 29rten fün gleich ben meiften übrigen Sulffulenten Yeidgt zu

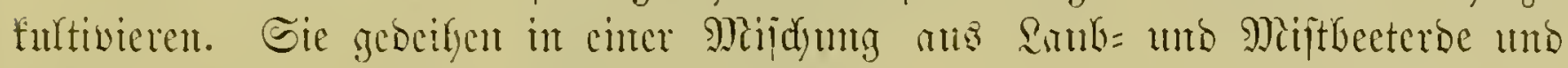

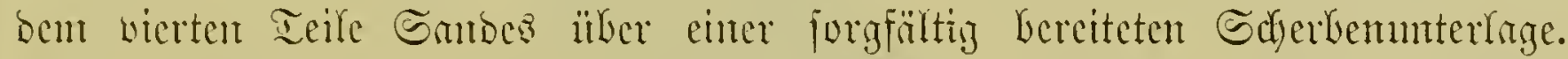

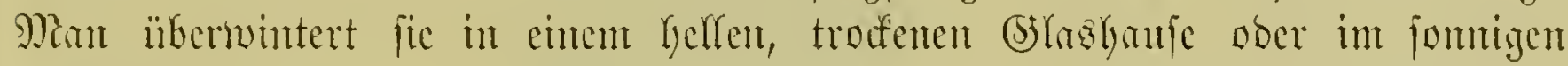
Stubenfenter bei $+5-8^{\circ} \mathrm{R}$. ober ciner nod) etwas nicorigeren Iemperatur,

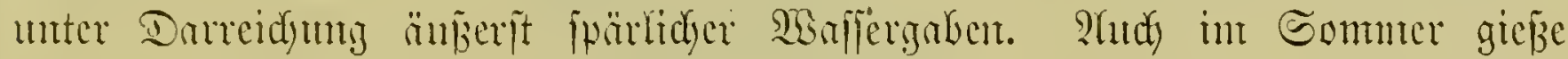

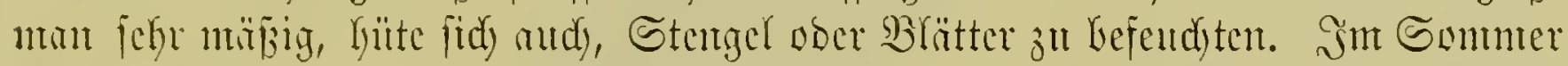

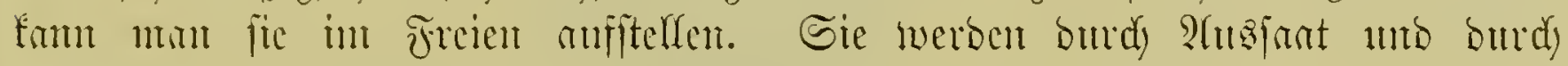

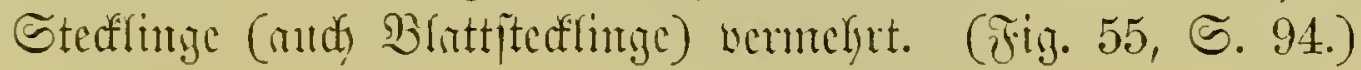

\section{9. (battung Rochea DC. Rodjea.}

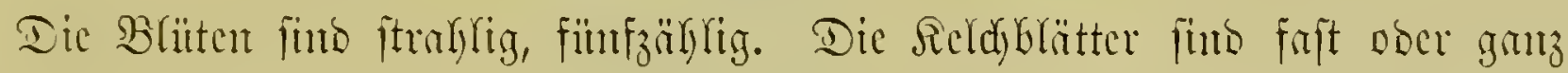

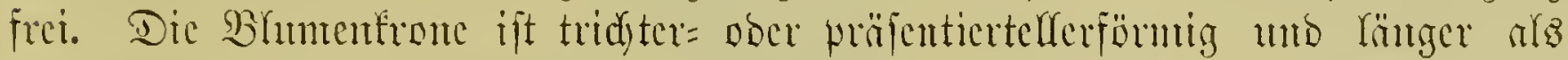

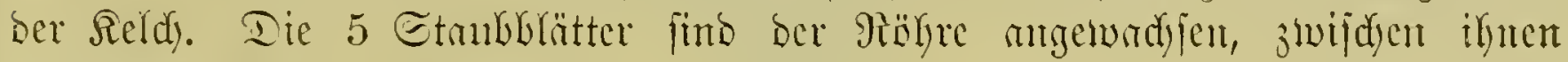
itchen jefr flecine Edyüpudyen.

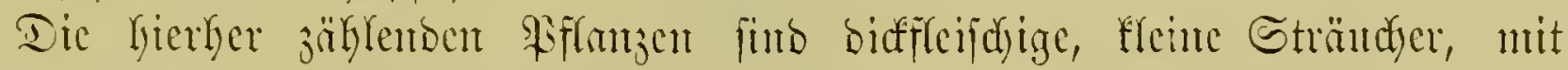

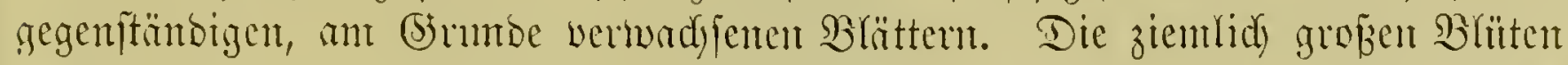
fins in Trugsorben faft fopfig zulanmentgebrängt; feltenter finto fie einjeln. Die

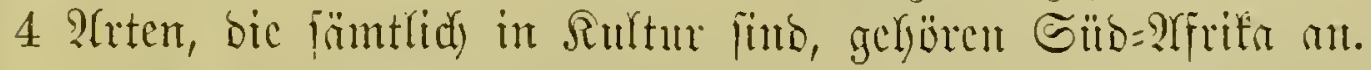
worben.

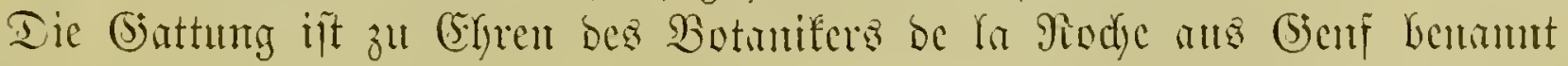

\section{Sdliiffel der befd̨rieberten Zrter.}

A. Stentgel aujrecht; Brïten in bichtgebräıgten Blïtenftäıden.

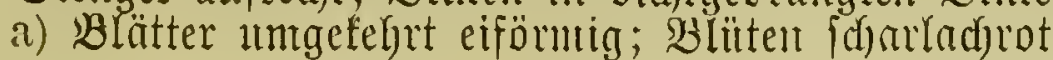
1. $\mathrm{R}$, coccinea $D C$. 
b) Blätter laulzcttlich.

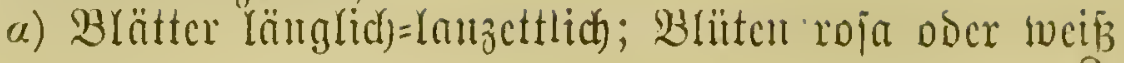

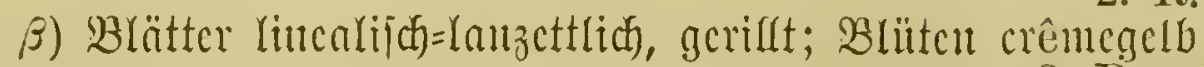

2. R. versicolor $D C$.

3. R. orloratissima $D C$.

B. Stengel niçerYiegend; Blütenjtände wenighlïtig

4. R. jasminea $I C$.

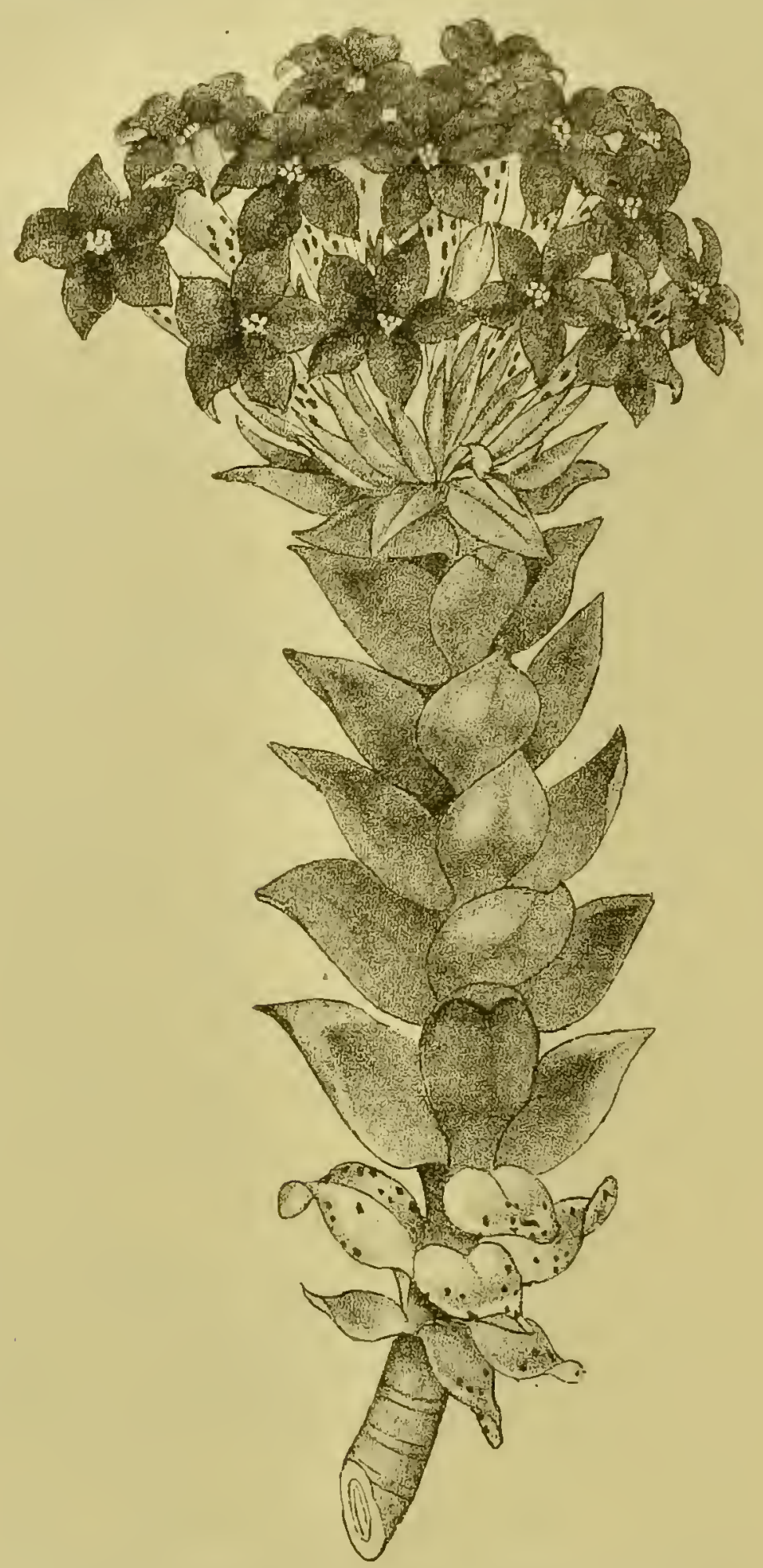

Fig. 56. Rochca coccinea DC. Edarlady= Mindiea.

\section{Rochea coccinea $D C$. Edhatad $=9 i o d j a$.}

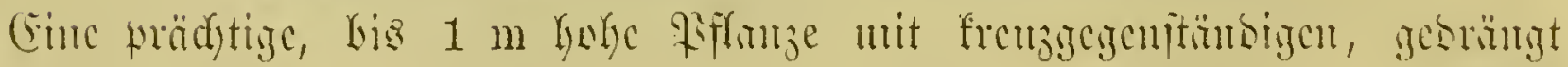

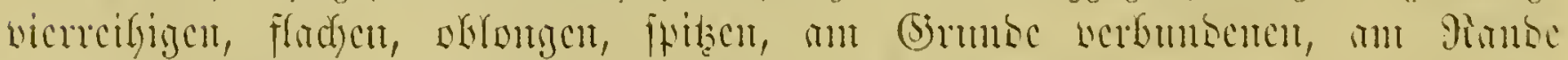

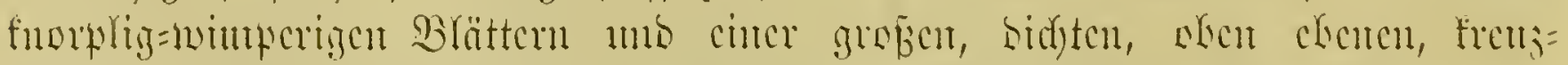

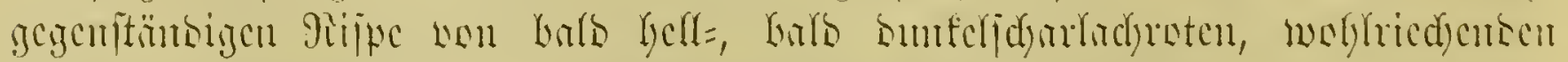

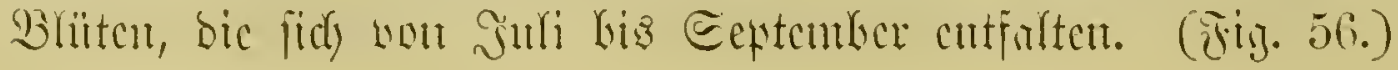




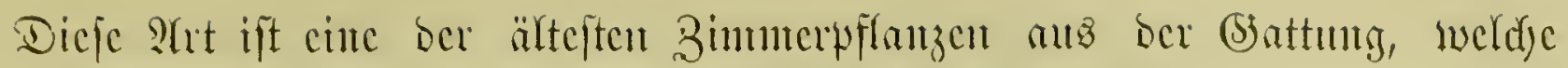

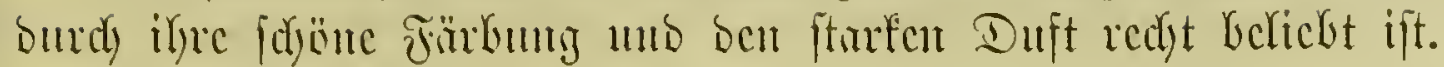

\section{Rochea versicolor $D C$. Beridjicbenfarbige Modjea.}

(Crassula capitata Lodd.)

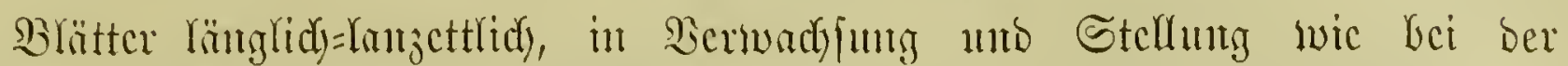

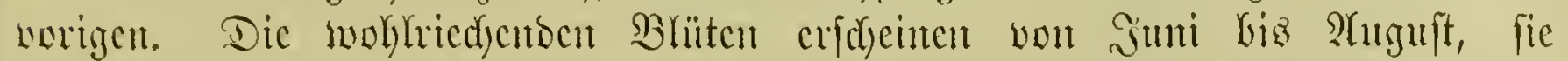

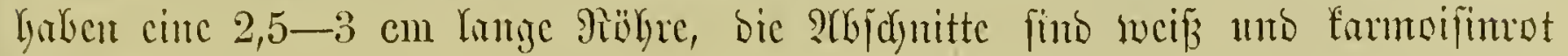

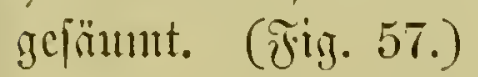

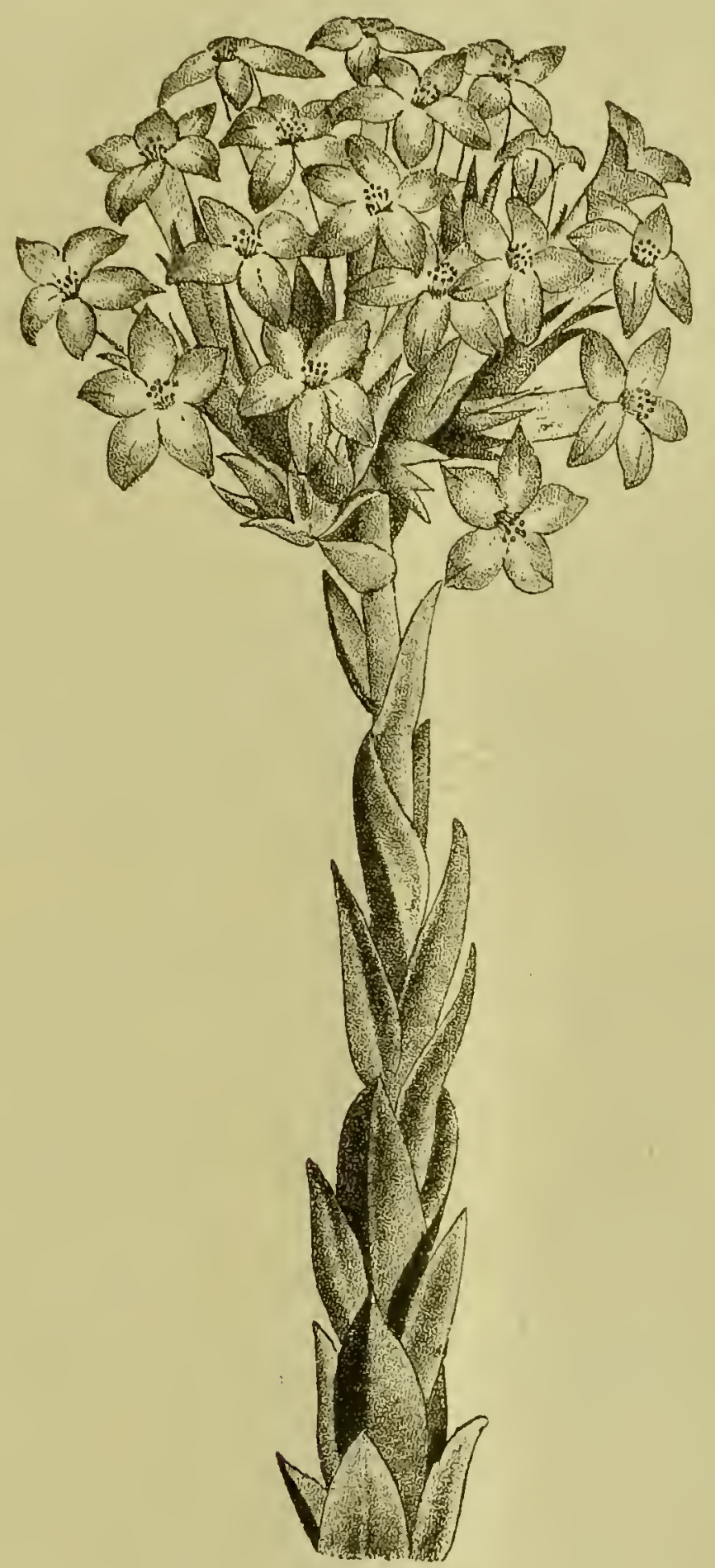

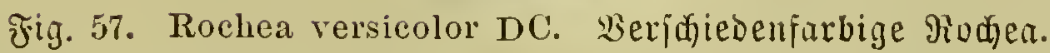

\section{Rochea odoratissima $D C$. Dujtenbe Piodjen.}

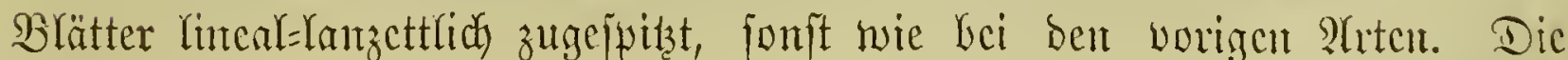

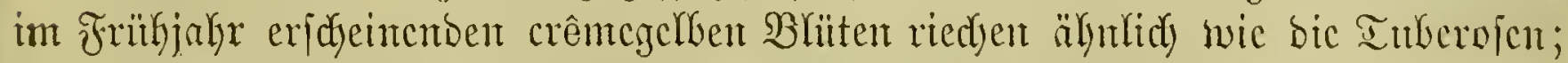

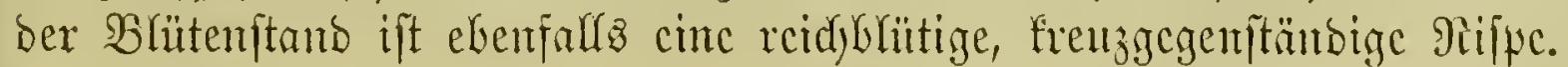




\section{Rochea jasminea $D C$. Sazminartige $\mathfrak{R o d j e a . ~}$}

Dieje jierliche Afrt hat eincu anfftrebentoen, nur biz $20 \mathrm{~cm}$ hohen Etenger

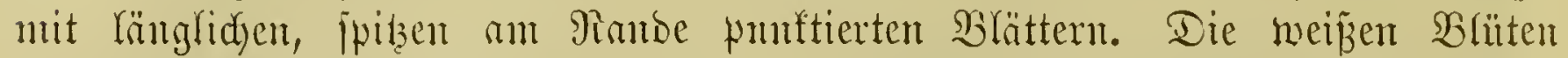
itehen in geringer Babl (meijt mur 1-2) an (Enbe bes Stengels, fie entwidfeln fid) int Sonnucr mo bujten nad) Jazmin.

Jil neuerer Beit ift cin Bajtarb R. coccinea $\times$ jasminea erjeugt

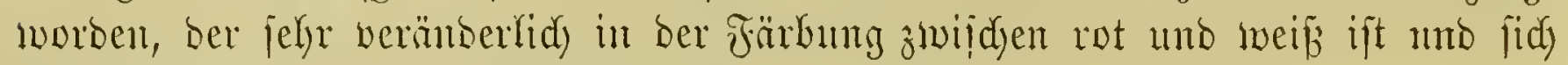
als renfterpiflange red)t empfichlt.

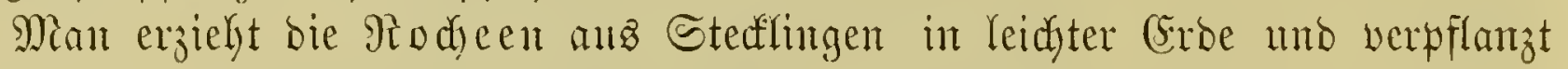

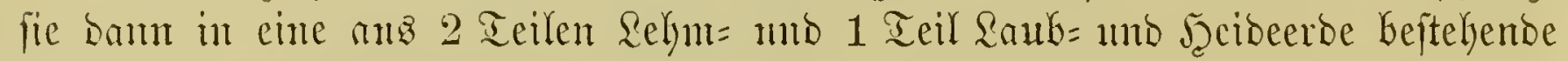
Miijdung. Sm erften Singre läß̈t man fie, bamit fie fid reid veräiteln, nidyt zur SBłüte fonmen. Sie werben in Sinter ipärlidy, im Eommer etwas reidy= ridyer gegulfen.

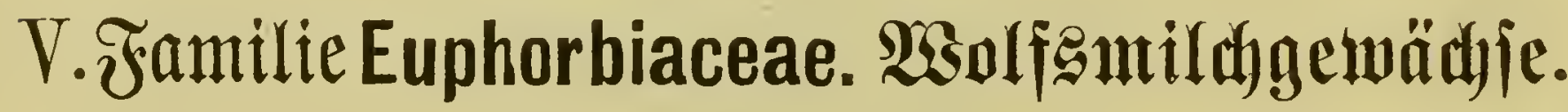

Sie ift midyt allein cine ber gröpten, fonbern aud eine ber formenteidjiten

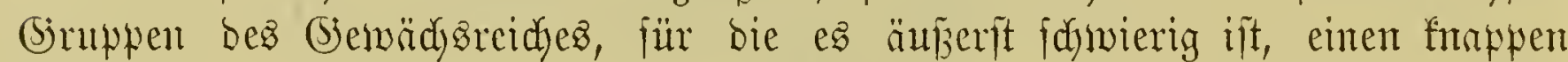
(Sharafter ju entwerfen, weil alle Mertmafe won eingehtur (Sattungen Durd $=$ brodjen werben. Die ben alfermeiften Formen jufwumenten Merfmale fint bie

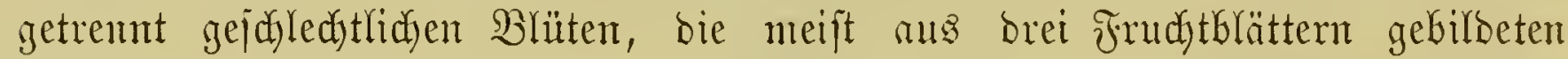

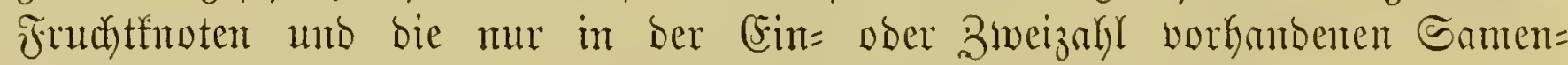
anlagent in jebent Fadje. Die Blätter ftehen meift abwedjelnts.

Man fennt gegenwüntig mehr ahs 3500 2trten, bie juar in affen Bonten

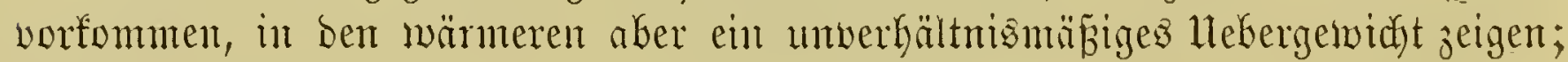

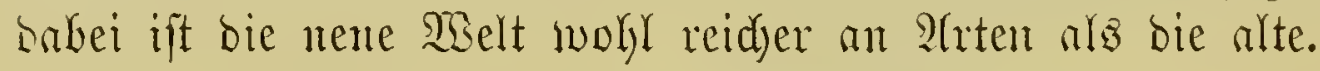

\section{(Błattung Euphorbia. Bolfentild).}

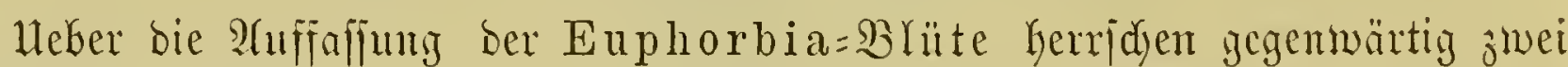

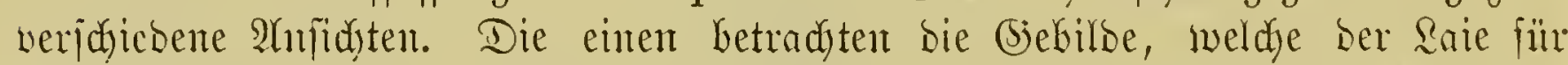
Błlüten halten word, ebenfalls für joldje, fie bejitzen aujen cine glocten= ober

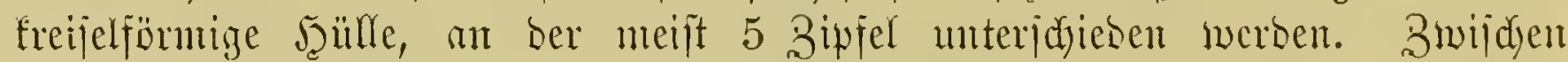

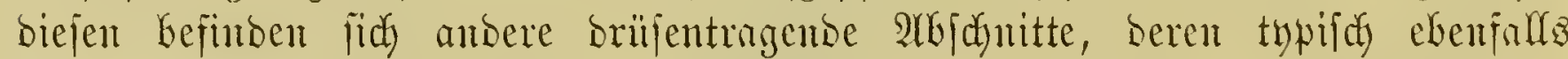

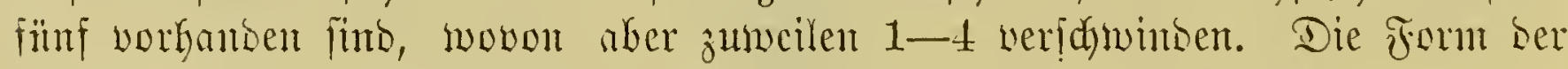

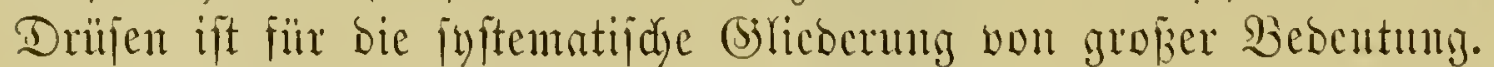

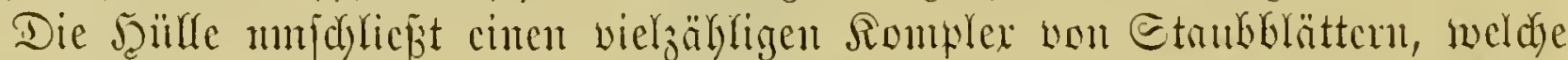

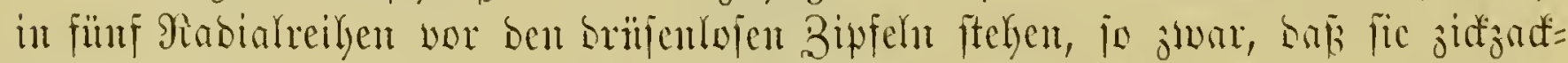

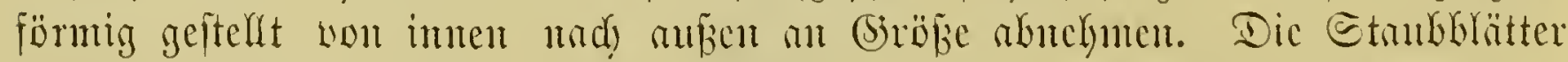

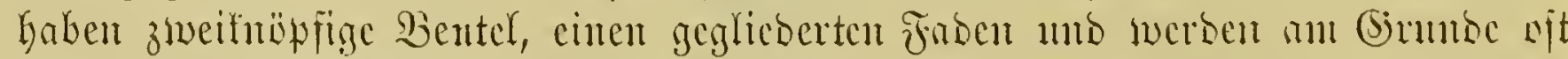

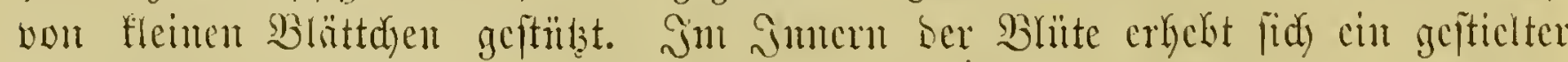

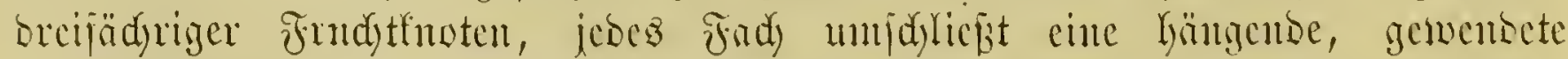

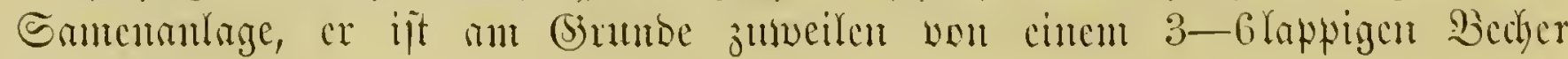
mungcber.

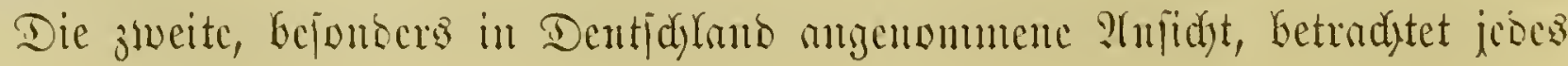




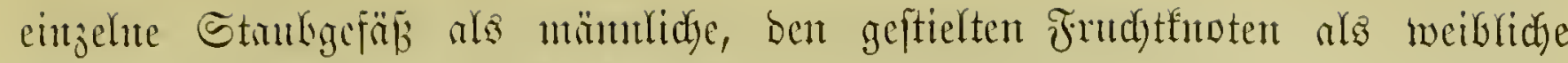

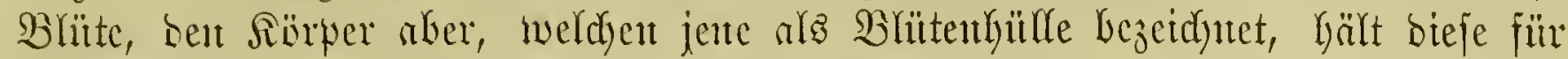

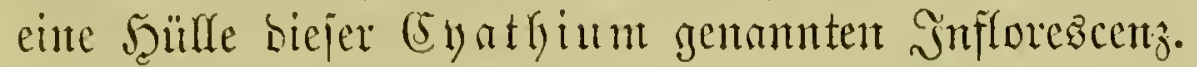

Dic orudgt ift cinte fadjpaltige, breiflappige Sinplel. Die Samen werben

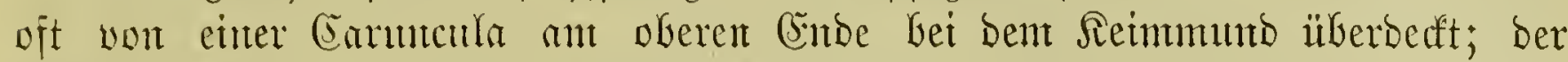

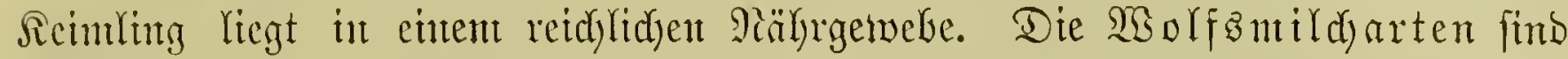

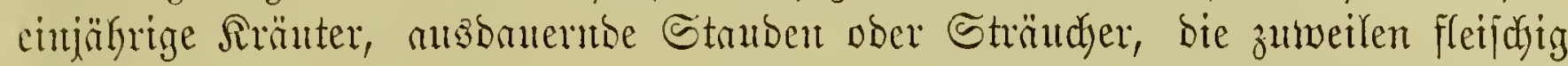
werben unb in ber Iradyt bie verjdjebenen Siejtalten ber Sifteen mieberyolen.

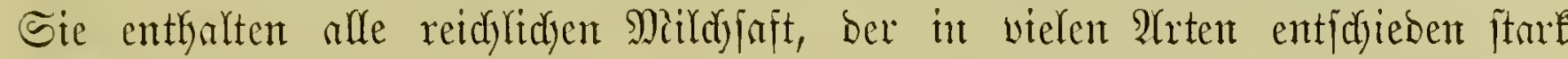

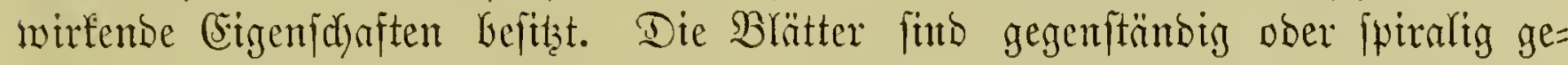

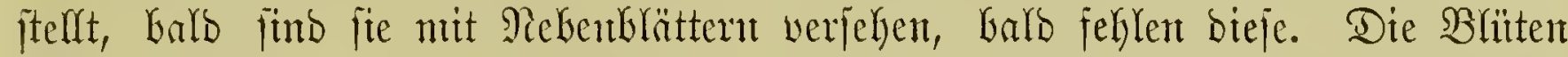

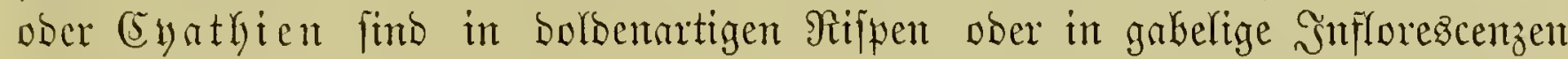

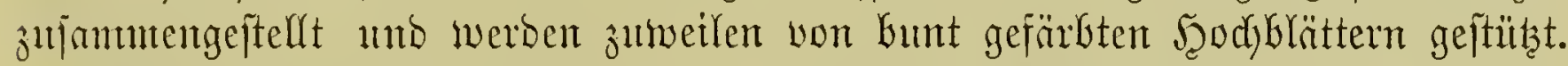

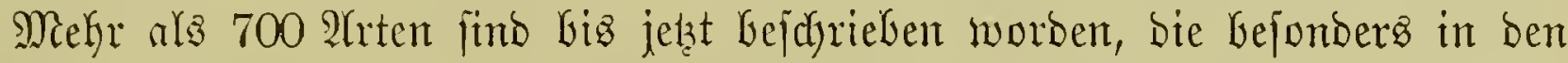
wärmeren Rlimaten beiber Semijphären gebeifen; budy find audy bie gemäß̈igten

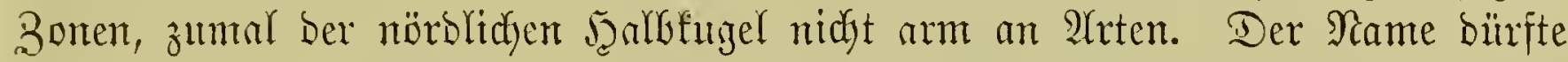

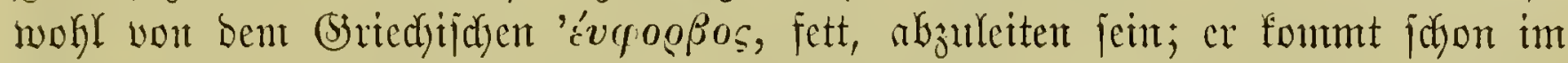

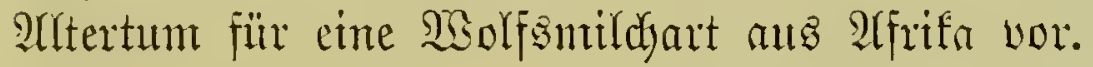

\section{Sdllïffel fïr die befariebenen Urten.}

A. Sörper biaf, fleifhig, faftųartig, olne Blätter oder ntit kleinen Blättern (bergl. auch E. neriifolia L., Die ipäter fattugähnlich wirb).

a) Siörper fantig, fänlenfïrnmig.

c) Rörper Dreifintig (jelten vierfantig).

I. Sërper ftumpf Dreifantig, Santen tief gelappt, BSlieder am Brunde chlintbrifich zufantmengezogen

II. Sörper jharf Dreifantig, Ganten nicht oder wenig gelappt

ค) Sörper 7-8=tantig

b) Sörper thigelig ober feutenförntig, kurz.

a) Rörper etnfad), gerippt

2. E. Hermentiana Lem. 2ion Dem Mnittelförper gehen zahlreiche, fternförmig geitellte, bünnere

B. Sräuter ober હträ̈ucher mit gró̉en, bleibentoen Blättern.

3. E. heptagona Limn.

a) Stamunt unit Stacteln berieher.

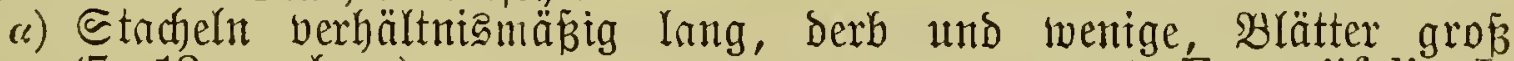

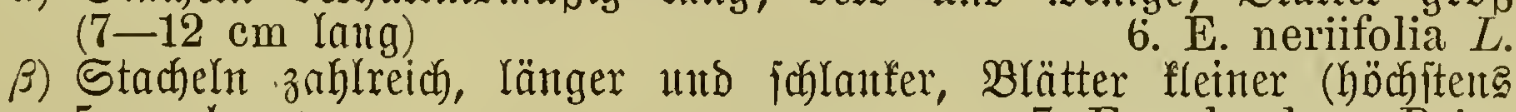
$5 \mathrm{~cm}$ lang)

b) Etengel oder Stamm und Sieite unbetwehrt.

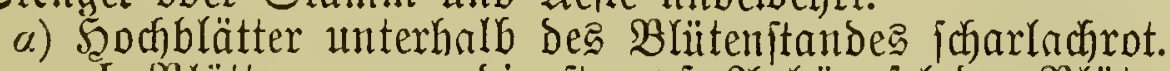

I. Blätter ganzranbig ftumpf, 2Unbängiel Der Blïtenthülle füntf

8. E. punicea $S w$.

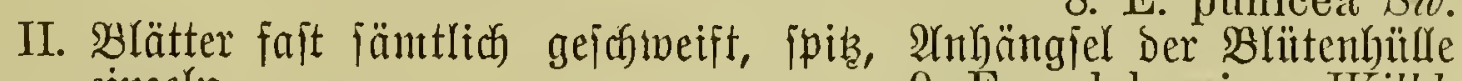
einzeln

9. E. pulcherrima Willd.

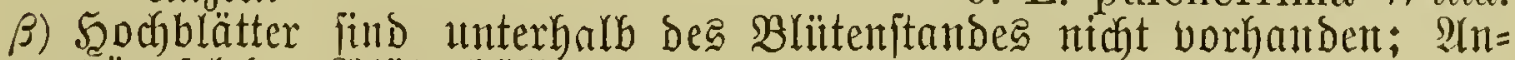
hängiel ber soliutenhitife rot

10. E. fulgens Karv.

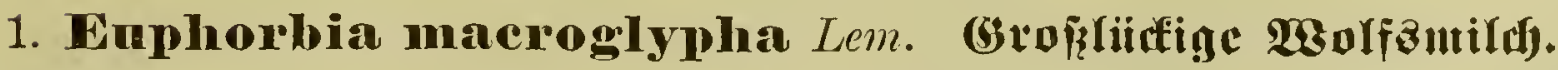

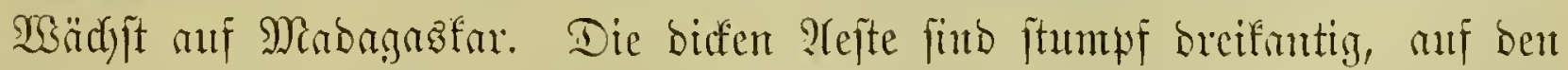

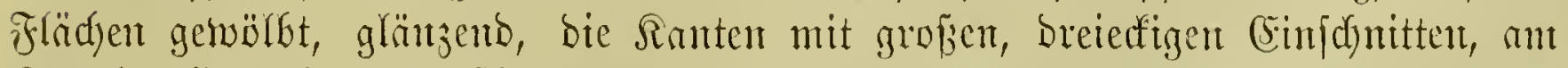

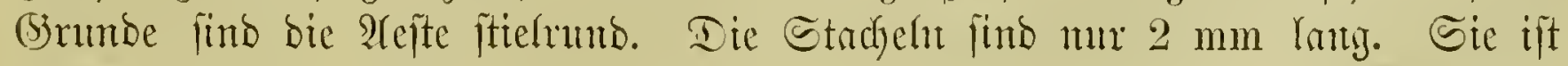
cinte ber jänjten 2rrten. 


\section{Euphorbia Hermentiana Lem.}

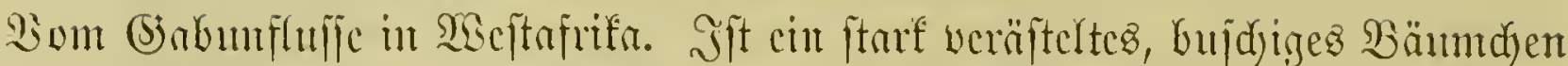

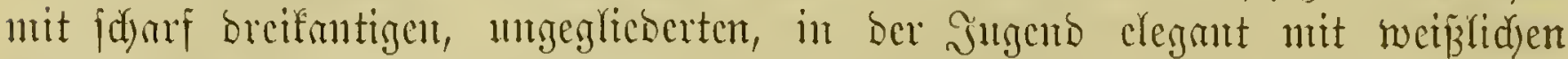

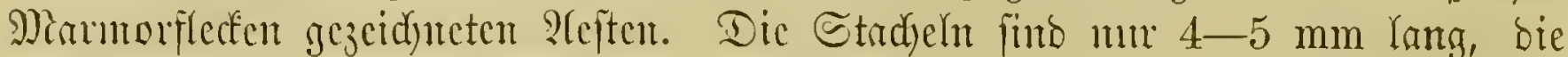
B̧ätter fütó lanjettlid) ober idjmal ipatelförmig.

\section{Wuphorbia heptagona $L$. Eicbenfantige Euphorbic.}

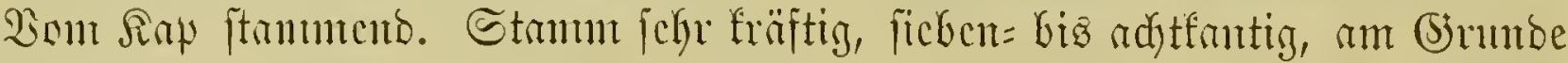

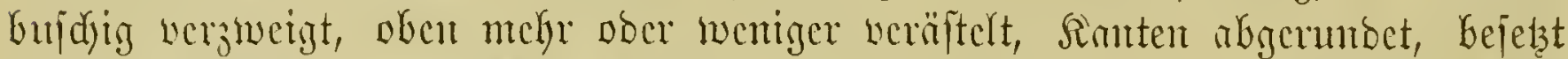

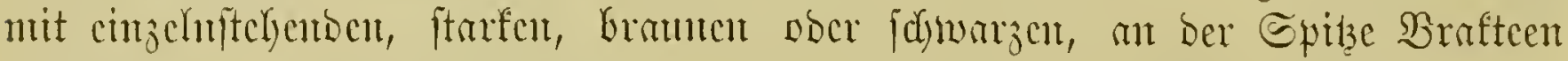

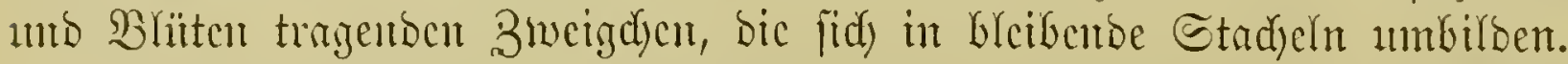

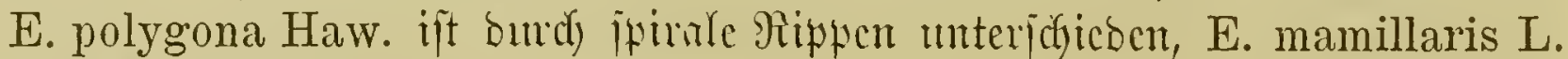

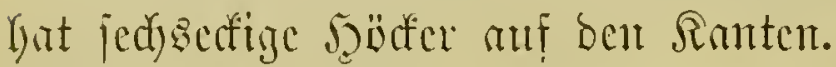

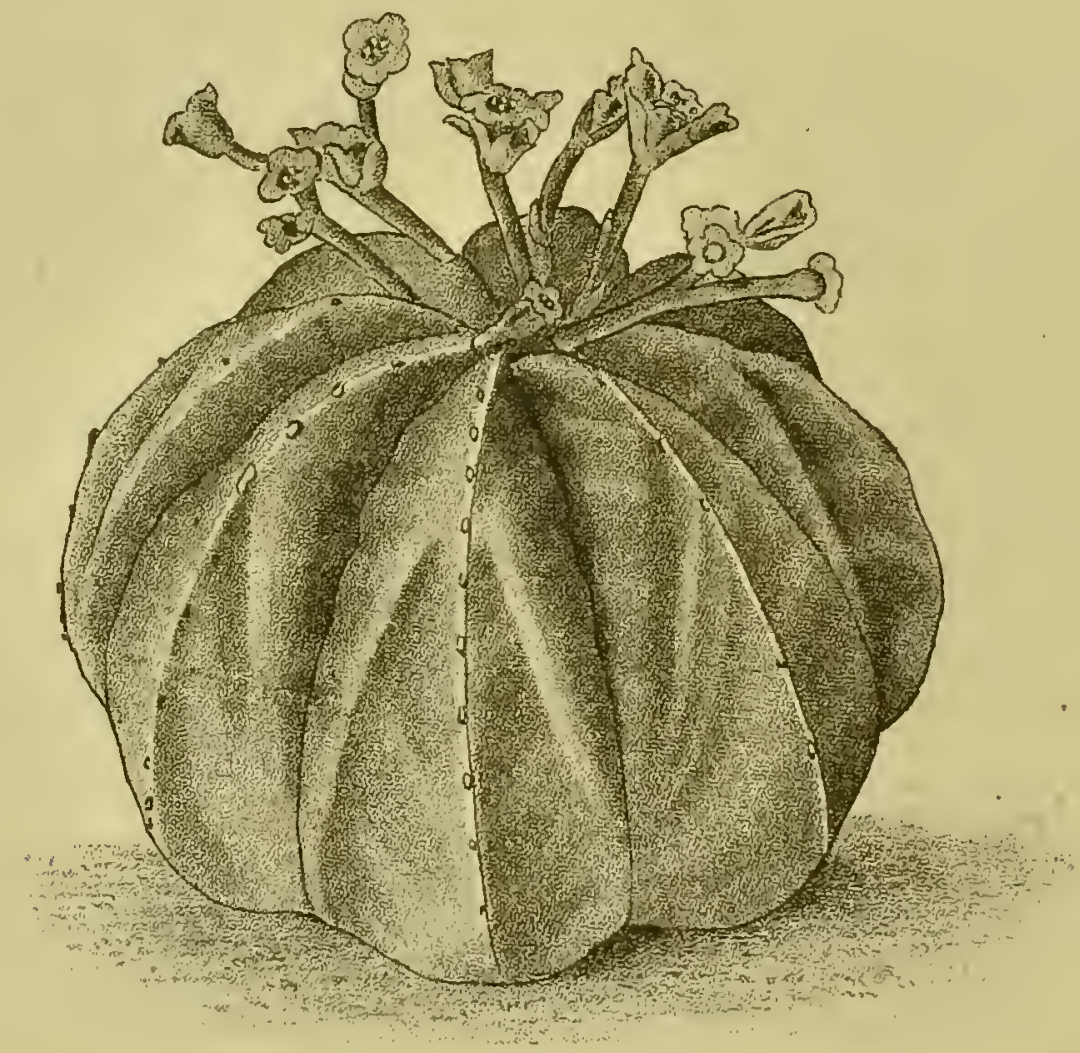

Fig. 58. Euphorbia meloformis גit, Jiefonen=920lïmild.

\section{Emphorbia meloformis Ait. Meloncn=:2Bolfzunildy.}

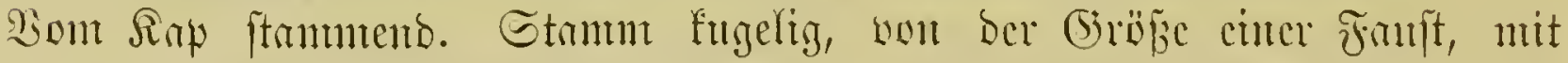

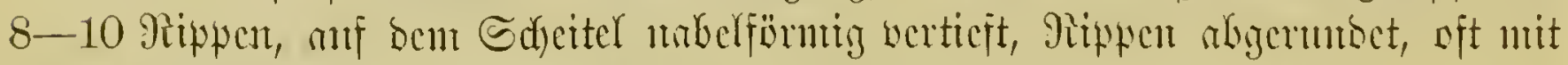
fdjicfen Bebraftreifen yon Dunfleren ober Grämulidycur Grïn gejiert uns anf

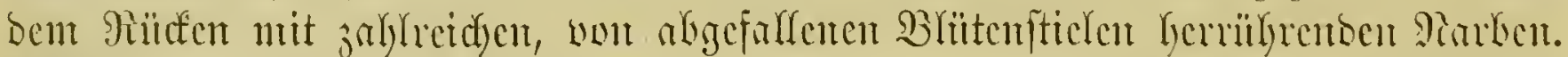

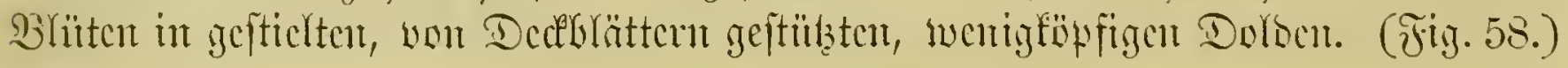

\section{Emphorbia Caput Medusae $L$. Miednienlinut.}

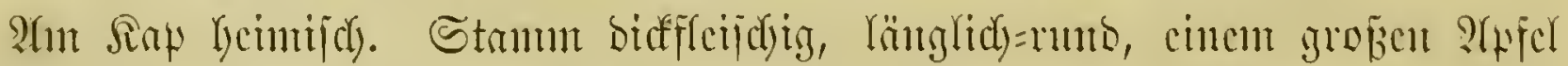

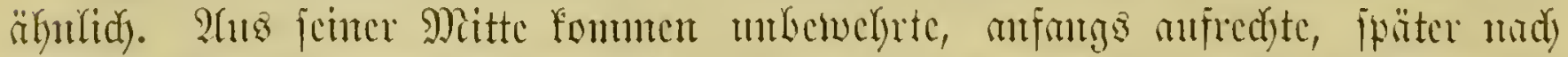

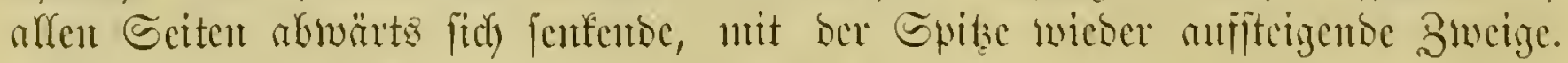

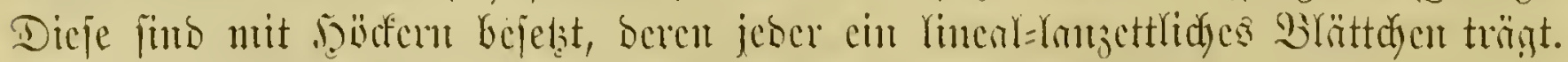

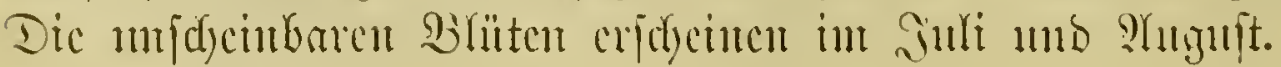


Dic var. major Ait. (E. Commelini DC.) ift waflydycintidy un cine Form, bic ans Bucigfteffingent entiftmoben ift.

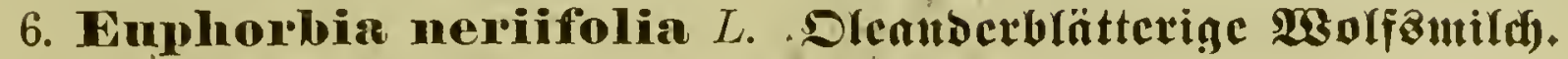

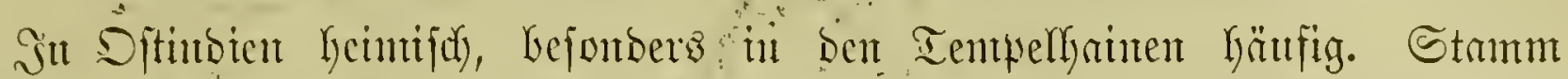

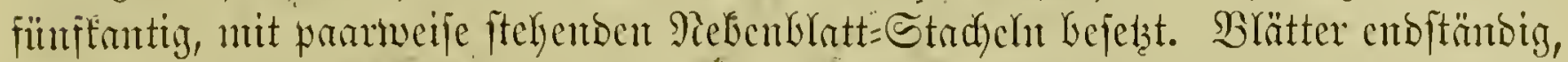

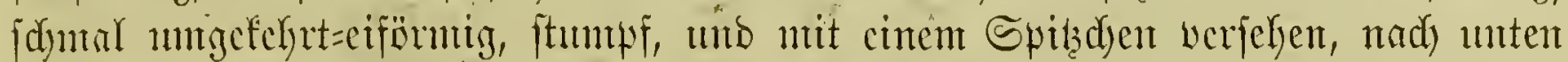

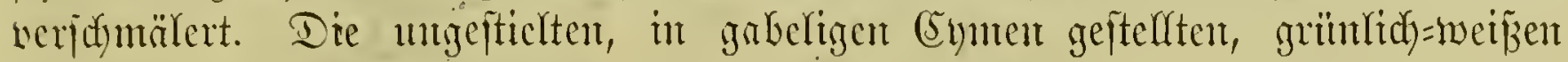
Blüten int Sint- Sult.

Irme bieje YYrten überwintert man int Silaghatje bei $+5-8^{0} \mathrm{R}$. ober in

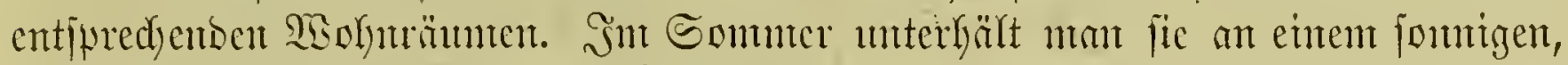

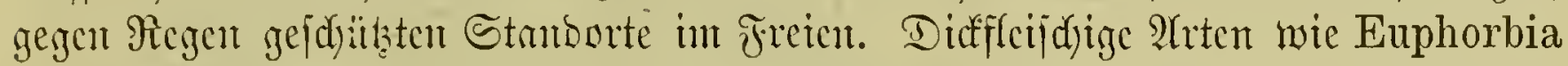
Caput Medusae unt meloformis bält man im Winter beffer im Warmbaje

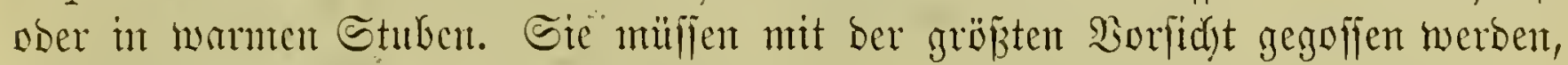
Da Präjie ifrent Ulitergantg herbeiführt.

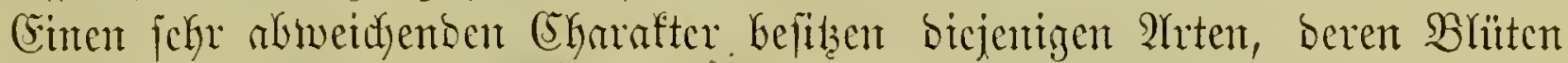

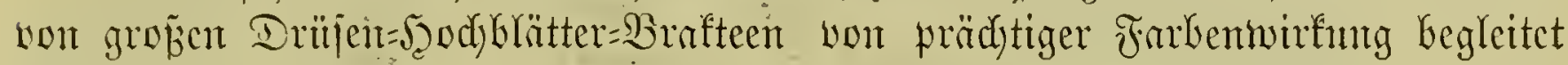
werben. Srsir füfren rier nur entige ber fdjöniten auf:

\section{Euphorbia splendens Bojer. Etrahlende Euphurbic.}

Yui Miabrigastar zu Şauje. Dieje ber "E. pulcherrima Willd. an Sdjünheit

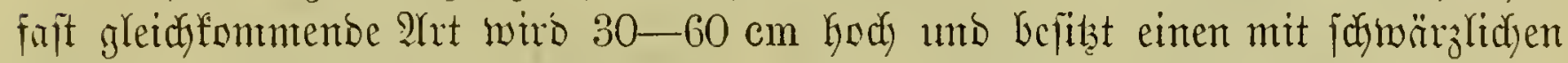

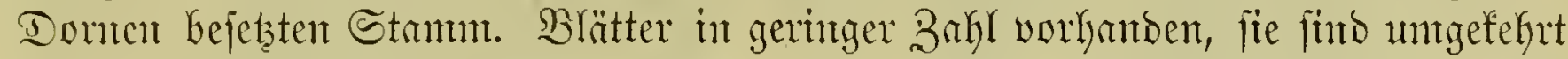

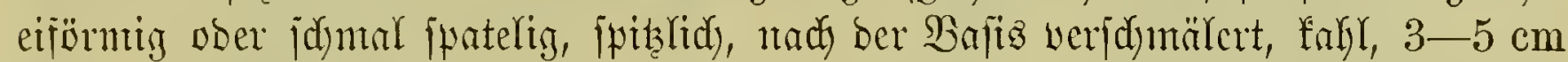

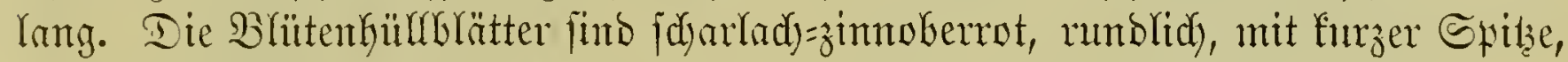

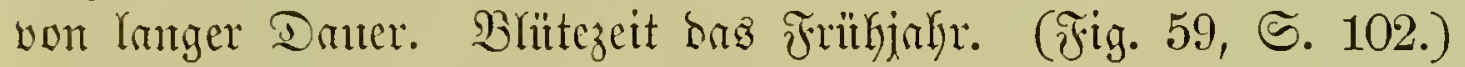

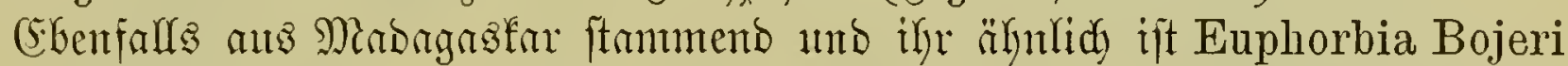

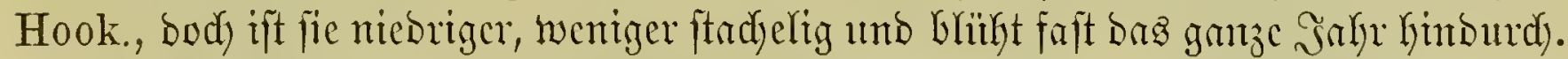

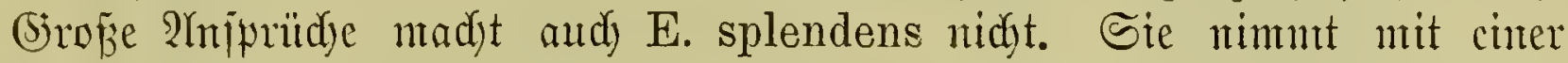

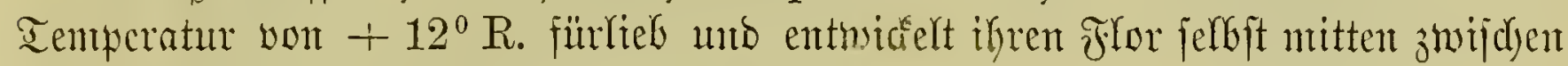
reid) beblätterten (S)mü̈bjen.

Sor ber einen obcr Der anteren in Bhlite ftefentoen (Suphorbie biejer $2(b=$

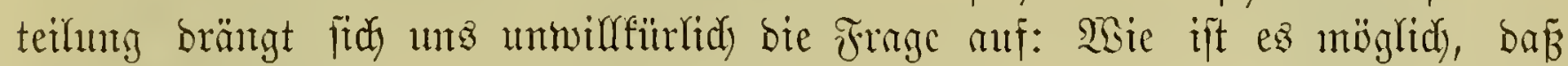

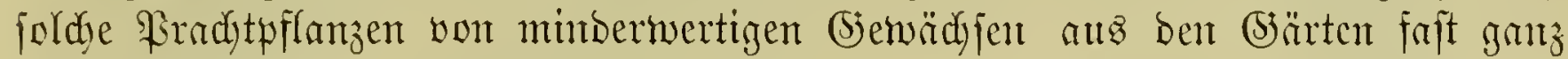
verbrängt werbon founten?

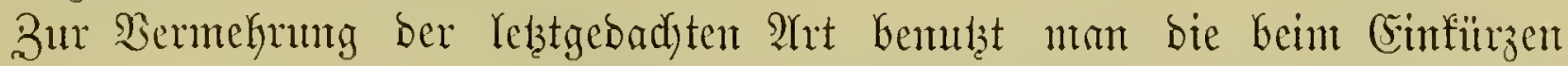
gemonnenten Bmeigfpitzen als Stecflinge. Man pflangt bieje in Töpfe mit einer

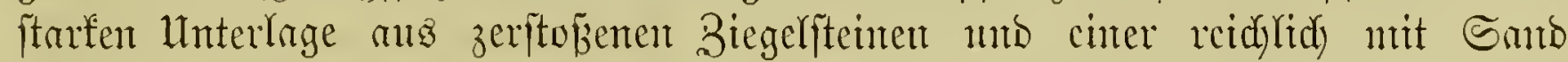

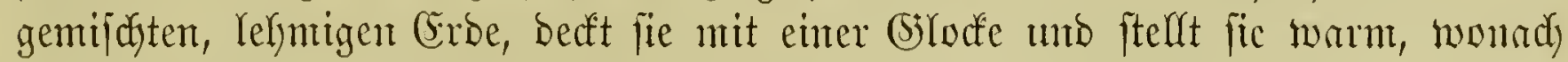

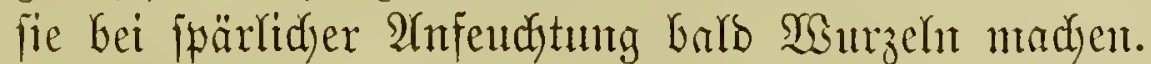

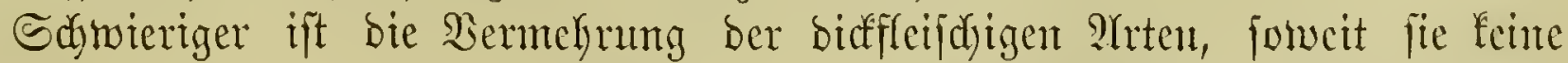
Sproffen erzengen. Nimme man ifyten bie Spitze, um fie zut Bifloung junger Triebe anzuregen, fo verfalfen fie Yeidyt ber Fäulluis. Mefrere Arten aber bringen

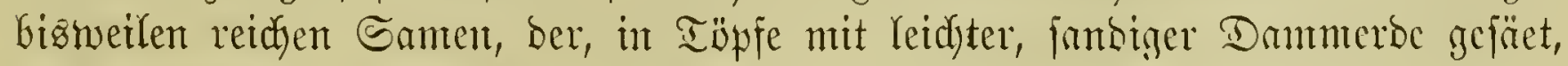
bald aufgeht uno fdüne fräftige Bsflanzen licfert. 


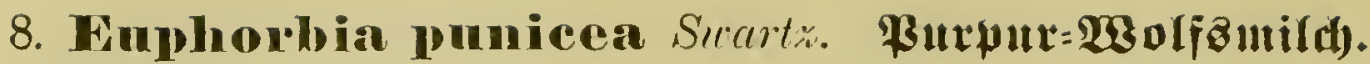

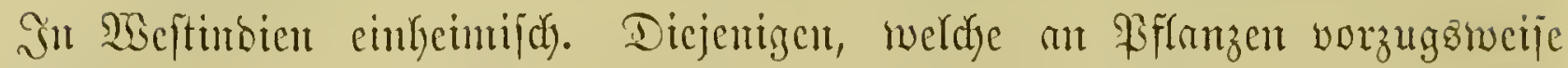

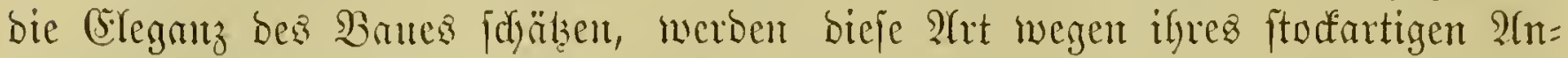

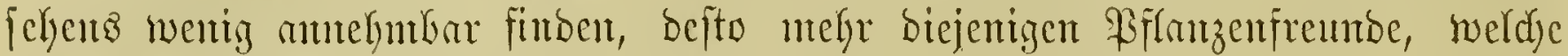

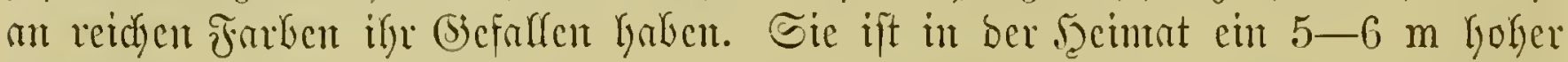

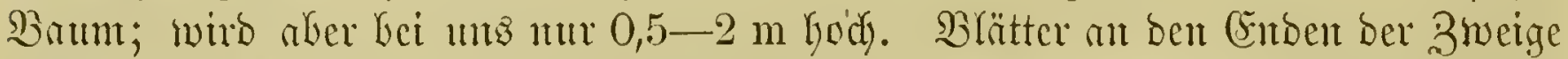

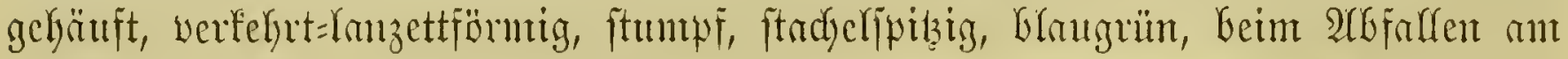

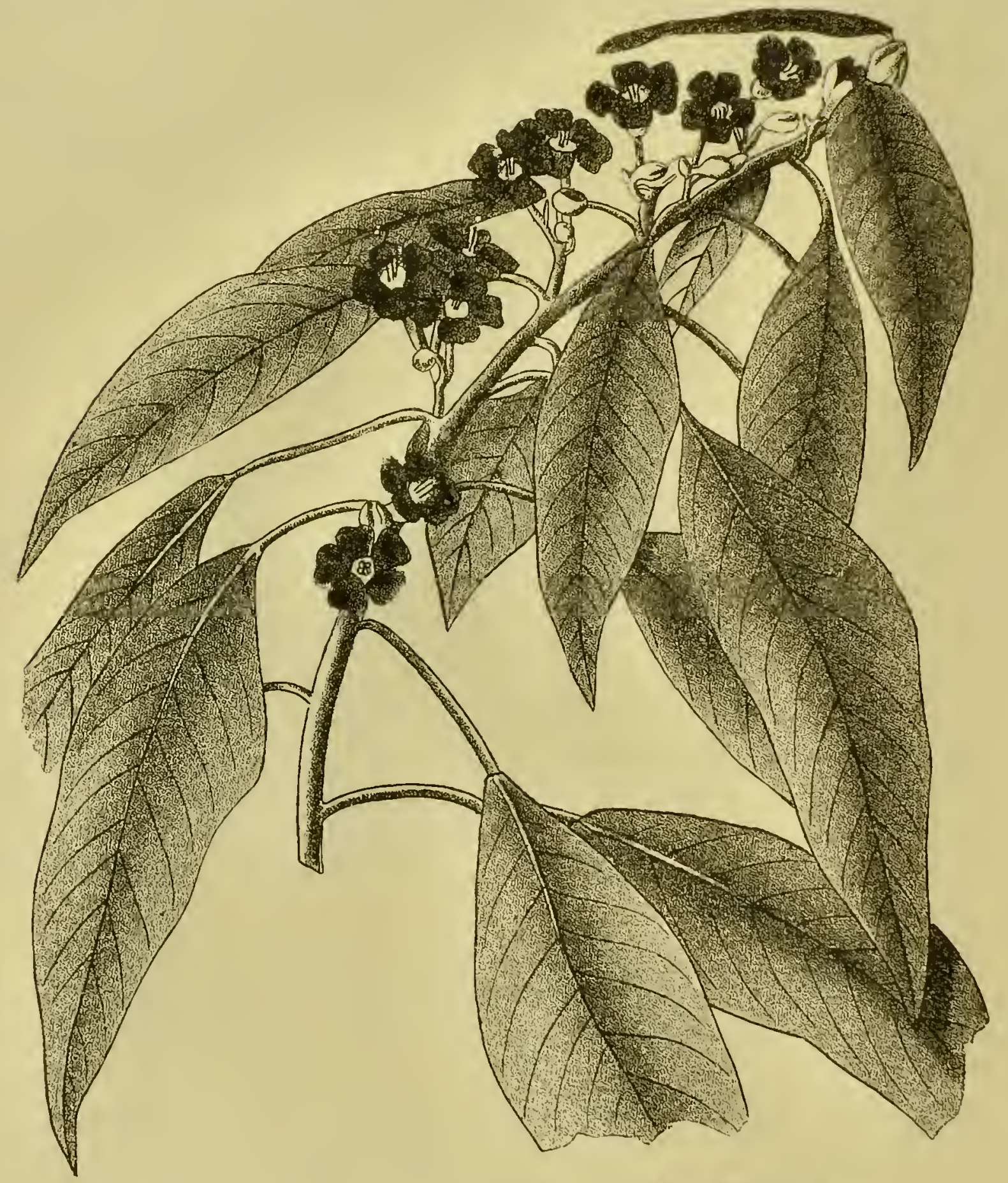

Fig. 59. Euphorbia splendens Bojer. Etrahtenoe Euphorbic.

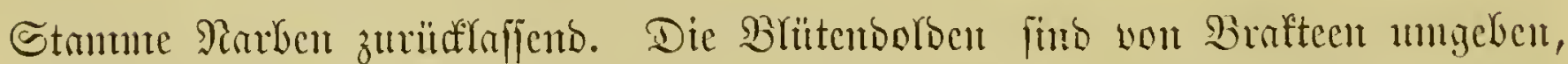

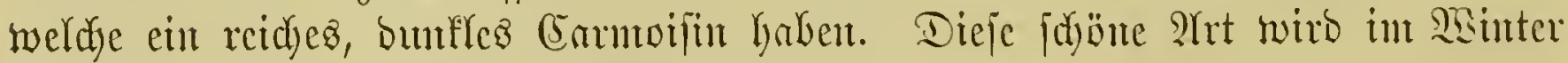
int sammlyuje unterbalten. (Fig. 60, S. 103.)

\section{Enphorbia pulcherrima Willd. Edjünfte $\mathfrak{B Z o r j a ̈ m i l d ) . ~}$}

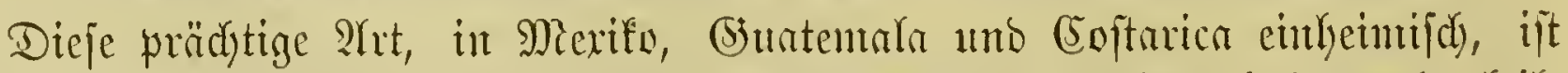

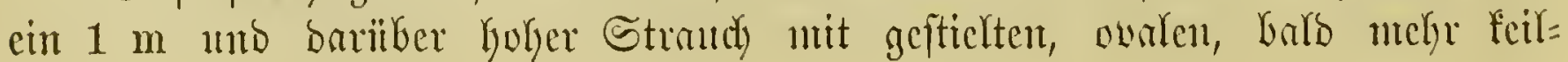




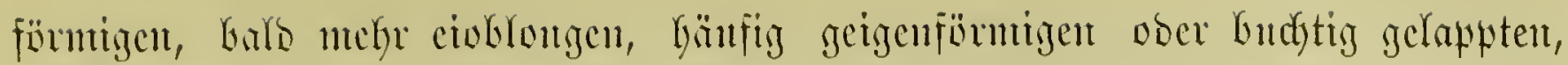

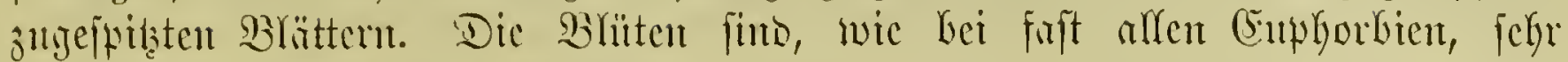

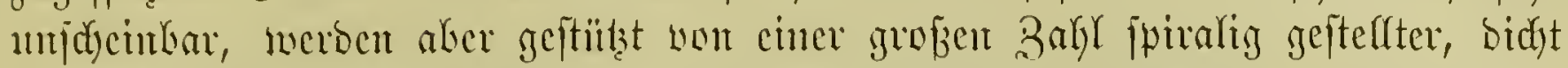

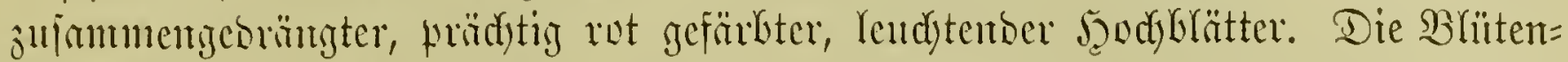

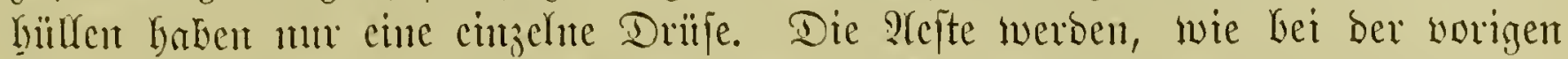

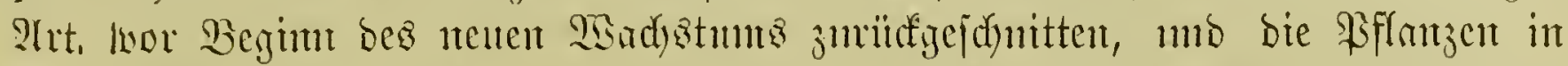

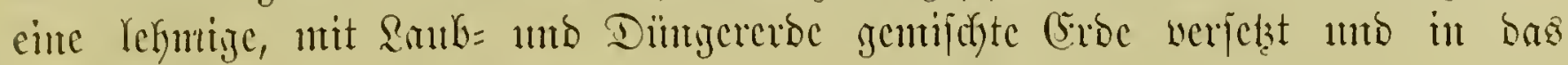

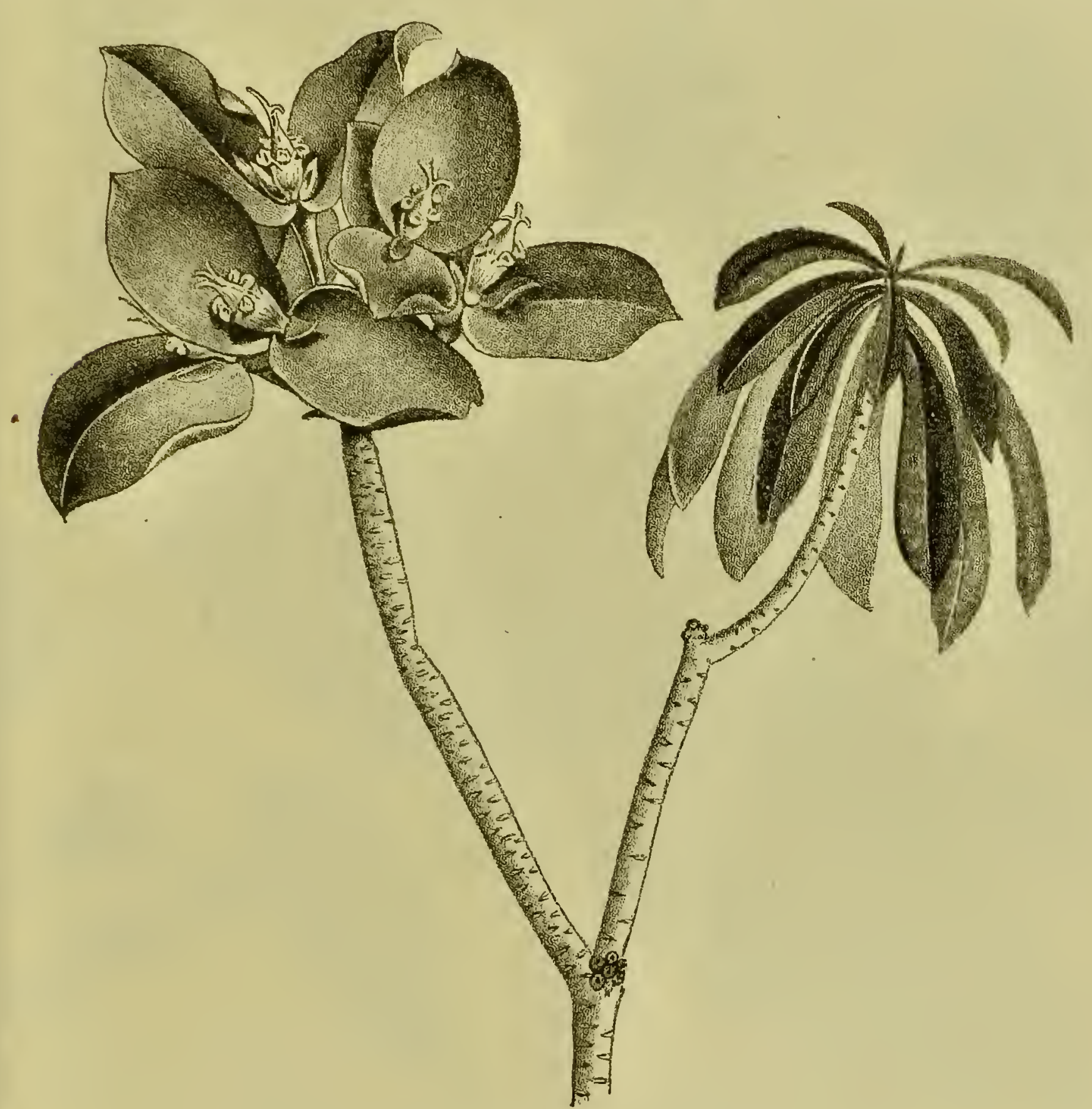

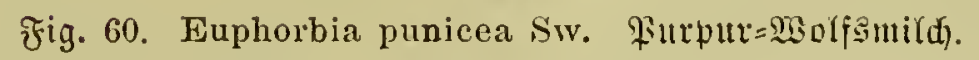

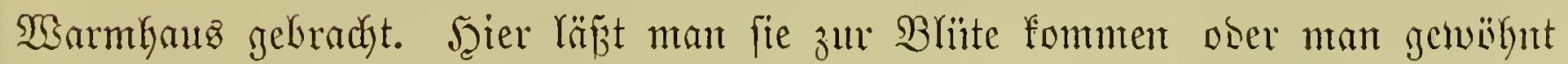

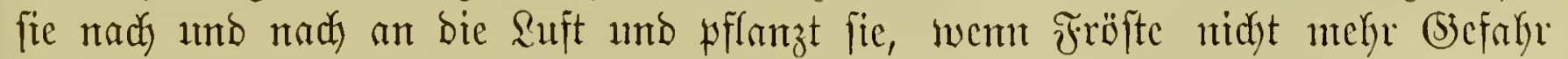

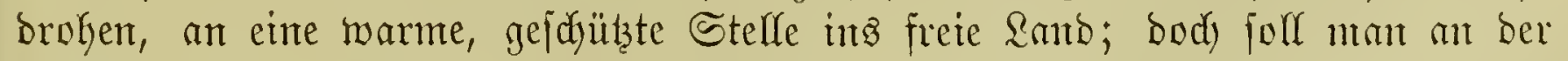
Bflanzftelfe bon Boben $1 \mathrm{~m}$ tief ausheben, bie Brube etma $60 \mathrm{~cm}$ hod mit

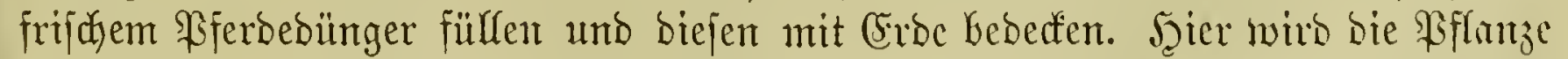

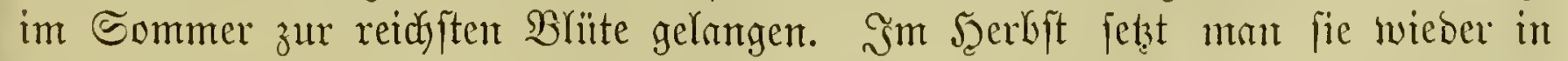

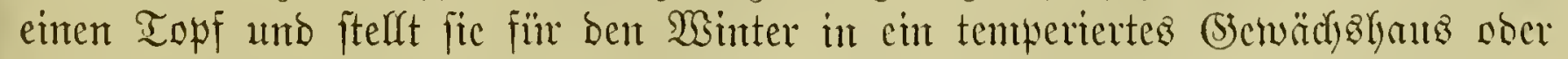
in einen anberen entipredyenten SRum. (Fig. 61, S. 104.) 


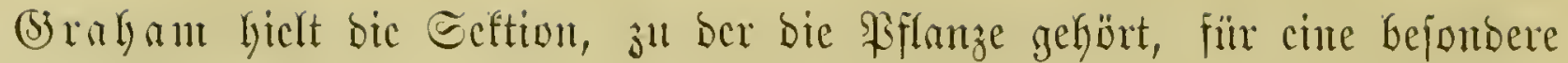
(b)attunis und nody lyeute ift fie als Poinsettia pulcherrima bejontoers befannt.

\section{Euphorbia fulgens Karw. Qeudtende $\mathfrak{B g}$ olfämild.}

Sie ift in Micrifo heimifd. Dicje herrtidye Bierpflanze, weldye aud ben Piancu E. iacquinifflora Hook. fülyrt, Gefitzt cinten glatten Stamm mit an ber

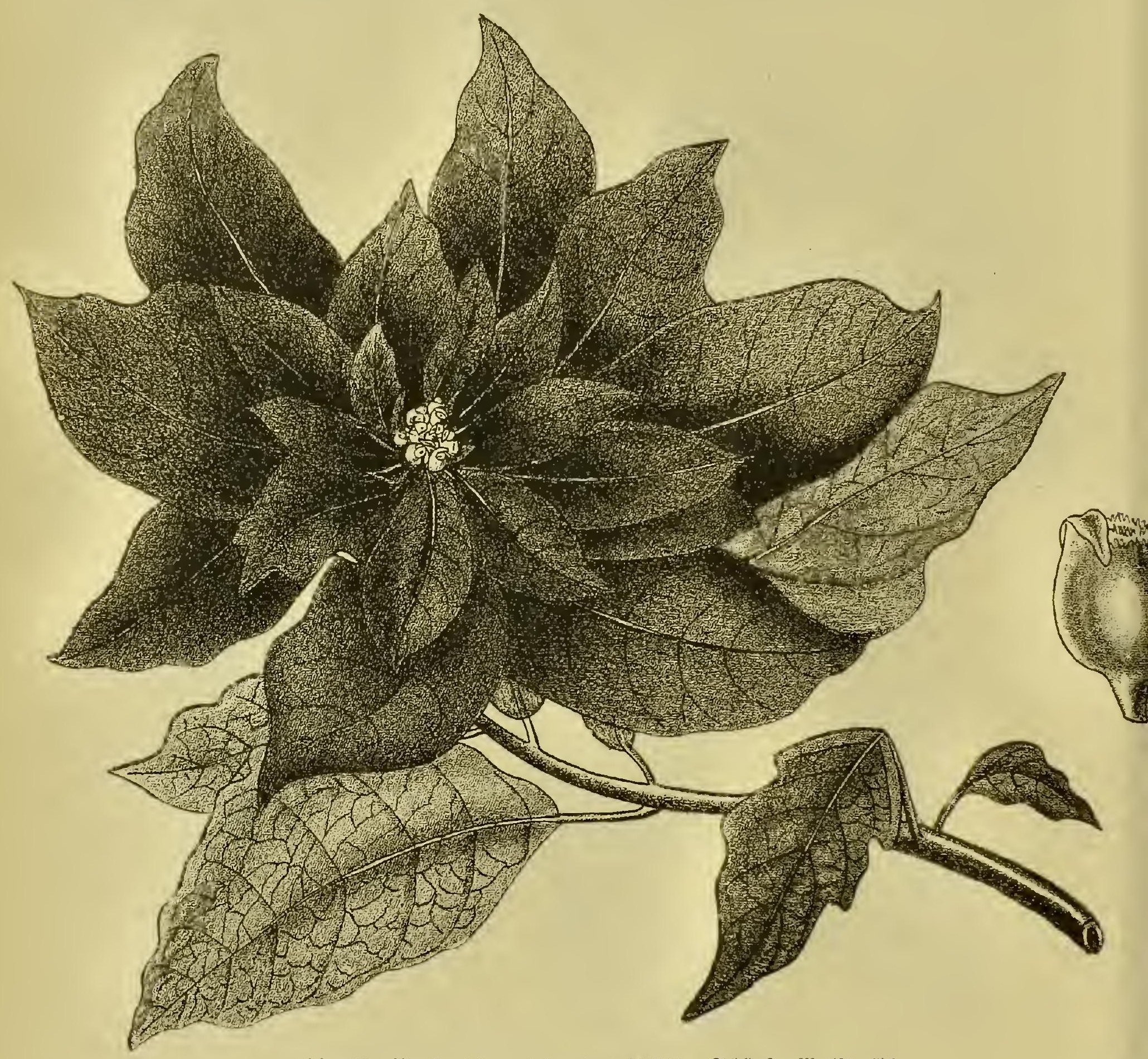

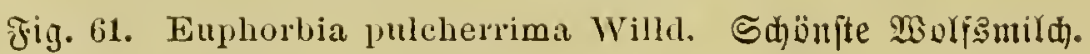

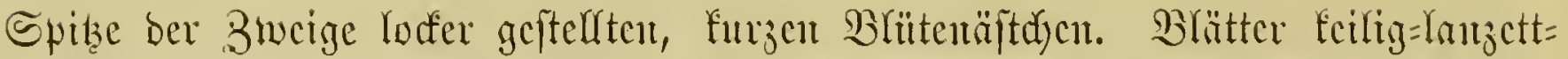
förmig, lang gejpitzt, farly, geftielt, mit bent Sticle $10-12 \mathrm{~cm}$ lantg, $1,5-2 \mathrm{~cm}$

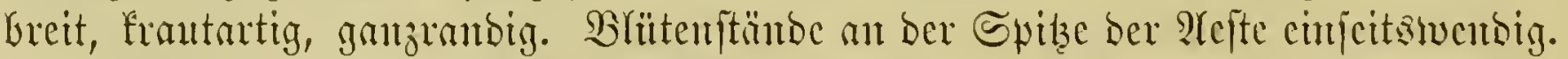

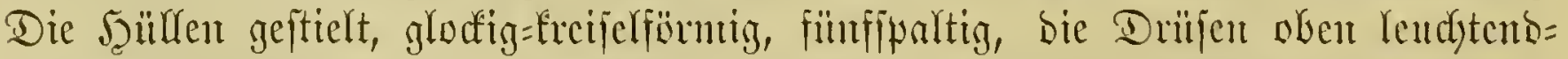

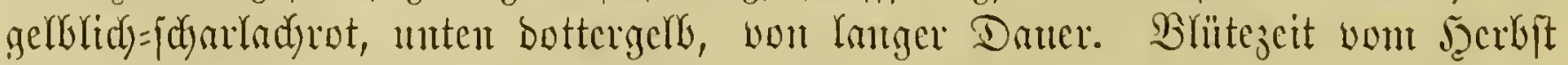

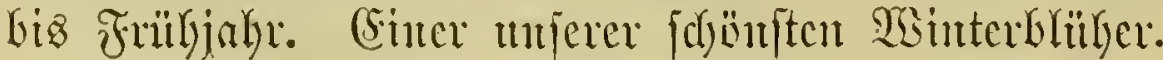

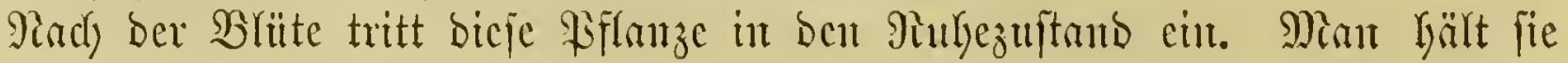




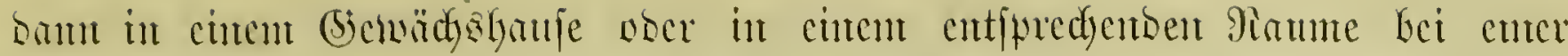

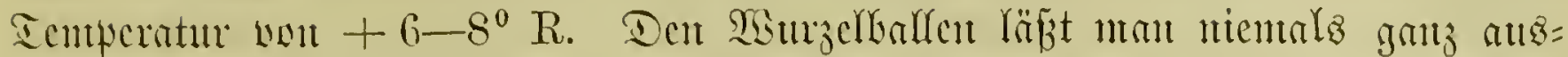

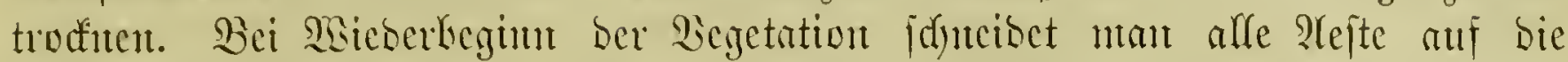

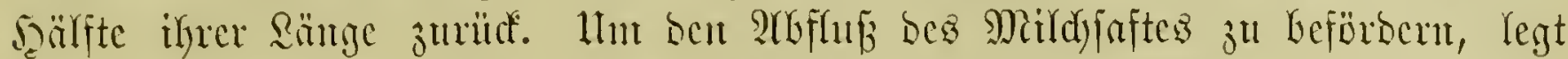

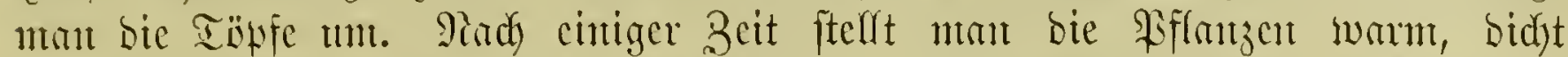

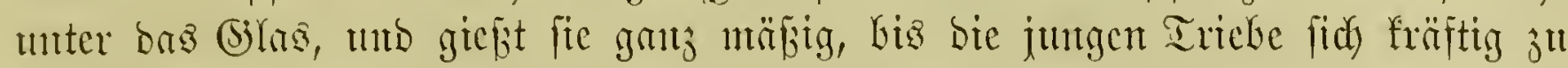

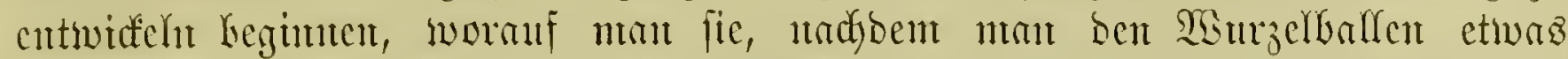

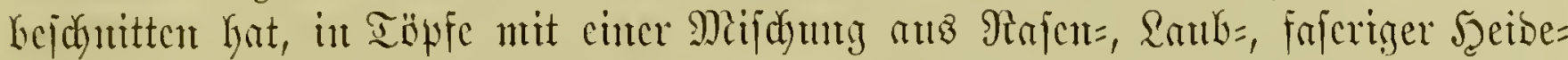

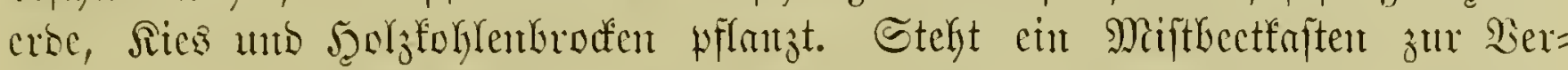

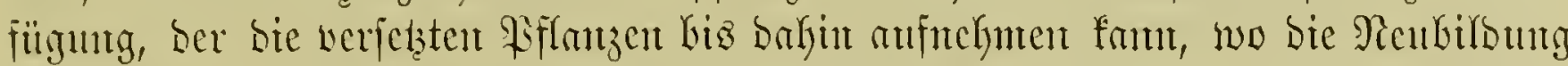

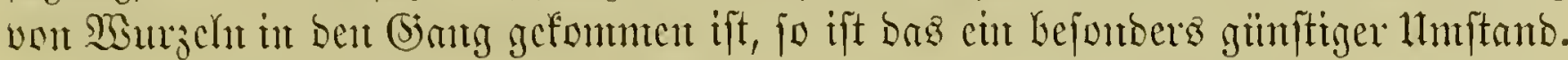

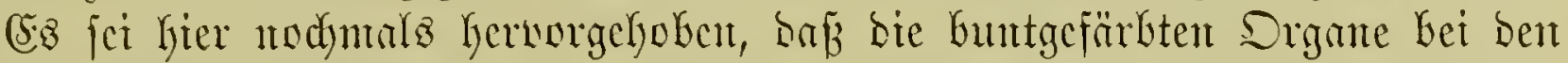

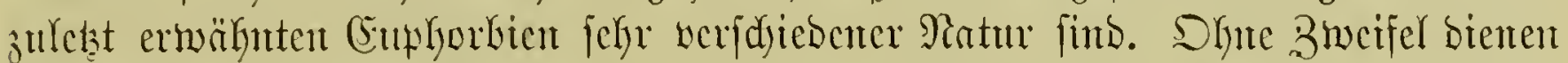

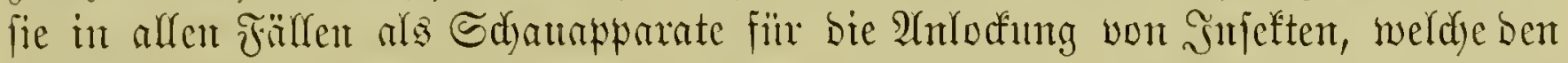

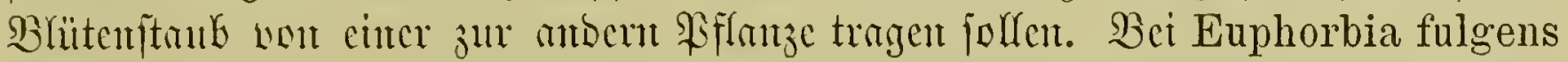
wirb bie Funftion bes Edyanapparates yon ben Drïjen ber Şülle überntonment, ๓n E. punicea un E. splendens färben fid bie Brafteen (Deffblätter) Ychbaft,

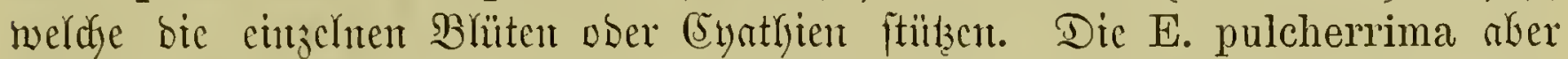

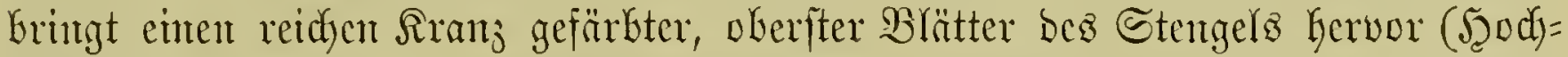

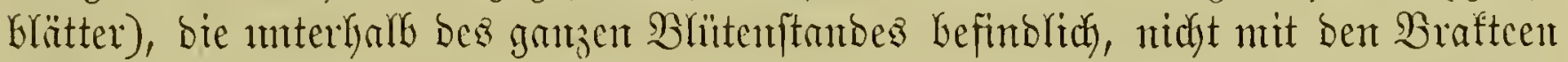

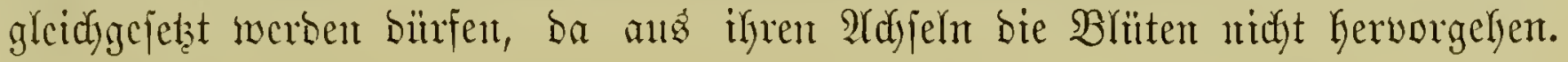

\section{Familie Cactaceae. Saftusgemä̌die.}

\section{Einleitung.}

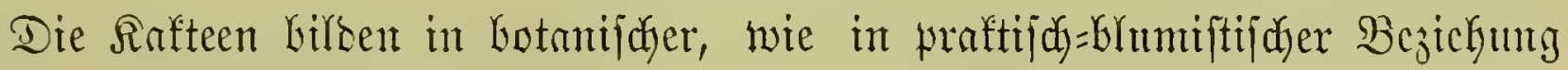

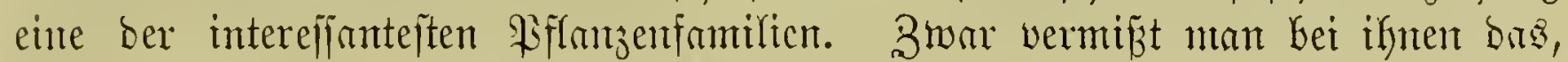

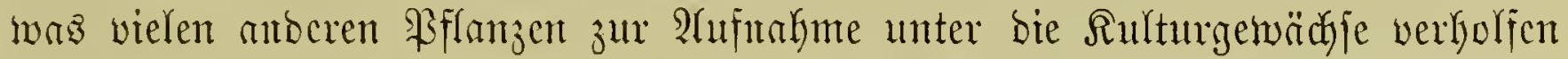

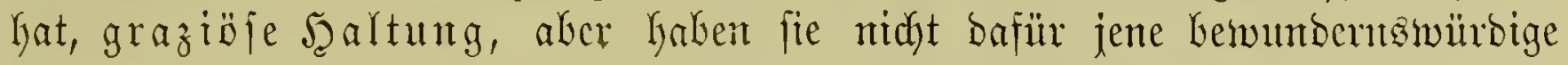

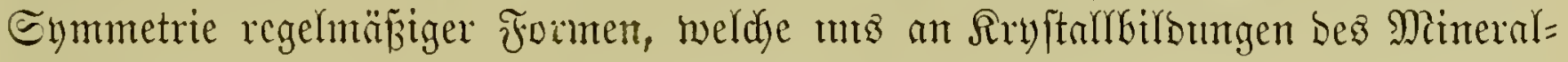
reidyes erimern, an benen man fid nidyt jatt jeken fann?

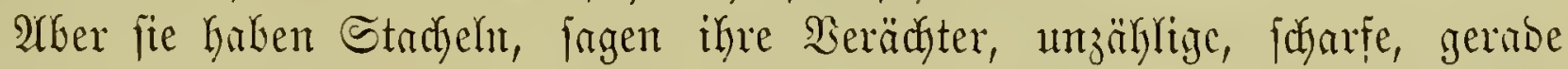
uno geftümmte, Gişweilen jognr angelhafige! 120 hr wahk - aber ift bent bie

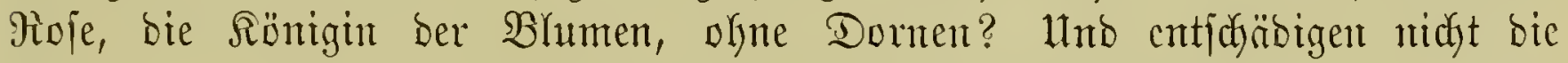
Stradjeln ber Rafteen für bie (Siefahl, bic bem täppifd) Zugreifenbon broht, burdy bie unendlidge Mannigfaltigfeit in Gruppierung, Bahl, Form unb Färbung, uns

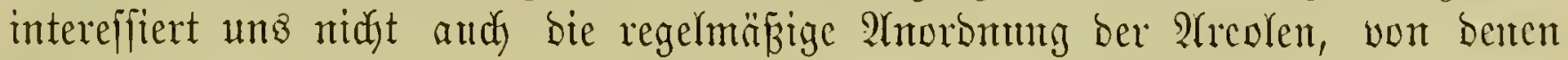
fie getragen werben?

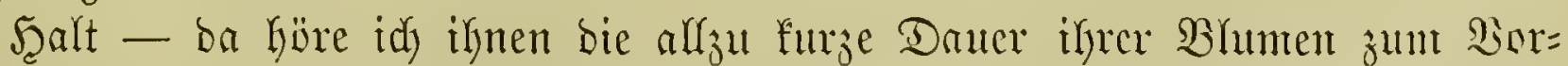
wurf madjen. Ja - bas ift mafyr, aber mu in bem Fall, bar fie ber volfen

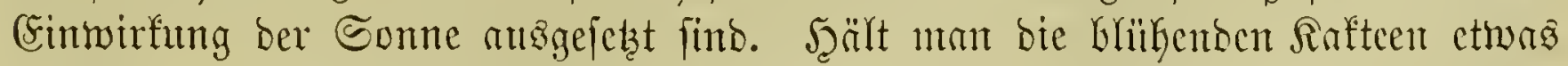

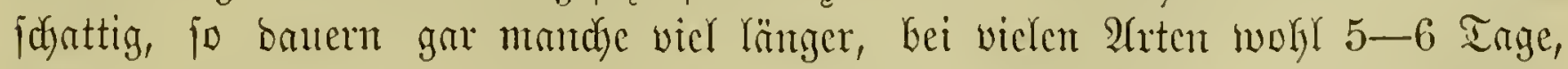

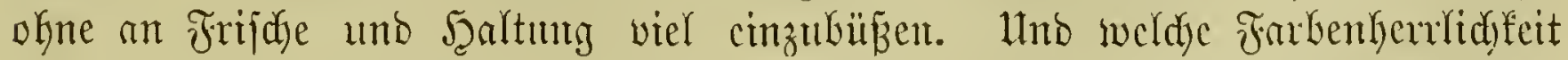

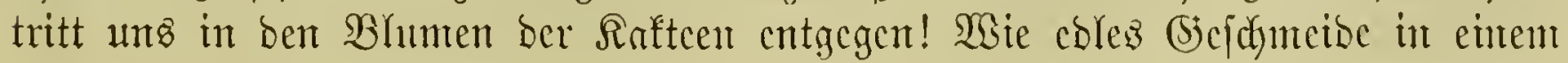




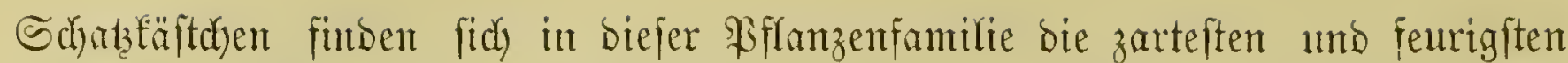
Färbungen gejanmelt. Den Güdyften Silanz aber erreidyt bas Rolorit in ben Bhtumen bez Cereus speciosissimus, in benen Yeudfender Furpur und

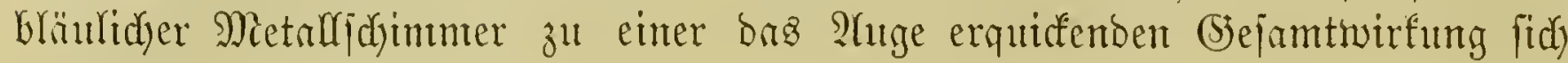
wereinigen.

Arber ba wernefme idy etwas, bas in ber That gegen bie Rafteen zul fprechen

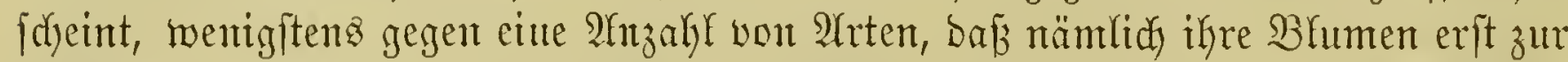

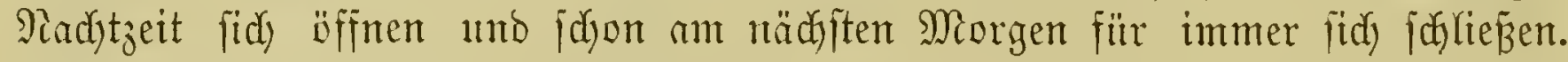

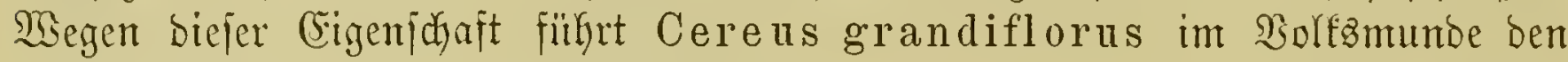

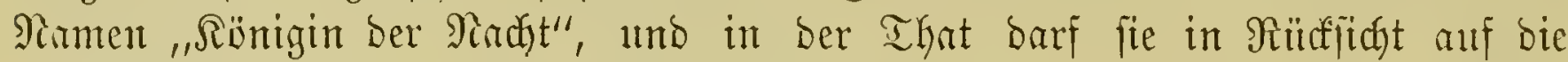
eble Form, bas reiche Rolorit umb Den Kerrlidyen Duft ber Błlüten eine Rönigin

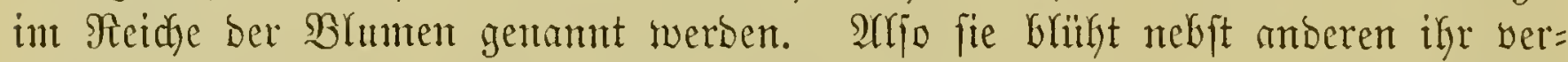

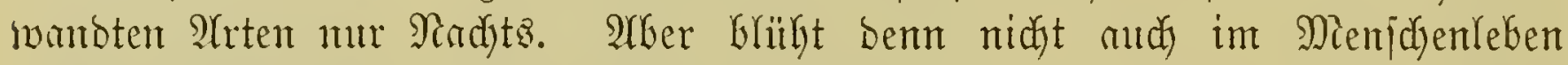

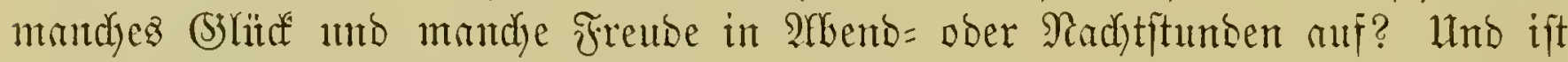

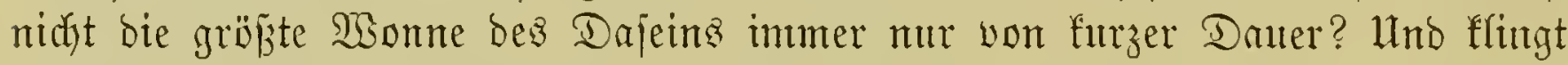

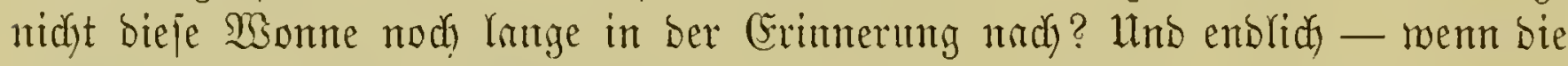

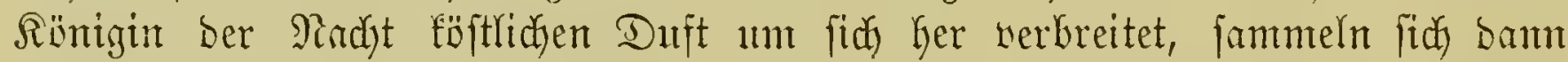

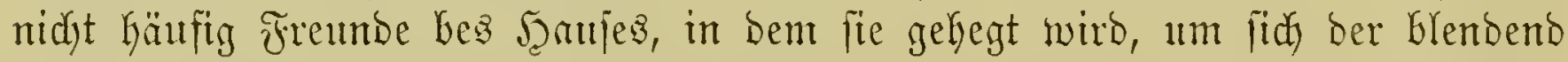

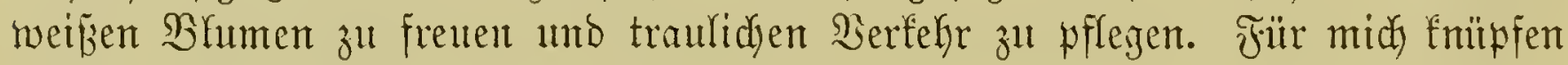
fid) Die angenelgmiten (Erinmerungen an mandje Rä̈bte, in benen bie Rönigin Jov Gielt.

Weldy reidyent Flor entwideln oft lange Beit Gindurdy mieber bagegen fo wiele Rafteen weridiedener Bjattungen! Hufer jenem Cereus speciosissimus nemre id inter mberen Phyllocactus phyllanthoides, crenatus, Ackermannii, Echinocactus Ottonis, Echinopsis Eyriesii. Die Thismahl ijt grof̧!

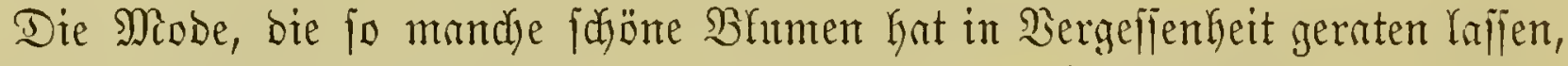
ift an ber Frmitlie ber Sintteen fajt ohne Edjaben vorübergegangen.

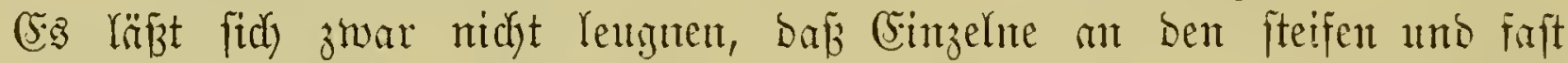
mathematijd)=regelmä̈Bigen Sfflanzen mur ein geringeres Bergnitgen gefunben Gaben; aber gefören nidyt bie Safteen anf Der anderen Seite jull ben werbreitetiten Etubenblumen. In viełen Siegenoen bilben Phyllocactus phyllanthoides,

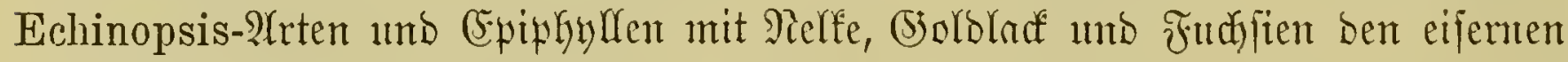

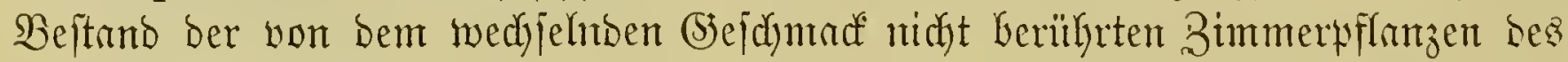

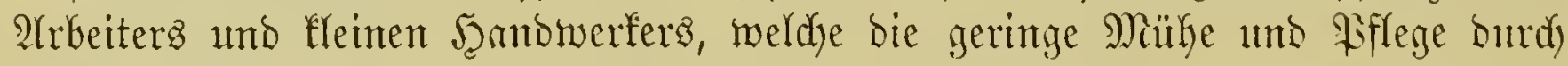
eine freimillige uns üppige Bhlütenpradyt reichlidy wergelten.

Die edyten Pffanzenfreunde aller Qünder Gaben aber nientrar ermangelt,

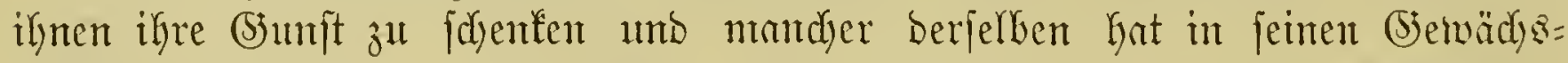

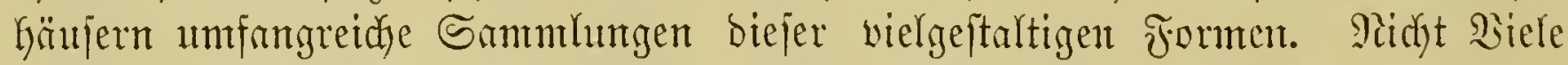
finto aber in ber Rage, fid foldye foftipielige Eimridytungen günnen ju bürfen; es giebt unter ben walgren Siffangenfreunden nidyt wenige, benen mur einige Stubenfenfter zur 2Hufnabme won (Bemädyjen zur Serfügung jtehen. Bjernbe aber für fie fint bie Rafteen wie gefdyaffen, dent jelbit berjenige, weldyer für bie Bfflege mur wenig Beit itbrig hat, wirb feine Mïhe burd einen reidgen Sofn critichäbigt felien. 


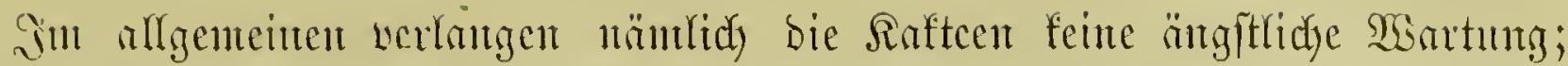

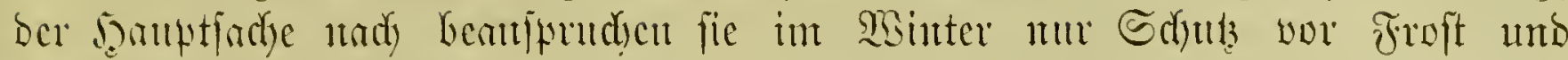

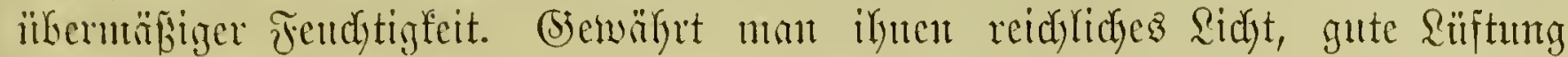

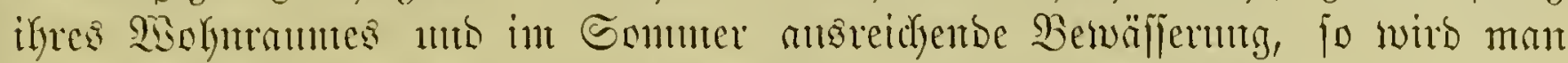

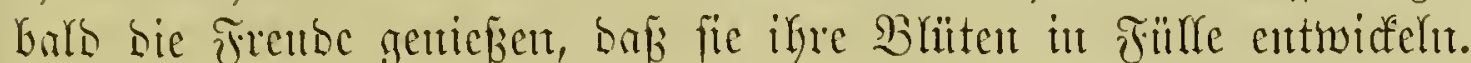

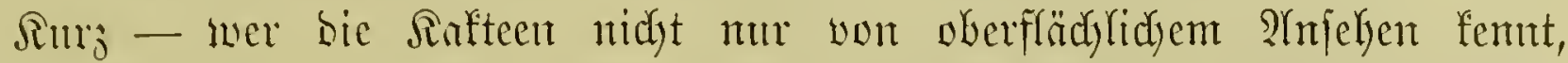

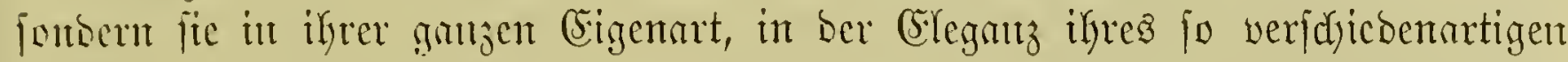

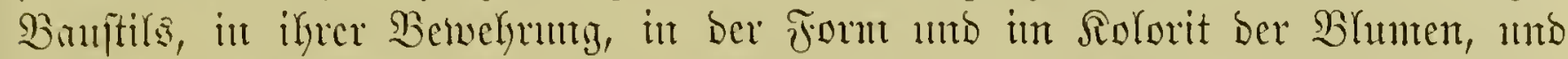

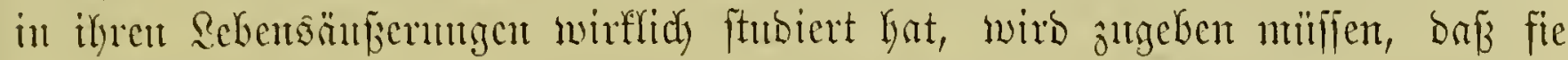

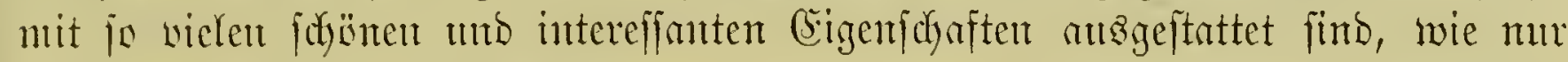
wenige andere Siflanjenfmullien.

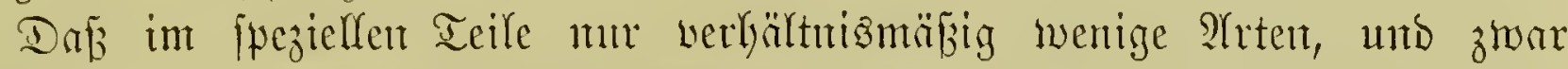

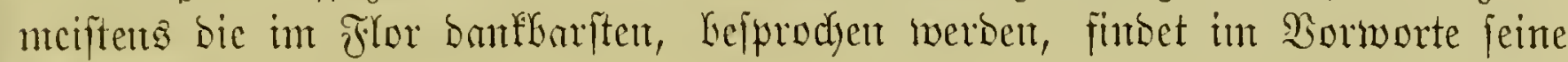
Grflärutrg.

\section{A. 2llgemeiner Teil.}

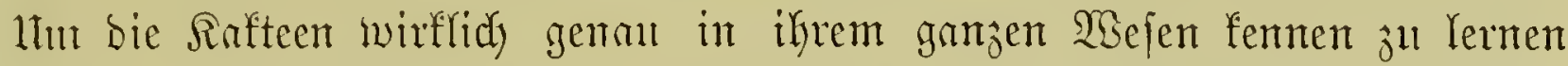

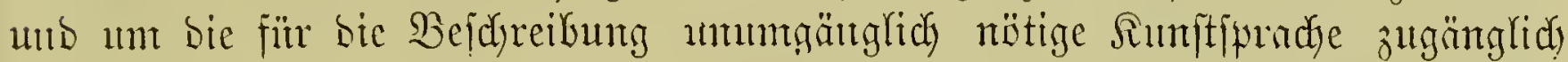

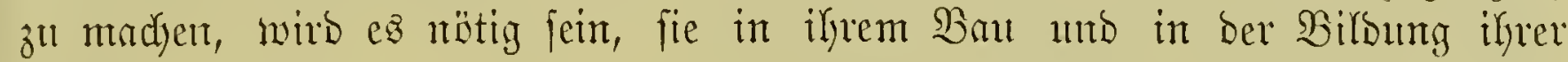

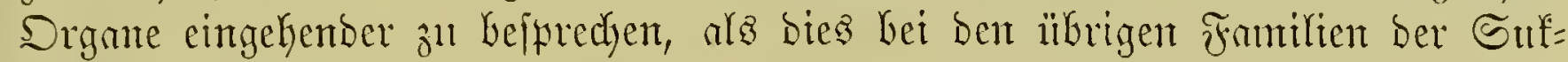
fillenten erforberlid ijt.

(E⿱ faltigfeit in ber Forntenentividflung Darbietet, als bie Safteen. Da jehen wir

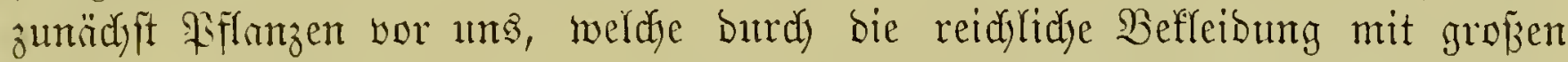

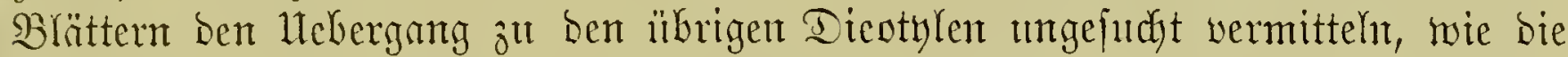
Feiresfien. Bum Teil finto es fröftige, ftottlidye, vielverzmeigte, anfredste

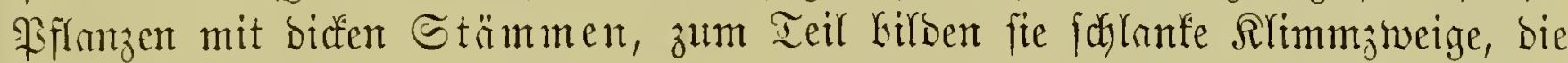

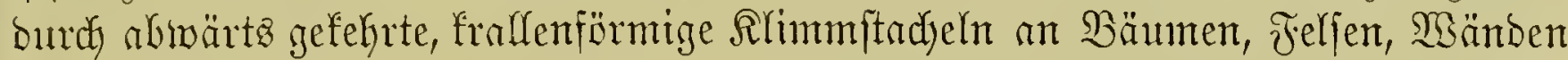

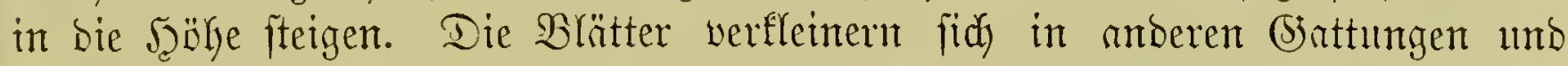
breiben zuYetzt mur alz furze, breijeitige Sdyütwdyen wahrnebmbar, meift von io

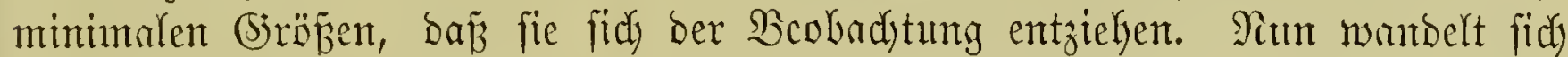
aber bie (jejtalt ber Stämme in unenblidjer Miannigfaltigfeit ab. SBald erfdyeinen sie Bafteen in ber Form yon aufredyten, rumben ober fintigen Säulen, bie zu= weilen einfady bleiben, jumeiten aber hody oben am Stamme fteife; fenfredyt

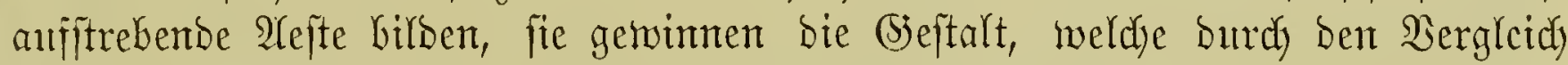
mit einem $\mathfrak{A}$ rmYeudyter an treffentoften wiebergegeben wirb.

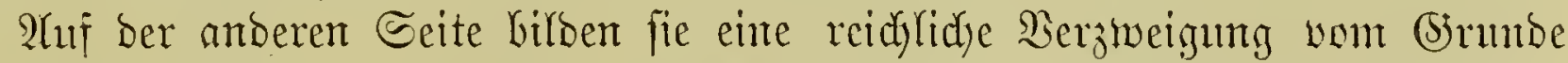

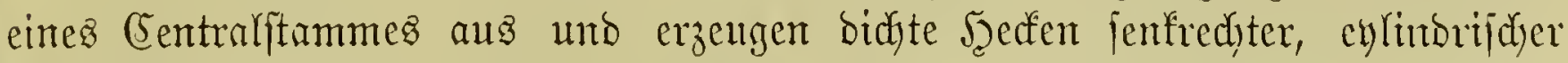
ober fantiger Etäbe, bie fidy jn cinem unburdjoringlidyen Diffidyt verminent.

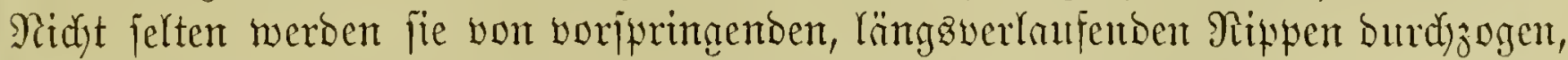
bie burdh mehr ober wentiger tief einjdneibenbe Rerben gegliebert werten. Sier=

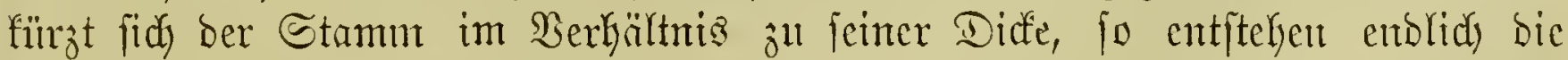

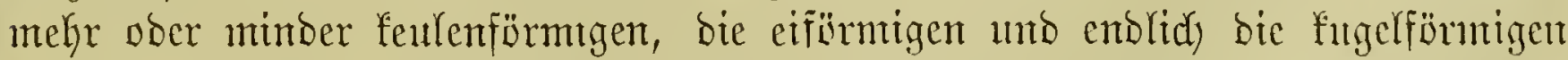

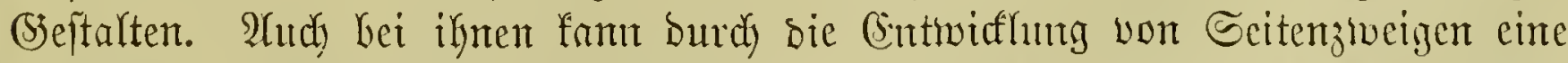

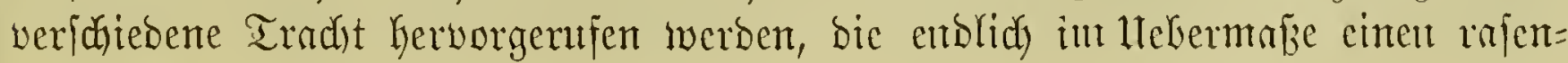




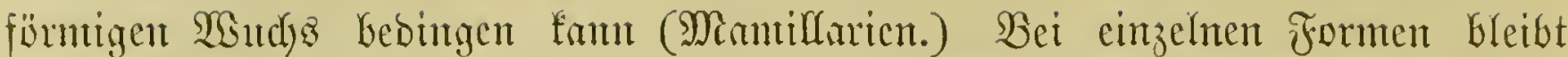
ber fejte Berband ber Iödjterjprofic nit ber Miutter nidgt gemahrt; bie eriteren

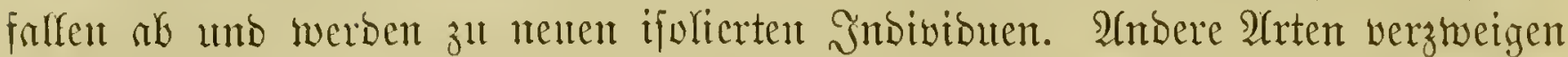
fid) niemalz (Melocactus), eine (5rjecimung, bie für bie Rultur von Bebeutung ijt, weil bieje mur butd) Snmen erfalten, niemals aber burdin Stedfinge ver=

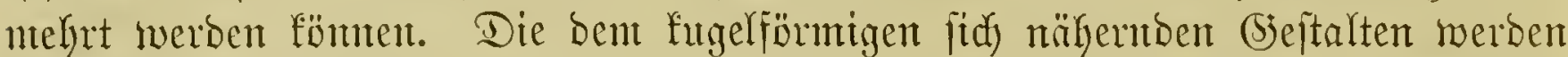
gleidjfaffs gewöhnlidy burdy Santen gejiert, bie mieberum oft in veridjiebenter Tieje geferbt finto. Seier ift aber jenes Mara ber Sonderuntg nidyt felten crreidyt,

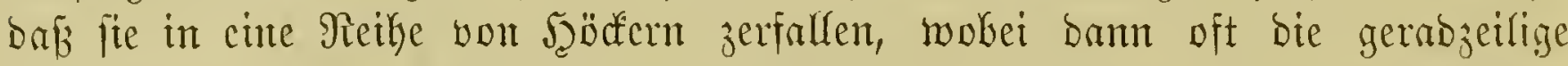

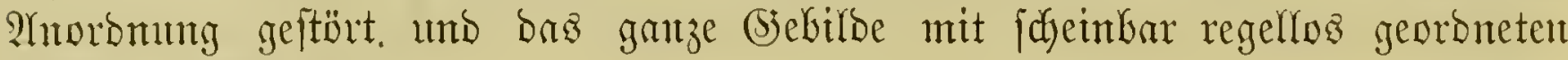
Görcern Kefleibet ift.

Der Durdynteffer biefer fäulenjörmigen ober an bas fitgelige herangehenden

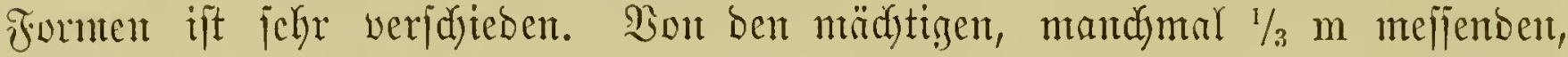

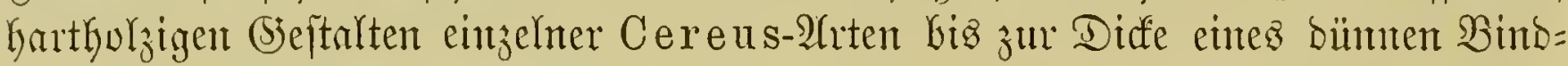
fabens, wie Rhipsalis pendula jeigt, fimben wir alle 3mijefyentajze. Die

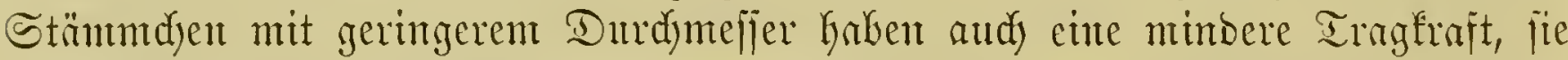

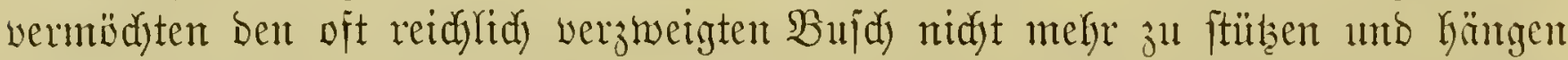

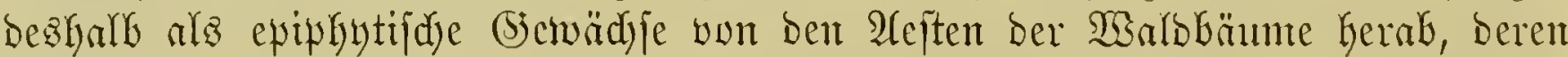

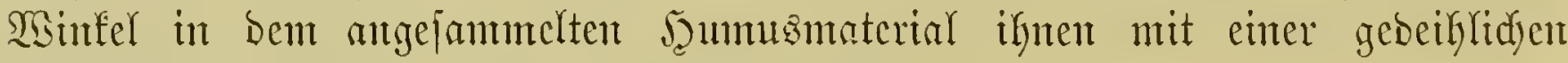

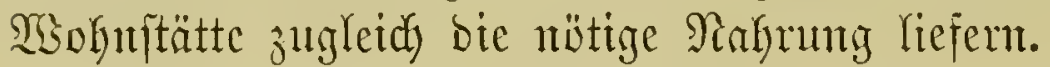

Sine zmeite Entwifflungåreige liefern uns bie (Sattungen mit blattartig verbreiterten Stämmen (Epiphyllum, Opuntia $2 c_{0}$ ), bie oft in cinter Derartigen

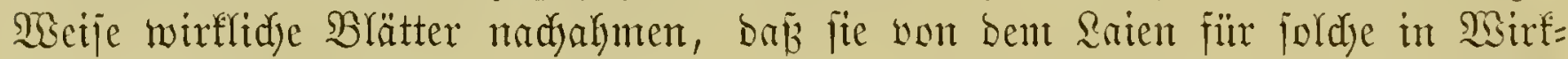
Yidjefeit gefalten werben. Bei ifnen wirb ber Berbans int ben fäulenförmigen

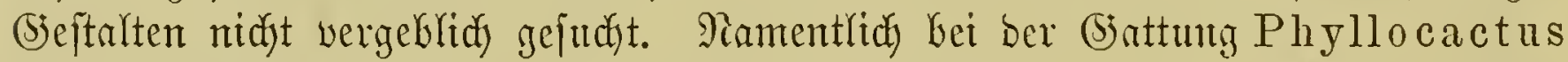
fins Brwifanenglieber von bent Glattartigen Stännmen zu ben breifantigen nidyt jelten jut funben unb atd bei ber Gattung Rhipsalis tritt aus ber einen Frläd)e zllweilen ein britter Frlïgel hervor.

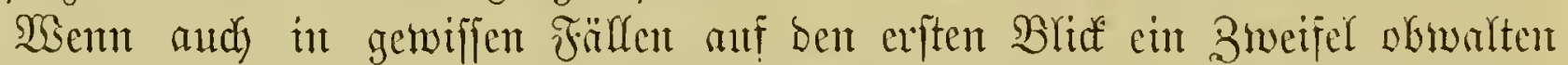

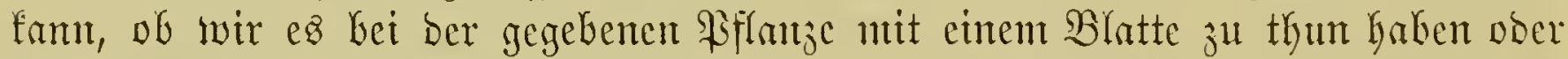
mit einem fegr fladgen Stengel, jo mirb bem aufmerfiamen Biedbadyter bie

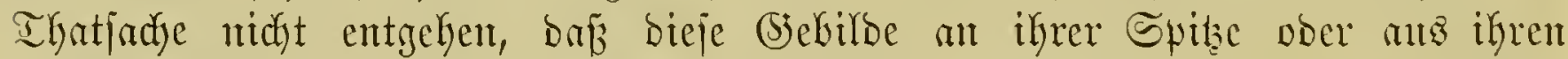

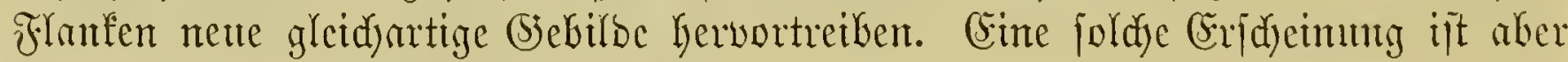

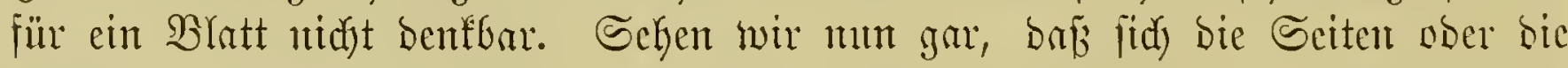

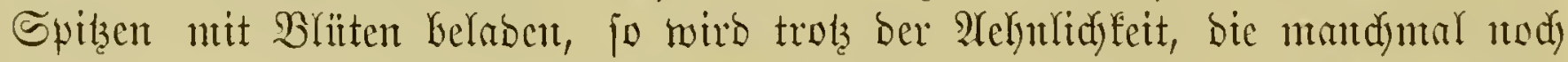
burd) eine ben Blättern entipredyende geervatur crgägt wirb, body feit Bweifel wbwalten, weldyer Natur bieje Rörper fint.

Dem inmeren Ban mad) Gaben alfe Safteen in ifyrem Stante bic für iffre

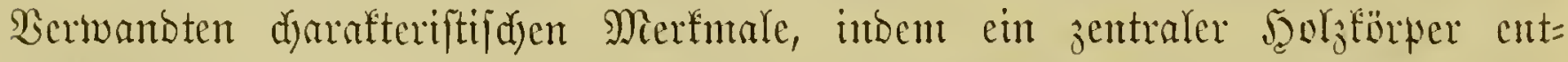

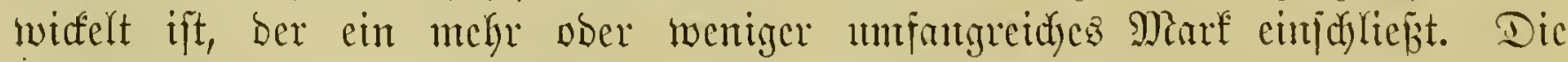

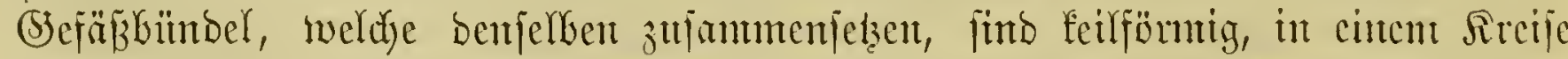

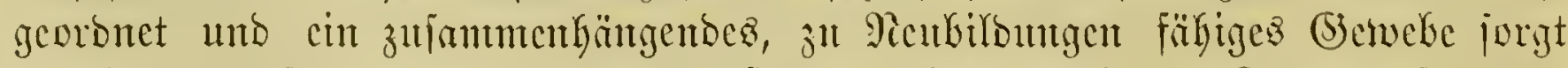

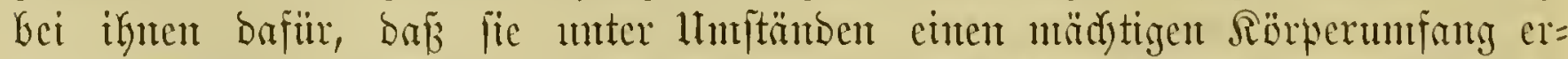

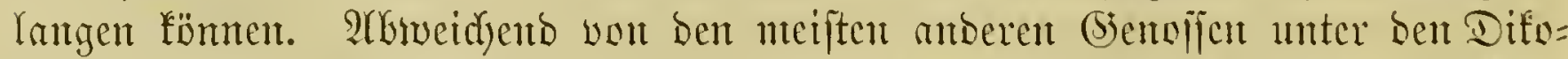

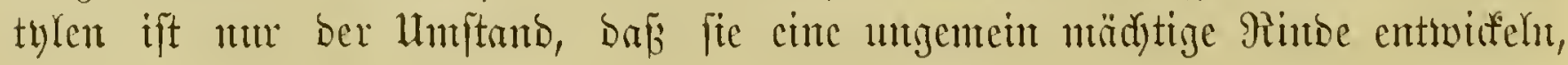




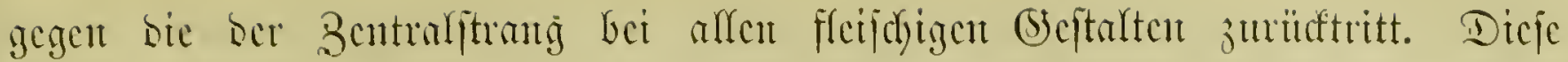

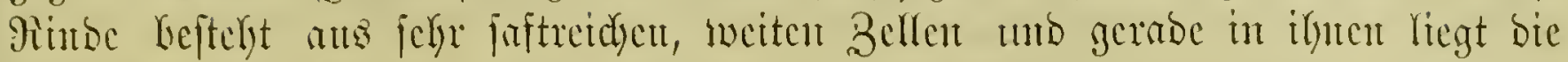

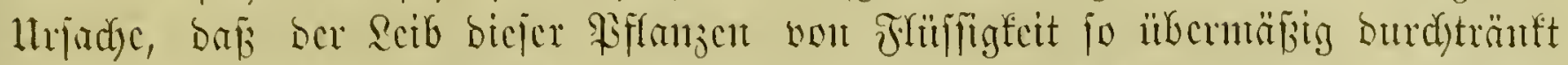

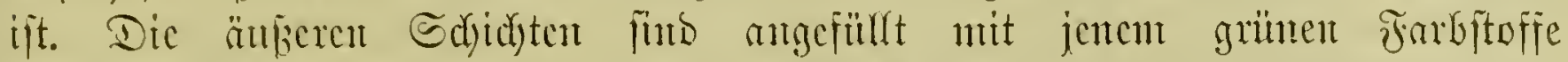

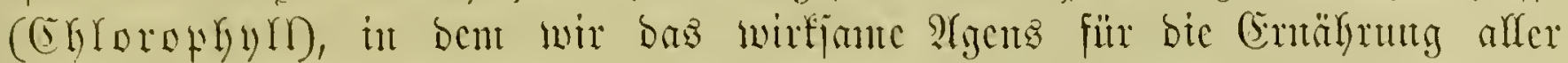

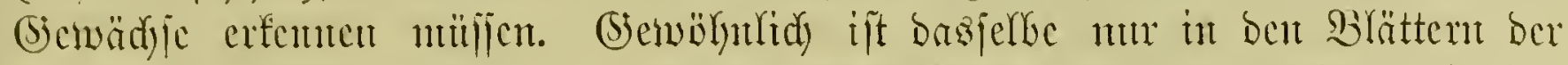

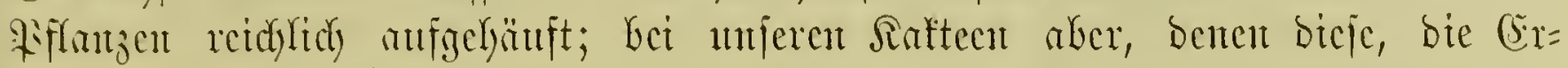

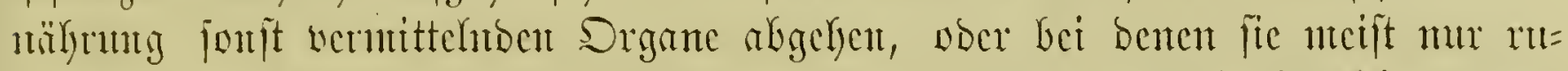

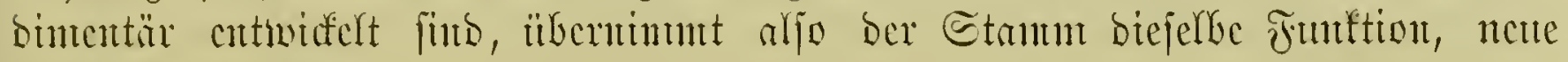
Baruttoffe jull bilibent.

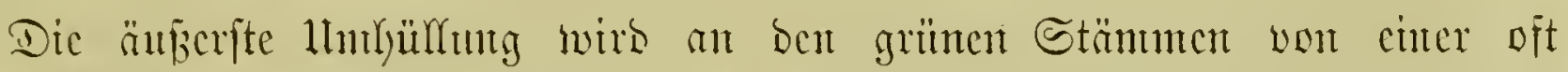

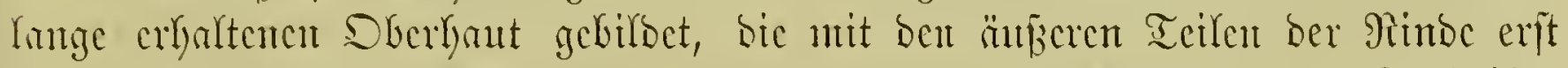

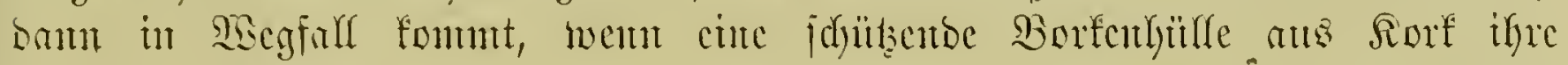
jutftion iibentinut.

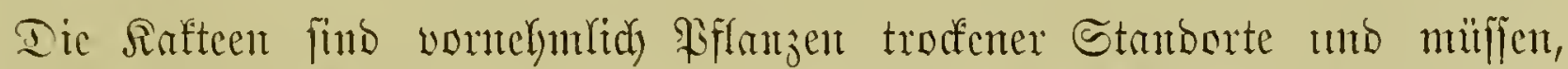

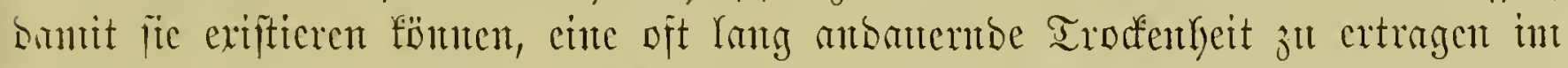

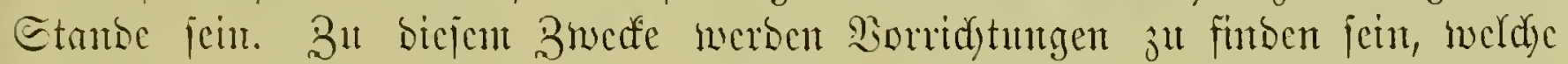

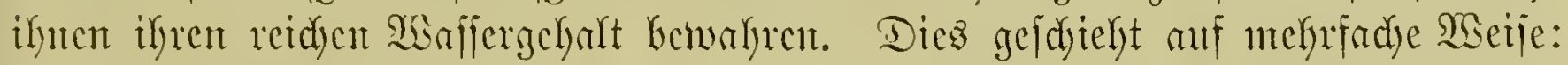

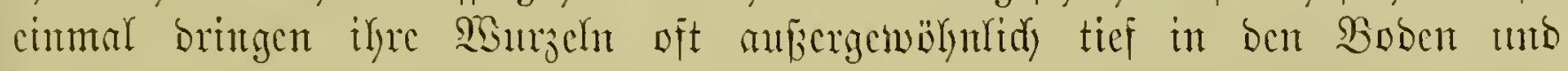

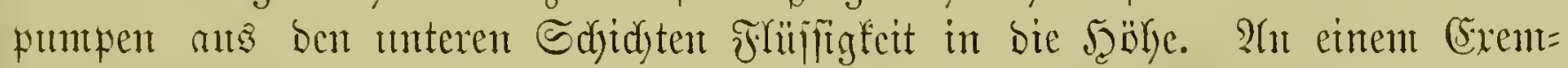
Hrare von Melocactus violacens Pfeiff. Ketrug bie Ränge ber Mintugel baz

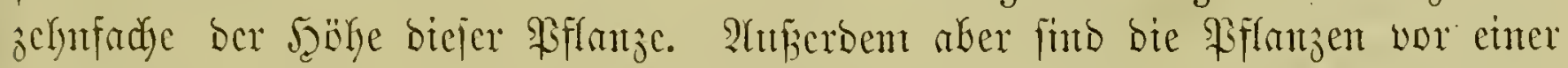

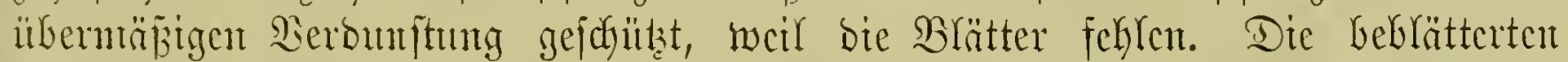
Feireśficn mieberum und bic mit blattartigen Stämmen verfebenen Rhipsalis

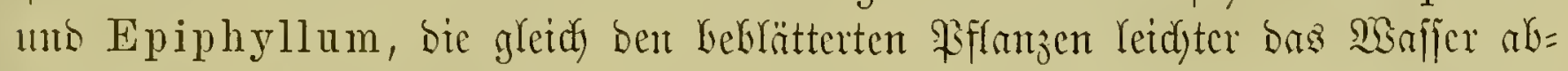

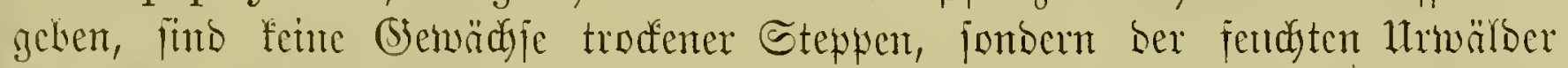

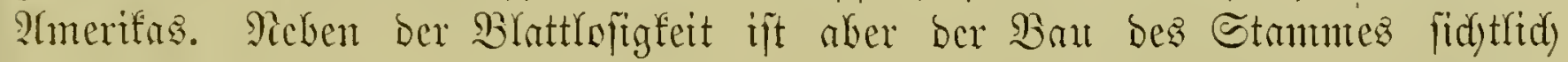

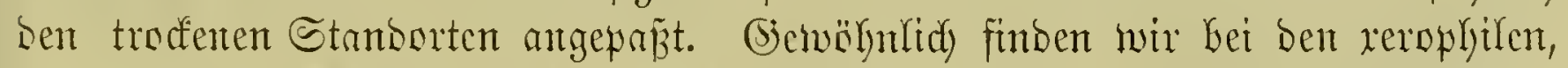

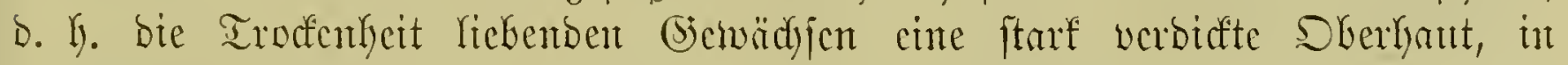
weldye bie Spartöfinungen, gering an Bahl, tici eingejenft liegen (Froteacen,

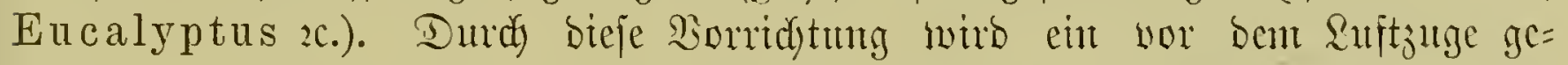

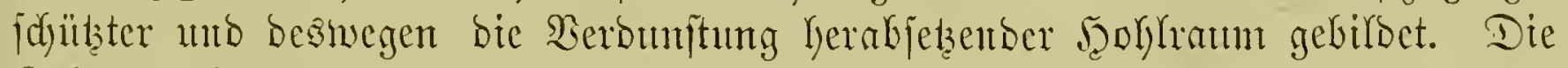

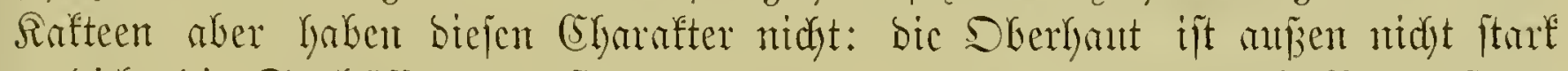

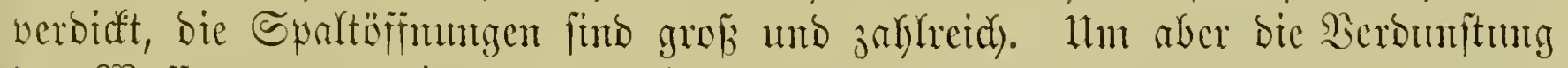

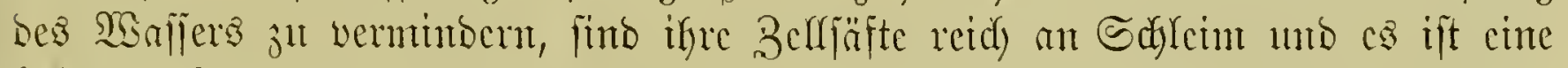

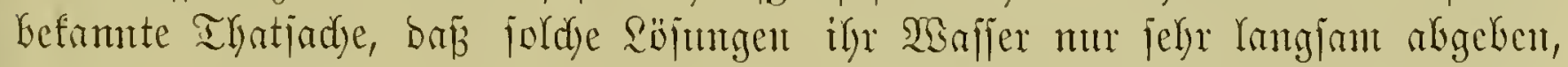
wie ber Bogelfem jeigt, ber trige = ja modyculantg flüffig blcibt.

Die Belfen ber Sberkant enthalten fehr oft foldye Mengen vou oxarjantem

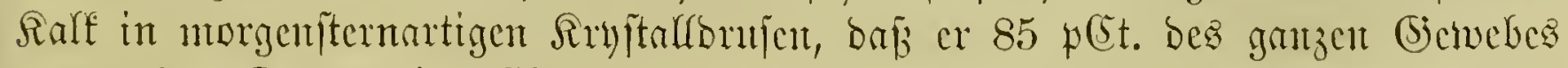

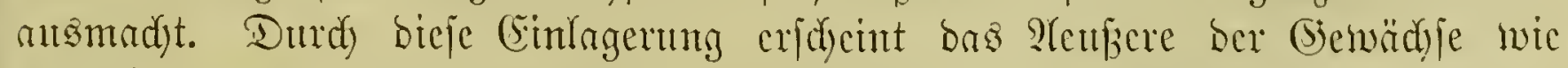

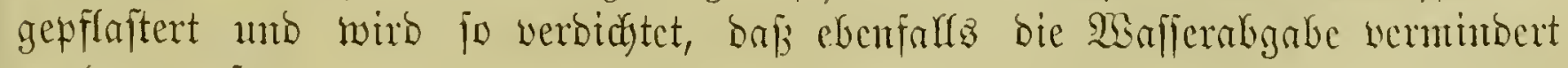
werbent muí.

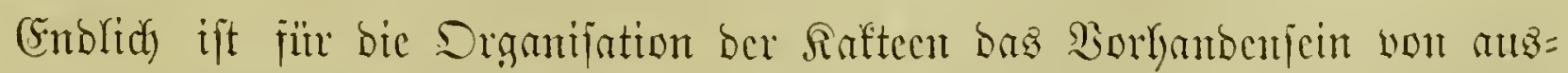

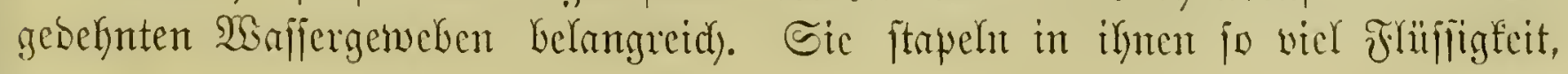


Dnß jut Beit ber Dïrre bic wafferbebürftigen Beswebe in gemïgender Menge

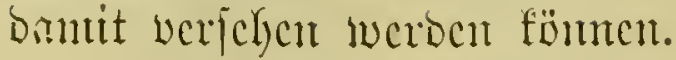

Dic B̧rätter mbetreffent, fo fün bicjerben, wic crwälynt, bei ben \$eires= fien nurmal entwidfelt. Sie haben eine veridjicben gejtaltete, meijt oblonge ober

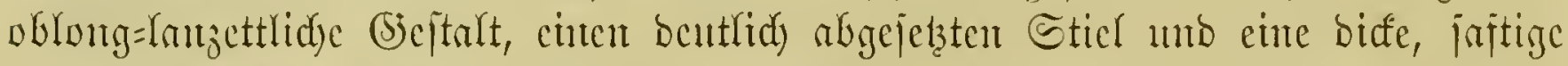

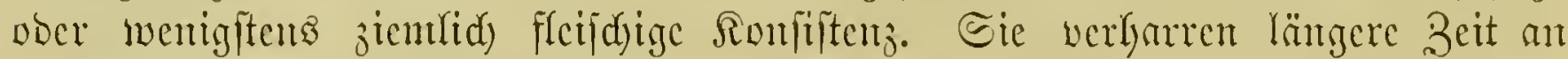
ifren Bucigen und bie alten fallen in ber פecimat erft ab, jobald wieber neue Gervorgetricben worben für. Dic Spunticn bagegen crzengen fürzere oft ge= frï̈mmte, melyr vergäntglidye Blätter, ben fie Glciben mur an ben jüngeren (5ilicberm erfyalten. Ifr ber (O)attung Rhipsalis, Phyllocactus, Epiphyllum unb cingehen (Eereen fint fie, wem and mur rubintentär, bod) in ber Form oreifeitiger B̉ipfeldyen Ycidyt ober bod) nody bei ciniger $\mathfrak{A}$ ufmerffamfeit nady=

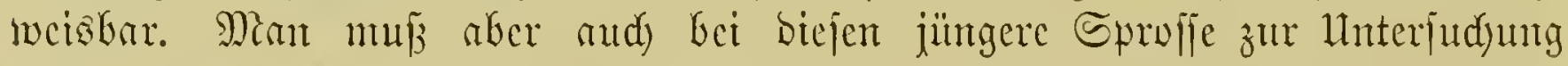

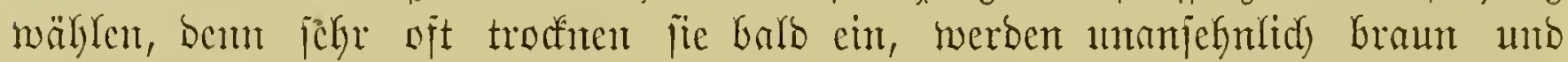

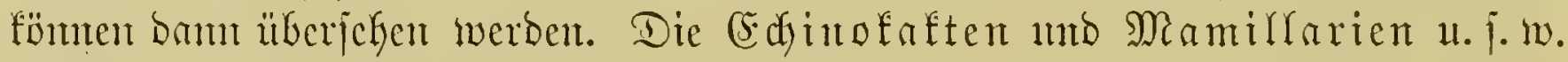
jeigen bagegen audy in jugenblidyem Buftande feite Spur von Brättern. Trobs=

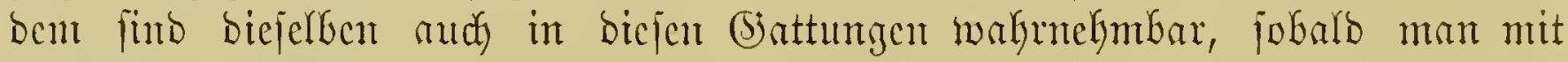

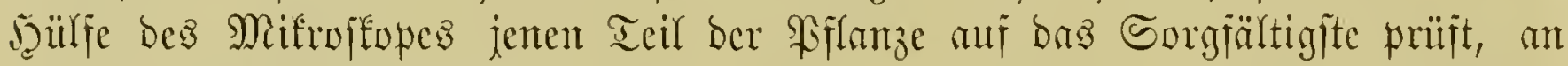
bem bic 24usgliebcrung ber Drgane erfolgt, bic oft tiẹ im Bcntrum eingejente Stefle, welde ber Bisgetationsfegel gentannt wirb. Dort entitelyen pie in ber

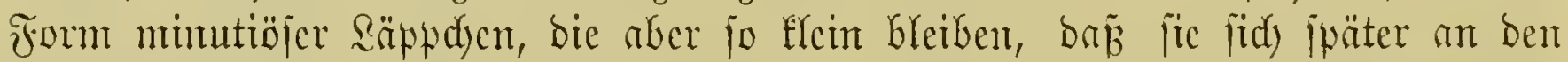

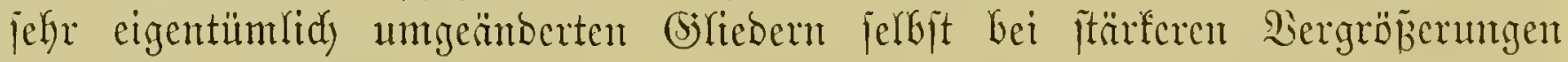

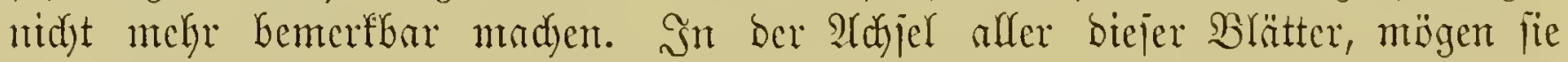

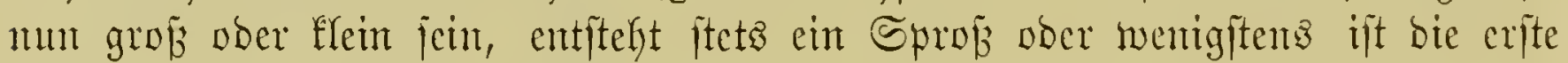

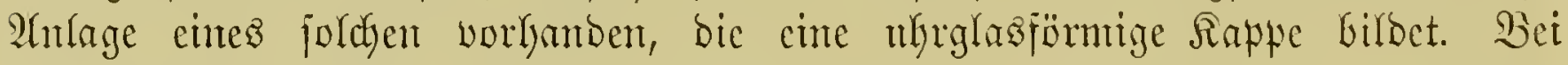

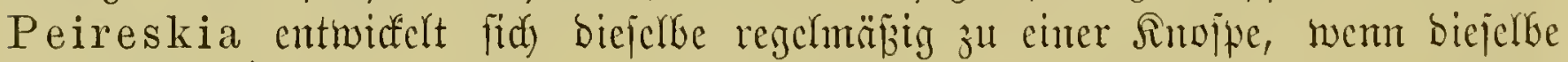

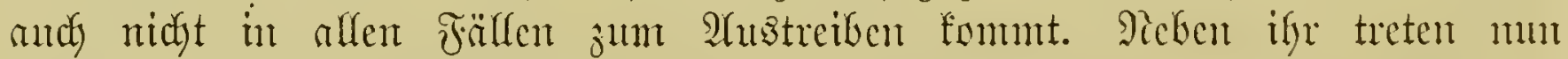

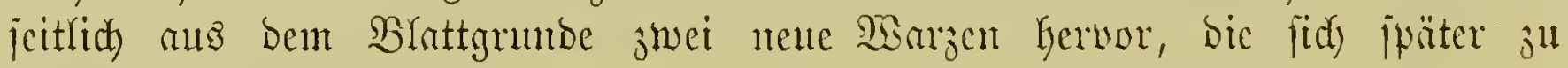
Strdyeht atshilont.

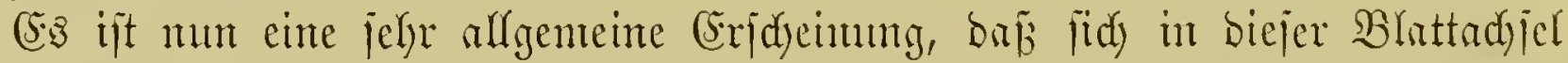

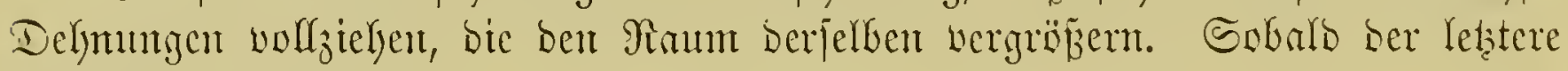

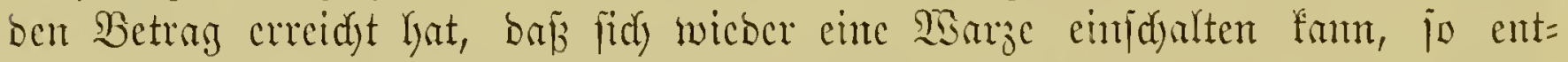

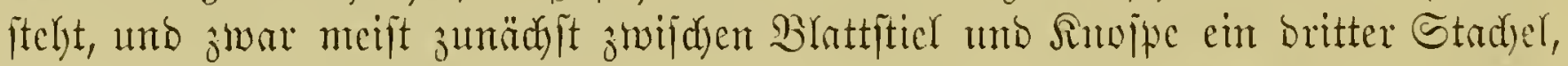
bent fid in aufiteigenber Reibe, b. K. und bem Stengel ju, ber bas Blatt

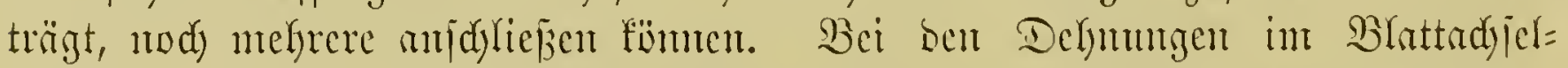

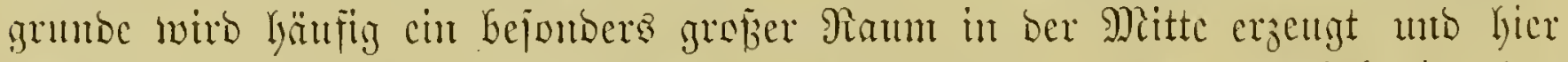

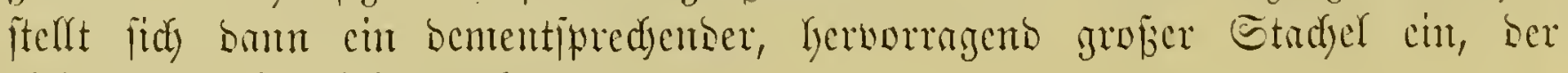
nidyt felten bie übrigen ïberragt.

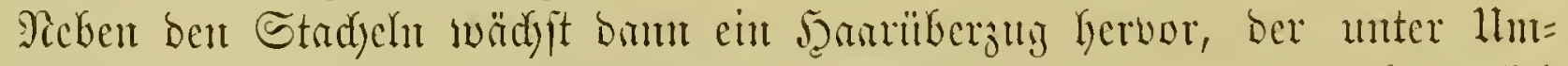

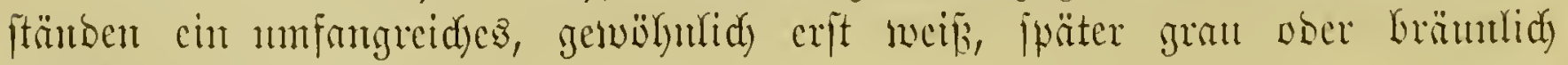
gefärbtes \$solifter baritclft.

Man lyat genteint, baj bicje Stadyeln untgemombelte Brä̈tter jecin,

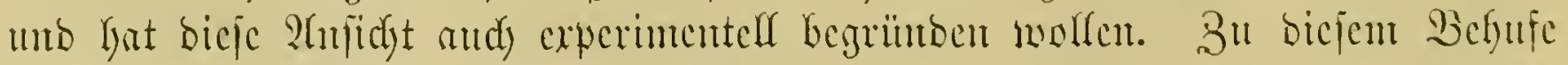

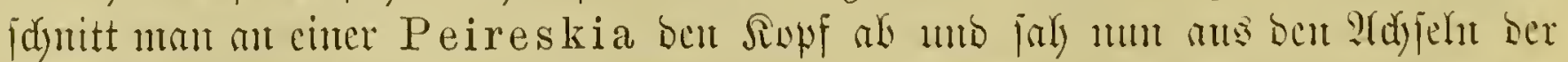

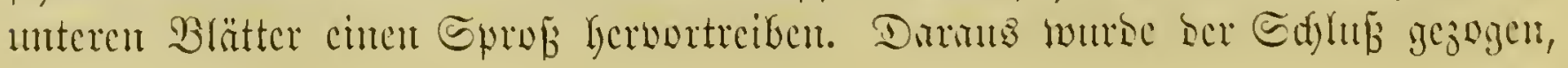




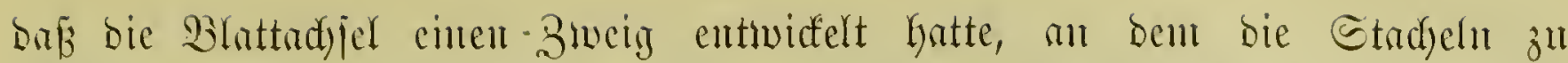
Blättern ungemantolt morben waren. Bei biefem (Experiment hat man aber

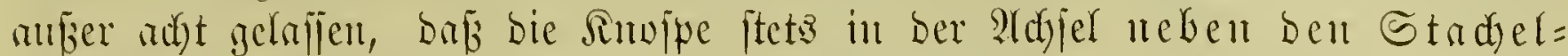

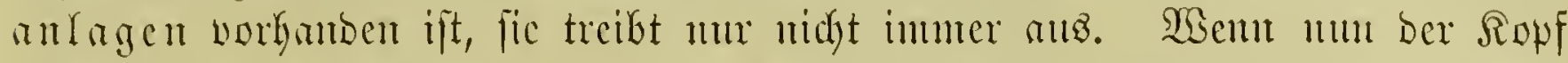

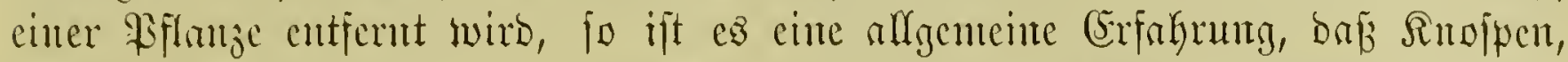
bic jouft in gingezuftanbe werkarren, zul einer energifderen Thätigfeit angeregt werben, eine Erfdeinumg, weldye bei ber becapitierten Peireskia ebenfalls in

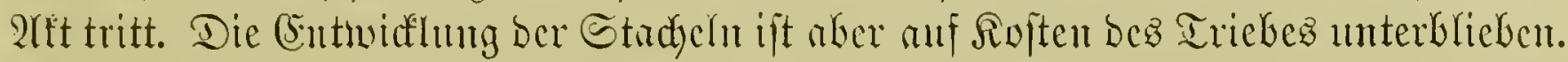

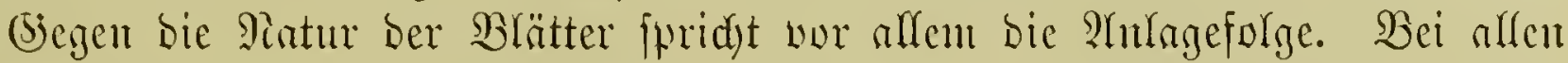

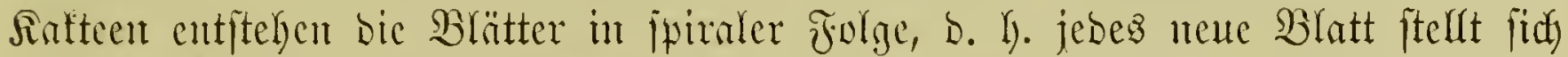

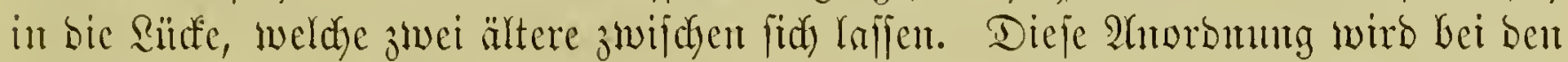
Stadyeln ber Beiresfien unb wie wir gleidy fehen werben, ber amberen Rafteen

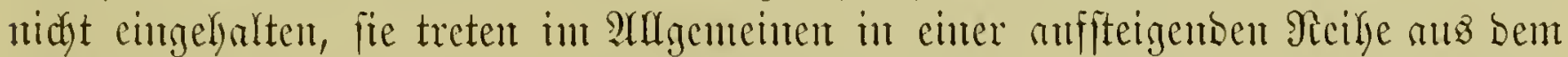

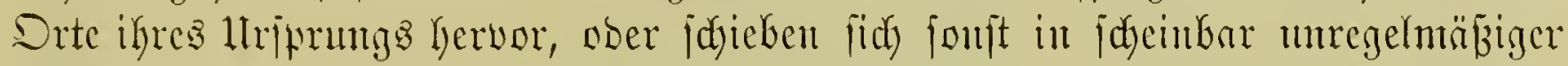

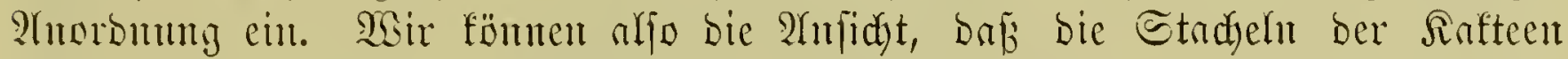

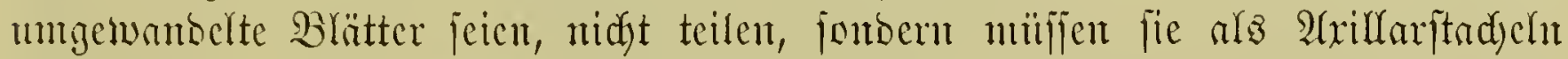

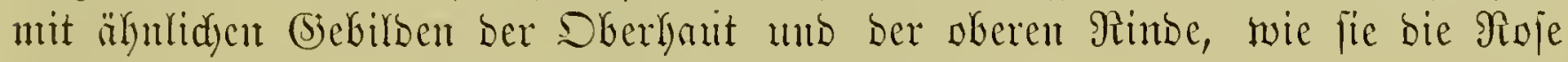
ober bie Rojffaftanienfrüde bieten, Gonvlog jeben.

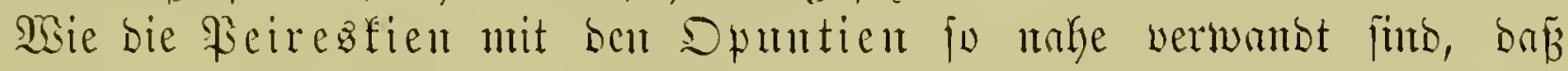

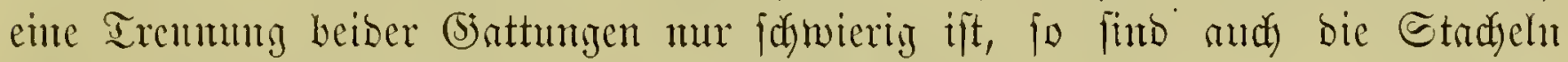

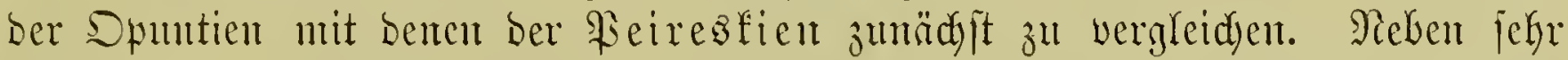

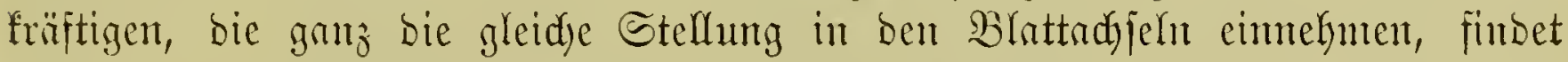

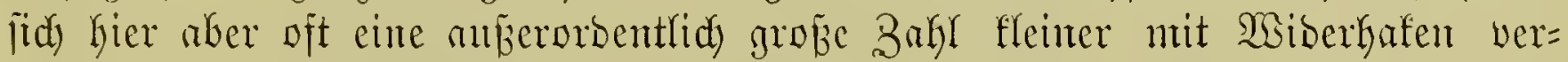

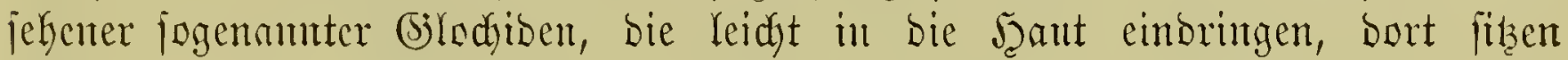

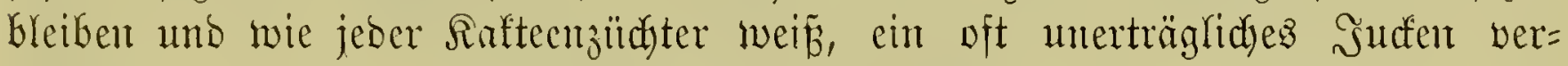
urjadyen. Sie erjdeinen ebenfallz anf bem 2hbjelgrumbe ber Blätter in auf=

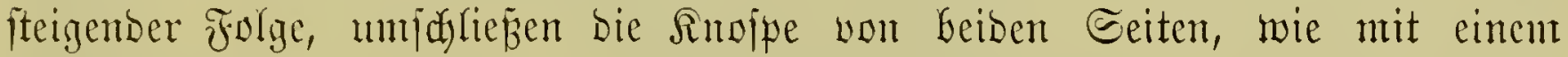

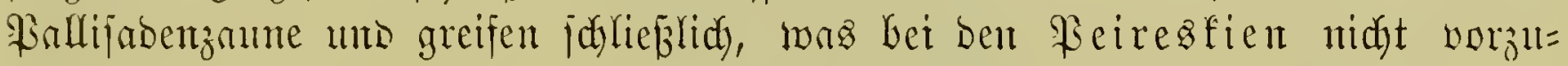

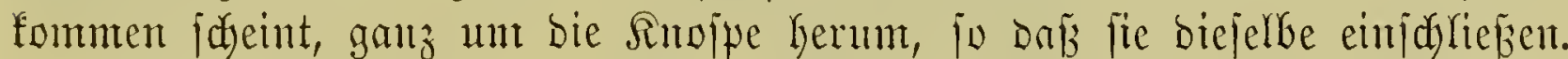

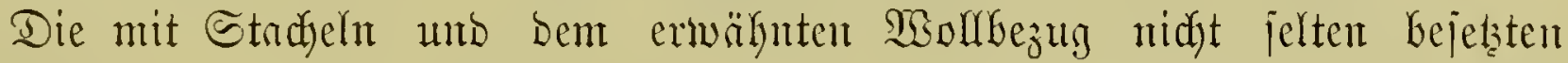

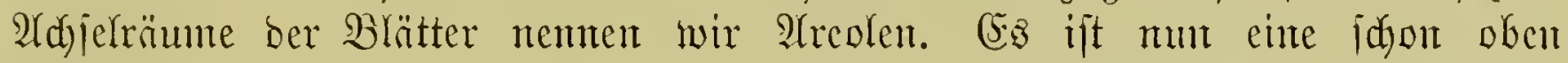

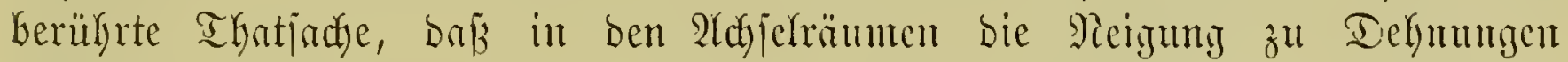

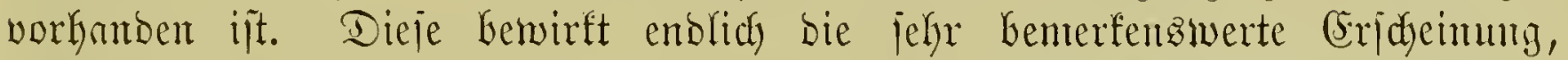

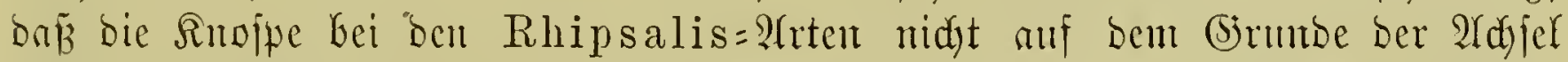

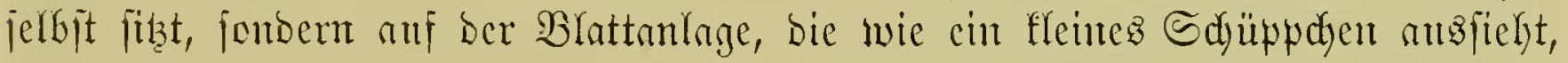

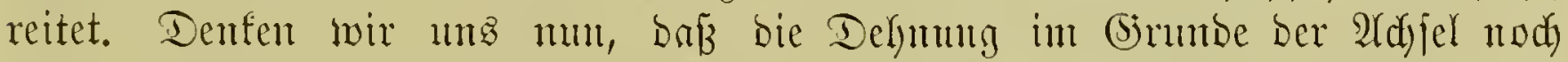

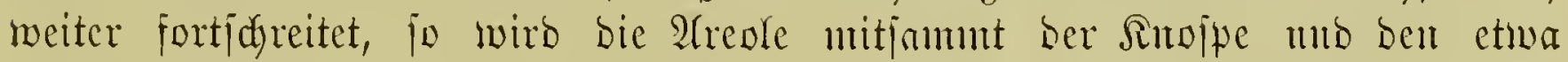

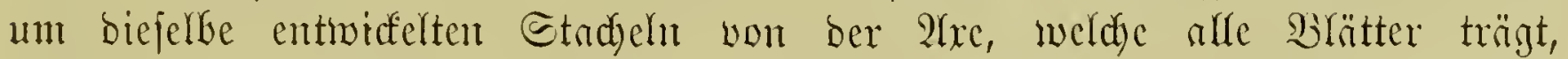

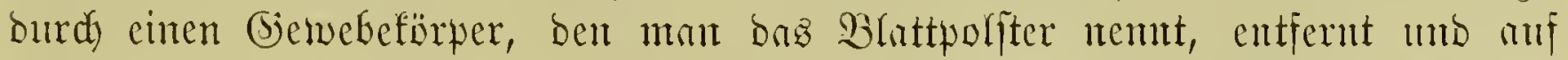

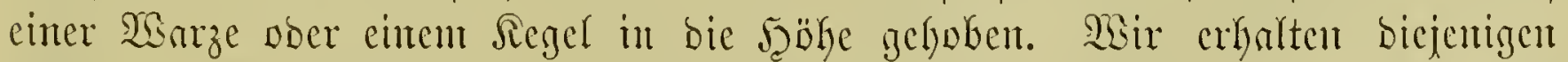
Rörper, weldye uns bie Mianiflarien unb gewiffe (Ed)inofaften zeigen, bei

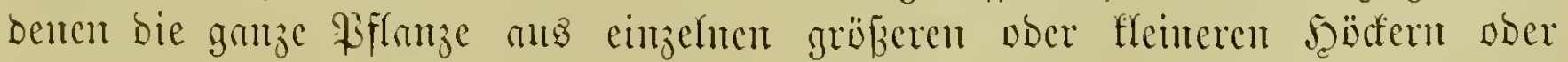

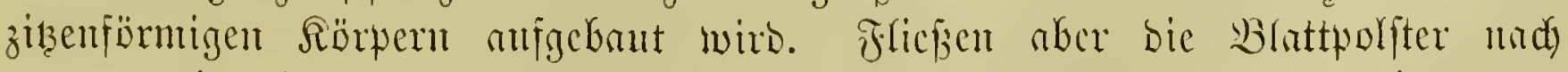

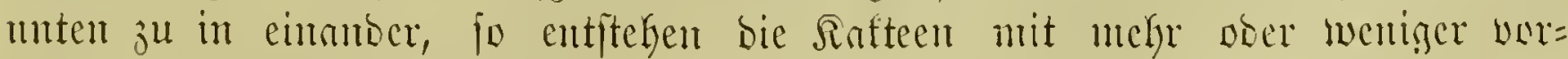
fpringent fantigen etrimmen. 


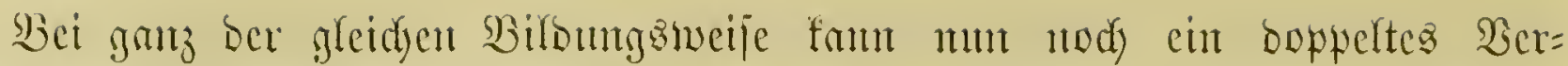

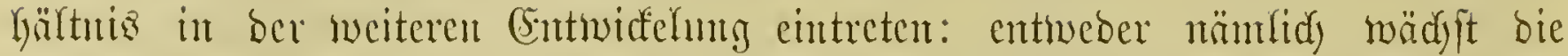

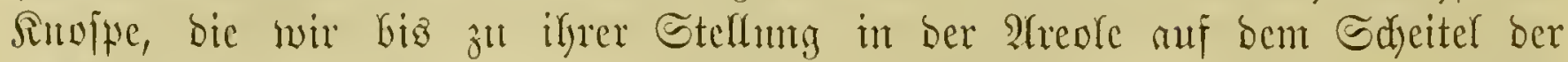

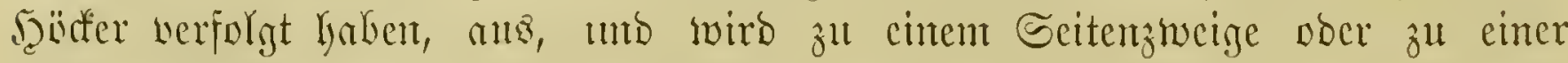

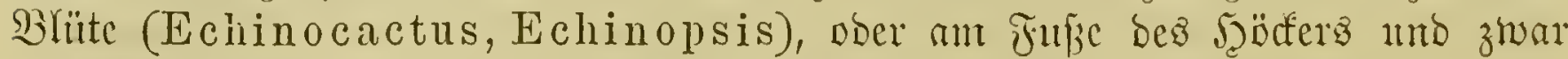

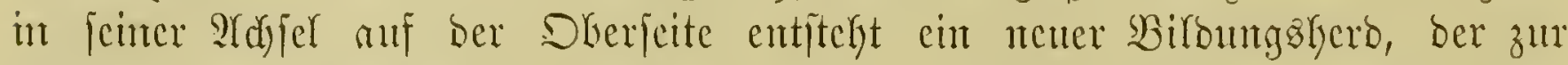

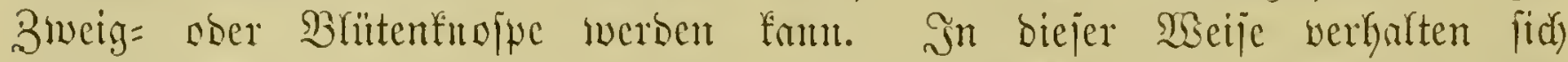
Mamillaria, Pelecyphora unt Leuchtenbergia, bie bentgemä̈́ nidjt

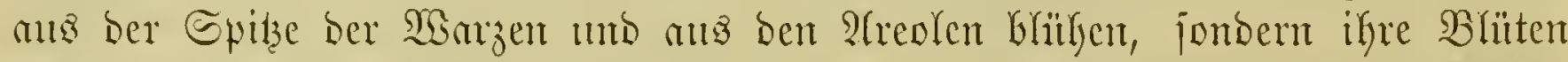

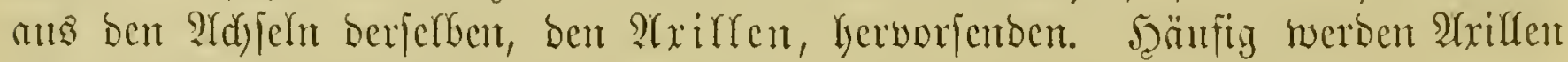

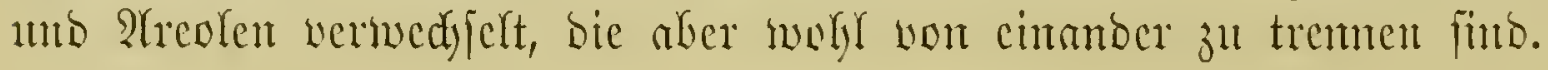

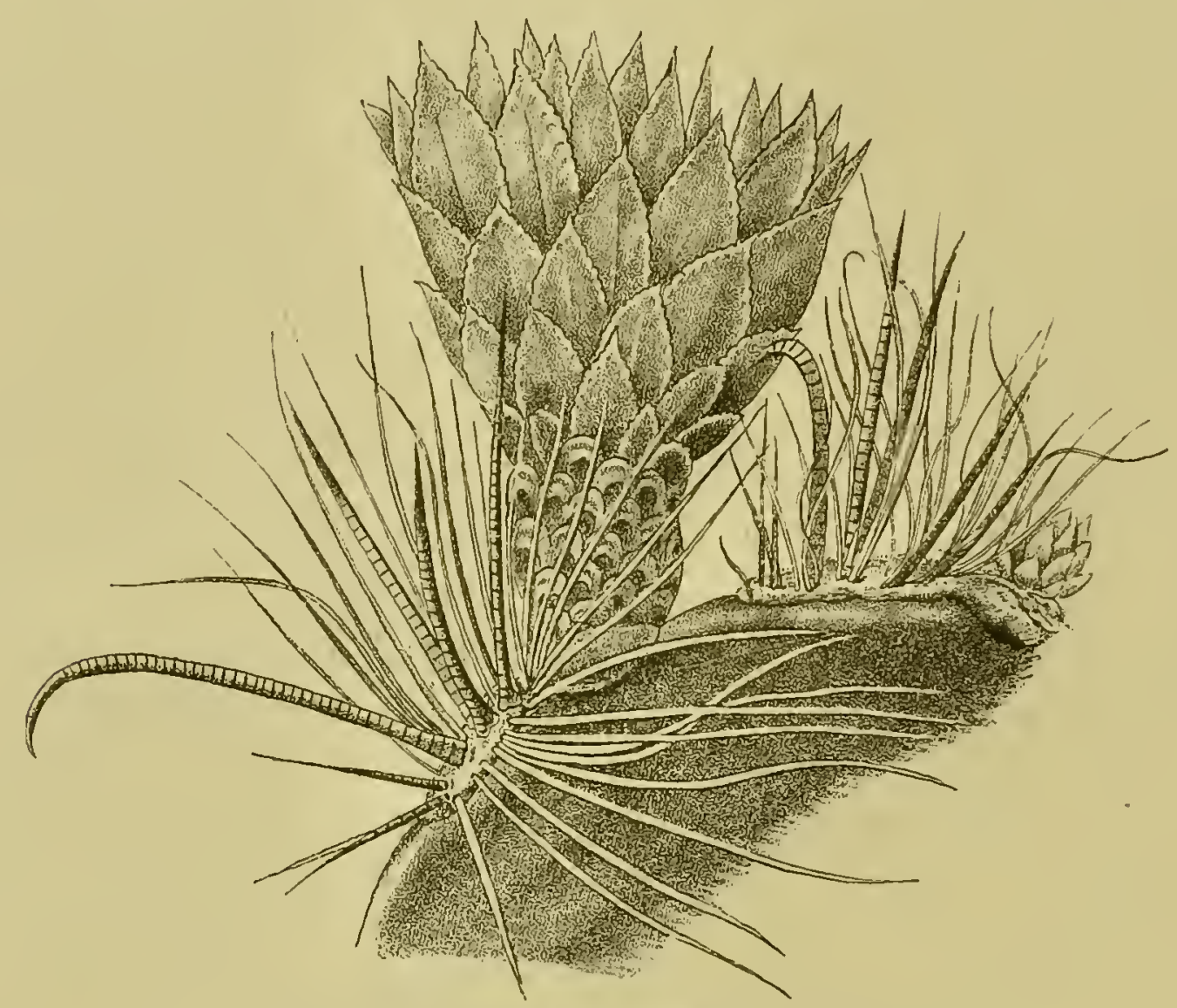

Fig. 62. Echinocactus Wislizeni Engelm.

Aud bei Echinocactus, Cereus, Mamillaria entitefen bie Etadjeln

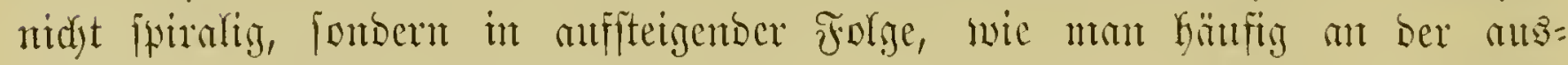

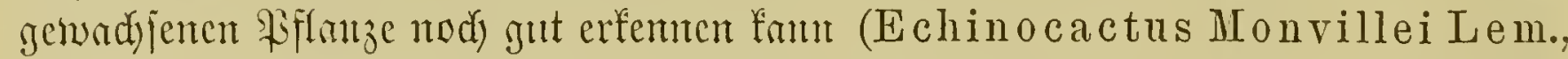

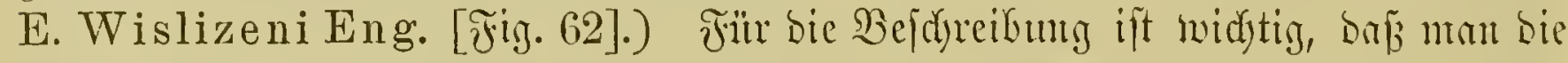

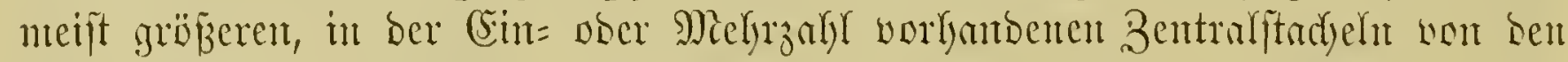

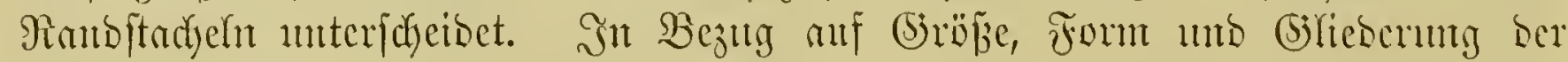

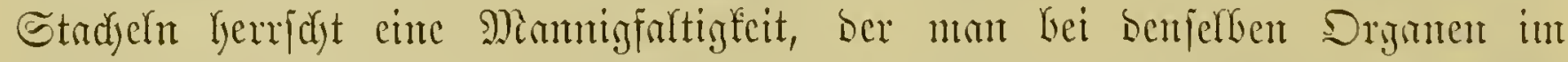

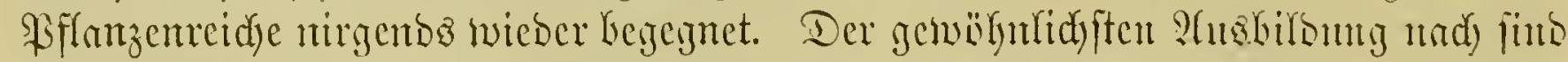

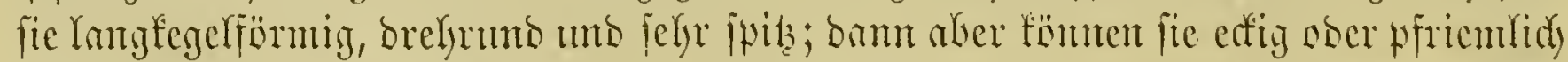
fein, zunveifen werben fie platt uno jeigen bant anf ber Dherjeite eine paralfele

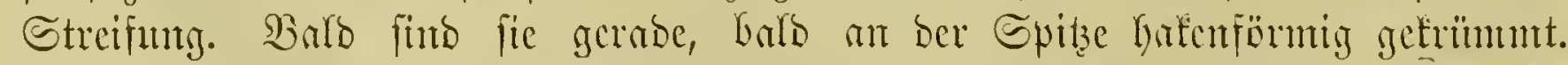

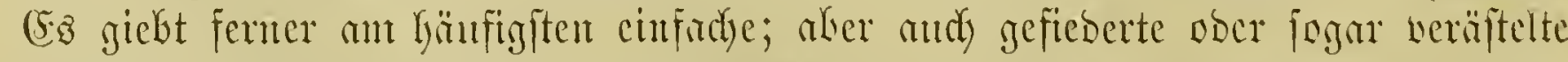

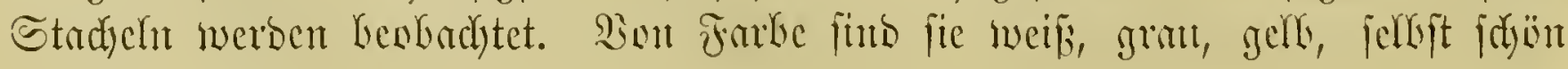




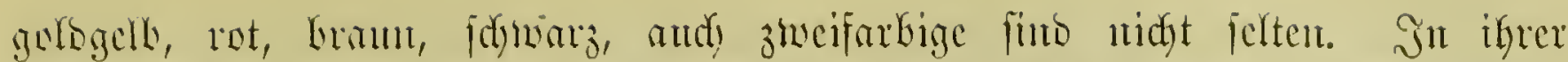

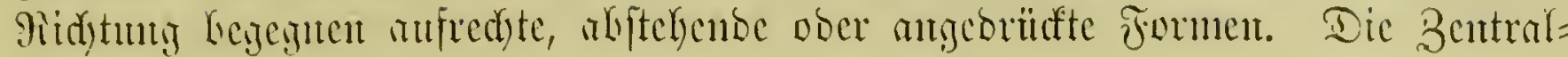

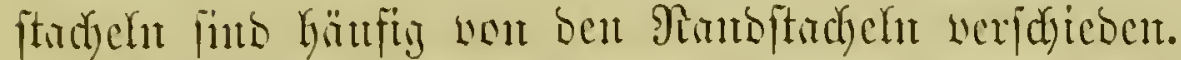

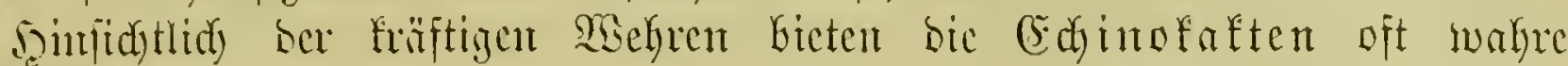
Extrutitioffe, montentlidy fints E. cornigerus, cylindraceus, Johnsonii. Monvillei, Lecontei, longihamatus, Wislizeni ju crmälyntr.

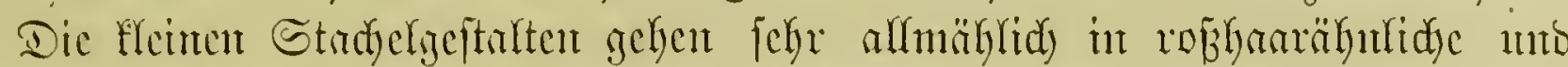

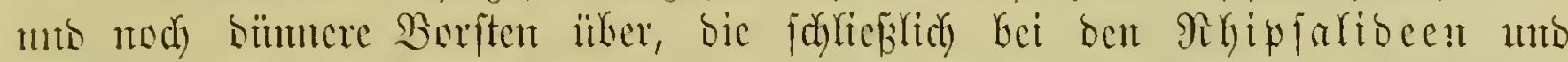

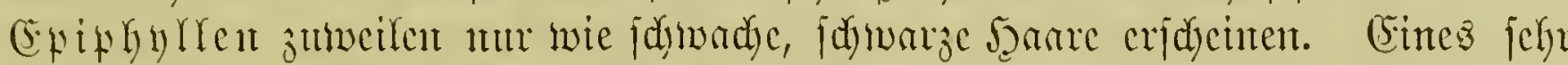

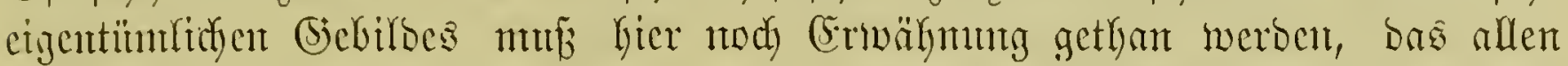

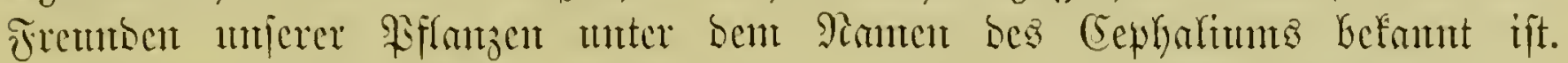

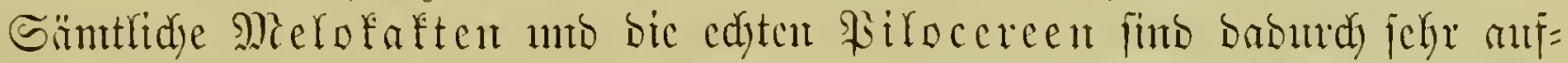

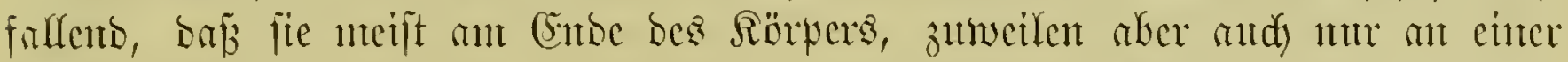

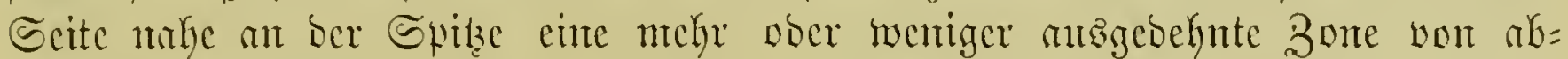

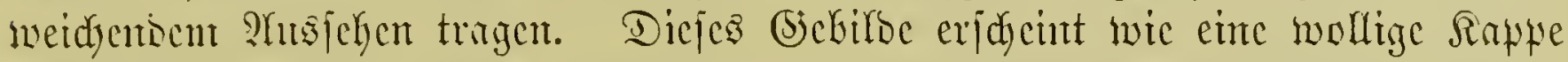

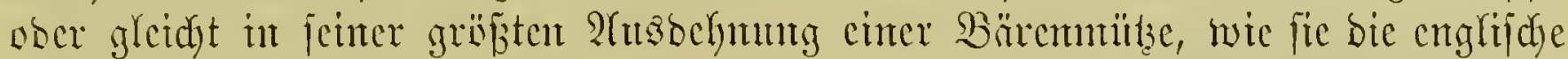

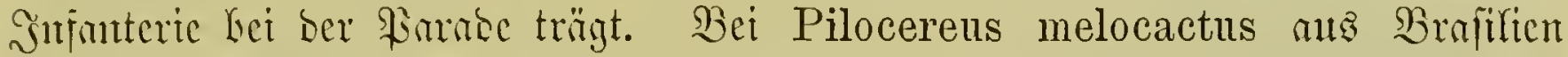

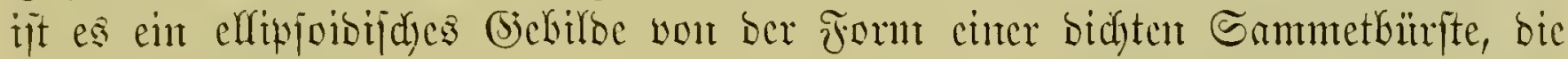

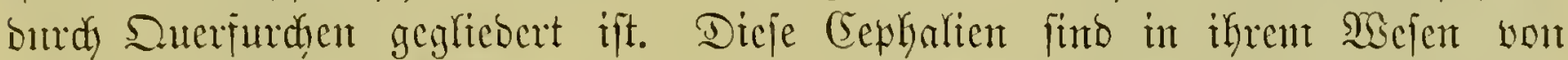

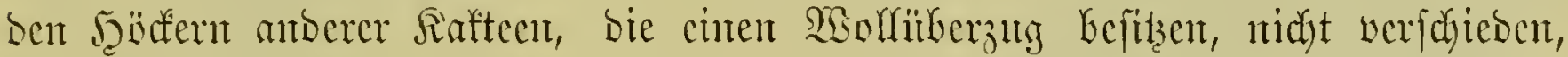

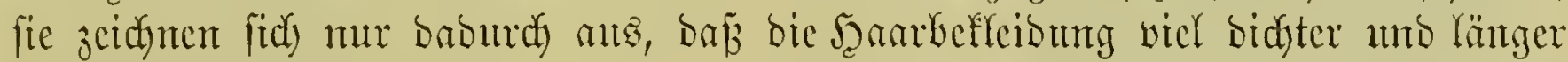

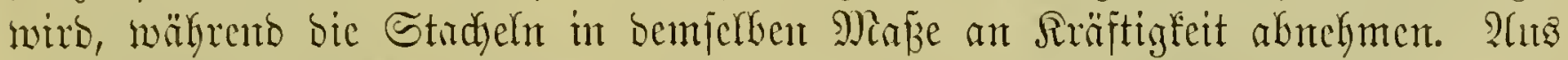

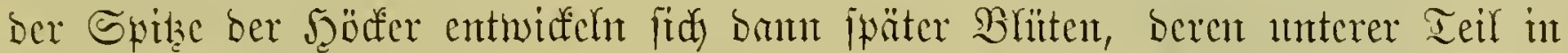

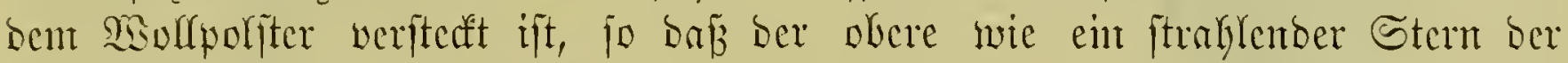

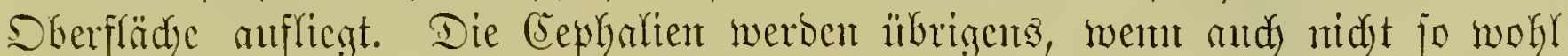

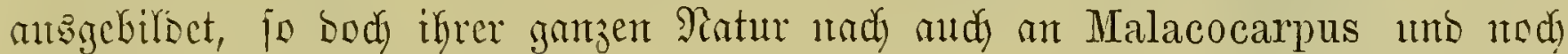

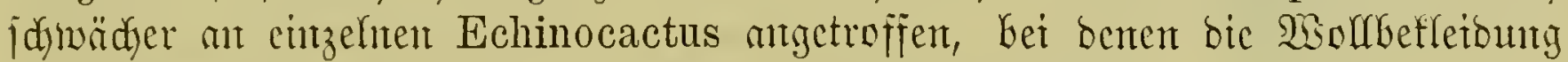

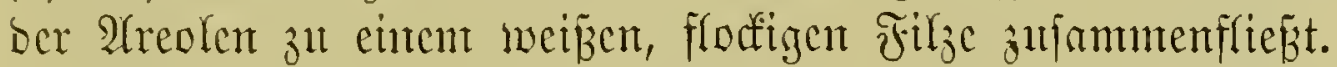

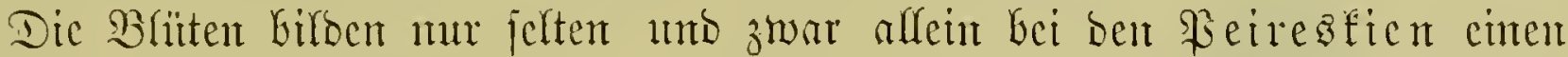

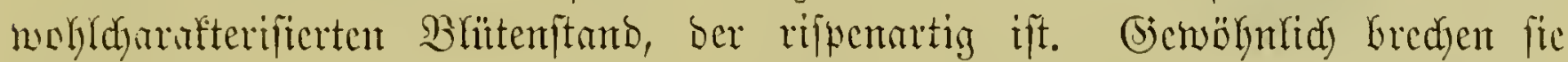

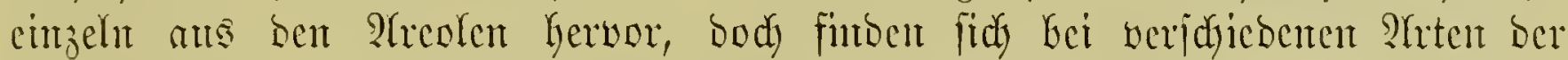
(jottung Rhipsalis (Rhipsalis pachyptera unb bejontor Den Lcpisnticn)

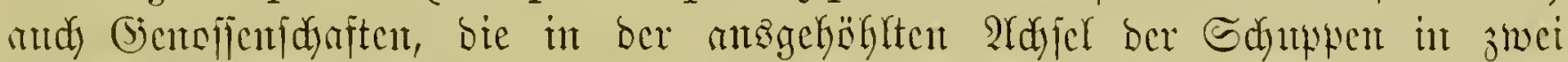

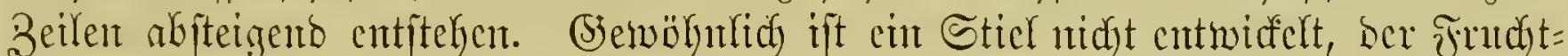

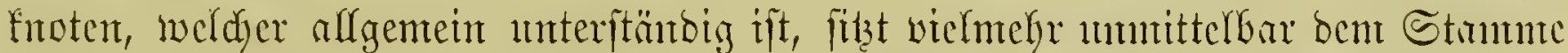

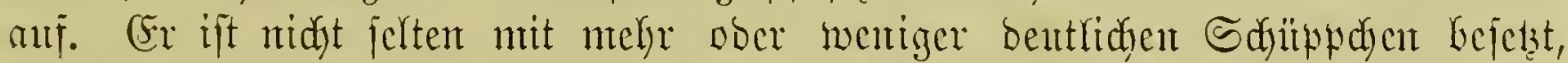

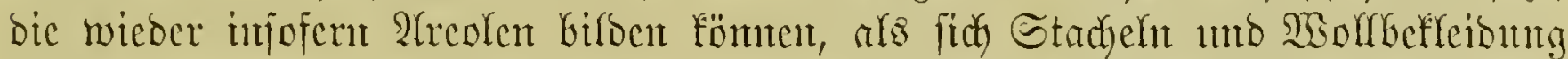

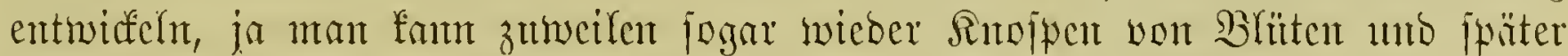
Frübte aus ifnen hervortreten fehen (Dpunticn, Secirestien). (Sir ift ent=

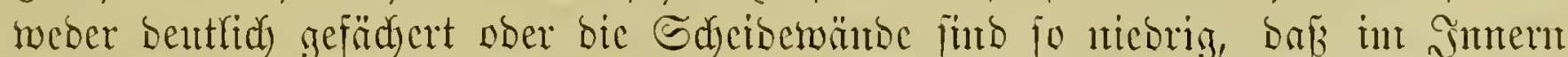

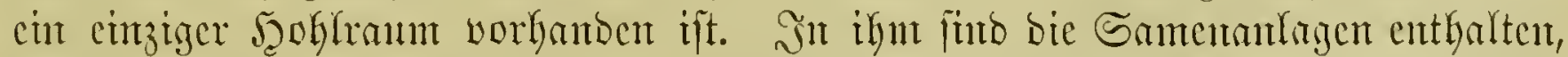

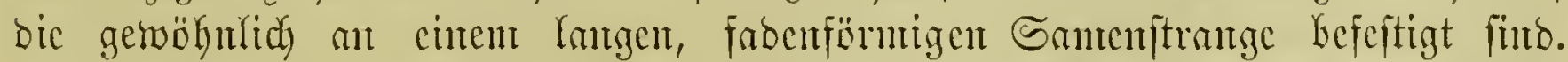

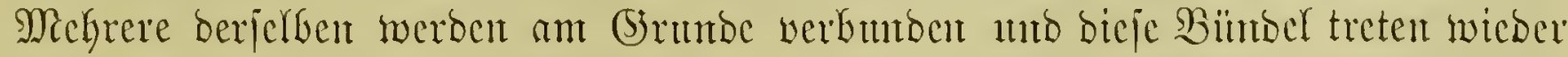

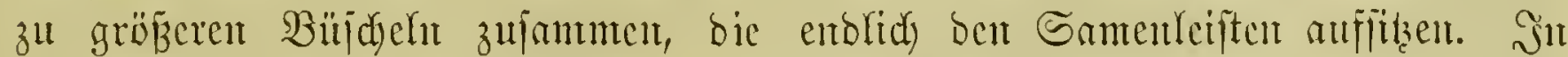
anberen Fä̈lfen futb bic Samenanlagen ganj furz gejticlt.

Suffulenter. 
Dantit mun bic Befrudftumig fidfer anzefülynt wird, finto gewifife Bor=

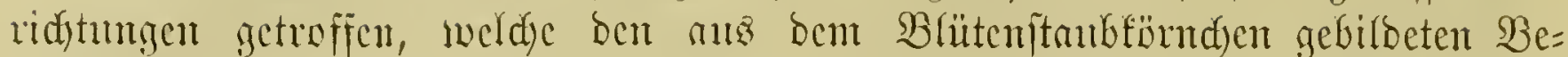

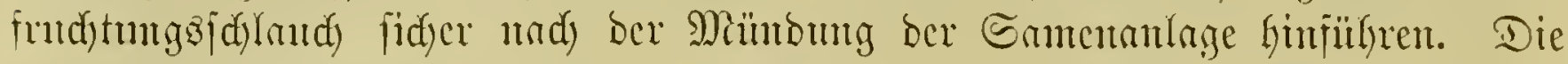

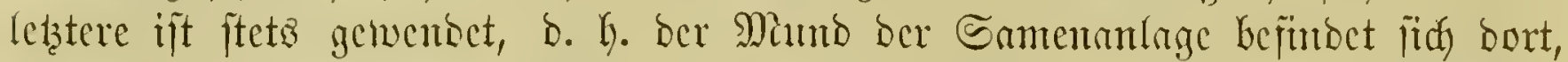

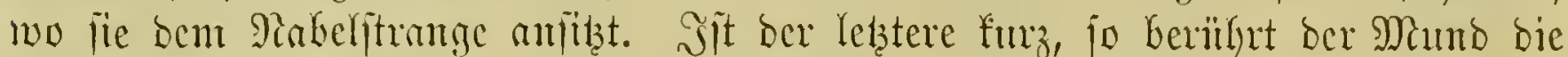

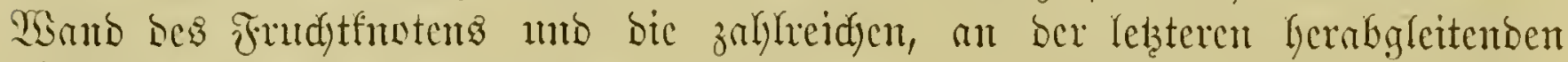
Ëd)ländye gelangen leidgt lyincint. SSEenn bagegen cin längerer Eamenttrang ent=

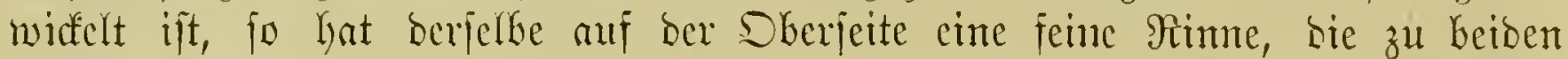

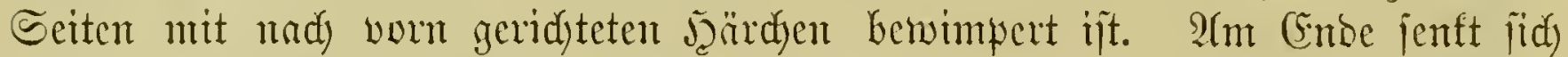
Dam ber Mimo ber Samenanlage in bicje Rime finein und ber in ifr fort=

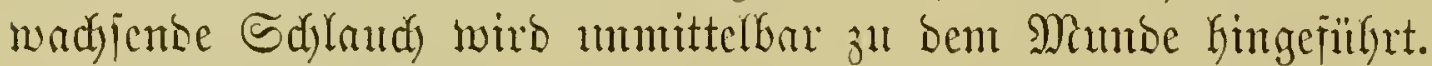

Die Blïtenljülle wirb, ba man entweber einen grünen Reldh von gefärbten

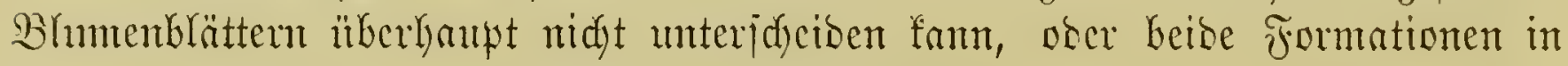
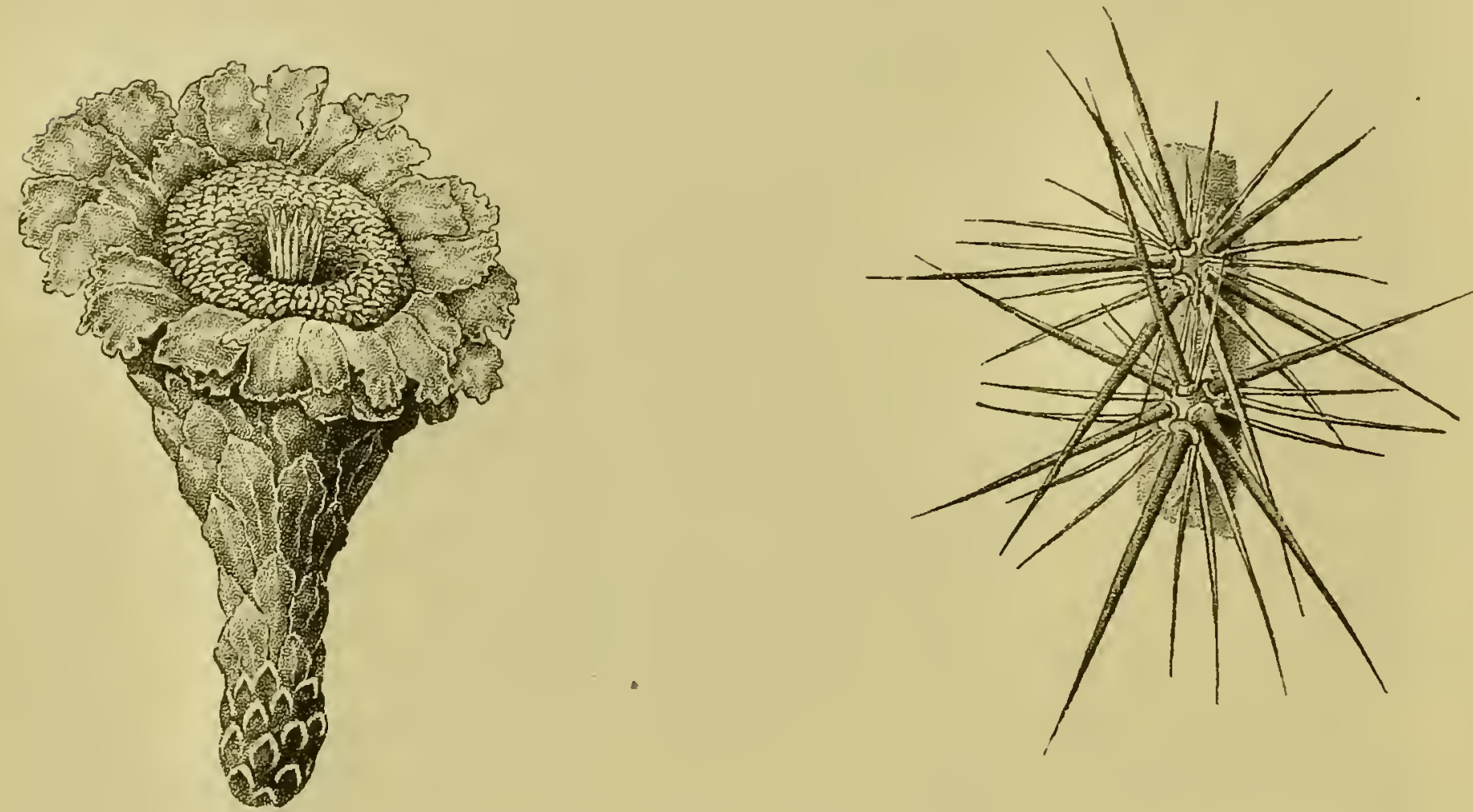

Fig. 63. Cereus giganteus Engelm.

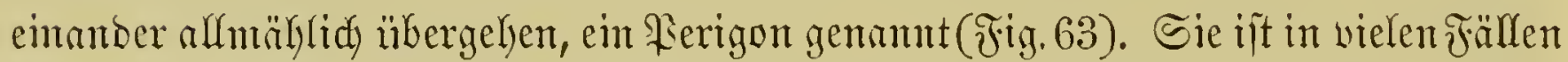

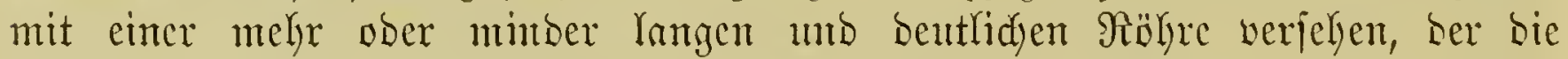

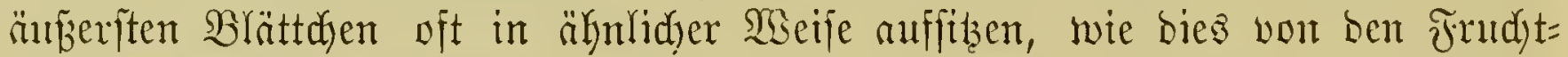

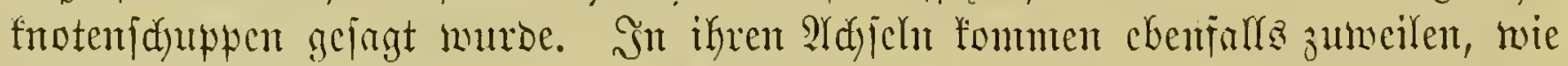

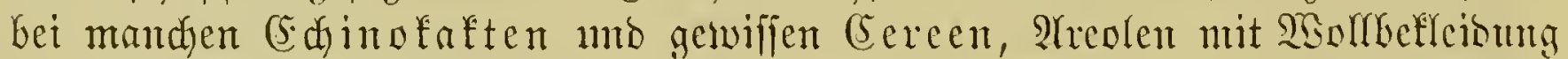

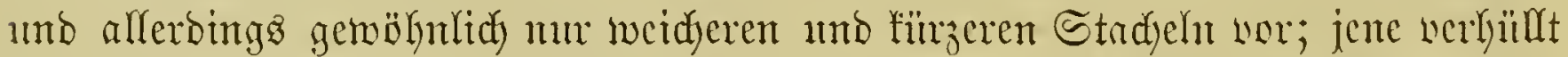
bie Rähre bam unter llmitänoen wie mit cinem floctigen Fitjüberäuge. Bei ben flemblütigen Formen ber Rhinjalibecn, bei ben Recrestien mo

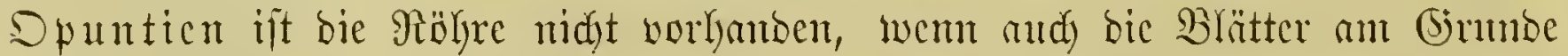
zujanmenbängen. Die Yeketeren uno bejonbers bie Siattung Nopalea jeigt

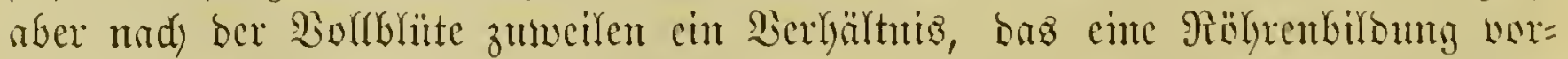
täujd)t. Bei ihnen ijt ber Fruddtfnoten an ber Epize mit cinter freijeffïrmigen

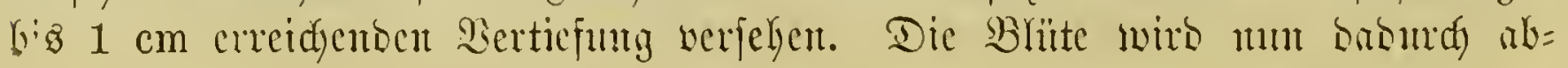




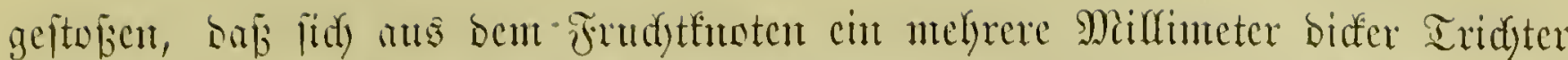

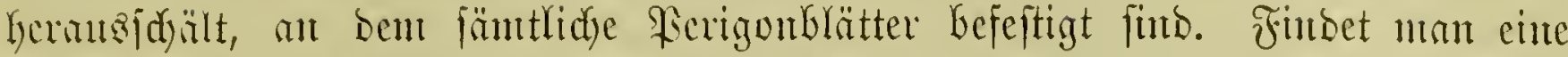

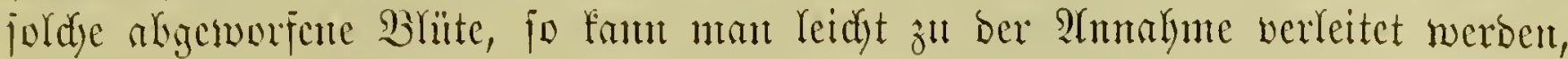

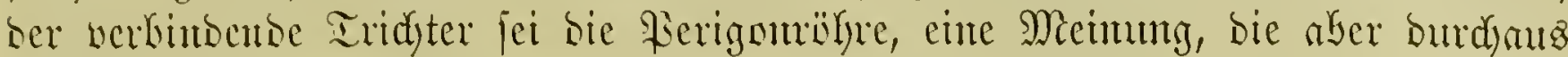
midet ridytig ift.

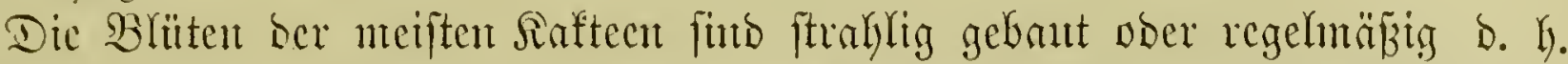

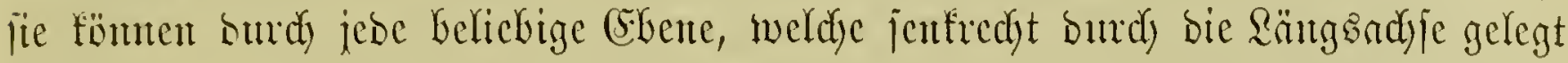

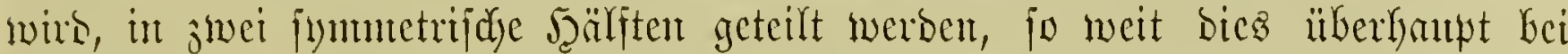

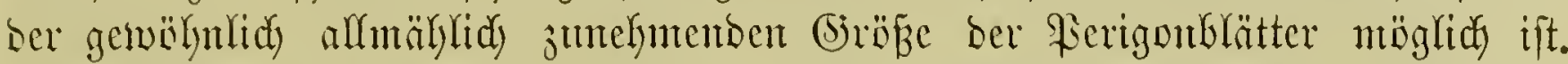

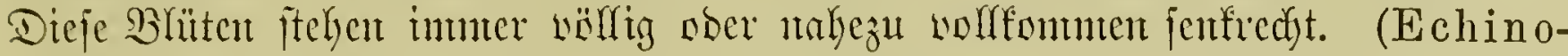
cactus, Ma millaria, Melocactus). Die judräg ober wageredyt aufgehangenten

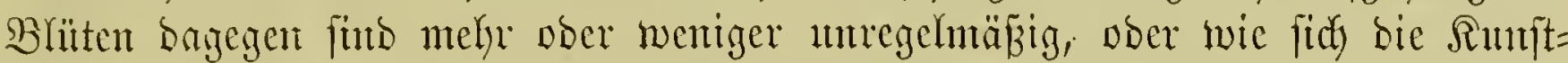

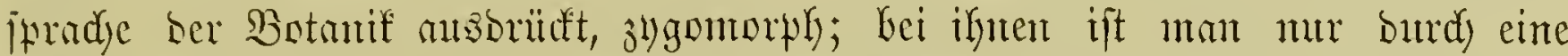

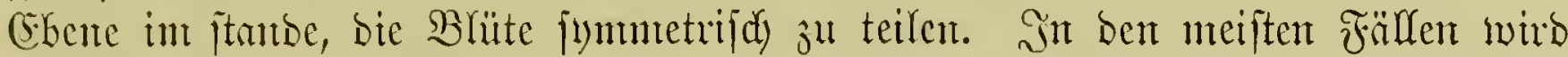

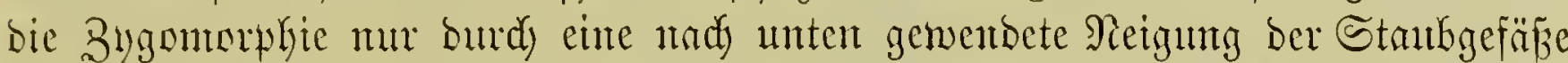
unb mogh aud bes (orriffels angebeutet (Echinopsis); jomit fommt fie burch

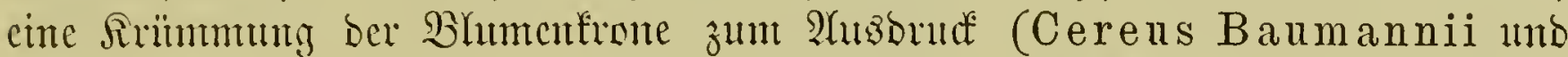

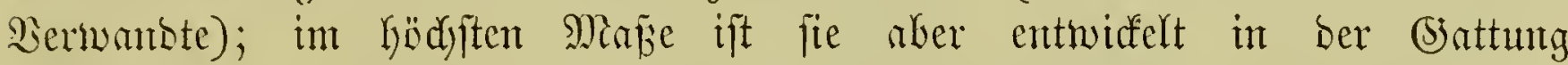
Epiphyllum, woldye Bhäten anfweift mit eitter bentlidxen Sonterumg ber

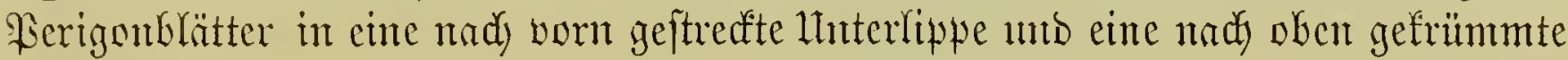
Sberlippe.

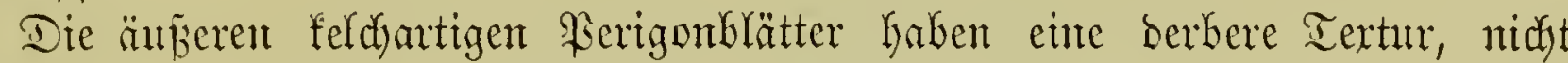

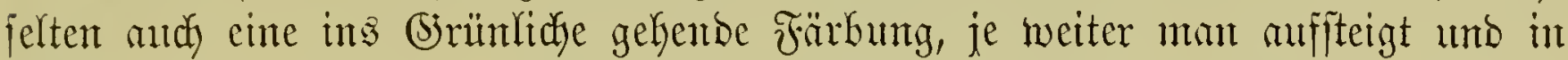
ons Sinnere Der Blïte vorbringt, befito zarter werben bie Bhlätter umb befto

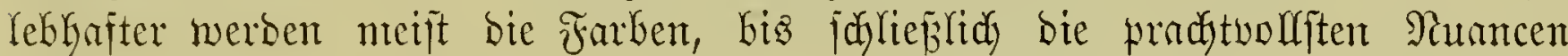
erjengt werben, bie überfaupt bie Ratur in ben Blüten Kervorzubringen vermag.

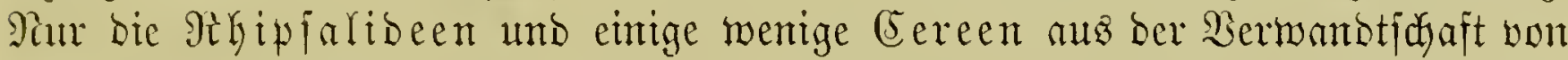

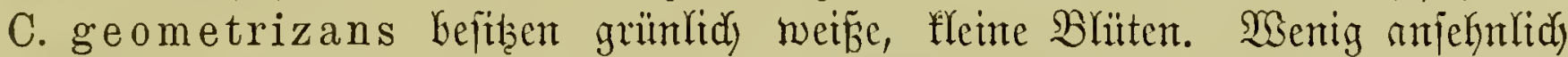
fint and bie rötlidfen ber Melocactus-Mrten umb bie ber Mamirfarien

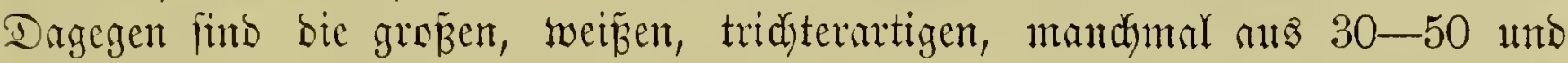

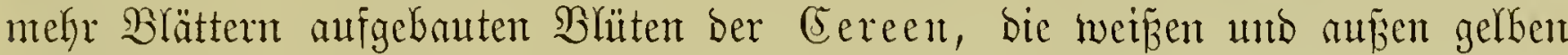
ber Rönigin ber Aladft (C. grandiflorus Mill.), bie gelben vieler (E) d ind= cacten, bie pumpurroten ber Prghllocacten unb (5piphyllen von auferorbent= lictyer sintung.

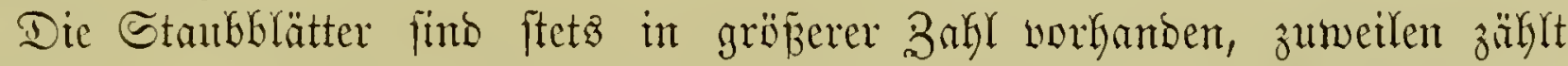
man ifger an humbert unb mehr. Sie fitzen faft immer im Simnern ber

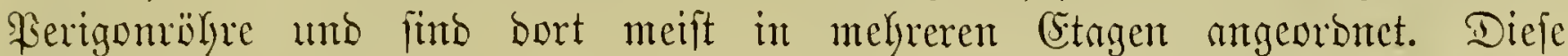

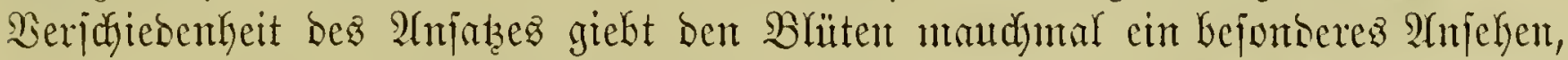
intom bie tiejer angehejteten, inneren, mit langen Irägern verjekenten cin intreres Bümbel bitlden, bas von einem ftrahligen Sranje, ber anfred)ten, am Berigonjaume bejejtigten, äuß̉eren untgeben mirb. Nur jelten fitzen aud einige

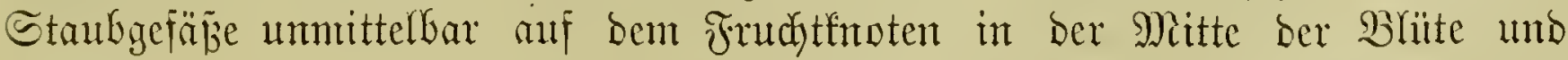

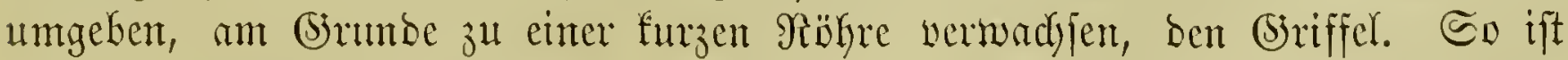

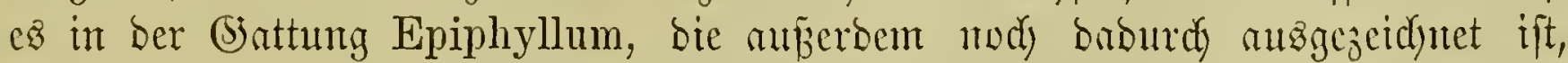

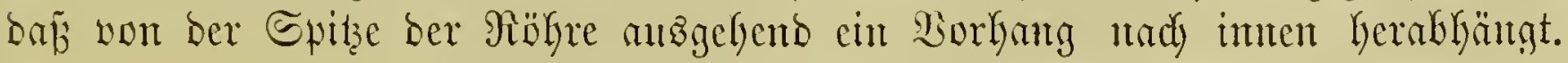




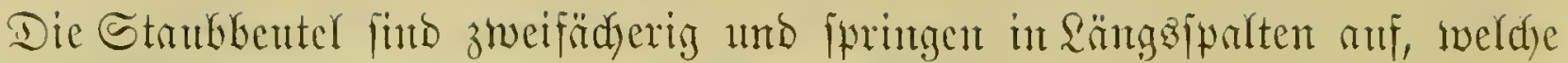

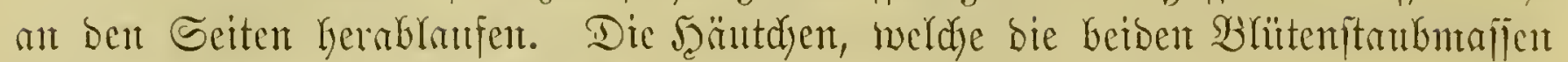

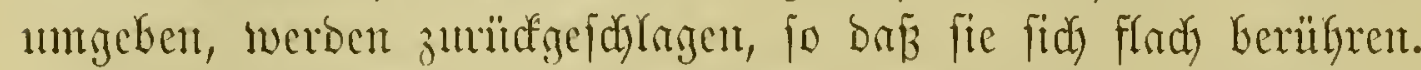

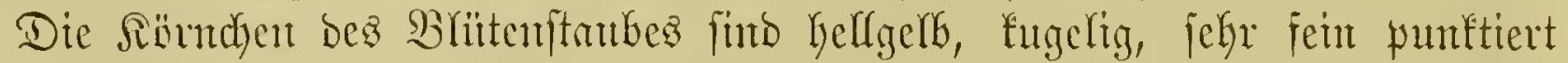

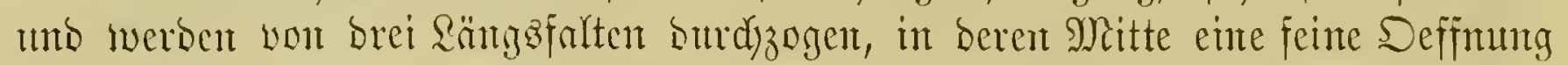

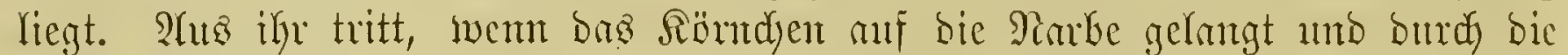

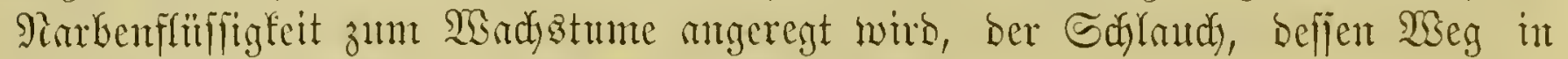

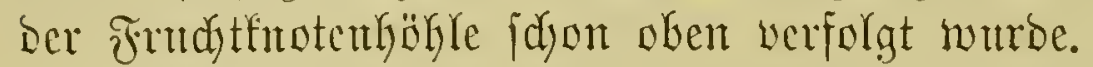

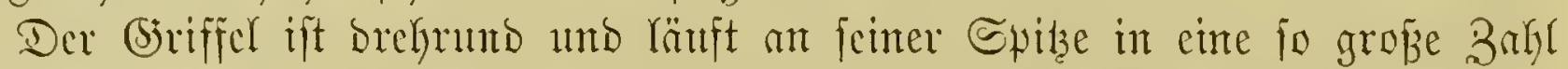

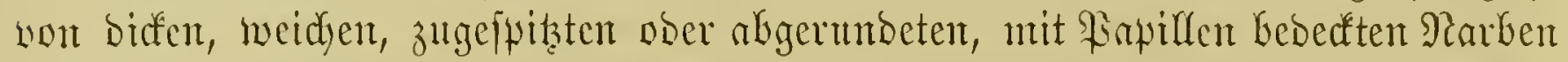

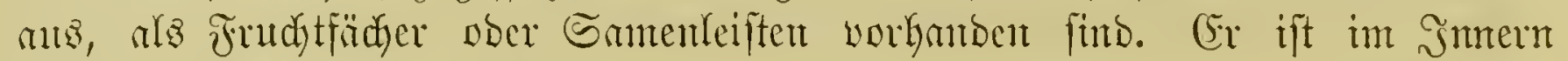
Gobly uno aufent böldig fargl.

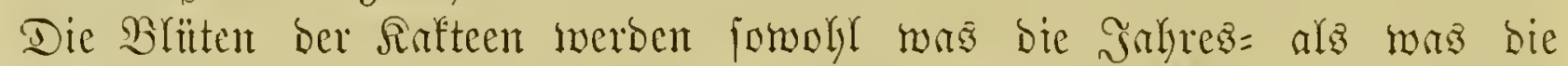

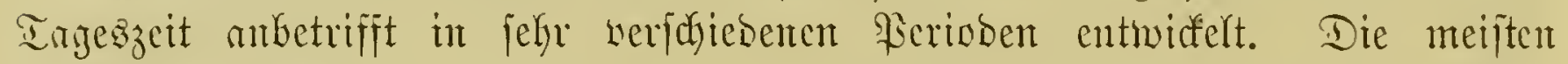

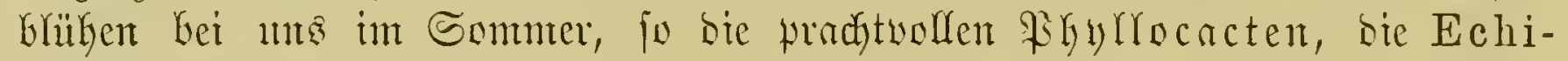

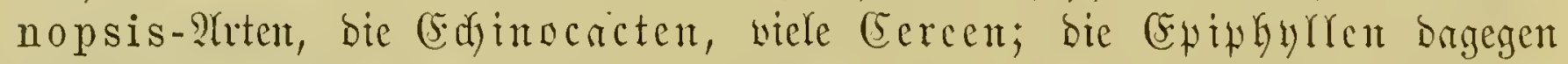

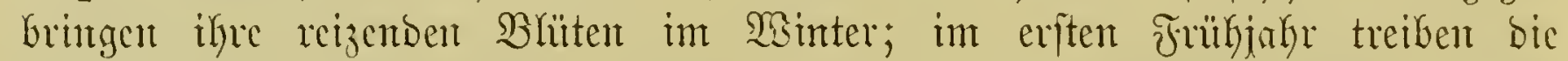

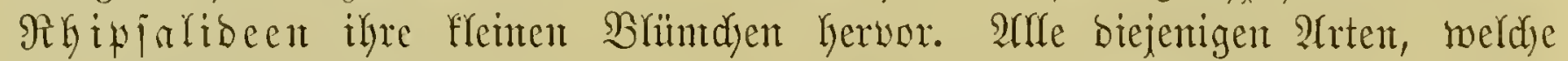

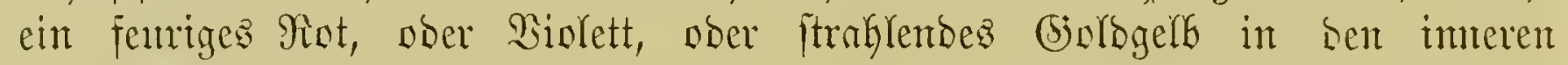

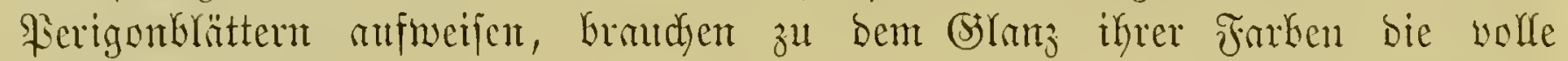

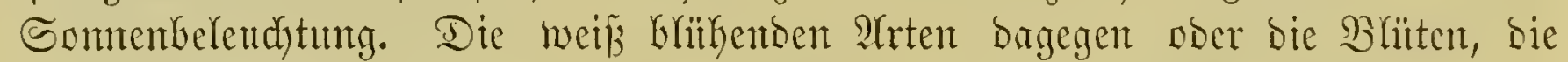

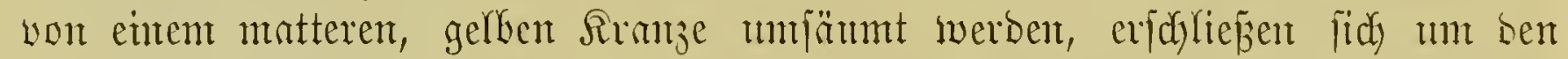

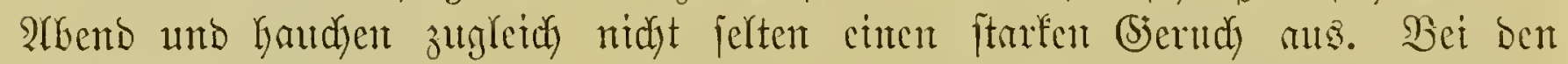

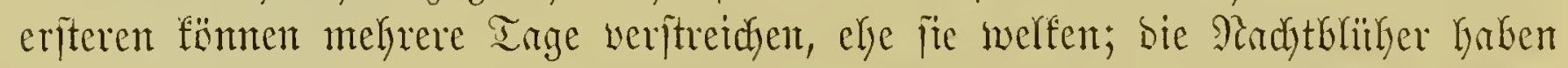

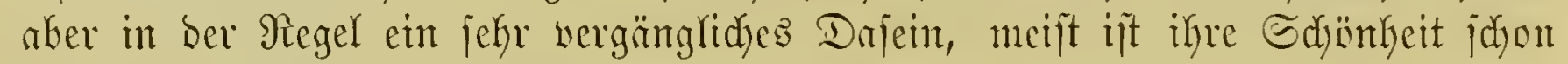
ant ü̈dyjten Morgen worbei.

Die Rafteen fömten jich im alfgenteinen nidyt ferbjt beitüubent, weil bie

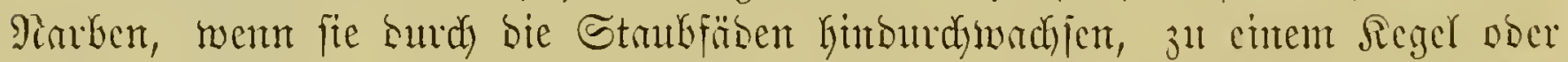

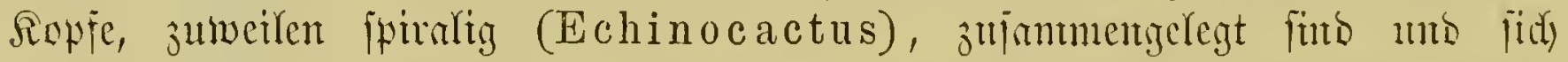

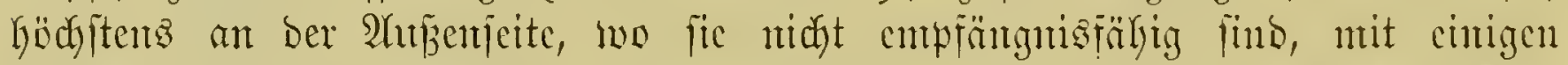

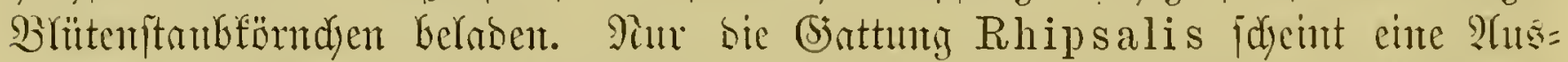

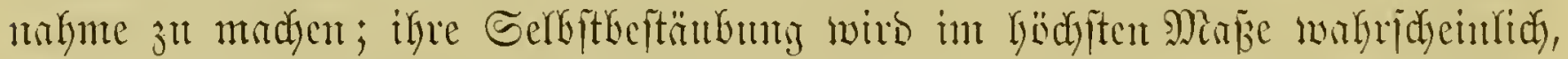

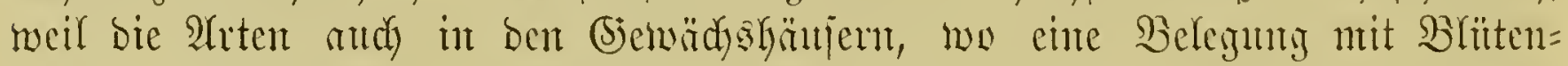

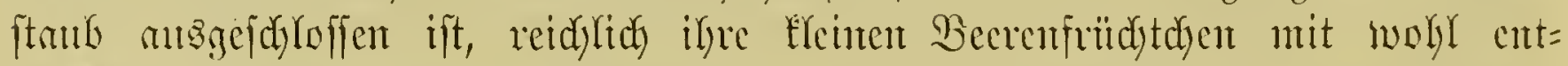

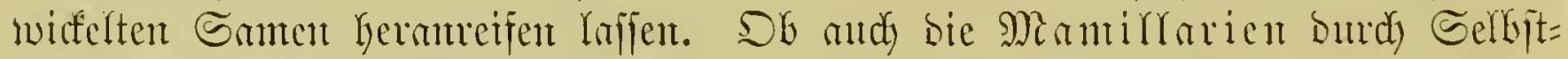

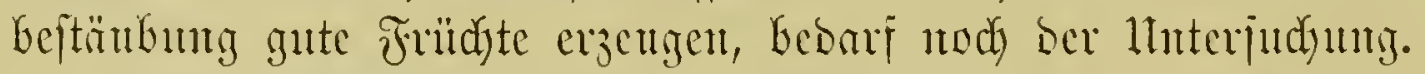

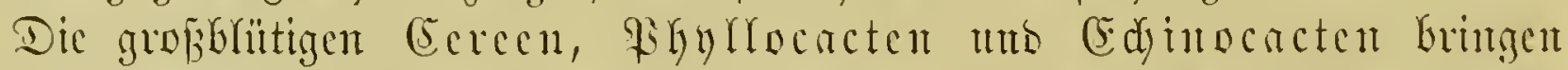

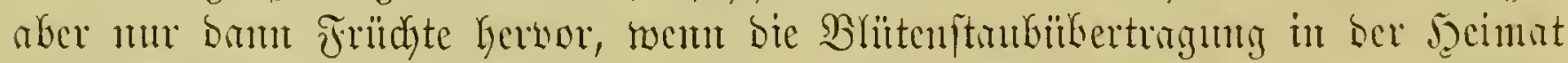

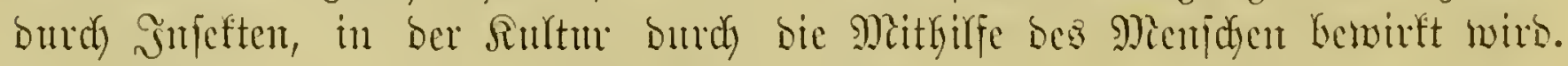

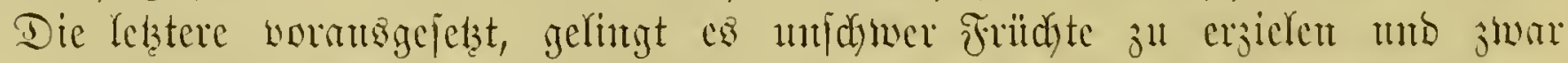

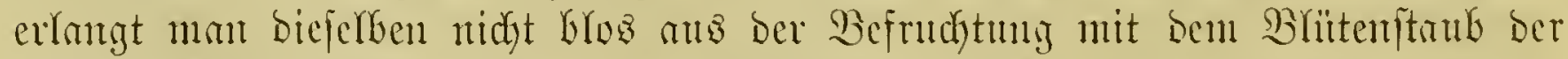

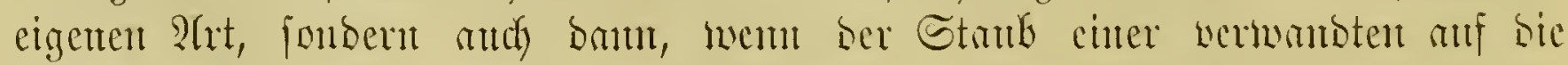

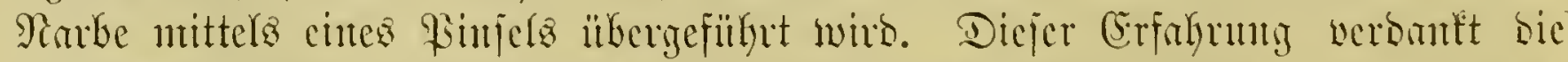

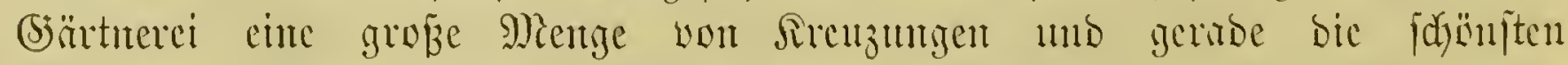

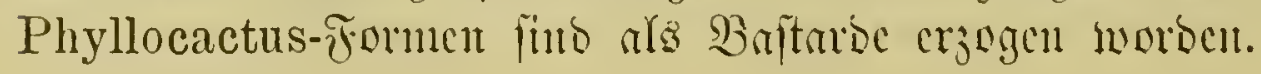




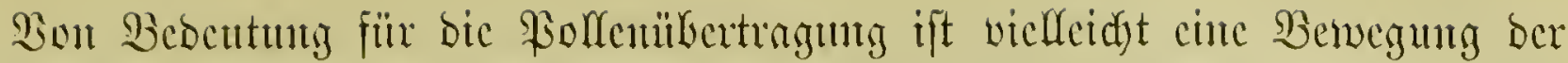

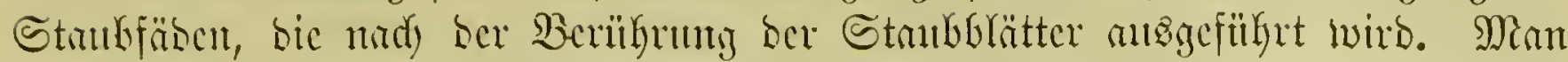

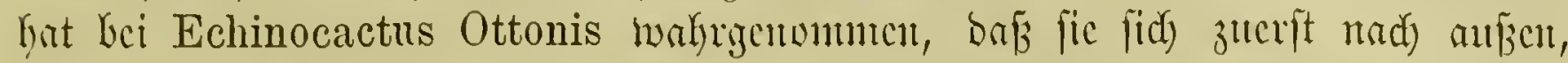

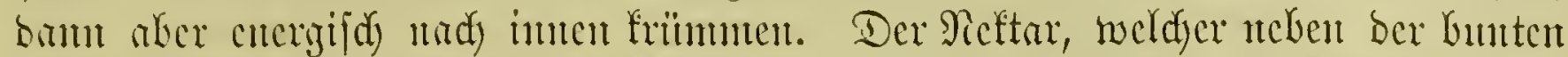

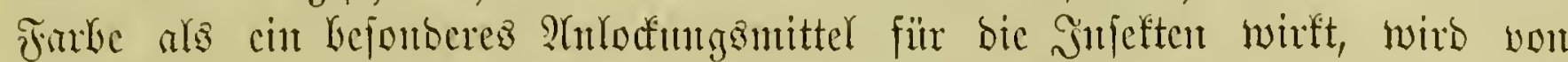

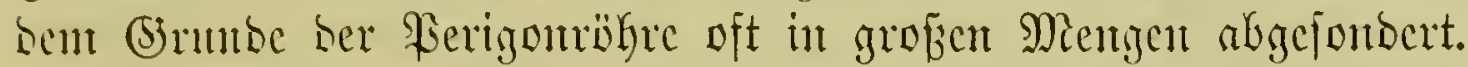

Dic Frild)te ber Safteen finto meift fleijajige mis faftige Beeren. (Fig. 64.)

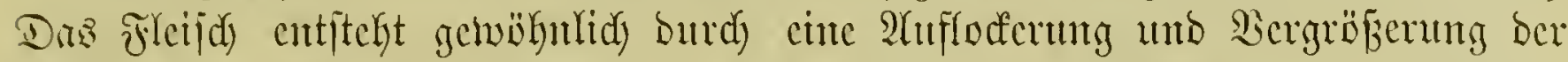
Frudjtfinotentwatb, bod) wirfen and vielfad) bie Maberiftränge ber Sancu= mllagen mit, inbent bicjelfon verfdecimen (Cereus, Phyllocactus). Iroctencr finto nur bic Früdte von Echinocactus. Went bic Früdjte, wie bei

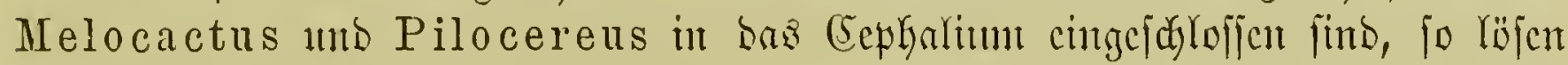

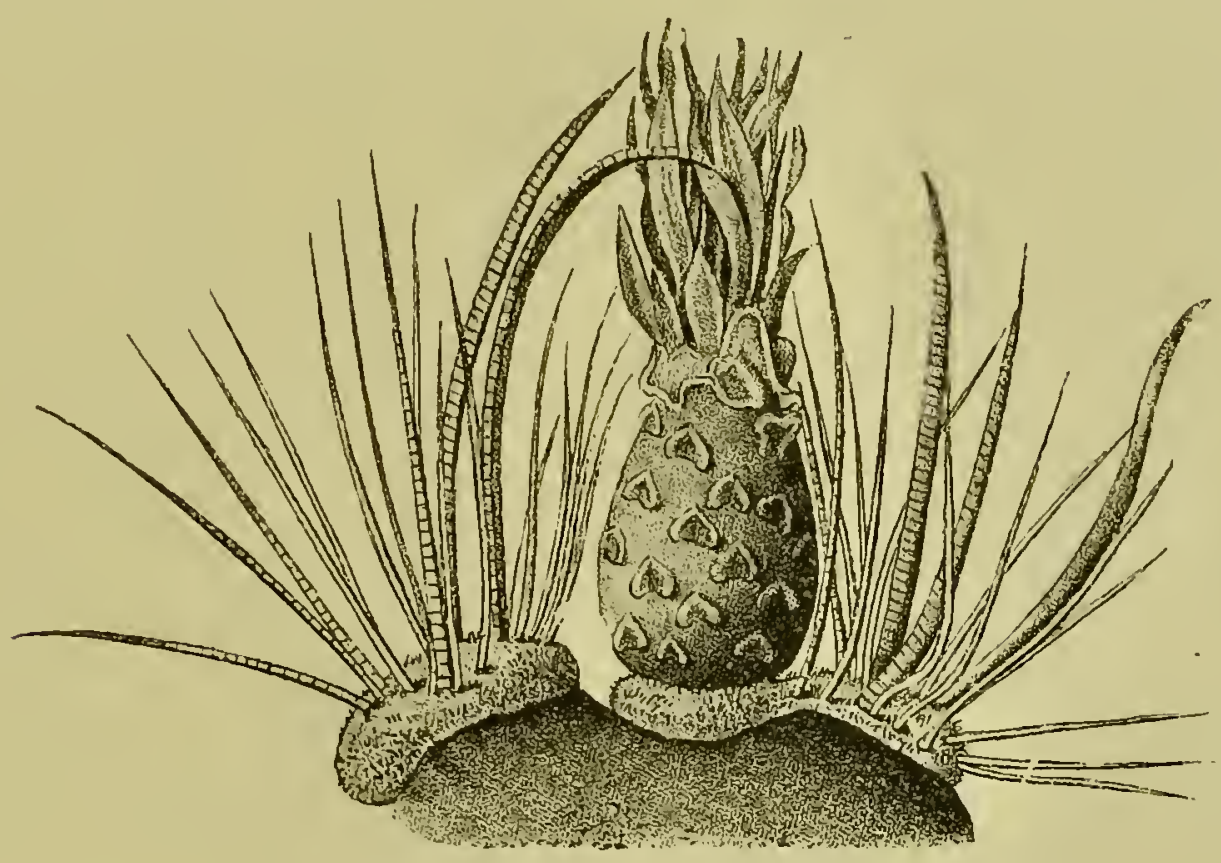

Fig. 64. Echinocactus Lecontii Engulm.

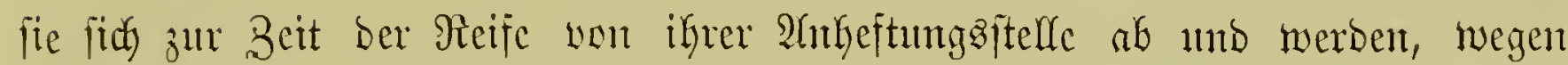

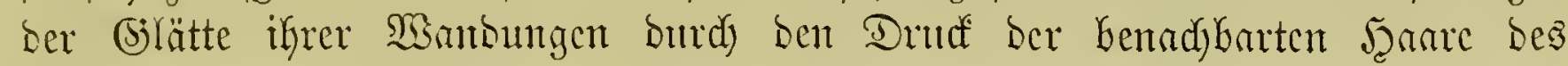

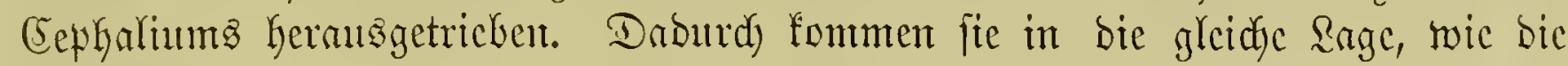
frei ftefonden, oft gefärbten Früdste bor ilbrigen (Sattungen unb bieten fid) mun

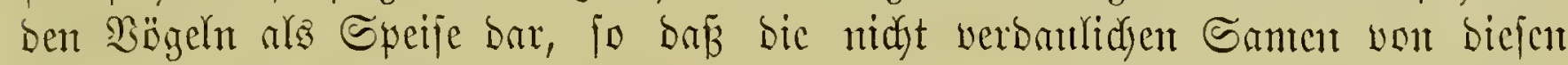
Tieren veritreut merben.

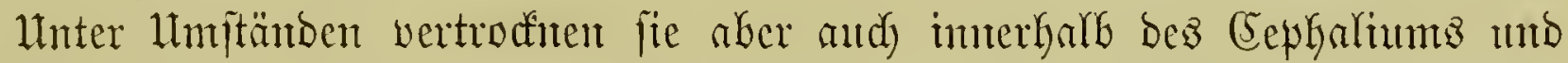
fönnen ipäter ans ifm Kermisgejudt werben. Die Samen mander Melofaften

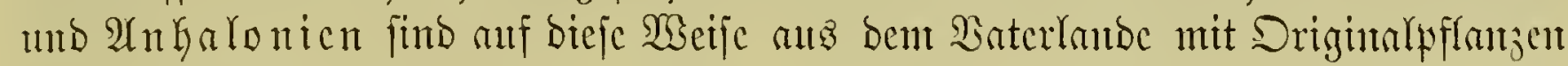
bei uns cingefüfrt worben.

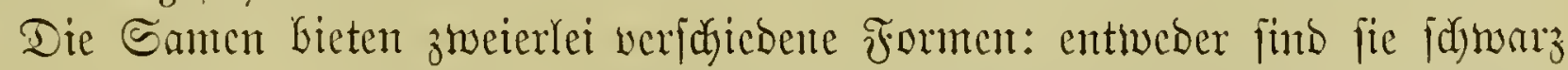

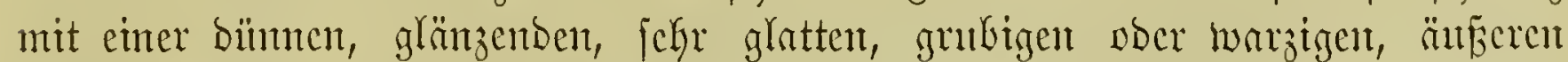

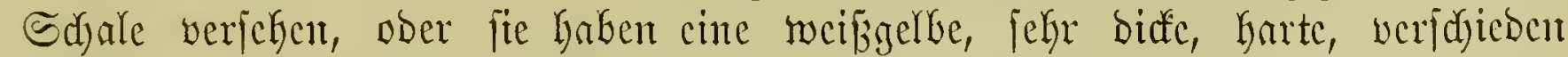

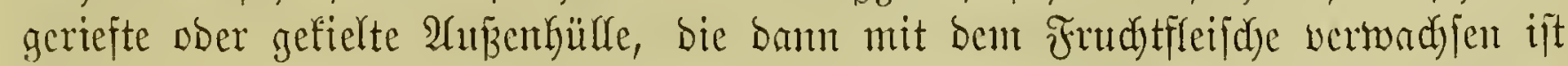

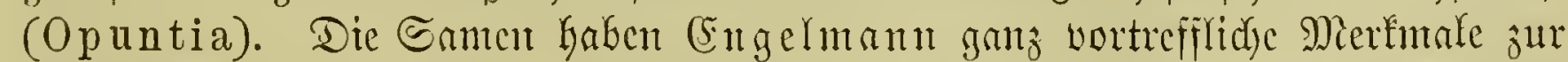

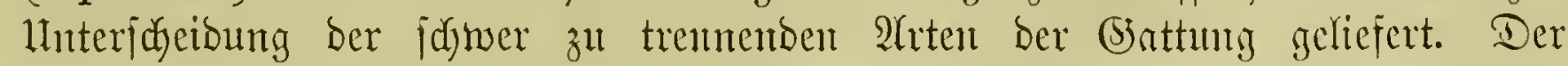

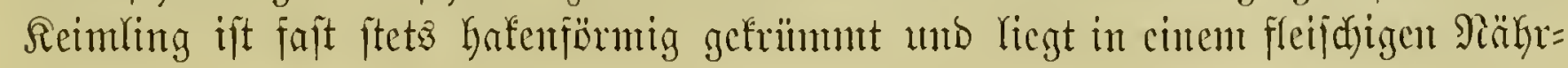


gchebe. Die Siembrätter finto immer Grattartiģ, riegen flad an einanber poer

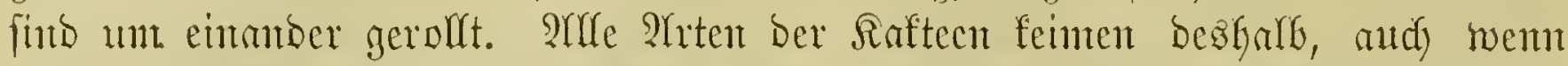

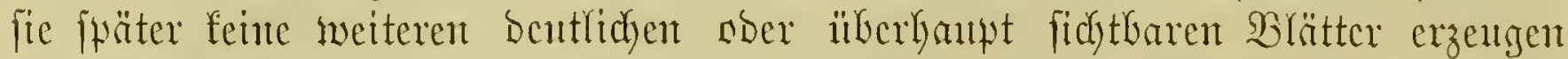

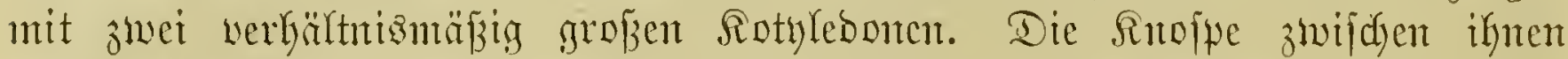

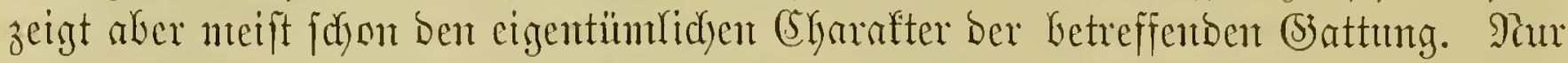

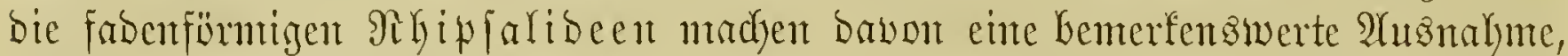
intom fie Semrfflanzen crzengen, weldye oft eine gam antore Tradjt befitzen,

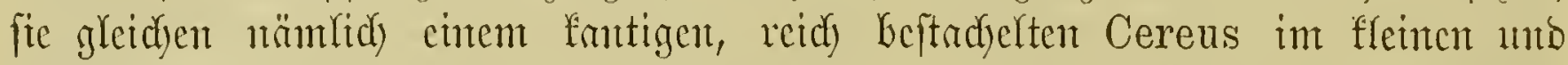
Gringen erft fpäter bic für fie cigentümlictyen. Ginbfabendicfen ober Grattartigen

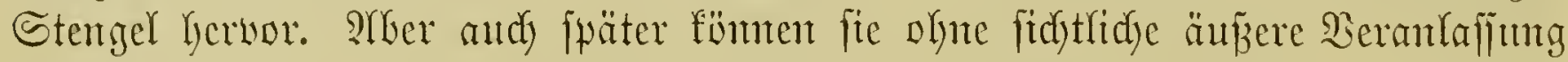
gelegentlidy wieder Bweige wout ber crftut Beid)affentyeit crzeugent.

Berbreitung ber Raftecn. Pad bis in bie nettere Beit Ginein war man

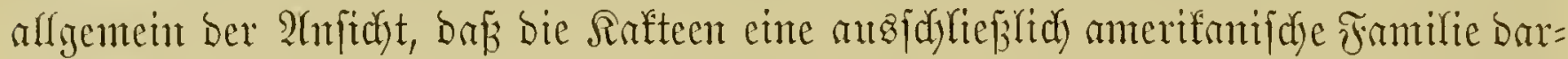

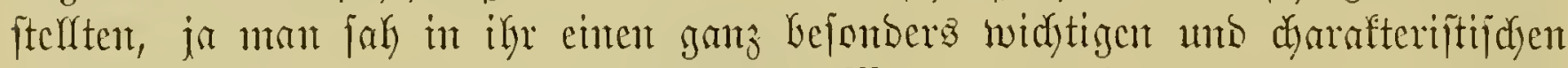

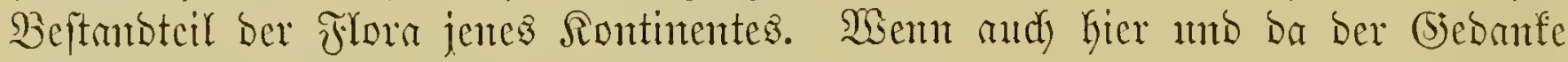

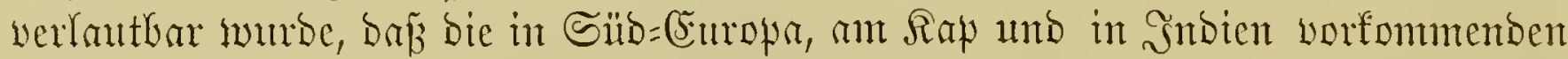

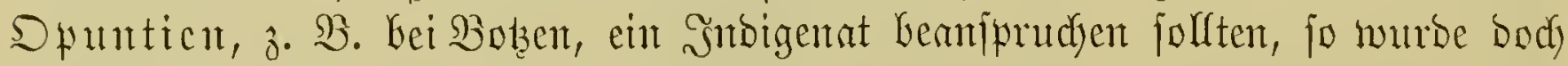

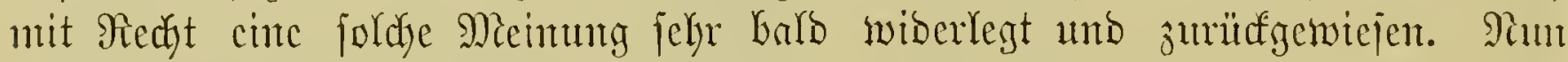

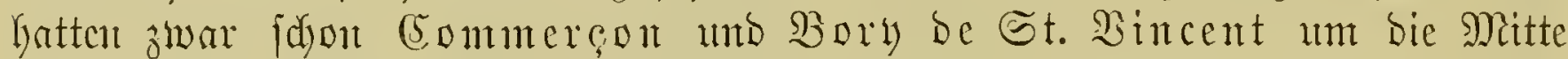

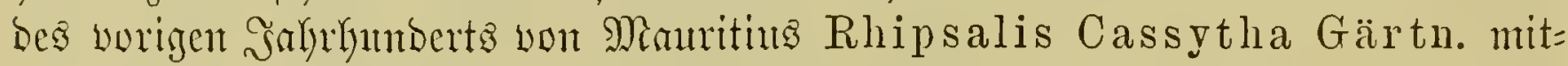

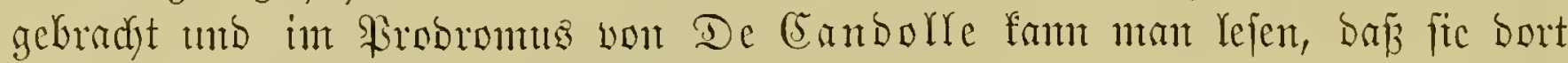

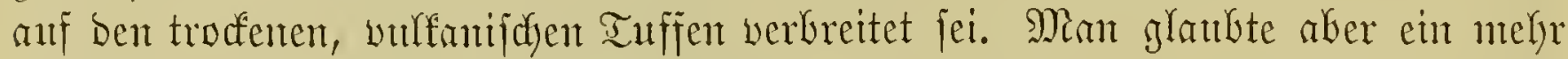

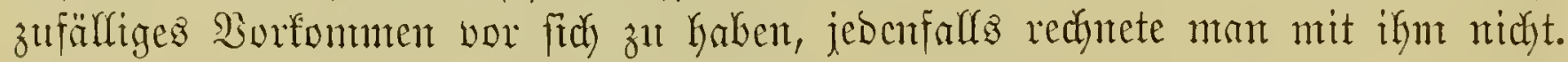

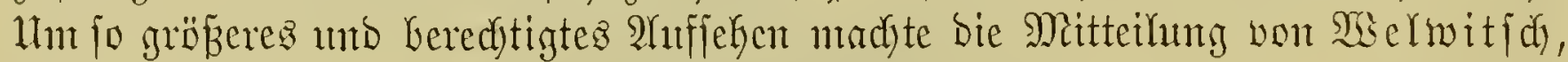

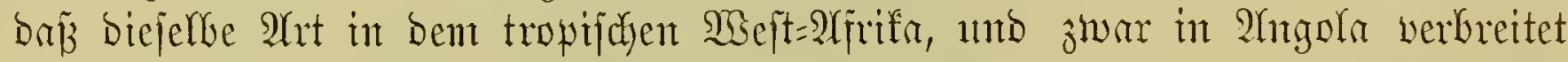
fei; neuerbings haben wieberholte Fumbe ans ber biegent an Congd, won

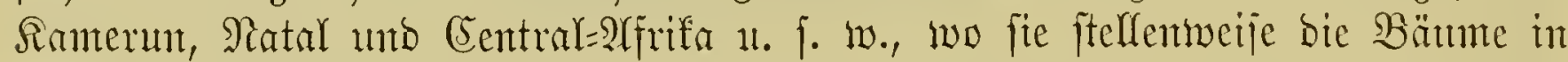

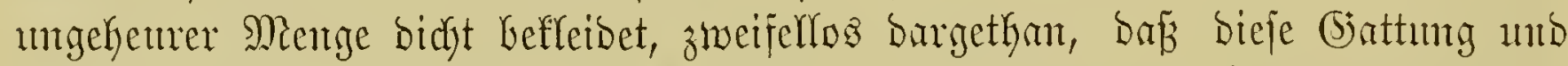
mit irge alfo bie Safteen in âfrifia heimita find. Ja es jajeint jogar, als ob

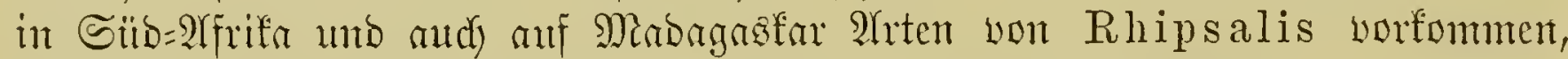

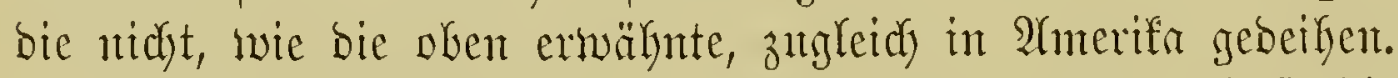

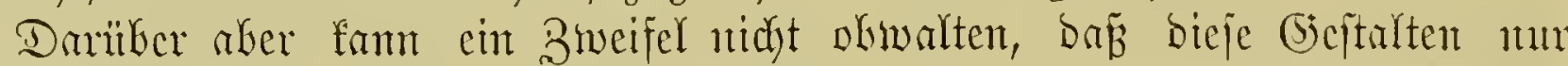

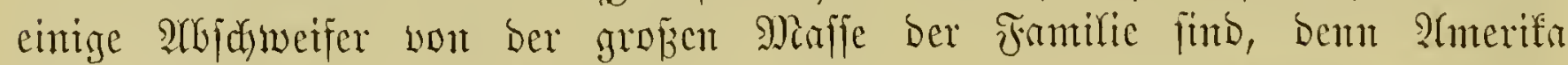

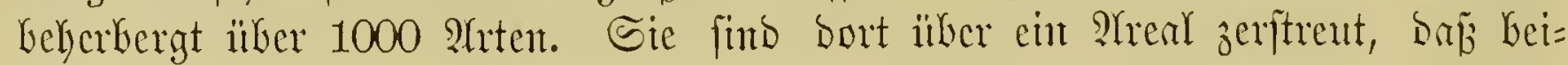

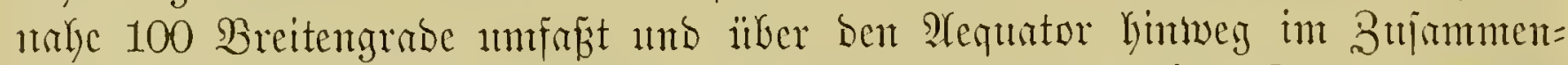

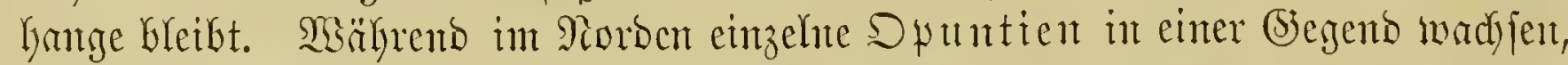

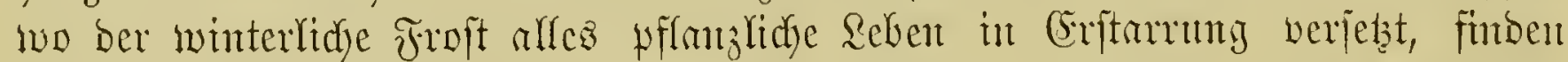
anbere Shten ifre (sxiftenz auf ben böllig idyattentojen Felsflippen, bie won ben

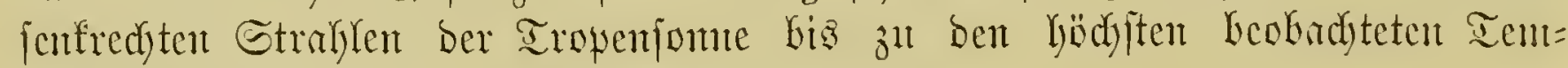
peraturgraben ber freien Ratur crmärmt werden.

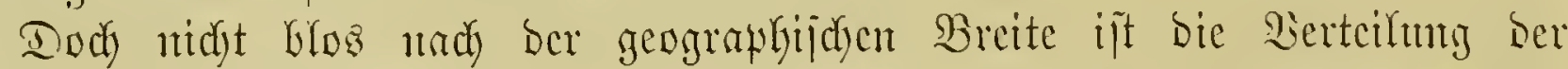

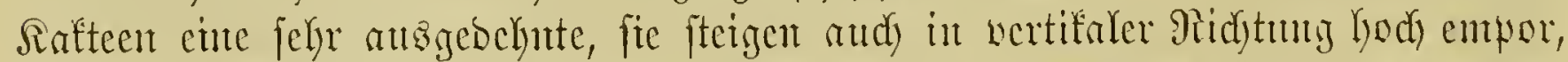

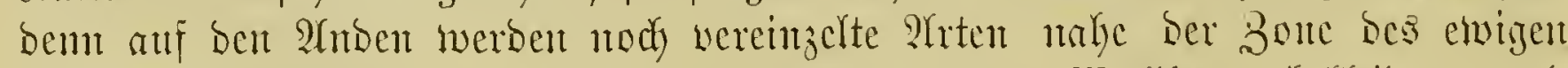

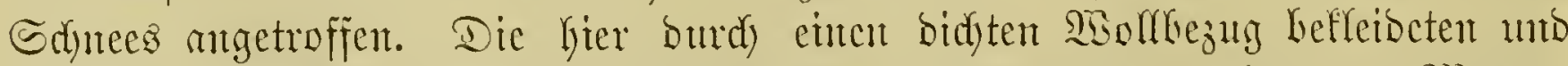

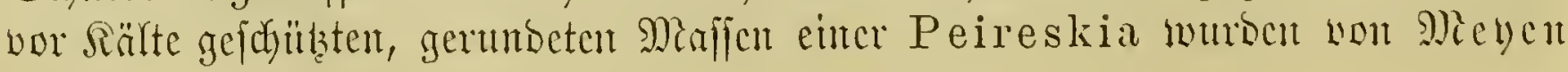




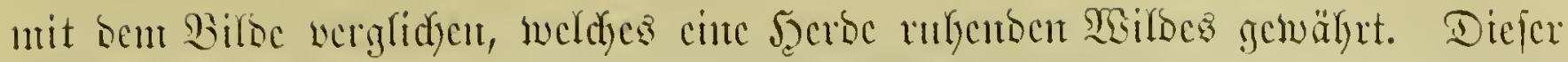

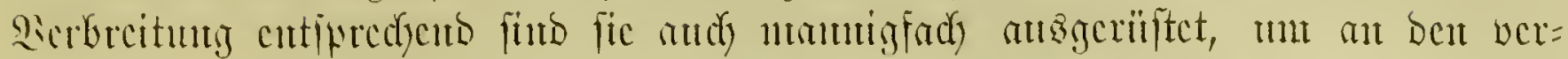

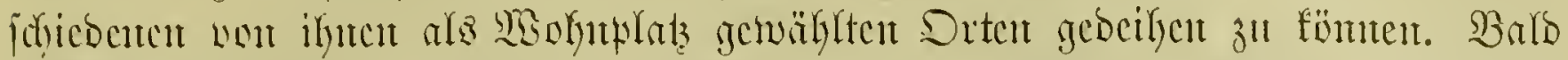

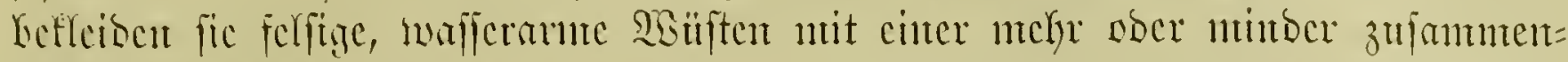

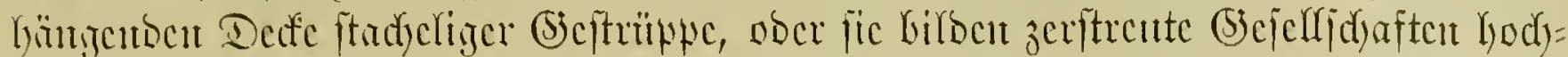

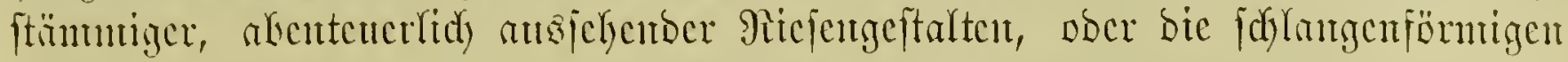

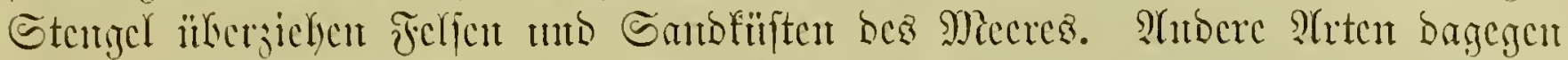

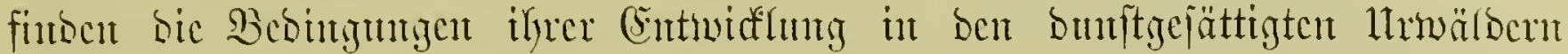

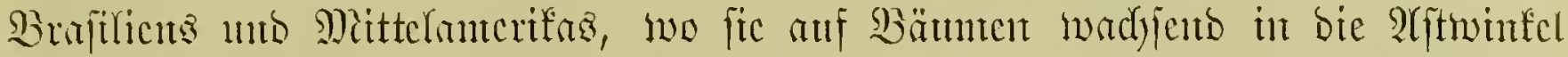

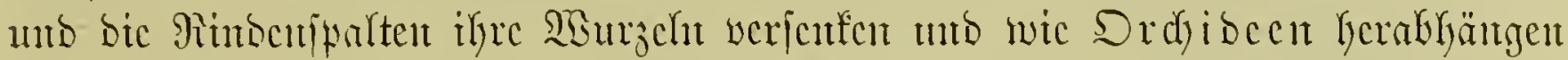

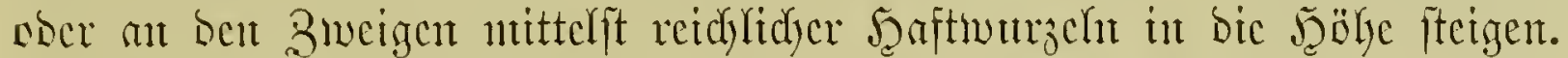

Das Rantb, jweldyes anf gleidy gropent 2lreale mit anberen Diftriften bic ntciften Mrten mefweift, ift Mexifo. Bon hicr ans bringen fie bis und bem $59^{\circ}$ uörblidfer Breite bor, wo uds cinte Opuntia (O. missouriensis Eng.)

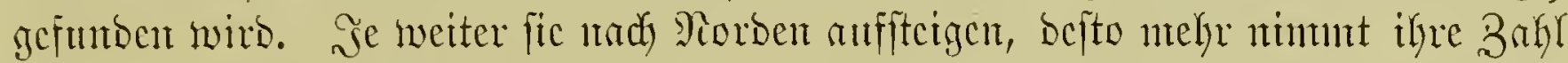

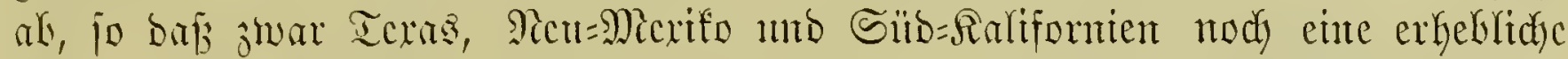

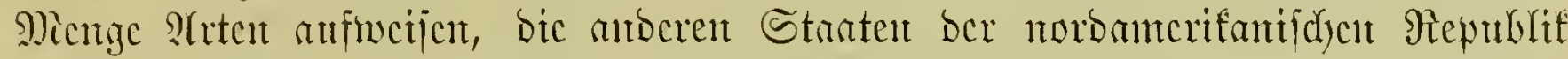

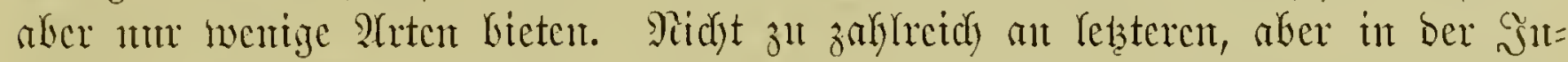

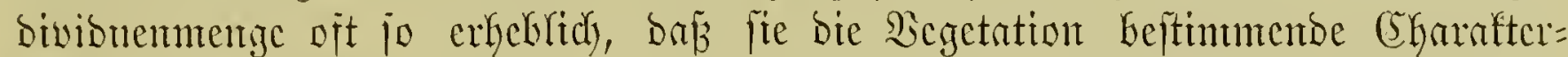

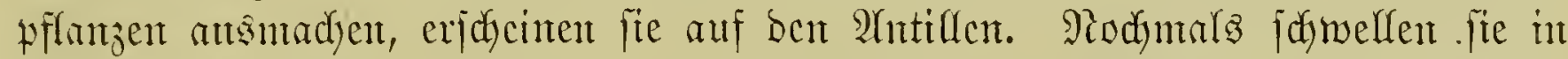

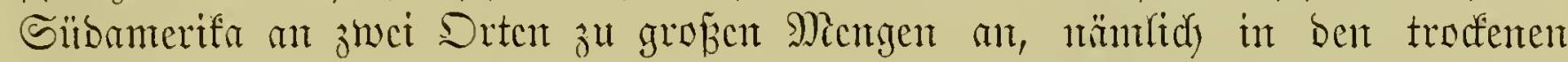

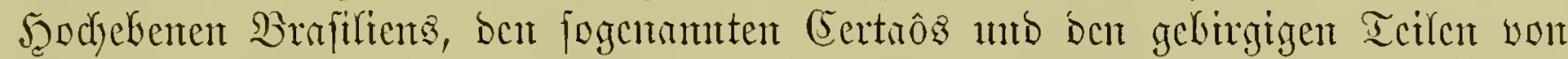

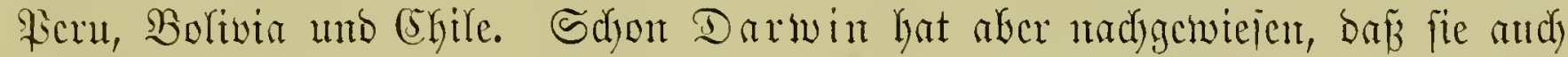

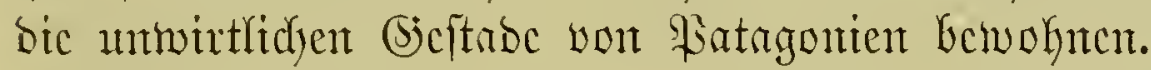

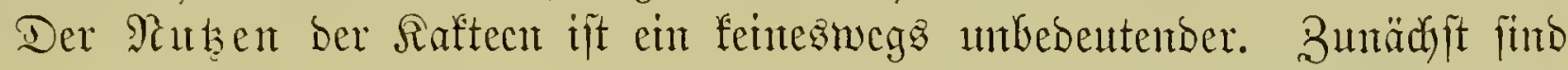

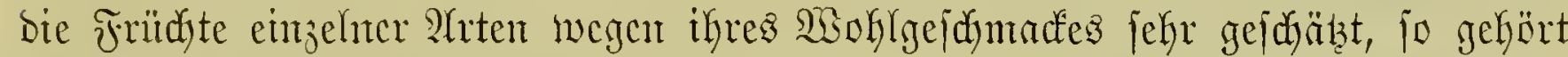
3. $\mathfrak{B}$. bie won Cereus triangularis L. zu bent amgenelymiten Sritionten Brafiltens. Sor allen werbat aber bie Beerent volt C. giganteus Eng. unt

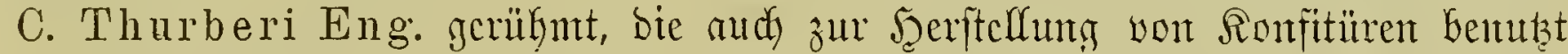

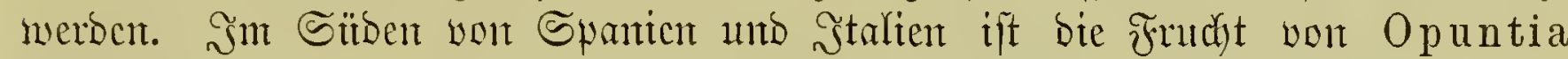

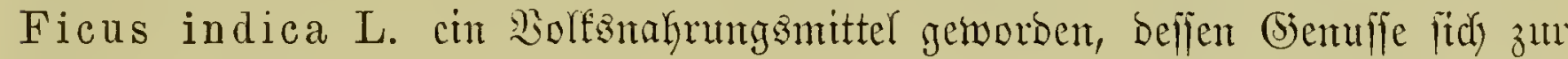

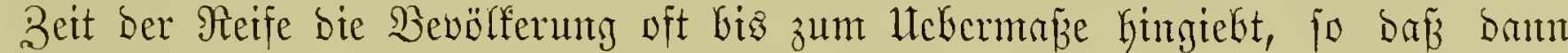

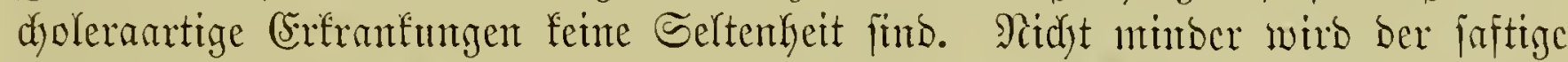

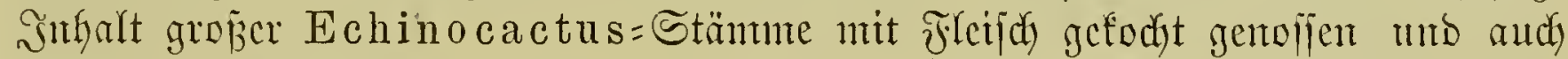
bie blattartigen Gjlieber gentifjer Dpuntien gebent cinte gute Pafyung ab.

Sm Sintern won Brajilien Kerridyt oft eine joldye Dërre, baj bie bort wer=

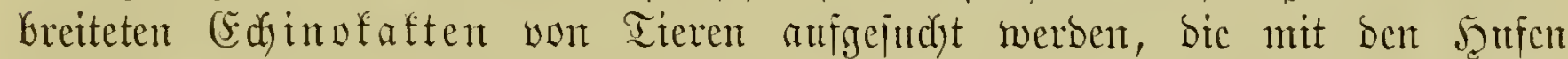
bie bajoncttartigen Etadjeln entfornen, unt an bon jaftigen Juthalt ifyren Durjt zu itillen.

Nopalea coccinellifera Mill., Opuntia Tuna Mill. mo atocre

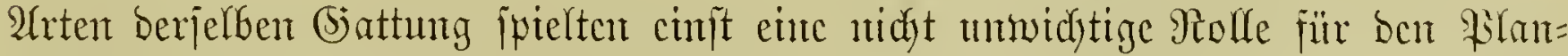

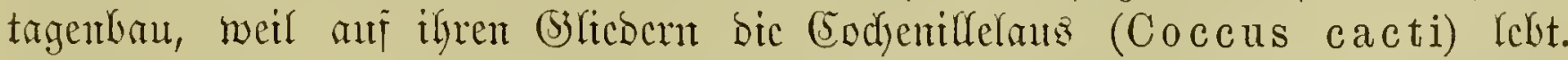

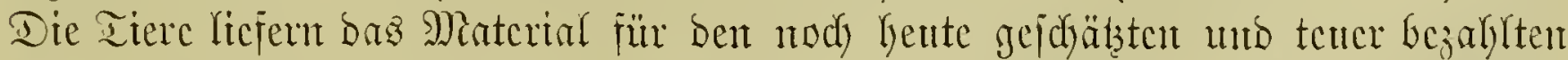

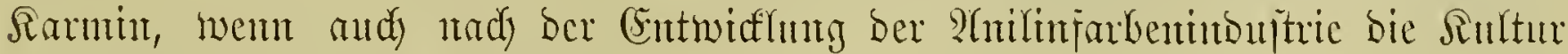
in erkeblichem Maje gcjutfen itt. 


\section{Die Cinteilung Der Salteen in Battungen.}

Eine juarfe Sdyeibunt ber Rafteen in wohl umgremzte, ithergangàloje Gattmingen hat mit anferorbentlidy grofen Edjwierigfeiten zu fämpjen und ijt

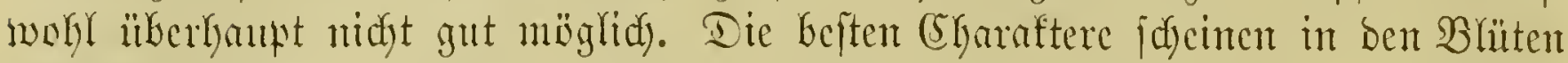
unb ben Samen jull Viegen; ba nun won cinem nidjt geringen Tcile ber bejdyrie=

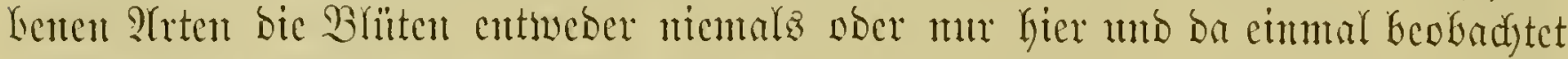

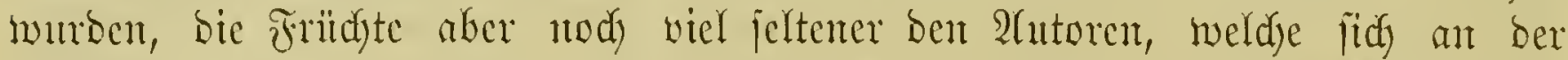

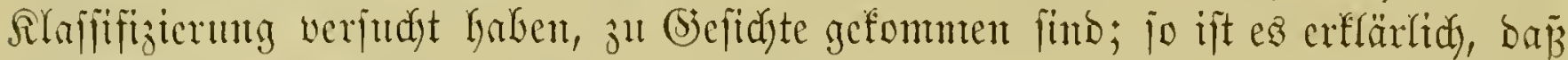

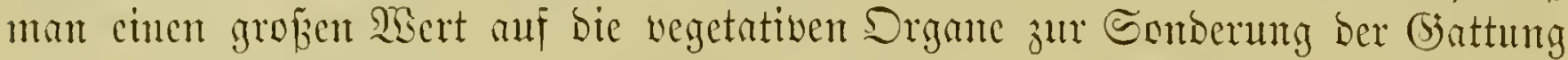

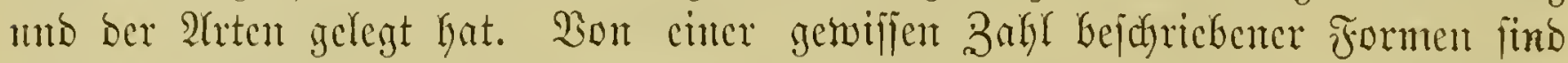
leiber bie Driginale verloren gegangen, ein midyt gemug jul beflagenber 1tebelfitant,

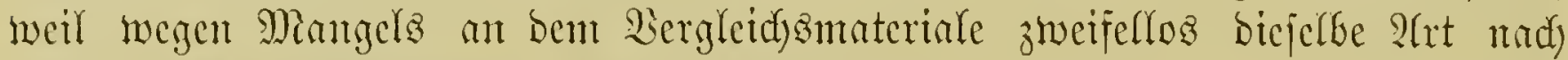

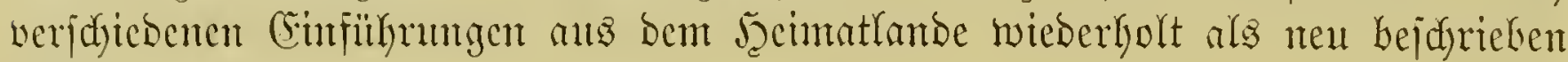
mulube.

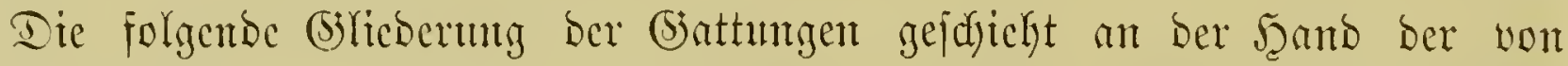

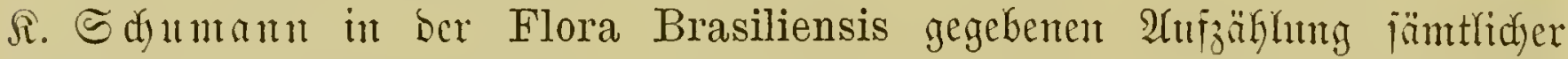
(Bejd)ledter. Sintige berjelben, rämlidy Melocactus, Nopalea, Pfeiffera, Eulychnia unt Eriosyce fint weggelafjen worben, ba bicjelben gegentuärtig

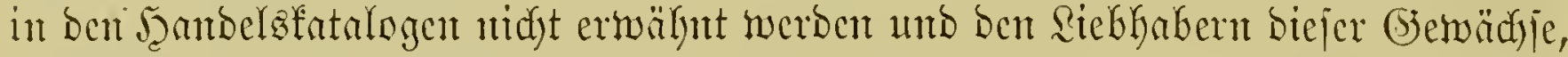

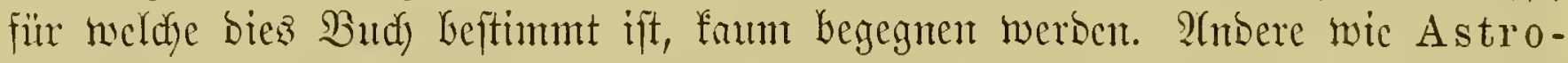
phytum, Disisocactus, Echinocereus, finto neu aufgenommen, aus bem

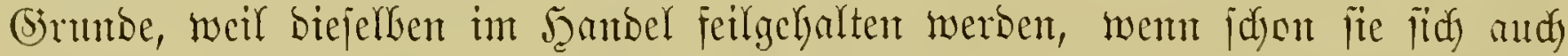

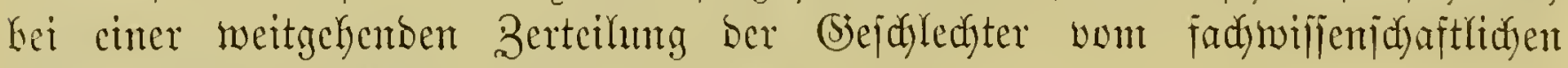
Etrubpunfte ans faum muredyt erfarten laijer.

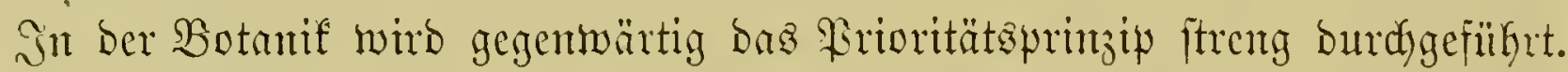

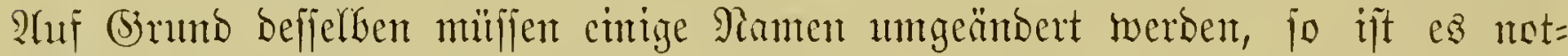
menbig für Pilocereus Lemaire ben älteren $\mathfrak{x}$ feiffer'ichen Aamen Cepha-

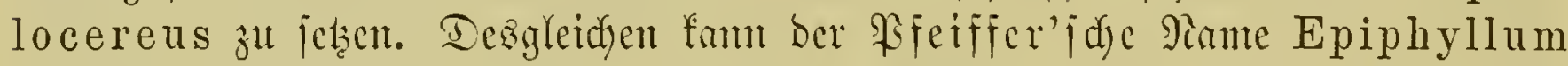
fïr E. truncatum nidyt mefr auredyt bejtehen, weif Epiphyllum wort

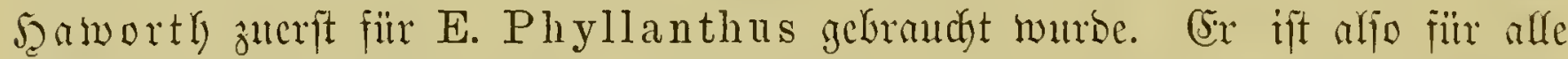

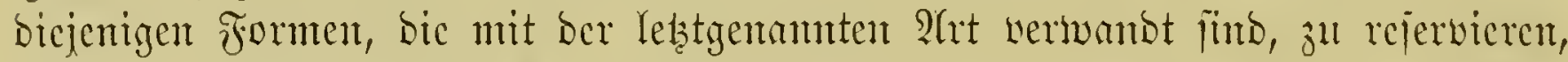

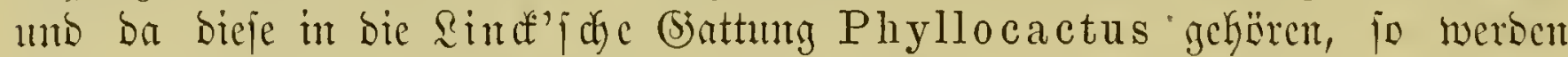

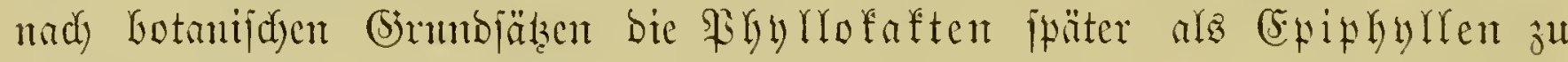
bezeidyen jein. Fin Epiphyllum truncatum aber unb E. Altensteinii

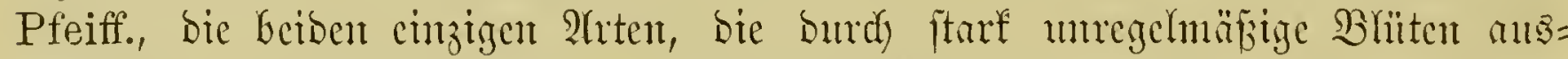

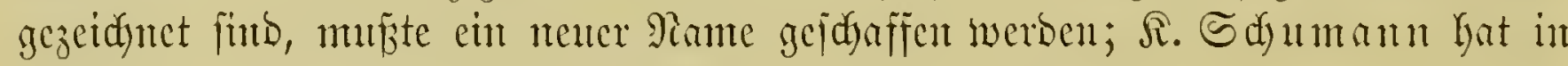
ber Flora Brasiliensis bafür Zygocactus vorgejdylagen.

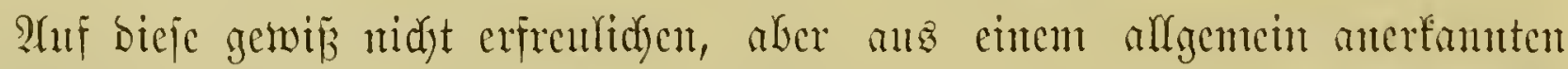
Frinzip fid ergebenten Folgerungen, jollte an biejem Drte mur fur bingewiejen

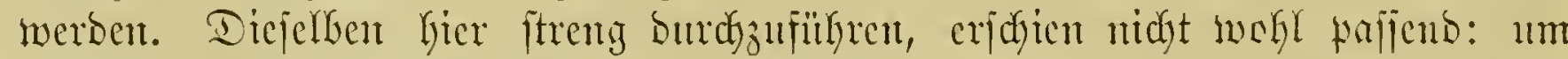

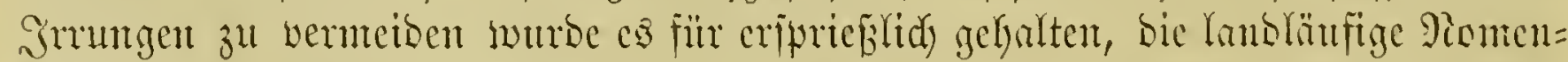

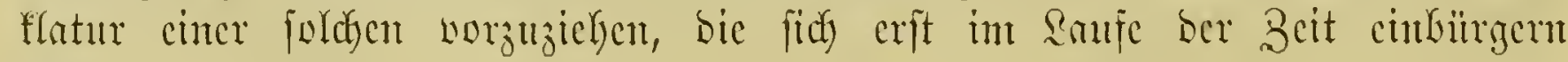
farm. 


\section{B. Epezieller Teil.}

\section{Sdyliifiel für die befdriebenen Gattungen.}

I. Cereoideac: Fettpflanzen mit feiuen ober mtr fehr kleiten, fahmppigen Blättem; Samenanlagen meift mit langent Sabelitrange. Stadhelu micht wiberhatig (zutweilent aber hafig gefrïntut).

A. Blütent trichterförmitg.

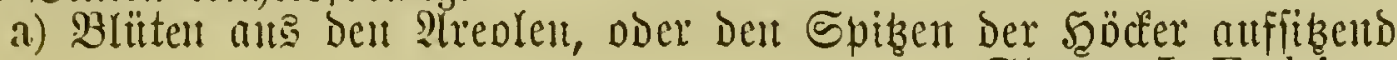

a) Stanu verlängert, oft berzweigt, fantig ober gerippt.

I. Shute (Eephalimm

II. Mit (Sephalitunt
1. Cereus Hav.

2. Echinocereus Eng. 3. Pilocereus Lem.

B) Stamm verlängert, verzweigt, fantig geflügelt, blattartig, zum minbeiten Die jïngereat Silleder.

I. Blïten regelntǟing

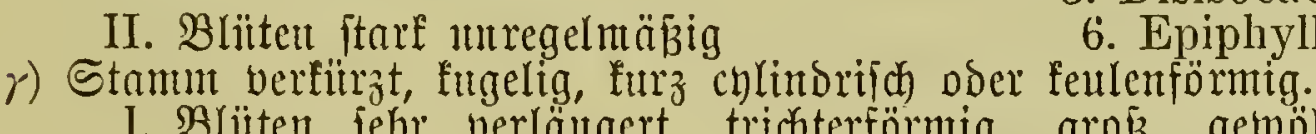

4. Phyllocactus $I k$.

5. Disisocactus Lindl.

I. Blüten fehr verlä̆tgert, trichterförnig, groß̧, gemöhnlid faft ipantentang

7. Echinopsis Znec.

II. Blïten furz, mittel oder fleit, nienals über $8 \mathrm{~cm}$ lang.

1. Ureolen lange Beit bleibento.

* Beerent rot, fleifchig und fehr jaftig 8. Malacocarpus S.-Dyck. : Beeren grünlich, trodetter

2. Areolen bald verjhtwindend

9. Echinocactus $L k$.

10. Astrophytum Lem.

11. Anhalonium Eng.

b) Blitten aus Dent 2(xillen b. h. oberbalb der $\mathfrak{3 a r z e n ~ h e r b o r t r e t e n d ~}$

Stamm II. Mamillarieae.

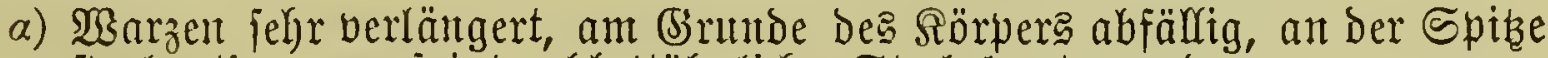
itrohartige, zugeipiąte, blattähnliche Stacheln tragend

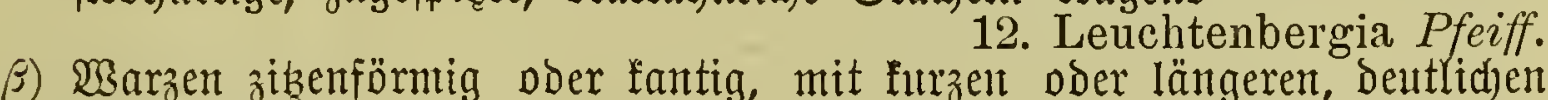
Stacheln bejest

13. Mamillaria $L$.

B. Blüten radförmig

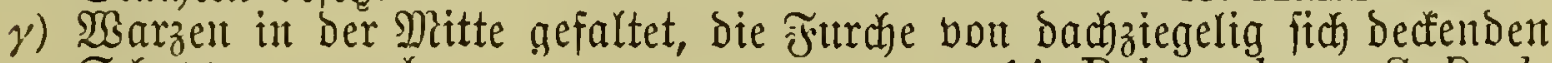
Schlippen umgeben Stami III. Rhipsalideae. 15. Rhipsalis $D C$.

II. Opuntioideae. Fettpflanzen meiłt mit flachen Bsliebern ofhe Blätter ober

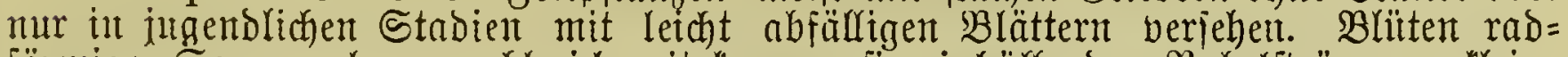
förmig; Samenantagen zahlreidh mit Łurzen, fie eithbürfenden Nabelfträngen; fleine Stacheln mit MBiderhafent (\$Slochident)

16. Opuntia $L$.

III. Peireskioideae. F̧ettpflanzen mit datterndent $\mathfrak{B l a ̈ t t e r n . ~ B r u ̈ t e n ~} \mathfrak{r a d}=$ förmig; Stachelı nicht twiberhaftg; Samentanlagent wentge, mit furzen Rabelfträngen, bon lebeterent nidgt umbülllt

17. Peireskia $L$.

\section{Słattung Cereus Haw. Fadfelfaftıts.}

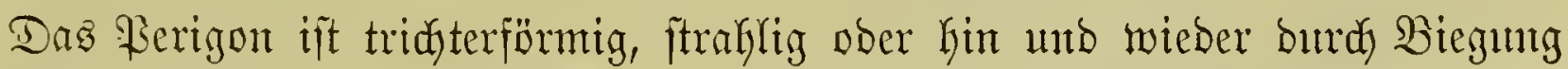

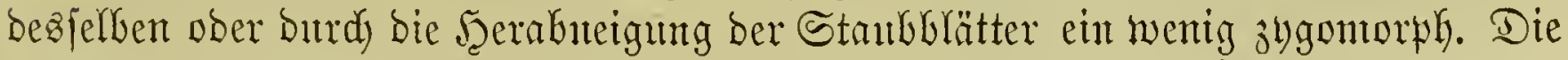

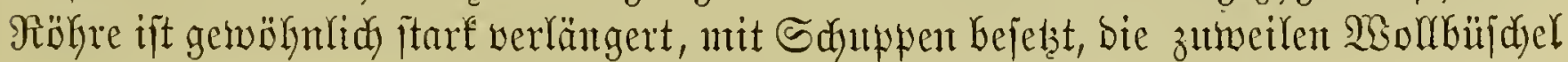

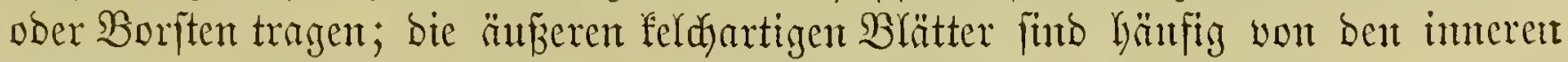

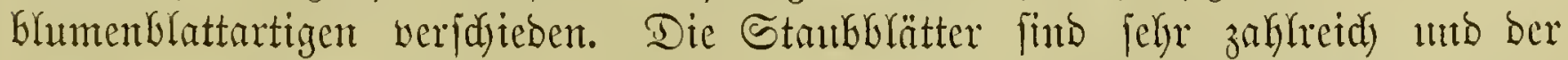
Bhumentronentöbre in mehreren Btagen angeheftet, fie finto jtets fïrzer alz ber Rerigonjaum. Der Frudeftenoten ift fligelig ober cylinbrijd, nidjt eingejenft,

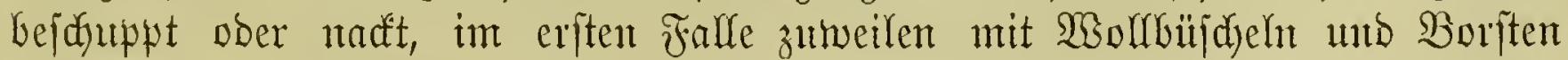
beffeibet; er umidjliej̃t zahlloje, an langen Rabelfträngen bejejtigte Smuten= 
mulagen. Die Früd)te finto freijdyige Beeren mit vielen Samen, fie füb be=

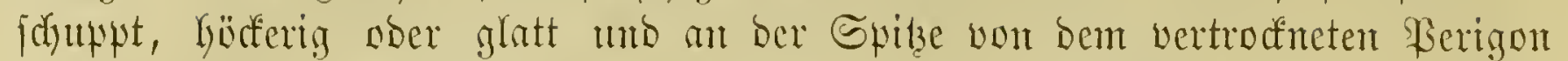

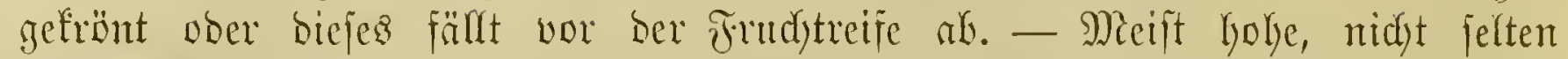

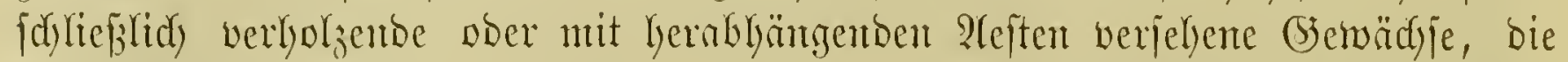
von jenfred)ten gitppen burdjzogen werben; anf Yetzeren ftehen bie Areolen, bie

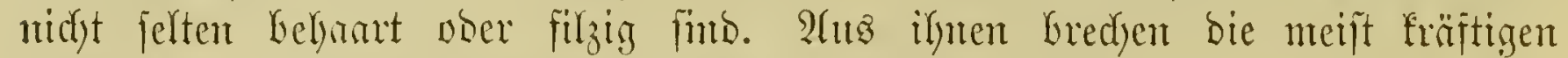

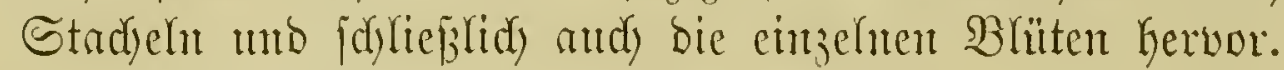

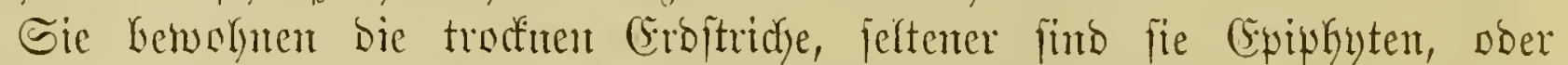

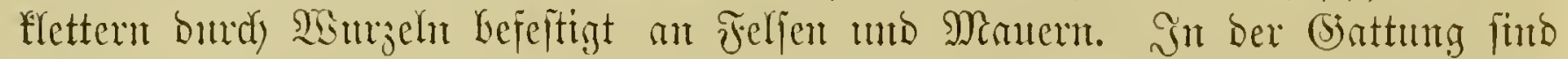
natye an 150 Arten bejdyricben worben, bie von Ralifornten Giz nady ben argen= tinifdyen Freiftaraten wadjent.

Der Nime ftanmt ans bent Enteinifden, in bem cereus bas Madjalidit

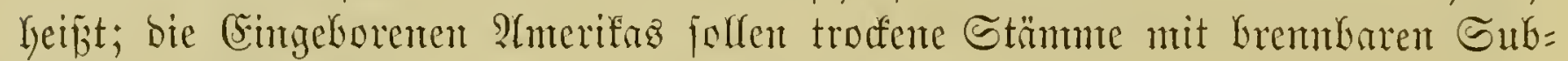

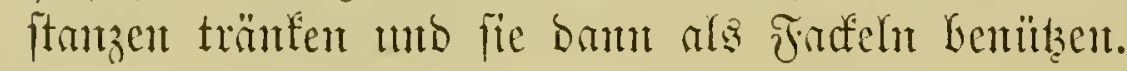

\section{Sçliififel für die befdrriebenen Zrten.}

A. Stamm aufredht, olgne Rnftmurzeln.

a) Stamm ungegliedert, fteif anfrecht auch im âter.

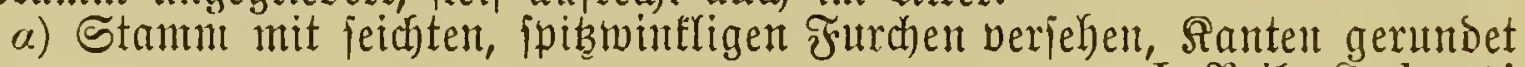
I. Reihe Sulcati

1. C. chilensis Colla.

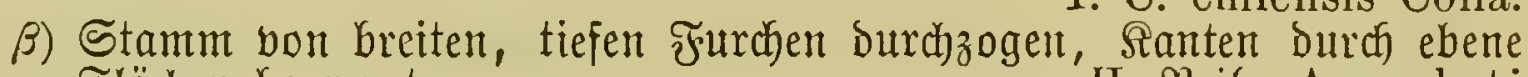
Flächell begrenzt

II. Reife Angulati

2. C. peruvianus Haw.

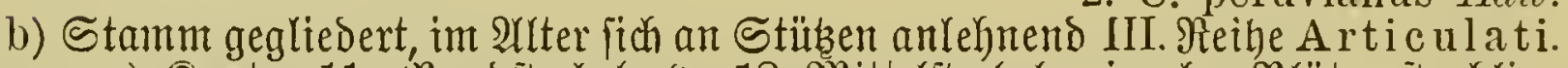

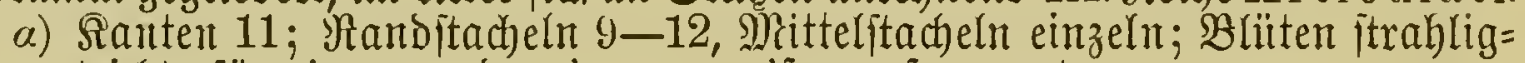
tridgterförmig, gerade, imnent weiß

3. C. serpentinus Lagasca.

乃) Sianten 13-16; Manditacheln 12-18, Mittelitachein 2-4; Blüten ge= $\begin{array}{ll}\text { friimment, faft zmeilippig, gefbrot } & \text { 4. C. Baumannii Lem. }\end{array}$

B. Stamm niebergeitrectit ober flettertib, Bweige zumeilen hängend, oft ntit Ruftwurzeln veriehen

a) Stamm von vielen engen Frurdent burchzogen, Sä̈der bidht gebrüngt

a) Stamm fajt aufredyt: Blüten ziegel= bis jujarlachrot

1. Sruppe Flagriformes.

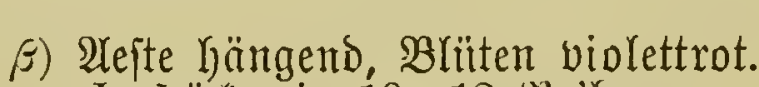

I. 5̧öcter in $10-12$ औeiber.

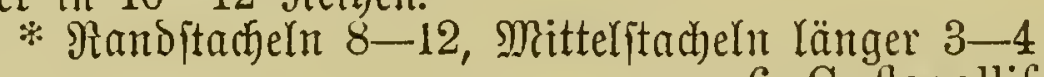

** Siunditachelı 6-8, Mitteritad)elı. fiürzer 4 -5

5. C. Martianus Zuce.

7. C. flagriformis Zuce.

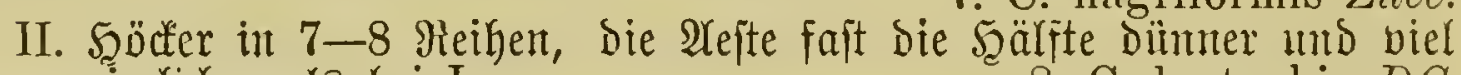
zierlicher ald bei I

b) Stämme nidht gefurcht, Stad)elporfter weiter entfernt.

8. C. leptophis $D C$.

a) Stäntme fajt rumb

2. (5rtwpe Extensi.

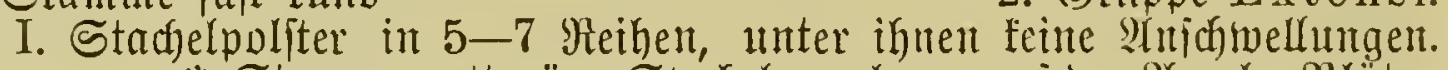

* Stamm neattgrün, Stadjeln mel)rere anf Der Slredle, Blüten anţent gelb oder prange, intuen weiź.

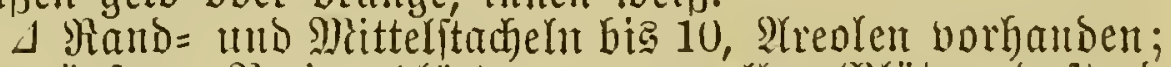

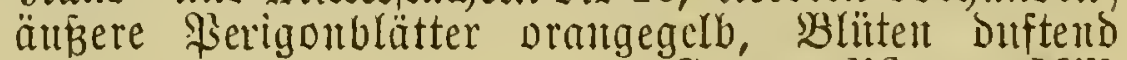

9. C. grandiflorus Mill.

$\Delta \Delta$ Rur Randftacheln bie 6 vorbauben, futrz; Prreoleu nicht behaart, äußere łserigonblätter branngelb, BBlïten gerudito ${ }^{2}$ 10. C. nycticalus $I \lambda$. 
* Stanm Dunfelgrïn, Stadjeln einzeln, Błüten gelb.

11. C. Macdonaldiae IIool:

II. Stadjelpolfter in 4 Reihen, unterharb Derjerben ein voripringender siöter

3) Stümme 3-4=fantig.

12. C. rostratus Lem.

3. Bimppe Speciosi.

I. Stamm nieserliegents, grẗn 13. C. coccineus S-Dyck.

II. Stantm nehr nufredit, rot ïberlanfen 14. C. speciosissimus $D C$.

\section{Cerens chilensis Coll. Chilenifducr Fanfelfaftus.}

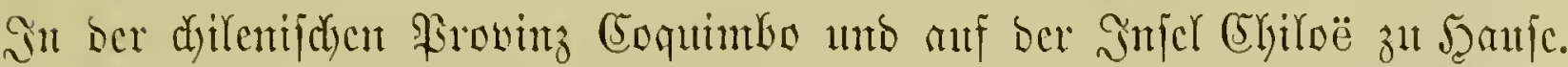

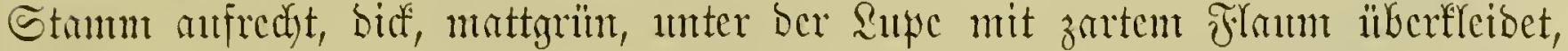

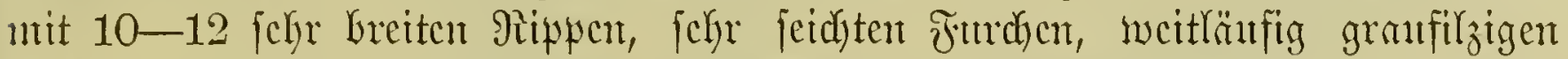

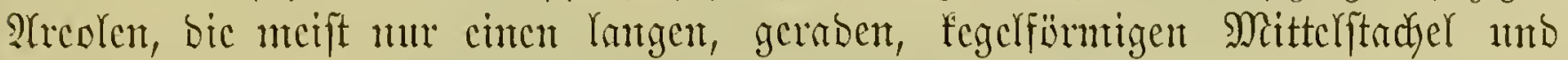

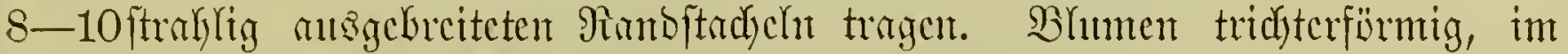

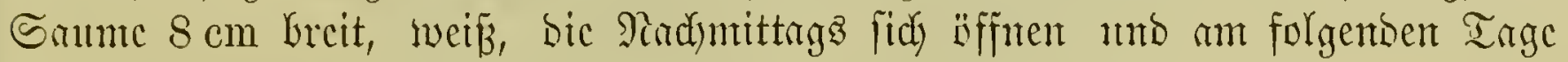

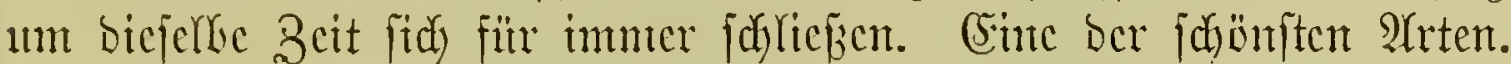

\section{Cereus pernvianus Haw. Beru=ðnuffelfaftuz.}

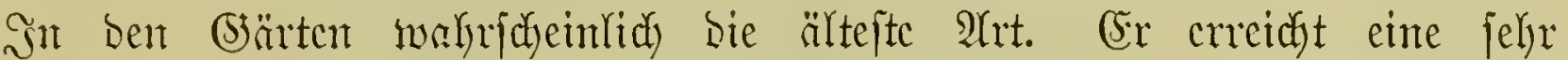

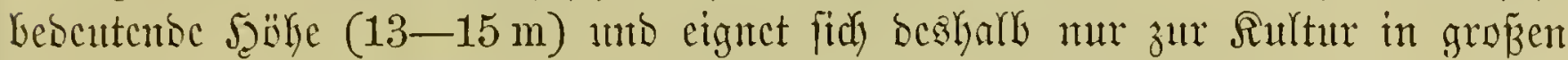

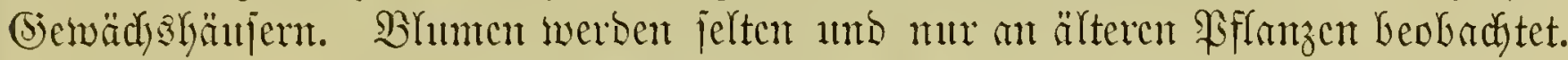

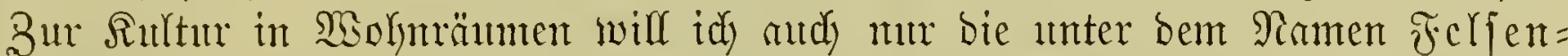

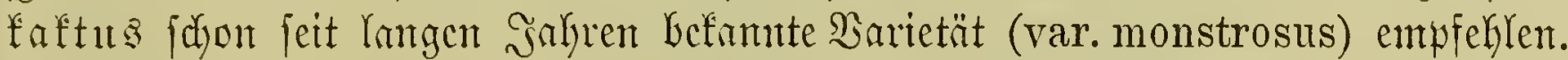

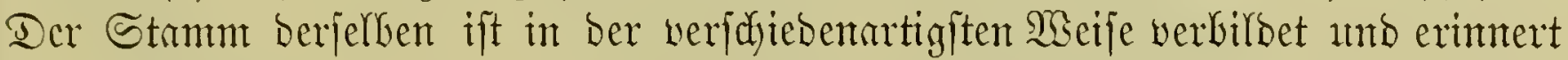

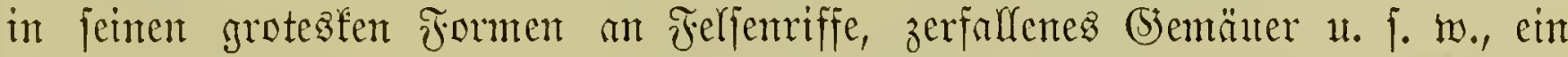
mumberlidjes Durdeinanber von Enolfen= ober feulenförmigen, höfferigen, fromen=

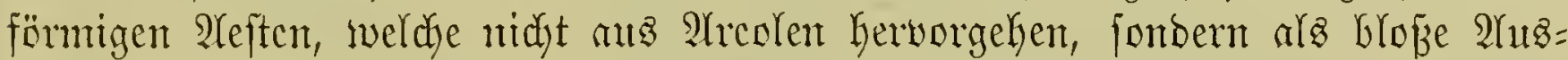

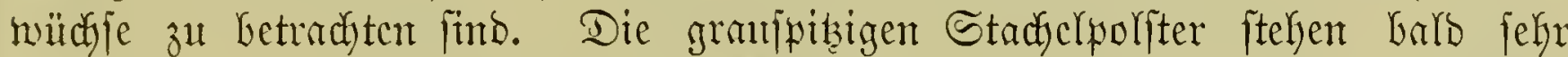

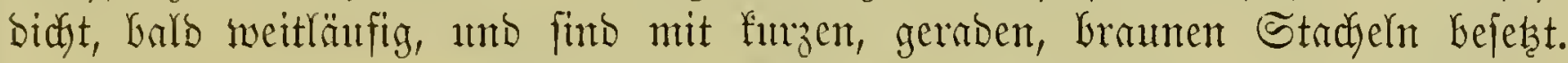

\section{Cerens serpentinns Lag. Sallangen=ซarfelfaftnz.}

Sn Mexifo eintheintifdy. Stamm aufredyt, fpäter an Stüken angelelynt, biz $4 \mathrm{~m}$ hod und barilber, bei $4-6 \mathrm{~cm}$ Durdemeffer, mit 10-11 ftumpfen Sinten

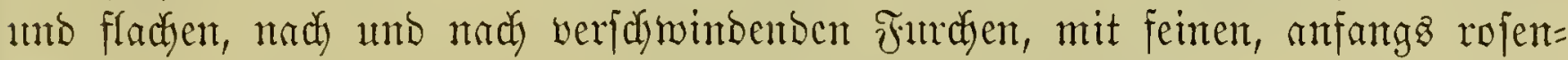
roten, bann weizen Stadyeln, won benen einer in ber Mitte ber Arrolen unto

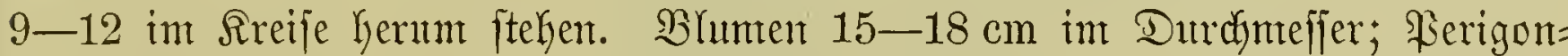

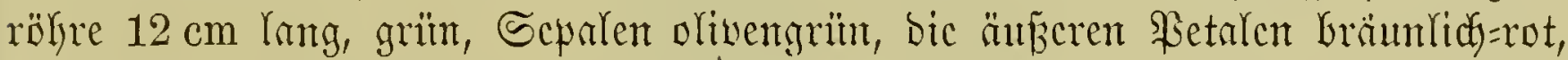
Gorizontal misgebreitet, bie imneren idyneemeif. Sine nidyt geringe Bierbe finto bie meit überragenbent meižen Staubfäben mit gelben 2hththeren. Die Bhhtmen

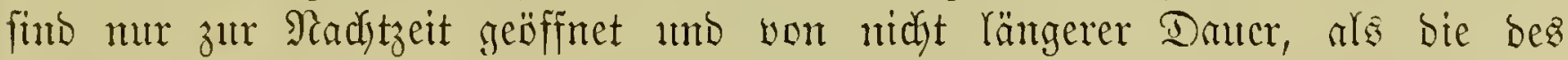

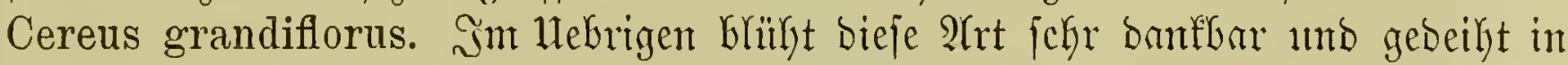
einem fomigen Stutbenfenfter vortrefffich. Âm beften befoumt ibr cine locfere

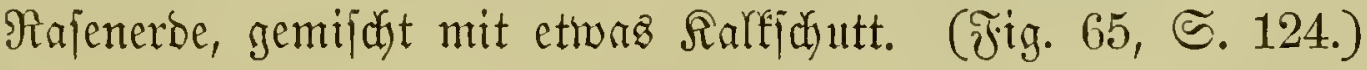

\section{Cerens Bammannii Lem. Baumaun's gadfelfaftus.}

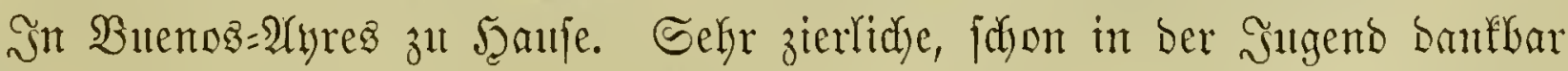

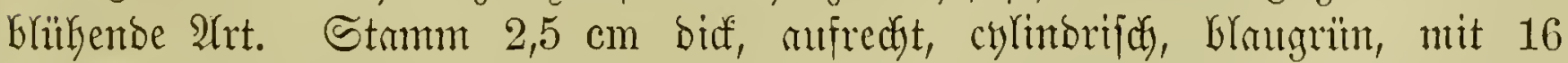

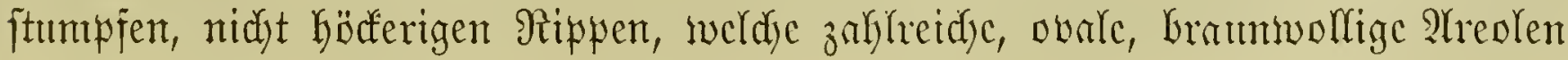


mit je 4-5 bram gefledten Stadjeln tragen. Bjhmen zahlreidy, mit gegen $6 \mathrm{~cm}$ lantger, gefrïmmter Röbre, lebhaft orangejarbig. Blütezeit ber Sommer.

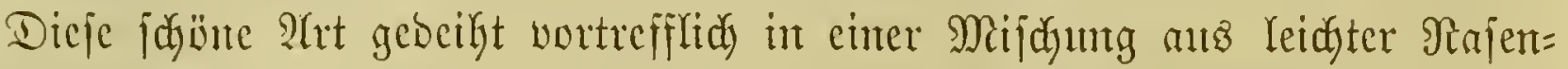

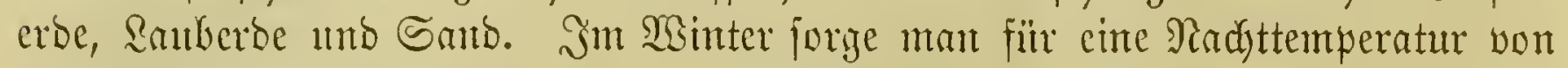
+ 80 R.; im Sonmer jetze man bie Siflanzen ber Sommerbärme aus unb fartize öfter morgens ober abenos.

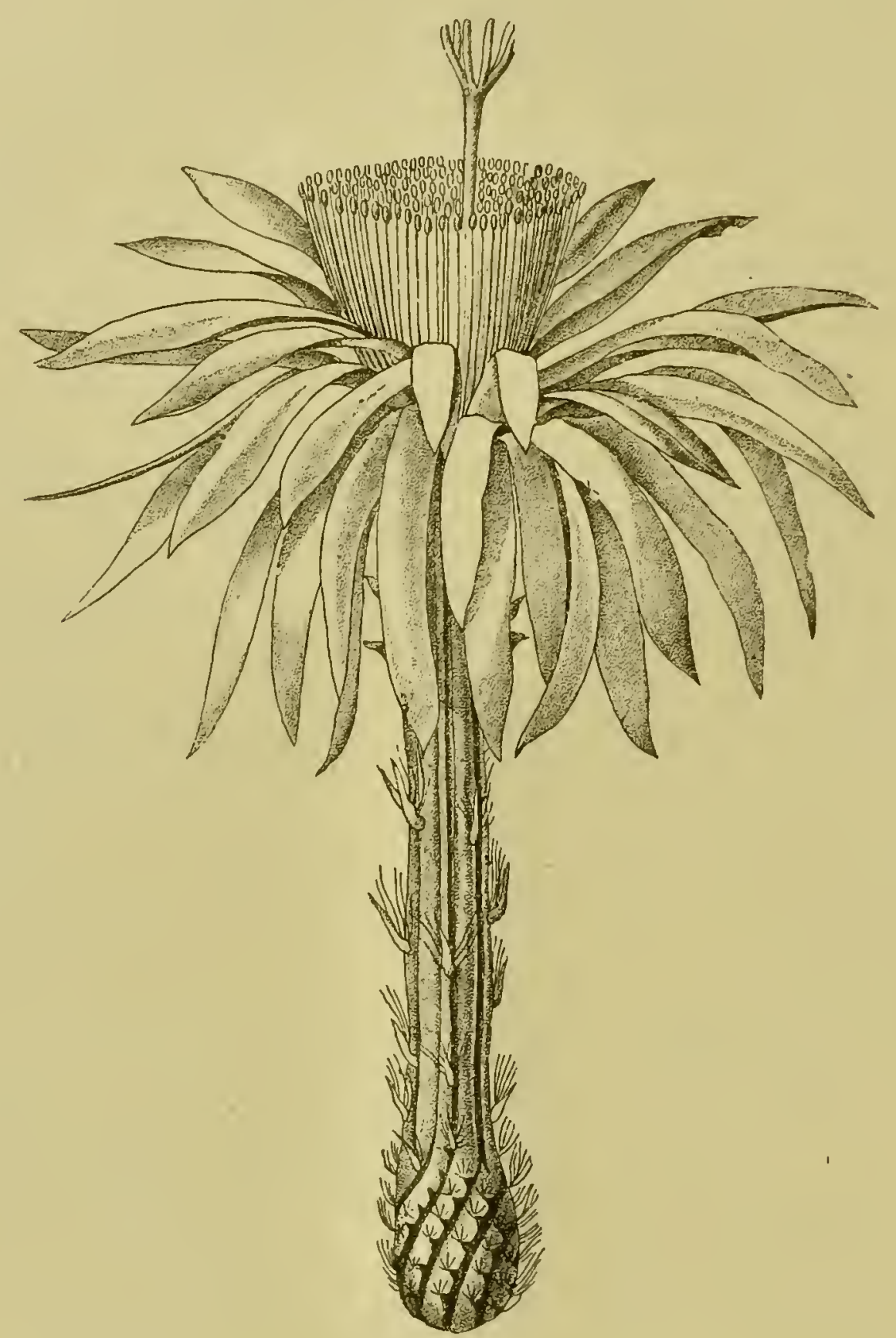

Fig. 65. Cereus serpentinus Lag. Shlangen=テadelfaftus.

\section{Cerens Martianus Zuce.}

Mexifo. Strmm fajt aufredyt, an ber Brafizäätig, mit 8-10 jujwadjen,

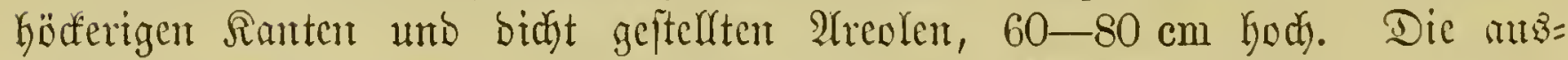
gezeidynet fön̈nen, gegen $10 \mathrm{~cm}$ langen $1 \mathrm{mb}$ volffommen aufgeblït $5-7 \mathrm{~cm}$

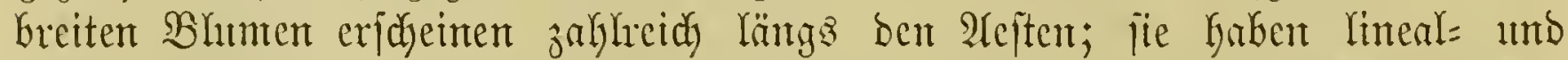

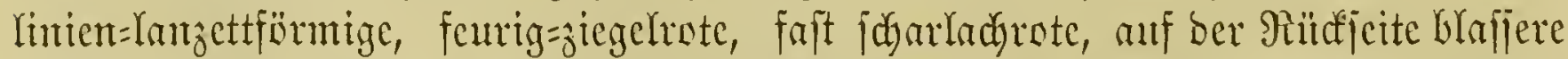

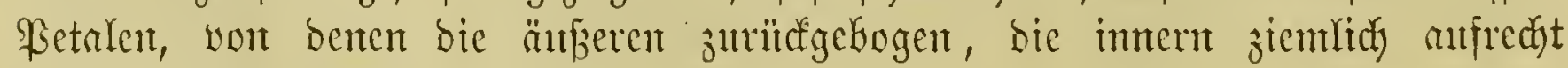

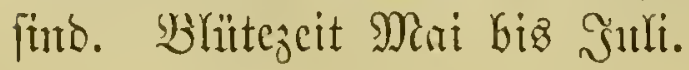




\section{Cerens flagelliformis Mill. Pcitidjen= Saftur.}

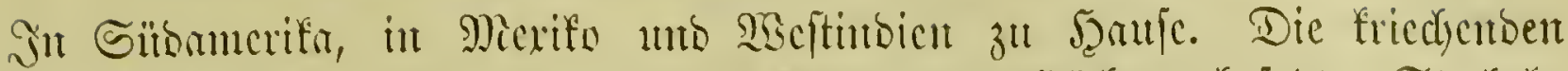

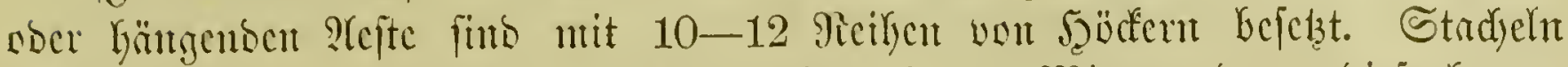

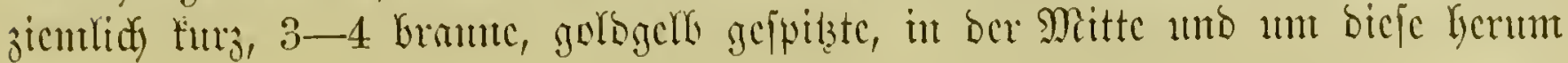

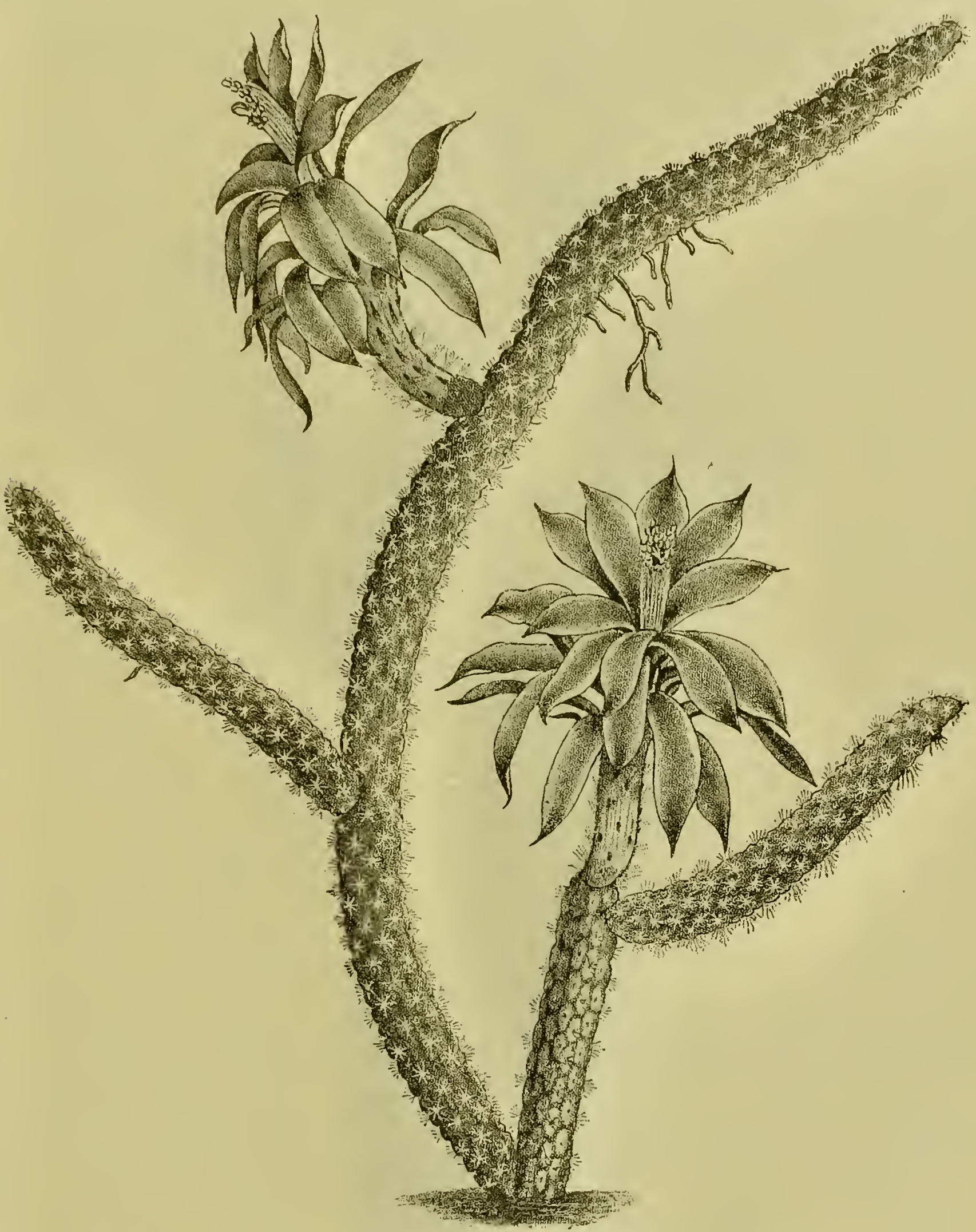

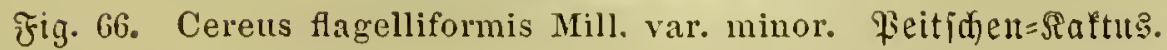

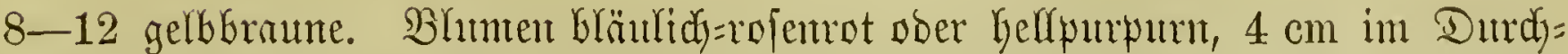
meffer uno bis $8 \mathrm{~cm} \mathrm{lang,} \mathrm{im} \mathrm{Früljjahre} \mathrm{und} \mathrm{im} \mathrm{Sonmter.} \mathrm{Bur} \mathrm{Befetzung}$

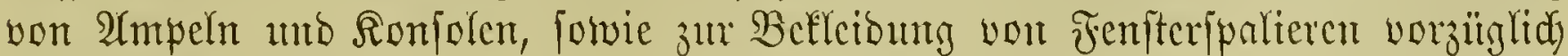
gut geeignete $\mathfrak{A} r t$. 


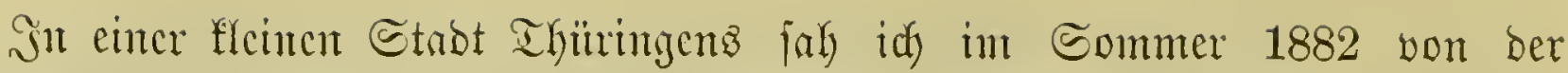

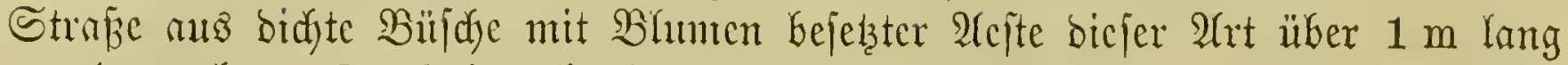

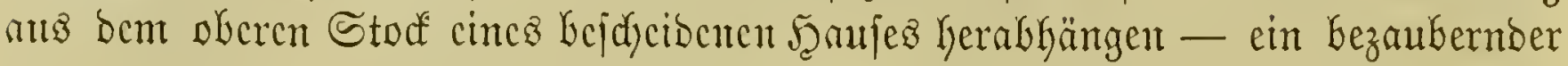

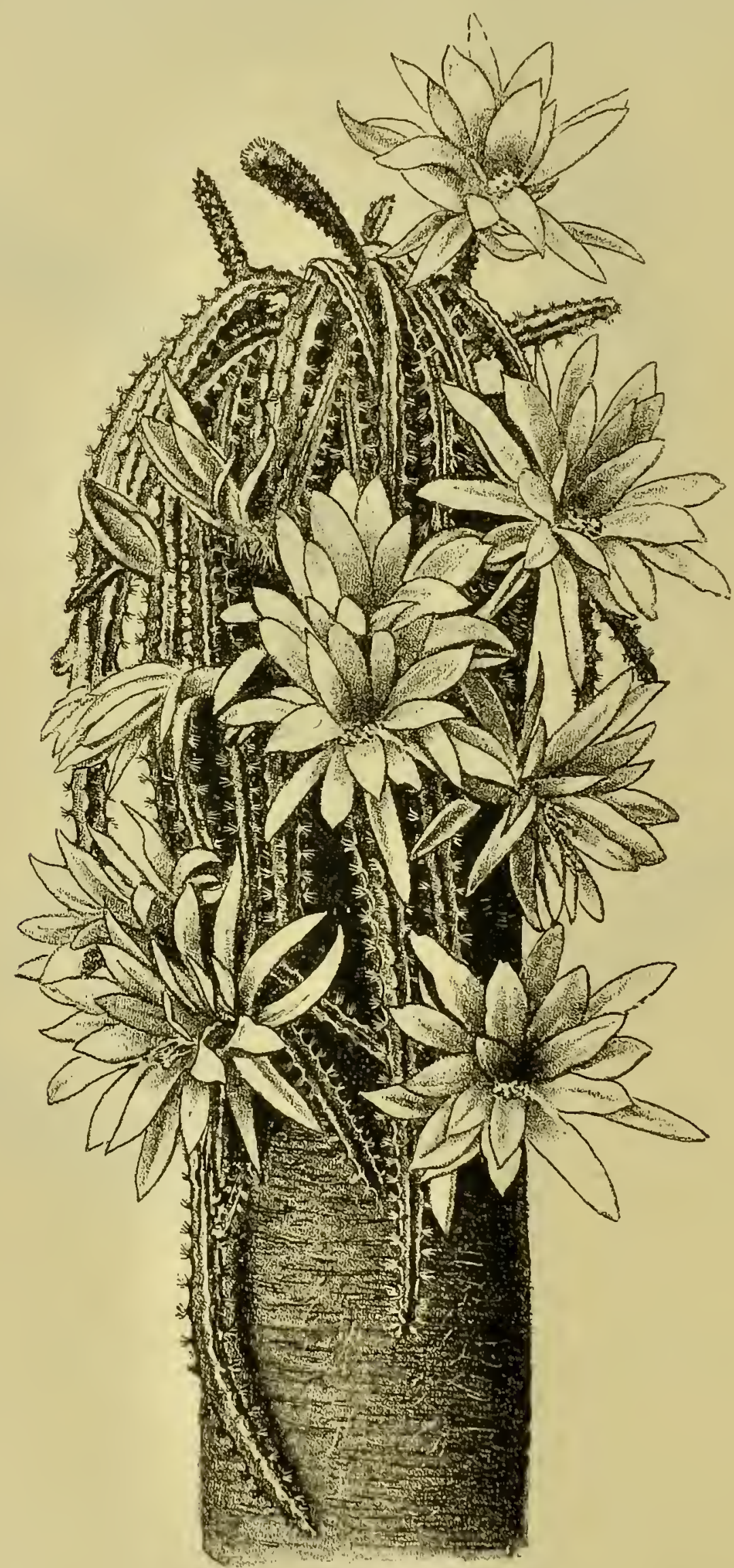

§ig. 67. Cereus hybridus Vulcan.

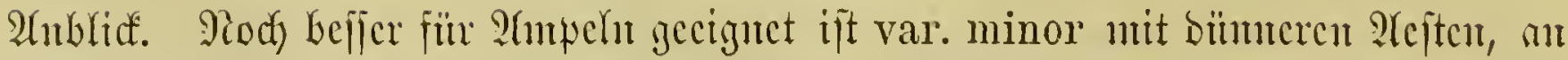
Rcidjblütigfeit abcr jtcht bicje Barictät ber Stanment nadj. (Fig. 66, S. 125.)

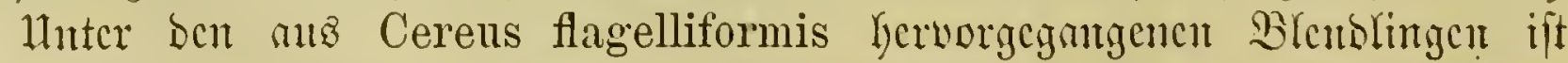

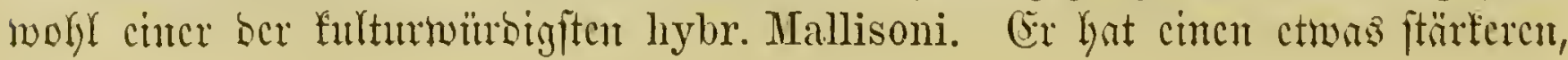




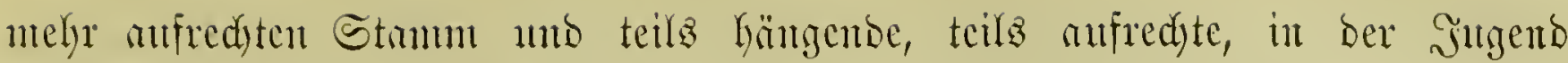

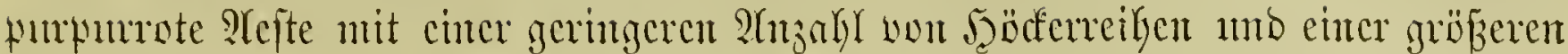
won Stadyehn. Dic prödytigen Blumen haben cinen Durdyntffer won $12 \mathrm{~cm}$

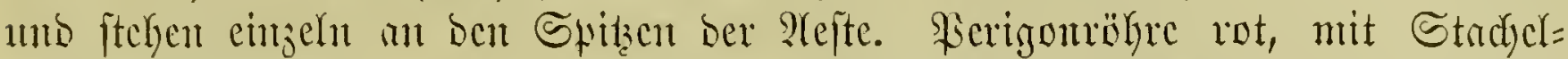

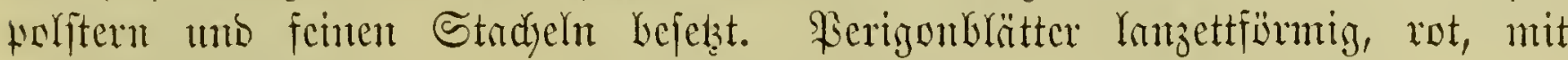

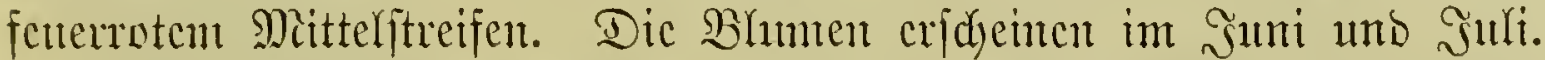

Dieje Barictüt brïht an banfburiten, wenn man fie nidyt jut marm bält.

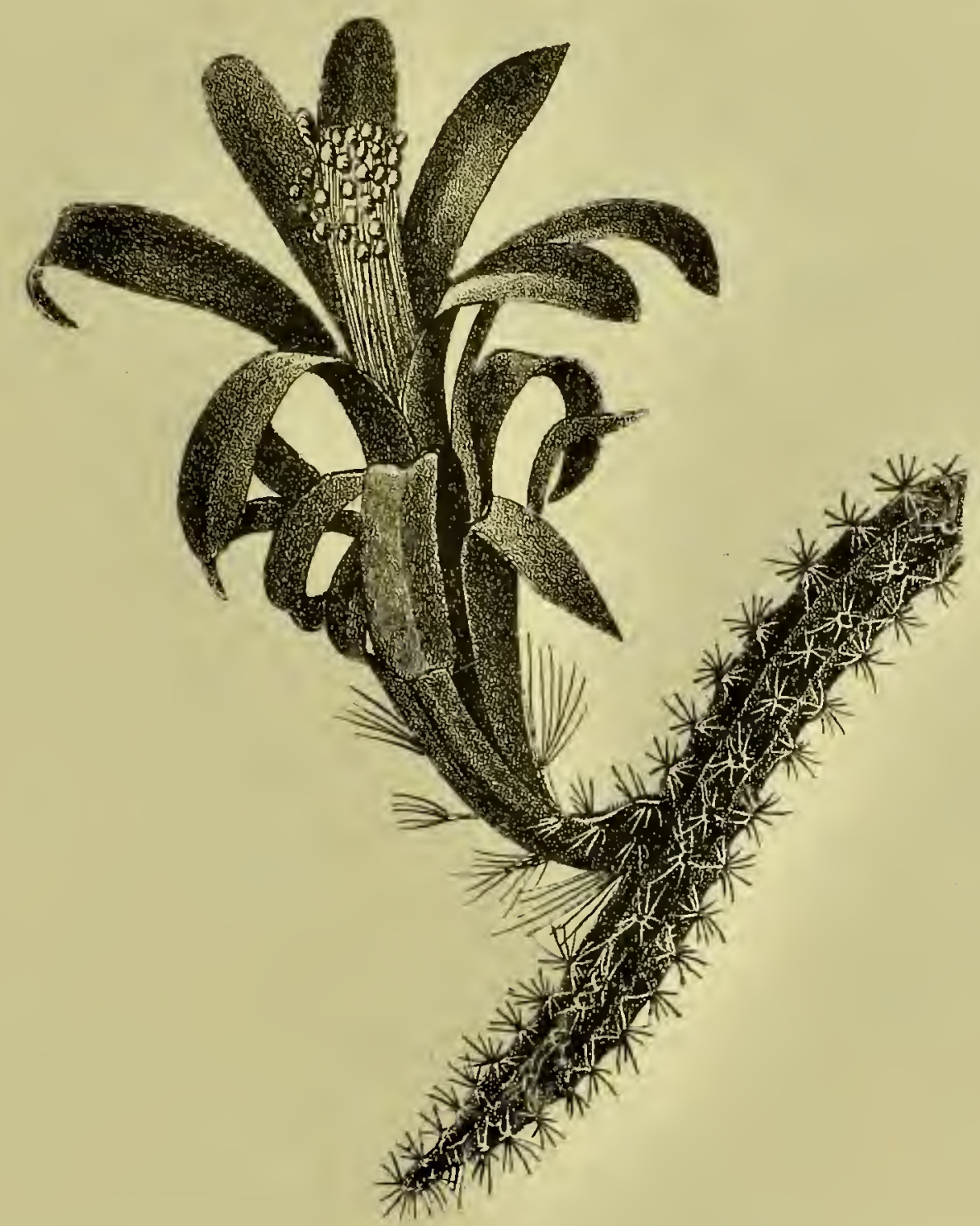

Fig. 68. Cereus leptophis DC. Wourmidrlangen=Fadelfaftus.

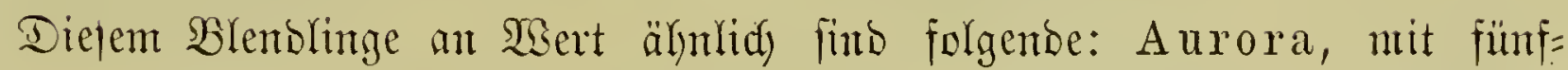

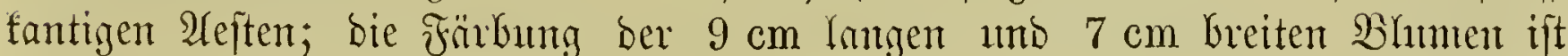

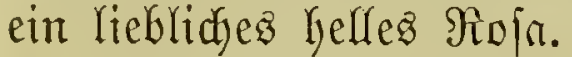

Splendens, mit vierfantigen, etruas ryängenben 2reften. Die Bhłmen

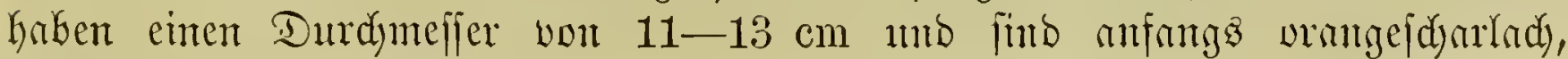
ipäter farmoifin.

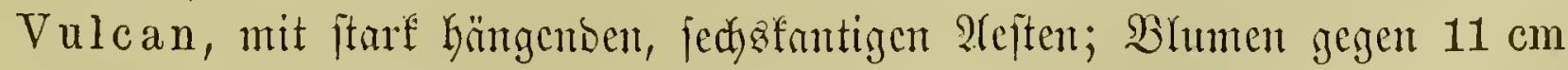
lang unb $10 \mathrm{~cm}$ im Durdymefifer, feurig=idjuladyrot. (Fig. 67, S. 126.)

\section{Cereus flagriformis Zuce. Geifzel=Fadfelfaftü.}

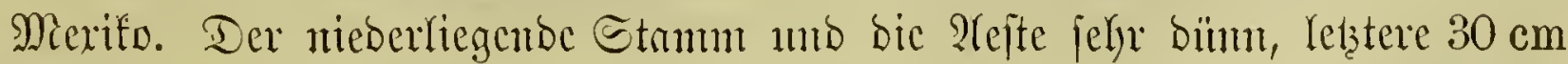

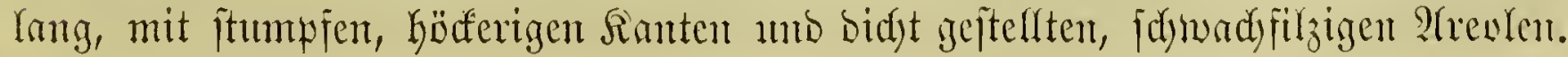




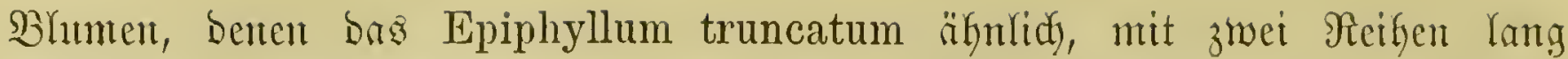

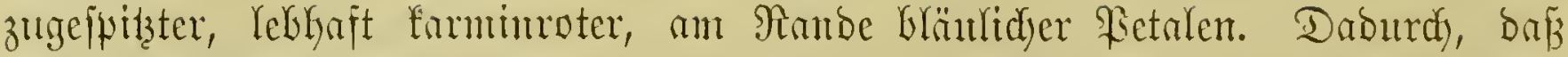

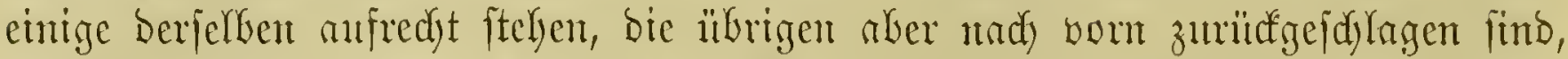

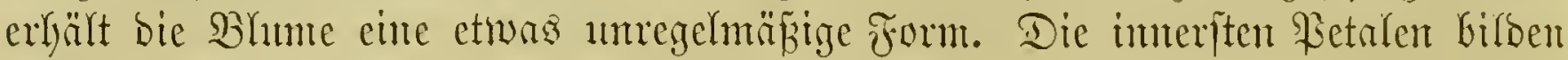
einten glocfigen Tridster. B̉̆ütezeit Miai-Suni.

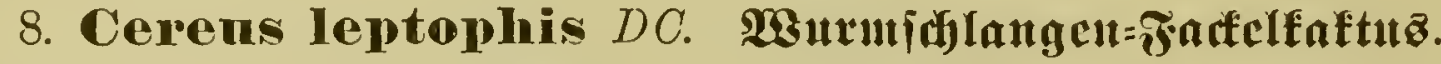

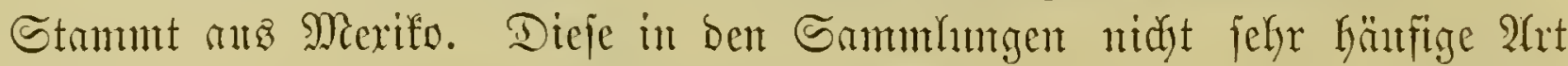

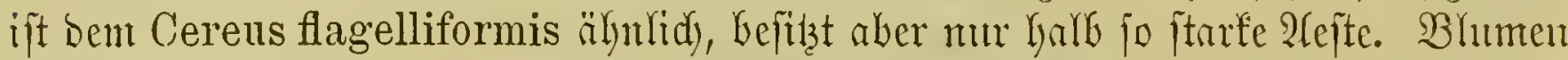

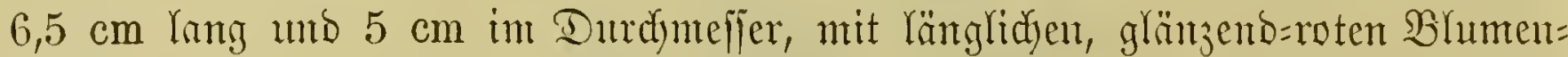

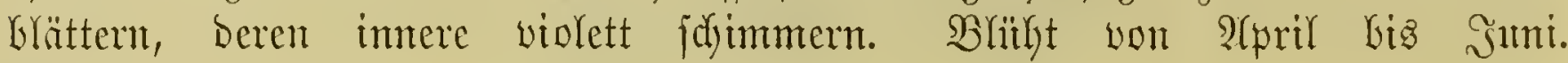
(ซึig. 68, ․ 127.)

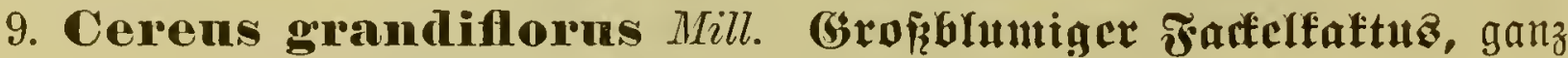

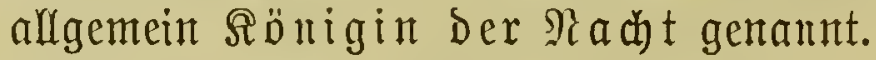

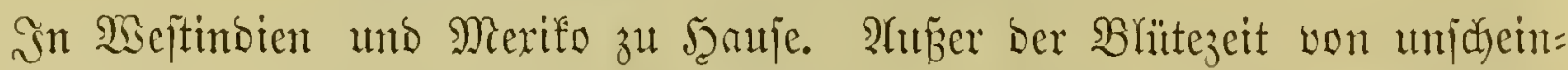

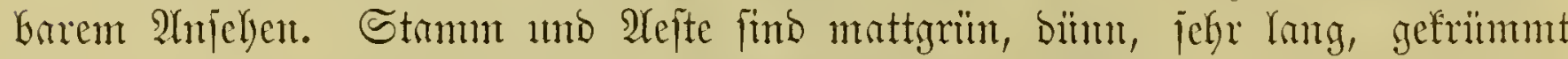

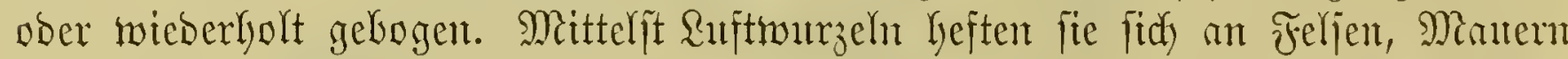

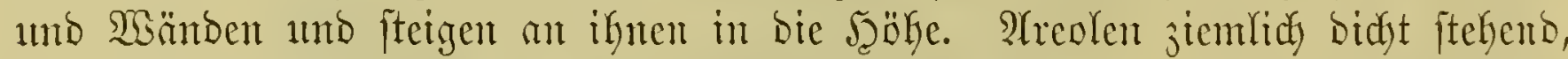

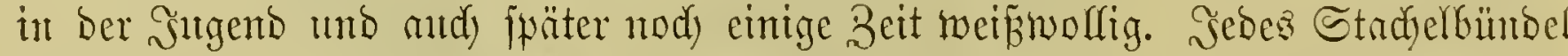

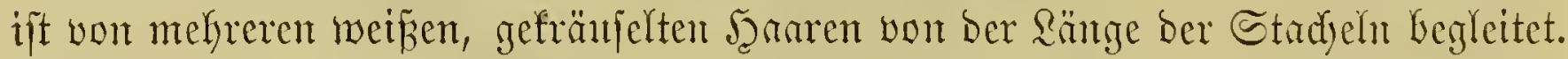

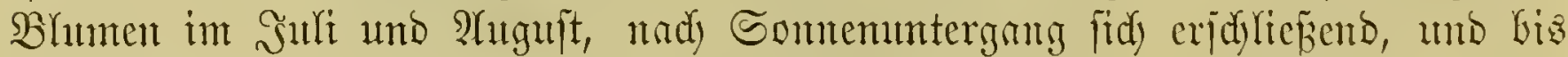
zum nädjiten Miorgen (8-9 ulyr), felten länger, bauernd. Sie find $20-25 \mathrm{~cm}$

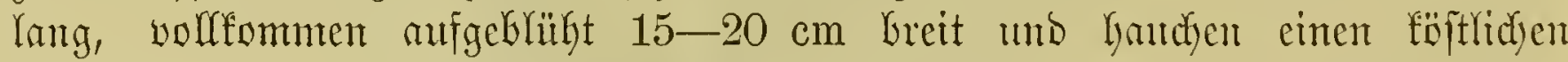

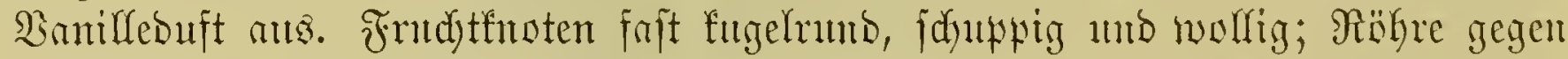

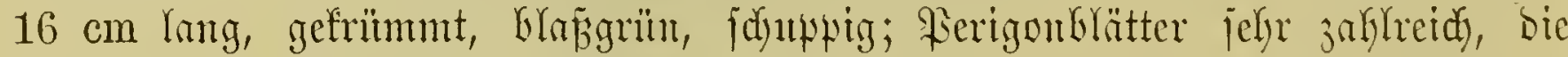

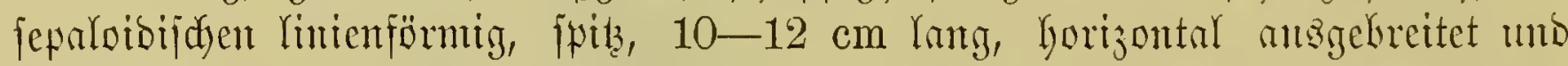
ipreizent, orangegelb, bie petaloibifdyen etwas fïrzer, aber Greiter, Glentento=neiź,

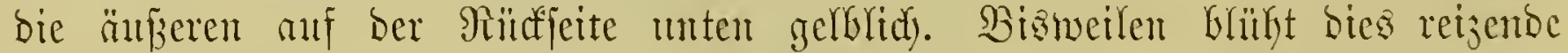

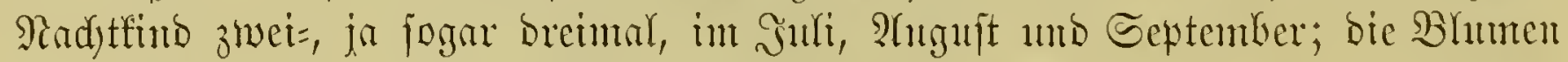

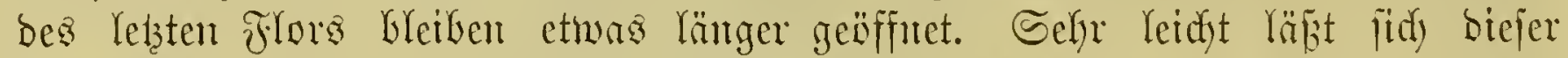

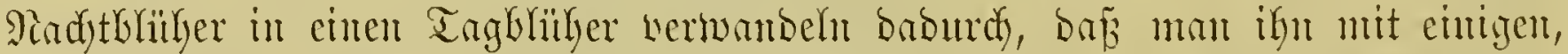

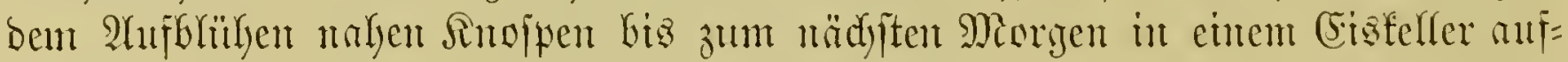

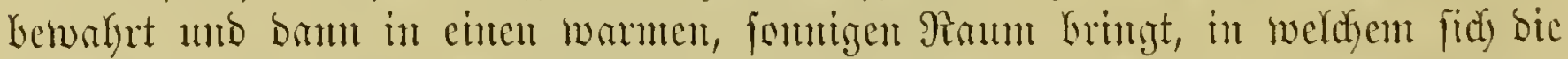

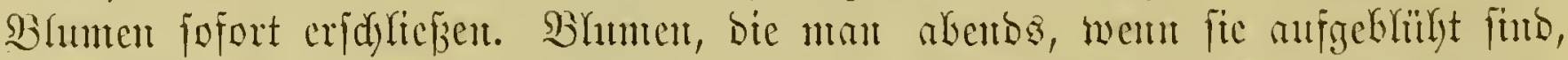

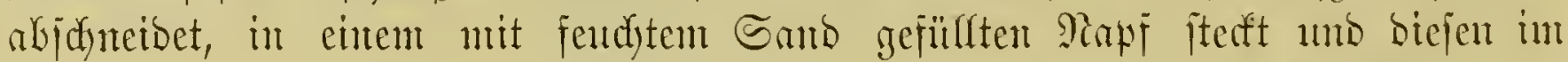

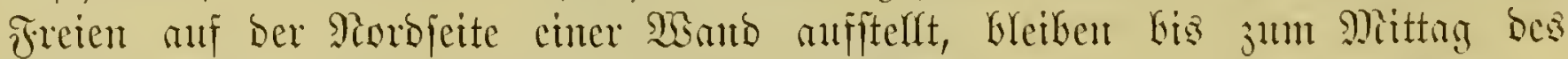

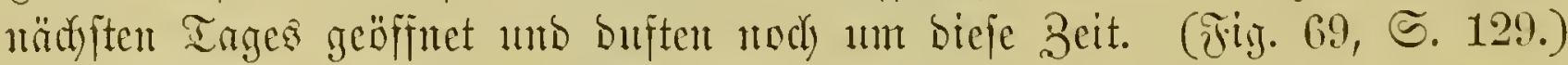

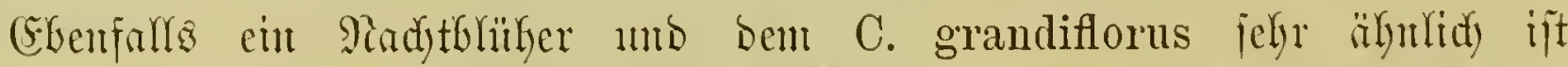

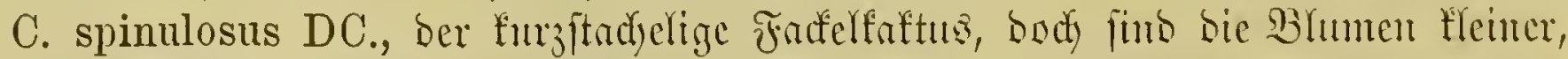

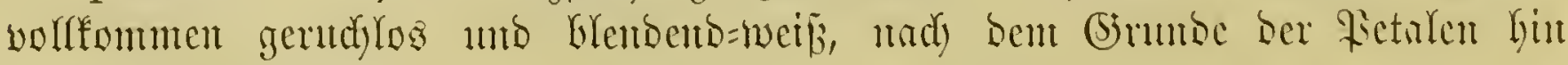
rojenrot angefiandyt.

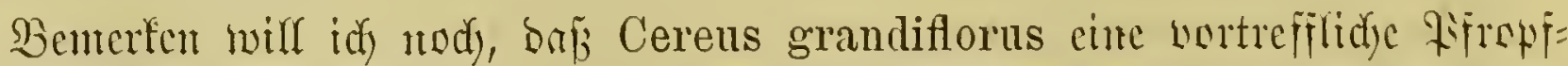

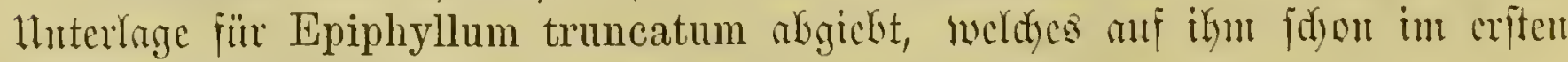

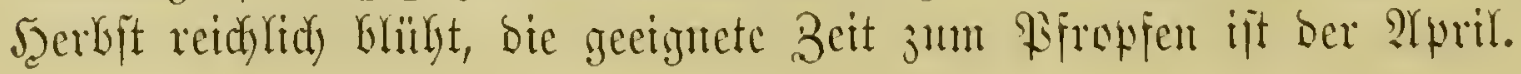




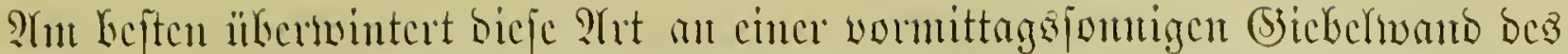

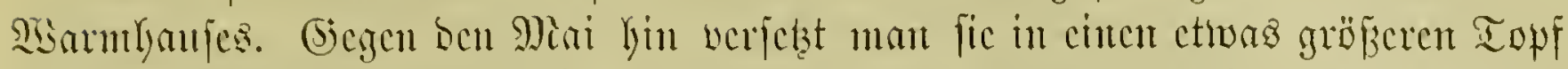

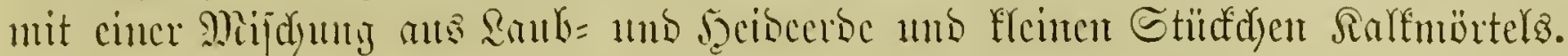

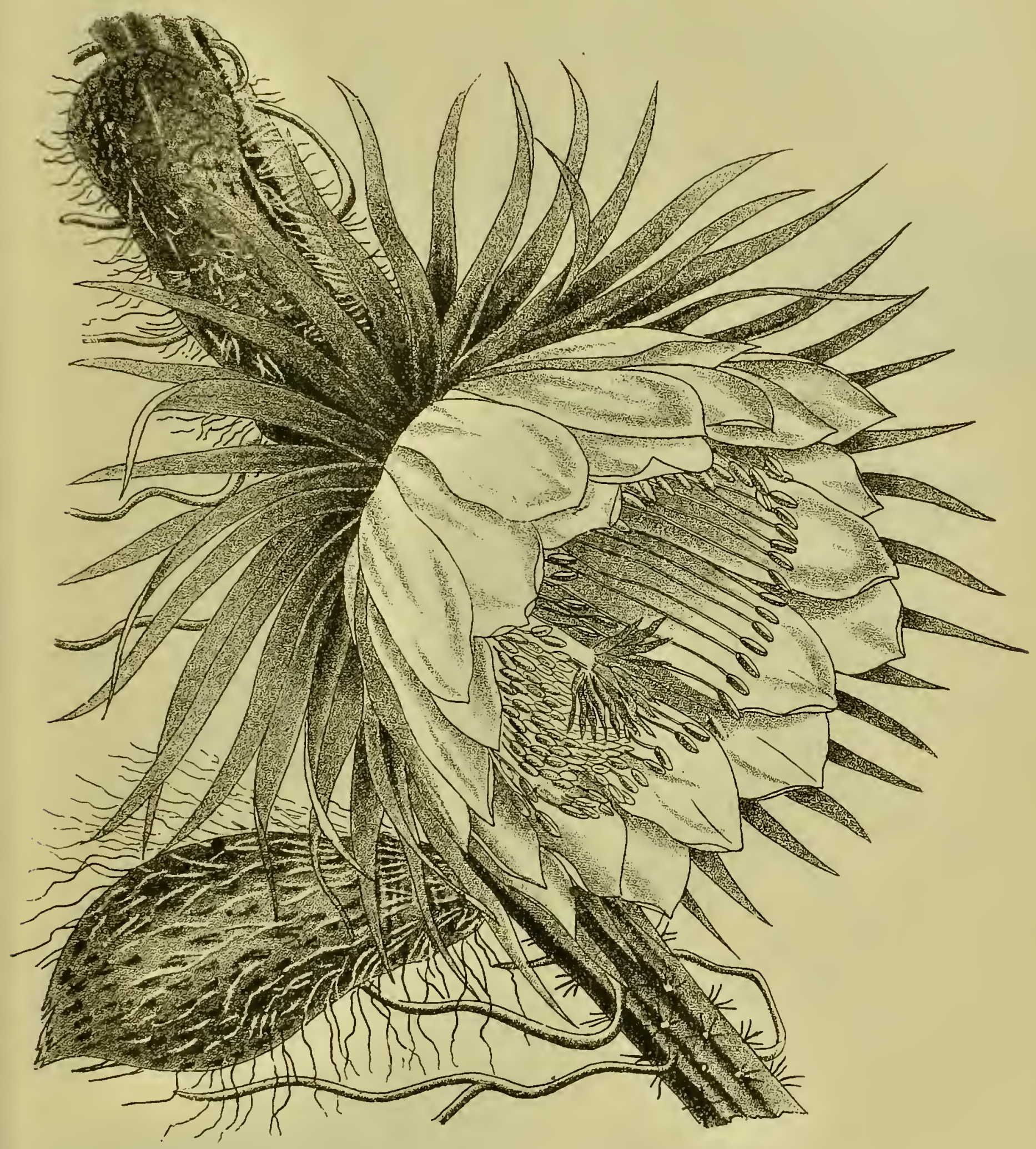

Fig. 69. Cereus grandiflorus Mill. (Brojblumiger ซacteffattus.

\section{Cereus nycticalus $L l_{i}$. Madjtidjüucr Farfelfaftuz.}

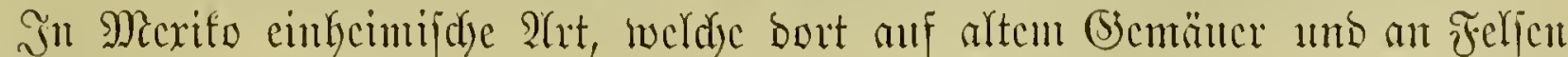

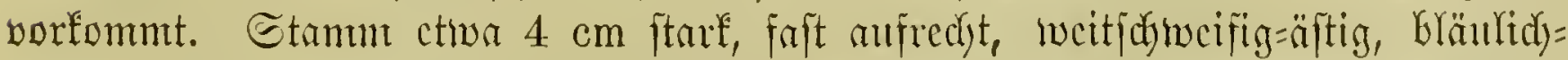

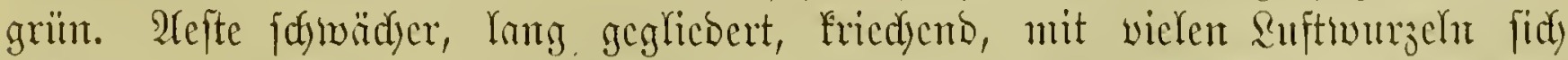

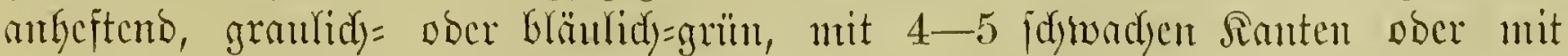
ebenio vielen Reifen won Etadyelpolfitern. 
BGhmen im Juli, benen bes Cereus grandiflorus ähnfidy un ebcnfalls mur

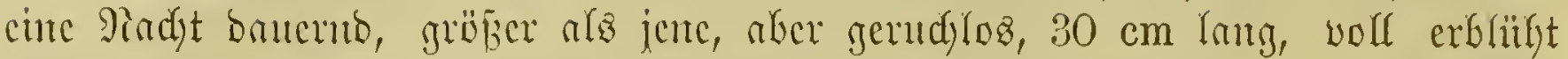

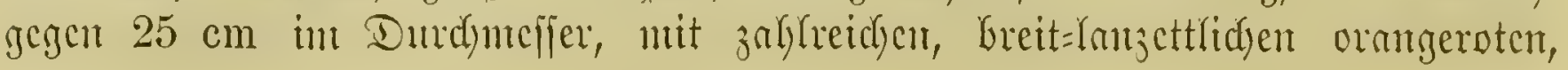

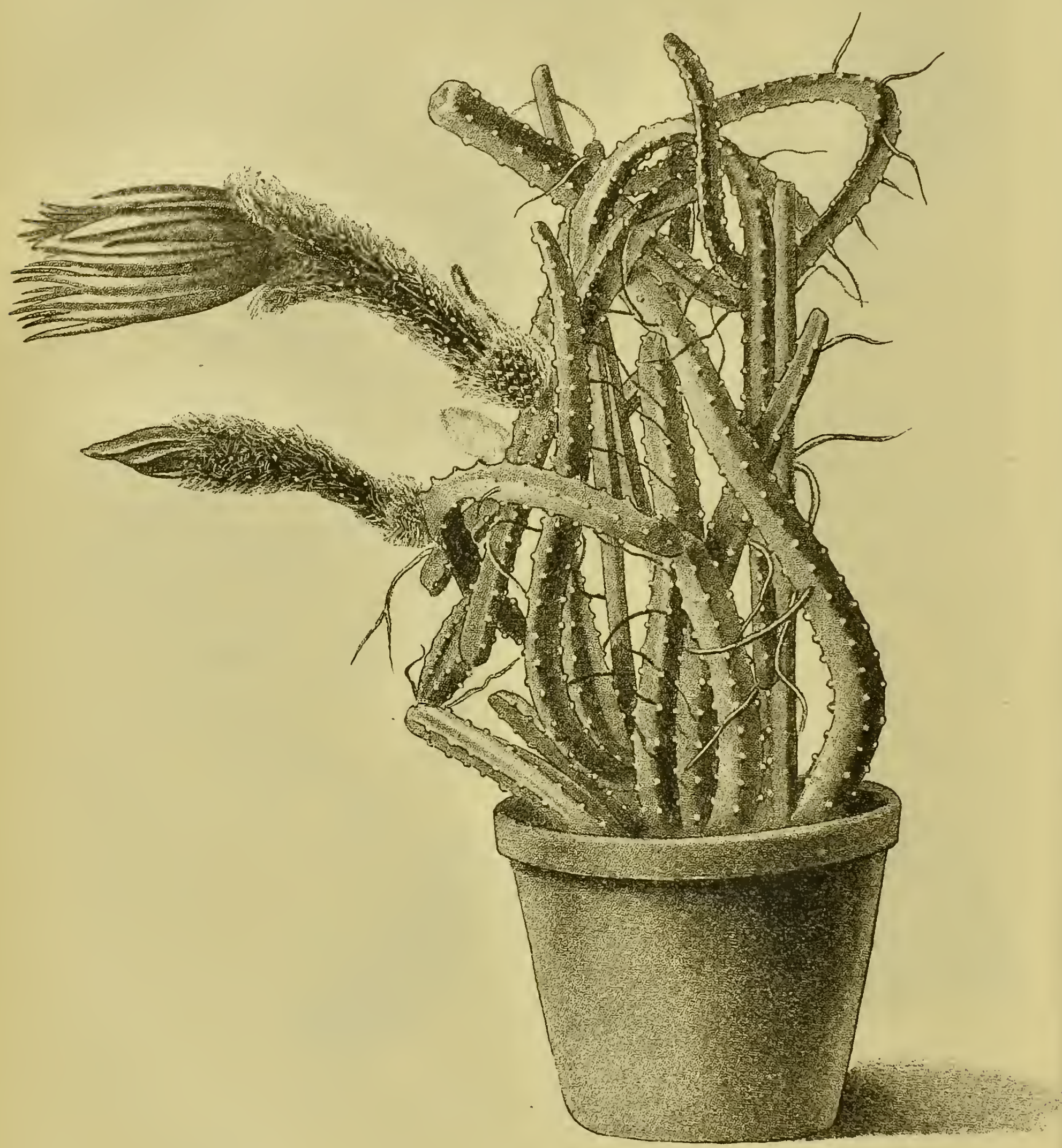

Fig. 70. Cereus nycticalus Lk. Fantidüner Facfelfaftus.

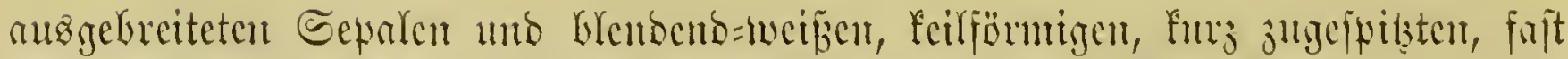

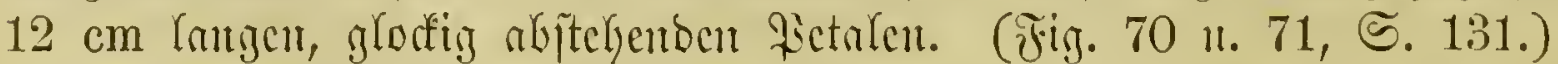

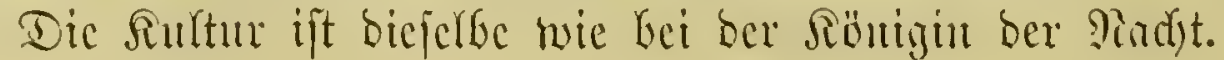




\section{Cereus Macdomaldiac Hook.}

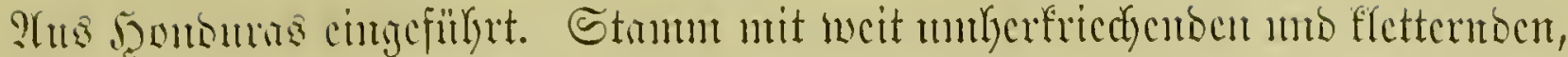

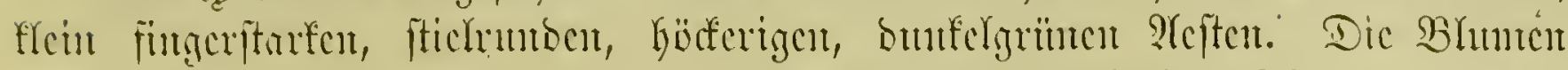

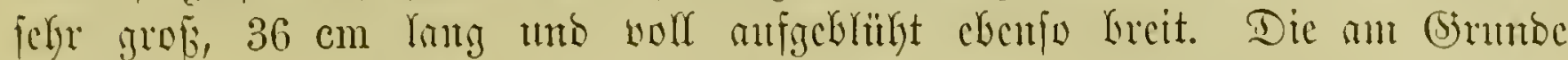

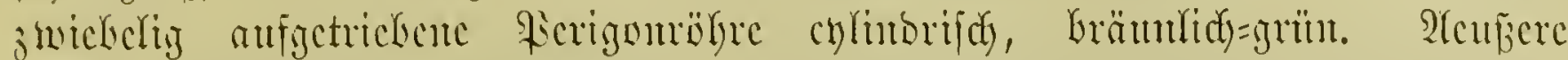

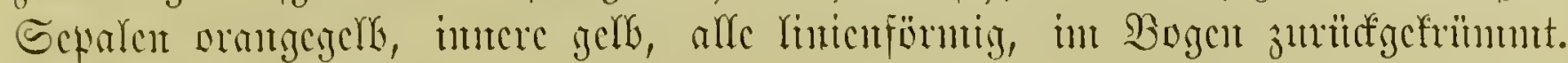
Sictrlen fpatclförmig, mciñ.

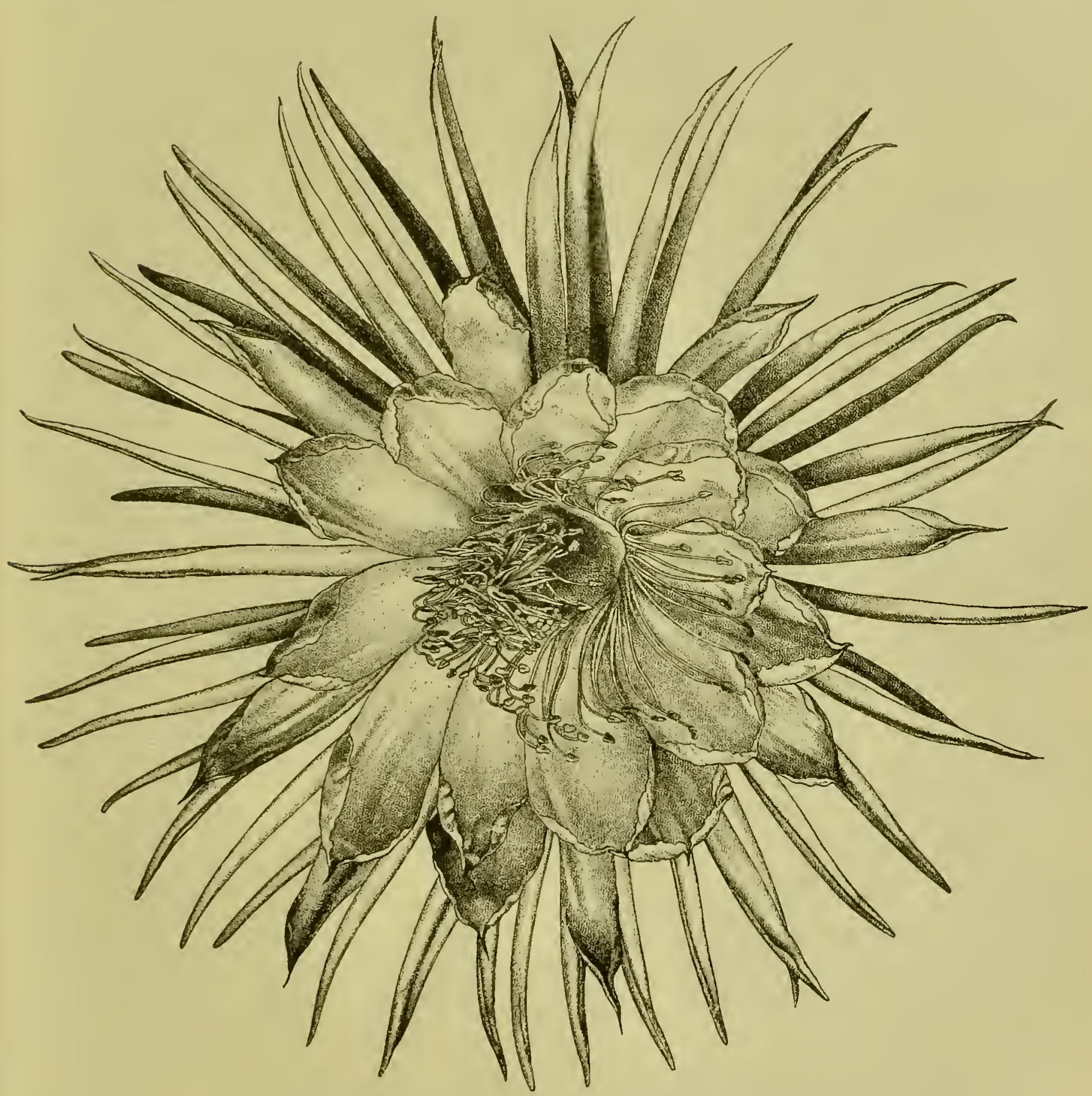

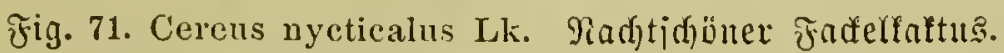

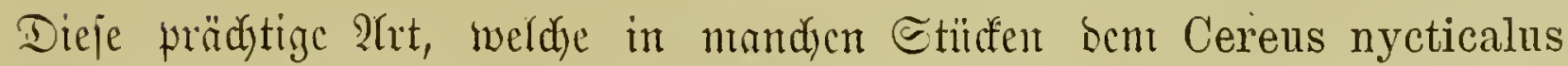

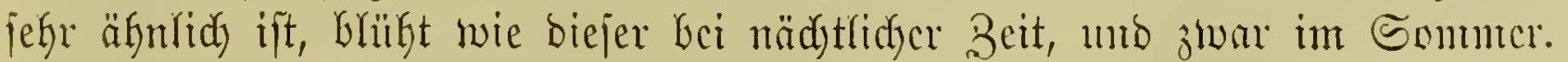

\section{Cereus rostratus Lem. G(f)}

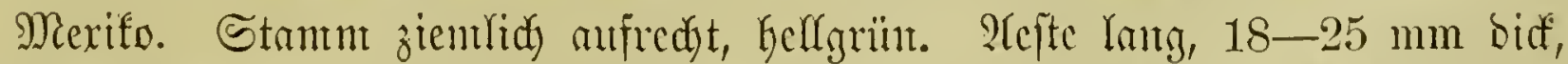

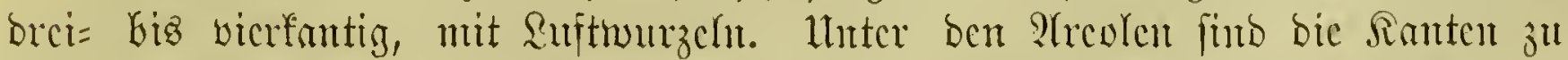
eiment hafenartigen, cinem Edjiffsjduabel verglcidbaren Sorjprunge ansgejogen. 


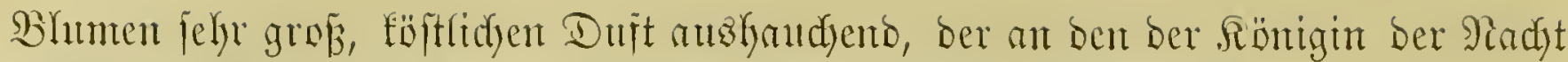
erimmert. Ferignmb̈gre $13 \mathrm{~cm}$ lang, mit blattartigen Edyupen bejelzt; bie

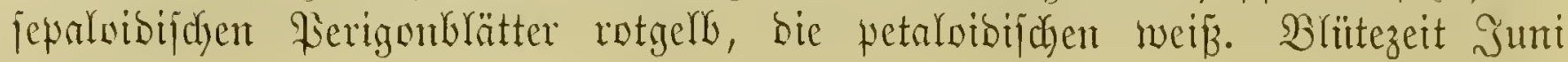
bis Jitli.

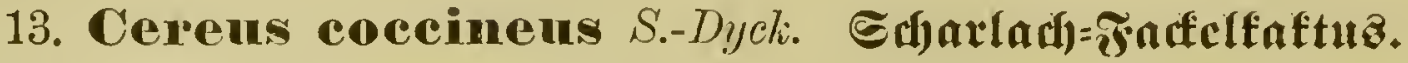

Merif́. Strmm fajt nieberliegent, mit $15-30 \mathrm{~cm}$ Iangen, ansgebreiteten,

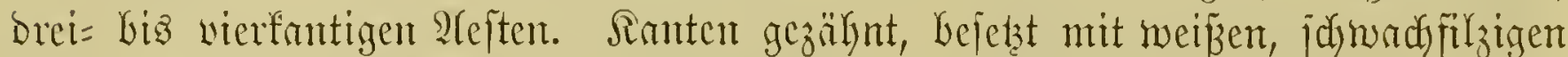

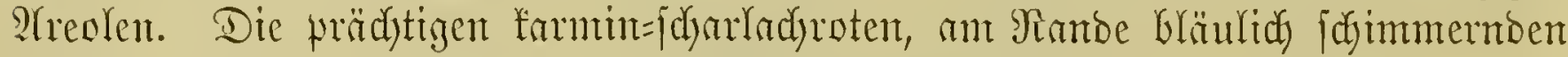
Błumen haben $15 \mathrm{~cm}$ im Durdymejer. Bhätezeit bав Frühjahr.

\section{Cereus speciosissimus $D C$. Brö̈dtigitcr Fadflfaftuz.}

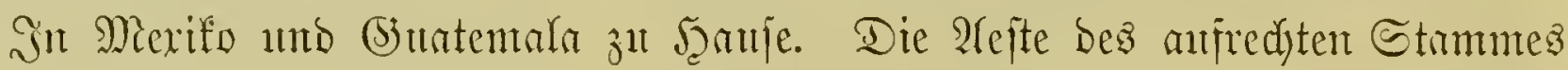

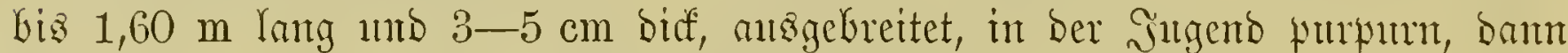

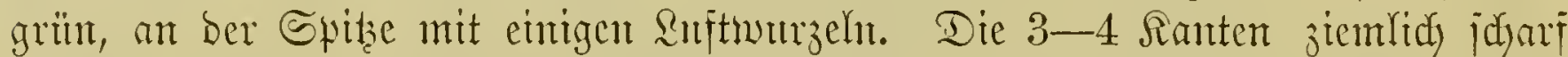

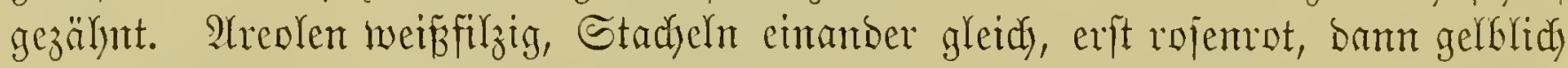

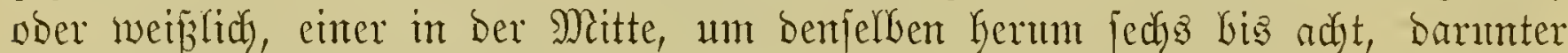
zwei bis brei etwas fitrzere. Błhment ben ganzen Sommer findndy, $12-15 \mathrm{~cm}$ in Durdymeffer, mehrere Inge lang geöffnet, mit fleijdjigen, Yintealen, rüttidy=

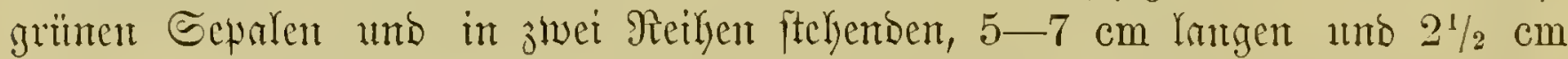

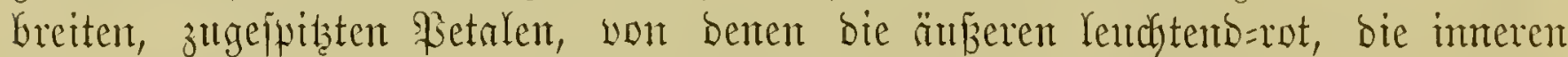
feurig=purpurrot mit bläulidyem Eammetichimmer; bie zahlreidjen Etanbfäsen unten griin, mady oben jdyarladyrot wie ber gleidylange (Siriffel.

Itm won biejer Sfflanje einen reidyen frlor ju erjielen, joll man fie im Barmbanje an einer redjt fomigen SBant jieken und fie int SBinter mager unb trodfen halten.

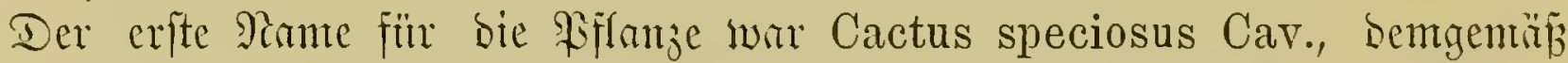

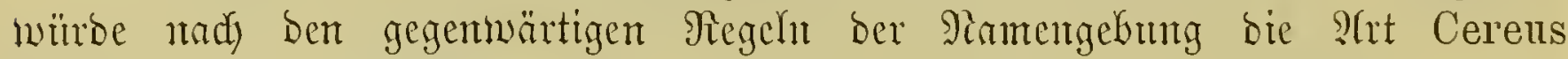
speciosus heifzen mitifien.

Bon C. speciosissimus, bejututet burd C. grandiflorus, ijt eine grutge

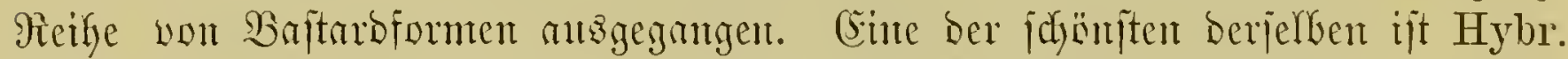
Maynardii. Bon ber Mutterrflanje hat fie bie Mejte uns bie Bhlütenform, nit

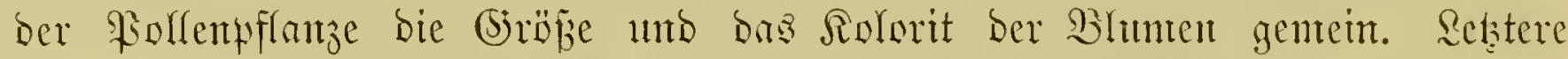

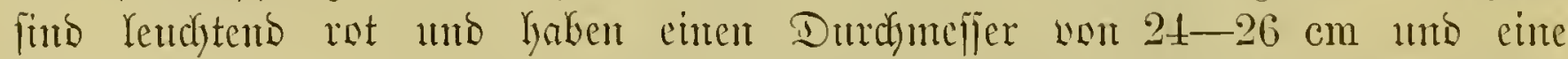

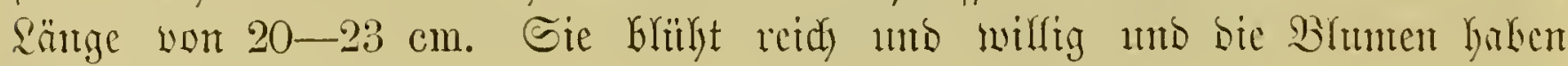
cinc breitügige Dauer.

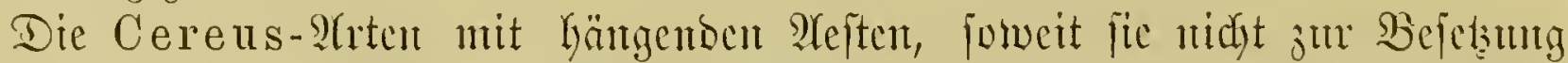

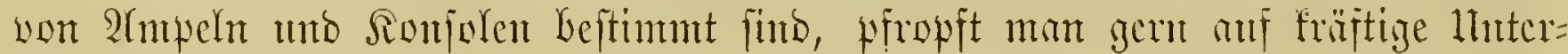

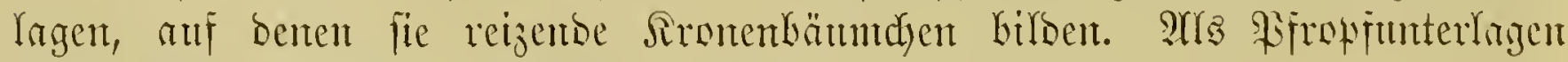
Gaben fidy an bejten bewälyrt Cerens pernambucensis Lem., C. platygonus Hort. berol., C. rostratus Lem. Into C. spinulosus DC., jomic bie fä̈ter Gejonoer ju bejpredyenden Peireskia spathulata Lk. et O. Imb P. subulata Mhlpf.

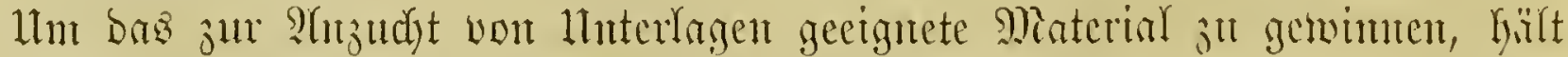

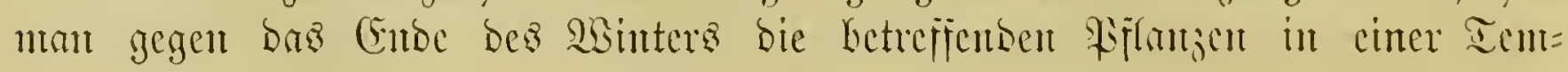


Heratm sou etwa $+12^{0} \mathrm{R}$. Bejpribt man fic ban mo wam bei beiterent

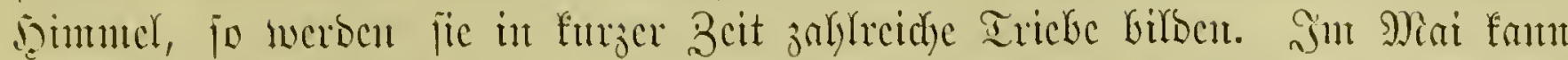

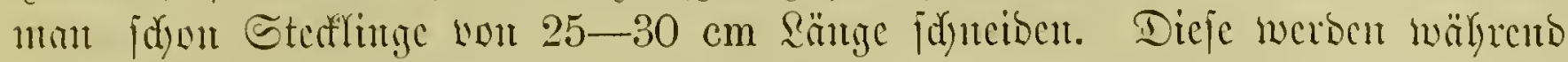
einiger Inge bic Solnuttfläduc ber Sonnc jugefelyet, unter (S)las gelyalten, bis

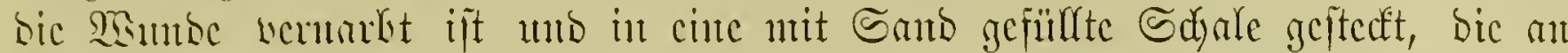

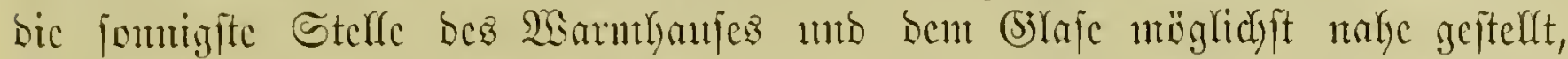

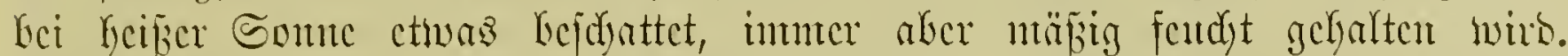

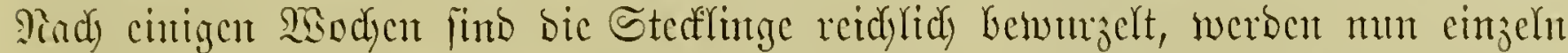

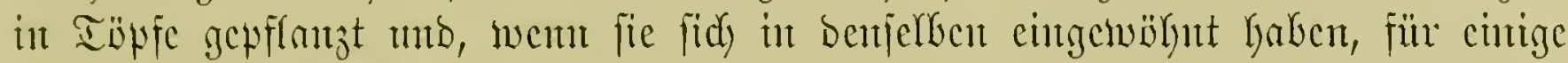

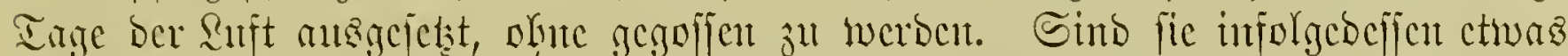

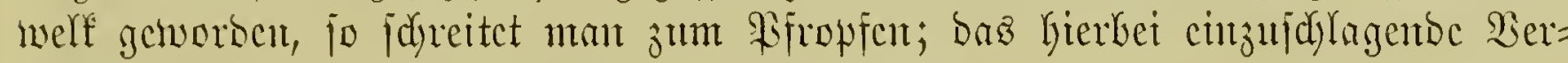
fahren futbet man unter Epiphyllum bejdyrieben.

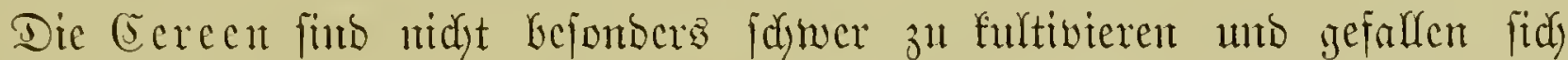

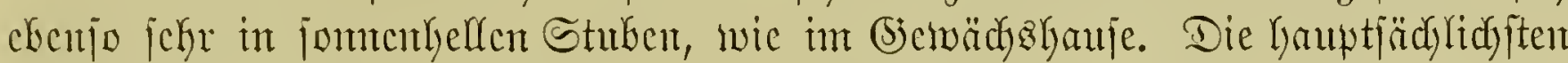

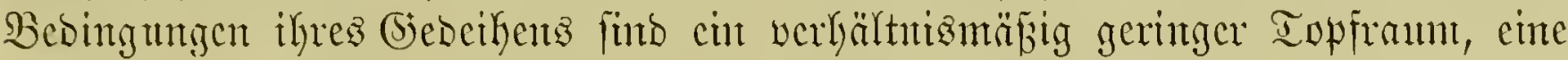

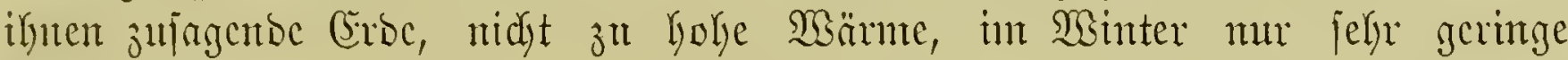

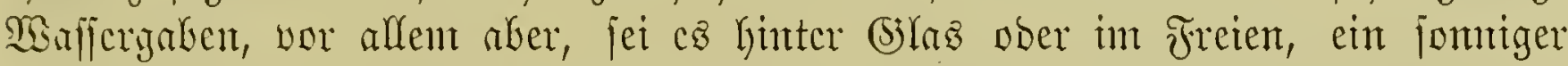

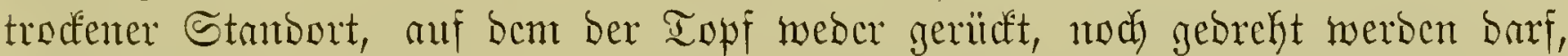
ganz bejonbers bann nidht, wenn bic Blütenfinojpen in ber (Entwidfelumg id)on weit vorgefdritten find.

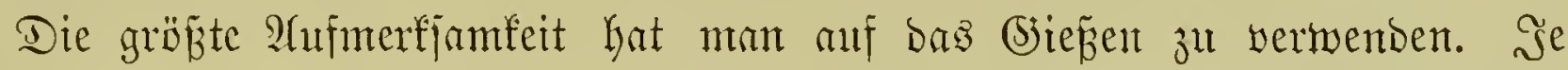
biffitümntiger bie $\mathfrak{A}$ rten und je ntebriger bie Iemperatur, in weldyer fie im Sinter gelyalten werben, Defto jeltener und weniger barf man giçen. Fecids=

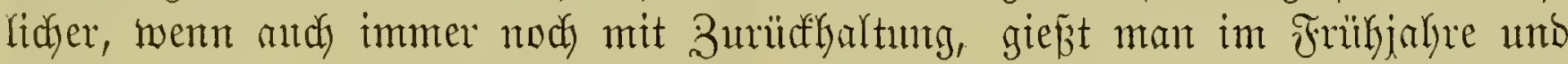
im Sommer. Sit jebem Fafle aber hat man bie Bentebung bes Strmmes ju vermetion.

Die meiften Arten, wie and bcren Baftarbformen, nelymen im SBinter mit

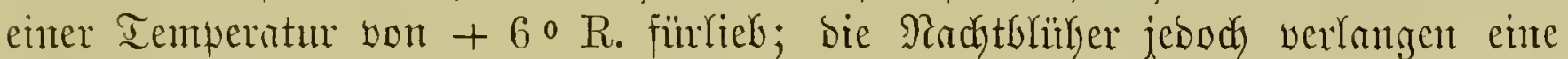
Foldye vou $+8-12^{\circ} \mathrm{R}$. Dieje find $\mathrm{cB}$ aud, socldye in einem falten und

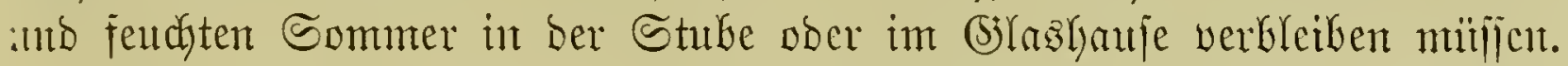

arfe Sereen werben ben (S)laje möglidyit nalye anfgeftell, von Sunt aber bis zum Septentber im Freien, an einter fonnigen Stclle, an weldyer fic gegen

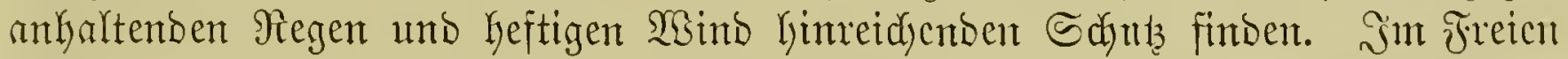

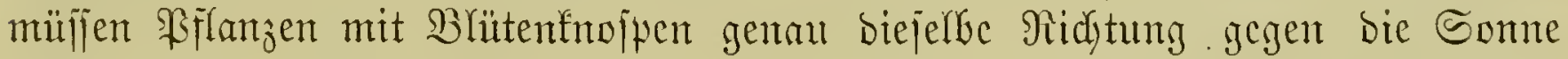
erhalten, wie worker.

Das ben (Sereen gebeiblidyjte (Srbrcid) ift eine Ycidyte, Malyrbaftc Damm= erbe, mit bem fünften Ieile Sanbes gentiddt. 2reltercu Fiflanzen gebe man

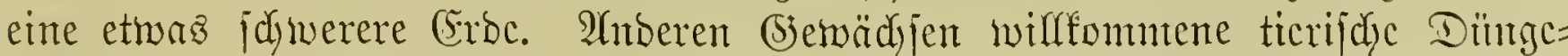

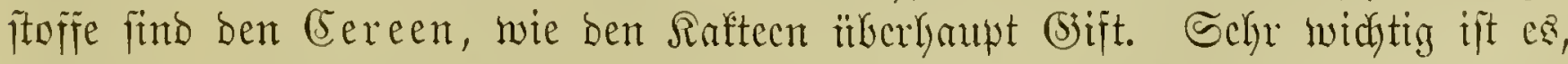

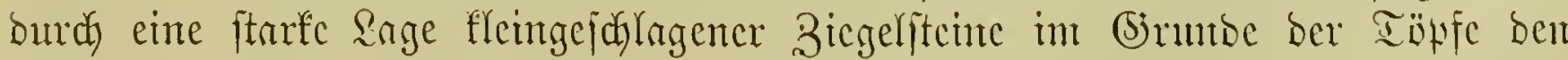
\$anjerabzug zu beförbern.

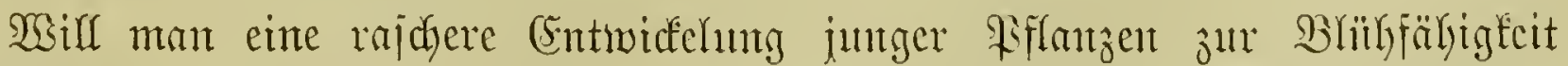
Gerbeifülyren, jo pflamze man jic int Junt an chuc warme, jomtige Stclle bes

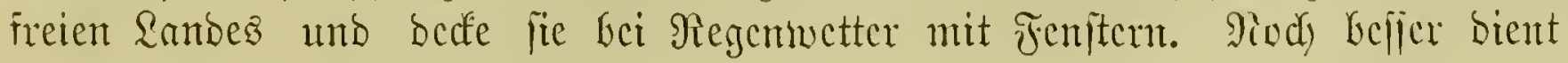




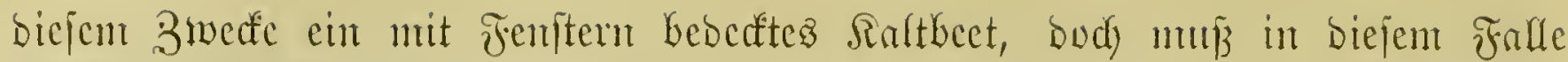
ftets für reidjliche Rüfturg gejorgt werben. Sn ben erften Tagen bes Eeptember

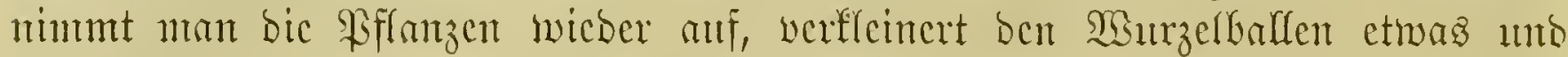

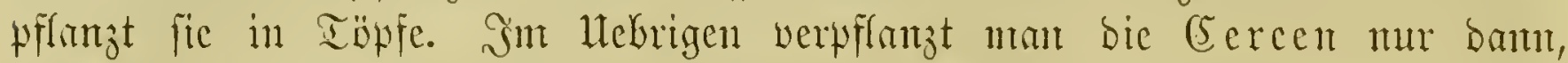

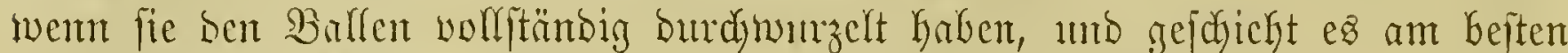

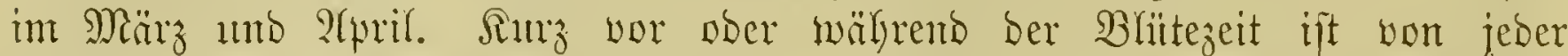

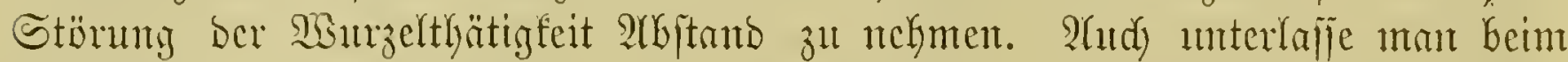

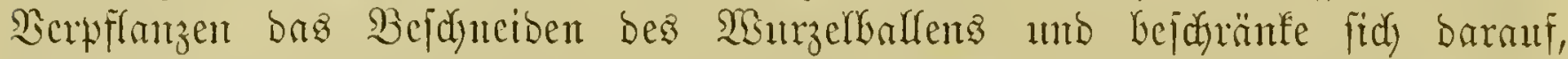

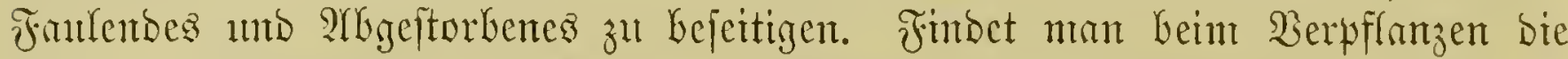

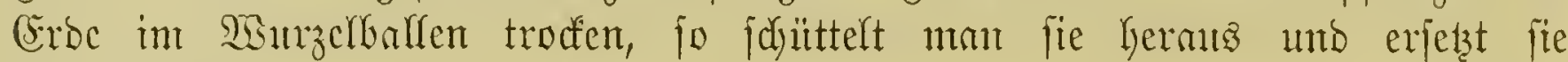
Dutrdy frifdyc.

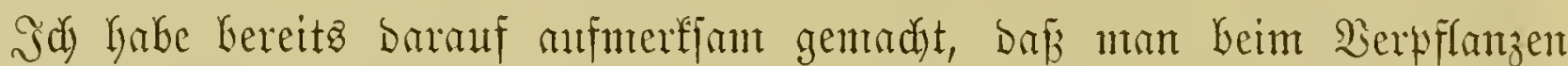

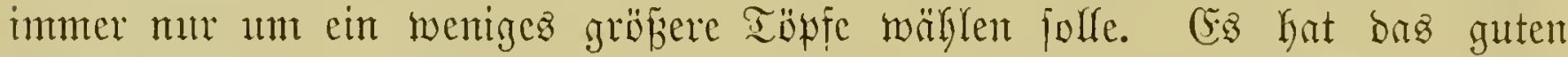

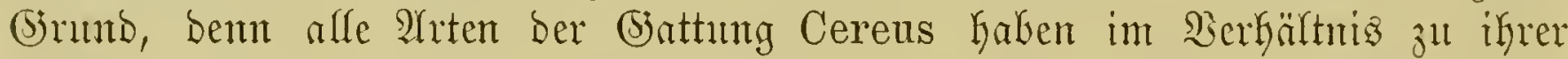

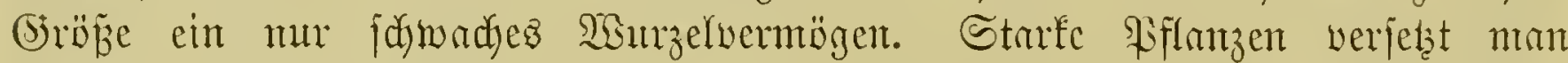

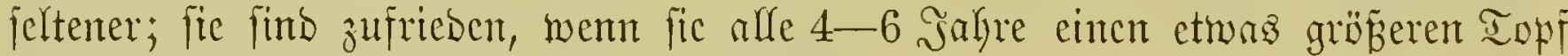
erfalten, unb blülyen bann um fo banfbarer.

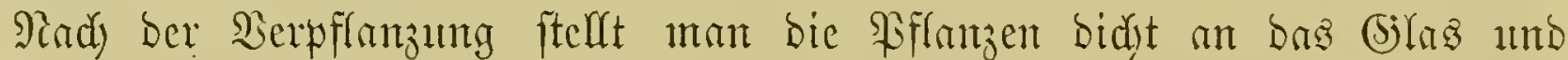

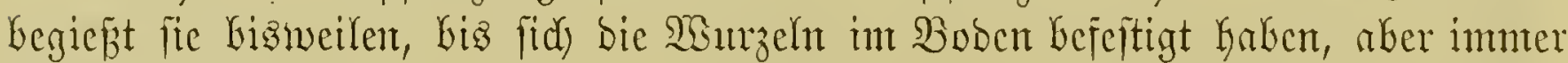
fchr mäßjig, gatz bejonbers in bem Falfe, wem bie \$fflanjen aus bem freien Ranbe wieber in Töpfe gefummen finto.

Bur Entwolfelung eines frithen ant reidyen Flors bient ca, wem bie

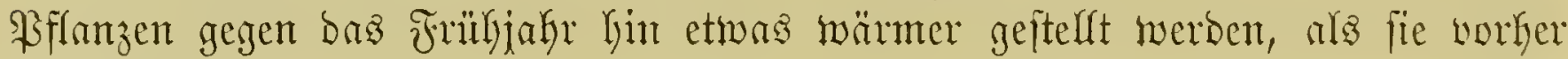
geituniocr.

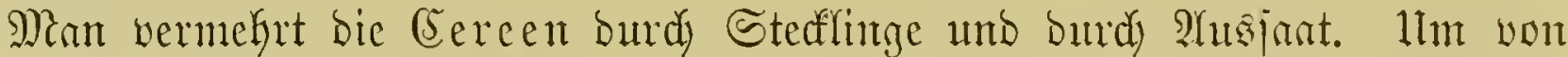

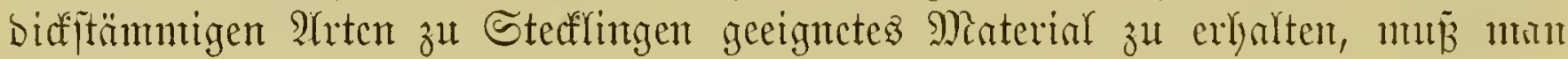

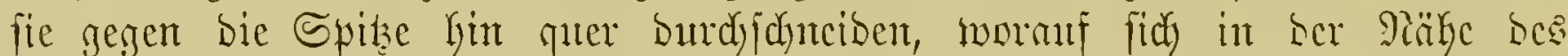

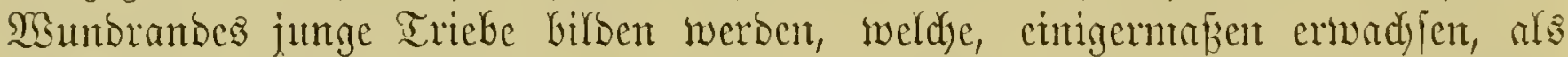

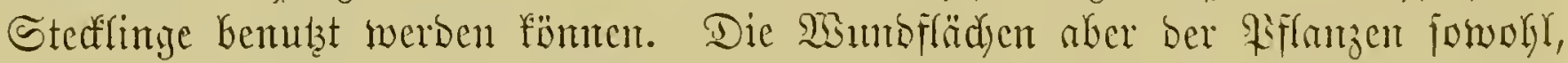

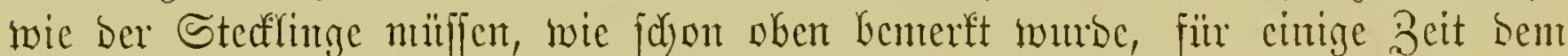

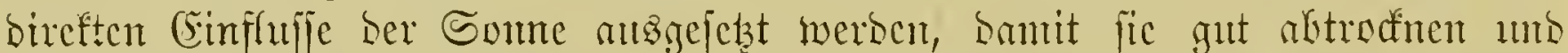

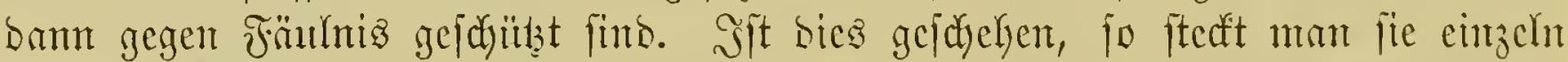

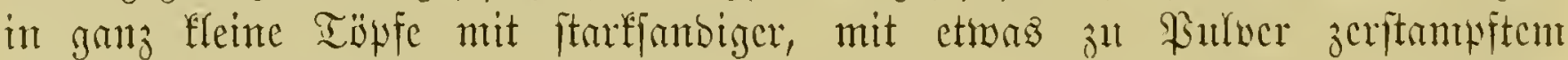

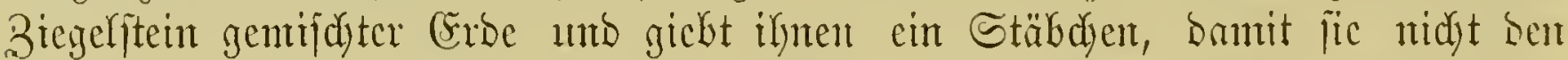

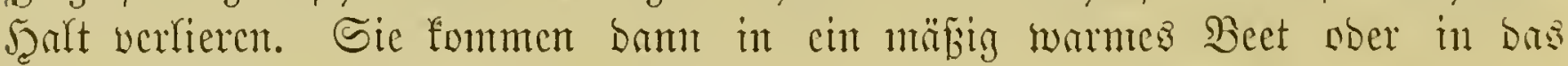

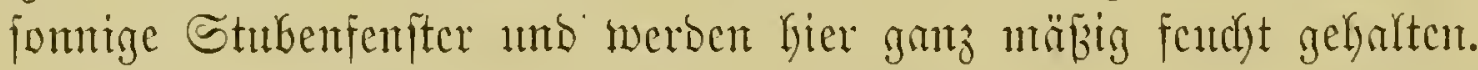

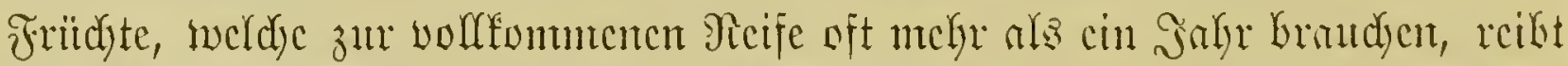

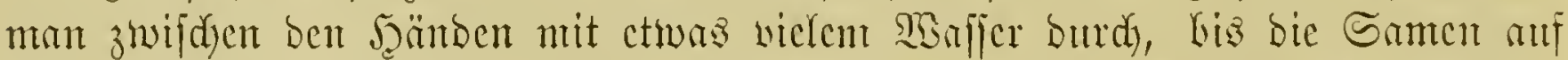

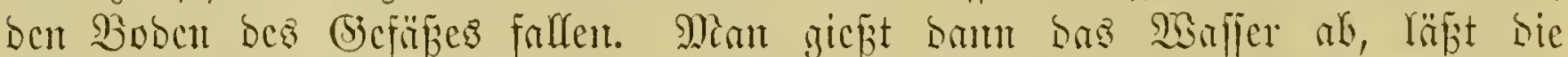

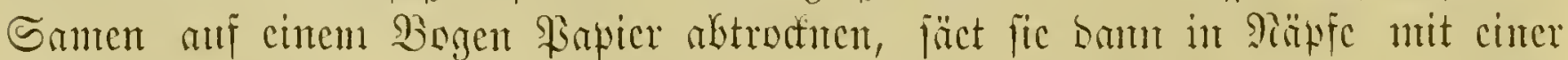

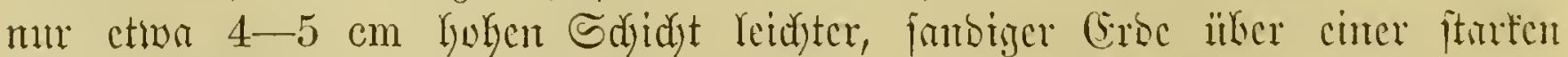

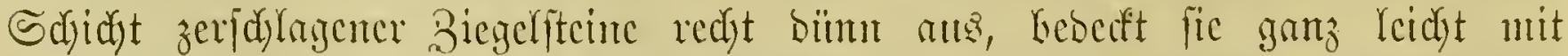

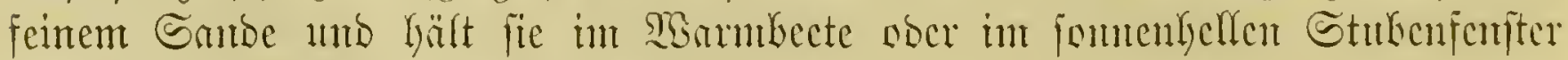

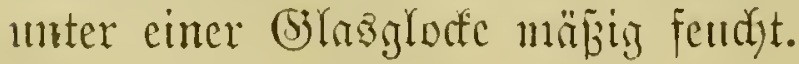




\section{2. (jattung Echinocereus Engelm. כgelfadellaltus.}

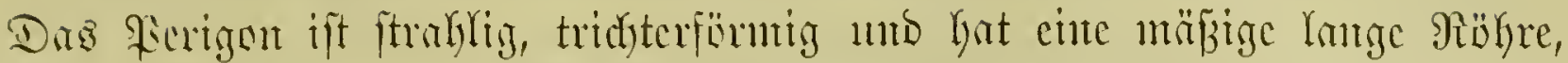

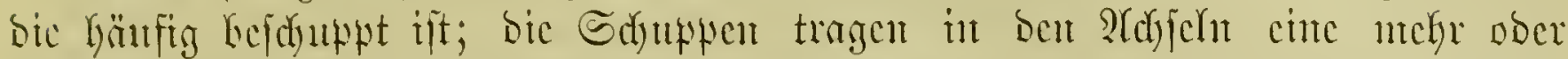

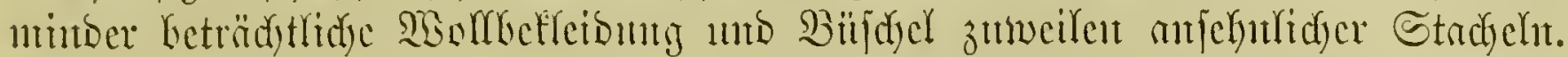

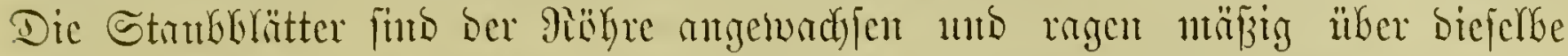

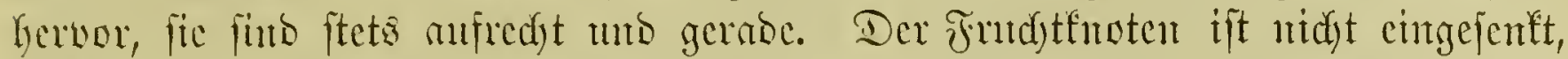

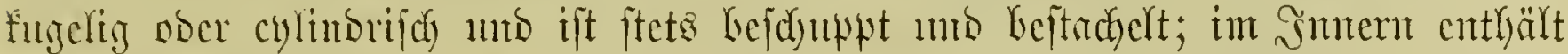

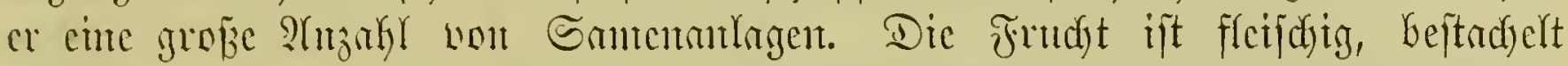

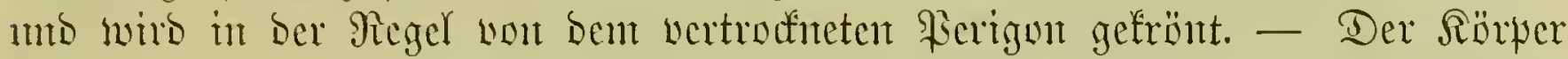

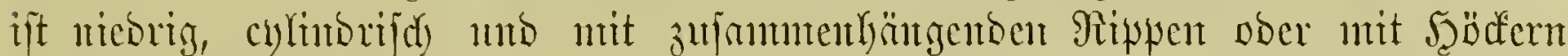

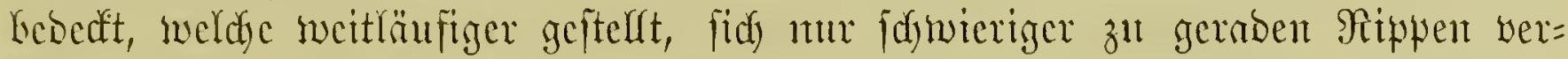

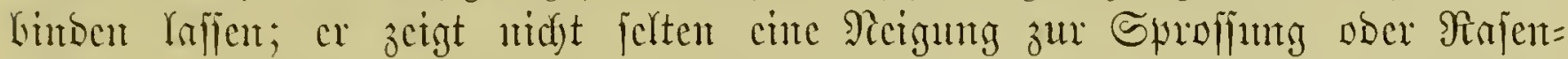

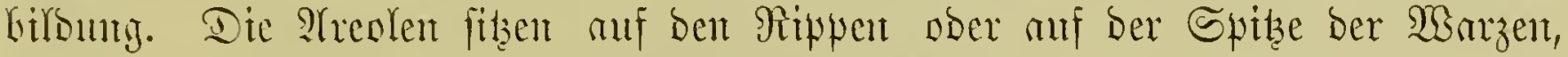

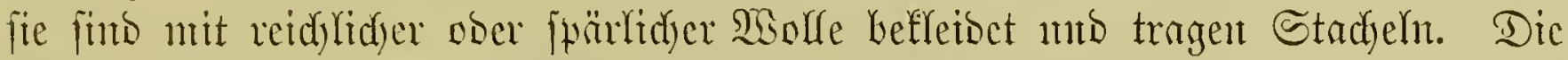

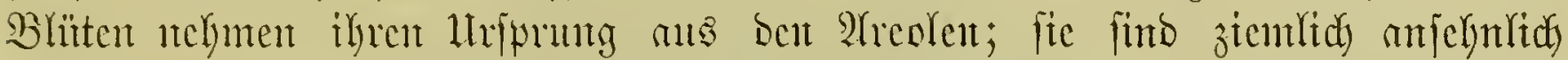

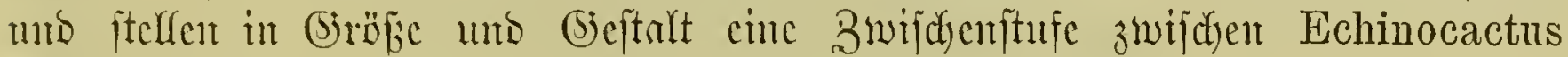
unto Cereus bar.

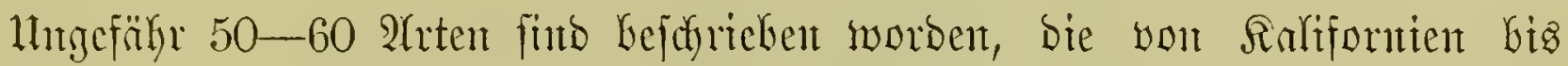
Mexifo gebeifen. Sie wadjen bout anf fanbigem umb felfigem Boben.

Der Rante ijt aus činos (Sgel) unb Ce reus zujammengejebt.

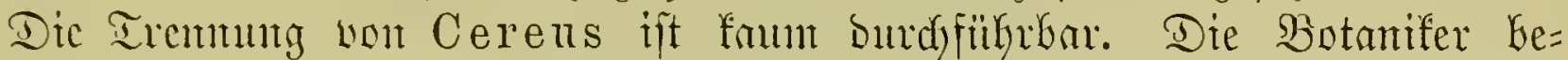
tradjten, Gejonbers madjoem fid) aud (5itgelmann, weldyer bie (biattung auf=

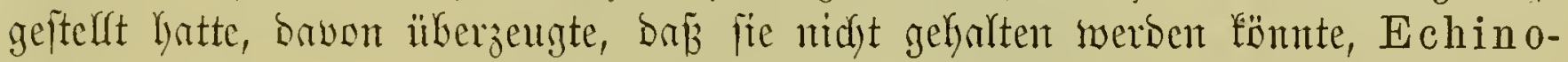
cereus un fül einte Section von Cereus.

\section{S丸lülfel für die befhriebenen Zrten.}

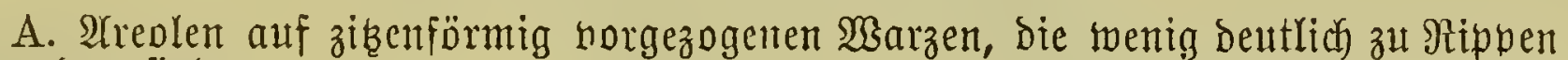
verbutben find.

a) S马ödferreilen $4-5$

b) ŞD̈̈ferreilyen $S-10$.

1. Peilhe Pentalophi S.-D.

a) Randitacheln 10, Mittelitacheln 2; Stachelpoliter nadet

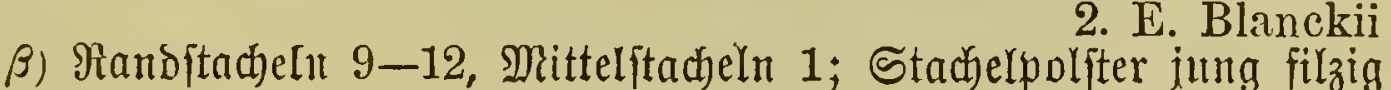

3. E. tuberosus Poselg.

B. 2Yreolent auf Deutlidyen Rippen.

a) $\mathfrak{U}$ reolen bou einamber abftehend

II. Aeifye Decalophi S.-D.

a) Rörper furz, faum doppelt fo lang als breit, lugelig oder eiförmig.

I. Stadjelu fehr furz, faum fidjtbar

II. Stadjelit lang.

4. E. subinermis Eng.

1. Siörper einfach oder mäßig fprofient, alle Stacheln fräftig, am (Srunde zmiebelig berbidt

5. E. Fendleri Eng.

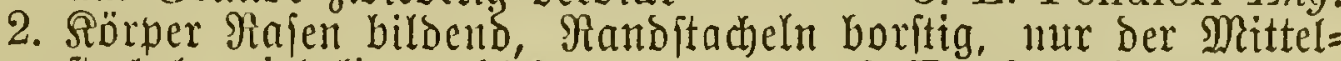
ftachel zriebelig verbiat

6. E. phoeniceus Eng.

(3) S̊̈̈rper verlängert, unten chlindrif h, oben fantig.

I. SRattiftacheln 5-7, syittelftacheln 0 , alfe bald abfallent

II. Randftacheln 8-13, Mittelitacheln 1-4, lä̈t. paucispin bleibend.

Heispinosus Eng.

1. Wudje rajenartig, Sërper uitht jiber $15 \mathrm{~cm}$ lang

2. Sörper einzeln ober ant Sornde mit wentian, fürzerent હproffen, itber $20 \mathrm{~cm}$ lang. 
* Mittelifachel 1, Sianditacheln 7-12, weiń, 20-25 mm lantg. * Mittelitacheln 4

9. E. enneacanthus Eng.

$\Delta$ Sippen 10; Randitacheln 8-10, 12-22 mm lang

$\Delta \Delta$ Nippen 11-13; Siandftadheln $13,5-13 \mathrm{~mm}$ lang

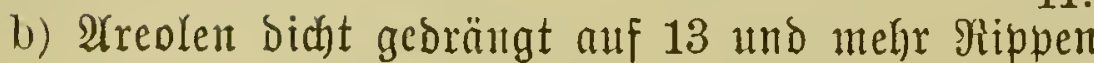

11. E. Engelmannii Parry.

III. Reihe Pectinati S.-D.

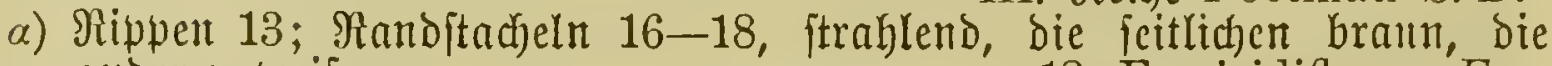
anderen tweí

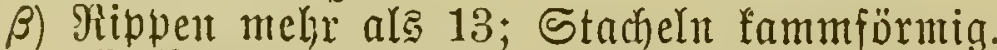

I. Randftachelıt 20-30, weís, zumeilent rojenrot.

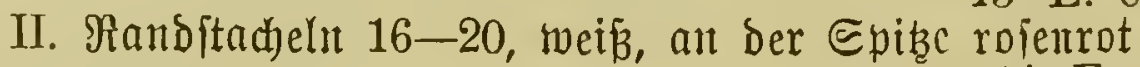

12. E. viridiflorus Eng.

13 E. caespitosus Eng.

14. E. pectinatus Eng.

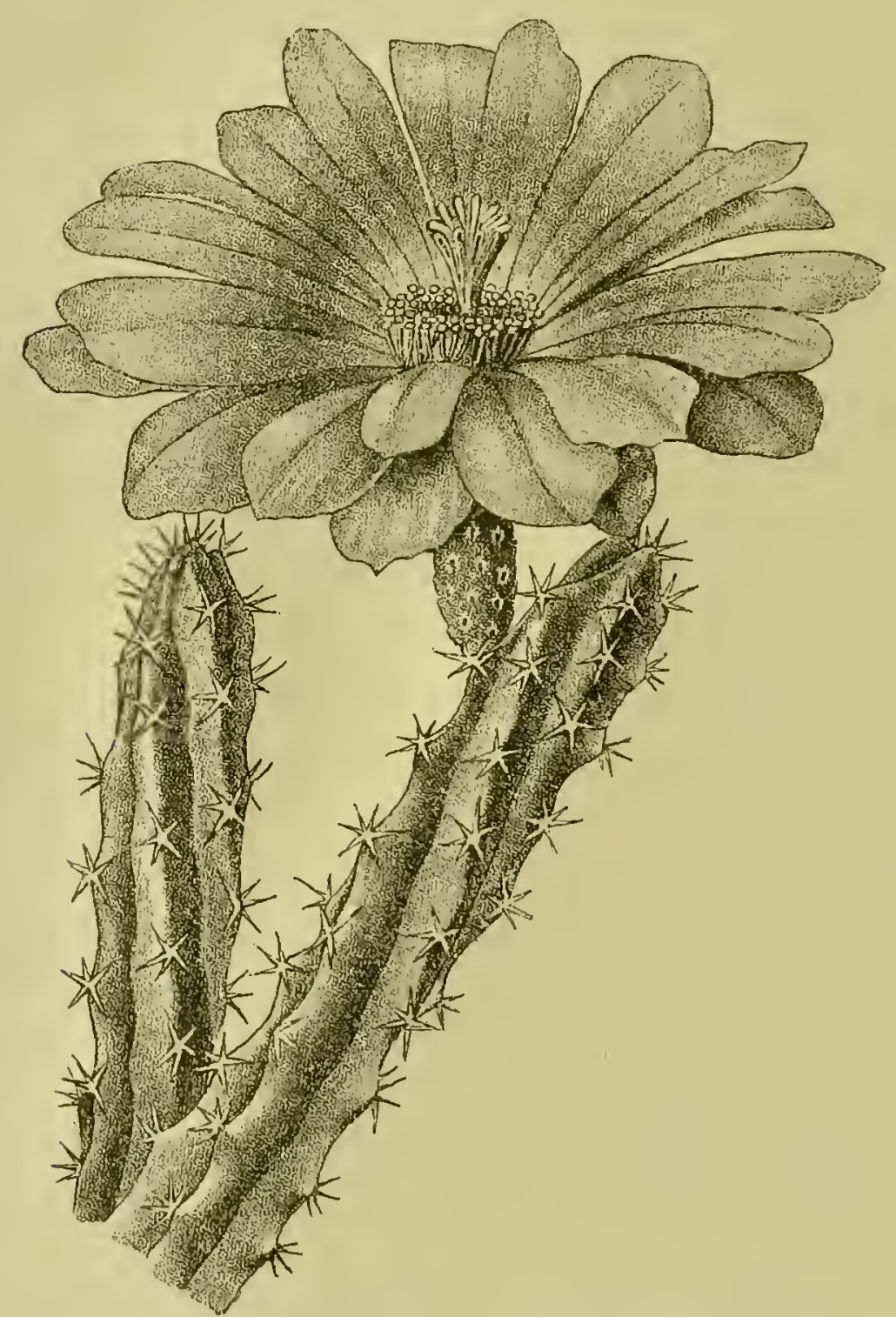

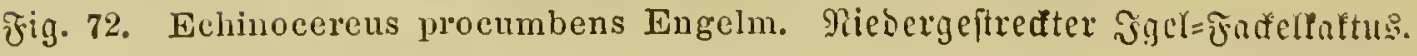

\section{Echinocereus procumbens Engelm. Micbergeitrefter $\mathfrak{J g e l}=$ Fanfelfaftus.}

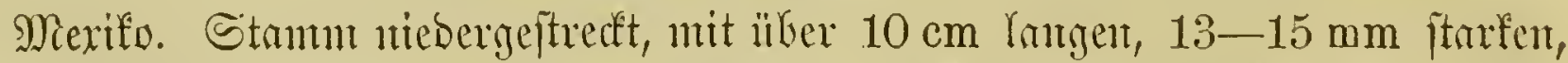

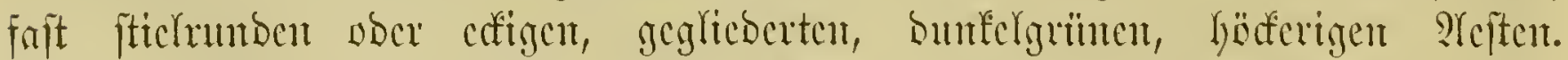

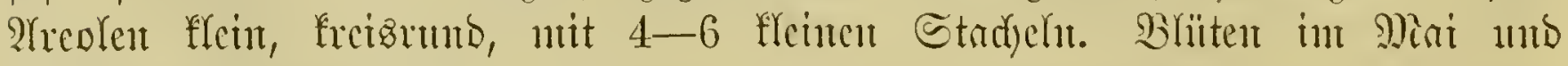

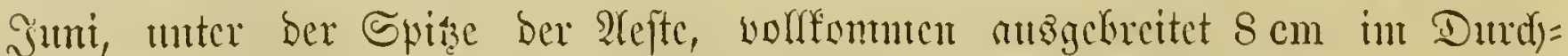

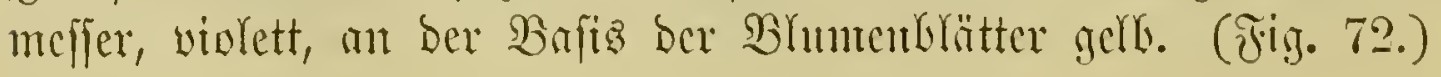




\section{Echinocerens Blanckii Pos. Blaut' Tgel=Farfelfnftus.}

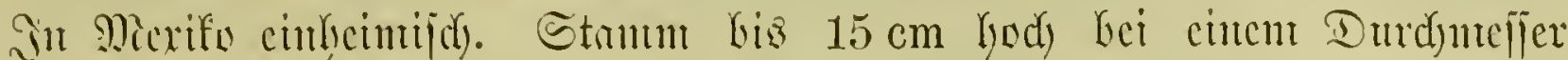

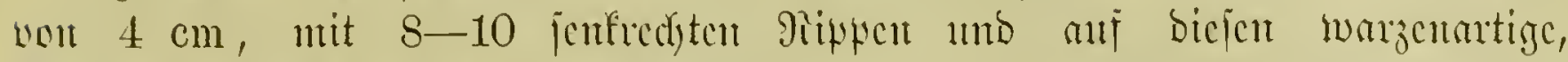

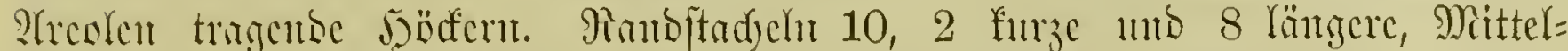

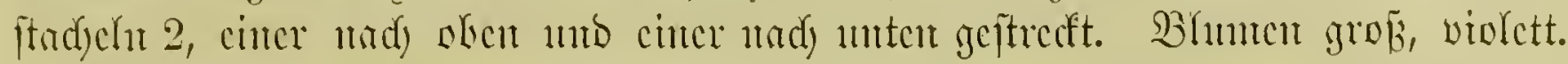

\section{Echinocereus tuberosus Pos. Futflenwtracliger $\mathfrak{I g} \mathfrak{c}=$} Finfelfiftutz.

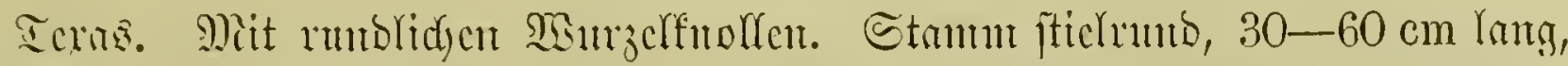

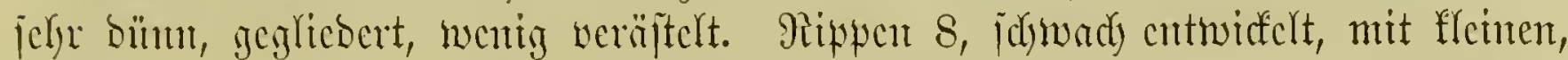

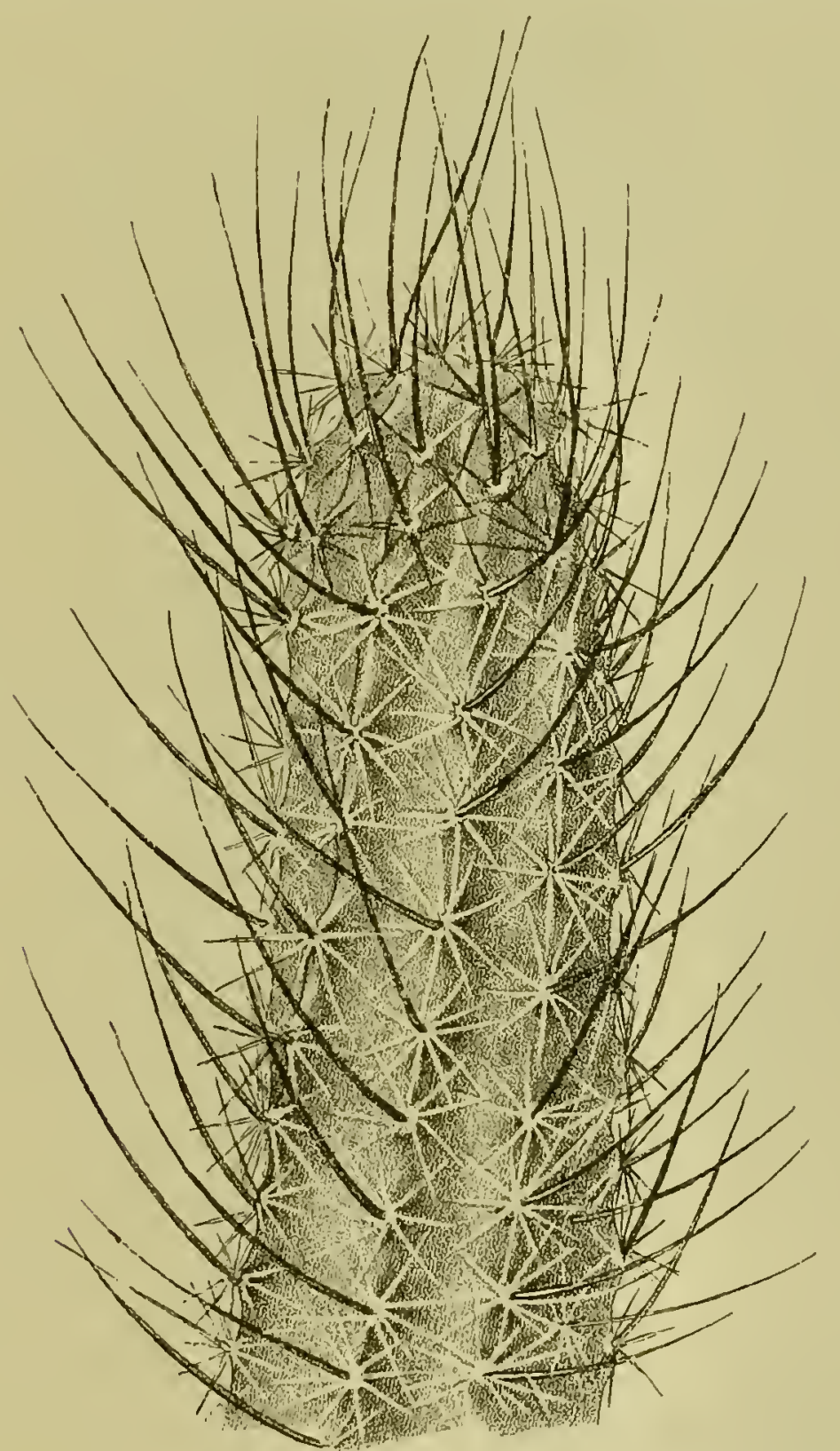

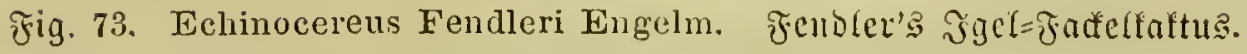

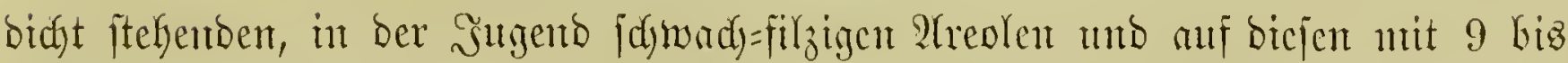

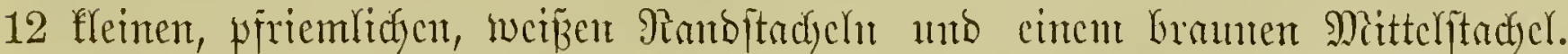

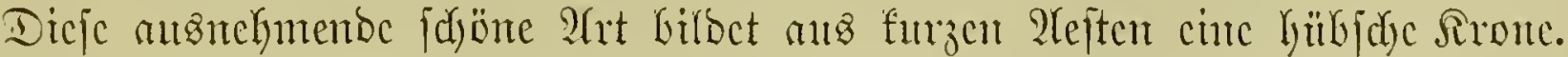

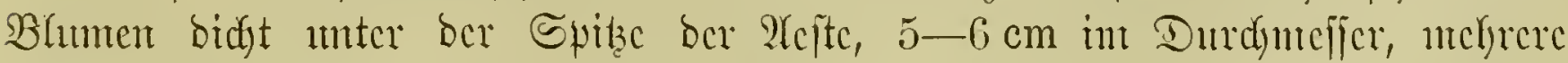

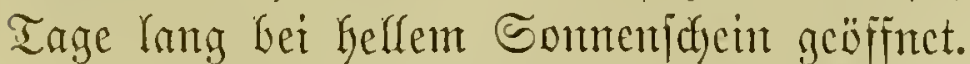

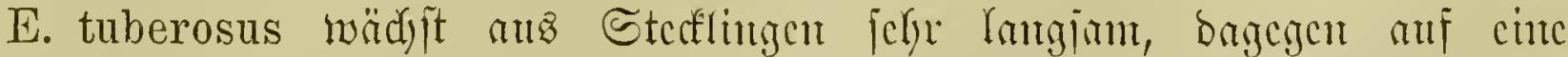

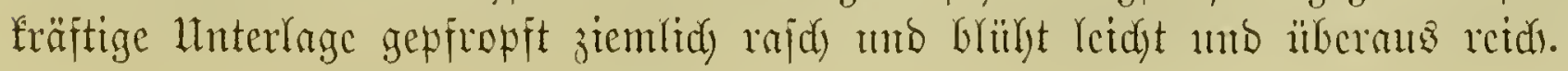




\section{Echinocereus subinerm is Engelm. Fait itadiffojer Jgel=} Farfelfaftuz.

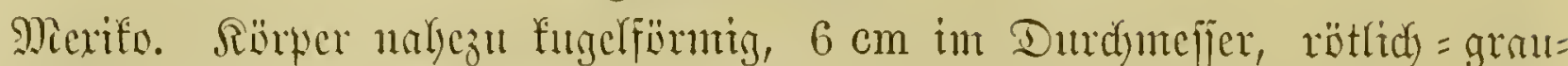

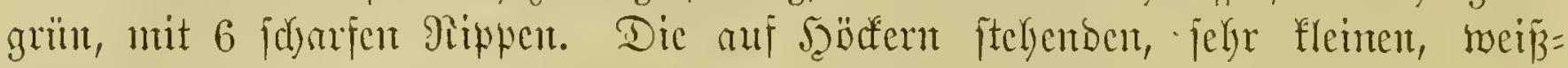

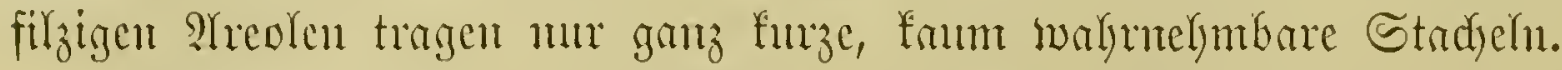

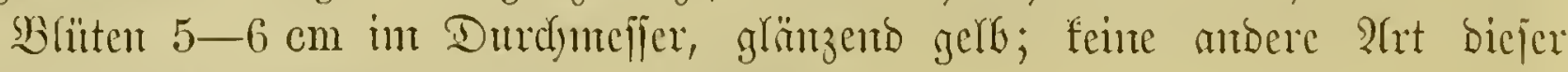

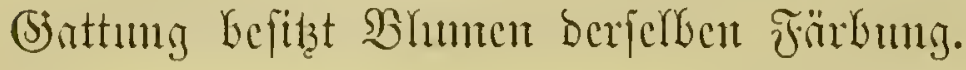

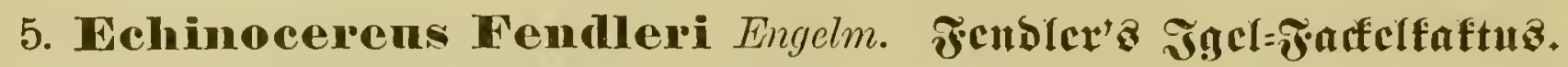

Ths Pien=Micrifo cingcrüfyrt. Stanm meift cinfady, ciförmig, $10-20 \mathrm{~cm}$

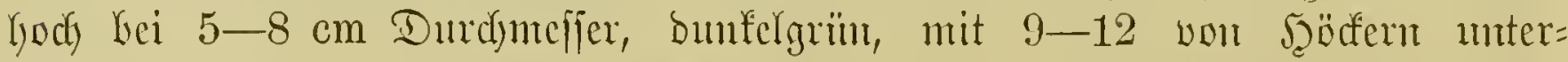

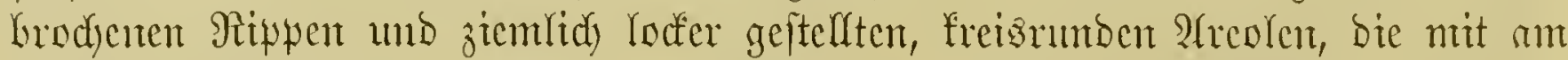

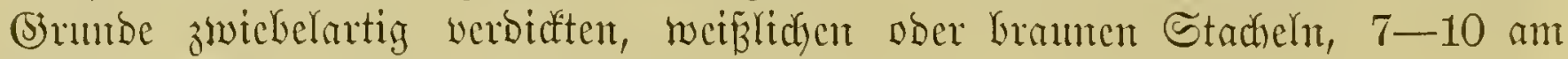

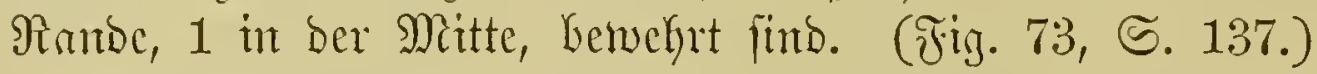

Błhunten bidyt am Sdyeitel, bis $9 \mathrm{~cm}$ brcit, purpumot.

\section{Echinocereus phoenicens Engelm. Burpur= Jgel=\{adfelfaftuz.}

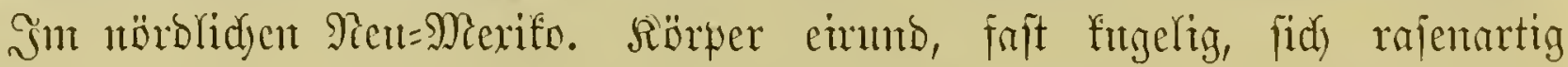

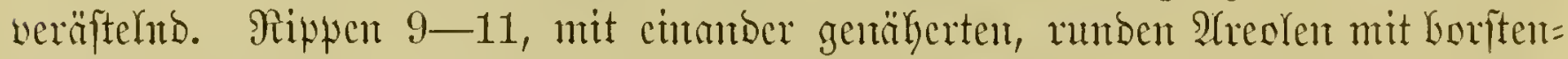

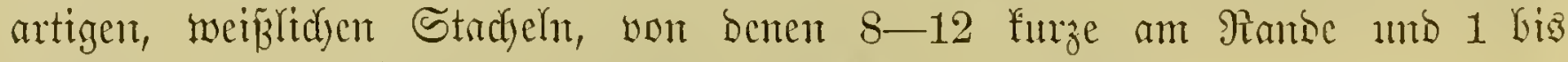
3 Yängere, an ber Bafis znvebelartig verbiffte in ber Mitte.

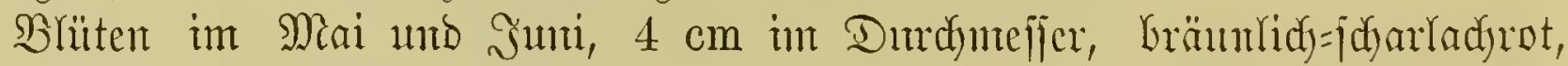

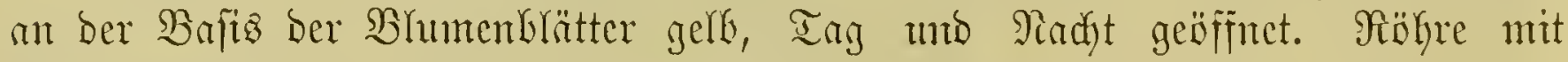

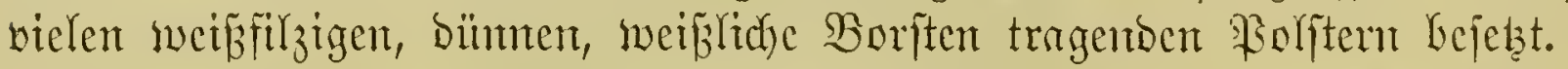

\section{Echimocerens pancispinus Engelm. P(vurtad)eliger $\mathfrak{g g c l}=$ Fathelfaftus.}

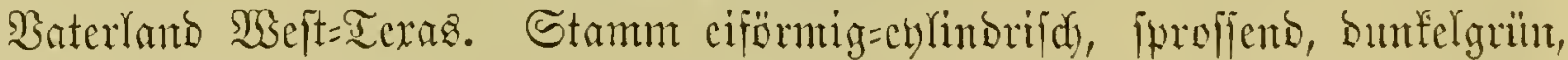

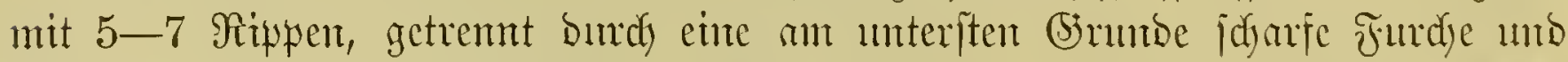
mit meitlänfig geitelften $\mathfrak{H}$ reolen. Dieje tragen $6-8$ am Girmbe verbicfte,

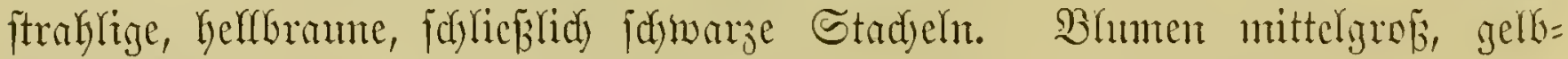

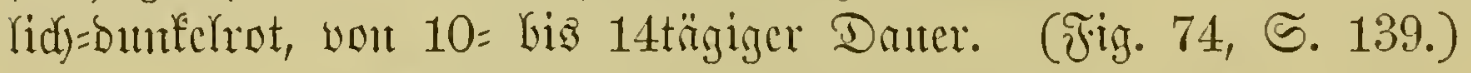

\section{Echinocerens Salm-Dyckianus Scheer.}

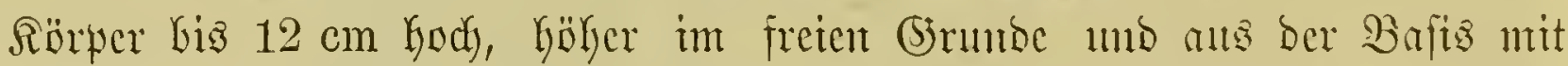

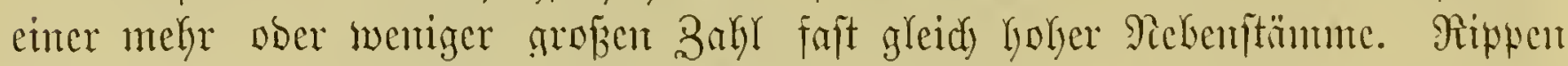

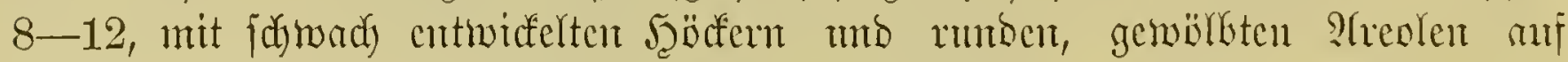

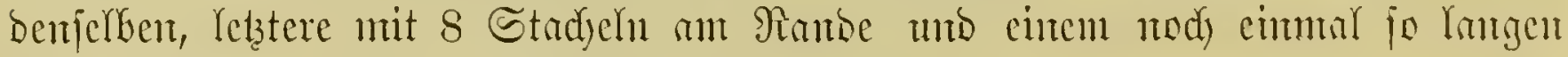
in ber Mritt. SBłïten muknuibenfarbig.

\section{Echinocereus enneacanthus Engelm. Mcutitadichiger $\mathfrak{s g c l}=$ Fantelfaftuz.}

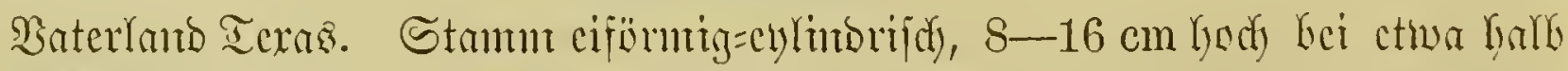

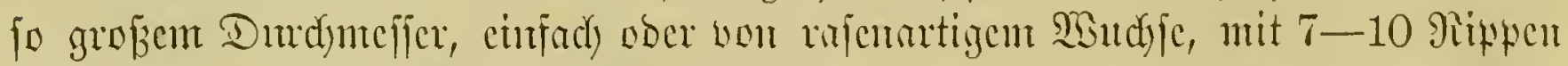
unto freigrunben SYreolen mit meift $S$ Stadyehn, bie unt cinen Yängeren in ber Mitte

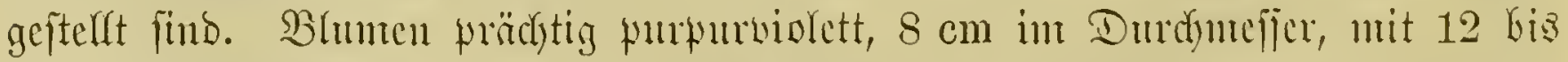

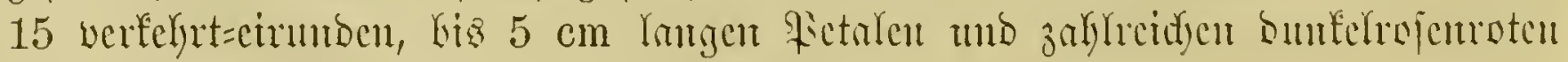

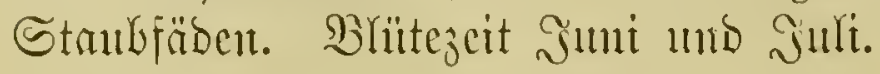




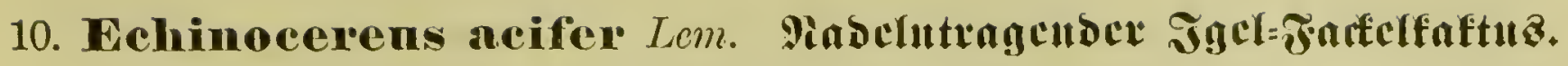

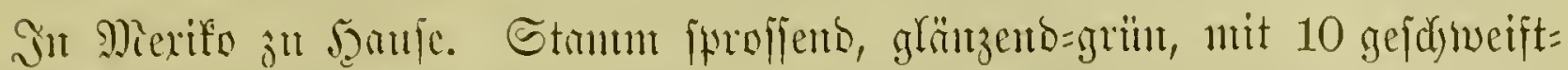

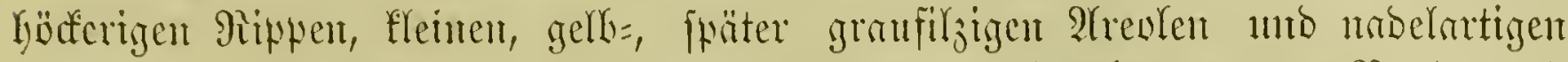

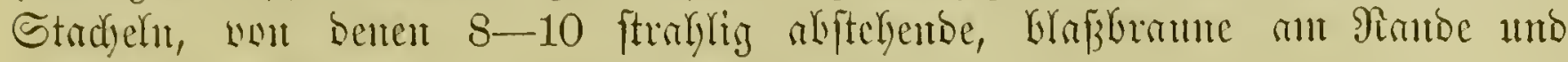
4 ftärfere, funturbramte, $4 \mathrm{~cm}$ lantge in bor Mitte.

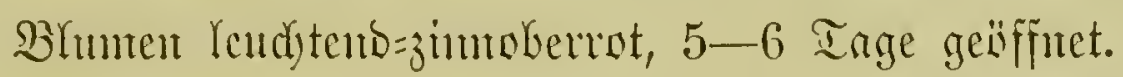

Var. E. durangensis Poselg. Gefiłzt orange=f(d)arfadjute Bhluntut.

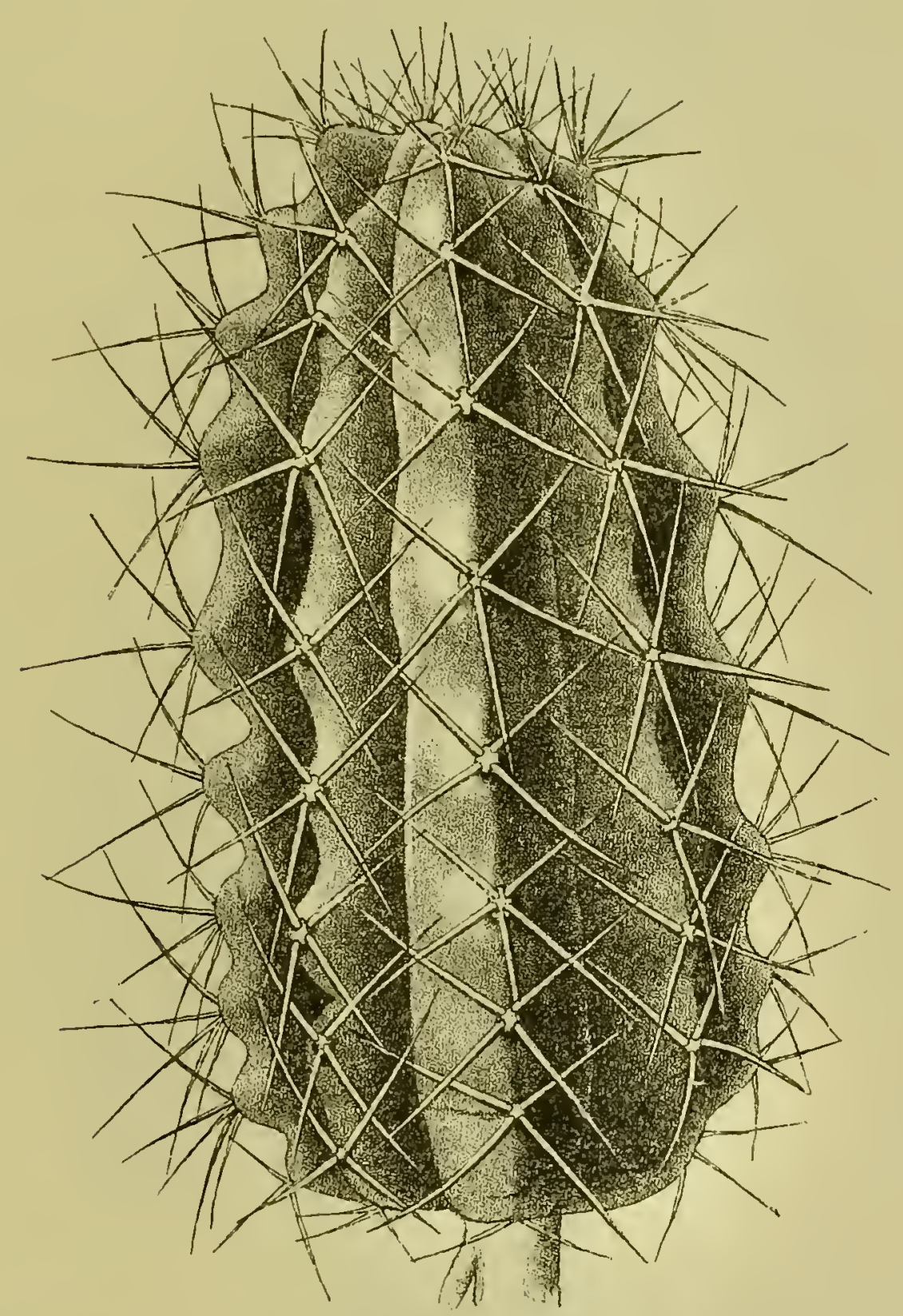

Fig. 74. Echinocereus paucispinus Engelm. Armitadeliger Igel=Fradelfaltus.

\section{Echinocerens Engelmannii Parry.}

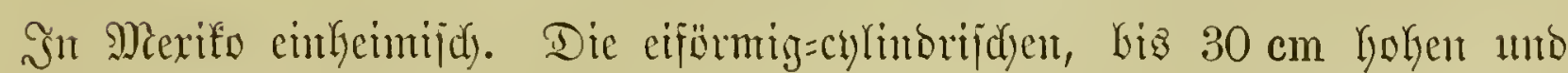

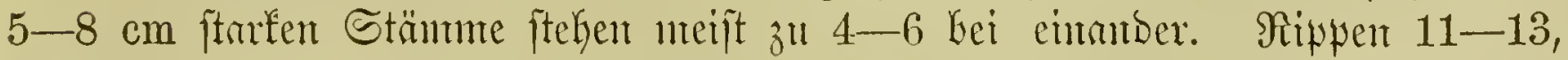

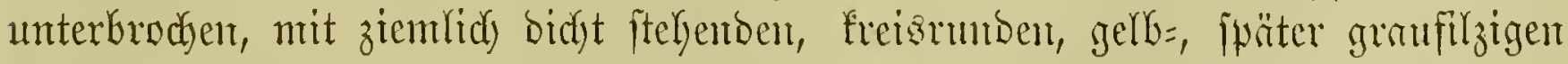

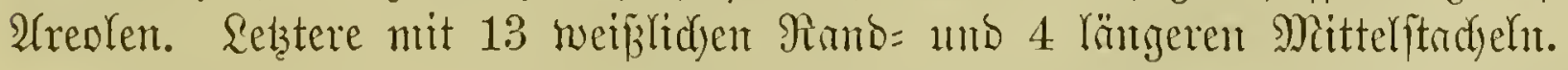

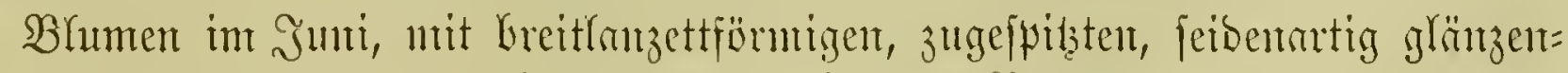
ben, purpurroten, nady bem Grumbe Gramuioletten Setalen. 
12. Echimocereus viridiflorss Engelm. Grünfliibenocr Jgel= Farfelfaftus.

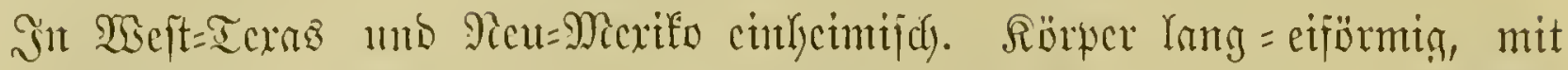

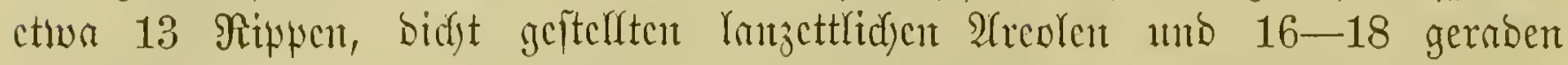

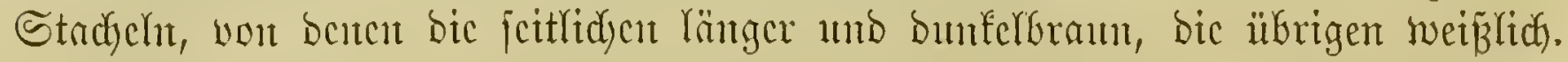

Şlïtcu jeitlidy, $3 \mathrm{~cm}$ im Durdyucjicr, mit 12-15 jmarngogrünen ßetalen. $\mathfrak{B}$ Yïtçzcit im Mai.

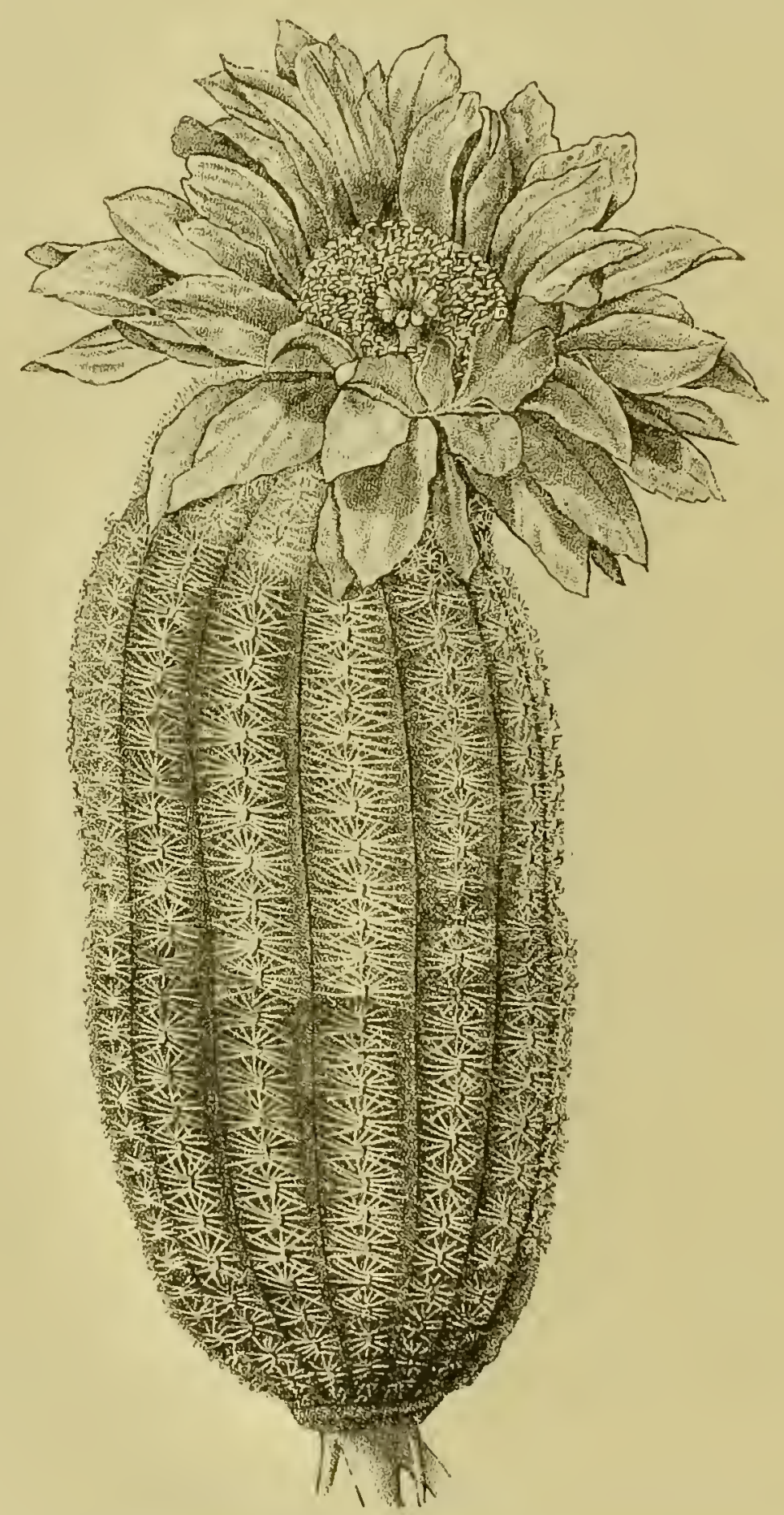

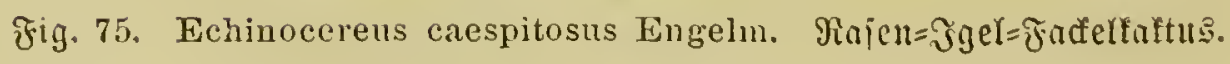

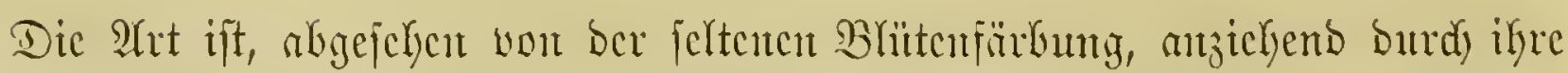

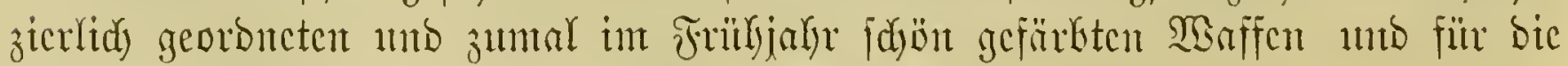
Rultur in Stutben maf bas wö̈mrite ju cmifferlent.

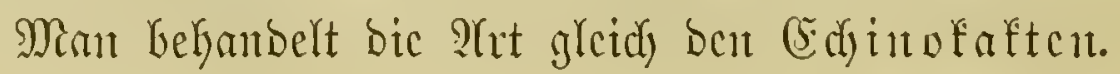


13. Echinocereus caespitosus Engelm. Paicu=:gel=Fanfelfaftuz.

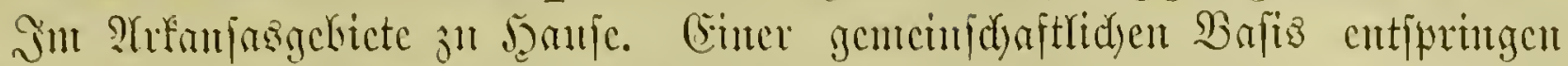
mefrere lang=cifümige, an wheren Tcile fproffente Stänme mit 13 bis

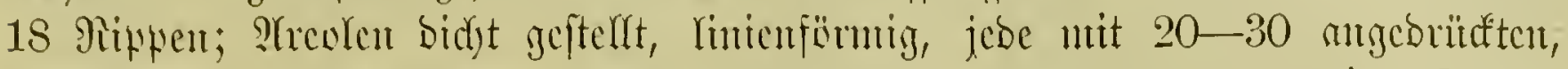

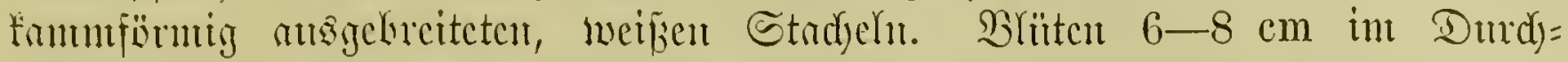

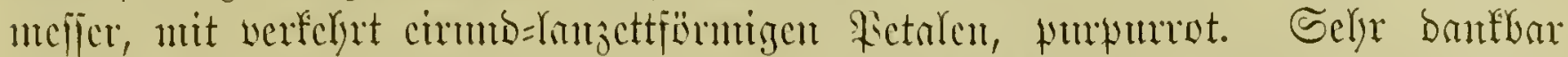

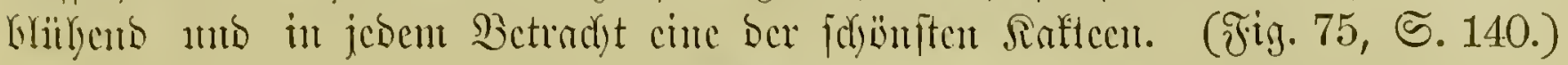

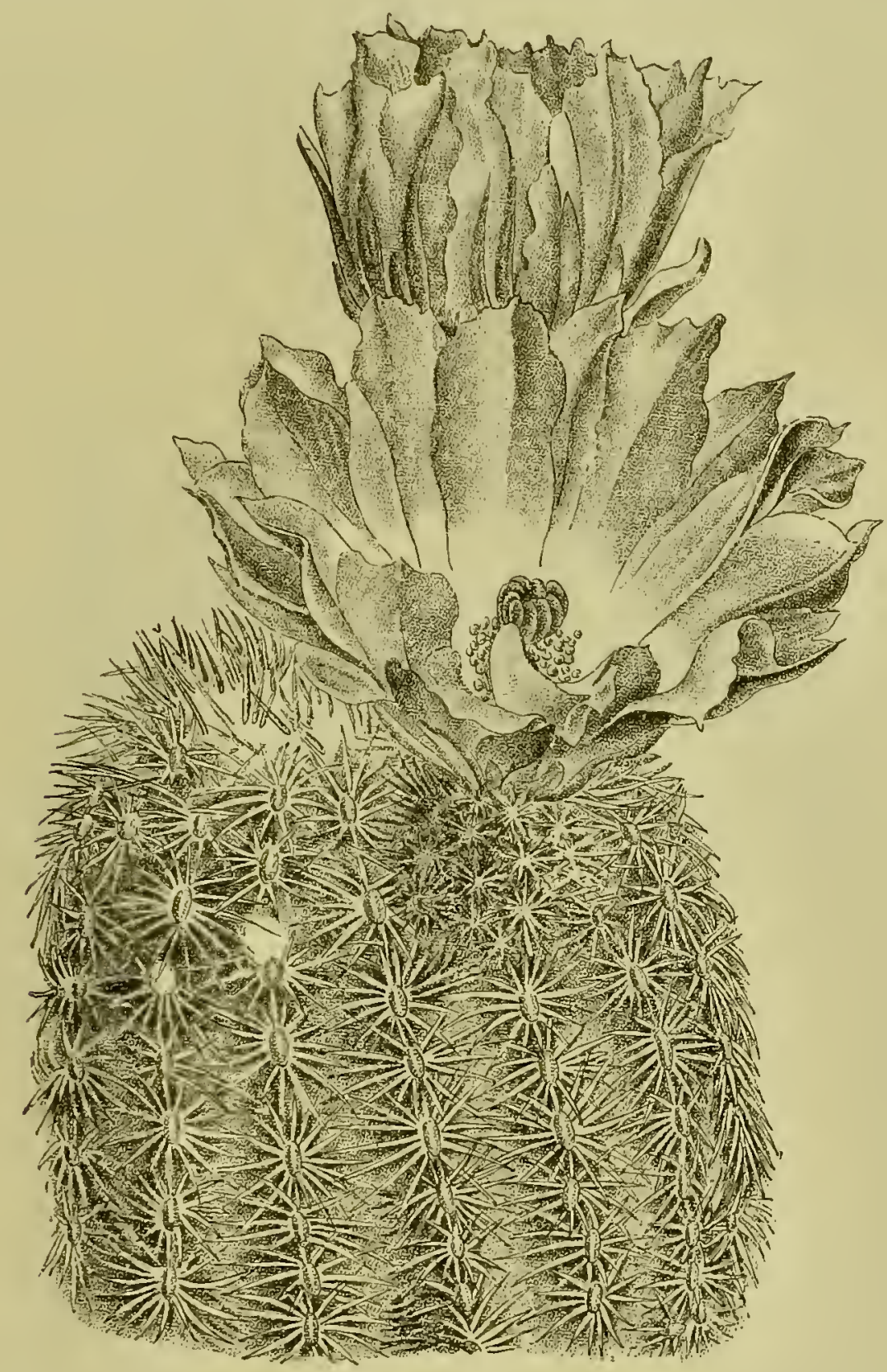

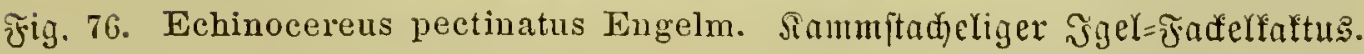

\section{Echimocerens pectimatus Engelm. Sautuitadyeriger $\mathfrak{J g e l}=$ Farfelfaftuz.}

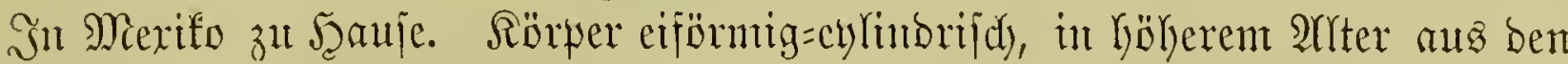

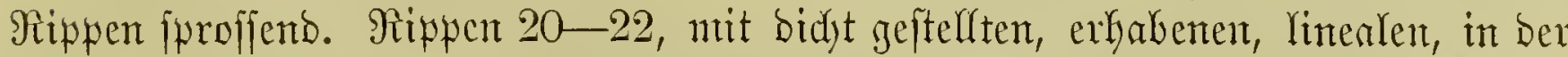

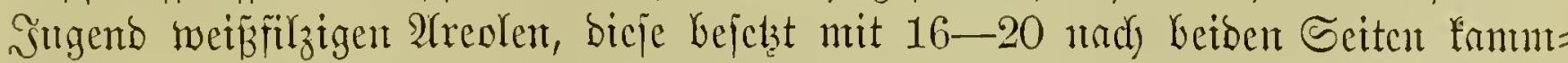

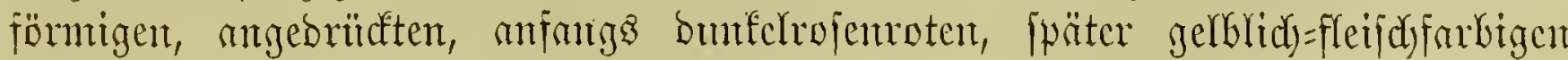
Etadyeln.

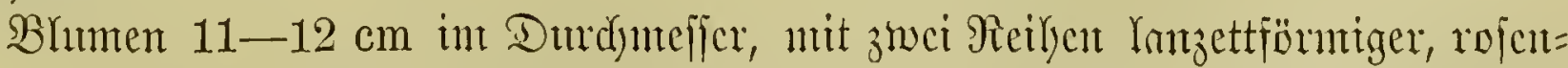

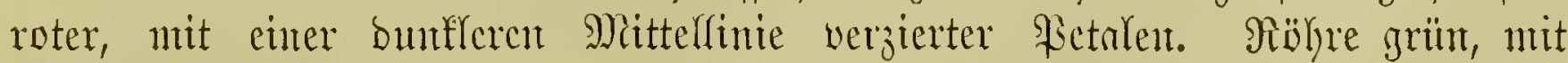
bejtadjelten Şäbefern beję̧t. 
Var. robusta, in alfen Icilen fräftiger cutwiefelt, $10-20 \mathrm{~cm}$ hod unb

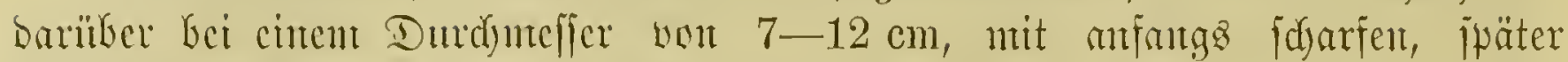

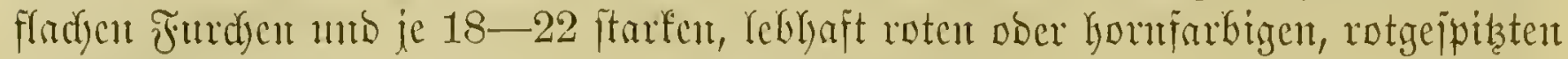

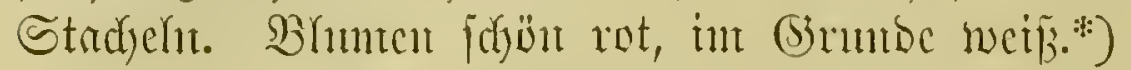

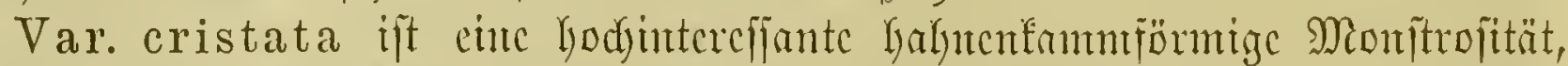

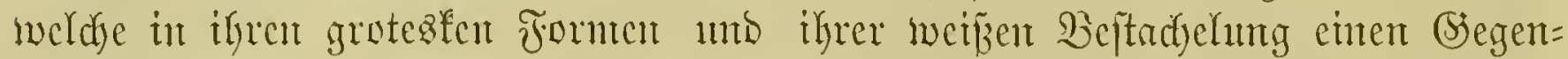

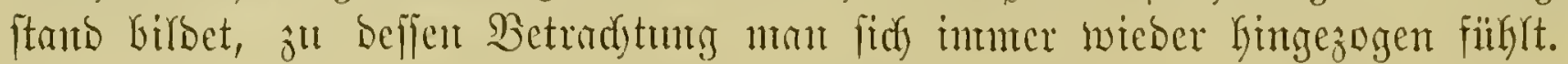

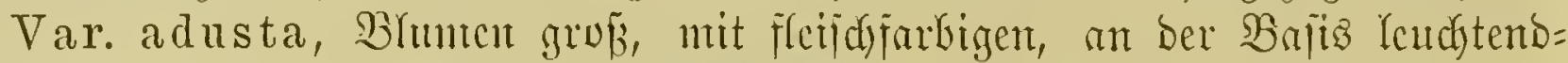

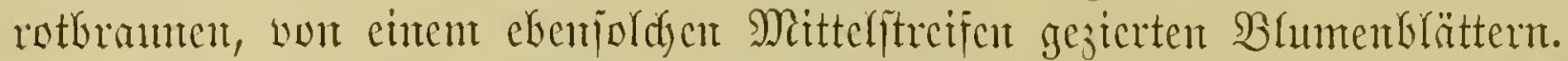

Var. rufispina, B̉lunter gro rojentot mit cintent butflen Mittelitriche.

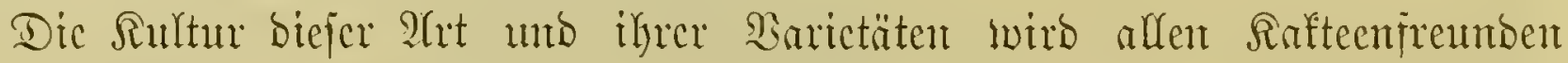
anf bas wärmite cutpfolylcu!

\section{Gattung Pilocereus Lem. Şaarfacfelfattus.}

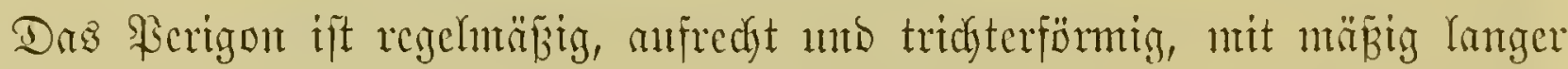

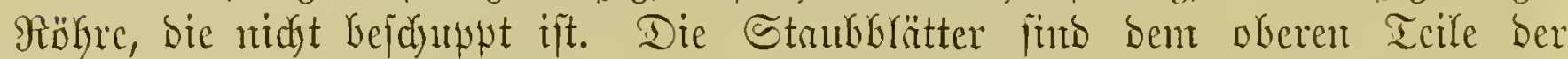

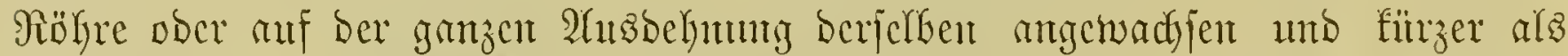

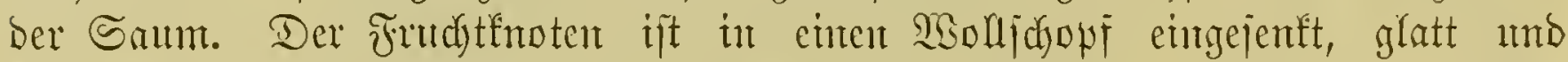

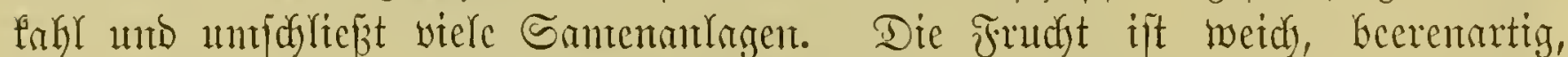
glatt und wirb bon bent vertrochuenoen Siserigon gefiönt, fic ift juerit ein=

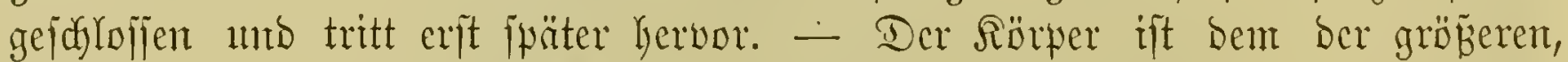

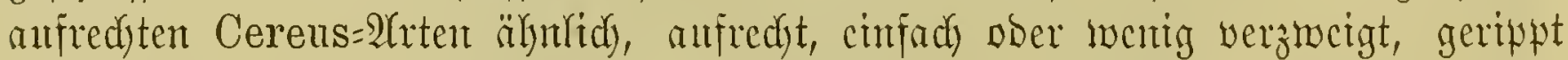
unb trägt an ber Spibe ober an ber Seite cin Sepralintm, bas ans langen

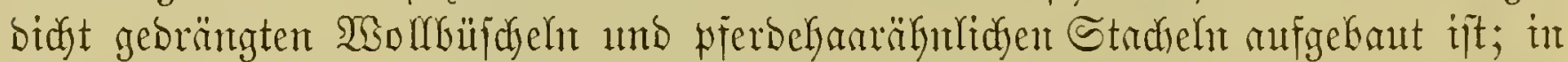

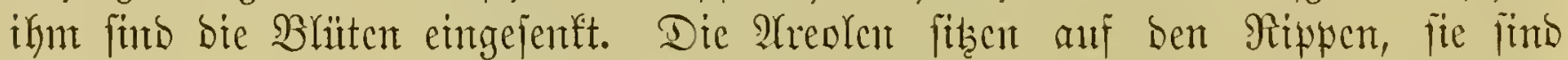

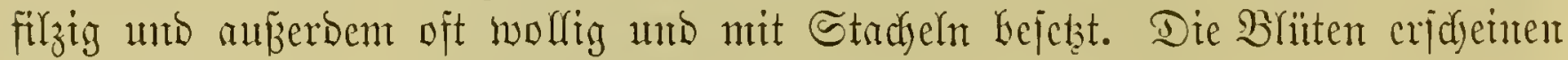
fut melyeren aus bent (5cphalium.

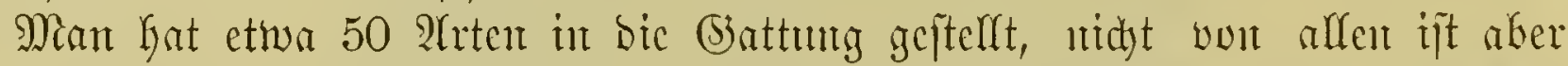

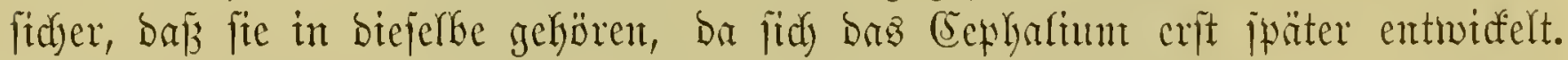
Sie ift gewifjerma

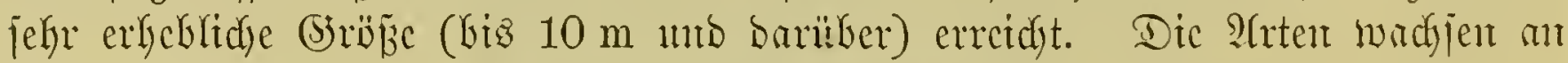

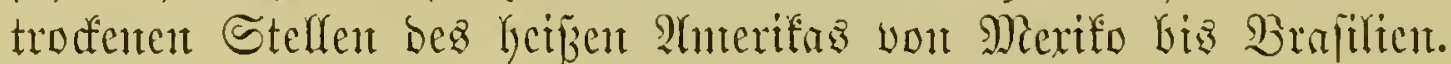

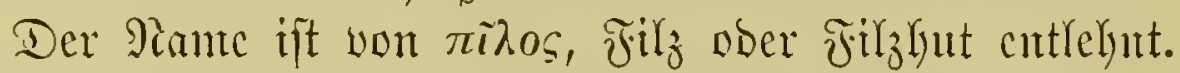

Die (5)attungabezcidunung Cephalocerens Pfeiff. ijt ctwas älter als bie obige mtb wirb bealyalb gegentuärtig won ben Botantem bevorzugt.

ed)liiffel für die befd̨riebenen 21rten.

A. Rippen $7-11$

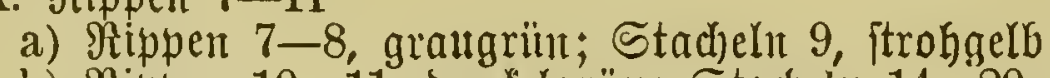

b) Rippen 10-11, Dunfelgrün; Stacheln 14-20, hornfarbio

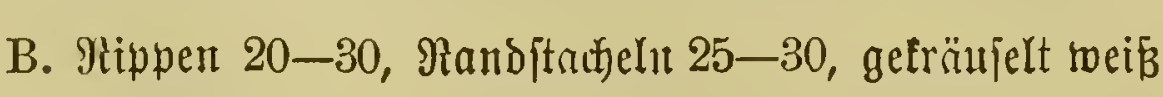

I. Reihe Oligogoni.

1. P. Houlletii Lem.

2. P. fossulatus $L a b$.

II. Seibe Pleiogoni. 3. P. senilis Lem.

*) Siach (Sartenflora, f̧ft. 19. 1890. 


\section{Pilocerens Honlletii Lem.}

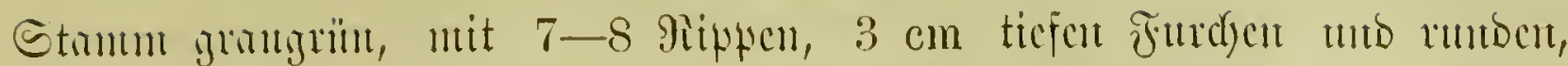

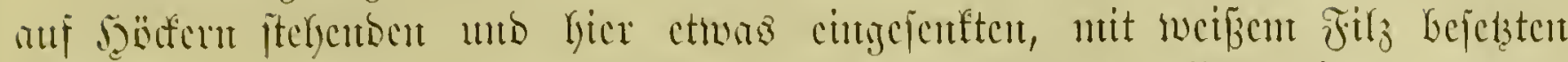

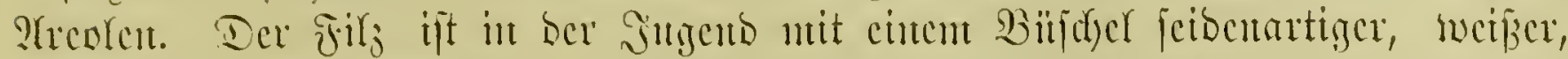

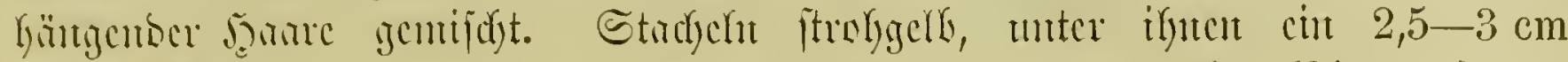

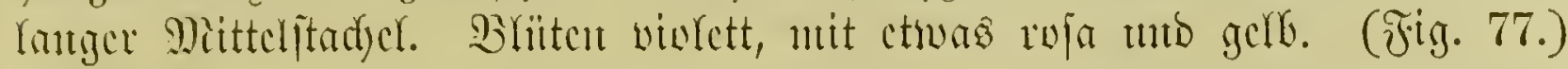

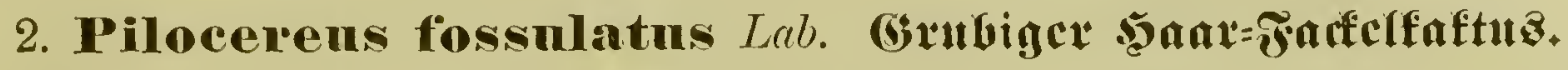

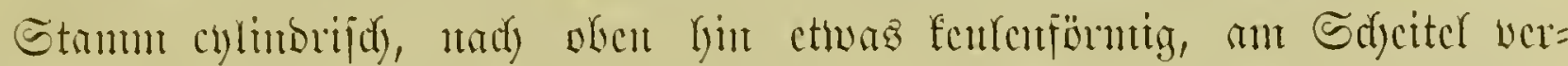

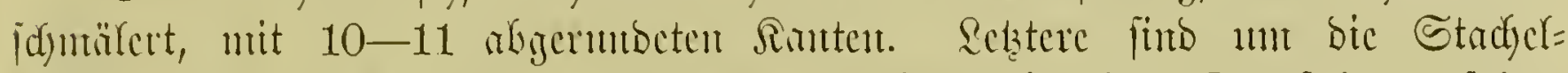

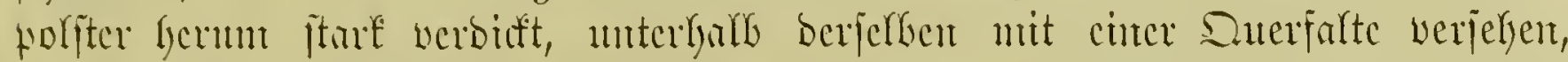

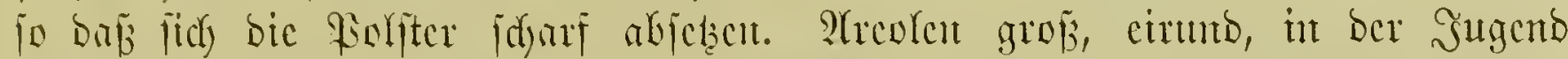

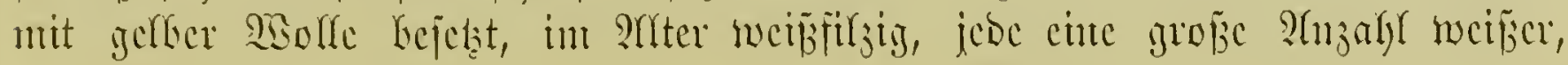

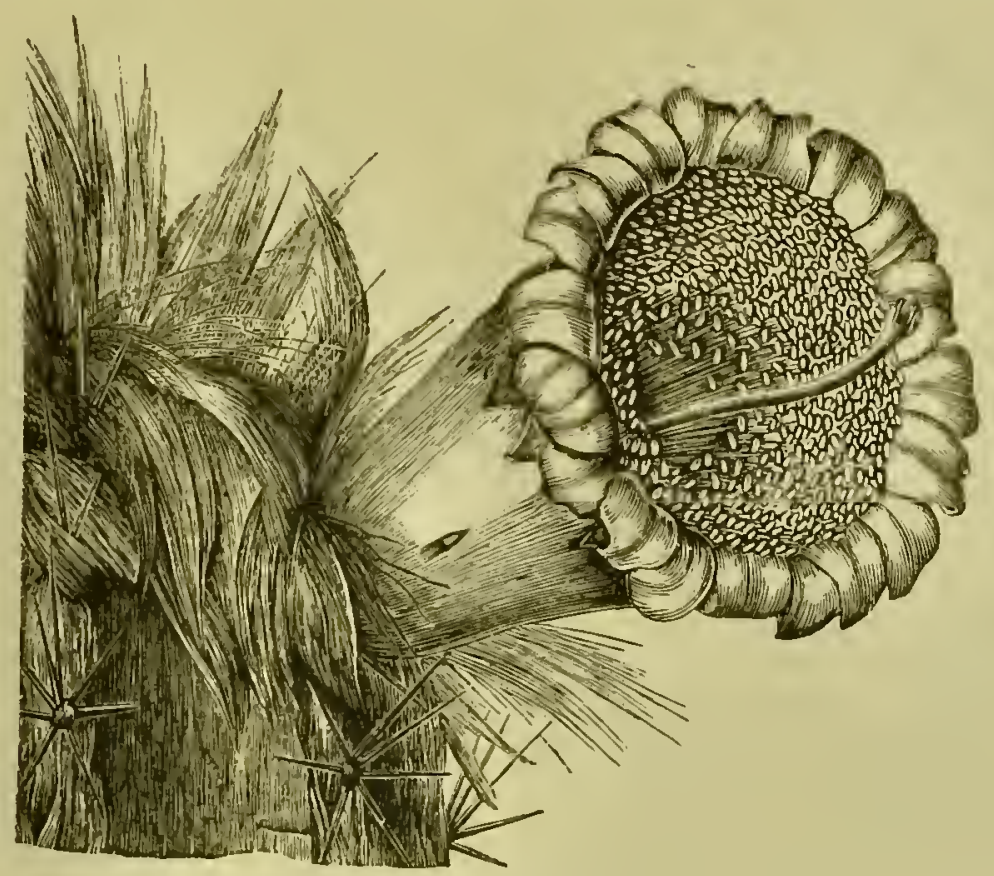

Fig. 77. Pilocerens Houlletii Lem.

jeibenatiger, 3-5 cm Yanger 5aarc tragcub, weldbe auf bom Sobeitel einen

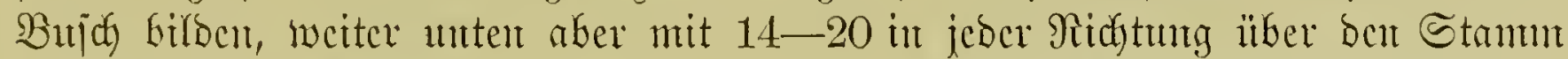

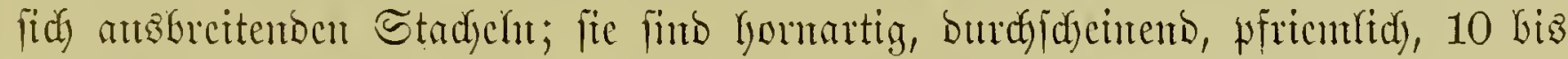

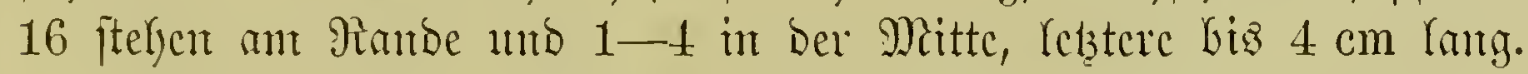

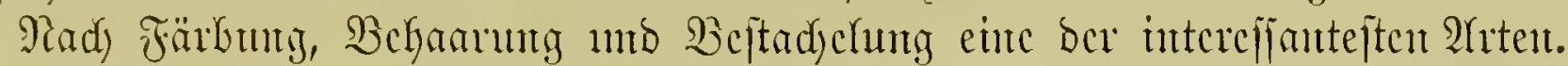

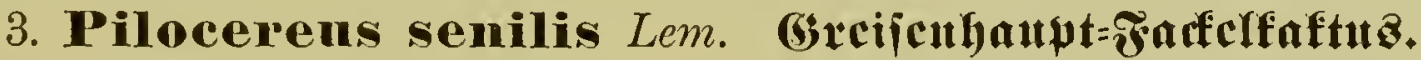

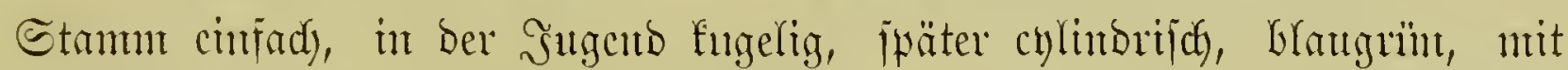

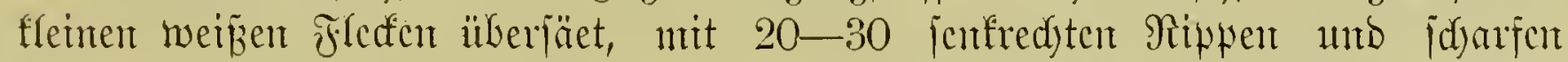

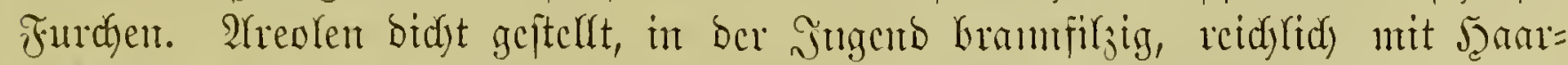
jtadych bejelzt, jpäter itchen zwijdycu bicjen cigentlidye Stadych (anfangz 1-2, bann 3-5), bercu interifter $5-7 \mathrm{~cm}$ lamis mo itare abuärto geridstet ift. (Fig. 78, 厄. 144.)

গ⿰亻⿱ Së̈be vorfontmen. 


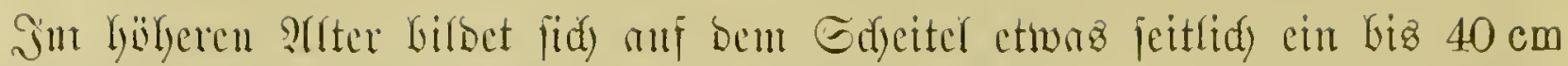

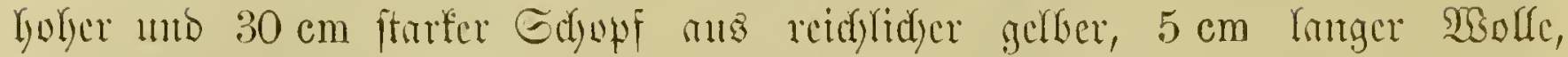

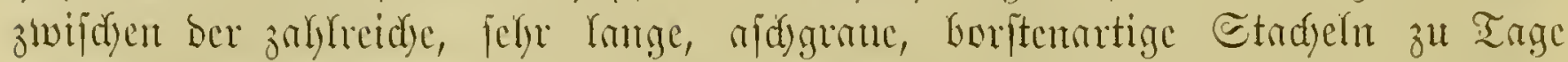

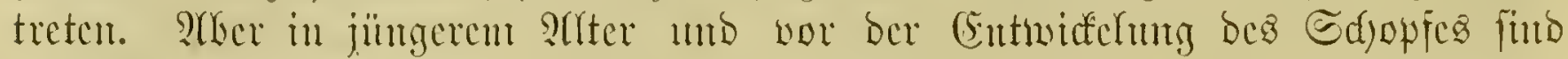

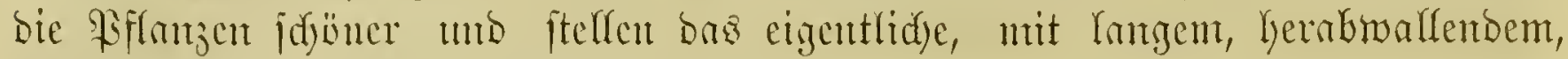

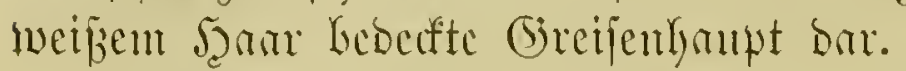

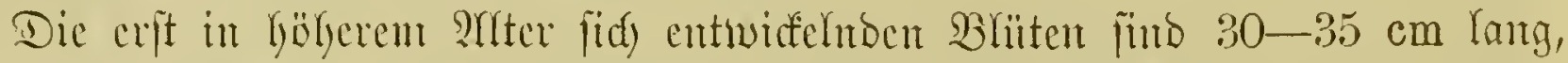

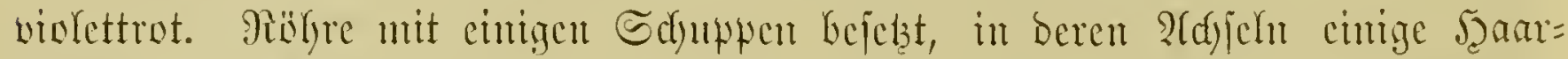

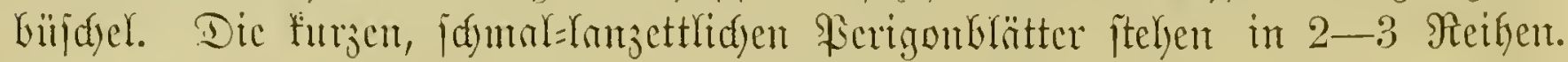

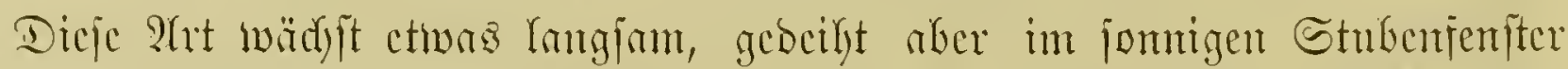

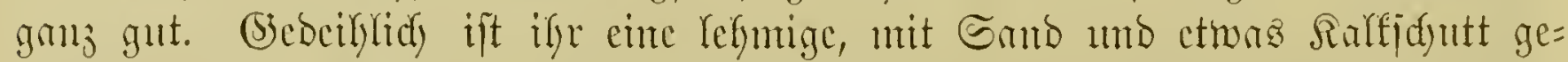

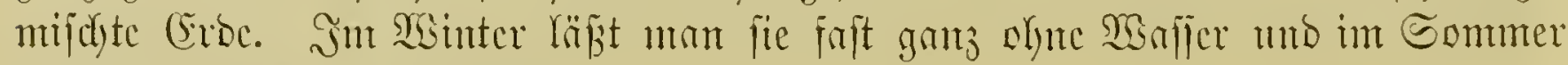
bebarf fie reciajlidjer Rüjtung.

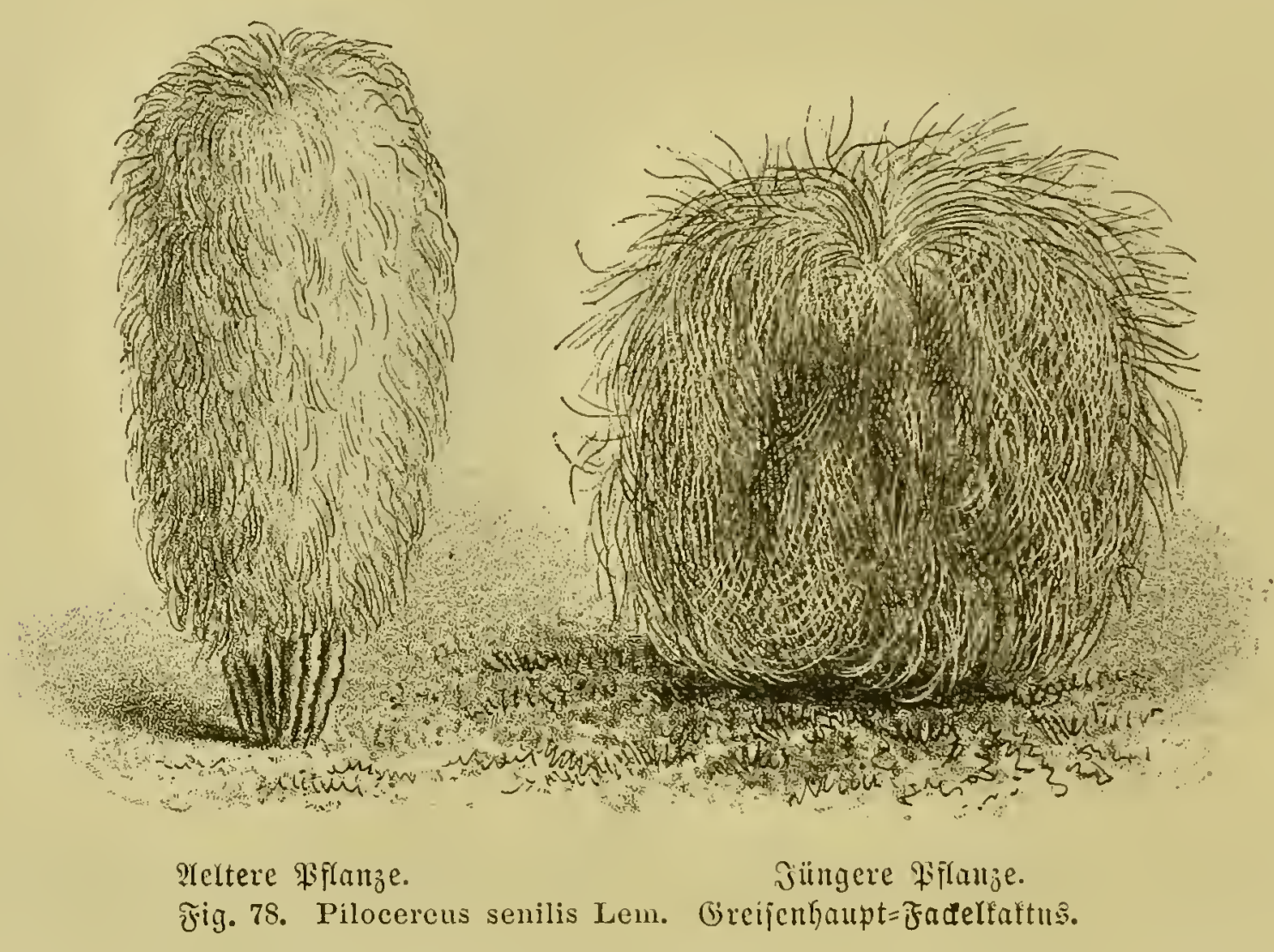

Dicjer Art ftelyt Pilocereus Dautwitzii Seitz jelyr mare, bock liegt bie

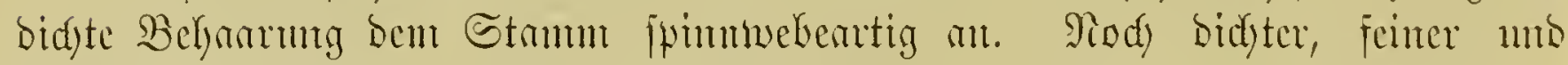
Yänger ift bic Belyanumg bei P. Haagei Pos., beffen Strmum ansitht, als wäre cr in Sartte geljillut.

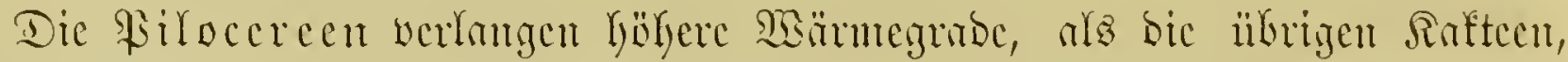

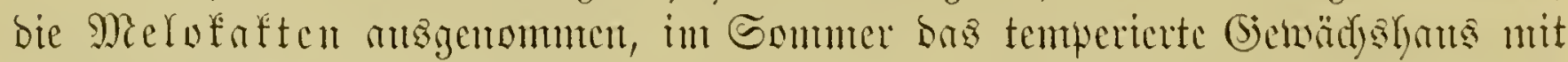

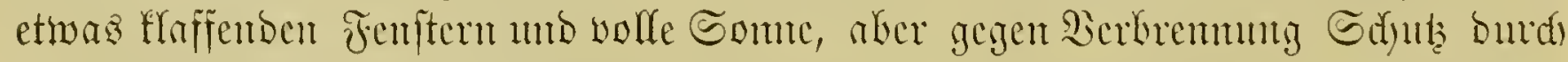

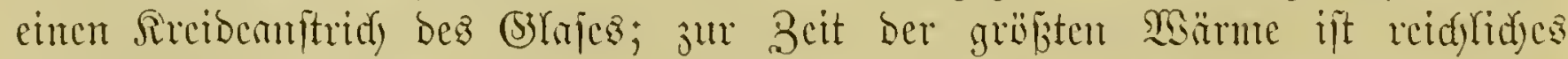

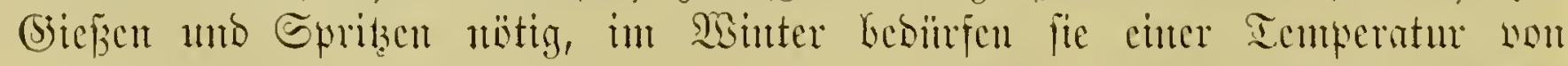

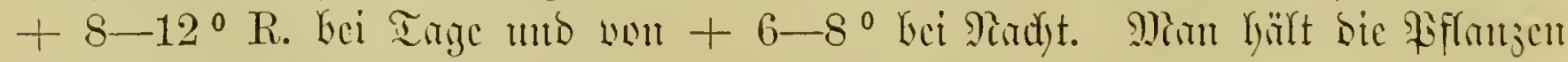

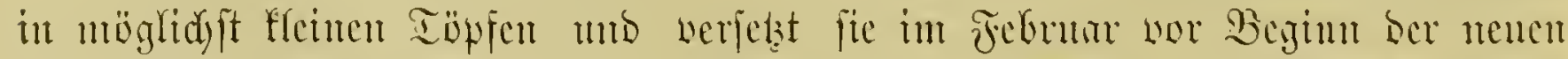

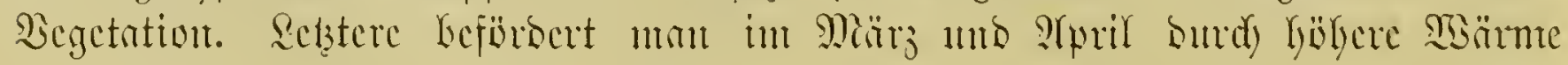




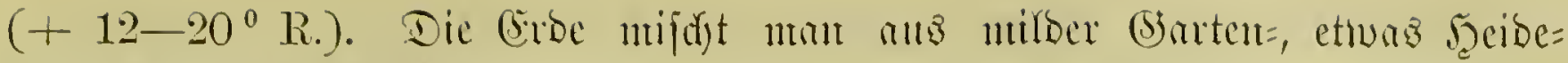
erbe unb flurem Sirlfidyutt.

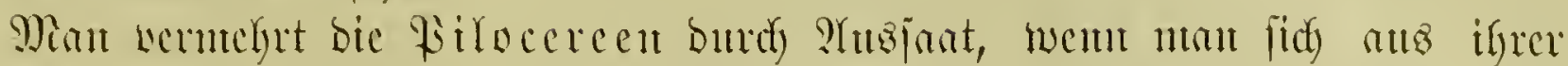

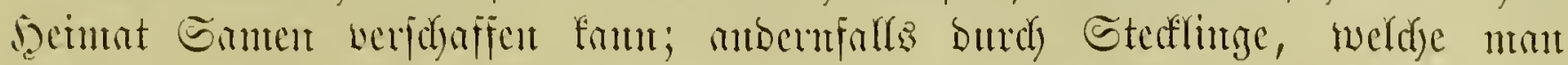

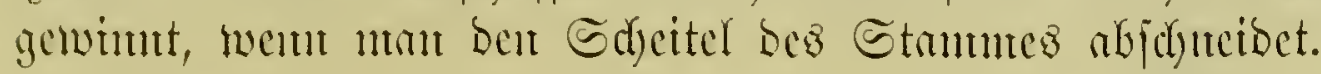

\section{Bjattung Phyllocactus Lk. Blattelaftus.}

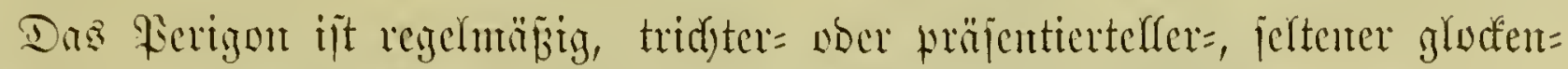

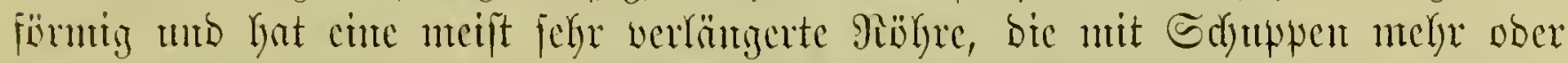

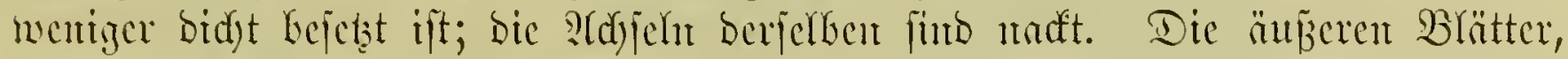

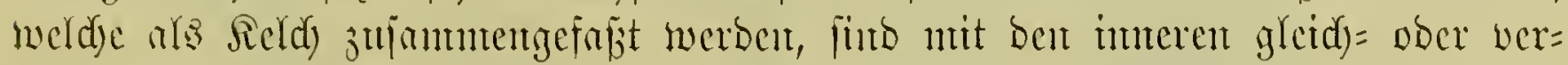

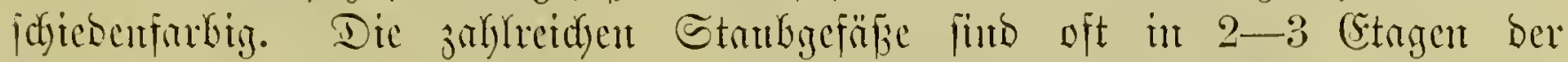

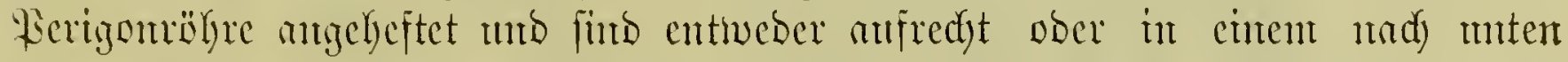

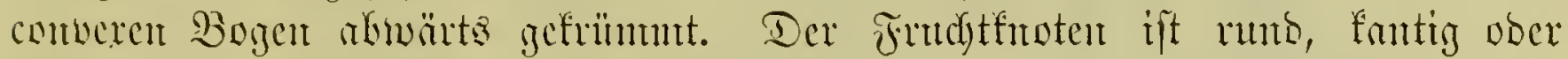

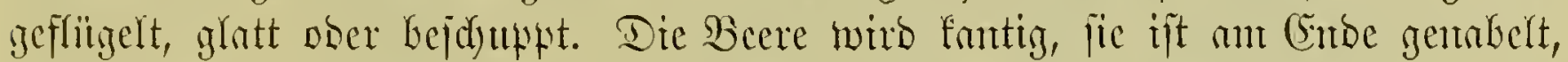

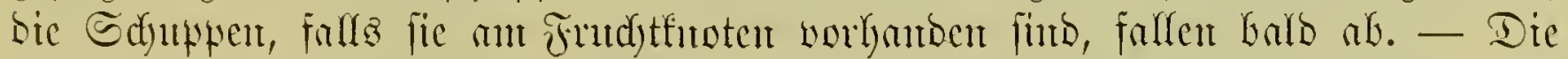

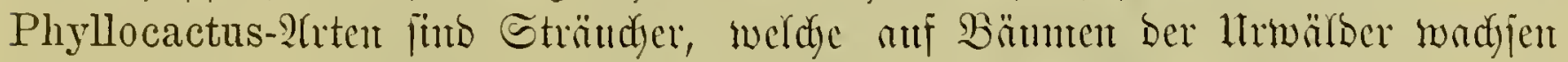

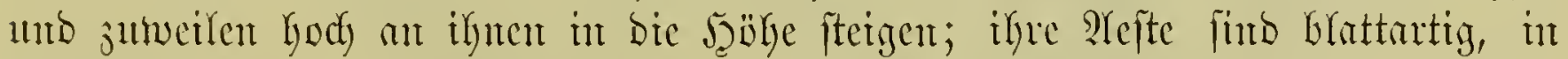
ber Singent aber bringen fie nidft felten breifintige Zweige hervor, bie älteren

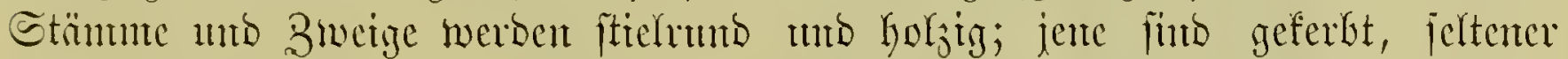

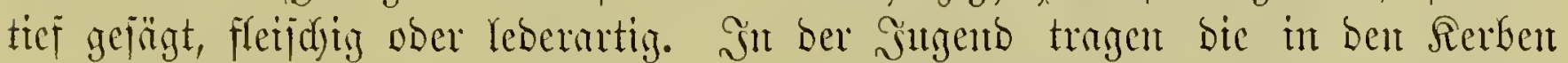

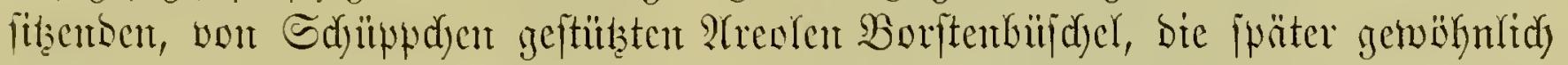

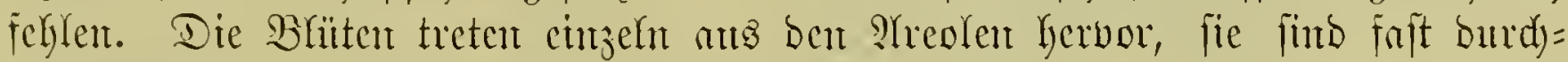

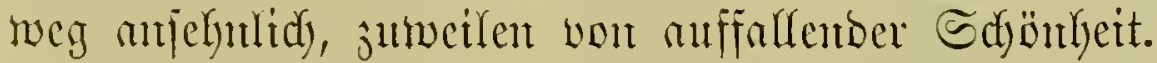

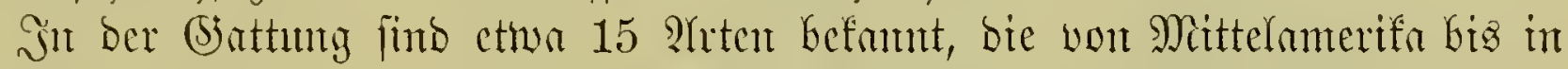

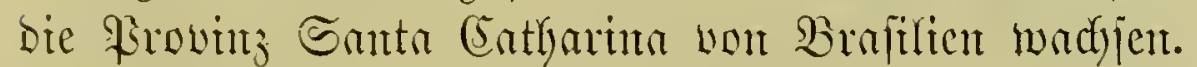

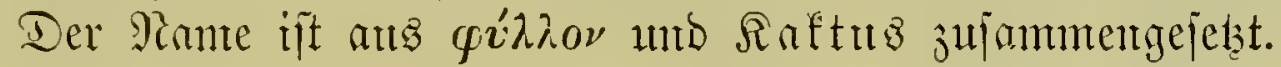

Sđllüffel für sie bejđriebenen Urten.

A. ßerigonröhre türzer als die halbe Ränge der Blüte.

a) Frudhtfnoten 4-5 tantig; in Der Iracht Den (5piphyllen ähnlich, mit turzen, geferbten, zahlreichelt $\mathfrak{A}$ ejten.

a) Blüten rojenrot 1 . Ph. Russellianus $K$. Schumann.

B) Blüten jdarladrot ing zinnoberrote 2. Ph. Gaertneri K. Schumann.

b) Fruchtinoten ftielrund, \&refte verlängert, lanzettlich.

a) Slefte dunfelgrïn,

ß) 2Yejte hellgrüm, Blüten $16-18 \mathrm{~cm}$ lang, fáharlachrot

3. Ph. phyllanthoides S.-Dyck.

4. P. Ackermannii S.-Dyck

B. ßerigonröhre fo lang oder viel länger als die halbe \&äıge Der Blïte.

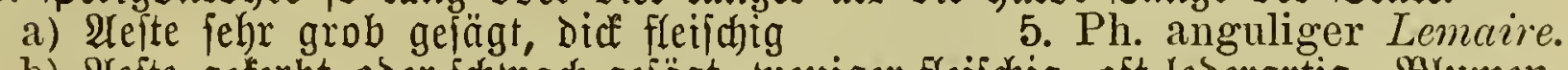

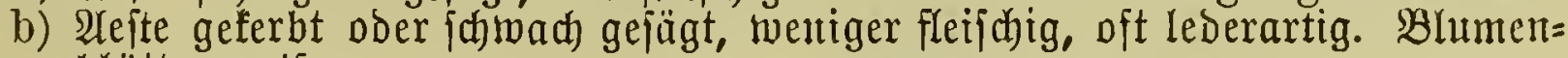
blätter tweíb.

a.) \$erigonröhre $10 \mathrm{~cm}$ lang; Reldublätter bräunlich

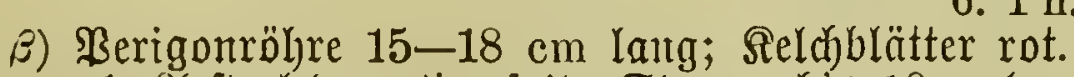

6. Ph. crenatus S.-Dyck.

1. Sefte lederartig, ipib, Stamm bis $10 \mathrm{~m}$ lang, lletternd

2. Arefte fleifhiger ftumpf, Stamm niebria

7. $\mathrm{Ph}$. grandis Lem.

8. Ph. Hookeri S.-Dyck.

હuffulenten.

10 


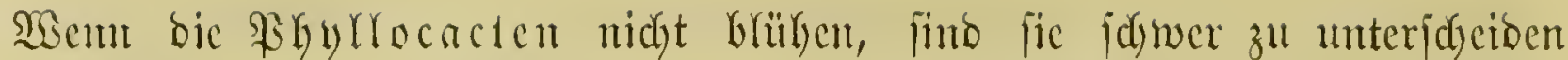

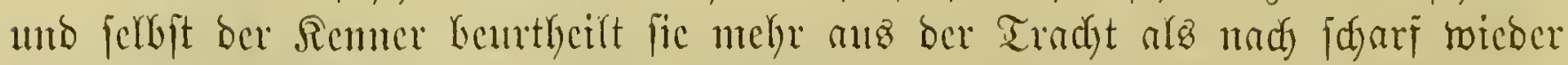

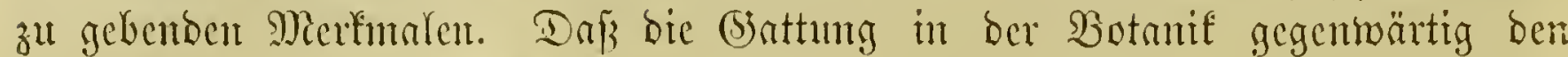

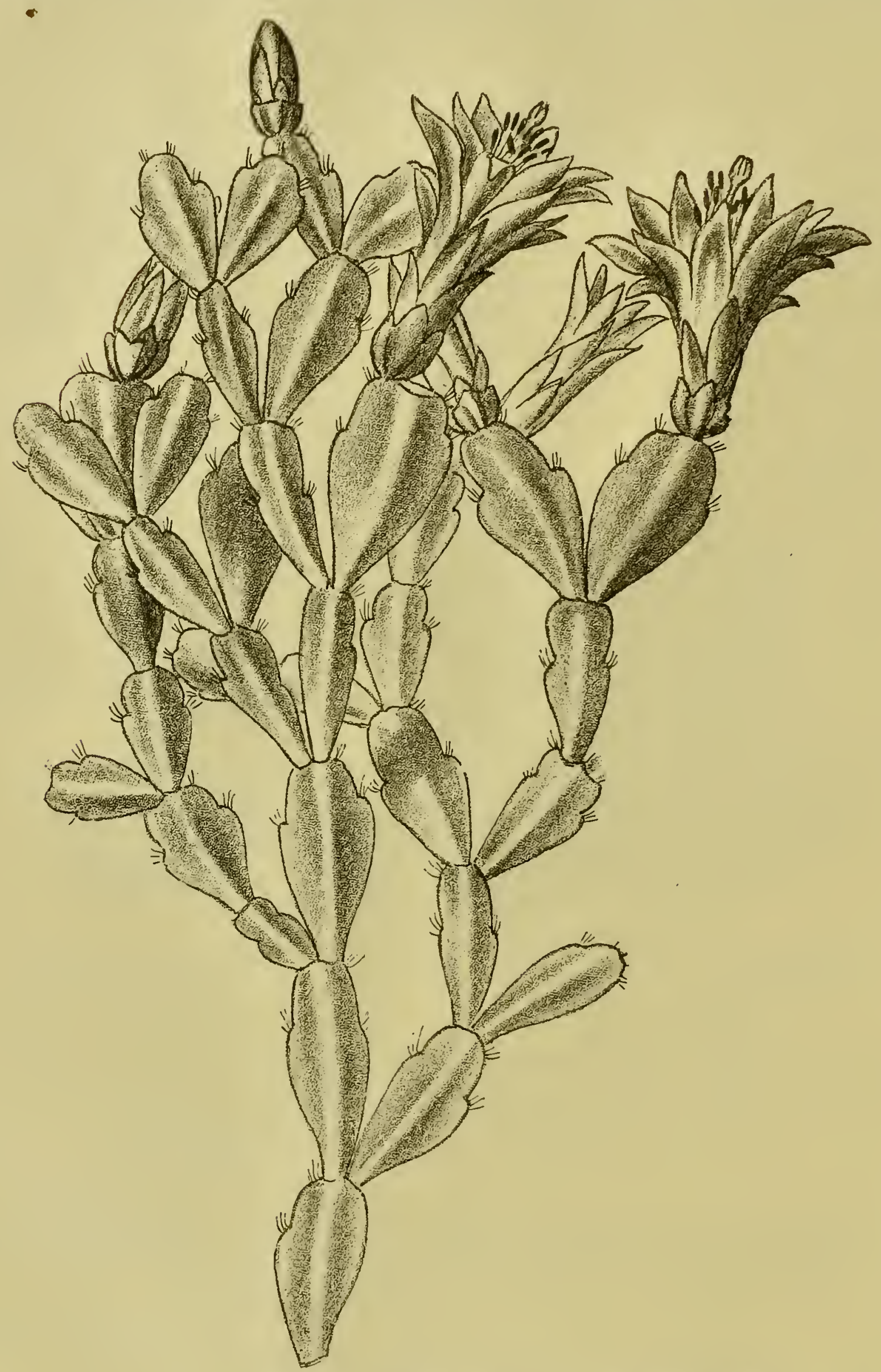

Fig. 79. Phyllocactus Russellianus K. Schum. Miufiel's Brattfattu․․

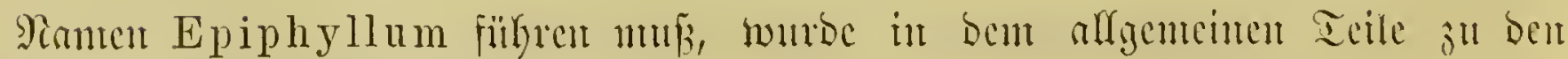
Sinftecu bereits ermälynt. 


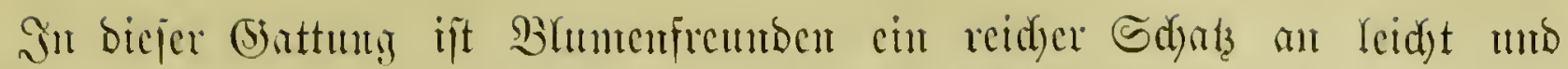

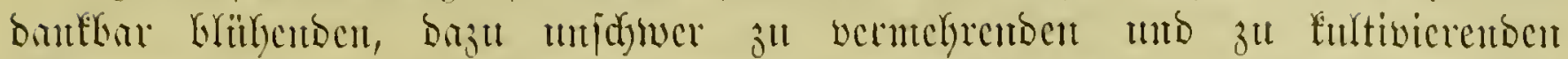

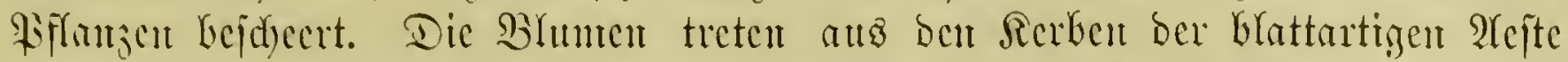

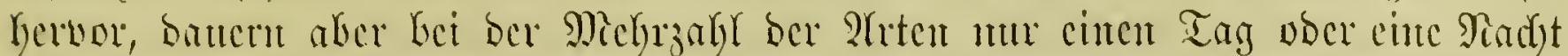

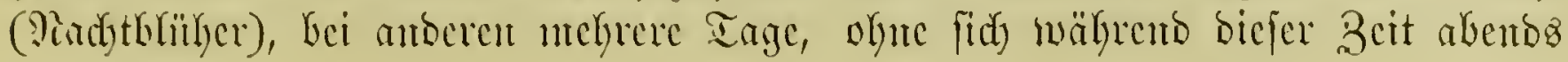
jul jojlickisu.

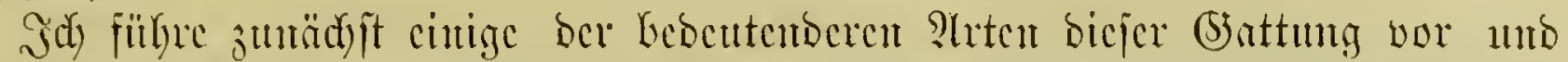

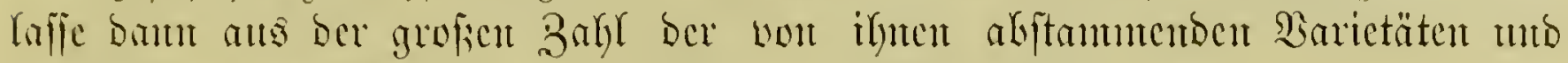

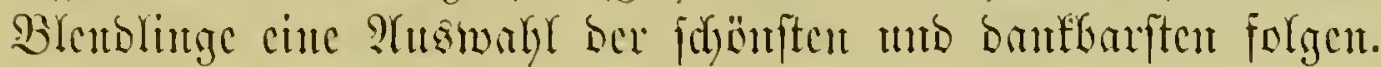

\section{Phyllocactus Russellianus $K$. Schuman. Rufiell' BInttaftur.}

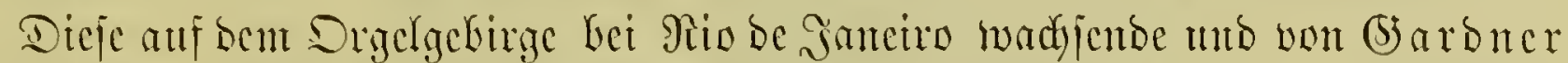

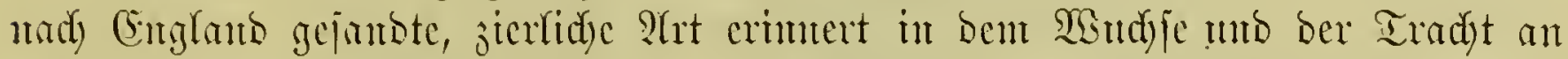
cin Epiphyllum, wofür es bis in bic netefte Bcit gebalten murbe. Dic zient=

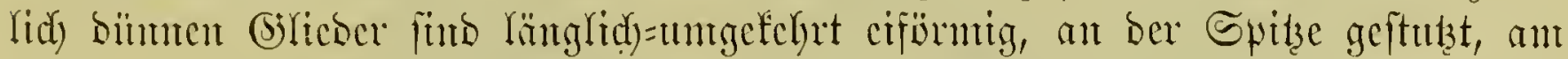

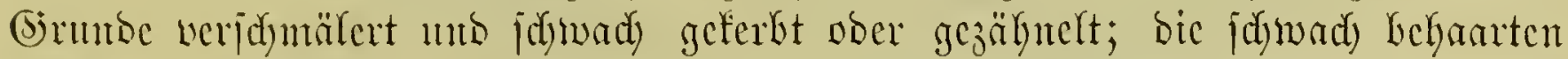

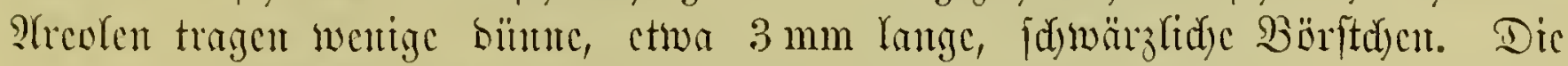

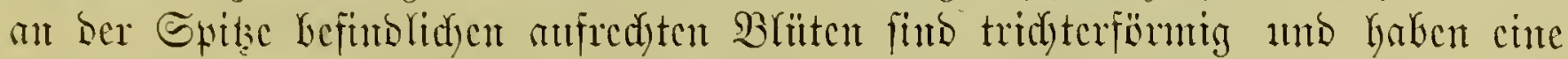

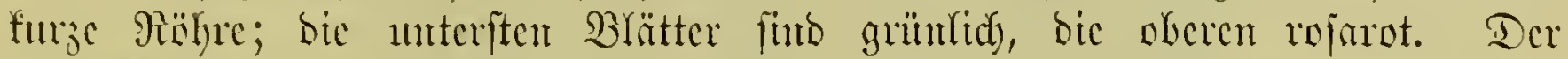
Frud)tfinten ijt 4-5 timtig, faft geflïgelt. (Fig. 79, હ. 146.)

\section{Phyllocactus Gaertmeri $K$. Schumann. Gärtucr's Blattfaftuz.}

(5r murbe ans ber Sirovinz Eanta Catharina cingeführt. Die Kanbigen

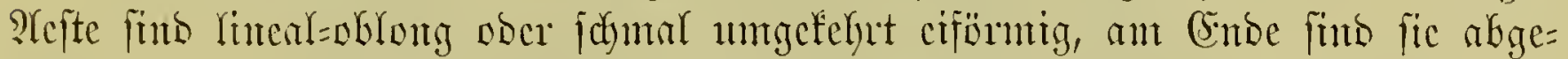

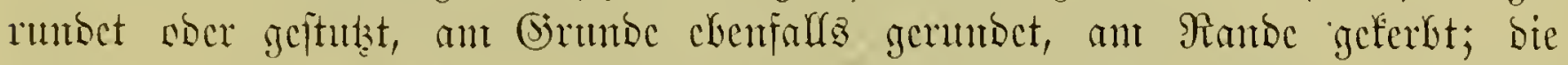

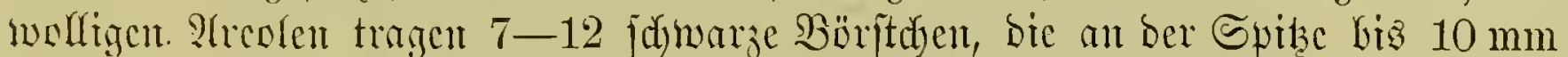

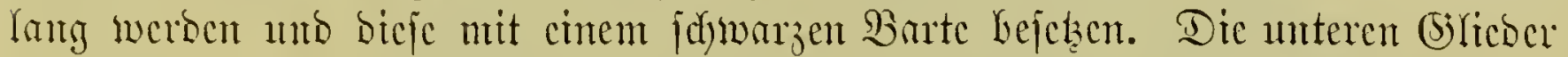

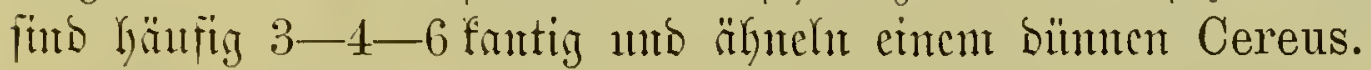

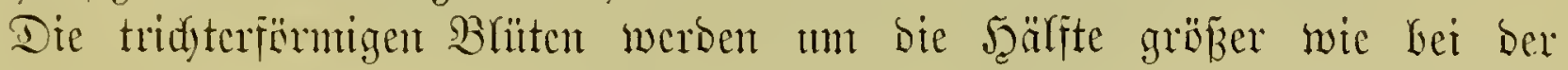

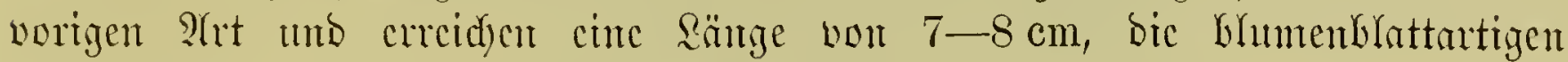

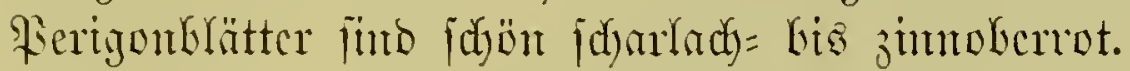

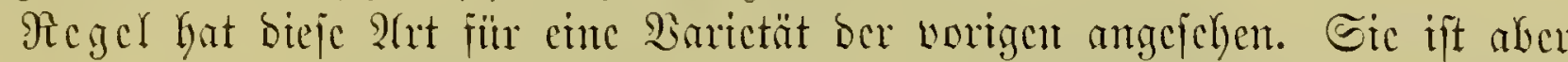

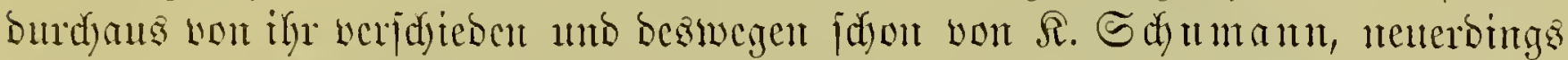

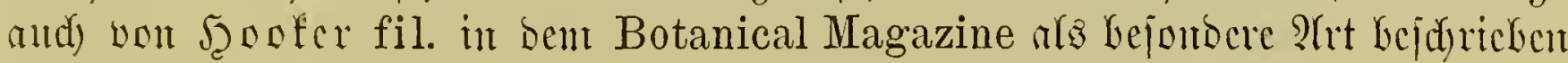
morbon.

Man fam bie Biflange and) wie E. truncatum anj Peireskia als Rroncu=

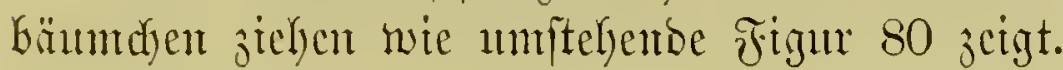

\section{Phyllocactus phyllanthoides S.-Dyck. Phyllanthuzartigcv Blattfaftus.}

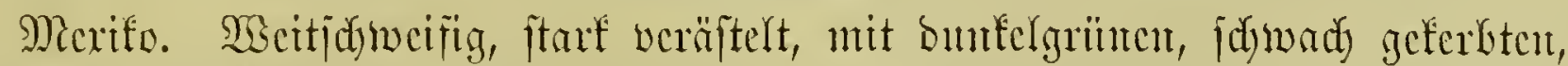

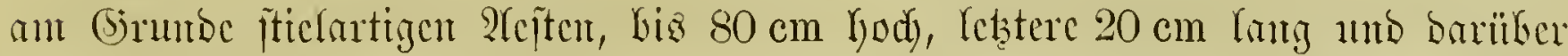

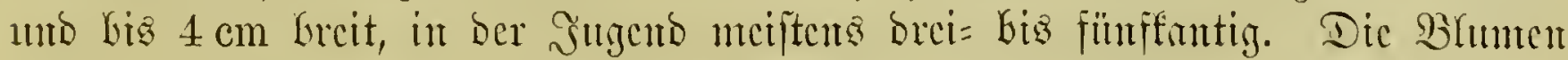

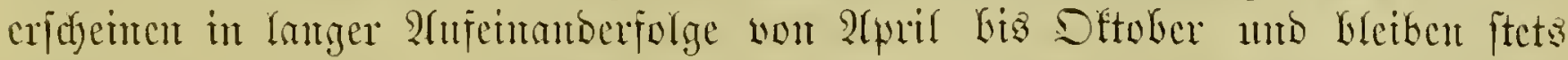

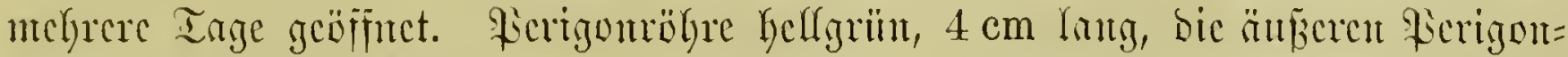

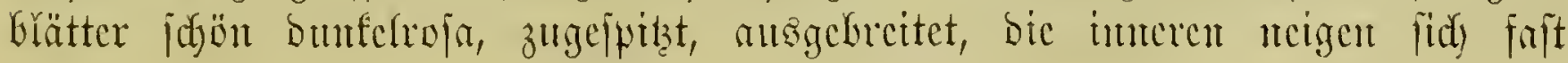




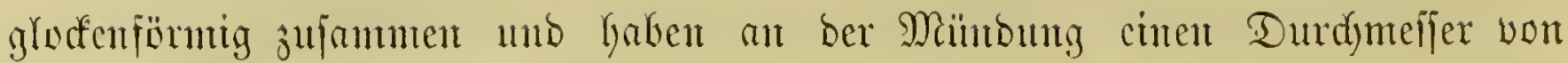
ctmo $2,5 \mathrm{~cm}$.

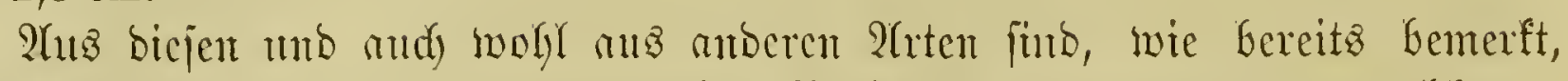

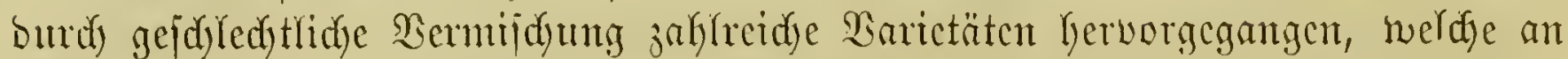

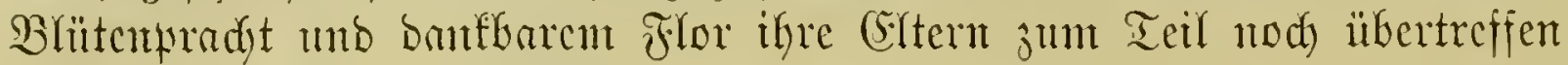

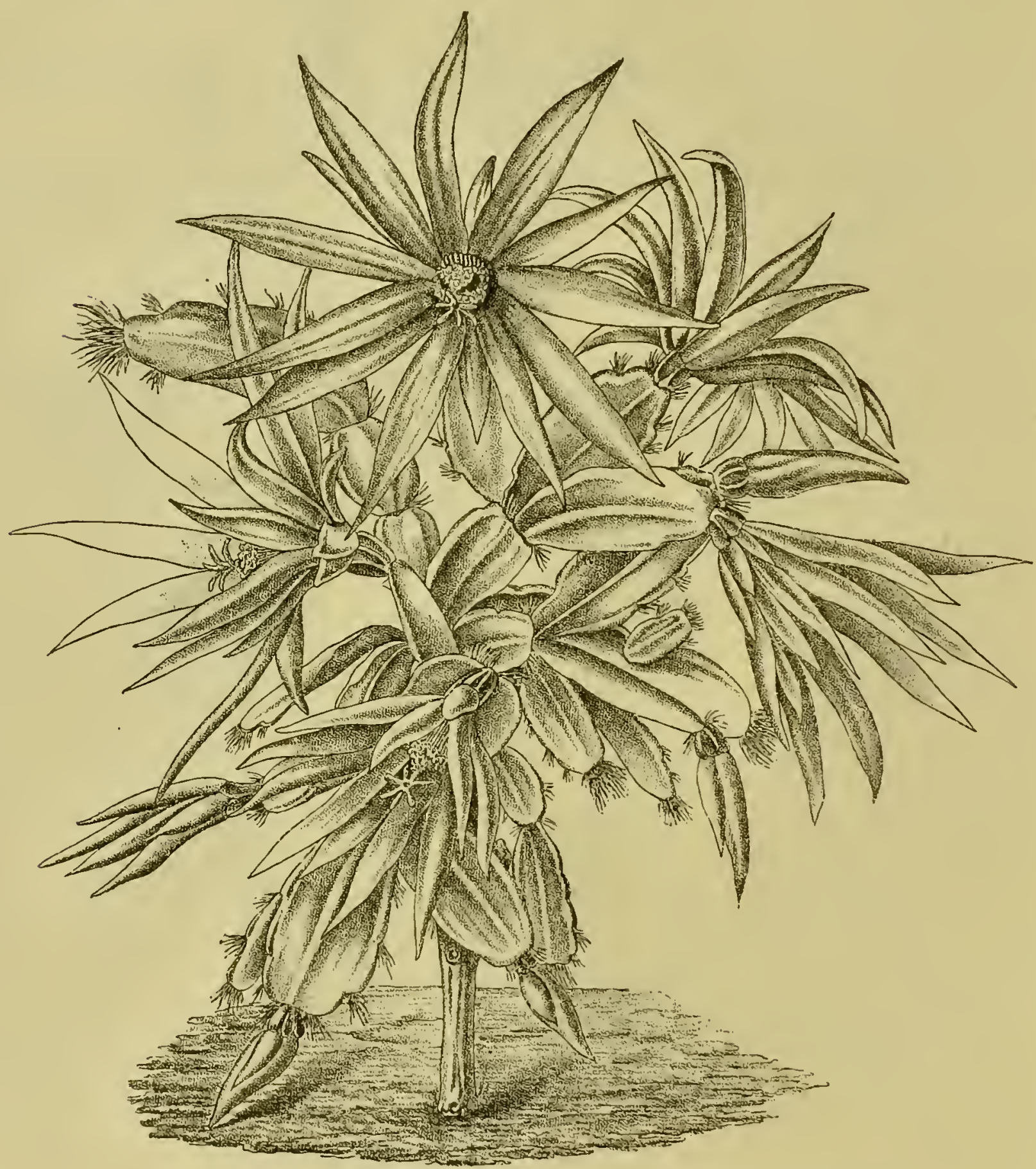

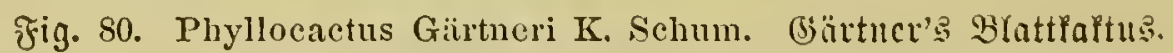

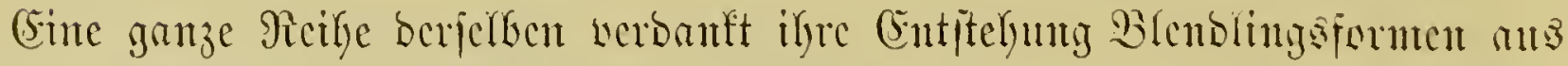
Cerens grandiflorus speciocissimus, bejudtytet burd) Phyllocactus Hookeri S

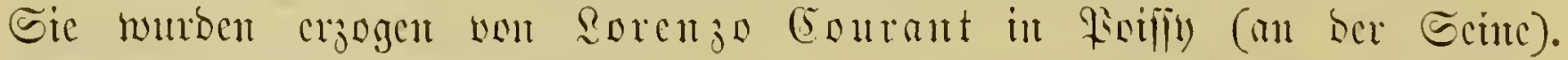

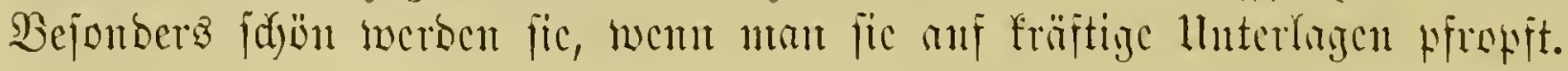

\section{Phyllocactus anguliger Lem. (Ph. serratus Labour.)} 3ahu= 3 lattfaftus.

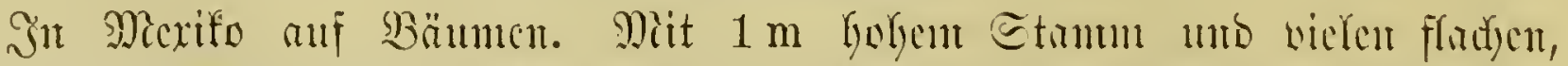

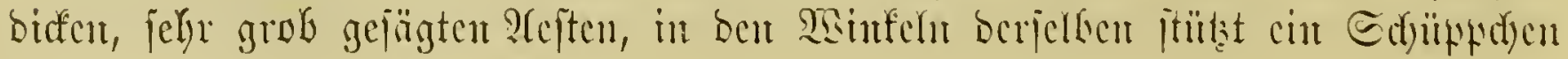




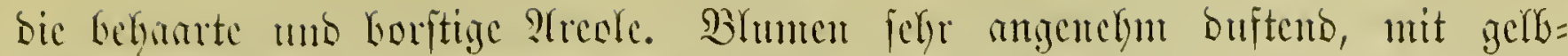

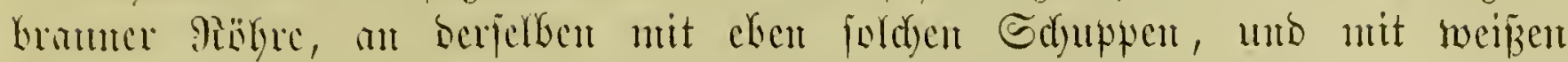

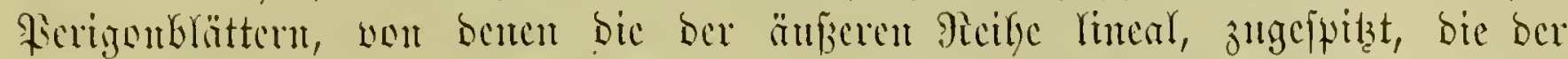

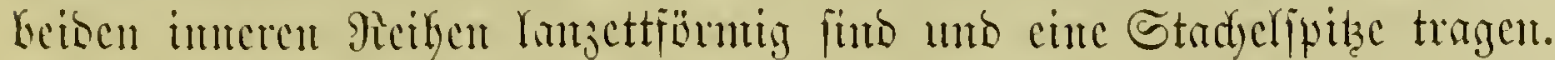

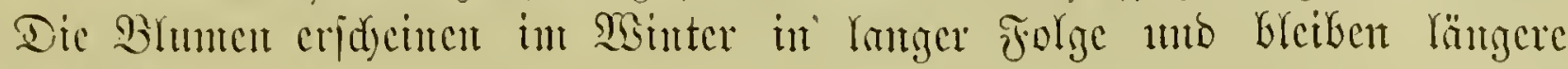
Beit geöffittet.

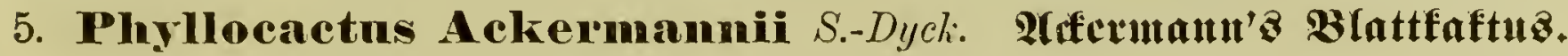

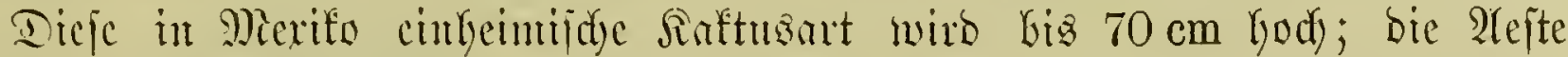

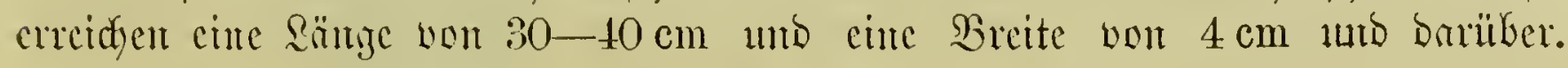

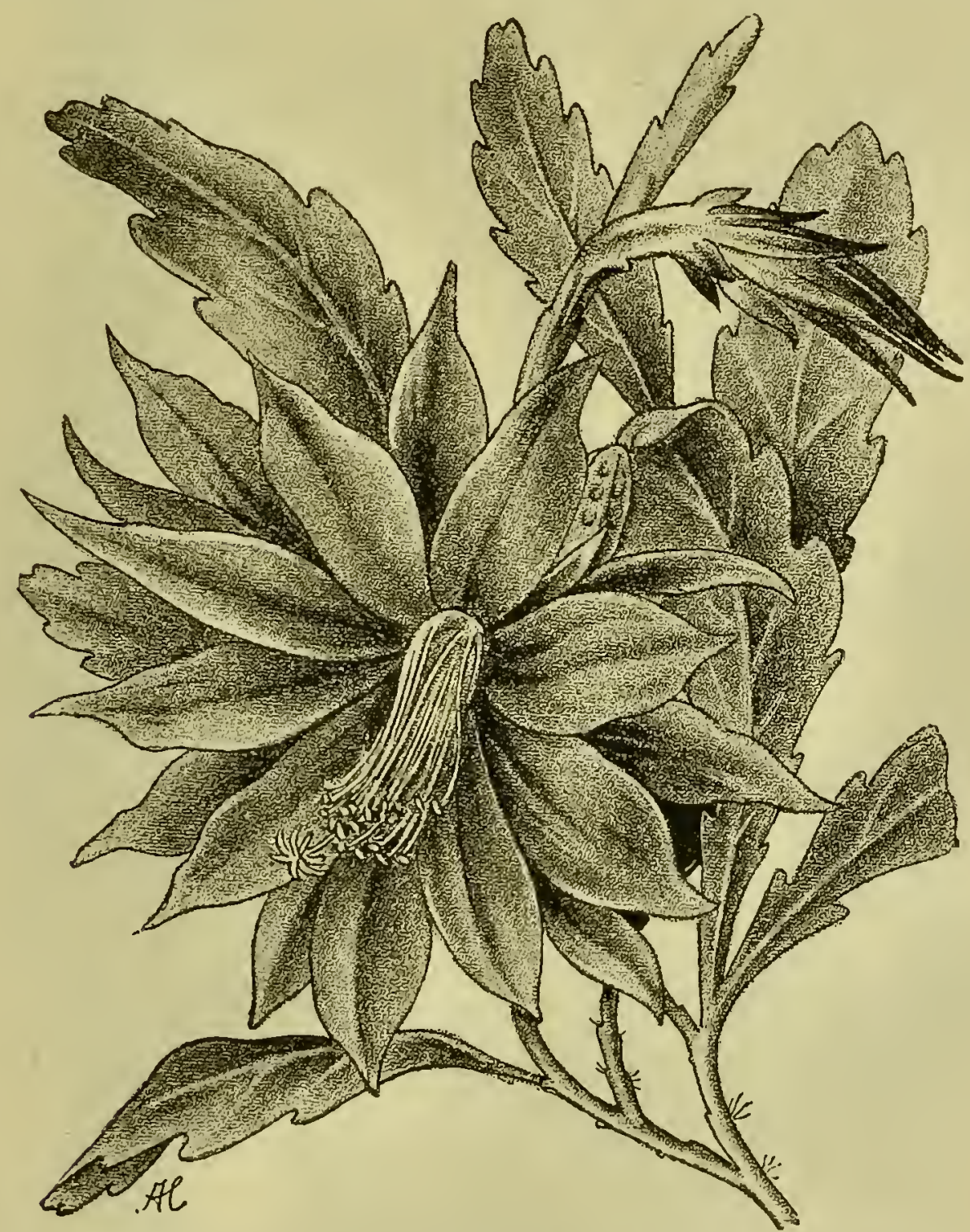

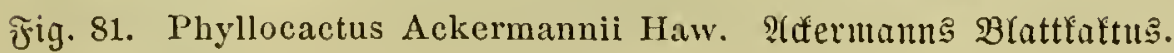

Sebzere funb von Gelfgrüner Farbe (in ber Sugent purpurbram geranbet), grob gefererbt.

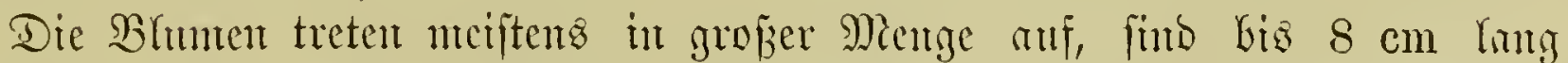

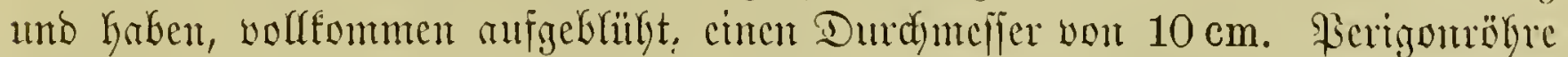
etwa $4 \mathrm{~cm}$ long, glatt, grün, mit cinigen rötlidjen Edjupen; bie unterften

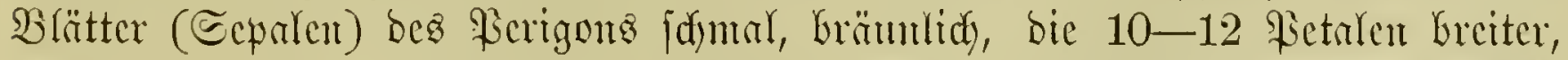

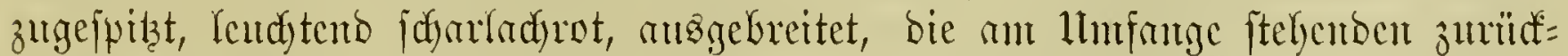

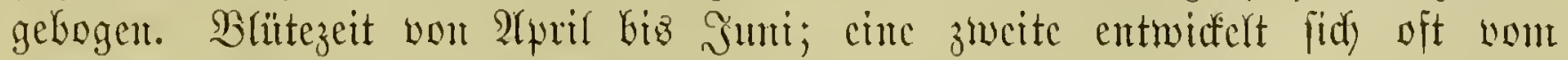
September bis in ben Miovember Gjutein. (Fig. 81.) 
6. Phyllocactus crenatus S.-Dyck. Geferbter Blattfaftut.

Sn 5onburas (Mittelantrifa) einheimifids. Etamm genen $60 \mathrm{crn}$ hodj, burfelgrün, oben blattartig berbreitert, mit iteil=aufredyten, blattartigen, etruaz

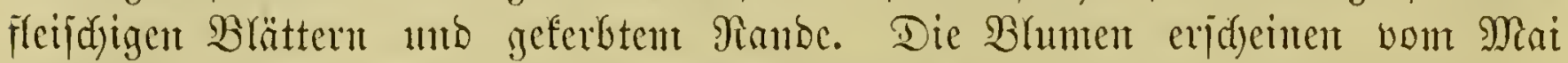

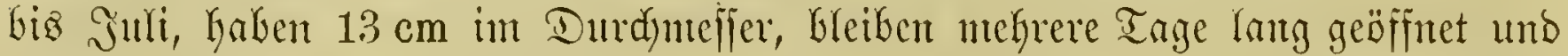

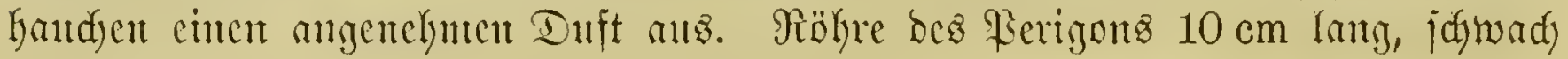

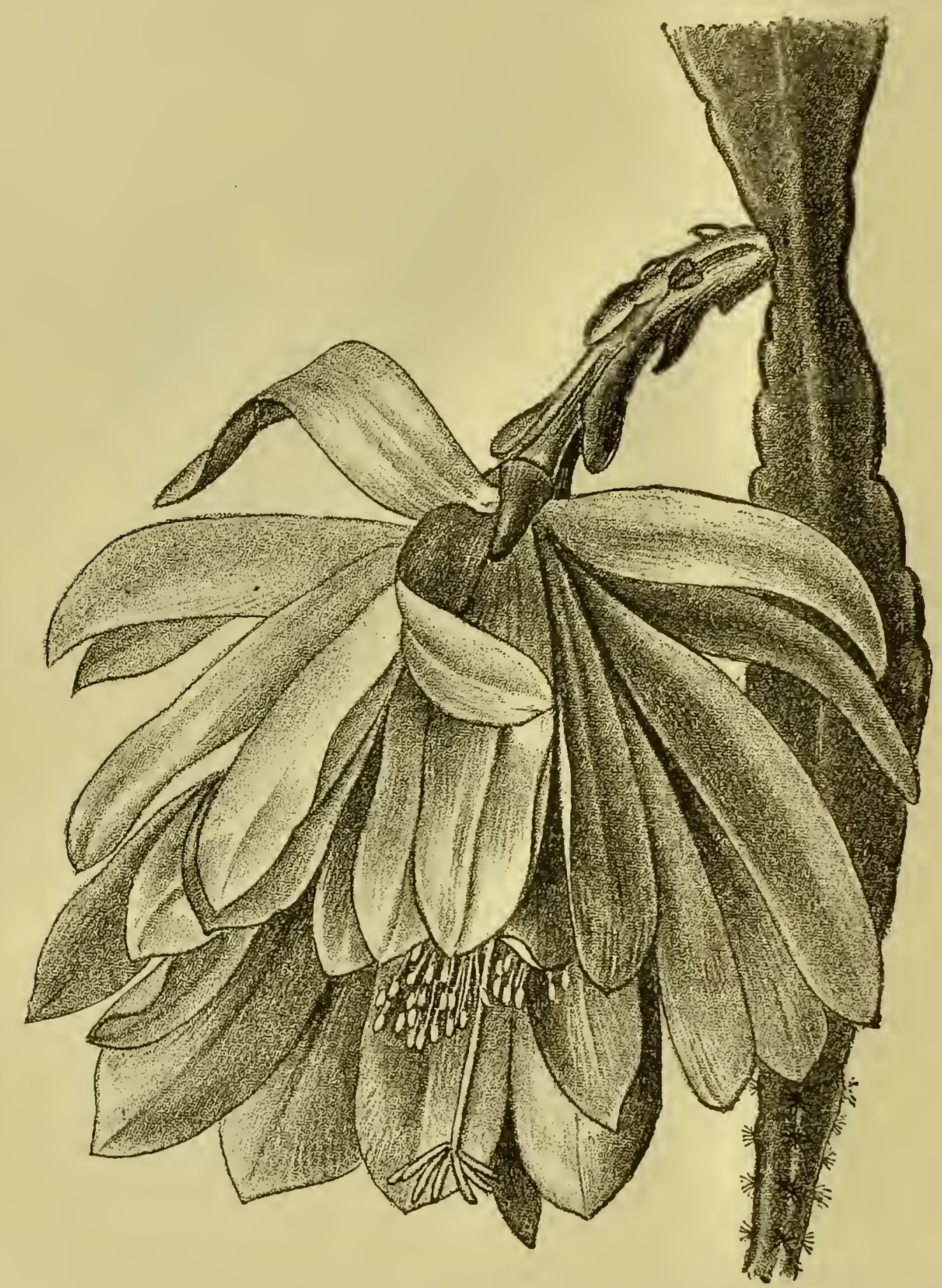

Fig. 82. Phyllocactus crenatus S.-Dyck, var. roseus grandiflorus. Gieferbter Blattfoftus.

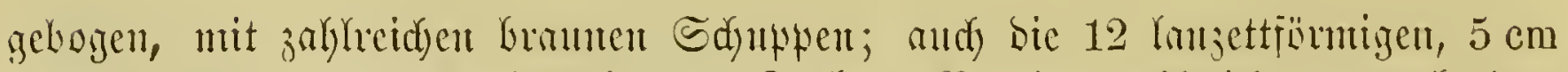
langen Sepalen haben cine Krante Farbe. Fetalen zablreidy, alsigebreitet,

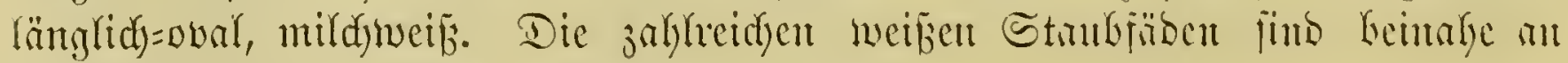

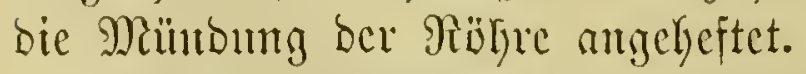

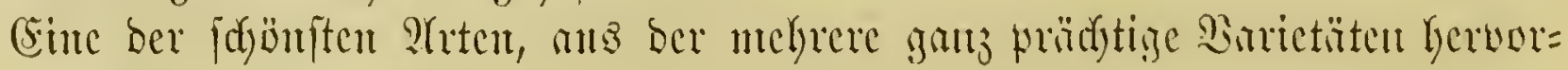
gergatign finto. (Fig. 82.) 


\section{Phyllocactus grandis $\mathrm{Lem}$. Grofzer Battfaftuz.}

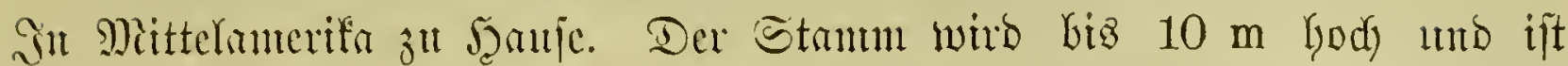

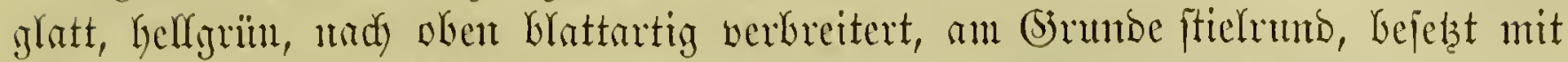

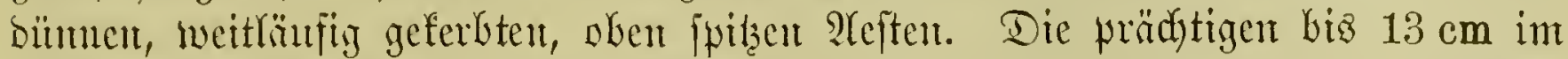

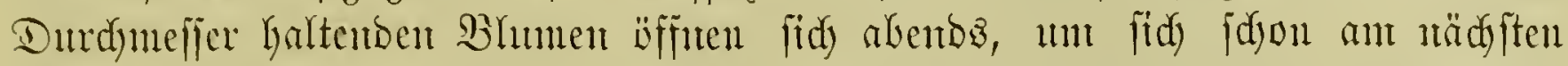

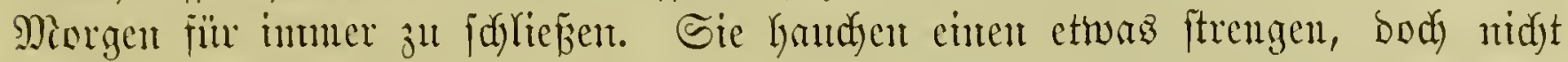

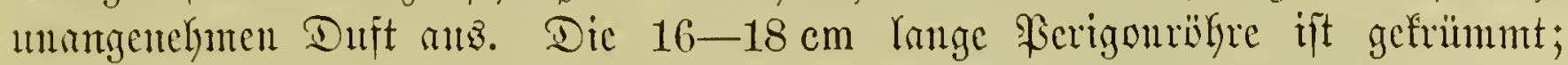

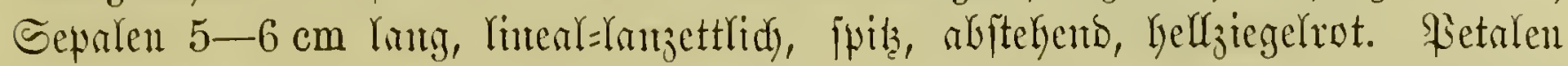

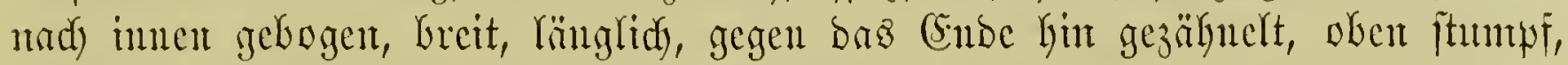

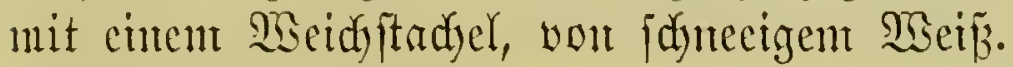

\section{Phyllocactns Hookeri S.-Dyck.}

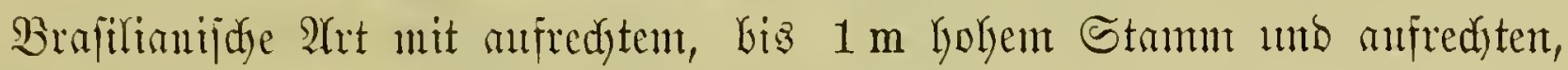

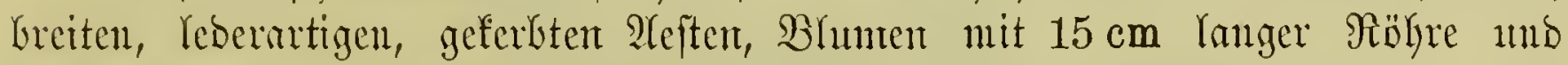

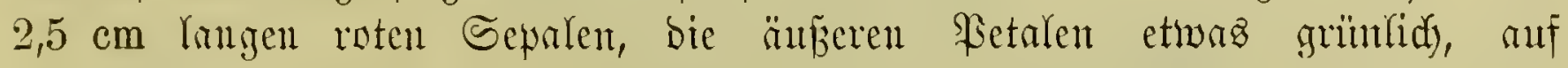

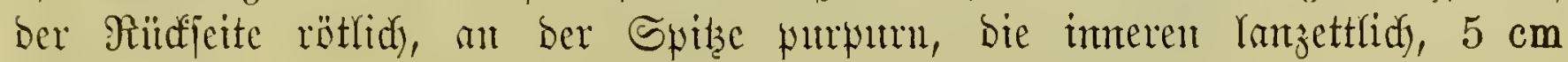
lantig, iweín.

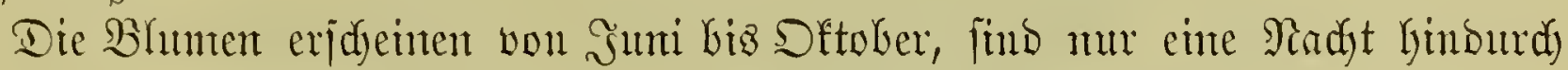
geöffnet unb haudjen einen fdmadyen, an Samilfe erimnemben Duft aus.

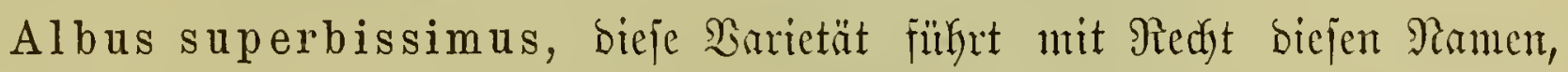
benn fie ift unter ben weiphbülyenoen bie alleridyönfte.

Aurantiacus superbus, bic meiftens in Menge auftretenben Bhumen

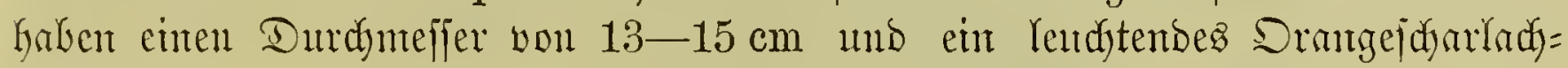
Solorit.

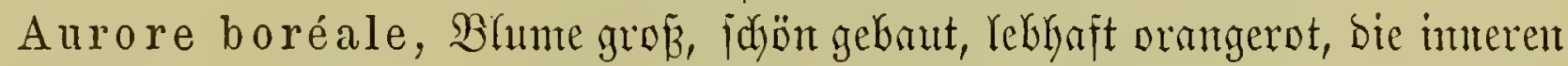
Rerigonblätter firidjrot.

Beauté de Passy, B̉hmen fefr groß̉, roja ins firjdrote.

Binderi, Bhume won $12 \mathrm{~cm}$ Durdmeffer; Sepalen abjtehent, farmin=

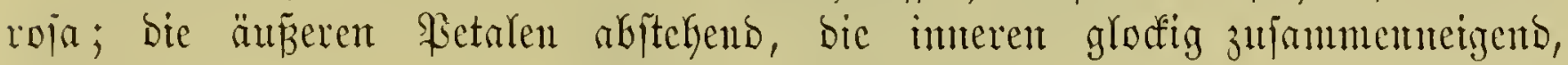
id)arlachrot.

Blindtii, bie Aejte mit einer violetten Ripse. Blume von mittlerer

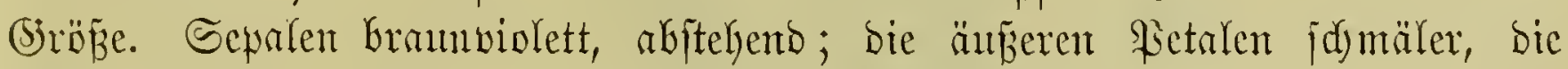

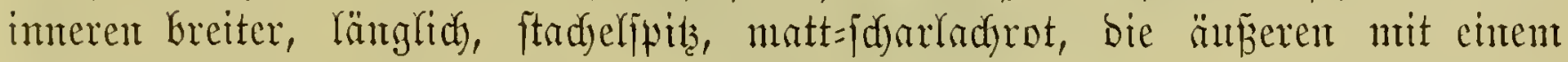
violetten Streifen in ber Mitte.

Dr. Boisduval, Bhume von Mittelgröß̈e, feutrot, bie łerigonbrätter violett eingerajt.

Bollwilleriana, BShme von $12 \mathrm{~cm}$ Durdmeffer; bic Ferigonblätter $2 \mathrm{~cm}$ breit, farminjarafadyrot.

Boule de feu, Bhme groß̧, Yebraft orange, imere Fetalen violett.

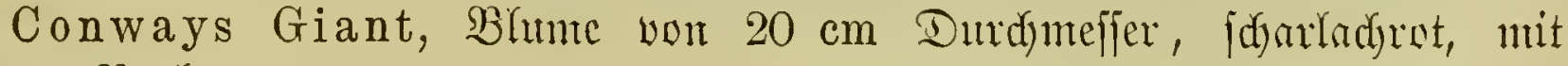
violetter Narbe.

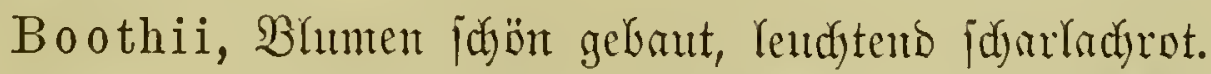

Coop eri, Blumen grob, gelb. Sine wahre Fradytpflauje.

Crenatus amarantinus, Shlume vorzüglidy foün, won. frifder, lita= rojentroter Förbung. 


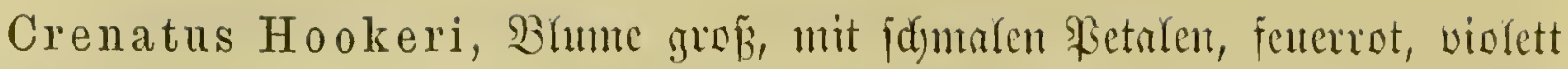
gerambet.

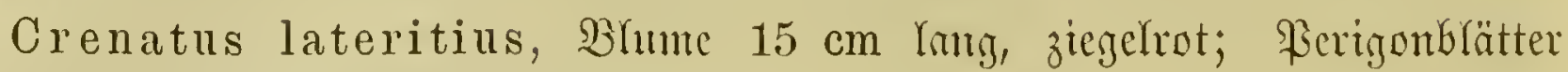
Yineal=Yamzettiörmig, ftad)elfprizig.

Crenatus splendens, Bhame bis $20 \mathrm{~cm}$ Yang, pumpurojemrot; Betalen

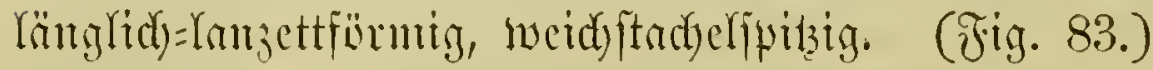

Crenatus Vogelii, Bhrme $16 \mathrm{~cm}$ mo bariuber im Durdymefier, mit meiftens 30 BhumenGlättern von jart=rojentoter Förbung mit einem lifafarbigen Edjimmer.

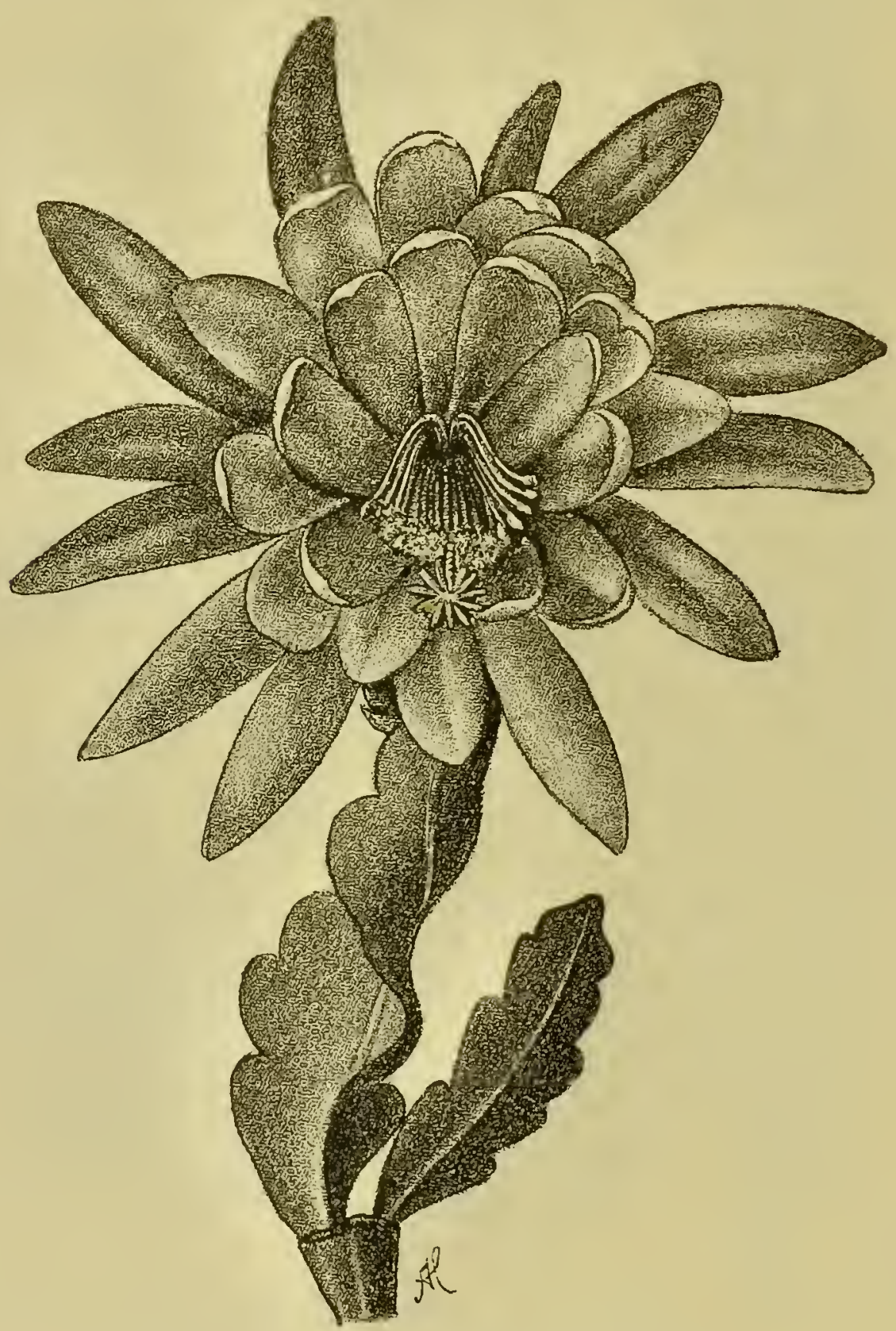

Fig. 83. Phyllocactus hybridus splendens.

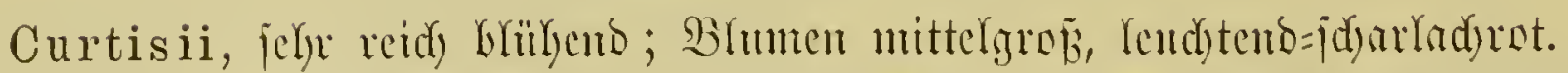

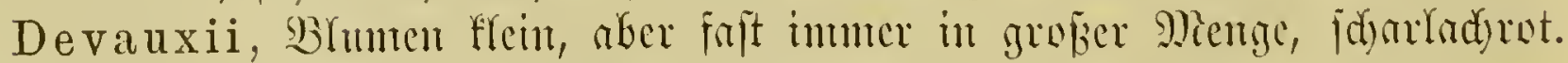

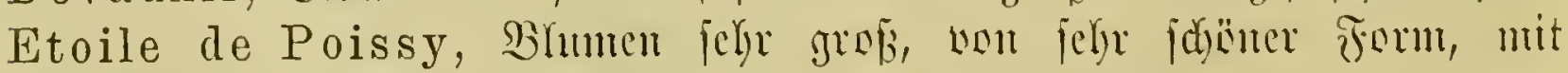

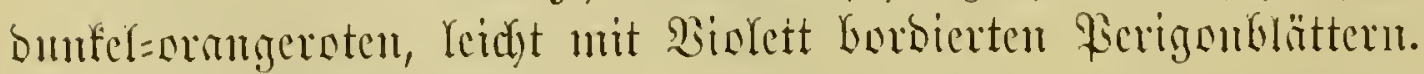

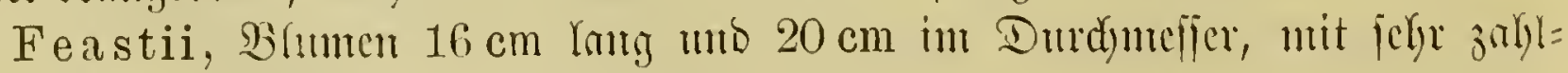

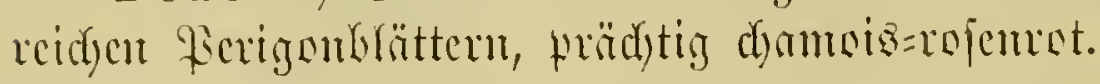




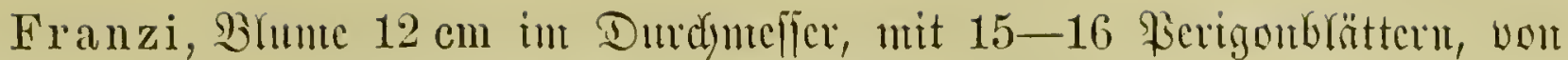
benen bic änfieren fitsurladyrot, bic imteren violett. (Jig. 84.)

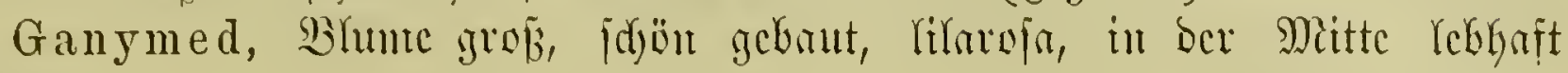
finjodrot.

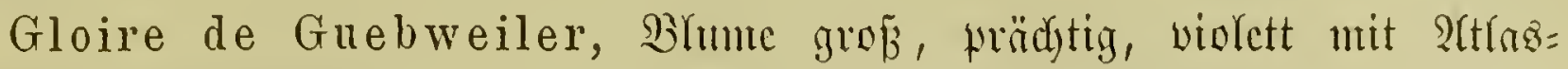

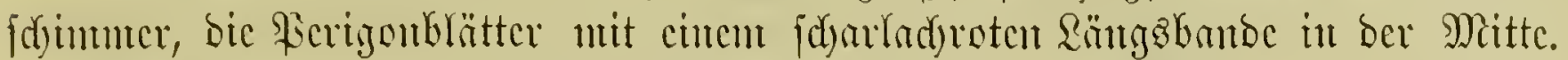

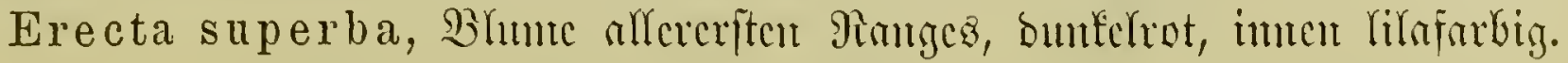

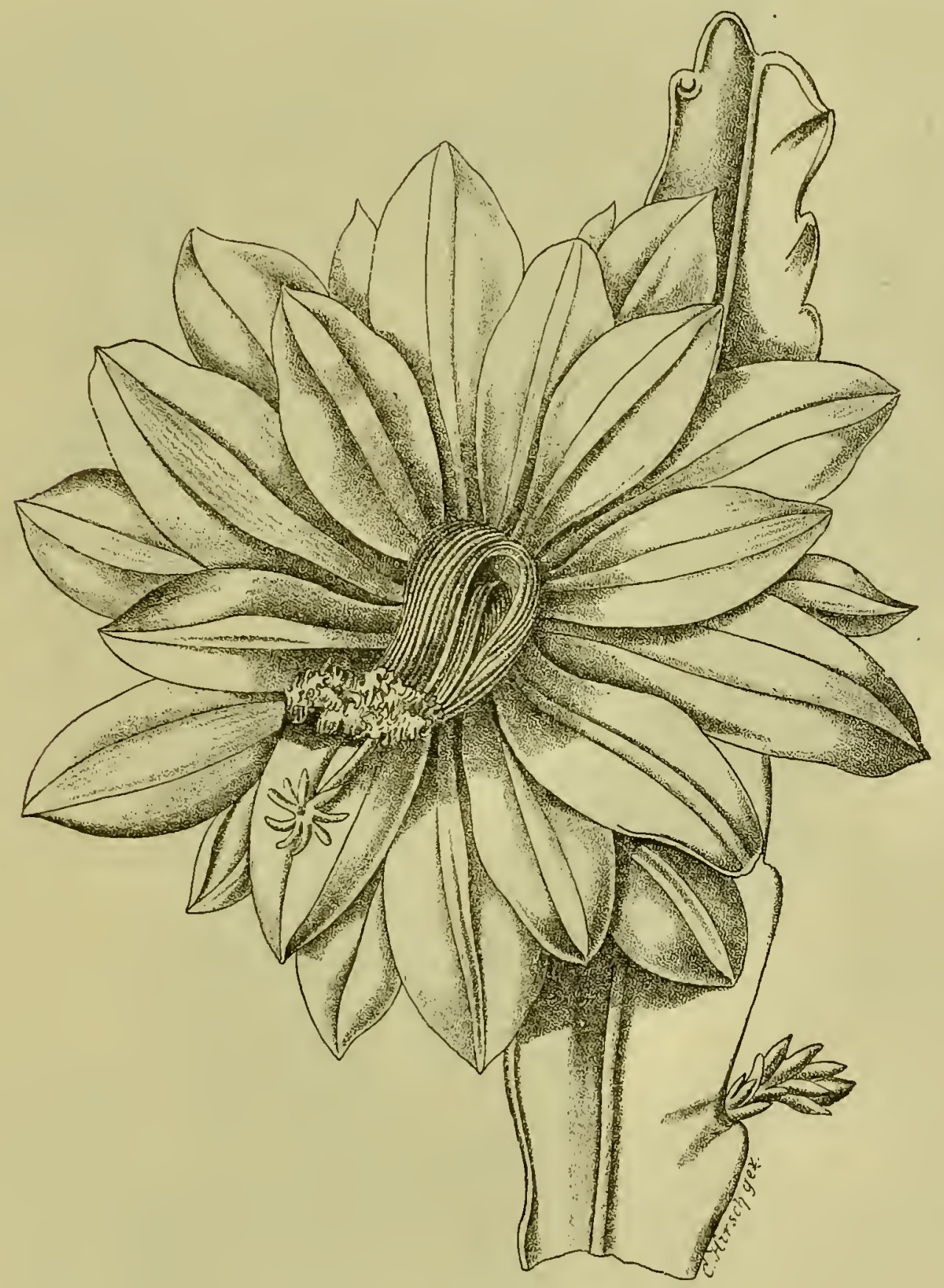

Fig. 84. Phyllocactus hybridus Franzi.

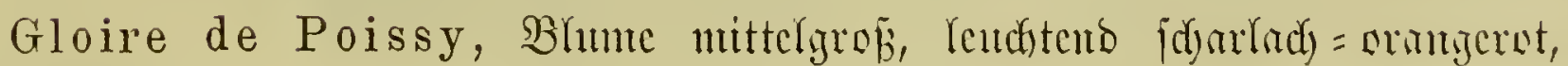
biolett Gorbiert.

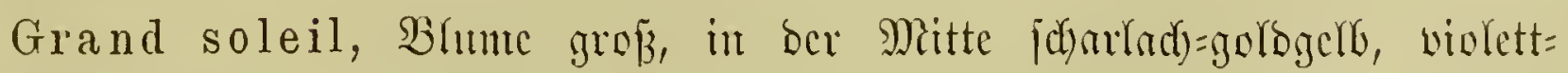
Fencrrot germbet.

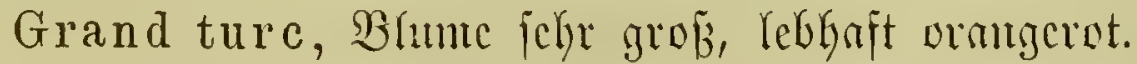

Grenat irisé, B̉hme großj, auggebrcitet, grmatrot mit fammetartigem Edjummer. 


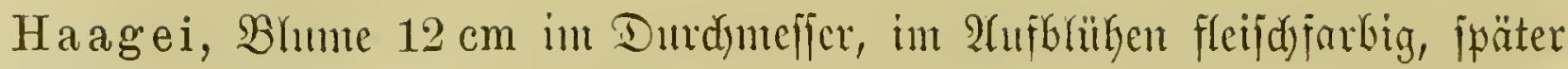
farmutura.

Ignescens, Bhume $20 \mathrm{~cm}$ im Durdfmeffer, flad) anzgebreitet, feurig= butfelfidartadjrot.

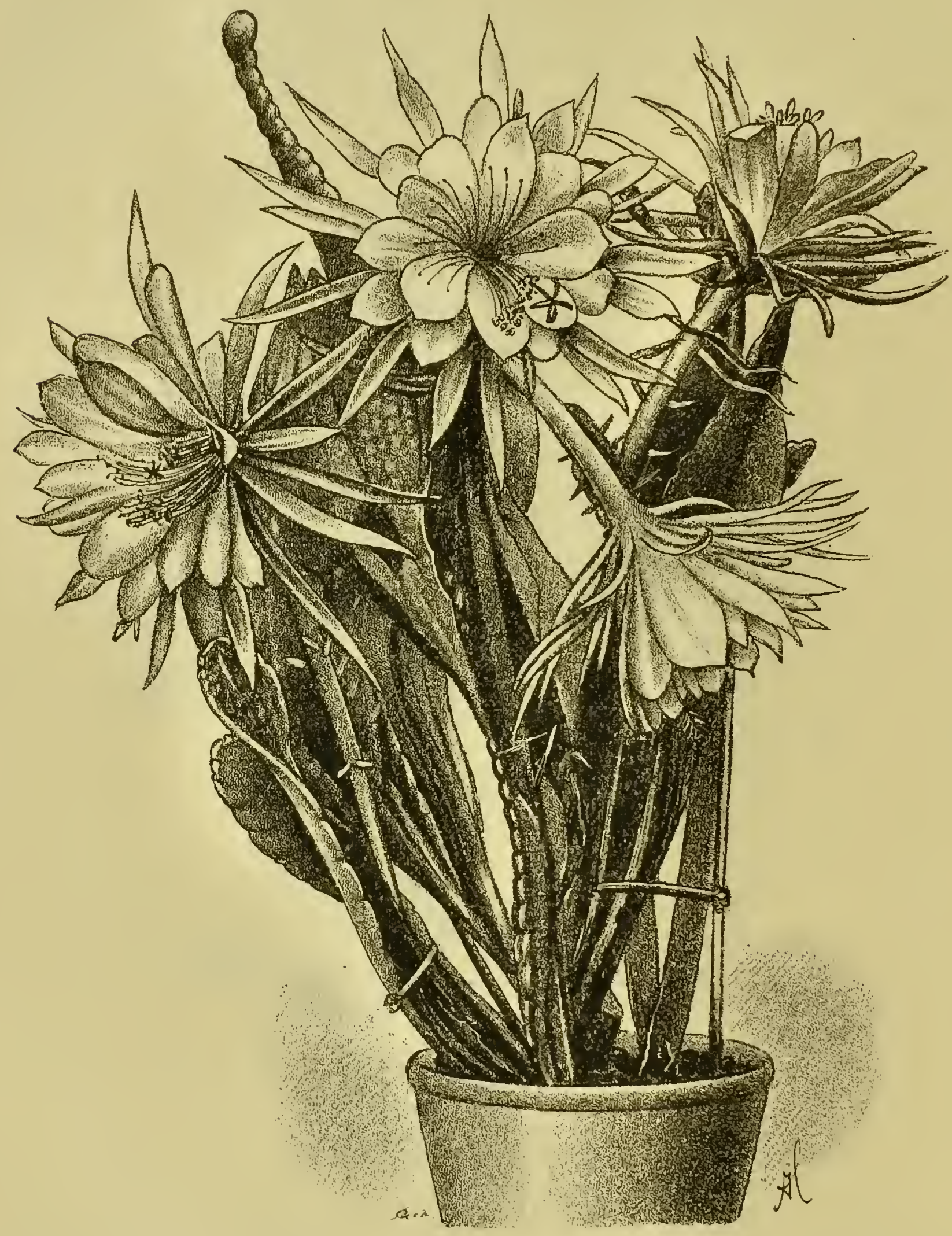

Fig. 85. Phyllocactus Pfersdorffii.

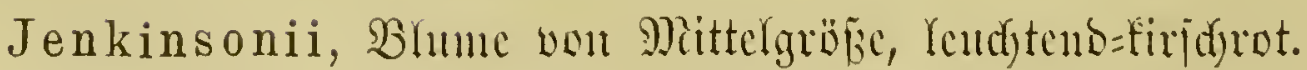

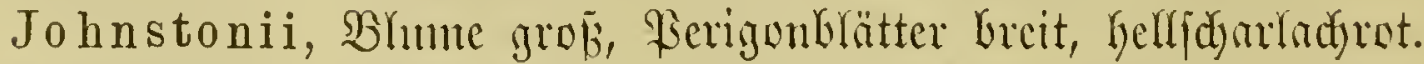

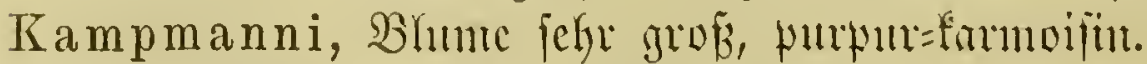

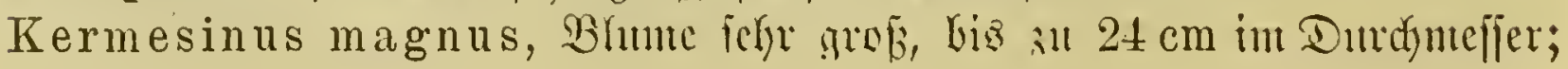




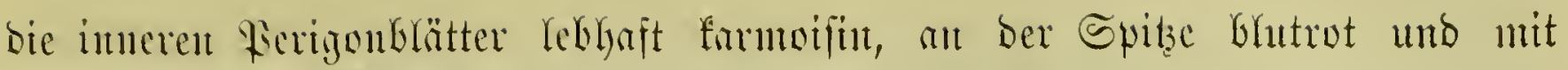

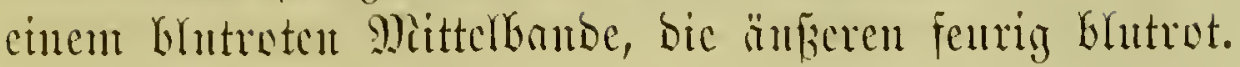

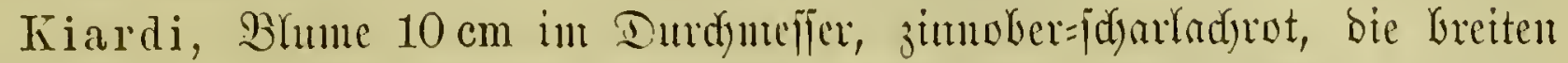

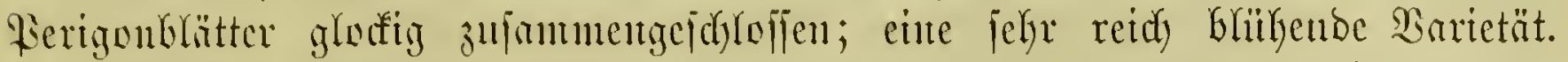

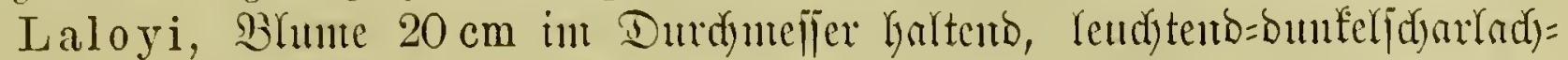
rot mit bläulidem Sdjumer; Perigonbrätter $12 \mathrm{~cm}$ lang und $4 \mathrm{~cm}$ breit; eine

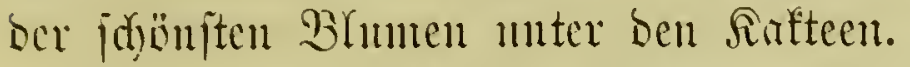

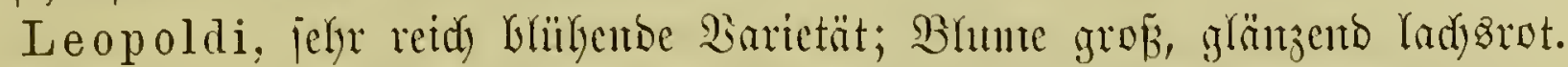

Lorenzo Courant, Bhume grob, vou herrlidyent Ban, purpurviolett.

Madame Courant, Błhmen fleijd) frutbentrojemot.

Madame Edmond Courant, mux mittelgroje, aber gans reizenbe Błume vou zartent Rifafolorit.

Madame Lemaître, B̧hume grobj, wohl gebaut, cerijerot.

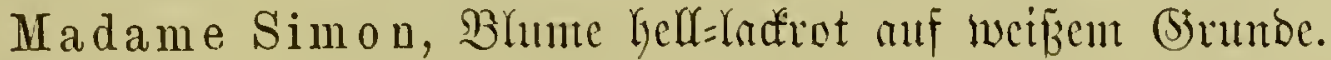

Multiflorus, Bhumen meift in grober Menge anfreteno, mittelgroßß, reuditeno idjurliadyrot.

Neuberti, Blume finmoifinot, bläulidy judumterno.

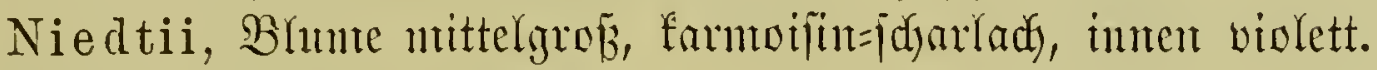

Niveus, Blume reinueij.

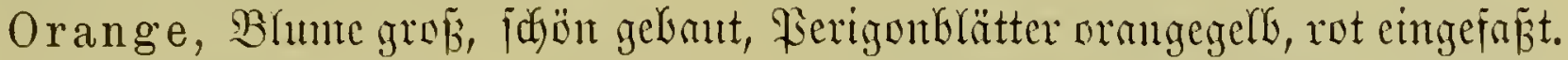

Pfersdorffii, Błumen von $20-23 \mathrm{~cm}$ Durdumefier, angentym Duftend, rein weif, inten mehr ralyntweif (Fig. 85, ऽ. 154.).

Phyllanthoides Général Garibaldi, Błumen jelyr groj̉, juarlady, mit farmotiumoten Gdyeir.

Pluton, Blume außerorbentlidy grob, Berigonblätter jantal und iptbs, lebrait orangerot.

Preisleri, mittelgroje Bhe Bume mit breiten Perigonblättem, Yend)tend jadruadrot.

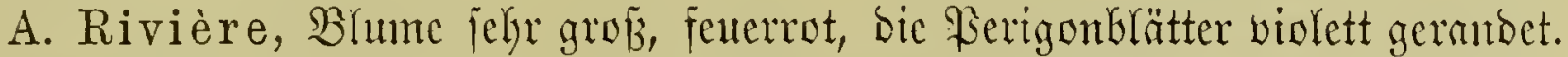

Roseus grandiflorus, BYlunte $17 \mathrm{~cm} \mathrm{Kang,} \mathrm{mit} \mathrm{Cinten=lanzettförntigen,}$ weicfitadyelpibizen Perigonblättern, roja=lila.

Roseus perfectus, Bhume zwax mu flem, aber won jöner, jart=biolett= rojentroter Färbung.

Schlimii, miț breifantigen 2(eiten, Bhune von etwas tridbterförmtigem

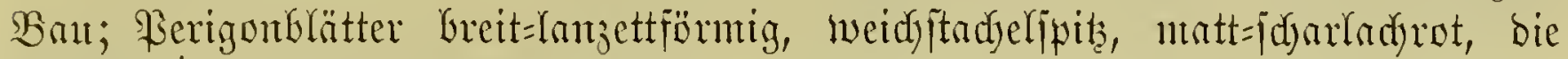
unteriten mit violetten Mitteljtreifen.

Selloi, Bhume jefr grob, Yeudjtend=biolett, an ber Eptise ber Berigun=

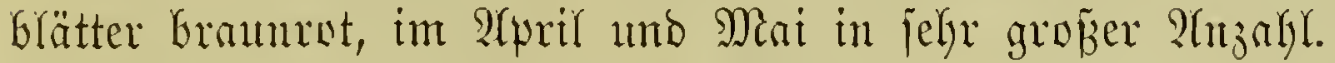

Speciosus albiflorus, Bhume $12-15 \mathrm{~cm}$ in Durdmeljer, weib, nad) ben (Sirumbe ber Rerigonblätter bin etwas gelblid.

Triomphe de Poissy, Bhunte jefre grob, jefre jübu gebant, Perigon=

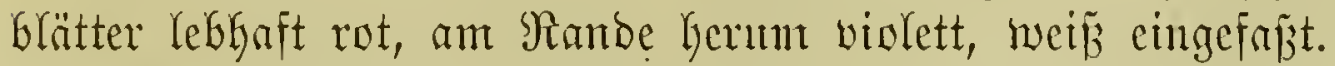

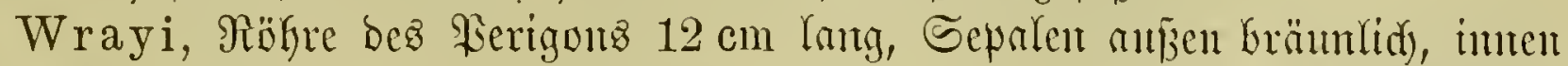

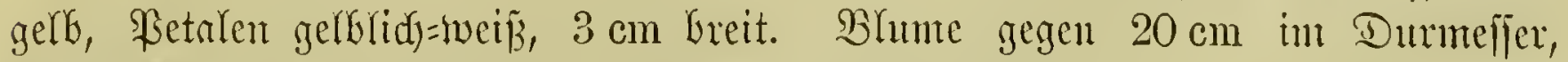

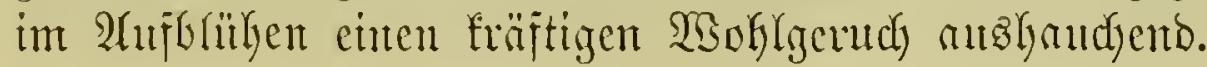




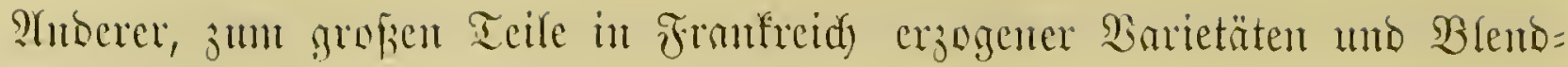
linge wolfen mir rier nidst weiter gebenten.

Die Sultur ber Brattfaftus ift nit feinen bejonberen Ednuierigfeiten ver=

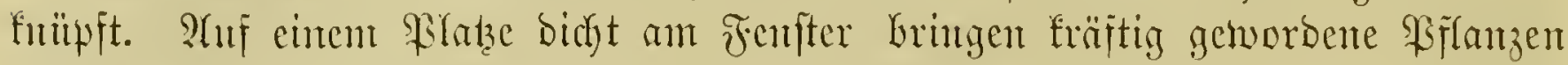

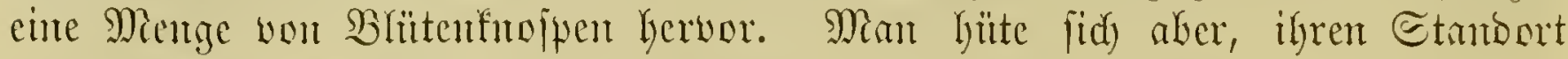

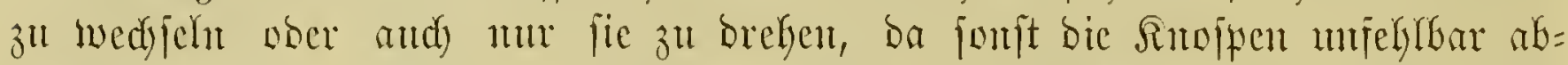

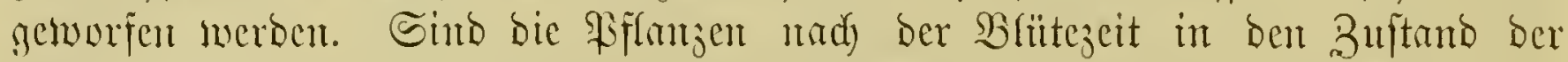

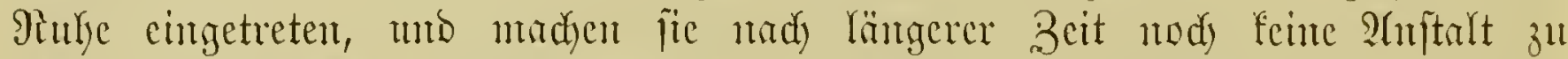

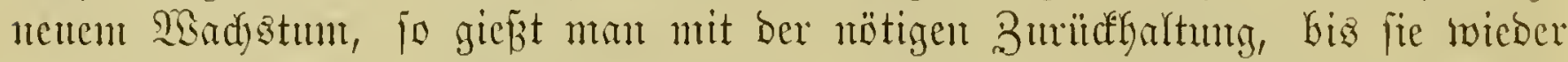
in Segetation treten, verpflangt fie bann, joweit fie befjen bebourftig, verjebt fie

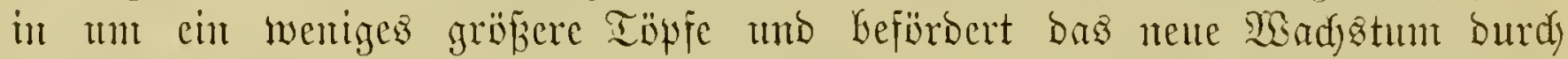

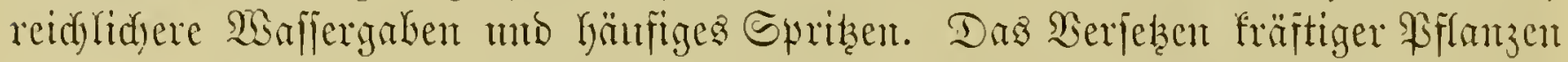

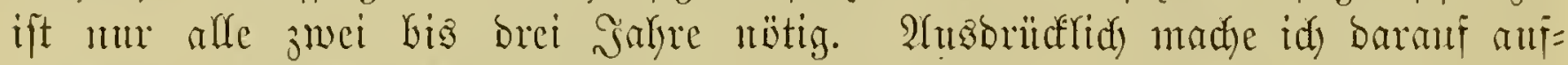

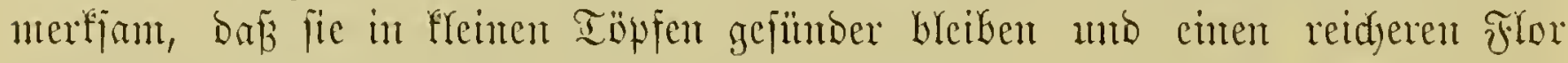

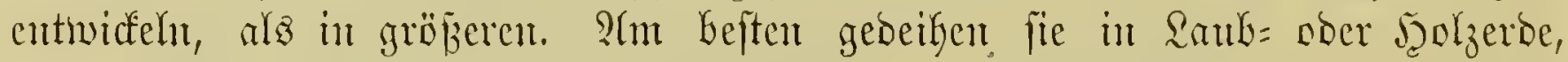

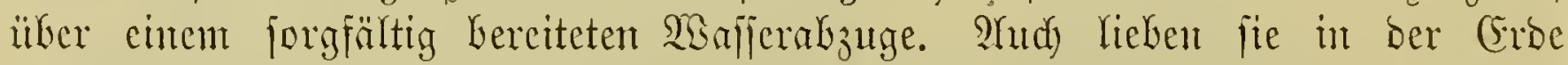

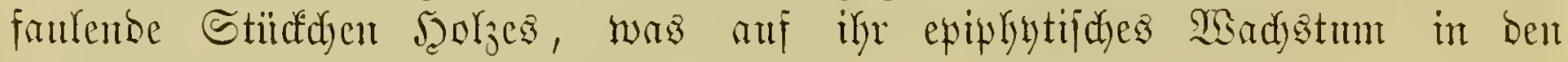
Itrwälocur iffer Secimat Kintocutet.

Sat man cinen unfaffenteren Beftand bon Biflanzen, fo ift es yorteiflyaft,

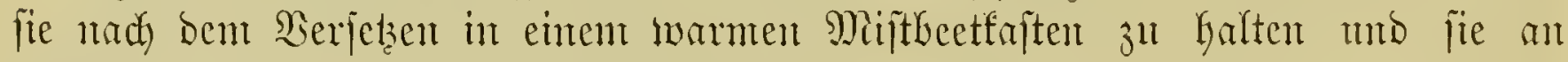

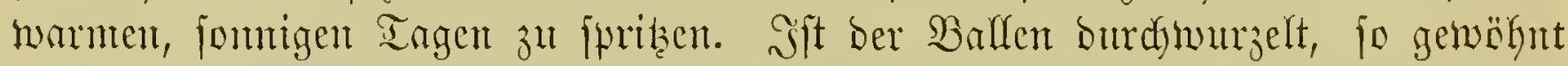

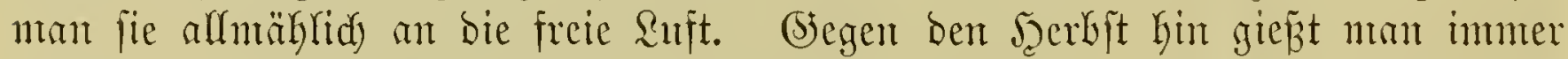

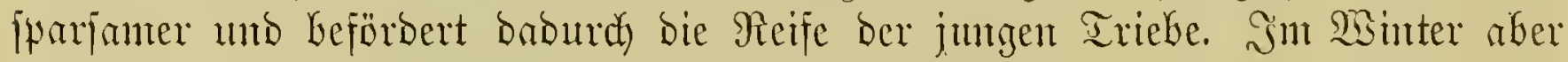

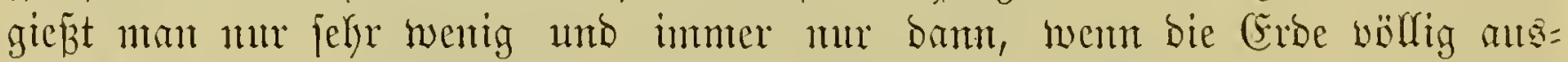

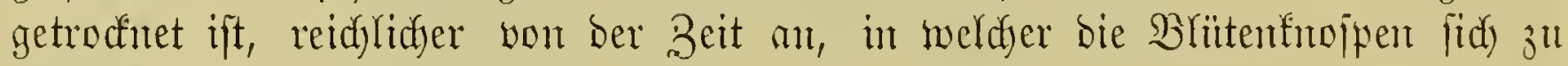
cuttuvicfern beginnent.

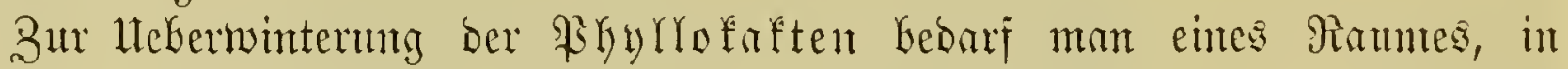
Dent eine Temperatur won $+10-120 \mathrm{R}$. muterhalten wirb unto eines helfen, jomigen Etanoortes; Phyllocactus Ackermannii un Ph. phyllan-

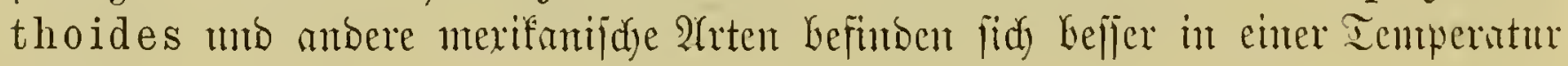
vou $m$ mu $+3-5^{\circ}$.

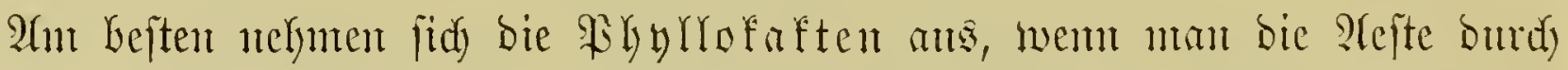

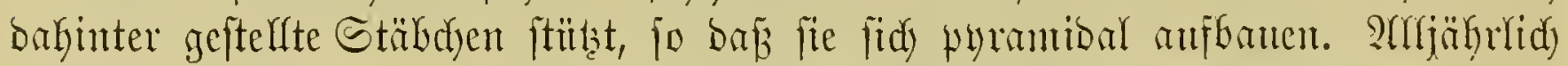

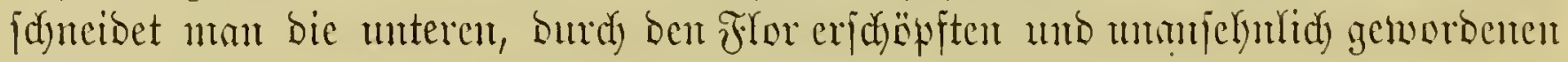
Tejte ab.

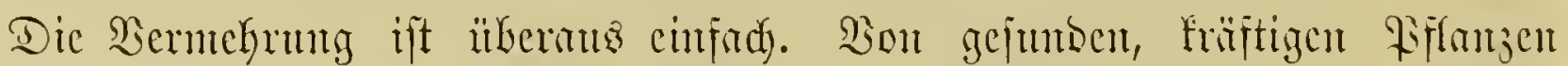

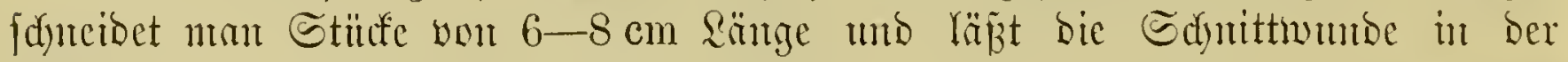

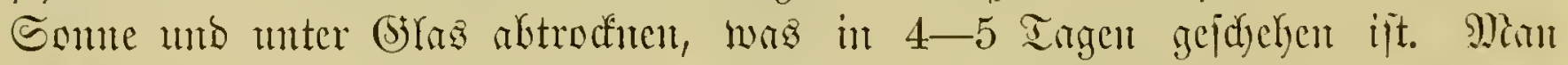

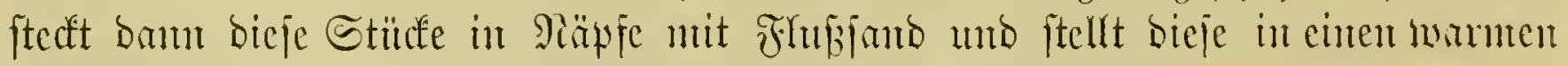

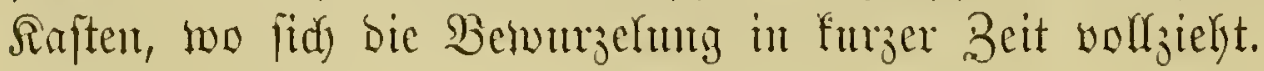

\section{5. (S)attung Disisocactus Lindl. Bierblattfaltits.}

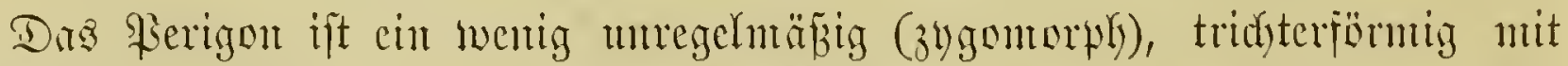

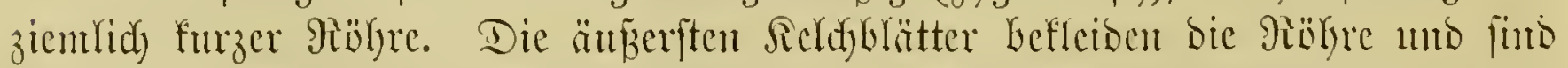

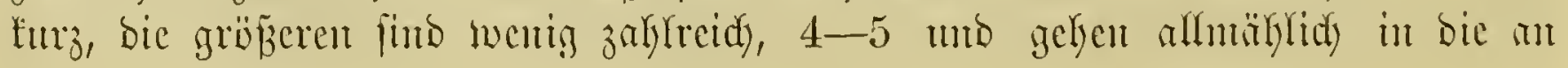




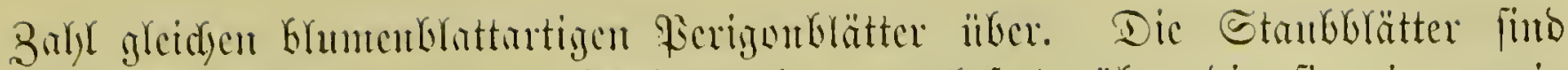

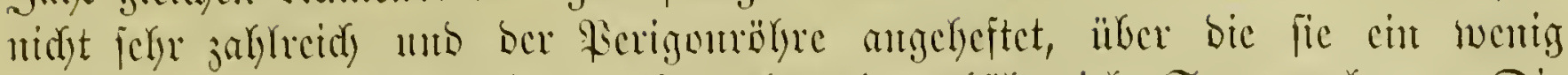

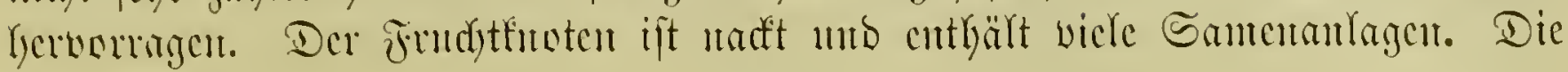

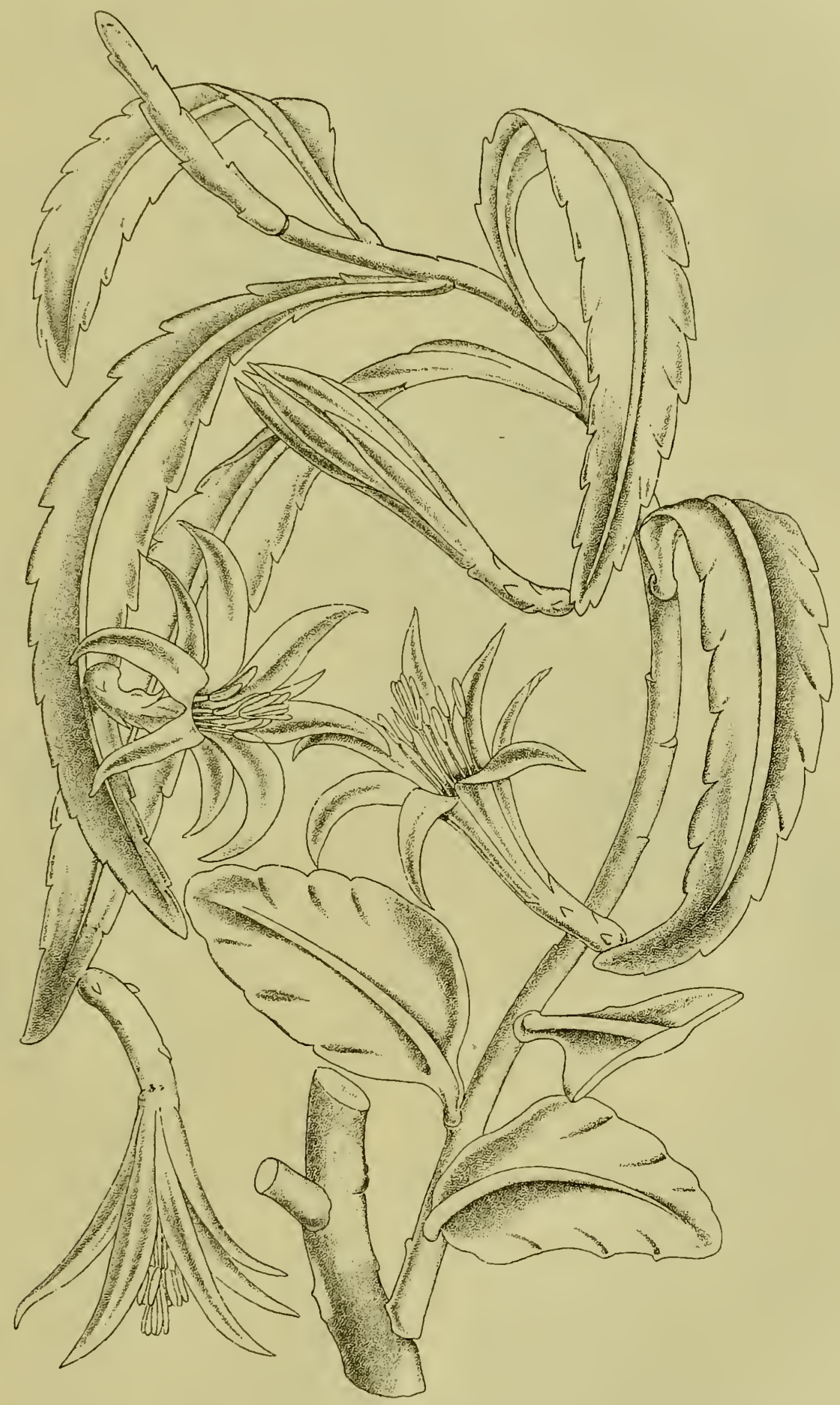

Fig. 86. Disisocactus biformis Lindl. 3wiegeftaltiger Bierblattfaftus.

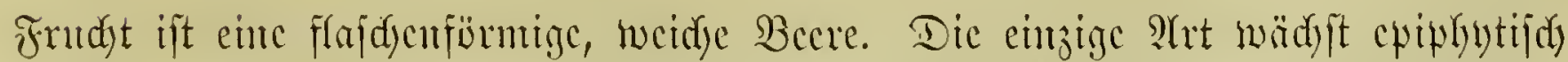
auf Bäumen, yon bencn bic Bweige herabfängen. Die äYteren merben ftichuno 


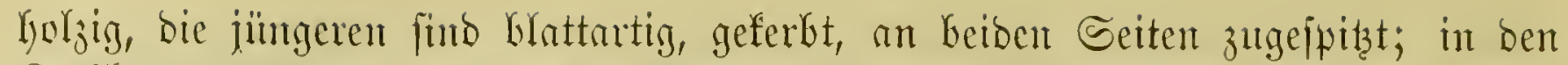

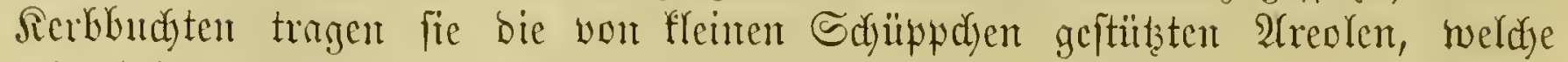

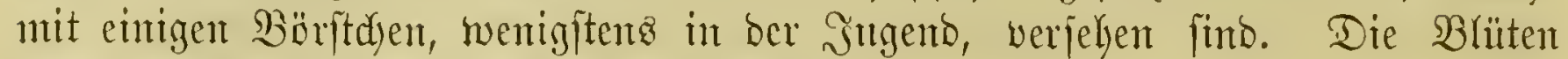
treten anz ben wberen 2heolen ber Bweige.

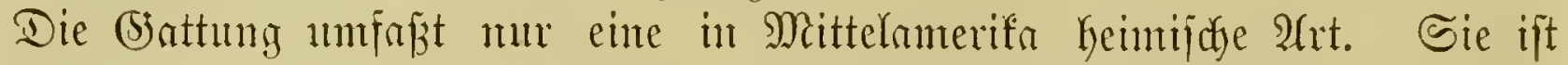
won Phyllocactus mu burd bie geringe Bahl ber Glumenblattartigen Perigon=

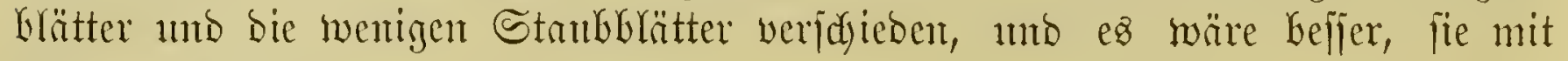
ifyr 3ut verbinton.

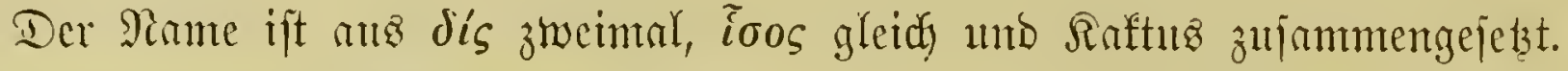

Disisocactus biformis Lindl. (Disocactus*) biformis Lindl.) Bwicgeitaltiger Bierblattfaftus.

Die Pffrange ftellt einten werzweigten $60-100 \mathrm{~cm}$ hohen Etraud bar, befien Stamm im Topfe mur burd) Stäbe aufredjt gefyalten werben finm, ber in ber

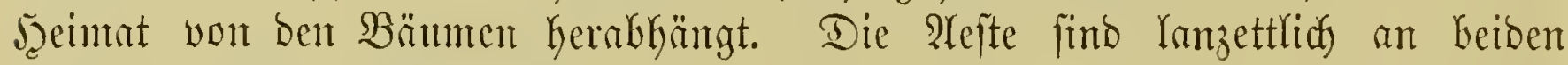

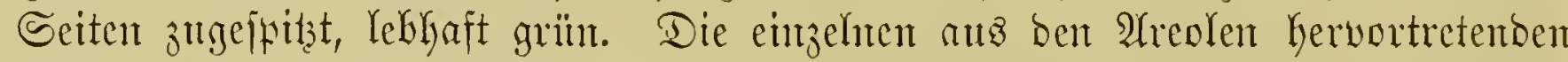

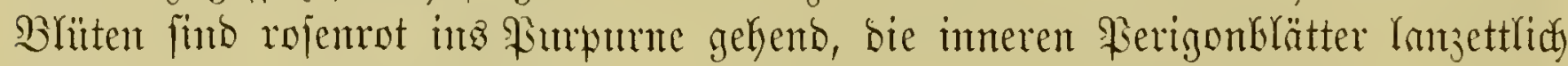

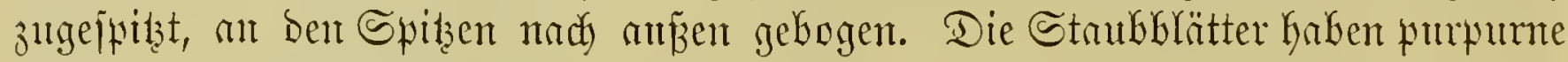
F̈̈̈bent uno weißze Bentel. Die Frutht ift rot.

Dieje fäöne undo intereijante Siflanzenart erforbert jum (jobeiben einen redyt

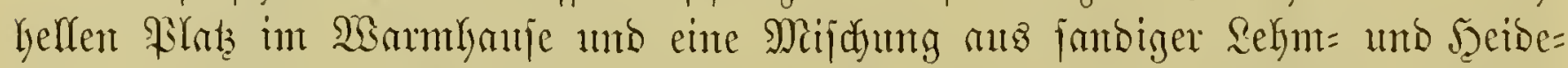

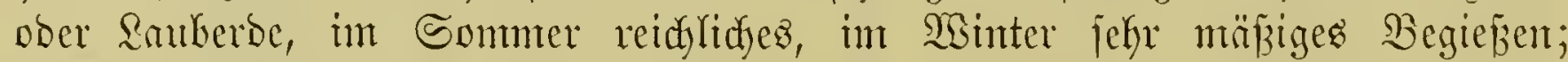

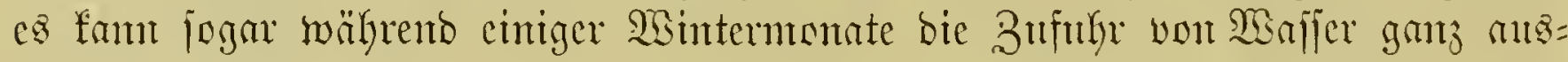
gejez̧t werbent.

\section{Battung Epiphyllum Pfeiff. Bliederblattfaltus.}

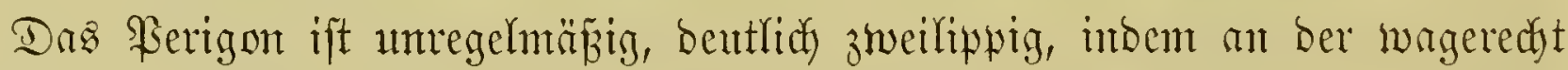

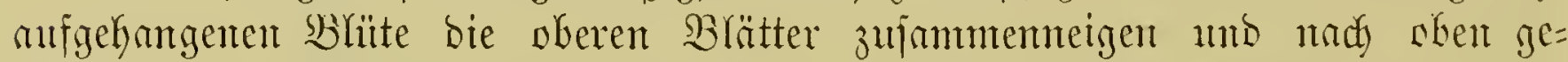
frümmt, bie unteren gernbe vorgeftredett ober nad) unten gefrünmt finto. Die

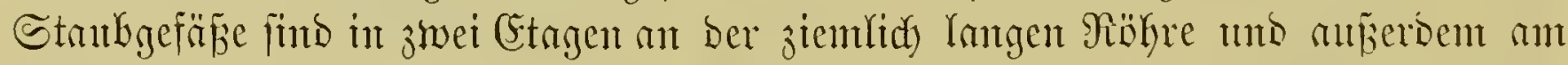

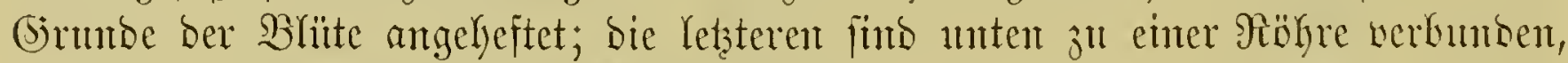

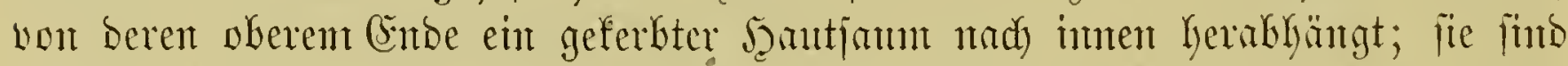

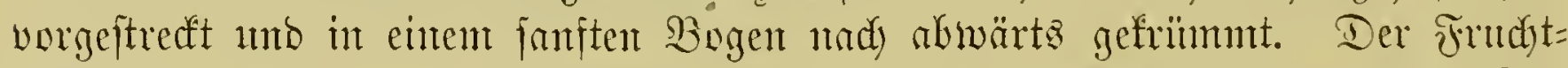

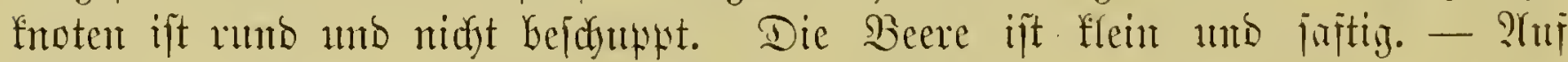
Bäumen wadjento Sträucher mit jehr verjweigtem, gegliebertem, holzigem

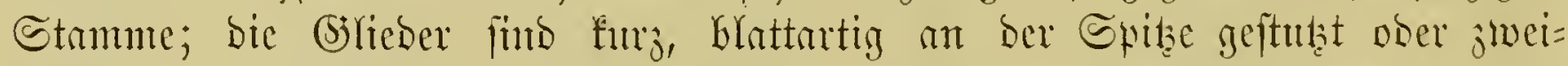

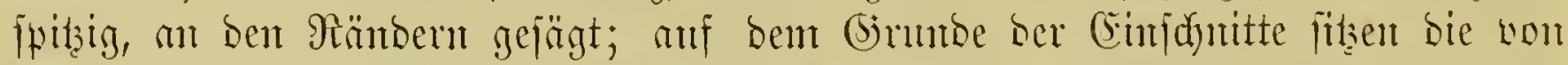

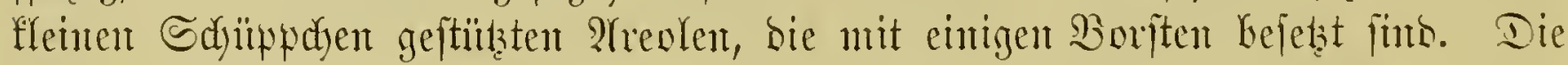

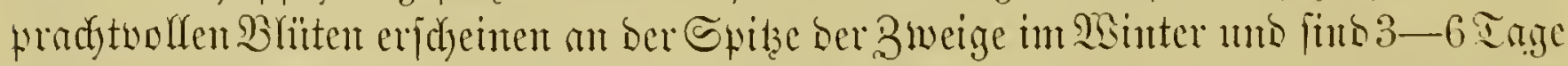

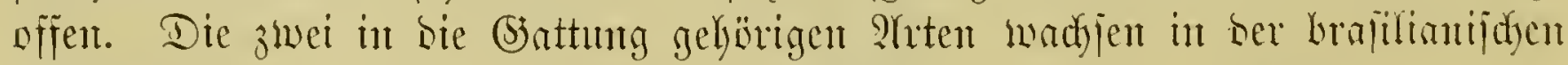

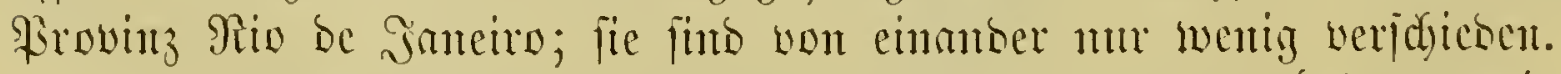

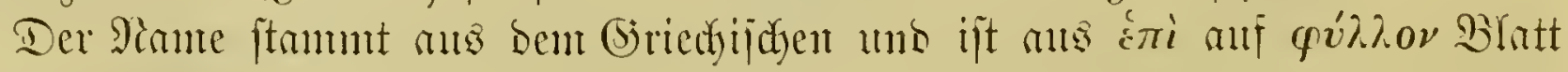
ònjammentgcję̧t.

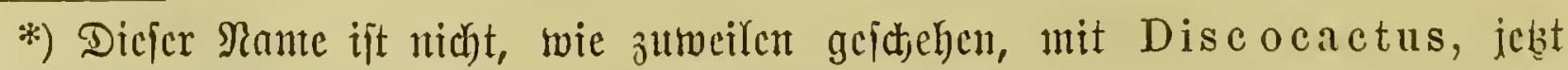
cine Seltion bout Echinocactus zul verwedyjern. 


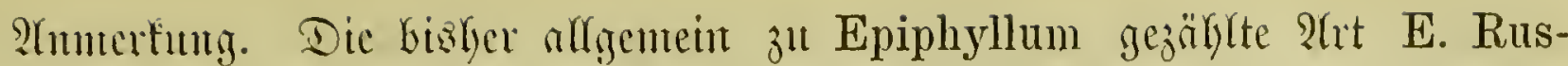

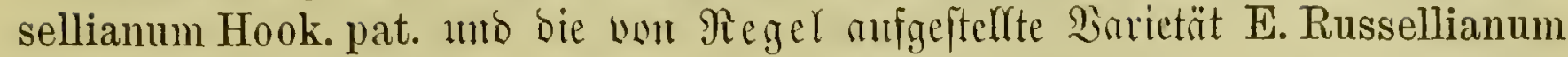

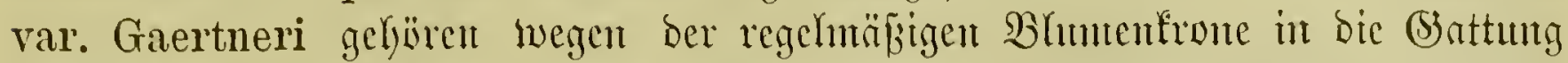

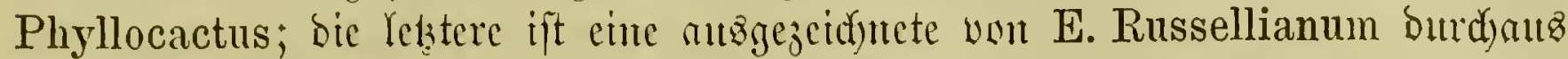

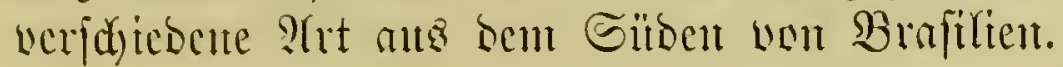

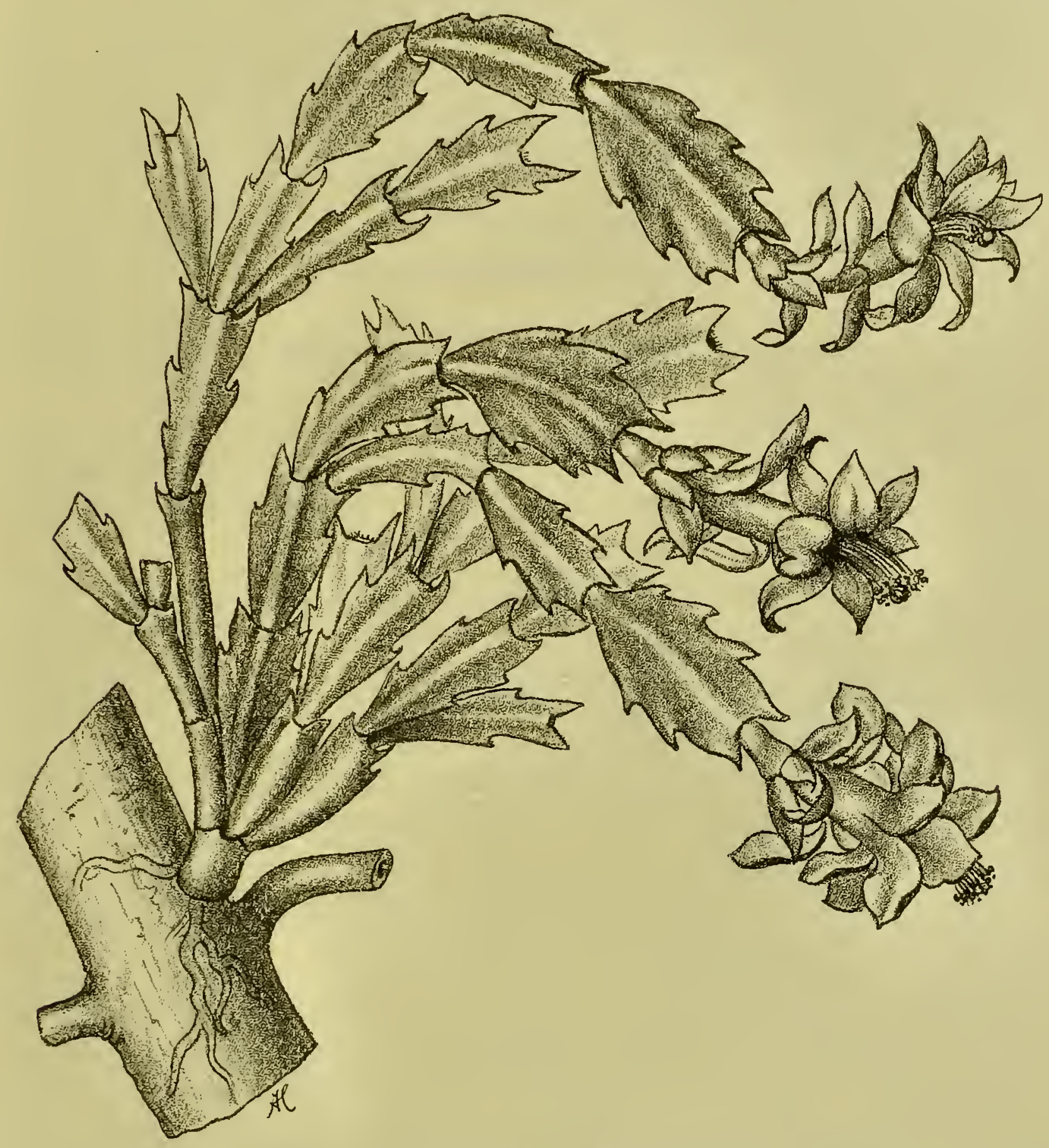

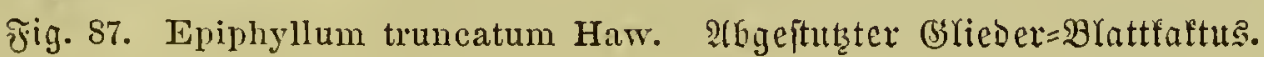

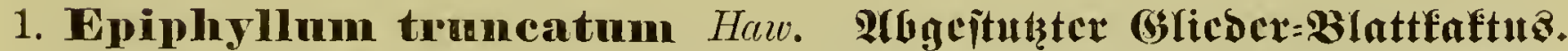

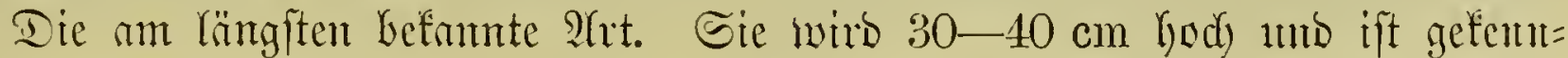

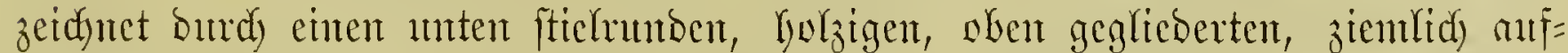
redjten Strmum uno int Bogen Kerabhängente, pumpurrot germibete, fadwads

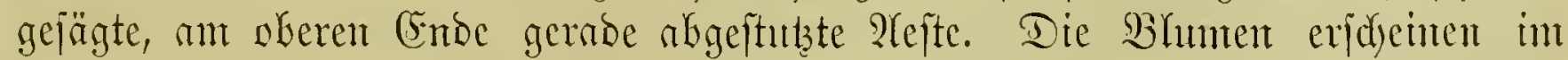

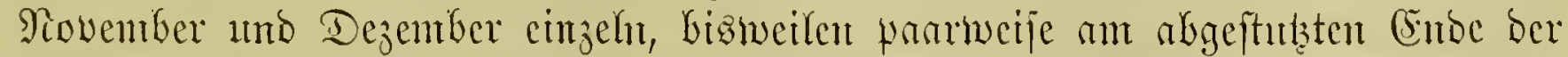

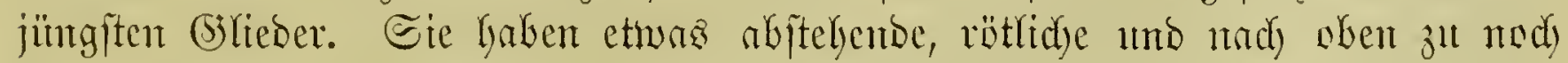

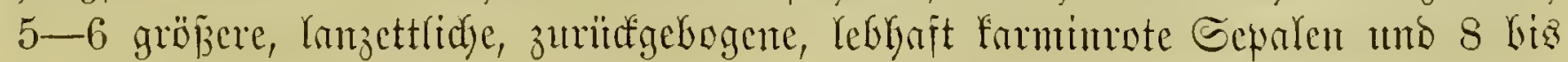




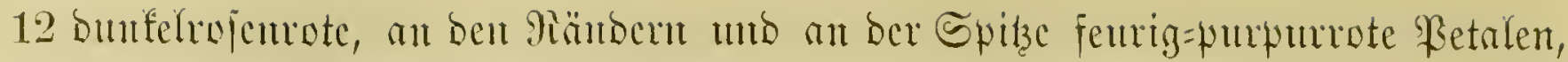

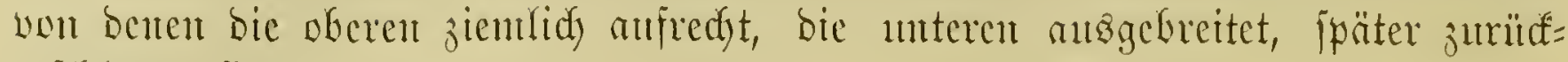
gejdylagen fint.

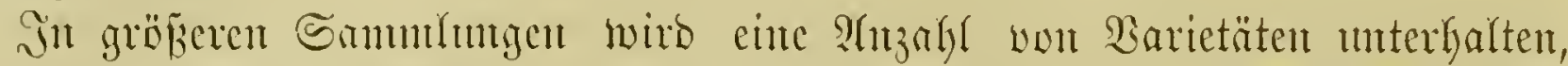

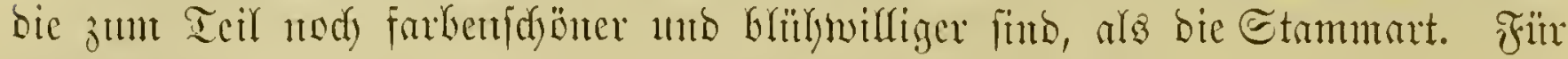

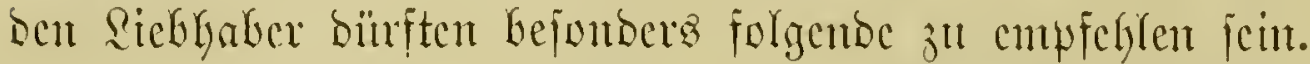

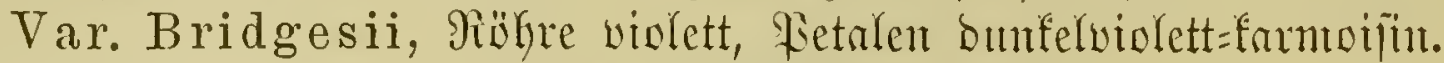

Var. coccineum, Bhumen jomilad)wot.

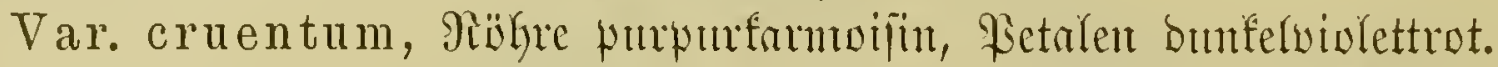

Var. magnificum, Ferigombibre rojaviolett, Fetalen bunfelrot.

Var. multiflorum, Bhanen orangefdarfad).

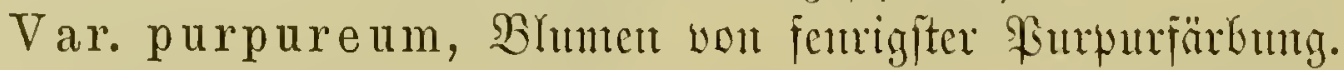

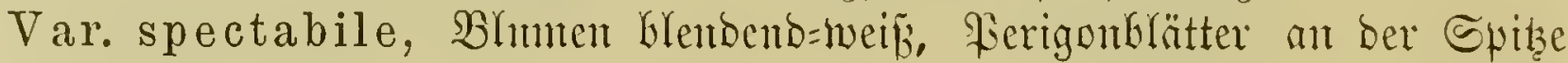
firmtimoja.

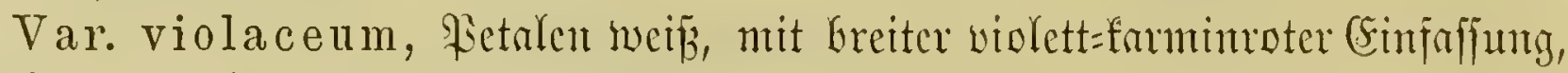
Staubfäben wciß̄, Briffel pumum.

Sarkyfdeinlid ift Epiphyllum Rückerianum, bie oft für eine be= jonocre Ât gelyalten wirb, aud) nur cine Sincietät bes E. truncatum, biejem

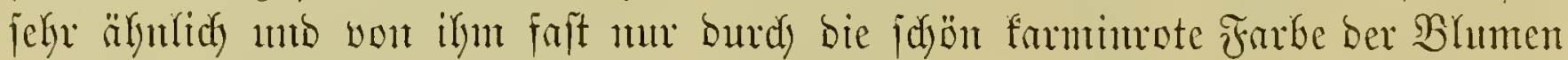

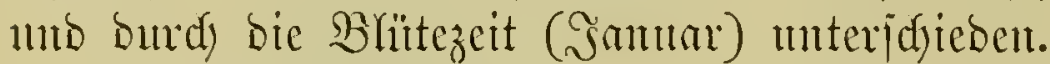

Frobuft einer Rreujung beß Epiphyllum truncatum mit cincm Cereus ober Phyllocactus ift Epiphyllum Makoyanum. Dafjelbe befitst eine Błhite

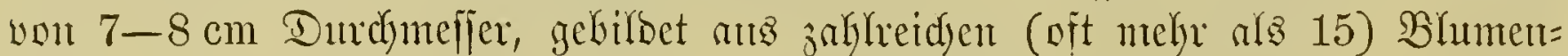

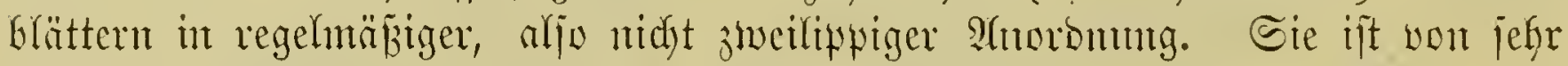

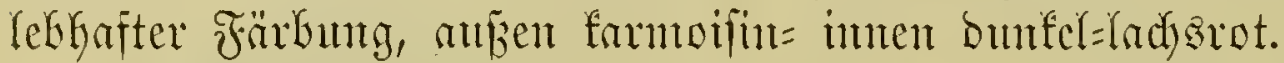

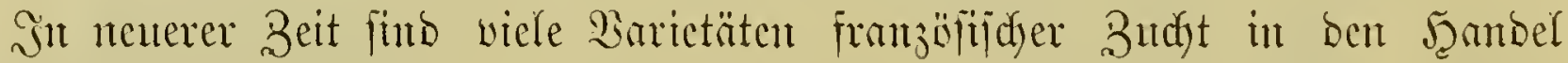
gefommen. Das Jommal "Revue horticole" empfichlt vor alfen anberen folgentid:

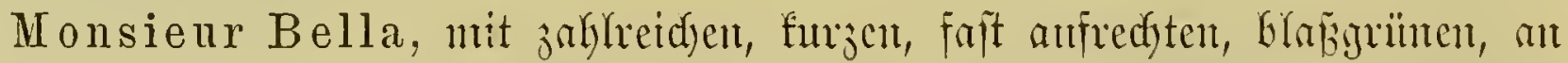

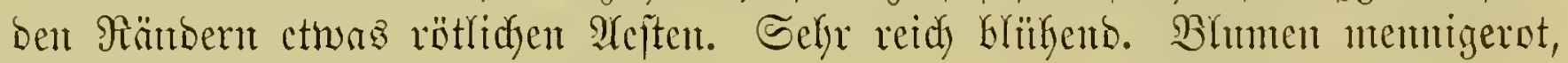
in ber Mitte fleijdfrirbig=roja.

Madame Edouard André, Bltmen wolffommen angigereitet, rojemrot,

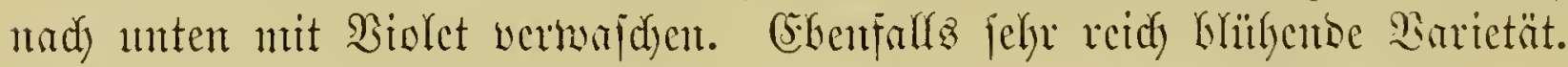

Monsieur Edouard André, bic jahlreidyen Stänme tragen etwas

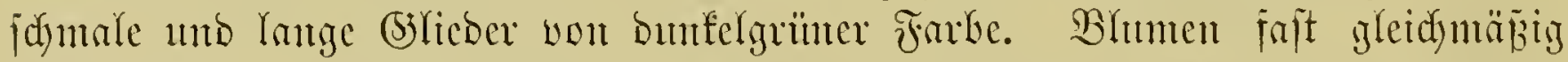
bunfelviolett. Der fehr reidje Flor fälat in bie Mionate Dejember unb Jantar.

Monsienr Chatenay, faft aufredyte, furje, Greite, grünc, an ben Piänoen

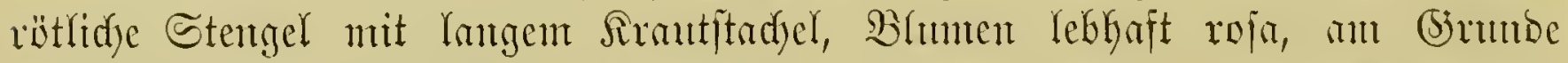

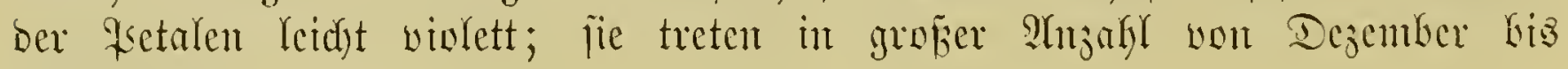
Februar auj.

Monsieur E. Madelain, lanje, jiemlid) amfred)te, Geffirtüt Stenjer.

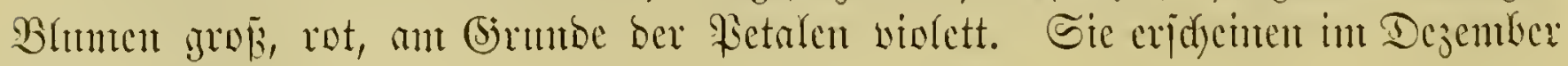

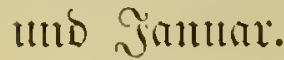

Prnbere in menefter Beit in ben Jember gegebente Barictäten Guben vor ben Gier anjefï̈lyrten nidyts vorins. 


\section{Npiphyllum Altensteinii $P f r$.}

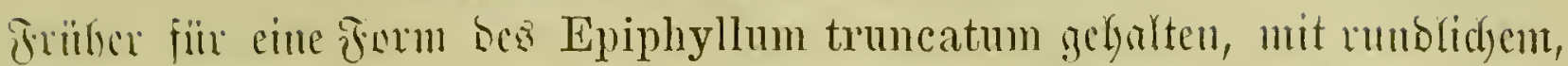

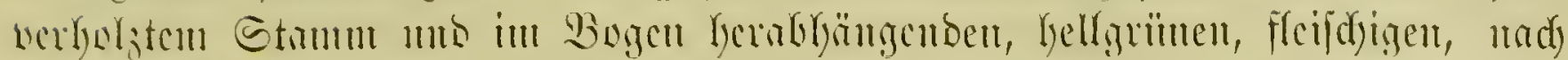

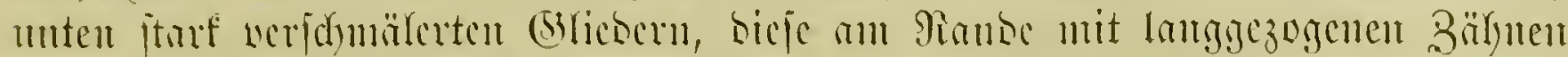

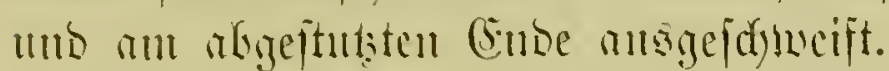

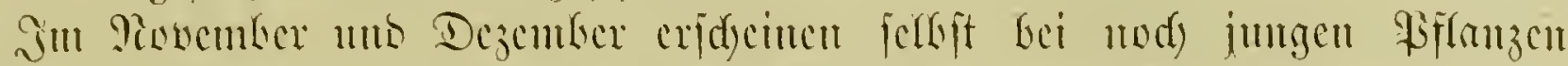

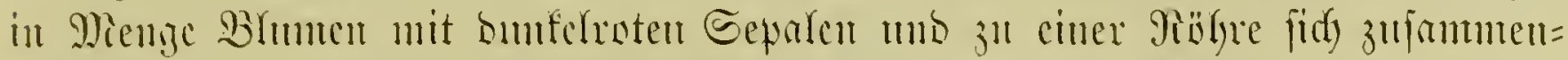

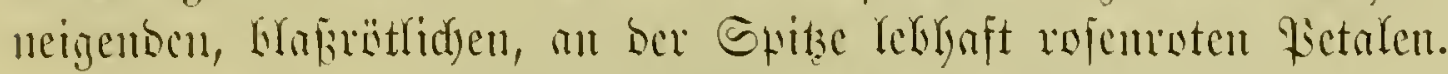

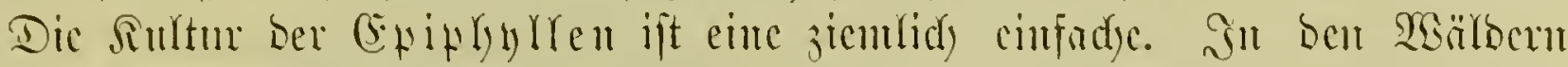

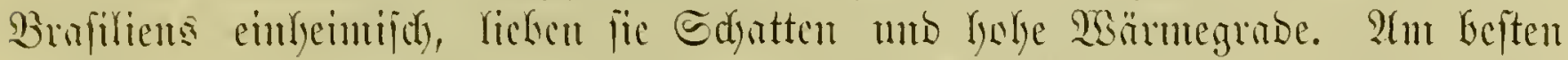

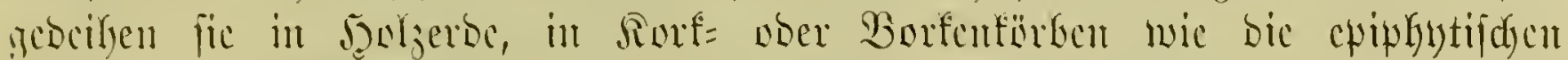

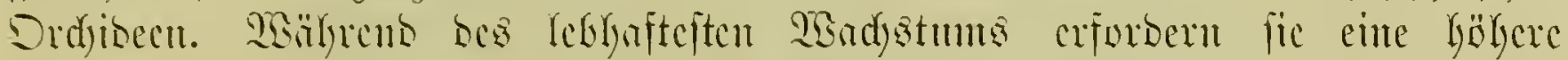

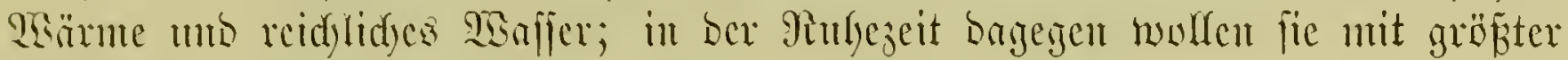
Burinffialtumb gegofien jein.

Sin Stuben ijt cinc Temperatm wou $+12^{\circ} \mathrm{R}$. ansreidyent. Stm meiften

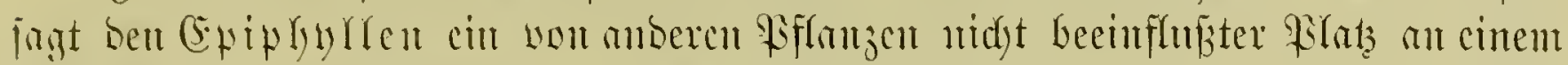

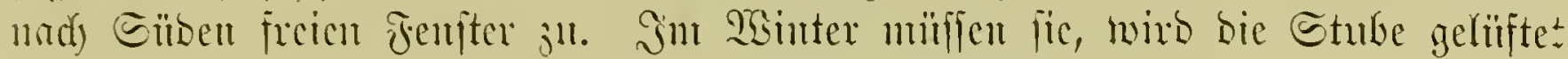

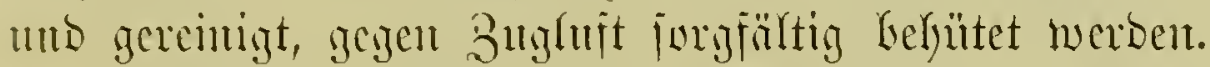

Jin fritherer Beit wurben bic (Epiphylren burd) Etceffinge vermeryet, aber

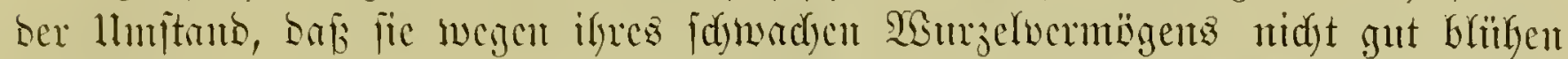

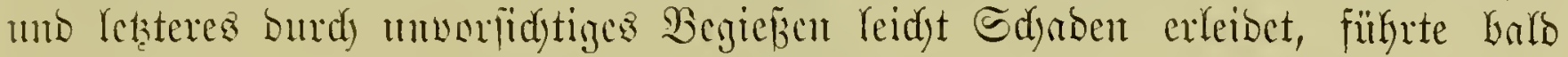

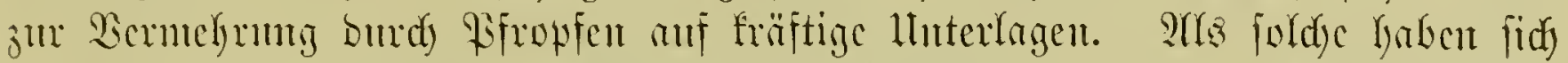
Peireskia aculeata Plum. uno P. subulata Mhlpf., nad) eincr zuverläffïgcn Mit=

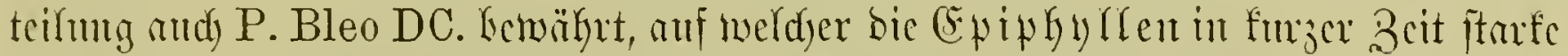

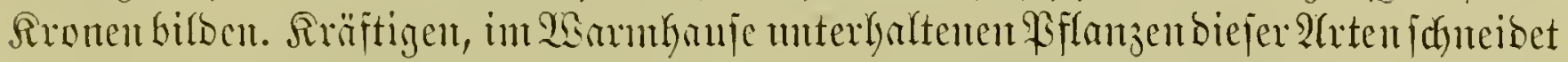

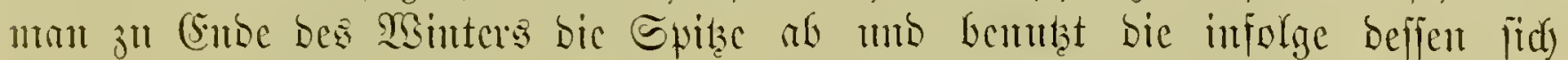

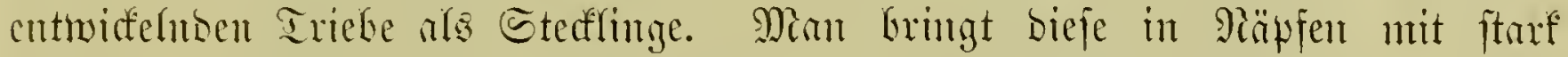

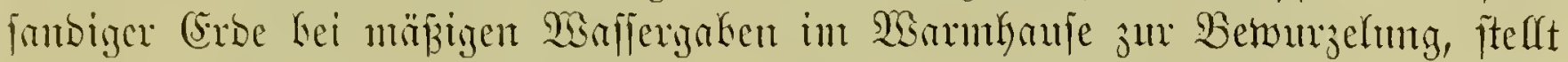

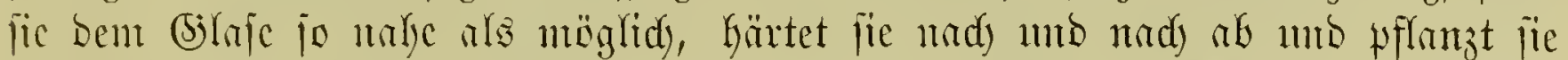

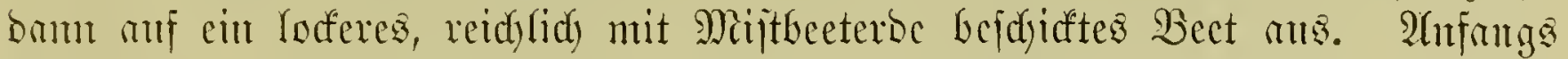
2)

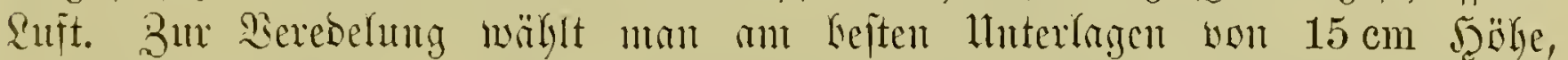

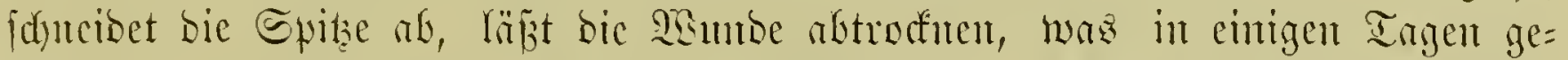

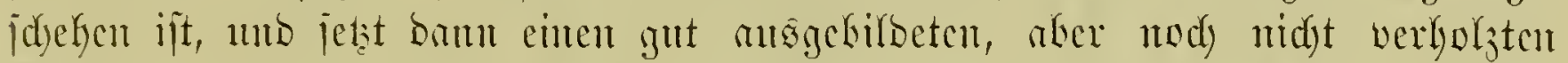

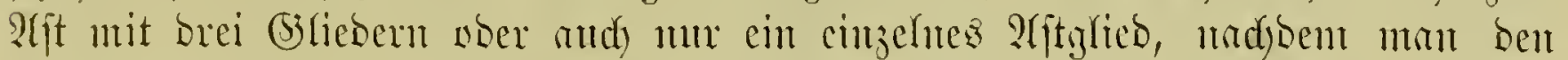
einen coer bas anbere menten etwas jugejdärft hat, in ben jenfredyt gejührten

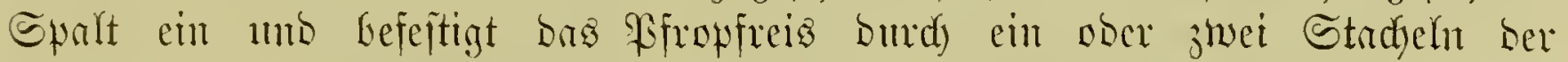
Peireskia ober ber Gleditschia triacantha. Die Riflanjen werben gut burd)=

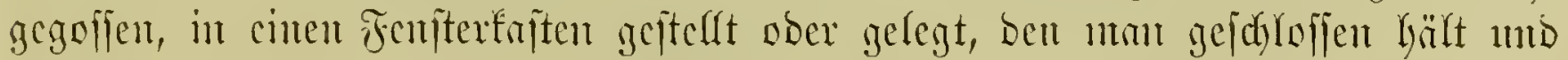

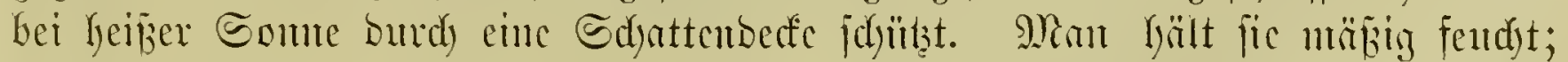

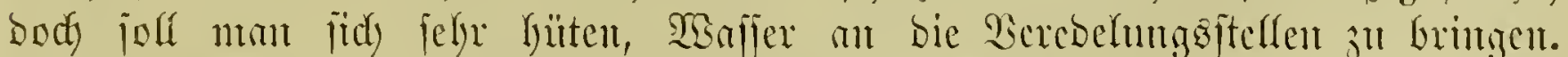

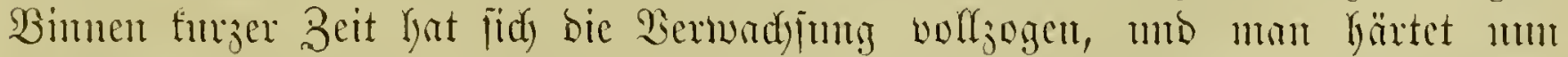

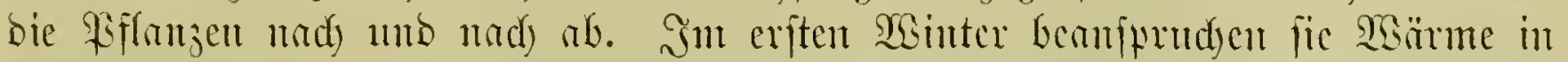

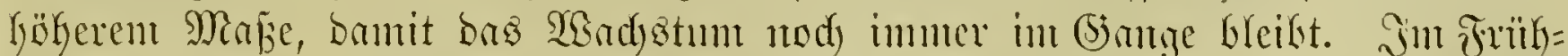

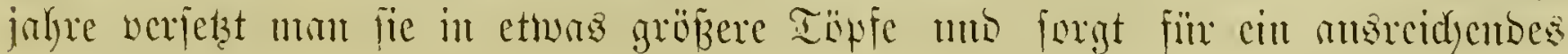




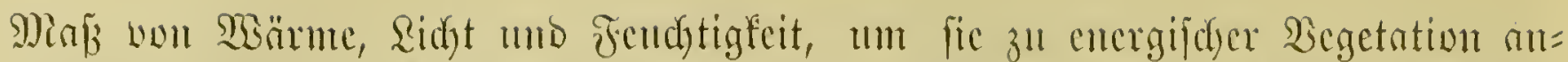

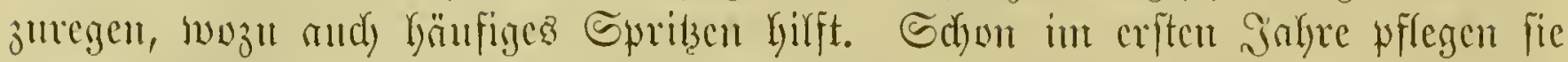

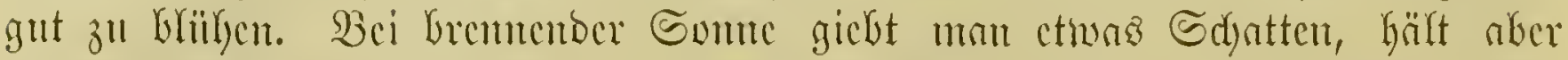

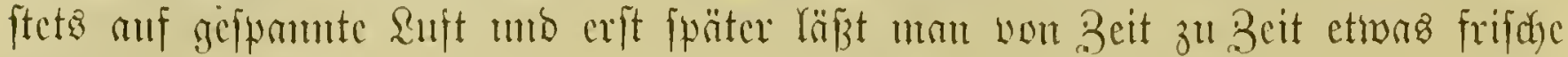
guift žu.

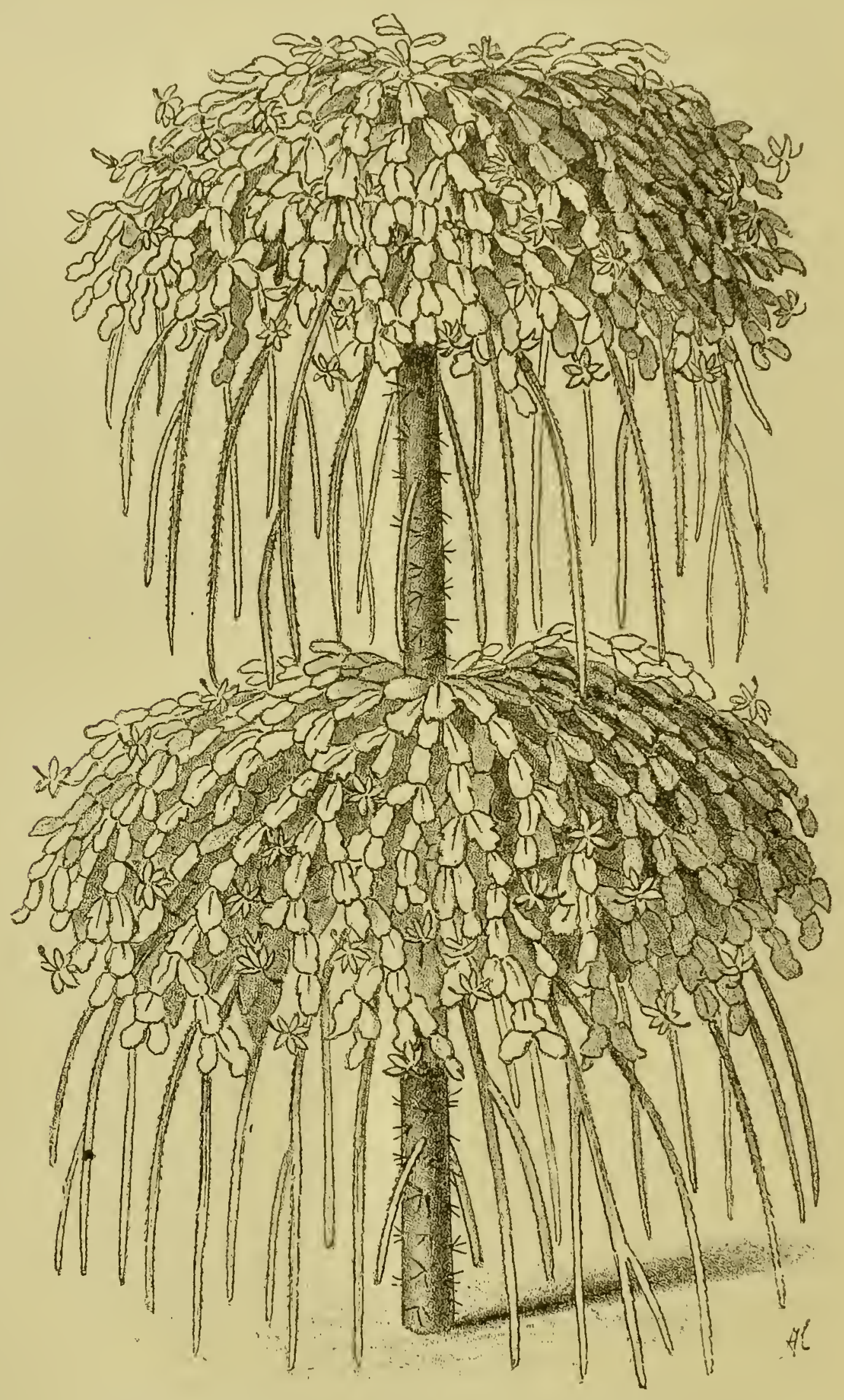

Fig. 88. Epiphyllum mit Cereus auf Peireskia gepirobft.

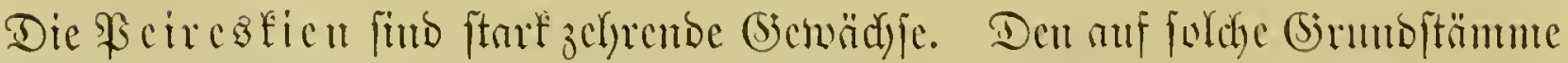

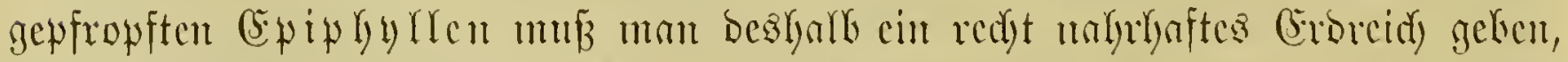

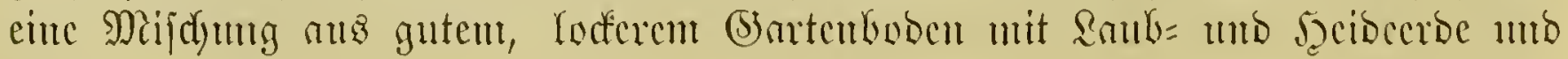




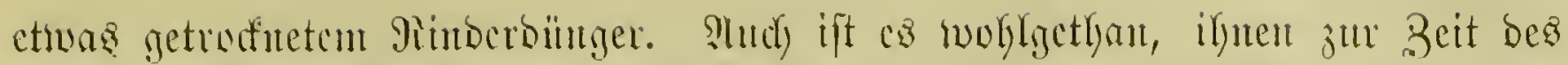

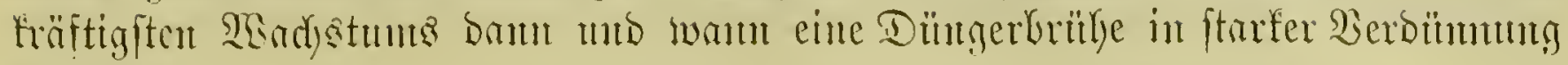
jut reidyen.

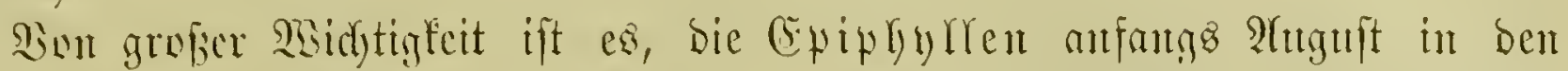

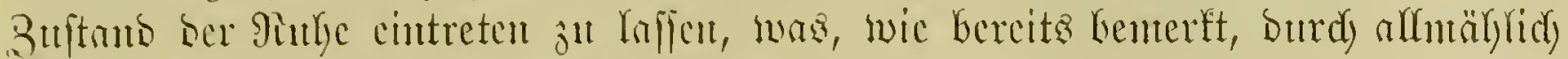
wermintocrte s.

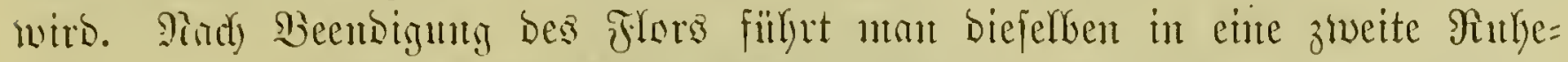

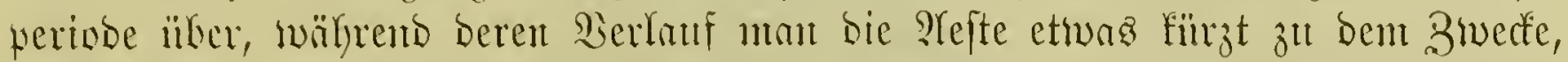

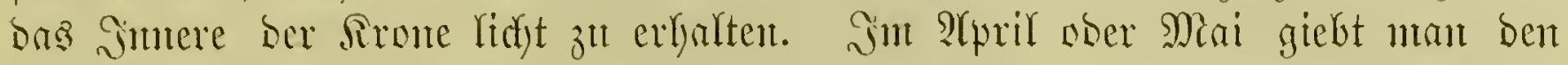
Bifluman frifdyes (arbreich.

Şn gan atagejcidunetem (5ffeft ift ein mit Epiphyllum truncatum unb Cerens flagelliformis gentifoter, in zwei Catrgen bejetzter Peireskia= Stanm, weldyen nebentekente Figur 88, bie auz Gardener's Chronicle entlehnt ift, Dariftellt.

Peben ben von uns ermälynten Unterlagen aber werben eintige CereusTrent, alfen anberen voran Cereus Macdonaldiae zu biefent Bmerfe

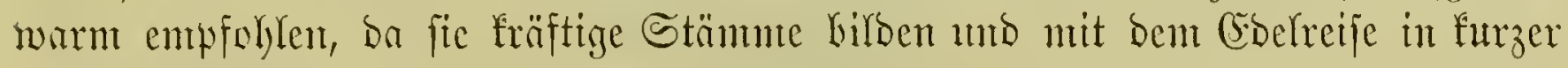
Bcit volffonmen gut verwadjen.

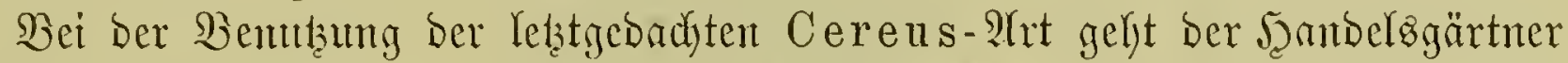

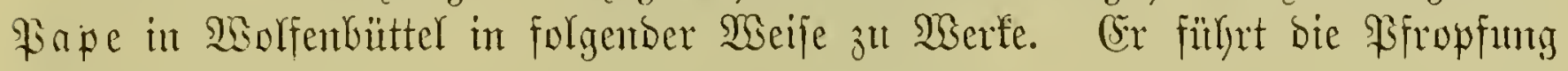
im Februar ats.

Die Sercbelungent werben in einter Iemperatur won $+12-14^{\circ} \mathrm{R}$. unto

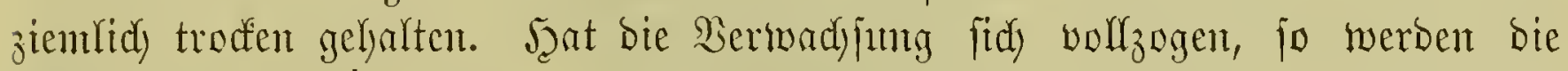
Piffanjen ber volfen Somme auggejetzt unto reidylidyer gegofien, bei bremtenter

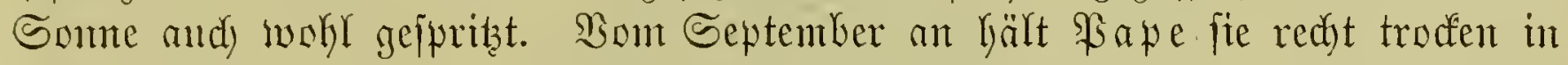
einer Iemperatur von $+7-10^{\circ} \mathrm{R}$. und anf einem Stantorte, ber ifyen im

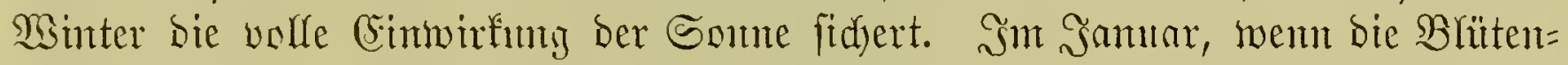

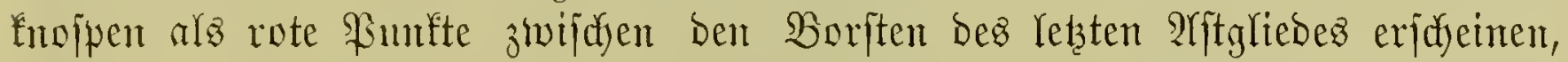

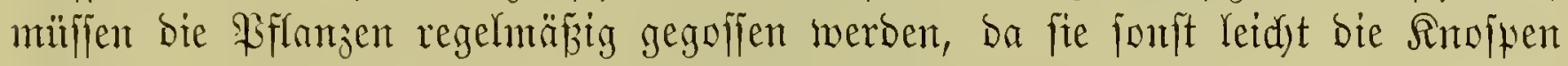
abwerfen. Zur Serlängerung Des FYrers wirb es bienen, einen Teil ber Ber= edelungen etwas märmer ž lyayten, als bie anberen.

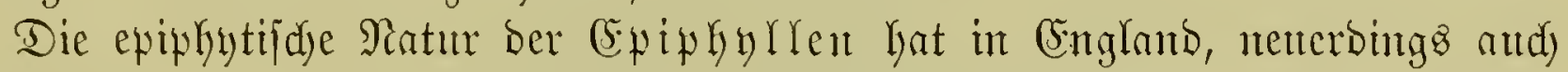
in Frantfreidy, ju einer cigentïmtidyen beforativen Berwertung berfelben gefïlyrt,

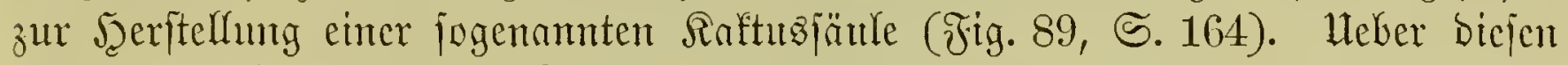

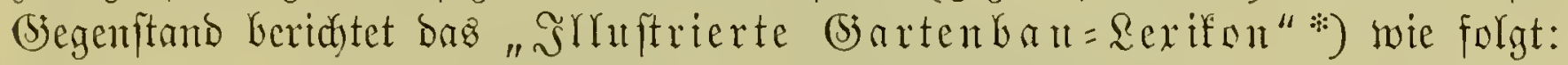
"Şat man ben abgeftorbenen Stanm eines Bammann, z. B. einer Dicksonia

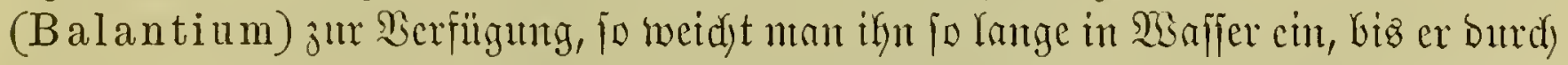

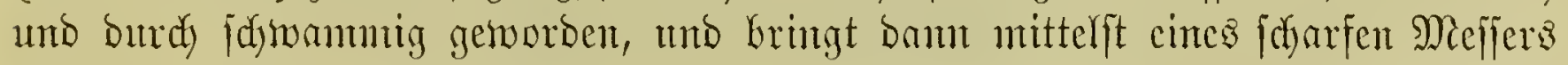

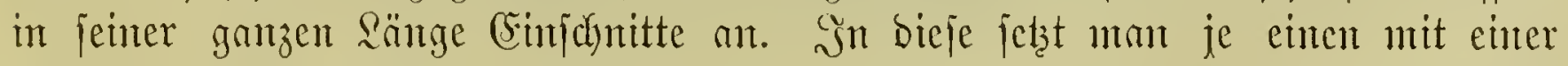

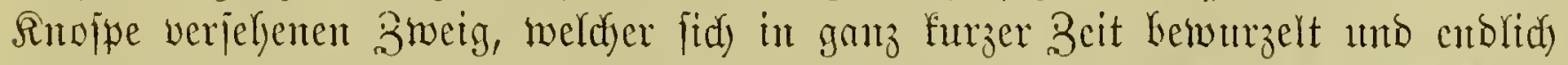

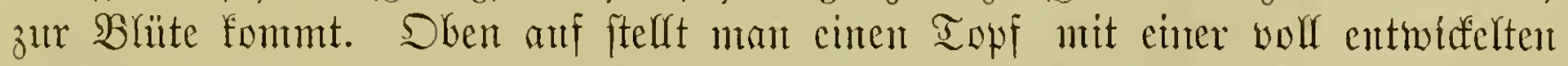

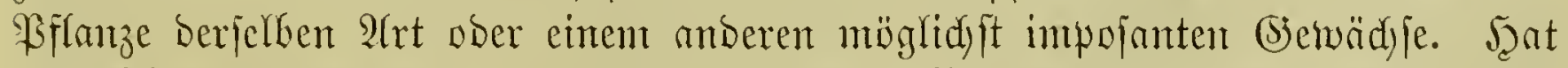

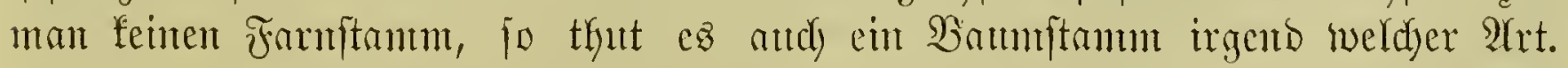

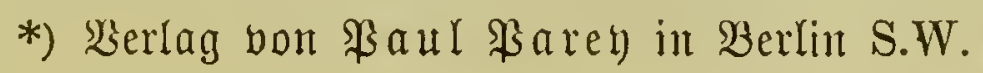




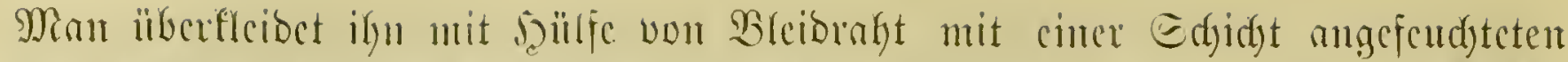

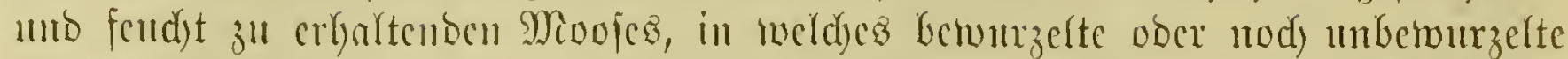
Bueige bes Epiphyllum truncatum cingeftzt werben. Der Effeft ift cin

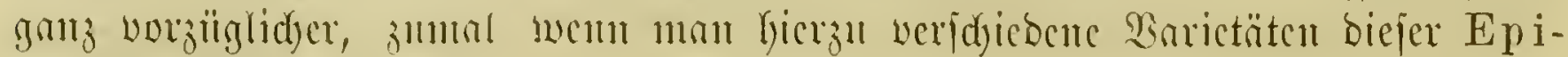

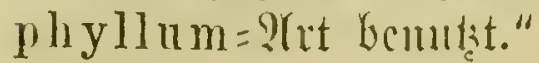

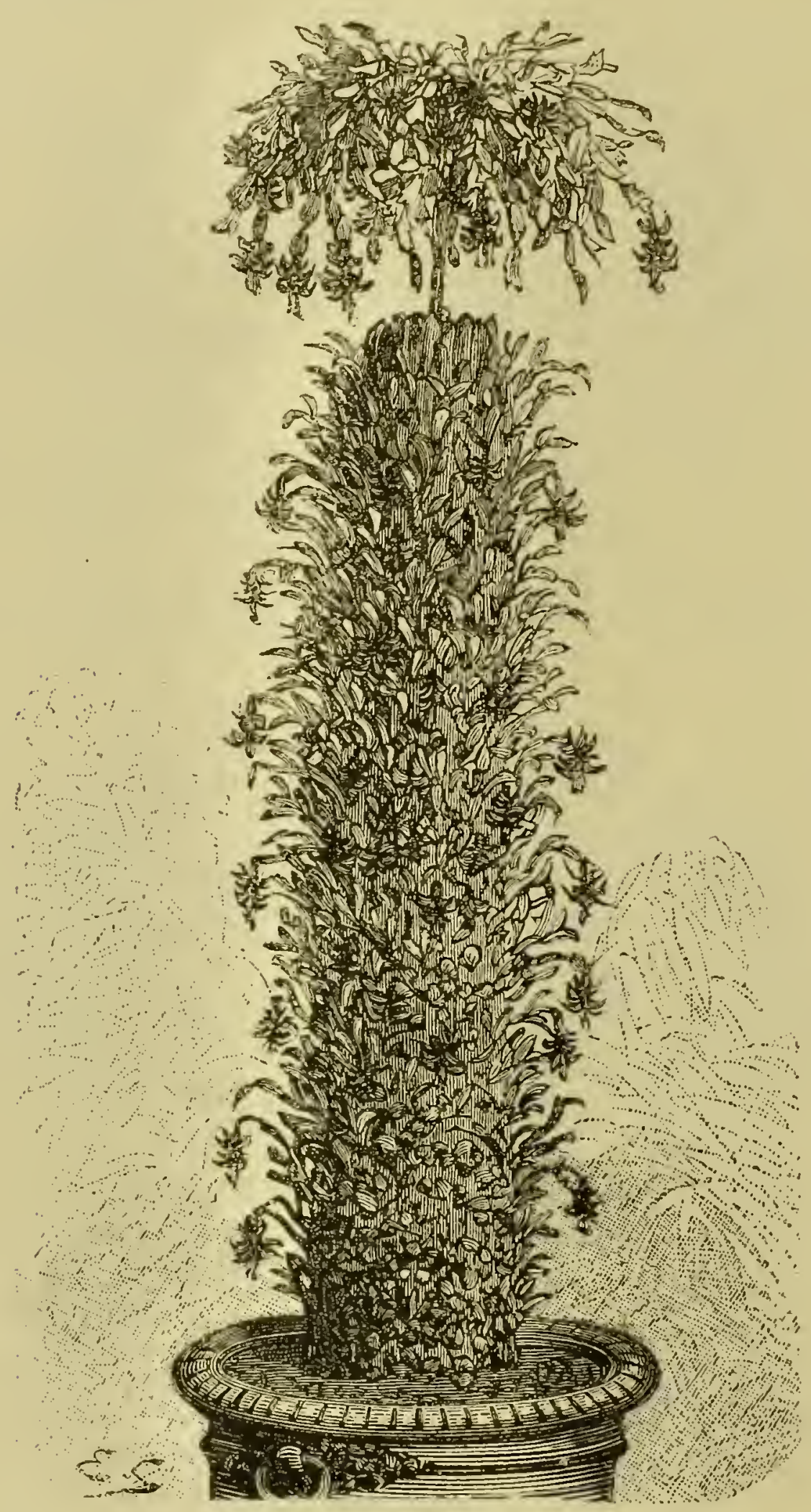

Jig. sy. siatusiäule.

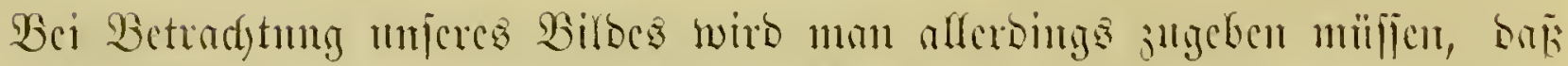

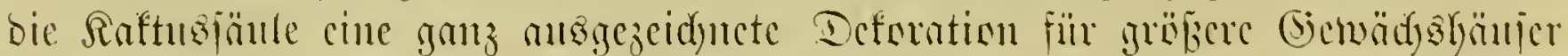

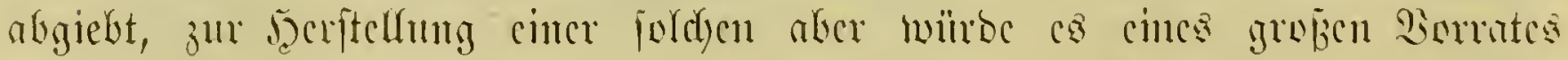

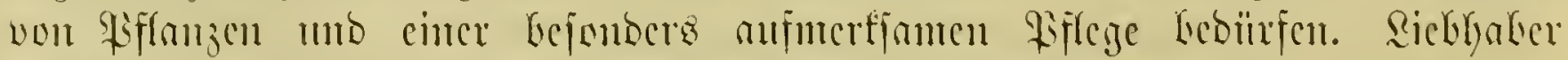

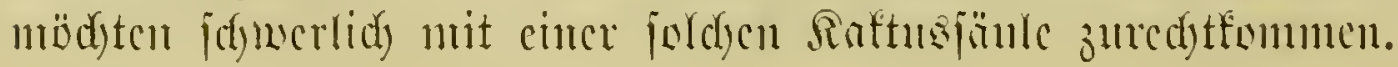




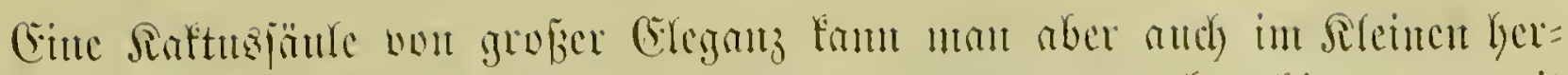
jeffen, imben mat cinte ftorten Peireskia-Strmm von oben bis ment mit (5pipharren bejelst.

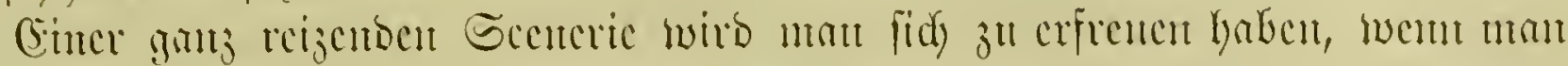

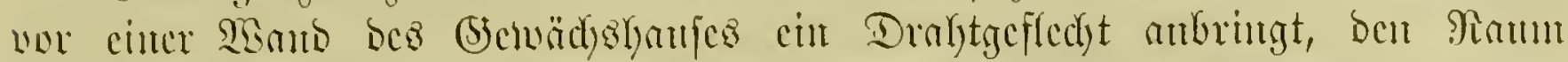

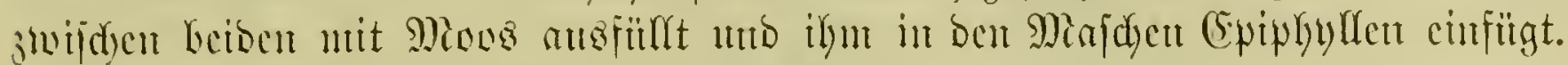

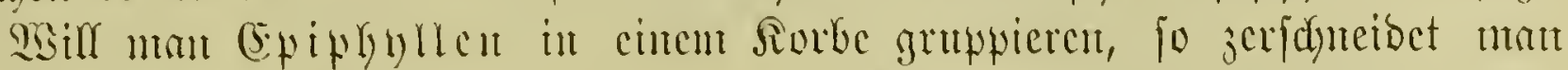
Det Stamm cincr Peireskia in 5-6 Stïcficten, bepfropft biefe mit Epi= phyllum - wem es fein fonn jebes mit ciner anocren Siarictät unto ftecft

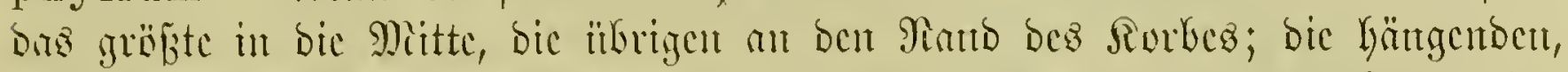

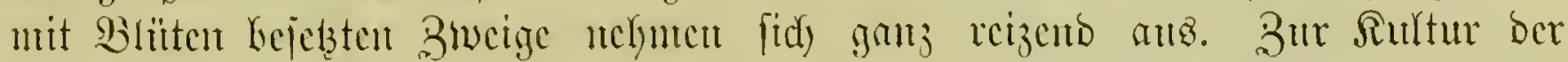

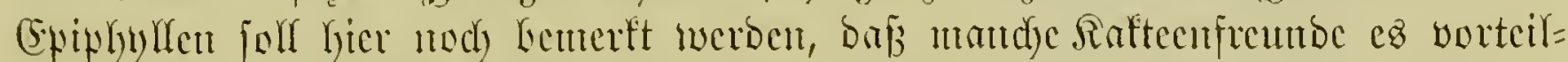

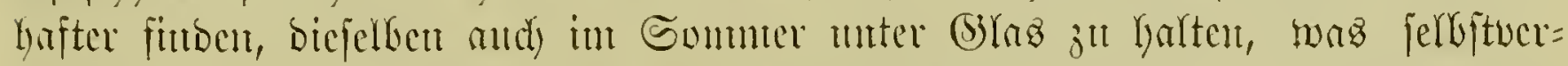

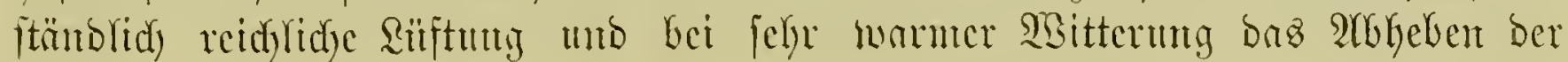

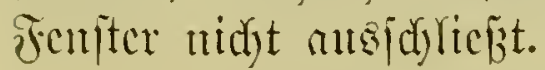

\section{Battung. Echinopsis Zucc. Secigelfaftus.}

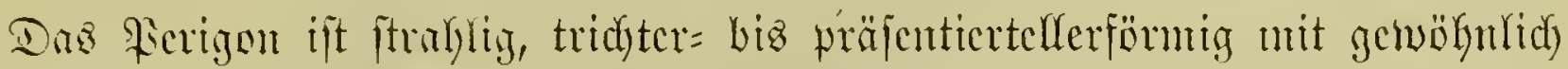

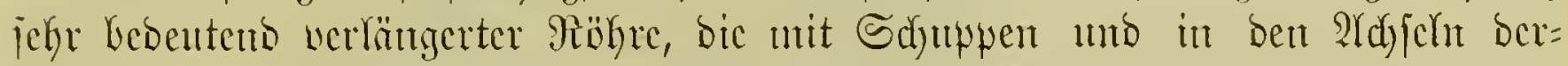

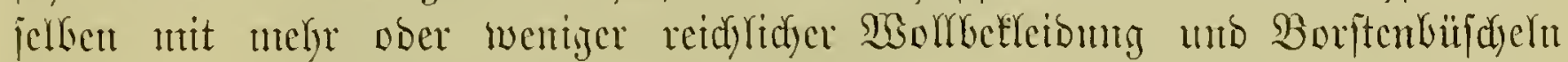

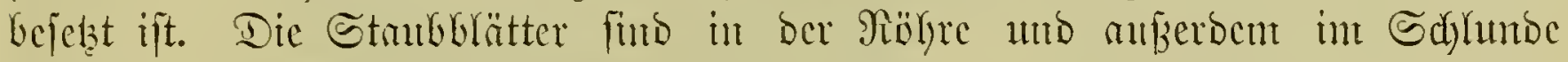

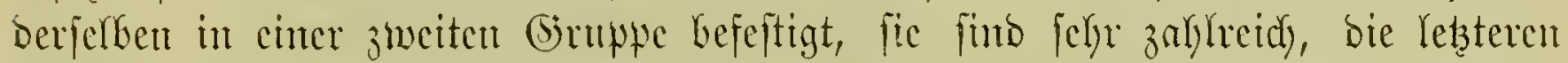

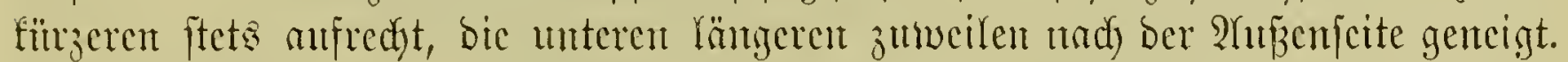

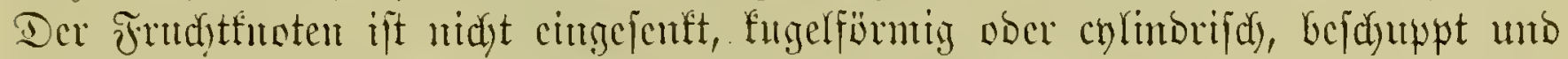

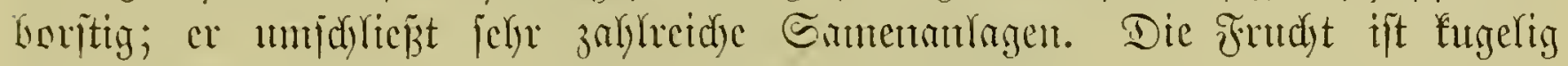

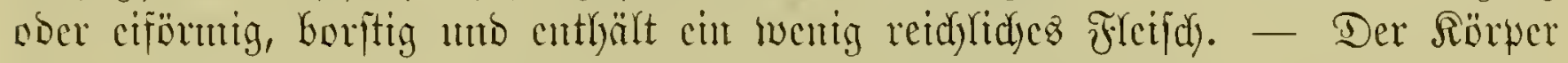

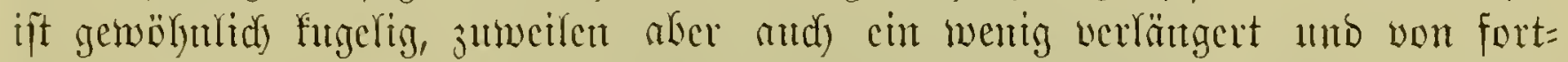

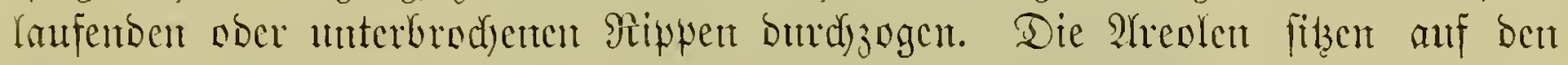

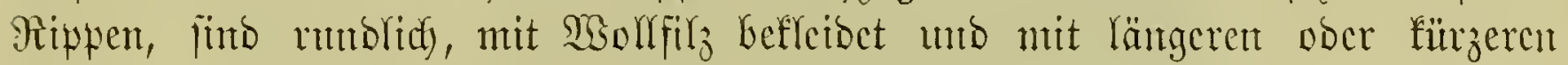

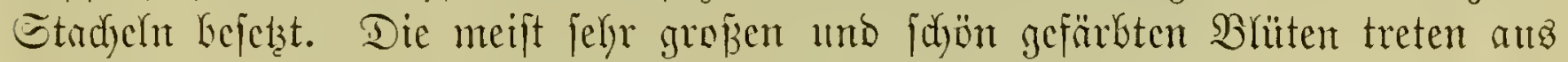
ber Mitte ber Areolen unb fitzen in Der Reger an ber Seite bez Rörperz.

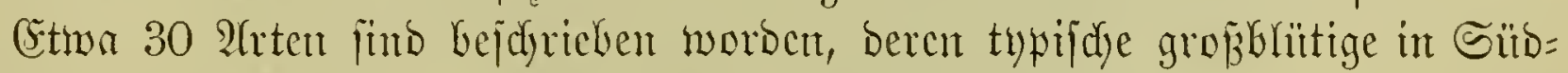

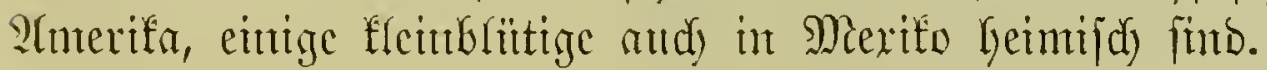

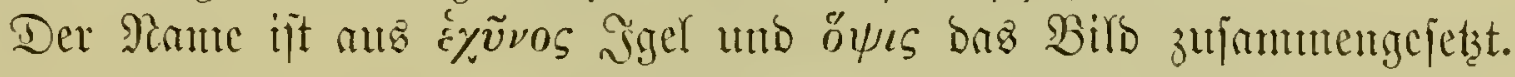

SÆlüfjel für sie befdrriebenen 2 rten.

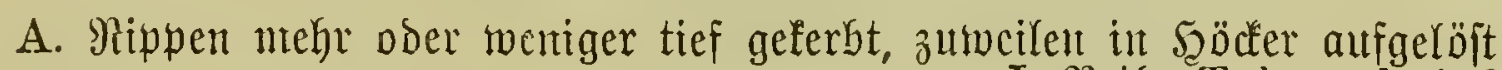

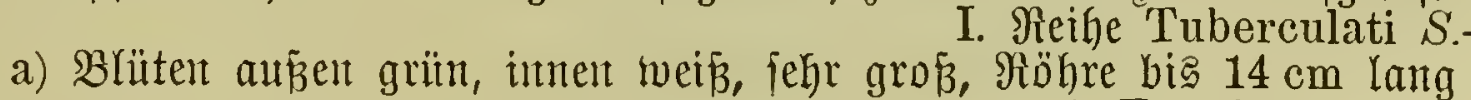

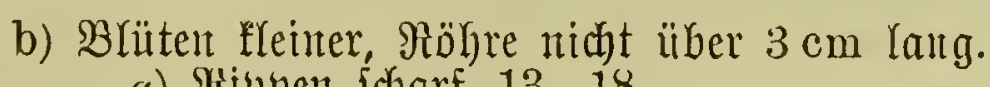

1. E. cristata Salm-Dycl.

a) Stippen ficharf, 13-18.

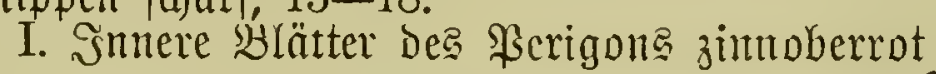
II. Innere Blätter bes łerigonts gelblich, roja, violett ober Drangernt 3. E. Pentlandii S.-Dycli.

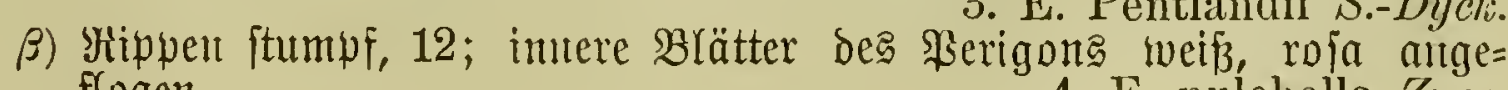
flogen

4. E. pulchella Zuce. 
B. Rippen fortlanfend.

II. Reihe Costatae S.-D.

a) Sörper vielfact Sproffen treibend, Stadjeln furz oder fehr furz, Rörper lugeliag.

1. Snntere Periģonblätter rofentrot.

1. Santoitachcln tweiplich, Mittelftacheln gelblich, an der Spize braun.

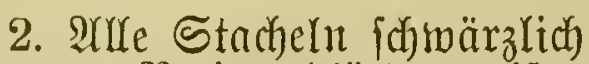

5. E. multiplex Zuce.

II. Snntere ßerigunblätter weif.

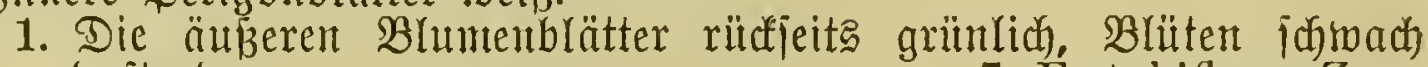
Duftent

7. E. tubiflora Zucc.

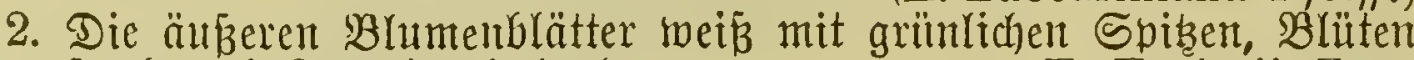
ftart nach Sagmin riechend

P) Rörper legelfürmig
b) Rörver nicht Sproffen treibend; Stadjeln lang (ïber $2 \mathrm{~cm}$ mefiend).

8. E. Eyriesii Znec.

a) Stachelut gerabe

(3) Stadeln gefrilmmt

10. E. valida Monv.

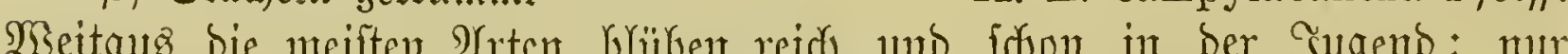
einige mentige erlangen ihre Brïgfähigfeit erft in böberen arter.

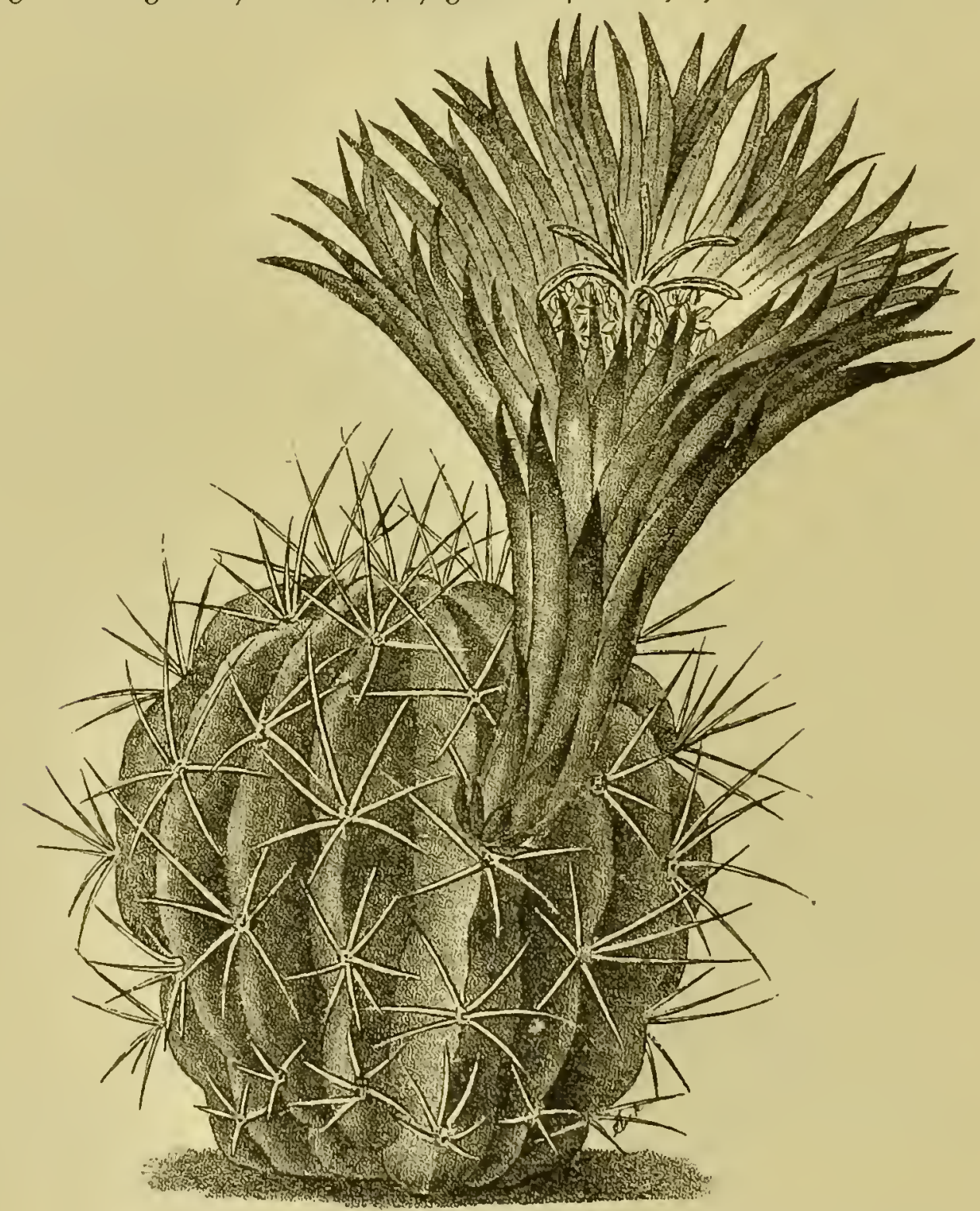

శig. 90. Echinopsis scheerii S.-1)yck. Sdeer':, Sccigelfafus.

1. Echinopsis cristata S.-Dyck. (E. Misleyi Lab.)

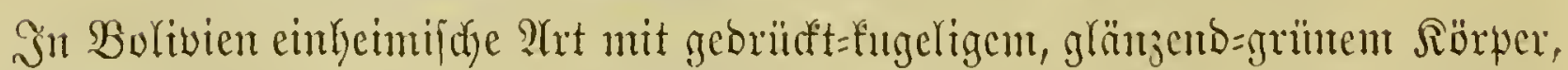

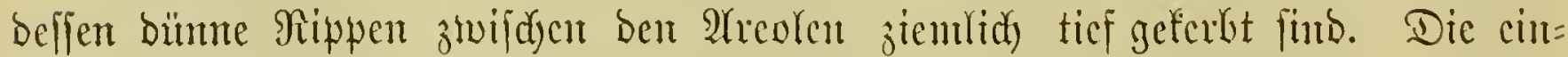

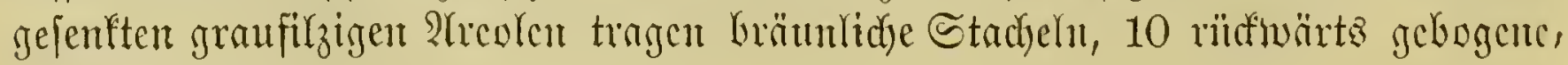




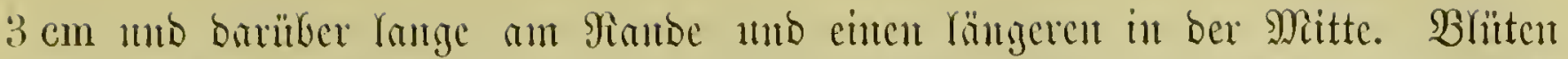

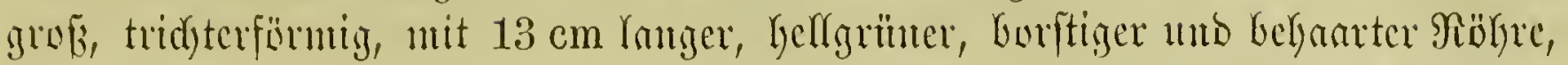

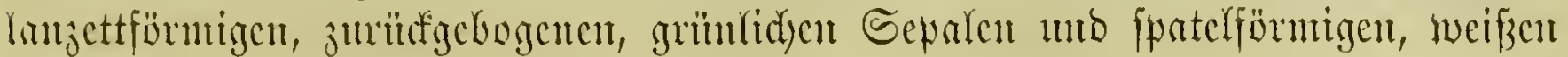
Pietalen.

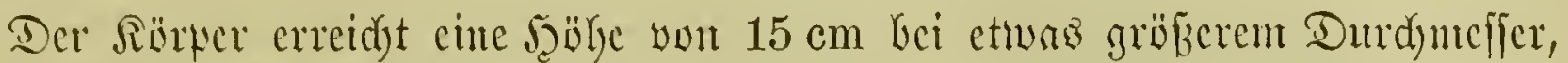

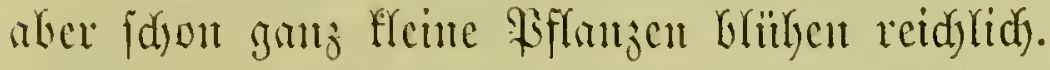

\section{Echinopsis Scheerii S.-Dych. Grjecr'z Gecigelfaftur.}

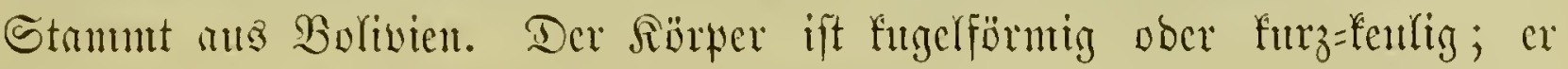

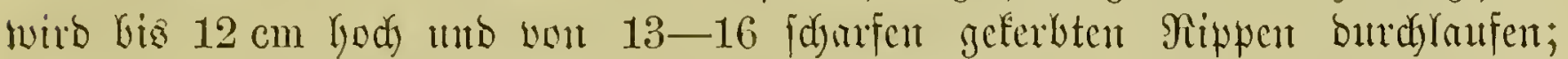
ar treibt reidylidye Scitenfproffen mo ift bou reffgrüner Farbe. Die Stadyeln

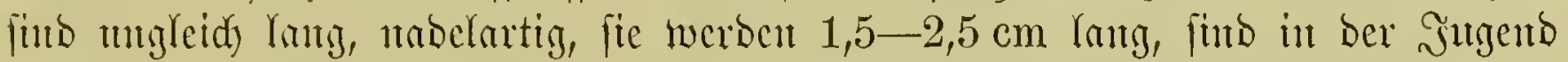

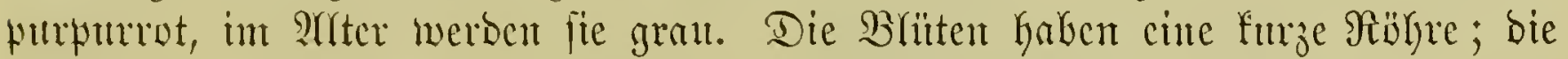

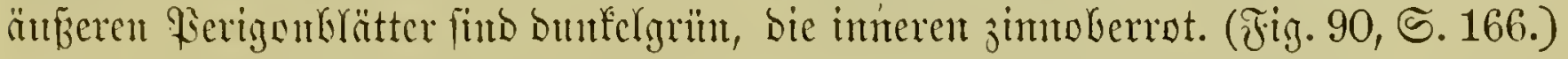

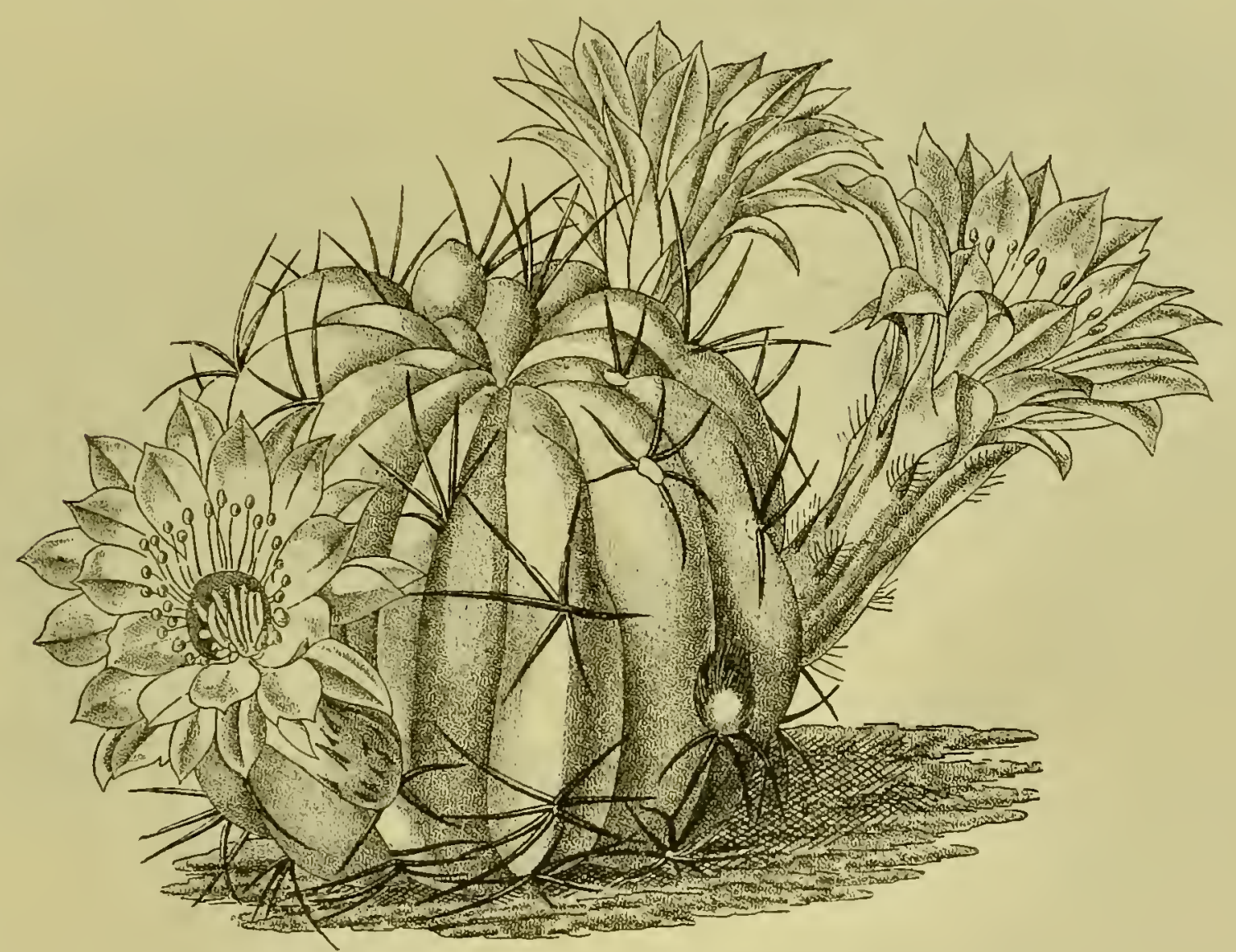

Fig. 91. Echinopsis Pentlandi S.-Dyck. Sientrand’s Secigerfaftus.

\section{Echinopsis Pentlandii $S$. Rentfant'z Eccigelfaftuz.}

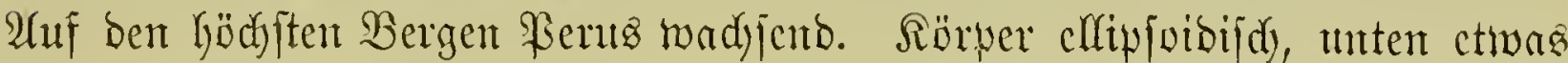

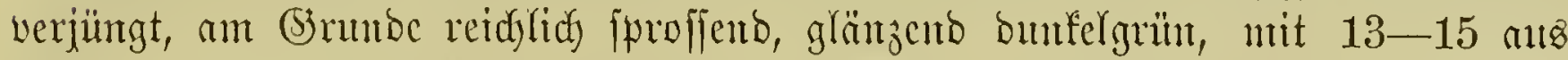

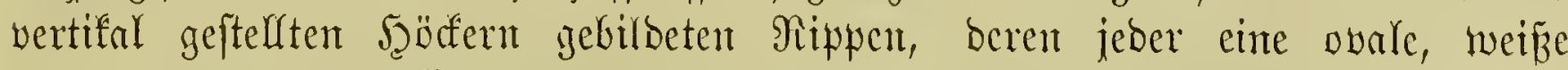
Arvede trägt. Strdjeln nabelartig, an Ränge mo Stürfe muleid), 8 fitrahlige,

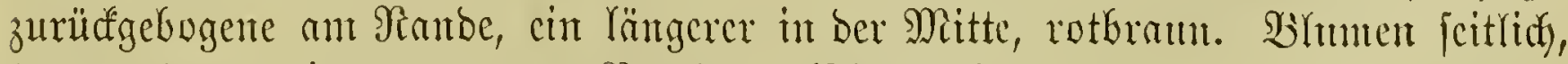
$2,5 \mathrm{~cm}$ lang, mit orangeroten Fetnlen. (Fig. 91.)

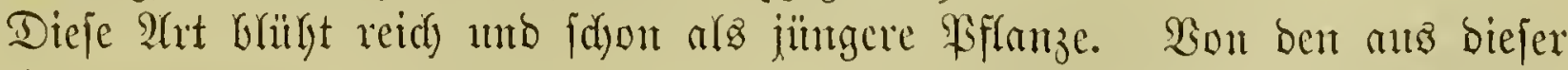

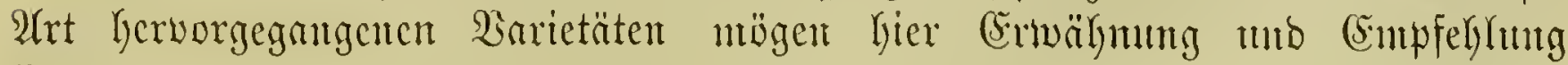
finden: 
Var. tricolor, mit puntmen Gepalcu mo ant Brrmbe gelben, oben retgetferen Retrien, turb

Var. Cavendishii, mit Duffelenten Bhhmen.

\section{Echinopsis pulchella Zuce. Micblid)er Eccigelfaftuz.}

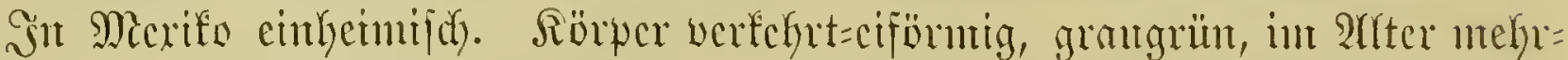

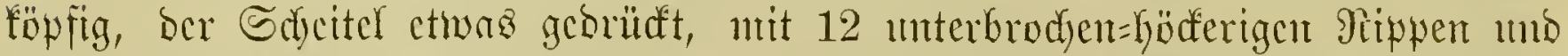

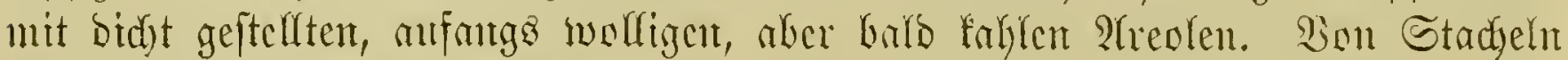
fitro mur $4-5$ funze vorlymbert.

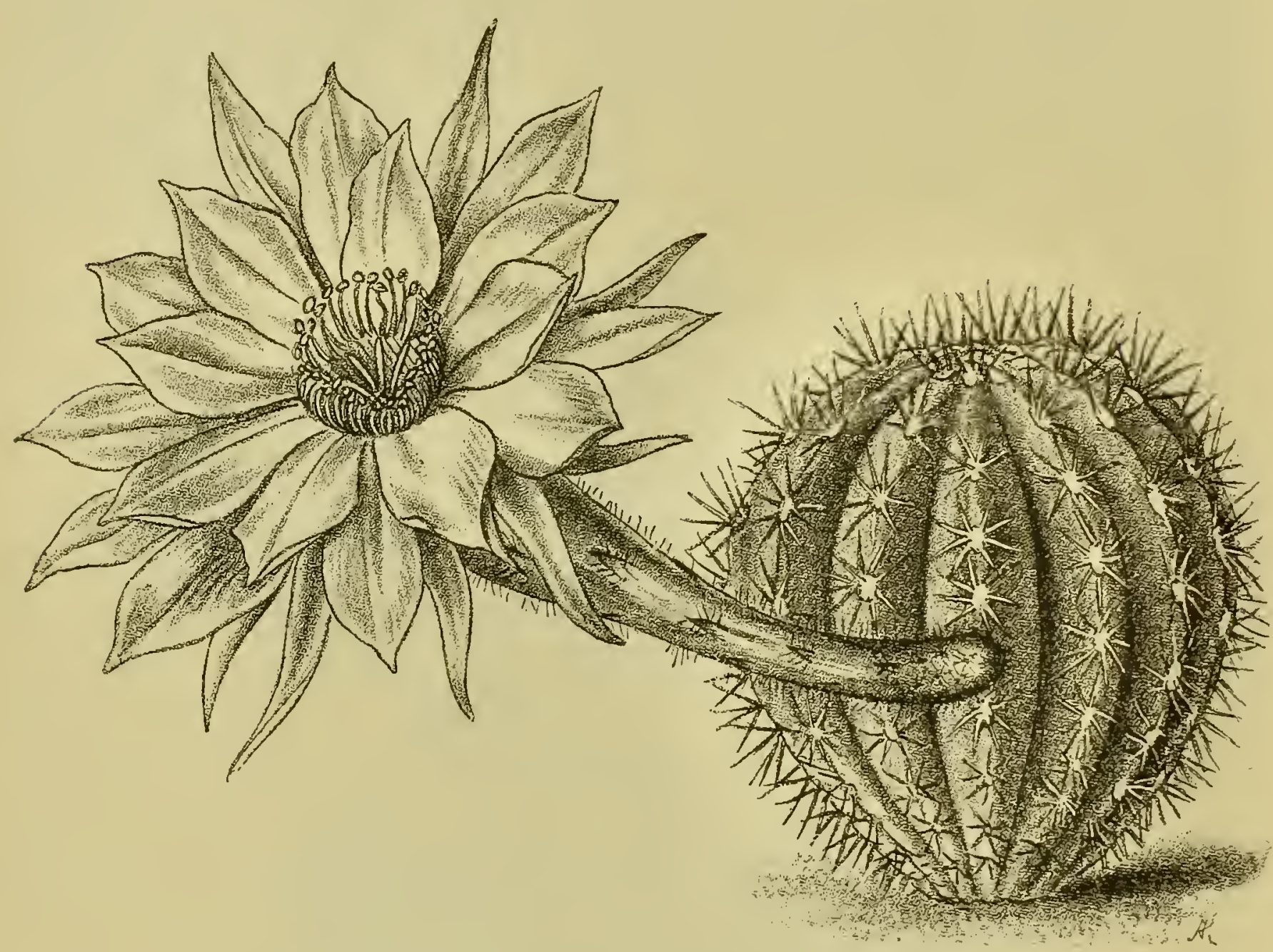

Fig. 92. Echinopsis multiplex Zucc. Sprofiemeider Sceigelfattus.

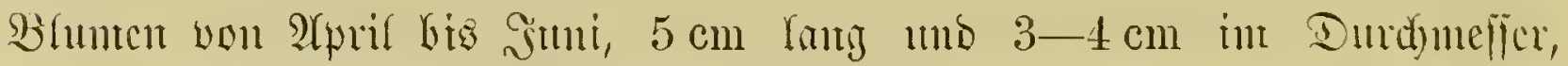

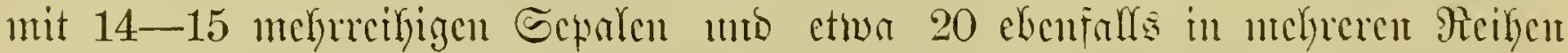

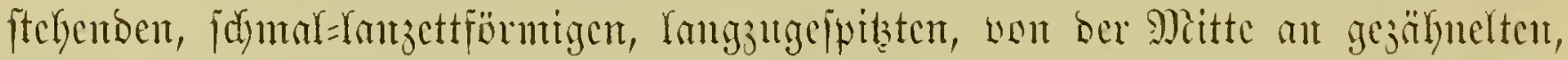

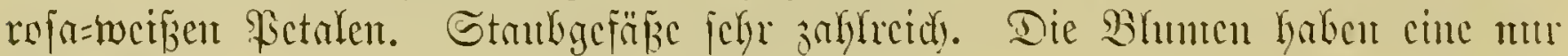
funze Damer.

\section{Echinopsis multiplex Zuce. Eproifenteidner Secigelfaftus.}

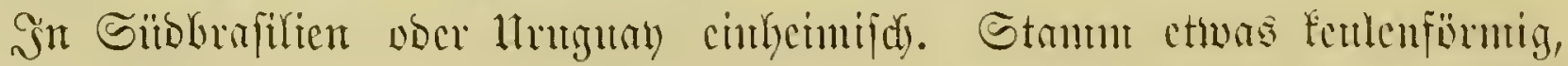

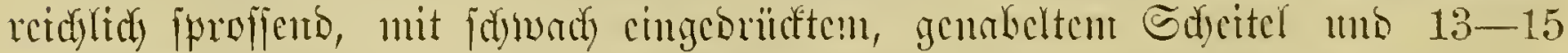

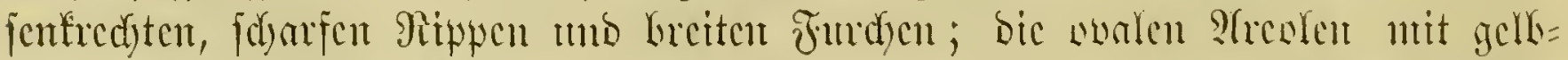

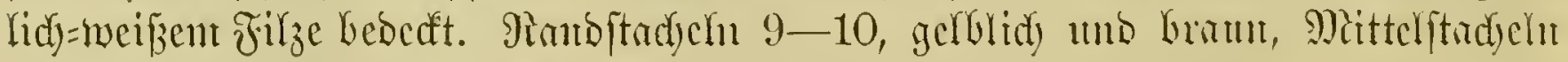

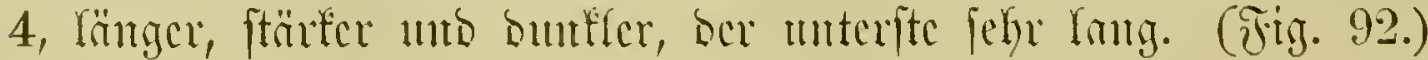




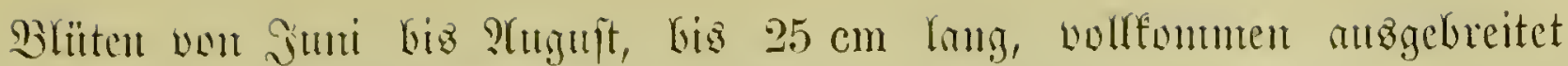

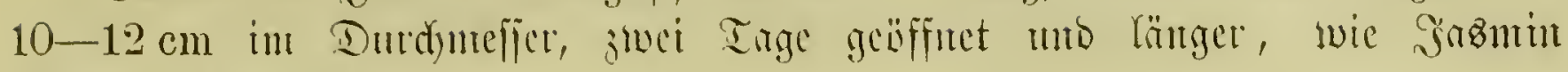

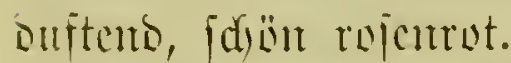

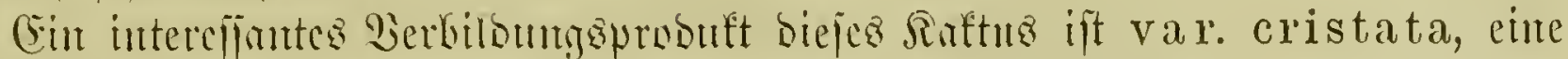
iener munftrïjen Furmen, bie fid) ztmeifen bei Fettpffanzen, wie Rafteen,

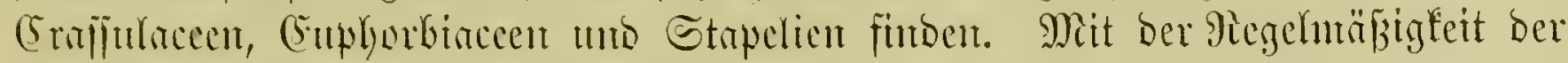

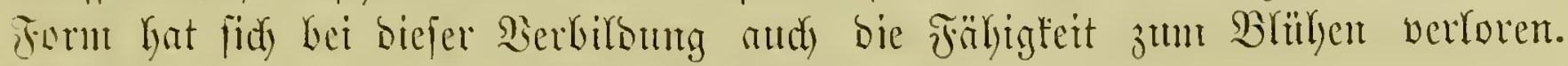
Fennody werbient fie einen Silats int founigen Stubenfenter.

\section{Echimopsis oxygona Zuce. Edfarifantiger Eccigelfaftuz.}

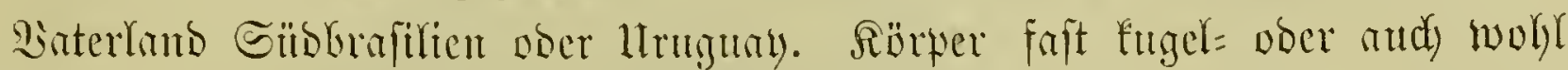
teutenförmig, 25-30 cm hod, bei cintem Durdyeffer von $20-25 \mathrm{~cm}$, nad) unten

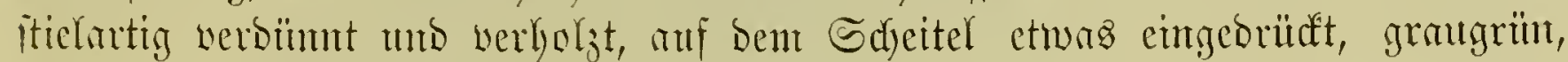

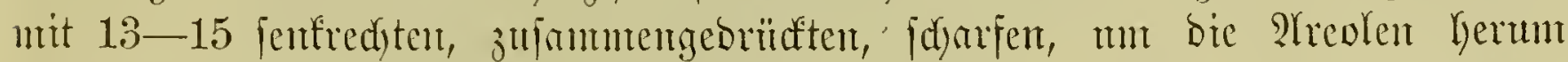

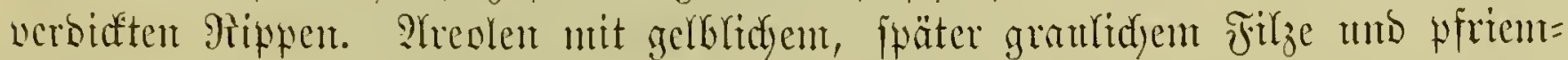

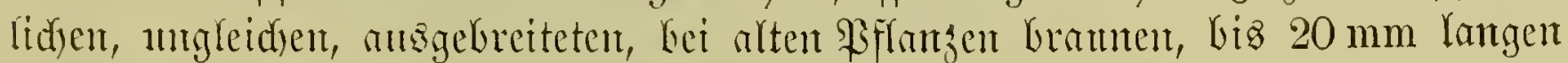

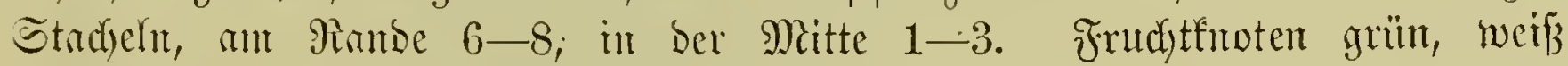

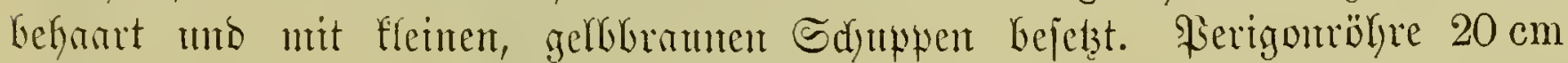

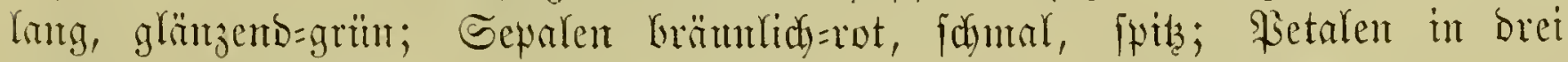

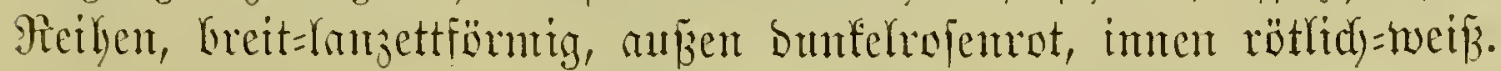

\section{Echinopsis tnbiftora Zuce. (E. Zuccariniana $P f r$.)}

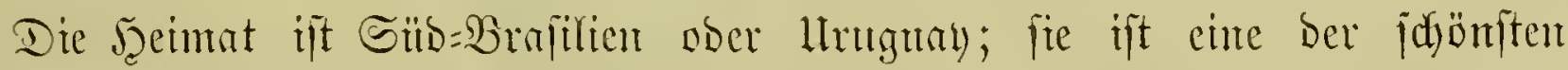

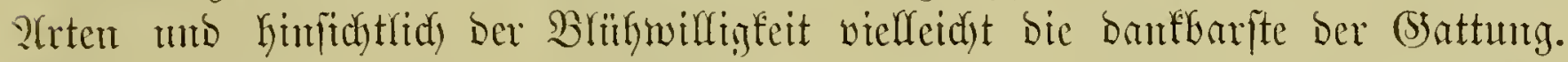

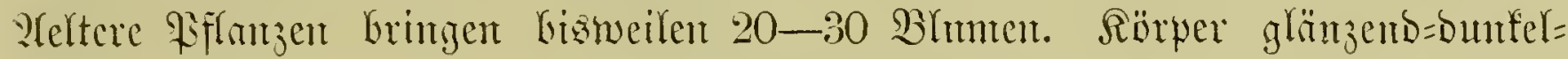

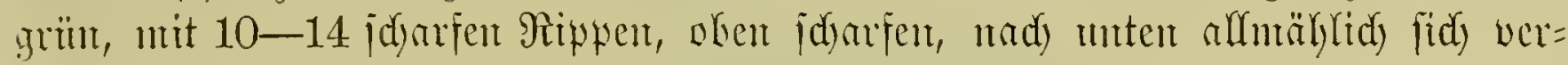

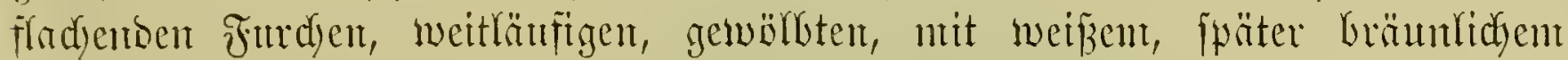

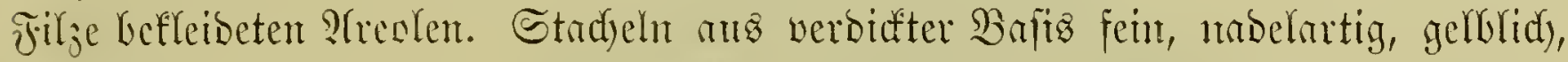

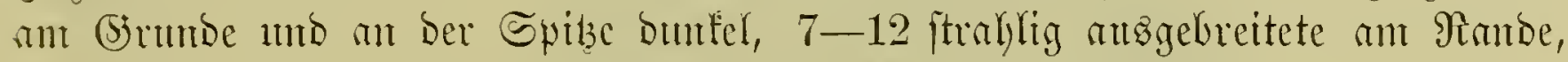
1-5 Yängere (Der unterfte $2,5 \mathrm{~cm}$ ) und ftärfere in Der Mitte.

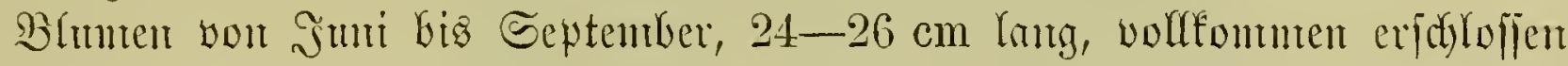

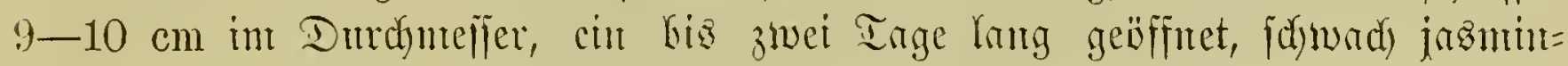

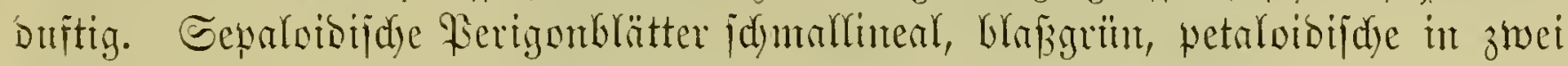
Reifen, $5 \mathrm{~cm}$ lang, idfuneeweir.

Der Eimfïfrumg aud) in flemere Sanmulungen wert ift hyb. Rohlandi, fyervorgegangen ans einer Srenzung unjerer 2frt mit Echinopsis oxygona.

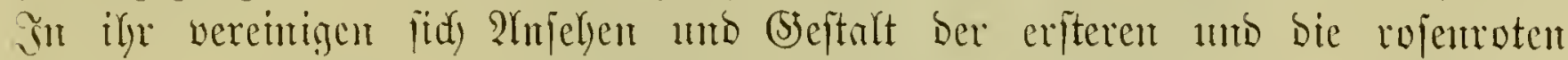

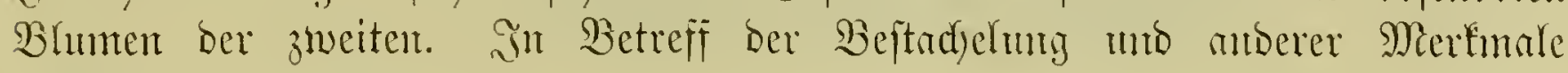
meicht j̈e von beciben ab.

\section{Echinopsis Eyriesii Zuce. Eryriez' Eceigerfaftuz.}

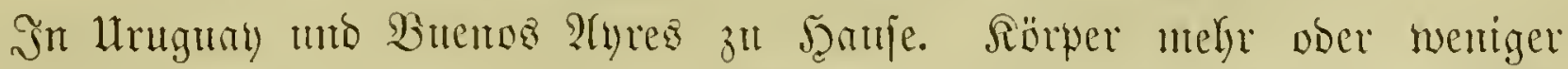

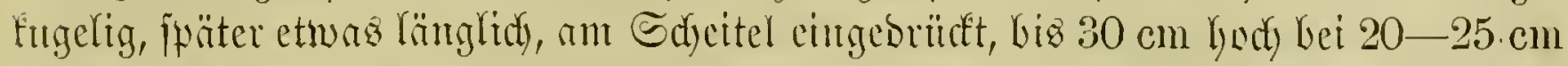
Durdymefier, mit 12-18 jientidy fdjarfen, werligen Pitppen unb breiten Furdyen.

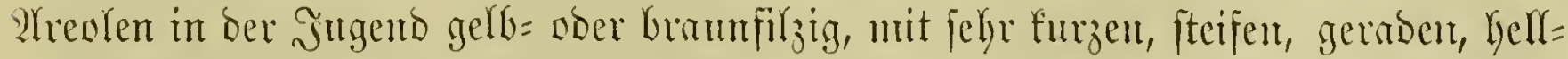
voer bunferbramen Stad)eln, 3-5 in ber Mitte, 8-12 un bieje herumgeitent. 
Blüten von Mai Giz Guli unb fpäter, $23-25 \mathrm{~cm}$ lang, $7-8 \mathrm{~cm}$ im Durdd= meffer, bis 60 Stumben lang geüffuct, abenos und morgens einen ftarfen

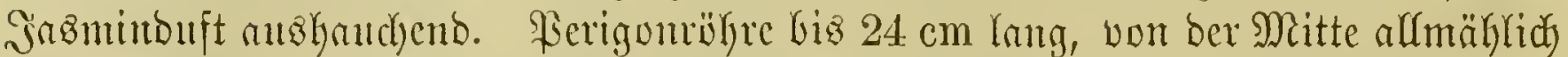

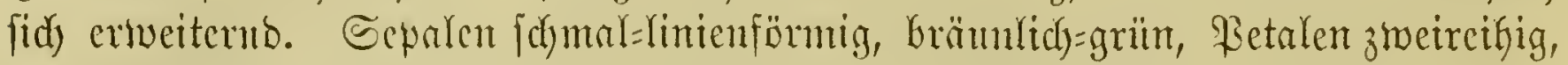

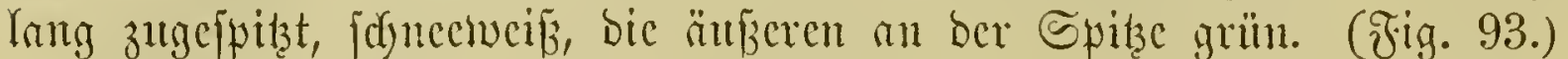

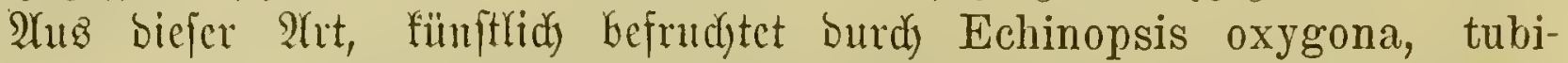
flora 11. a. find melyere Baftarbe fervorgegangen, won benen mur zwei (5r= wälynung finten mögen.

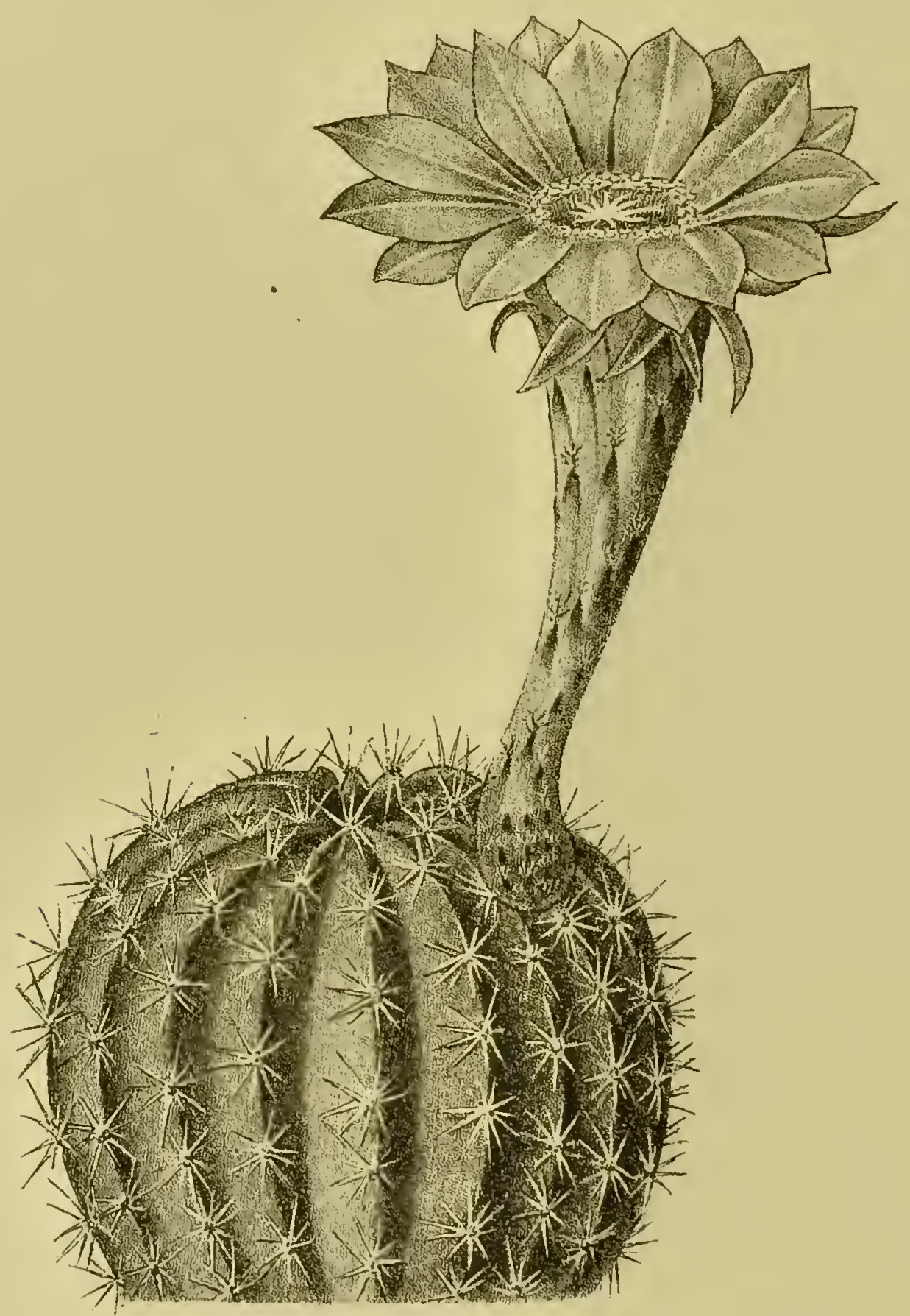

Fig. 93. Echinopsis Eyriesii Zucc. Enriç' Eecigelfaftus.

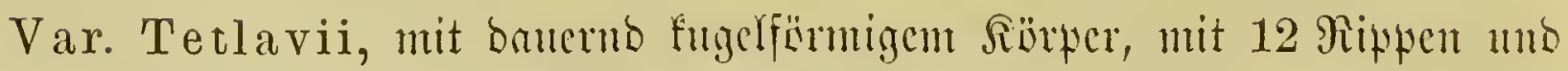
felor großzen, reinucifen Bhumen.

Var. triumphans, gemöhnlich mit bem Bufalac flore pleno, R̈̈rter

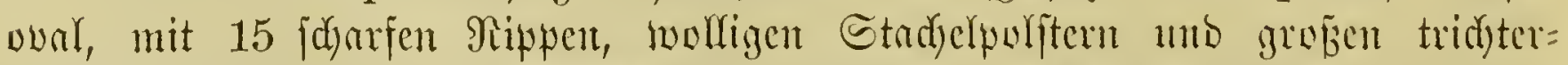

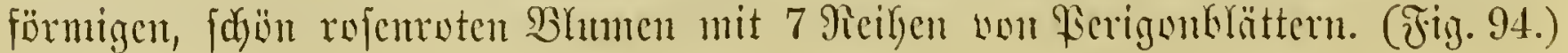




\section{Fehinopsis Decaisneana $L e m$.}

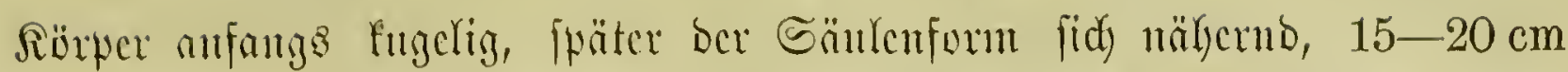

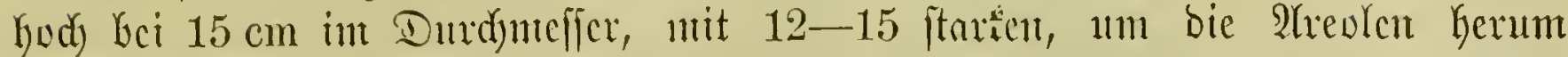

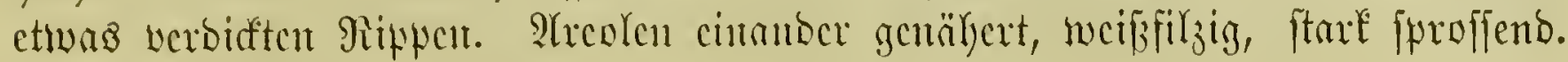
Bhlumen in Sonnutr, wcíb.

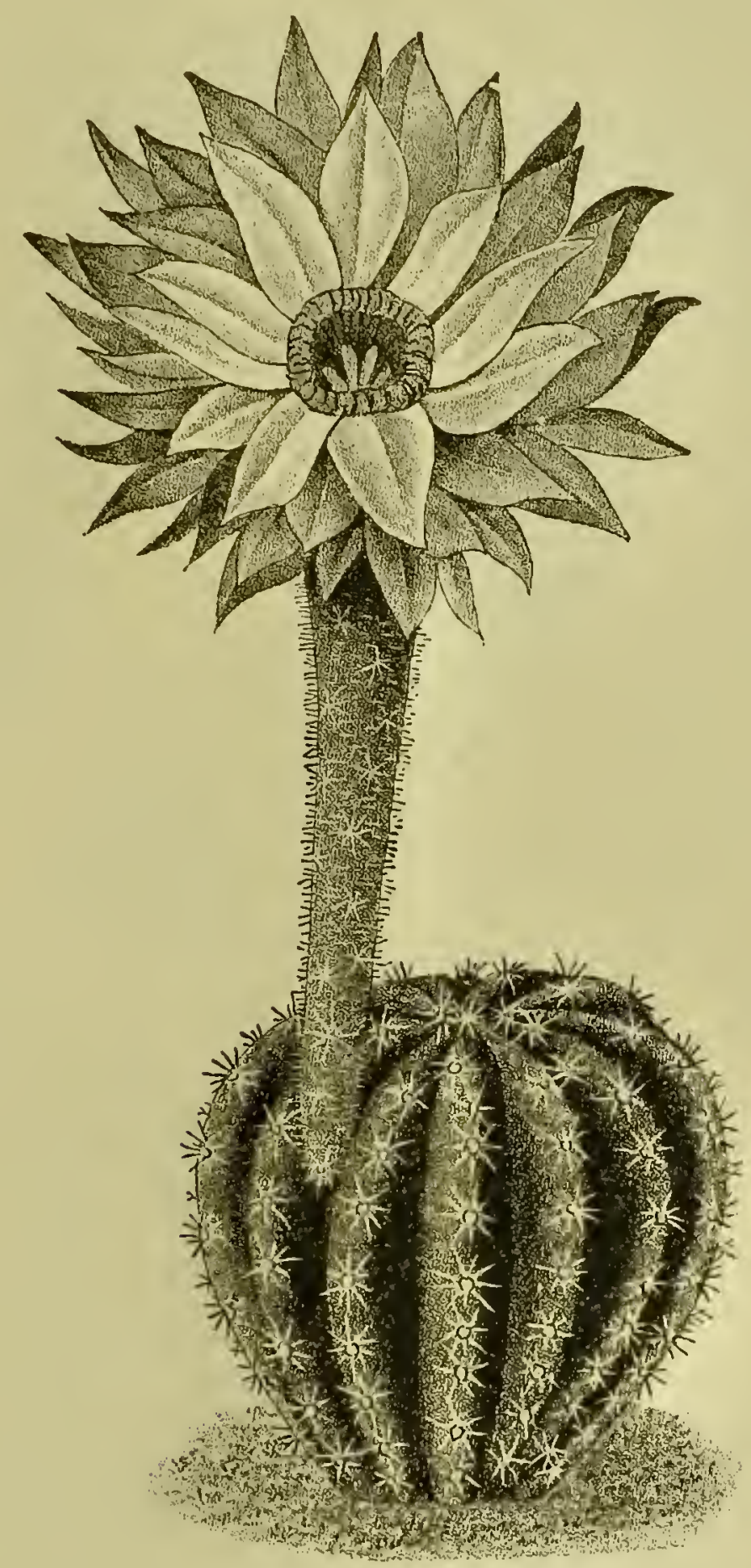

Fig. 94. Echinopsis Eyriesii Zucc. var. triumphans.

10. Echinopsis valida Monv. (E. Forbesii Hort. angl.) Rräftiger Gccigclfaftü

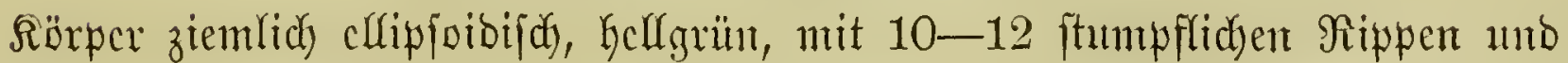

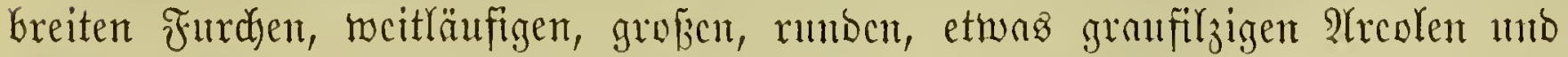

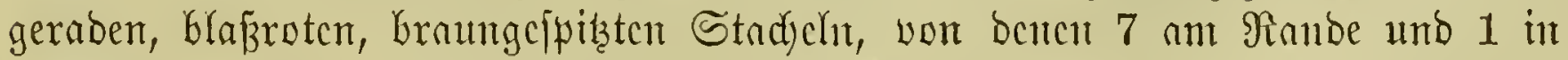

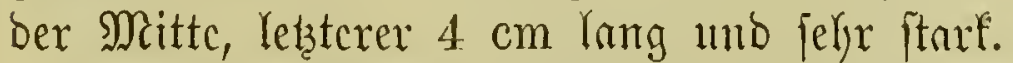

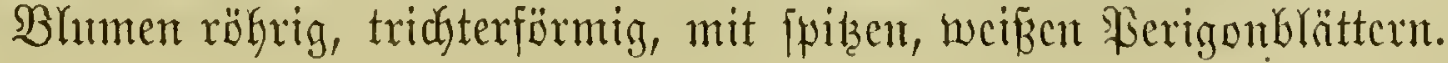




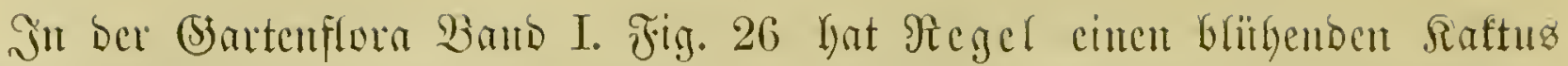

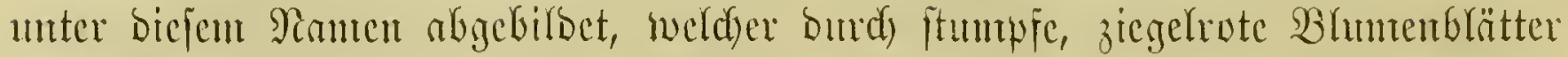

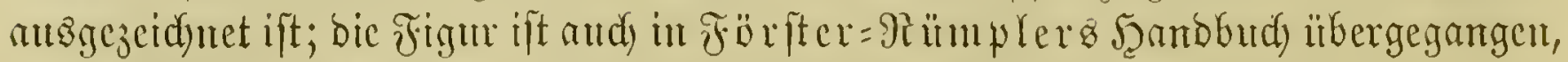
fie ftelft aber feme Echinopsis, furbern cincu Echinocereus bar.

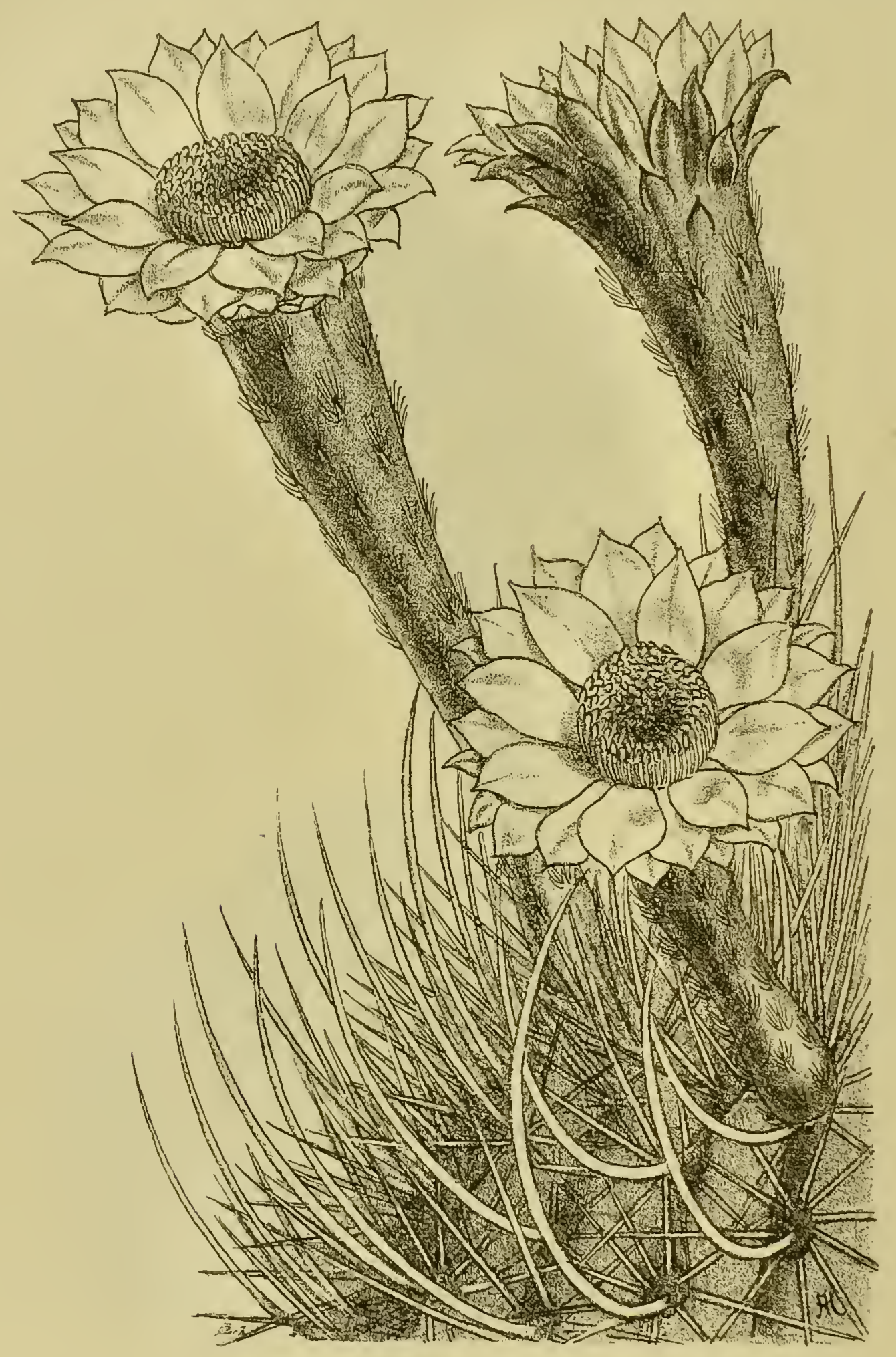

Fig. 95. Echinopsis canpylacantha Preiff. Sitummitadfeliger Ceeigelfattus.

\section{Fehinopsis campylacantha $P f$. (rumumitadjeliger Eccigelfaftus.}

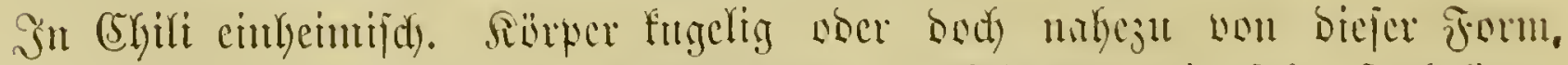

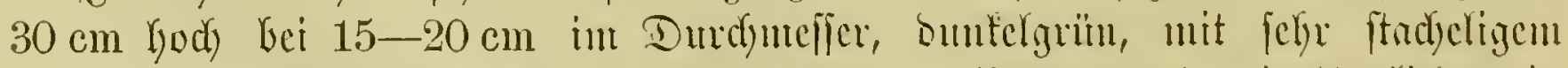

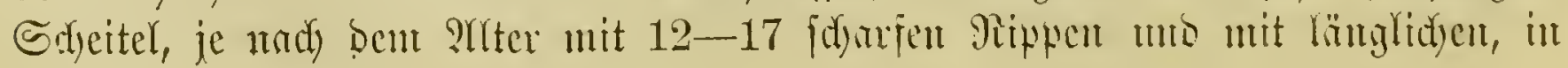




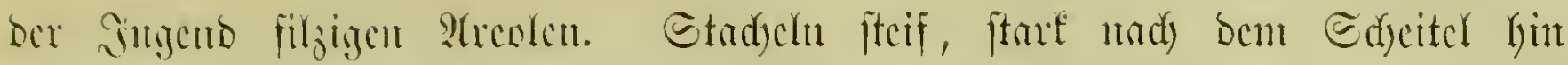

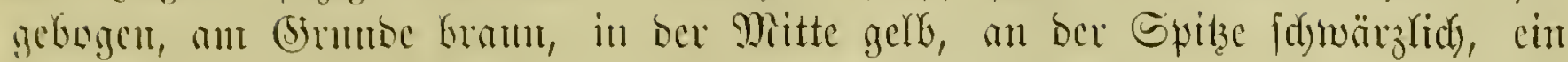

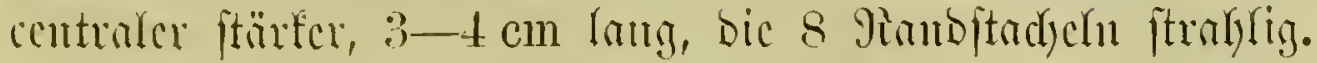

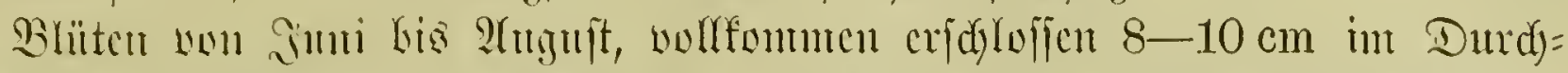

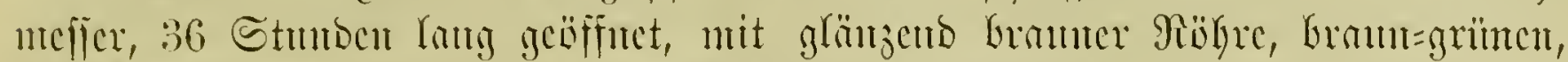

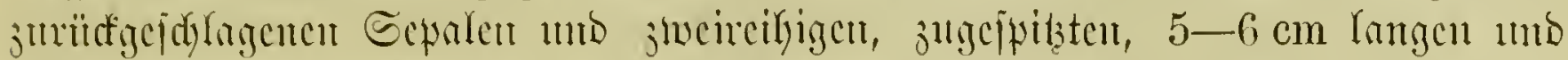

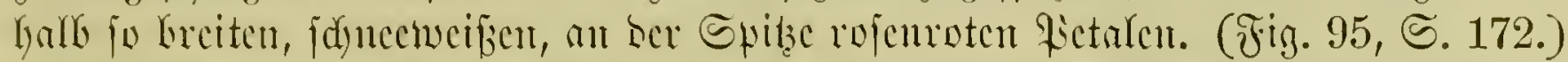

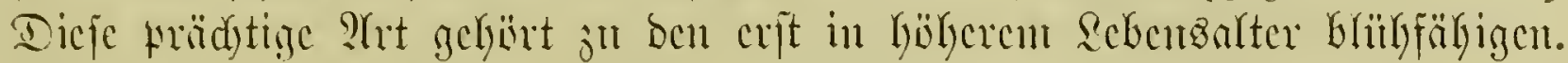

Der ältejte Piante für biefe 2 het ijt Echinocactus lencanthus Gill.; bcr= wegen nun Echinopsis lencantha Zucc. bem vbigen Ramen vorgezogen werben.

\section{Battung. Malacocarpus Salm-Dyck. Beidhberfaltü.}

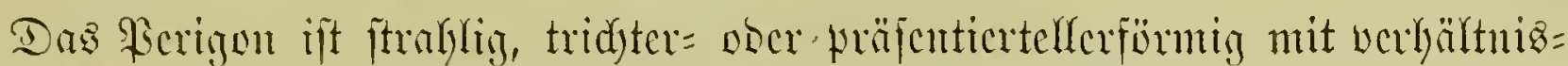

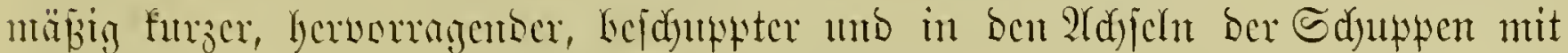

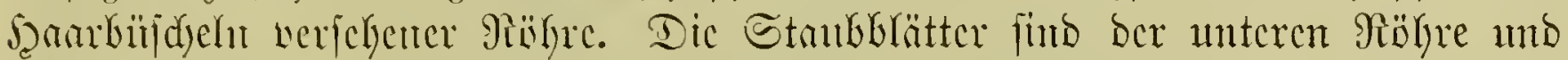

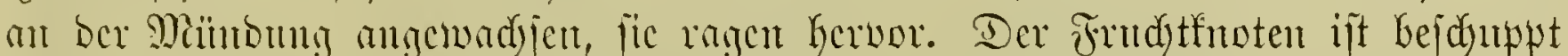

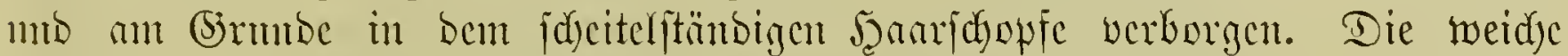

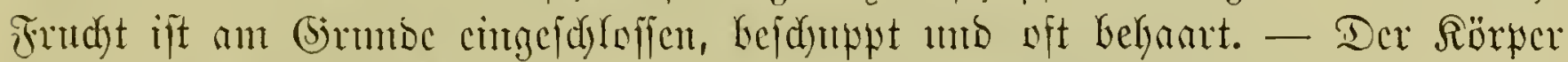

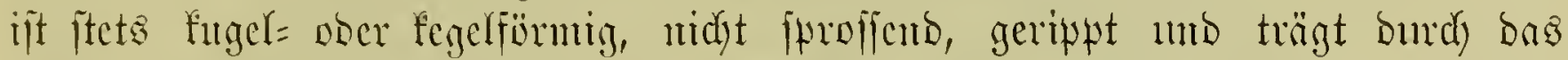

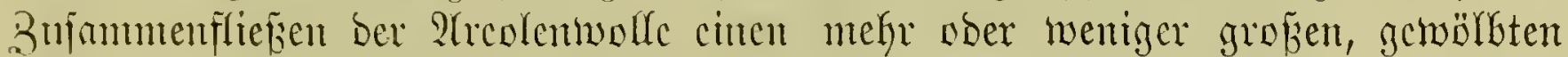

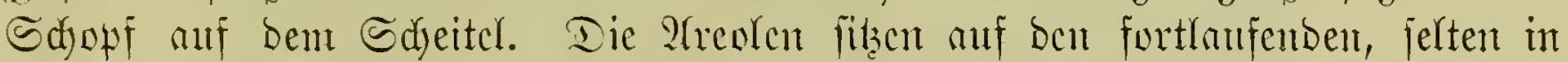

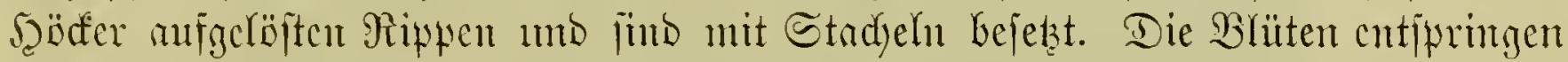

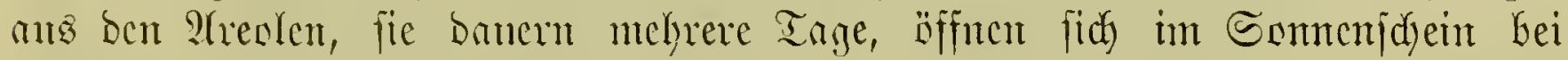

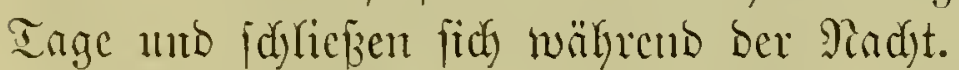

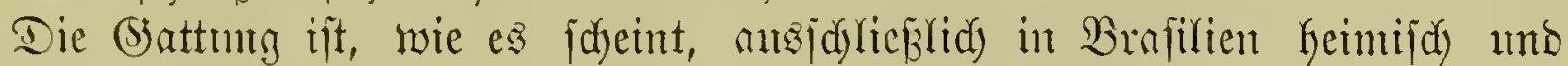

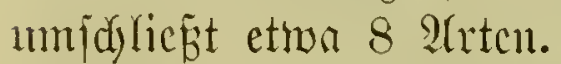

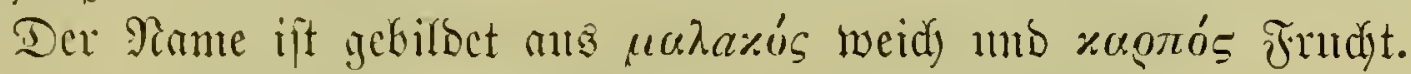

\section{Sdlïffel fïr die befariebenen Urten.}

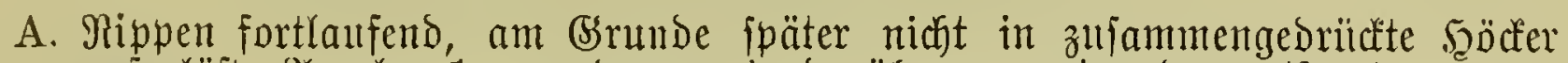
aufgelöft; Areolen $1 \mathrm{~cm}$ obcr wenig barilber bon einander entfernt.

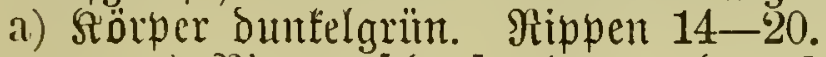

a) Rippent fajarf, aber alt Dent Eeiten gewölbt

b) P) Rippen jeitlich) zujammengebriict

3. M. Martinii Lab.

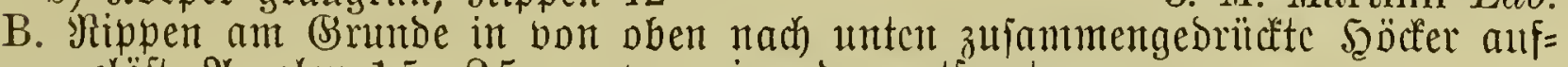
gelöit, Ureblen 1,5-2,5 cm von eintanecr entfernt.

4. M. Sellowii S.-Dycli. (M. Sellowianus.)

\section{Malacocarpus corynodes $S$. Etrcitforbcu=:Beidjbectfaftus.}

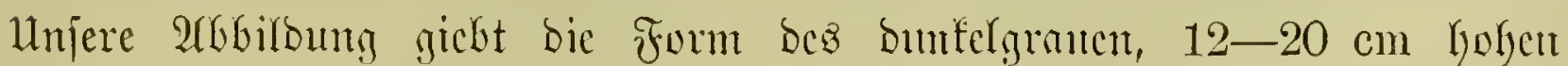

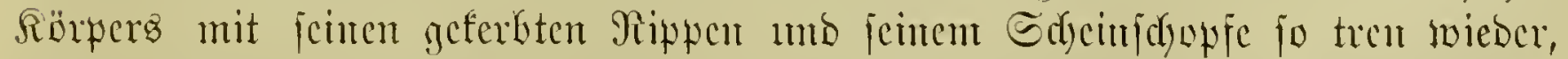

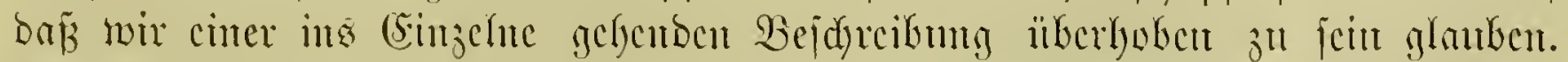

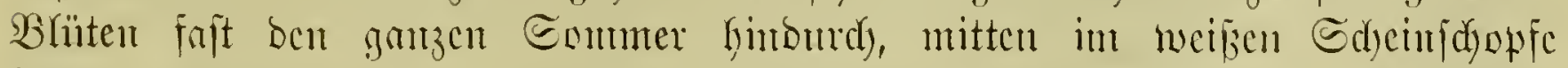

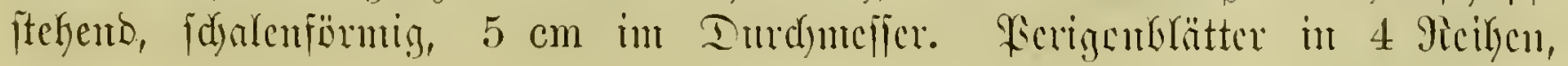


limeal, an ber Spilje gejälyndt, ftrolggelb; bic adyt= bis zelniftrahlige Rarbe

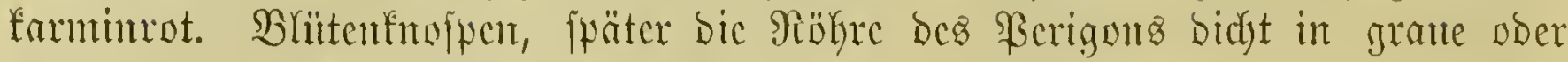

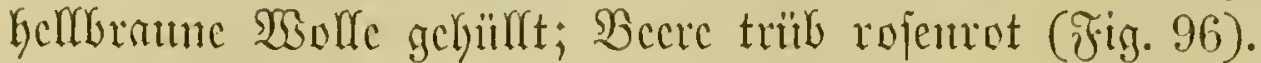

\section{Malacocarpus acuatus $S$. Edjaxipipiger 23 cidjbecrfaftuz.}

Die Sycimat ift Süb=Brafilicu ober Hruguay. Rörper won fugeliger Form,

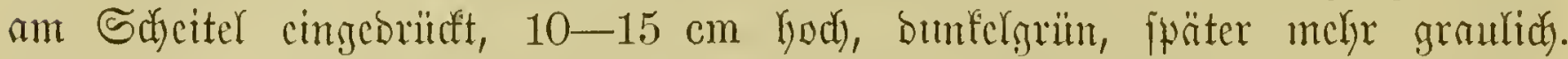

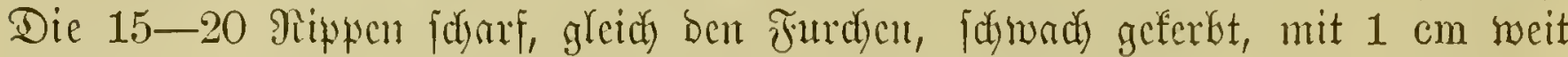

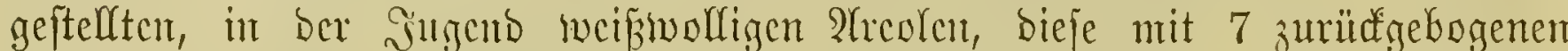

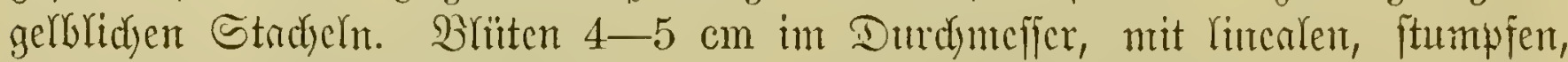

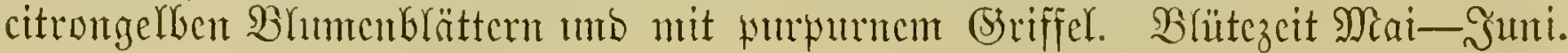

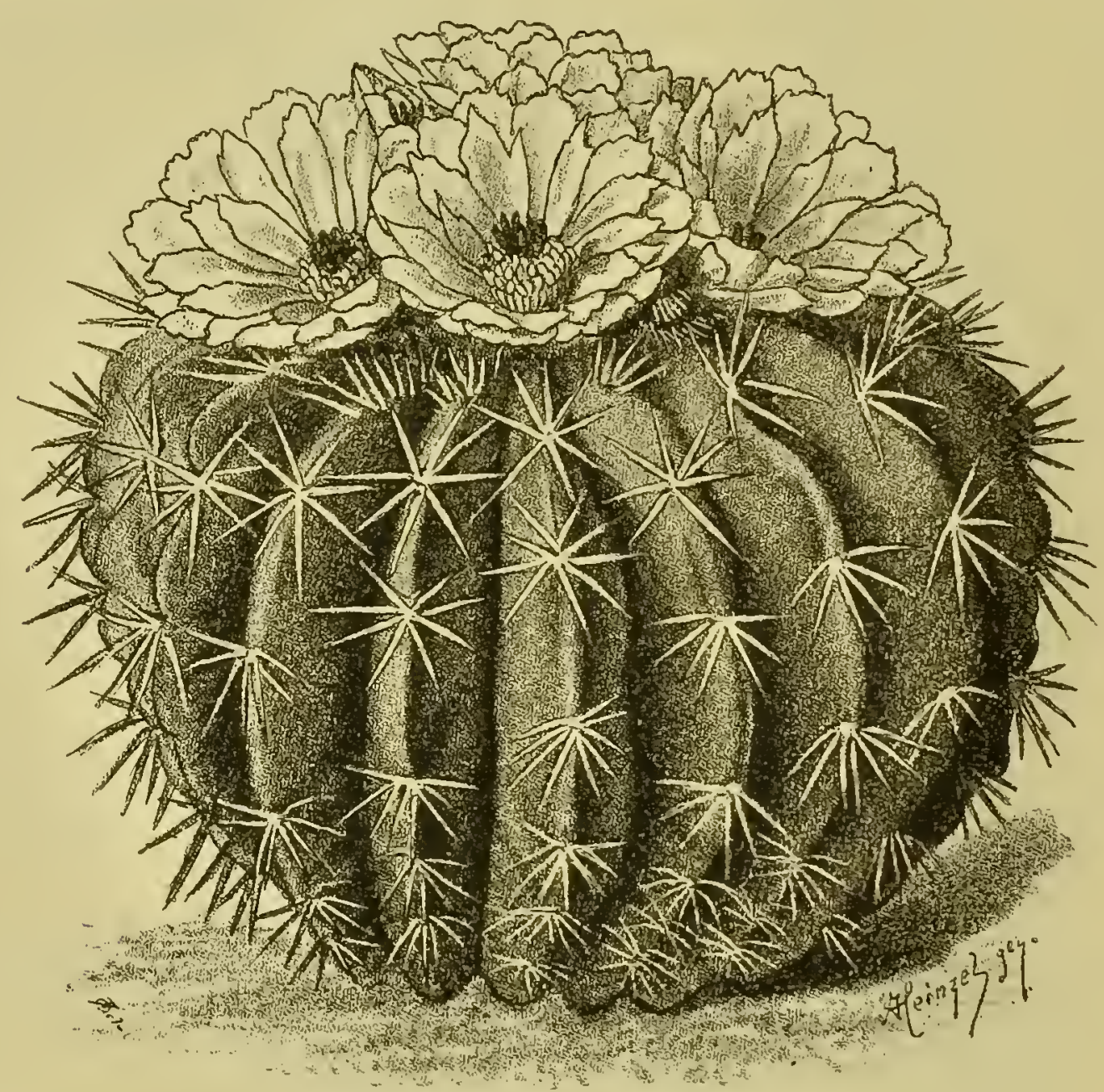

Fig. 96. Malacocarpus corynodes S. Streitfolben=2akeid)berfinftus.

\section{Malacocarpus Martinii Labour.}

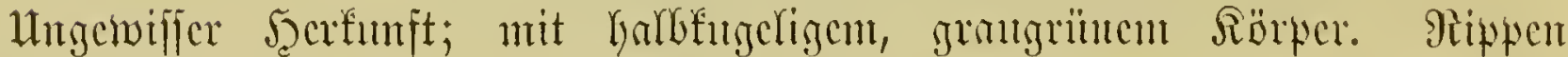

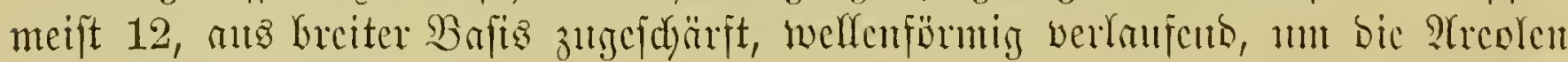

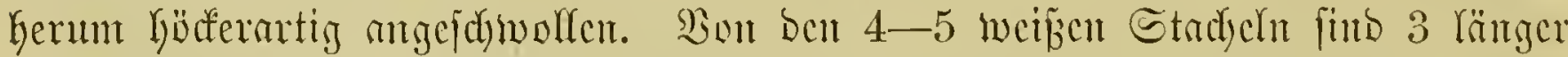

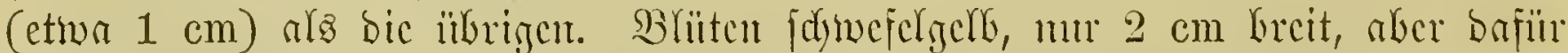

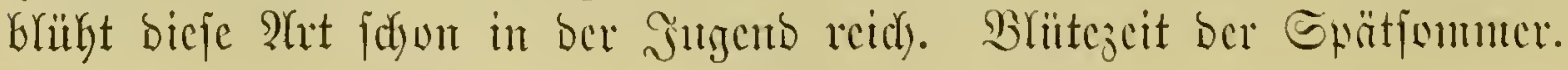

\section{Malacocarpus Sellowii S.-Dyck. Gullow'z MBcidjbcerfaftuz.}

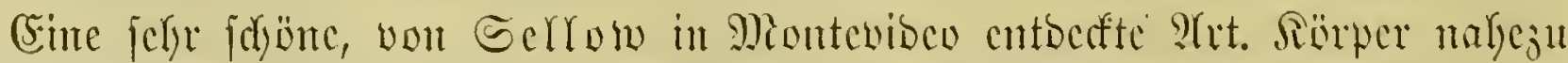
won Sutgelform mit mur wertig cingebriteftem, worligem Edyeiter mo 14-18 


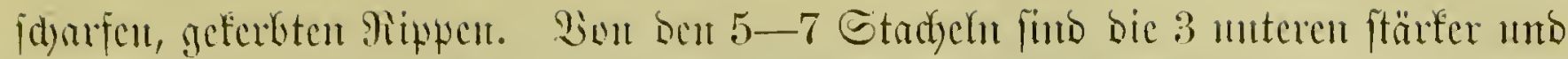
länger (faft $2,5 \mathrm{~cm}$ ) als bie ïbrigen, alle aber anfanges hormatig, rötlid) gefpitzt,

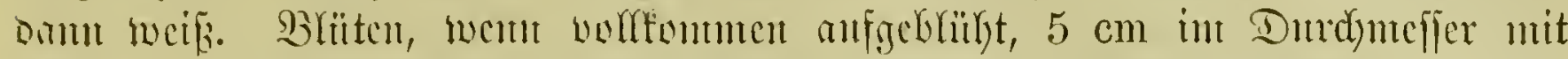

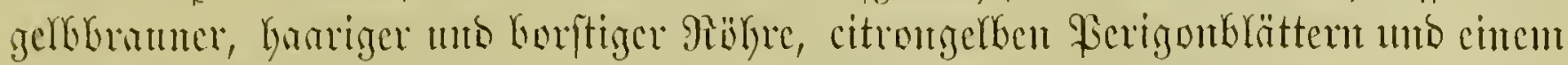

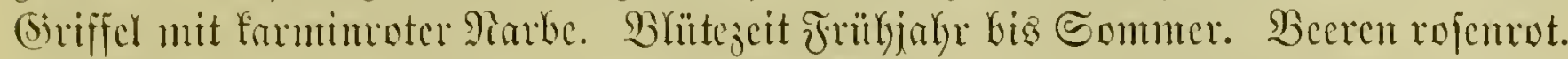

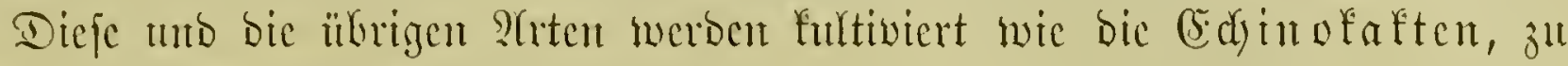
ocucu fie frïber and geredynet ivmben.

\section{Gattung Echinocactus Lk. et Otto. Sgelfaftü.}

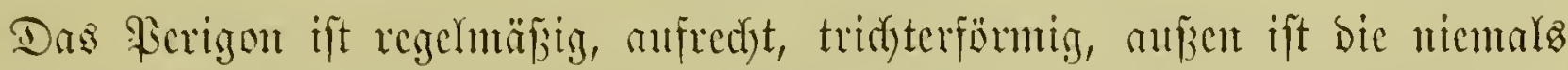
itme verlängerte giöbre mit Gdyupen bejebt, weldye wie bic am Frudytfinoten in

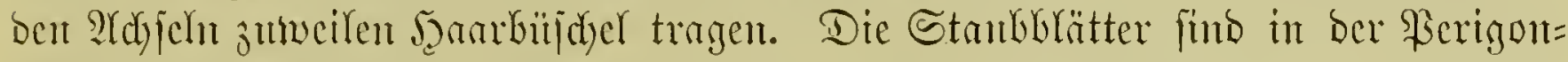

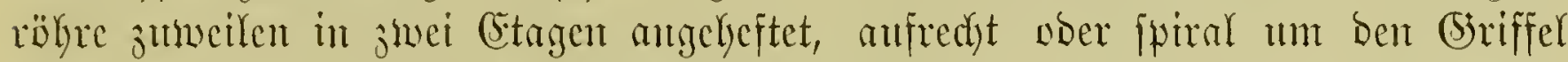

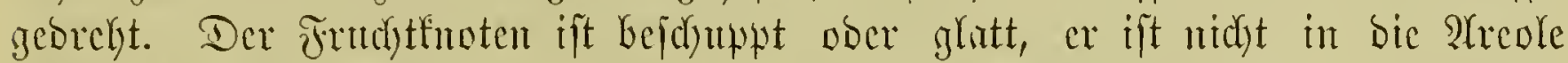

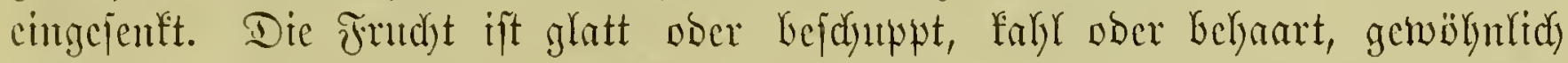
wenig faftig ober Gals ganz troden. Der Sërper ift faft ftets kugclig ober furz ch) limbrifd), felten ift er verlängert ober fenlenförmig, gerippt ober bie Rippen fimb

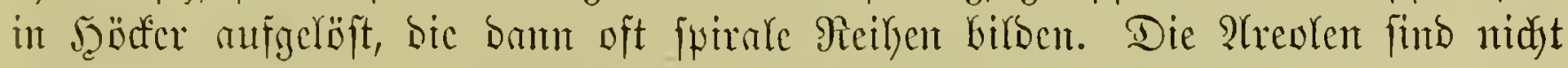

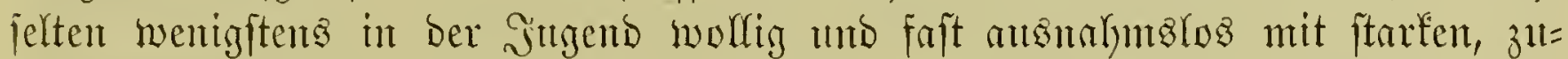

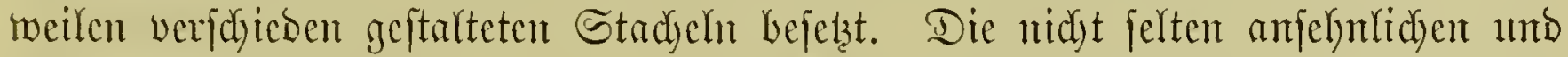

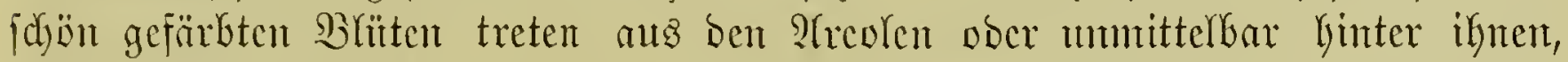

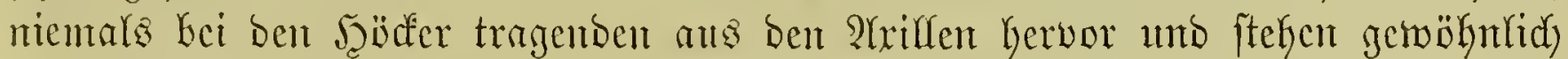
wom Edyeitel entfernt, feltener bredjen fic in ber Nähe besferben Gerwor.

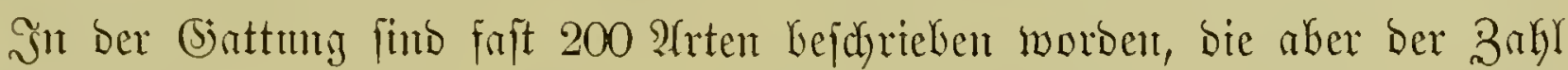

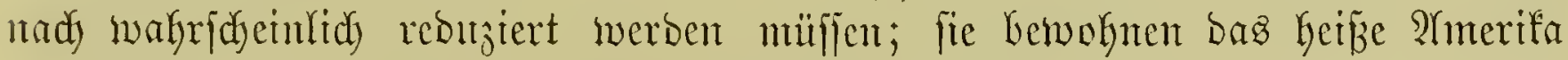

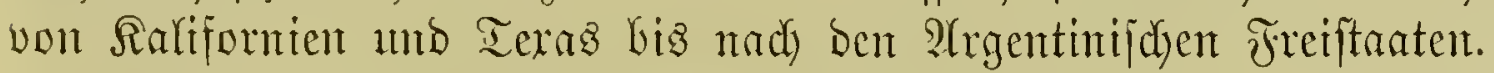

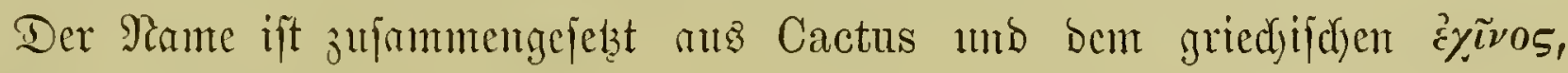
ber Jgel.

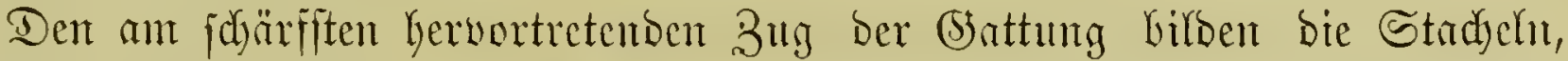

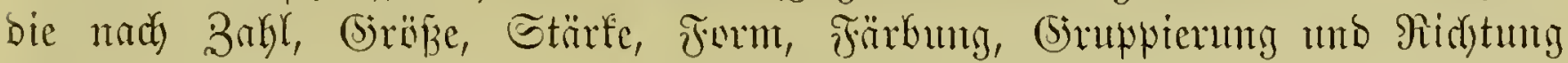

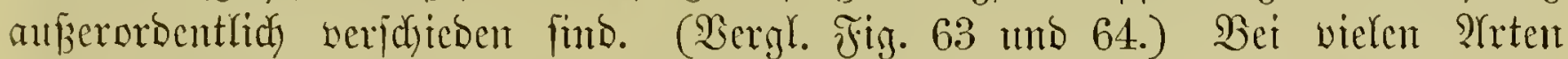

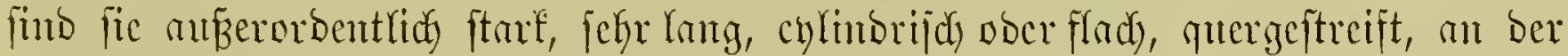

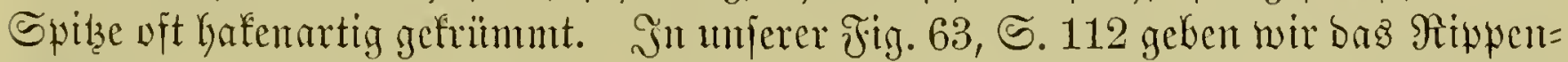
fragment bes Echinocactus Wislizenii mit zwei भreolen, jebe berjefben mit 4 Mittelftadjeln, woldyc alfe platt und geringelt find und won benen bie oberen brei aufwärts, Der untere, ber breitejte und rängfte, mady unten gebogen, uno mit 19 teils cafigen, fdyad) quergeftreiften, mebr ober weniger zuridfgebogenen,

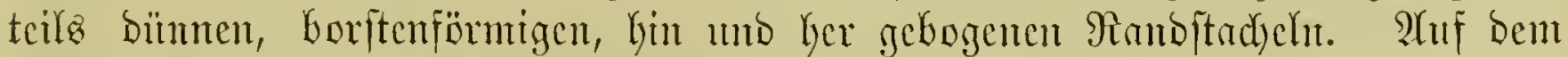

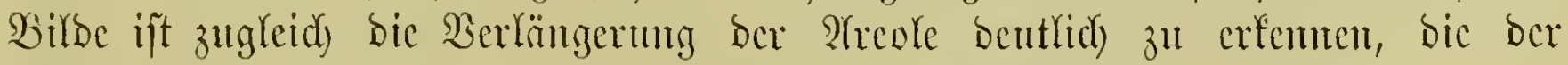
unteren mit ciner Şhme, bie ber bberen mit ciner Sirofpe.

So fdyer aud biejer brokenden Bewaffumg wegen mit ben (5d) in ofaten zu werfebren ift, jo intereffieren fie bud eben biejer Etadjeh wegen in lyolyen Strabe. Bubem werdienen viele ihrer ahten wegen ihrer bejonberen Form, wie wegen ifrer Blitbrulfigfeit alfgentein fultiviert zu merben. Bor affen bie forgenben. 
S丸liiffel für die befdriebenen Jrten.

A. Sämtliche Stacheln gerabe poer gleichmä̈ig, aber niemals blos an der Spibe gebogen.

a) Rippcu fortlanfend, nicht tief geferbt oder in Şöcfer aufgelöft.

a) Sippen fehr hod, fichar, wenig zahlreich, bei uuferer art früher ober fpäter fpiral georeht

1. E. ornatus $D C$.

ß) SRippen miedrig, genmbet, meiit zahlreidy II. Reihe Microgoni S.-D.

I. AYredlen eingejent, Sörper ługelig I. Srumpe Jmmersi.

1. Rippen 16-20; Das (Sentum des Sörpers all weite (5nt= fernung itachelfrei, Stadjeln gerabe

2. E. concinnus Lemaire.

2. Mippen 12; das innerite (5entrum mur ftachelfrei, Etachelut gerabe

3. Rippen 5-6 (höhjteng 8), Stacheln gefrimmt

4. E. denudatus Otto et Dietr.

II. ATenlent oberflächlid, Sïrper verlängert II. (Sruppe Emersi.

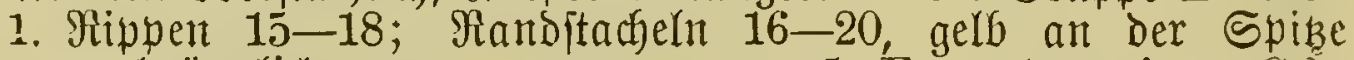
bräunlich 5 . E. castaneoides Cels.

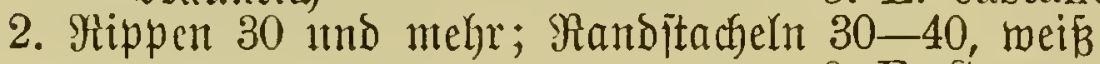

6. E. Scopa Ll. et Otto.

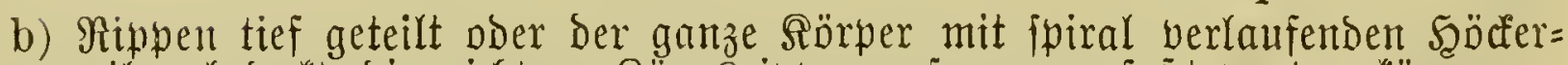

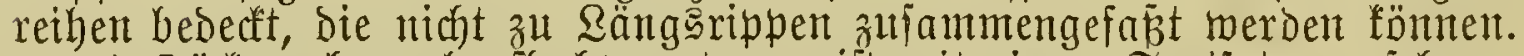

a) Sö̈cker oben abgeflacht, unten meift mit einem Fortiake verieben, in

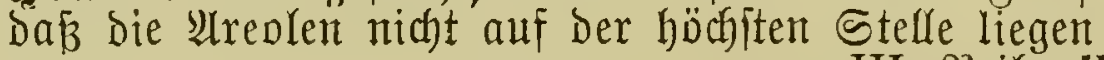

I. Röpper gelbgrïn, Ranbitacheln 12 , Mittelftacheln 1

III. Yeike Hybogoni S.-D.

II. Sörper grau= oder dutufelgrïu.

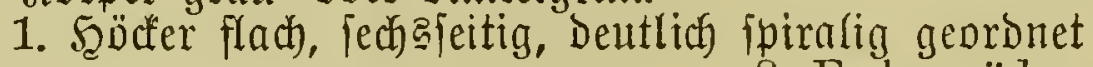

7. E. Monvillei Lem.

2. Ђૃöcter rundlich. * Stacheln 5
* Stacheln mehr als 5.

$\Delta \Delta$ Randitacheln 5-7, Mittelitacheln 2-4

10. E. gibbosus $D C$.

11. E. Jussieui Monv.

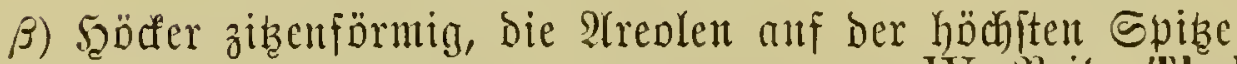

I. Şöffer in 8 sieigen geftellt

IV. Peihe 'Theloidei S.-D.

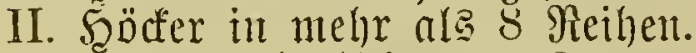

12. E. bicolor Gal.

1. Stadheln flein, mur $2 \mathrm{~mm} \mathrm{lang,} \mathrm{angebrïct,} \mathrm{Nittelitachel} 0$

13. E. Odieri Lem.

2. Gtachelu gröper, 3. I. anfrecht ober abjtehent, Mlittelftadheln vorhanden.

* Randitadjeln anged rïct, Mitteljtad)eln $1-3$, nicht geringelt

14. E. mamillosus Lem.

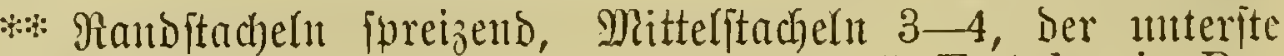
geringelt 15. E. tulensis Pos.

B. (Einer poer melyrere ber Mittelitadycln mur an ber Spibe gefrïnmt.

V. Jteihe Uncinati S.-D.

a) Dic gefrünmente Stadycln an ber Spize janft, hormiörmig gebogen, flad)

I. Siruppe Cornigeri.

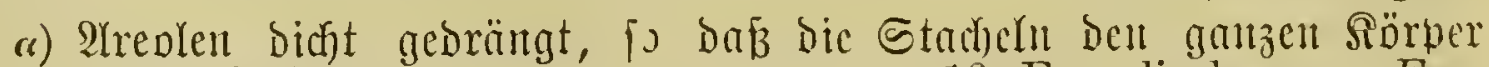
bicht bebeden 16. E. cylindraceus Eng.

ß) Streden weitlüufiger geitellt.

I. Mreolen treis= ober nierenförmig; Rippen nicht noer mä̈ig tiç geferbt. 
1. Der größzte Mittelftad)e big $4 \mathrm{~cm}$ laug, ant (35lunde $8-9 \mathrm{~mm}$ breit, außserdent 3 ftarfe, anfred)te, geringelte

17. E. cornigerus $D C$.

2. Der nur fuäter entwidelte einzelne Mittelitadjel big $2 \mathrm{~cm}$ lang IIII) höb) ftent $4 \mathrm{~mm}$ breit

II. Sreolen lïnglich; Prippen tief geferbt.

1. Ilitter Den unteren Mittelftad)el 5 Randftadyeln, bie oberen 9)ittelitachelu gerabe

19. E. Wislizenii Engelm.

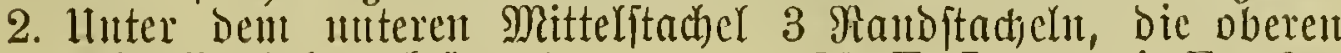
Mittelftacheln getrinumt

20. E. Lecontei Engelm.

b) Die gefrimmten Stadjeln luz angelyafig gebogen, ftielnund ober fantig, niid)t flad).

a) Stad)elı bis $8 \mathrm{~cm}$ lang แ⿰亻 Darïber, oft geidhlängelt

ß) Stadjelı wentiger ale $5 \mathrm{~cm}$ lang.

21. E. longihamatus Gal.

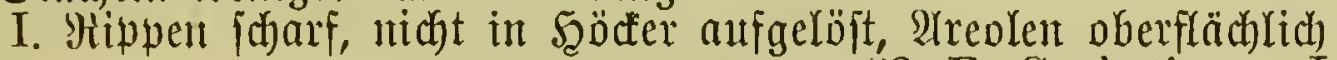

22. E. Cachetianus Lem.

II. Sippen tief gebuchtet, $\mathfrak{A}$ reolen eingefentt 23 . E. sinuatus Dietr.

III. Siippen in zikenförntige Şöcfer anfgelöft.

1. Rantoftachelı höchjtens 14 , 9) rittelitachelıt 4 .

2. Sanditacheln 15-18, Mittelftacheln $3-4$.

24. E. brevihamatus Engelm.

25. E. Scheerii S.-Dyck.

\section{Echinocactus ornatus $D C$.}

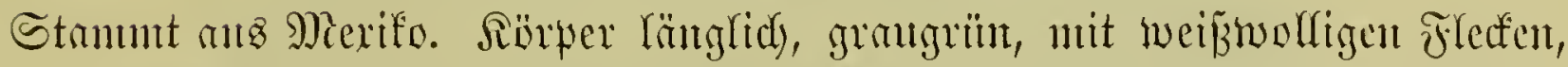

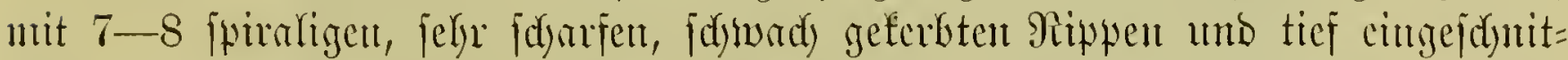

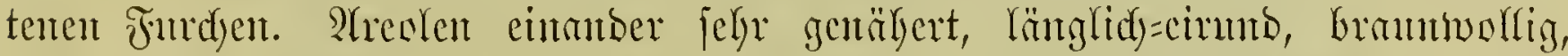

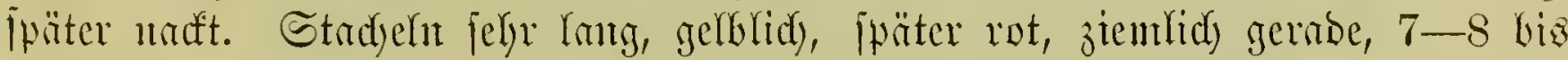

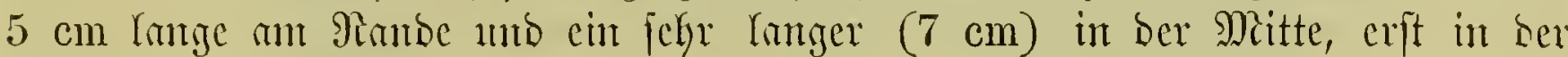
ipäteren Beit fich nolf entwictelnto.

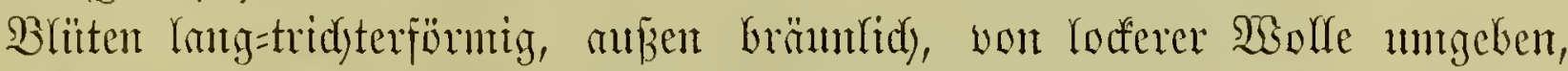

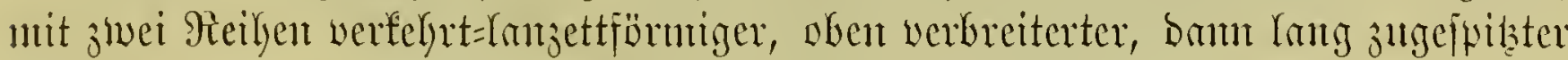

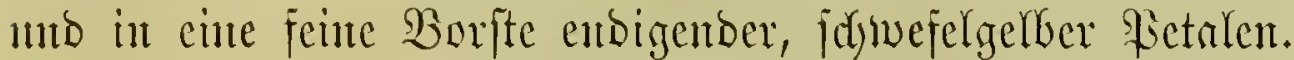

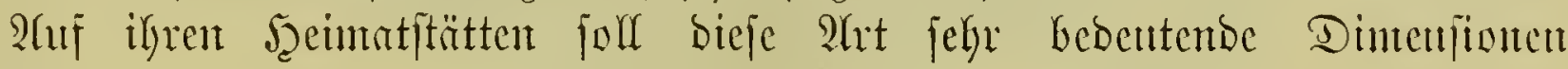
erreidyen.

\section{Echinocactus concinnus Lem. (Eleganter Jgelfaftuz.}

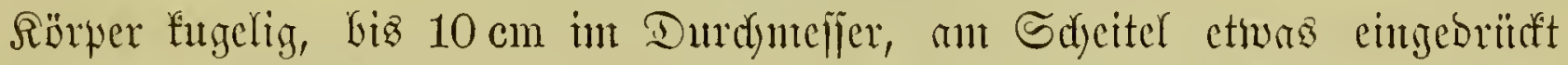
und anf weite Stredfe ftrdyelfret, rebyajt grün, mit $16-20$ jentredyten, breiten

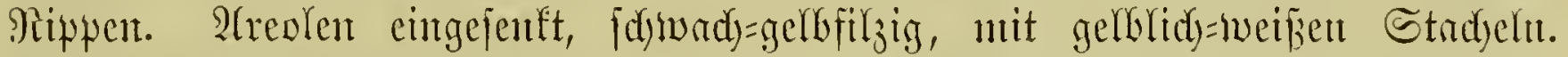

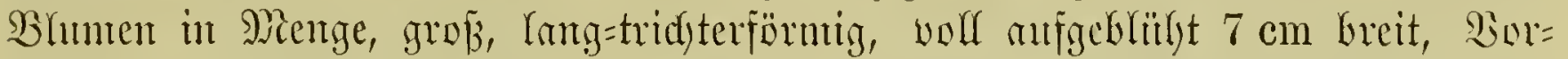

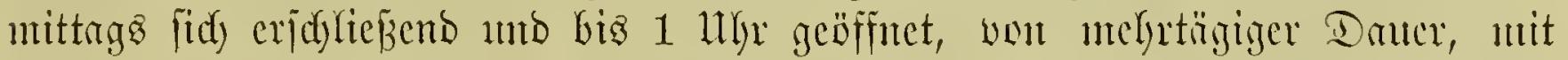

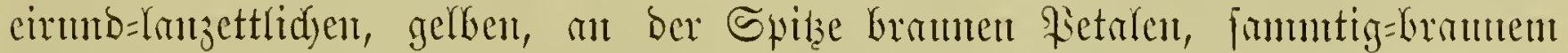

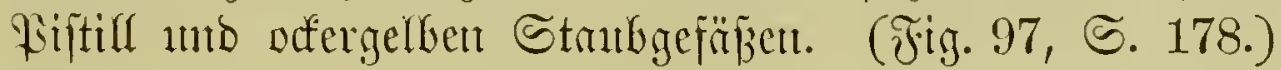

\section{Echinocactms Ottonis Lehm. Dtto'z Ggelfaftuz.}

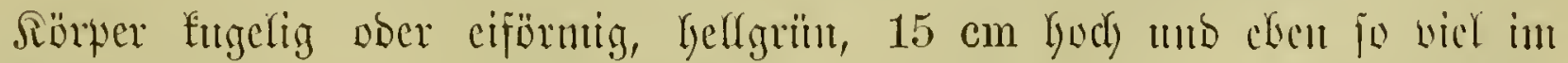

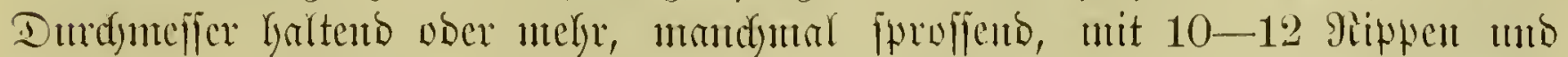

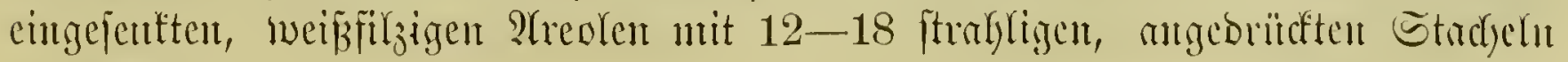




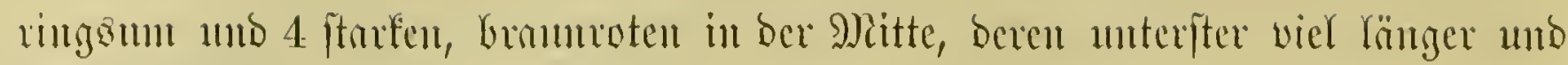
rerabgetogen.

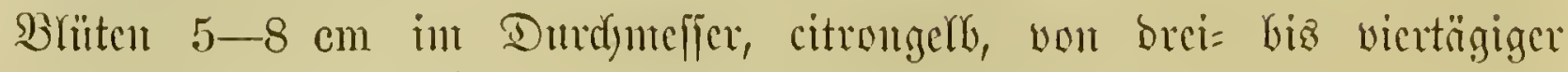
Druter (Jig. 98, ๔. 179).

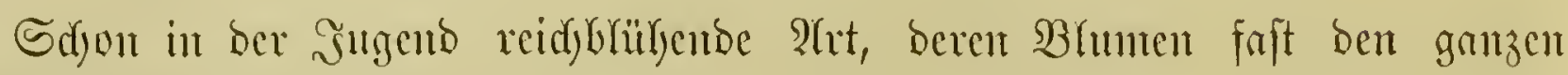
Sommer rintourd) anf cinntore folgen.

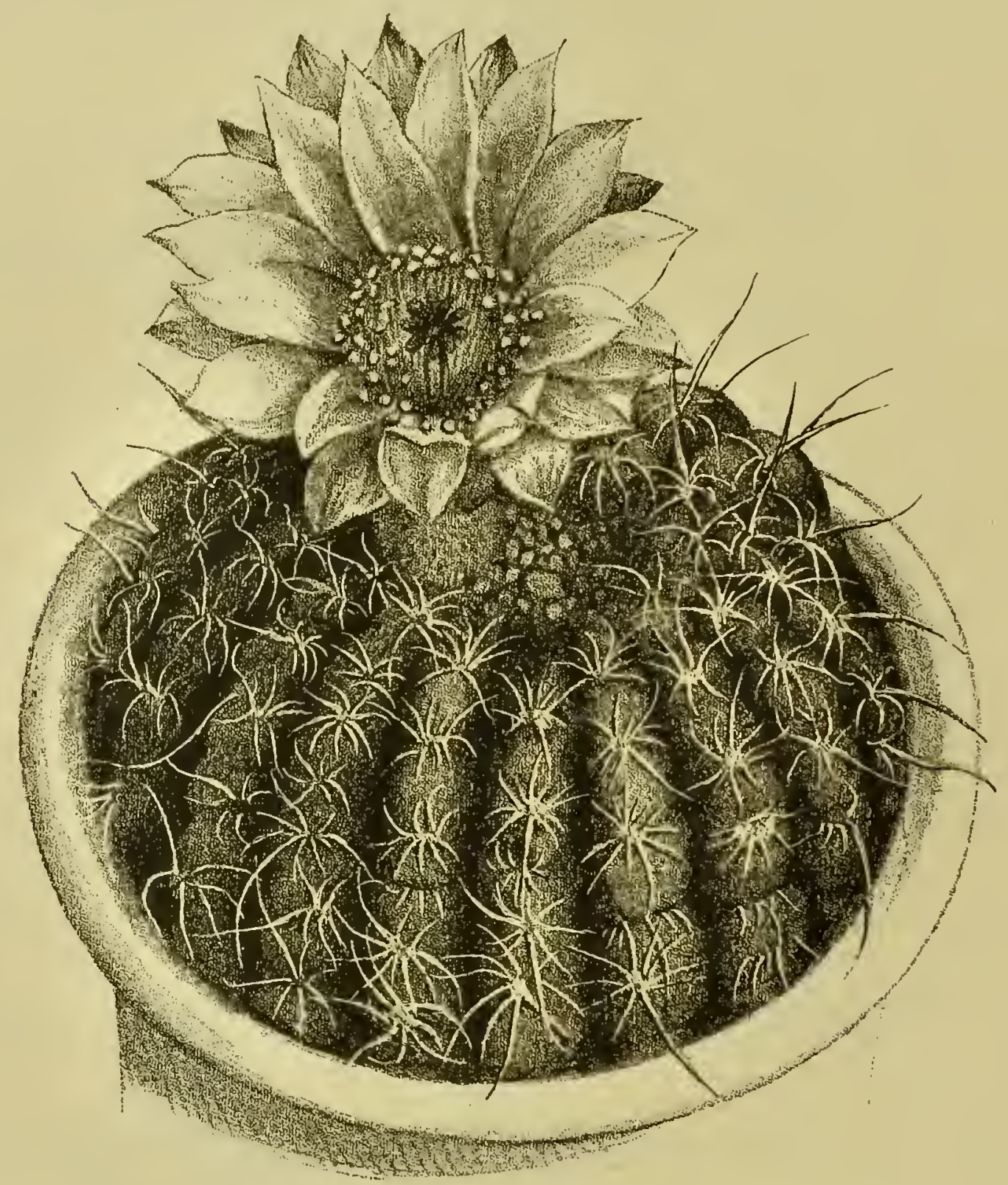

ซig. 97. Echinocactus concinnus. Lem. (5) Leganter ร̌gelfaftus.

\section{Echimocactus demmdatus $L k$. et $O$. Madfifiditeliger Igelfaftus.}

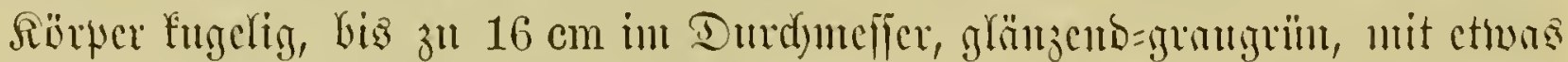

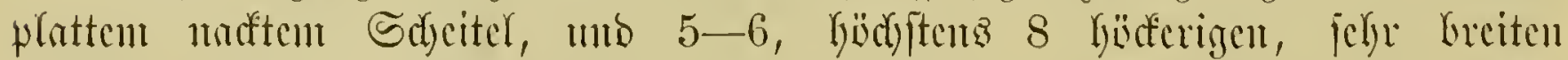

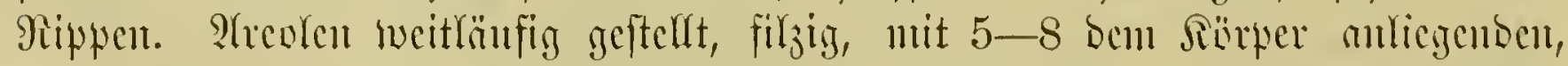

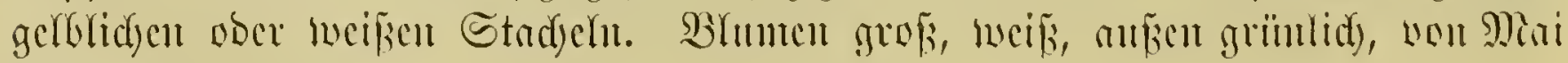
bis gumi.

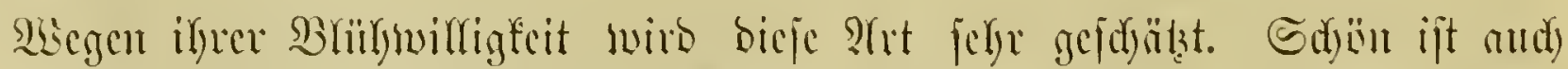

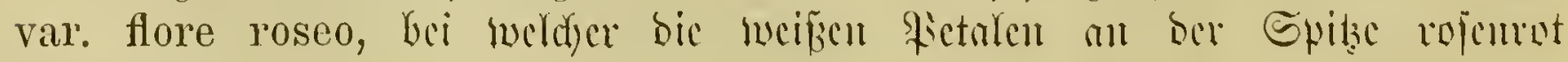
gefürbt finto. 
5. Echinocactus castaneoides Cels. Binunitndigcligev Igulfoftus.

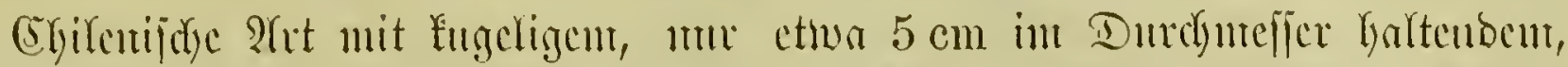

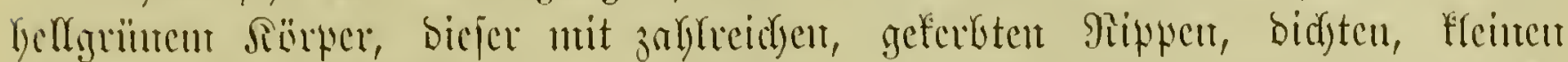

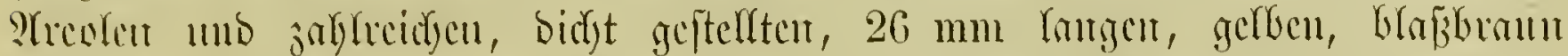

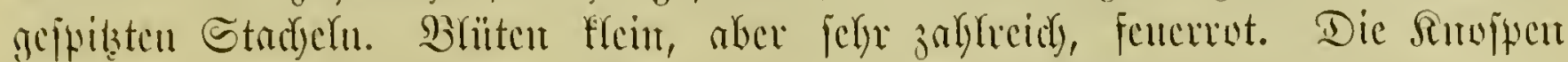

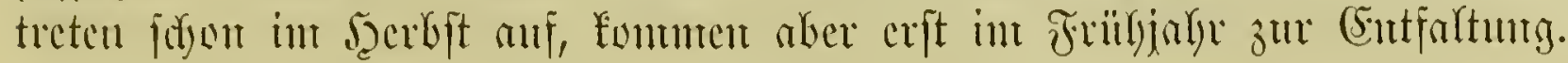

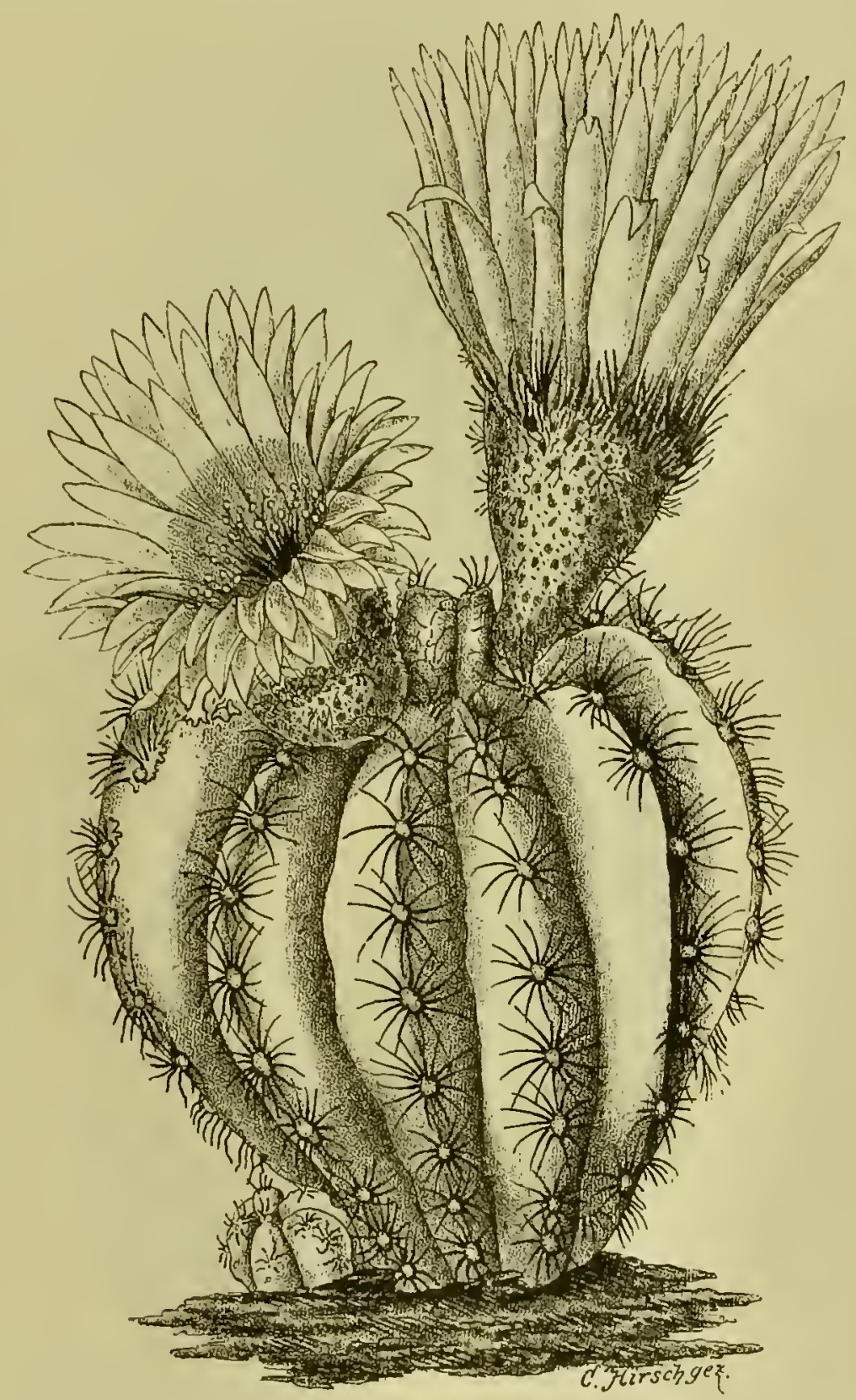

Fig. 98. Echinocactus Ottonis Lehm. Stto'\& Igelfaftus.

\section{Echinocactus Scopa $L k$. et $O$. Bcien=פgyclfiftuz.}

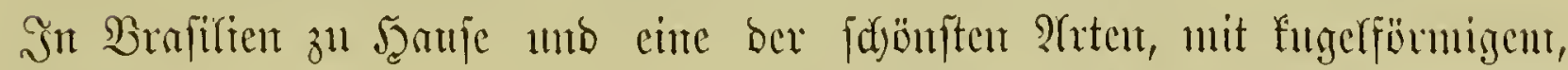

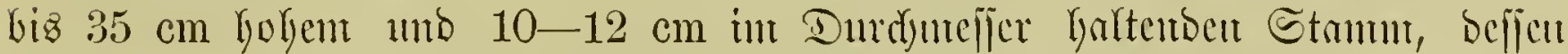

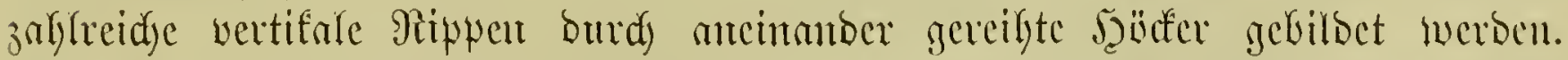

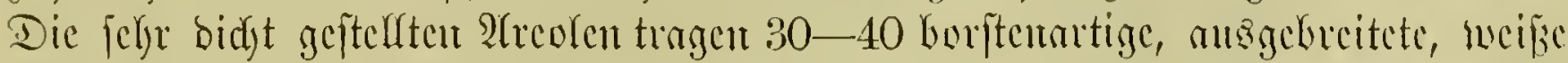

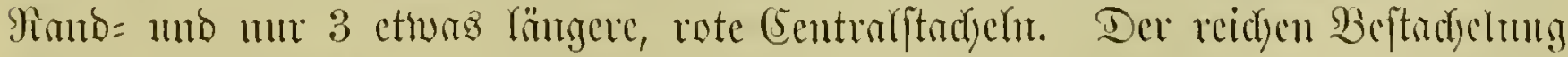

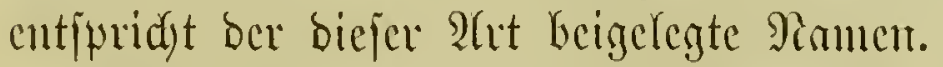

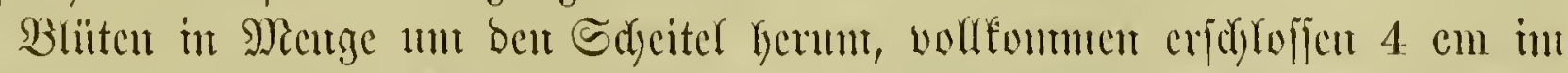

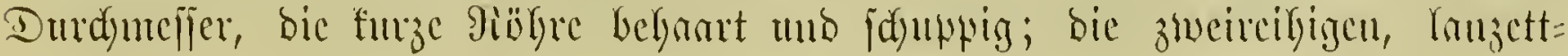




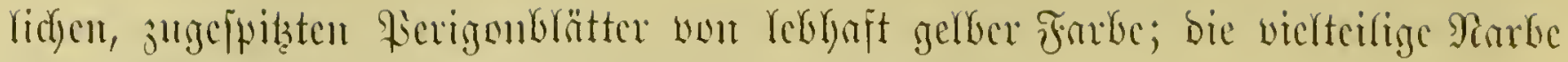

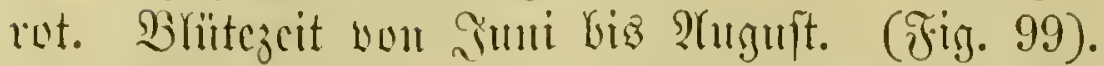

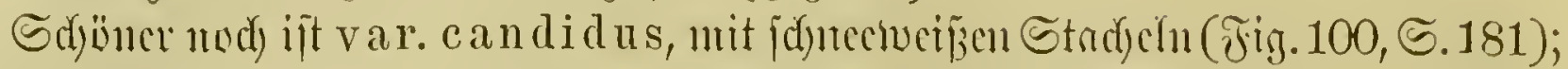
var. candidus cristatus ift cine felyr intereffante Monjtrojitüt, bas joünjte

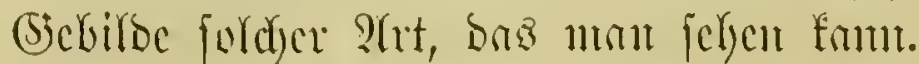

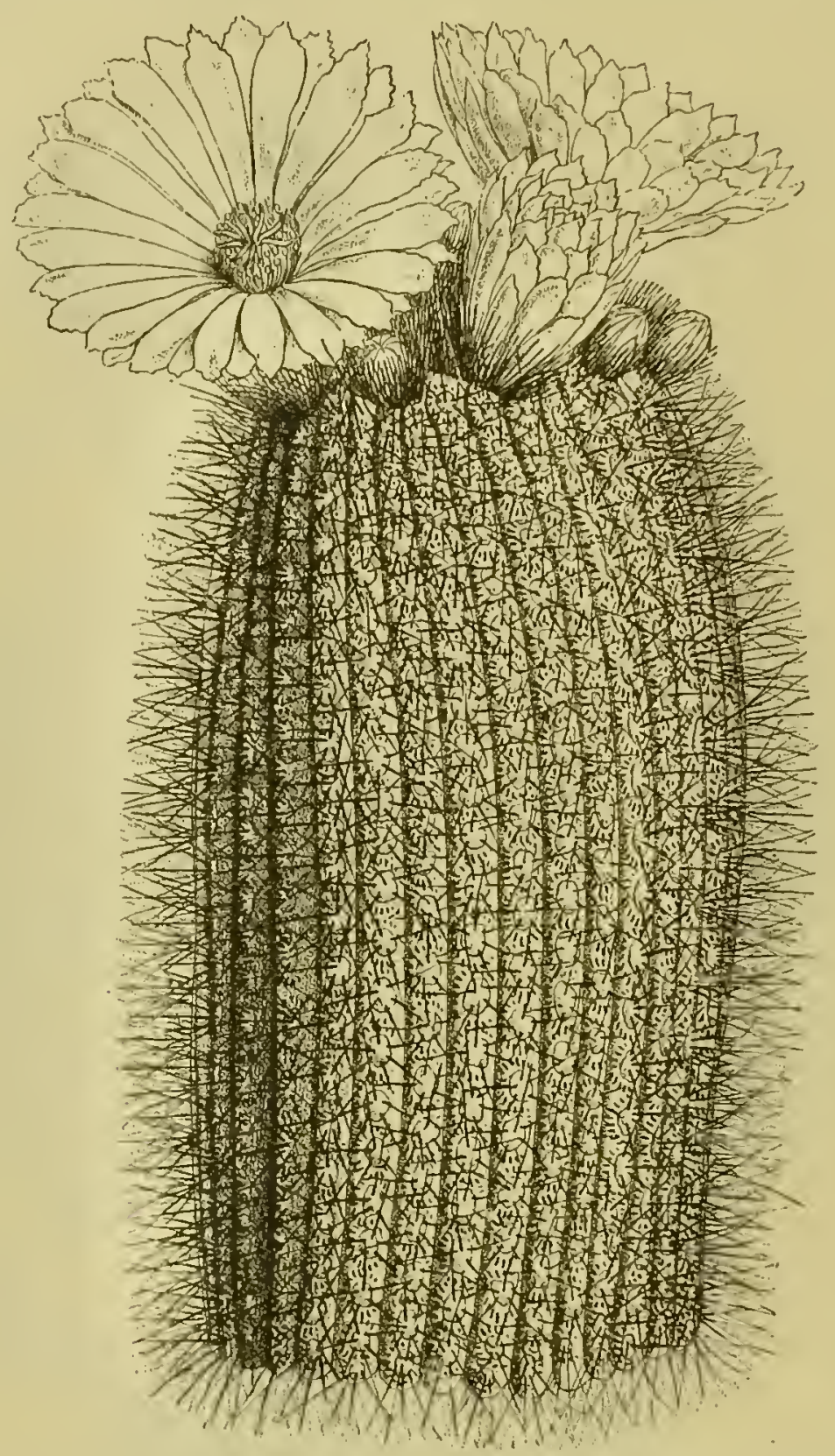

Fig. 99. Echinocactus scopra Lk. et 0 . Bejen=jgeffaftu’.

7. Echinocactus Monvillei $L \mathrm{~cm}$.

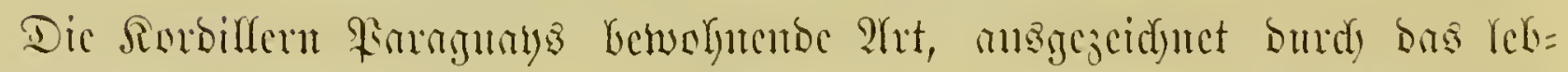

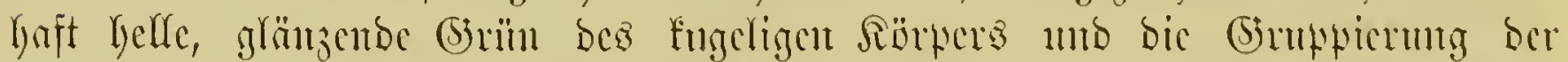

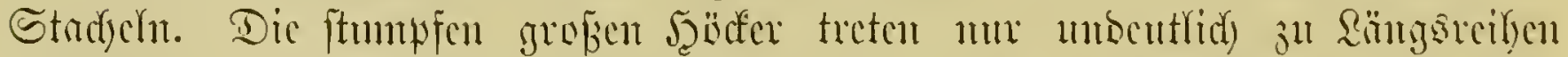

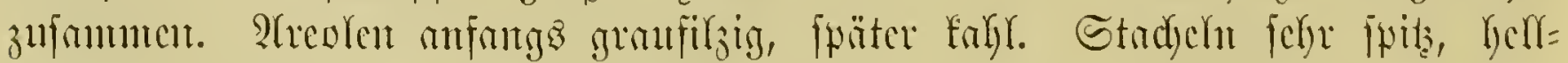

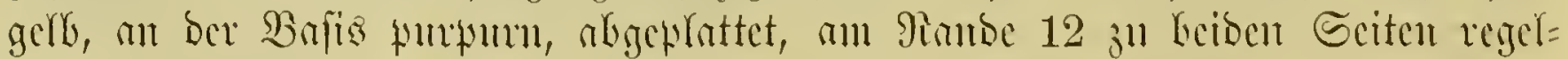

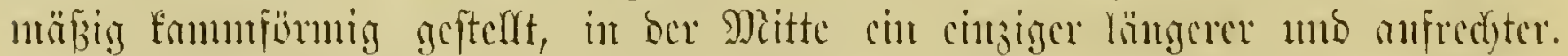

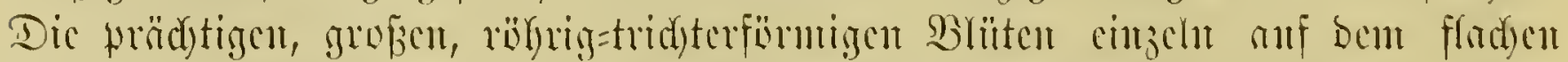

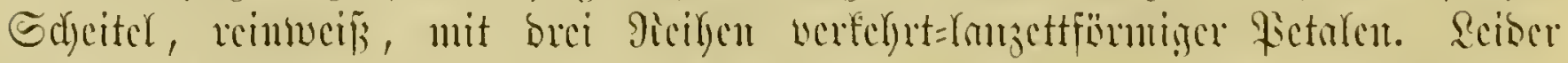

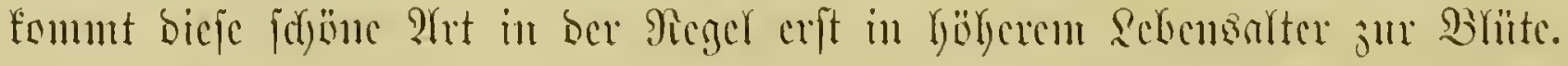




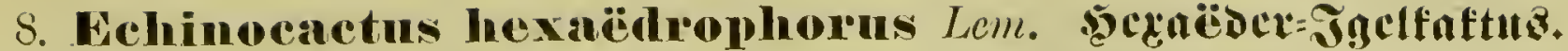

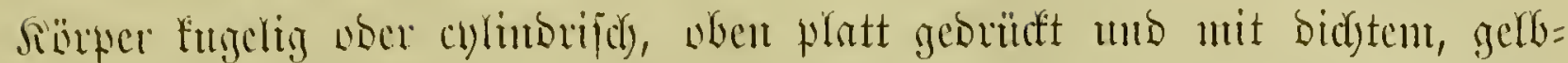

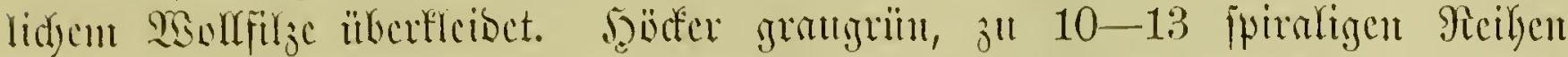

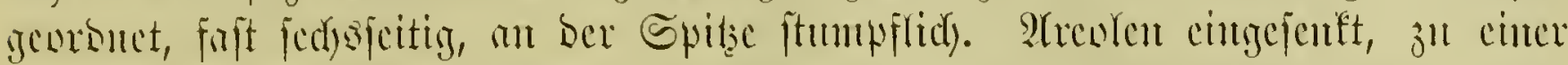

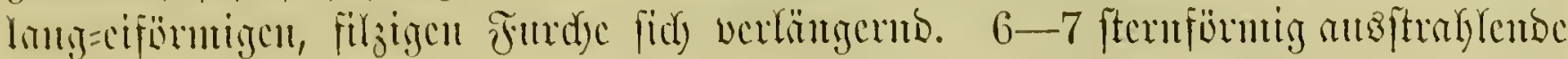

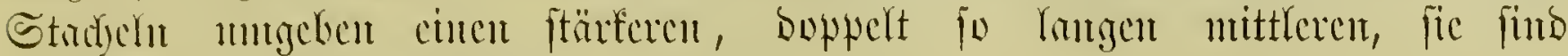

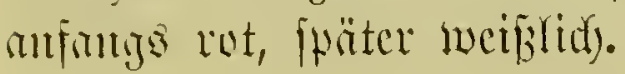

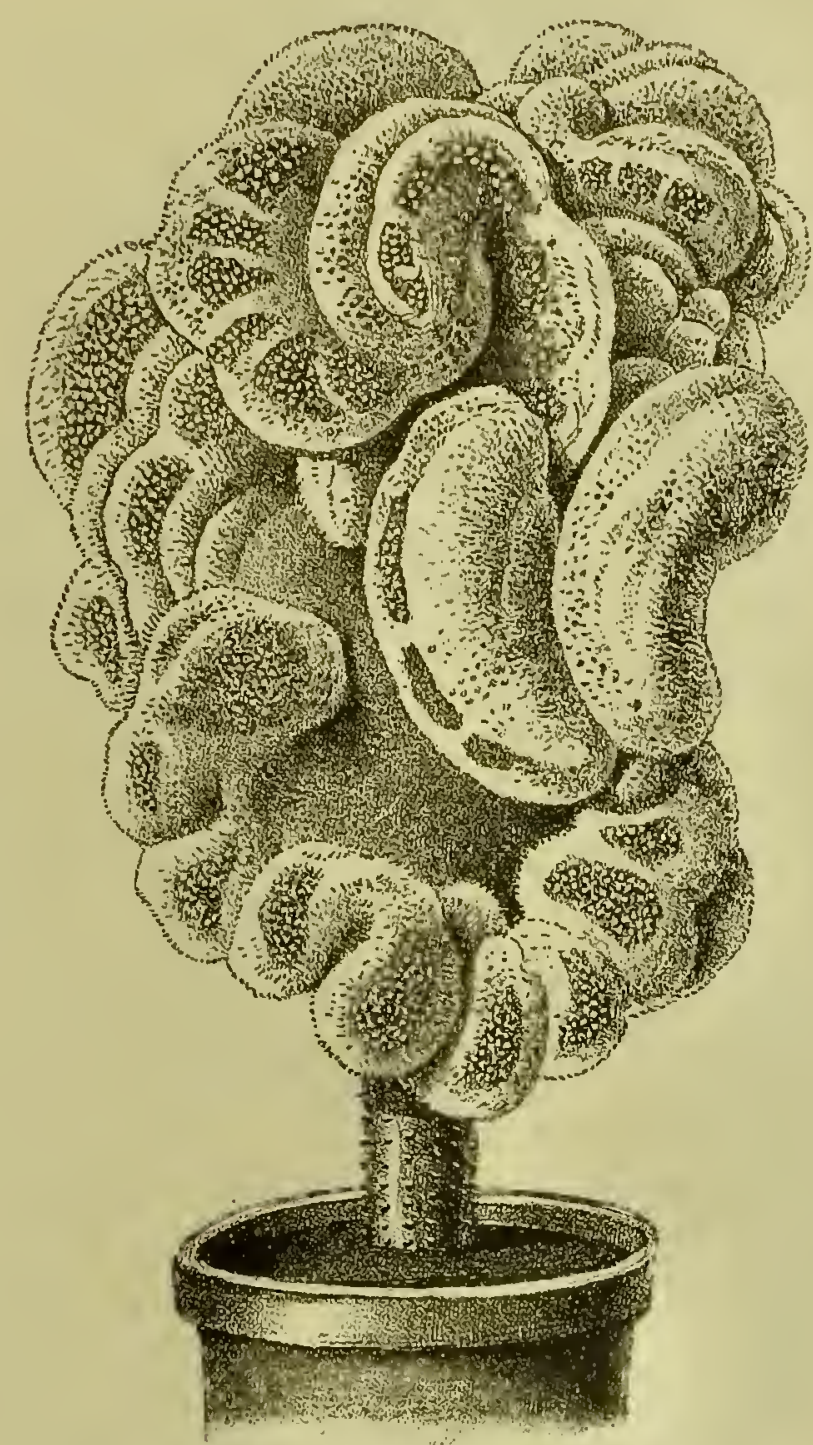

Fı. 100. Echinocactus Scopa var. candidus.

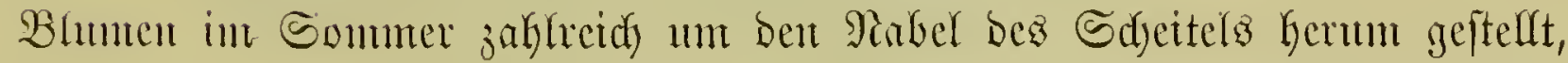
$5 \mathrm{~cm}$ lang bei 7 -8 cm Durdymeffer. Sepaten purpurrot, Fetalen Yinent=

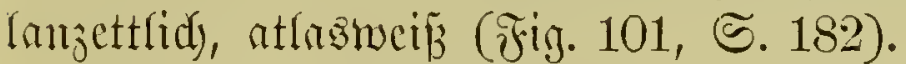

Eime ber jojünften $\mathfrak{A}$ reten iffer (Şattung!

Sine ifrer $\mathfrak{B}$ mrietäten (var. roseus) Gat rojemote $\mathfrak{B}$ humen.

\section{Echinocactus Durselianus Cels.}

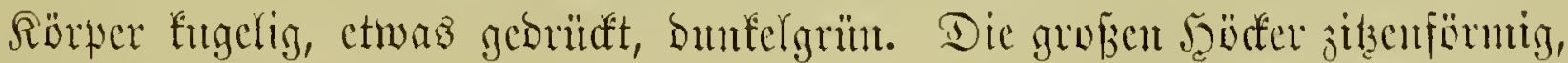

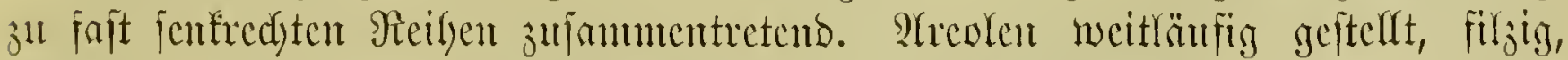

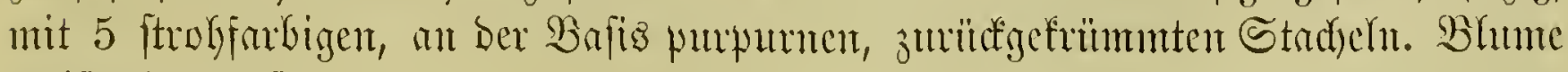
weingelb, groj.

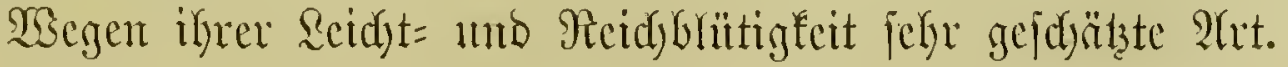




\section{Fehimocactus gibbosus $D C$. Gehjöferter Jgelfaftuz.}

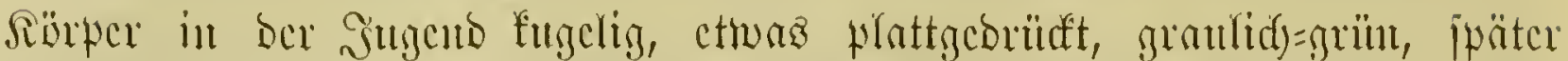

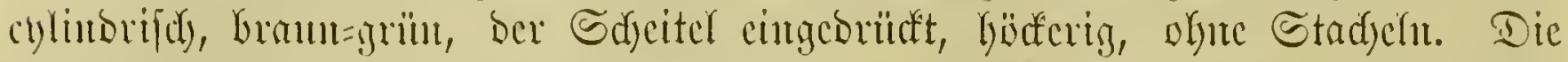

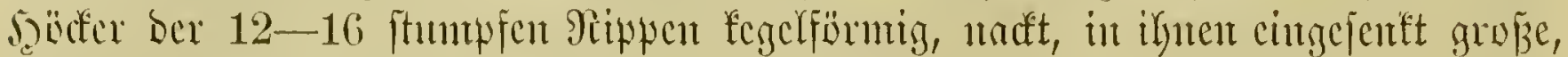

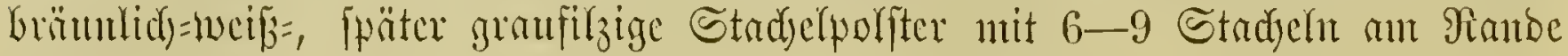

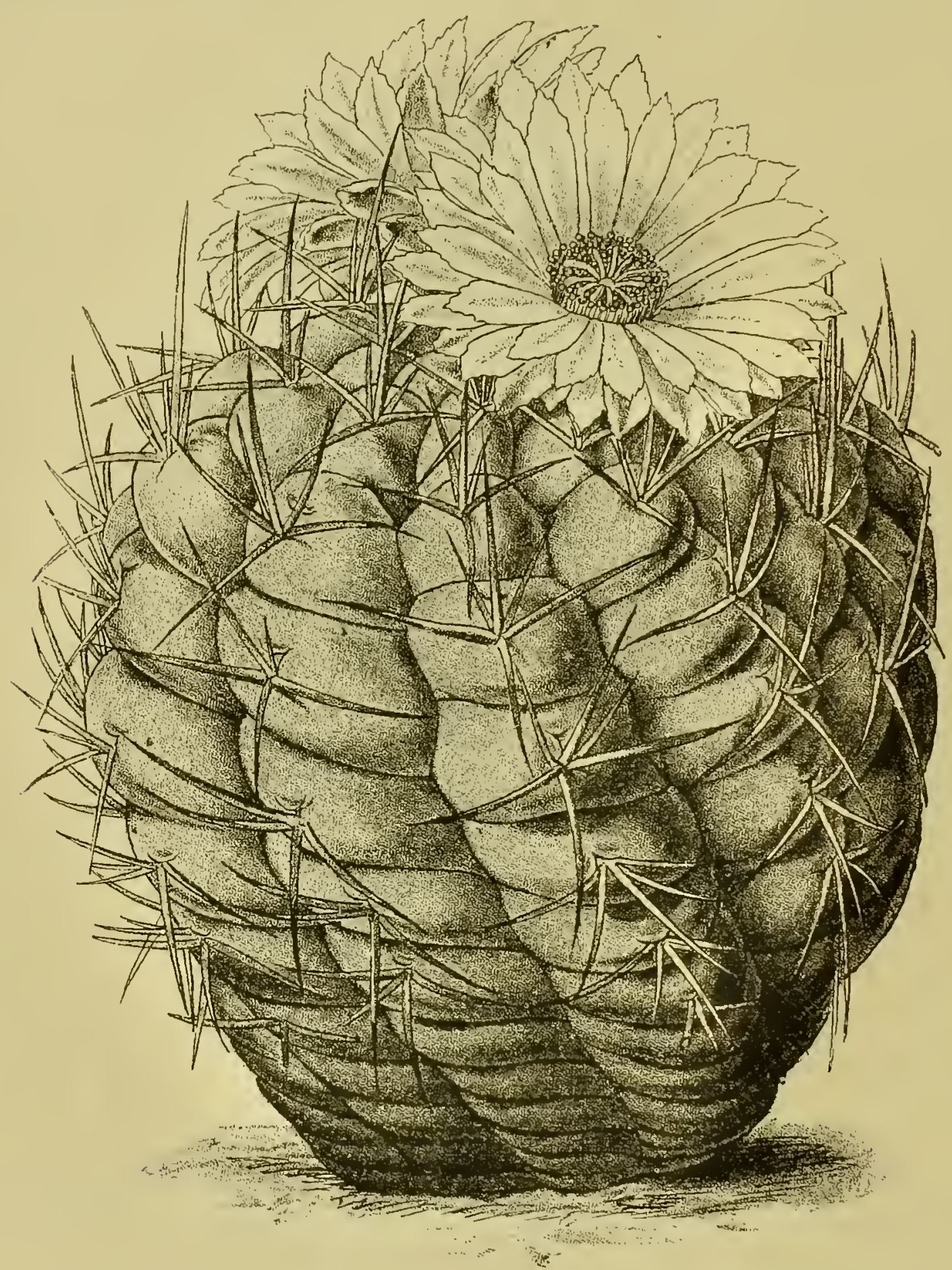

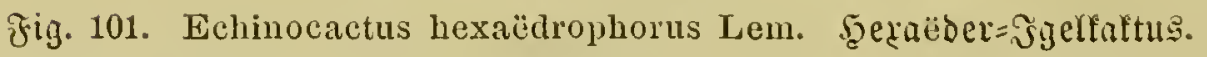

แnd cincm in ber Mitte. Meiftens fintot man in ben Sammlungen jünume

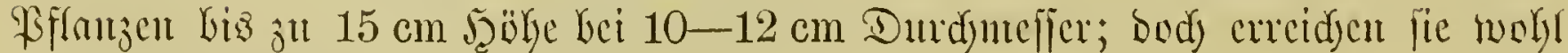
bie boppelte 5öbc.

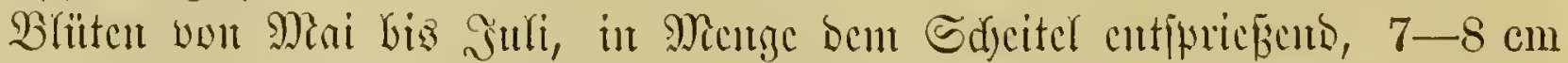

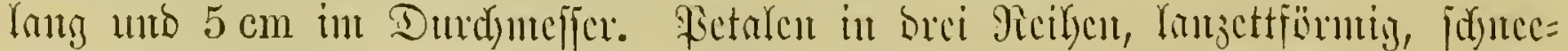

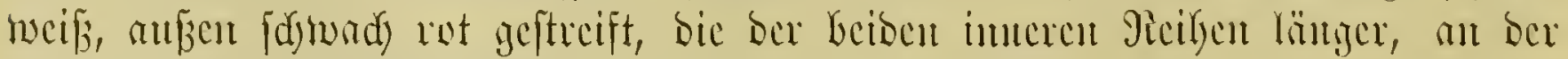
Spize ethua jurïngebogen. 


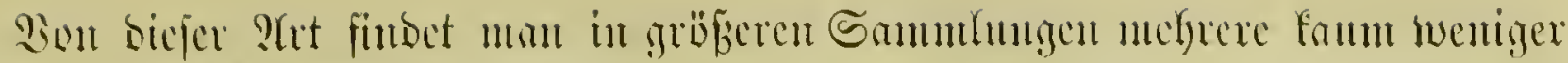

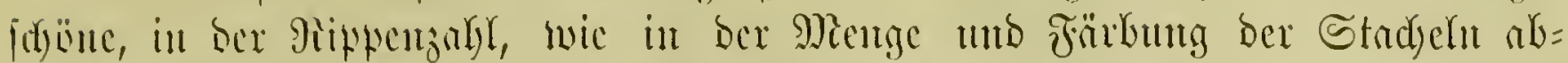

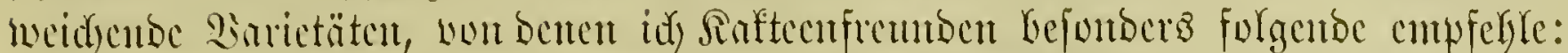

Var. cristata, cunc intereffante Gafucufanmfümuge Nivuftrofität; anf

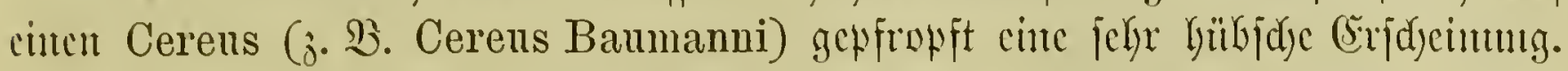

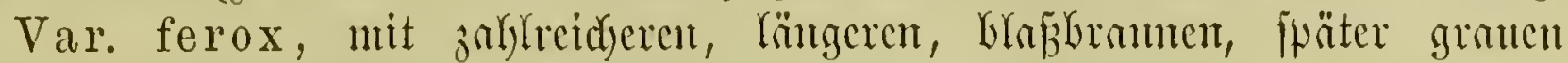

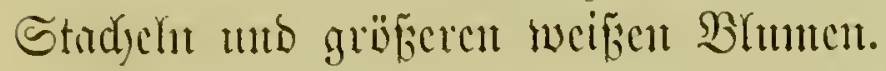

Var. Schlumbergeri, mit Gräunlidyen, fpäter grancu Stad)eln mo mit

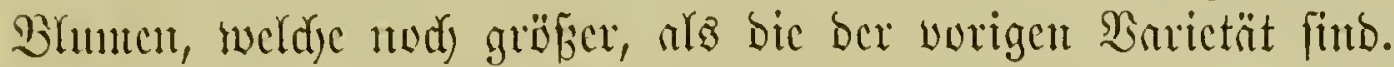

Dic Keiben Kelitgenanten Sarietriten brïlyen reid) unb willig wic bic Gtanumant.

\section{Echinocactus Jussieni Monv.}

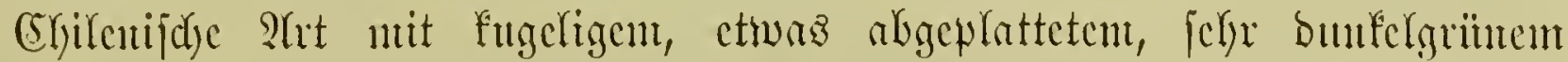

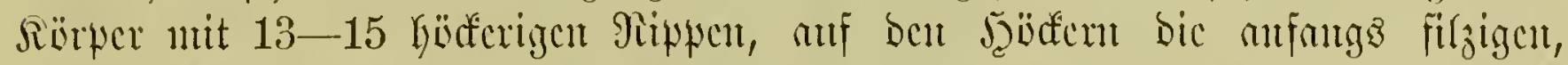

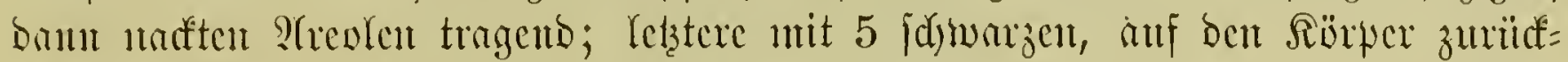

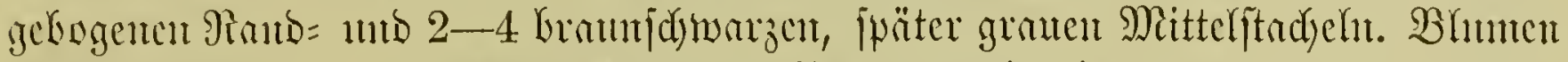

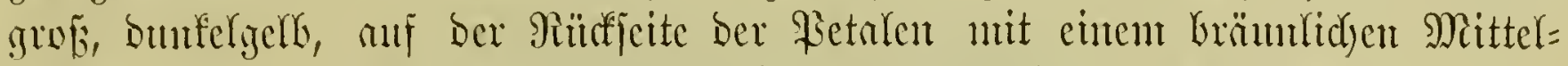

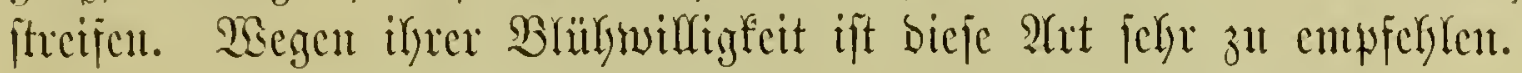

\section{Echimocactus bicolor Gal. Buttitadjeliger Jgclfaftuz.}

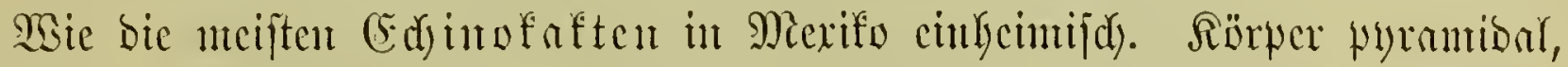

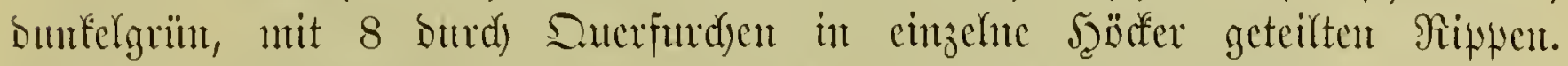

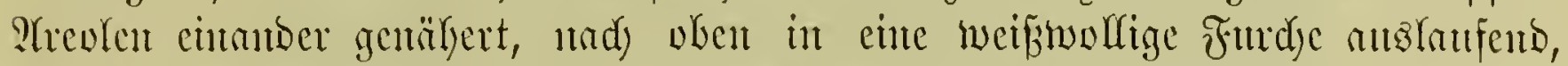

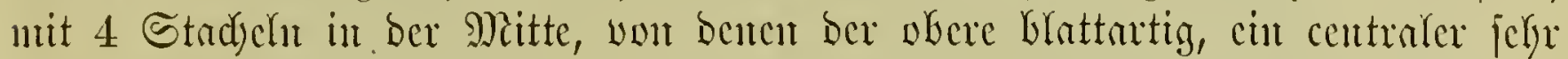

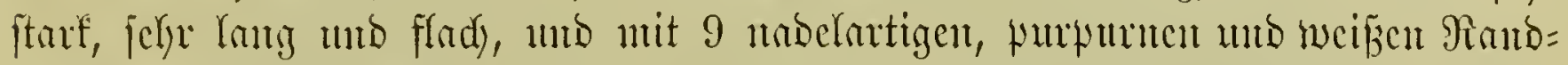

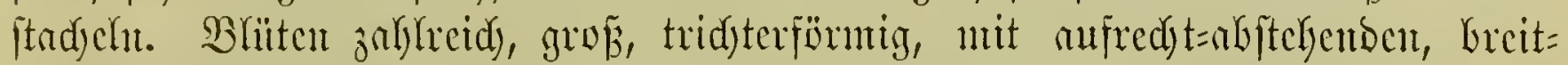

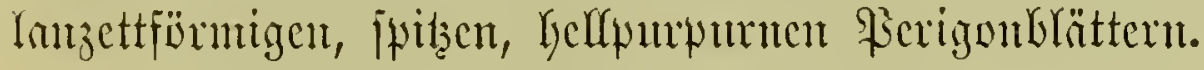

\section{Echinocactus Odieri Lem.}

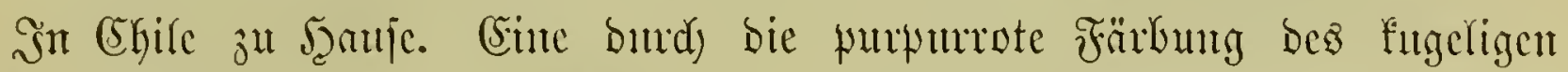

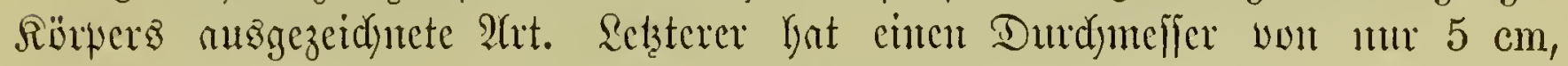

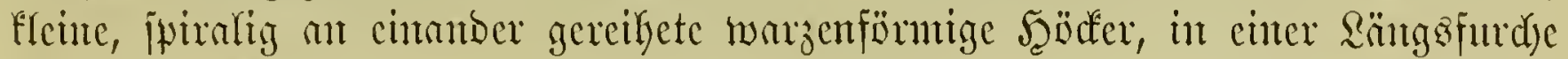

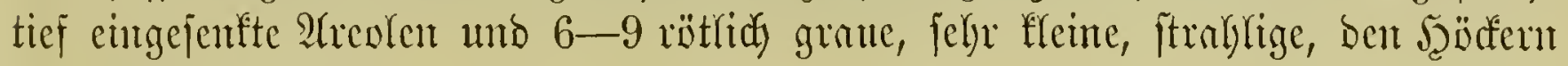
angebriudte Gtradjeln.

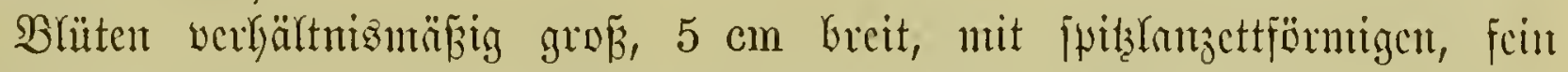

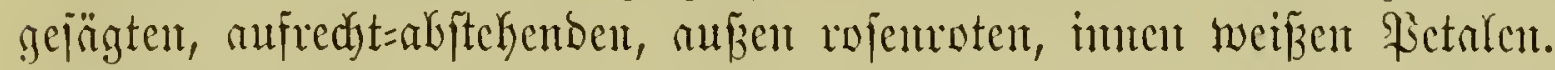

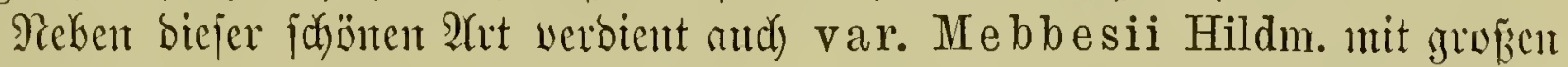

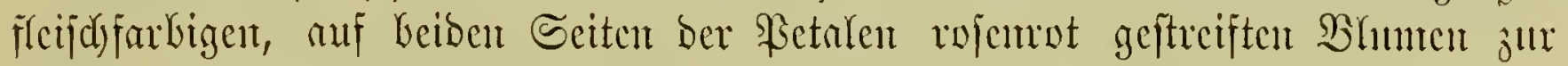
Rultur entwfolylen ju werben.

\section{Echinocactus mamillosus Lem. Slciuwarzigcr Jgelfaftuz.}

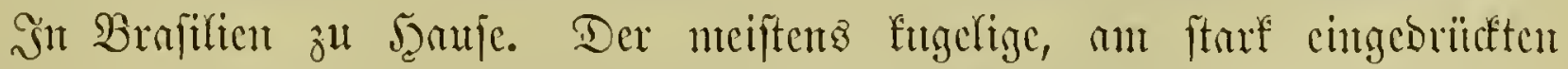

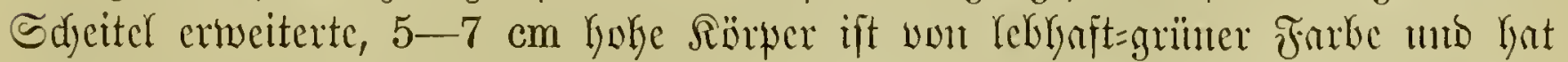

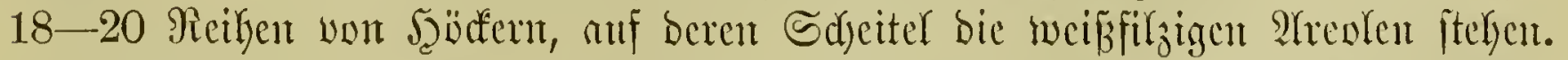

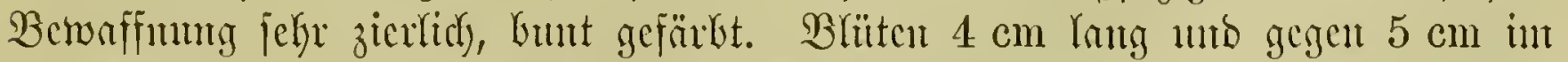

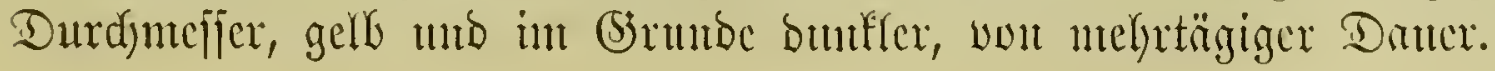




\section{Helnimocactus tulensis Pos.}

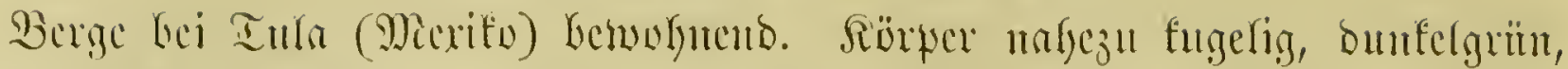

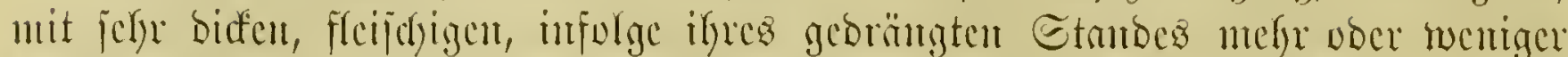

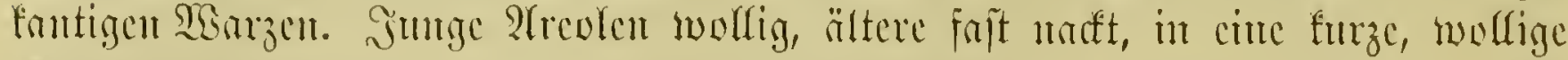

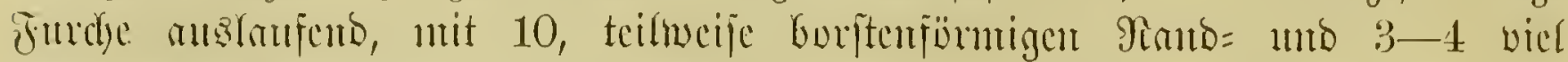

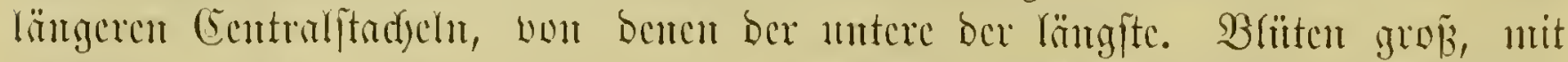

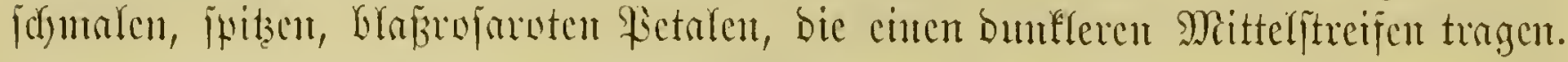

\section{Echimocactus cylindraceus Engelm. (Eylindrijucr Jgelfaftus.}

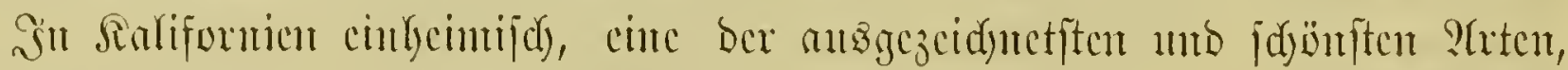

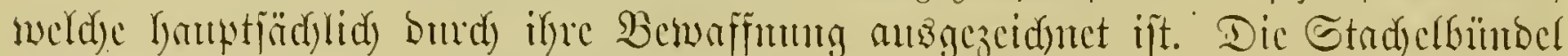

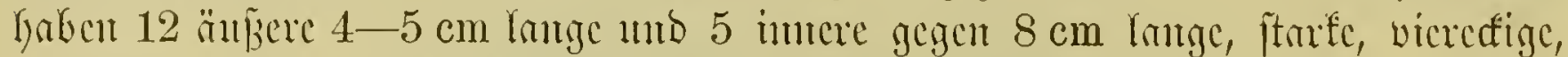

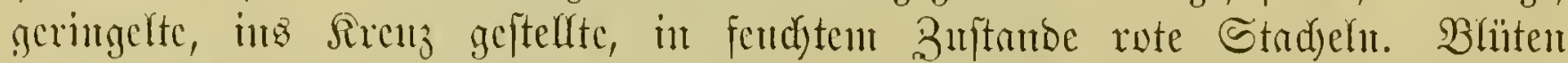

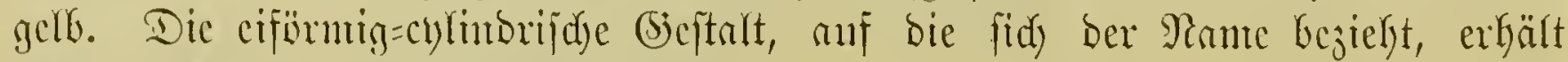
biejer Saftus erjt in räherent arrter.

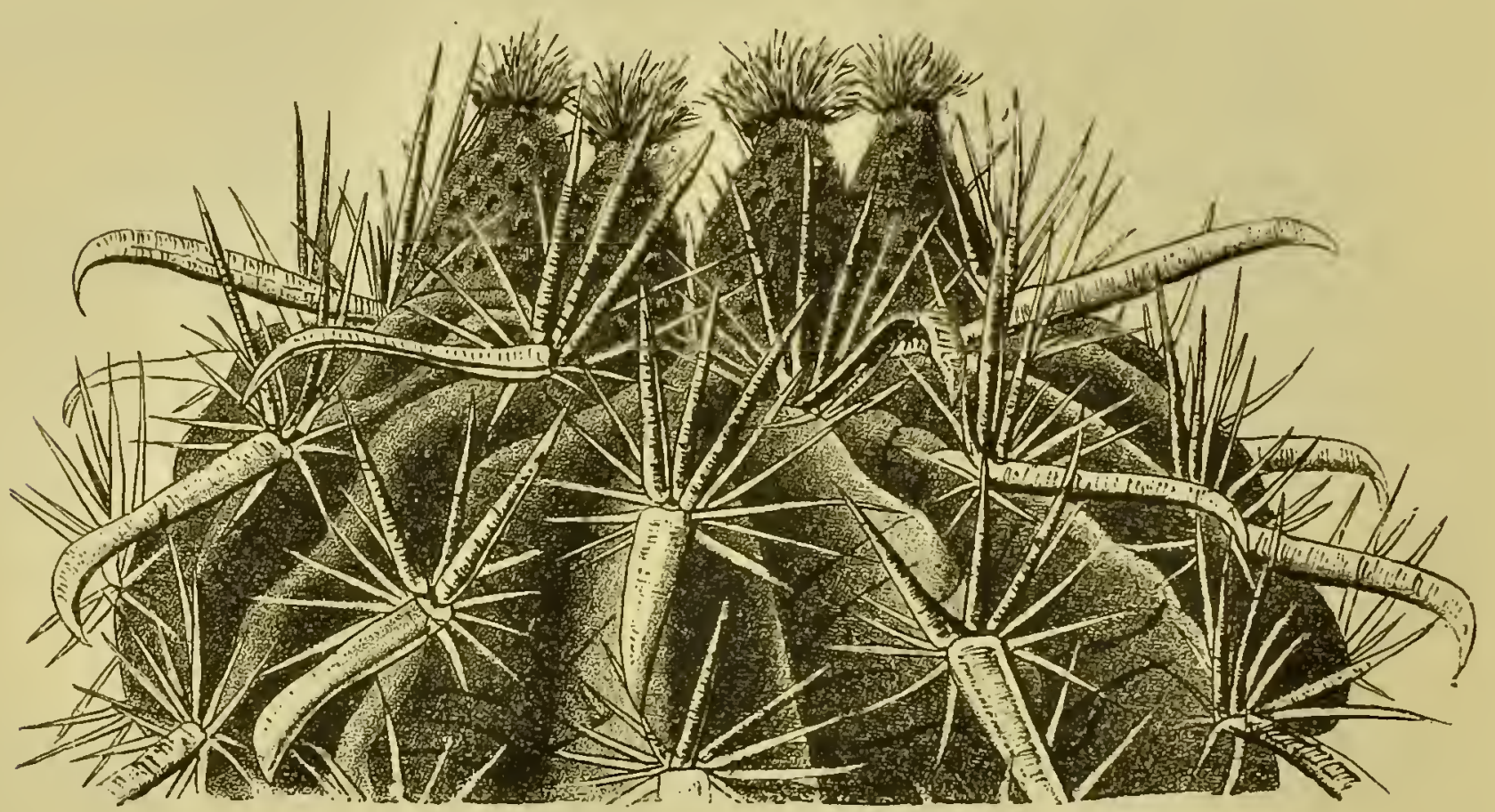

Fig. 102. Echinocactus cornigerus DC. Sgüntertragcuder Эgettaftus.

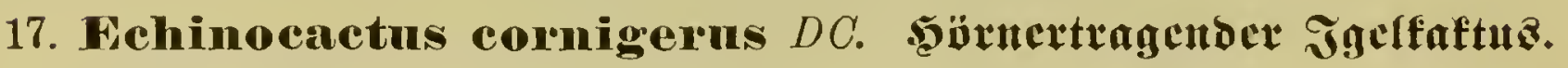

Rörper fingelig, bor Schcitel etwas afigeplattet. Bei älteren Biflangen

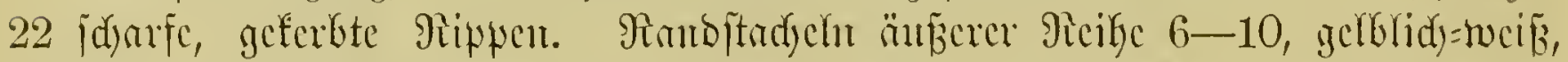

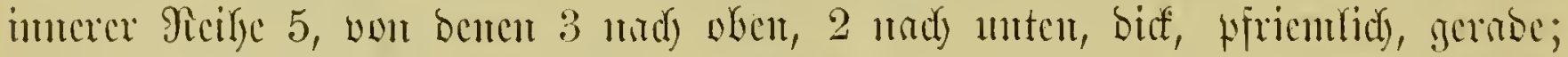

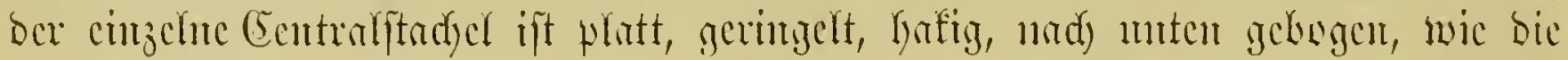

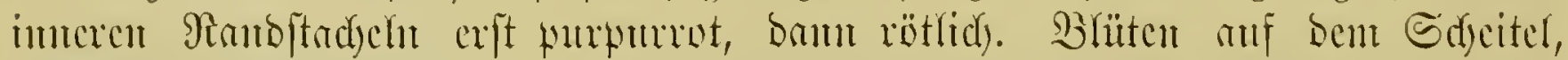

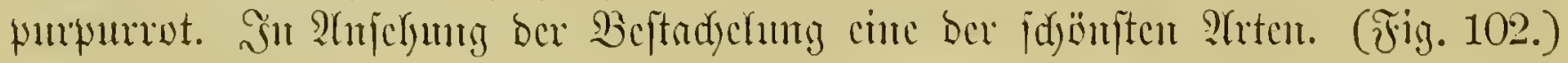

\section{Echimocactus texensis $H_{p} f$.}

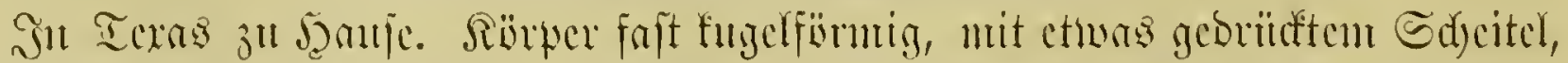

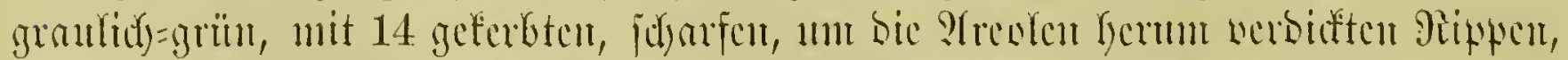

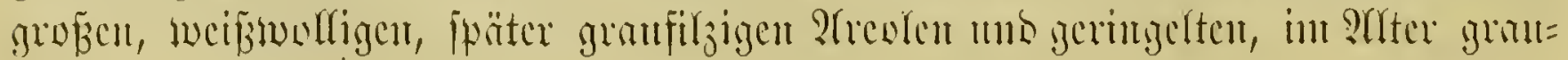




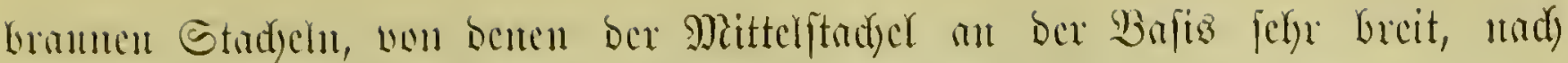
unten an bie giipke angebrïift, hormartig gebegen. (Fig. 103.)

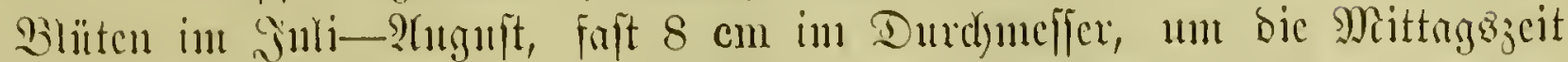

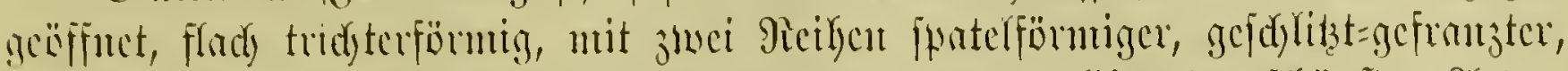

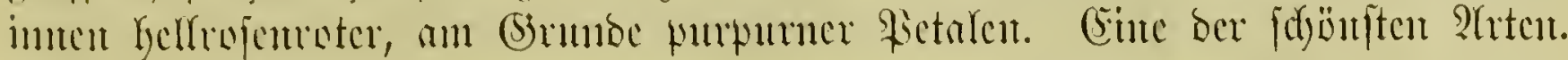

\section{Felhinocactus Wislizenii Engeln.}

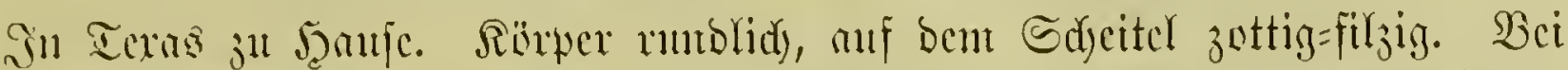

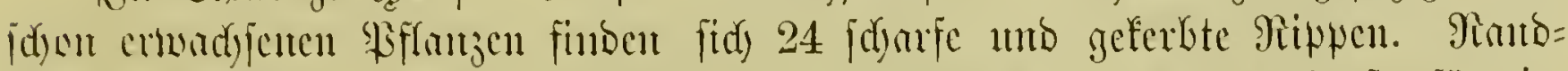

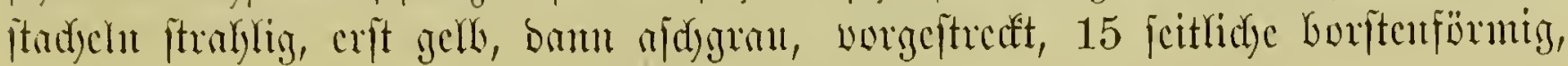

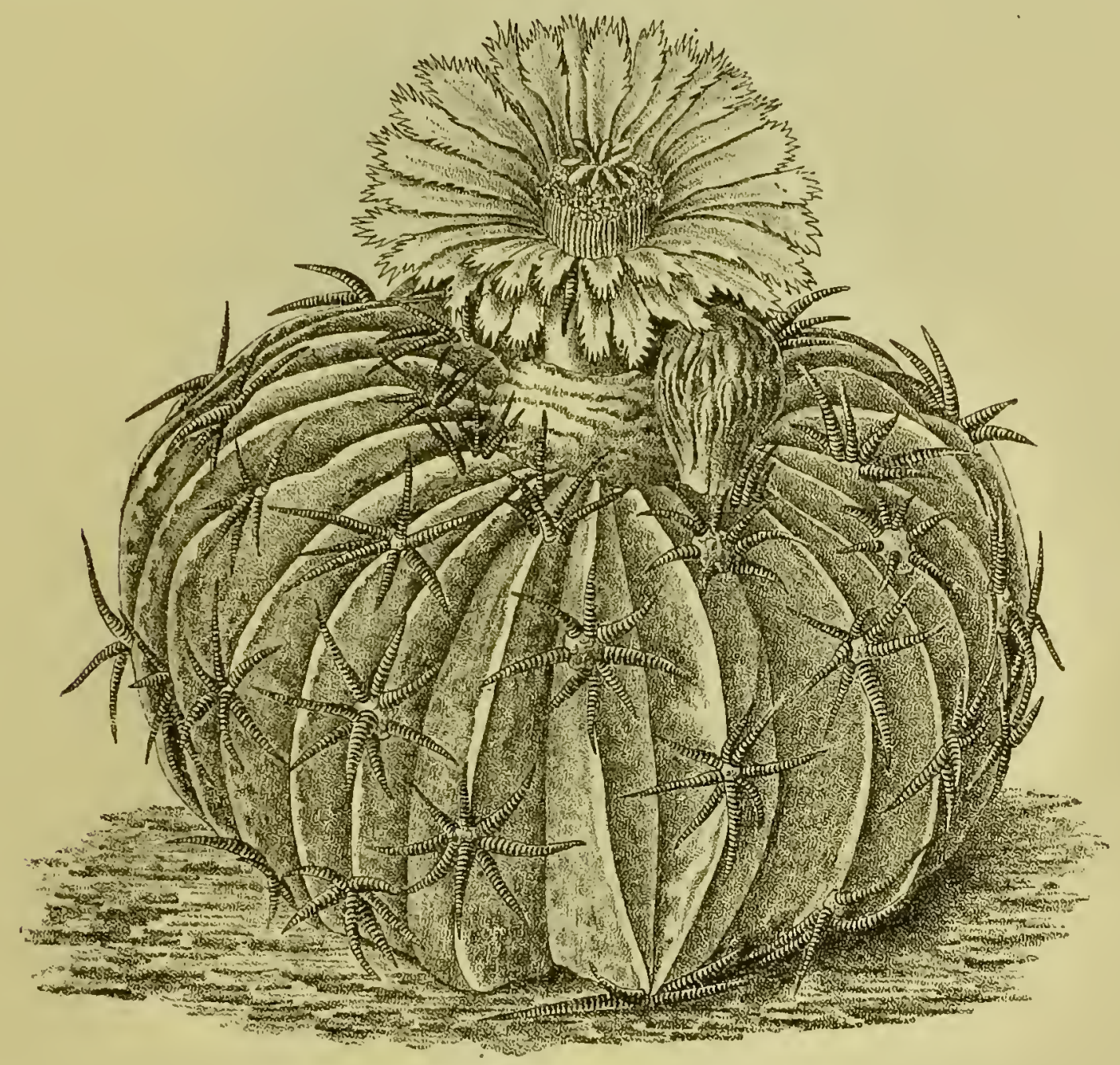

Fig. 103. Echinocactus texensis $\mathrm{H}_{\mathrm{p}} \mathrm{fr}$.

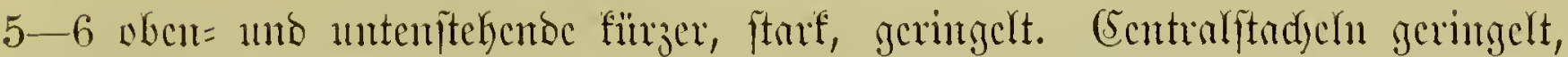

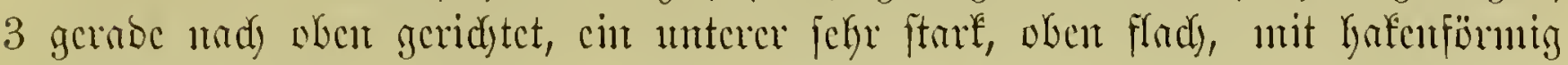

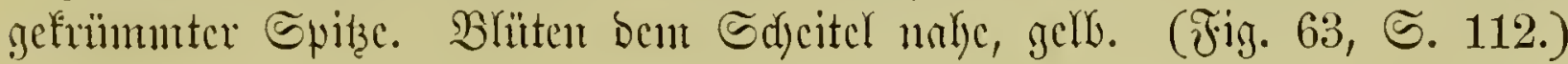

\section{Echinocactus Lecontei Engelm.}

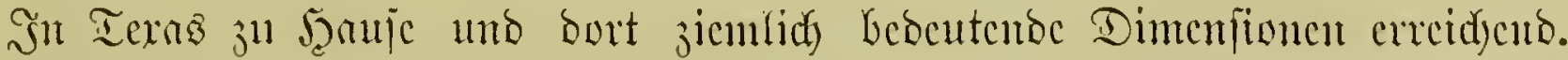

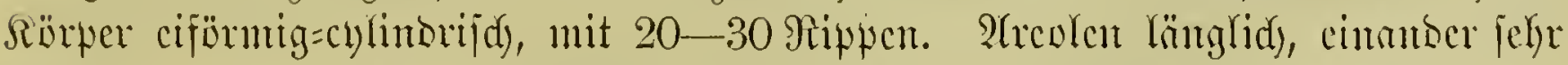

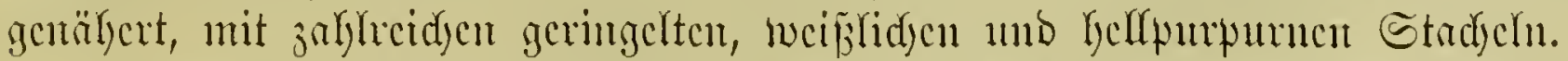

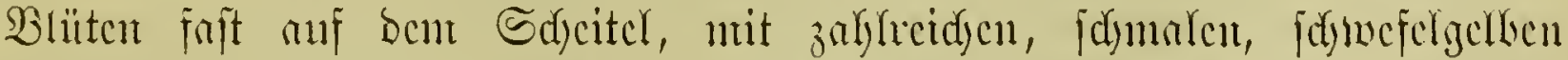
Fictalen (Fig. 64, S. 117). Dieje 2frt ift jelgr nafe verwemst mit Echinocactus

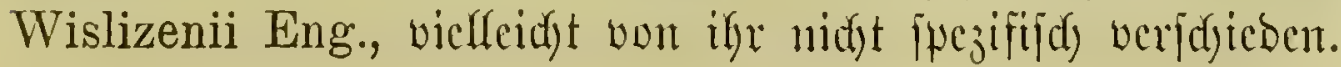




\section{Hehinocactus Iongihamatus Gal. Eanghafiger Jgclfatuz.}

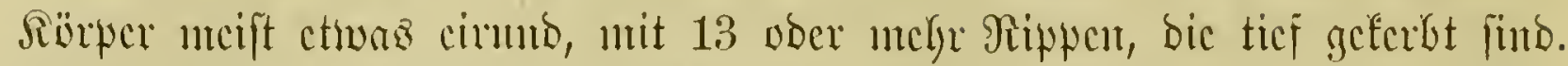
Son ben 4 cefigen, geringelten Mittelftadych ijt ber unterfte merift ber längfte

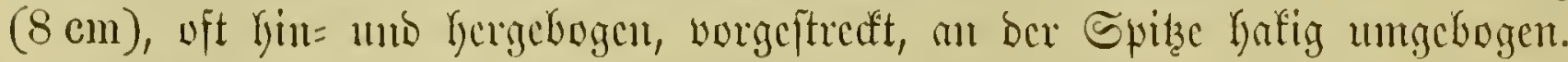

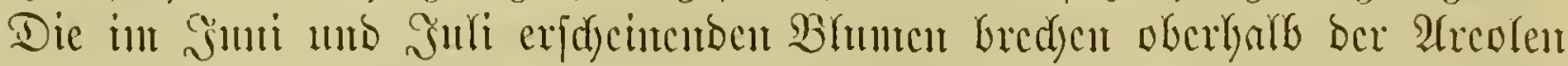

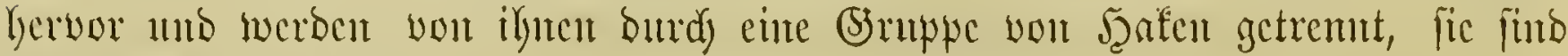
getb, int Grumbe rot.

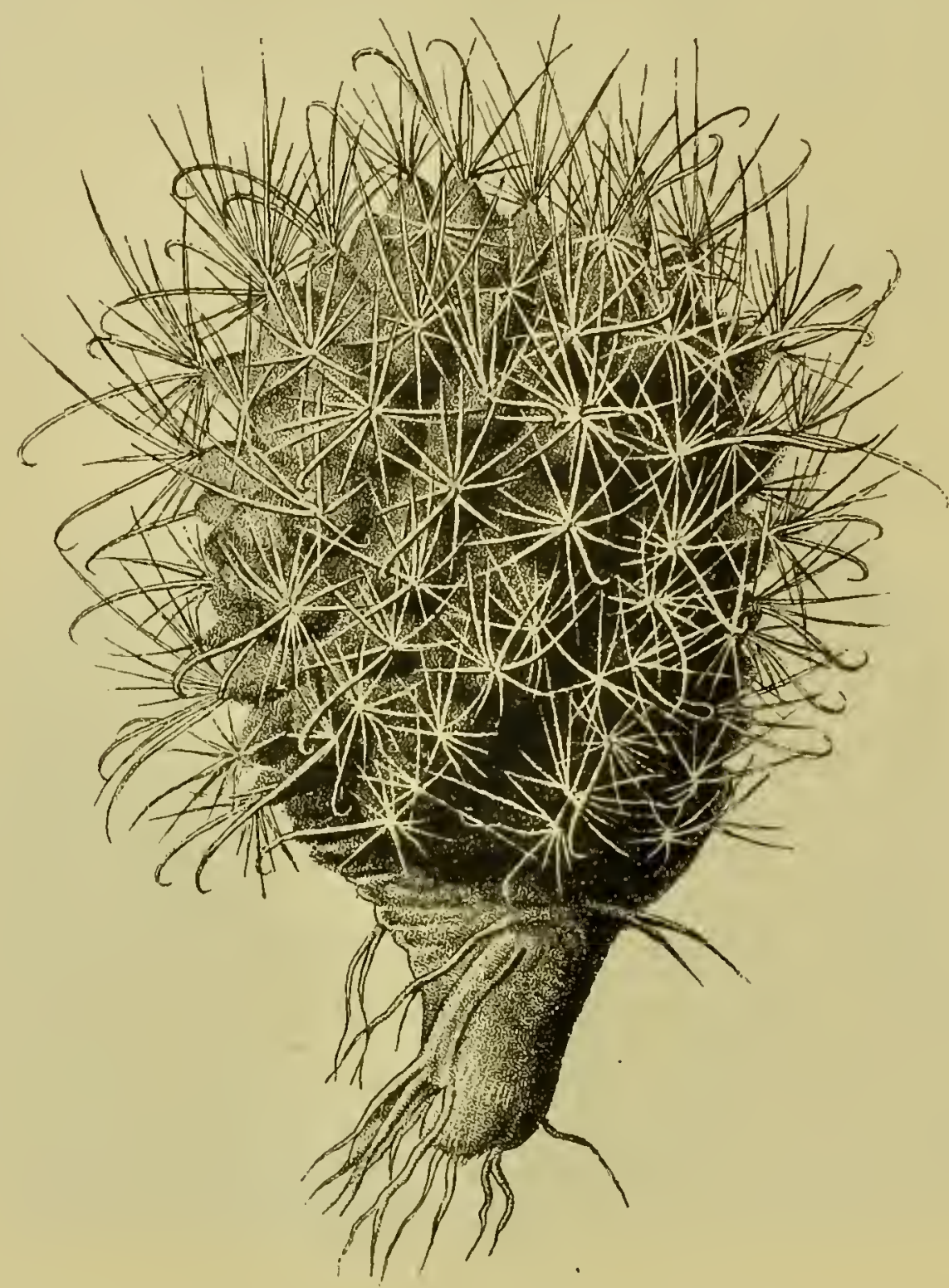

Fig. 104. Echinocactus brevihamatus Engelm. ふurzhafiger Jgelfaltuæ.

\section{Wehinocactus Cachetianus Lem.}

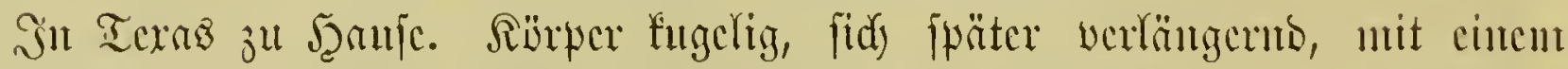

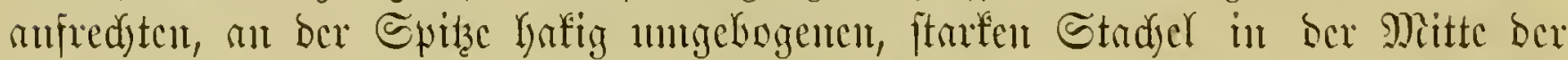

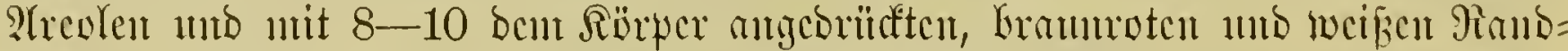

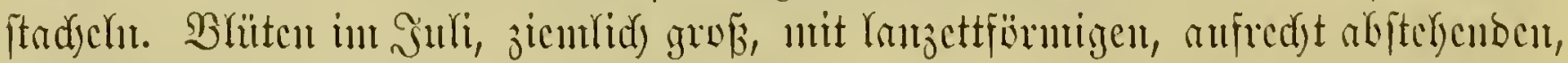

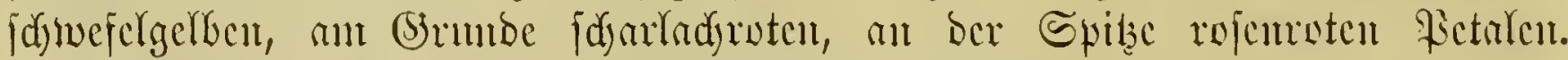

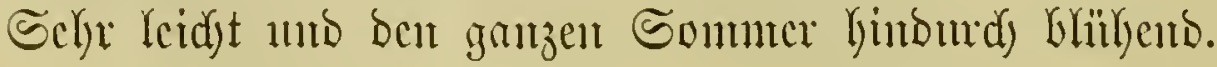

\section{Echimocactus simmatus Dietr. Budhtigcr Jgelfaftur.}

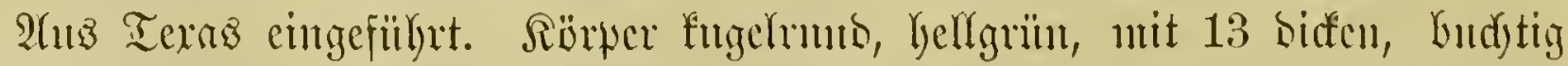

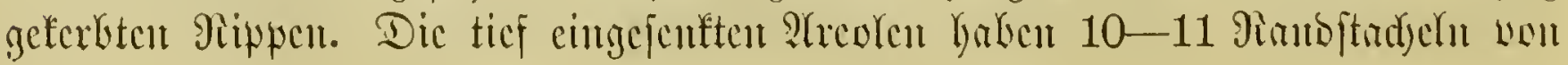




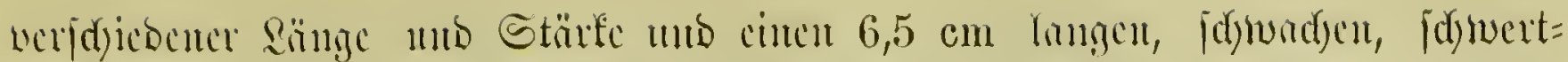

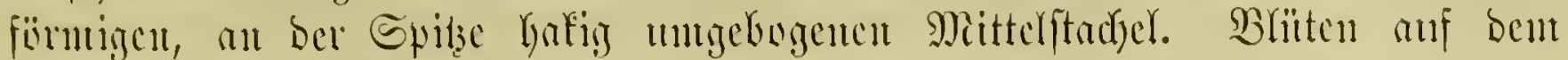

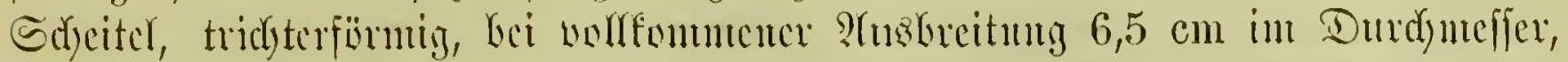

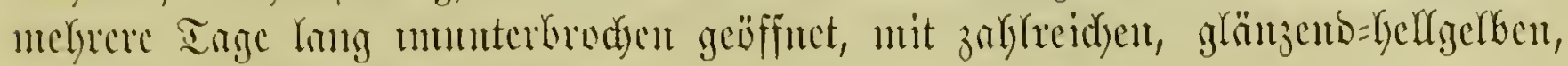
werkelyet=kargettfïrmigen Fetalen.

\section{Echinocactus brevihamatus Engelm. Iux zhafigct Igclfaftur.}

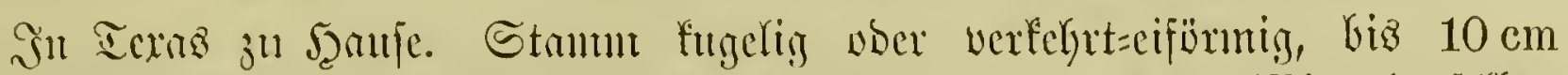

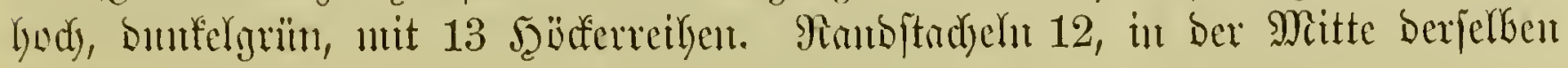

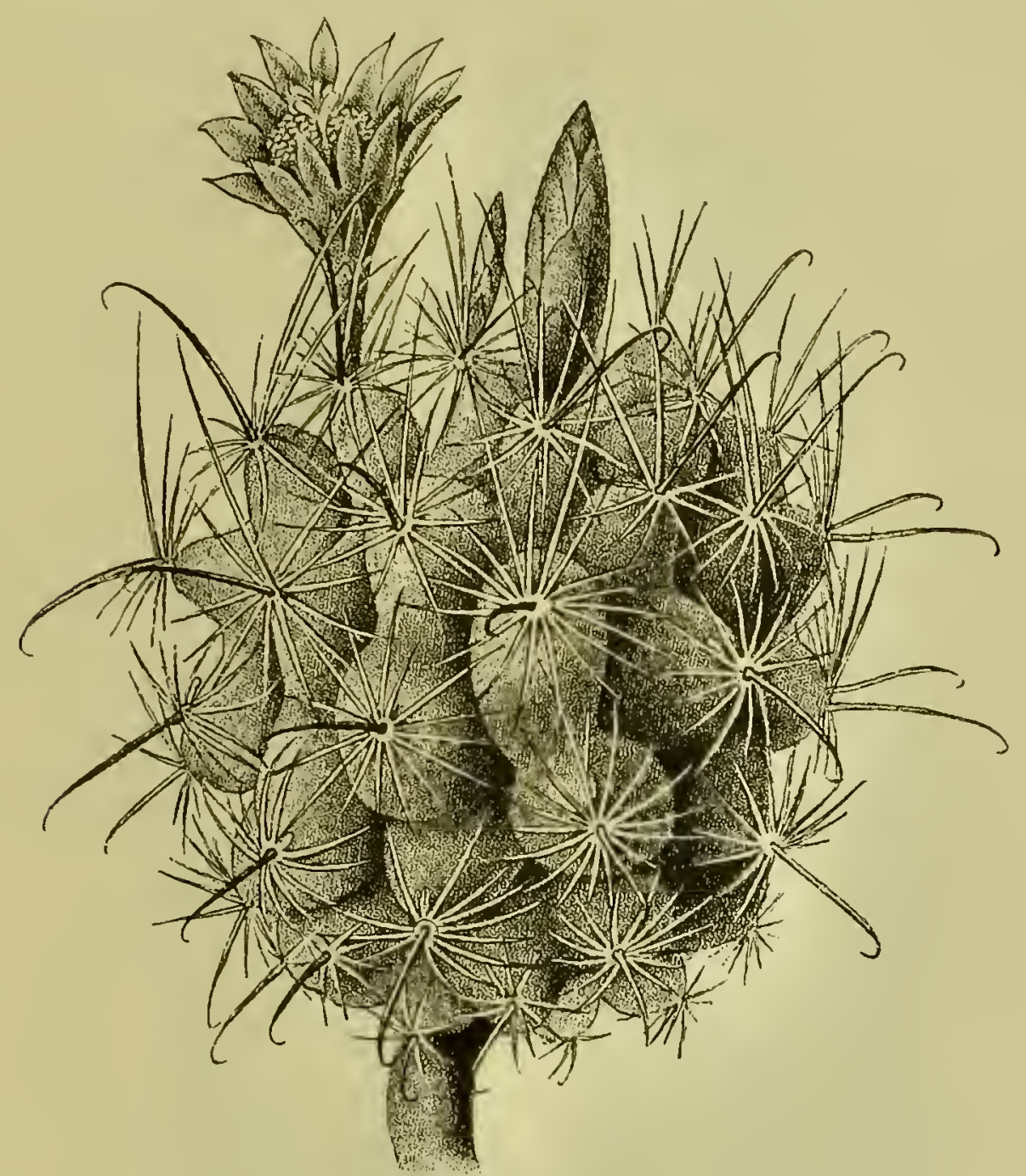

テ̛ig. 105. Echinocactus Scheerii s.

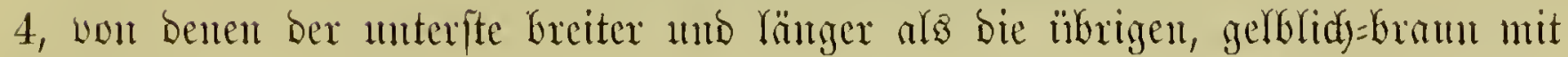

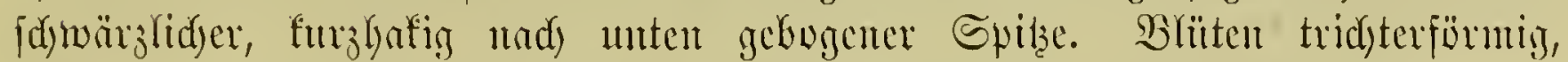

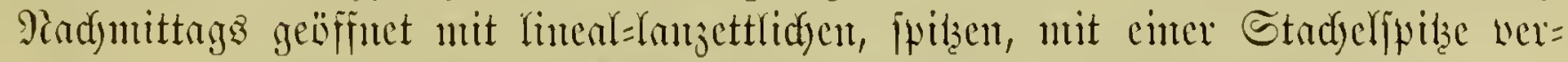

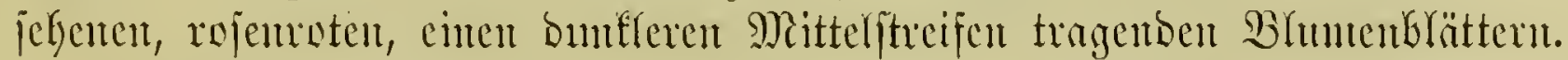

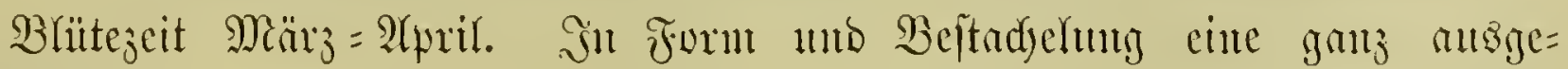
zeidyute $\mathfrak{A}$ rt.

\section{Fchinocactus Scheerii S.-Dycl.}

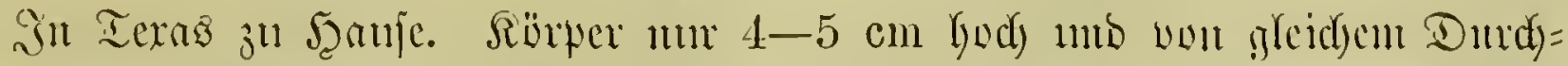

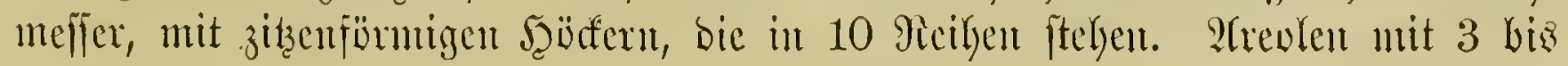


4. effigen, Kunten Mittelftadyelu, won benen ciner angelfafig gefrümnnt ift unb

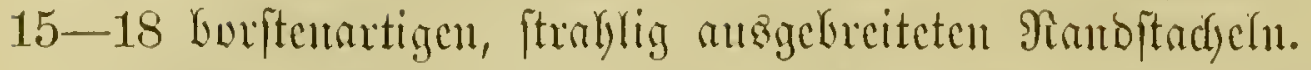

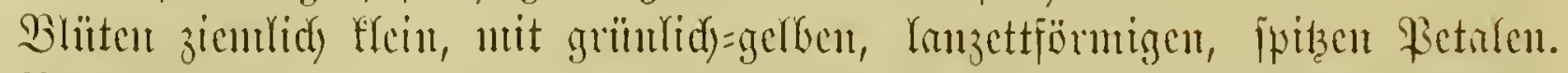

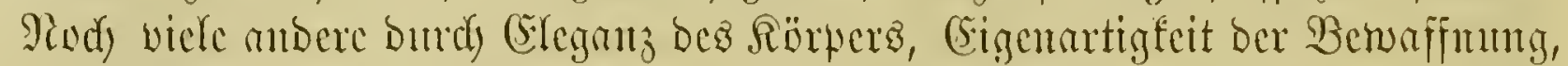

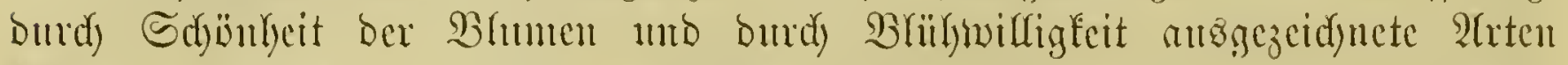

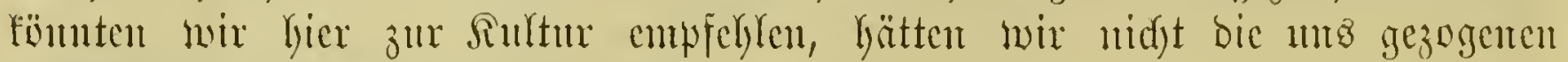
rïumlichen Grenjen jul relpefticen.

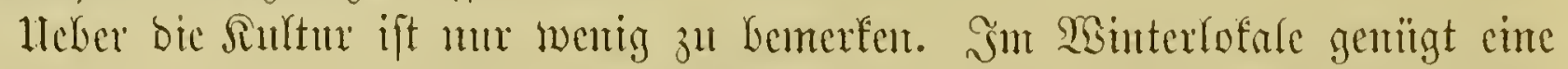
Temperatm won $+3-5^{\circ} \mathrm{R}$. Sint Sontuter pffanze man fie in ben Firaten und

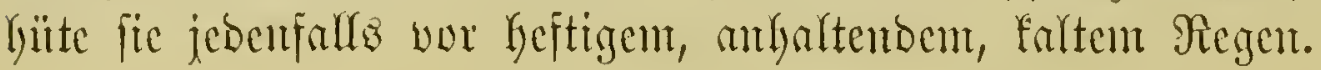

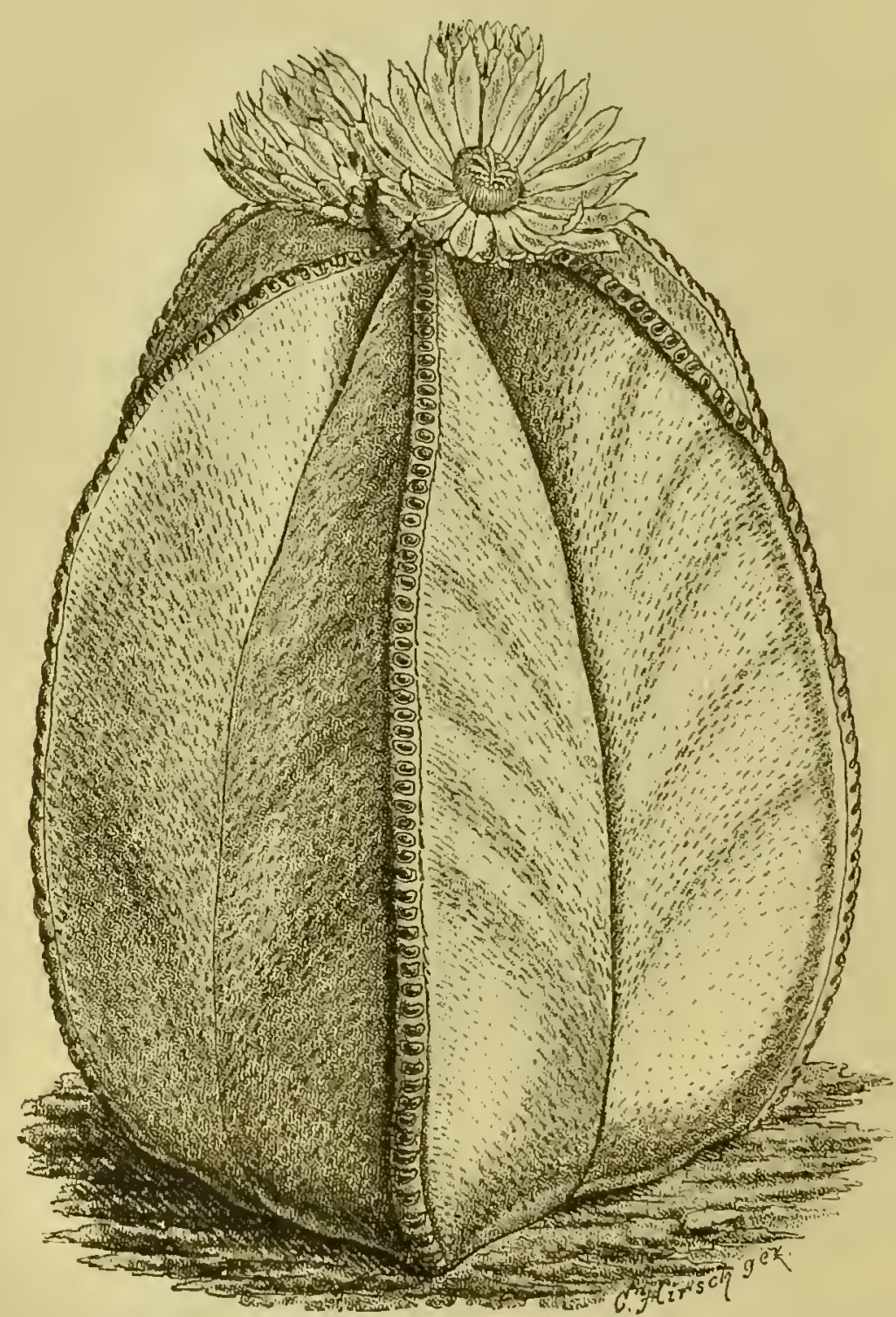

₹ig. 106. Astrophytum myriostigma Lem. WHuttierter Sterutuftus.

\section{0. (5)attung Astrophytum Lemaire. Sternfatus.}

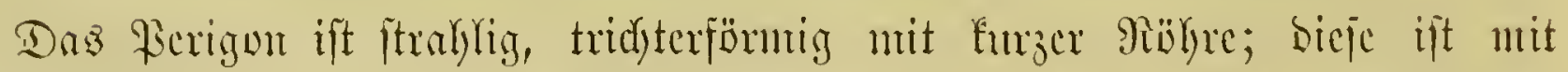

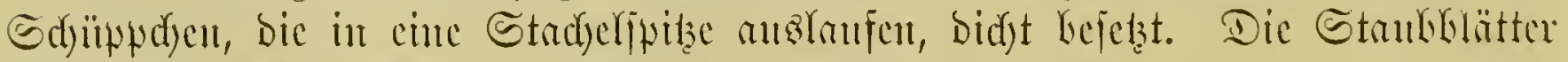

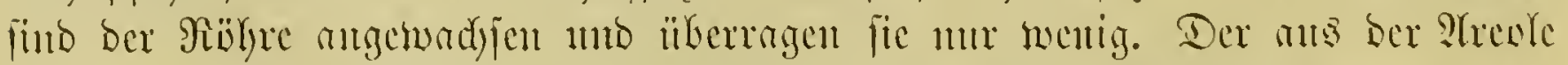

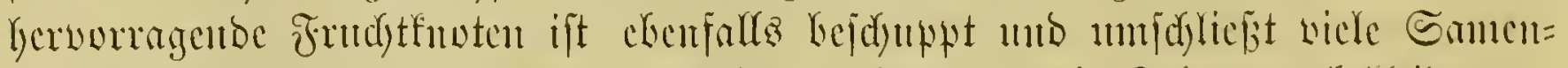

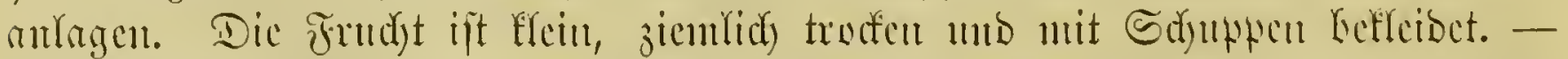

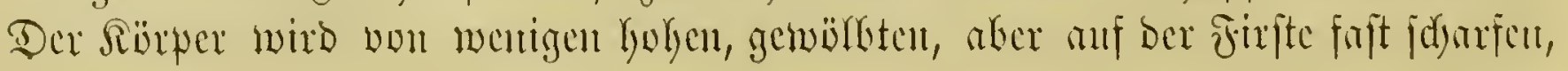




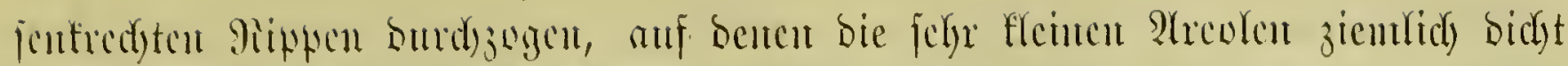

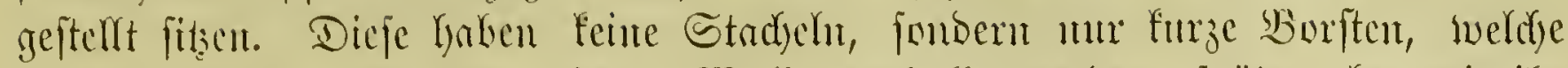

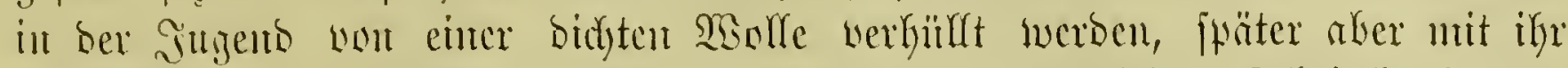

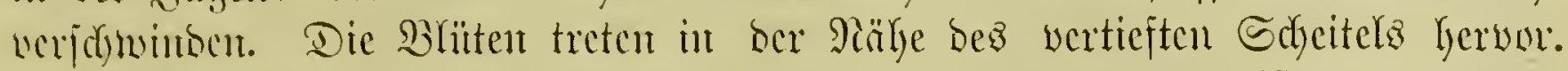

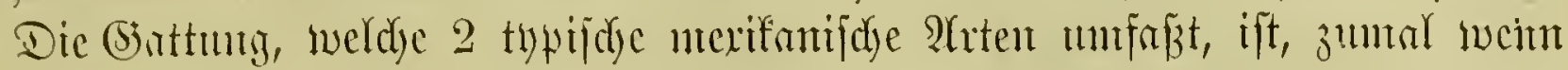

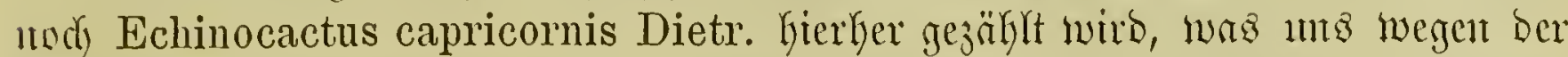

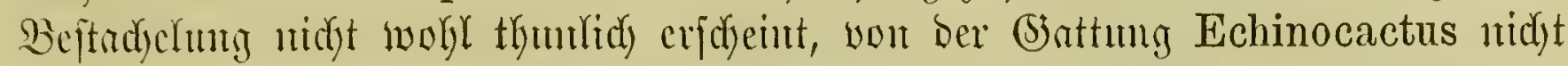

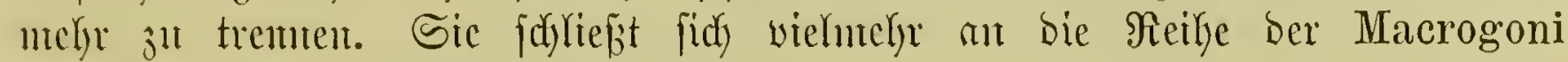
frejiefl an ben E. ornatus DC. an.

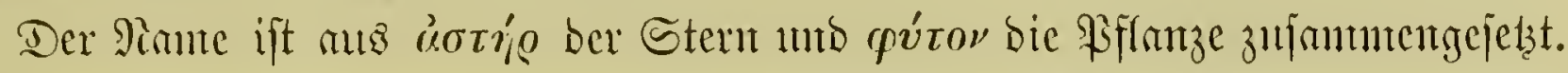

\section{Astrophytum myriostigma Lem. Punfticrter Gteruffuftuz,

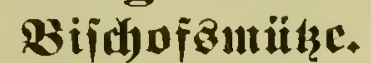

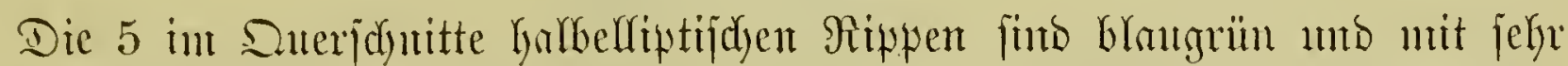

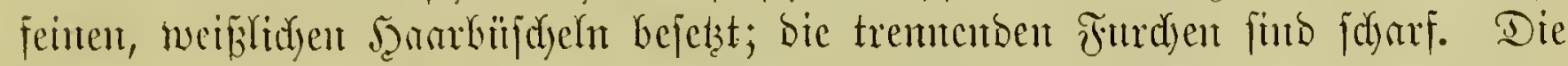

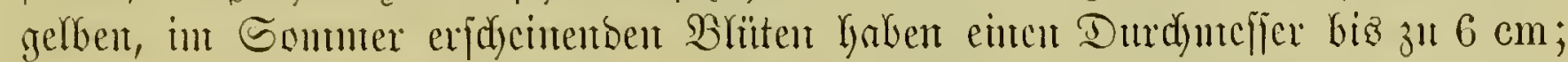
bie Ferigunblätter haben anf ber Intcrjeite cincur roten Mittelfitrcif mb cinte bunfelbrante Spitze; fie ried)en angendyun nad) Shjt. (Jig. 106, S. 188).

\section{1. Şattung Anhalonium Lem. Âloëlaltuş.}

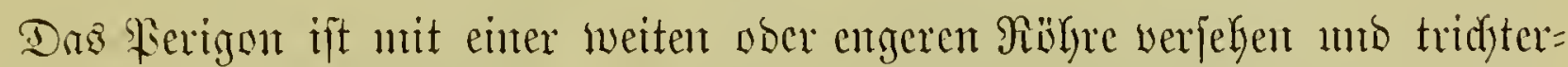

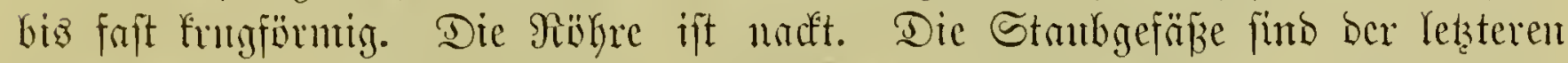

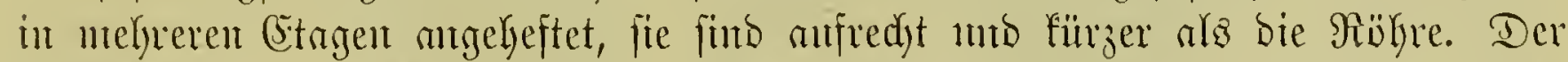

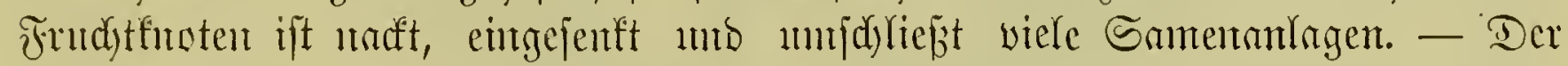

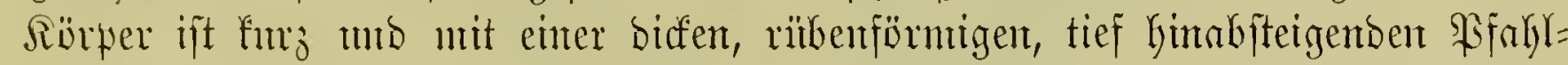

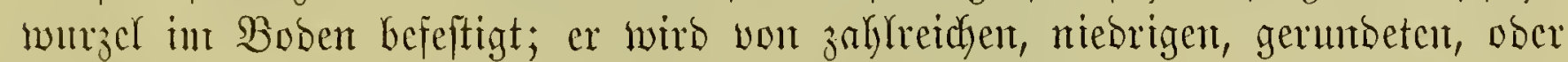

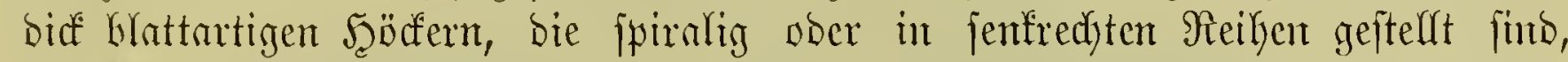

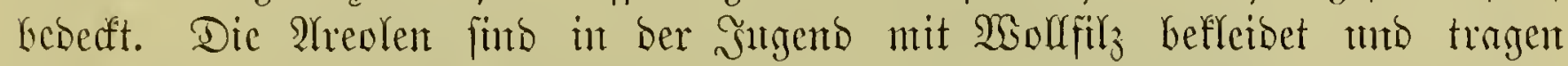

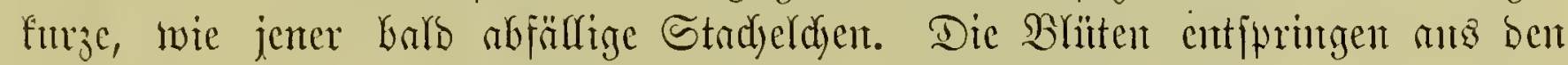

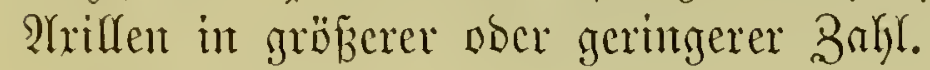

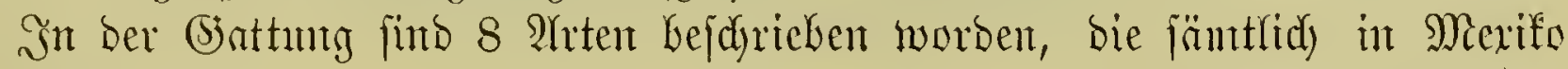
eintheimifidy fints.

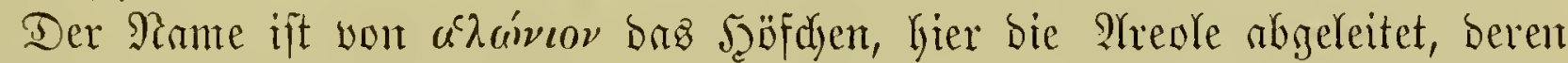

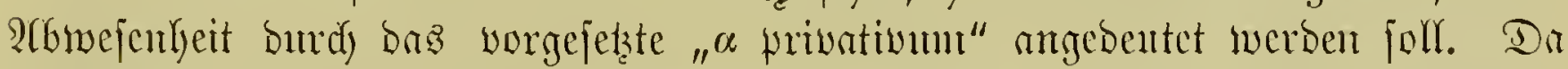

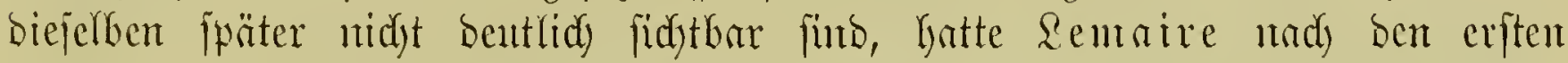
(Sxemplaren geglaubt, ban fie ïberbaupt feryltert.

\section{Shliiffel für die befdricbenen 2rrtert.}

A. Szöbeter flach, in 5-6 fenfrechtent Reigen

1. A. Williamsii Lemaire.

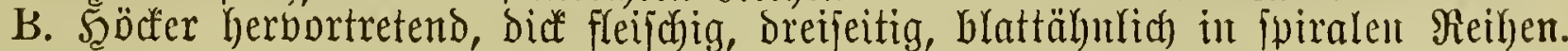

2. A. Engelmannii Lem.

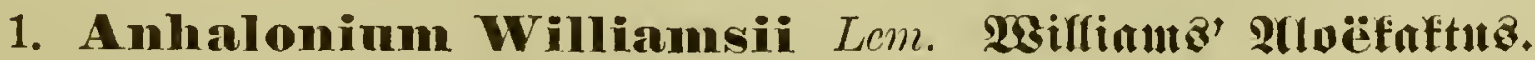

(Echinocactus Williamsii Lem.)

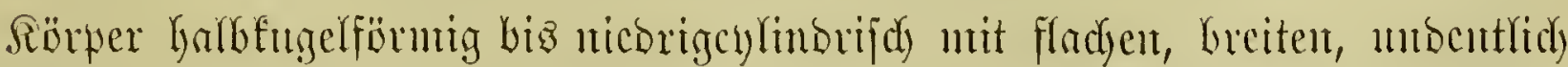

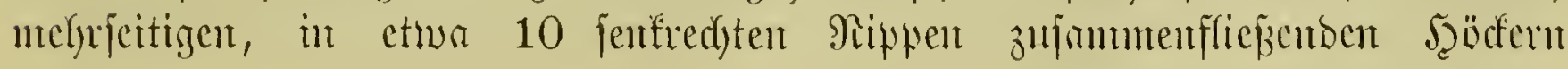




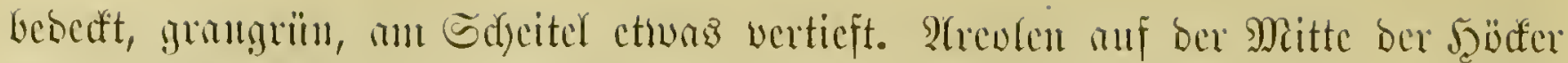

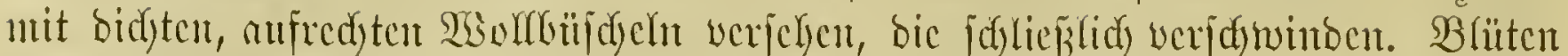

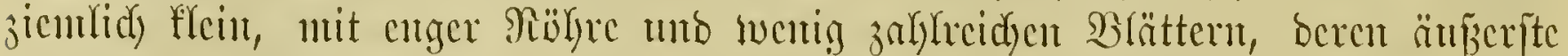

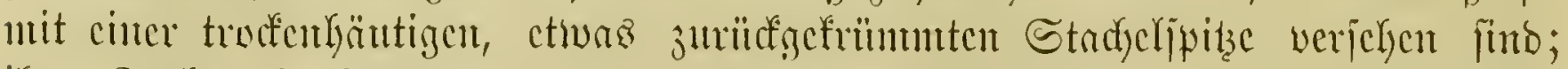

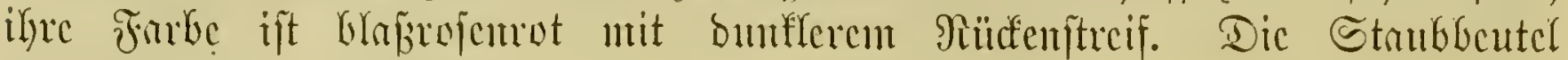
fitto gelb. (Fin. 107).

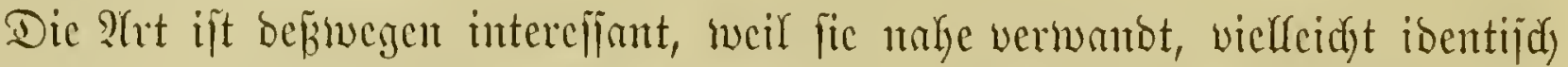
ift mit A. Lewinii Hennings. Dicje cutfärlt, wic melyere andore Baftecn, cinten

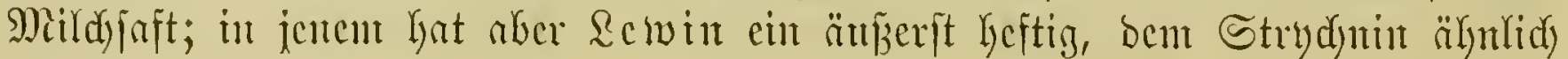

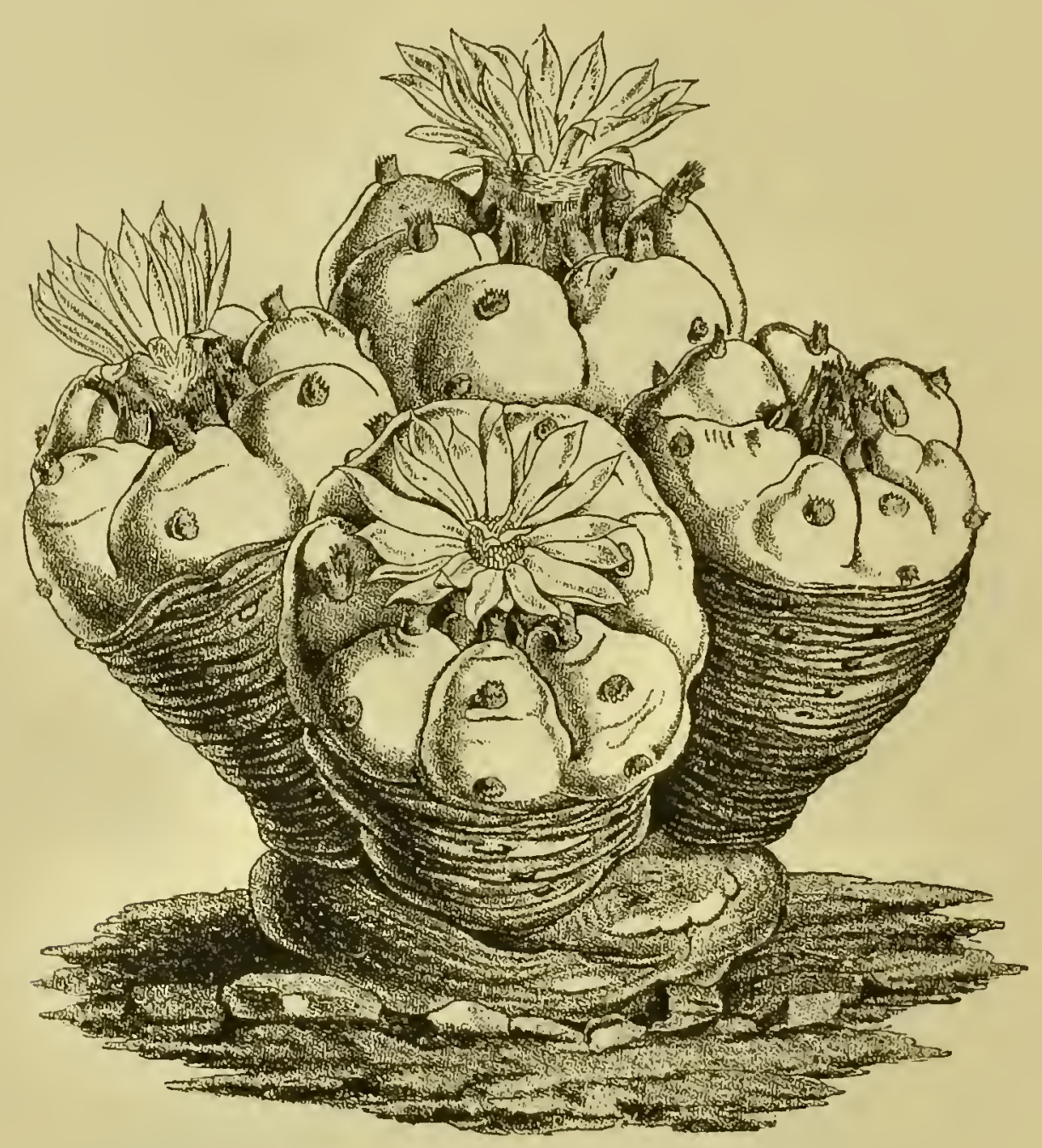

Fì. 107. Anhalonium Williamsii Eng. "Wiffiants MTloëfaftus.

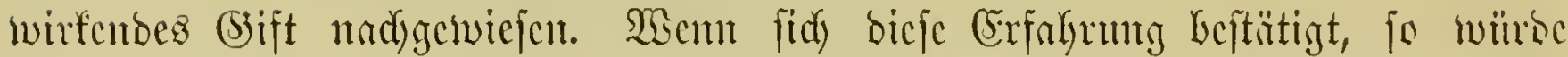
bie merfwündige Ihatjadye vorlicgen, baß in cinter Fantilic, bic int gansen int=

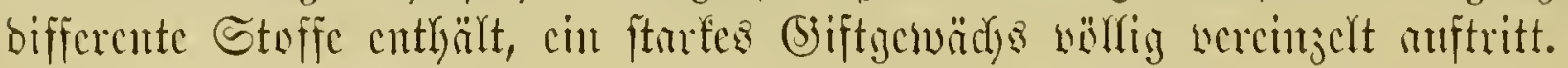

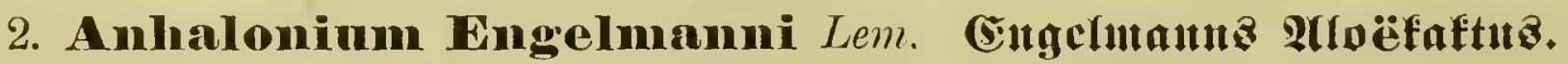
(Mamillaria fissurata Engelm.)

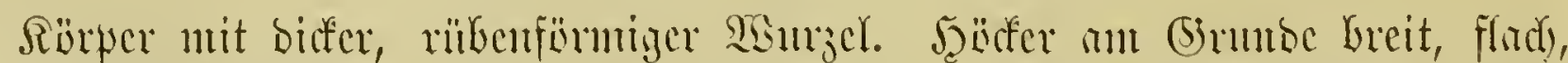

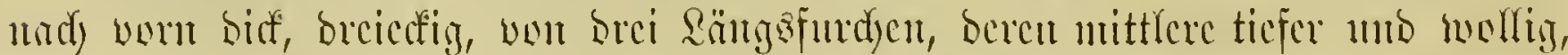

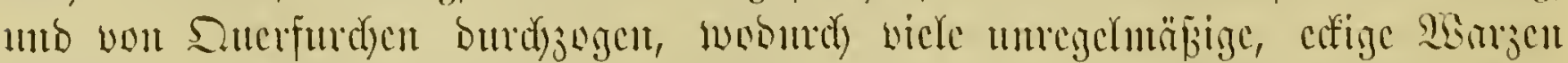

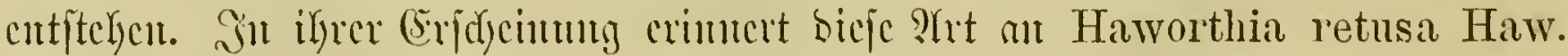

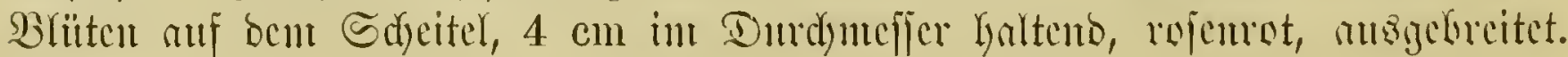




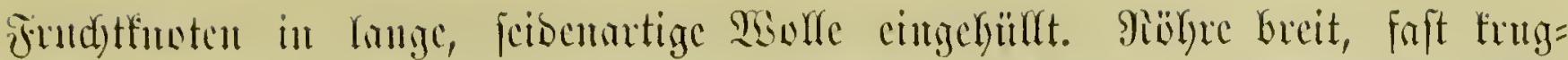

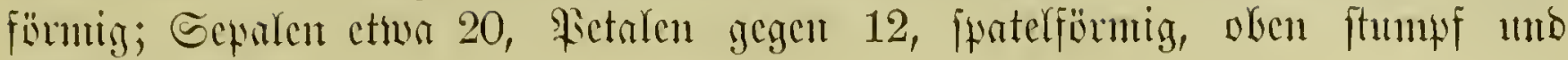
weidfitrodyerpibizig.

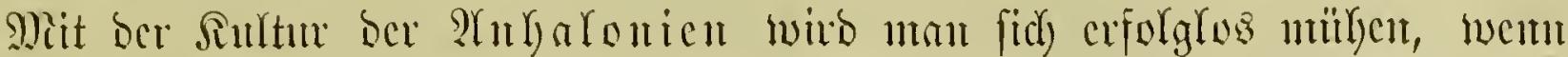

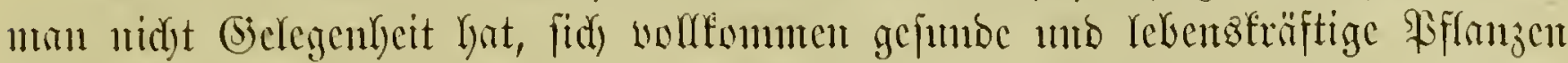

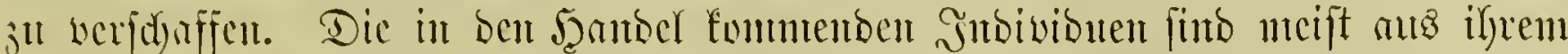

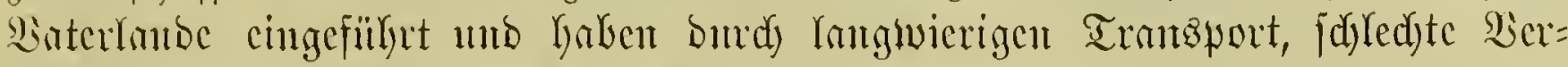

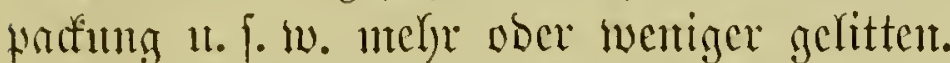

Sim günftigeren Falfe pflanje man fie in cine Yefmigjombige, nit flein=

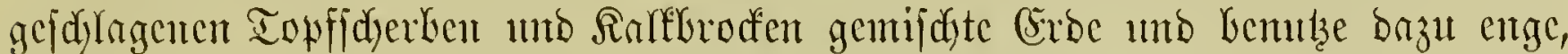

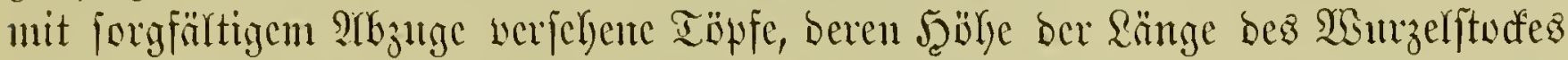

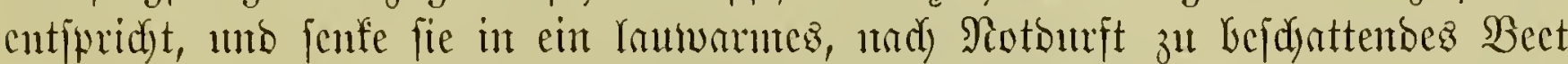

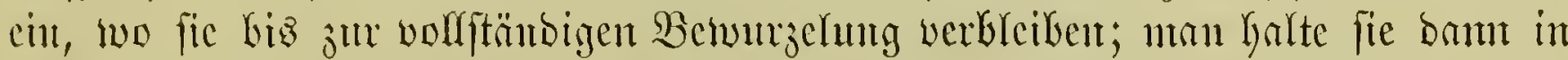

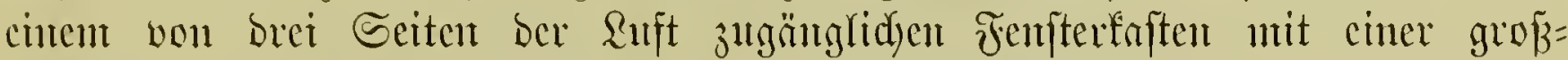

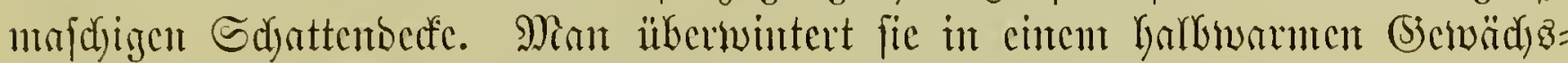

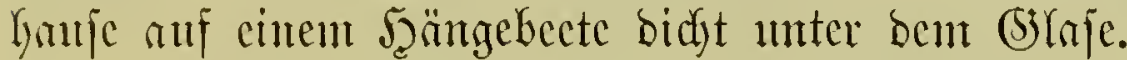

\section{Battung Leuchtenbergia Fisch. Frismenfaftus.}

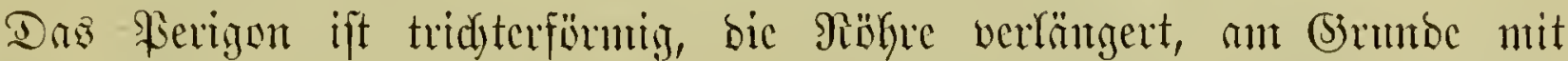

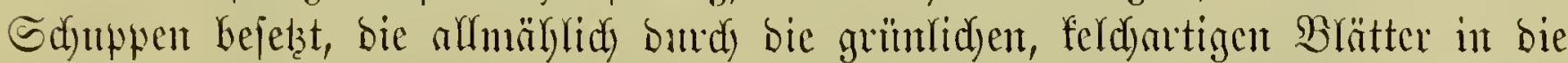

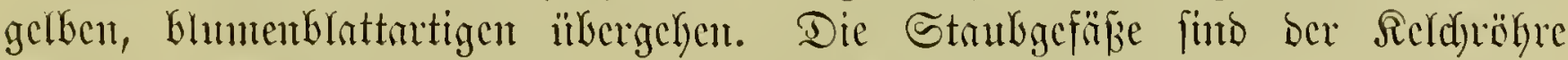

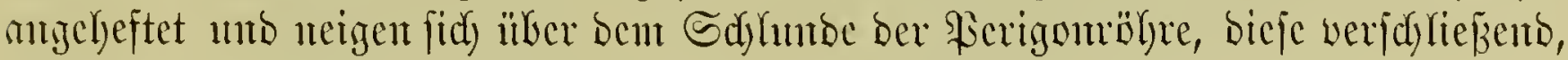

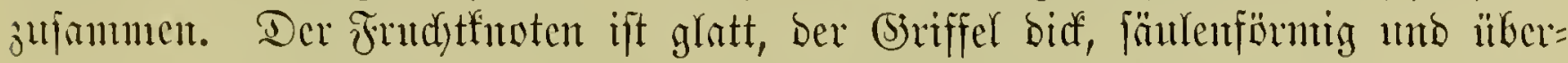
ragt bie Strubblätter mu unt cin geringes. - Der biffe Strmm ijt fleifdig,

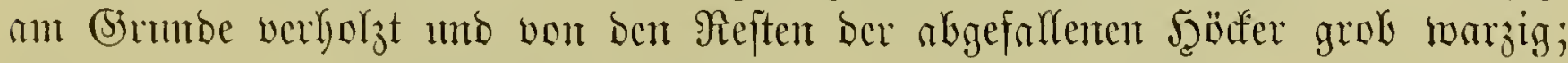
weiter oben ift ex mit jwirnlig gejtellten, verfüngerten, finntigen, nad) oben zu=

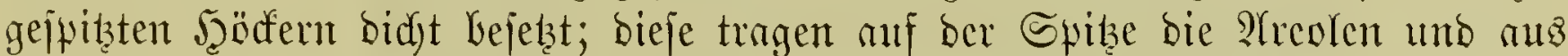

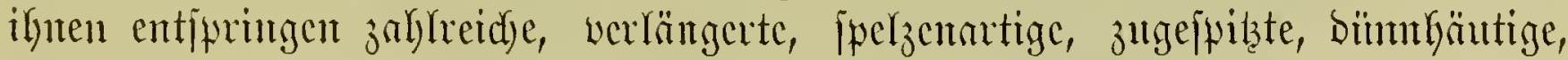

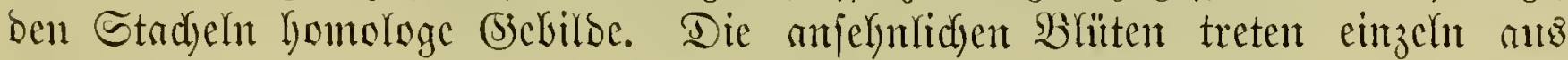
den Ariflen herwor.

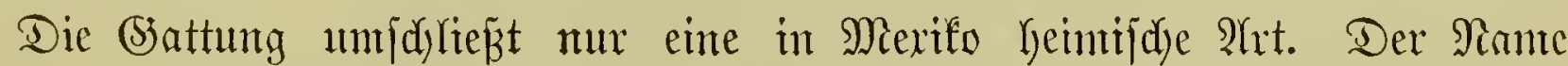

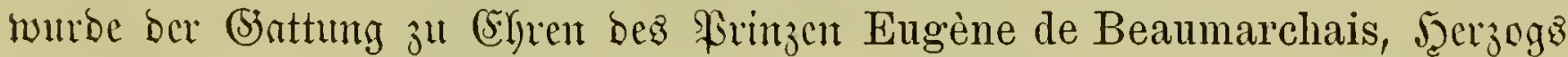
von Scudtenterg, eines ruffifden Prinzen, gegeben.

Heber bie Etelfung int Enftente ift Yange geftrittent worben; che bie Briute befount wor, glaubte utan fogar, baj fie nidjt ju ben Raftaccen gebüre. Der

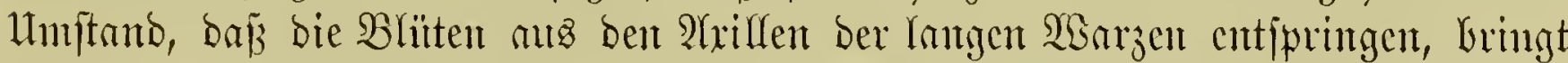
fie befier zut ben Mamiflarieen alz zut einer anberen Bruppe biejer Fantilic.

\section{Lenchtenbergia principis Fisch. Füritlidjer Prisuncufaftus.}

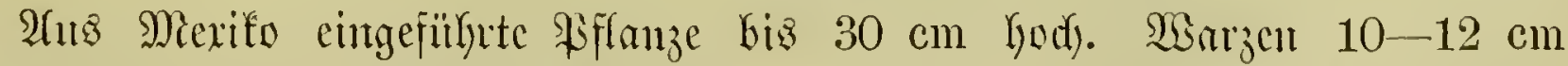

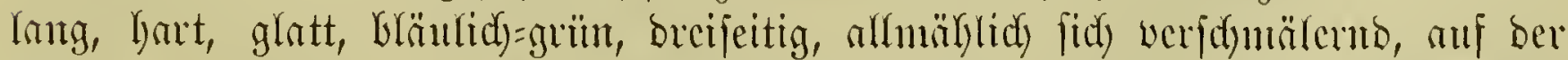

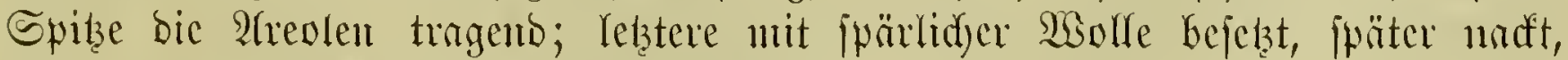
mit 6 bis 7 ijabellgelben, langen Spelzer. 


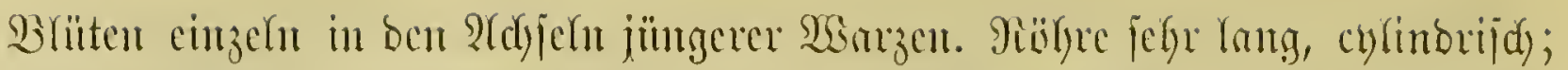

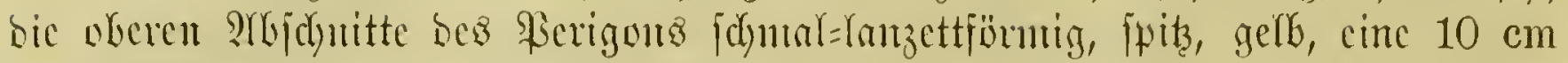

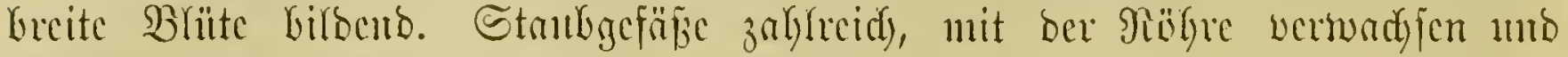
crift am Fintoc berjerben frei werbento (Fig. 108).

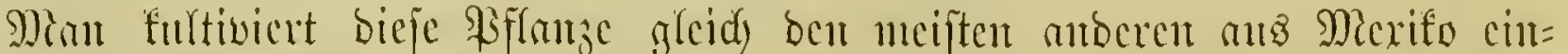

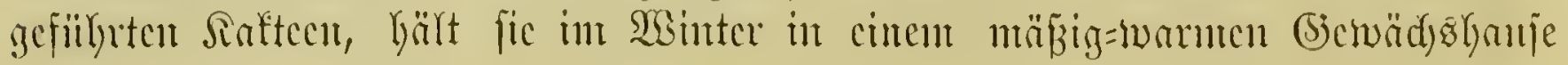

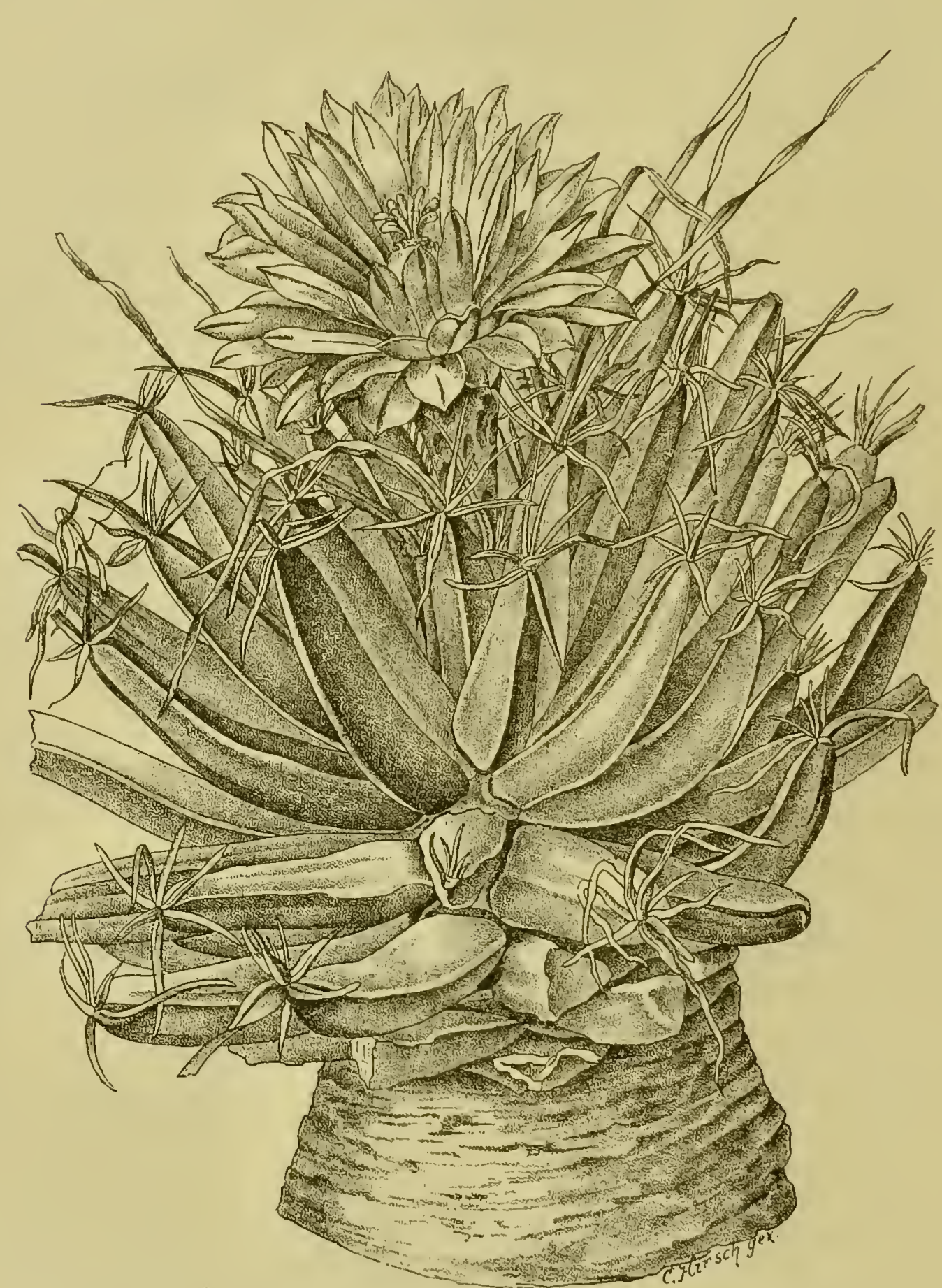

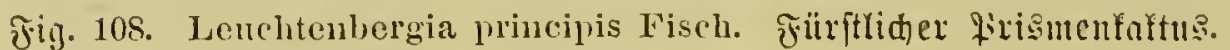

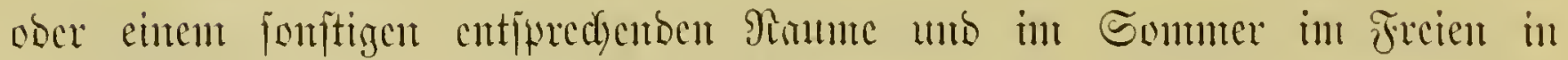
joutniger Sage unto gegen Regen gejdjülat.

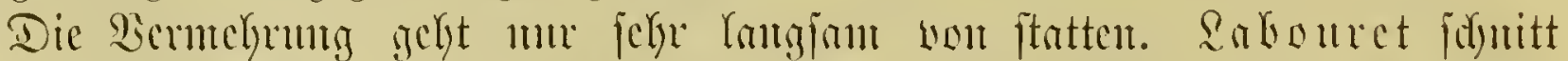

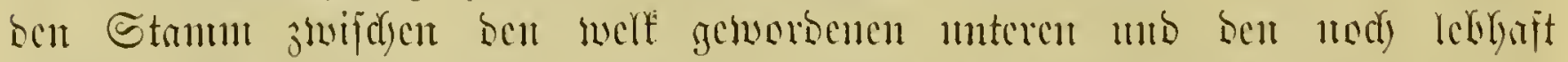

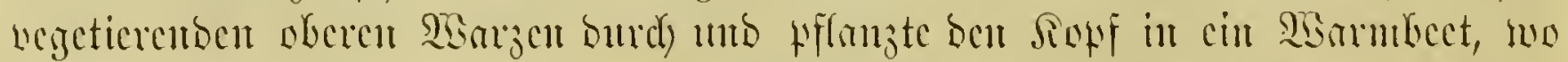

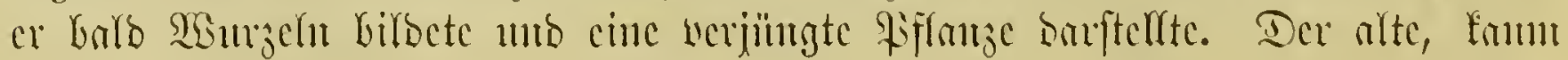




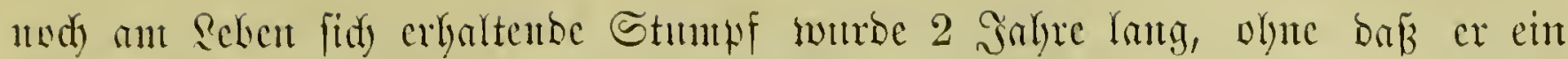

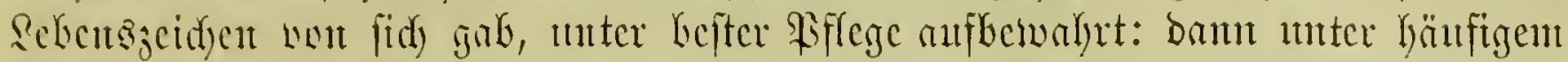

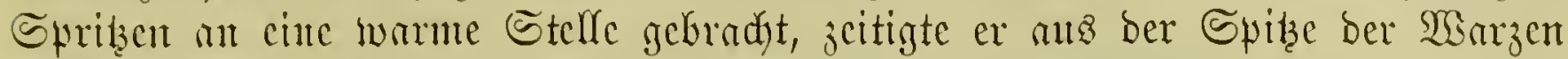

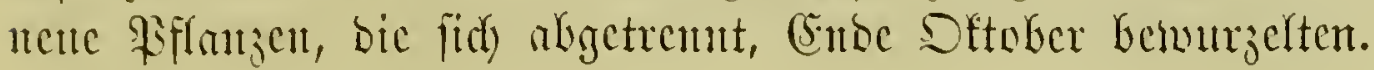

\section{3. Şattung Mamillaria Haw. $\mathfrak{B a r z} \mathfrak{e n f a f t u z . ~}$}

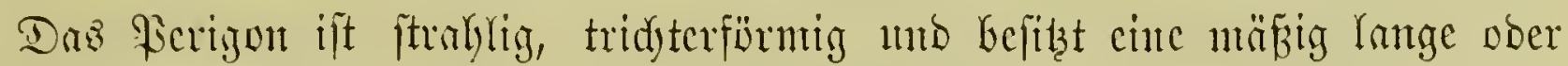

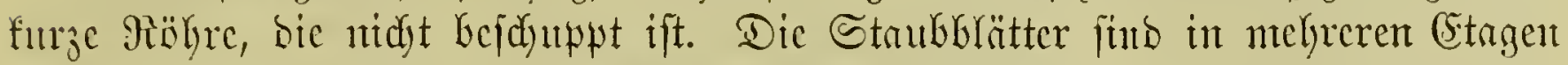

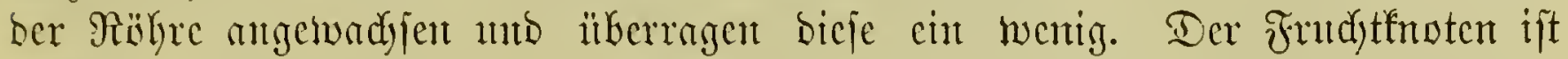

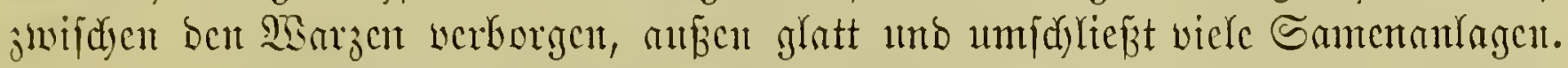
Dic Beere iff jaftig, verläugert, oblong ober feulenförmig und wirb zutweilen

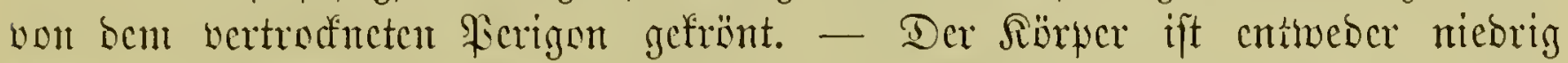

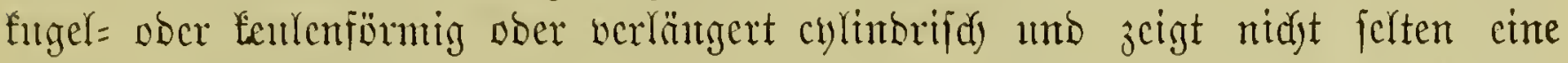

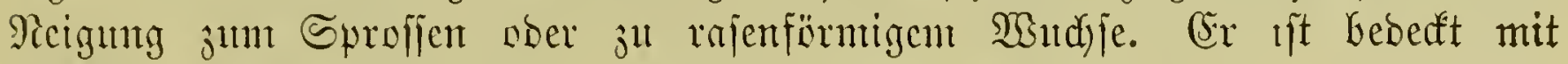

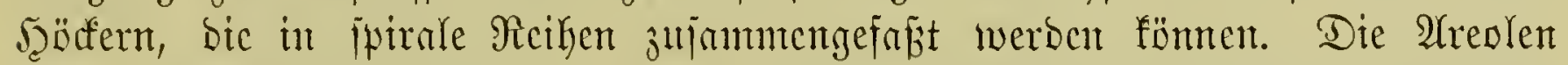

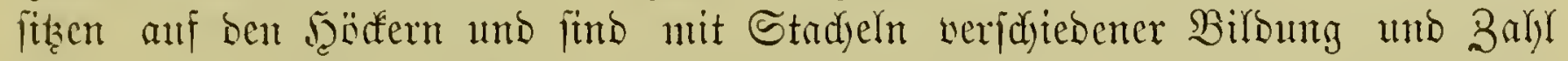

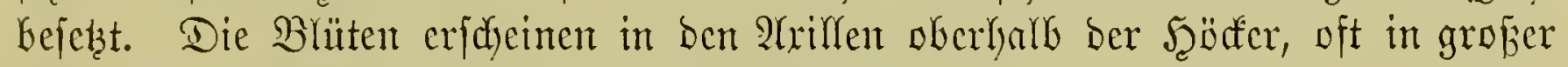

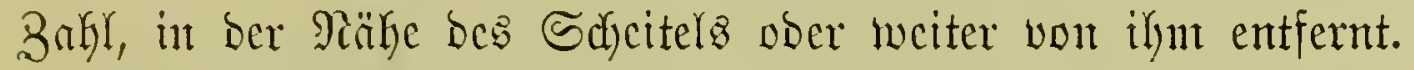

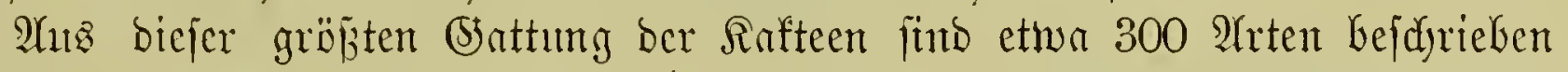
worben, bie jum allergrö̈pten Teile in Mexif́ und ben benad)barten Ieilen bor Bereinigten Straten wadjen. (Sinige fonmen aud auf ben weititsijden

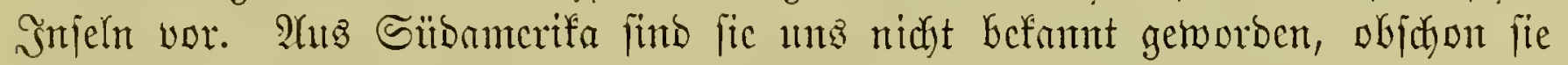

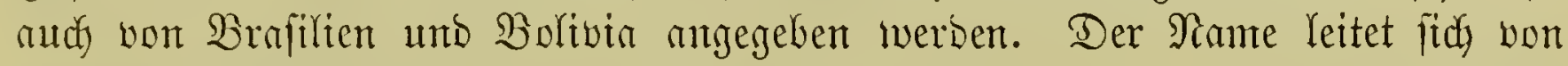

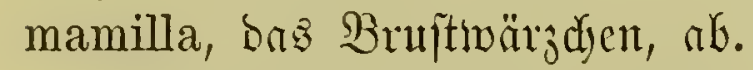

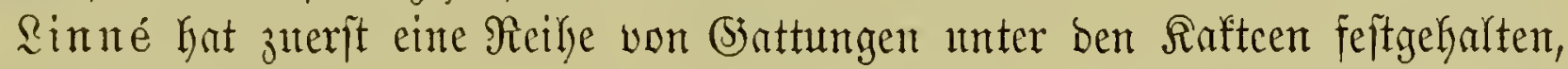
päter hat or fie aber alfe ju ber Bjejantgrattung Cactus verbunben. Sn neupter Beit hat man vorgeidglagen, ben Sinné'juen (Sattungzmamen Cactus, ber aus ber botantifen Montenflatur völlig verfdymunben ift, wicber für Mamillaria einjufüfren, eine Bornafme, bie nidyt empfehlenşwert ift.

\section{Sdlilifiel für die befđriebenen Zrten.}

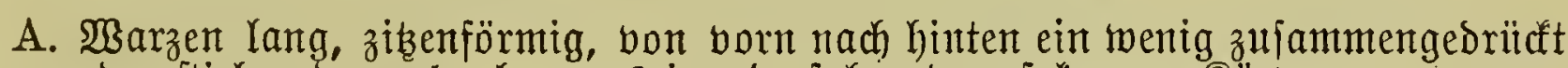
oder ftielrumb, nach oben auseinanderfahrend anf łurzem Sörper

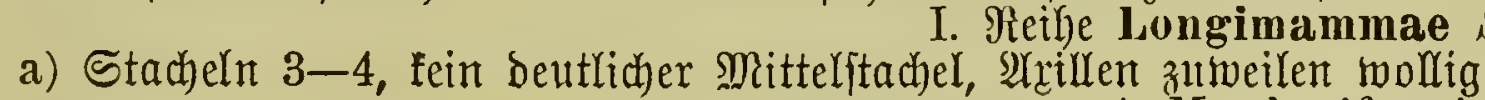

b) 1 . M. uberiformis Zuce.

b) Stacheln 4-10, 1-3 Mittelftacheln, AYrillen fahl 2. M. longimamma $D C$.

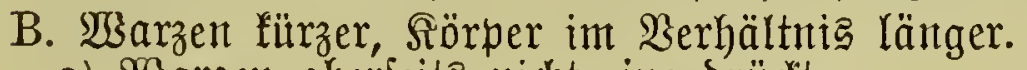

a) $\mathfrak{M a r z e n ~ o b e r j e i t s ~ n i d h t ~ e i n g e b r i u c t e t . ~}$

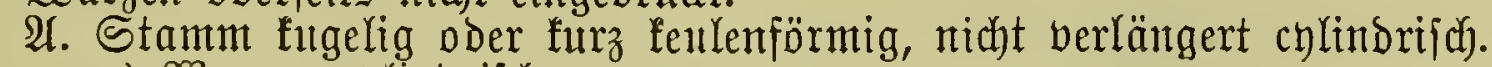

a) MGarzen ciltinorifit).

I. Jiansftacheln weich, zumeilen haarförmig ober feisig, bie interen etwą fefter, nidyt felten ein beutlicher (Eentrafftachel.

1. Rajen bildend

II. Reihe Crinitae S.-D.

$$
\text { * Mitterftachel gerabe }
$$

3. M. pusilla $D C$.

2. 4. M. glochidiata Mart. fprofijen, baher nicht 
* Mittelftachelit 3, bon denen \& aufrecht gelblich, mit röttichen Spiken, der britte länger gefrïmmt, purpurfarbig * sinittelftachel $1-3$, alle idwarzrot

5. M. Schelhasei Pfeiff.

6. M. Grahami Engelm.

II. Manditacheln boritenförmig, die Mittelitachelı beutlich berjoieden

III. Sieike Heteracanthae $S .-D$.

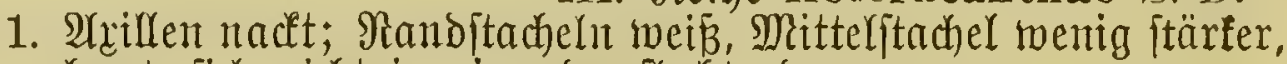
bunt, fich nicht in einander flechtent

* Rörper fleiu niedergeorü 1. Bruppe Polyacanthae. flocfig behar't 7 . M. micromeris Engelm.

*: Rörper chlintrija bis feulenförmiq.

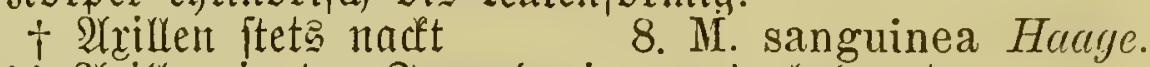

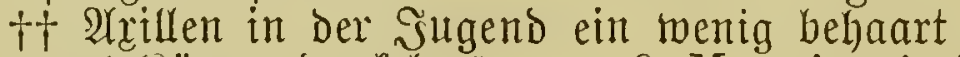

$\triangle$ Siörper butfelgriin 9. M. spinosissima Lem.

$\Delta \Delta$ Sïrper hellgrün 10. M. sphaerotricha Lem.

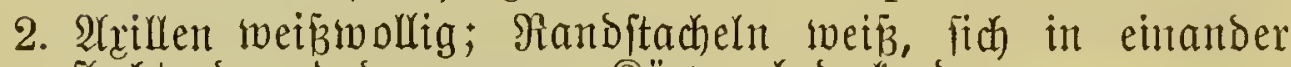
flechtend und den ganzen förper bedcfend

* syittelitachel fehlend, Rand

Sirunde gelb 11. M. Schiedeana Ehrby.

tacheln am (5nde weich, am + Uriflen ftart mollig.

$\Delta$ Mittelitacheln 1-2 gerade, zierlich wein mit braulter Epise $1 \mathrm{~cm}$ lang 12. M. bicolor Lehm. $\Delta \Delta$ s) ittelitad)eln furz, 2-3 $\mathrm{mm}$ lantg, Derb, gefrümmt

13. M. formosa Scheidw.

†† Irturen menig mollig 14. Haageana Pfeiff:

3. Mittelitacheln 2-6, gelblid) bis rot

3. Siruppe Chrysacanthae.

* Rörper einfach, fugelförmig; OYxiflen nadft.

†) Sanditacheln gelb, ein Mittelitachel bratn, Die anderen bräunlid gelb 15 . M. chrysacantha Hort. Berol.

††) Yanditacheln weifs, Mittelitacheln bräunlichrot

16. M. rutila Zuce.

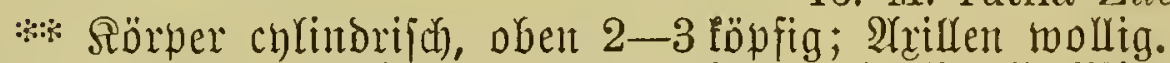

+ warzen hellgrin; Sianditadeln hellgolsgelb, Mittel= itacheln rotbraun

17. M. Odieriana Lem.

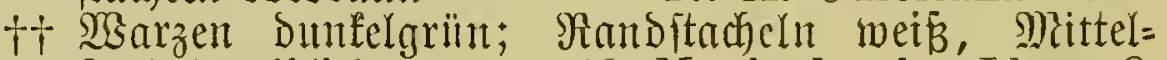
ftachel gelslich 18. M. rhodantha' Lh. et O.

4. Randitacheln weip, ftrahlig, boritenförmig, zahlueich; Mittel= ftacheln 2-6 gerabe oder gefrimmt, fahlgelb, rot oder fichiouralich 4. (S3ruppe Discolores.

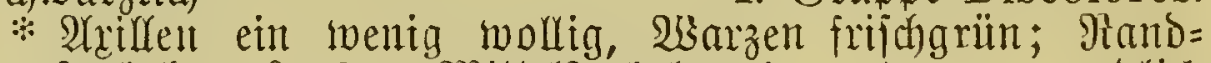
itadheln 20-22, Mittelitadyeln 4, rotbraun, endich ichivarz, gefrïmmt 19. M. phaeacantha Lem.

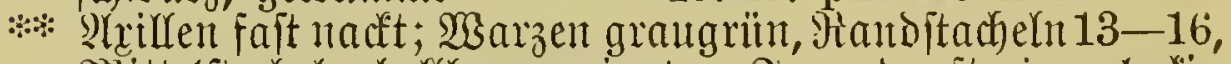
Mittelftadeln hellbraun, in ber sugend dft einer hatig

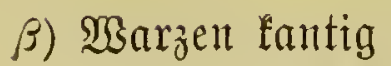
20. M. coronaria Hax:

I. Ẇarzen mäвig lang und bide.

1 Mittelftacheln einzelı, nad) unten getrümnt; 2 sarzen viertantig

21. M. uncinata Zuce.

2. Mittelftadeln mehrere, ber mittelite etwas gebreht, wage= red)t, $\mathfrak{B a r z e l l}$ mebrfantig 22 . M. centricirrha Lem.

II. Warzent lantg Into Dice.

1. Stacheln 5-10.

* Randitad)elı 13, ıngleidh $(5-10 \mathrm{~mm}$ lang), 罗ittel= itacheln 2

23. M. Grusoni Rge. 


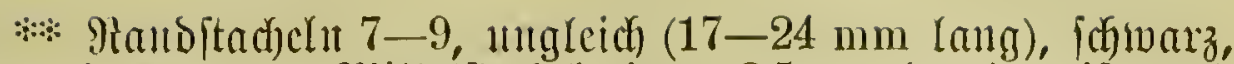
ball gran, 9)ittelitachel ciner $(2,5 \mathrm{~cm}$ lang) meift nad oben geriditet, fdumarz 24. M. melanocentra Pos.

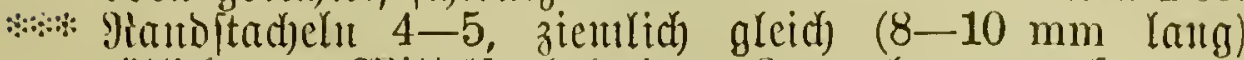
rötlidforall, Mlitterítad)el einer (3 $\mathrm{cm}$ lang), naif unten gerid)tet, getrimunt, nattweiß nut bunfler Spize

2. Sleibento Strudjell 2-4.

25. M. Krameri Miihlpf.

: strillen wollig, areolen jung zottig, Stadheln meits 3

26. M. magnimamma Hau.

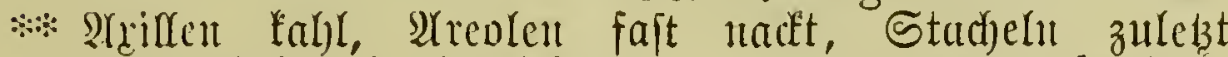
gewöbulict) 2 , itatf gefriimmt 27 . M. macracantha $D C$.

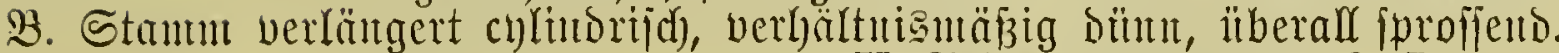

V. Gicilic stelligerne $S .-D$.

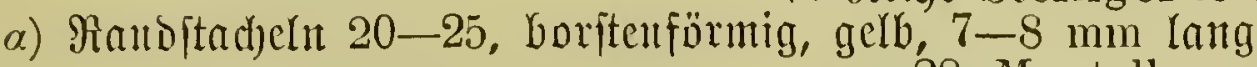

ß) Sanditadeln 1t-16, fein Goritenförmig, weiß

28. M. stella aurata Mast.

29. M. gracilis Pfciff.

b) Marzen oben eingedrilteft

VI. Reife Aulacothelae S.- II.

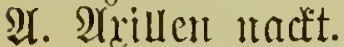

a.) Stachelı 16-24, gleidh, fantnförmig, nicht $1 \mathrm{~cm}$ \ang, meiß̧lichgelb, \{päter grau

30. M. pectinatus Engelm.

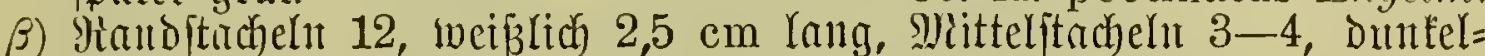
bralti, bis $4 \mathrm{~cm}$ lattg 31. M. macromeris Engelm.

3. Arillen wollig.

a) ธtachellt Dick, iteif, gefrïmmt, gelblichwei反

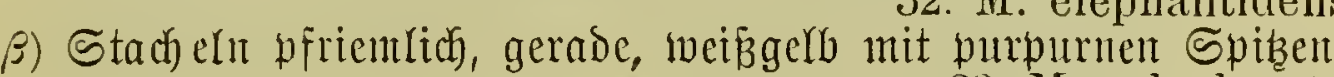

33. M. sulcolanata Lem.

\section{Mamillaria uberiformis Zucc. Bitzenfaftuz.}

Sn ben (jebingen Mexifos heintifd, mit faft fugeligen, etwa $10 \mathrm{~cm}$ hoben

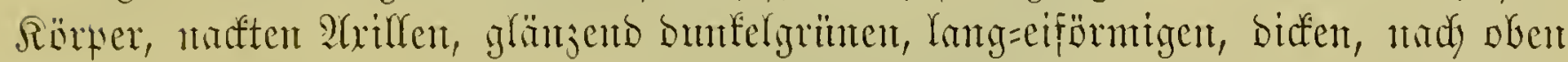

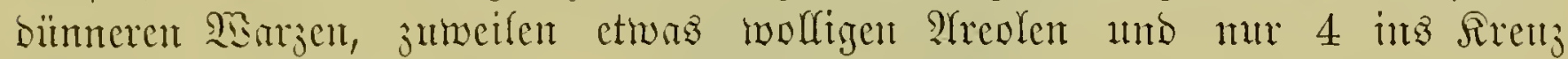
geftellten Etrdychr. (テig. 109, ऽ. 196.)

Bhüten $4 \mathrm{~cm}$ im Durdymefier, goldgelb, atben etwas grïulidy. Die Stanb=

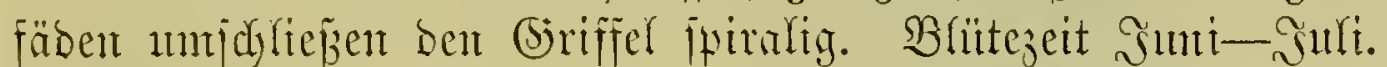

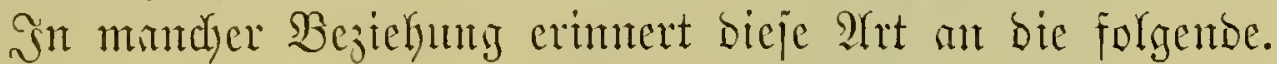

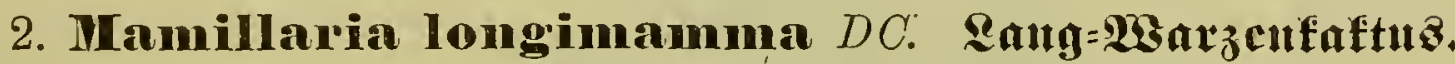

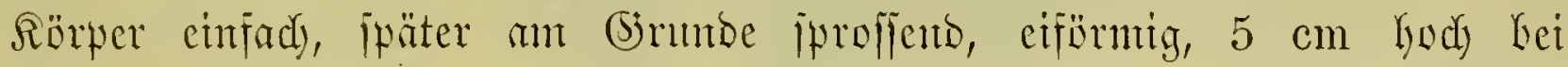

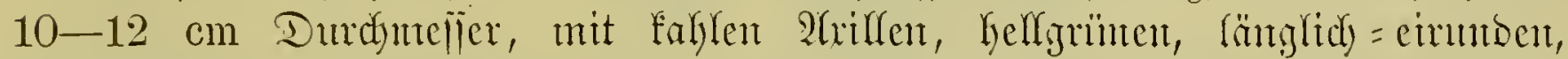

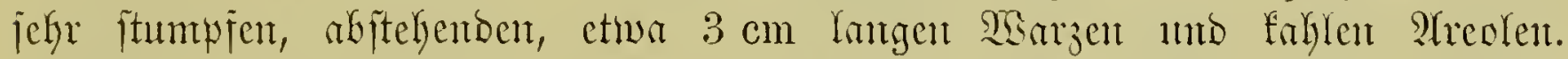

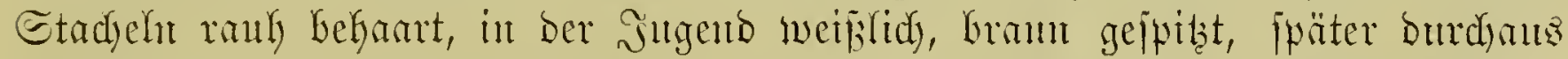

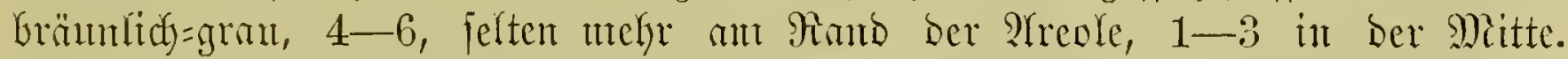

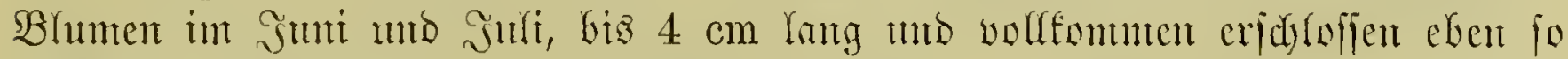
breit, citron=gelb, mur in volfer Eonme geöffuet.

Bon ibren Barietäten bejthen var. congesta jaflreidyere gebrüngtere und

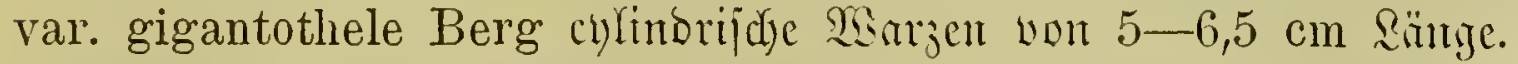

Diejer $\mathfrak{A}$ rt ftelyt in vieler Bejielumig mbe Mamillaria uberiformis Zucc.,

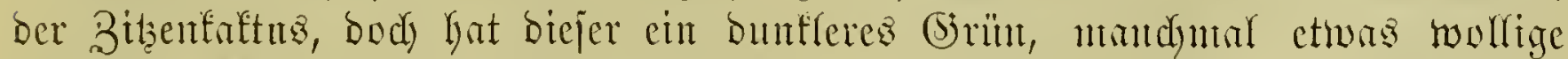
Axillen, biffere, babei ituntpiere Sargen, eme geringere Babl von Etadyeln bei

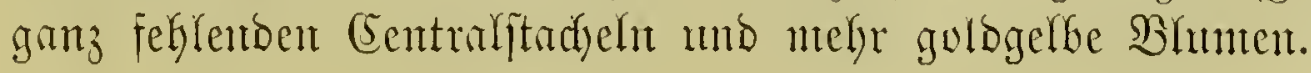




\section{Iamillaria pusilla $D C$. $3 \mathfrak{w e r g}=\mathfrak{M} \mathfrak{a n} \mathfrak{z} \mathfrak{e n f a f t u}$.}

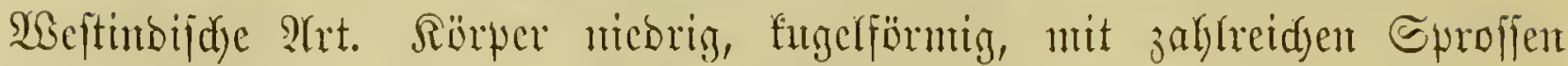

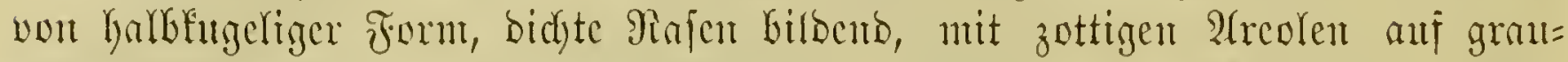
grïnen Şarzen, mit 12-20 hanrfürmigen, gernoen ober gefräujelten weiz̄en

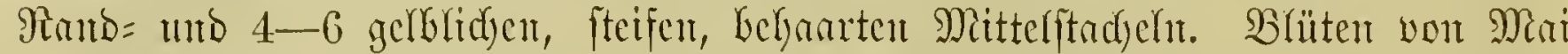

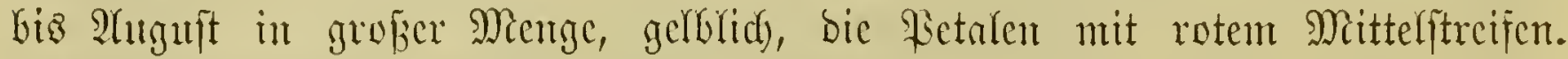

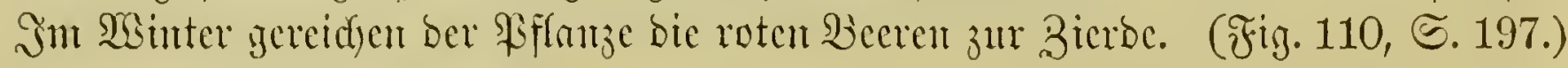

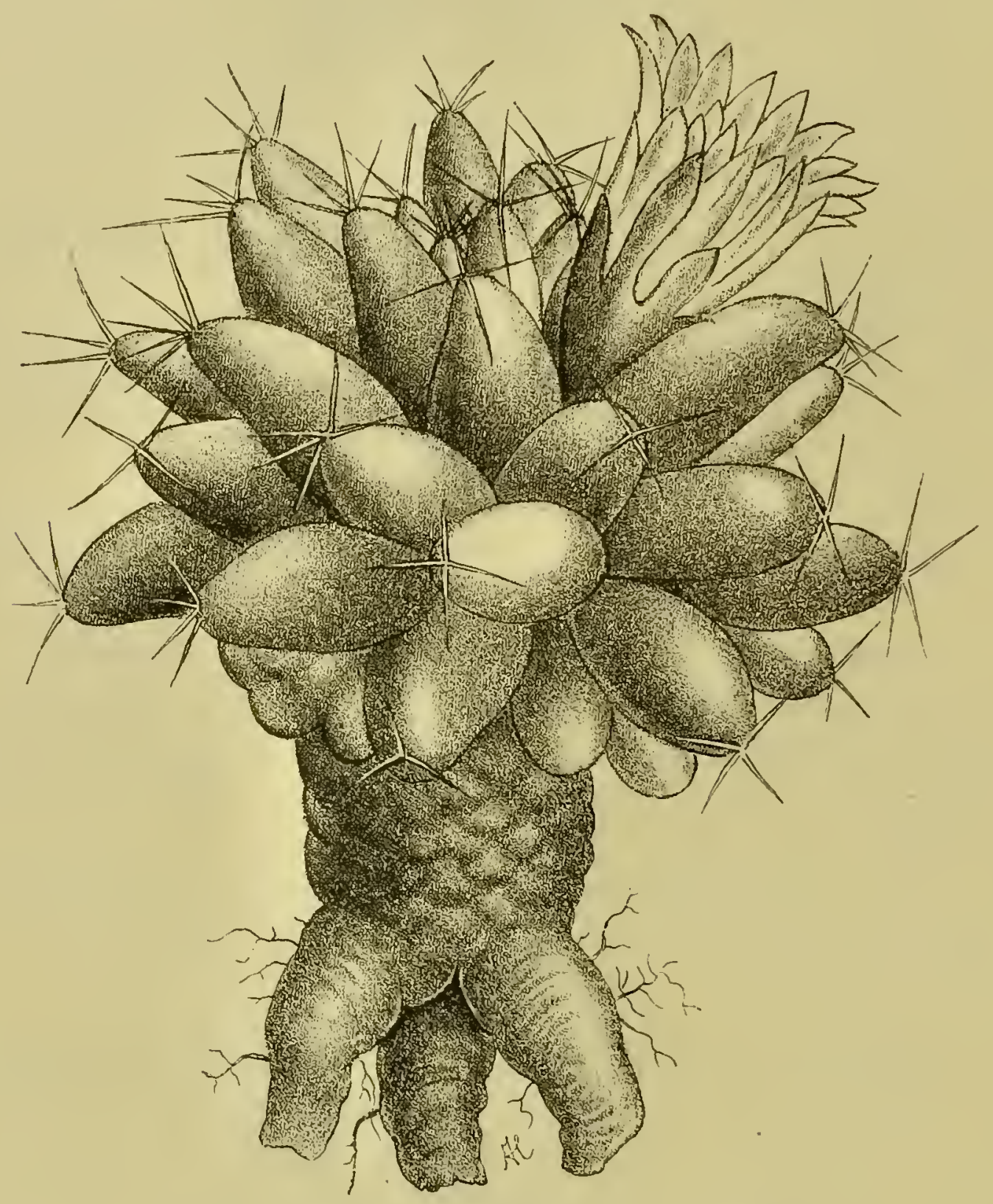

Jig. 109. Mamillaria uberiformis Zuec. 3itzentaftus.

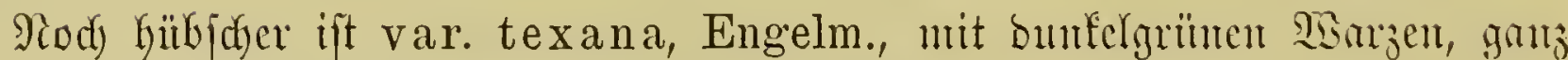

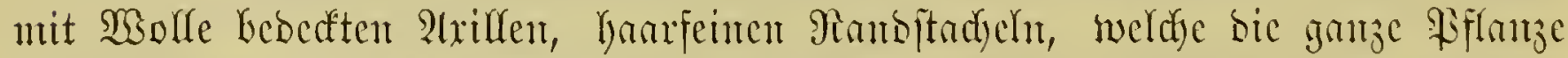

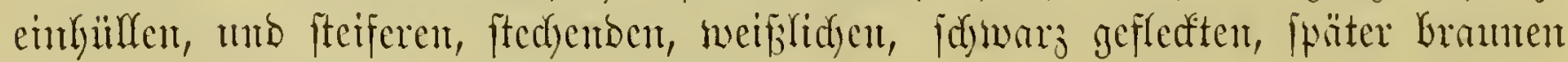
und an ber Spritze fownargen Mittelftadjeln.

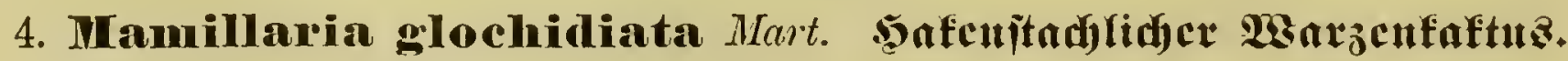

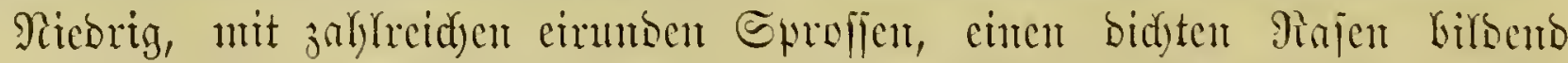

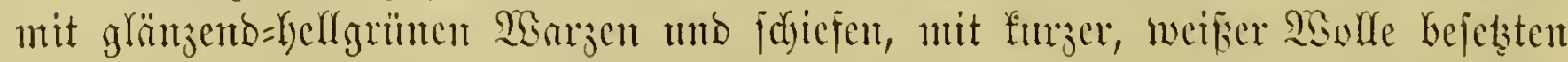

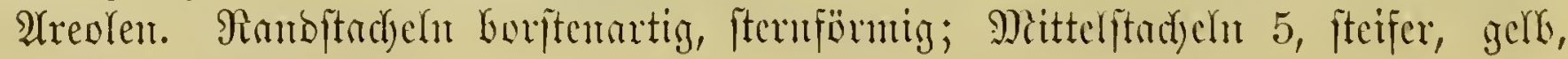




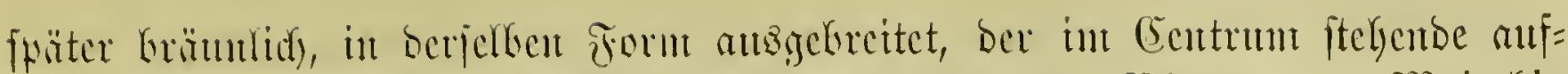

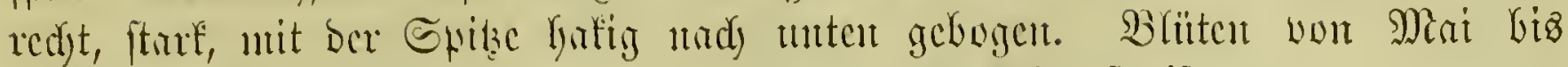

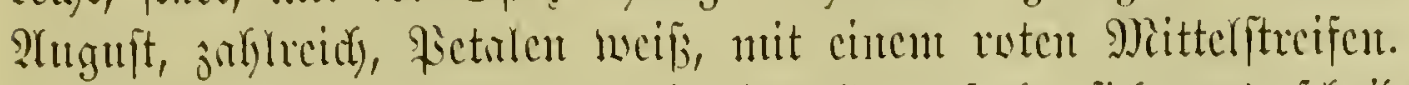

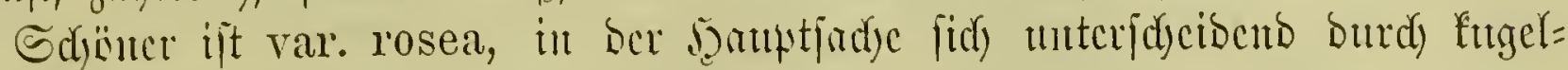

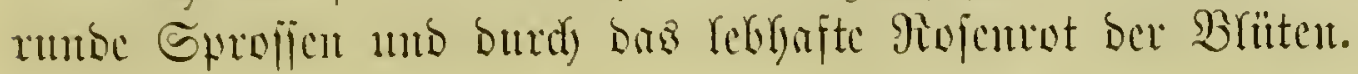

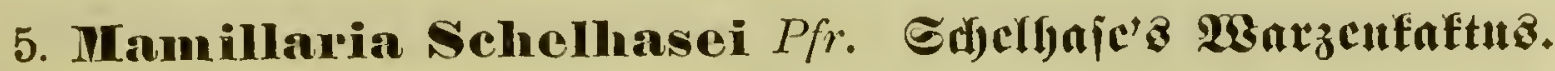

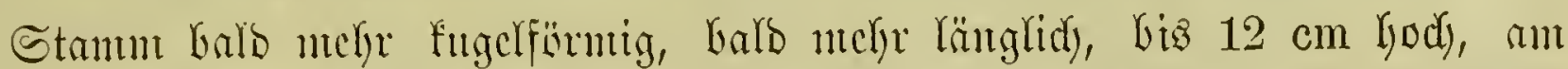

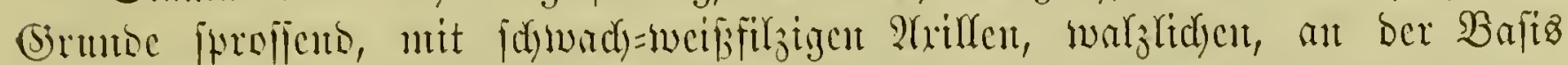

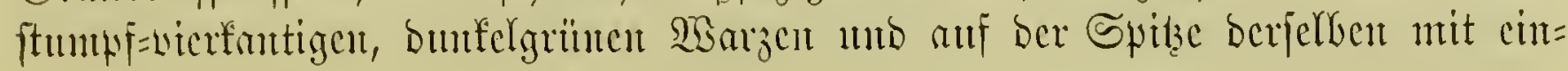

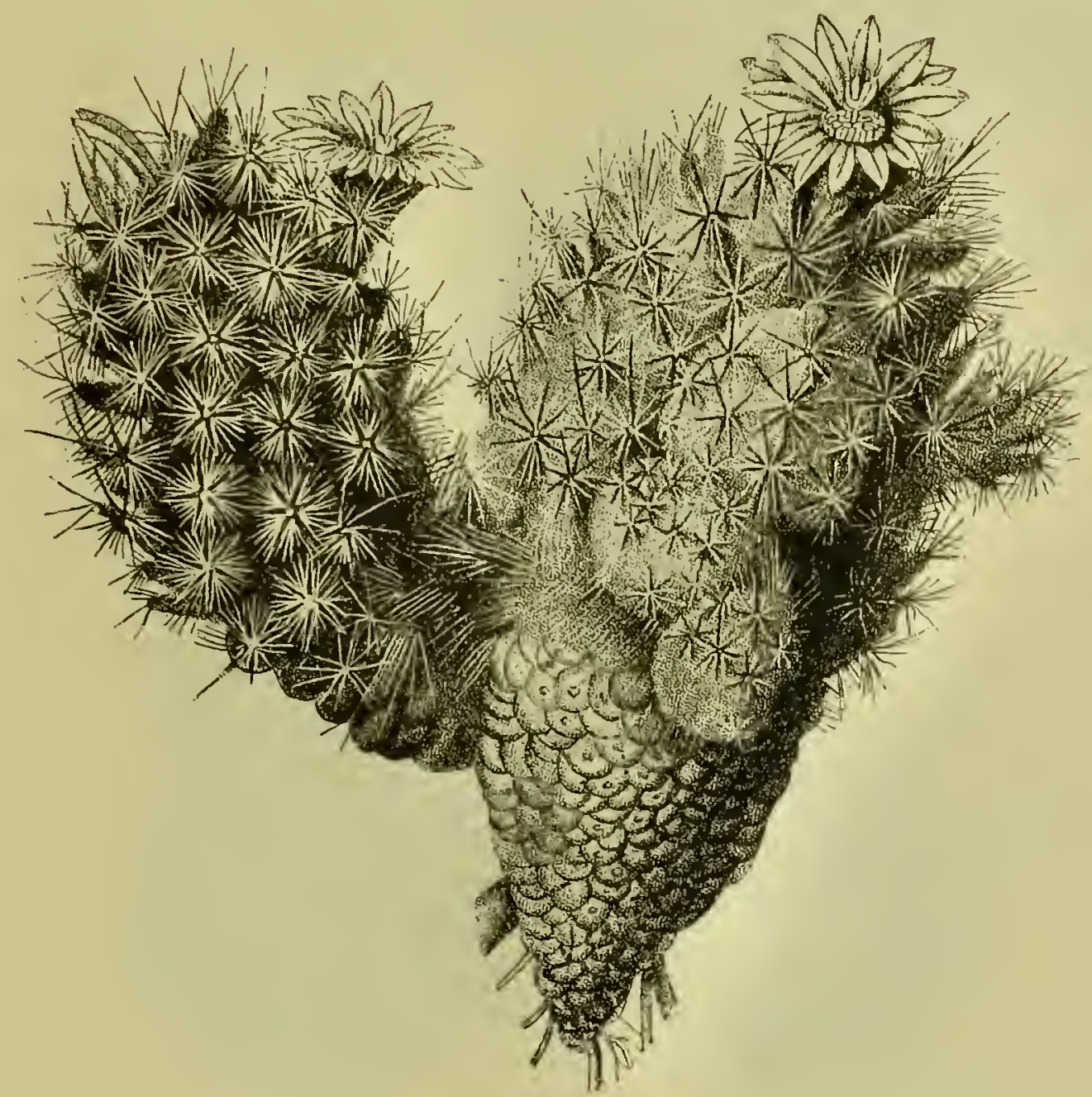

Fig. 110. Mamillaria pusilla DC. 3werg=\$3arzenfaftus.

gejenften $\mathfrak{A} r e o l e n$, bicje mit 15-20 borftenförmigen, weiß̄en, fternförmig aus=

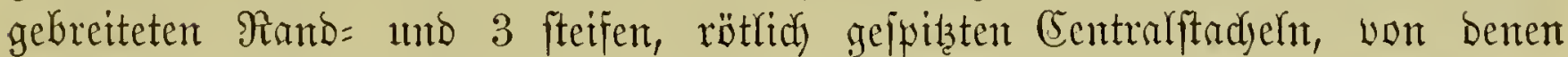

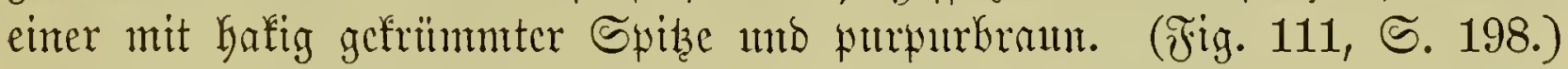

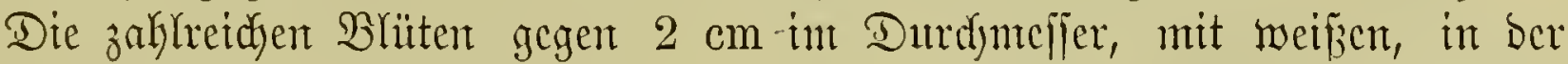
Mitte rotgeftreiften ßserigonblättern.

\section{Mamillaria Grahami Engelm.}

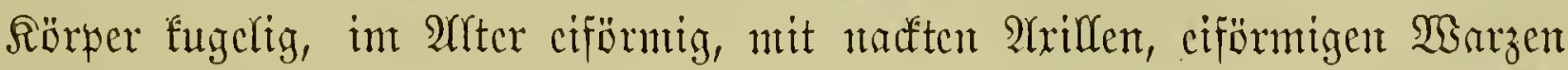

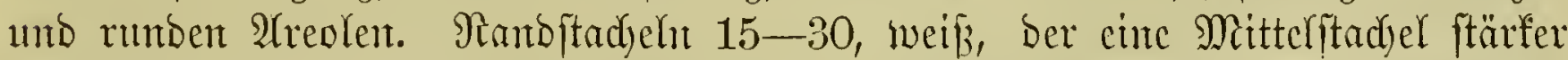
und länger, Kafenförmig gebogen, fdjmarzrot. Brüten int Sicije um ben Edjeitel geftellt, hochrot. (Fig. 112, S. 199.) 


\section{Mamillaria micromeris Engelm. Slcin=:Barzenfaftuz.}

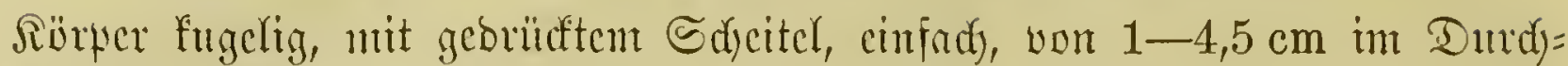

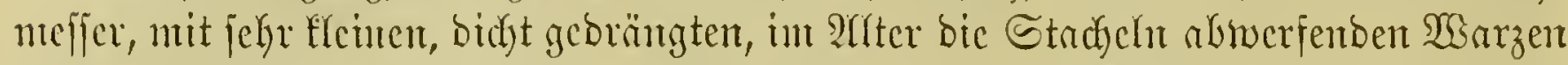

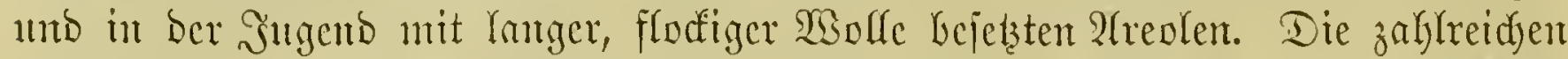

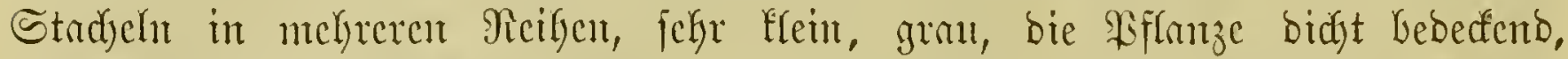

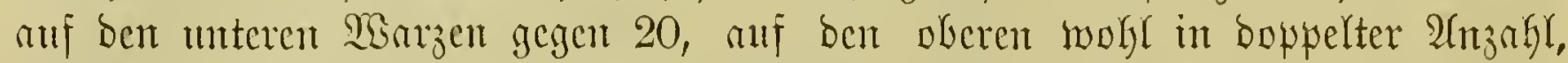
fternartig anzgebreitet, bie wheren 1 m vicles länger, nad) oben feulenförmig,

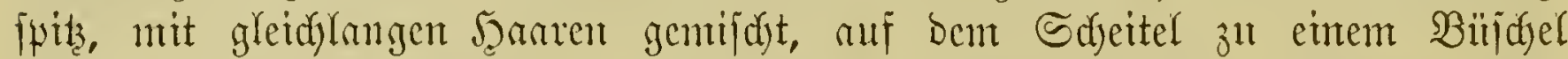

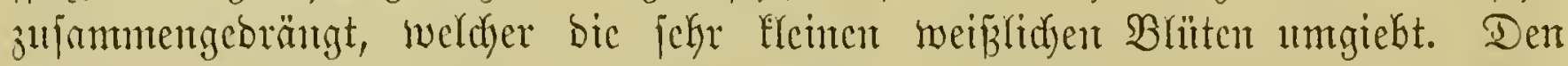

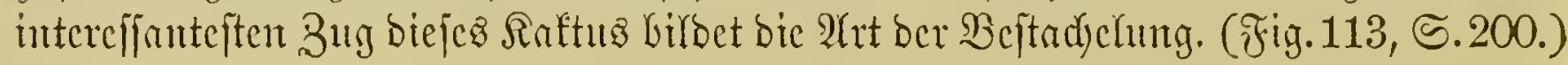

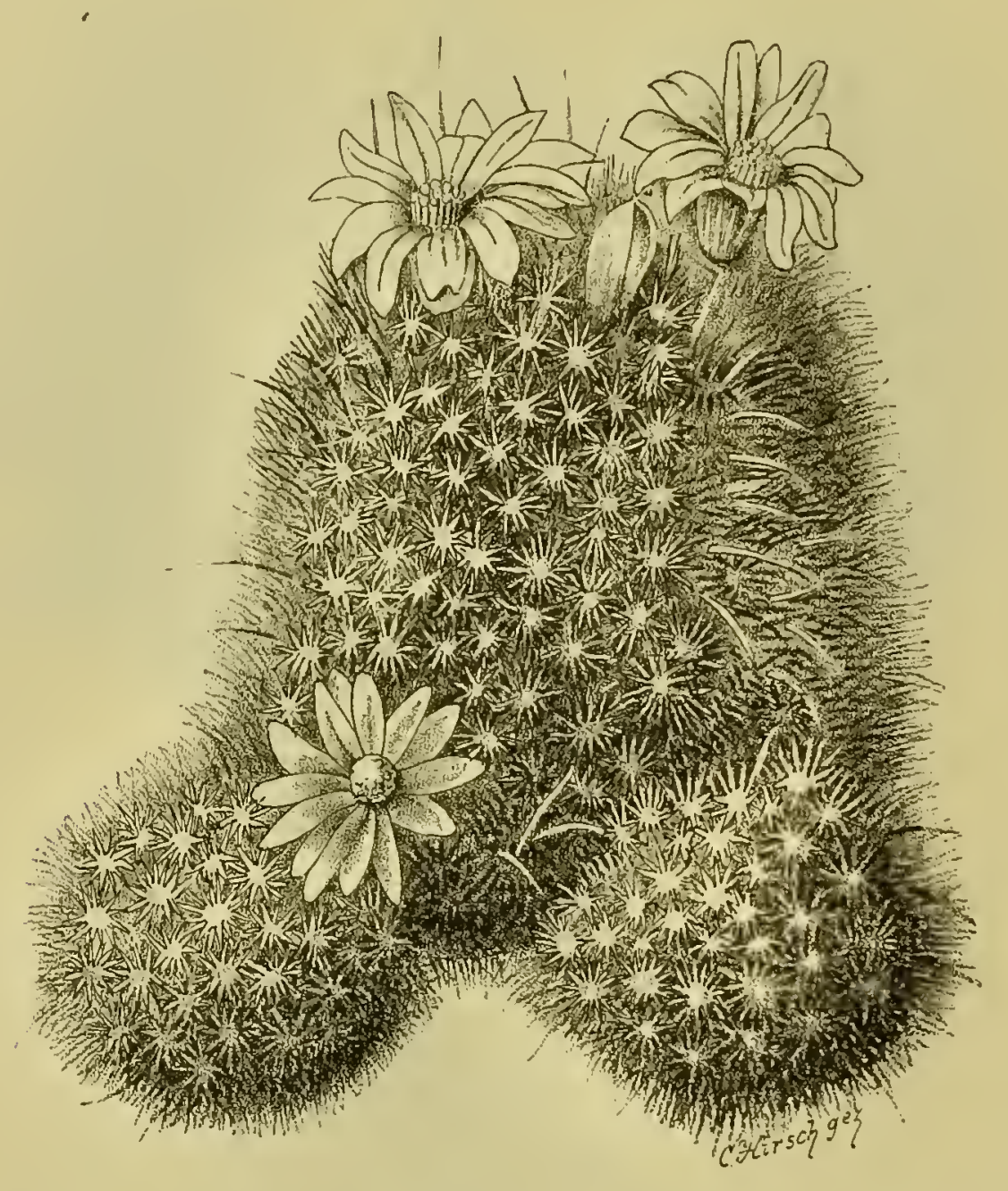

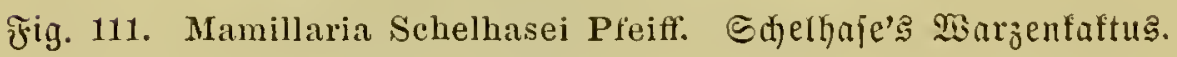

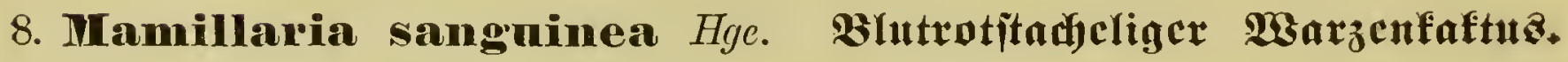

Stamm Yäuglidy=eiförmig, $12 \mathrm{~cm}$ hod) bei $8 \mathrm{~cm}$ Durdjmeffer, mit fegcl=

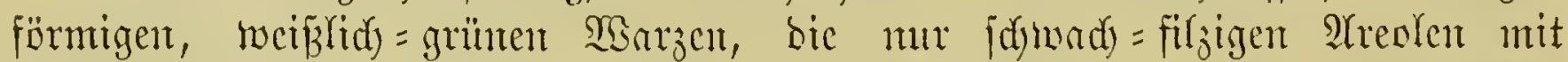

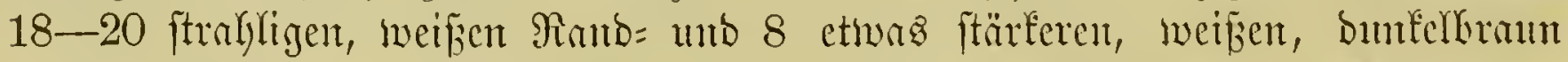

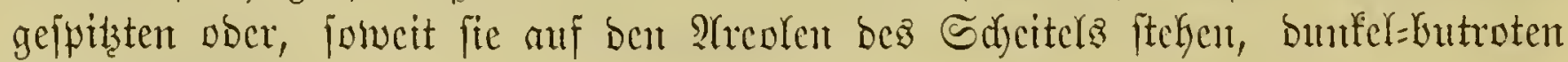
Sentralitadyelnt.

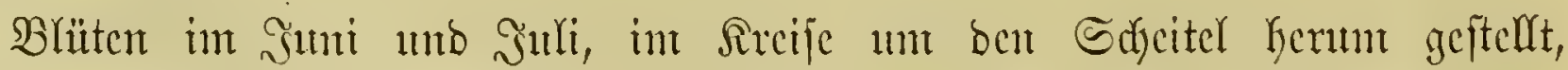

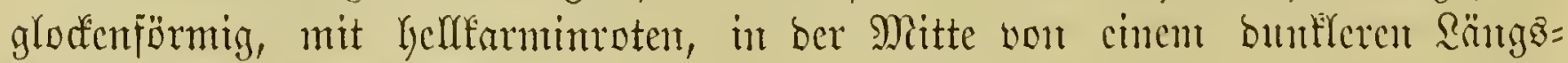

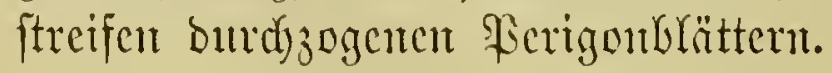




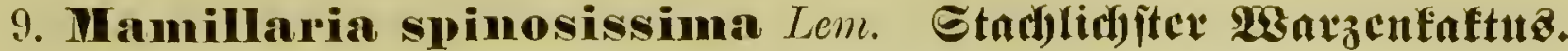

Strum cinfad), fänlenfiumtig, meiftens 10-15 cm hod bei $8 \mathrm{~cm}$ Dumd $=$

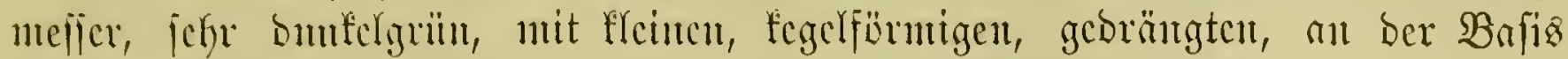

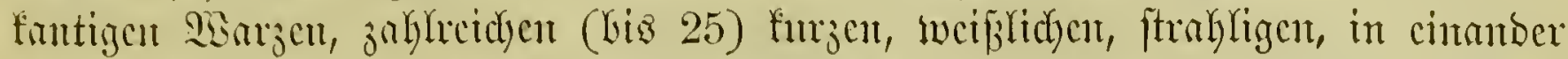

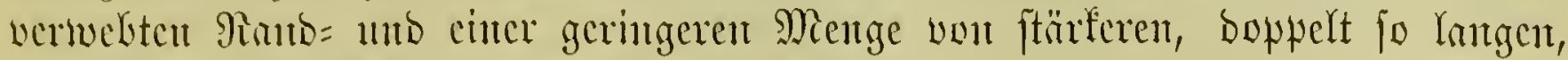

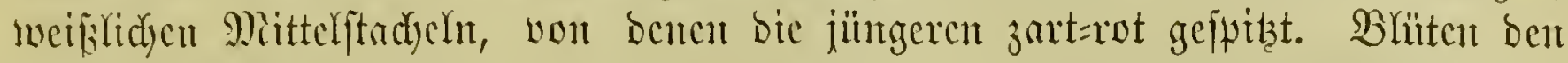

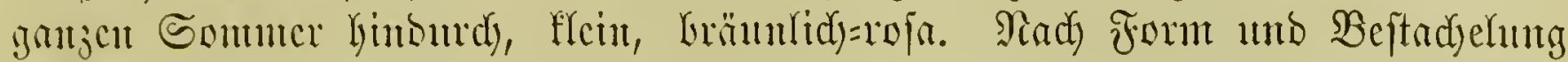
eine ber foüuten ?lotent.

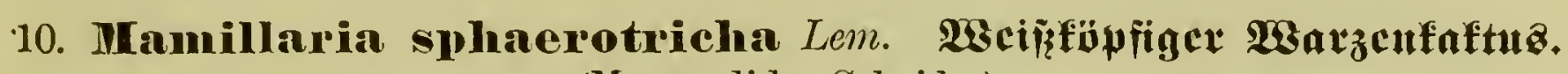
(M. candida Scheidw.)

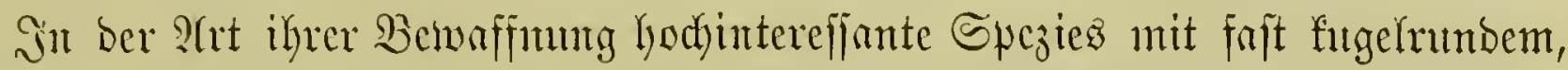

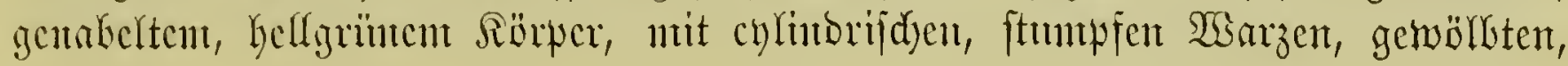

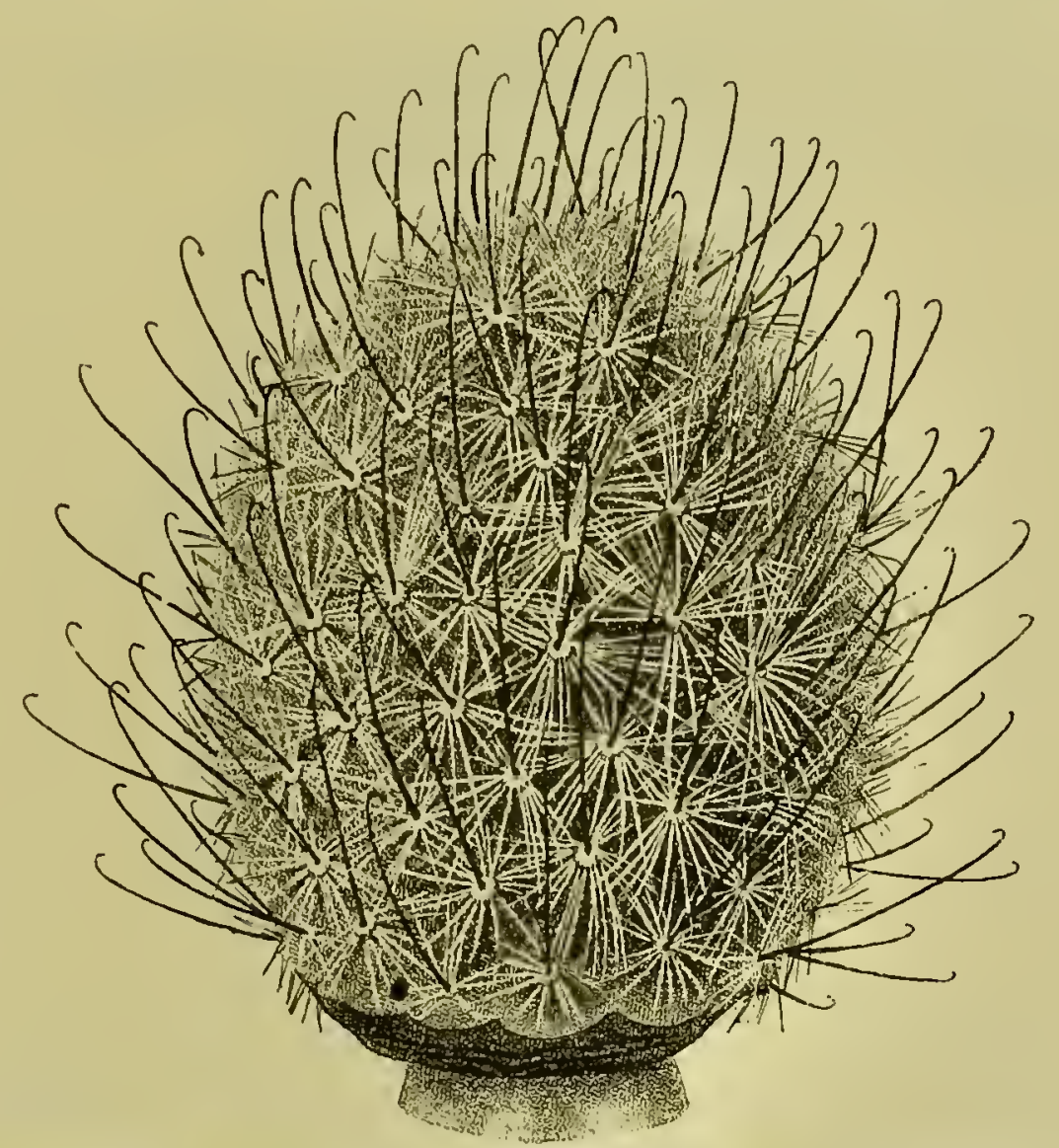

Fig. 112. Mamillaria Grahami Eng. (Brafam's Warzenfaftus.

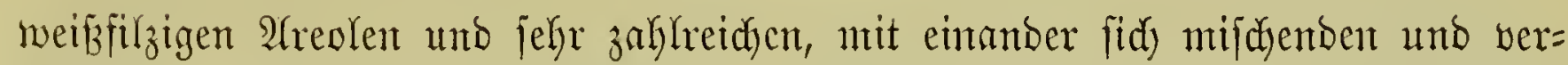

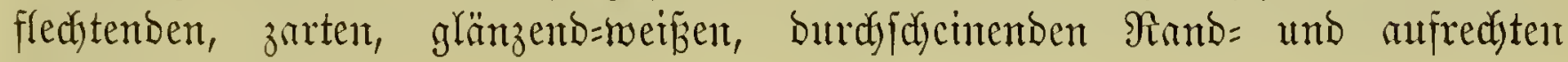
Eentralitadyeln.

Błäten mit aujredyten, fleifdjfarbigen Ferignublättern.

\section{Mamillaria Schiedeana Ehrenb. Gdjiebe'z Marzenfaftuz.}

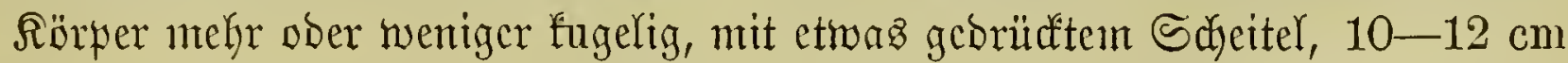
hod, erft im höheren 2llter jprofjent, bunfelgrün, mit fefre wolligen 2lriflen, bidjt georängten, walzlidyen, nadj oben fid verjüngenben Warrzen und eintgejenften,

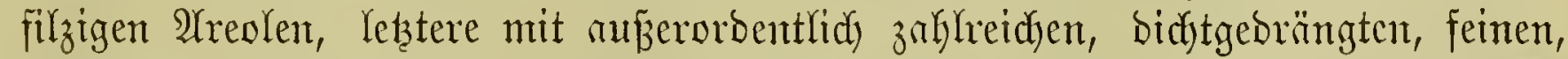
horizontal ansfitrablenben, weifflidyen, am Sorutbe gelben, an ber Spitze flocfig behanten Strdyeln. 


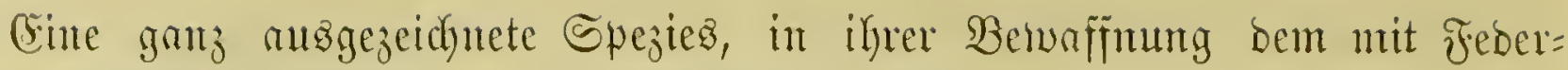

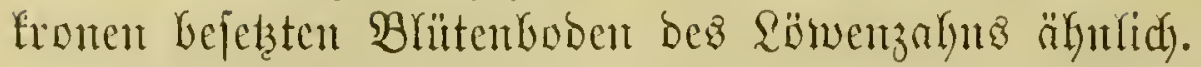

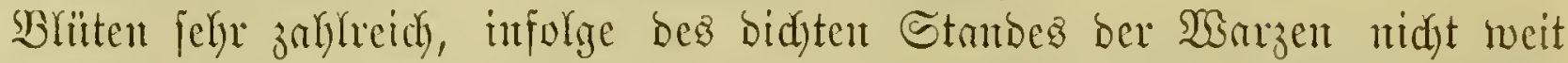

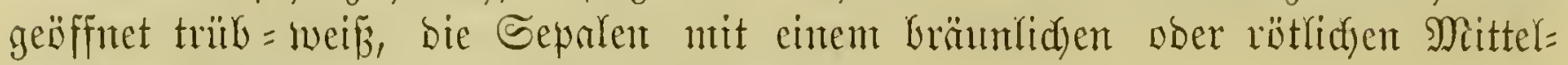
ftreifen. Şlütezeit September bis Dezentber.

\section{Mamillaria bicolor Lehm. 3weifaxbiger $\mathfrak{B a n z} \mathfrak{e n f a f t u}$.}

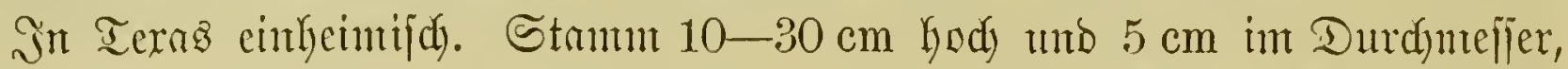

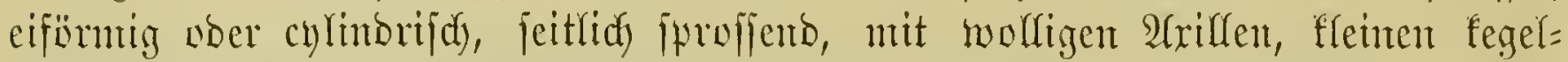

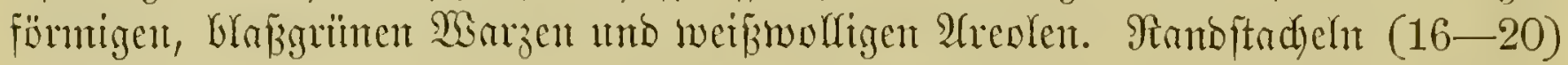

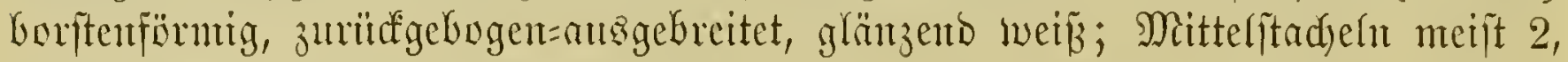

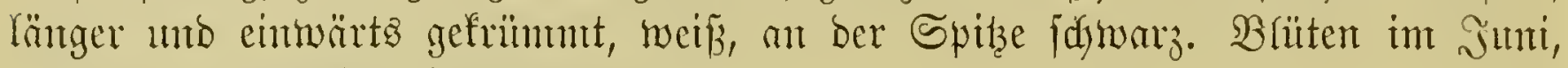

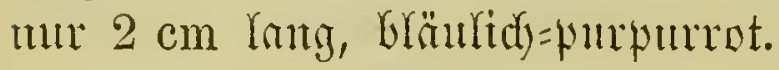

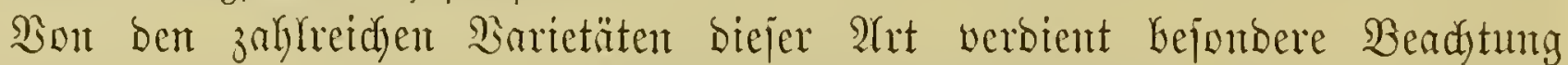
var. cristata, eine jefr interefijante, nicbrige Mentrofitüt, mit unregelnuäßig hin= mith hergebogener Edjeitelfante.

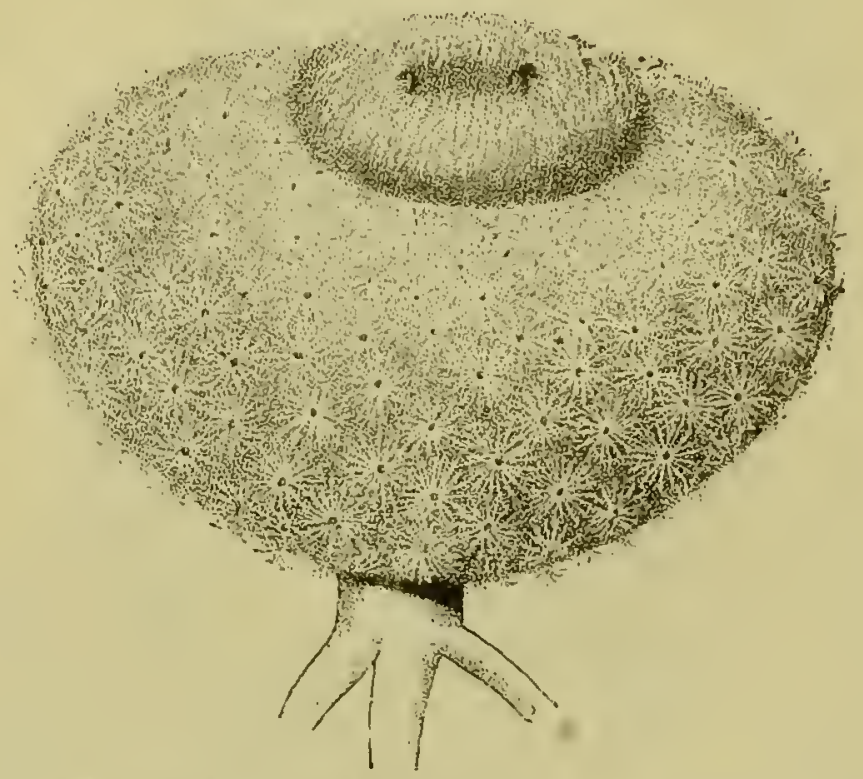

Fig. 115. Mamillaria micromeris Eng. Sitcin=2saracufaltus.

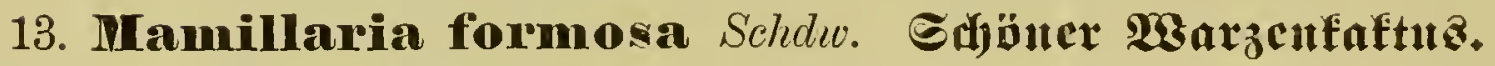

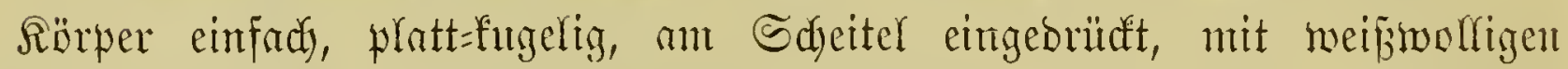

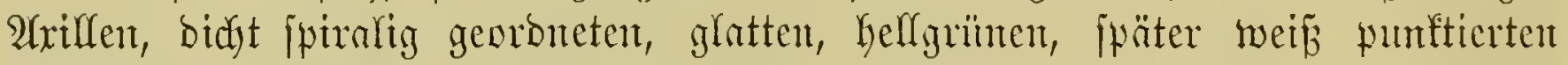

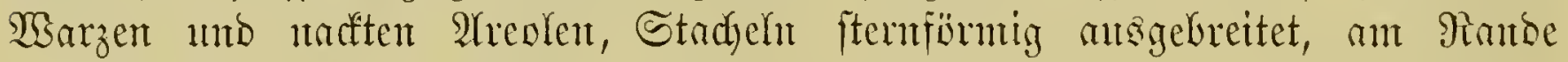

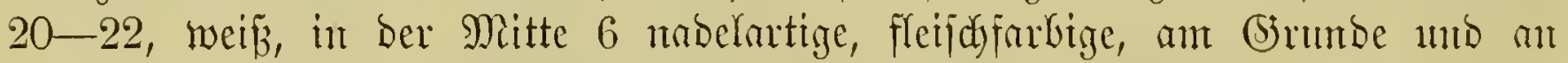

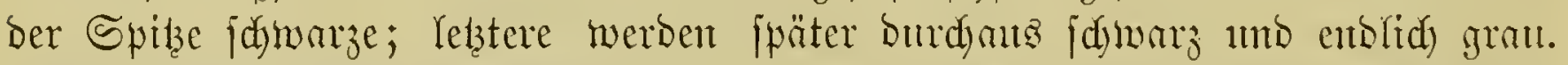

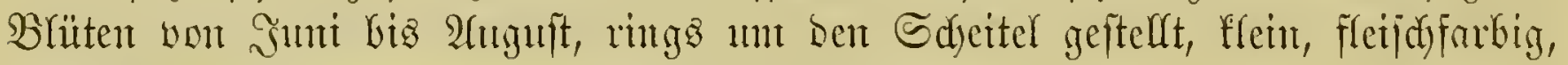
bie Petalen mit eintem rojentroten Mittelftreifen.

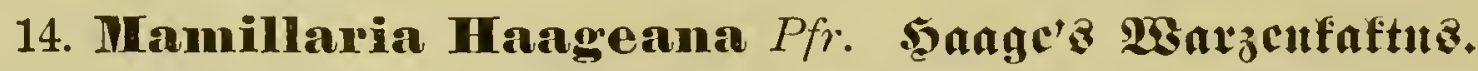

Der faft flugelige, fpäter fid) etwas werlängembe Sï̈rper wirb nody nidgt

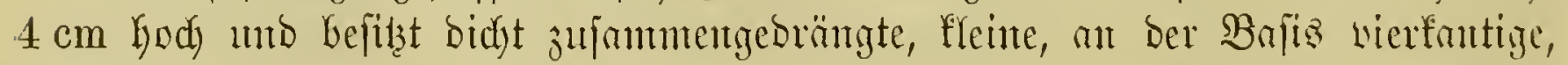

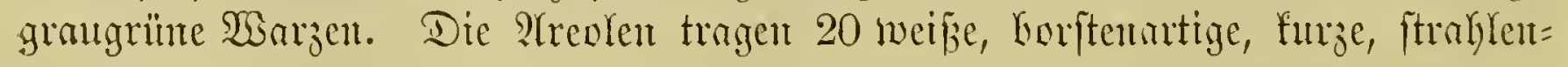




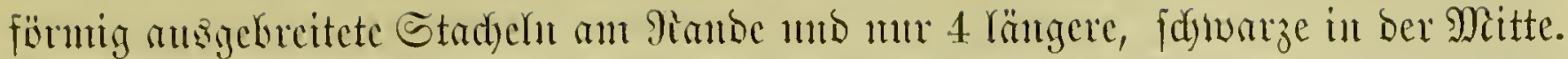

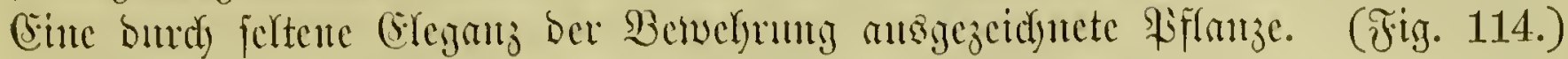

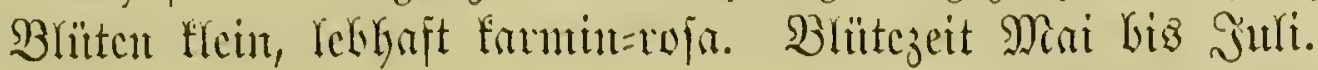

\section{Mamilladia chrysacantha Hort. Berol. Golofindfeliger Qsinx}

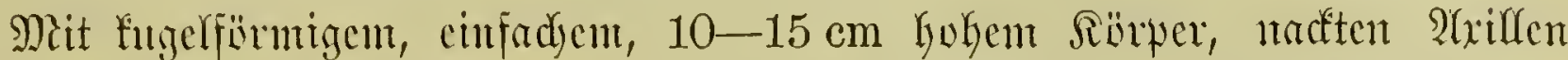

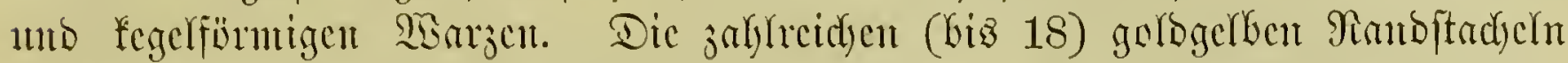

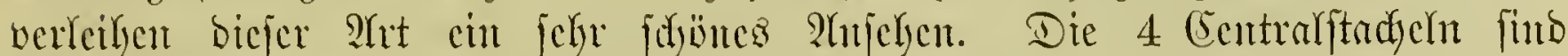

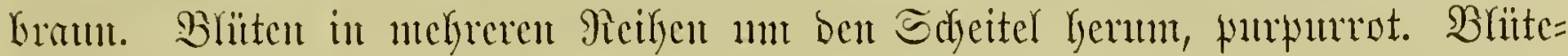
jeit Mari bis Sulli.

Dicjer 2 ret ähulid ift M. fuscata Hort. Berol. Deren melyr brame

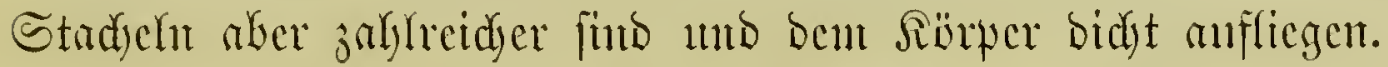

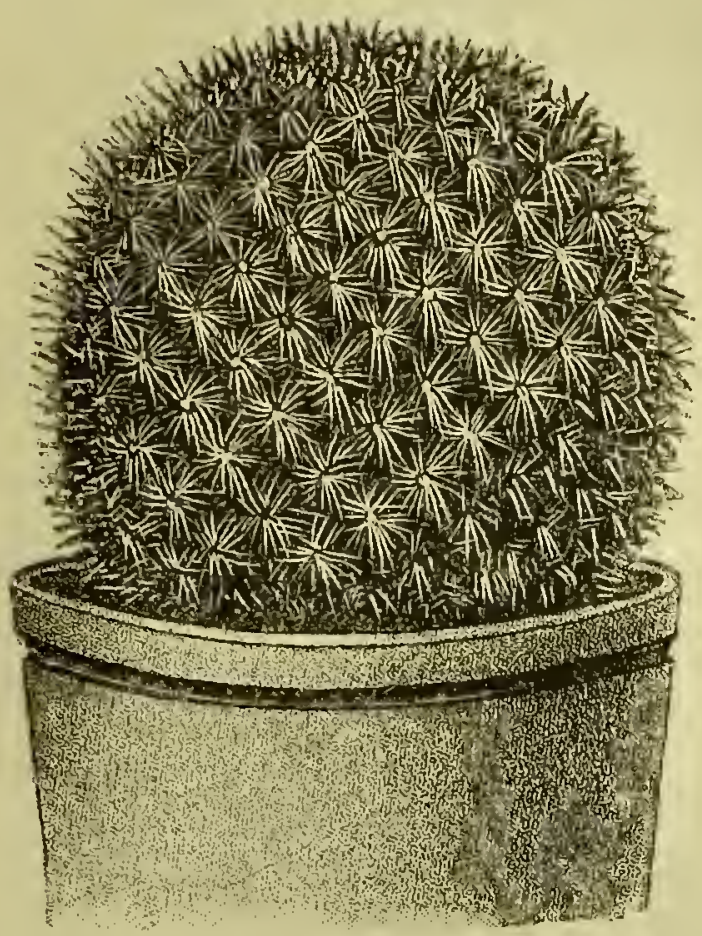

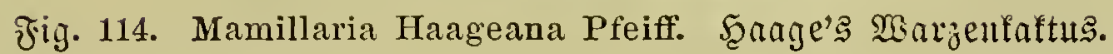

\section{Mamillaria putila Zuce. Röthlid)er $\mathfrak{B a n} z \mathfrak{a n f a f t u}$.}

(M. Eugenia Scheidw.)

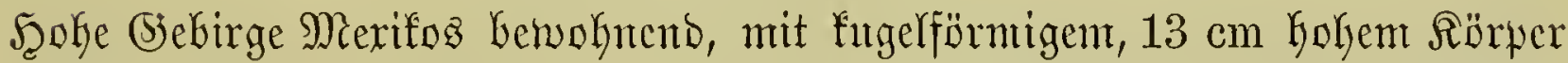

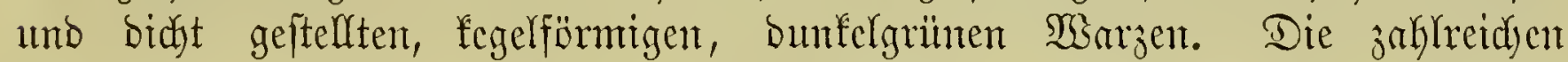
gefpreizten unb etwas gefrïmmten Stadyeln bräuntidy=rot, ber unterfte vich länger, als bie übrigen.

Blüten in mehreren Ireifen um ben Sdyeitel herum, purpurrot, bie Scpalen von matterer Färbung. BBhütezeit Suli biz 2luguit.

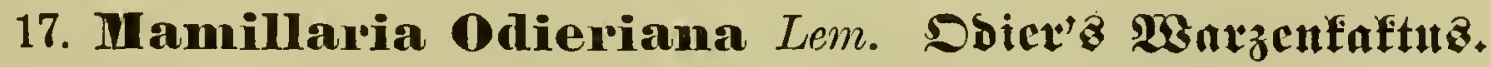

Stamm fugelf̈̈rmig, fpäter Yänglidy, $8-10 \mathrm{~cm}$ hod bei $5-8 \mathrm{~cm}$ Dutrdy $=$

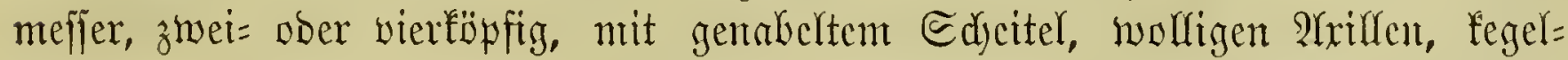

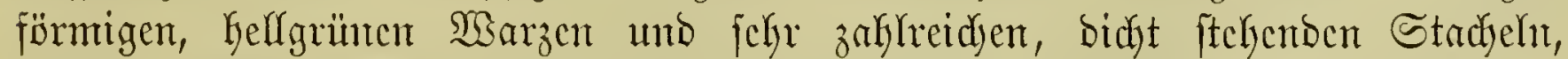

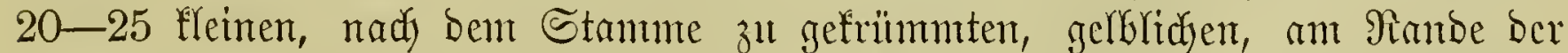

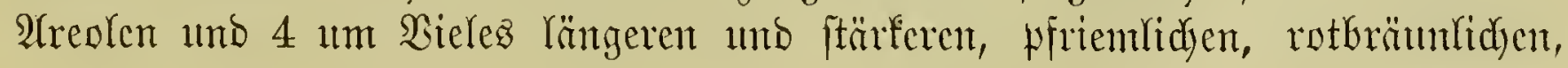




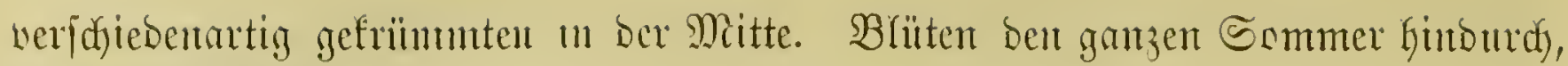
violett=rumpturtot.

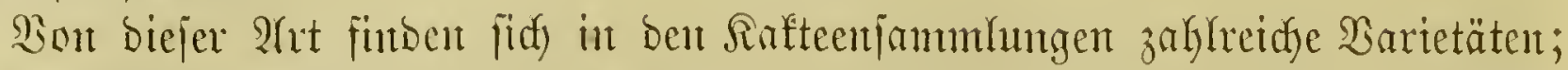

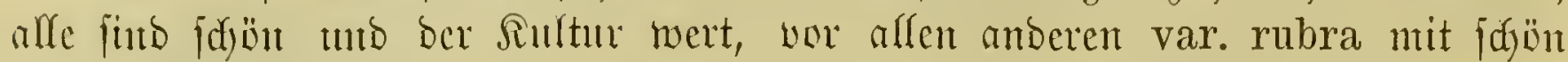
rot gefärbtent Stadjelıt.

Bieflecdyt aud mur eine Sarietät ber Mamillaria Odieriana, jebenfallz ifr. felgr nalje verwatot ift bie folgenbe 2 trt.

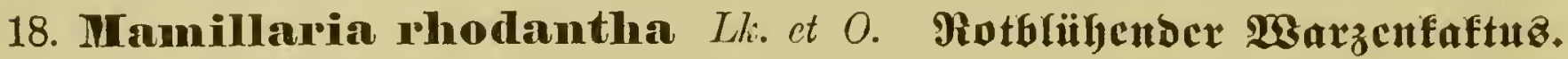

Rörper cultinbrifdy, $30-35 \mathrm{~cm}$ hod bei $8-10 \mathrm{~cm}$ im Durdymefijer, in

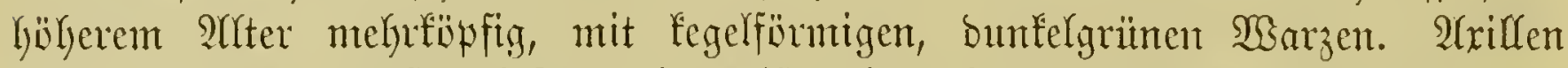

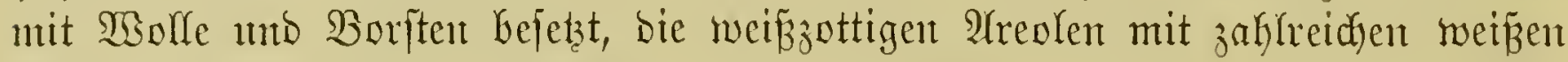

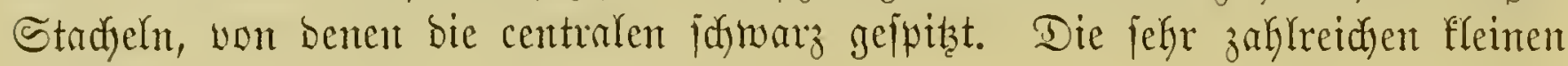
Bhäten Yebraft purpur = (nidyt rojen $=$ ) rot.

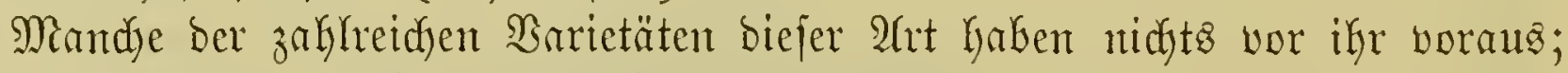

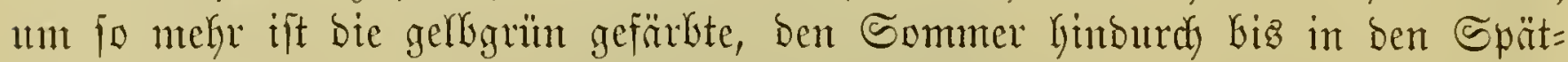

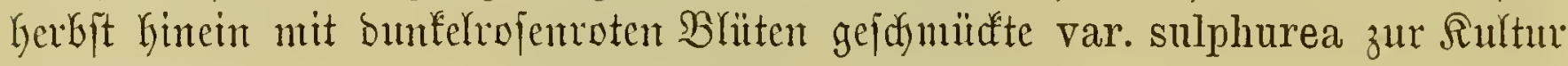
zll empielytent.

\section{Mamillaria phaeacantha Lem. Dutuflitadjeliger $\mathfrak{B a r z} \mathfrak{c}$ faftuz.}

Rörper futgelig, einfacty. Areolent weif̧urllig und mit einigen langen,

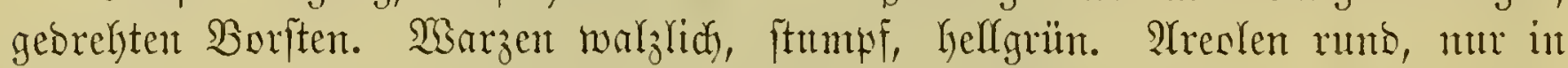

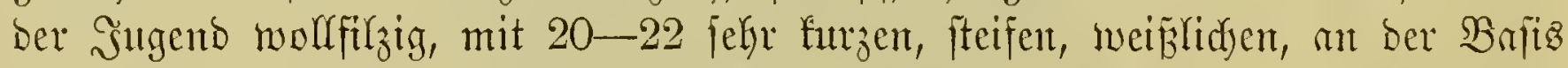

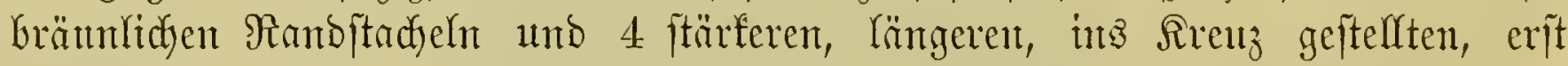

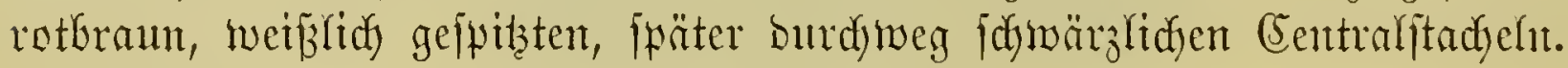

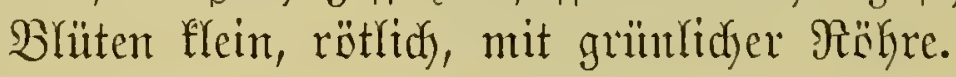

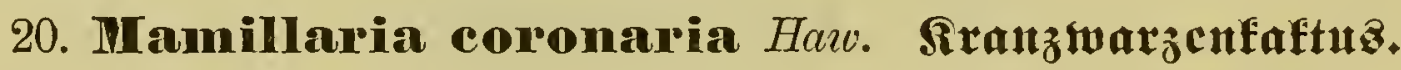

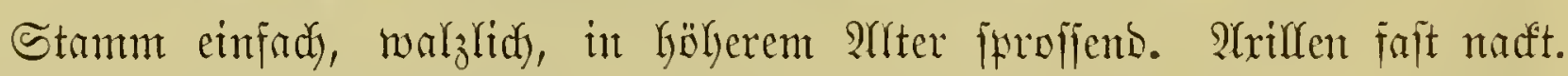

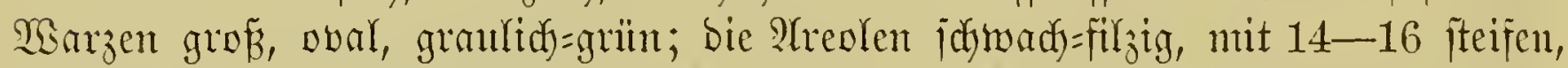

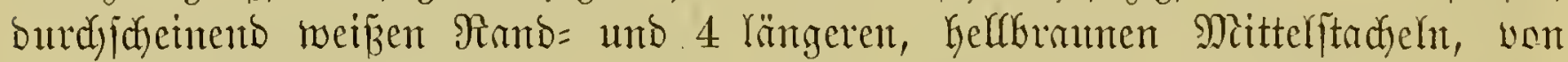
Denen kei jüngeren Fflanzen ber unterfte ber lüngfte unt sben Gafig umgebogent.

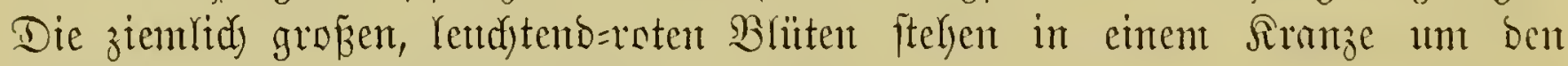
Sdyeitel Gertm. Bhätezeit Irprif uno Mai.

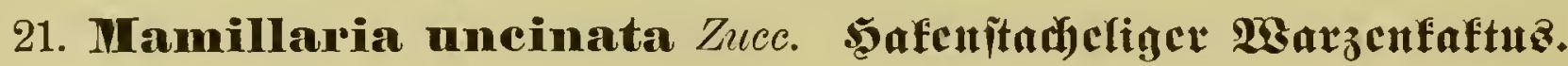

R̈̈rper fugelförmig ober etwas länglidy; obere Âtilfen mollig, untere narft.

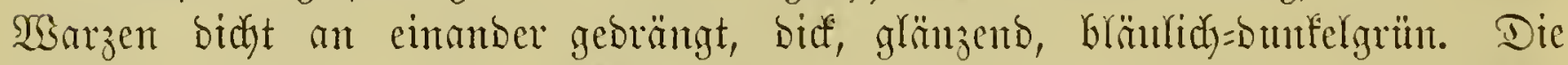

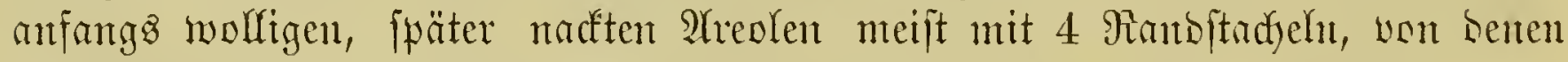

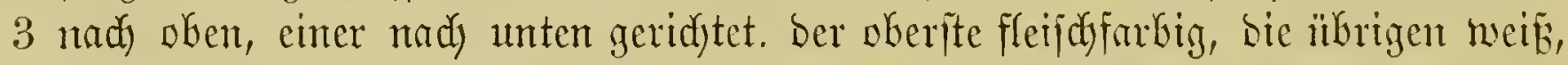

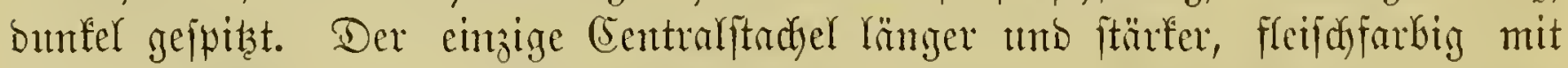

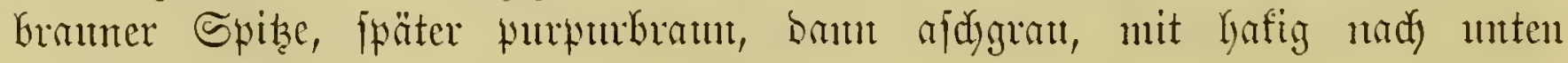
gebogetter Spitze.

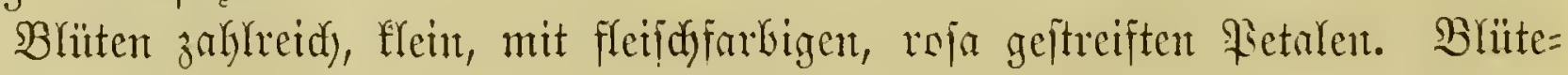
zeit Mai-Suni. 


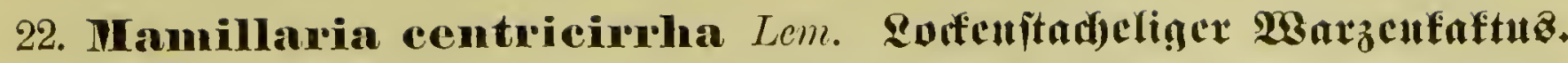

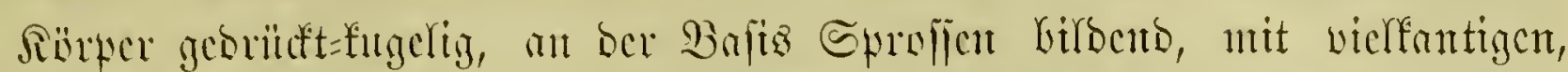

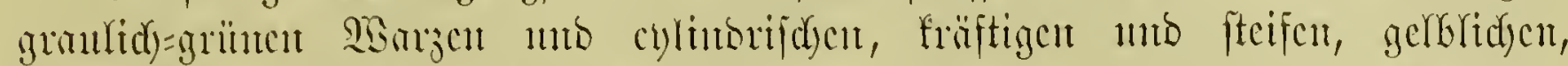

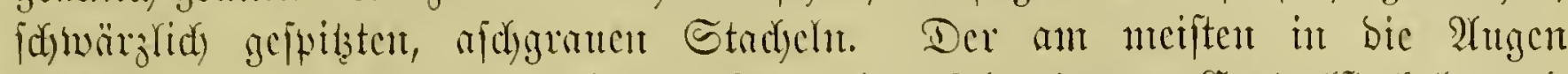

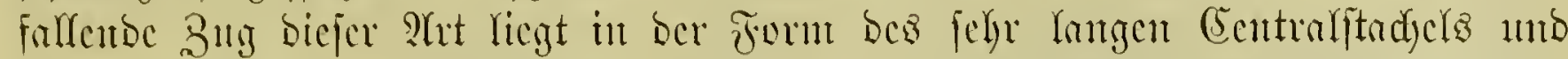

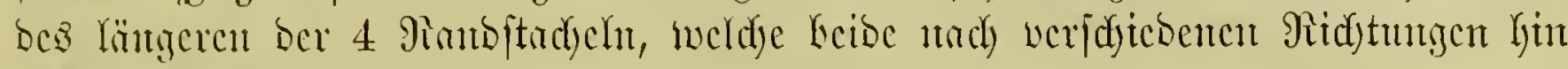
locfig gebrelyt finto.

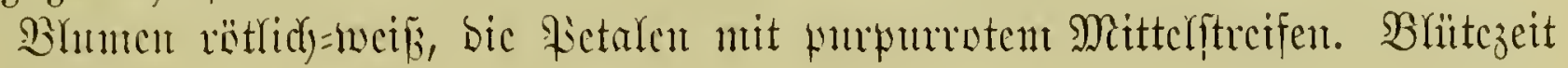

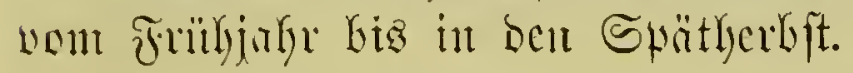

\section{Mamillaria Grusoni Rge. Grujou'z $\mathfrak{B a r z c u f a f t u z .}$}

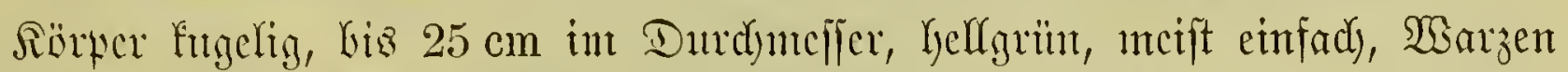

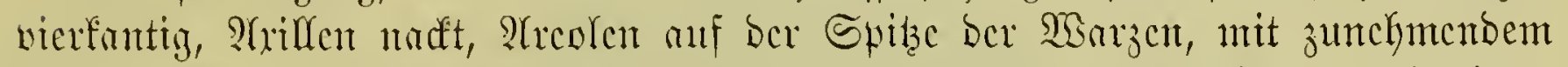

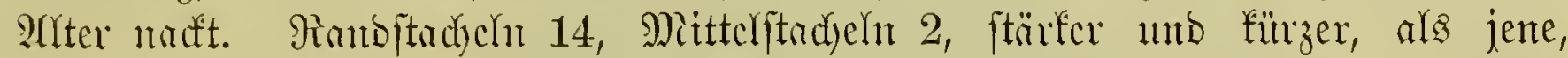
cinter gernoc abftchent, ber andere etwas und oben gerid)tet, alfe gerabe, anfangs

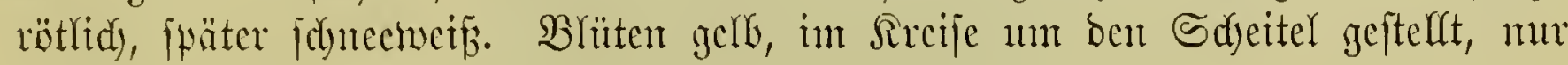
$2,5 \mathrm{~cm}$ int Dudjurfier.

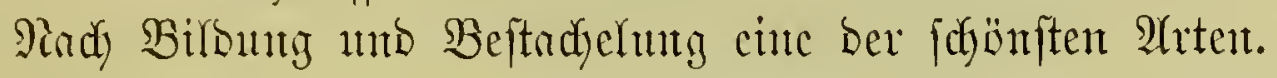

\section{Mamillaria melanocentra Pos. Sdhwarzitadjeliger $\mathfrak{B a x} z \mathfrak{c u f a f t u z}$.}

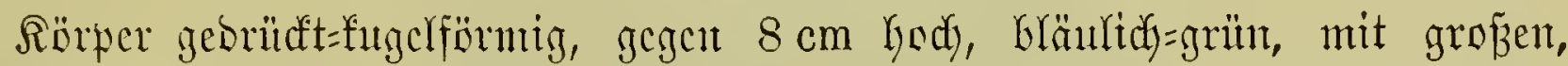

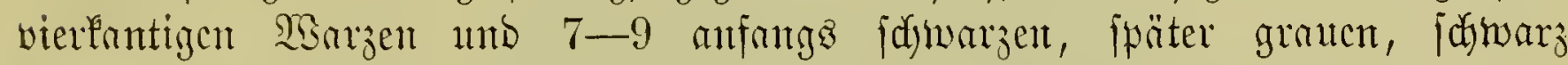

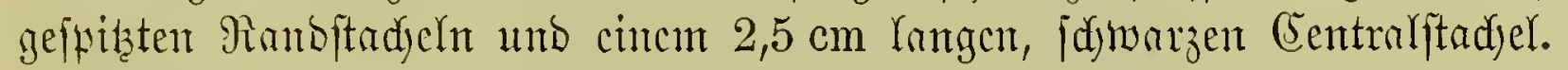

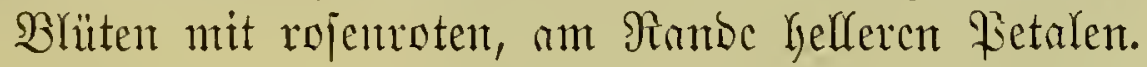

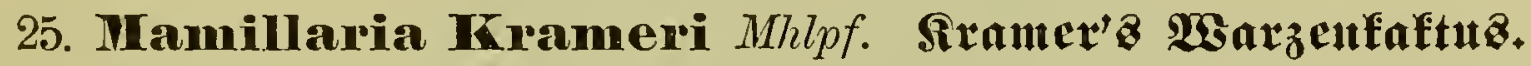

Rörper fungelig, mit etwas gcorïhftem, ftarf genabeltem Sdyeitel, im alter an ber Bafis iproflento, mit jodyr wolfigen, mit bor Beit aud mit Boriten bejebzten 2triffen, vierfantig=pyramibalen, graugrünen, braumrot angelaufenen

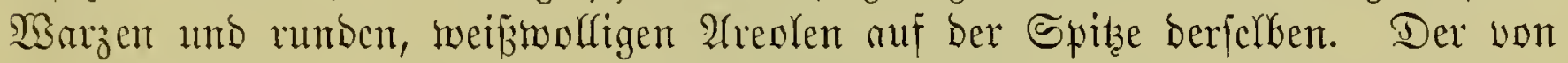

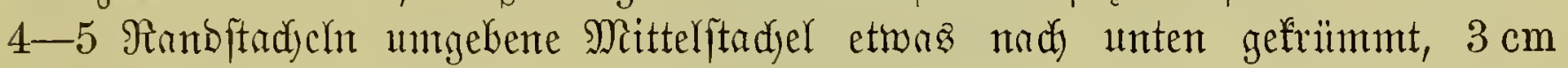

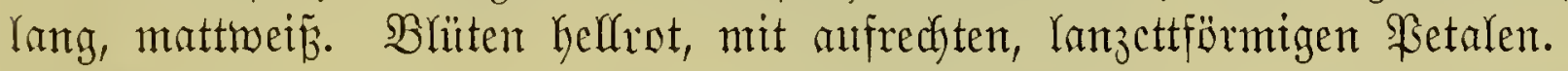

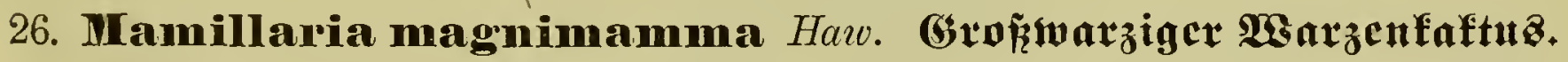

Der mefy obcr ninber fingelige Sörper 10-15 cm hody, mit nacften

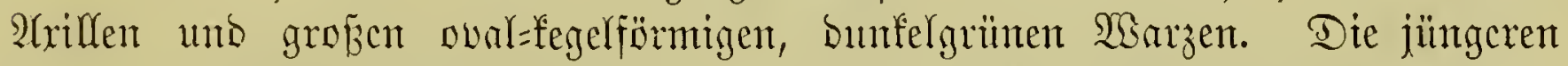

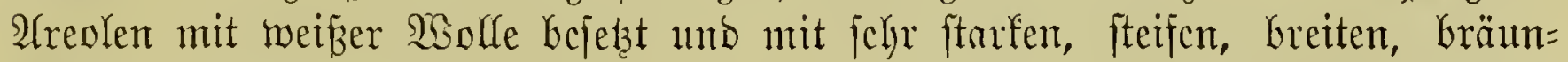

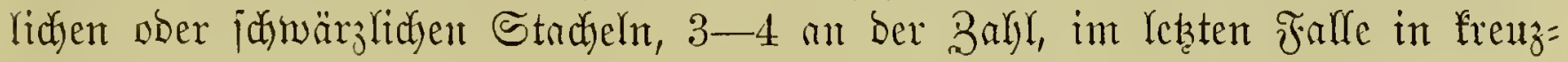
förmiger Stelfung.

B̧lüten bidyt um ben Edyeitel Kernm; bie gelblidy=neipen Fictalen mit rotem

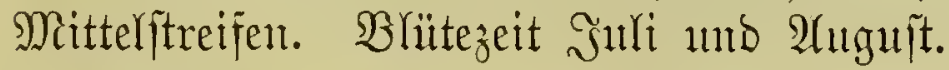

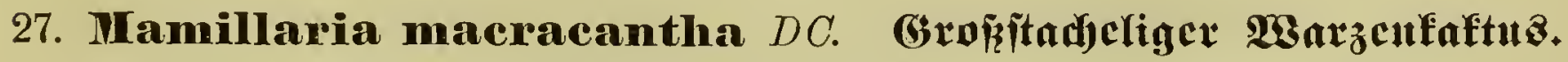

(M. recurva Lehm.)

Stamm fugelig, 10-12 cm hyod, mit ctwos abgeplattetcm Sdyeitel uno

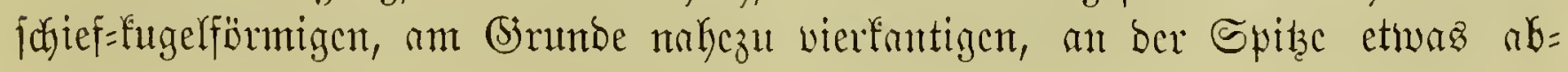




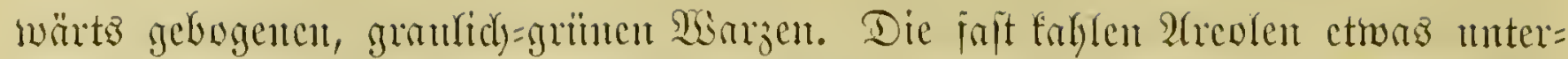

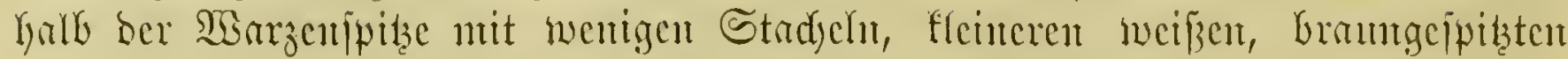

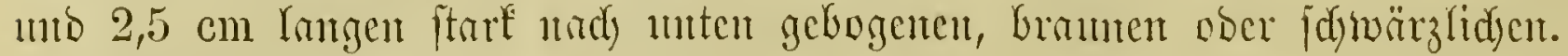

Blüten $2,5 \mathrm{~cm}$ breit, im Sircije 1 m ben Edyeitel berum, fyeffermuntot. Blïtejeit Mai-Smit.

\section{Mamillaria stella aurata Mart. Golditcult=:Barzenfaftuz.}

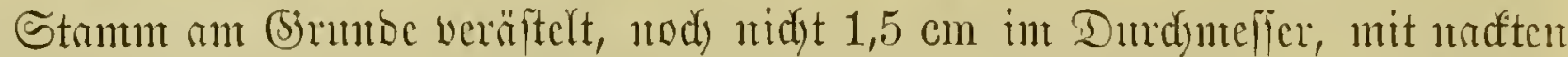

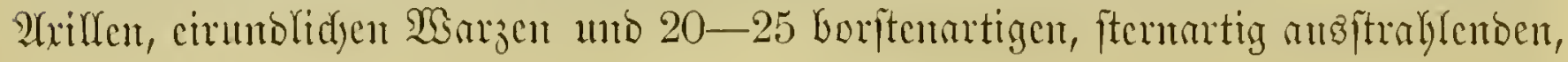

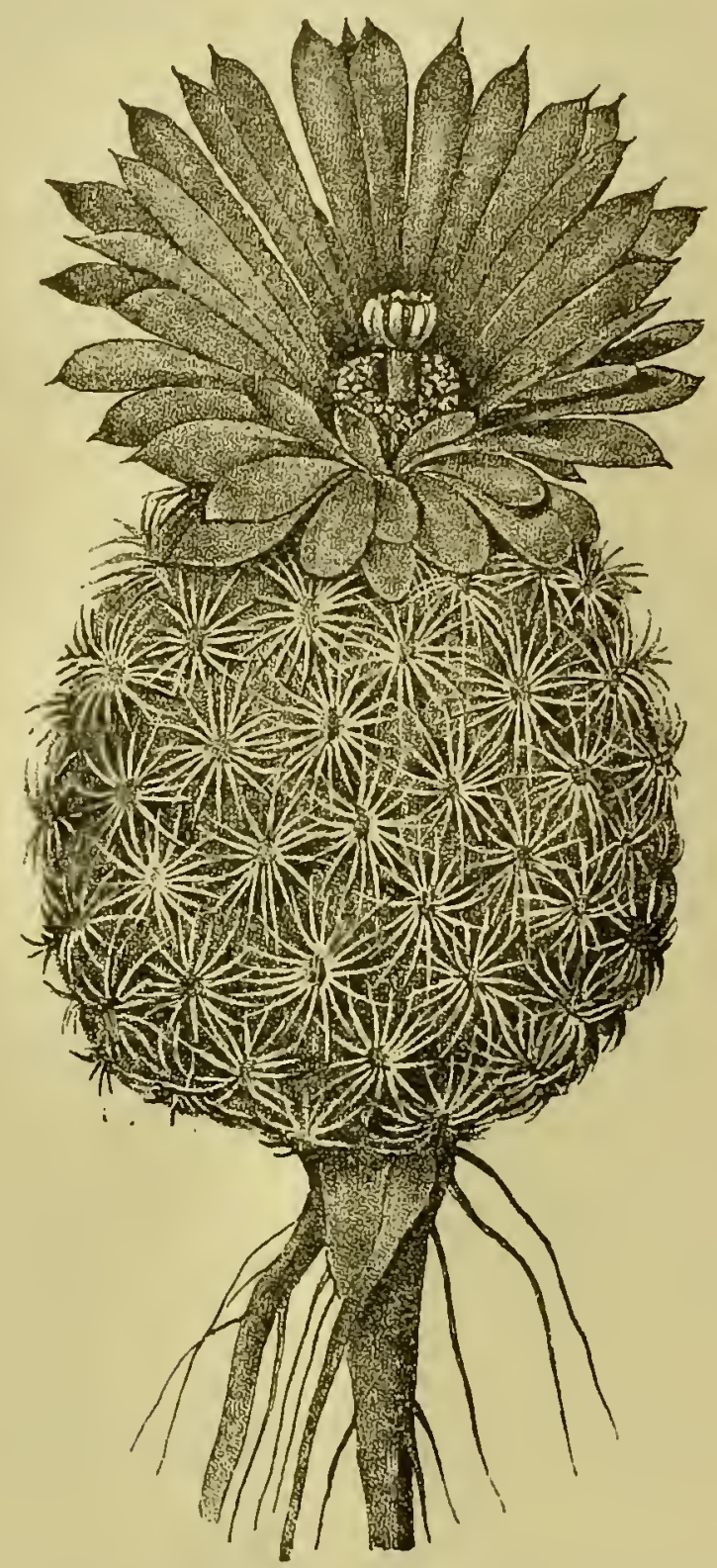

Fig. 115. Mamillaria pectinata Eng. Sammitad)lider $\mathfrak{W} a r_{j}$ enfaltus.

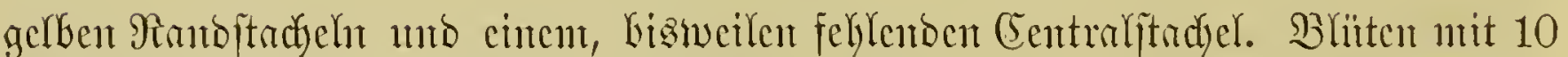

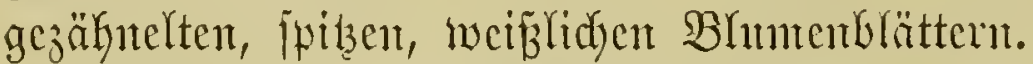

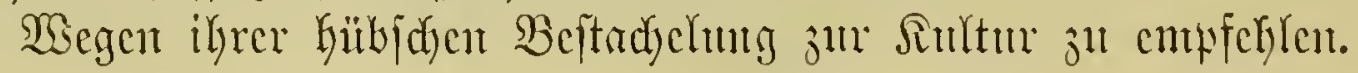

\section{Mamillaria gracilis $P f r$. Biculidfer $\mathfrak{B a r z a t f a f t u z .}$}

Stanmm $10 \mathrm{~cm}$ hody bei $4 \mathrm{~cm}$ Durdjnteficr, it jeiner ganjen Ränge

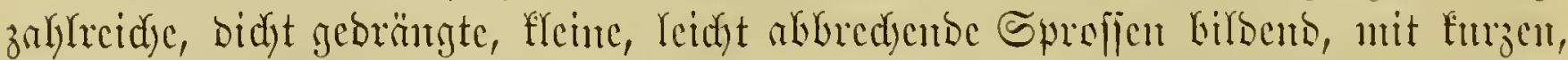

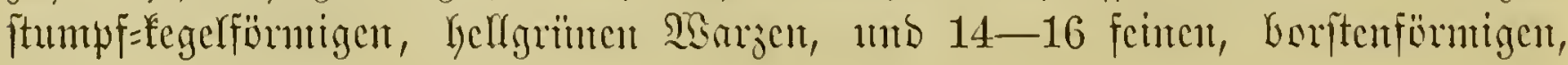




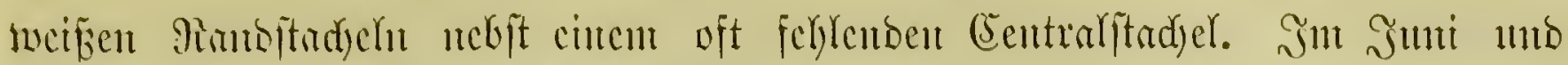

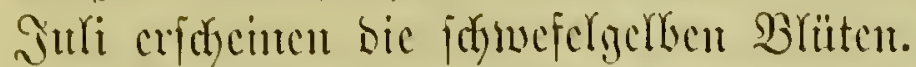

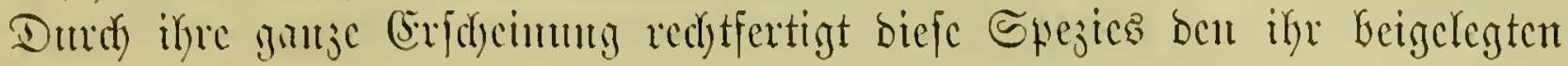
Mimitut.

\section{Mamillaria pectinata Engelm. Sianuitadicliger $23 \mathfrak{n} z \mathfrak{c u f a f t u}$.}

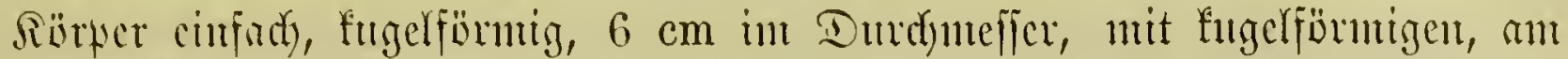

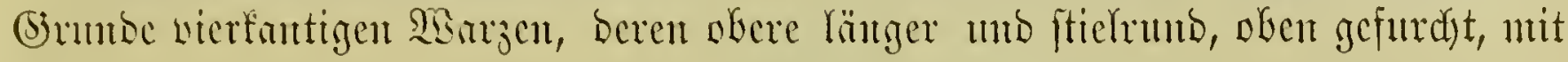

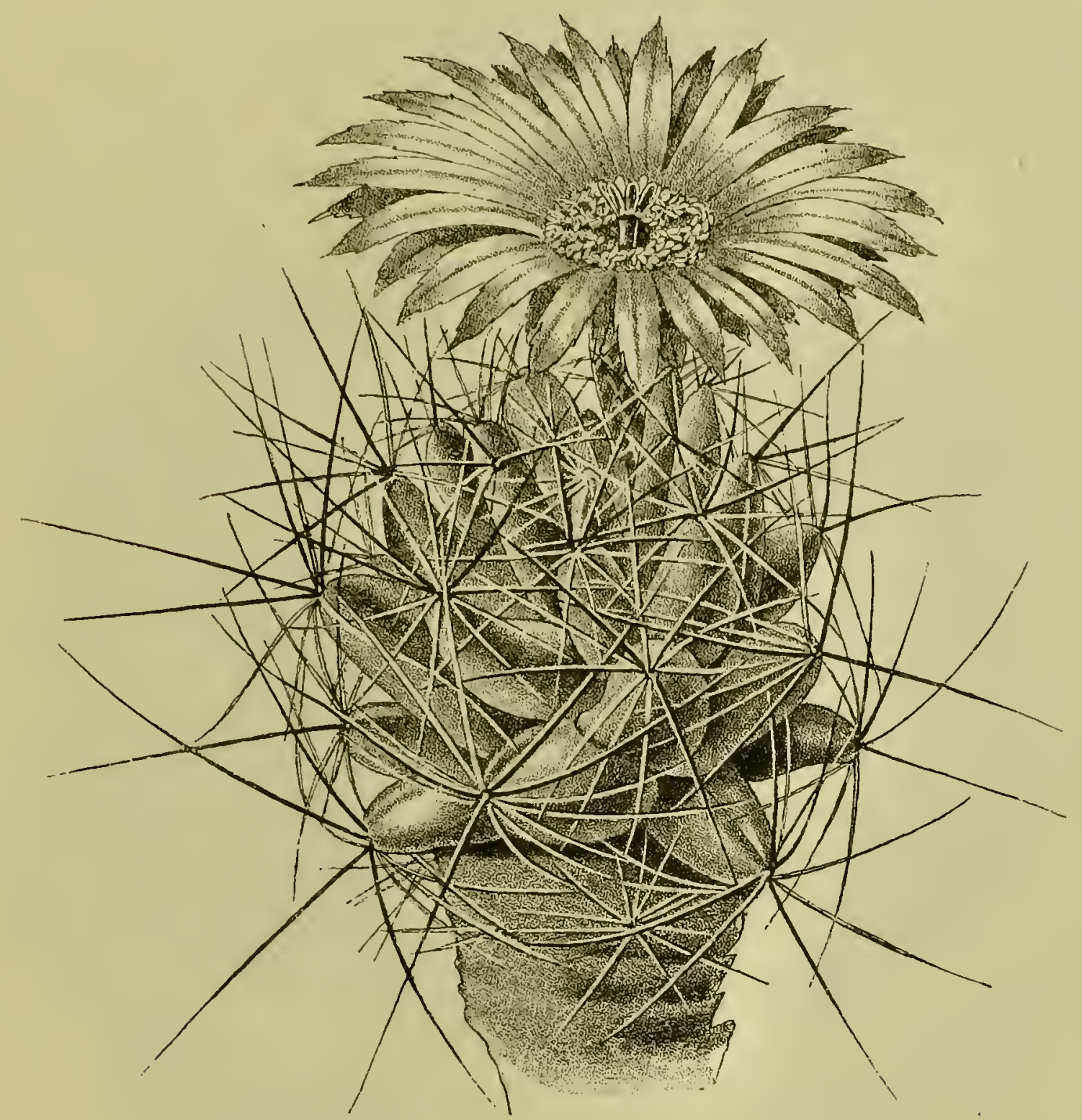

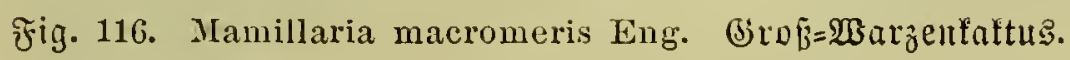

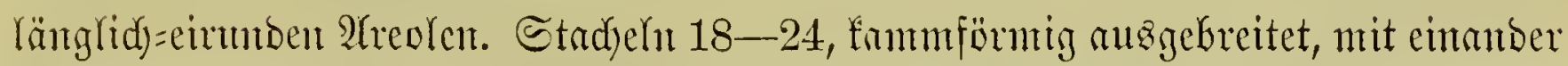

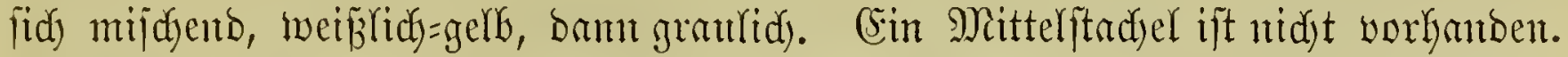

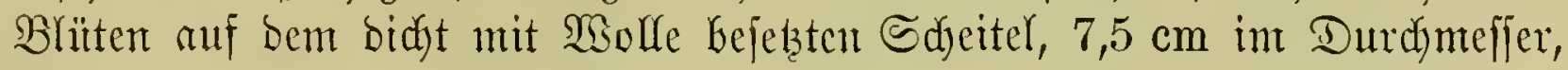

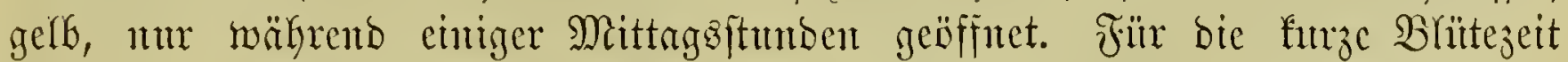

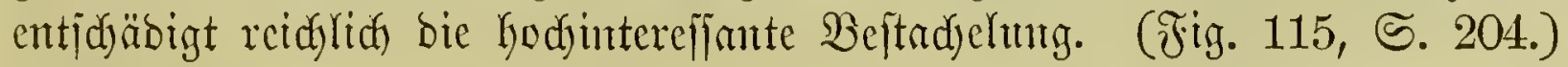

\section{Mamillaria macromeris Engelm. Groiz=:Marzenfaftuz.}

(Coryphantha macromeris Lem.)

Sö̈rper einfad, mur $5 \mathrm{~cm} \mathrm{hody,} \mathrm{cinmb,} \mathrm{nit} \mathrm{frei} \mathrm{ftchenben,} 3,5 \mathrm{~cm}$ Yangen, cylindrifden, anfredjten, etwas eimuärts gebogenen, anf ber wberent Seite von 


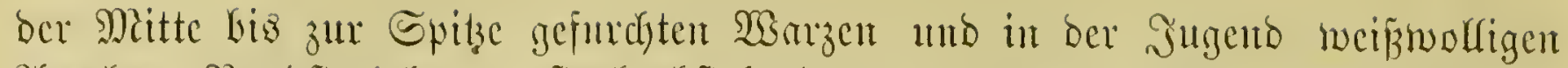

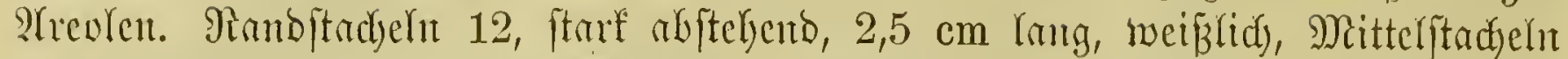

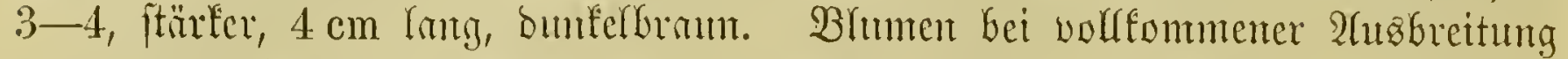

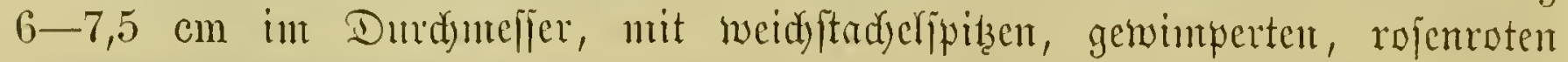

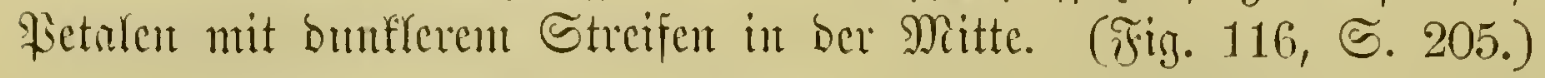

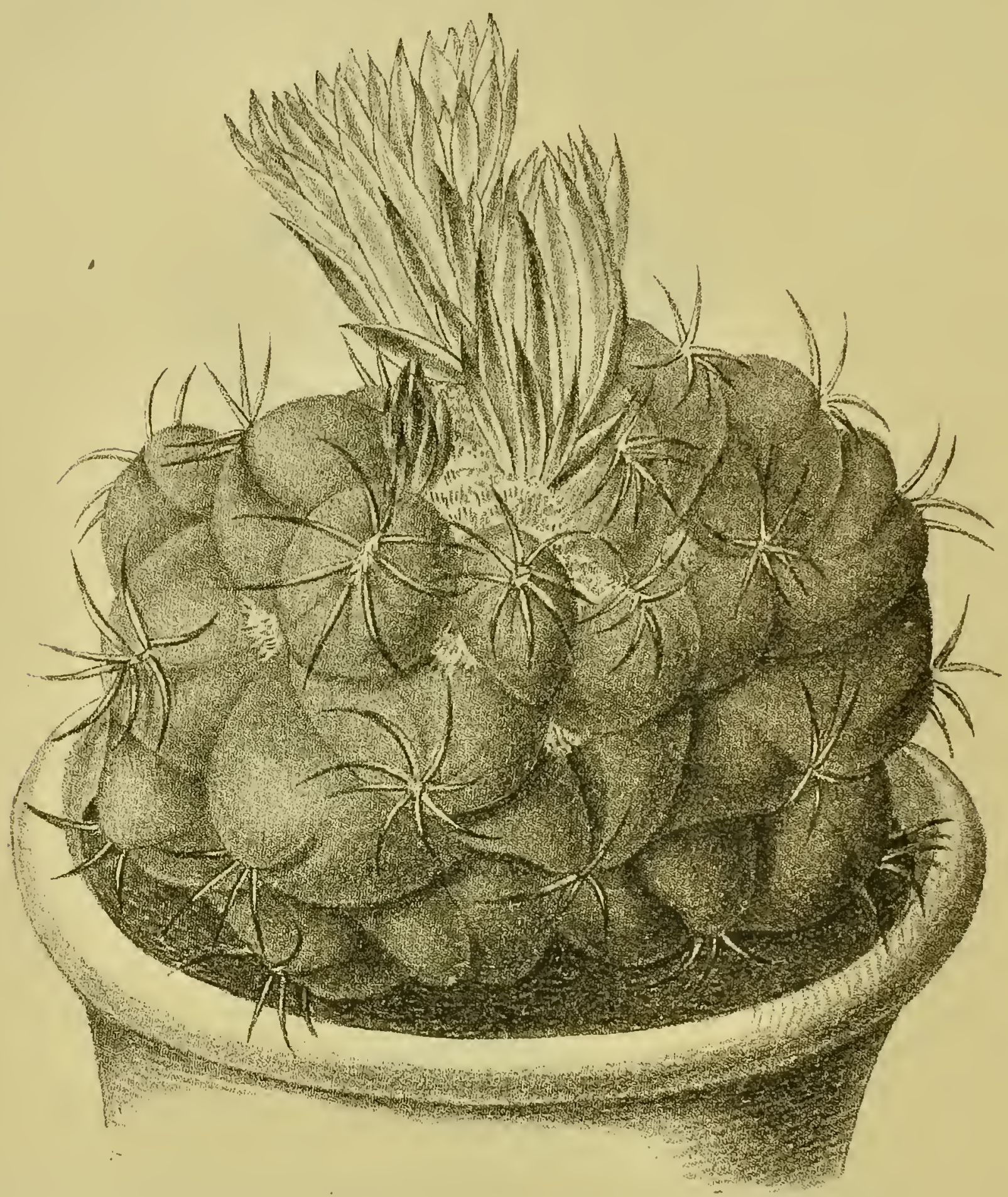

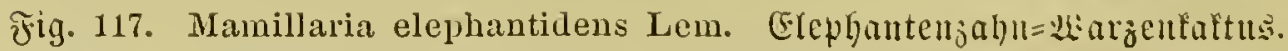

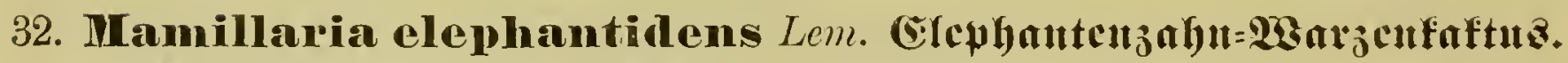

(Mamillaria bumamma Ehrenb., Coryphantha elephantidens Lem.)

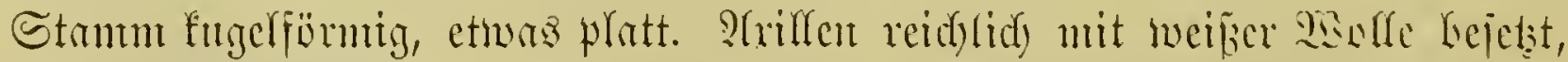

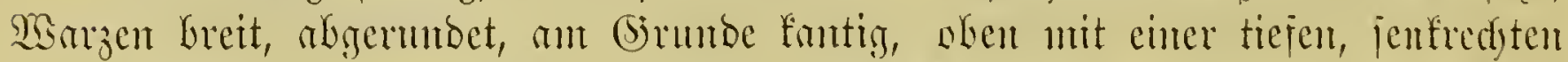

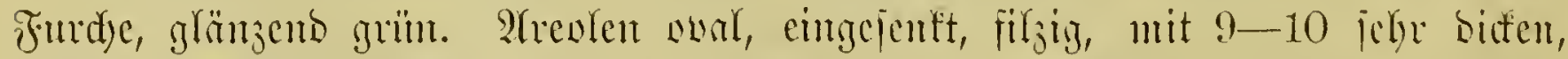

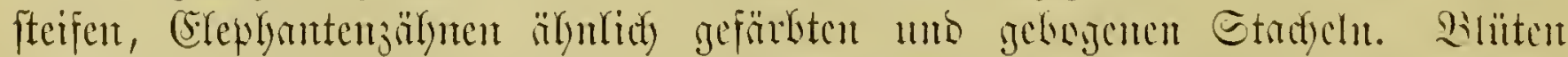

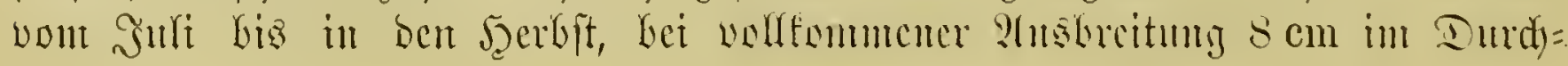




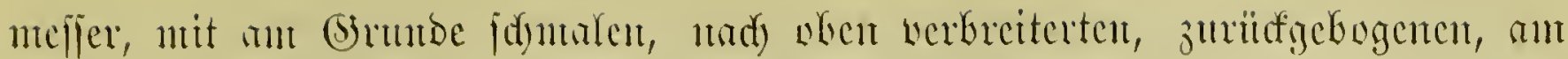

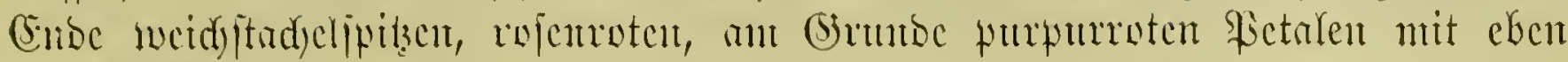
joldyer Mittellinic. (J̈tg. 117, S. 206.)

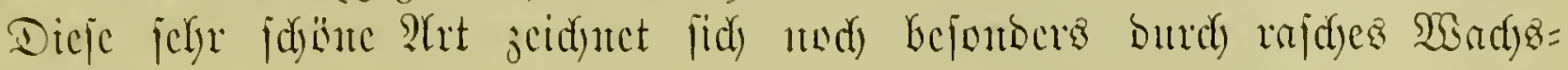
tแแนเ ณแษ่.

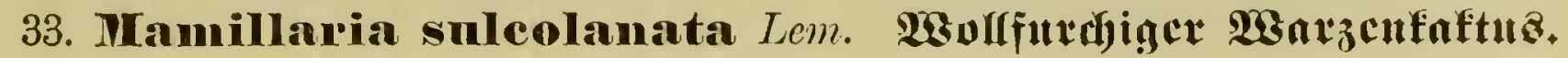

(Coryphantha Lem.)

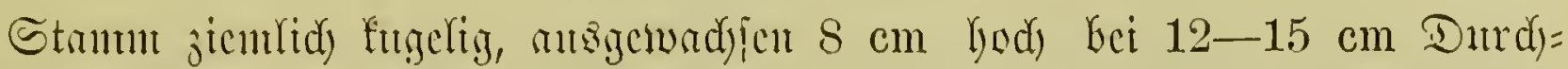

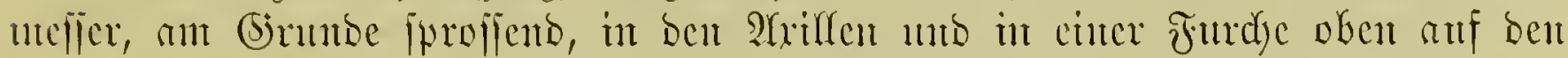

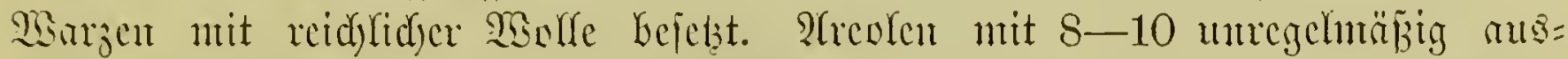

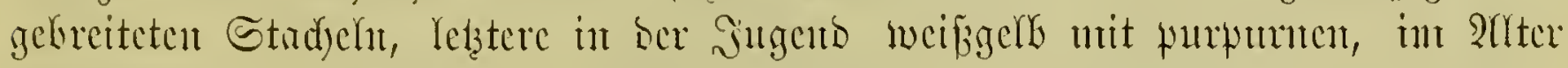

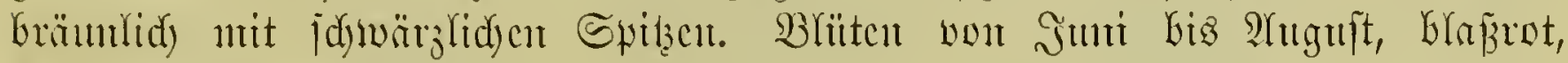
frecin unto minbebentents.

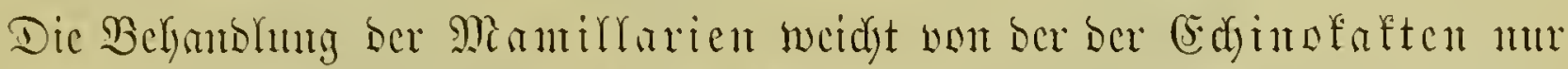

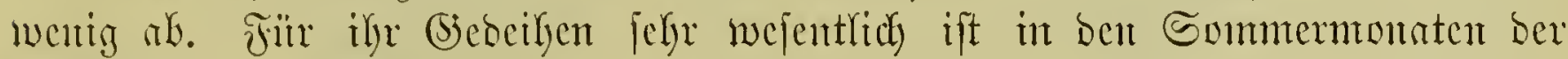

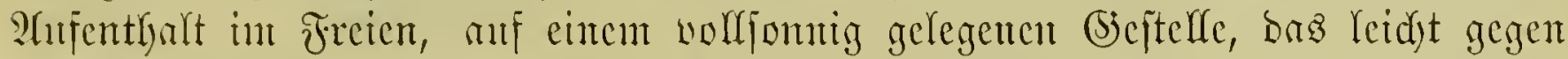

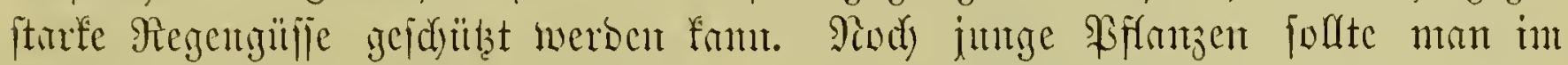

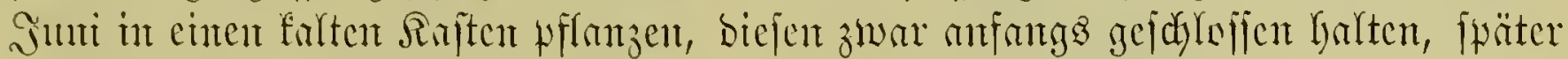

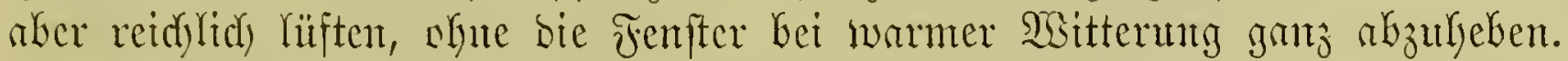

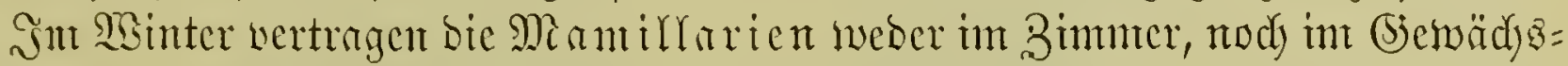

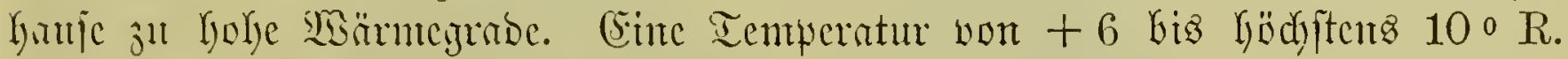

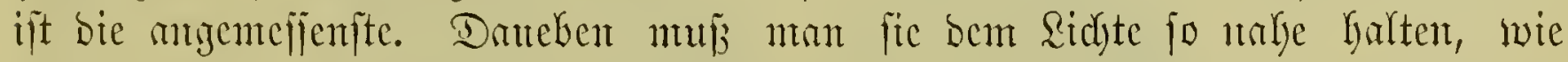

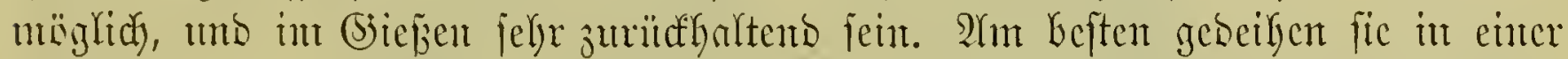

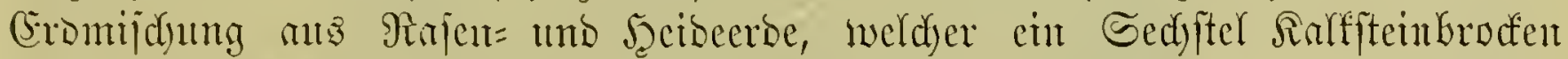

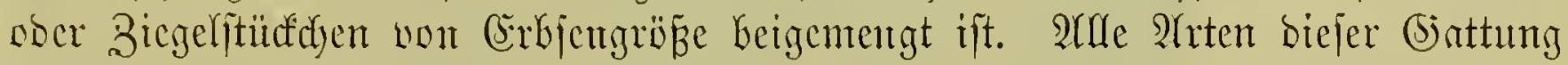
follten unt flad gepflangt werben.

\section{Battung Pelecyphora Ehrenberg. Alijelfaftus.}

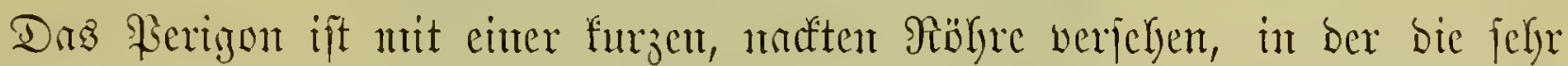
zahlreidyen, ausgebreiteten, Den Perigumanu nidyt erreidjenten Strubbrätter an=

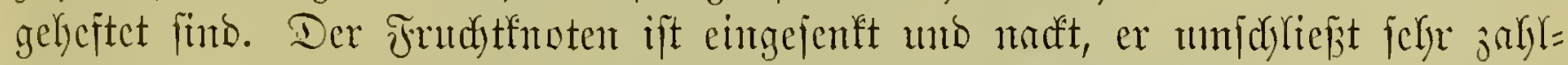
reidje Santentanlagen. Die Frudyt ift eine oblonge, fpitze, fleijdyige BBecre, welde

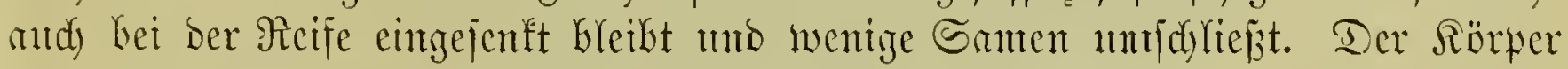

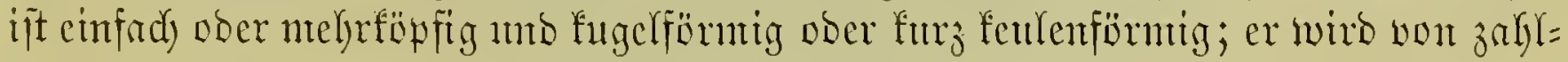

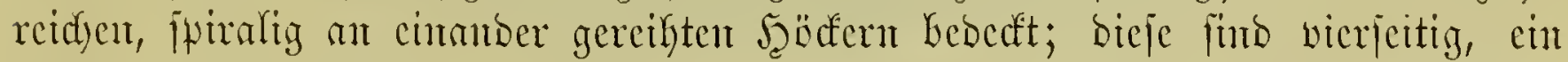

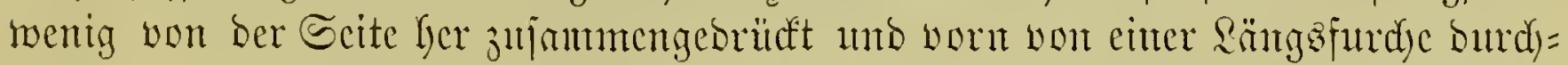

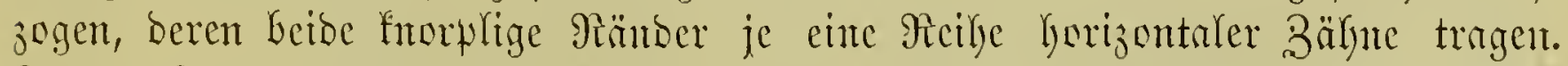

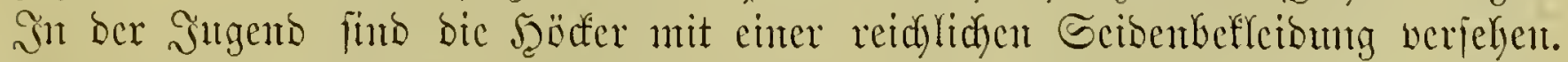

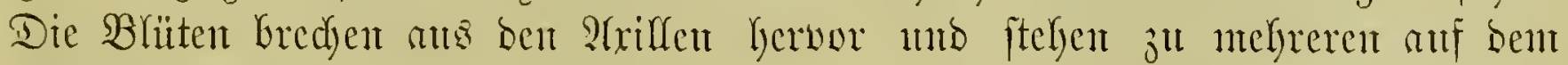
Sdyeitel.

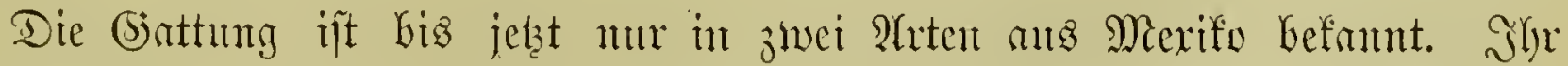

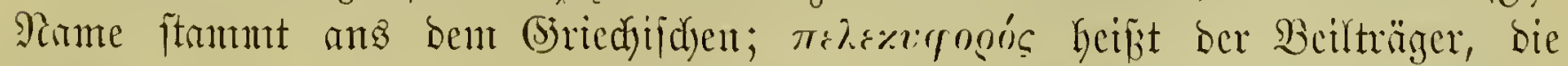

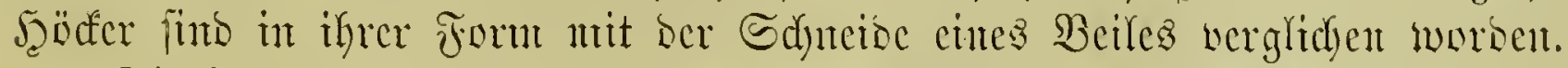

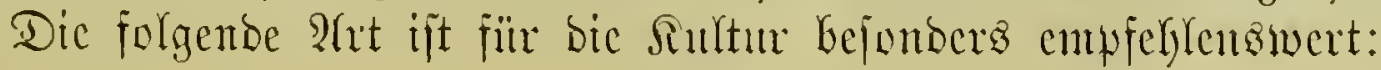




\section{Pelecyphora aselliformis Elrenb. Alifelfaftur.}

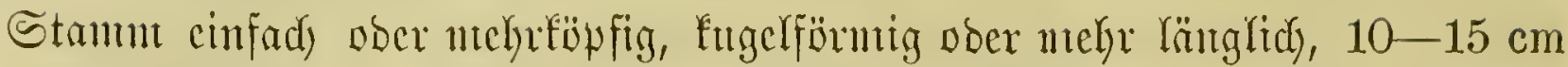
lodd, graulidy=grün, auf bent Edycitel ctwas gebrïuft und genabelt. Wasarzen fpiralig georbutet, bidjt gebränigt, an ber Bafiß verbicft und rantenförmig, bann

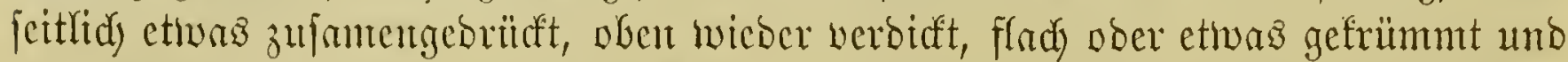

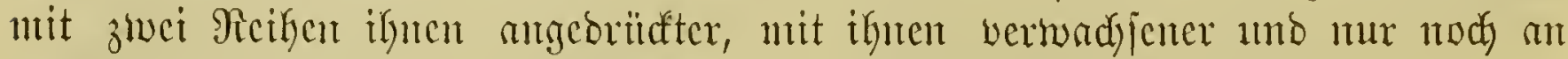

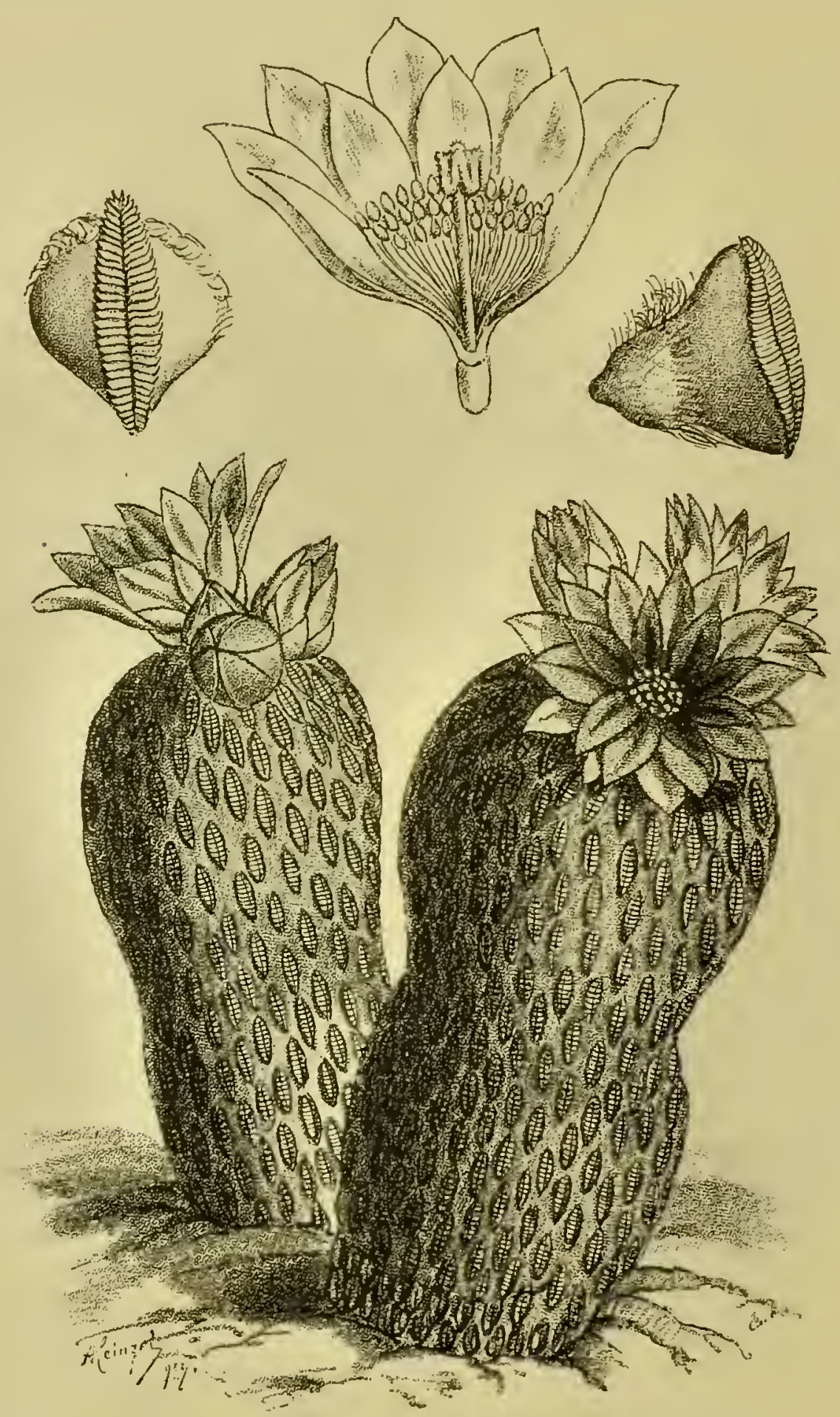

Fig. 118. Pelecyphora asellifurmis Lhrenb. Mifelfaftus.

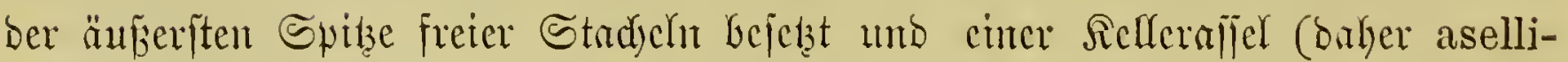

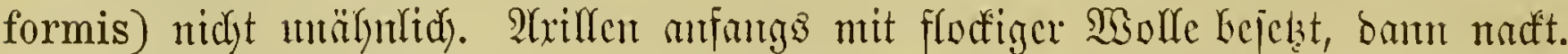

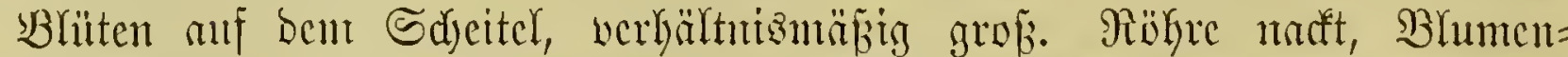

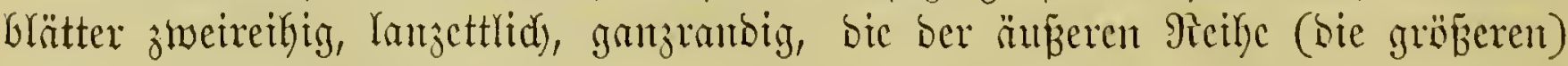

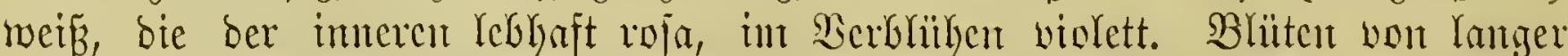

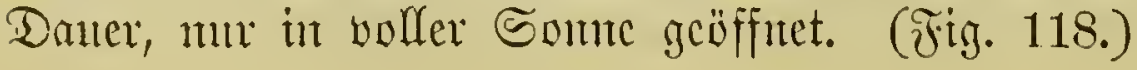


Var. concolor unterjocidet fidy wou ber Strmmant mu burdy bie cinfarbigen,

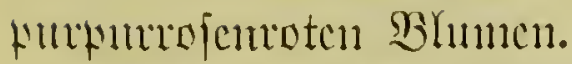

Diejer in jeber Bejiehung föbue Sortus ift jur Sultur jebr cutpeblenswert.

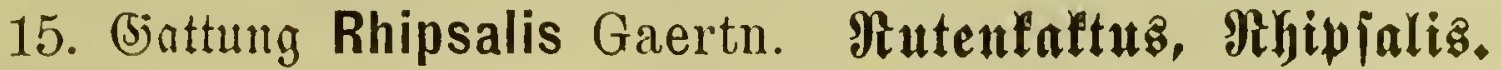

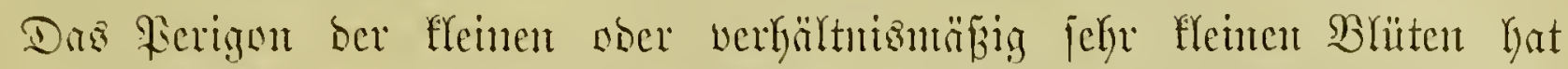

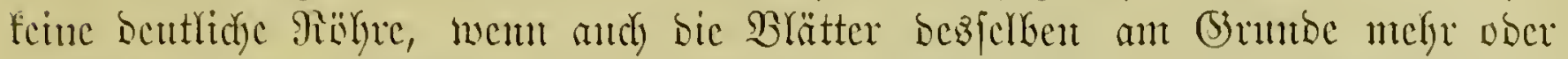

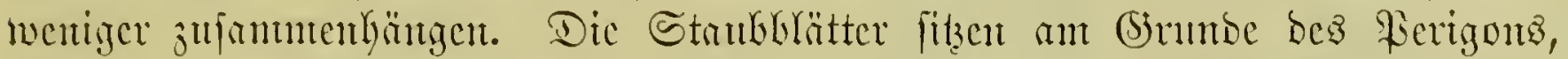

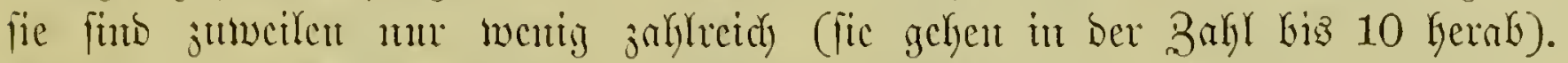

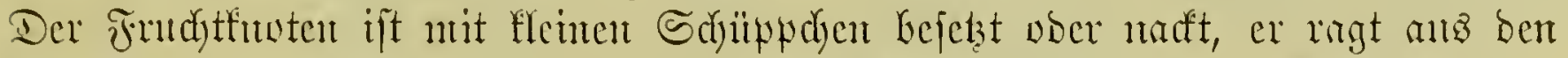

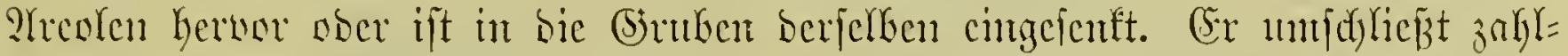

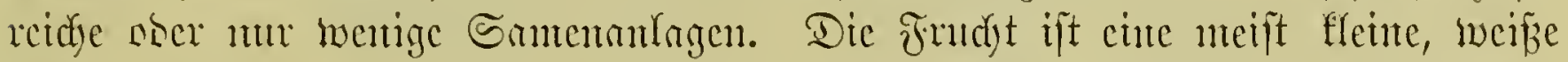

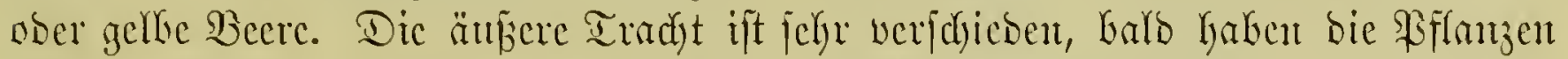
Ginbfabcurtige, werjweigte Stengel, barb find fantige, bals blattartig werbreiterte,

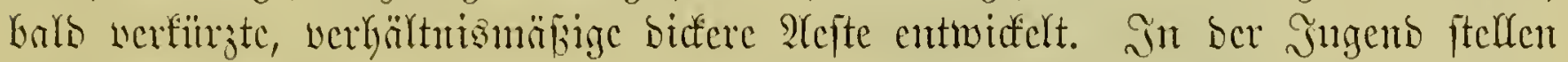

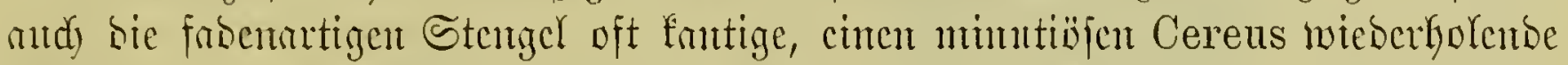

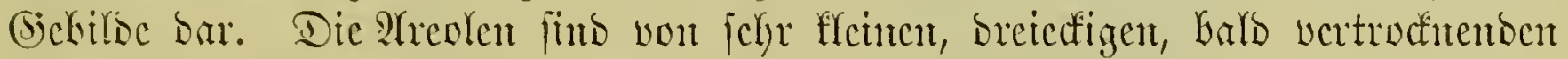

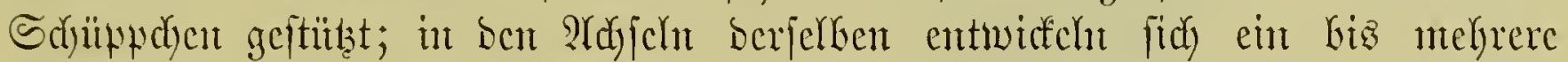
borftentartige, furje Stadyeldyen, bie ans einer ntefr ober weniger reidylichen

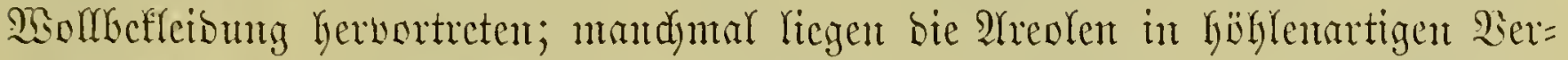

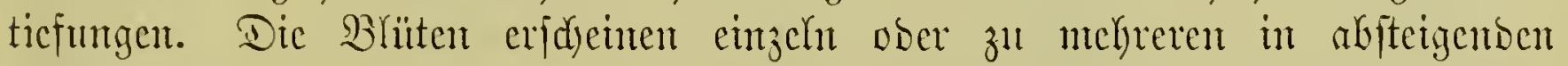

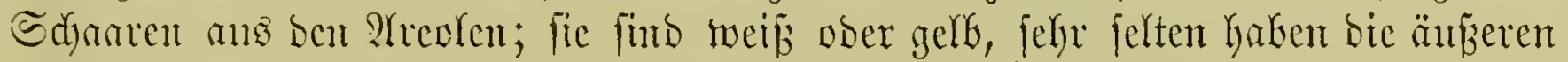
Blätter cinten purpurroten ?ִuffug.

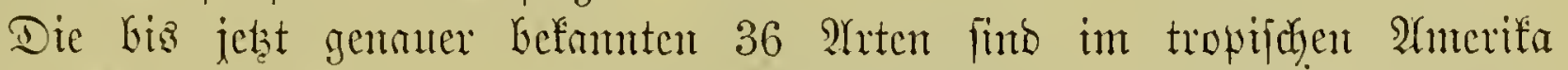

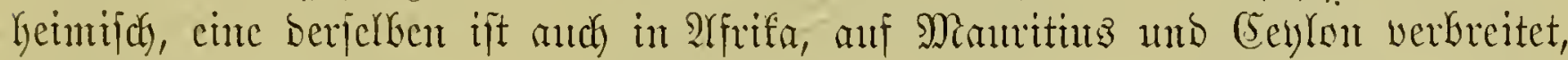

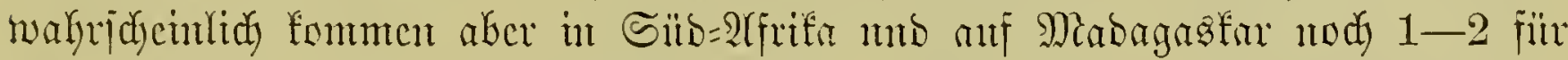
bieje (biegenten eigentümlidye âten wor. Sie wadjen als spiphyten anf Säumen, gescifyen aber auch an wöltig fterilen Felfen.

\section{Sぬlïlfel für die bejhriebenen Urten.}

A. 2rule Ueite wenigitens ipäter ftielrumb, hängend

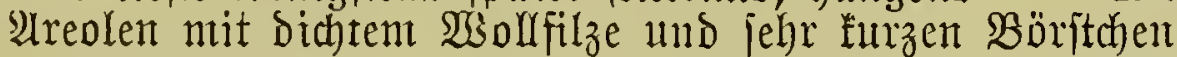

I. Reife Teretes S.-D.

1. R. pulvinigera $L d b g$.

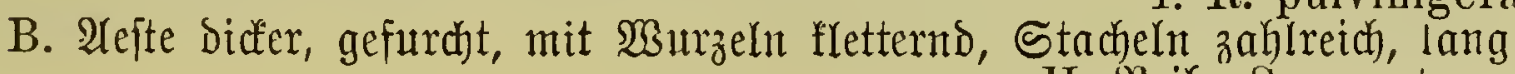

II. Aeife Sarmentosae S.-D.

C. Áte blattartig verbreitert

a) 2Yefte grob gezähnt mit beutlichen Mittel= mo Seitennerben

b) $\mathfrak{A}$ eite geferbt.

3. R. Houlletii Lemaire.

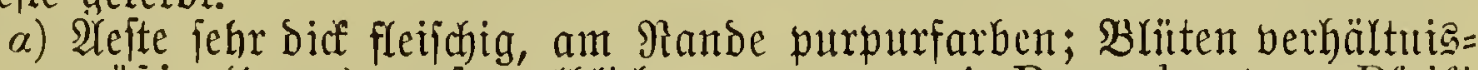
mäвig $(1 \mathrm{~cm})$ großs, gerblich

4. R. pachyptera Pfeiff:

ア) Ilefte lederartig, grün; Blïten llein (höbftents $7 \mathrm{~mm}$ lang) weib́.
I. Sefte ant siande flach
II. Hefte am Sande fraus
5. R. Swartziana Pfeiff.
6. R. crispata Pfeiff.

\section{Rhipsalis pulvinigera $L$ indl. Politer tragenter Mutenfaftuz.}

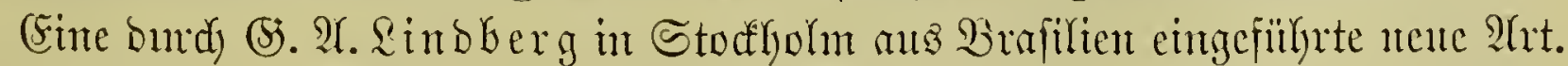

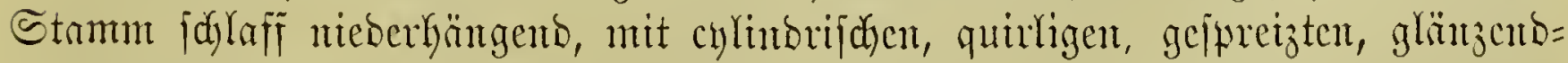
bunfelgrünen, mur 3-4 mm jtarfen $\mathfrak{A c j t e n . ~ F o l j t e r ~ i n ~ r e g e l m a ̈ ̈ ̈ i g e r ~ S p i r a l e , ~ j u x ~}$ 


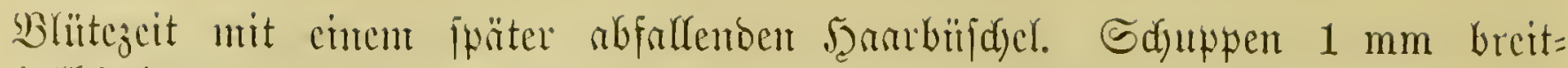

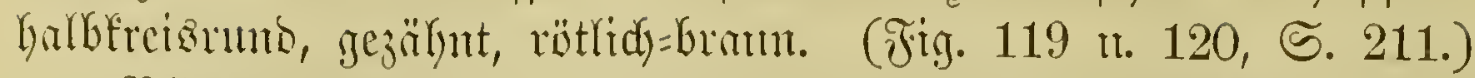

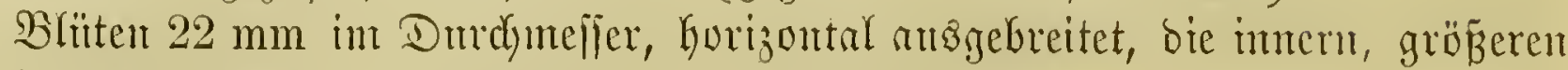
Fetalen weif́, getbgrün angehaudst, bie äm

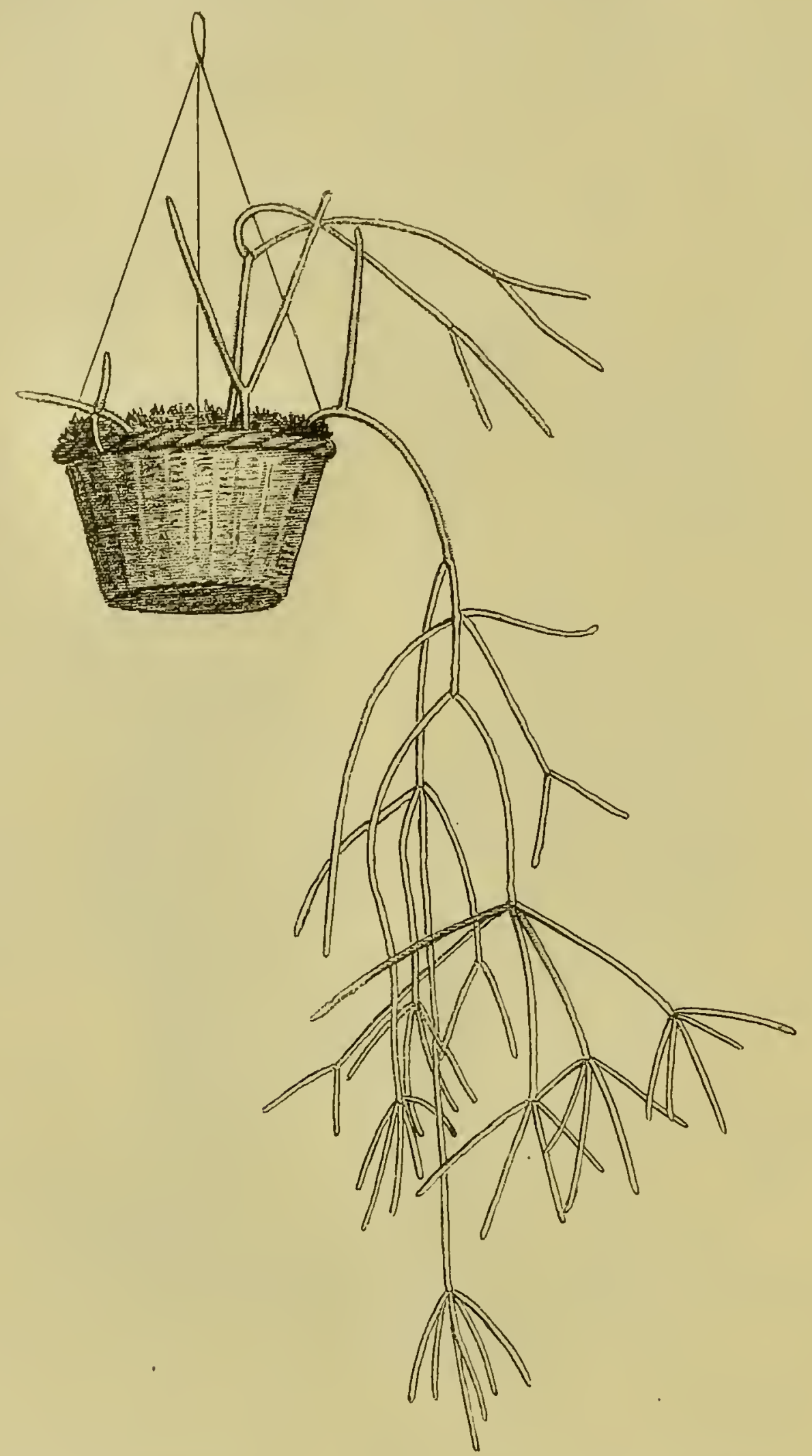

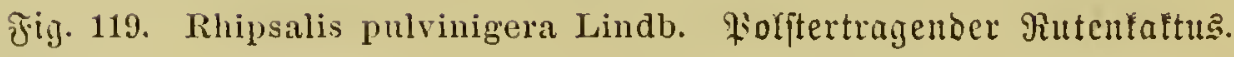

\section{Rhipsalis sarmentacea Otto et Dietr. Banfeubcr Butenfaftus.}

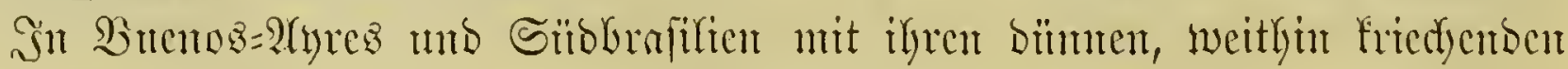

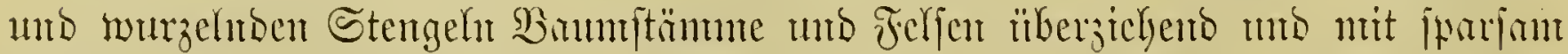

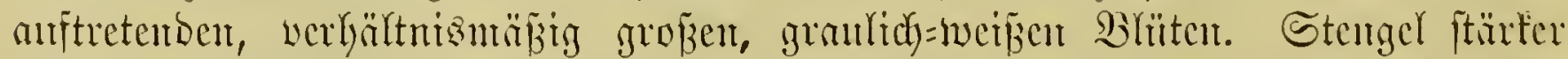

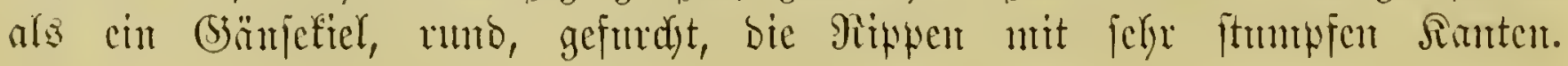




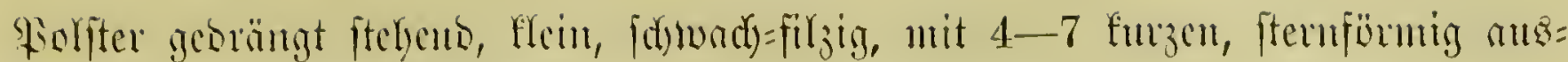
gebreiteten, dïmen Burten.

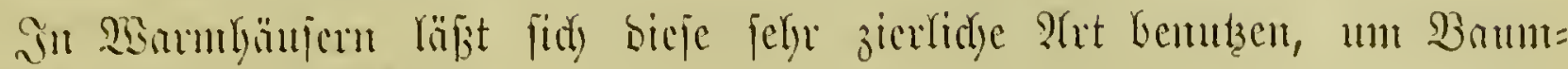
ftïmme bantit jull liferffeion.
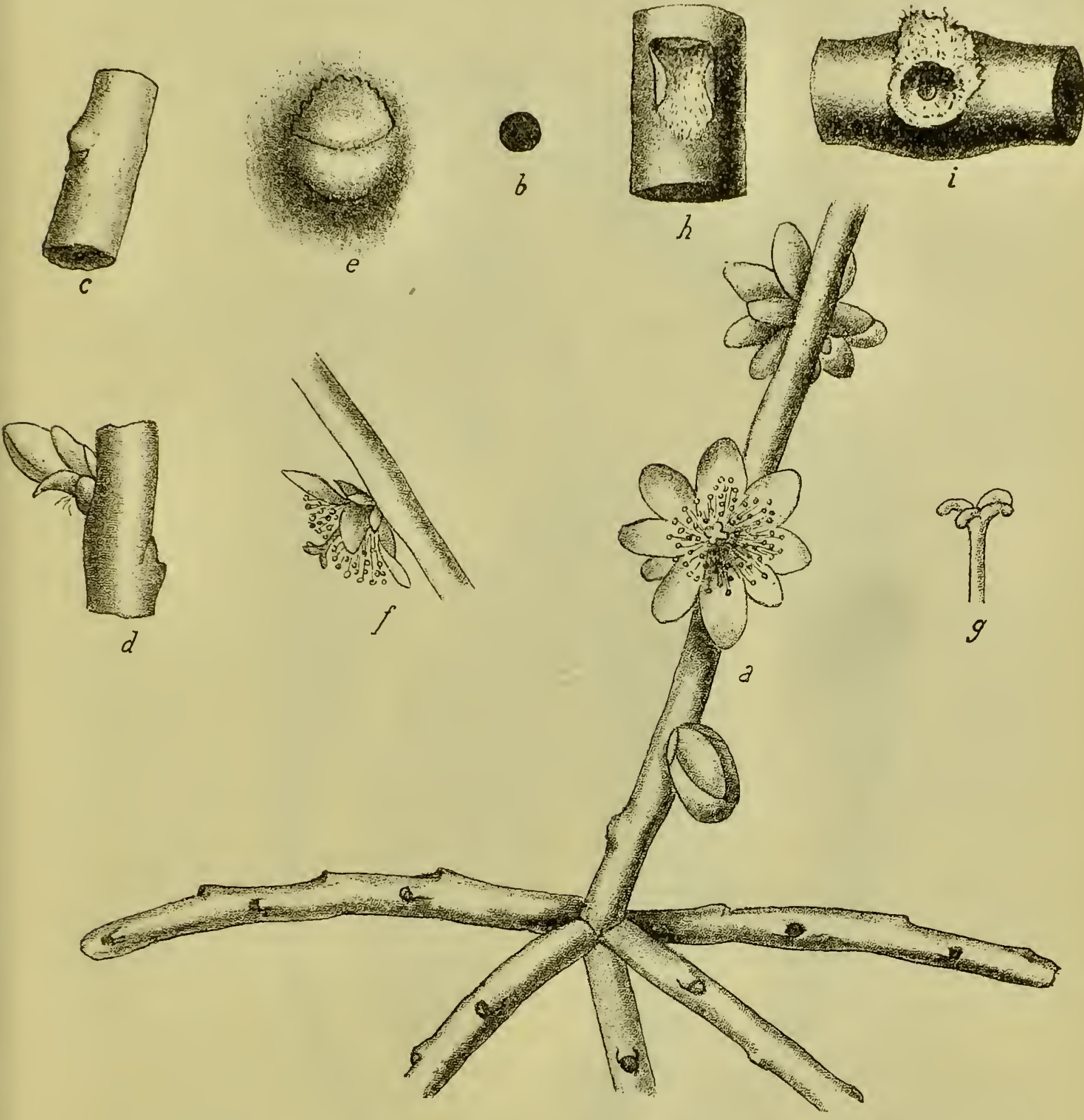

Fig. 120. Rhipsalis pulvinigera Lindb. Folftertragenber 9intenfaftus.

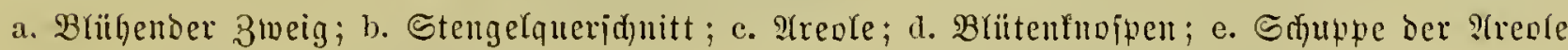

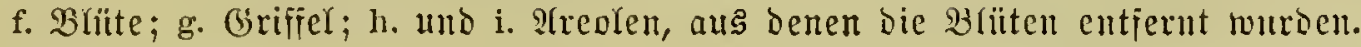

\section{Rhipsalis Honlletii Lem. Soulfet'z Hhipjaliz.}

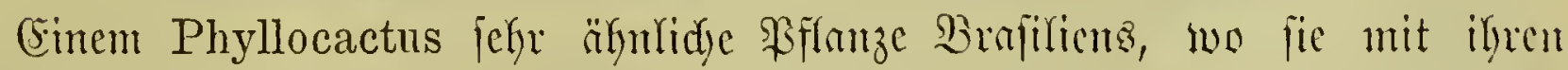

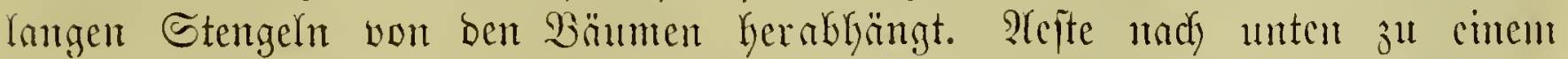

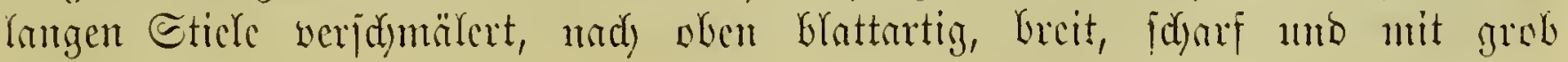




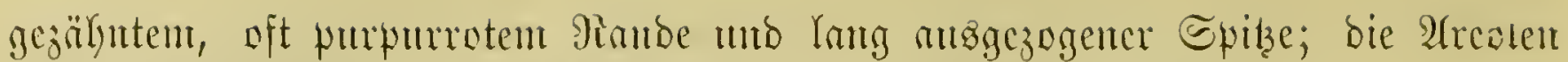
in beu Butdent won eiucr breifeitigen Edjupke geftitizt. (Fig. 121.)

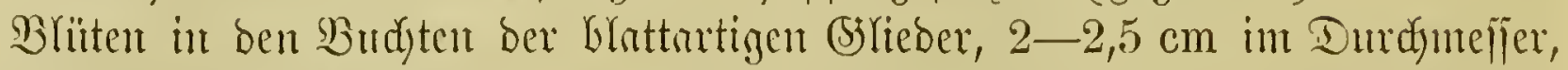

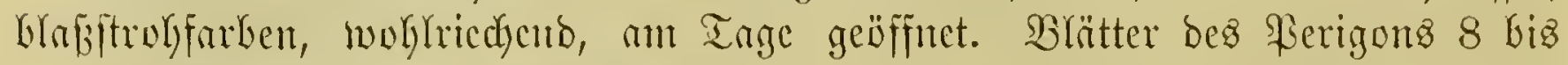

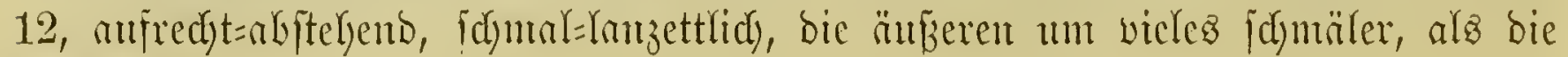
innererr.

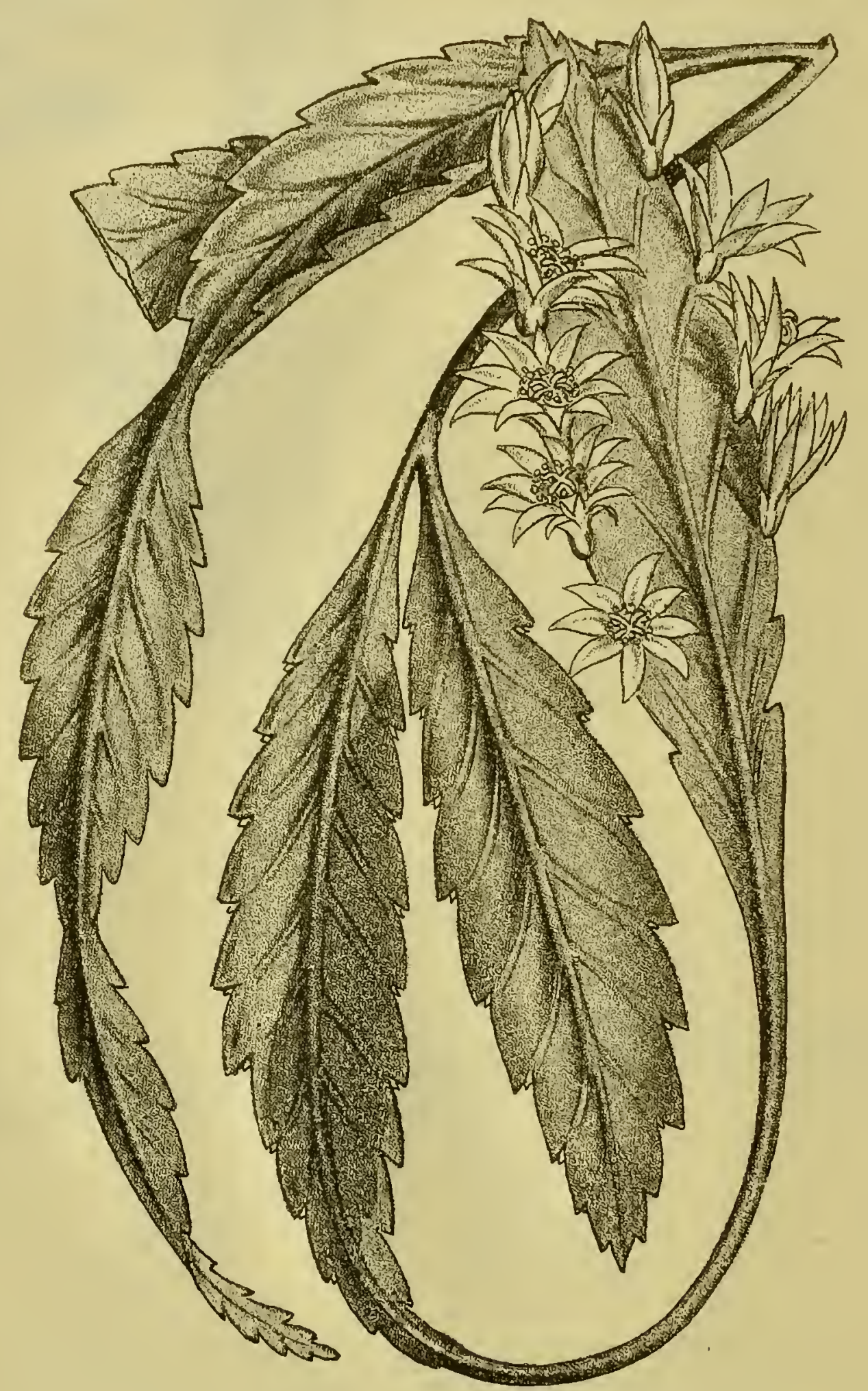

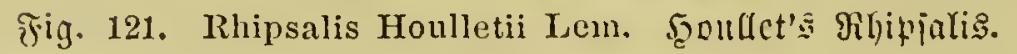

\section{Rhipsalis pachyptera $P f r$. Dirfglicberiger Mibipjaliz.}

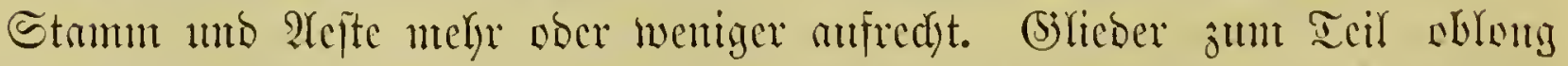

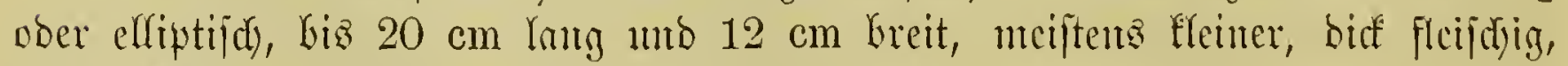
sft ftark geripst, geferbt, grium, am Rambe rot. 


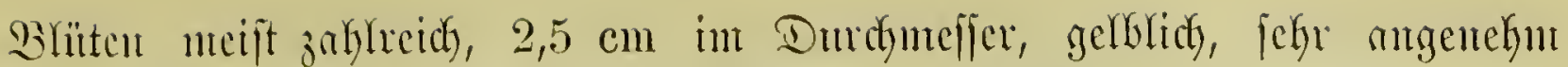

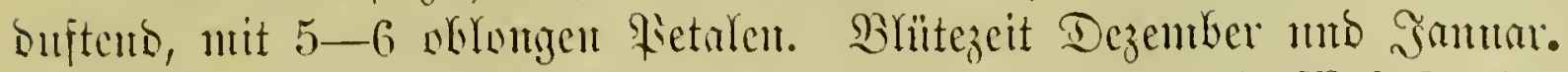

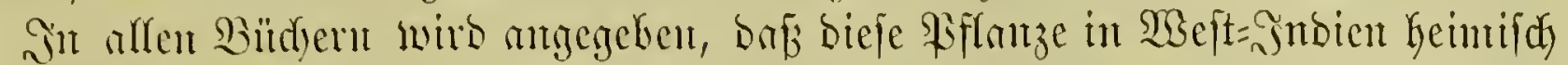

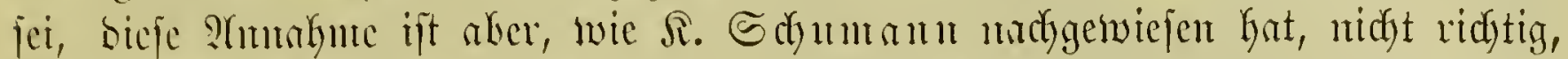

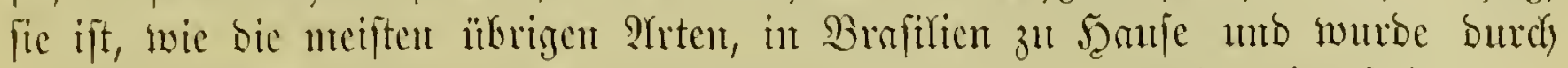

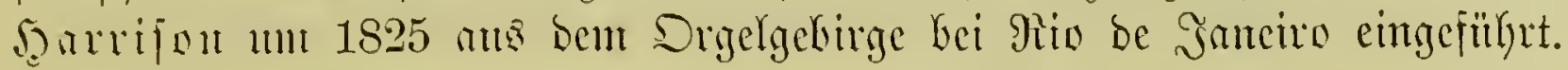

\section{Rhipsalis Swartziana $P f r$. Gumx' Rhipjalis.}

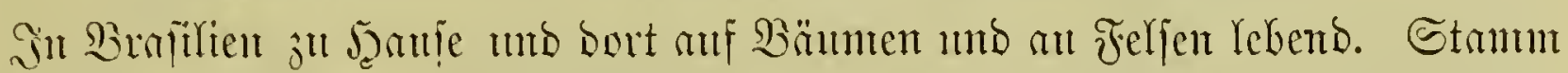

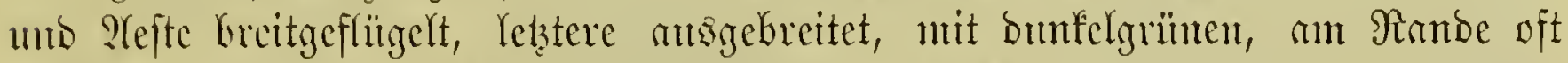

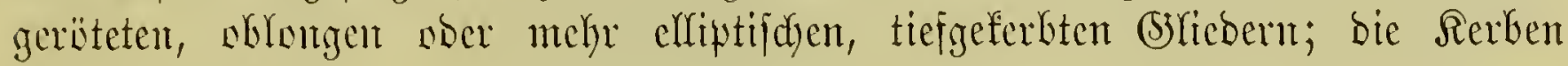
ipriter gand forkgl.

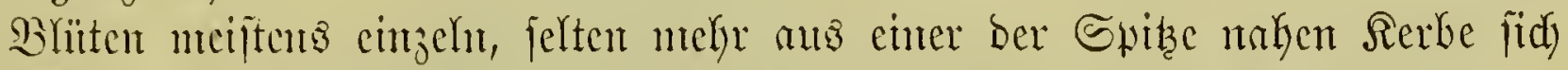

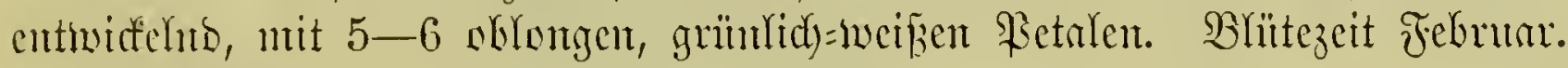

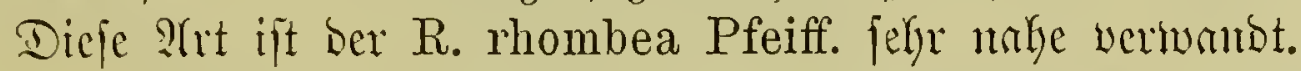

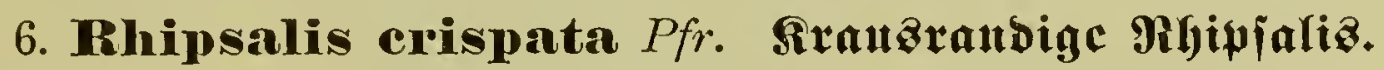

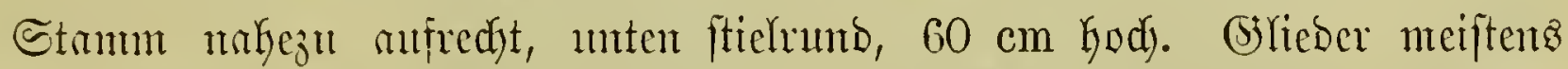

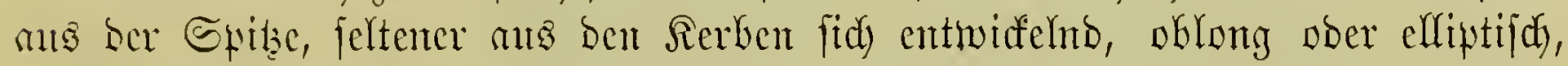
reberartig, tief geferbt, mit frmilem Rambe, getblids=grün.

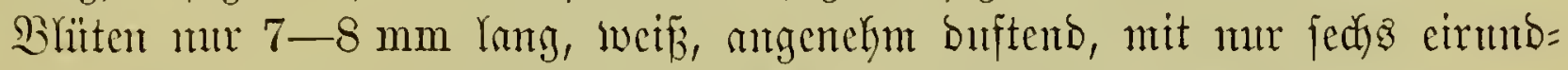

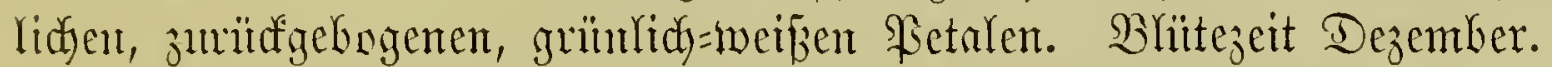

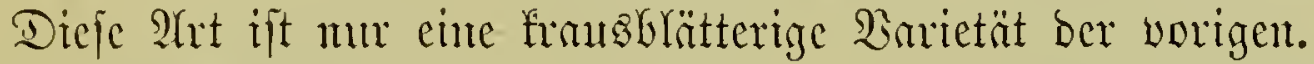

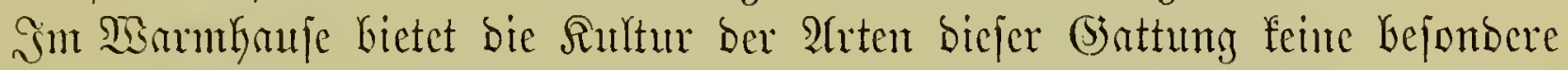

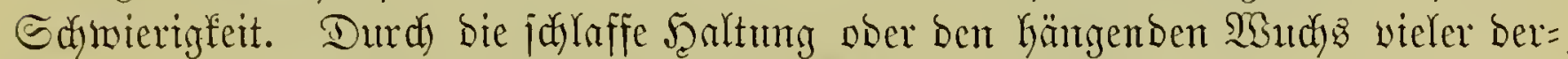

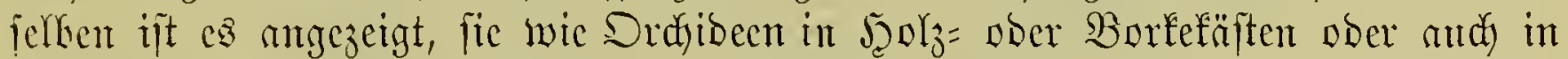

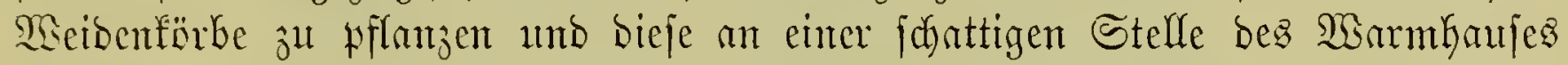

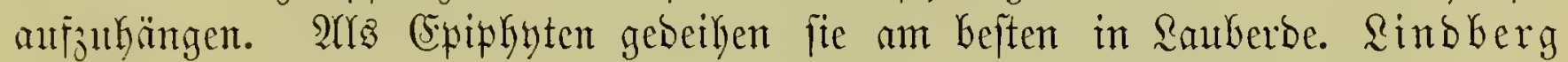
curpfichlt, bie Sïorbe ober Räften innen mit Moos zu überfleiben und fie bann

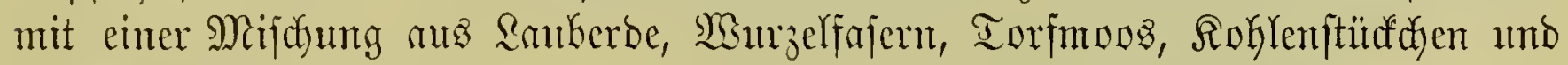

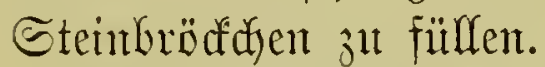

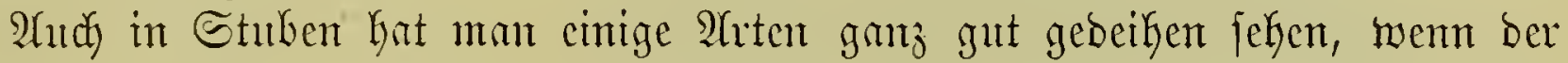

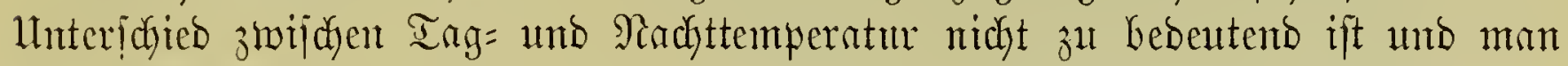
Durd Bejprizen ber Rörbe u. j. w. für ctwas feutute Ruft forgt. Rinbberg empfiefly für Stuben bie vbent bejurticbene Rhipsalis pulvinigera Lindb.

\section{Bsattung Opuntia Tournef. Feigenfaltıts.}

Das Ferigon ift ftrahlig, aufredyt, ant (5irunbe nidyt röhrenförmig, wenn aud bie Brätter bort zufmmmenfängen. Die Strubblätter find jefr zahlreid

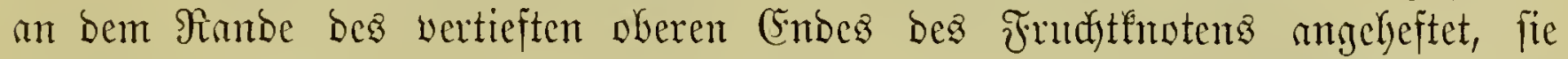
find fürzer als bas Berigon, zuncilen fint fie am Brumbe verbunben. Der

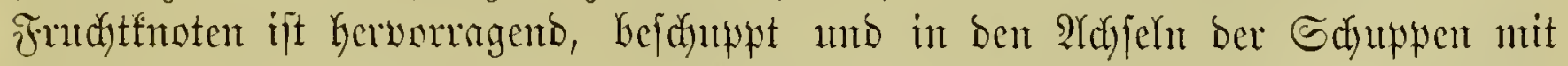

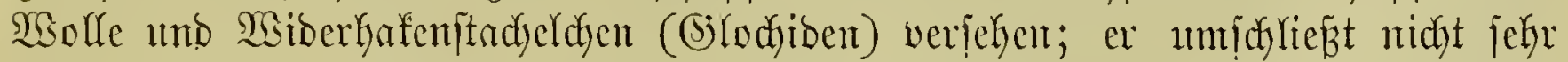

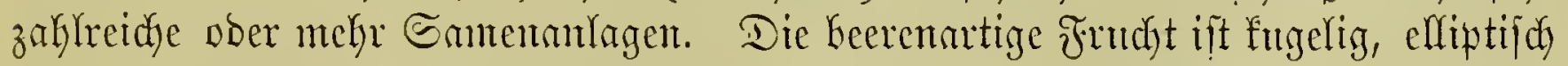

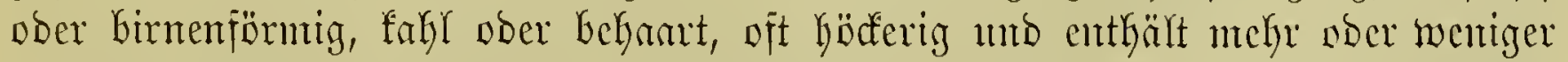
zahlreidye Eamen. - Etrüudjer doer SBänme mit fladyen ober rumben, bejtadyelten 


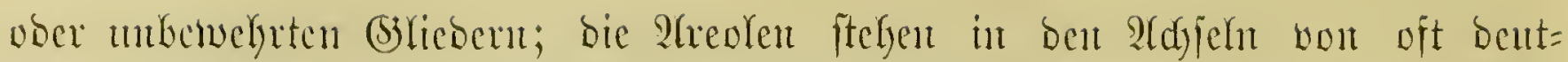

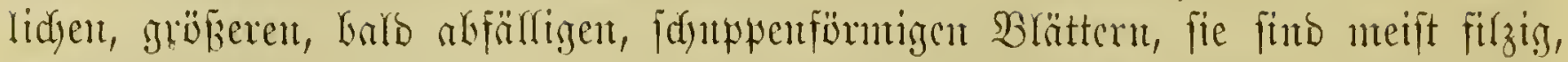

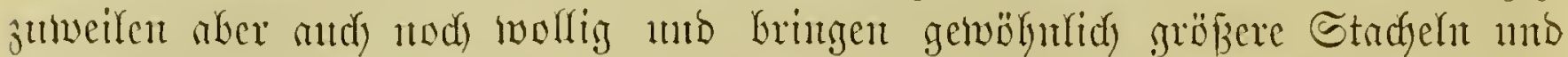

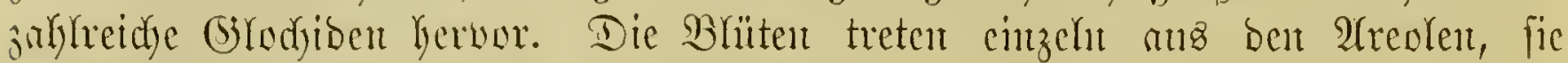
finto jutweifen anjehntidy unto jäün gefärbt.

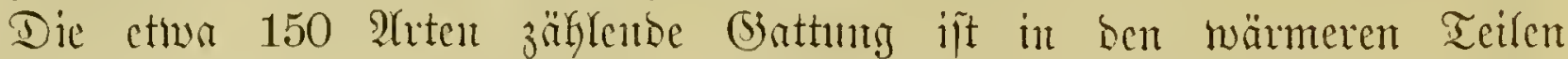

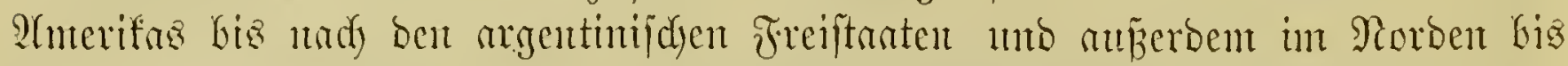

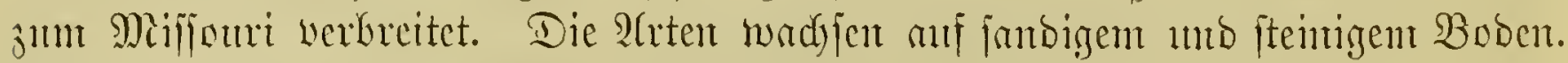

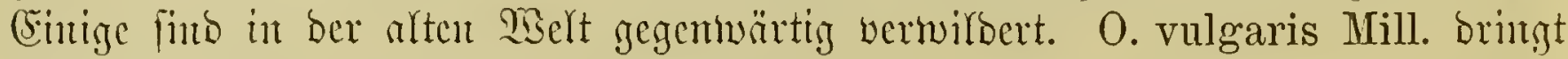
fogar bis Sild =Tyral wor.

Der Rime leitet fidy won bent Ramen jenter Teile bes Rofrifden Ranbes in

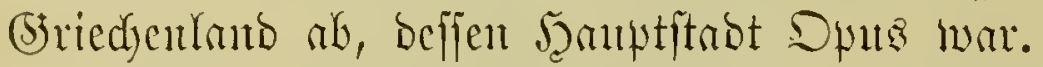

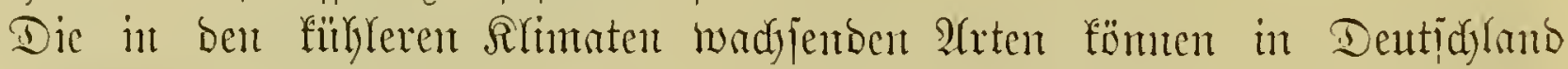

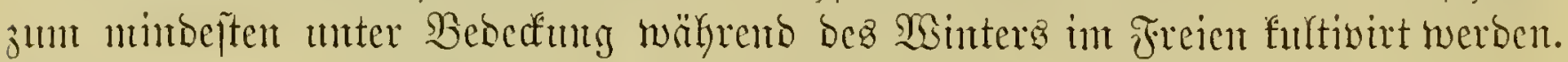

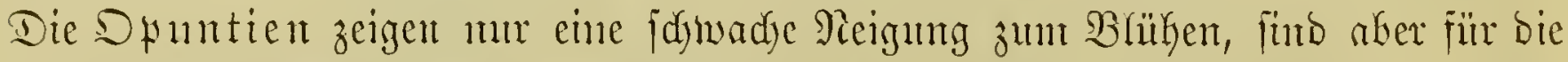

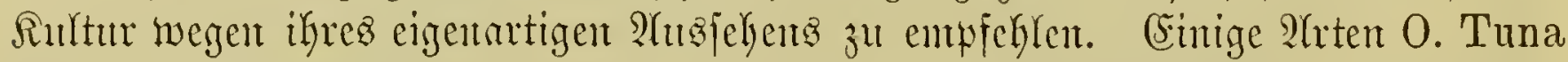

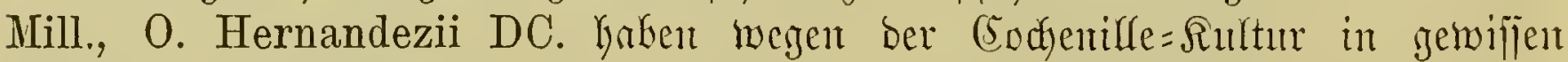

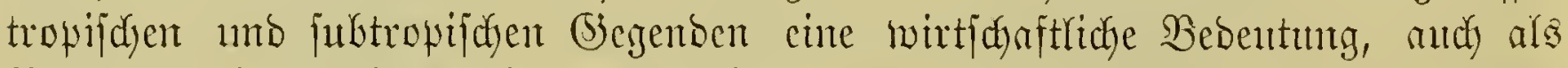

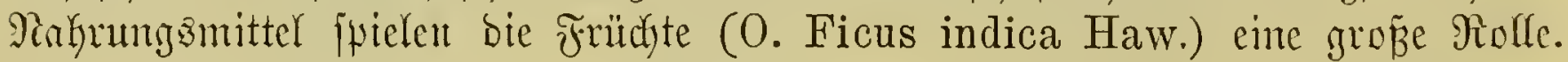

\section{Sđlïffel für die befdriebenen 2rten.}

A. Straff auffrechte, hokhe, vicl veräftelte Sträud̆er.

a) ISlieder elliptifich oder eiförntig, flach.

a.) Stacheln 3, Stadelpoliter zientlidy gedrängt 1. 0. triacantha Hax.

B) Stacheln 4-6, Stachelpoliter weitläufig

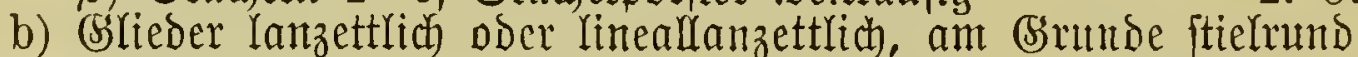

2. 0. Tuna Mill.

B. BSTieser aufresht, umgefehrt eiförmig, menig berzmeigt.

3. 0. aurantiaca Gill.
a) Stacheefog in erwactiencm Buitande
b) Mit zahlreichert fräftigen Stachelı verjęen
4. 0. basilaris Engelm.
5. 0. Emoryi Engelm.

C. Sieberliegende Rflanzen ober aufftrebende Strältcher.
a) BSlicber flach.
a.) (B) lieser beitachelt

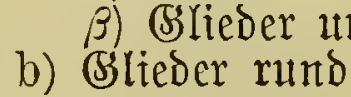
b) Giebor mino
6. 0. comanchica Engelm. 7. O. Rafinesquii Engelm. 8. 0. brachyarthra Engelin.

\section{Opnntia triacantha Haw. Divijtadjeliger Feigenfaftuz.}

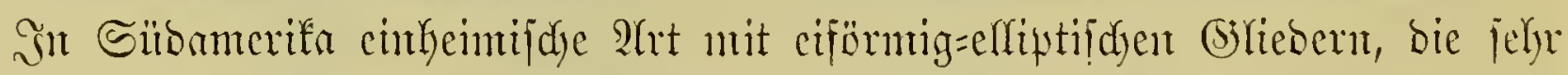
fleinte rote Brättedyen tragent. 2freolen jiemrlid bidyt gejtelft, gewölbt, in ber

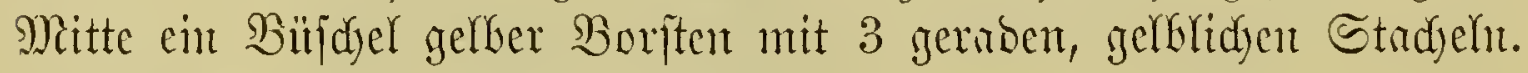

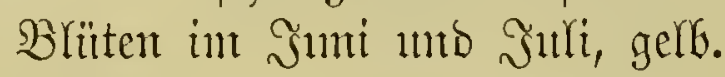

\section{Opuntia Tuna Mill. Codfutente-Feigenfaftus.}

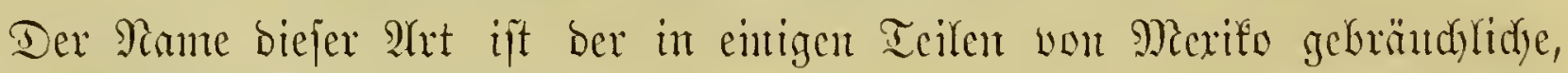

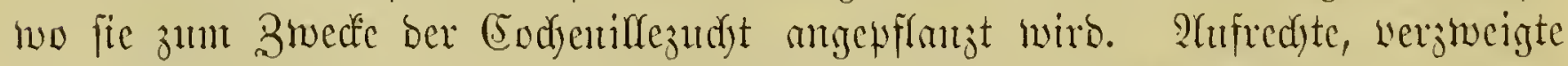

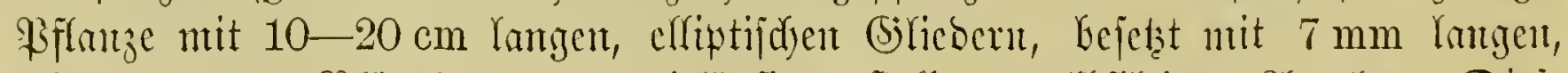

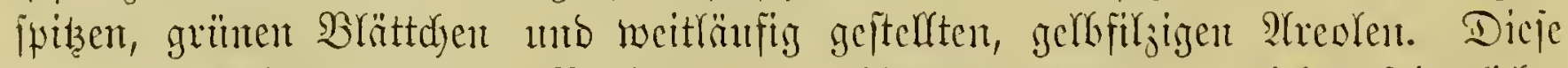

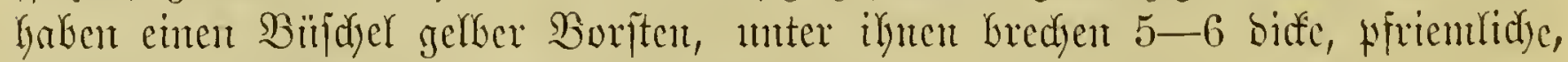

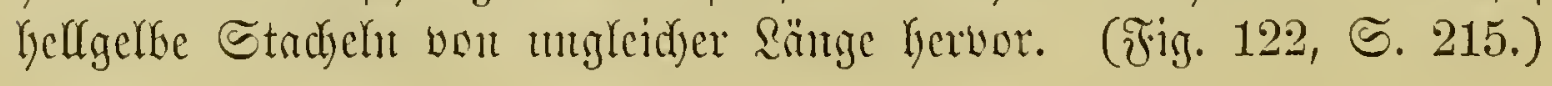




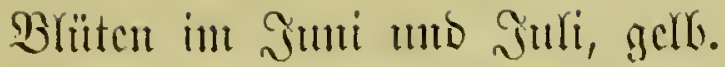

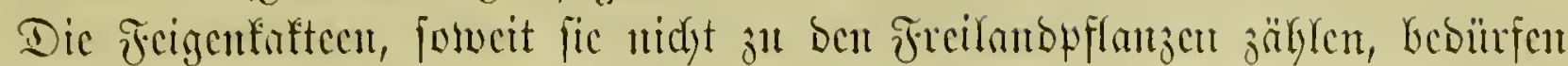

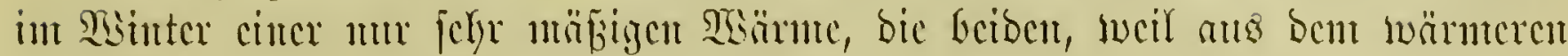

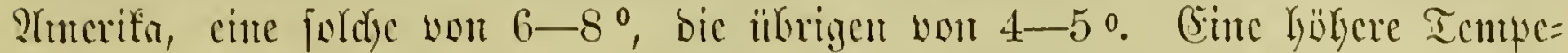
ratur bat cin geiles

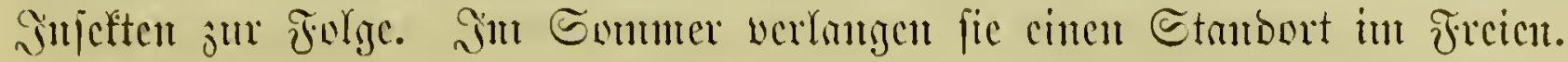

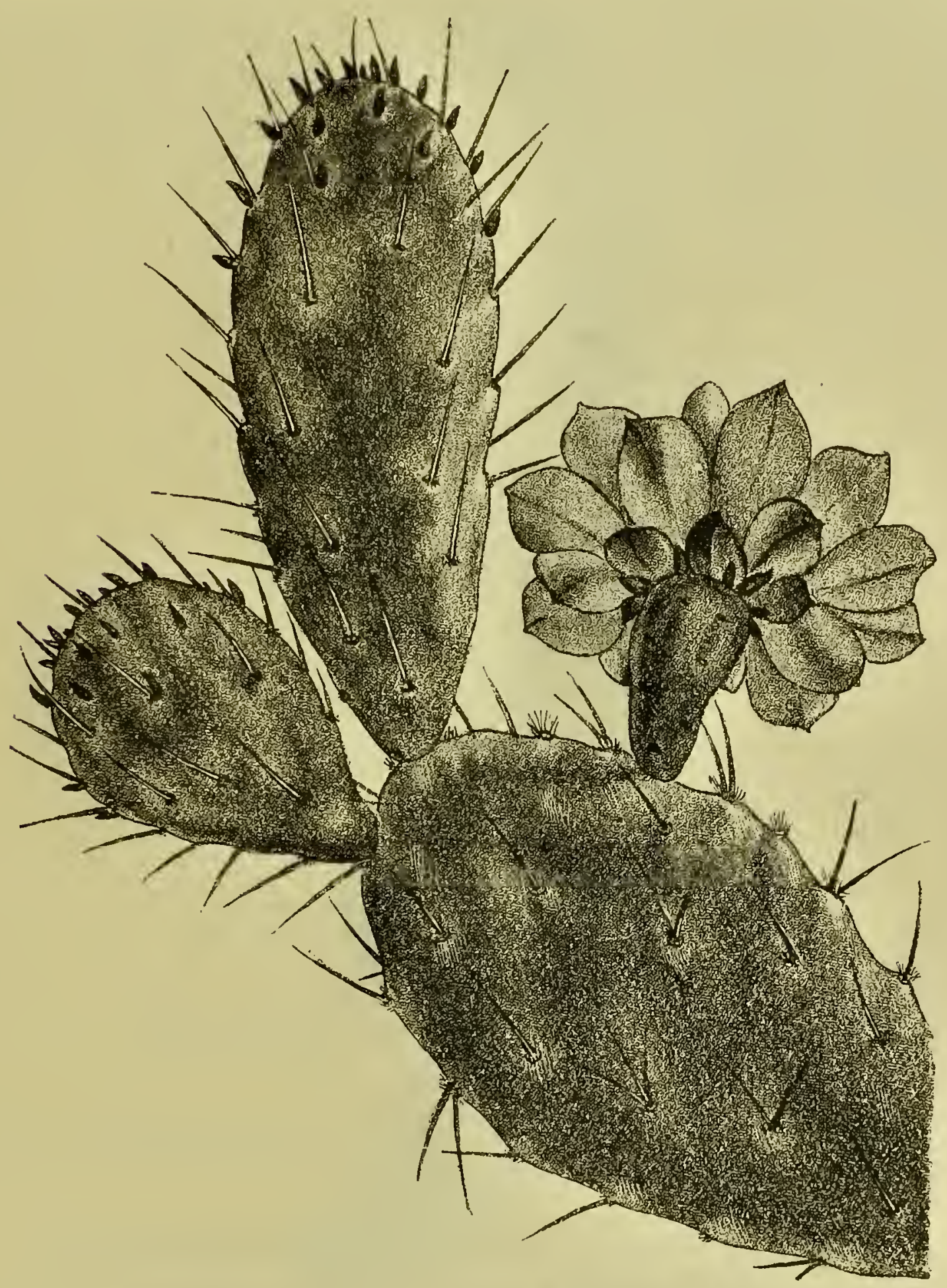

Fig. 122. Opuntia Tuna Mill. Codenifle=Fcigcufaftus.

\section{Opnntia aurantiaca Gill. Drangen=₹cigenfaftu .}

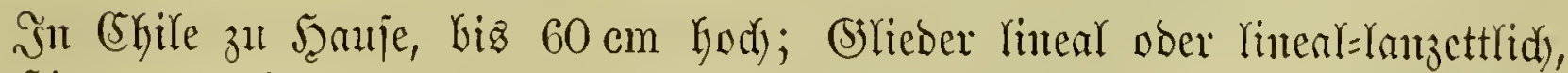
mit fitielnumber Bafiz und zujammentgebrüufter Spitze, 10-12 cm lmug unt $2-2,5 \mathrm{~cm}$ breit, glänżend=bunfelgrün, um bie \$orffer Kerum mit eincm braun= grünen Fłleçen, mit fpiłzen, roten Brättchen. 


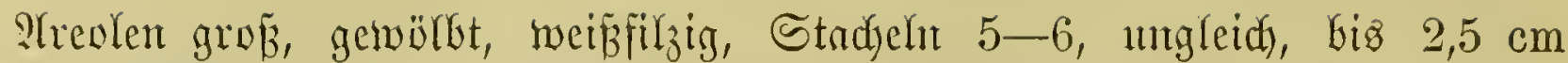
lang, bie oberen braum, anzgebrcitet, bie unteren weiß, Kurz unb boritenartig.

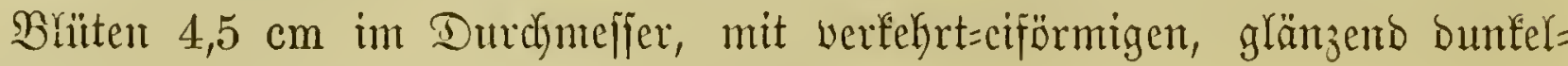
getben, wben an Rande eingebogenen Fetalen.

\section{Opnntia basilaris Engelm. Grumbäitigcr Feigenfaftuz.}

In Sallifornien cinfreinifdye, in ber Forn bon allen moeren Dpuntien

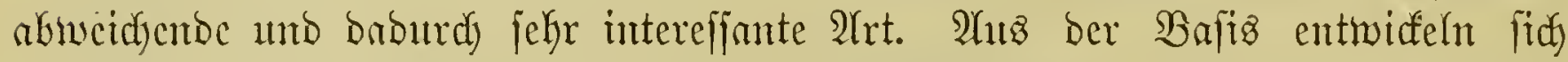
in größ̈erer ober geringerer Bahl verfefret=eirunde, gegen $20 \mathrm{~cm}$ lange behante,

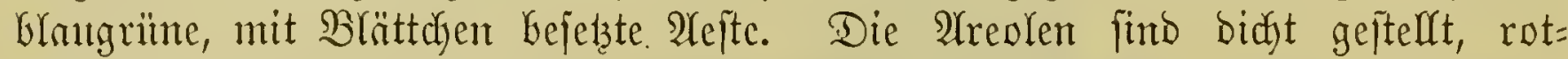
bran befant und mit vielen ganz furzen, boriftenartigen, barb abfalfenden Stadjeln bejeķt. (Fig. 123.)

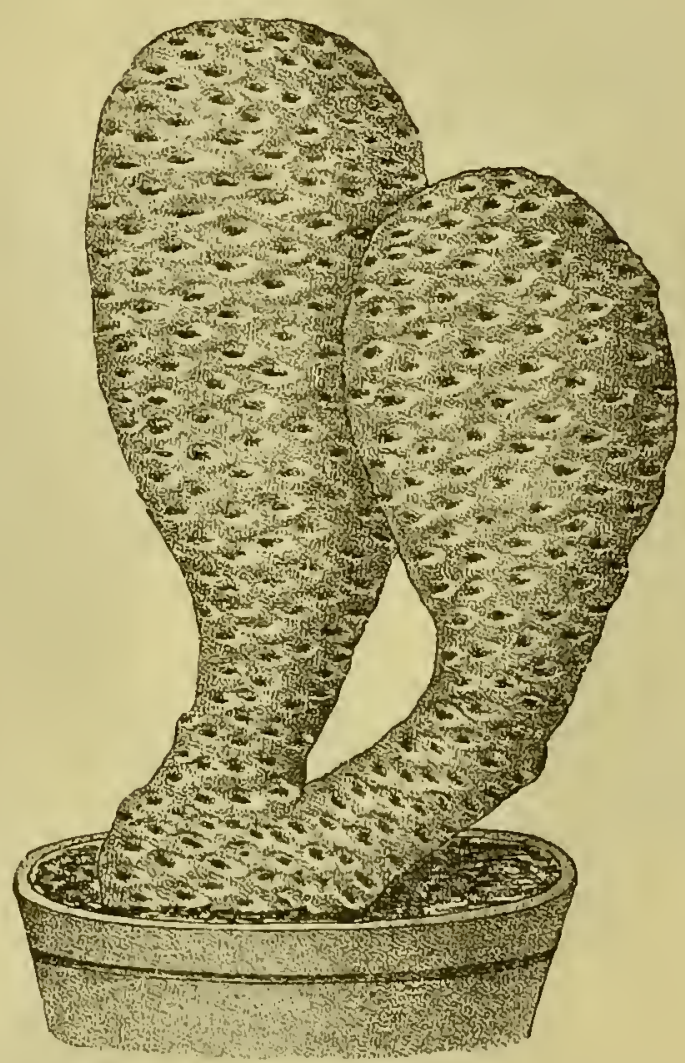

F̛ig. 123. Opuntia basilaris Eng. (3run๖äftiger Feigentuftuঙ.

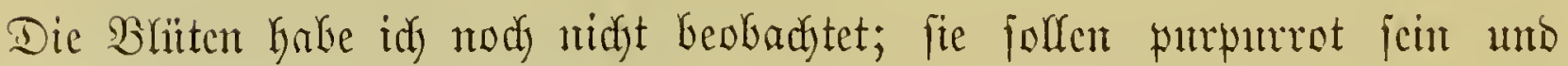
cinen Durdymeffer won $6 \mathrm{~cm}$ hatben.

\section{Opuntia Emoryi Engelm. Eutocy'z Feigenfaftuz.}

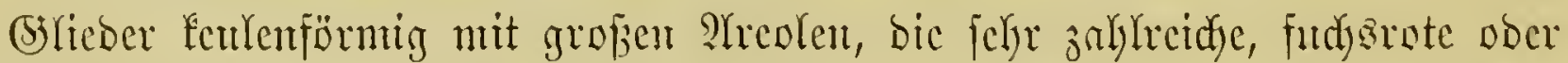

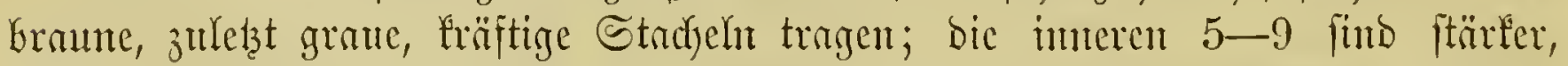

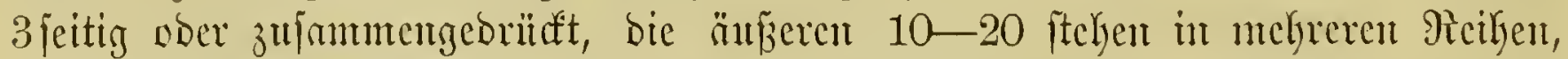

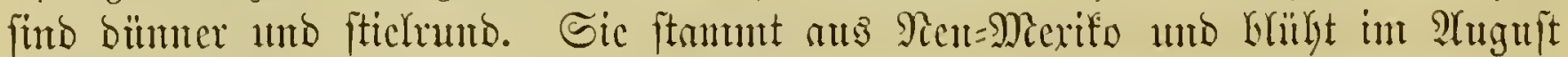
unto Septentber. (Firg. 124, S. 217.)

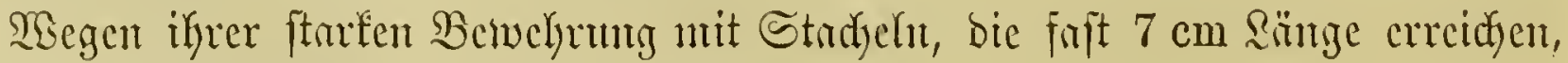
eine Der intereffanteften wärmeren STrten. 
6. Opuntia comanchica Engelm. Comandje= Fcigcufaftuß

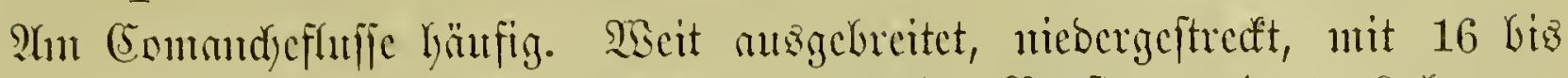

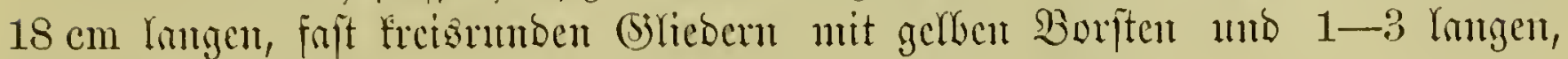

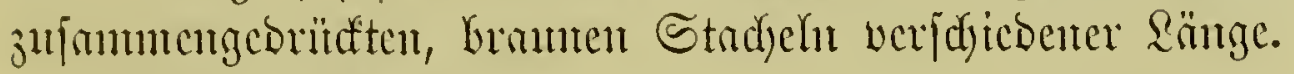

Błïten flén, gelf.

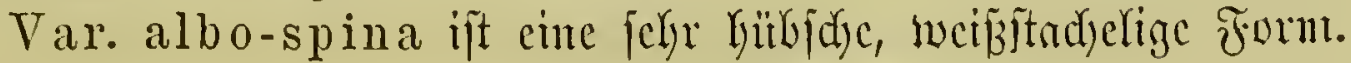

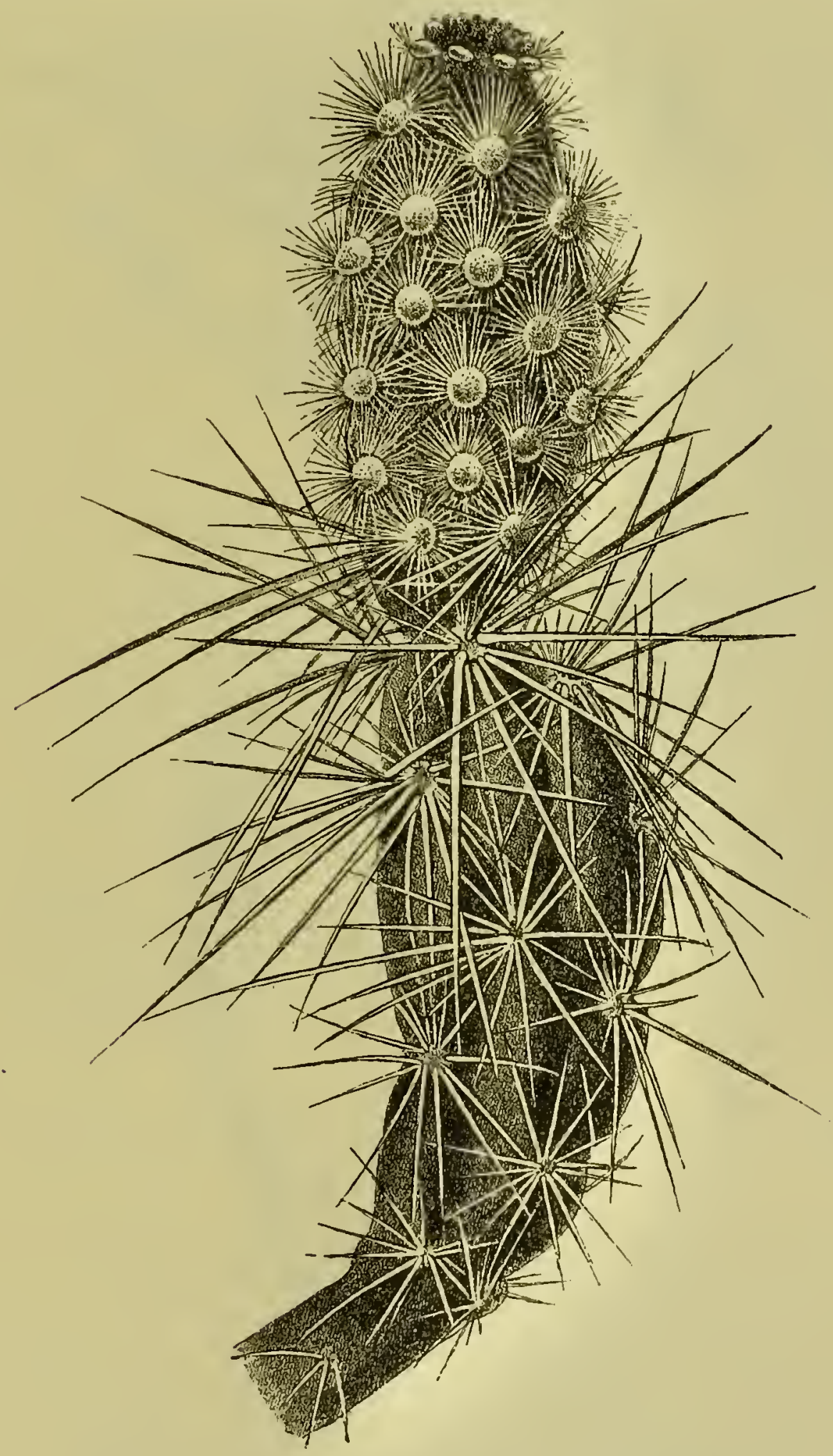

fig. 124. Opuntia Emoryi Eng. (Fmory's Feigentaftus.

\section{Opmntia Rafinesquii Engelm. Rafincżue'z Feigentaftuz.}

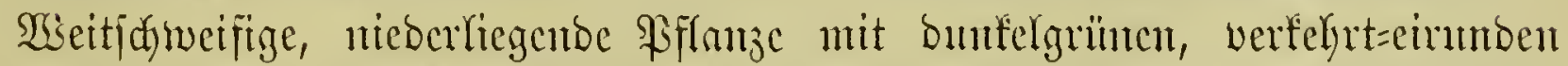

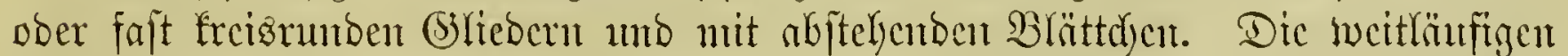
2freolen tragen bïnne, rote Borjten anb mut wentige rot=kntnte, itarte Stadjeln. 
Bhitten im Mai unt Jumi, zalfreidy, bis $12 \mathrm{~cm}$ in Durdymeffer, Gellgelb,

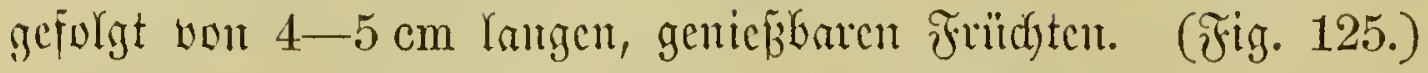

Var. arkansana Engelm., ant Ranjas zu F⿻alje, ijt etwas fräftiger unb

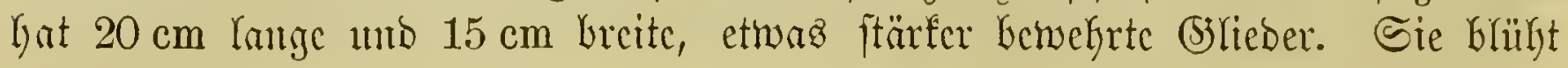

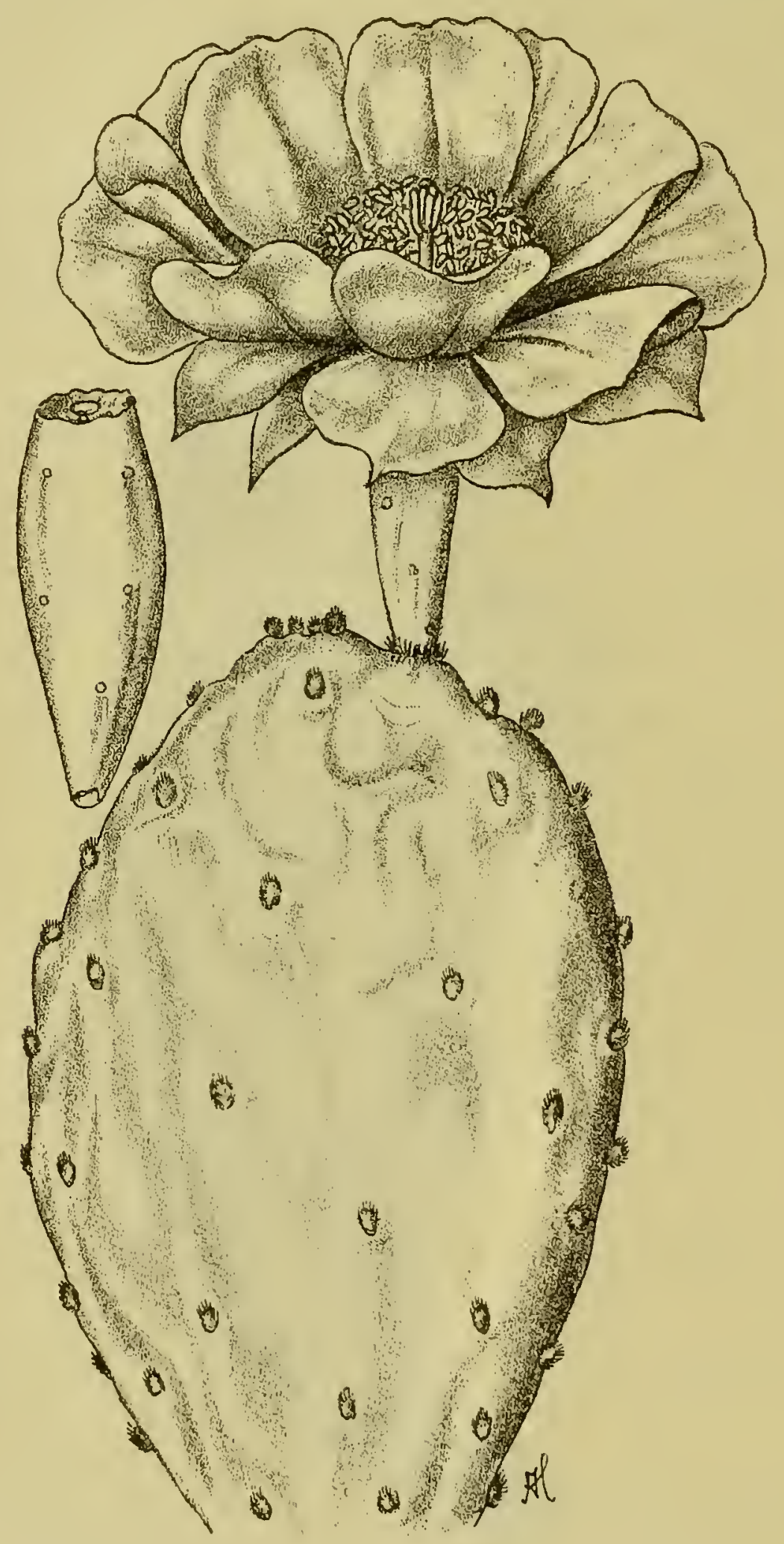

Fig. 125. Opuntia Rafinesquii Eng. Jafinç̨ue's Jeigenfaltus.

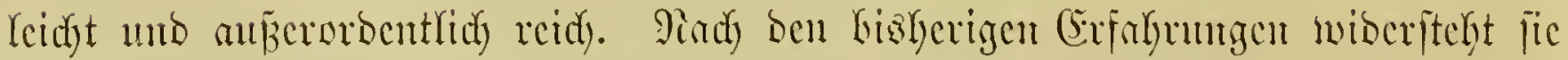
bem Frujte nody beffer, als bie Strmminat.

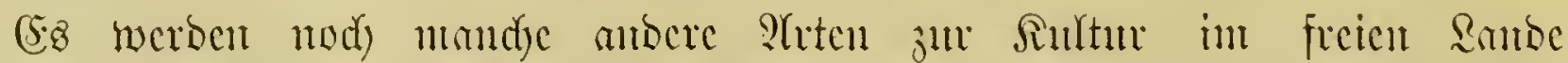
curpfoblen, unter biefon Opuntia arborescens Engelm., Engelmanni S.,

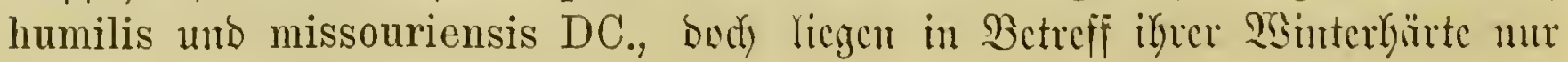




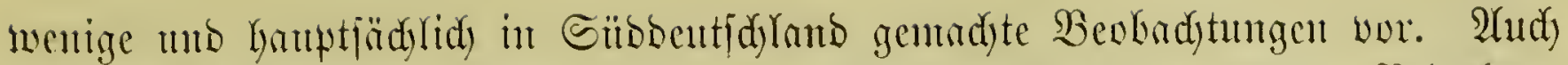

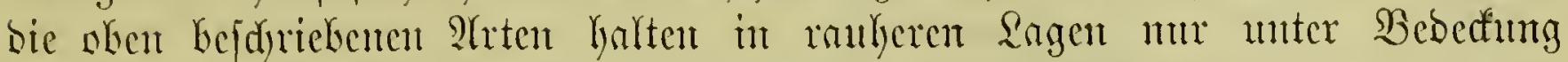

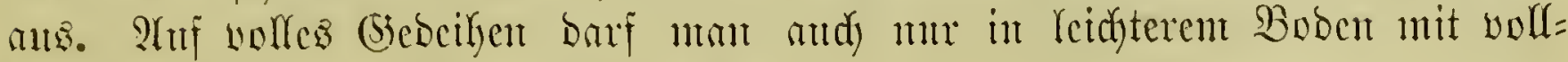

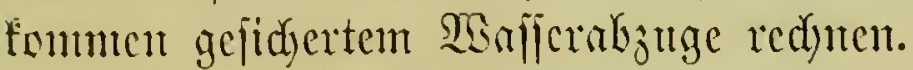

\section{Opuntia brachyarthra Engelm. §atraglicbrigcr Fecigenfaftuz.}

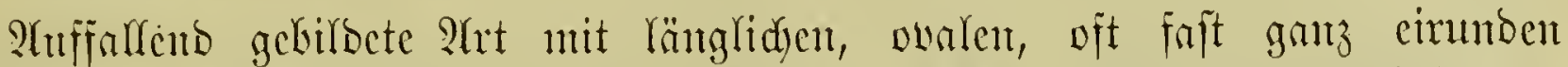

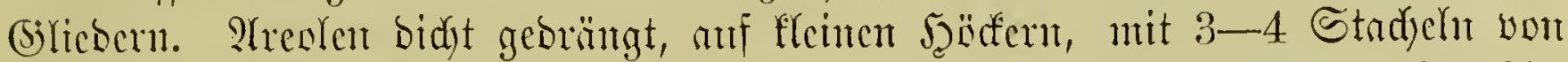

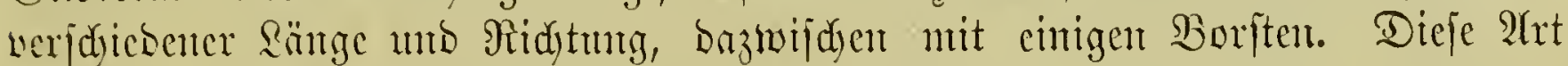

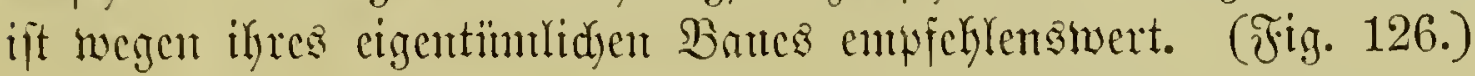

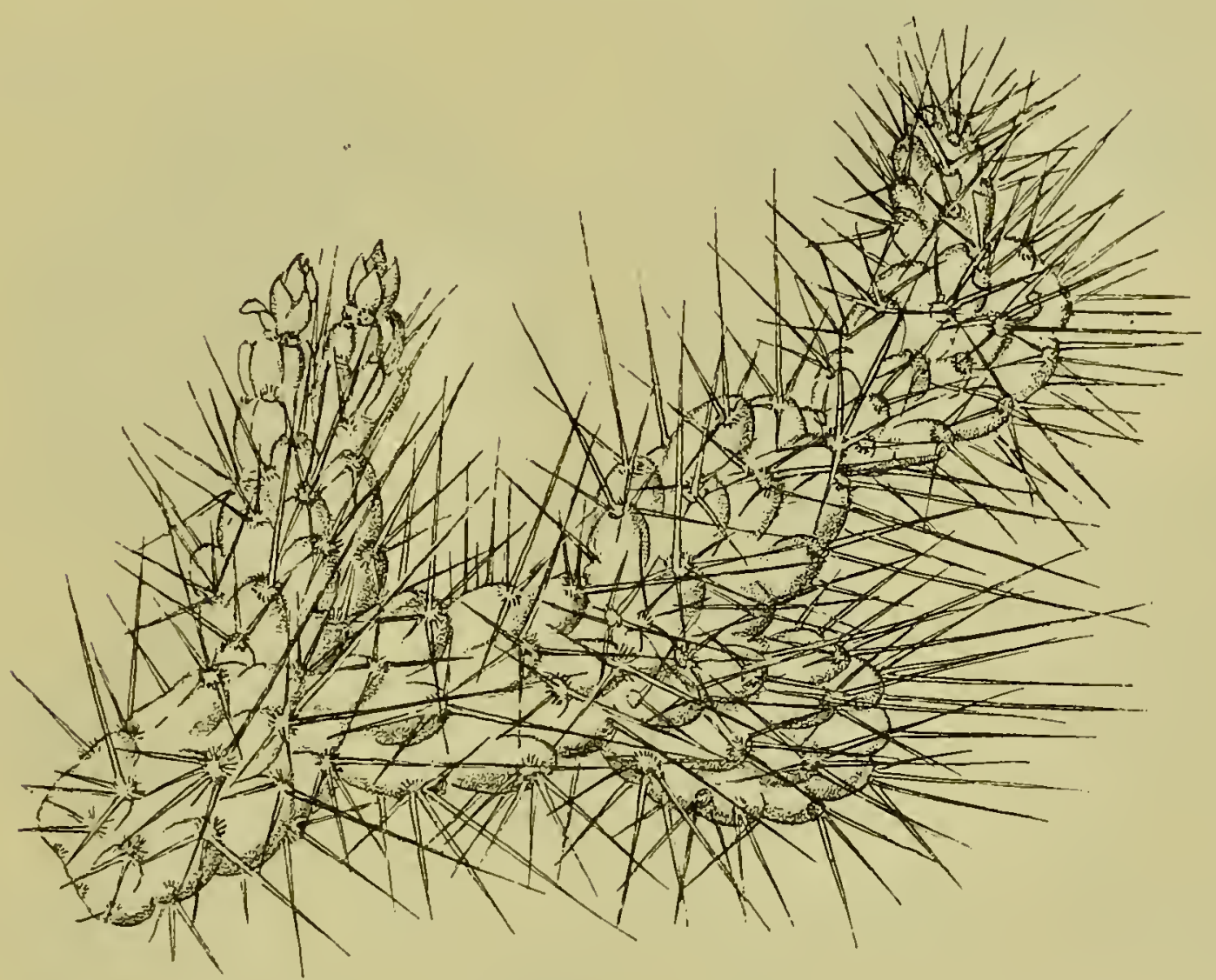

Fig. 126. Opuntia brachyarthra Eng. Siurgglieoriger Feigenfaftuß.

\section{7. (S)attung Peireskia Plum. Raubfaftıs.}

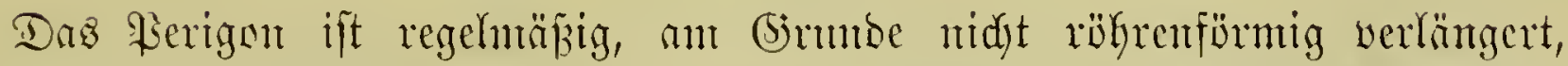

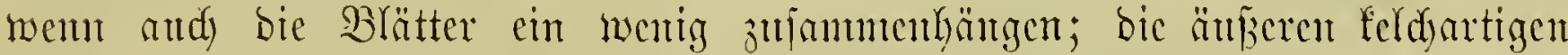

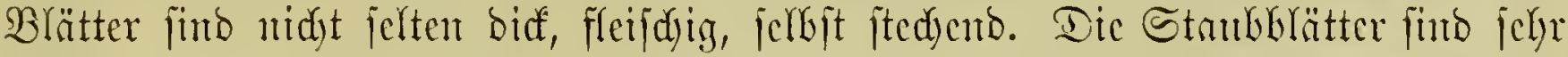

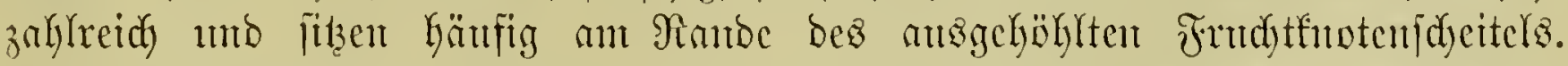

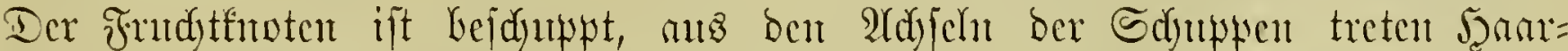

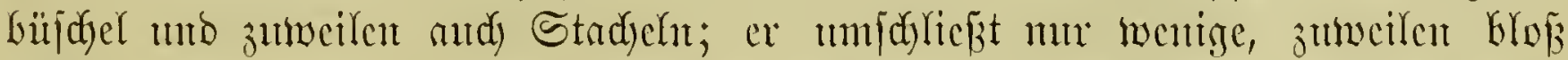
5 Samenanlagen. Dic Frudyt ift cine jaftige, wenig= ober mekriantige Bece. -

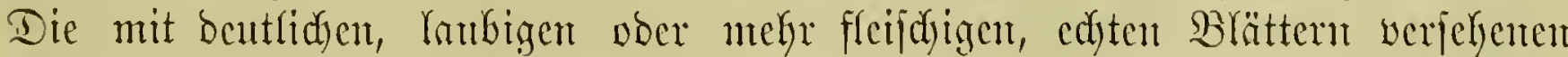

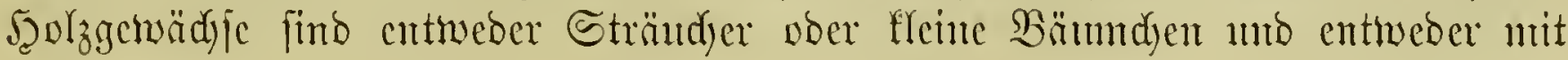




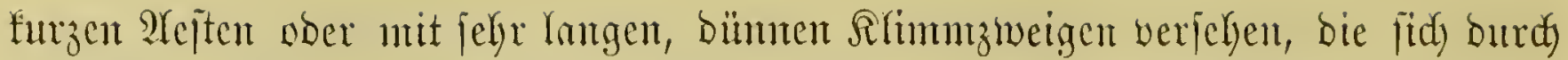

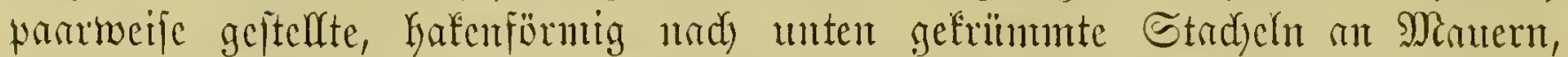

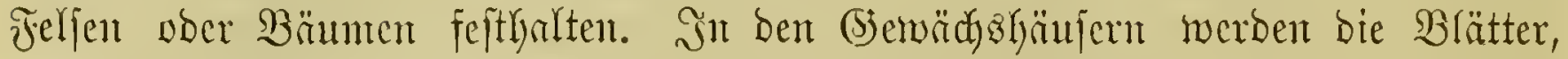

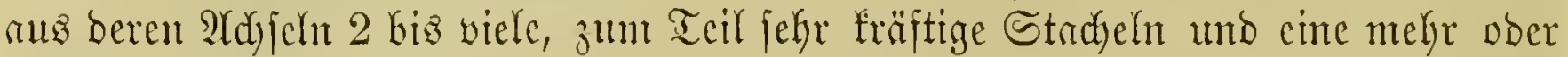

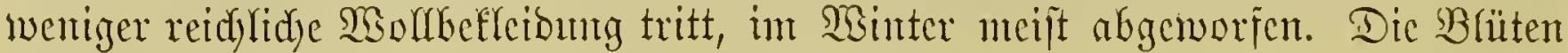

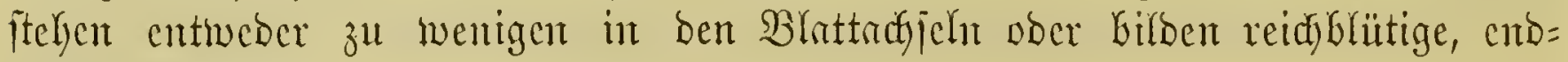

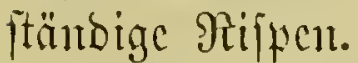

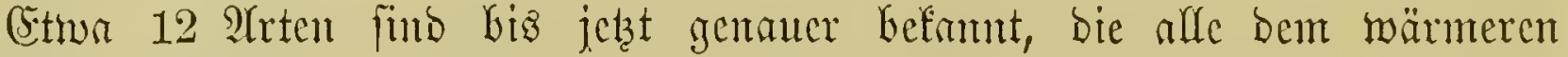

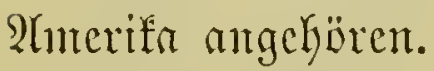
morben.

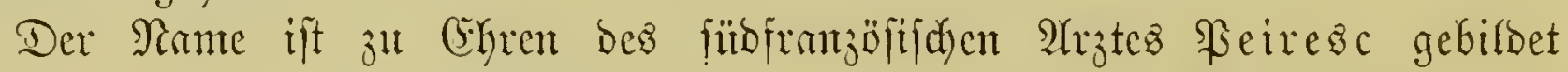

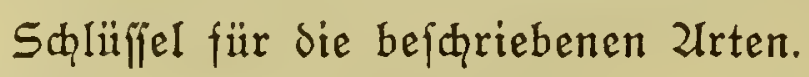

A. Blätter biđä, fleịchig.
a) Blätter pfriemlich
b) Blättcr ipatelförmig, itumpf
c) B̧ätter lanzettlich, fpił
1. P. subulata Miihlpf. 2. P. spathulata $L$. et $O$. 3. P. calandriniifolia Pfeiff.

B. SBlätter laubia, mäßì flcif́nig.

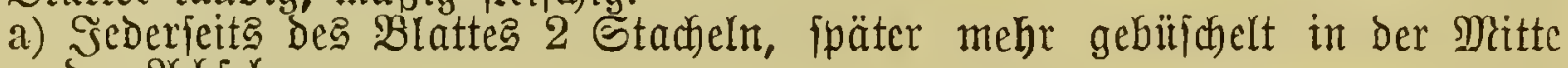
ber $2 \mathfrak{A c h f e l n}$.

a.) Stadeln gerabe

4. P. zinniiflora $D C$.

ß) Stacheln hafenförmig, nach inten gefrümmt 5. P. aculeata Plum.

b) Snn Der sBlattachfel viele gerabe, träftige, lange Stacteln

6. P. Bleo H. B. Kth.

\section{Pereskia subulata Mhlpf. Płricntublätteriger :anbfaftuz.}

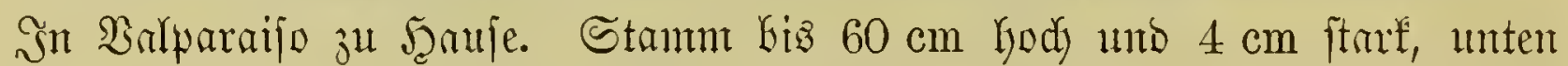

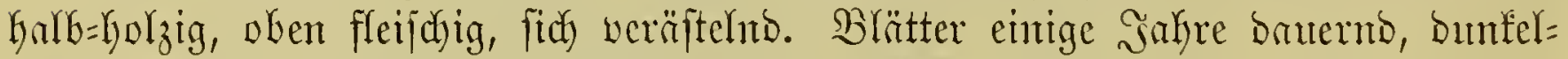

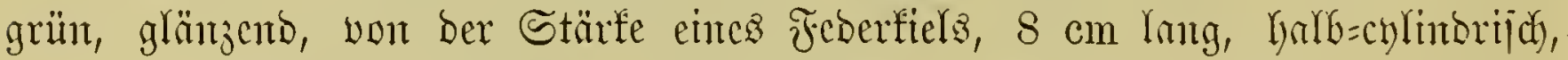

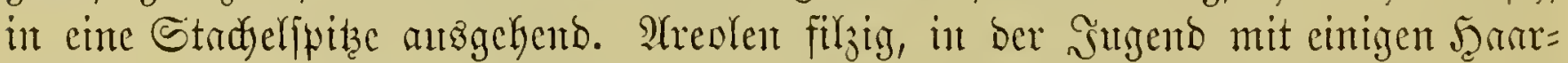
Gorjten, far̈ter mit 2-4 gernben, 8-9 cm langen, brofgelben Etrdjelı. Sic fomm als Pfropfunterlnge für Epiphyllum bienen.

\section{Peireskia spathulata $L k$. et $O$. Epatchblättcrigcr $\mathfrak{E a u b f a f t u}$.}

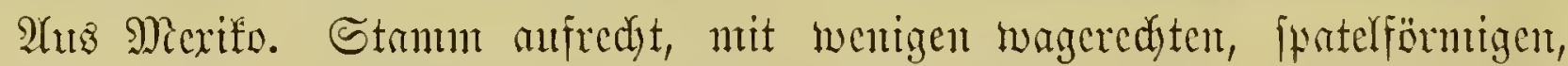

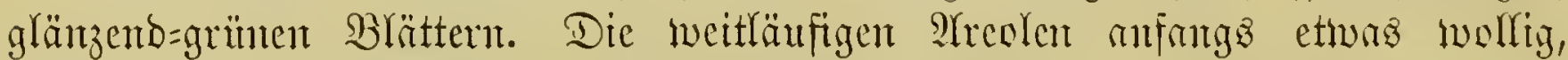

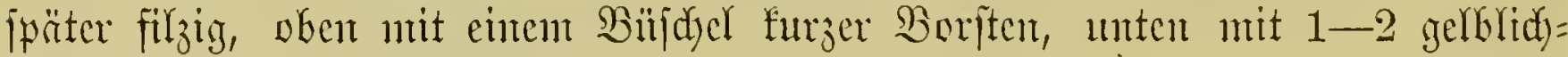
weißzen, germben Stridjely.

\section{Peireskia calandriniifolia Hort. Berol. Eafanbrinicublättcriger saubfaftus.}

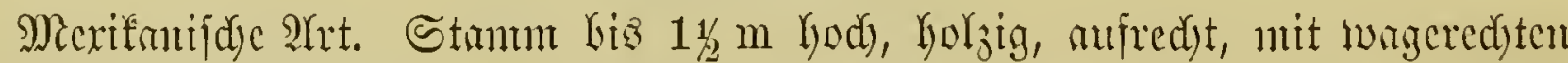

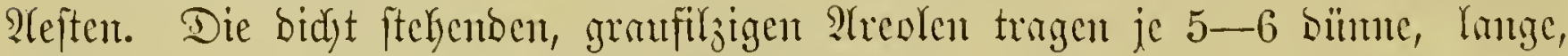

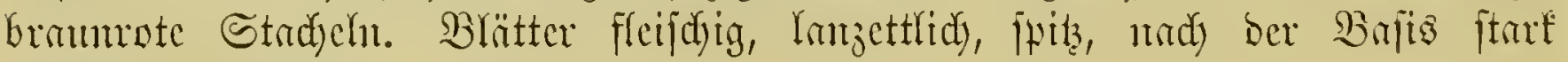
verfa)

\section{Peireskia zinniiflora $D C$. Biunicublitigcr :anbfaftus.}

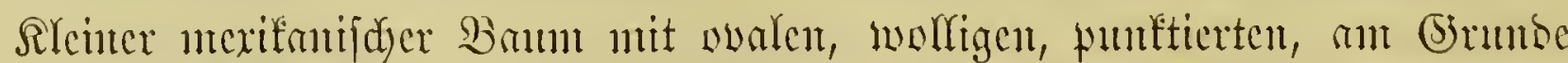

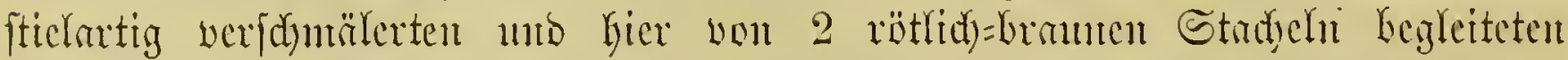
Bhättern, fpäter aus ber Mitte ber Blattadjel $3-5$ gebiijudedte Stadjeln. 
Brïten bencu bcr Zinnia elegans ähulidy, cinjeln, cnoftändig, 2,5 cm im

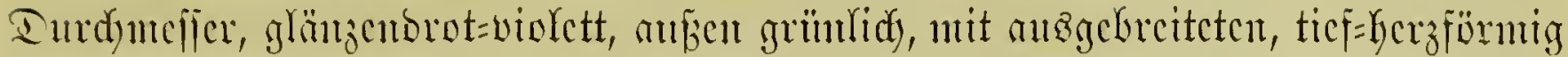

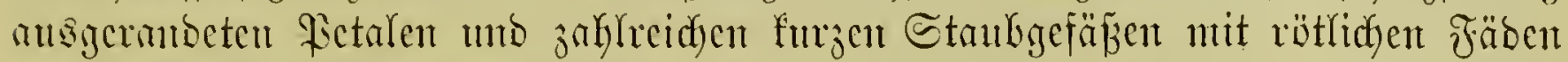
uto gelben Strublicuteln. (Jig. 127.)

\section{Peireskia acnleata Plum. Gtadjeligar Raubfaftut}

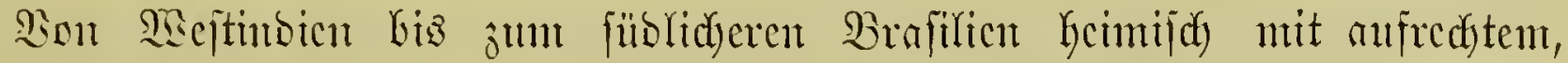

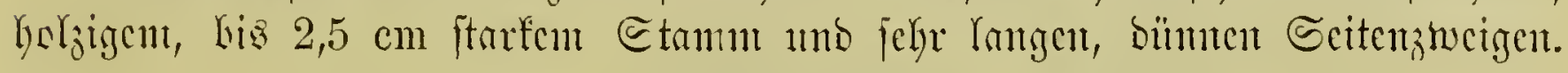

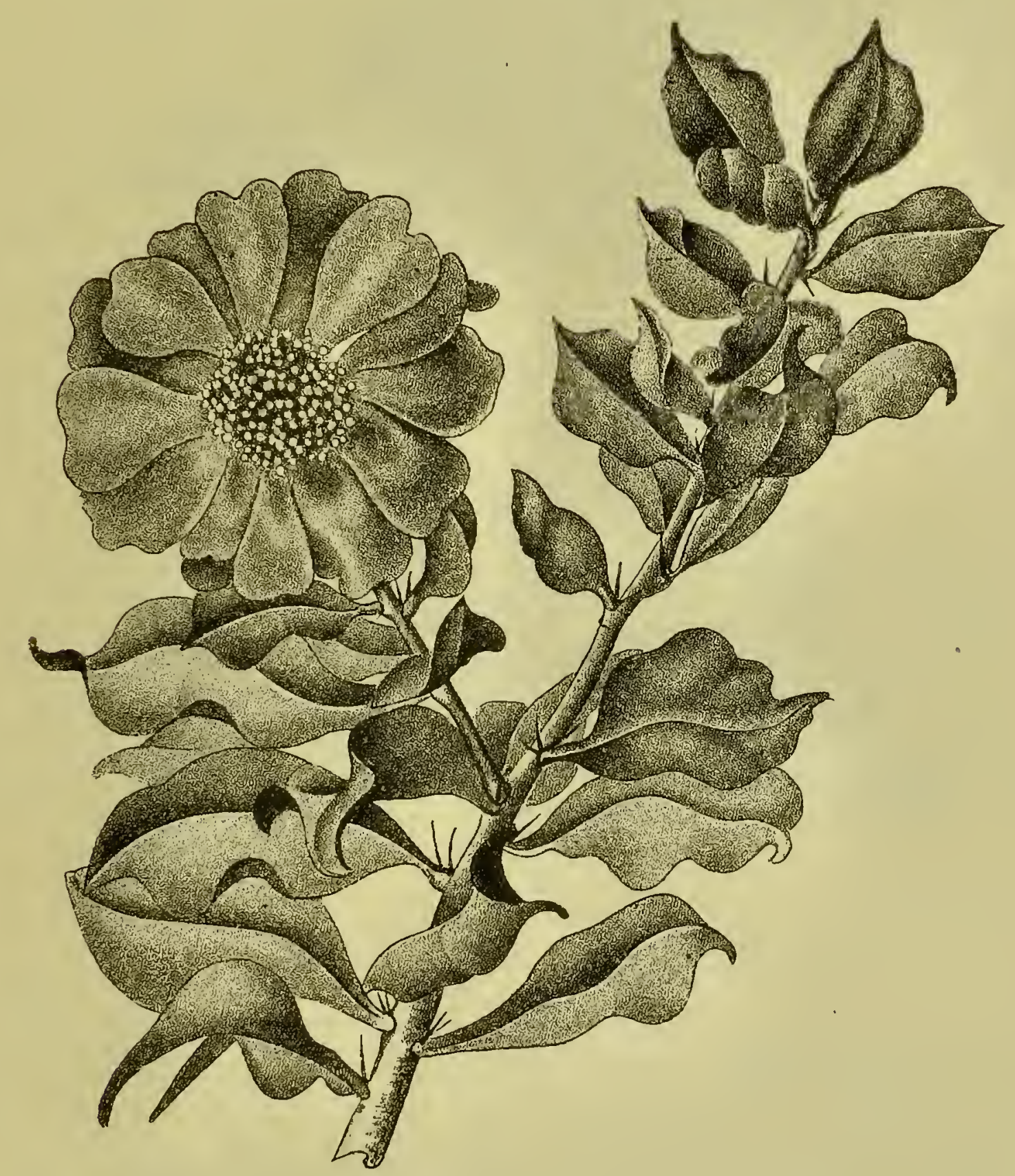

Fig. 127. Peireskia zinniiflora DC. Binniabrütiger \&aublaftus.

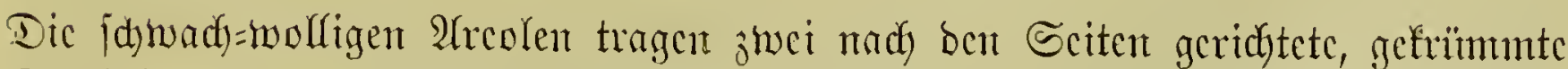

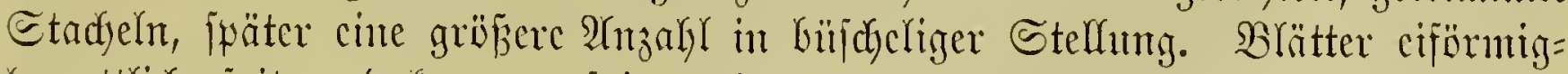

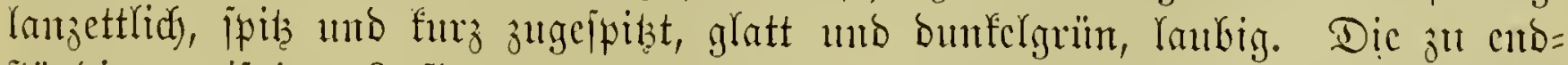
ftändigen, rippigen Snflorescenzen verbutbencn Blïten Kaben linicnförmige, grünc Gcpalen und ovale, weiñs, öweireigige Fetalen. 


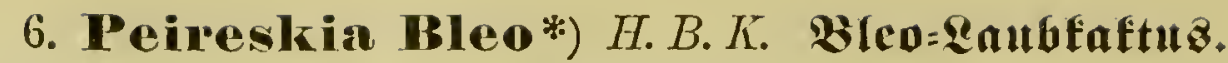

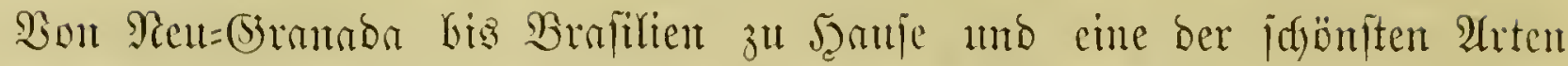

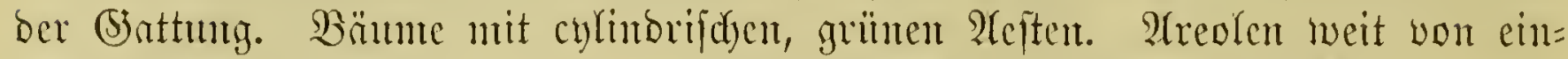

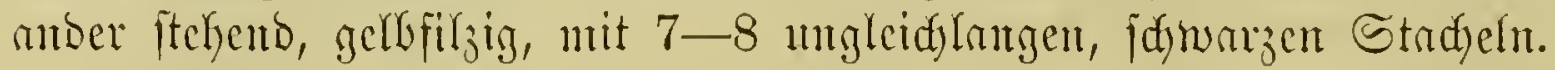

B̧äten im Miai uno Juni, gejtielt, mit furzen grünen Seprlen, ovalen,

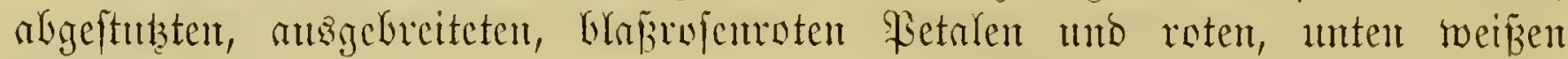
Strubfï̈betr.

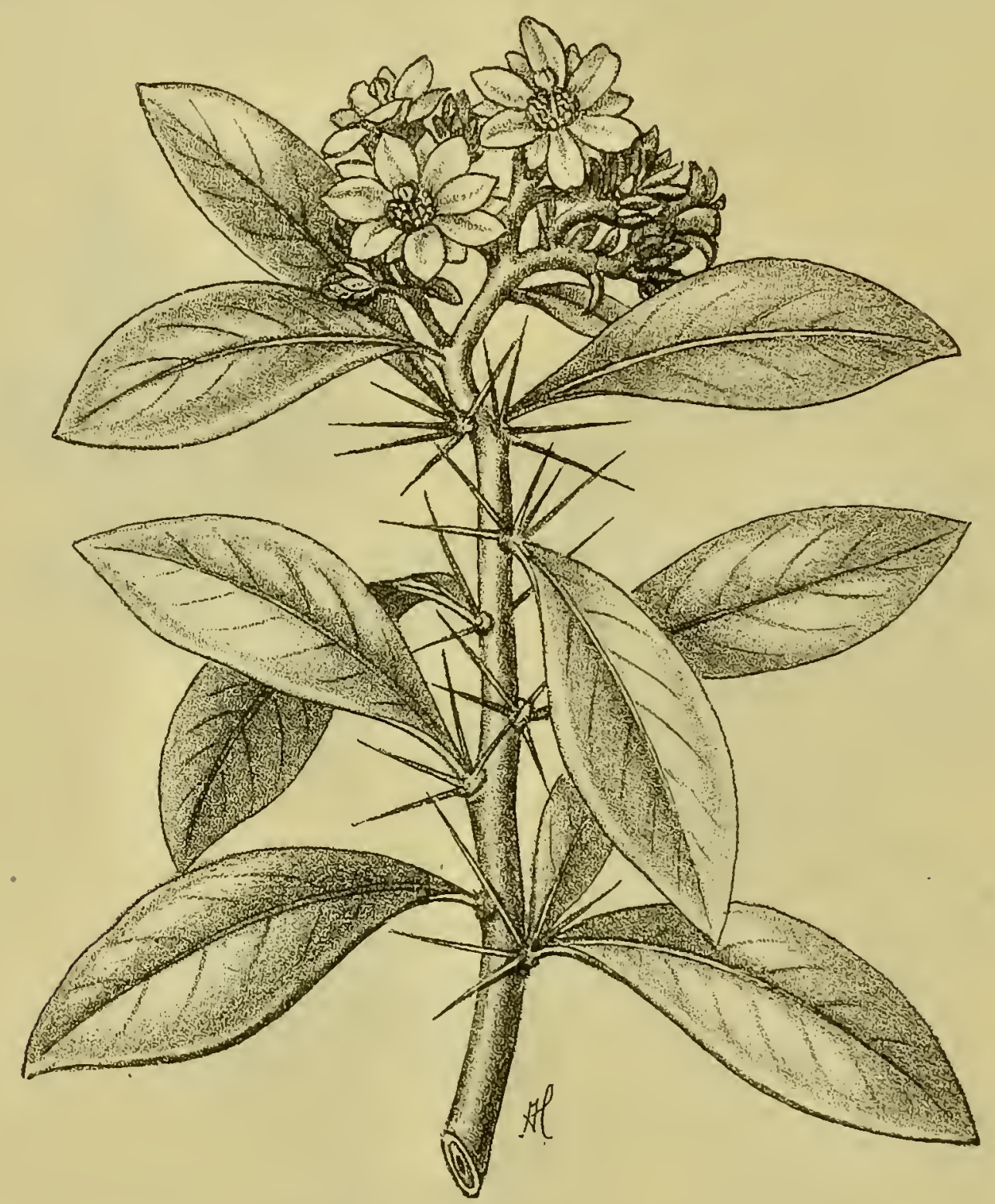

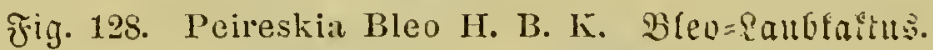

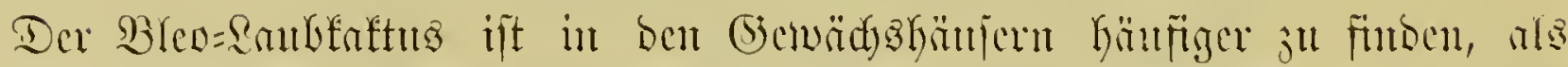

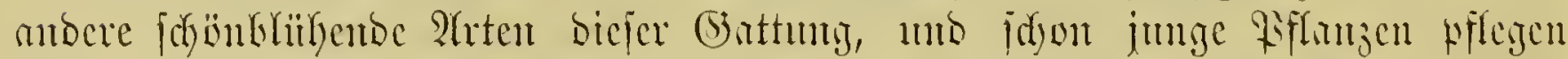

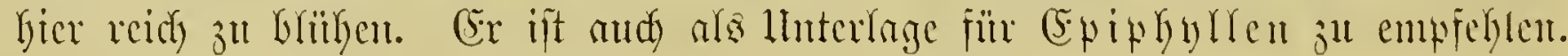

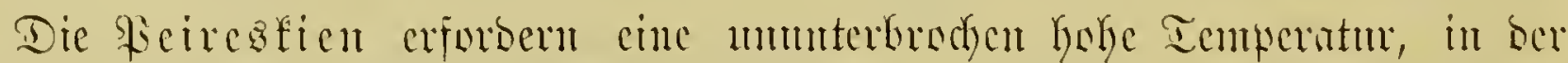

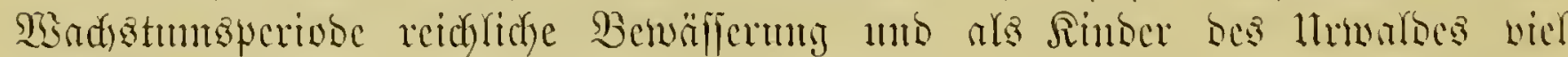

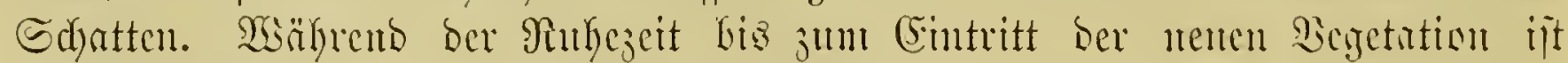

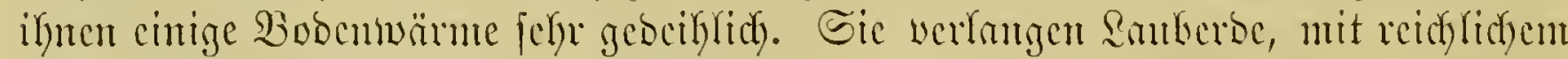

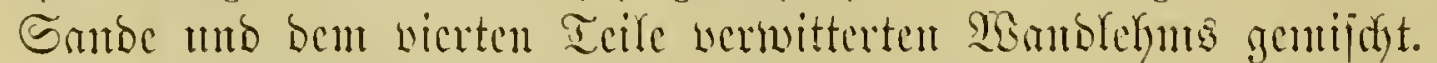

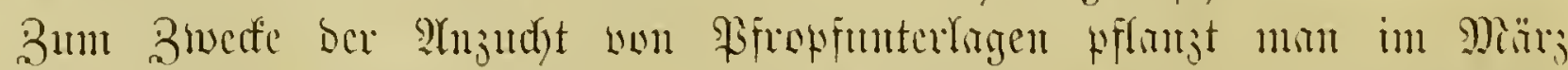

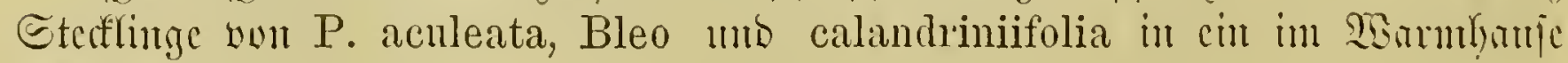

:5) Der in Sien=-Brranada gebräuchliche siame. 


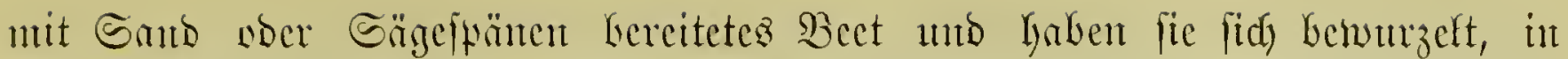
jientlidy fleine Tüffe, bie mtan biz anfangs Miai bidjt unter bent Bjfafe hält, unto bant $15 \mathrm{~cm}$ weit auseintmber in cint abgetragentes Miftbeet, int weldyent

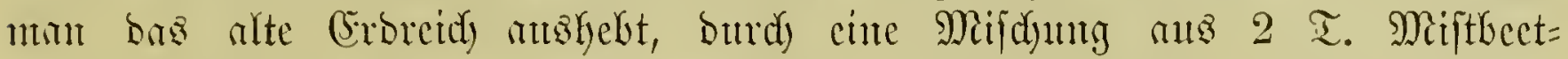

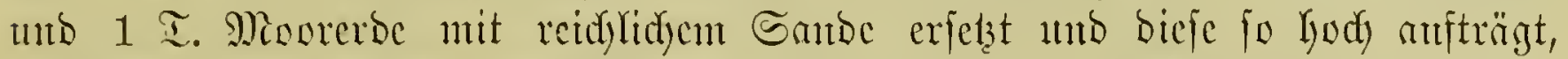

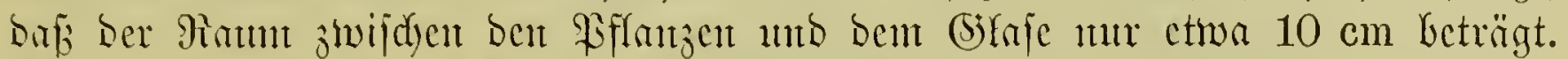

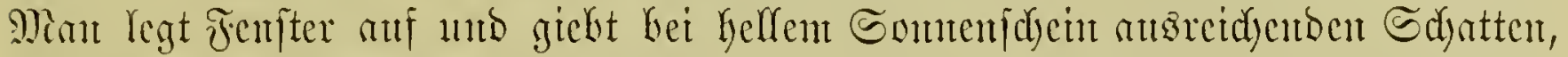

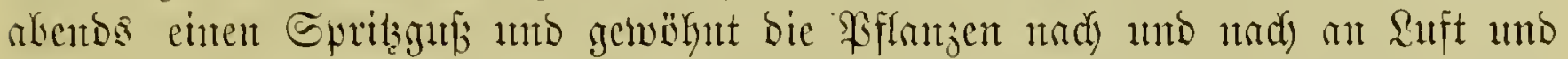
Ridjt, bis bic Fenjter enblidy weggentonment werben fönnent. Dann unto mann

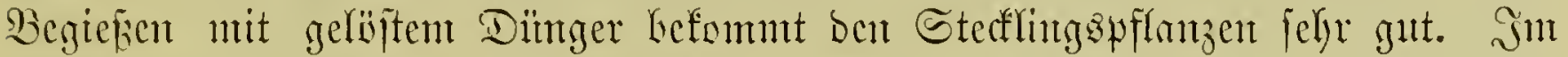

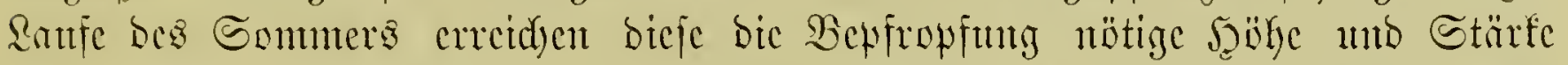
unto werben bis anf etwa ziwei Fintger breit riber ber Stefle, an wefder ntan

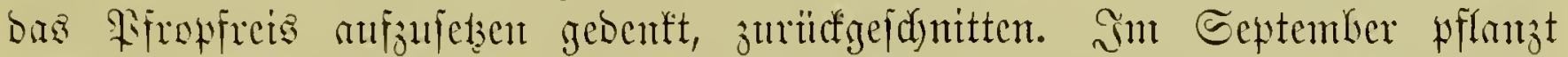
man fie in jemfich ffeine Töpfe, bie mit ber oben empfurfenen (Eromifdymg

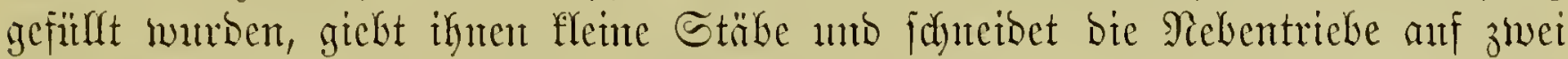

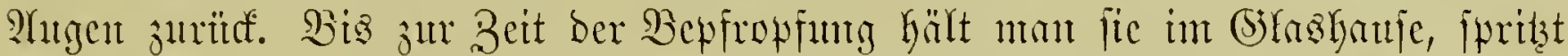

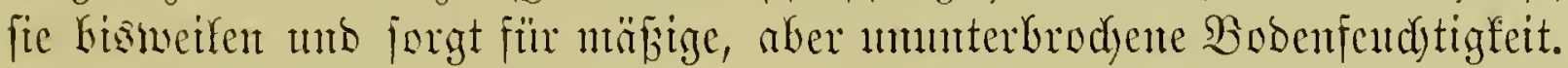

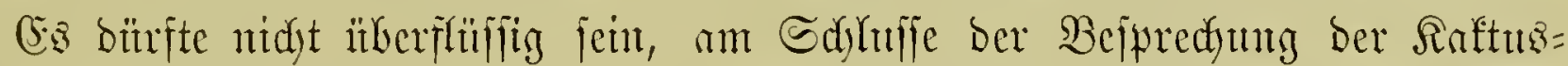
Arten bie Gişger ïber bie Rultur u. j. w. jerjtrent gegebenten Bemerfungen

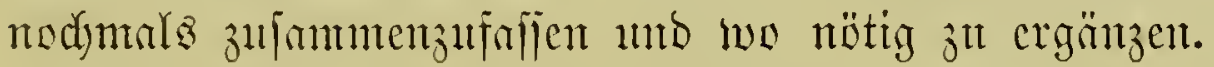

\section{Zlusfaat.}

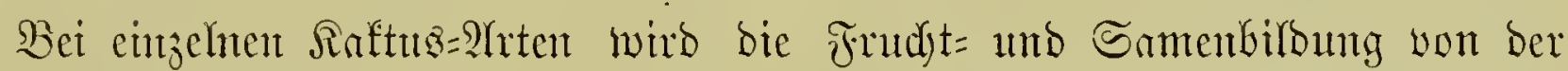

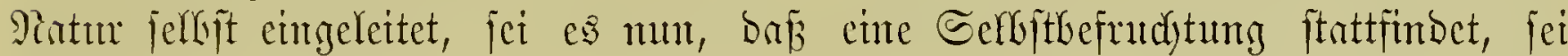

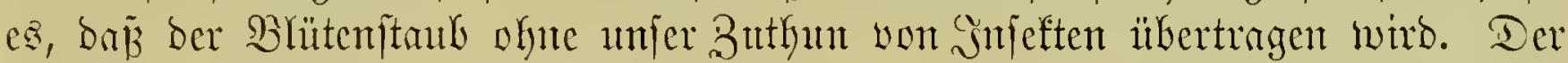

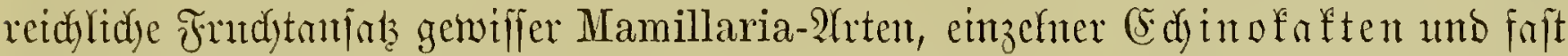

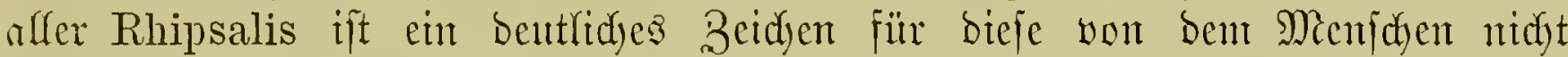

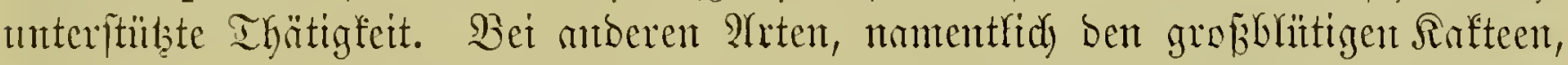
fonm aber bie fünftlidye Befrudytung nidyt woble amgangen werben; fite ift unt is mefyr angezeigt, afs bie Necigung zut Baftarblifbung nidyt alfein unter ben

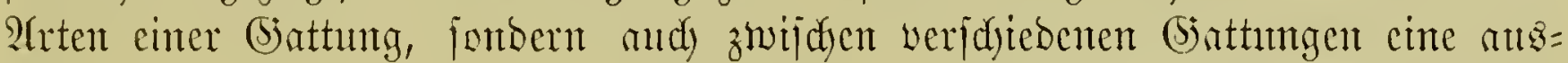

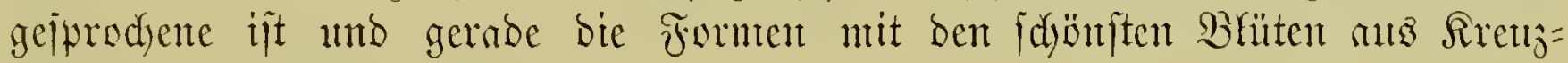
befrudytungen er jeft norden fint.

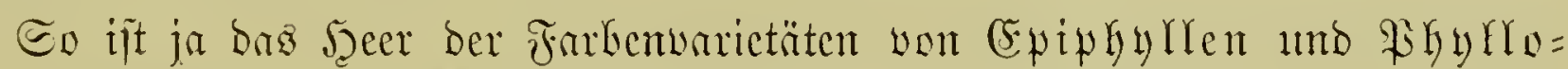
faften nadweistar ats fünftlidyer Befrudytung Kervorgegangen.

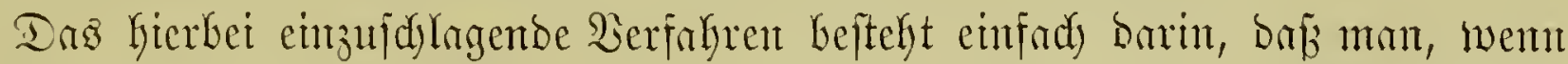

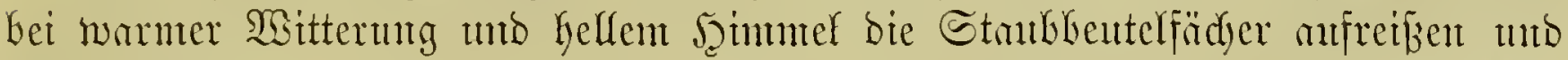

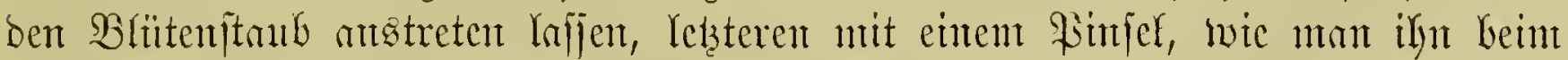

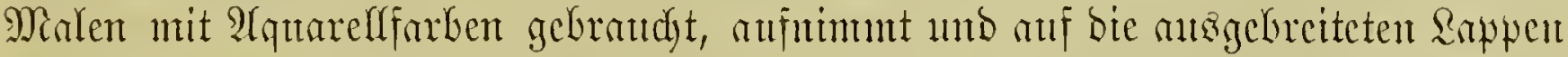

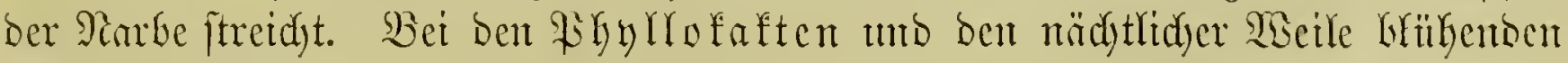

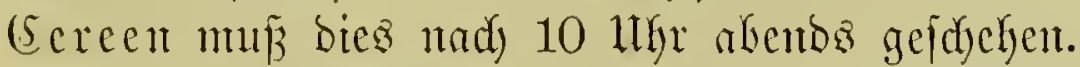

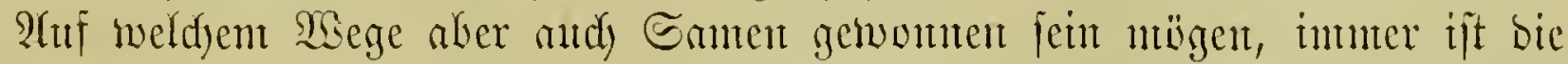

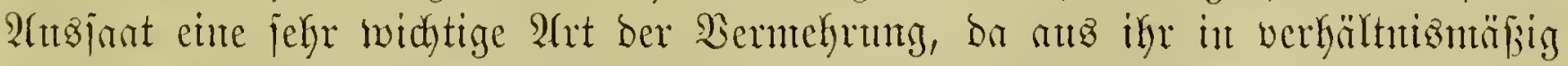

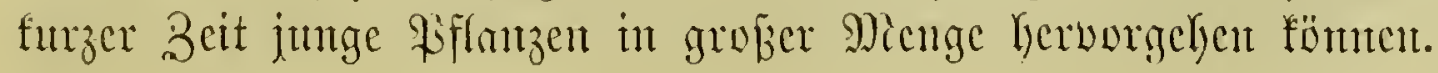




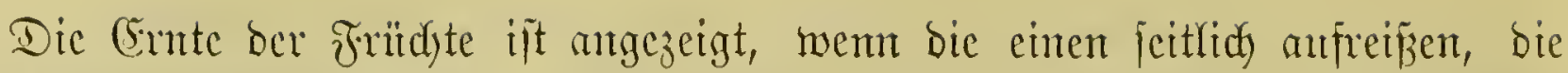

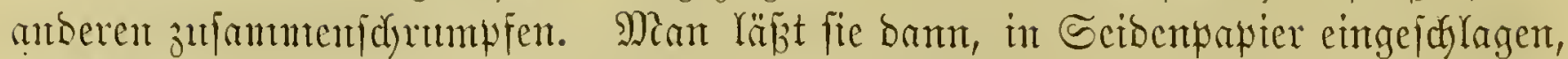

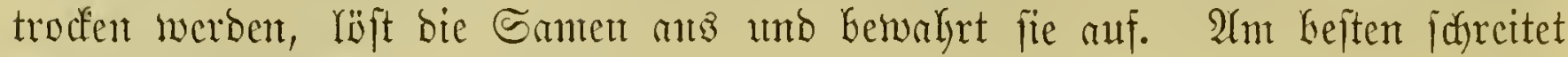

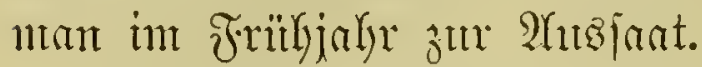

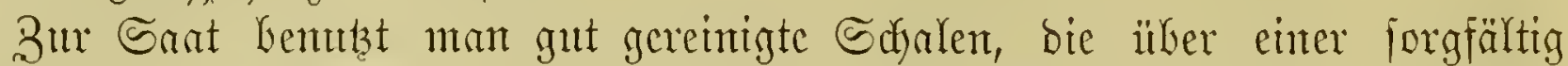

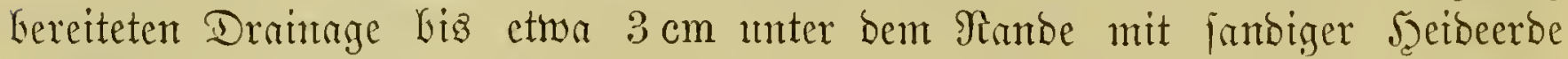
gefüllft werben. Reżtere ebnet man mittelift eines glatten Brettchens, bie Samen

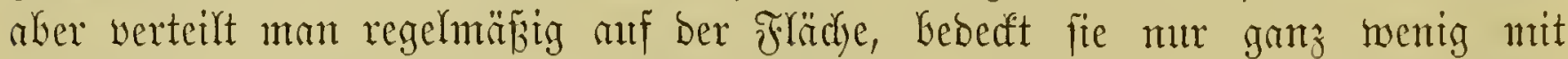

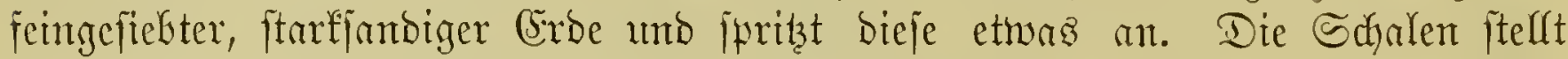

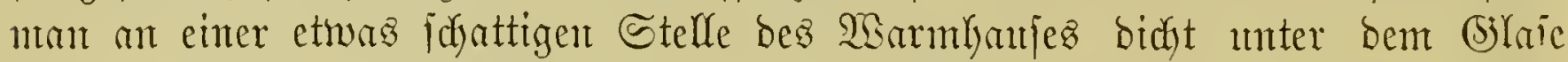

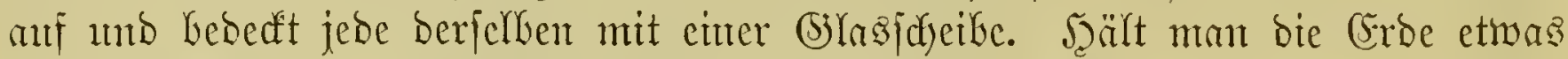

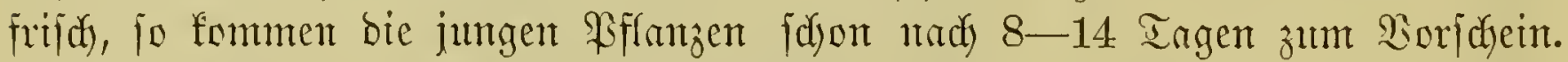
Stets mun fïr. Bejdattung Sorge getragent werben, io oft cine joldye angezeigt

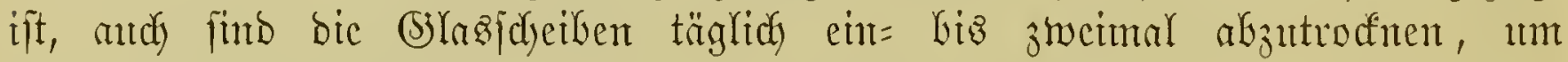

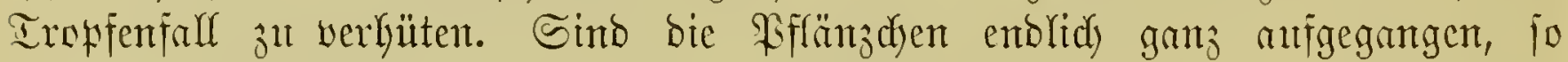

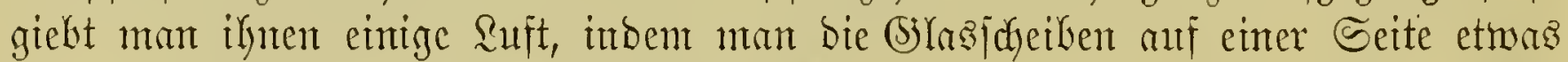

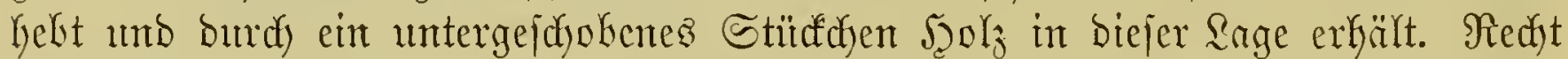

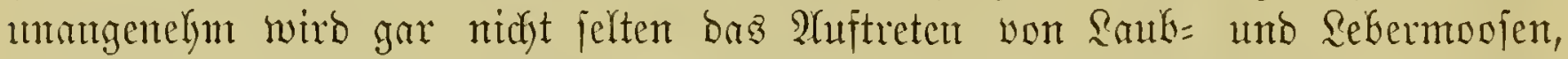

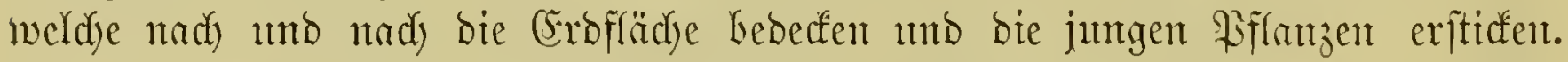

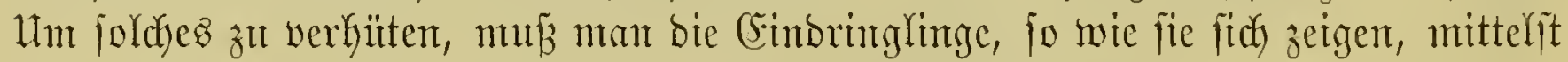

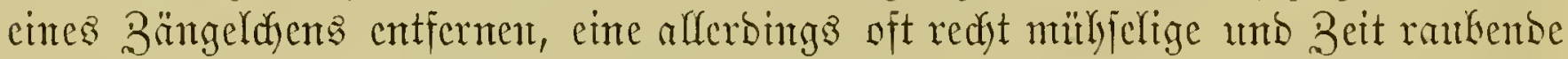

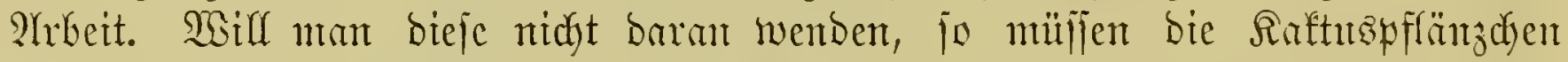
piffert werben. But biefer Brozedur pifegt man, ift jene Beranlaffung nidyt

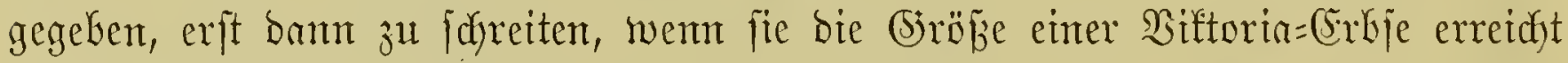
Gaben. Sorzeitiges Sifiteren ijt anch bann geboten, wenn man jut bicht gejäet Gaben follte.

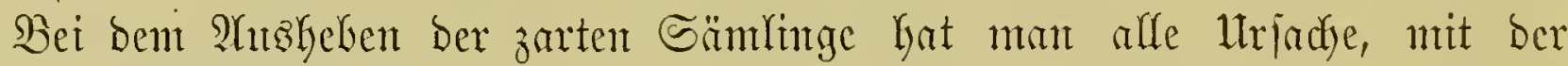

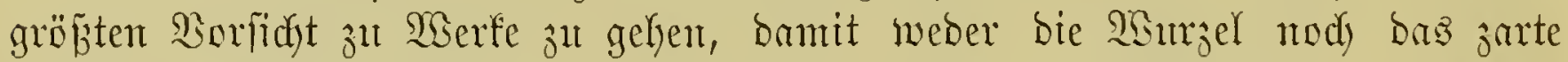

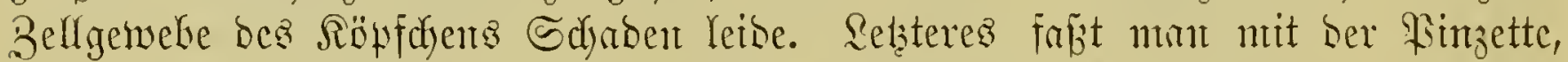

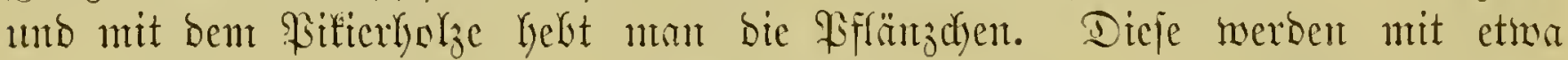

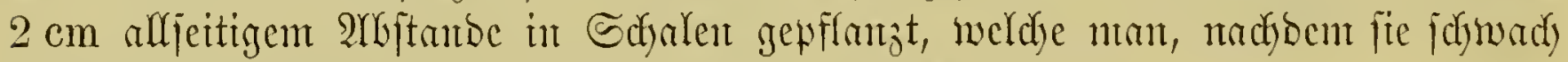

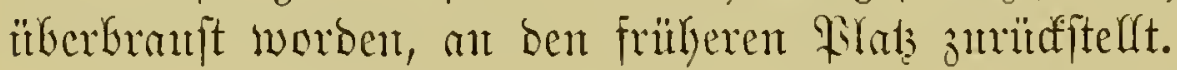

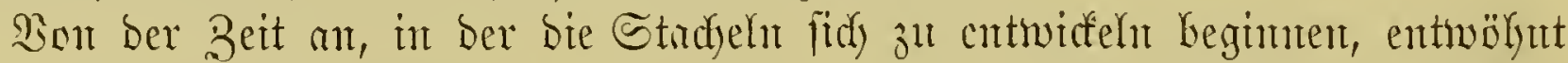

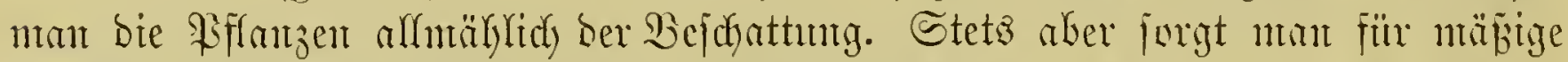

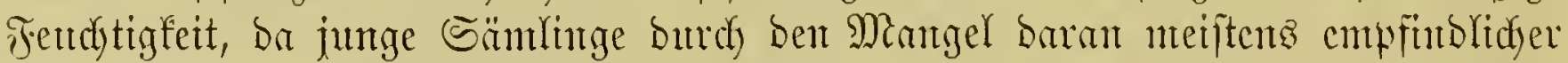
Yeiben, afs ältere Wiffanzent, unto infolge beffen oft zut Brumbe gehen. Bei jorg=

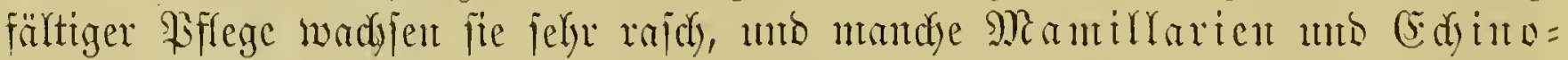

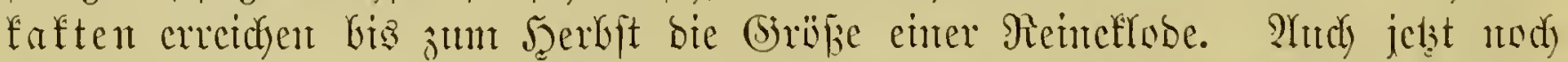

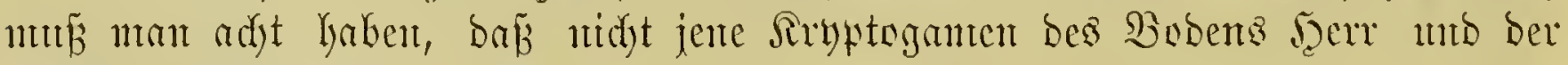
Siffanzen Serberben werbent.

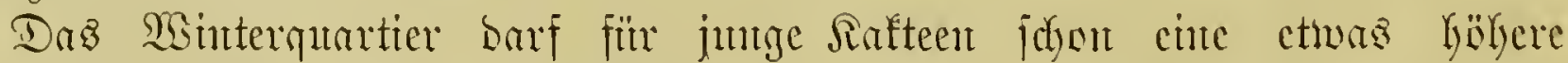

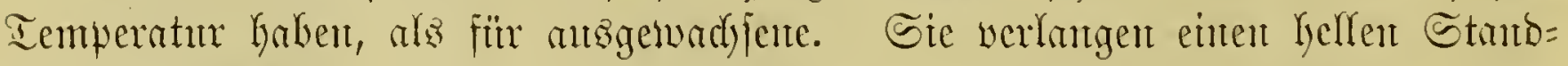

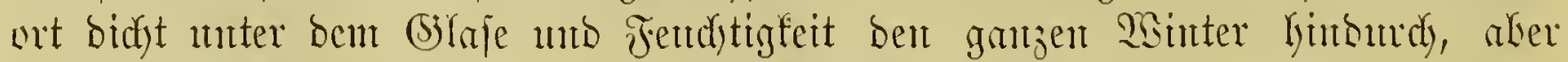

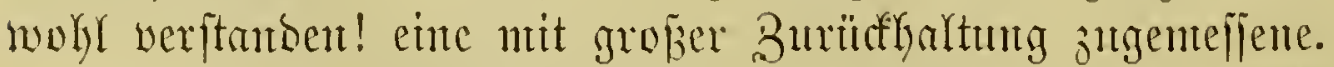

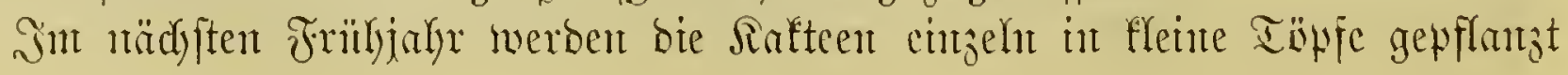




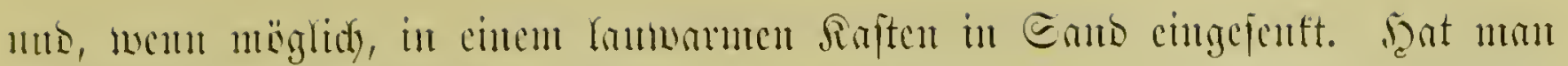

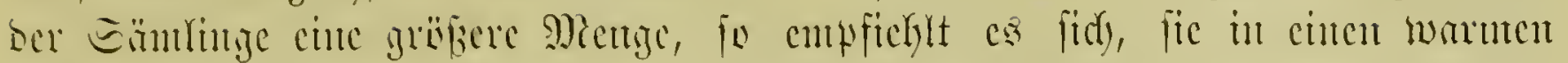

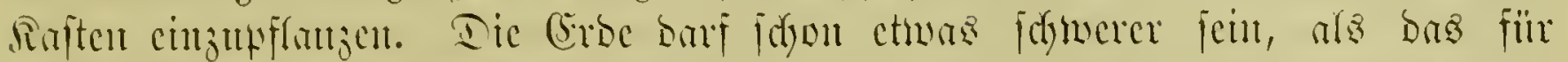

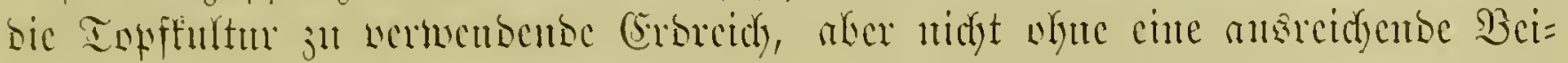
nenyutg nou Emt.

\section{Kafteenfeinde.}

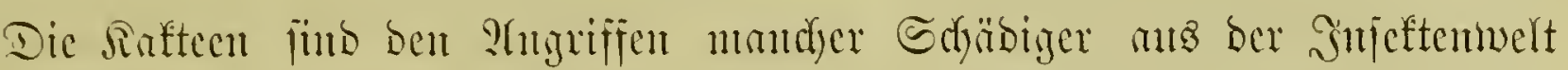

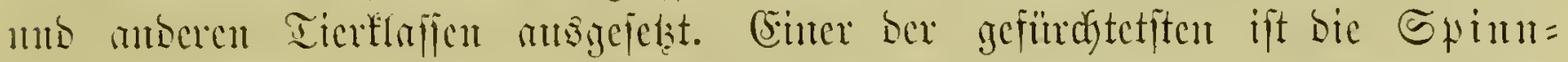

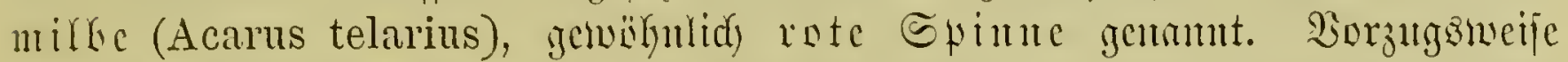

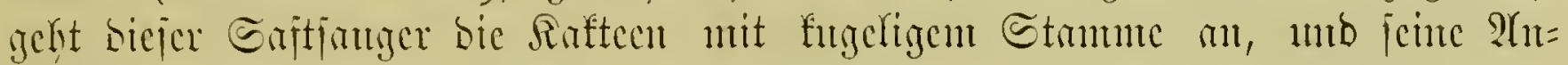

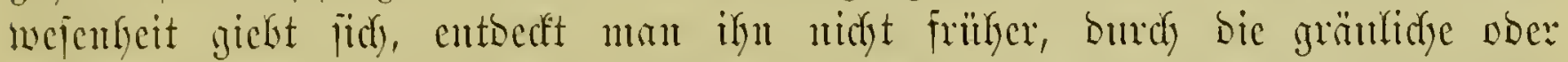

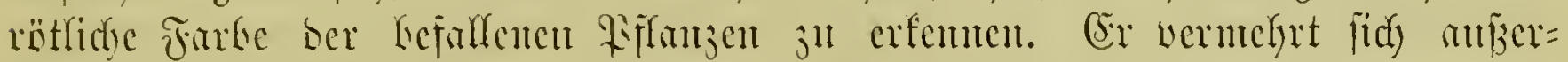

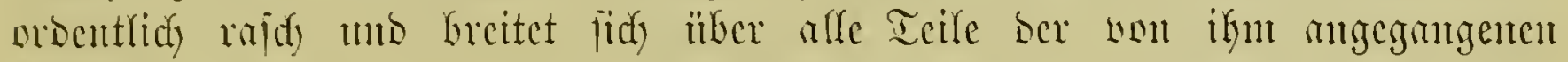

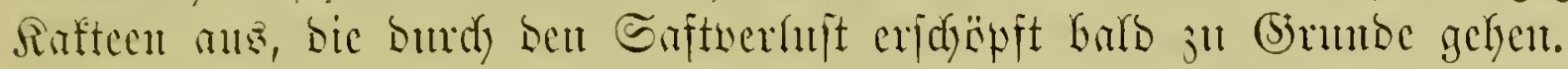

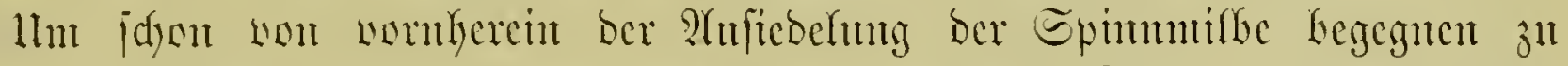

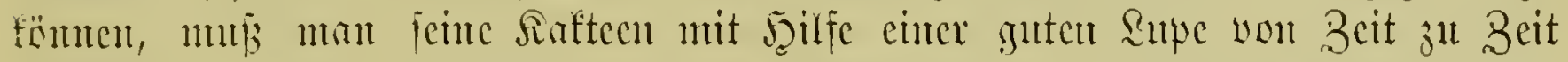

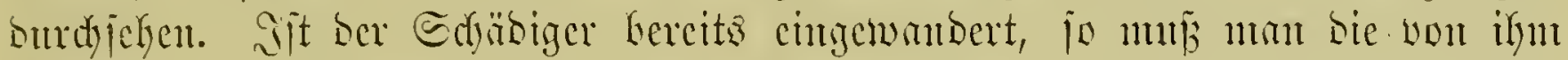

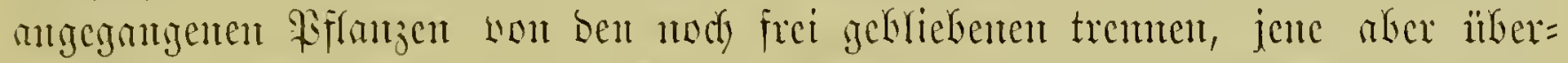

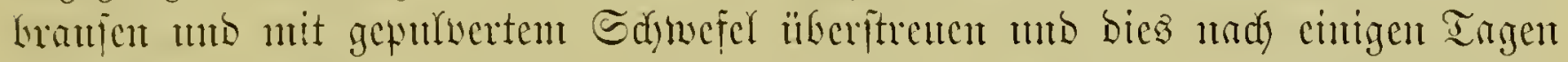

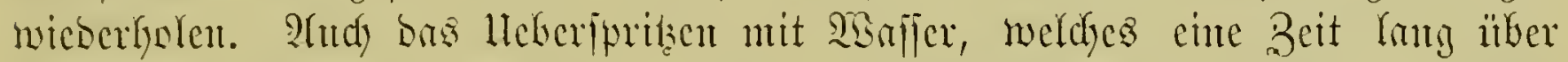

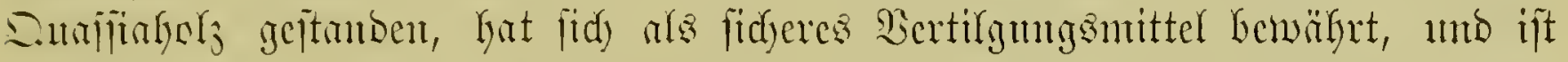

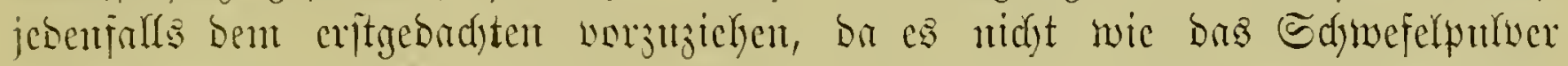

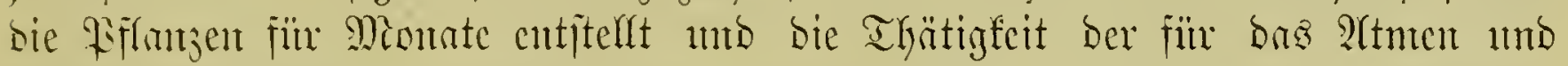

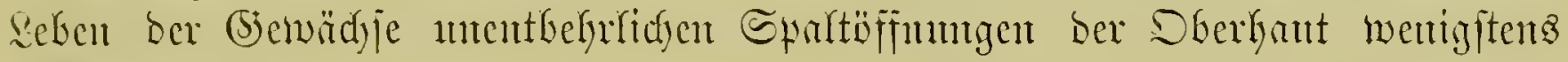
teirlweije miffebt.

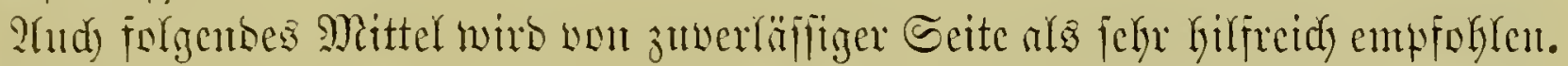

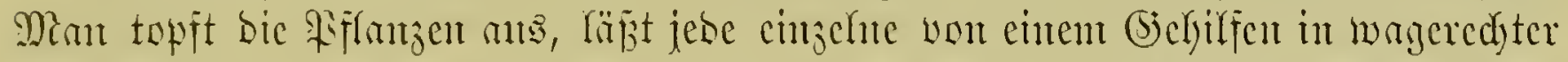

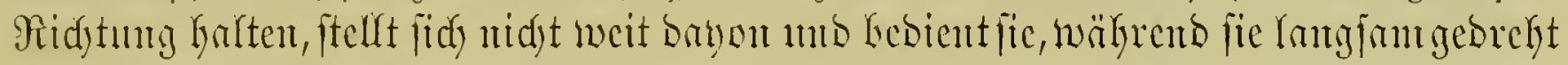
wirs, mit cinent cinjigen

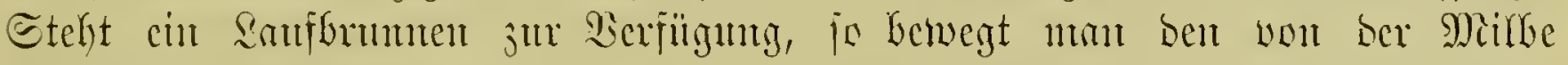

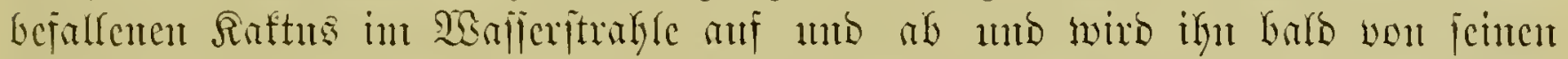

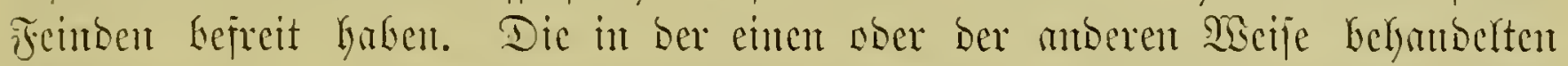

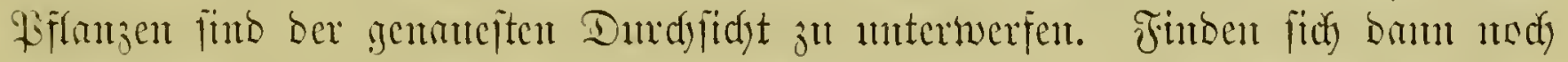

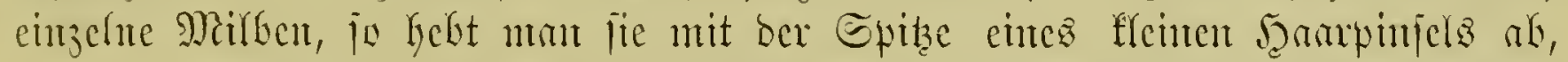
ben man mit cinen RYebemittel bejeudetet Gat. Die wieder eingetopften Raftecu

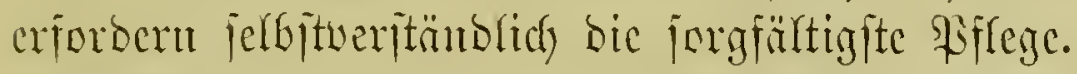

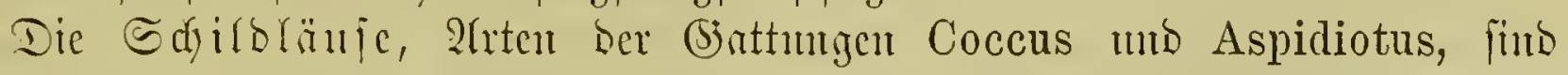

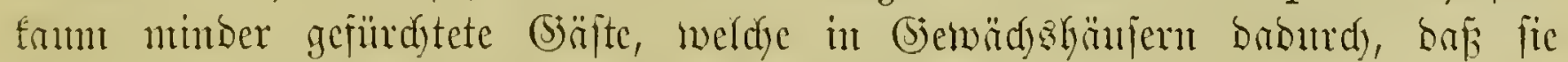

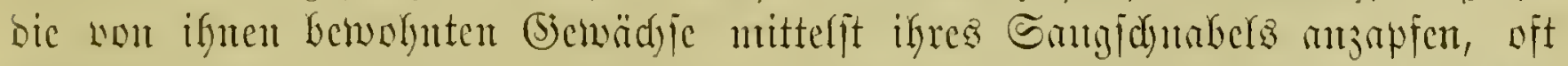

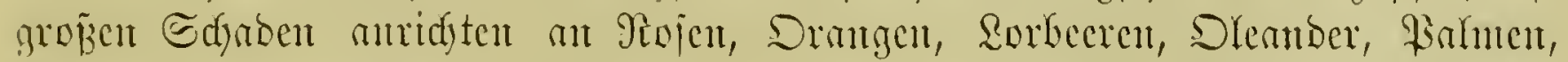
2hrnta, Baffecbünmen, Dracrencn

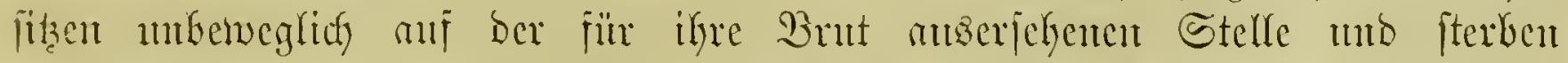

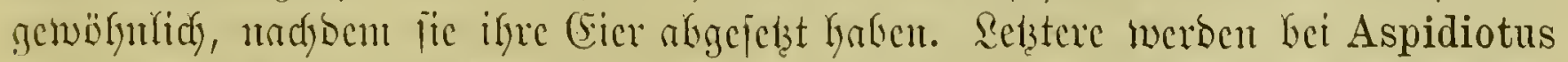

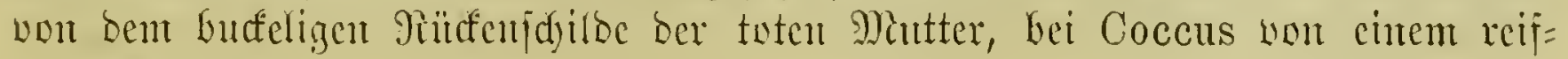




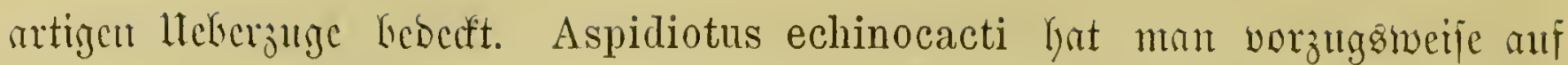

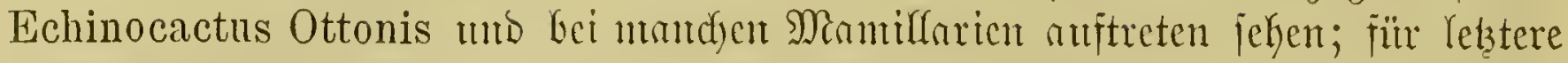
meroen Coccus mamillariae uto C. adonidum, bie Sdjirblnus bes Saffeebrumtes,

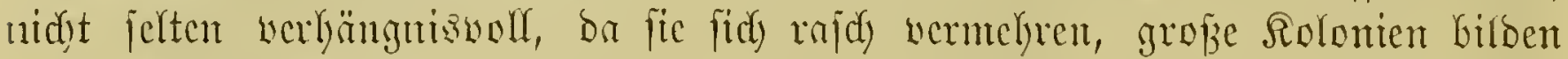

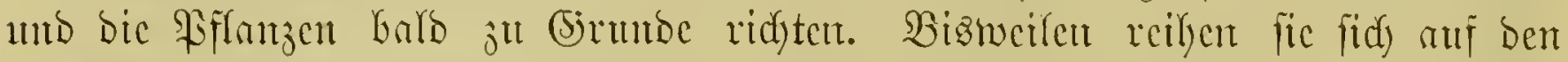

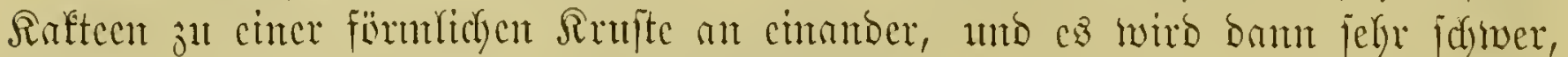

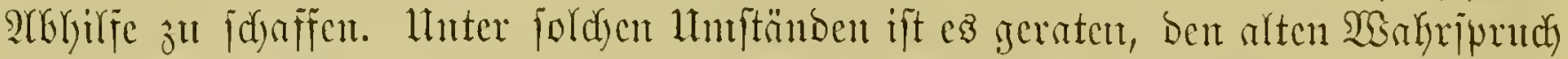

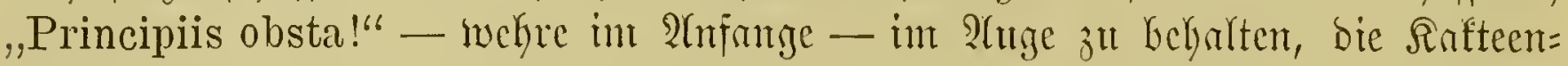

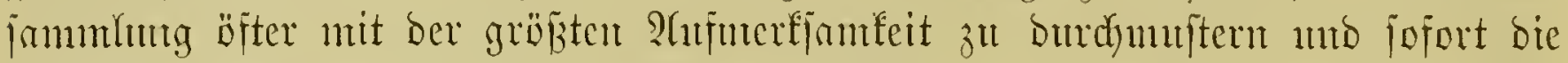

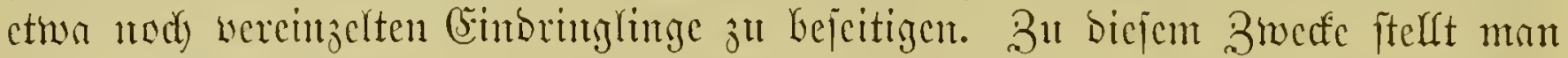

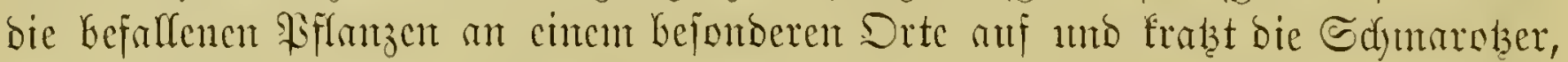

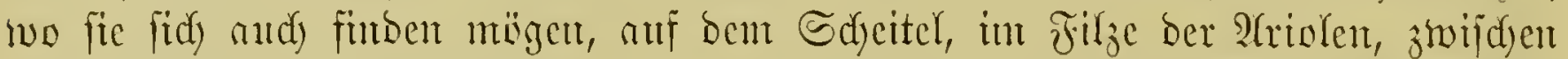

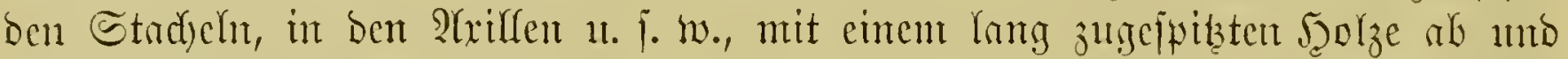

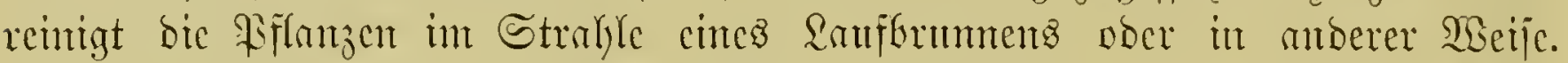

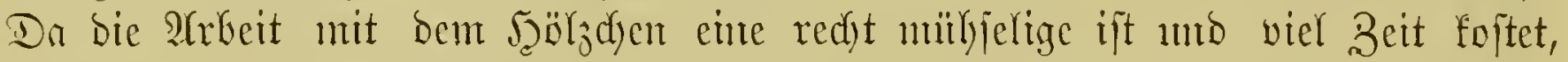

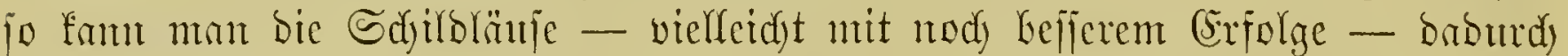

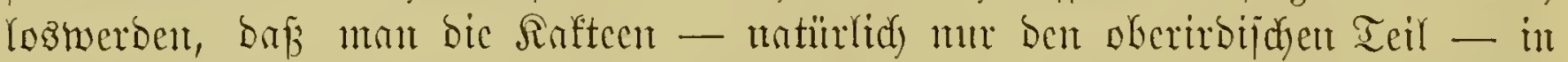

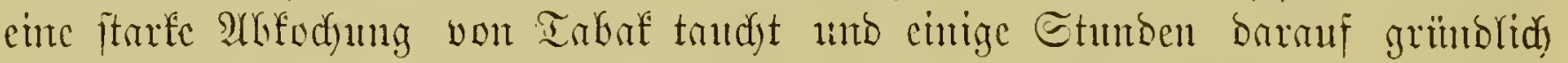

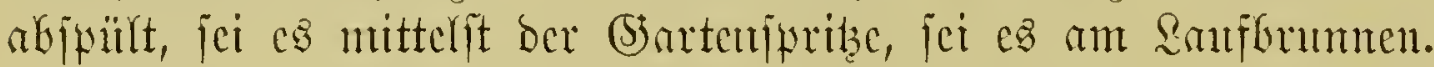

Silcute Ratten befreit man nady Iafdenberg von biejen Edjäbigent

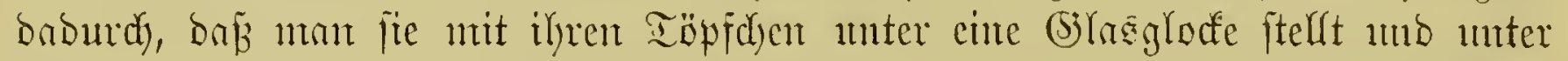

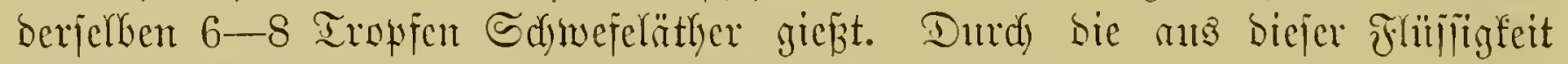

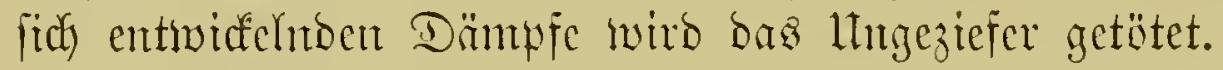

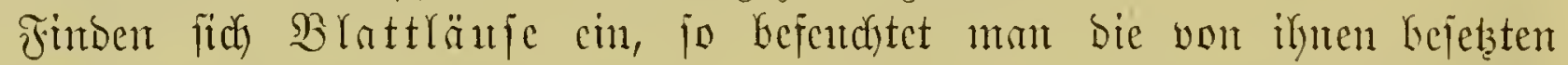

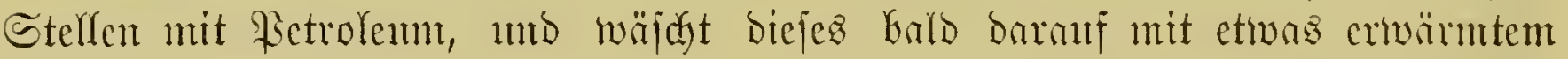

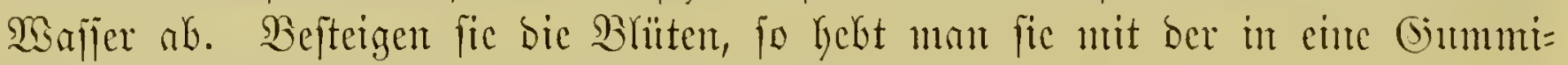

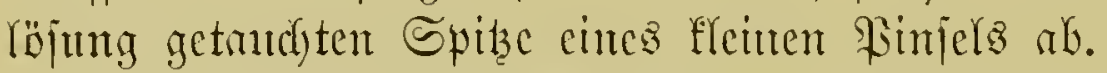

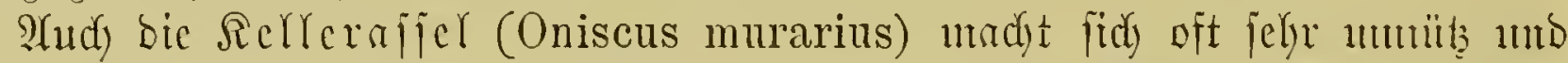

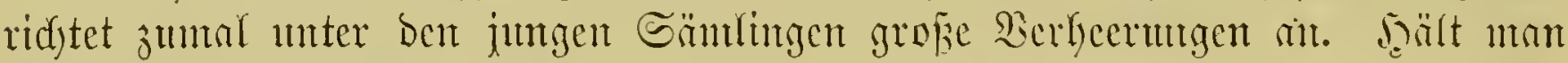

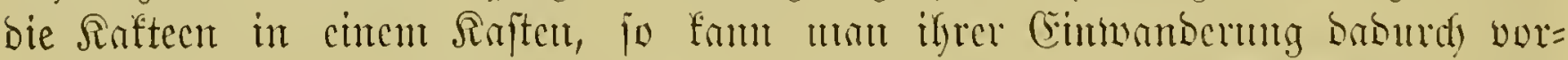

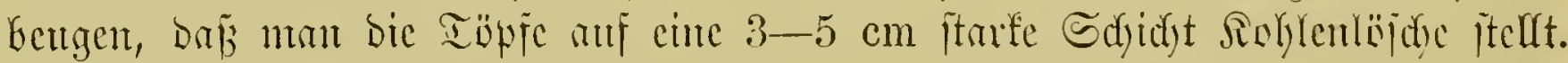

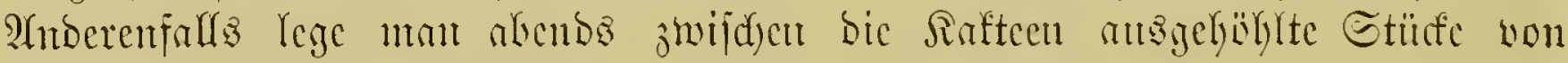

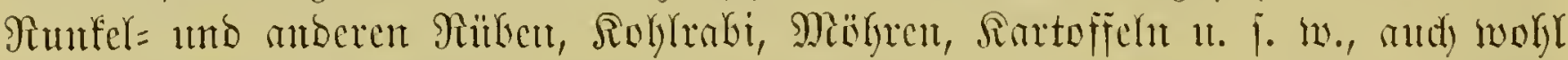

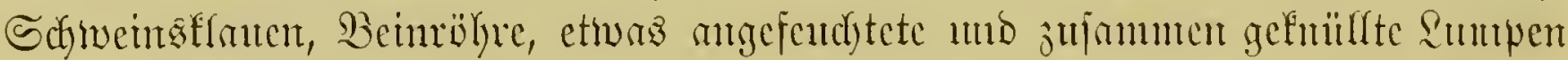

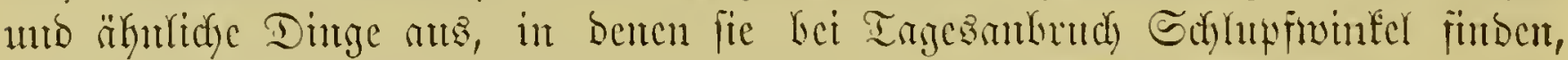
fo baj man ifjer Yeicht Kabgaft werben und fie in Menge töten famm.

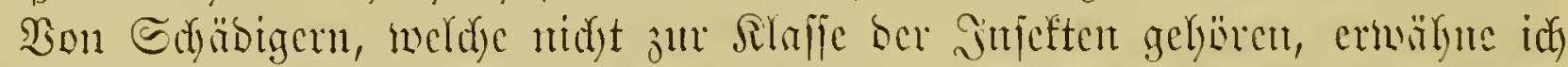

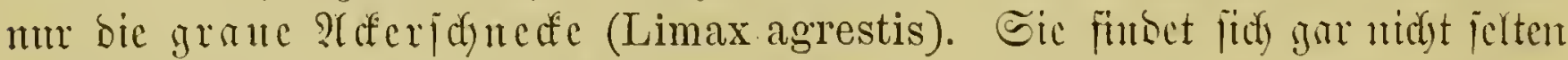

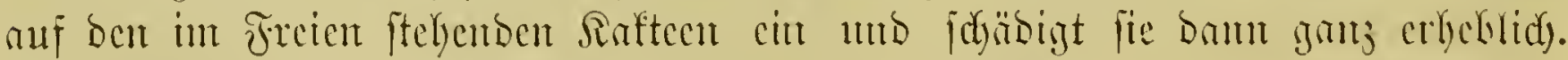

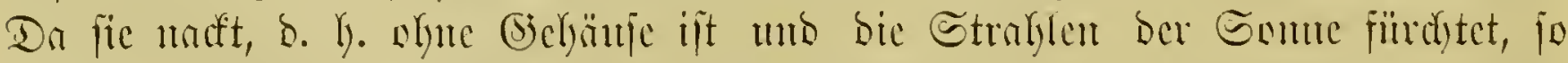

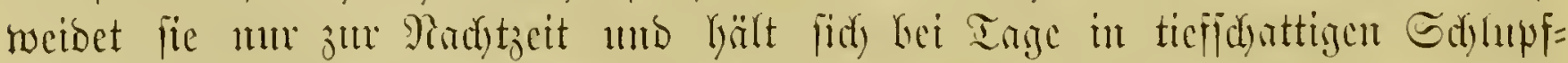

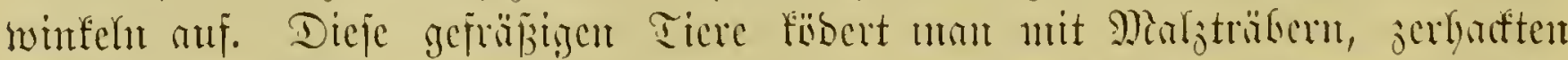

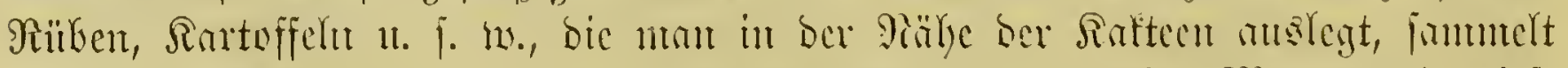

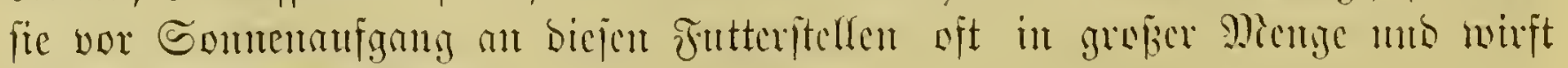
fie bem Soufgeflitigel wor. 


\section{Kranfheiten Der Kafteen.}

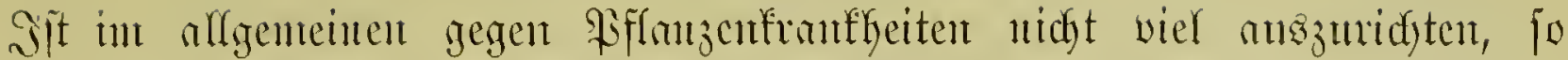

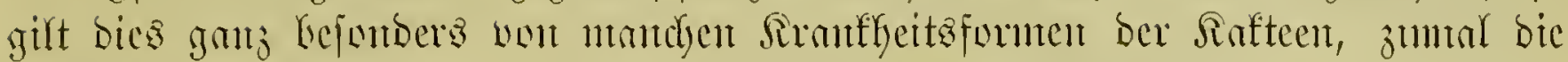

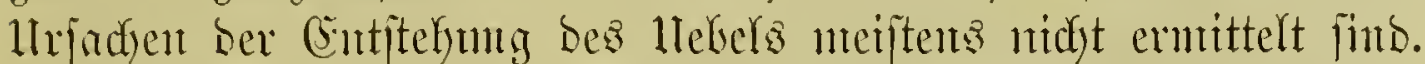

Mit Redyt gefündytet ijt bie Stammfämle, weldye cutweder vom Sdyeitel

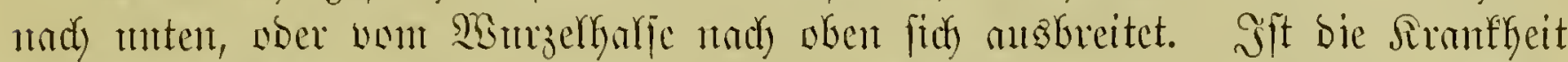

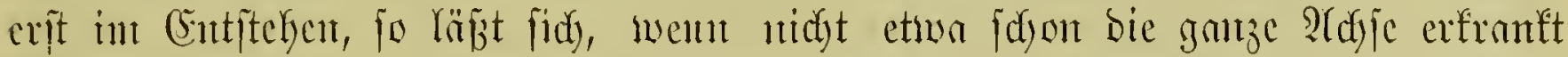
ijt, int erjtent Falfe ber untere Ieif bes Strmune zur Erzengung von Material

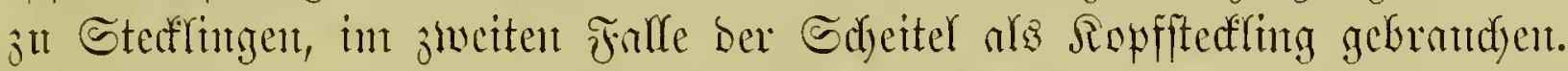

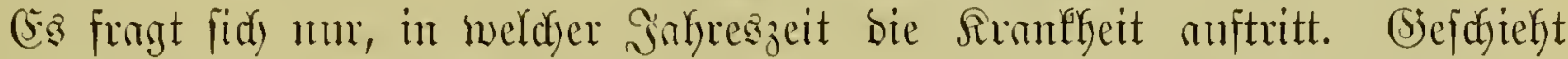

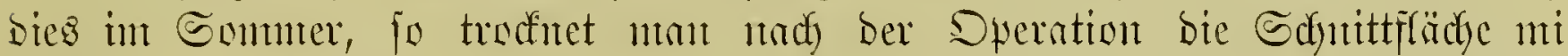

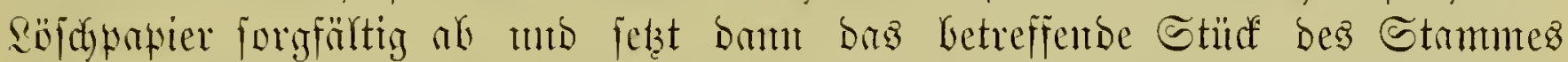

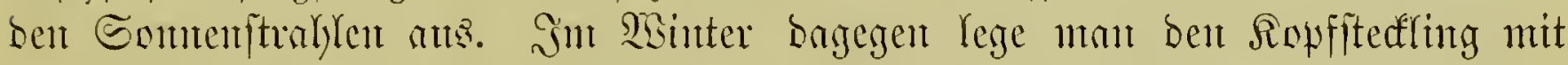

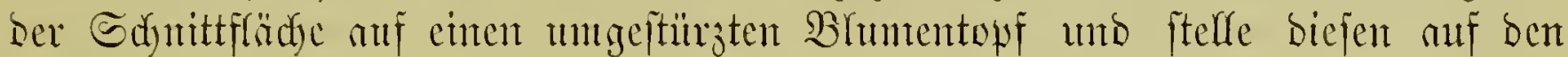
Dfen Gis bie

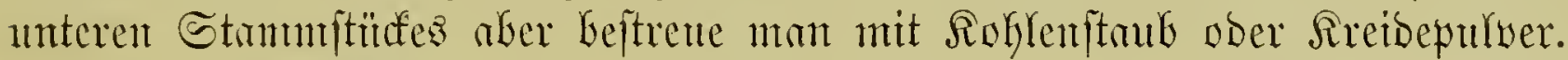

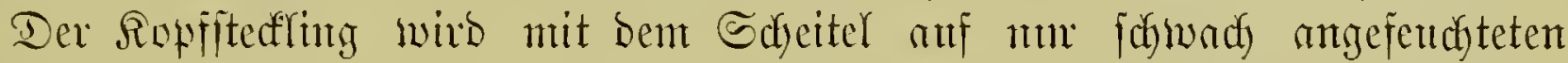

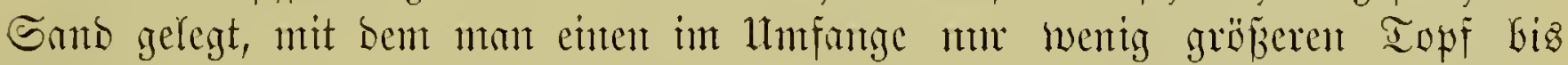

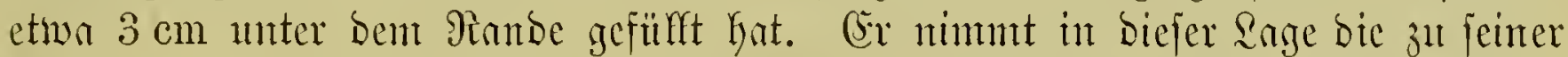

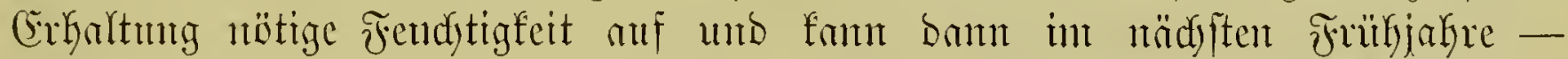

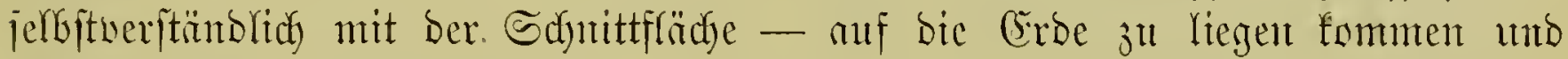

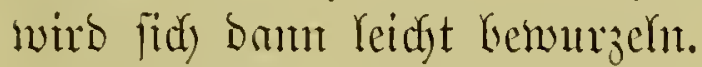

Bişweilen tritt Fäule an einjelnen Stelfen Des Strmunes arf. Soldje

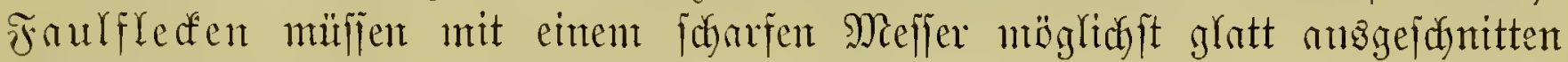

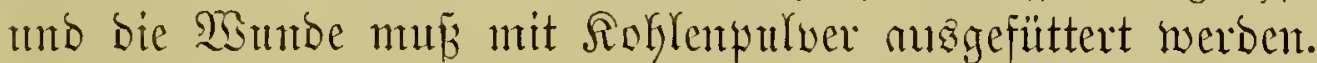

Bei anberen Formen ber Fönle pffegt Seilung von ferbjt einzutretent. Bei

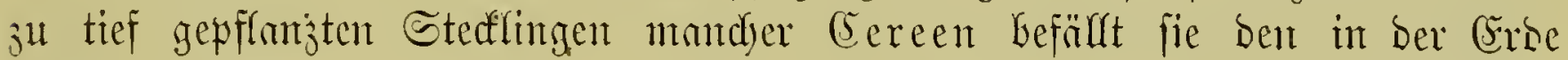
itehenden Teil, geht nady unt nach etwas aufwärts umb madyt baum baalt,

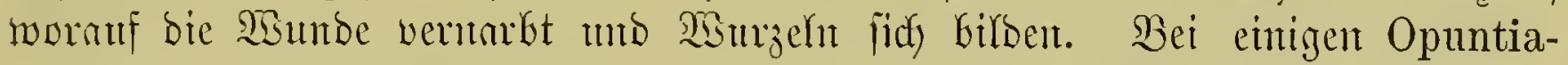

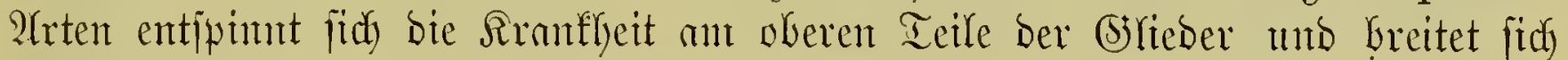

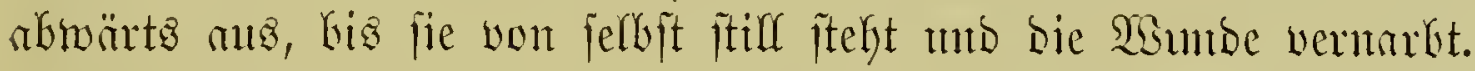

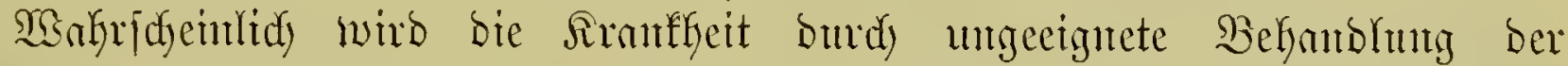

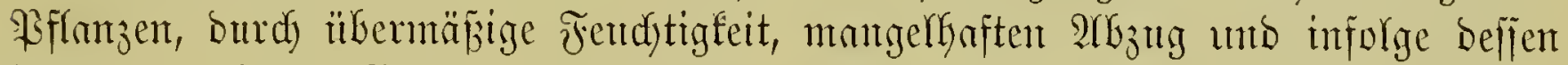

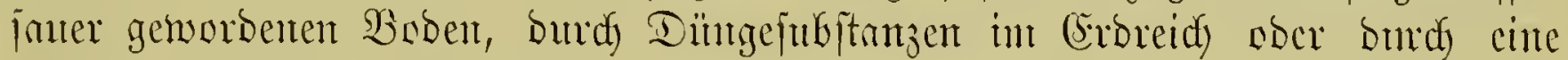

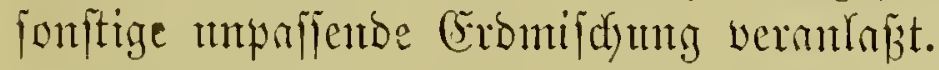

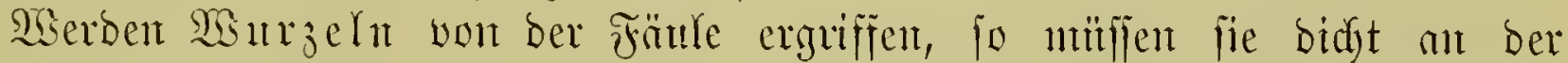
Itriprungsiftefle meggejdyttten werben, woranf ntan fie bald burd) juntge erjetzt

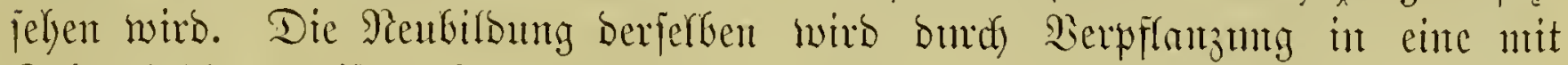

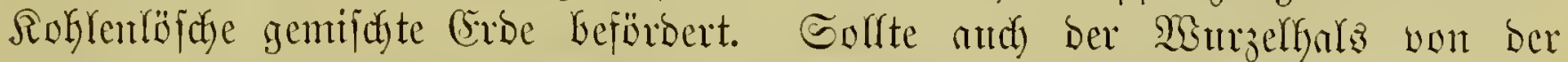

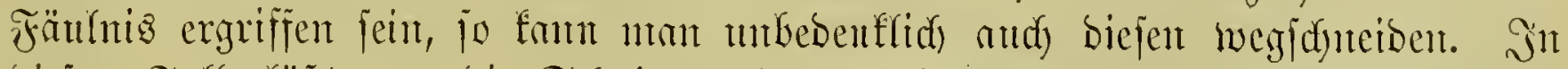

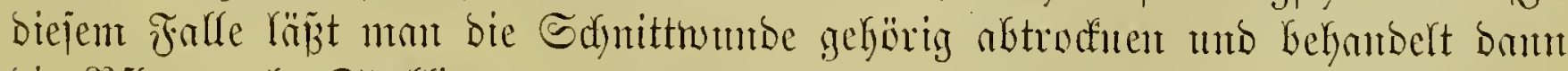
bie Siflanze als Stedfititg.

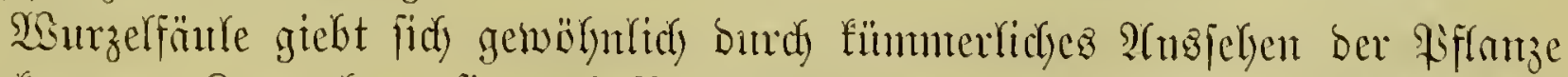

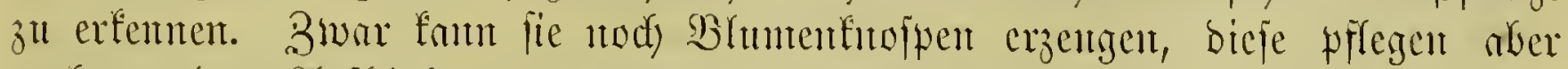
trod) vor bem ?atfblïgen zu welfen unb abzufarfen. 


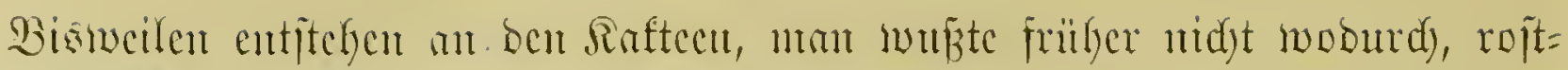

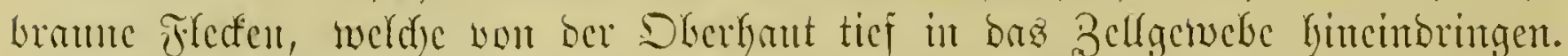

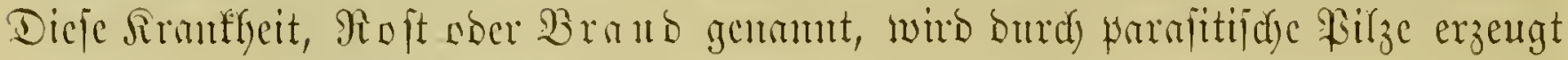

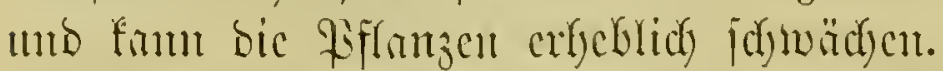

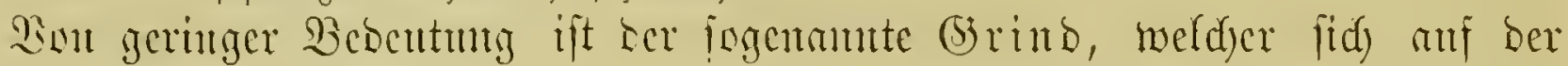

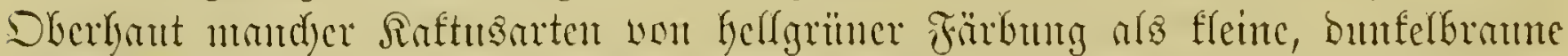

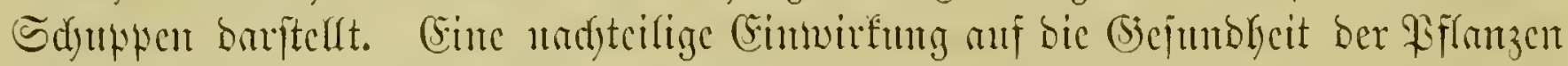

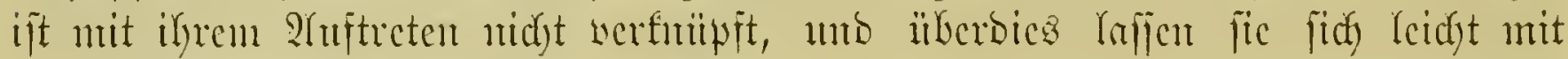
ber Exitie cintes Febermeffers abjeben.

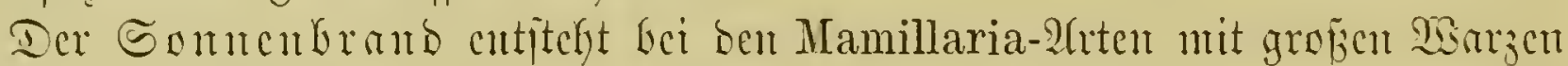

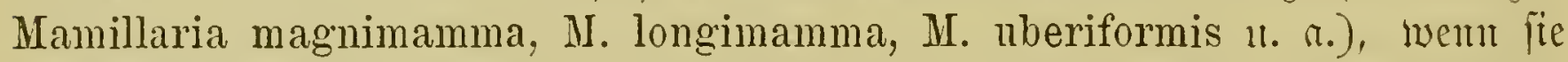

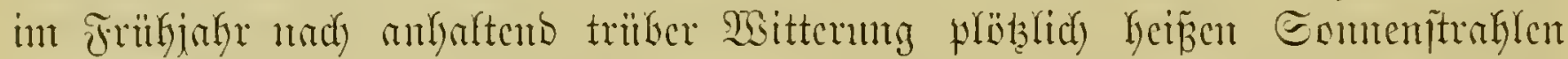

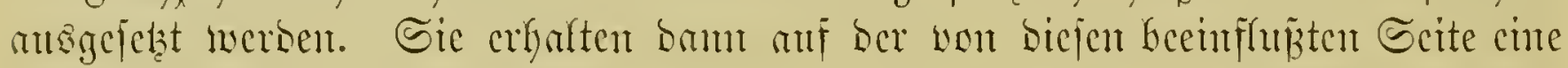
bunfelrotbrante Farbe. Stellt num jie aber io, baj bic frantfaft affigierte

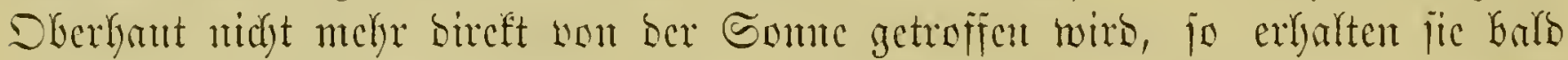

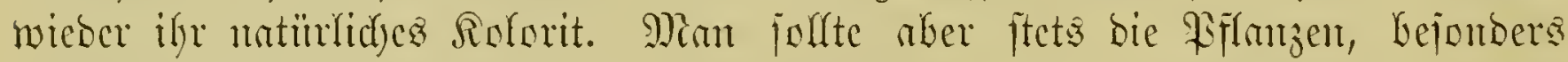

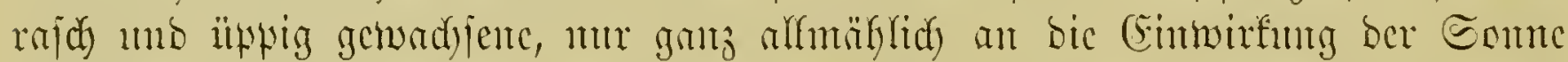

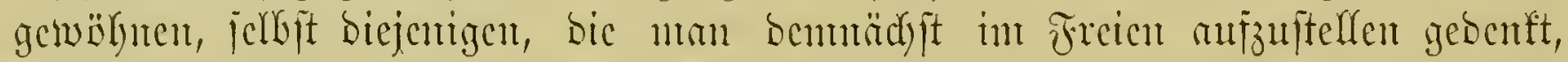

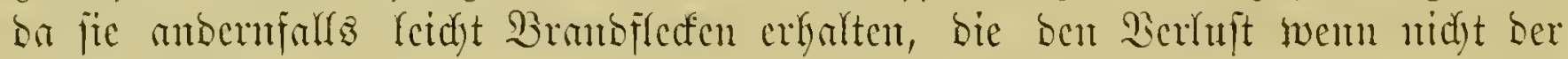
gantzen Riflanze, jo bod) eintiger Teile zur Fulge hatent fö̈men.

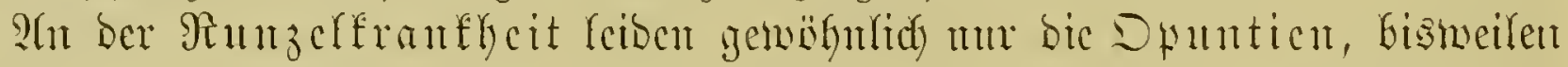

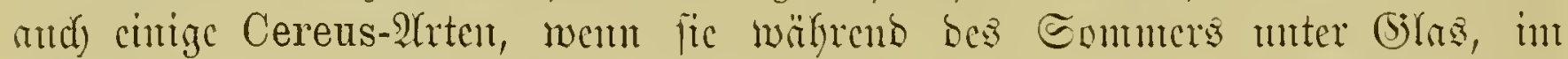

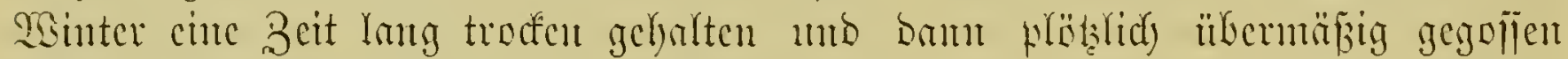

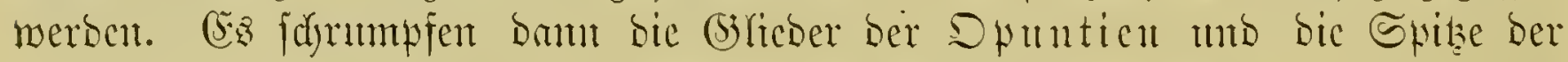
Ecrees jufanmen, werbent rutzerig, fpäter mafjerjüd)tig unt gehen baran zu

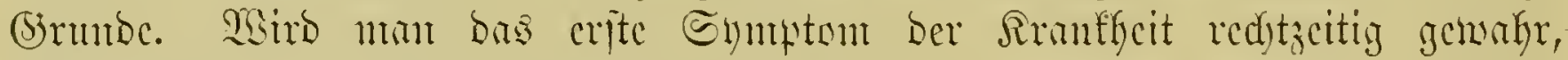

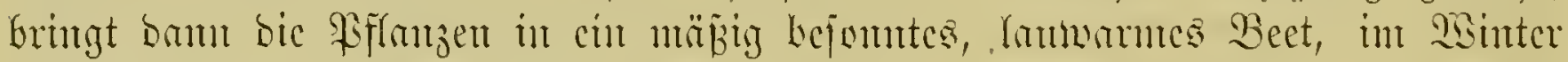

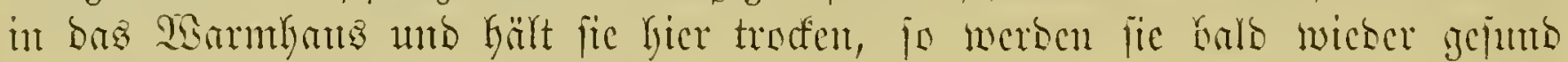
nerbent.

Dic. Breidjudet befäfft meiftens nur junge Riflangen ber Giattungen Cereus unt Echinocactus. Mit bcu Ahftreten bes burd) bou Pimucu mige=

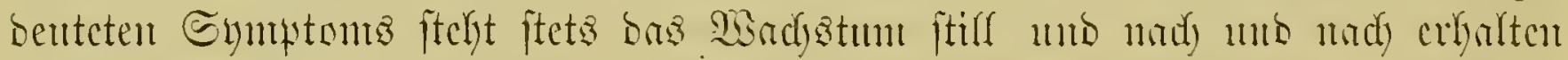

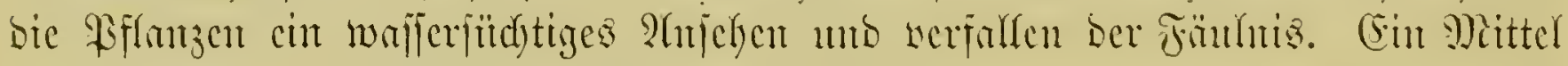

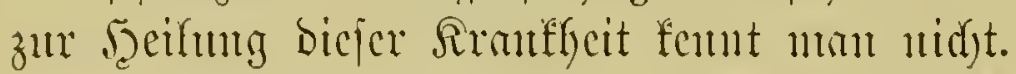

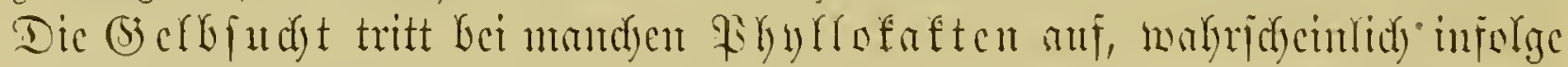

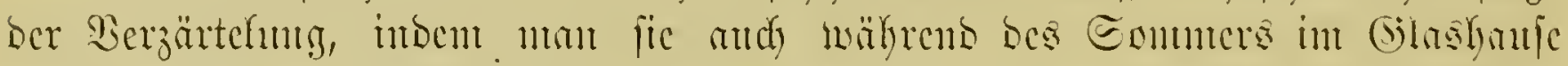

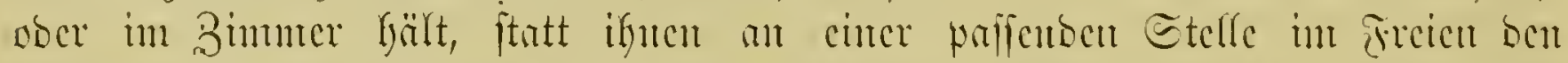

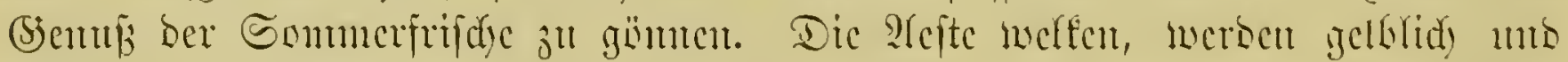

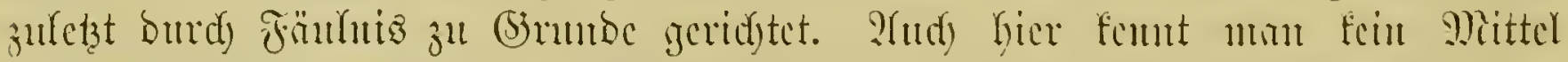

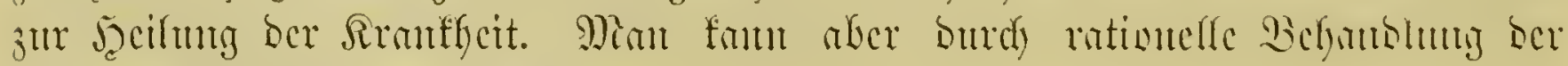
Wfflanzen ifgr 9 luftreten verfüten.

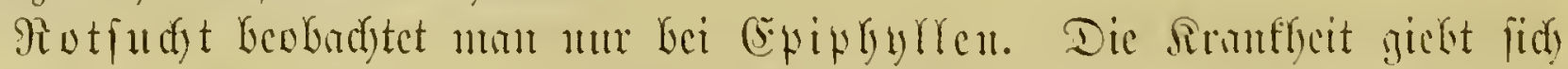

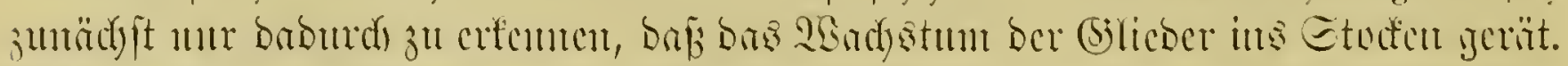

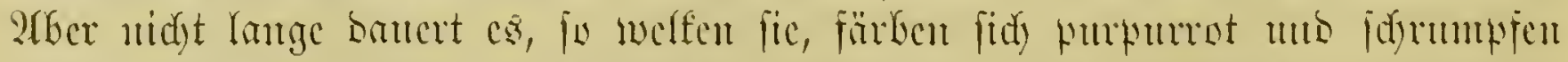

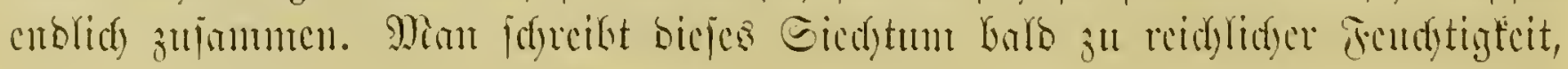




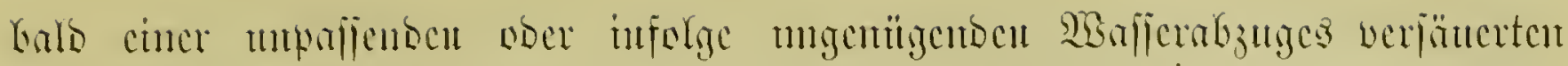

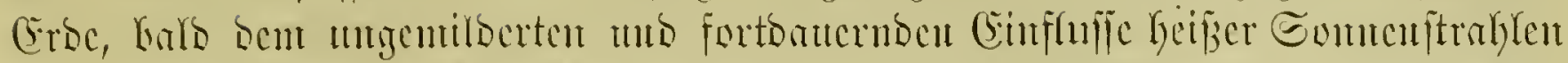

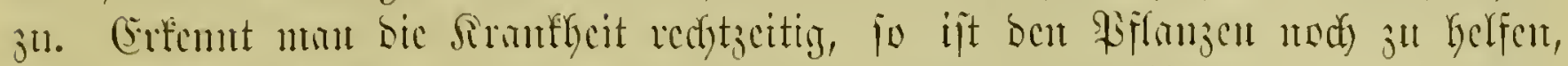

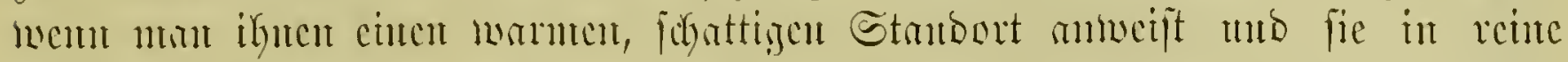

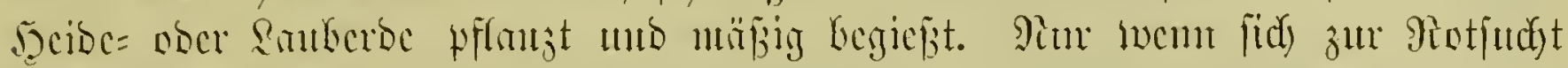

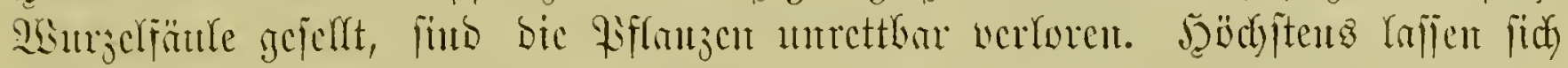

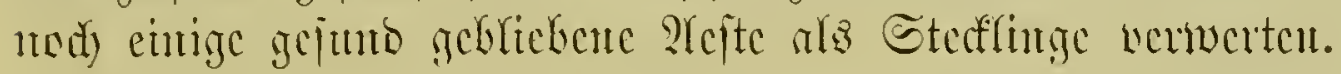

\section{Kultur.}

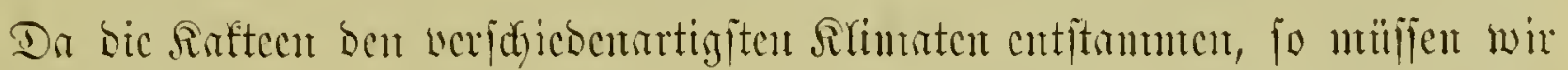

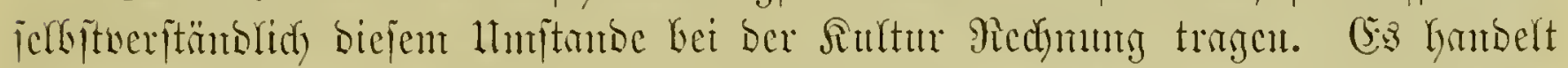

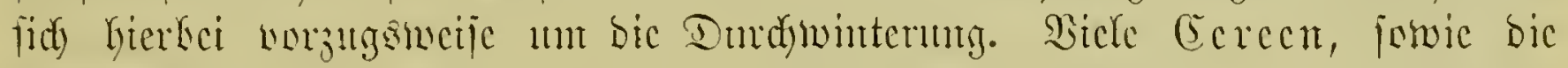

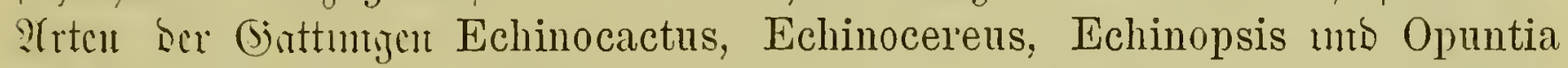

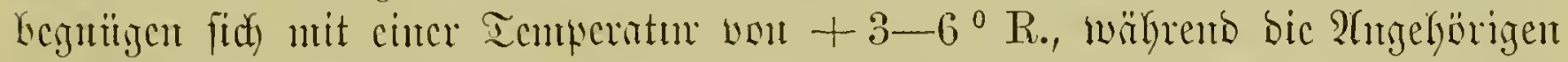
Scr Gattungen Epiphyllum, Nelocactus, Phyllocactus, Pilocereus uno Rhip-

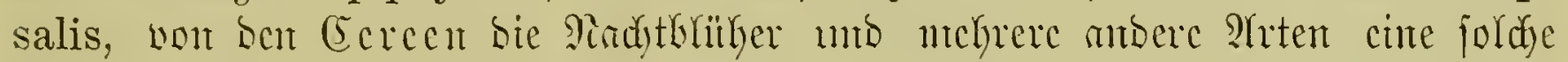

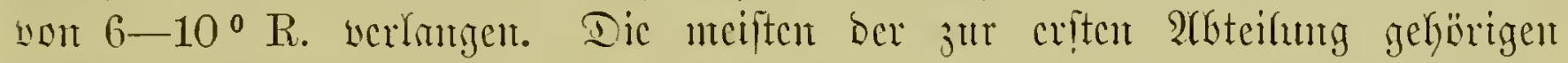

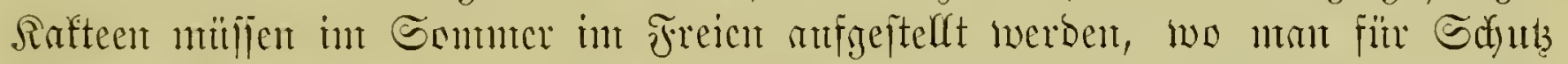

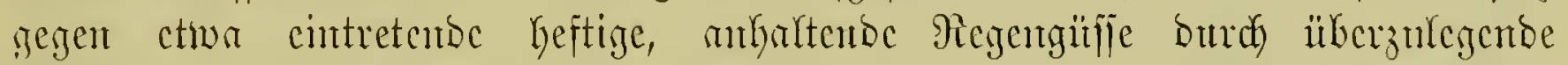

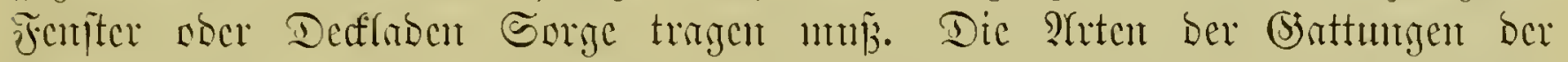

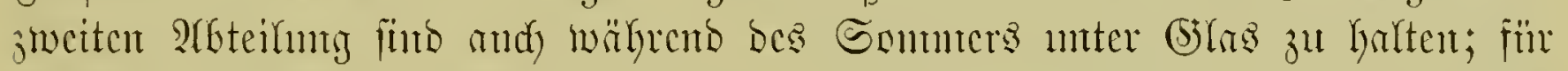
Phyllocactus unt Pilocereus ift ca jchr vortcilfaft, wcut man in ber wärntitcn

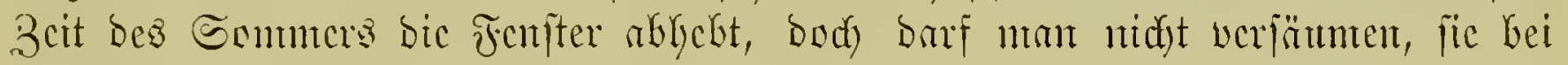

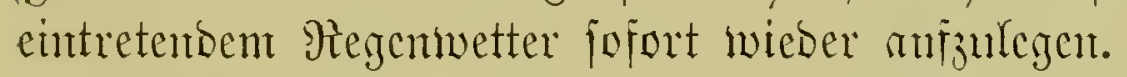

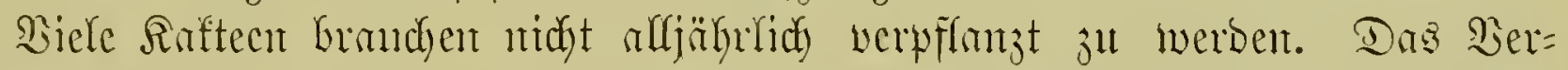

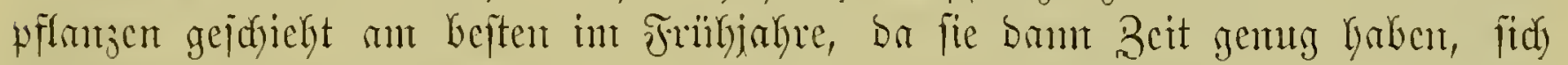

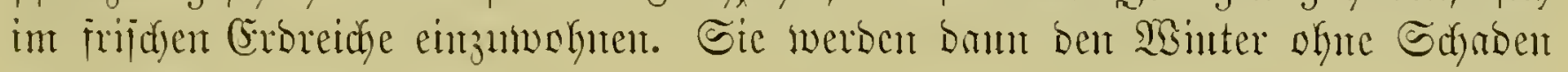
wertrager.

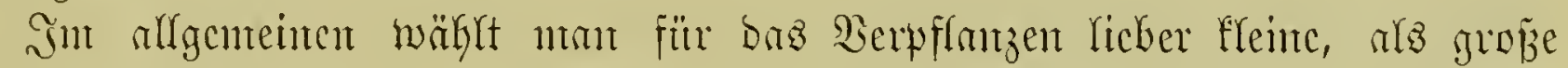

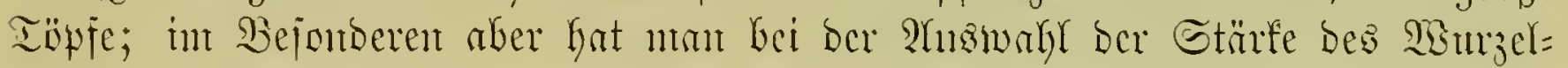

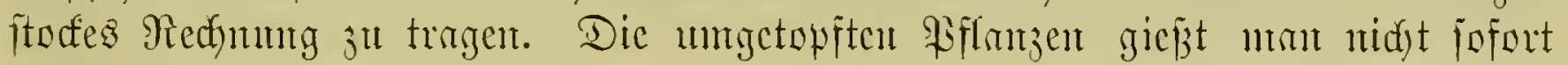

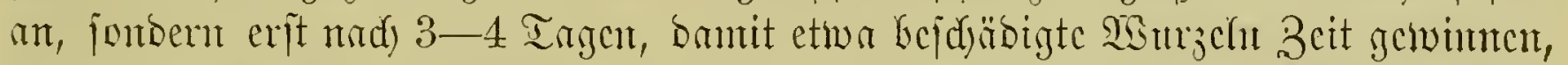

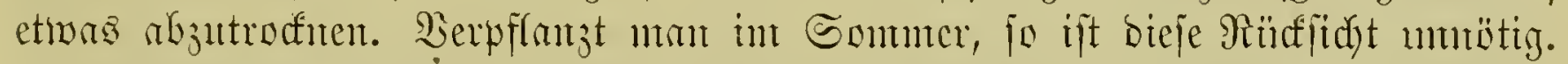

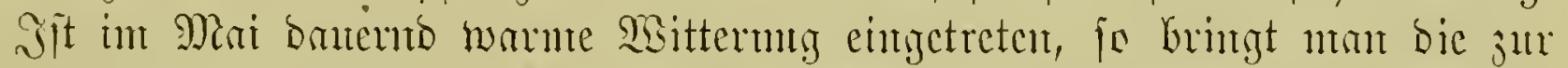

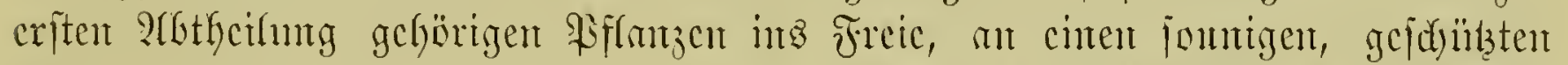

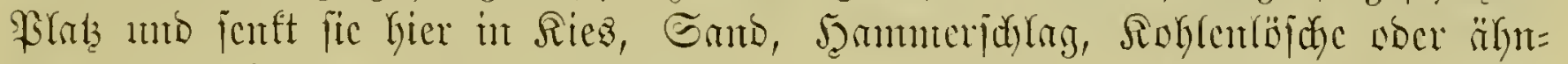

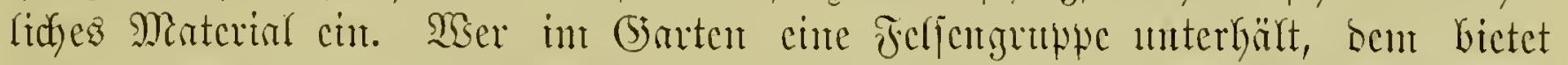

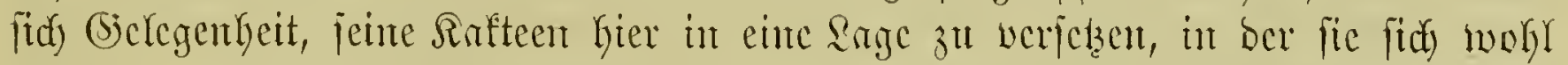

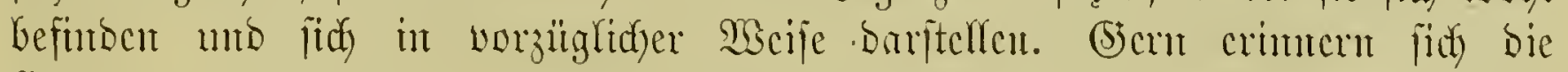

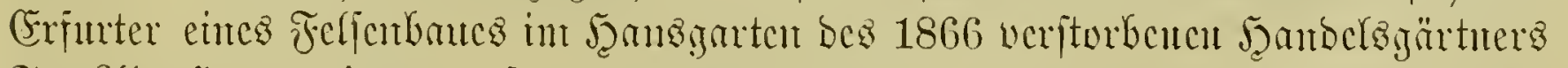

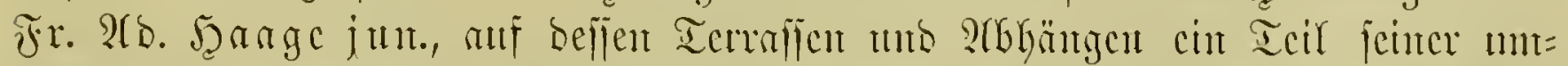

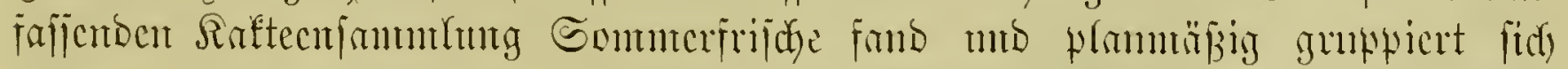

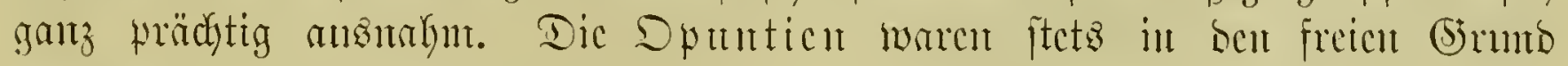
gepflimit.

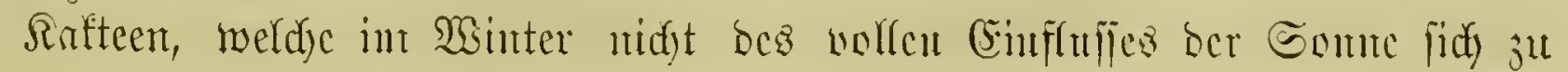




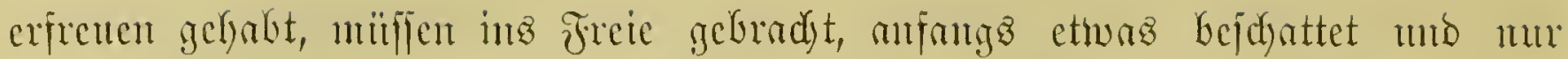

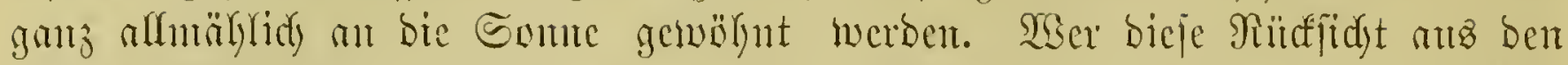

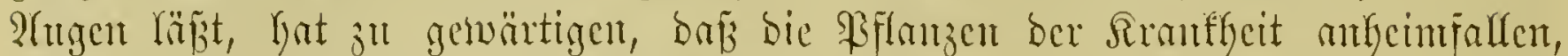

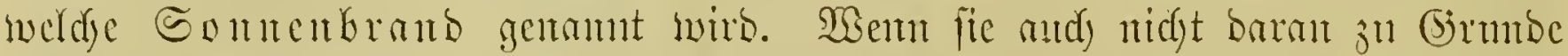

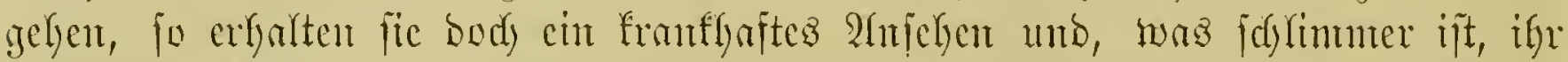

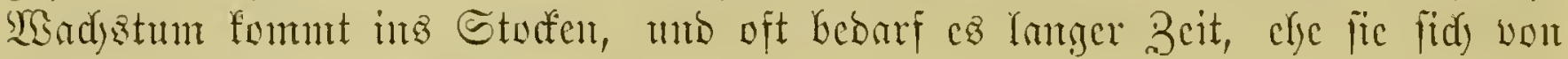
bicjem Sicdytume ertyolen.

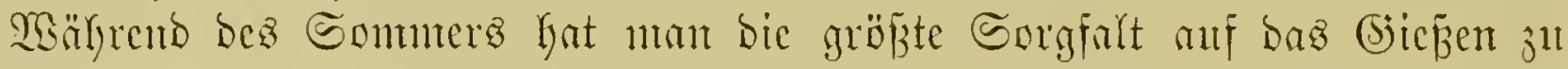

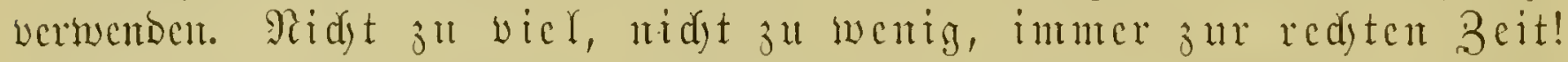

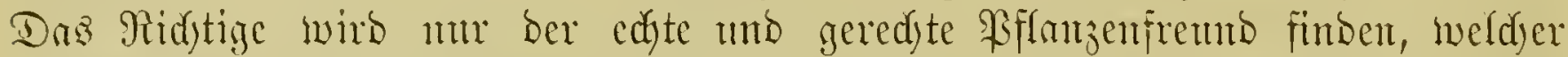

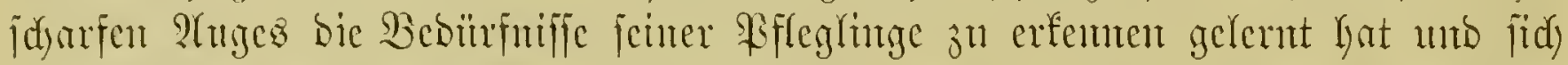

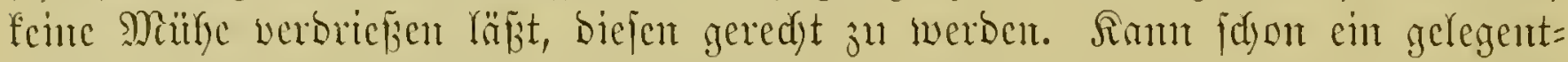

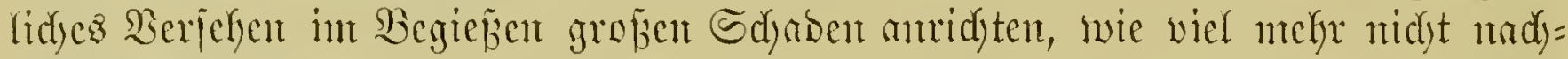

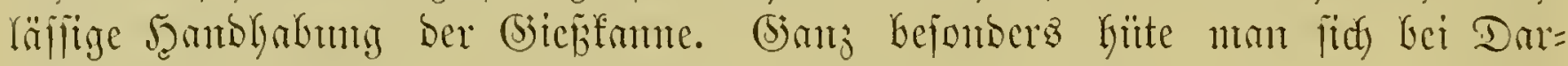
reid)mis wou

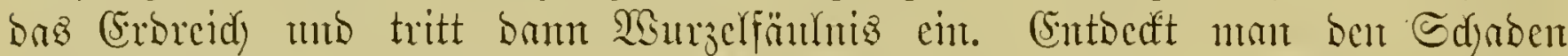

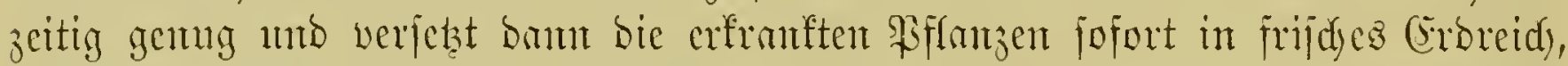

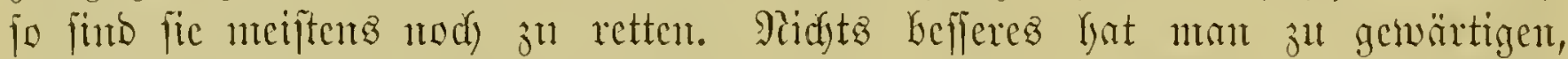

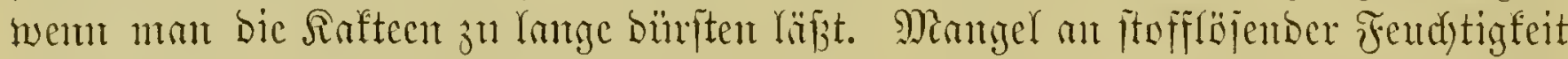

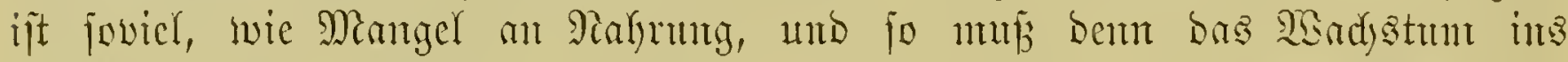

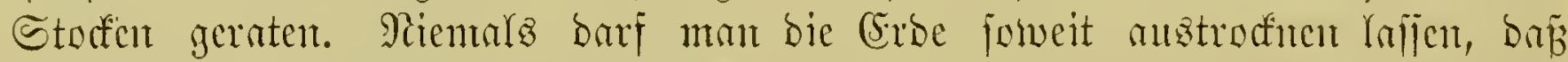

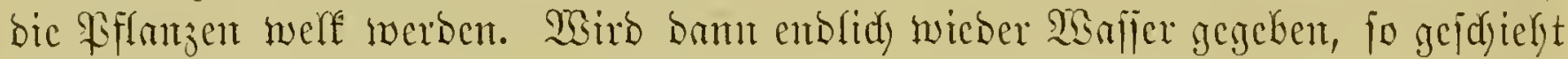

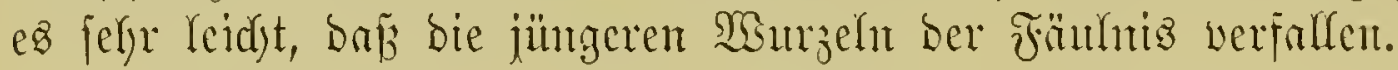

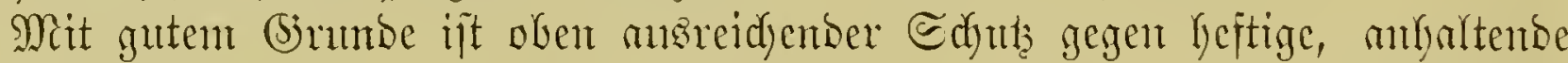

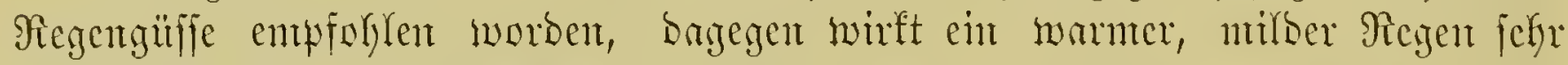

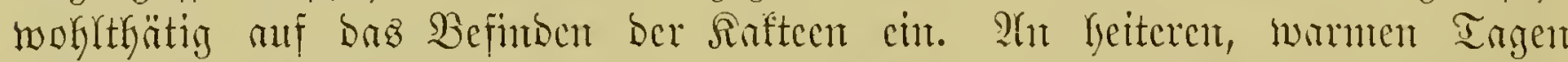

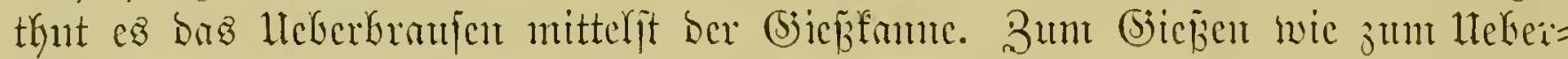

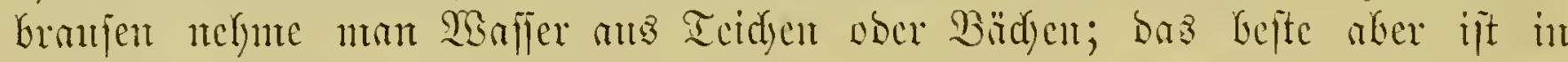

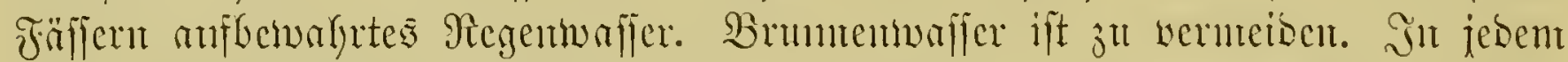

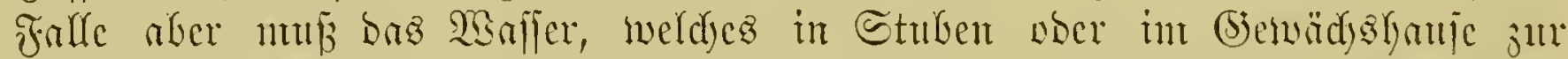

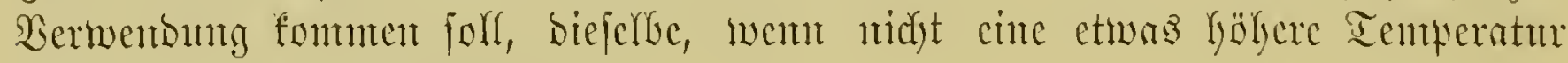
Gefiżen, ala ber Sillturraum.

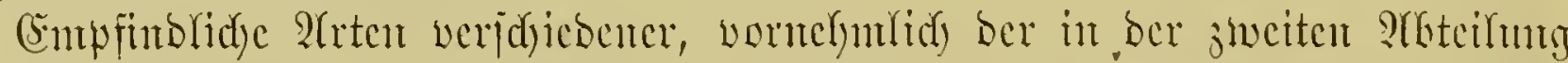

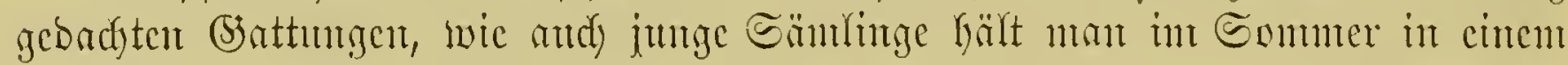

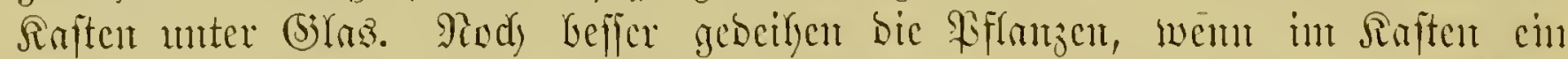

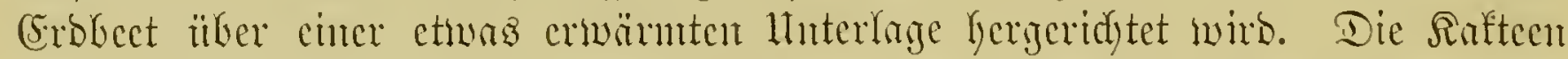

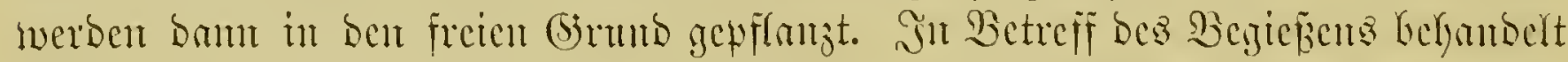

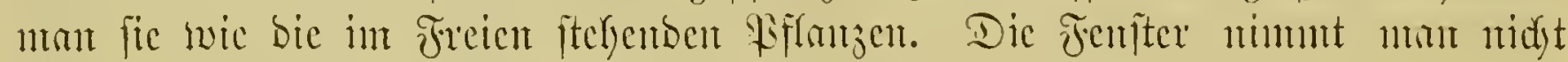
lyintweg, giebt afer bei gecigneter 2 sittermin bie nütige \&uft.

\section{Derntehrung.}

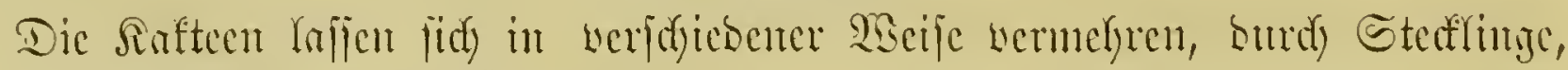
burdy Sifrupfen und burdy ?tusfant.

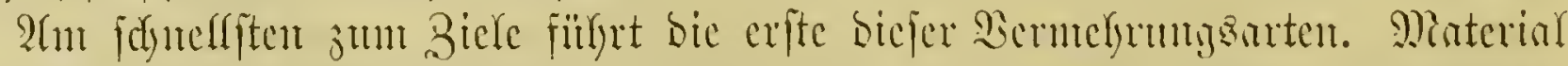
rierfür ift won ben Banttungen Cerens und Pilocereus, fonic won cinigen 


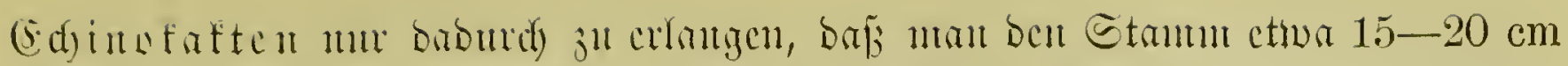

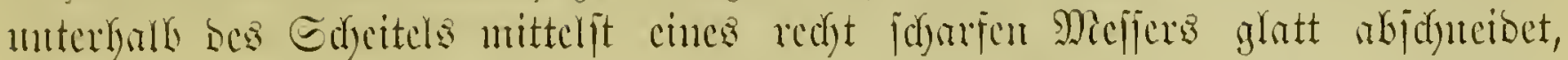

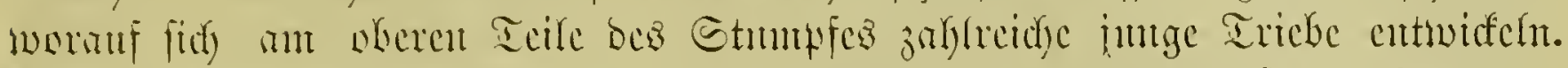

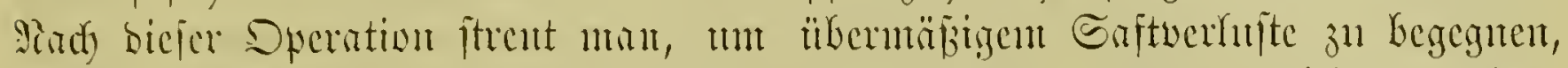

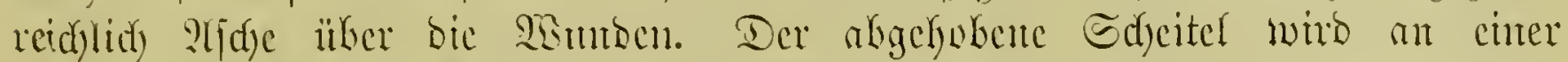

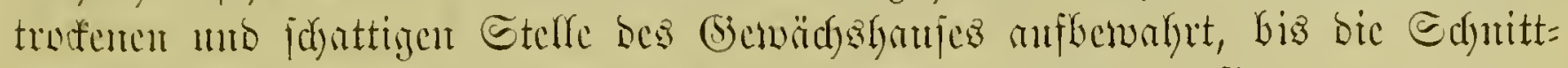

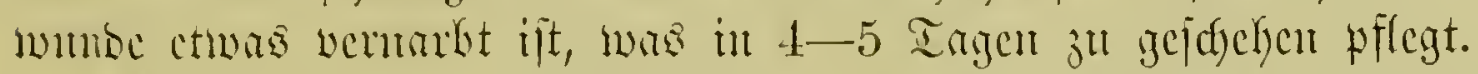

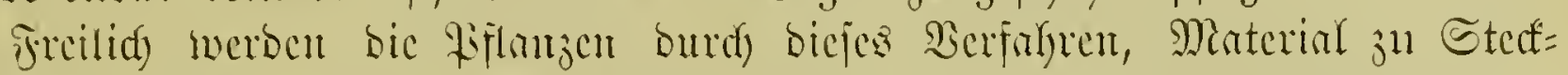

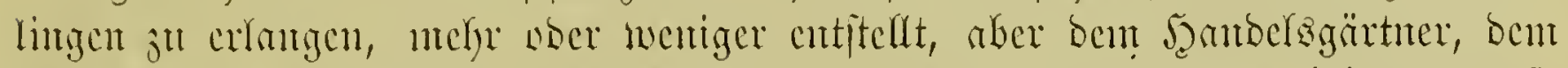

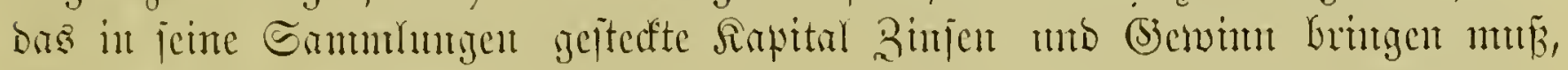

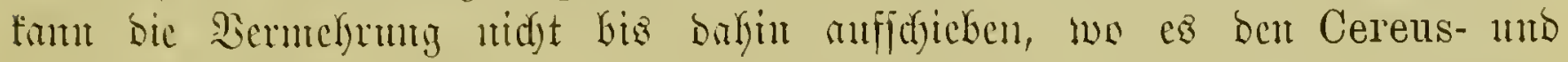

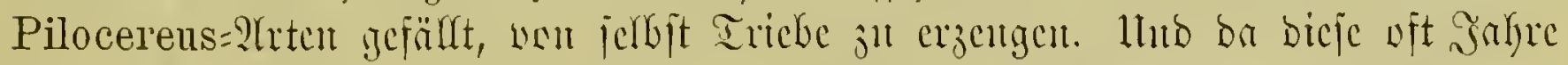

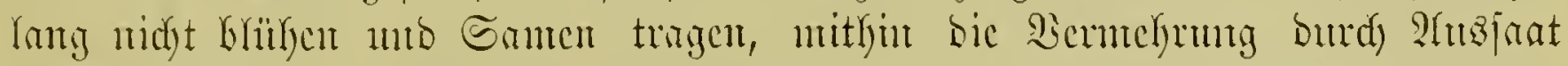

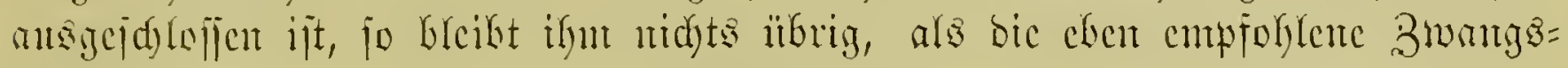
majresgel.

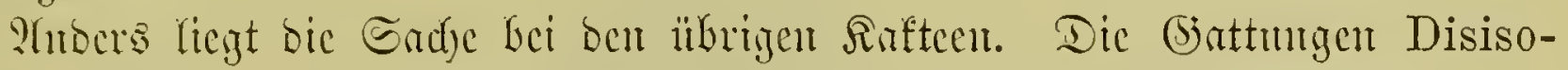
cactus, Echinocereus, Epiphyllum, Opuntia, Peireskia unt Rhipsalis crjertgen wou jelbit jeitfidye Iricbe in genïgentor Menge, Echinocactus, Echinopsis, Malacocarpus utb Mamillaria Gringen Triebe and an ber Bafis. Sn jebent

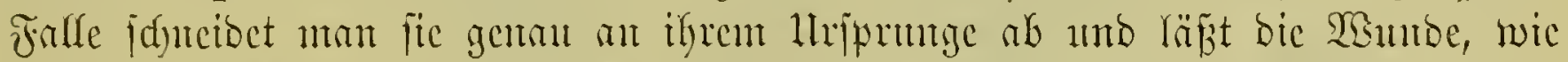

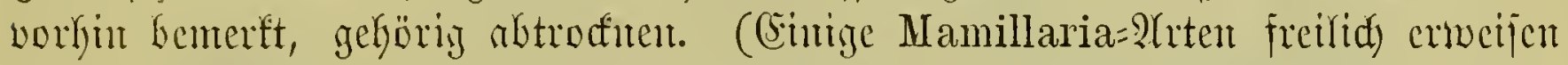

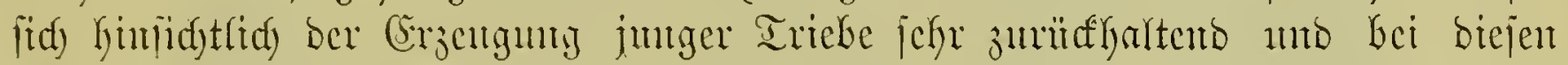

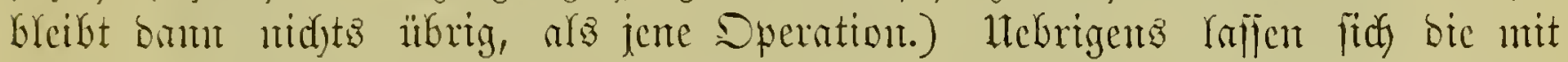

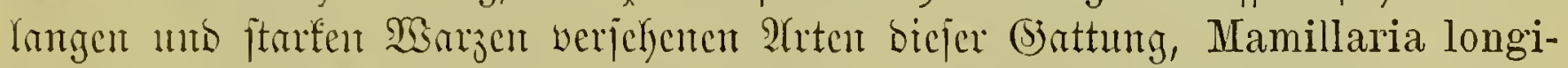

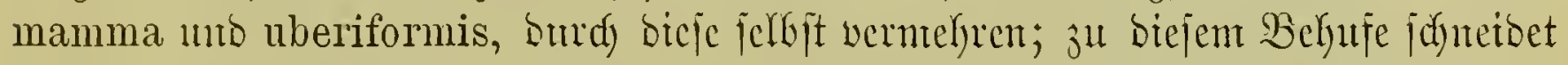

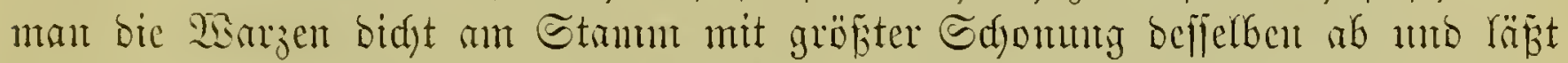

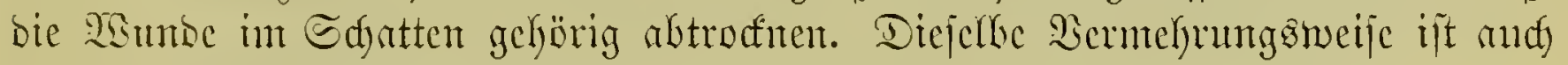
bet Lenchtenbergia geluntyen.

Bei Grattartig verbreiterten Tricber, aljo bei Epiphyllum uno Phyllocactus,

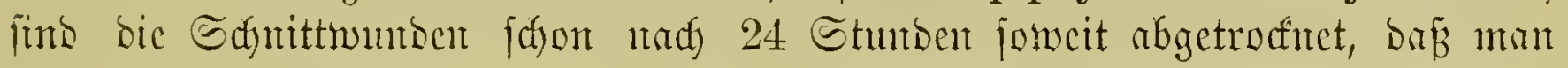

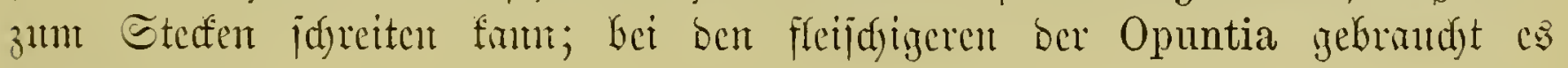
längerer Beit.

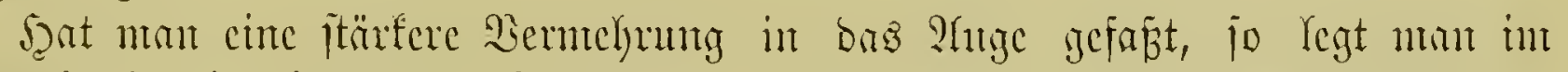

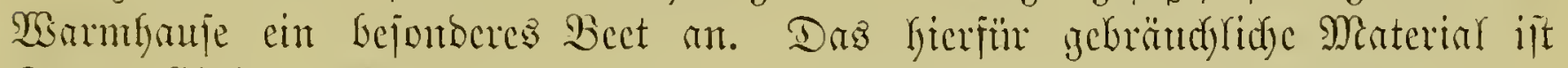

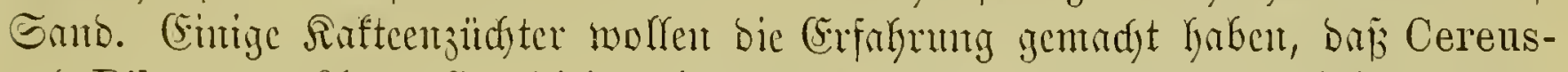

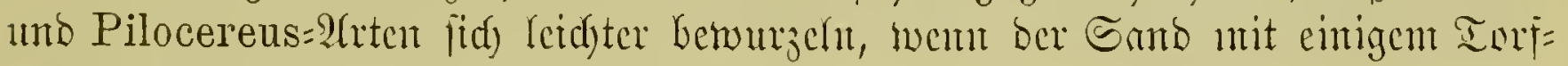
ntoos (Sphagnum) gemijat wotro.

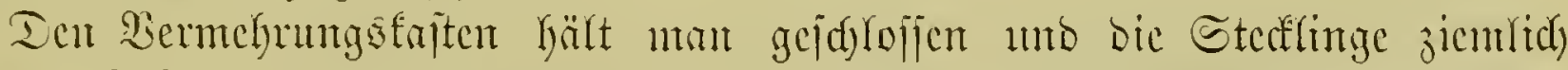

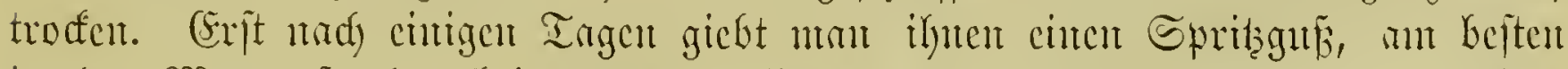

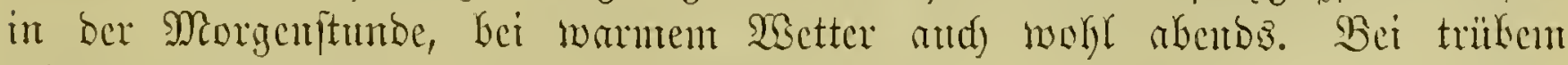

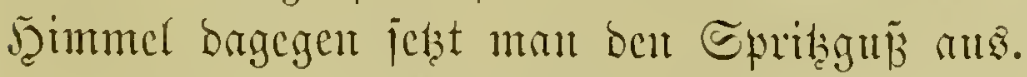

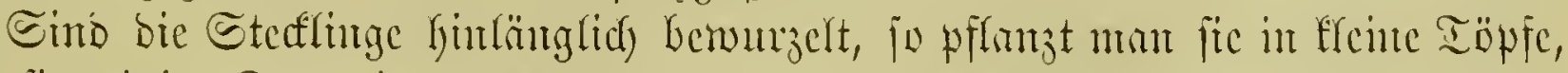

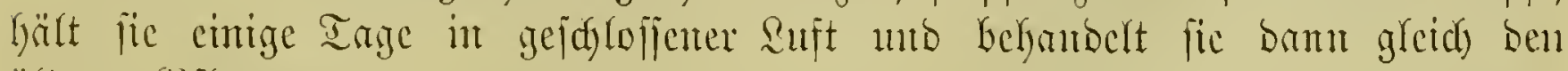
älteren Wiflarzen.

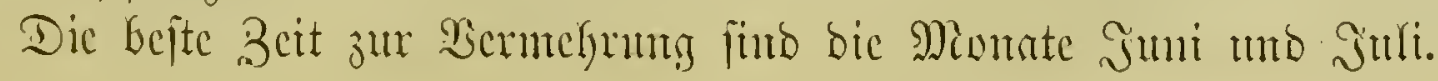




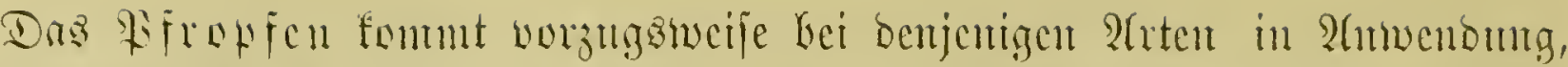

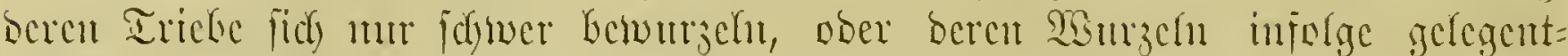

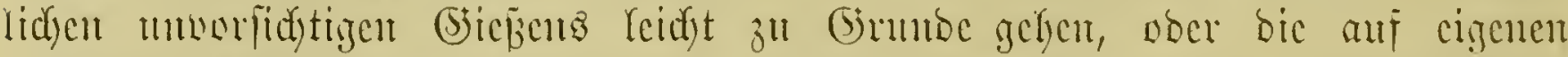

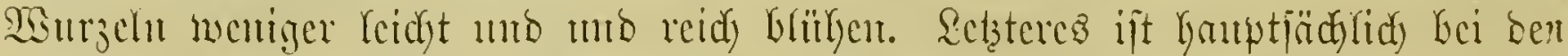

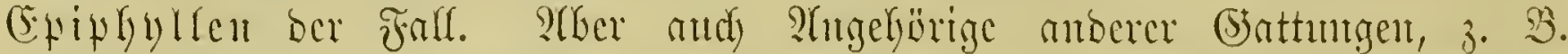

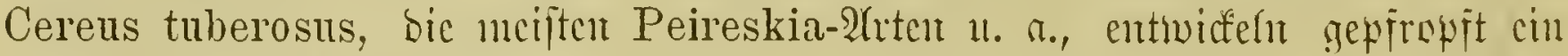

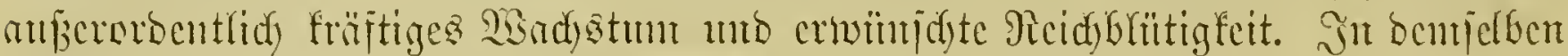

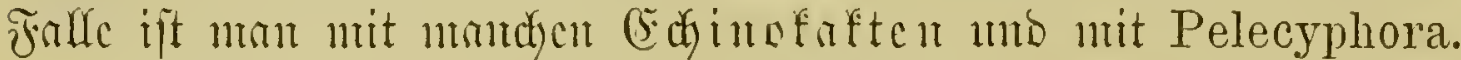

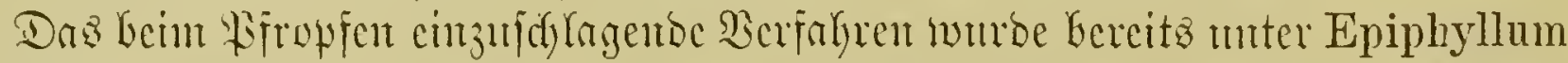

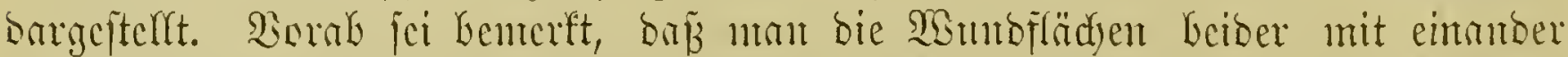

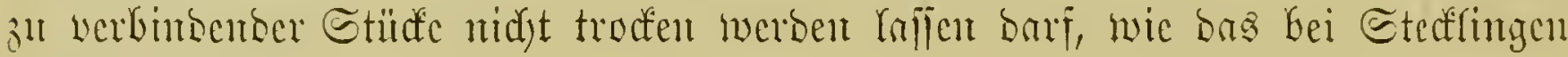
untwenbig iit.

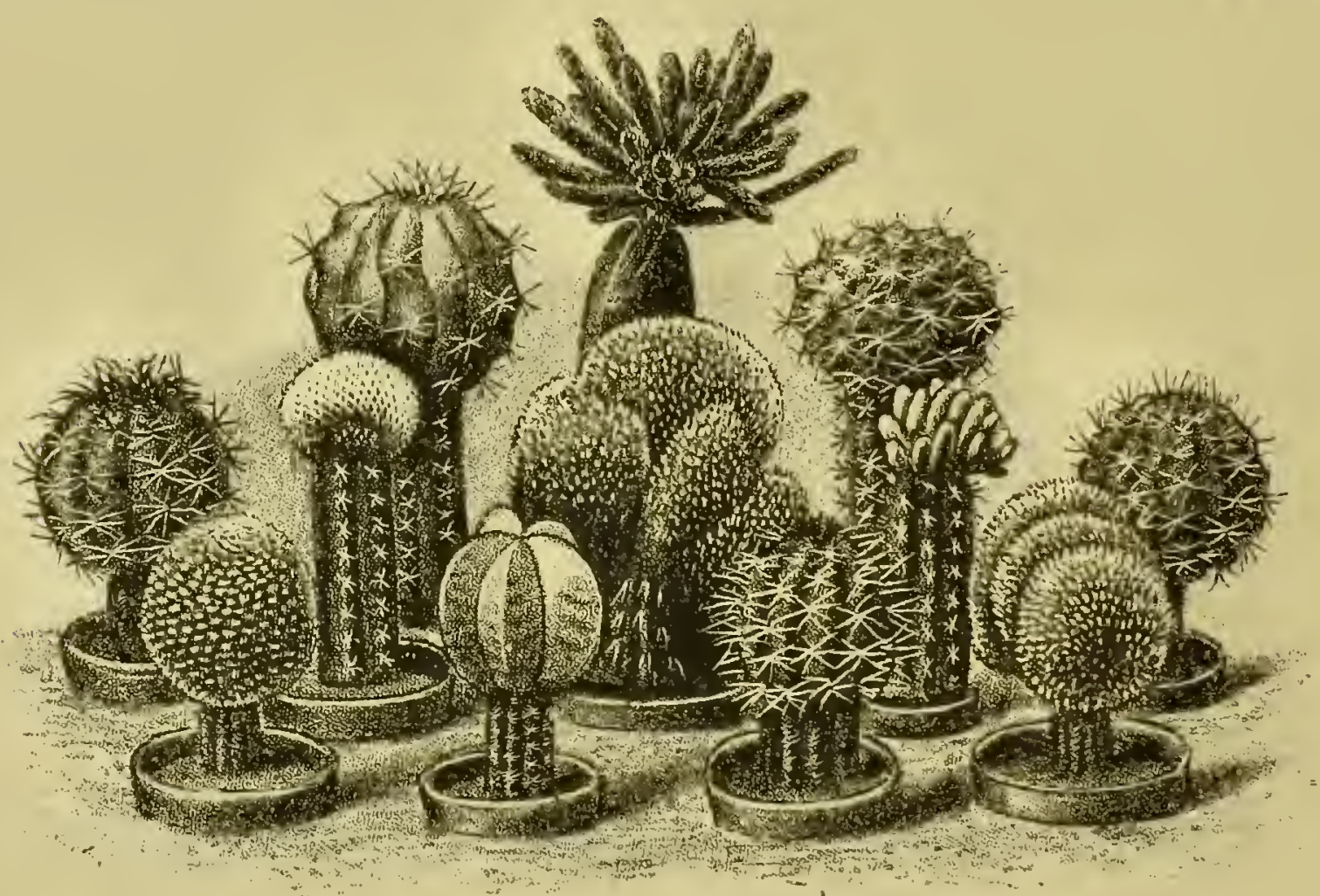

Sig. 1Е9. Sicfiropite saften.

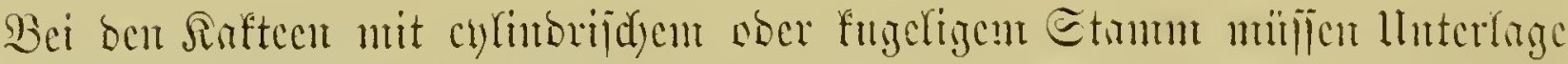

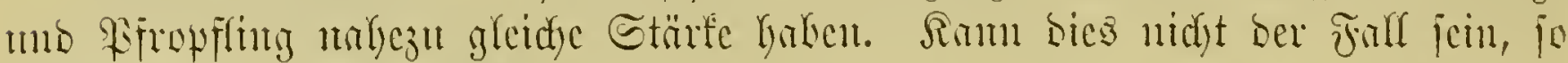

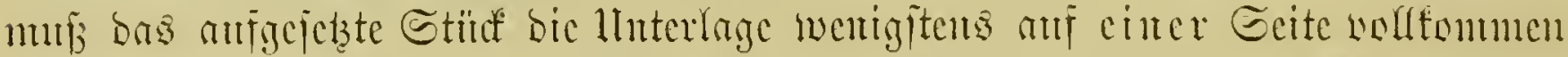

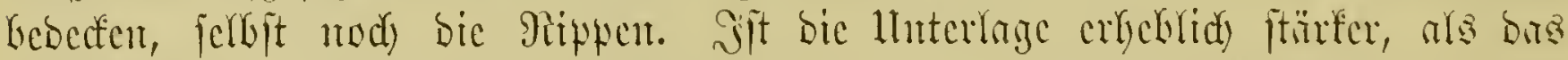

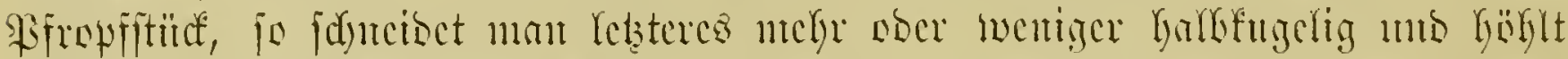

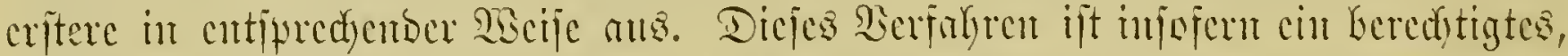

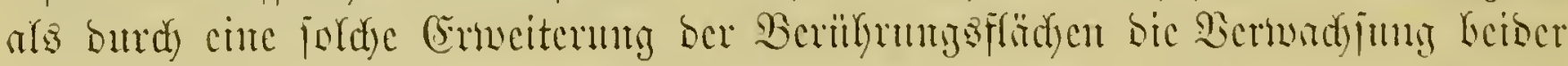

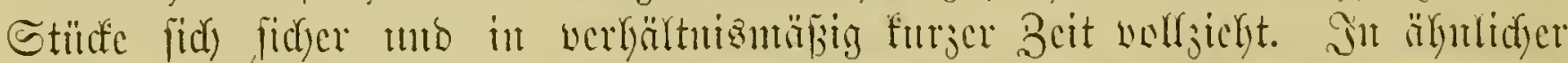

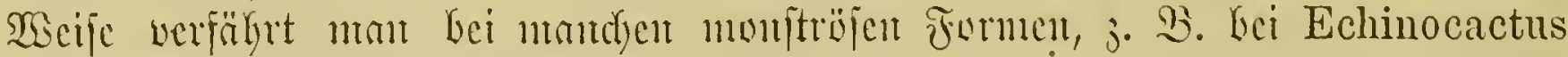

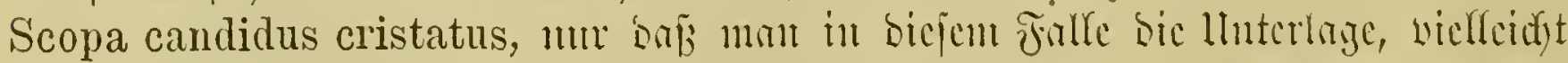

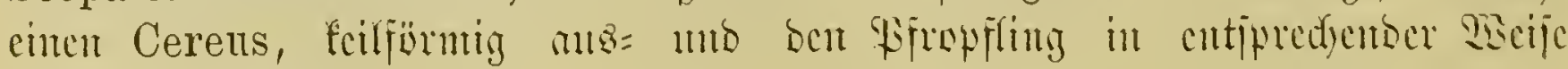
आujulteioct. 


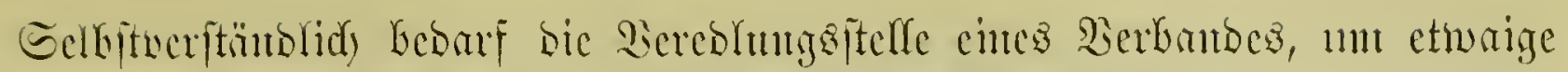

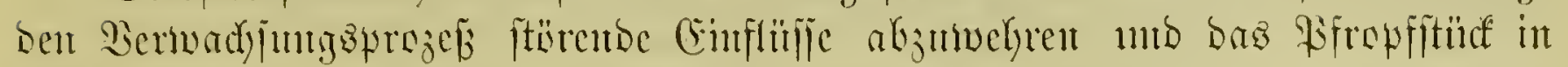

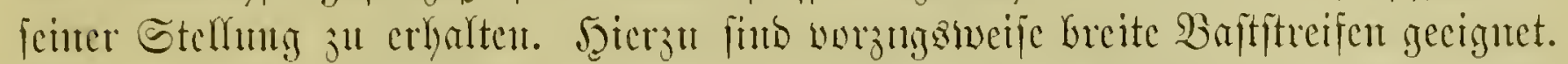

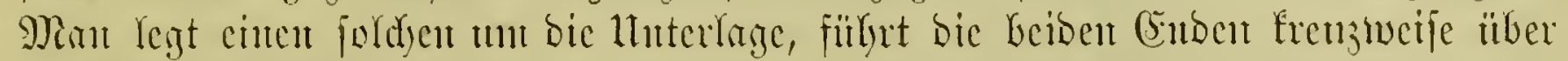

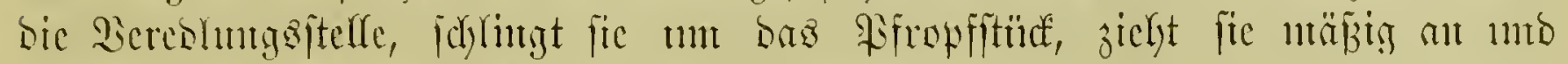

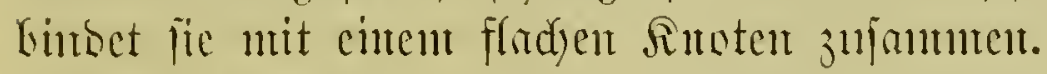

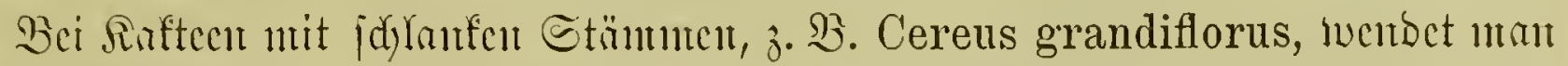
licker Spaltpiroffen nocr Sopulation an, bei Epiphyllum bas Sifrepfen in bie

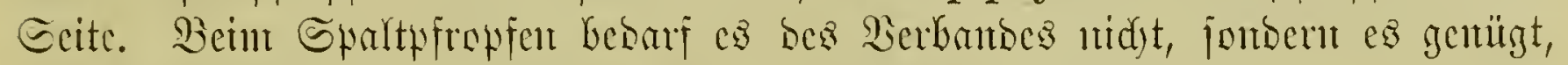
Das Proffitün ntit Dent Strdyer cinter Peireskia zu befeftigen.

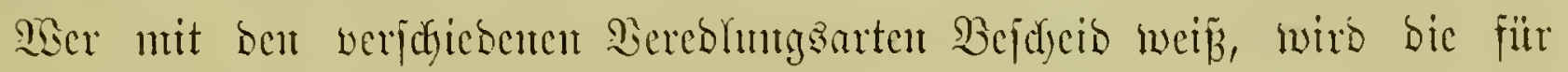

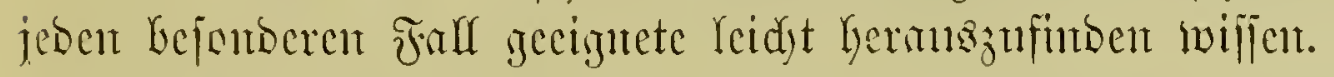

Die werebelten Bffanjen Gringt ntan in cinten falten Saftent, befien Fenter

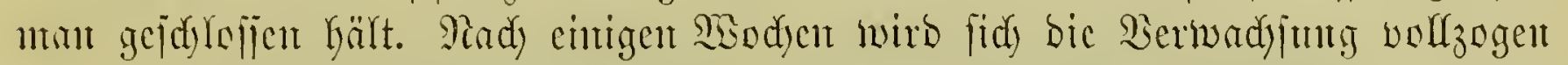

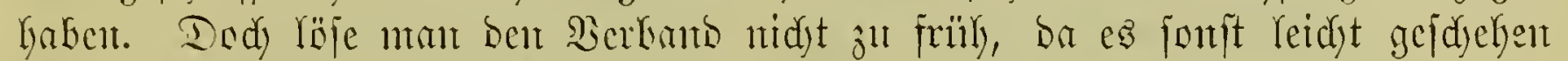

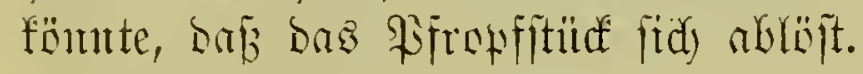

Daj bas Sifropfen, abgejehen wan anberen widjtigen Sorteilen, wielen

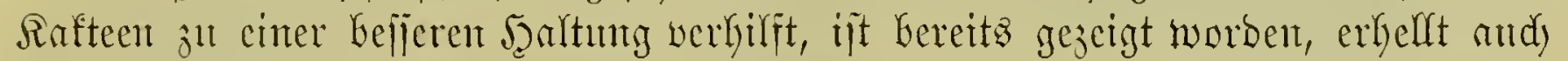

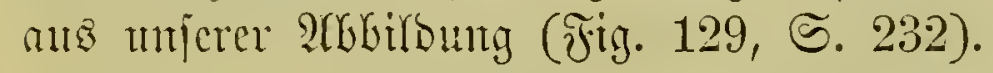

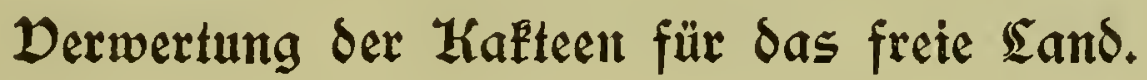

Das Sinterefje an Seppidyceten Gat in ntenerer Beit an Plusbreitung

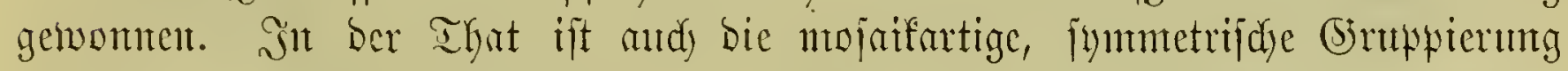

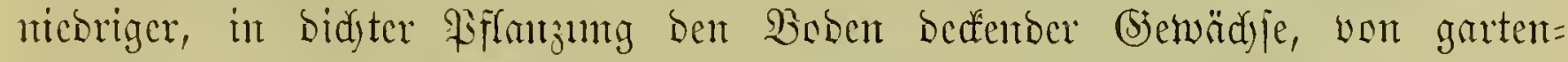

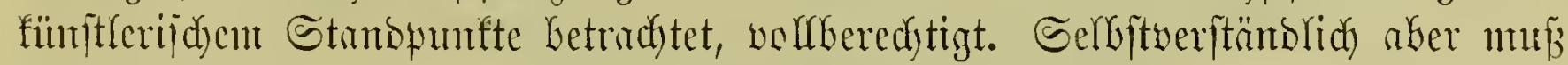

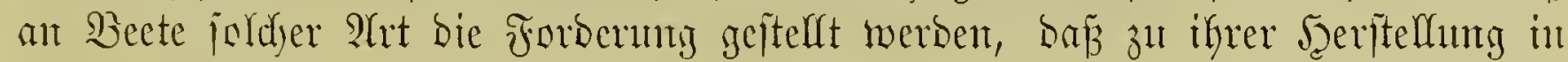

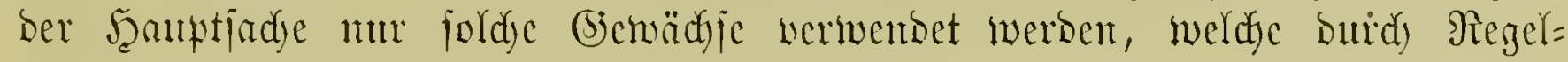

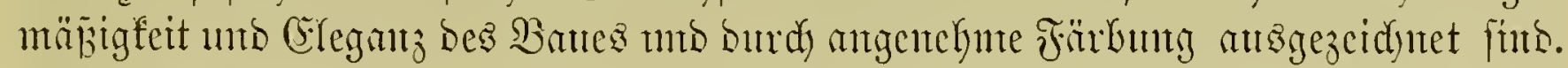

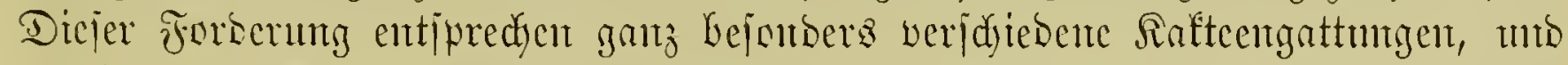

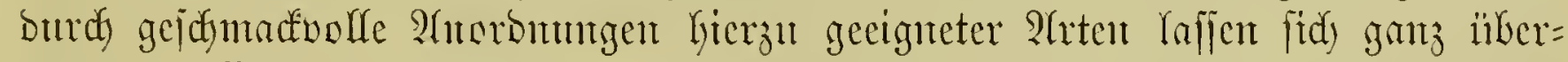

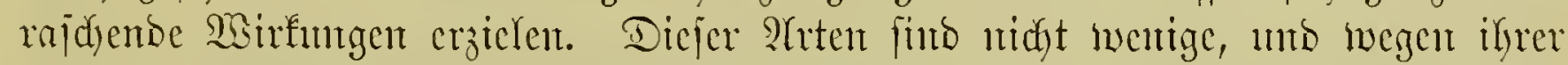

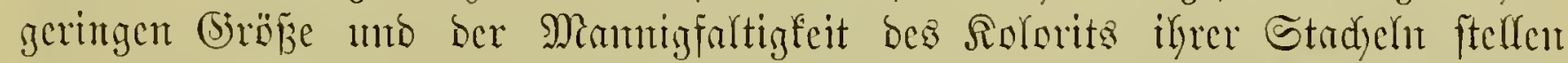

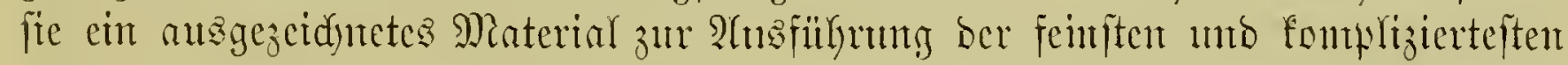

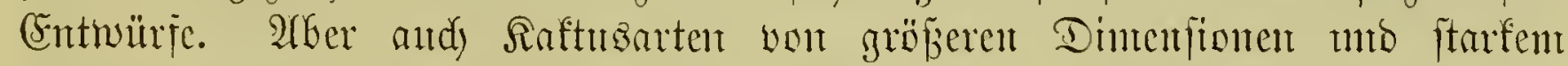

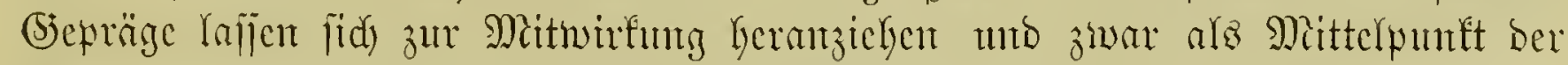

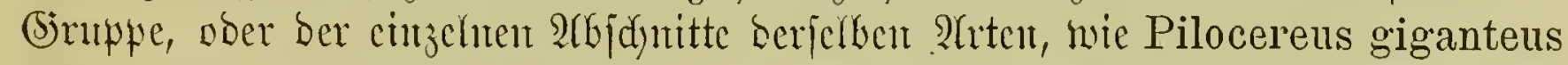

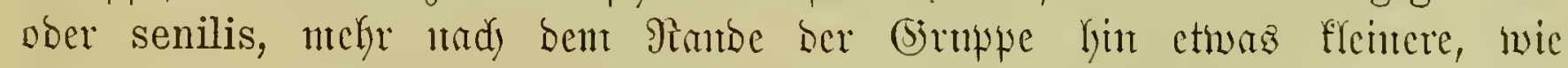
Echinocactus Wislizenii und cornigerus; ben Stunt aber birben intuter fleme

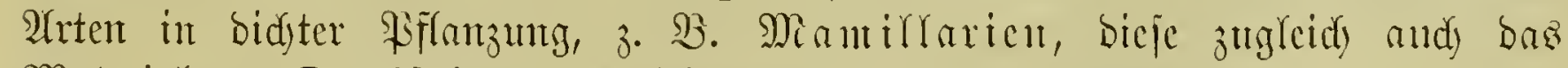
Material zur Durdjfitlyrutg ber feineren Detailz ber Beidyumig.

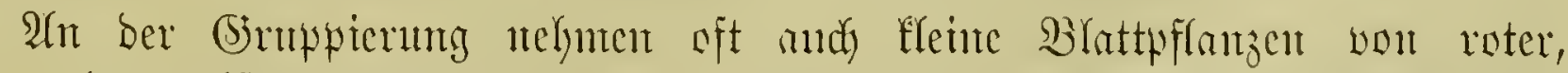

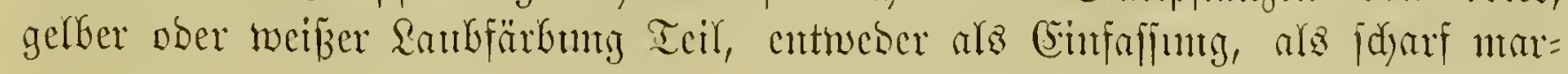




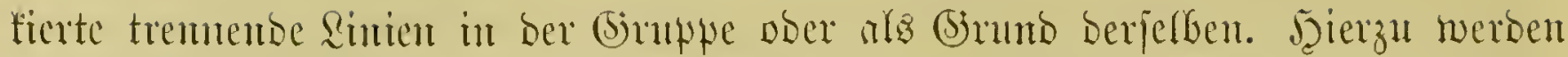
an meiften vermenbet bie verjoliebenften Farbenvarietäten won Alternanthera, Achyranthes, Iresine 1. F. W., jowic bic weiß̧blätterigen Antennaria tomentosa, Cineraria maritima, Centaurea candidissima uno Gnaphalium lanatum.

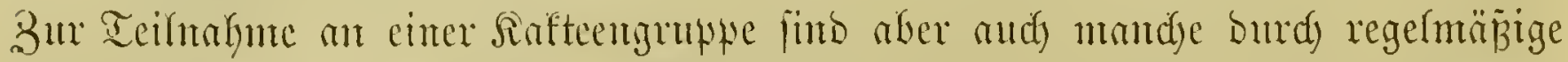

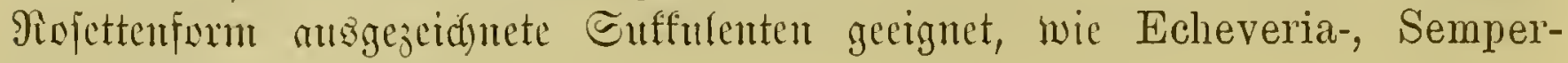
vivum-2̂rten unb moere.

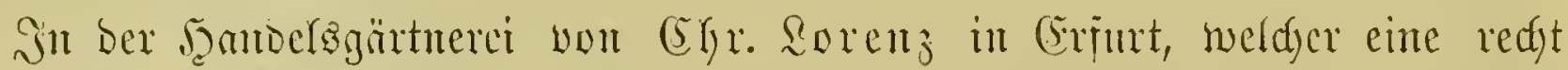

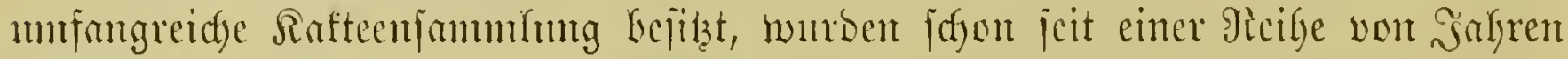

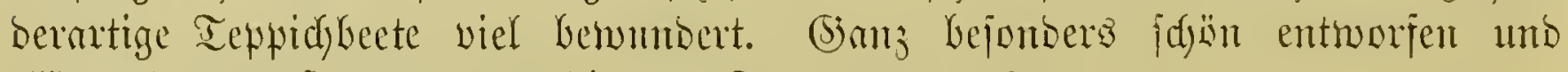
glänzent ausgejtattet waren bie bes Somntris 1889.

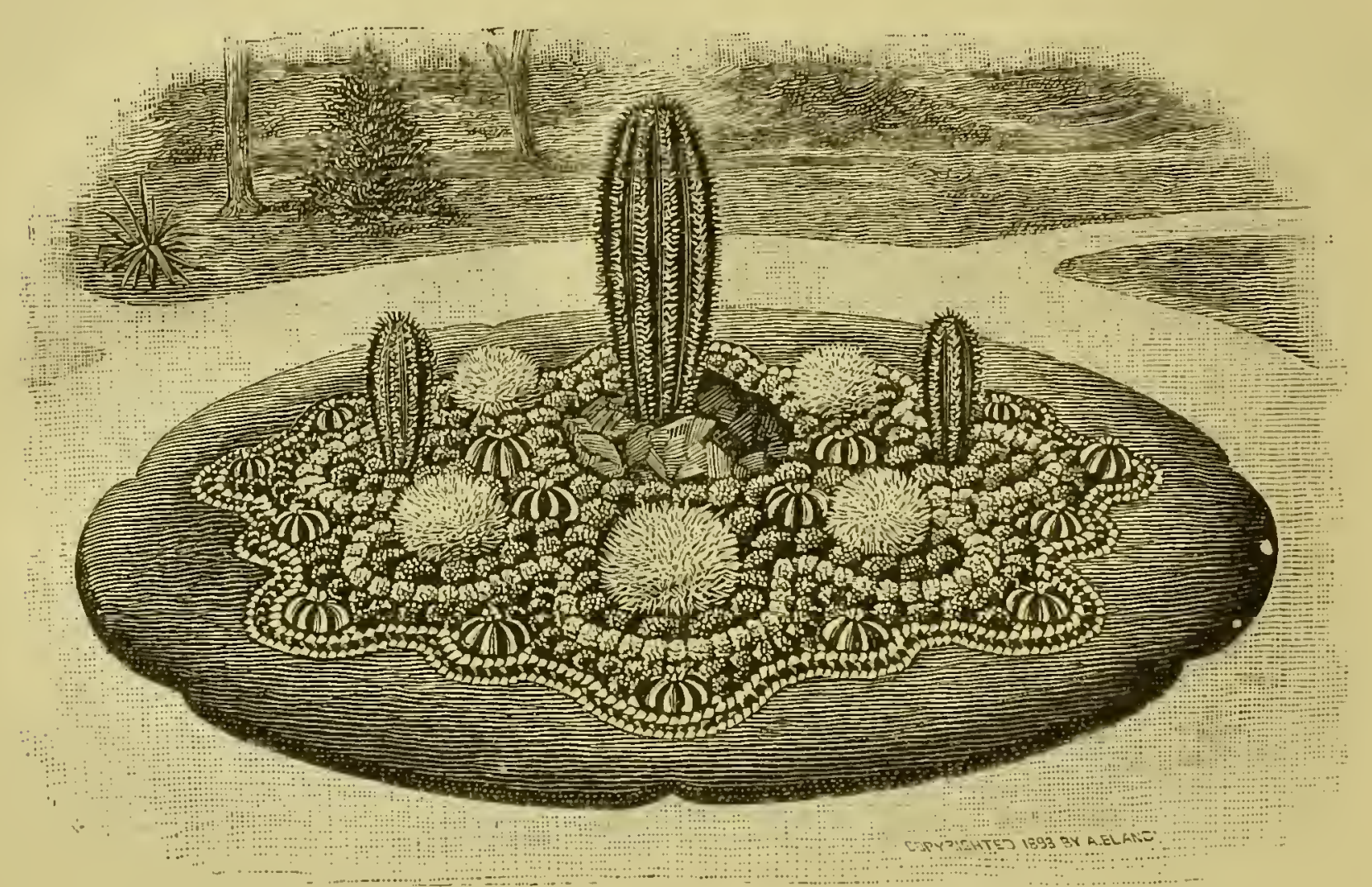

Fig. 130. Sifteenbeet.

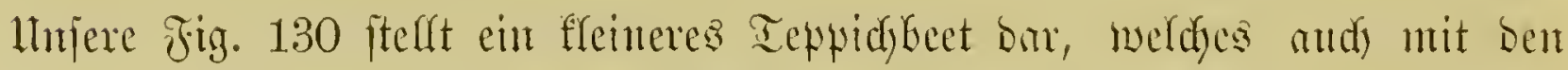

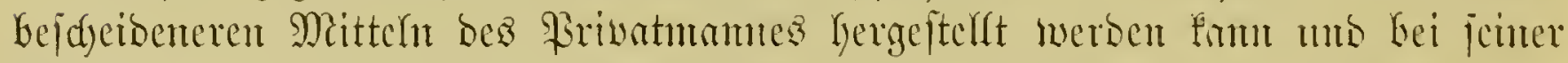

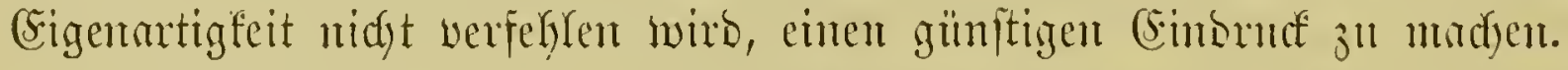

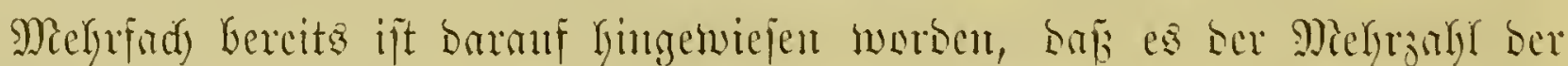
Rafteen jefre juträglich jei, jie. wä̈frem bes Sommers in Freien jul halten.

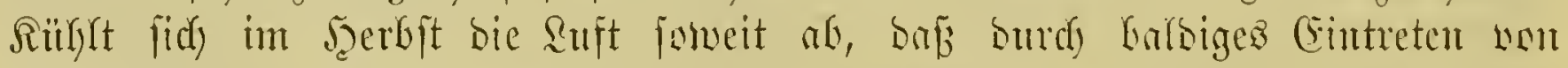

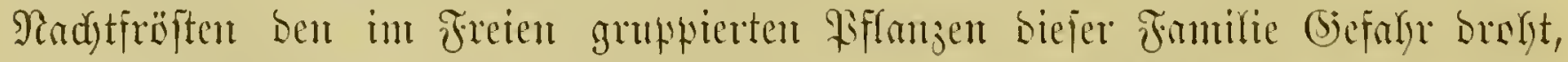

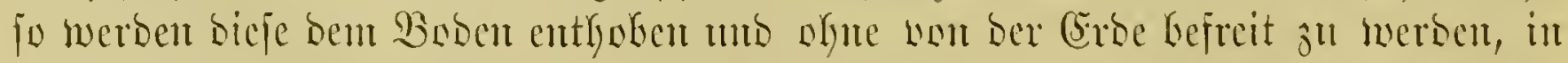

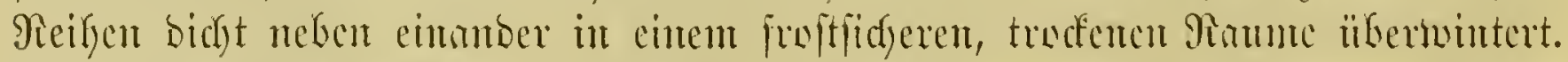

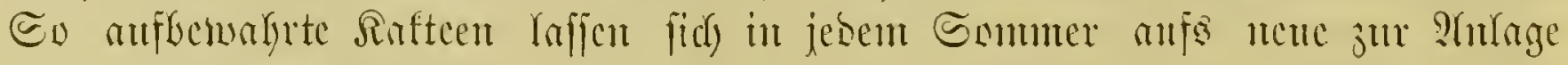
von Teppidybeeten Genulzen. 


\section{Famillie Asclepiadaceae.

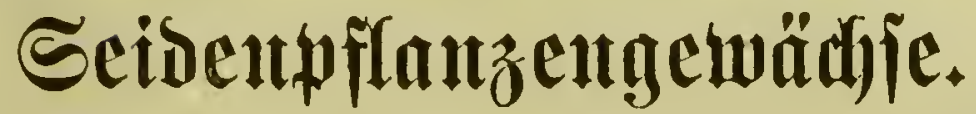

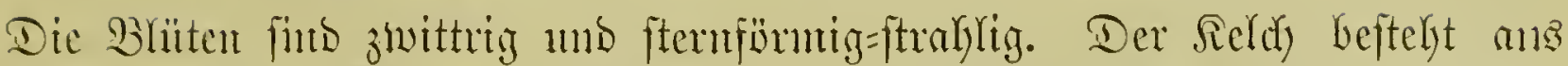

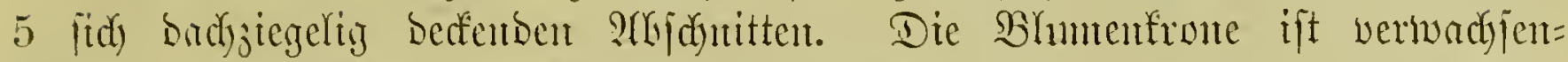

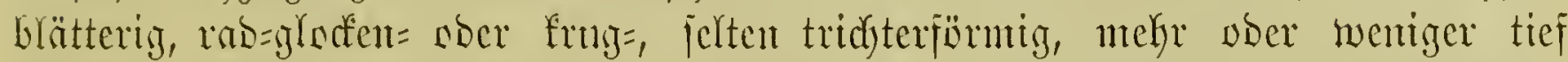

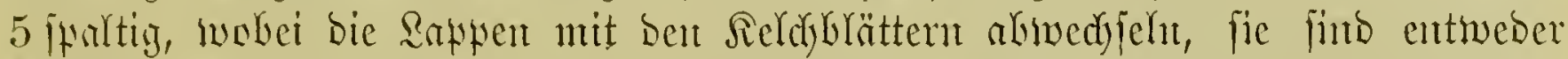

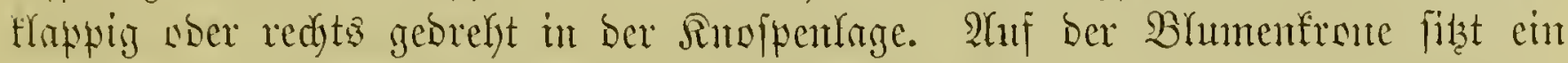

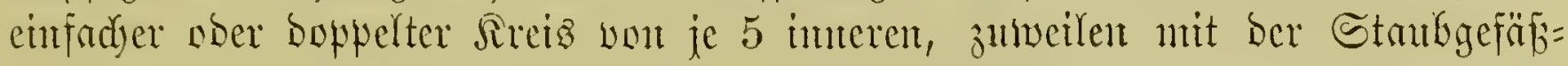
rëlyre werwadjente Bipfel (Corona), bie felgr mantigfaltig geftaltet finto. Die

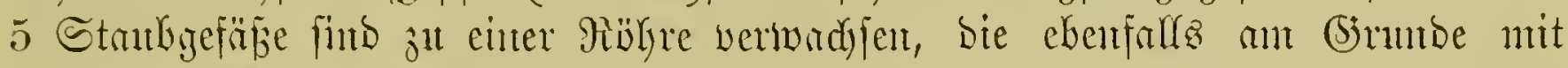

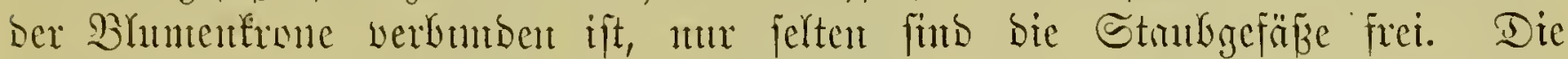
Strubbentel neigen ilber ber Narbe jujammen unb werwadjen oft mit ifyr, ein

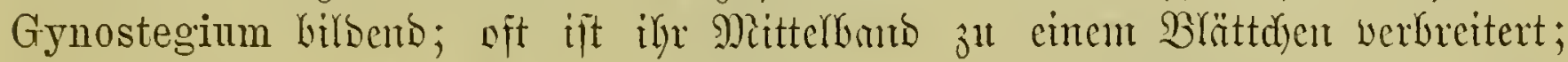

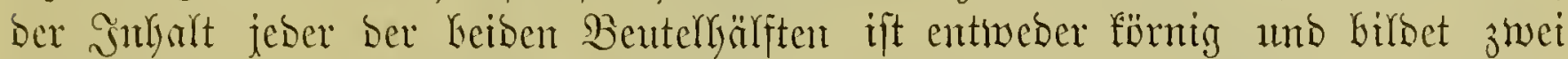
RYïntrdyen ober er ftelft eint wardsantiges Pollinitum bar. Durdy ein gejärbtes

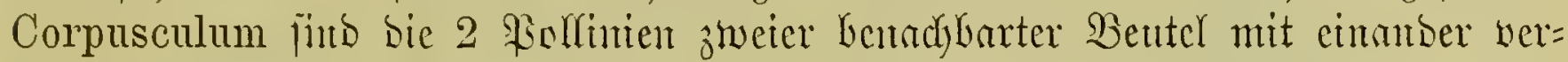

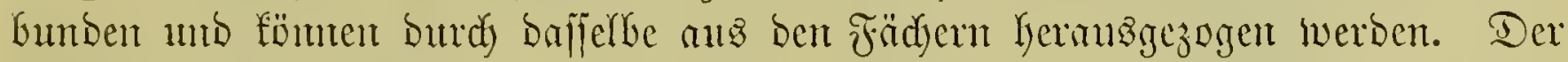

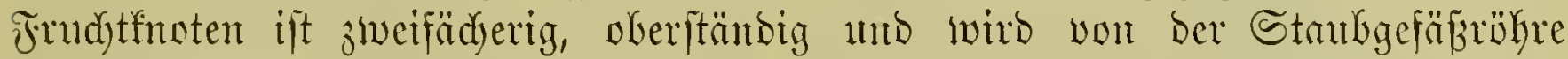

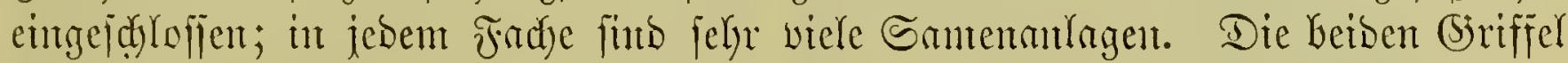

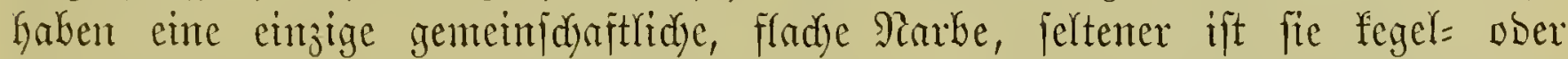

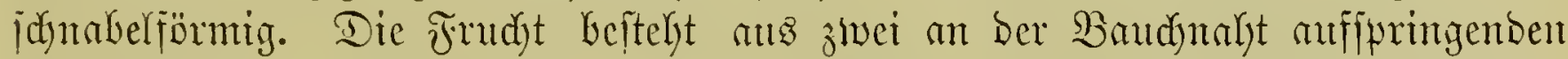

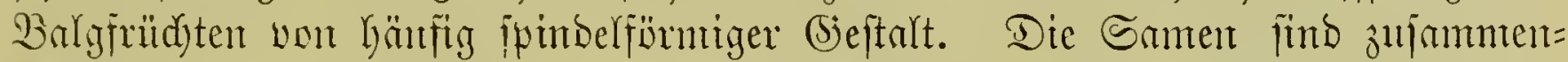

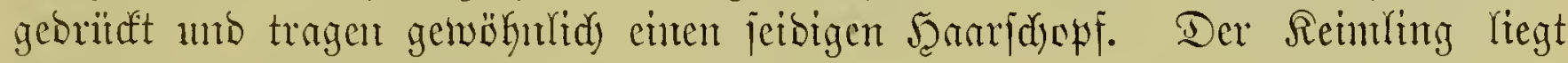
in eintent oft bünnen Pin̈frgemebe.

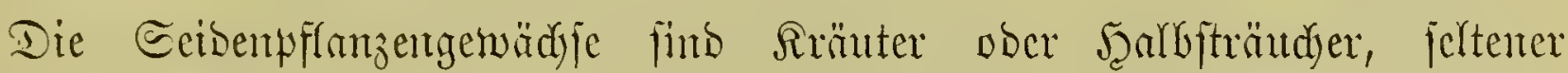

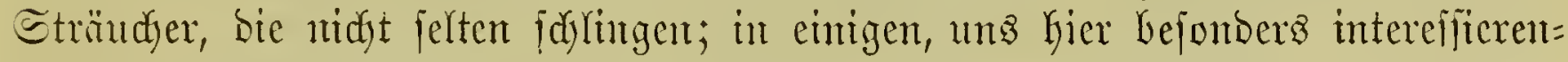

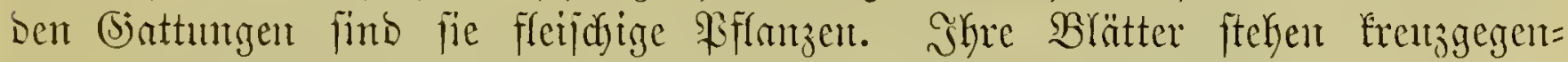

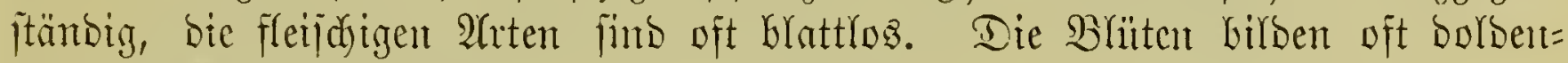
förmige Afggregate, jutweilen ftehen fie énzeln ober zu wenigen wereint.

\section{Sallïffel für die befariebenen Gattungen.}

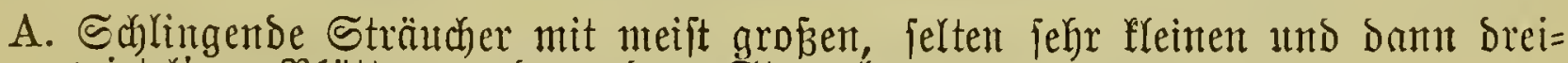
wirteligen Blättern und runtoem Ștengel.

a) Shumentronemröhre am Esrunbe balthig, oben chlindrif̧ verlängert

b) Blumenfrontenröhre fturz

1. Ceropegia $L$.

2. Hoya R. Br.

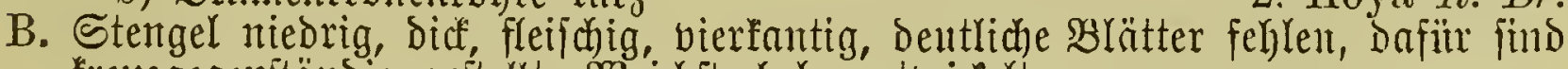
freelzgegenftäntoig geítellte sseichitacheln entwiofectt.

a) BBhmenfrone rabförntig mit langen Bipfeln, ohne 3iwifchenzipfel

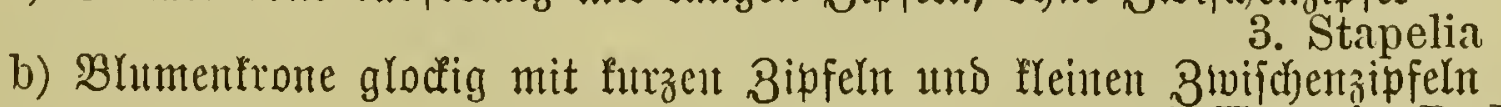

4. Huernia $R$. Br.

\section{1. (S)attung Ceropegia L. \&eudjterblume.}

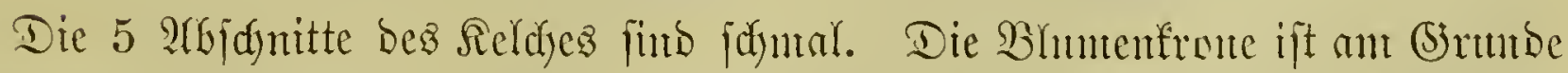
fugelf̈̈rmig mifgeblafen, bie Rëbre ift verlängert mo am Enbe in 5 häufig an 


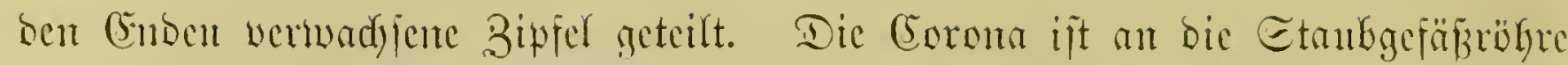
angebeftet, ring= ober bedyerfürmig, $5=$ voce 10 lappig uno enbet in 5 rängere nober fïrzere, bon Stanbbrättern gegeniberiftehende Fäbent. Die Etaubbrätter

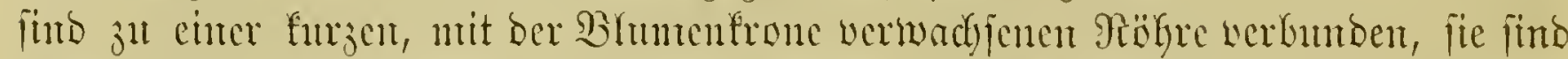

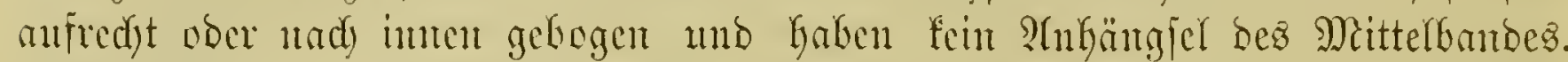

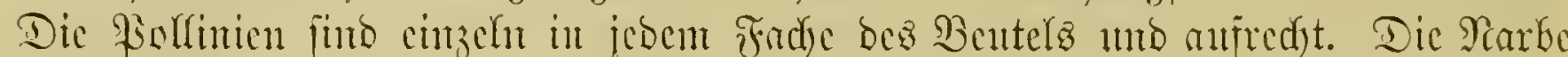

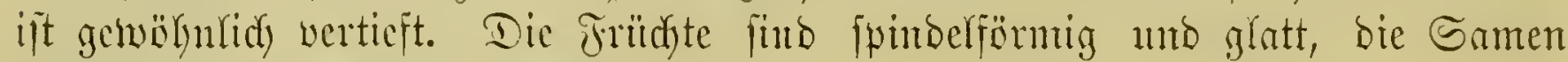
mit cinem Saaridyopje verjeben.

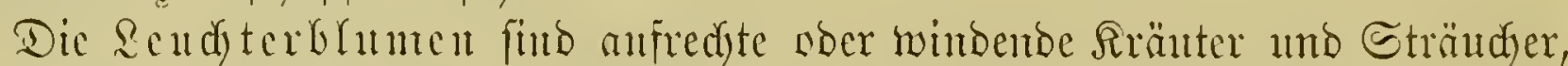

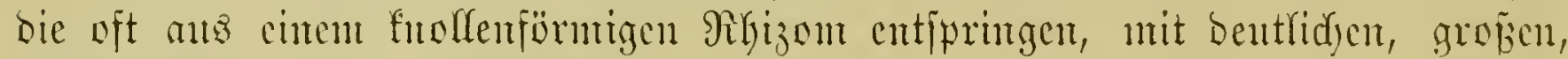

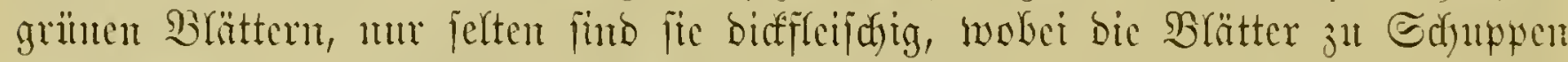
verfümmen. Die Bäliten ftelgen in borbenfürmigen Sinflorescenzen, jelter find mur 2-1 vorkanocu.

Dic etwa 50 SYrten wadjen int tropifden und jübliden affrifa, in Ditindien,

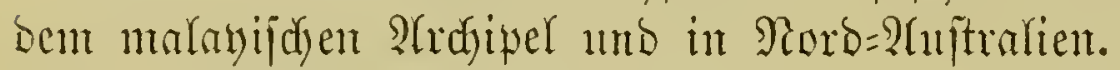

\section{S丸lüffel für die befdriebenen 2rrter.}

A. Blätter laubig, mehr ober sweniger fleijhig.

a) Blätter am (5)umbe feilförmig; B̉iitenftalto mur $1-2$ blütig.

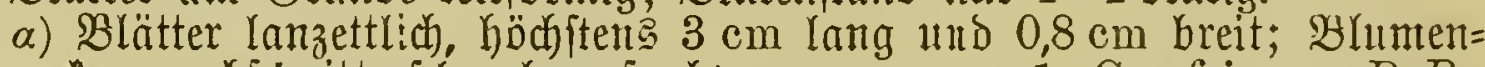
fronenabichnitte idmmal, aufredt

1. C. africana $R . B r$.

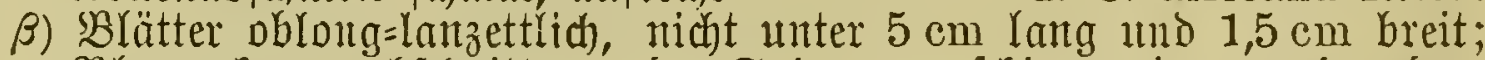
Bhumenfronenabidnitte alt ber Epike regenfofirmartig, aubeinander= fahrelld

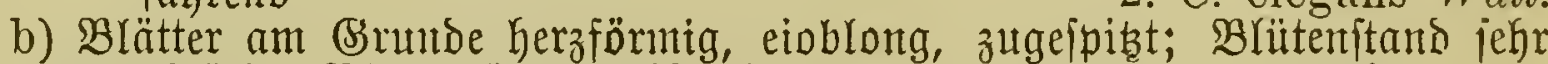
reidhblütig; SBlumenfrontenabidntte fegelförnig zufanmengeneigt

3. C. Cumingiana $D C$.

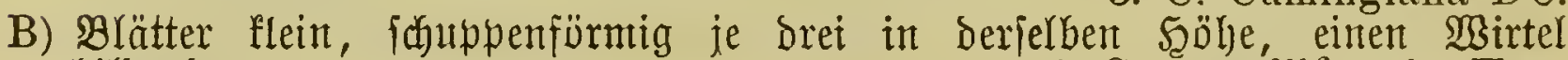
billoento

4. C. Stapeliiformis Haw.

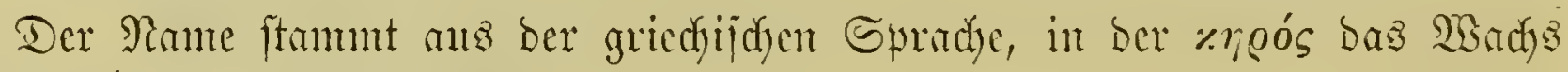

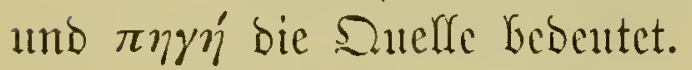

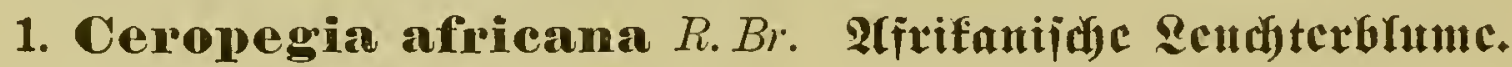

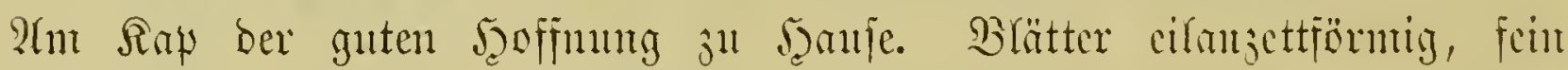

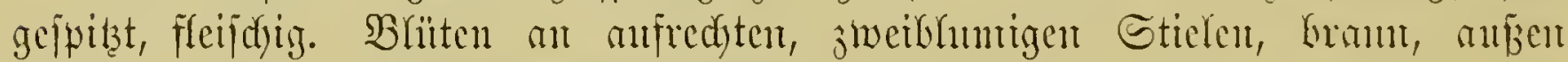

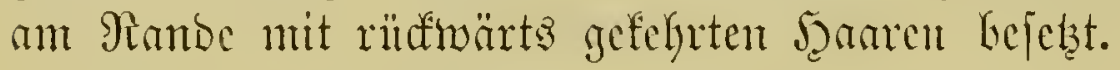

\section{Ceropegia elegans Wall. Feinc $\mathcal{E}$ cudjterblunte.}

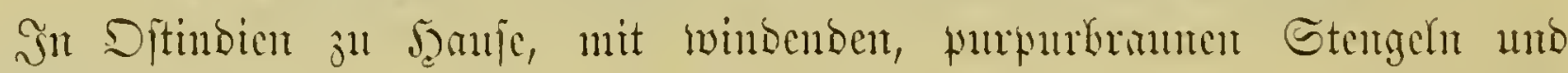

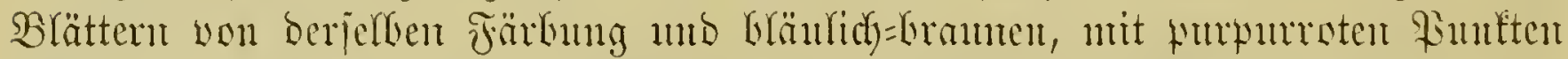

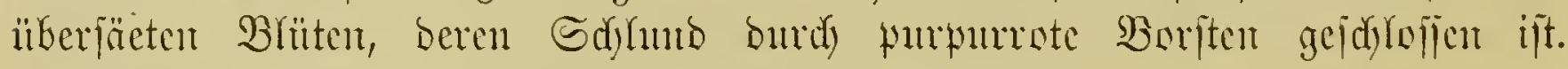
Bhlütezcit Sommter bis Jacrbjt.

\section{Ceropegia Cumingiana $D C$. (Emming's \&eudterblume.}

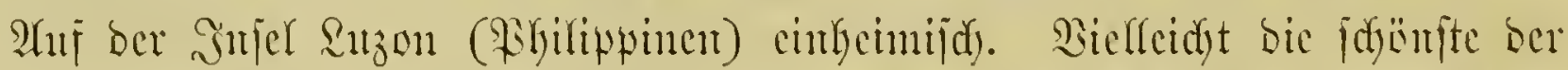

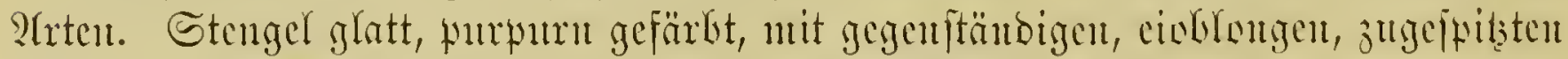

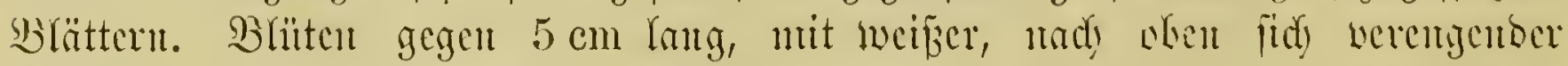

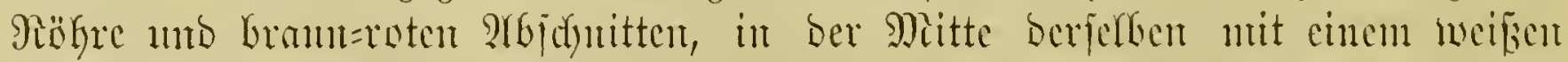

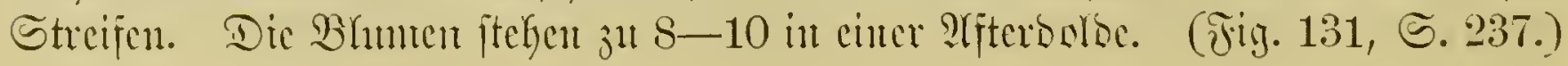




\section{Ceropegia stapeliiformis Haw. Stapelicuntige \&eudferblunte.}

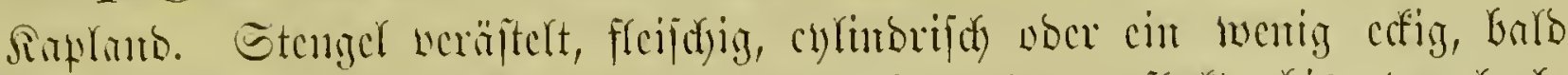

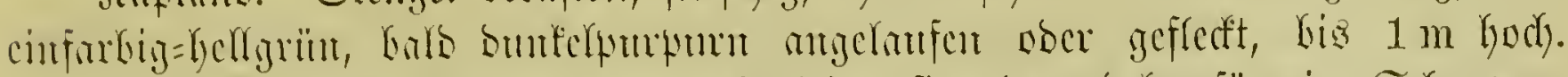

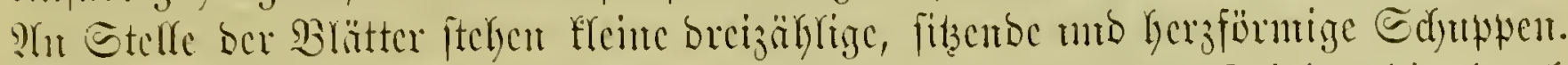

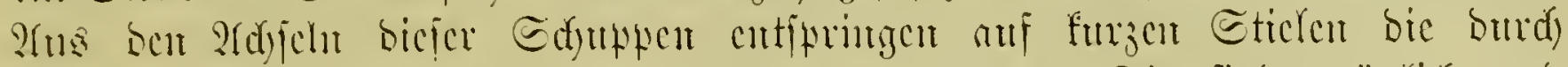

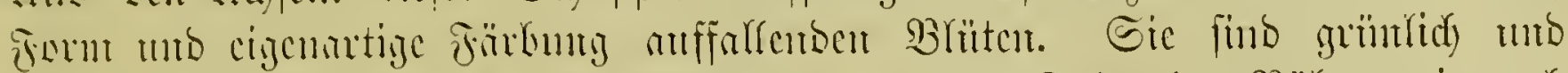

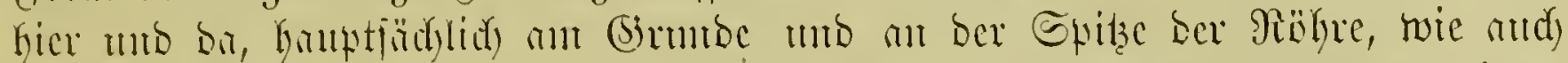

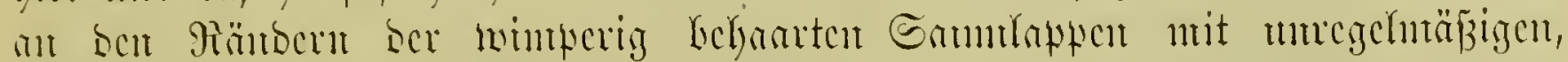

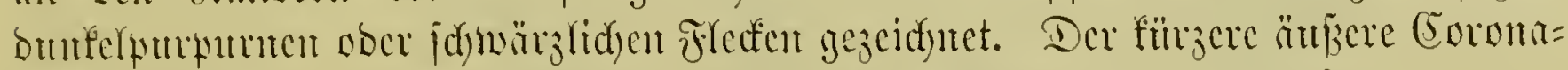

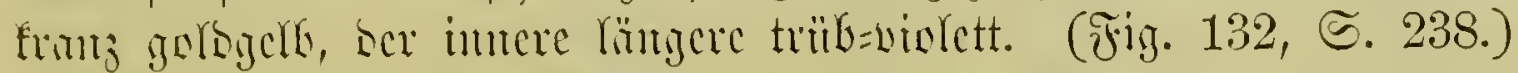

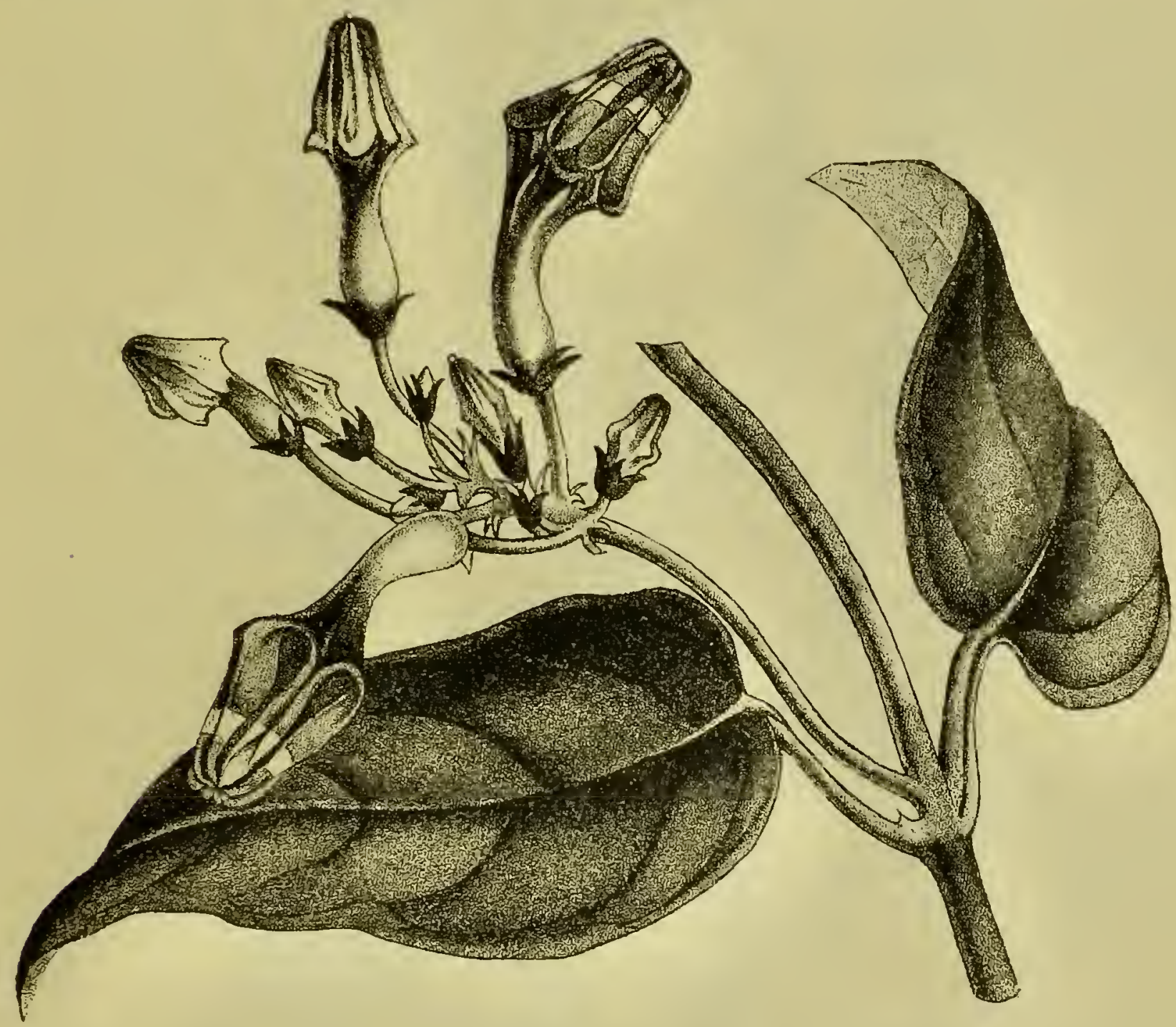

Fig. 131. Ceropegia Cumingiana DC. Cuming'z \&eudterblume.

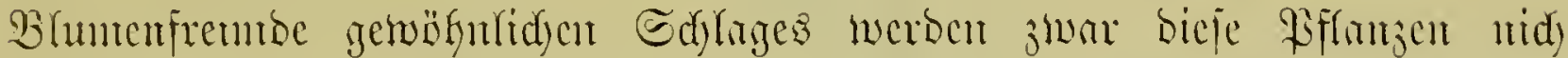

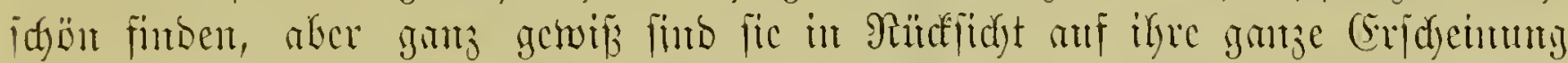

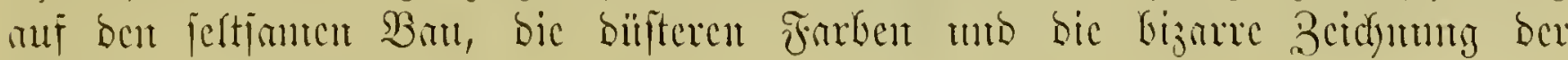
B̧fumen ber Silltul wert.

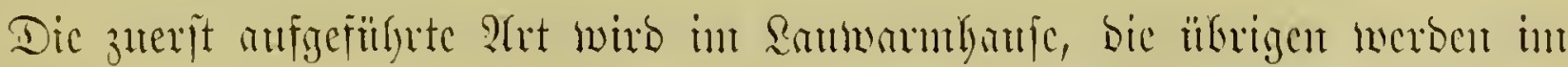

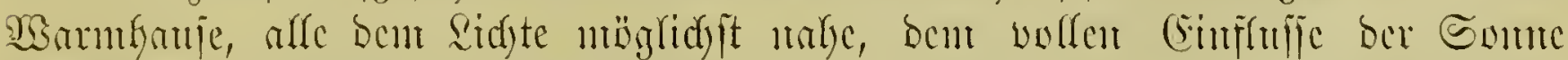

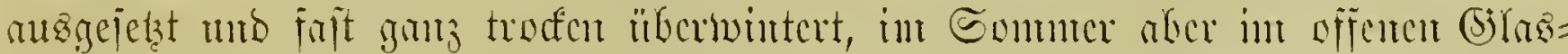

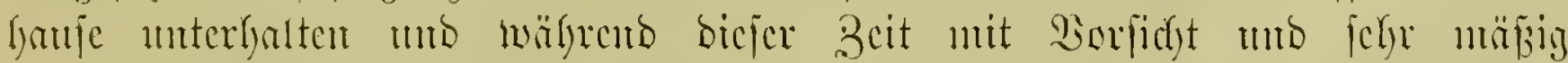

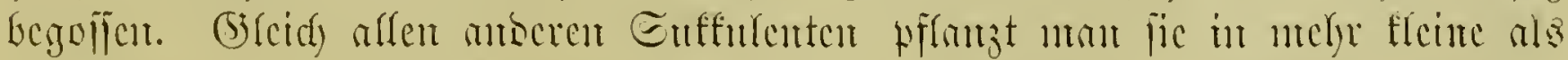
gu以 
mit ctwas altem Manerlebm mb Seeibecrbe, über eincr hohen, redjt forgfärtig bereiteten Godyerbentage.

Man wermelyt bic Ceropegicu ans jungen Trieben. Dic Edjnittmumbe ber

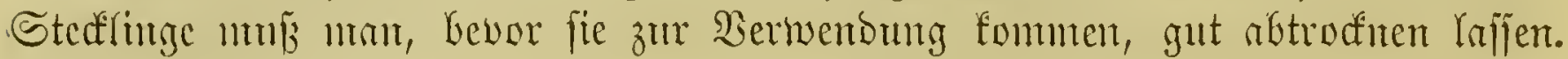

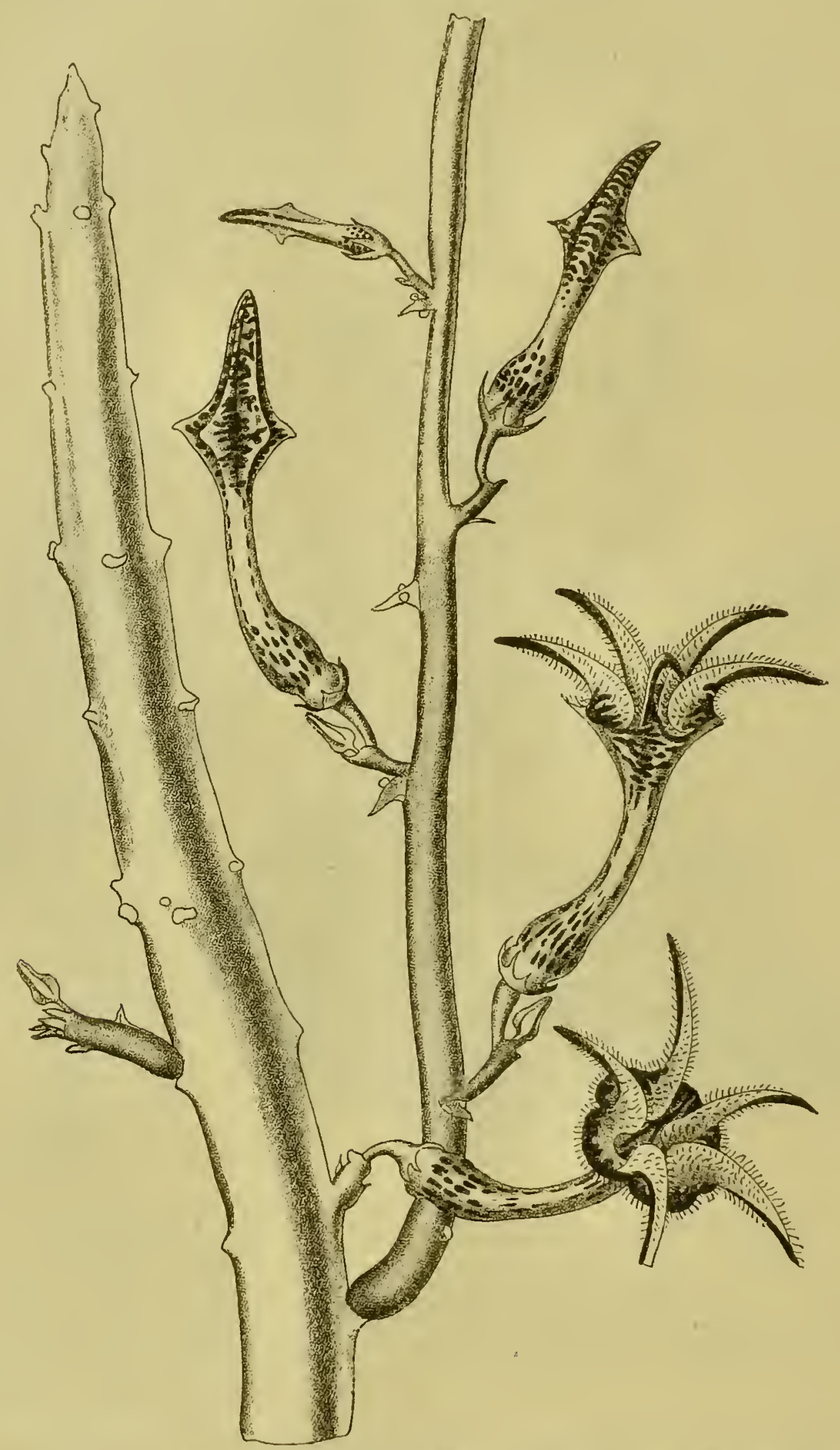

Fig. 132. Ceropegia stapeliiformis Haw. Staperienartige Icudterblume.

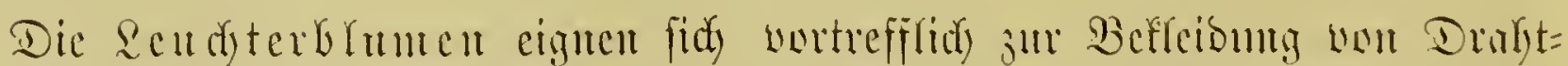

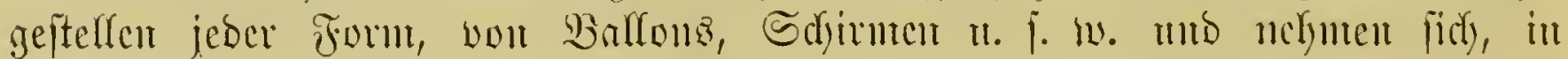

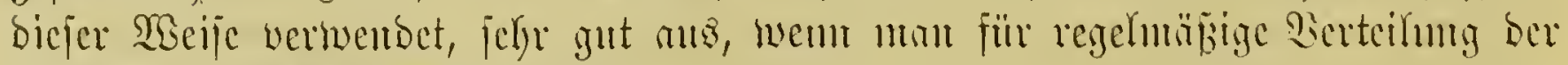
Etenigd milo areite Enrige trïgt. 


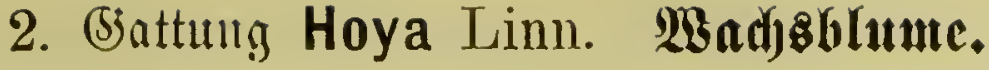

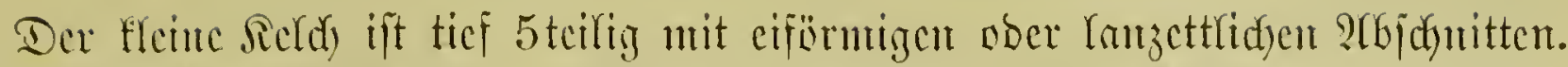

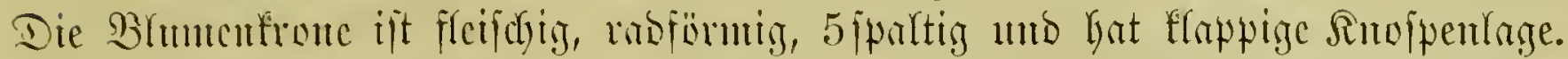

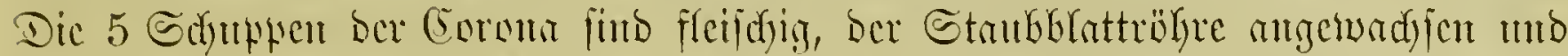

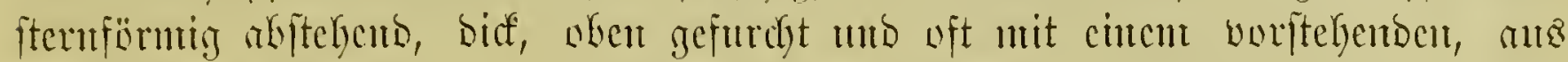

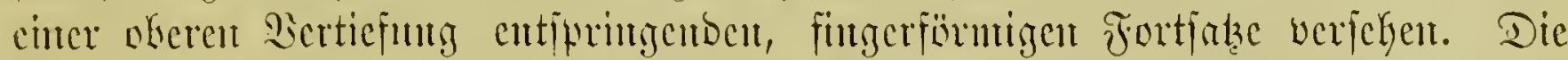

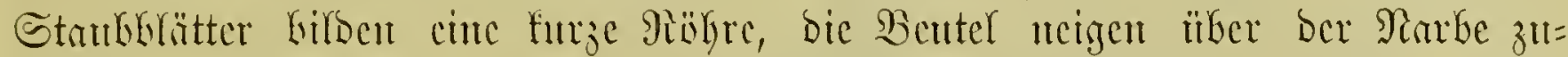

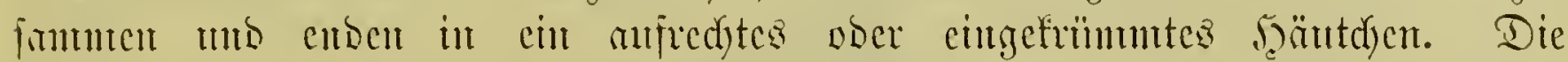

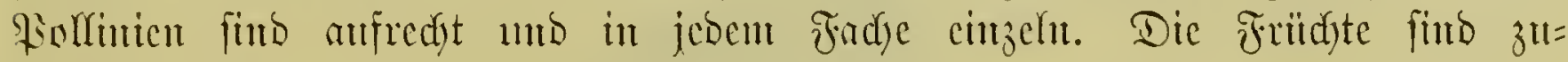
geipitist, glatt.

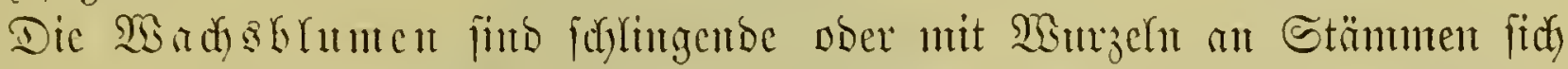
fejthaftenbe Sträudyer mit gegenftänbigen, fleifdjigen obcr Yeberartigen Brättern.

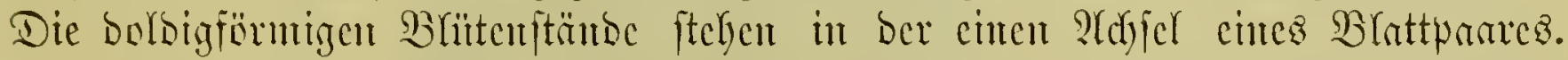

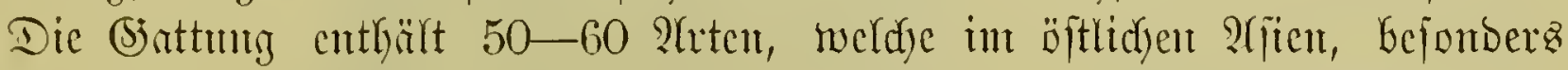

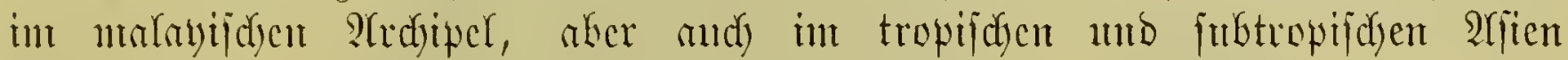
wardjen.

\section{Sdiliifiel für die befdriebenen 2 rten.}

A. Blätter ohne Seitemterven.

a) B̉lätter hödhften $3 \mathrm{~cm}$ Iang, von der Ronfijtenz der Burbauntblätter; Slumentrone iveis, (Evrona antethyitfarben

b) Brätter nicht unter $8 \mathrm{~cm}$ ¿äıge, Dicf, fleif(t)ia.

a) Blätter fingerlang; Blumentrone meip̉lich ober ins rofige gehend, (Soroura rötlich

2. H. carnosa Rob. Brown.

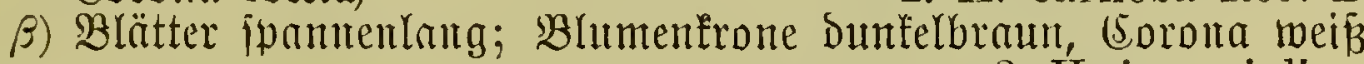

3. H. imperialis Lindl.

B. Blätter Deutlich oreiterbig; Błumenfrone grïnlidugelb, (Sorona purpurrot

4. H. cinnamomifolia Hook. ful.

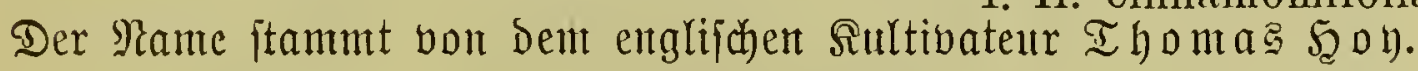

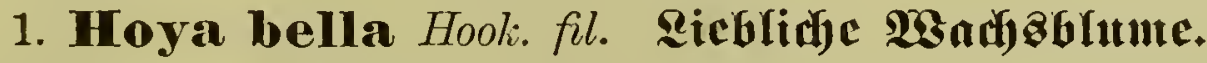

Sie ijt cine ber nicolidyiten Proten, weungleidy feine cigentlidye Sodyling=

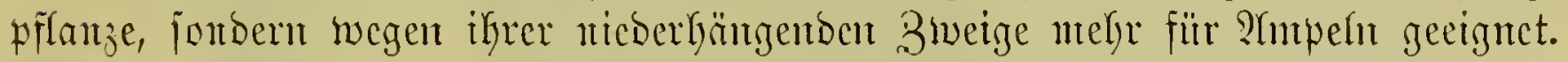

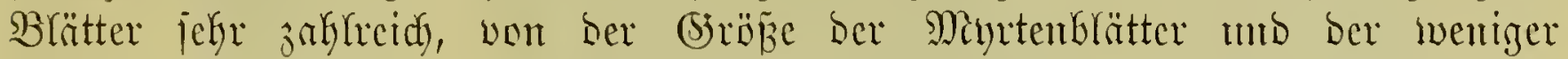

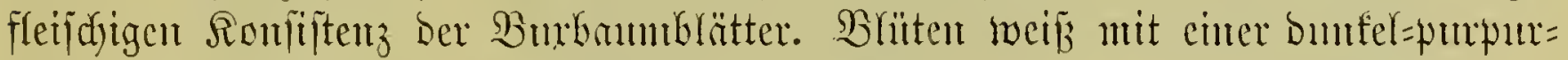
farbigen Broutc, jobaí fic, wie Botanical Magazine treffent benterft, eitem in Silber gejaf̧ten 2 methyite gleidyen.

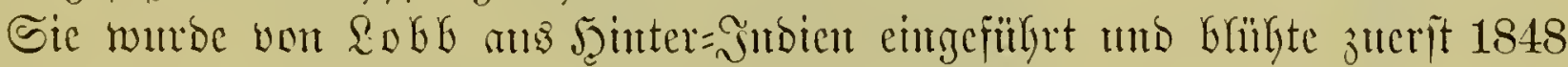
bei Beitd) \& હ̈̈rne in (5xeter.

H. bella, anf H. carnosa gepfropft, entwidéct cin fräftigca Sandyatum mo

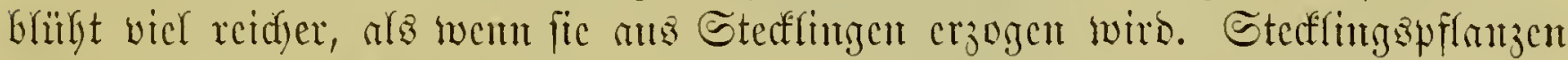

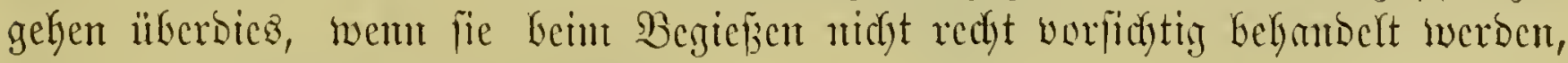

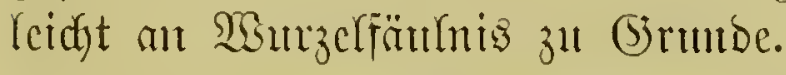

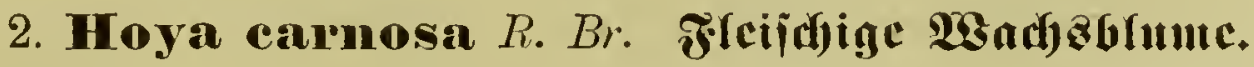

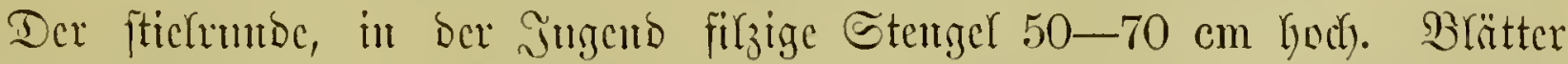

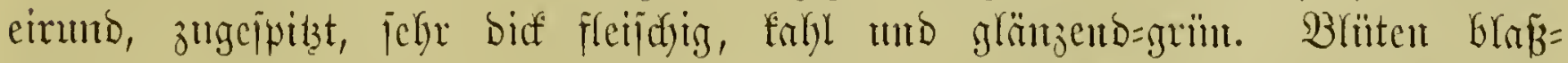

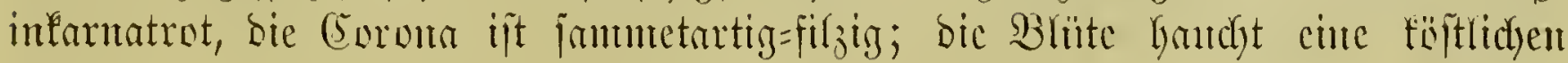




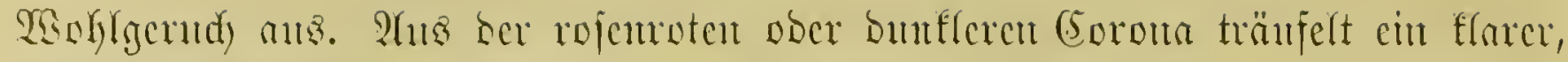

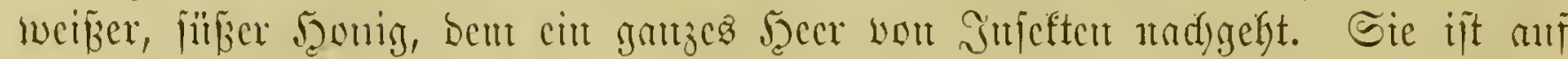

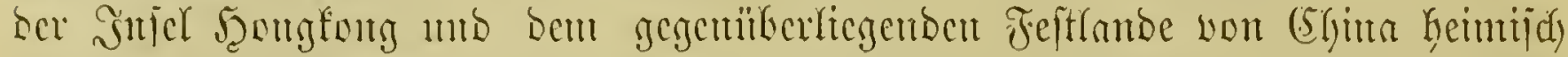

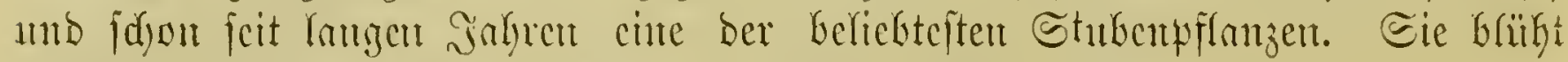

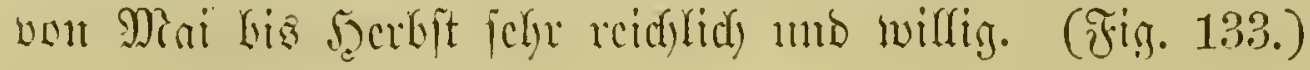

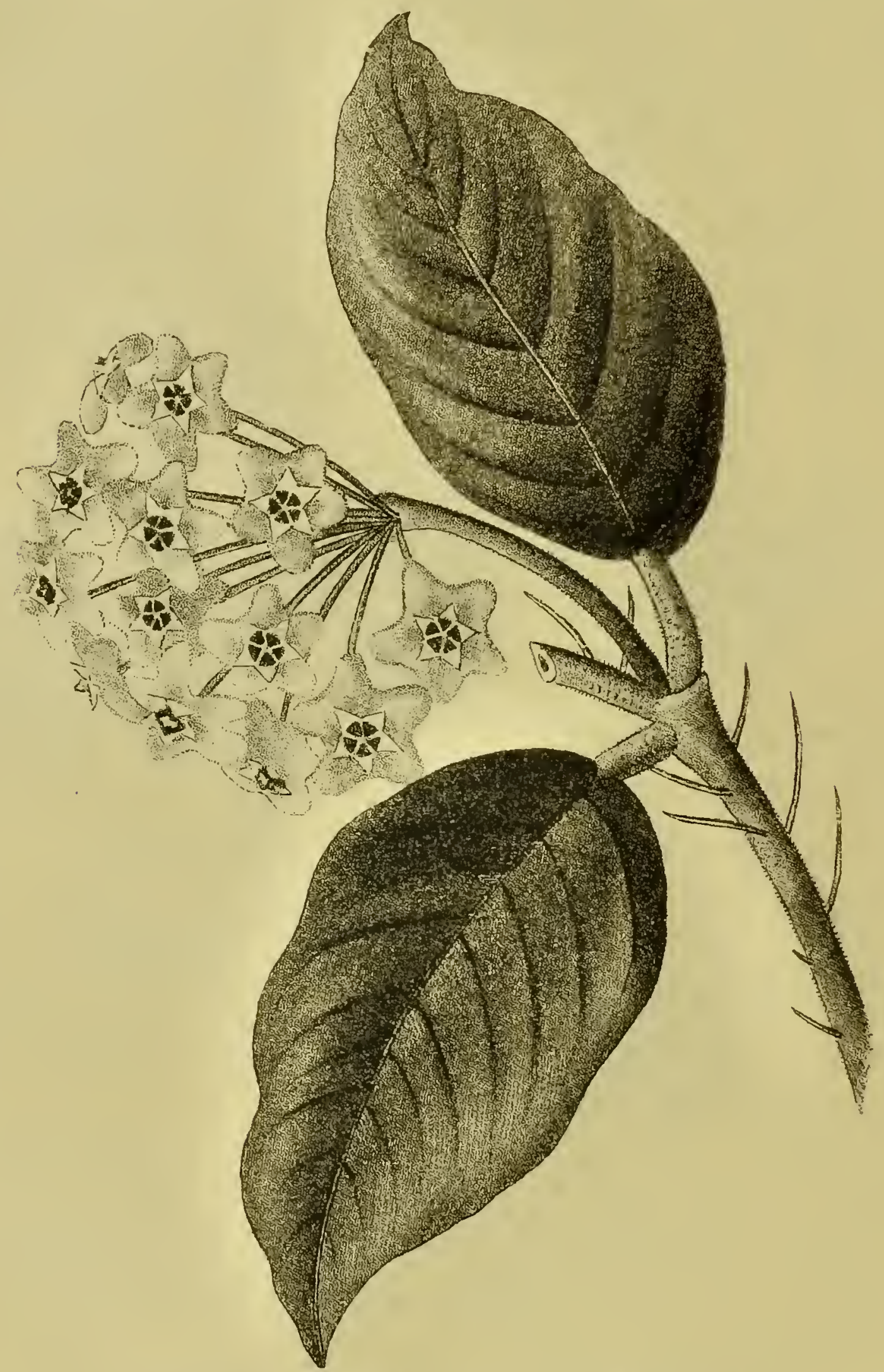

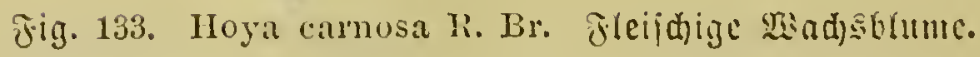

In Enffulcuten= Sammlnugen finbet man muter bem ginnen Hoya varie-

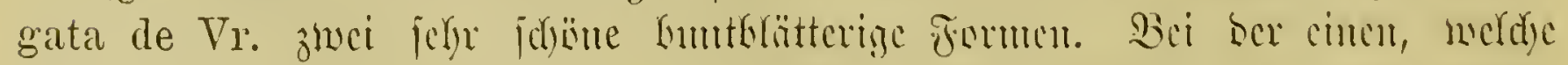

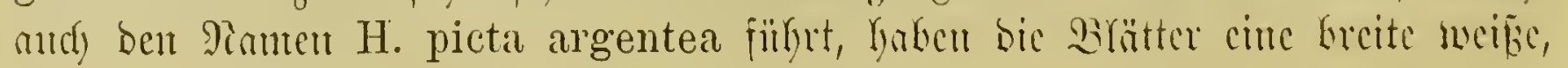




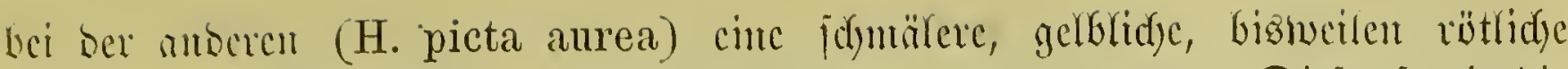

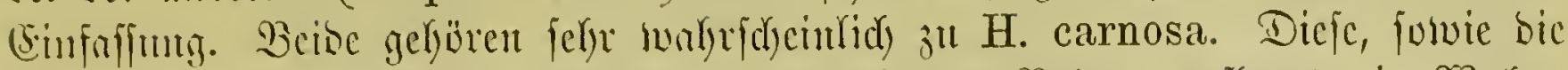

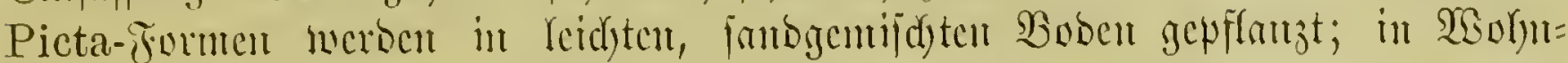

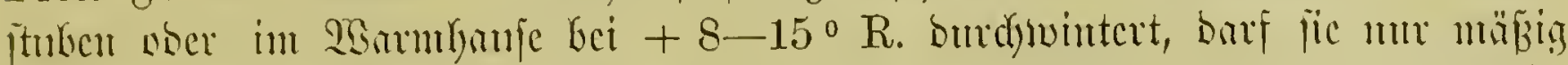

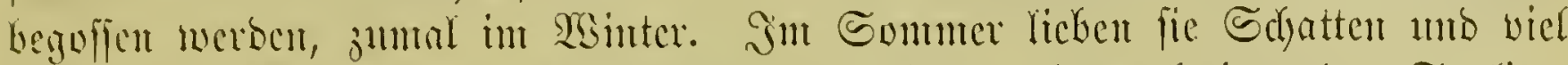

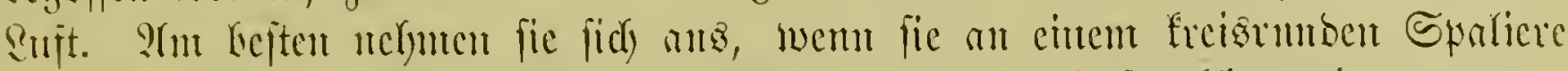

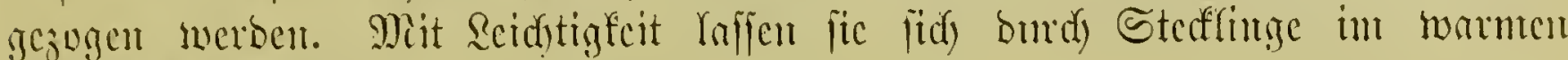
Mifthecte sermefren.

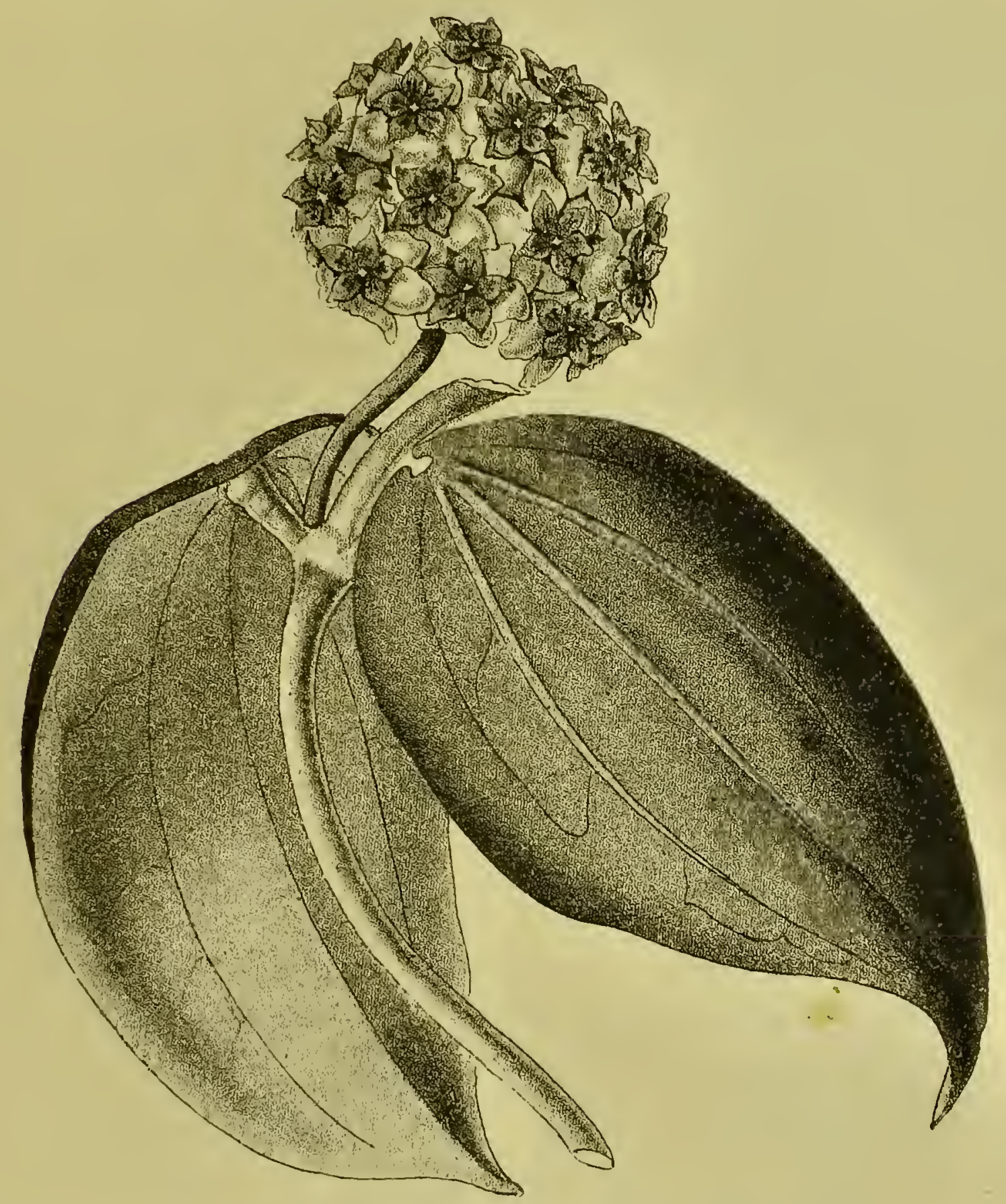

Fig. 134. Hoya cinnamomifolia Hook. Zimmtraumblätterige risad)ablume.

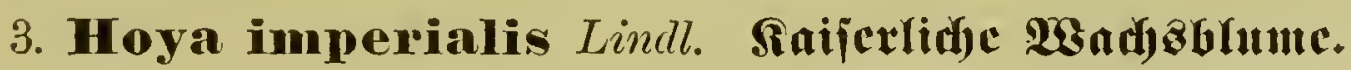

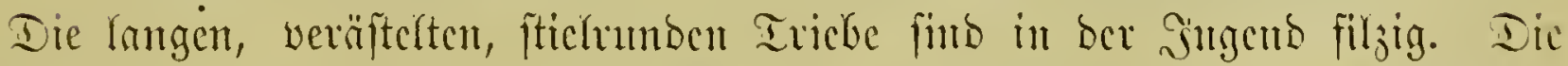
Brätter werben ïber fpamenlang, fie find oblong=lanjettlid), fmiz jugefprist,

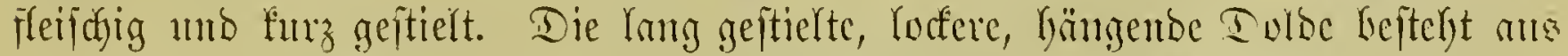

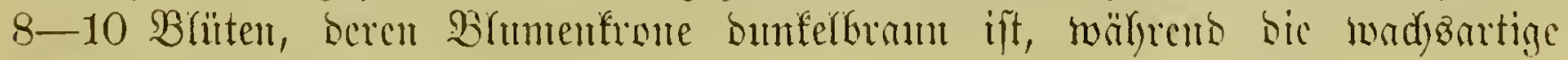
(5olona weifis int. 
Sic mädjt in Bontes !no mif Jawa; anf eriterwälnter Jujel wurbe fic

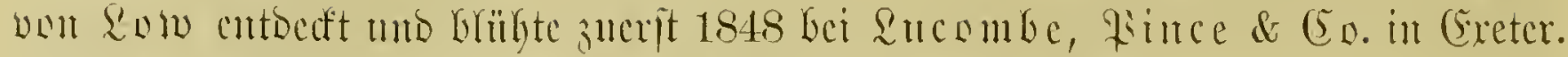

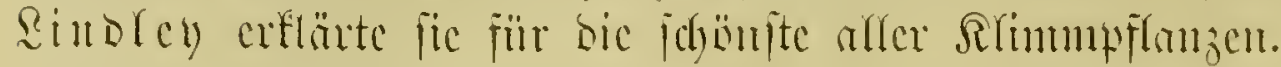

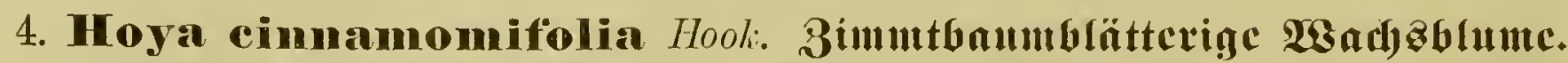

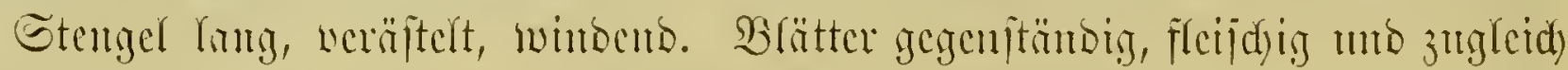

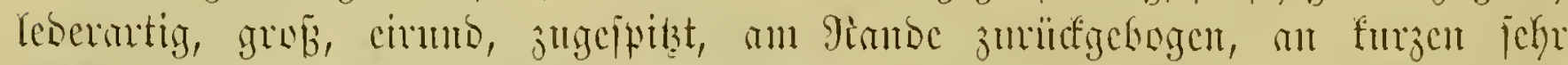

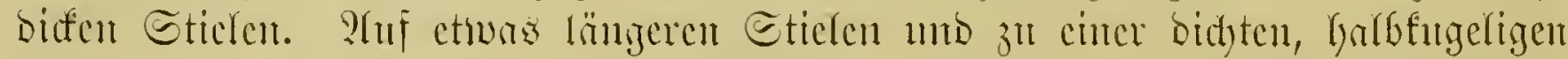

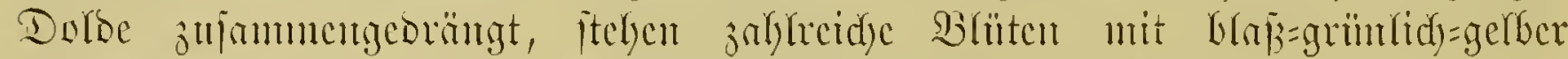

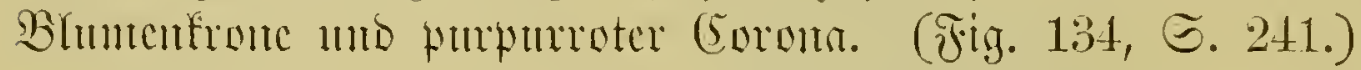

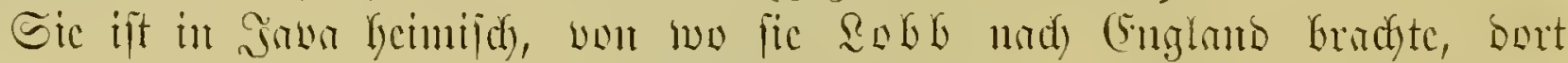

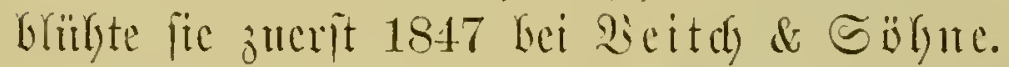

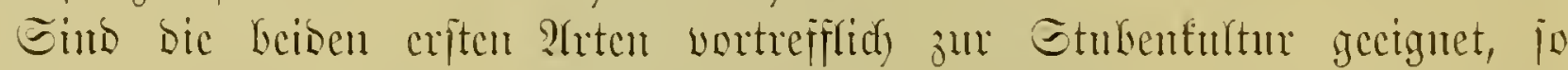

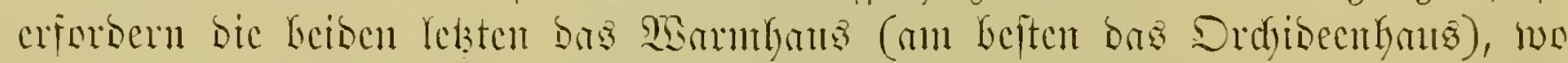

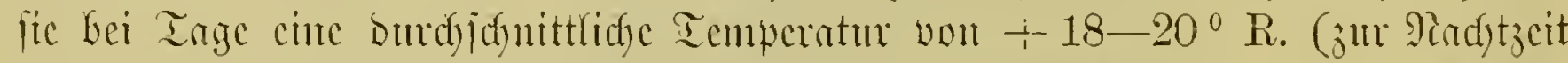

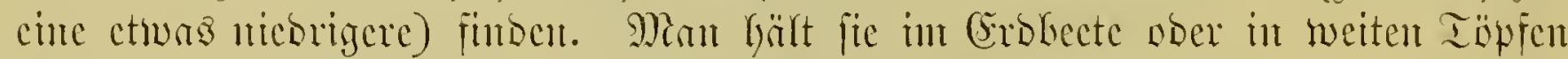

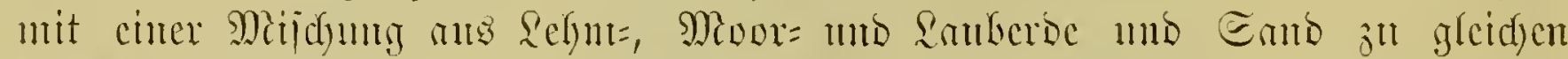

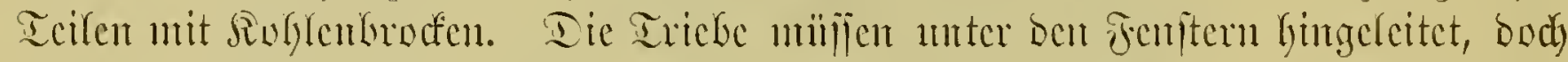

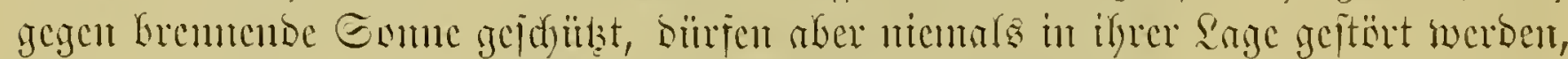

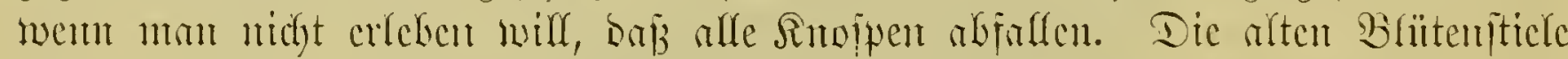

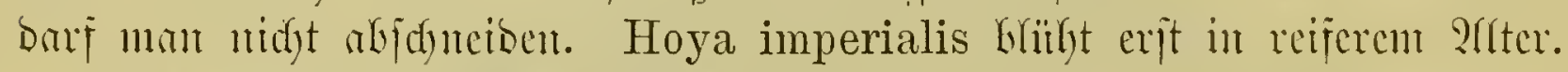

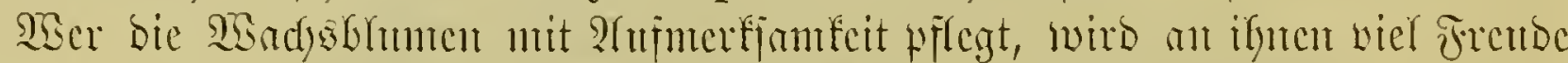

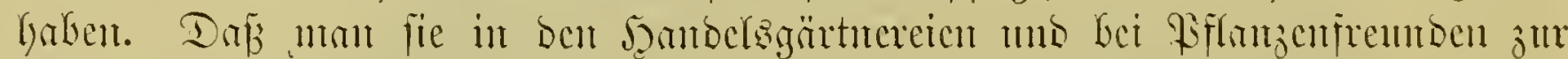

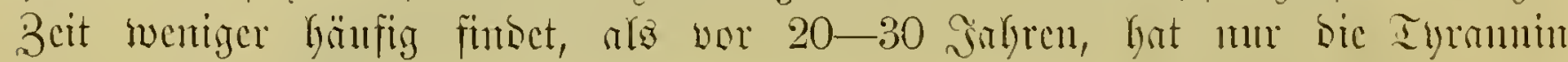
Minbe verfdullibet.

\section{3. (5)attung Stapelia L. Stapelie.}

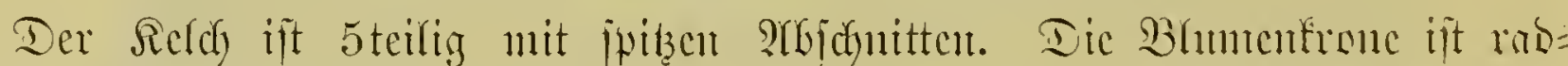

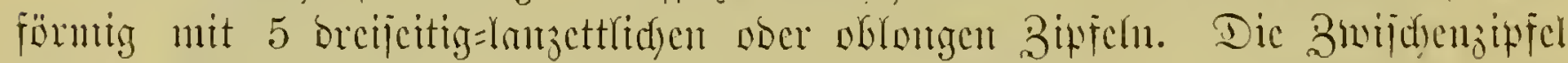

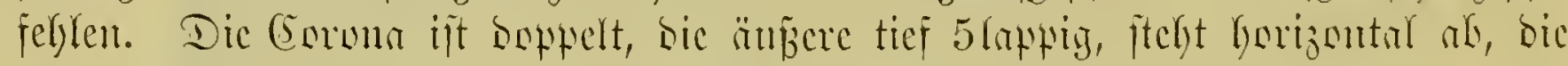

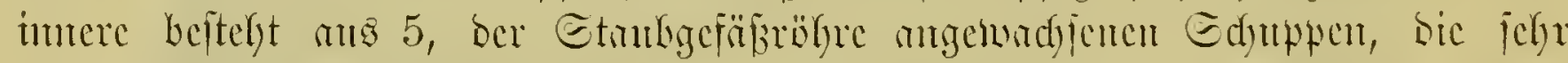

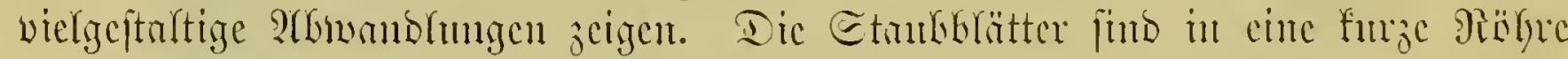

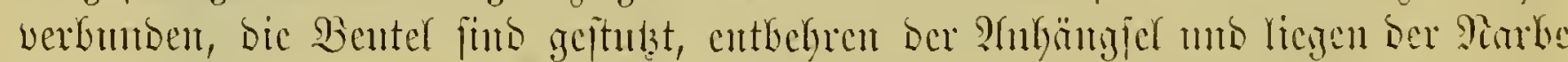

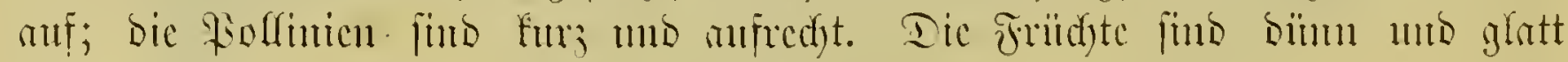

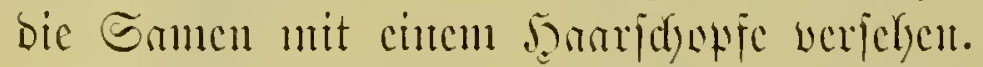

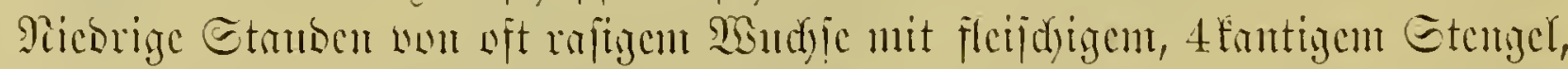

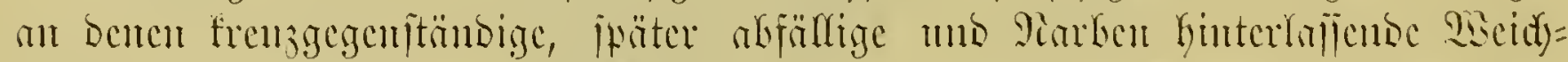

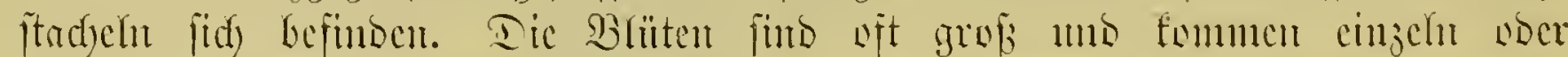

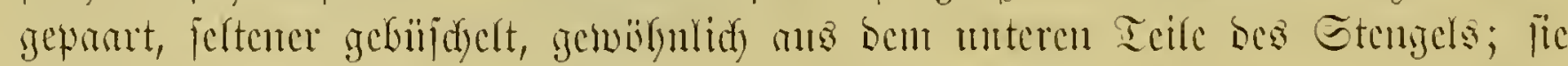

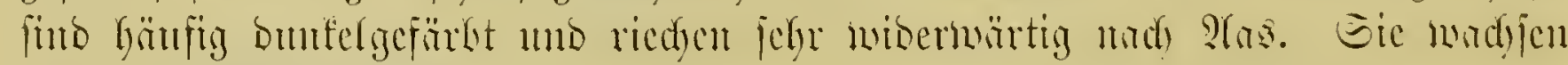
utur im fïblidyen 2fjrifi.

Sdliiffel für die bejhrieberen 3rtert.

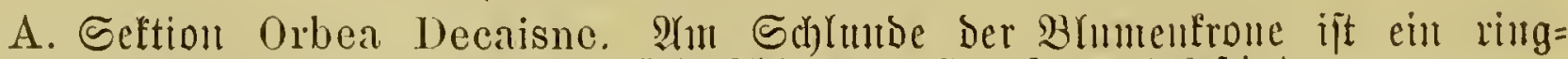

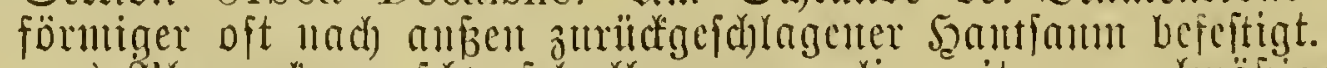

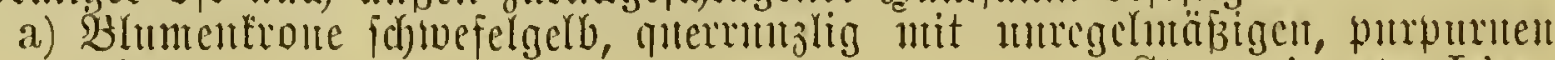
Flectert

1. St. variegata Limn. 
b) Brumenturone hellgelb.

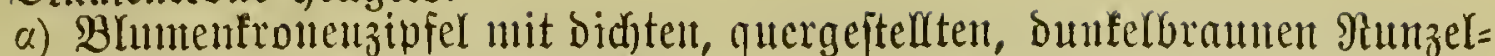
itrcifen bebeft, Rähre punftiert 2 2. St. orbicularis Andr.

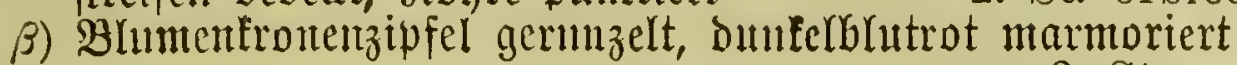

3. St. anguina Jacq.

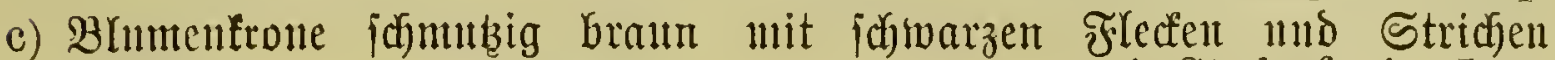
gezeidnet

4. St. bufonia Jacq.

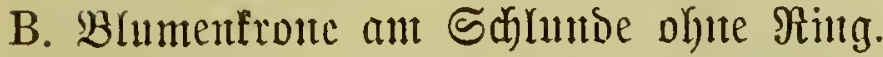

II. Scftion Stapletonia Decaisne. Roroffenzipfel bout einfadjen aufredsten, nidht feultig berbidten Saaren gewimpert.

A. Bhumentronenzipfel laugzottig.

a) Blumenfronenzipfel fatwarz purpun, grau befaart

5. St. grandiflora Masson.

b) Bhumentronenzipfel gelblidy mit blutroten @ueritridhen und Spizen unto Siändern, Saare purpurrot

6. St. hirsuta Linn.

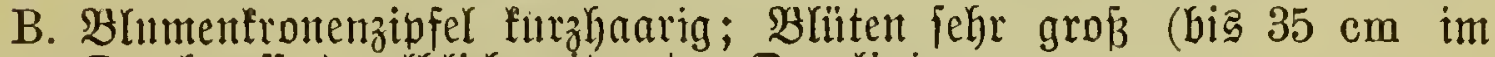
Durd)mefier) gelblich mit roten Duerlinten

7. St. gigantea N. E. Brown.

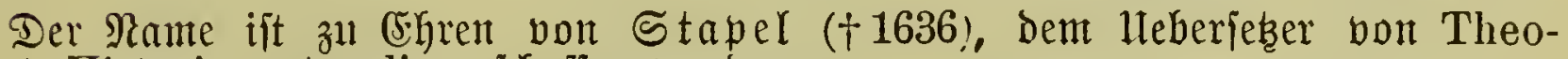
phrast, Historia naturalis gejdaffent worben.

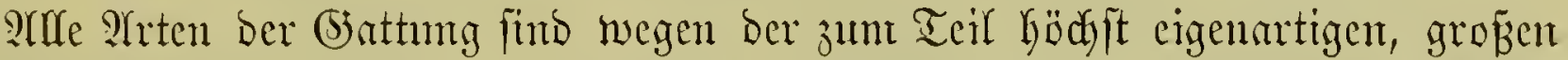

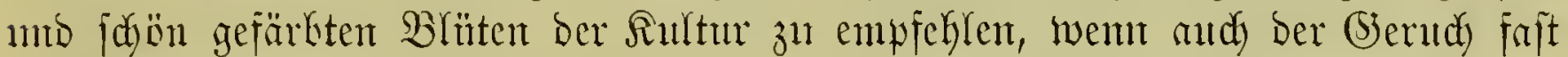

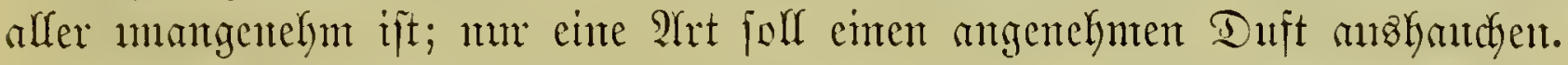

\section{Stapelia variegata Linn. Butte Stapelie.}

Der Stengel ift anfifteigend, vierfantig unt trägt ant Gruntoe cinzelne,

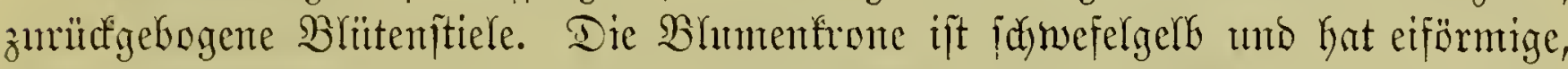
fpitze mit purwmoten Duerrunzeln und Flecten gejierte Bipfel; im Schlunde ijt iie Kelfer. (テrig. 135, S. 244.)

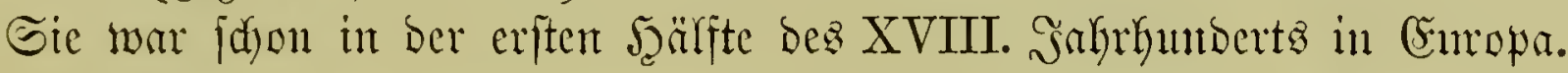

\section{Stapelia orbicnlaris Andrews. Edjeiben=Etruelie.}

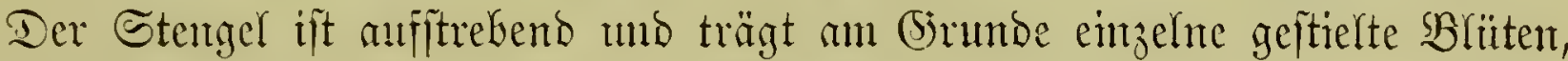

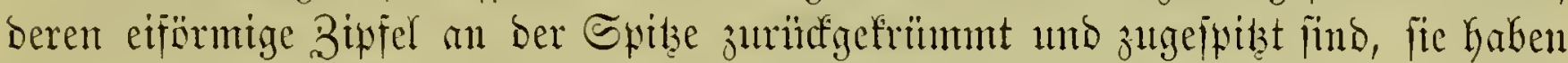
eine ftrolggelbe Farbe unto finto mit quergejtellten, bidyten, Gramen Streifen

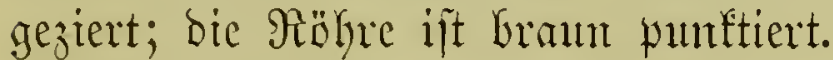

\section{Stapelia anguina $J a c q$. Sdhlangen=Stapclic.}

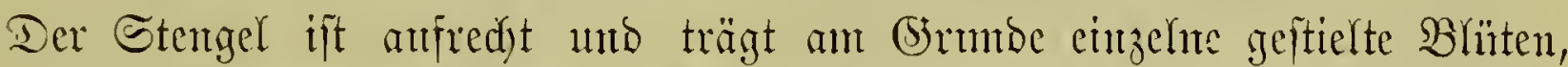

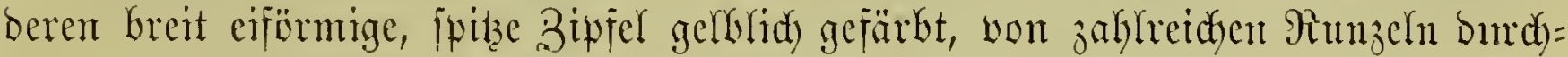
quert und bunfelfilutrot marmoriert funs.

\section{Stapelia bufonia Jacq. Sirüten=-Stapelic.}

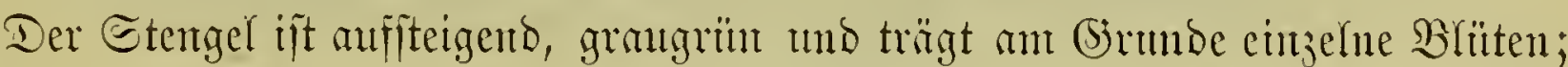

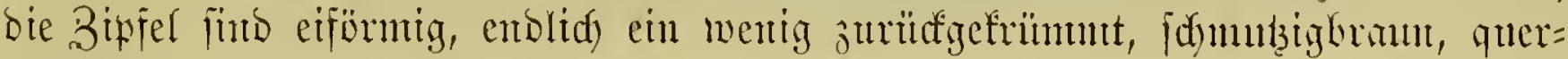
gerunzelt uno mit butferen Funften geflectt.

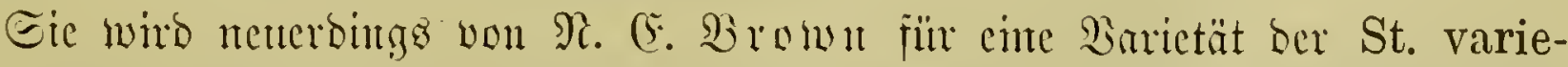
gata Linn. gebalten, ju ber aud St. Curtisii Roem. et Schult. und St. bisulca Don gejogen werber. 
5. Stapelia gramdiflora Masson. Grof̈blütige Etapclic.

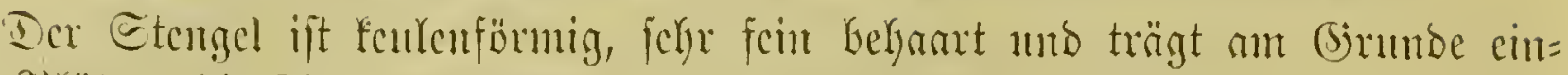

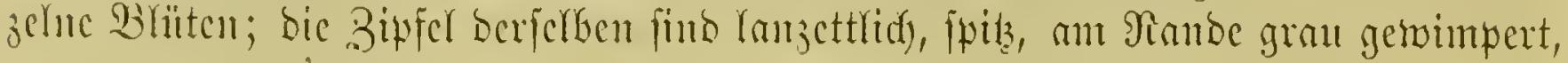

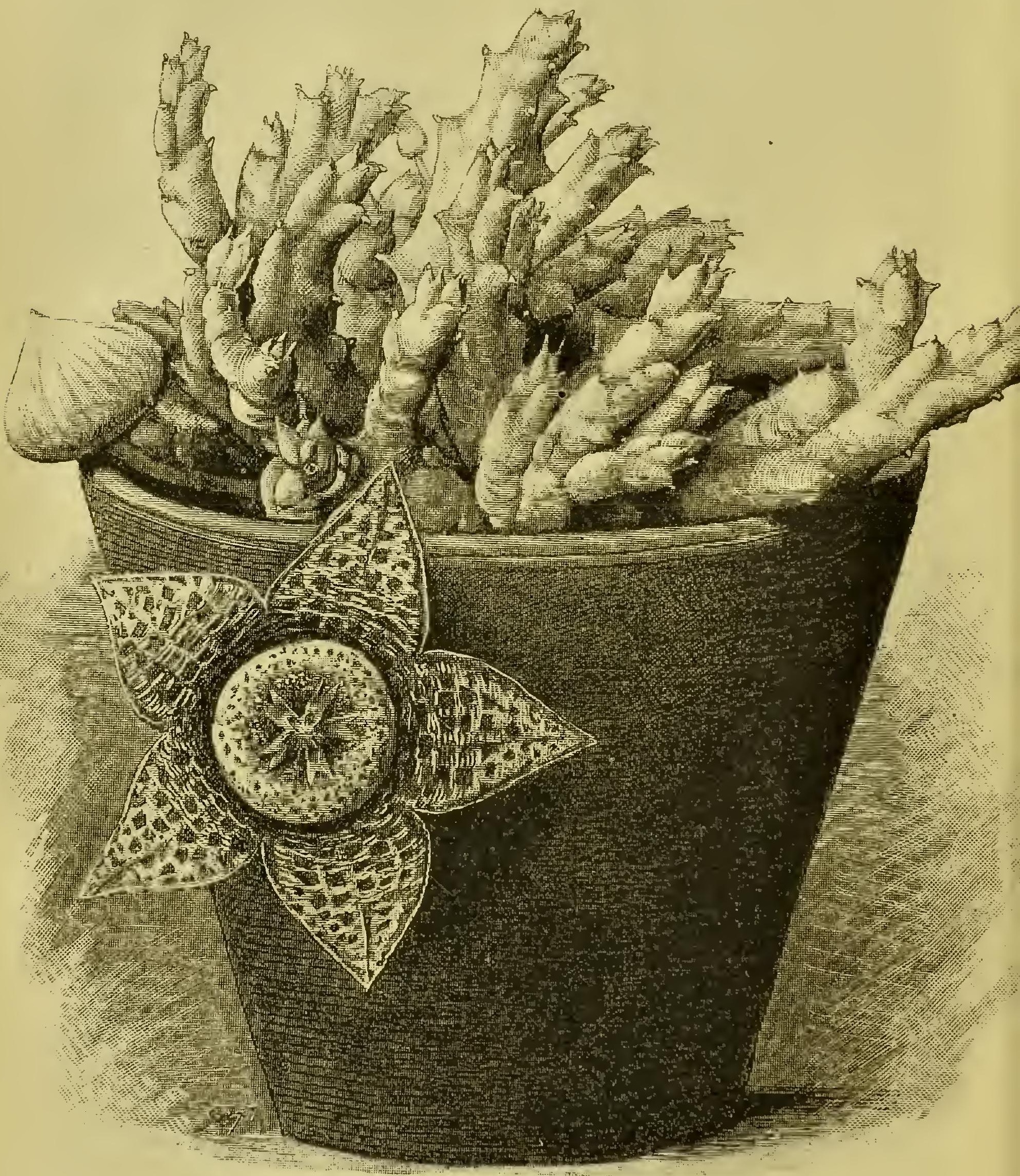

Fig. 135. Stapelia variegata Lim. Sunte Stapelic.

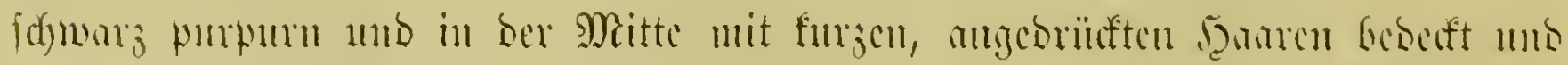
quergermuselt. (jig. 136, Є. 245.) 
6. Stapelia hirsuta Lim. Bichante Etapclic.

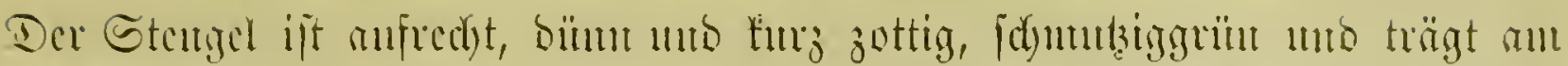

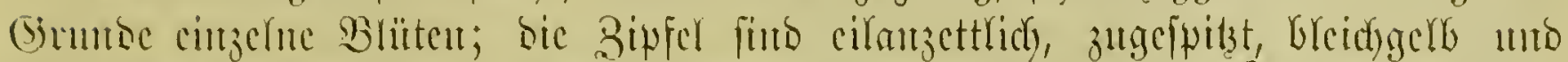

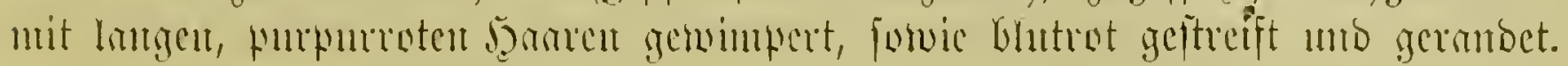

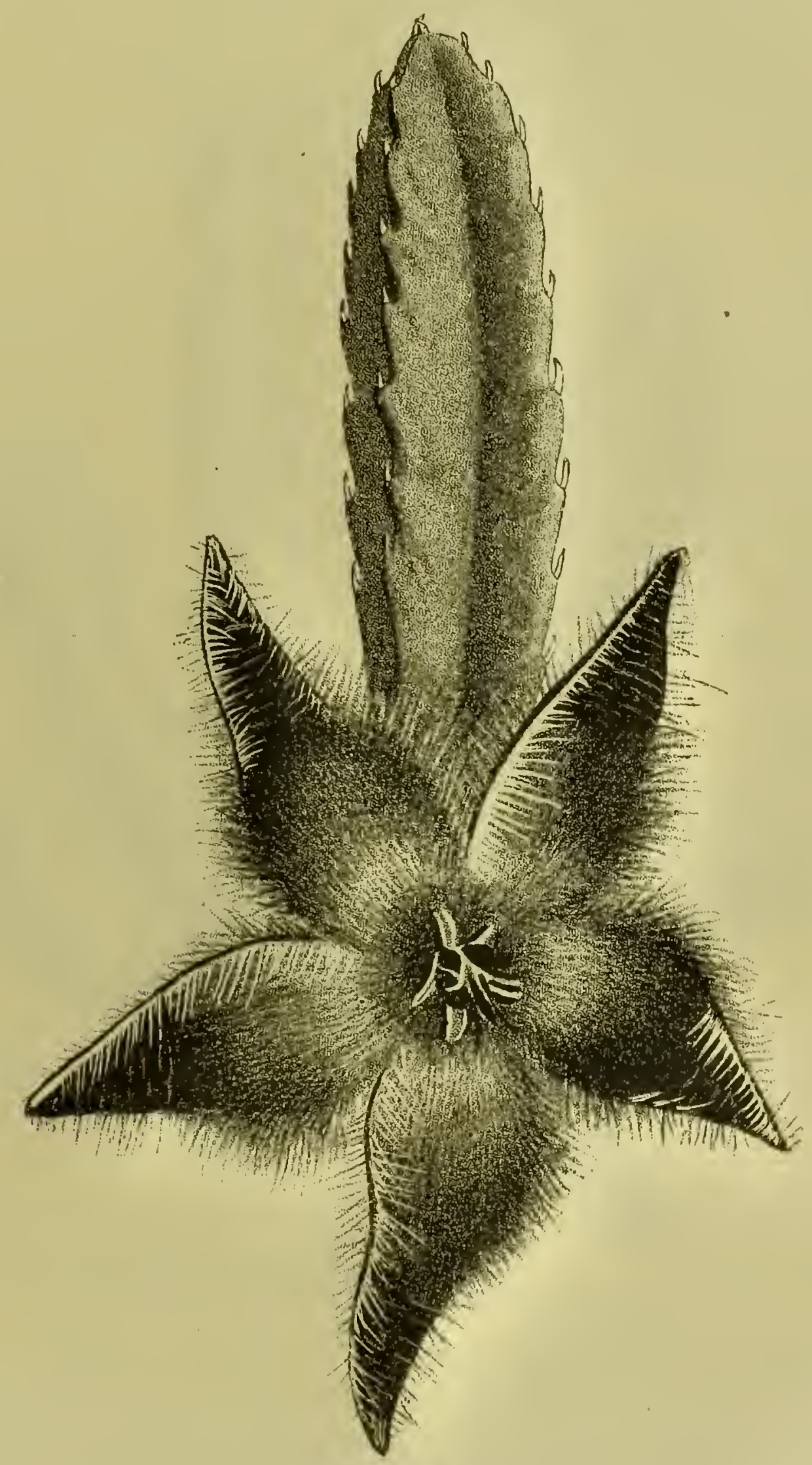

Fig. 136. Stapelia grandiflora Masson. Brobblitige Stapelie.

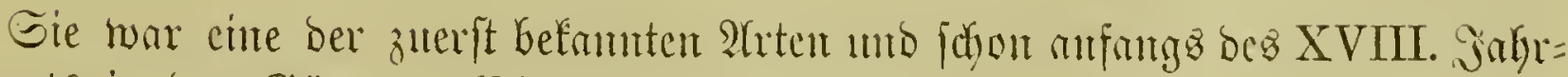

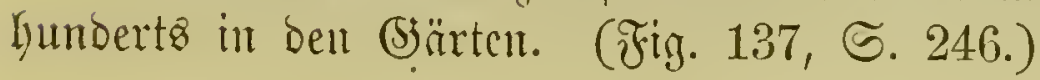


7. Stapelia gigantea $N$. E. Brown. Ricicn=Gtapelic.

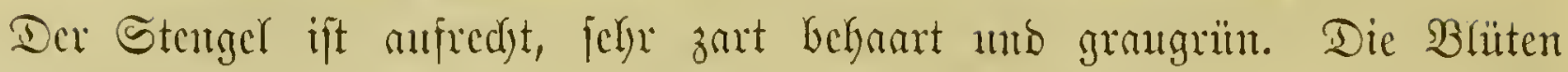

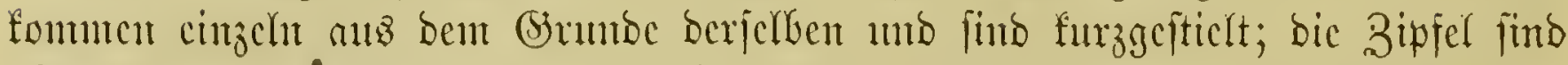

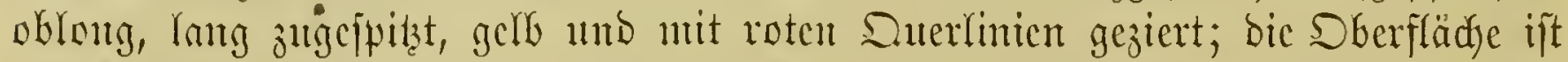

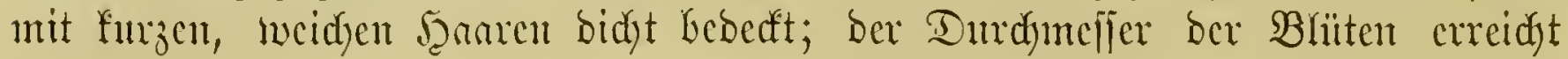
$35 \mathrm{~cm}$.

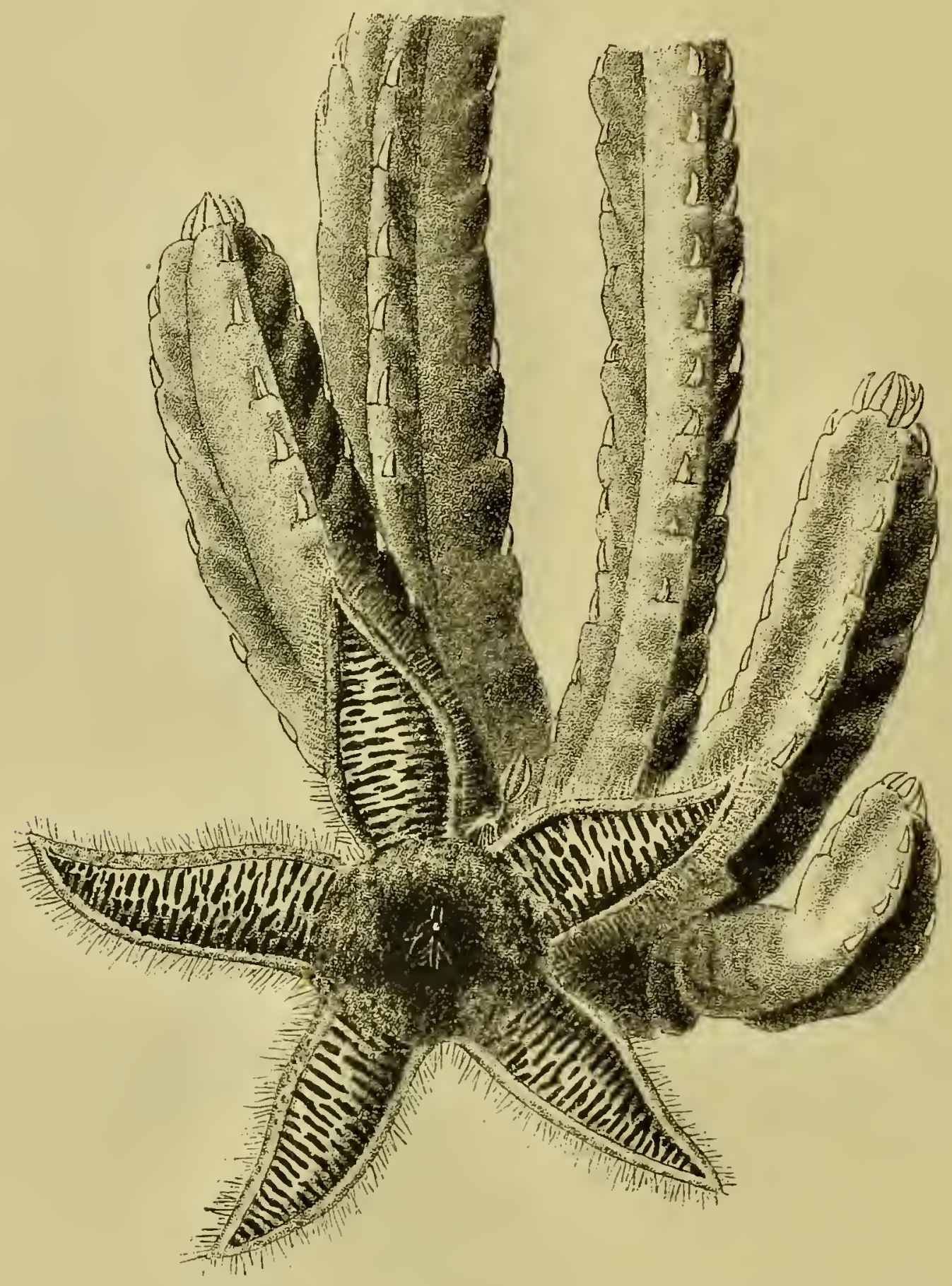

Fig. 137. Stapelia hirsuta Linn. Befaarte Stapelie.

Sic wurbe in ben $70 \mathrm{er}$ Singren ans ben Buthulanbe cingeführt nub ipäter

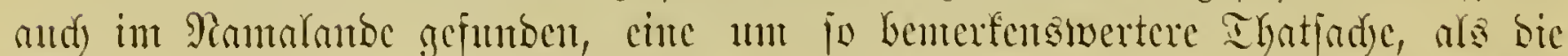

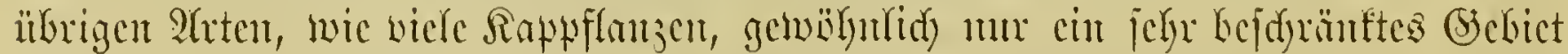

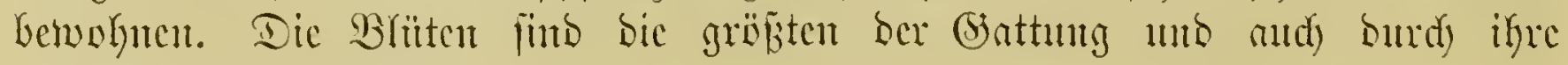
Förbung jelye anfinallemb.

Die Rultun ber Arten bicfer Gattung ift nidyt jdywierig. Sant man

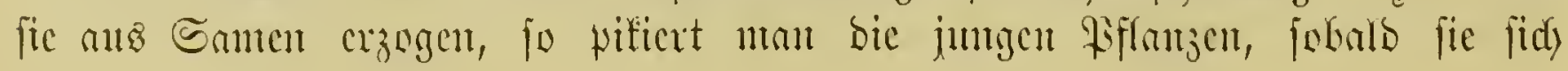




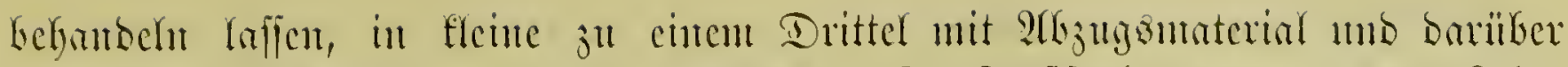

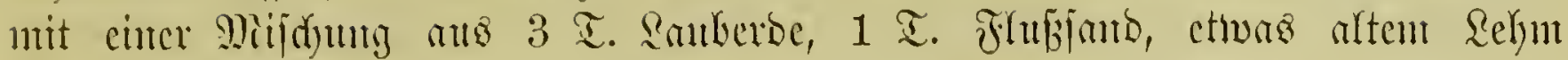

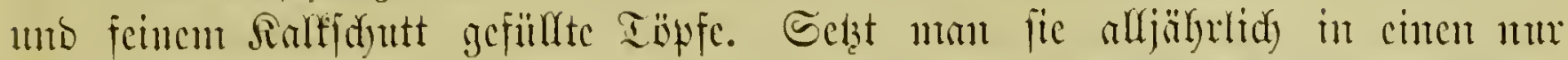

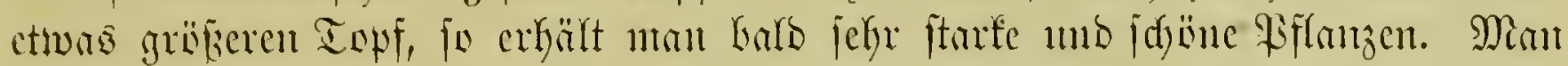

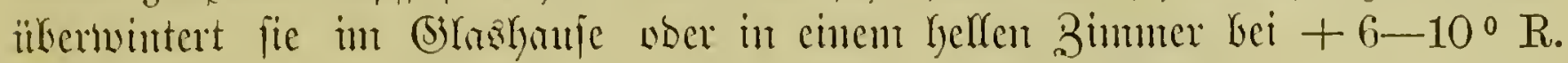

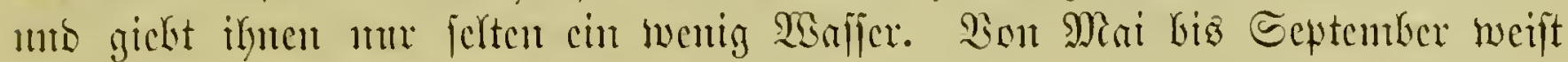

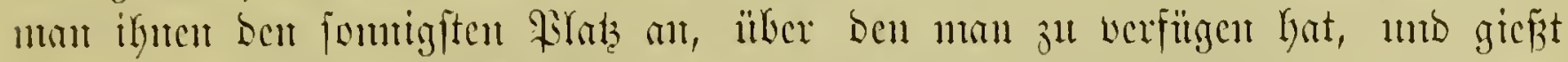

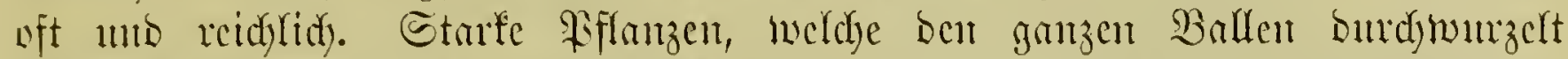

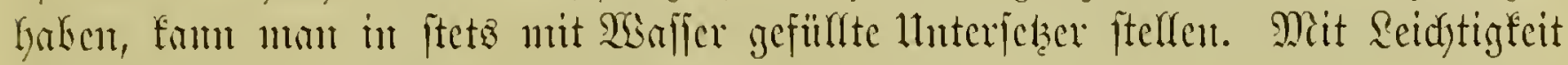

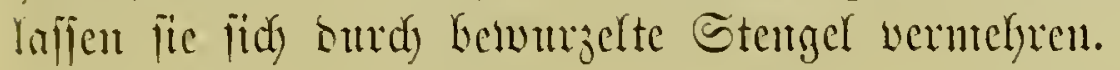

\section{4. (Jiattung Huernia R. Br. Şuernie.}

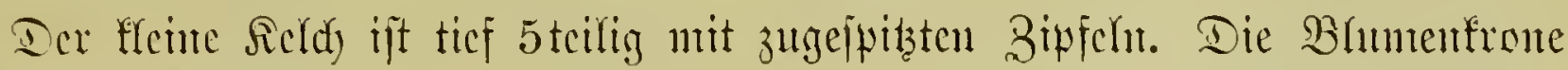

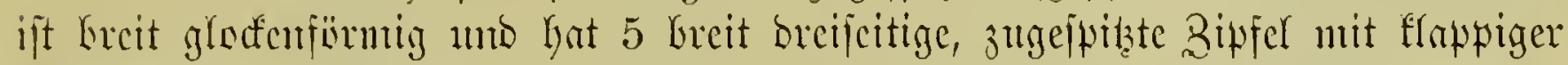

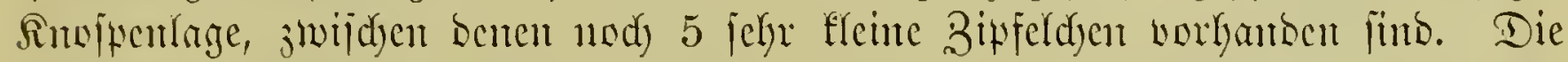

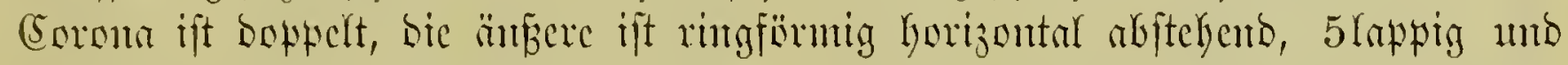

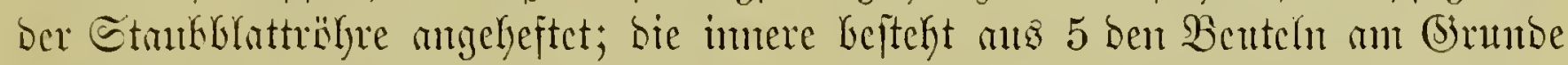

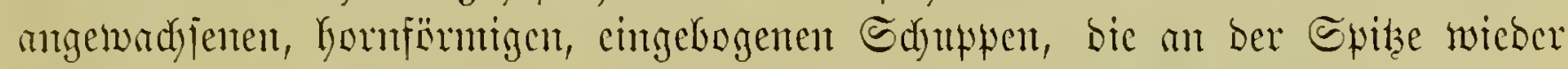

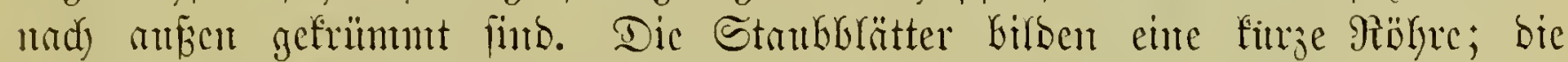

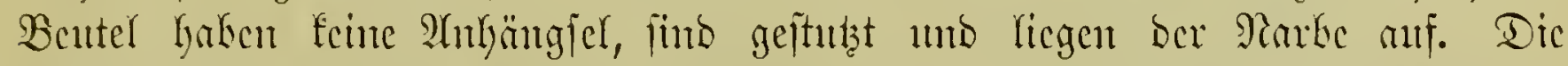

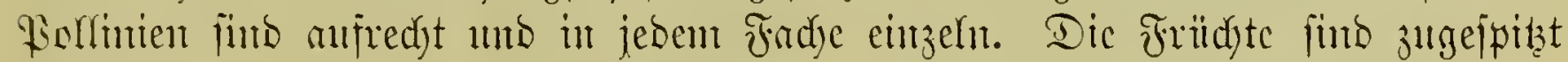
Intb glatt.

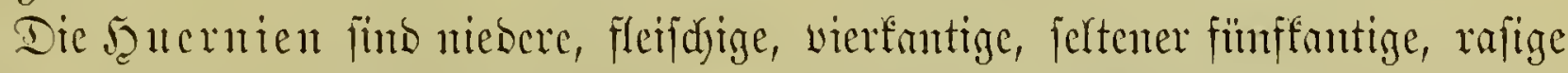

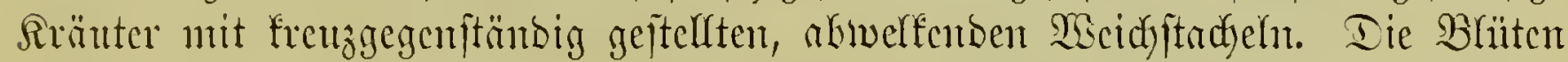

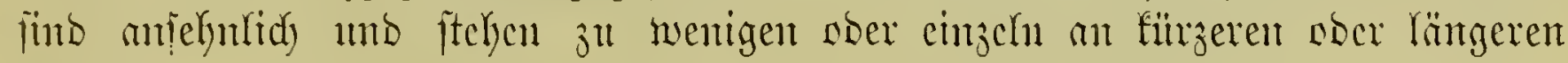
Sticlent.

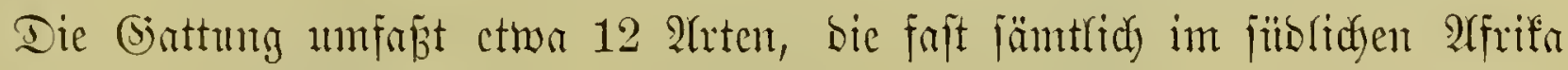
wadjicu.

\section{Sđliüfjel für die befđriebenen 2lrter.}

A. Die Blumenfronenröhre ift weiß und gegen ben braunbioletten Saum fdharf abgeiekt

1. H. oculata Hook. fil.

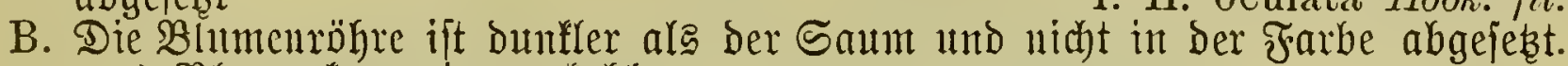

a) Blumenfrone inten faht.

a.) Stengel furz und bia̛, şrïte geruchlog

B) Stengel idhlanter, shlitte ftimlend

2. H. brevirostris N. E. Brown.

b) Blumentrone innett behaart.

a) Schlund von ben Saarent geidilofien

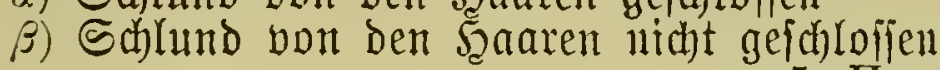

3. H. venusta Rob. Broun.

5. H. campanulata liob. Brown.

\section{Huernia oculata Hook fil. Giäugelte s̆ucruic.}

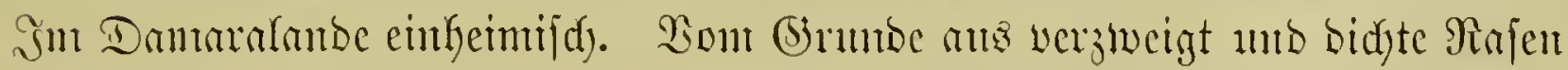

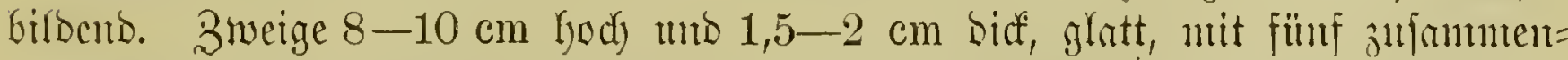

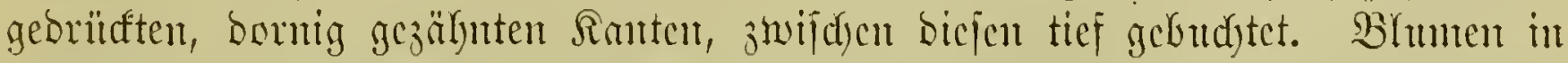

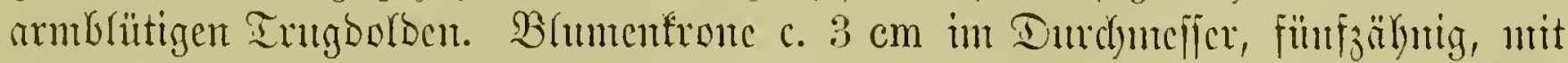

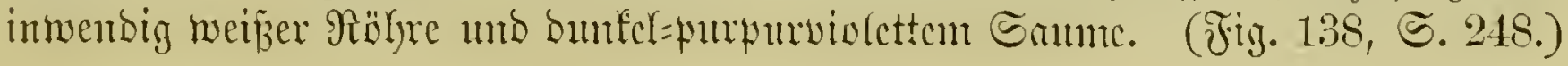




\section{Huernia brevimostris $N$. $E$. Br. Simzidnubclige sucruic.}

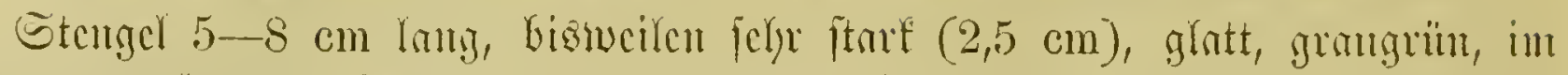
?ater purpubrim. SBlüten an ben jungen Bweigen, 4-6 anf cincm Etiele.

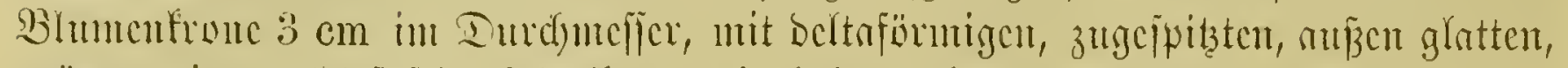

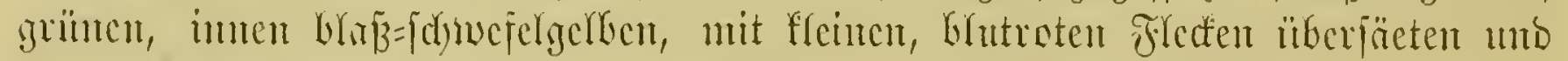

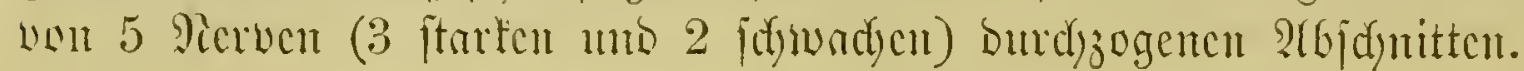

\section{Huenia venusta $R$. Br. Micizenbc S̈ucruic.}

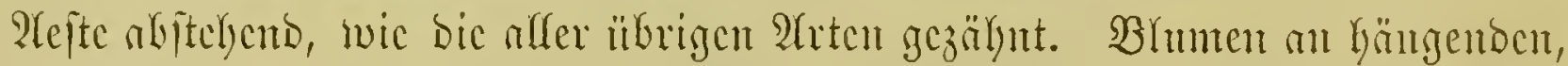

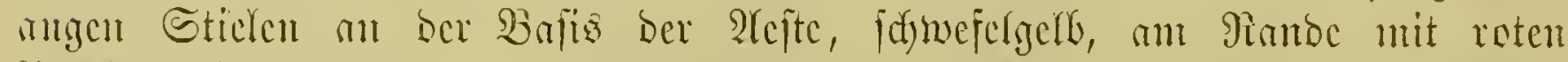

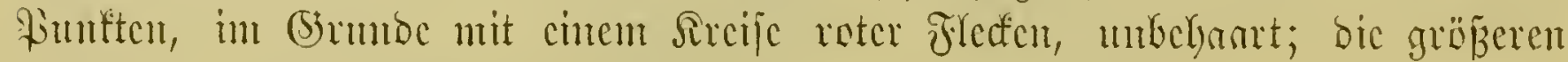

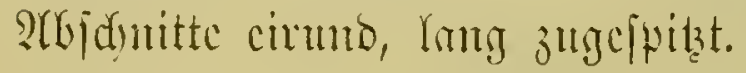

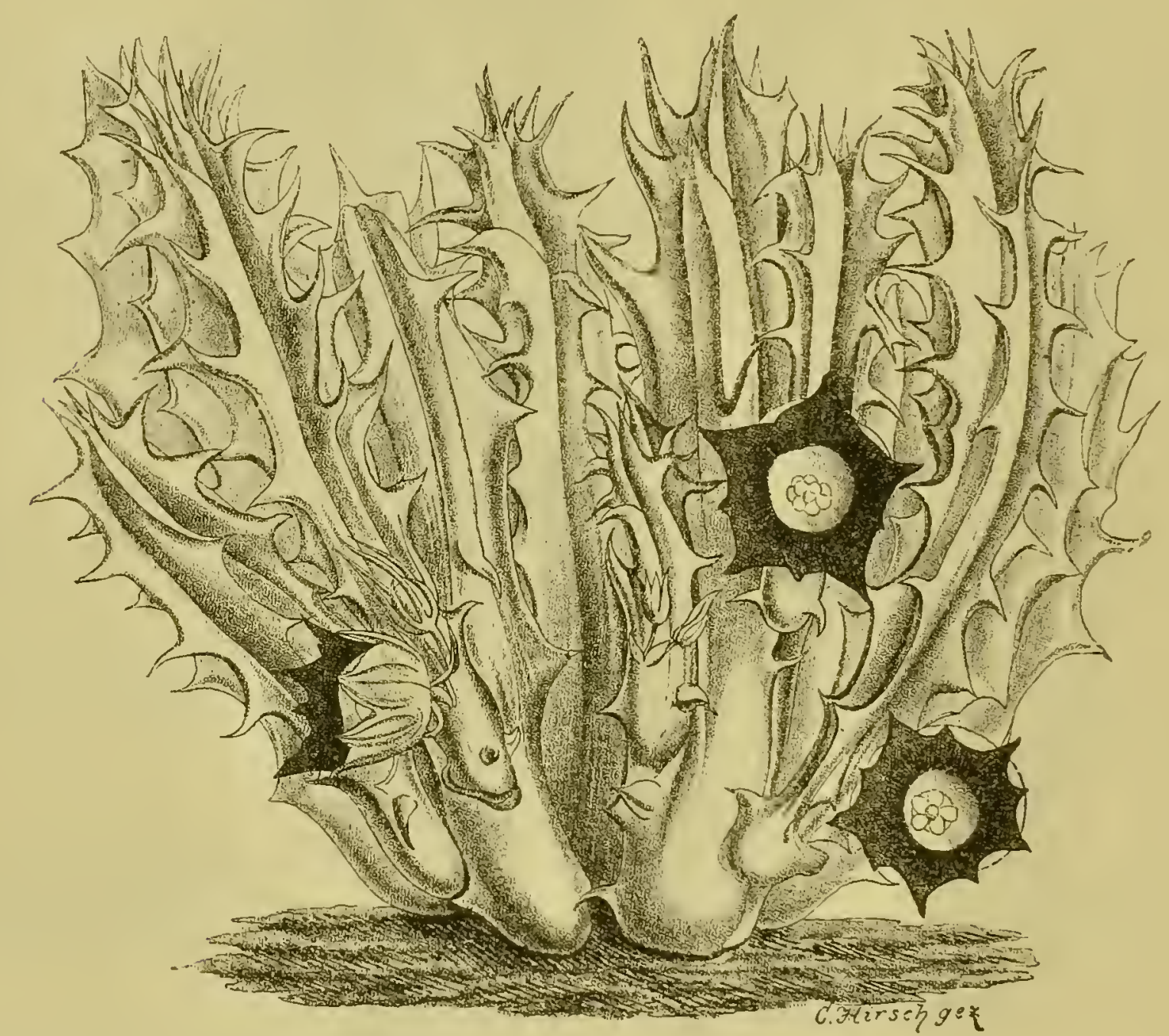

Jig. 13s. Huernia oculata Ilook fil. Geängelte Şแernie.

\section{Huemia clavigera Haw. Bärtige șucruic.}

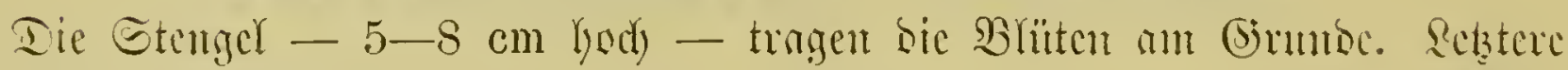

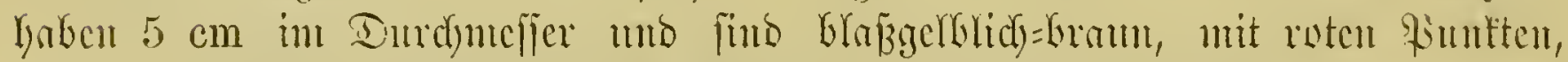

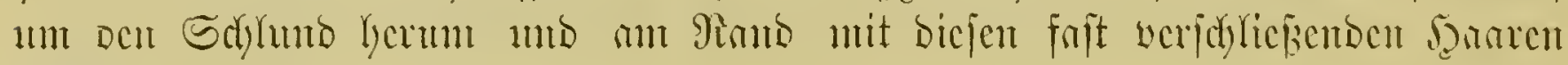
bcipelist.

\section{Huemia campanulata $R . B r$. Gsforfubritigc sucruic.}

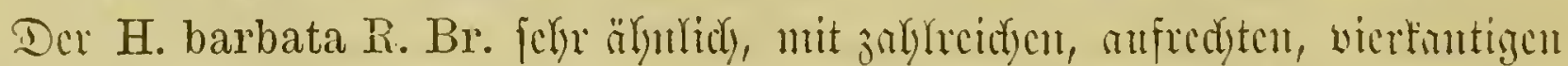

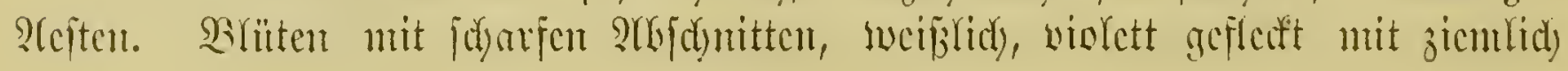




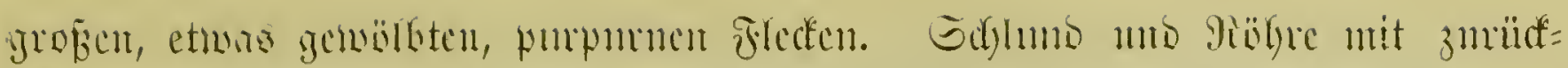

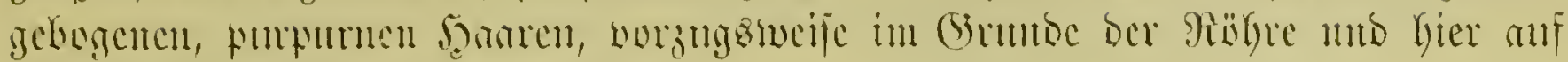

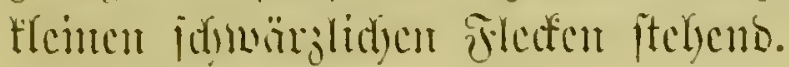

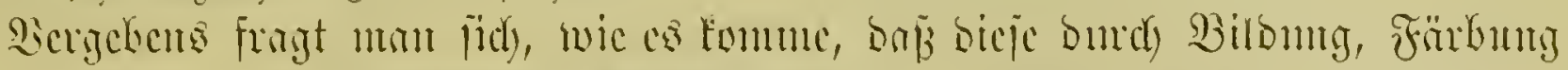

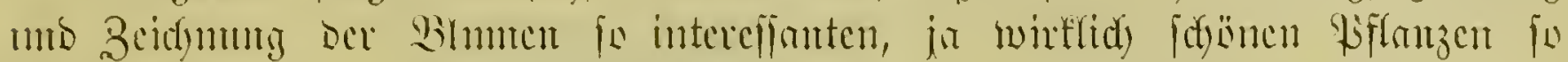

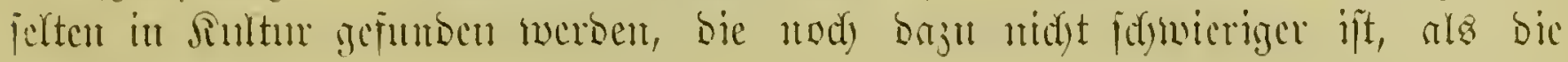
ser Stafelicu.

\section{Familie Compositae. Forbblïtler.}

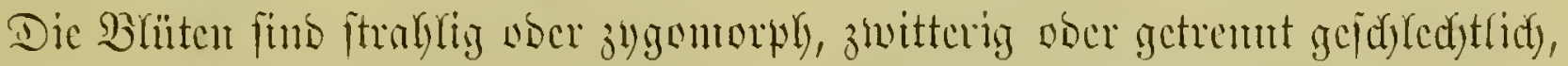

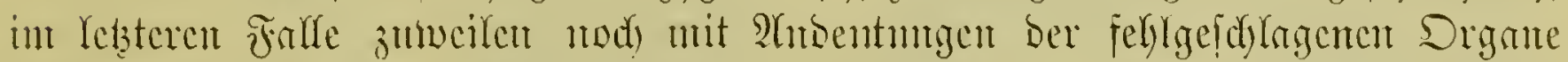

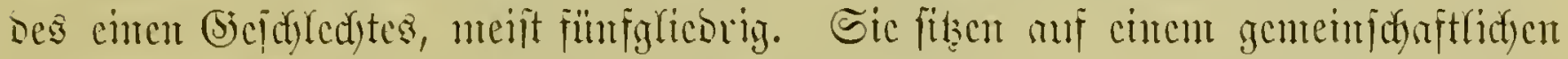

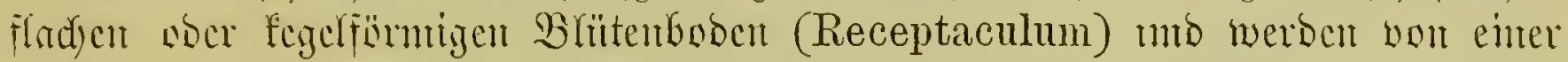

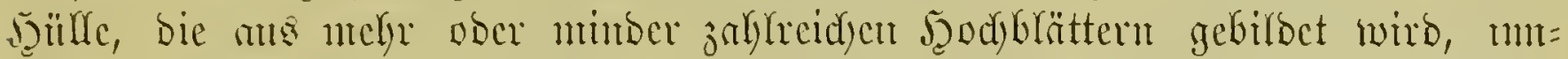

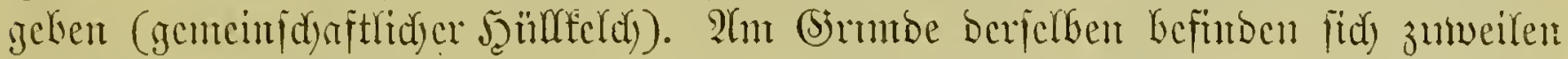

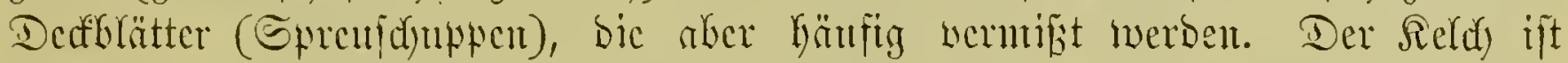

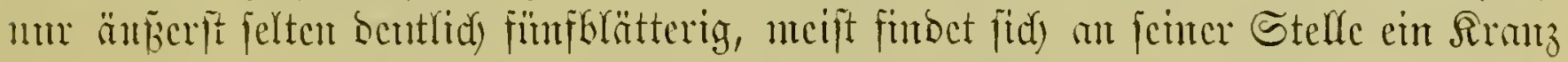

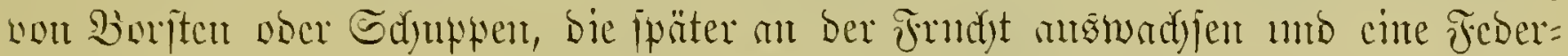

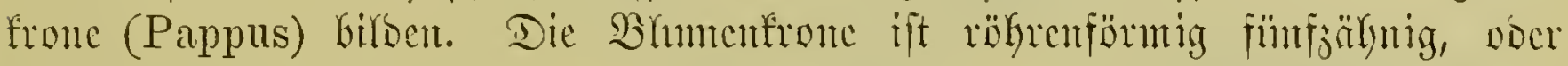
jungenf̈rmig unb 3-5jälynig, ober lippenförmig. Dic 5 Stanbblätter fïno der

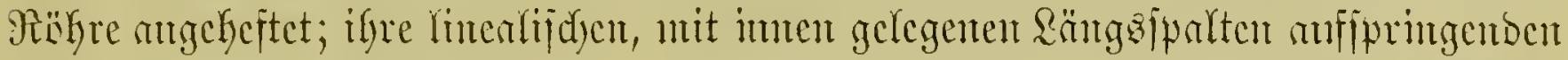

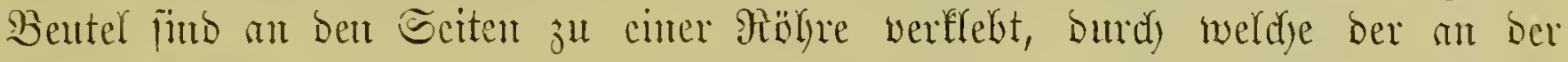

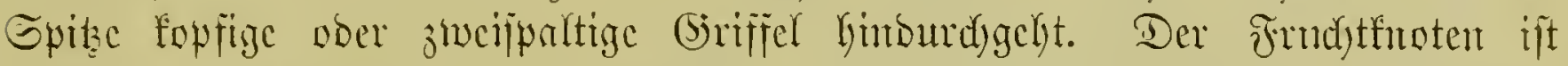

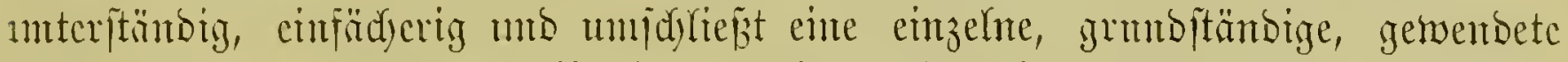

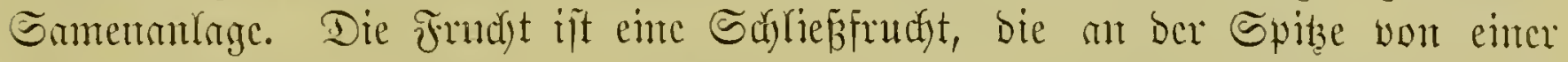

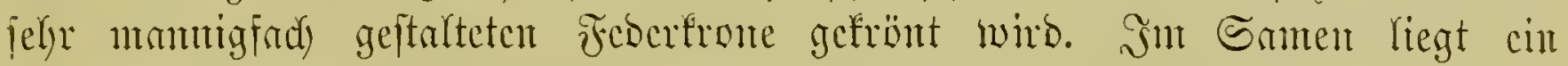

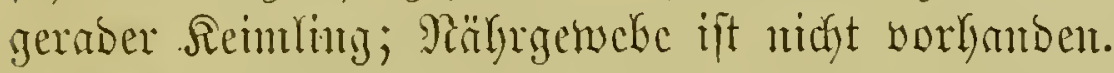

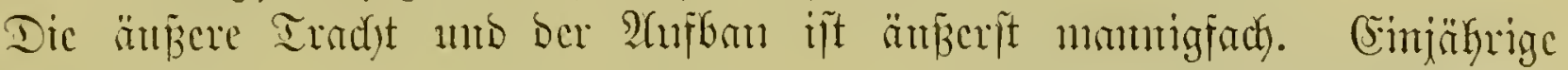

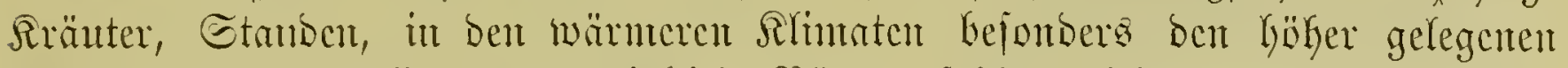

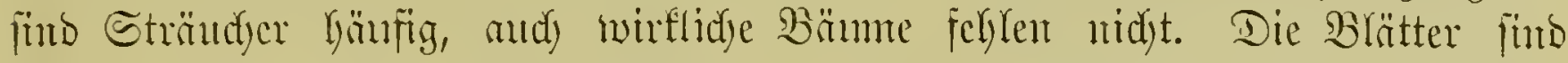

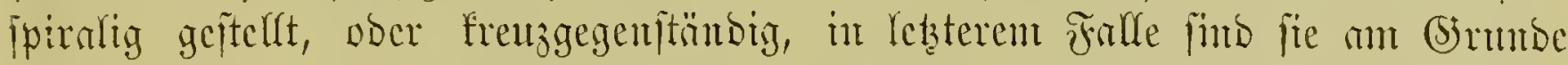

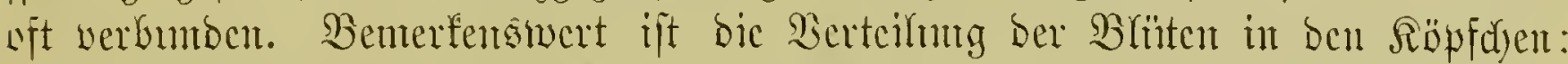

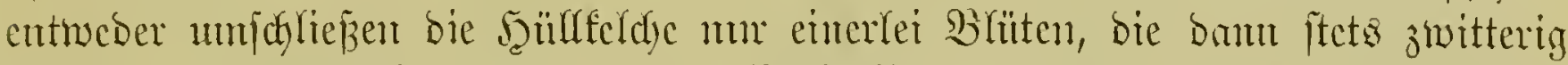

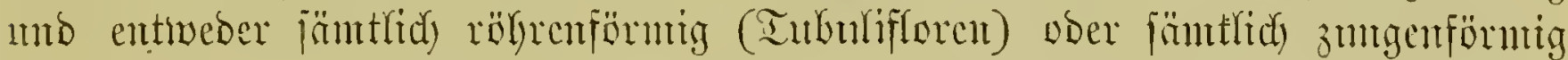

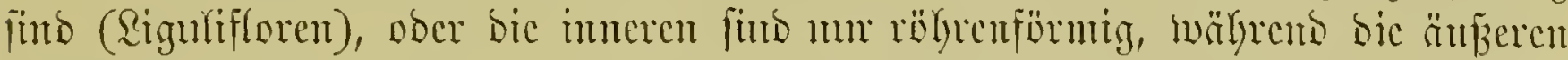

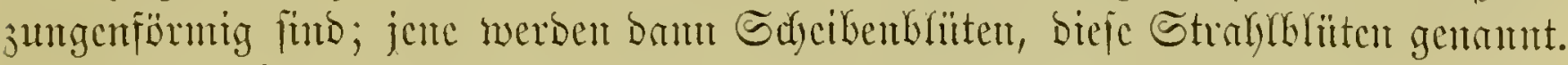
Dic erifteren finto zwitterig, Dic Yckzteren mur weibrict).

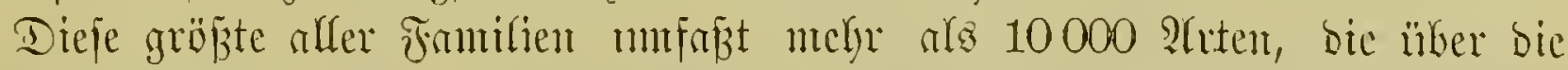

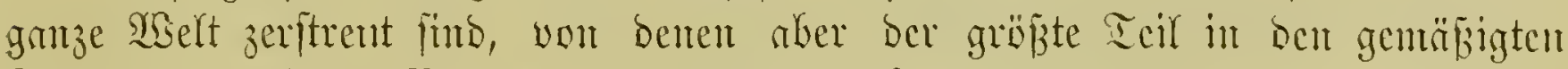

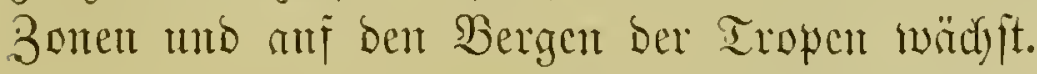

\section{Shlïliffel für die befproḑenen Battungent.}

Die Srei eribälntent Brattutgen gehören in bie Tribıs Der Senecionoideae,

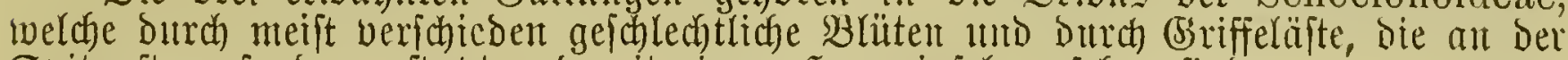

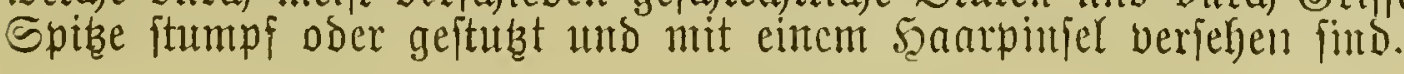


A. Man Sdeibenblüten entwicfelt, Briffeläfte nit $\mathfrak{A n h a ̈ n g f e l ~}$

B. Sd)eiben= und ভtrahlenblïten vorhanden, Sriffeläłte mit

a) Sd)eibenblüten unfrudbar

b) Schcibenblïten fruchtbar

1. Kleinia $D C$.

Szaarbüichel.

2. Senecio Linn.

3. Hertia Less.

\section{1. (J)attung Kleinia DC. STleinie.}

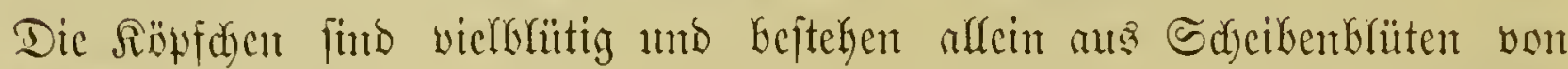

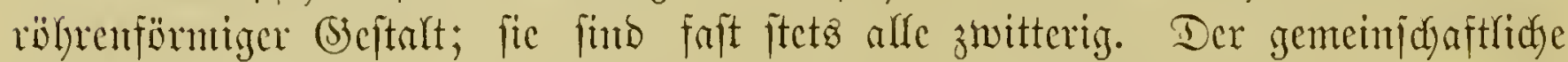

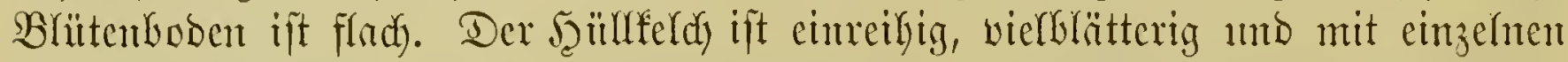

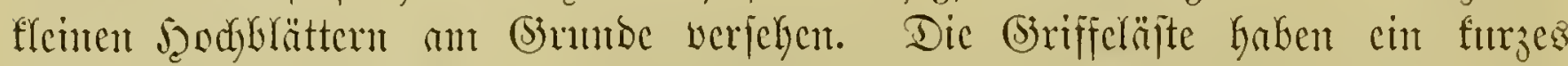

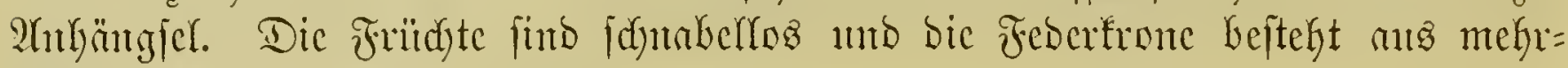
reifigen, ctwas rauken Borĩten.

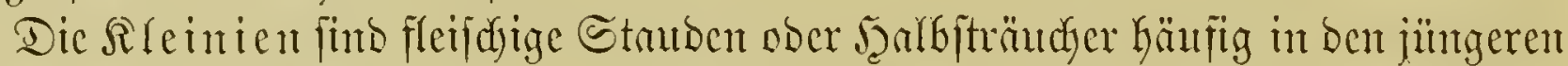

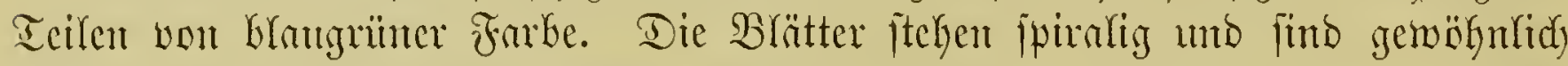
ganj. Die Rëpfdyen fint einzelut, enditänbig ober ju Dolbentranben vereinigt. Ungefägr 20 Prten fït kejdrieben worben, bie alle am Rap wadjen. Der

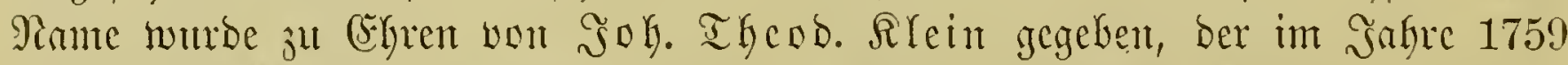

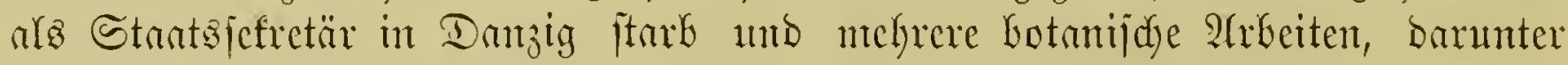
aud) eine ̈̈̈ber bic „Cacalia" gejdyricben hat.

\section{S丸liüfjel der befdriebenen Urten.}

\section{A. Blätter ganz.}

a) Blätter flach, gezähnt, fahl; şlïten orange

B. Blätter gebuchtet

1. K. fulgens Hook. fil.

2. K. tomentosa Hau.

3. K. articulata Haue.

(3)egenmärtig wirb bie Siattung Kleinia won ben Botanifern mit Senecio werbunben, weil fid bie angegebenen (SGaraftere als nidyt gant burdygehent, jonbern

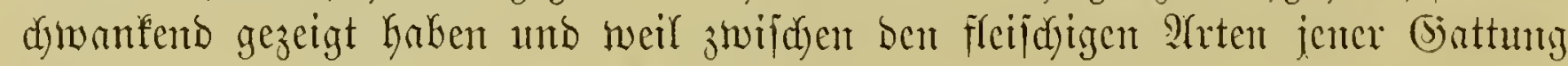
unto ben Rreinien Hebergänge nidyt fehlen.

\section{Kleinia fingens Hook fil. Scudftenbe Rlciuic.}

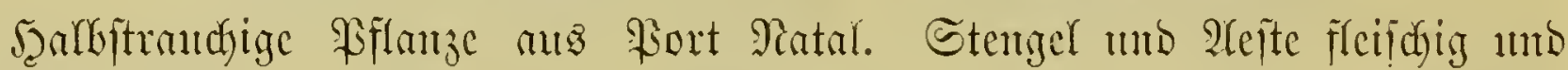

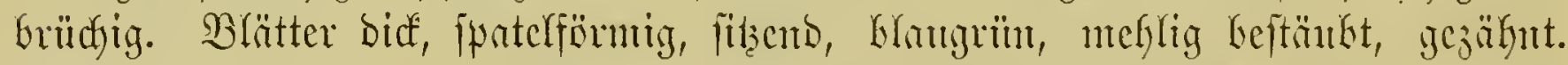

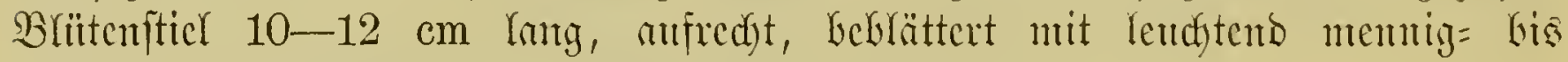
orangeroten Brütenföpfdyen. (Fig. 139, S. 251.)

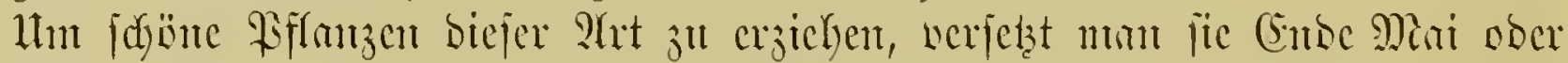
anfmigs Junt in. Das freie Ranto, pffrant fic im September wicber in Iöpfe

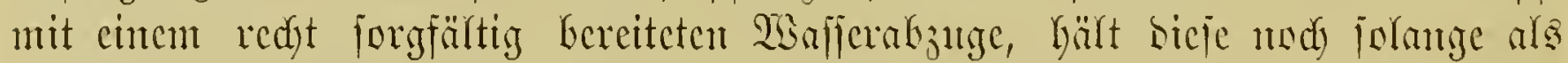

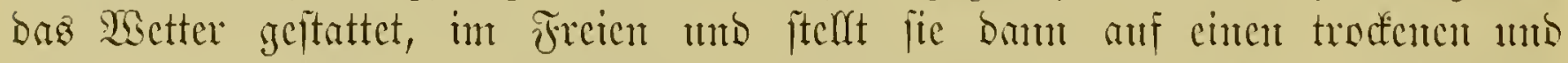

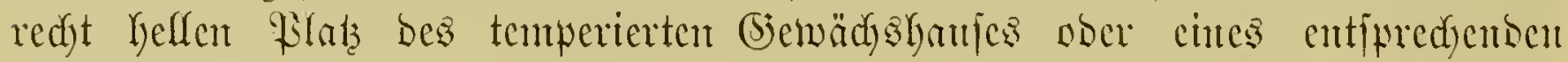
Boblumantos.

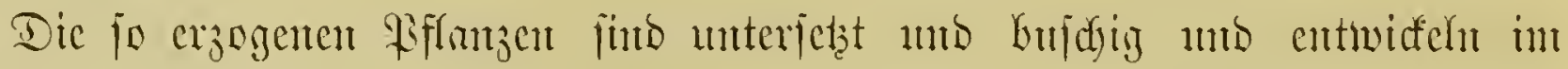
Friilgjabre cincu reidyen folst.

2. Kleinia tomentosa Haue. Filzige §lciutic. (Kl. Haworthii DC.)

Etengel rumb, bisffeifdig, anfredyt, mit fitichrunben, nad) beisen (Enben wer=

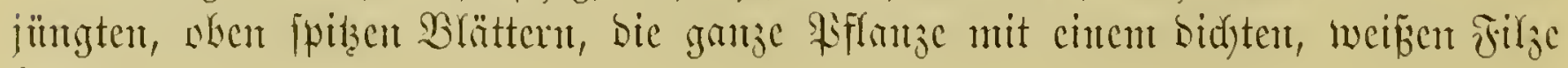
bebeeft. 


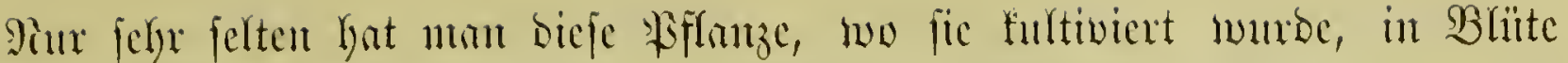

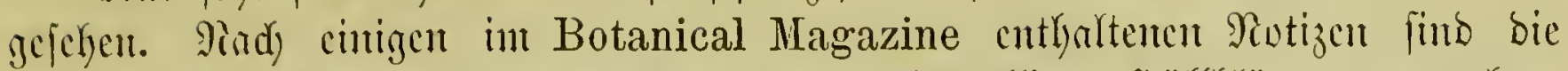

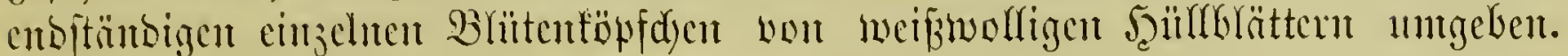

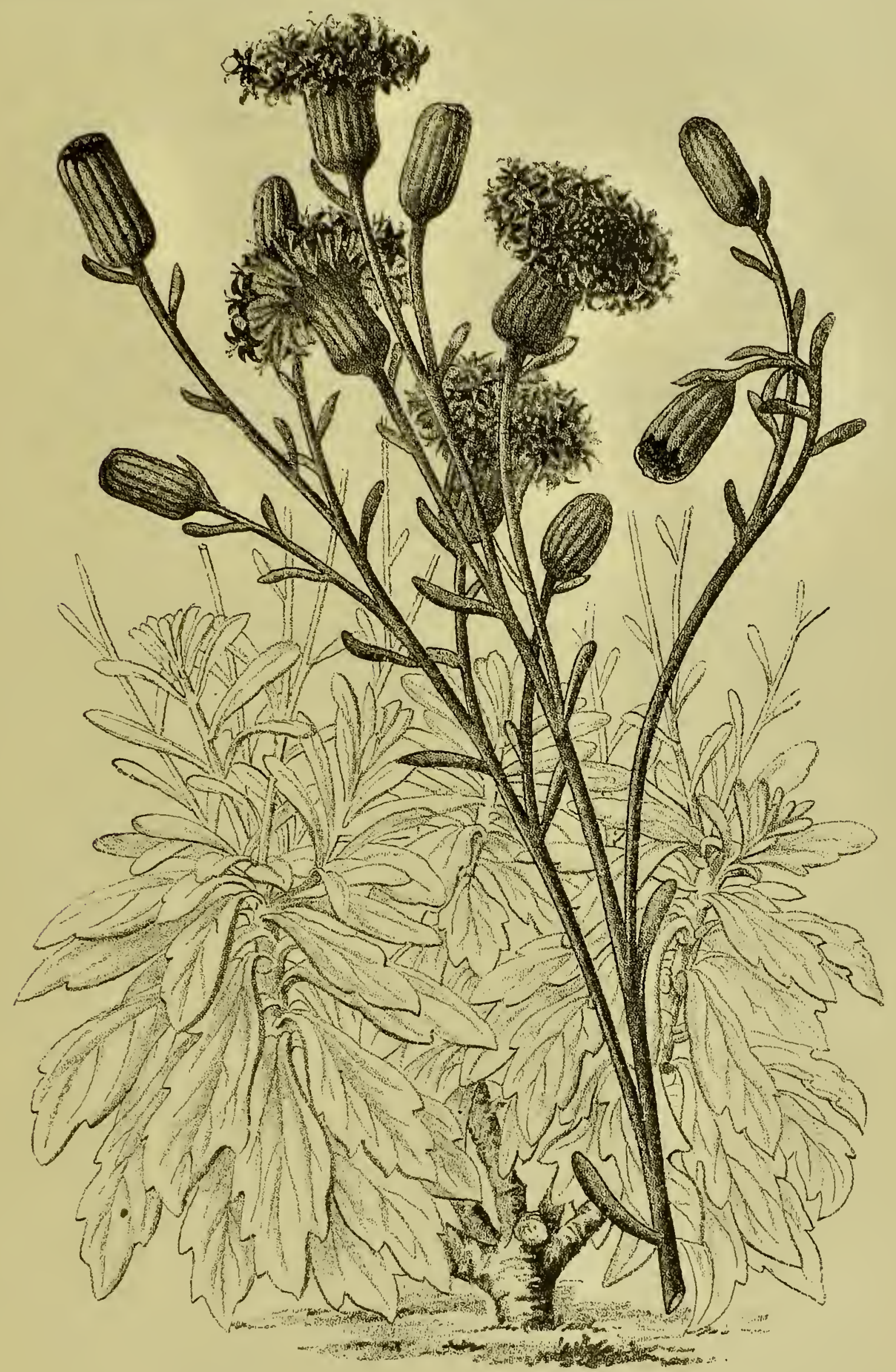

Fig. 139. Kleinia fulgens Hook. Brlánżnde Sileinie.

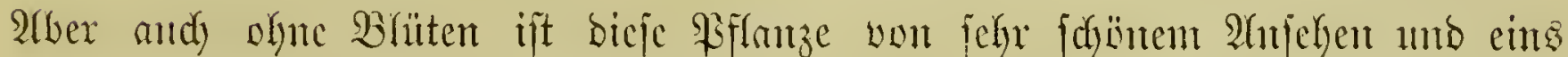
ber Sultur mürbigiten Stubengetuädjic. 


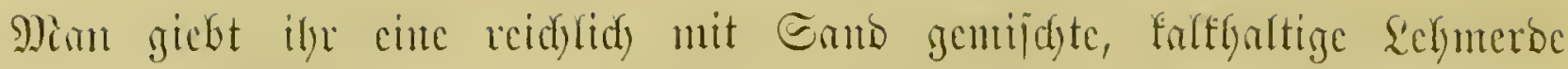

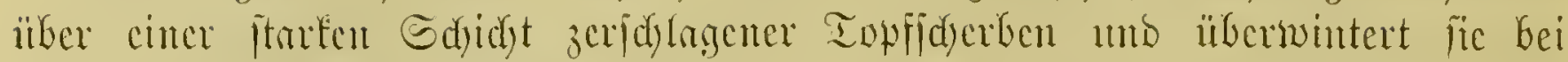

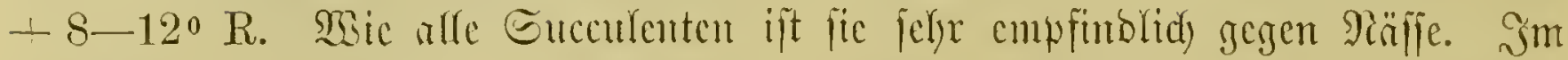

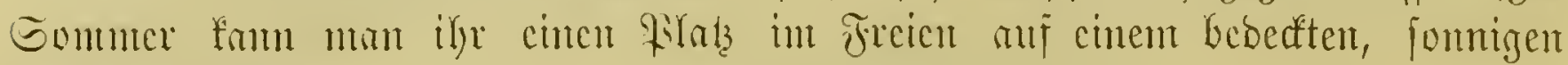
(5icjtelf mucifen.

\section{Kleinia articnlata $H a w$, Geglicberte $\mathfrak{I}$ leinte.}

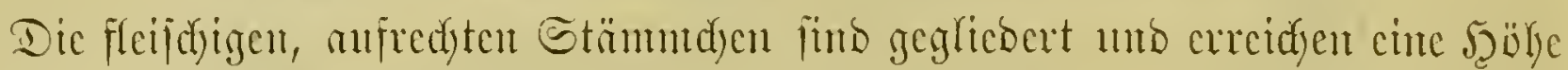

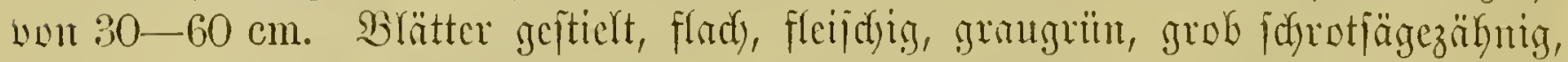

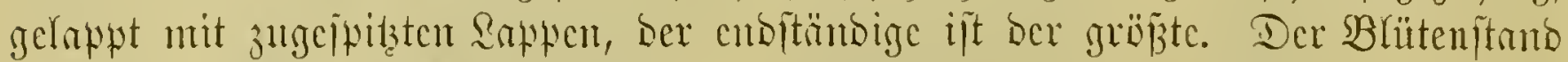

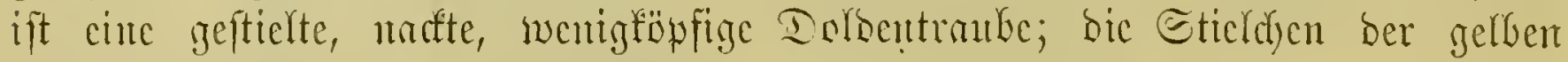
Shlüten find Yänger ats bic R̈̈pfd)en.

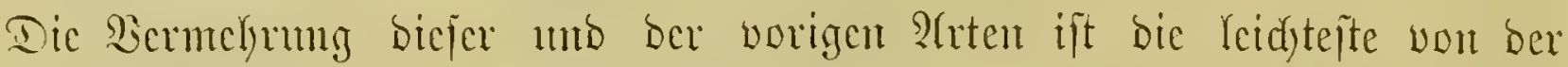

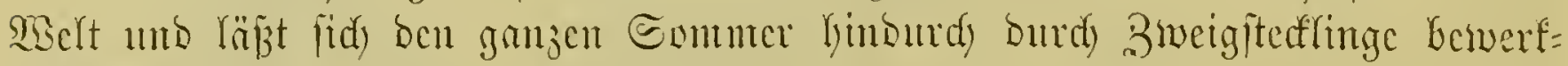

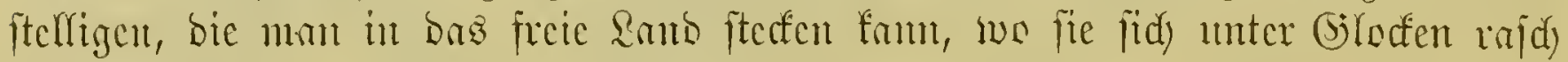
bemultzelut.

\section{Battung Senecio Linn. (3reistraut.}

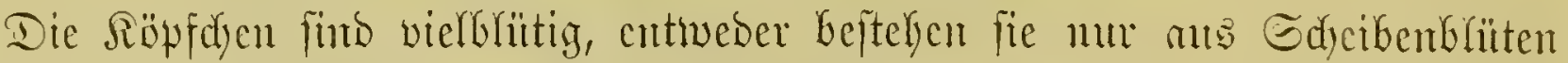

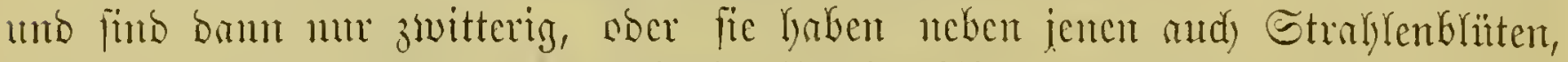

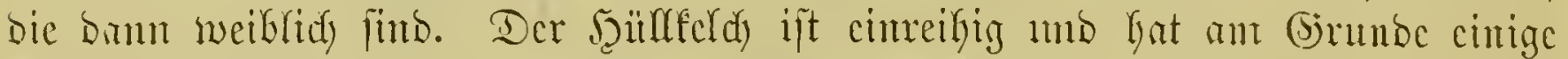

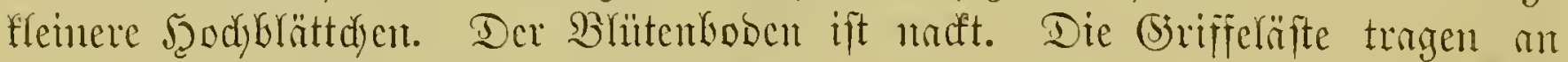

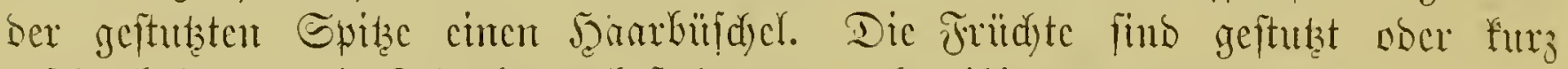

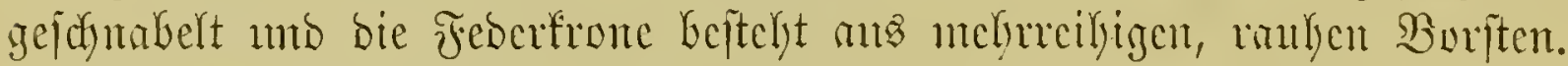

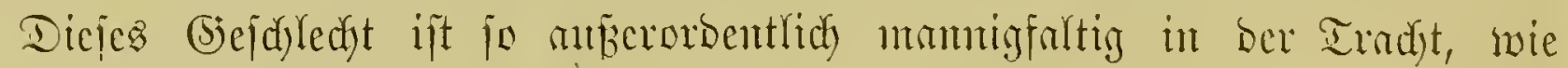

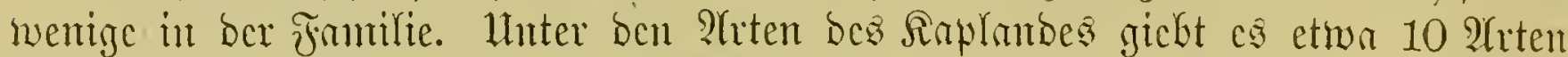

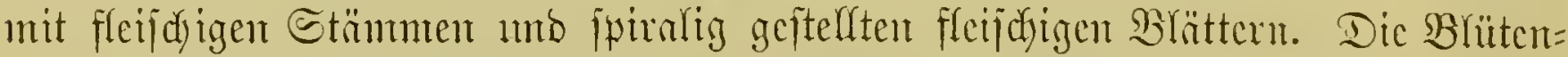

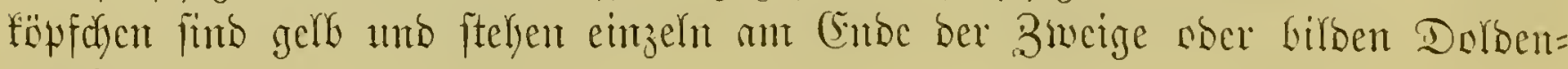
trauben.

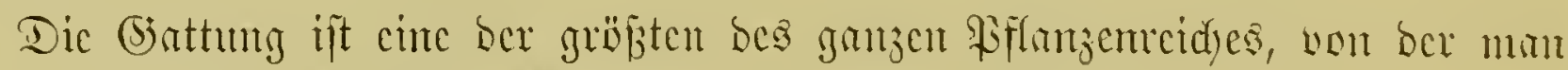

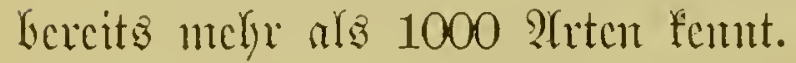

Der Minnte ift wout senex, Der (Sireis abgeleitet.

\section{Senecio calamifolius Hook. Febcrfielflätterigez Greisfraut.}

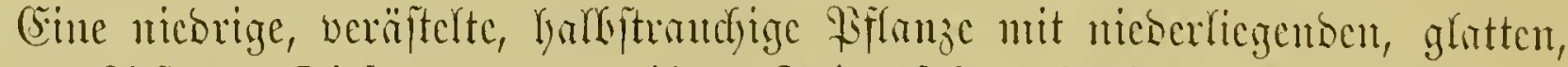

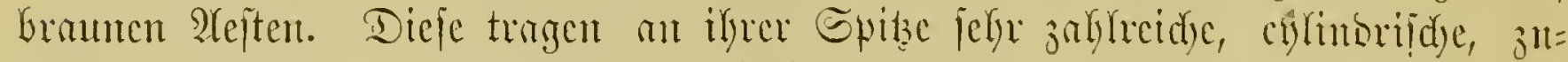

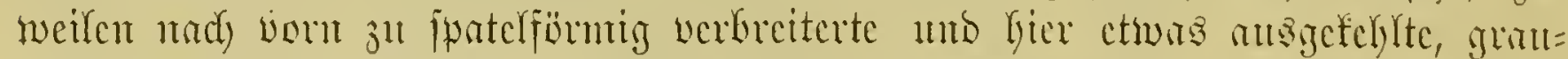

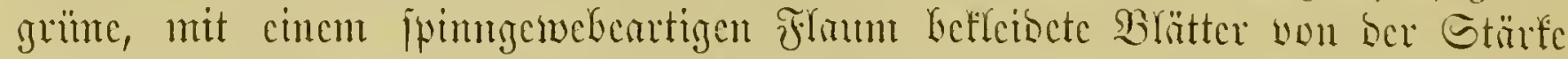

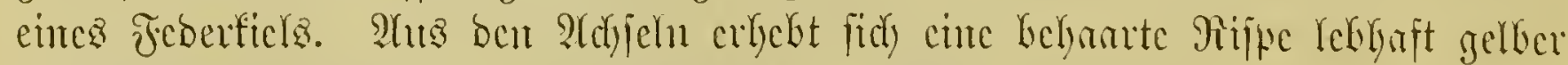

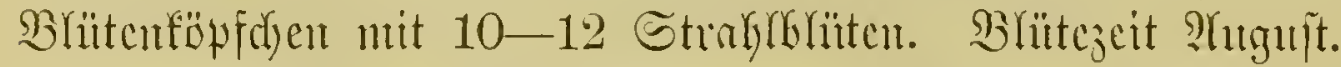

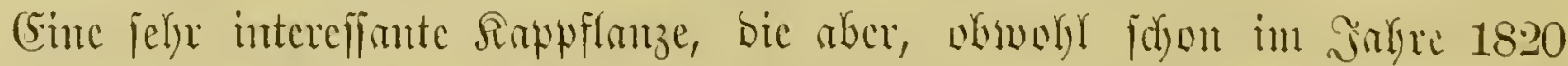
cingefïlyst, immer jelten geblicben ijt. Sic fom ganj wic Mesembrianthemum behanbelt merben. 


\section{3. (Sattung Hertia Less. \$̧ertic.}

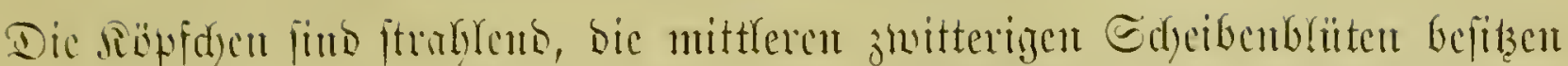

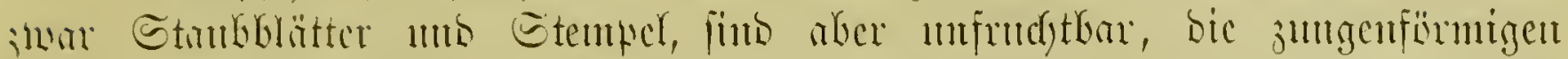

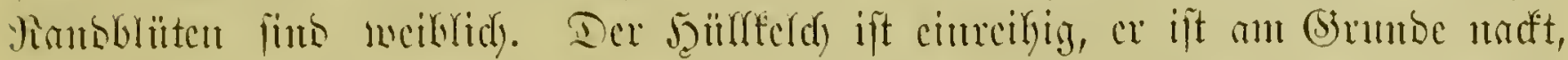

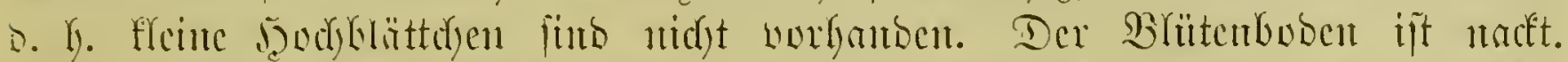

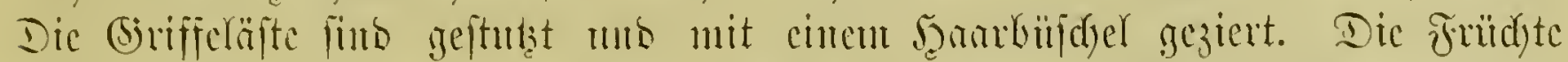

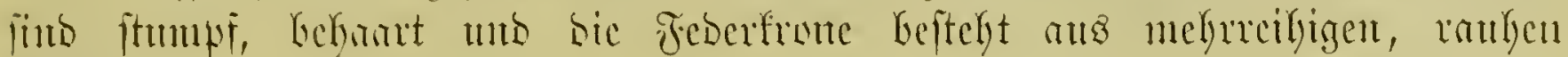
Boriten.

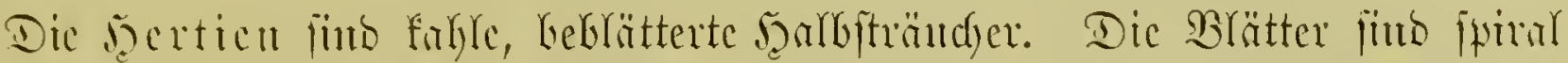

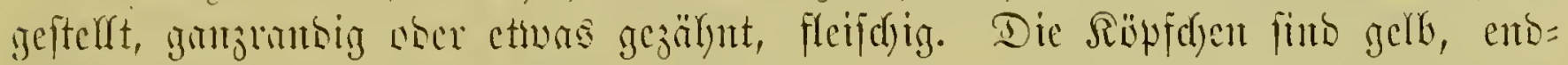

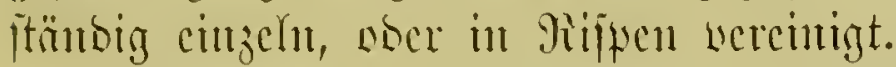

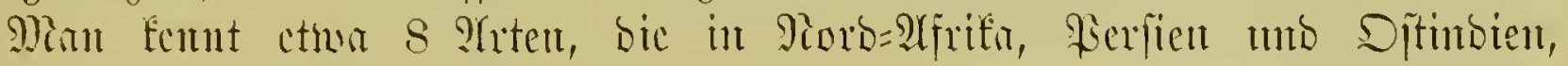
bejoubers aber am Ritp borfoumente.

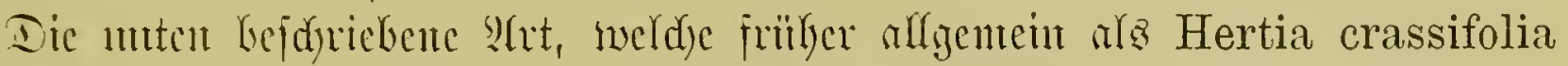

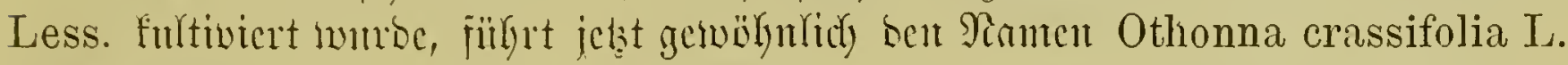
Sic miste aber von Othomna abgetrent werben, cine Bornafyne, bie Gereits

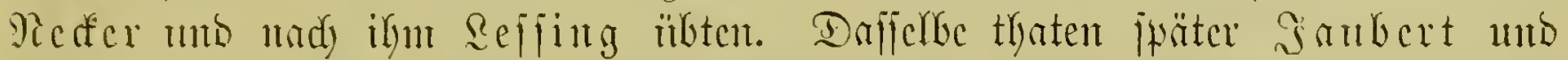
Spad, jie naunten bic Sattung Othonnopsis; ba aber Hertia bic Friorität flat, fo wurbe ber alte Riante wicber hergeitellt.

Hertia crassifolia Less. Dirfblätterige sertic. (Othonna crassifolia I.)

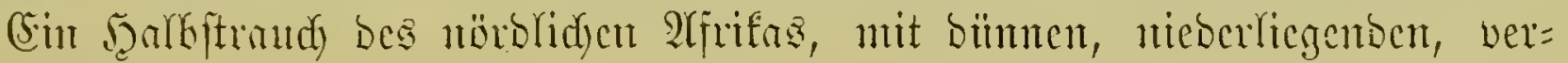

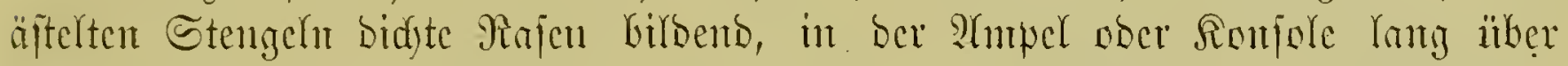

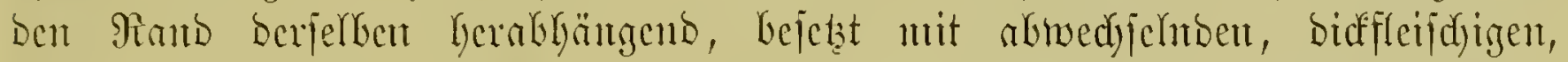

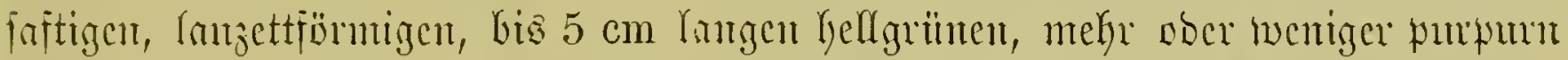

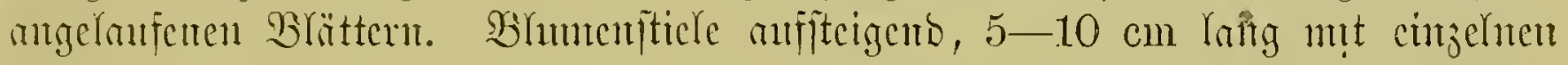
gefticlten, gelben Bhütenföpfdyen. B̧ütezeit Mari bis Sulti.

Sie ift vicfleidyt won $H$. cheirifolia nidyt weridjicoen.

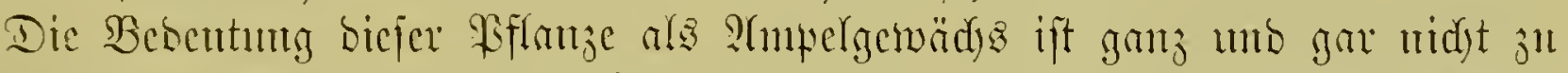

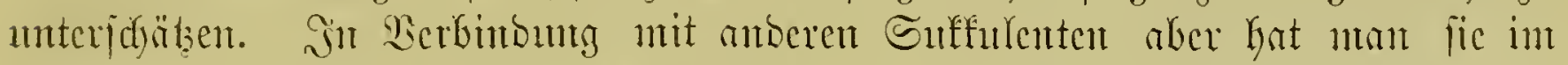
Sommer and für Teppidflecte verwentoct, in weldyen fie vorzugsimeife als

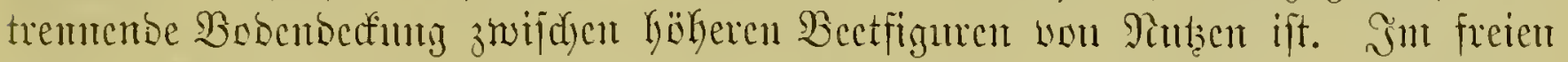

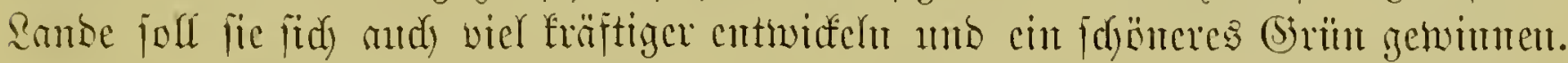

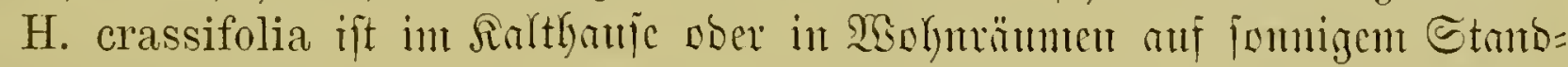
orte bei cincr Temperatur vou $+5-8^{0} \mathrm{R}$. 3n hiberwintem, in jebcur Falfe bei

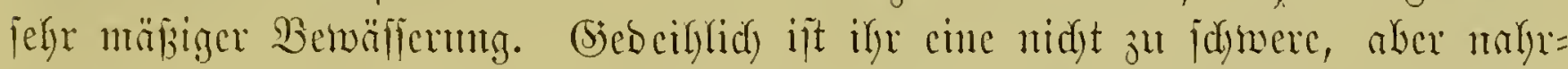

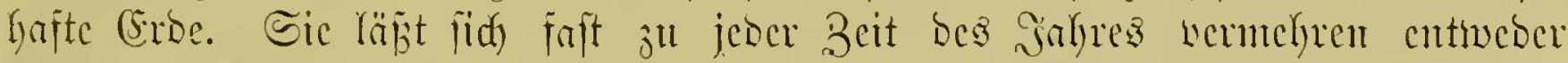

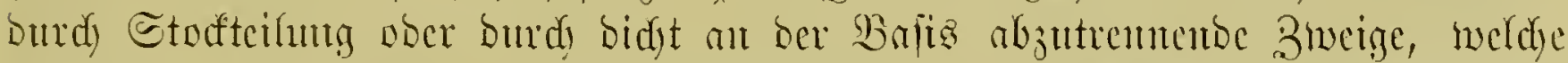

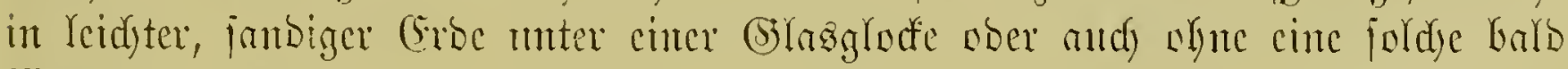
Manzeln madyen.

\section{Kultur ber nicht ju ben Kafteen gehörenden Suflulenten.}

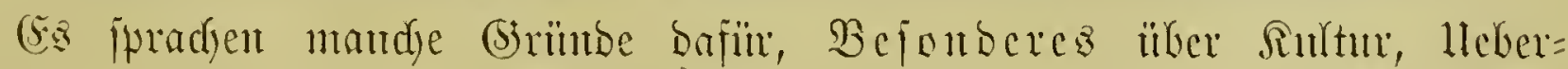

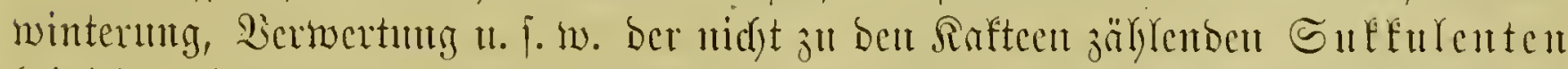

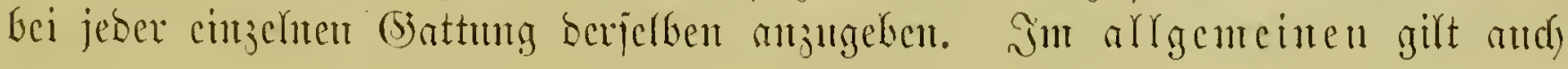




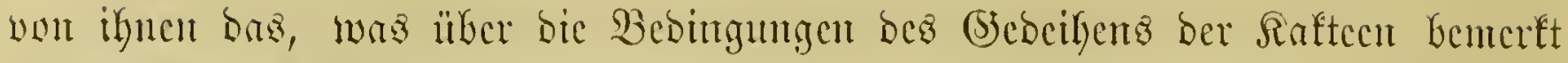

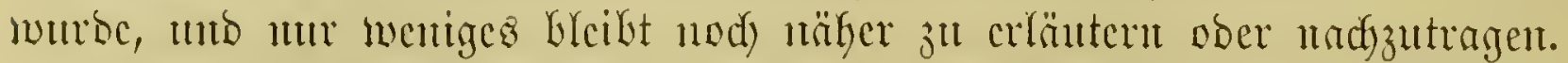

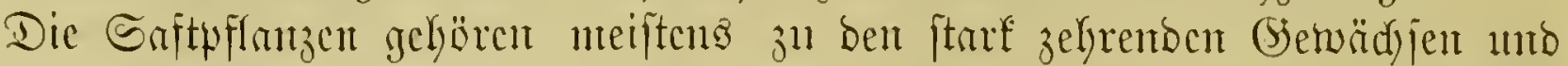

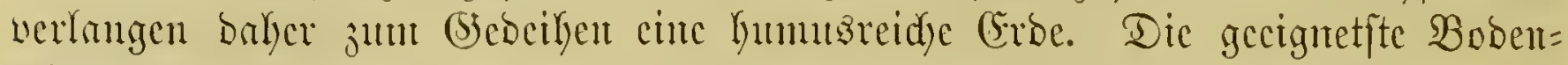

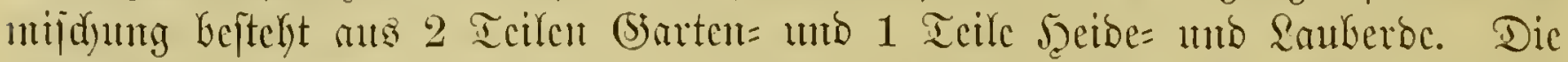

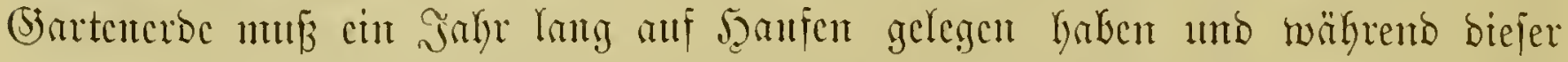

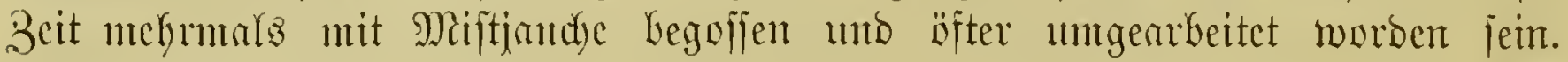

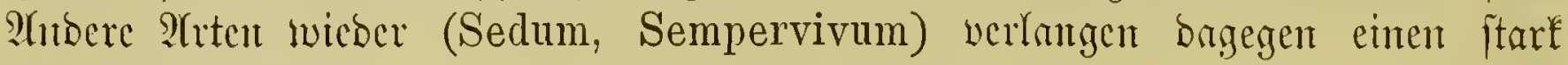
jantigen Bobcu.

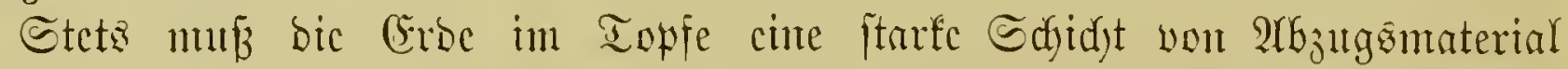

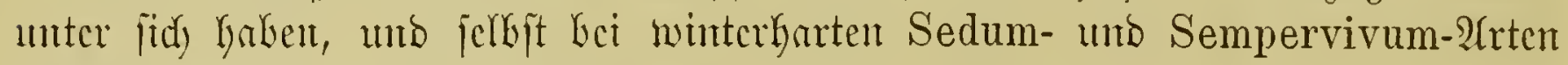

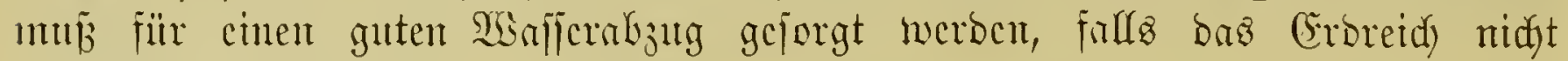
Dutred)lïjiig gemug ift.

Dic ltmpflanzung wirb am beften in März vorgenommen, Gevor bie Biflanjen wicber in Segetation tretert.

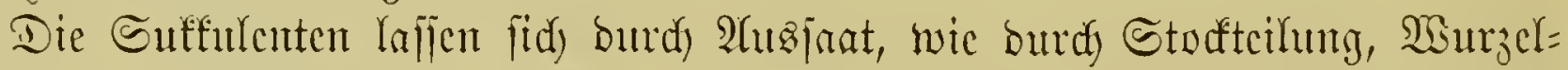

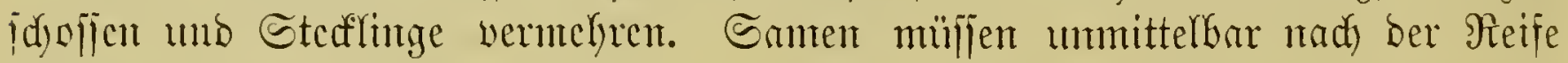

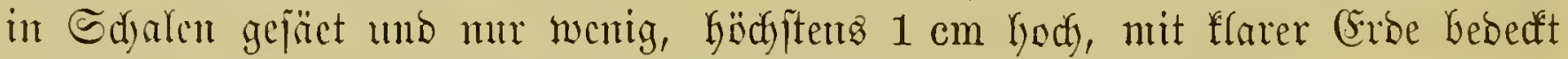
sverden, bie man burd) Ëfteres leidstes Heberbraujen fendyt crbält.

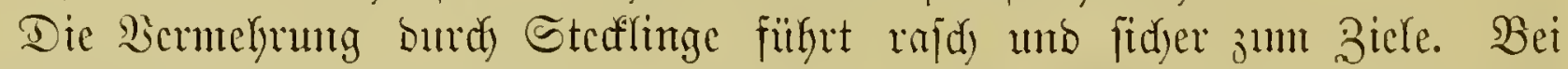

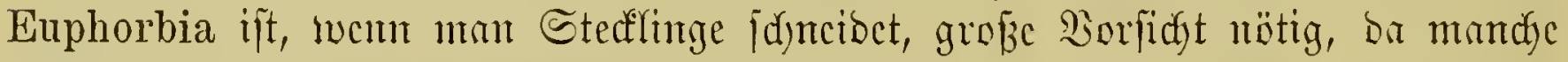

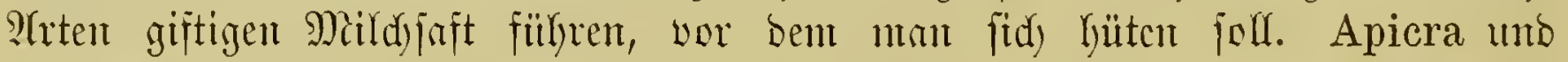

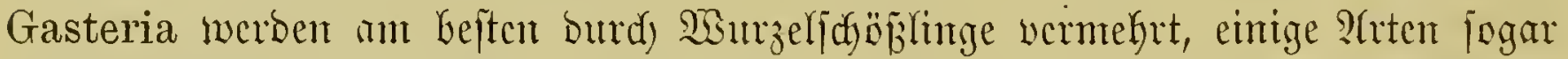
burdy abgejdynttene Brätter. Bei Stapelia fam bie Stofteifung in Ytrmentoung fonmen, cbemp bci Haworthia uto niebrigen Mesembrianthemum-?lrten.

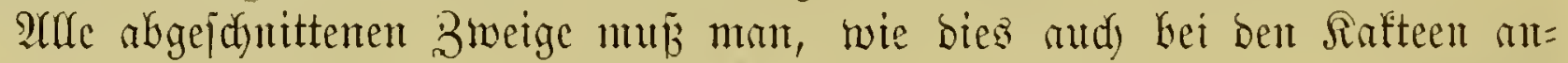

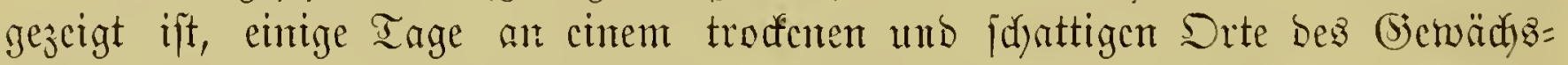

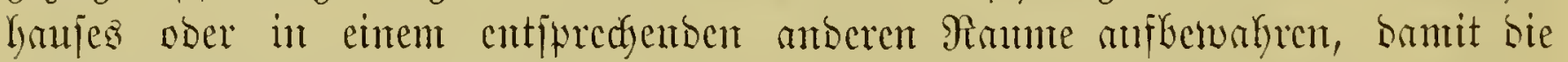

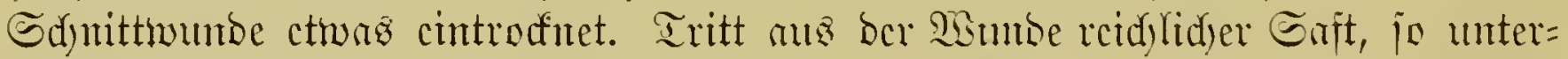
lajie man nidgt, fie bei ben abgettentent 3iveigen, weie bei ber Matterpflanjc,

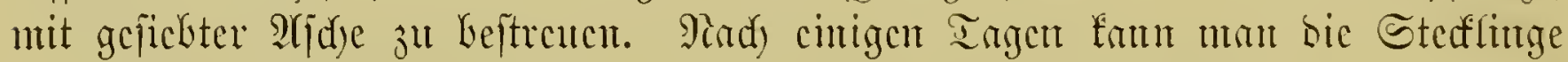

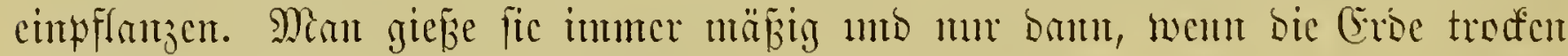

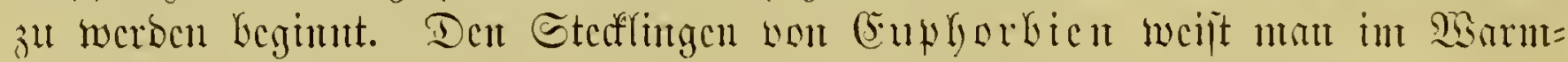

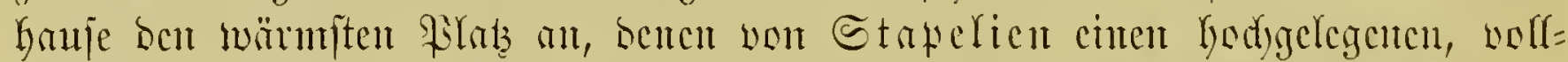

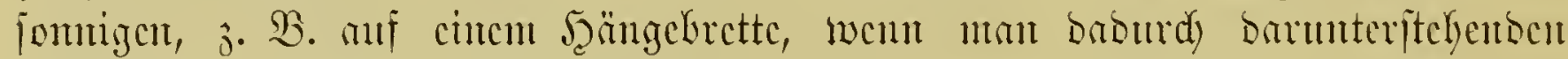
Fiflanjen nicht jut wich sidjt cutjiclyt.

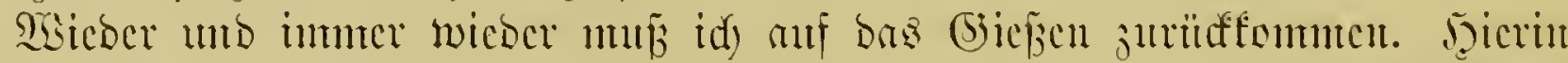

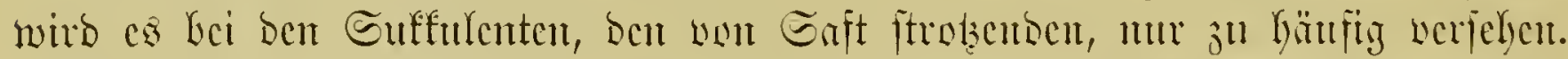

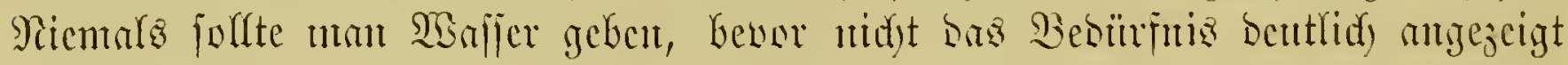

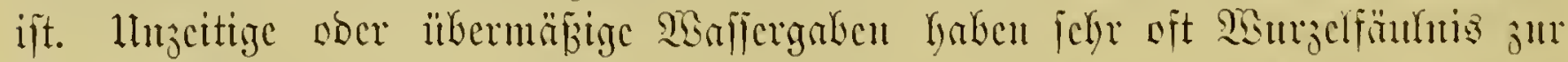

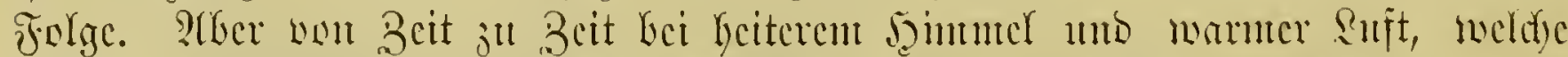

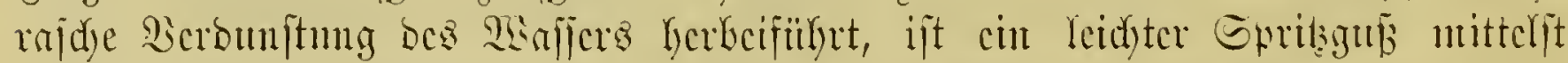

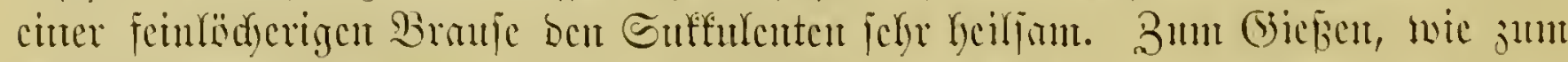

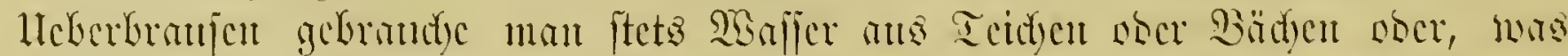

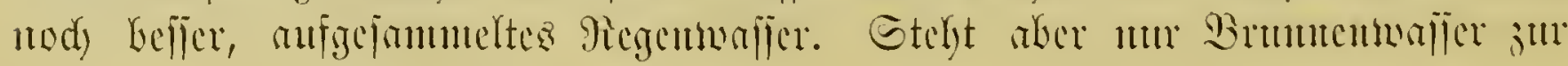




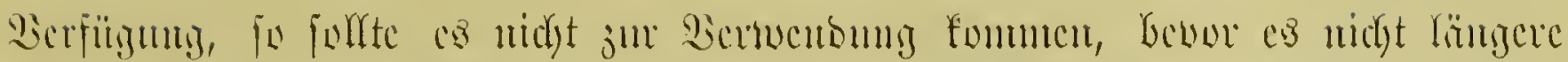

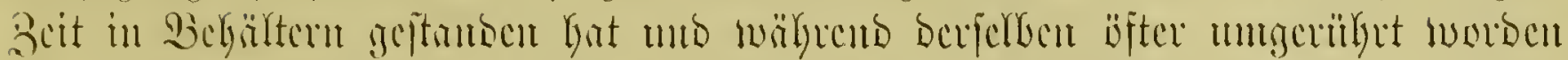

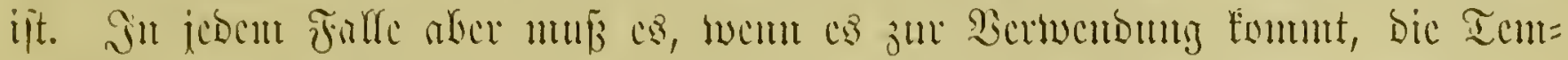

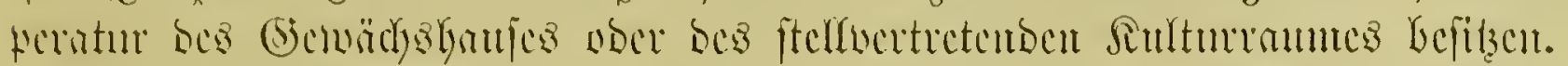

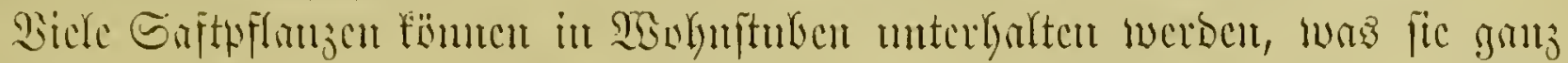

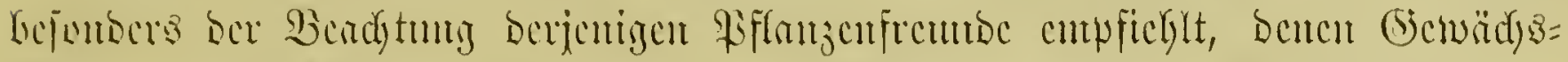

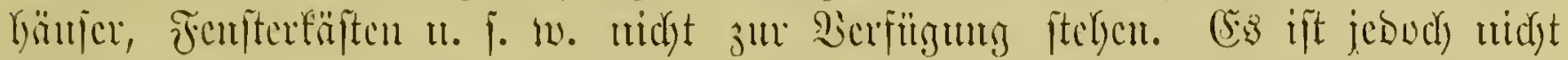

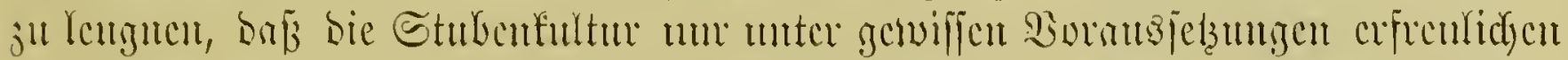

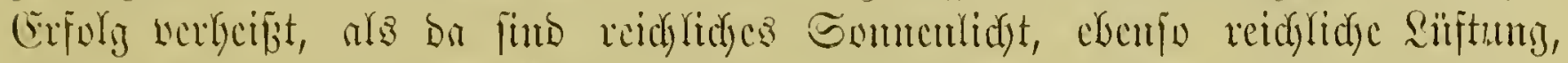

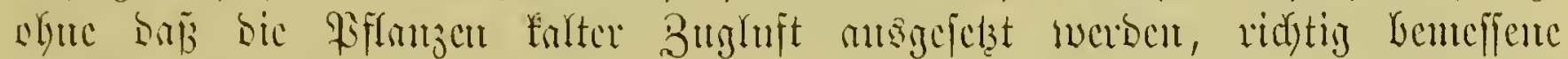

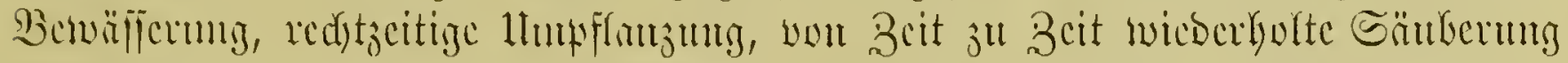

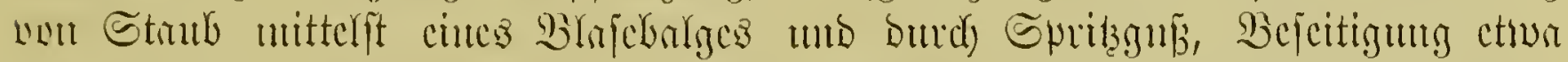

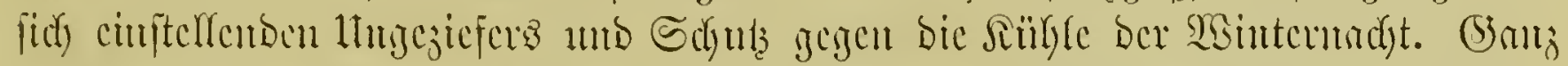

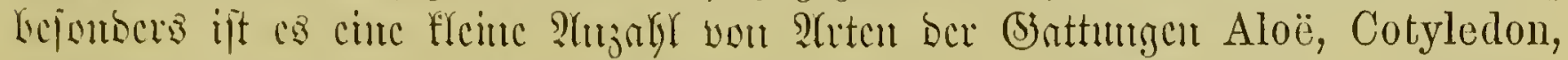

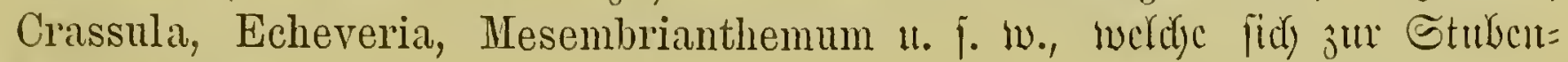
Eultur cigucn.

Mant priffe alfo, che man fid) mit ber \$sflege ber Sulfulenten befaist, ob

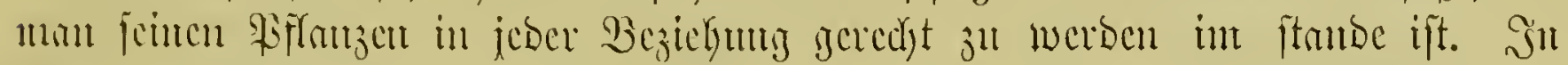

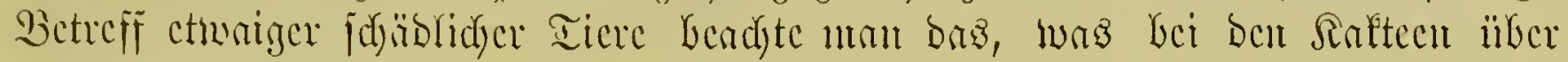
bicje gejagt monden ift.

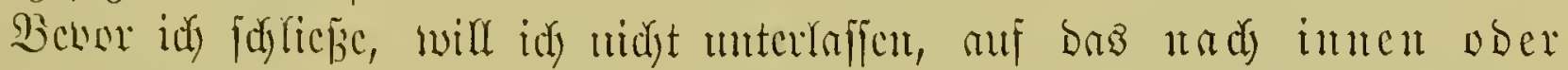

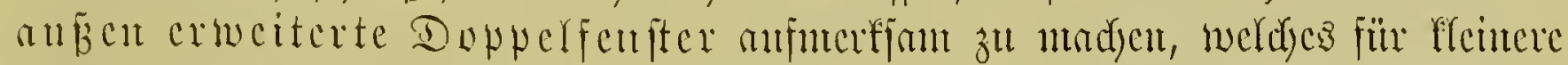

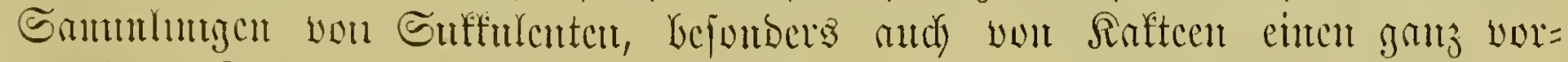

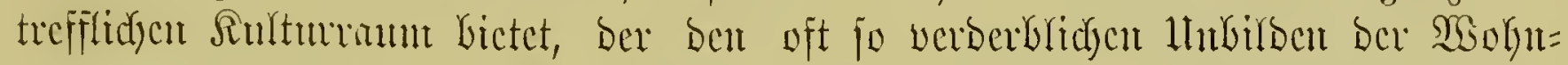

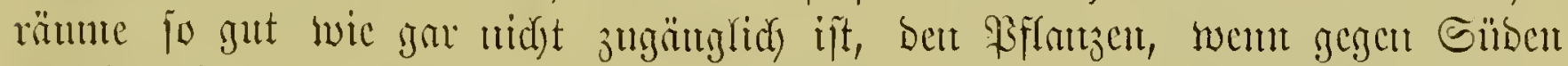

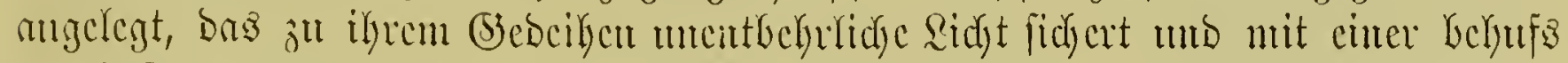

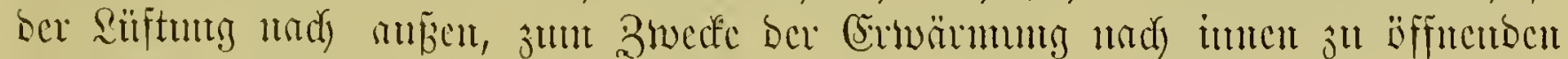

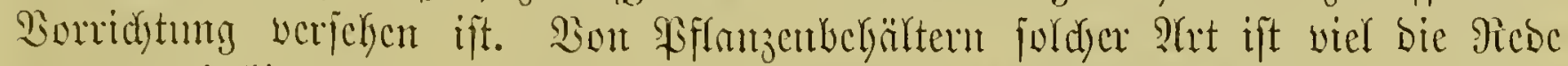

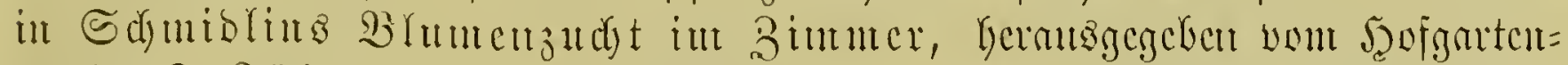

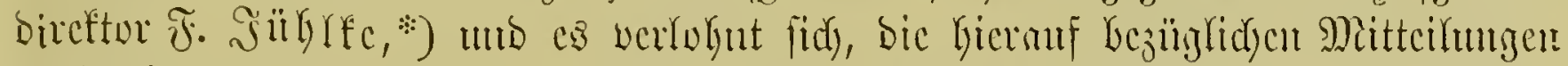

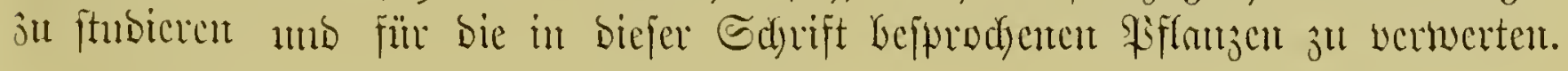

*) Serlag vou $\mathfrak{P a u l} \mathfrak{F} a r e \mathfrak{n}$ in Berlut. 



\section{Liegifter.}

Aloë L. 5.

- africina Haw. S.

- albo-cincta Haw. 10.

- aristata Haw. S.

- Bowica Haw. 8.

- brevifolia Mill. 9.

- conspurcata S.-D. 15.

- depressa Bak. 10.

- echinata Willd. 8.

- ferox Mill. 8.

- grandidentata S.-D.11.

- liumilis Mill. 8.

- Lingua Thbg. 15.

- longiaristata $R$. et Sch. 8.

- obscura Mill. 10.

- picta Thbg. 10.

- plicatilis Mill. 14.

- punctata Haw. 12.

-Salm-Dyckiana Schult. fil. 12.

- saponaria Haw. 10.

- scaberrima S.-D. 15.

- striata Haw. 10.

- subtortuosa S.-D. 22.

- tricolor Bak. 12.

- umbellata S.-D. 10.

- variegata L. 12.

આlıë 5.

- begramite 8.

- Botwic's 8.

- breifarbige 12.

- duntelc 10.

- gcflectic 12.

- geftreifte 10.

- gropzä̆lige 11. !łoë, lusblüttcrige 9.

- Micbrige 8.

- Sallit=Dudfidje 12.

- Scifall $=10$.

- viclftad)lidye 12.

- zinciacilige 14.

2)loëgetwächjc 5.

Aloineac 5.

Anhalonium Lem. 189.

- Williamsii Lem. 189.

-- Engelmannii Lem. 190.

Anthericinae 3.

Apicra Willd. 17.

- foliolosa Willd. 18.

- pentagona Willd. 17.

- spiralis Haw. 18.

Urpicra 17.

- blattrcicic 18.

- füıffantige 17.

Asclepiadaceac 235.

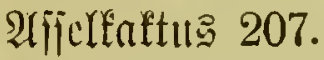

Astrophytum Lem. 188.

- myriostigma Lem. 189.

Blattfaftıls 145.

- 2déerntaul's 149.

- Ssärtner's 147.

- geferbter 150.

- groj̉er 151.

— phyllauthusartiger 147.

- Yuffel's 147.

$-3 a \mathfrak{a l l}=148$.

Brutblatt 86.

- gró̉feldriges 86.

Bryophyllum Salisb. 86.
Bryophyllum calycinum Salisb. 86.

Bulbine L. 3.

- alooides Willd. 4.

- asphodeloides Schult. 4.

- caulescens Linu. 4.

- latifolia Schult. 4.

- Mackeni Bak. 4.

- pugioniformis Lk. 4.

- rostrata Willd. 4.

Bulbine 3.

- aldëbrätterige 4.

- breitbrätterige 4.

- Doldbläättcrige 4.

— =stämutchen 4.

Cactaceae 105.

Cactus speciosus Cav.132. Calandrinia H. B. K. 27.

- discolor Schrad. 27.

- umbellata DC. 28.

(5alanorinic, Doldocnbriitige 28.

- zweifarbigc. 27.

Cephalocereus Pfciff. 142.

Cereus Haw. 121.

- Baumannii Lem. 123.

- chilensis Colla 123.

- coccineus S.-D. 132.

- flagelliformis Mill.125.

- flagriformis Mart. 127.

- grandiflorus Mill. 128.

- leptophis DC. 128.

- Macdonaldiae Hook. 131. 
Cereus Martianus Zuce. Didfulatt, fictlelblätteriges 124.

- nyeticalus Lk. 129.

- peruvianus Haw. 123.

- rostratus Lem. 131.

- serpentinus Lag. 123.

- speciosissimus DC. 132.

- spinulosus DC. 128.

Ceropegia L. 235.

- africana R. Br. 236.

- Cumingiana DC. 236.

- elegans Wall. 236.

- stapeliiformis Haw. 237.

Compositae 249.

Cosyphantha macromeris Lem. 205.

- cleplaautidens Lem. 206.

Cotyledon L. 69.

- coruscans Haw. 70.

- fascicularis Ait. 70.

- macrantha Sm. 70.

- orbiculata L. 70.

- papillaris Linn. fil. 70.

- tuberculosa Lam. 70.

- ungulata Lam. 70.

Crassula L. 89.

- arborescens Willd. 91.

- capitata Lodd. 97.

- Cooperi Reg. 94.

- falcata Willd. 93.

- lactea Ait. 92.

- perfoliata L. 93.

- perfossa Lim. 93.

- portulacea Lam. 91.

- ramuliflora Lk. 95.

- Schmidtii Reg. 95.

- spathulata Thbg. 92.

Crassulaceae 43.

\section{Didfblatt 89.}

- banutartiges 91.

- Sopper's 94.

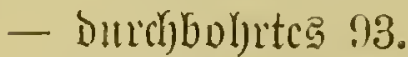

- milchiveifes 92.

- Portulal= 91.

- Sdfmist's 95.
93.

- ppatelblättcrigcs 92.

- vcrwad)jenblättcriges 93.

Dickbrattgcwäd fo 43.

- biformis Lindl. 158.

Disocactus biformis Lindl. 158.

Echeveria DC. 75.

- agavoides Lem. 83.

- bracteosa K. Sch. 77.

- caespitosa DC. 84.

- campanulata Kze. 84.

- canaliculata Hook. 77.

- coccinca DC. 76.

- fulgens Lem. 80.

- gibbiflora DC. 80.

- glauca Hort. 78.

- globosa Hort. 79.

- grandifolia Haw. 80.

- linguifolia Lem. 77.

- lurida Lindl. 77.

- pulverulenta Nutt. S3. 80.

- retusa Lindl. 80.

- rosacea Lind. ct Andr. 79.

- rosea Lindl. 76.

- secunda Lindl. 77.

(5)doueric 75.

- agabcurartigi 83.

- ansgeidyittate so.

- blangrime 78.

- bidfblätterige 77.

- eirleitsmendige 77.

- glänzande 80.

- glodeublumige 84.

- höefurblïtige 80.

- loblyblätterige 77.

- Heine 80.

- Pinder $=83$.

- ropentrote 76.

- jodjarladjusese 76.

- triibfarbige 77.

- jungcublättcrige 77.
Disisocactus Lindl. 156.

- pumila Van Houtte
Echinocactus Lk, et Otto 175.

- bicolor Gal. 183.

- brevihamatus Eng.187.

- Cachetianus Lem.186.

- castaneoides Cels 179.

- concinnus Lem. 177.

- comigerus DC. 184.

- cylindraceus Eng. 184.

- denudatus Lk. et Otto 178.

- gibbosus DC. 182.

- hexaëdrophorus Lem. 181.

- Jussicui Monv. 183.

- Lecontei Eng. 185.

- longihamatus Eng. 186.

- mamillosus Lem. 183.

- Monvillei Lem. 180.

- Odieri Lem. 183.

- ornatus DC. 177.

- Ottonis Lk. et Otto 177

- Ourselianus Cels 181.

- Schecrii S.-D. 187.

- Scopa Lk. et Otto 179.

- sinuatus Dietr. 186.

- texensis Hpfr. 184.

- tulensis Pos. 184.

- Williamsii Lem. 189.

- Wislizenii Eng. 185.

- leucanthus Gill. 173.

Echinocereus Engelm. 135.

- acifer Eng. 139.

- Blanckii Poselg. 137.

- caespitosus Eng. 141.

- Engelmannii Parry 139.

- enneacanthus Eng. $13 \mathrm{~s}$.

- Fendleri Eng. 138.

- paucispinus Eng. 138.

- pectinatus Eng. 141.

- phocniceus Engু. 138.

- procumbens Eng. 136.

- Salm - Dyckianus Scheer 133 .

- subinermis Eng. 138.

- tuberosus Poselg. 137. 
Echinocereus viridiftorus Eilg. 140.

Echinopsis Zuce. 165.

- campylacantha Pfeiff. 172.

- cristata S.-D. 166.

- Decaisneana Lem. 171.

- Eyriesii Zucc. 169.

- Forbesii Hort. angl. 171.

- leucantha Zucc. 173.

- Misleyi Lab. 166.

- multiplex Zucc. 168.

- oxygona Zucc. 169.

- Pentlandii S.-D. 167.

- pulchella Zucc. 168.

- Scheerii S.-D. 167.

- tubiflora Zucc. 169.

- valida Monv. 171.

- Zuccariniana Pfeiff. 169.

Epiphyllum Pfeiff. 158.

-Altensteinii Pfeiff. 161.

- Russellianum Hook. 147. 159.

- Russellianum Hook. var. Gaertneri Reg. 147. 159.

- truncatum Haw. 159.

Euphorbia L. 98.

- Bojeri Hook. 101.

- Caput Medusae L. 100.

- Commelini DC. 101.

- fulgens Karw. 104.

- Hermentiana Lem. 100.

- heptagona L. 100.

- macroglypha Lem. 99.

- mamillaris L. 100.

- meloformis Ait. 100.

- neriifolia L. 101.

- polygona Haw. 100.

- pulcherrima W. 102.

- punicea Sw. 102.

- splendens Boj. 101.

Eupliorbiaceae 98.

Jadfelfaftus 121.
Tarteffatm, 123.

— (jillitj(b) 123.

- Gici反zcl= 127.

- großjblumiger 128.

- ॥achtjchönter 129.

- Iscitjd)cu= 125.

- pernanifdicr 123.

- präd)tigiter 132.

- S(t)arlad $=132$.

- Sclllangen $=123$.

- Sdituadicl= 131.

- W3mmfdulangen= 128.

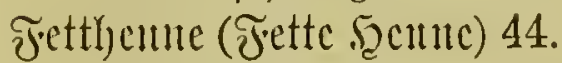

- anjehnliche 47.

- Bajtard $=49$.

- blane 50.

- (5iver: 48.

- inmergrïne 51.

- lamtichatfijache 51.

- Marimowicz's 54.

- Middentidorf'g 53.

- pappelblätterige 45.

- purpurut 51.

- rantige 51.

- Siebold's 46.

- viclföpfige 56.

Teigentüatıt 213.

- (5od)enifle $=214$.

- Somanche $=217$.

- oreiftachliger 214.

- (Entorl's 216.

- grumbäjtiger 216.

- kitrglicoriger 219.

- Drangent 215.

- Rafutcone'g 217.

Gasteria Duv. 14.

- conspurcata N. E. Brown 15.

- colubrina N. E. Brown 15.

- denticulata Haw. 15.

- disticha Haw. 15.

- maculata Haw. 16.

- nigricans Haw. 15.

- nitida Haw 17.

- pulchra Haw. 15.

- subcarinata Haw. 17.
Gasteria verrucosa Haw 14.

- obliqua Haw. 16.

(Siafteric 14.

- Dutufelgrïnc 15.

- gefledte 16.

- gläルzcแdc 17.

- Schlangch $=15$.

- j(t)öแte 15.

-- ichtwach getielte 17.

- Tharzest= 14.

- zivcizcilige 15.

(Sirazlilienartige (sicmächje 3.

(sireistrant 252.

- feocrficlblätterigca 252.

Scanfactelfaftus 142.

- Sireijenlinat = 143.

- grubigar 143.

5ุantalaub 58.

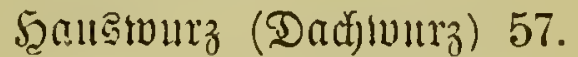

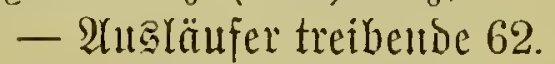

- banmartige 65.

- Bcrg $=60$.

- Diehjitengel $=66$.

- grofzblumige 62.

- lanarijche 64.

- आajen= 66.

- raubbliitige 62.

- ruifijche 62.

- ミdjeiben= 64 .

- ipintmebige 61.

- Mimper $=60.64$.

Haworthia Duv. 19.

- altilinea Haw. $2 t$.

- attenuata Haw. 23.

- clariperla Haw. 23.

- Cooperi Bak. 25.

- distincta N. E. Br. 24.

- granata Haw. 24.

- margaritifera Haw. 23.

- parva Haw. 24.

- pilifera Bak. 25.

- pseudotortuosa Haw. 22.

- radula Haw. 24.

- Reinwardtii Haw. 22.

- setata Haw. 26. 
Haworthia subulata bak. 24.

- tessellata Haw. 24.

- torquata Haw. 21.

- venosa Haw. 24.

- viscosa Haw. 21.

- vittata Bak. 24.

Şaluverthic 19.

- abcrutbige 24.

- soriter $=26$.

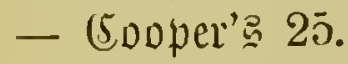

- gebönderte 24.

- geftreifte 24.

- haartragetide 25.

- flebrige 21.

- Mojait $=24$.

- Serlent $=23$.

- Syfrientent $=24$.

- Rcintwardt's 22.

- zllgeipibte 23.

Hertia Less. 253.

- crassifolia Less. 253.

Szertie 253.

- bičcblätterige 253.

Hoya L. 239.

- bella Hook. fil. 239.

- carnosa R. Br. 239.

- cinnamomifolia Hook. fil. 242.

- imperialis Lindl. 241.

Huernia R. Br. 247.

- barbata R. Br. 248.

- brevirostris N. E. Br. 248.

- campanulata R. Br. 248.

- clavigera Haw. 248.

- oculata Hook. fil. 247.

- venusta R. Br. 248.

Şuertie 247.

— bürtige 248.

- gcäıgelte 247.

- glocfenbrïtige 248.

- Eurzadunabelige 248.

- reizende 248.

Jgel=Fadelfattug 135 .

- armitadjeliger 138.

- Dramet's 137.

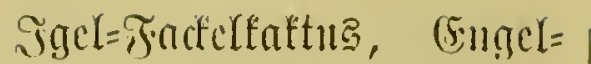
1110711'? 139.

- faft ftadycliofer 138.

- Jenter's 138.

- griïrblïbender 140.

- tammitadjeliger 141.

- Holfertintrzeliger 137.

- madelutragentoer 139.

- menuftad)eliger 138.

- riebergeitredter 136.

- \$itum $=138$.

- Sajert 141.

Jgellaftug 177.

- Bejen= 179.

- brautradeliger 179.

- buthtiger 186.

- bututftacheliger 183.

- chlindrijoher 184.

- eleganter 177.

- gehöcferter 182.

- F̌eraëder $=181$.

- hörnertragender 184.

- Kleiniwaràiger 183.

- furzhafiger 187.

- langhafiger 186.

- naditjdeiteliger 178.

- Dtto'g 177.

Siaftuggcwächje 105.

Kalanchoë Adlans. 86.

- crenata Haw. 89.

- farinacea Balf. 88.

- grandifiora W. et Arn. 87.

- laciniata DC. 88.

- spathulata DC. 89.

Sinlautdyoë 86.

- geferbte 89.

- groß̧blimige 87.

- mel)lige 88 .

- patelblätterige 89.

- ppib̨blättcrige 88.

Kleinia DC. 250.

- articulata Haw. 252.

- fulgens Hook, fil. 250.

- Haworthii DC. 250.

- tomentosa Haw. 250.

Silcinic 250.

- filazige 250 .
Stemic, gegliederte 252

- lendytende 250.

Rönigin Dcr Yadjt 128.

Sulffall frant 42.

Laublaftia 219.

- $\mathfrak{B l C D}=222$.

- calandrinienblätteriger 220.

- pfriemenblätteriger 220.

- fpatclblätteriger 220.

- itacheliger 221.

- żunienblïtiger 220.

Leuchtenbergia Fisch. 1.91.

- principis Fisch. 191.

Reud)terblume 235.

- afrifanifiche 236.

- Euming's 236.

- elegante 236.

- itapelienartige 237.

Liliaceae 3.

siliengewächje 3.

Malacocarpus S.-D. 173.

- acuatus S.-D. 174.

- corynodes S.-D. 173.

- Martinii Leb. 174.

- Sellowii S.-D, 174.

yiancepeffer 44.56.

- Mrkert Miegel'3 55.

- dictblätteriger 54.

- hübjuter 49.

- toeízer 54.

Mamillaria Haw. 193.

- bicolor Lem. 200.

- bumamma Ehrog. 206.

- candida Scheidw. 199.

- centricirrlia Lem. 203.

- chrysacantha Hort. Berol. 201.

- coronaria Haw. 202.

- elephantidens Lem. 206.

- Eugenia Scheidw. 201.

- dissurata Eng. 191.

- formosa Scheidw. 200.

- fiscata Hort. Berol. 201. 
Mamillaria glochidiata Mart. $196^{\circ}$.

- gracilis Pfeiff. 204.

- Grahami Eng. 197.

- Grusoni Rge. 213.

- Haageana Pfeiff. 200.

- Krameri Mïlllpf. 203.

- longinnamma DC. 195.

- macracantha DC. 203.

- macromeris Eng. 205.

- magnimamma Haw. 203.

- melanocentra Pos. 203.

- micromeris Eng. 198.

- Odieriana Lem. 201.

- pectinata Eng. 20 .

- phaeacantlia Lem. 202.

- pusilla DC. 196.

- recurva Lehm. 203.

- rloodantha Lk. et Otto 202.

- rutila Zucc. 201.

- sanguinea Haage 198.

- Schelhasei Pfr. 197.

- Scliedeana Ehrenb. 199.

- sphaerotricha Lem. 199.

- spinosissima Lem. 199.

- stella aurata Mart. 204.

- sulcolanata Lam. 207.

- uberiformis Zucc. 195.

- uncinata Zuce. 202.

Meoujenfaut 100.

Mesembrianthemaceae 31.

Mesembrianthemum L. 31.

- acinaciforme L. 36.

- albidum L. 34.

- aurantiacum Haw. 39.

- bicolor L. 41.

- blandum Haw. 38.

- brevicanle Haw. 36 .

- caninum Haw. 33.

- capitatum Haw. 36.

- coccinenm Haw. 41.

- crystallinum L. 42.

- cultratum S.-Dck. 35.

- deltoirles Mill. 39.
Mescmbrianthemum densum Haw. 41.

- depressum S.-Dck. 35.

- dolabriforme L. 35.

- elongatum Haw. 36.

- falcatum L. 37.

- falciforme Haw. 37.

- formosum Haw. 38.

- fragrans S. Dck. 35.

- Haworthii Willd. 40.

- lacerum S.-Dyck. 36.

- linguiforme S.-Dck. 35.

- longum Haw. 35.

- marginatum L. 42.

- microphyllum Haw. 40.

- pugioniforme L. 36.

- speciosum Haw. 42.

- spectabile Haw. 38.

- tenuifolium L. 41.

- tigrinum Haw. 33.

- virescens Haw. 37.

Mittagăblumengetuächjc 31.

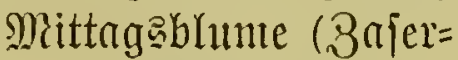
blume) 31.

- anjehuliche 38.

- anggerandete 42.

- Deltaförmige 39.

- Dicjtbeblätterte 41.

- Dold blatt $=36$.

- Siimblätterige 41.

- Duftige 35.

- grïnlidje 37.

- hobelförmige 35.

- S2umbe $=33$.

- fémblätterige 40.

- ponmeranzenfarbige 39 .

— prächtigc 42.

- reizcmise 38.

- Säbel $=30$.

- Edarlad $=41$.

- jobjute 38.

- Sidjelblatt= 37.

- weizliche 34.

- zerrijjelle 36.

- zungenblätterige 35.

Mabeling 71.

- besornter 73.
Siabcling, flactubäteriger 75.

— bäแgender 7 .

- tabler 74.

Siabelftant 69.

- Biijchel $=70$.

- genageltes 70.

- höeteriges 70.

- lreisblättcrigca 70.

- jojinmerndes 70.

Opuntia Tournef. 213.

- aurantiaca Gill. 215.

- basilaris Eng. 216.

- brachyarthra Ling. 219.

- comanchica Eng. 217.

- Emoryi Eng. 216.

- Rafinesquii Eng. 217.

- triacantha Haw. 214.

- Tuna Mill. 214.

Othonna crassifolia L. 253.

Pachydendron ferox Haw. 12.

- principis Haw. 12.

Pachyphytum bracteosum Kl. 77.

Peireskia Plum. 219.

- aculeata Plum. 221.

- Bleo H. B. Kth. 222.

- calandriniifolia Pfeiff. 220.

- spathulata Lk. et Otto 220.

- subulata Mühlpf. 220.

- zinniitlora DC. 220.

Pelecyphora Ehrenberg 207.

- aselliformis Ehrb. 208.

Pliyllocactus Lk. 145.

-Ackermannii S -D. 149.

- anguliger Lem. 148.

- crenatus S.-D. 150.

- Gaertneri K. Schum. 147.

- grandis Lem. 151.

- Hookeri S.-D. 151. 
Phyllocactus phyllan- Miochea, weridyicocnfarbige thoides S.-D. 147.

- Russellianus K. Sch. 147.

- serratus Lab. 148.

Pilocereus Lem. 142.

- Houlletii Lem. 143.

- senilis Lem. 143.

- Dantwitzii Seitz 144.

- fossulatus Lab. 143.

- Haagei Pos. 144.

Poinsettia pulcherrima Grah. 104.

Portulaca Linn. 29.

- grandiflora Hook. 29.

- oleracea L. 29.

Portulacaceae 26.

Bortulaf, grof̧blumiger 29.

ßortulafgewäd)je 26.

Prizmentaftis 191.

— fïritlid)er 191.

Rhipidodendron disti chum Willd. 14.

- plicatile Haw. 14.

Rhipsalis Gaertn. 209.

- crispata Pfeiff. 213.

- Houlletii Lem. 211.

- pachyptera Pfeiff. 212.

- pulvinigera Lindb. 209.

- sarmentacea 0tto et Dietr. 210.

— Swartziana Pfeiff. 213.

Mripialig 209.

— bictgliedrige 212.

- Şoulfet'g 211.

- Lrangrandige 213.

- Sivariz 213.

Rochea DC. 95.

- coccinea DC. 96.

- jasminea DC. 98.

- odoratissima DC. 97.

- versicolor DC. 97.

Rodjea 95.

- Duftende 95.

- jamuinartige 98.

- Sabarlad $=96$.
97.

Rojeltumuz 45.

Riutenlaftis 209.

- politertiagenoer 209.

Sedum L. 44.

- acre L. 56.

- Alberti Rgl. 55.

- album L. 54.

- Anacampseros L. 51.

- cyaneum Rud. 50.

- dasyphyllum L. 54.

- Ewersii Led. 48.

- kamtschaticum Fisch. 51.

- lydium Boiss. 57.

- Middendorfianum Maxim. 53.

- multiceps Coss. et Dur. 56.

- populifolium L. 45.

- pulchellım Mchx. 49.

- purpurascens Koch 51.

- Rhodiola DC. 45.

- sarmentosum Bge. 51.

- Selskianum Rgl. et Maack 52.

- sempervivoides Fisch. 45.

- Sempervivum Ledb. 45.

- Sieboldii Sw. 46.

- spectabile Bor. 47.

- spurium M. Bieb. 49.

Secigelfaltus 165.

- Evrieg' 160.

— fräftiger 171.

- frumutitacheliger 172.

- nicolicher 169.

- jadarfantiger 169.

- iprofienreidyer 168.

Scibentpflanzengetuächje 235.

Sempervivum L. 57.

-- acuminatum Schott 60.
- Maximowiczii Rgl. 54.
Sempervivum arachnoideum L. 61.

- arboreum L. 65.

- arenarium Koch 62.

- atlanticum Bak. 59.

- aureum C. Sm. 66.

- Boutignyanum Bill. et Gren. 60.

- caespitosum C.Sm. 66.

- calcareum Jord. 60.

- canariense L. 64.

- ciliatum Willd. 64.

- cornutum Lehm. et Schn. 63.

- fimbriatum Lehm. et Schn 60.

- Funckii F. Br. 60.

- glaucum Ten. 60.

- grandiflorum Haw. 62.

- Heuffelii Schott 64.

- hirtum L. 62.

- Laggeri Hort. 62.

- Maggridgei Hook. fil. 60.

- Mettenianum Lehm. et Schn. 60.

- Monanthes Ait. 66.

- montanum L. 60.

- reginae Amaliae Heldr. 62.

- ruthenicum Lehm. et Schn. 62.

- Schottii Bak. 60.

- soboliferum Sims 62.

- tabuliforme Haw. 64.

- tectorum L. 58.

- tomentosim Lehm. et Schn. 62.

- tortuosum Ait. 66.

- triste Hort. 60.

Senecio L. 252.

- calamifolius Hook. 252.

Stapelia L. 242.

- anguina Jacr. 243.

- bufonia Jacq. 243.

- gigantea N. E. Br. 246.

- grandiflora Mass. 214. 
Stapelia hirsuta L. 245.

- orbicularis Andr. 243.

- variegata L. 243.

Stapclie 242.

- beljante 245.

- bunte 243.

- grob̧blütige 244.

- Sir̈tent $=243$.

- Siejen= 246.

- Scheibent 243.

- (d)langent $=243$.

Stcruffaftus 188.

- punftierter 189.

Tiger $=3$ a ferblume 33 .

Umbilicus DC. 71.

- glaber Reg. et Wklr. 74.

- Lievenii Led. 75.

- pendulinus DC. 75.

- platyphyllus Schrenk 75.

- Semenovii Herd. 75.

- spinosus DC. 73.

- turkestanicus Regl. 74.
Bierblattfaftus 156.

- zrvicgeitaltiger 158.

2Bact)

- fleijdige 239.

- faijerlidre 241.

- riebridje 239.

- żumtutbaumbrätterige 242.

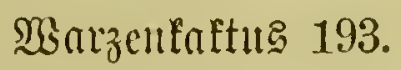

- blutrotitridyeliger 198.

- Dimferftacheliger 20\%.

- (5) rephantenzaly 206.

- golditadjeliger 201.

- Bolditernt 204.

- Gin $\bar{B}=205$.

- gropjitadbeliger 203.

- grofzmarziger 203.

- Sintion's 203.

- \$aage'g 200.

- halenitadyeliger 196.

- fammitadjeliger 205.

- Silein= 198.

- Sranter's 203.

- $\operatorname{Rranz}=202$.

- Rantg= 195 .

- loctenjtacheliger 203.

- Dier's 201.
Warzentaftus, rötlicher 201.

- rotbriilnentor 202.

- Sdjelluaje's 197.

- Sdjiede's 199.

- fdub̈uter 200.

- jobmarzitacheliger 203.

- ftad)lidjfter 199.

- Weiß̋̋̈pfiger 199.

- wollfurchiger 207.

- zierlicter 204.

- zlveifarbiger 200.

- Biwerg $=196$.

Weichbeerfalttte 173.

- fcharfripptger 174.

- Gellow's 174.

- Streittolben $=173$.

Wolfamild 98.

- groflitclige 99.

- leudjtendoe 104.

- Dielonen 100.

- oleanderblätterige 101.

- \$umput $=102$.

- ¡đü̈ujte 102.

- fiebententige 100.

- ftrablende 101.

Wolfamilchgeruächje 98.

Bizentefltus 195.

Seite 6 lepe man für Excoecaria agallocha Aquilaria agallocha.

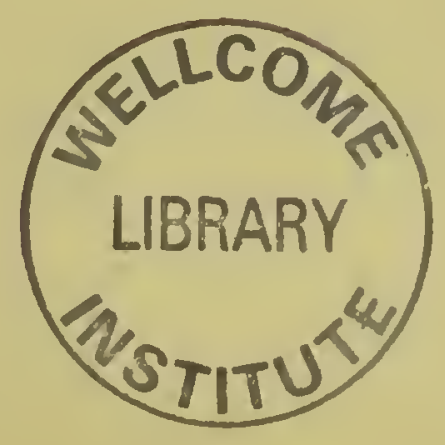





\section{Illustriertes \\ Gartenbau-Lexikon.}

\section{Zweite, vollständig neubearbeitete Auflage.}

Unter Mitwirkung von

Stadtgarteninspektor Bergfeld-Erfurt, Garteninspektor Goeschke-Proskau, Hofgarteninspelitor Jaeger-Eisenach, J. H. Krelage-Haarlem, Hofgarteninspektor Noack-1)armstadt, Dr. Rümpler-Praust, Dr. P. Sorauer-Proskau, Dr. v. Schlechtendal-Halle, Garteninspelitor Stein-Breslau, Prof. Dr. Taschenberg-Halle, Dr. W. Ule-Halle,

\section{herausgegeben von}

\section{Th. Rümpler,}

General-Sekretär des Gartenbau-Vereins in Erfurt.

Mit 1205 in den Text gedruckten Abbildungen.

\section{Preis 20 M. Gebunden 23 M.}

Die Zahl guter gärtnerischer Spezial- und Sammelwerke ist keine kleine; aber trotz allen und neben allen diesen Büchern muss ein Illustriertes Gartenbau-Lexilion jedem Gärtner und Gartenliebhaber, jedem Gärtner Gehilfen und Lehrling, jeder gärtnerischen Vereinsbibliothek und jedem fachlichen Institut eine aussergewöhnlich williommene Erscheinung sein.

In zahllosen Fällen erfordert die Beantwortung von Fragen, wie sie sich täglich im gärtnerischen Betriebe aufwerfen, das Suchen und Nachlesen in den verschiedensten Werken; das Gartenbau-Lexikon giebt eine augenblickliche, klare und bündige Antwort, und wo das Wort allein nicht genügt, antwortet zugleich eine Abbildung.

Mag es sich darum handeln, irgend eine gärtnerische Verrichtung oder ein Fremdwort erlkïrt, eine Blumen-, Obst- oder Gemüse-Sorte, ein Gerït beschrieben, die Biographie eines verdienten Gïrtners, die Specialitiit einer grösseren Handelsgüirtnerei etc. ermittelt zu sehen, das Illustrierte Gartenbau-Lexikon - aufgeschlagen an der betreffenden Stelle des Alphabets -giebt sofortige Auskunft!

Die auf dem Titel genannten Fachmänner haben sich vereinigt, um in der neuen Auflage jeden einzelnen Artikel des Lexikons an der Hand der neuen Resultate von Wissenschaft und Praxis zu prüfen, neue Artikel einzuschalten, die blumistischen und anderen Neueinführungen der letzten Jahre, soweit sie sich bewährt, zu berücksichtigen, kurzum eine wirklich in allen Teilen vermehrte und verbesserte Neubearbeitung dieses unentbehrlichen, bewihrten Handbuches der Gürtner und Gartenliebhaber zu schaffen. 


\section{STEIN's}

\section{Orchideenbuch.}

\section{Beschreibung,}

\section{Abbildung und Kulturanweisung}

der

\section{empfehlenswertesten Arten.}

Mit 184 in den Text gedruckten Abbildungen.

Gebunden, Preis $20 \mathrm{M}$.

Die Orchideenkultur hat in Deutschland wïhrend des letzten Jahrzehnts ausserordentlich an Ausdehnung gewonnen, und in den weitesten Kreisen ancrkennt man jetzt das Bedürfnis, Orchideen nicht mehr als cinzelne Prunkblumen, sondern auch in grossen Mengen in den Handelsgäirtnereien zu zichen. Für Orchidecnliebhaber und Züchter machte sich auch von Jahr zu Jahr mehr der Mangel cines guten Handbuches fühlbar, welches eine korrekte Schilderung der Arten und Varietiiten mit einer Kulturanweisung rerbindet und die empfehlenswertesten Formen in guten Abbildungen bringt. Geradezu erstaunlich ist es, dass der letzte deutsche Führer durch das Reich der Orchideen vor dreissig Jahren geschrieben wurde und dass seitdem immer nur Bearbeitungen einzelner Gruppen erschienen. Deswegen wird mit der vorliegenden Gesamt-Zusammenstellung Gïirtnern und Liebhabern in gleicher Weise gedient sein, da in ihr alle kulturwerten Arten berücksichtigt sind. 


\section{Gärtnerische Plankammer.}

M. Bertram.

Garteninspelitor in Blasewitz-Dresden,
Herausgegeben von

Fr. Bouché,

\section{Carl Hampel,}

Siädtischer Obergärtner zu Treptow-Berlin.

I. Heft.

Kartonniert, Preis $8 M$.

Inhalt:

Tafel I-V. Die Parkanlagen zu Drehsa bei Pommeritz in Sachsen.

Tafel VI-VIII. Der Königl. Grosse Garten zu Dresden.

Tafel IX-XII. Garten des Herrn Fabrikbesitzers Otto Schultz in Treptow-Berlin.

\section{Gärtnerisches Planzeichnen.}

Leilfaden für den Unterricht an höheren Gärtnerlehranstalten und Gartenbauschulen und zum Selbstunterricht für Landschaftsgärtner.

\section{Herausgegeben vou}

Max Bertram,

Garteninspektor in Blasewitz-Dresden.

16 Uebungsblätter und 24 ausgeführte Gartenpläne nebst erläuterndem Text. In Mappe, Preis 12 M.

Das Werk ist zunäichst für den Lehrer als Leitfacten beim Unterricht bestimmt, im weiteren dient es zum Selbstunterricht, und auch in der Praxis stehende Gärtner werden in den Plänen ausgeführter Gartenanlagen Material und Motive für eigene Arbeiten finden.

\section{Handbuch des Gärtnerischen Planzeichnens.}

\section{Leitfaden}

für den Unterricht an gärtnerischen Lehranstalten sowie zum Selbstunterricht.

Von G. Eichler,

Garteninspektor in Wernigerode.

\section{Zwoite, durchgesehene Auflage.}

I8 Farbendrucktafeln nebst einem Texthefte mit I25 Abbildungen.

\section{In Leinenmappe, Preis $10 \mathrm{MI}$.}

Die zweite Auflage ist ciner sorgfältigen Durchsicht unterworfen und hat eine wesentich praktische Umänderung erfahren, welche darin besteht, dass der Text in kleinerem handlichem Format für sich zum Nachschlagen zu gebrauchen ist und die lithographischen Tafeln einzeln wie Zeichenvorlagen benutzt werden können. Dadurch war es auch möglich, den früheren Preis von $14 \mathrm{M}$. bei dieser neuen Auflage auf nur $10 \mathrm{M}$. herabzusetzen. 


\title{
Das Chrysanthemum.
}

Seine Geschichte, Kultur und Verwendung.

\author{
Von M. Lebl,
}

Fïrstl. Hohenlohe Langenburg'scher Hofgärtner in Langenburg.

Mit 24 in den Text gedruckten Abbildungen.

Kartonniert, Preis $1 \mathrm{M} .50 \mathrm{Pf}$.

\section{Otto's}

\section{Rosenzucht im freien Lande und in Töpfen.}

\section{Zweite Auflage, vollständig neu bearbeitet}

von C. P. Strassheim,

Geschäftsführer des Vereins Deutscher Rosenfreunde.

Mit Textabbildungen und 10 Rosentafeln.

Gebunden, Preis $4 \mathrm{M}$.

\section{Riese's Wohnungsgärtnerei.}

Leichtfassliche Anleitung,

Blumen und Blattpflanzen mit Erfolg

ohne unstundliche und kostspiclige. Einrichtungen in unseren Wohnr:̈umen zu halten, zu pflegen und zu ziehen.

Mit 266 Abbildungen. Gebunden, Preis 5 M.

\section{Die moderne Teppichgärtnerei.}

Von W. Hampel,

Gräflich Schaffgotscher Garten-Inspektor in Koppitz.

147 Entwürfe mit Angabe verschiedenartiger Bepflanzung.

Vierte, umgearbeitete und vermehrte Auflage.

In Quartformat. Gebunden, Preis 6 M.

Die vierte Auflage ist wieder einer vollständigen Umarbeitung unterzogen; die Entwürfe sind um eine grosse Anzahl neuer vermehrt und die früheren zum grossen Teil dadurch verbessert, dass der ersten Angabe ihrer Bepflanzung noch eine zweite hinzugefügt ist, wobei hauptsiichlich die neuen Teppichpflanzen verwendet wurden. 


\section{Schmidlin's Gaptenbuch.}

Praktische Anleitung zur

Anlage und Bestellung von Haus- und Wirtschafts-Gärten

nebst Beschrcibung und Kultur-Anweisung der hierzu tauglichsten Bäume, Sträucher, Blumen und Blattpflanzen.

\section{Vierte Auflage.}

vollständig neu bearbeitet von

Th. Nietner, löniglicher Hofgärtner in Potsdim. und

Gen.-Sekretär des Gartenbatuvereins in Lirfunt.

Mit 751 in den Text gedruckten Holzschnitten und 9 farbigen Gartenplänen.

\section{Neuer Abdruck. Gebunden, Preis $10 \mathrm{Mr}$.}

In drei Auflagen hat sich Schmidlin's Gartenbuch bereits der Gunst des Publikums erfreut; die vierte Auflage ist einer den Fortschritten des modernen Gartenbaues nach allen Richtungen entsprechenden Umarbeitung von zwei Fachmainnern unterzogen worden, die in gegenseitiger Erg̈̈nzung alle Zweige der Gïrtnerei auszuiiben resp. zu behandeln berufen waren.

Es werden weniger grosse Abhandlungen gegeben über die Wahl eines Grundstiicks zu einem Garten, die Lage desselben, über die Verbesserung eines Terrains - Dinge, welche in der Regel keine Wahl zulassen - sondern es wird der rein praktische Standpunlit eingenommen, auf dem es sich darum handelt, gegebenen lokalen Verhältnissen mit diesen Mäingeln und jenen Vorzügen Rechnung zu tragen und auf hïufig beschröinktem Raum mit begrenzten Mitteln doch eine Gartenanlage zu schaffen, welche dem Geschmack und den wirtschaftlichen Zwecken ihres Besitzers zu entsprechen im Stande ist.

\section{Gartenbuch für Jedermann.}

Anleitung für Gärtner und Gartenbesitzer

zur praktischen Ausübung aller Zweige der Gärtnerei nebst Beschreibung und Kulturanweisung der

für die verschiedenen Zwecke geeignetsten Sorten Gemüse, Obst, Zierbäume, Sträucher, Rosen, Blattpflanzen und Blumen.

Aus der Praxis fur die Praxis bearbeitet von

W. Hampel,

Grällich Schaffgotscher Garten-Inspektor in Koppitz.

Mit in den Text gedruckten Abbildungen. Gebunden, Preis 6 M. 


\title{
Illustrierte \\ Gemüse- und Obstgärtnerei.
}

\author{
Bearbeitet von \\ Th. Rümpler
}

in Erfurt.

Mit 400 in den Text gedruckten Holzschnitten.

Preis 10 M. Gebunden 12 M.

\section{Die Gartenblumen,}

ihre Beschreibung, Anzucht und Pflege.

Von

Th. Rümpler,

Gen.-Sekr. des Gartenbau-Vereins in Erfurt.

Zweite, verbesserte und vermehrte Auflage.

Mit 154 Holzschnitten.

Gebunden, Preis 2 M. 50 Pf.

\section{Die Zimmergärtnerei.}

\author{
Von
}

Th. Rümpler,

Gen.-Sekr. des Gartenbau-Vereins in Erfurt.

Zweite, neu bearbeitete Auflage.

Mit 68 Holzschnitten.

Gebunden, Preis 2 M. 50 Pf.

\section{Die sehönblühenden Zwiebelgewäehse,}

ihre Kultur im Garten, Gewächshaus und Zimmer.

Bearbeitet von

Theodor Rümpler,

General-Sekretür des Gartenbau-Vereins in Erfurt.

Mit 150 in den Text gedruckten Holzschnitten.

Preis $10 \mathrm{M}$.

Alle blumistischen Schönheiten der in Rede stehenden Gewäichse wie auf einer Bildfläche zu sammeln, dadurch die in fachmännischen und dilettantischen Blumistenkreisen wachgewordene Stimmung zu verștärlien und in immer weitere Kreise zu verpflanzen und insbesondere diejenigen Laien, welche für die reizenden Pflanzengestalten aus den Familien der Liliaceen, Iridaceen und Amaryllidaceen Neigung und Verstäindnis gewonnen, in Betreff ihrer Kultur mit gutem Rate zu unterstitzen - das ist der Zweck dieses Buches.

Zu beziehen durch jede Buchhandlung. 
